\title{
Addendum Report: Additional Cultural Resources Investigations of the Vista Ridge Regional Water Supply Project in Burleson, Lee, Bastrop, Caldwell, Guadalupe, Comal and Bexar Counties, Texas
}

Mercedes C. Cody

Christina Nielsen

Brandon S. Young

Follow this and additional works at: https://scholarworks.sfasu.edu/ita

Part of the American Material Culture Commons, Archaeological Anthropology Commons, Environmental Studies Commons, Other American Studies Commons, Other Arts and Humanities Commons, Other History of Art, Architecture, and Archaeology Commons, and the United States History Commons

Tell us how this article helped you.

This Article is brought to you for free and open access by the Center for Regional Heritage Research at SFA ScholarWorks. It has been accepted for inclusion in Index of Texas Archaeology: Open Access Gray Literature from the Lone Star State by an authorized editor of SFA ScholarWorks. For more information, please contact cdsscholarworks@sfasu.edu. 
Addendum Report: Additional Cultural Resources Investigations of the Vista Ridge Regional Water Supply Project in Burleson, Lee, Bastrop, Caldwell, Guadalupe, Comal and Bexar Counties, Texas

Creative Commons License

(c) $($ ) (9)

This work is licensed under a Creative Commons Attribution-NonCommercial 4.0 International License 


\section{Addendum Report: Additional Cultural Resources Investigations of the Vista Ridge Regional Water Supply Project in Burleson, Lee, Bastrop, Caldwell, Guadalupe, Comal and Bexar Counties, Texas}

Mercedes C. Cody

Christina Nielsen

Brandon S. Young

Follow this and additional works at: https://scholarworks.sfasu.edu/ita

Part of the American Material Culture Commons, Archaeological Anthropology Commons, Environmental Studies Commons, Other American Studies Commons, Other Arts and Humanities Commons, Other History of Art, Architecture, and Archaeology Commons, and the United States History Commons

Tell us how this article helped you. 
Addendum Report: Additional Cultural Resources Investigations of the Vista Ridge Regional Water Supply Project in Burleson, Lee, Bastrop, Caldwell, Guadalupe, Comal and Bexar Counties, Texas

Creative Commons License

(c) (1)

This work is licensed under a Creative Commons Attribution 4.0 License. 


\section{Addendum Report: Additional Cultural Resources Investigations of the Vista Ridge Regional Water Supply Project in Burleson, Lee, Bastrop, Caldwell, Guadalupe, Comal and Bexar Counties, Texas}

August 2019

Texas Antiquities Annual Permit No. 7295

PREPARED FOR

Central Texas Regional Water Supply Corporation and VRRSP Consultants, LLC

PREPARED BY

SWCA Environmental Consultants 



\title{
ADDENDUM REPORT: ADDITIONAL CULTURAL RESOURCES INVESTIGATIONS OF THE VISTA RIDGE REGIONAL WATER SUPPLY PROJECT IN BURLESON, LEE, BASTROP, CALDWELL, GUADALUPE, COMAL AND BEXAR COUNTIES, TEXAS
}

\author{
Prepared for \\ Central Texas Regional Water Supply Corporation \\ 3711 S. Mo-Pac Expressway, Building One, Suite 300 \\ Austin, Texas 79746 \\ and \\ VRRSP Consultants, LLC \\ 2000 NW Loop 410 \\ San Antonio, Texas 78213 \\ Prepared by \\ Mercedes C. Cody, B.A., Christina Nielsen, M.A., and Brandon S. Young, M.A., RPA \\ SWCA Environmental Consultants \\ 4407 Monterey Oaks Boulevard \\ Building 1, Suite 110 \\ Austin, Texas 78749 \\ www.swca.com \\ Principal Investigator \\ Brandon S. Young, M.A., RPA \\ Texas Antiquities Permit No. 7295 \\ SWCA Project No. 31410-AUS \\ SWCA Cultural Resource Report No. 18-540
}

August 2019 
This page intentionally left blank. 


\begin{abstract}
On behalf of VRRSP Consultants, LLC, and Central Texas Regional Water Supply Corporation (CTRWSC), SWCA Environmental Consultants (SWCA), conducted further intensive cultural resources investigations of the Vista Ridge Regional Water Supply (Vista Ridge) Project in Burleson, Lee, Bastrop, Caldwell, Guadalupe, Comal, and Bexar Counties. The project will involve installation of a 140.2-mile-long, 60-inch-diameter water pipeline from Deanville, Burleson County, Texas, to north-central San Antonio, Bexar County, Texas. The area of potential effects (APE) will consist of the proposed centerline alignment and an 85-foot-wide corridor for temporary and permanent construction easements; however, SWCA surveyed a 100-foot-wide corridor to allow for minor shifts in the alignment.

This addendum report details the findings of additional cultural resources investigations between 2016 and 2018 , on the alignment. The Vista Ridge Project is subject to review under Section 106 of the National Historic Preservation Act (54 USC 306108) and its implementing regulations (36 CFR 800), in anticipation of a Nationwide Permit 12 from the U.S. Army Corps of Engineers in accordance with Section 404 of the Clean Water Act. In addition, the work is subject to compliance with the Antiquities Code of Texas (ACT) under Permit No. 7295, as the Vista Ridge Project ultimately will be owned by a political subdivision of the State of Texas. Furthermore, all human burials in the state of Texas are protected by law, as per the Texas Health and Safety Code Section 711 General Provisions Relating to Cemeteries and the Texas Administrative Code Title 13, THC, Chapter 22 Cemeteries, Sections 22.1 through 22.6. If human burials are encountered in the Project Area and the remains are determined to be Native American, they will be handled in accordance with procedures established through coordination with the THC; work in the affected area would only resume per THC authorization.
\end{abstract}

Between 2016 and 2018, SWCA investigated approximately 29.5 miles of the current 140.2-mile-long project corridor and the proposed 6.9-mile-long wellfield pipeline that was not previously surveyed during the prior 2015 investigations (Acuña et al. 2016). Investigations consisted of intensive pedestrian survey augmented with shovel testing and hand-excavated auger probes and/or mechanical backhoe trenching in select areas. In addition, SWCA investigated the 25.82-acre terminus site slated for the construction of an integration system (Atwood and Ward 2017). SWCA also surveyed additional mileage, which included rerouted areas that are no longer part of the currently proposed alignment. SWCA excavated 967 shovel tests, 96 auger probes, and 85 backhoe trenches during these additional investigations.

SWCA documented or further investigated 28 cultural resources within the Vista Ridge Project during the 2016 to 2018 investigations. Of the 28 resources, seven were isolated finds that did not warrant formal site recording or require additional investigations. The remaining 21 cultural resources include 15 prehistoric sites, three historic sites, and three multi-component sites with both prehistoric and historic cultural materials.

Of the 21 sites, two (i.e., 41BP960 and 41BP961) are currently UNDETERMINED regarding eligibility for the National Register of Historic Places (NRHP) or as a State Antiquities Landmark (SAL), and one site (i.e., 41GU177) was determined to be ELIGIBLE for listing on the NRHP and for designation as a SAL. SWCA conducted testing and data recovery excavations at site $41 \mathrm{GU} 177$ and the results of testing investigations conducted under Permit No. 7295 are presented as an appendix to this report (Rodriguez et al. 2017); the data recovery investigations of site $41 \mathrm{GU} 177$ were completed under Permit No. 8231 and will be a separate report. Additionally, sites 41BP960 and 41BP961 have been avoided by design alignment changes and will not be impacted by the Vista Ridge Project. The remaining 18 cultural resources sites are considered NOT ELIGIBLE for nomination to the NRHP or for designation as SALs and no further cultural resources investigations or avoidance are recommended.

In addition, SWCA documented two cemeteries (the Hill Cemetery and the Hoffman Cemetery) during the 2016 to 2018 investigations. Due to subsequent reroutes, the Hill Cemetery (located within the boundaries of site 41BP818) is now avoided and will not be impacted by the project. Mechanical scraping was conducted adjacent 
to the Hoffman Cemetery in compliance with the Texas Health and Safety Code; no evidence of interments was identified within the project area.

In accordance with 36 CFR 800.4 and the ACT, SWCA has made a reasonable and good faith effort to identify cultural resources within the project area. Two sites (i.e., 41BP960 and 41BP961) are recommended as having UNDETERMINED eligibility for listing on the NRHP or for SAL designation and one site (41GU177) is recommended as ELIGIBLE. The remaining 18 are recommended as NOT ELIGIBLE for listing on the NRHP or for SAL designation. Site $41 \mathrm{GU} 177$ has been mitigated and the results will be presented in a stand-alone report (Nielsen et al. 2019). The two sites (41BP960 and 41BP961) of UNDETERMINED eligibility have been avoided by design alignment changes and will not be impacted by the project. No further work or avoidance strategy is recommended for the remaining 18 archaeological sites identified during the Vista Ridge Project. 


\section{TABLE OF CONTENTS}

Abstract tow

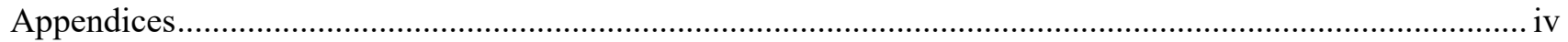

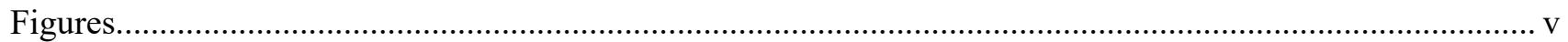

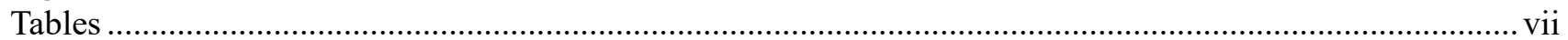

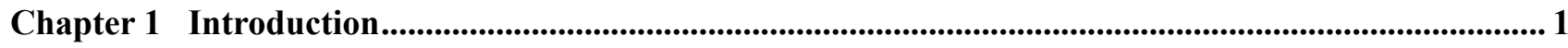

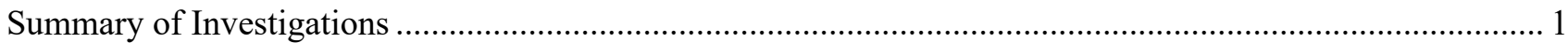

2015

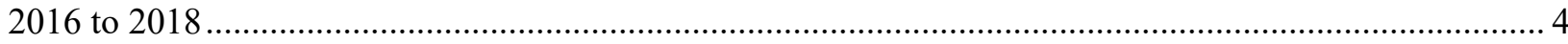

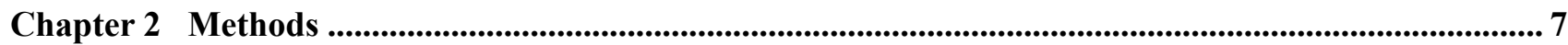

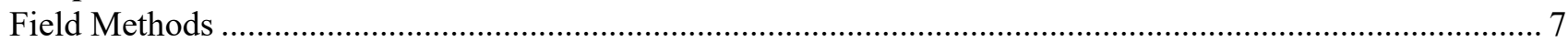

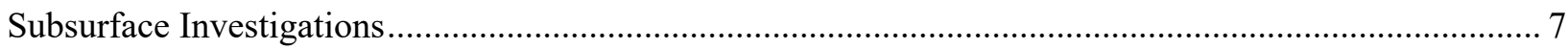

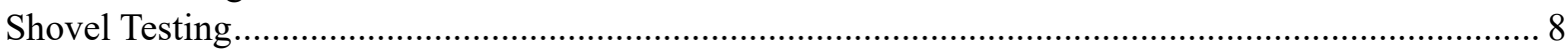

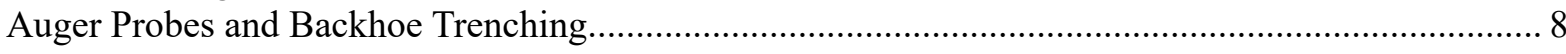

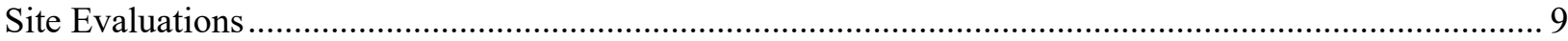

Chapter 3 Survey Results and Site Descriptions............................................................................................. 11

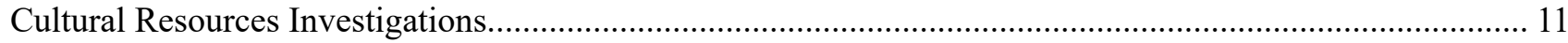

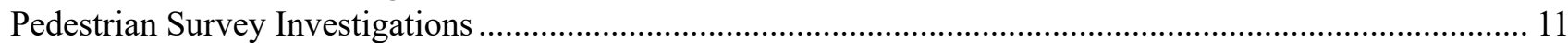

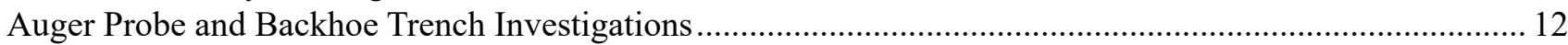

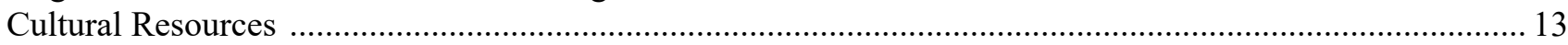

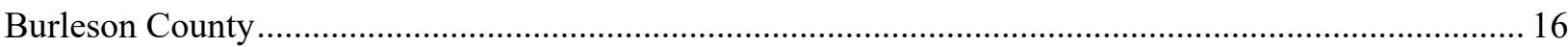

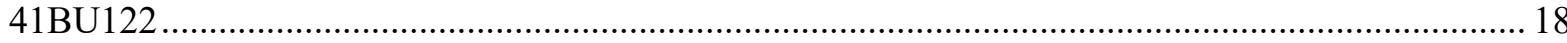

41BU123

41BU124

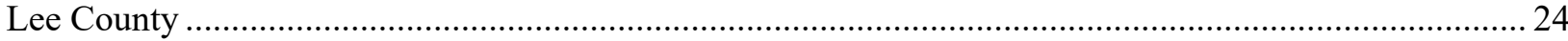

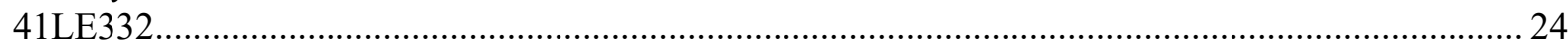

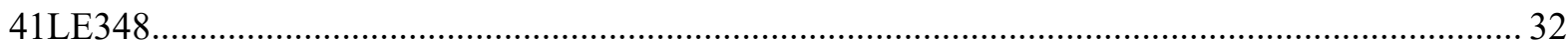

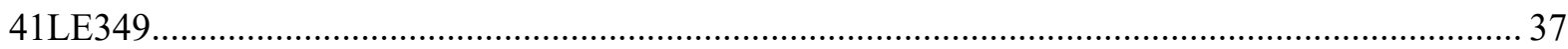

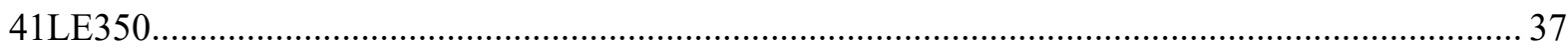

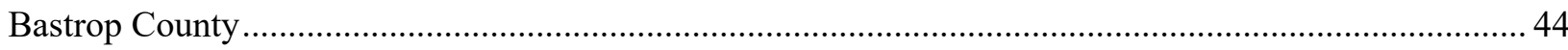

41BP818

41BP920

41ВР959

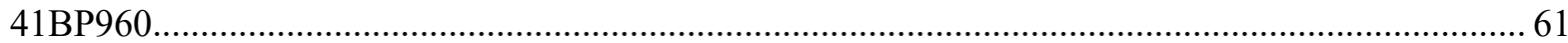

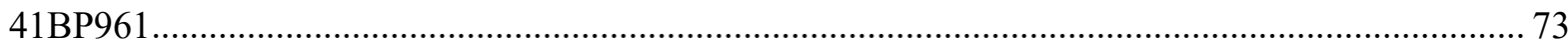

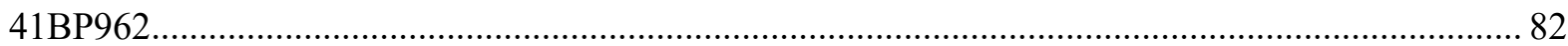

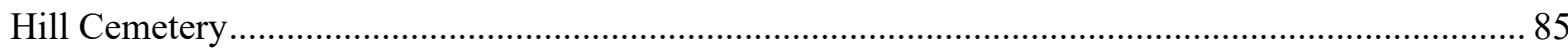

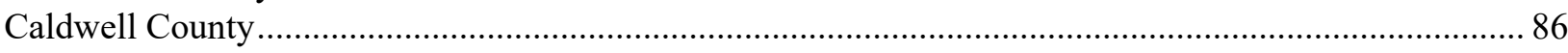

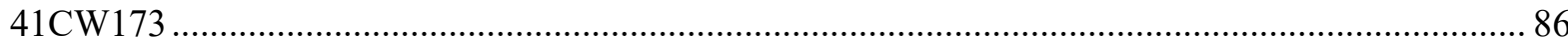

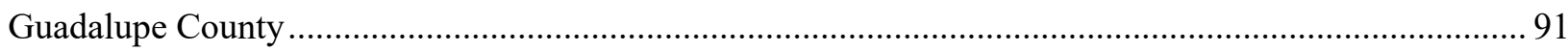

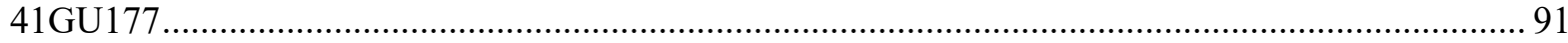

41GU180

41GU200

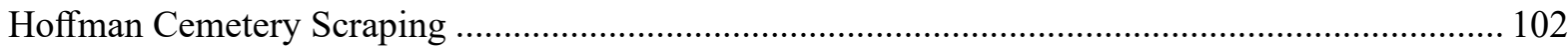

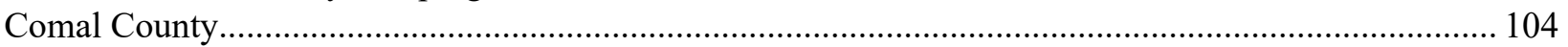




41CM394

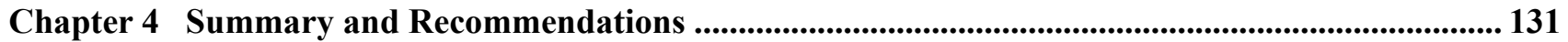

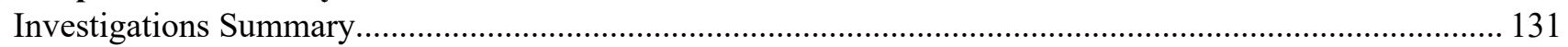

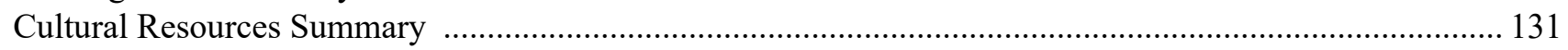

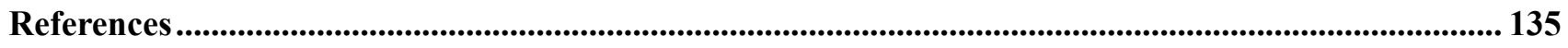

\section{Appendices}

Appendix A. Survey Results Maps

Appendix B. Shovel Test Data

Appendix C. Auger Probe, Backhoe Trench, and Column Sample Data

Appendix D. 41 GU177 Interim Testing Report and Research Design 


\section{Figures}

Figure 1.1a. General project area location map, northern half. …....................................................... 2

Figure 1.1b. General project area location map, southern half. ..................................................... 3

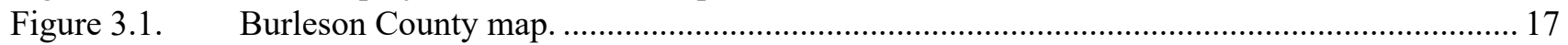

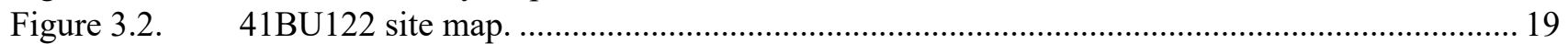

Figure 3.3. Overview of site 41BU122, facing east-northeast......................................................... 20

Figure 3.4. Biface and flakes from site 41BU122 in ST KH51 between $20-80 \mathrm{cmbs}$........................... 20

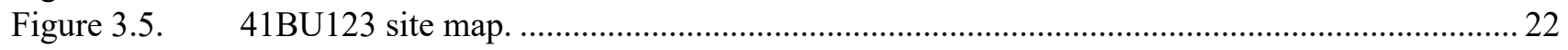

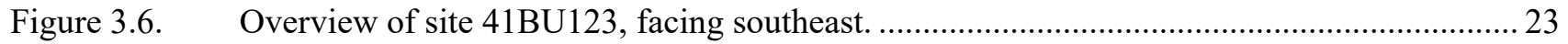

Figure 3.7. Possible perforator from ground surface of site 41BU123 ............................................. 23

Figure 3.8. Possible Perdiz arrow point midsection from ground surface of site 41BU123.................. 23

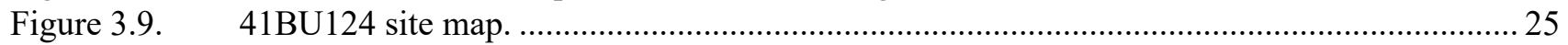

Figure 3.10. Overview of site 41BU124, facing southeast. .............................................................. 26

Figure 3.11. Secondary flake from site 41BU124 in ST MCC247 at 70-80 cmbs................................ 27

Figure 3.12. Utilized flake from site 41BU124 in ST CS40 at 90-100 cmbs.......................................2 27

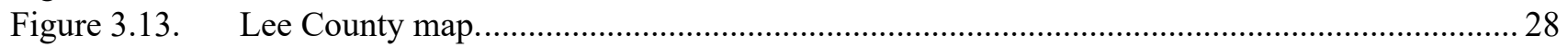

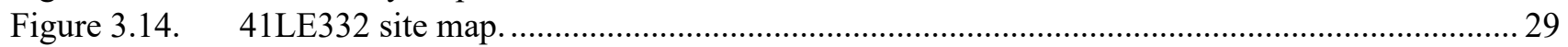

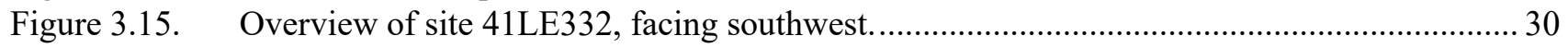

Figure 3.16. Tertiary flakes from site 41LE332 in ST MCC78 at 20-60 cmbs..................................... 30

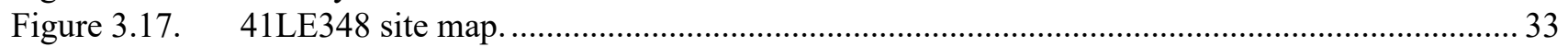

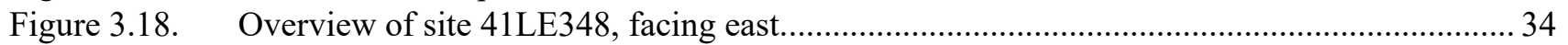

Figure 3.19. Overview of site 41LE348, facing west. Note noticeable swale in background. ................... 34

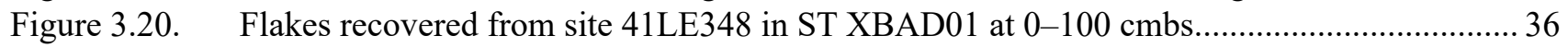

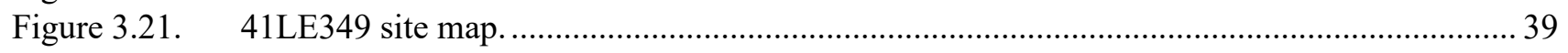

Figure 3.23. Primary flake from site 41LE349 in ST XMC12 at 90-100 cmbs. ................................... 40

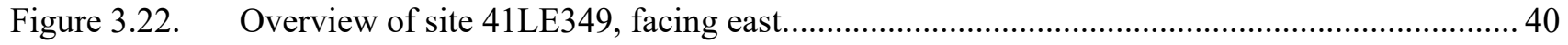

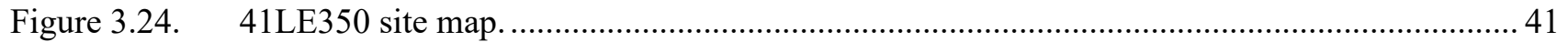

Figure 3.25. Overview of site 41LE350 from shove test AE512, facing west...................................... 42

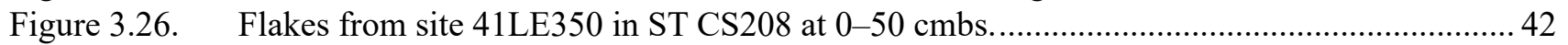

Figure 3.27. Charcoal and possible fire-cracked rock from site 41LE350 in ST CS207 at 0-80 cmbs...... 42

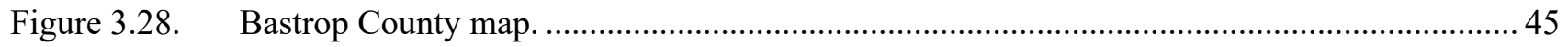

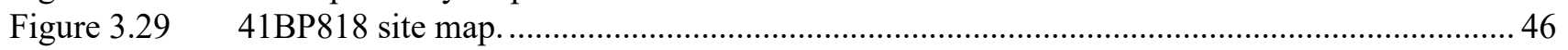

Figure 3.30 Overview of quarrying disturbances at site 41BP818, facing southeast. ............................55

Figure 3.31a Overview of spoil pile disturbances at site 41BP818, facing southeast. .............................. 55

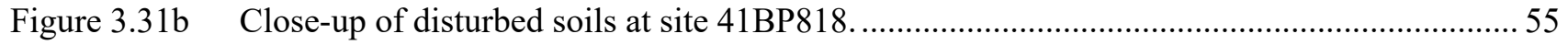

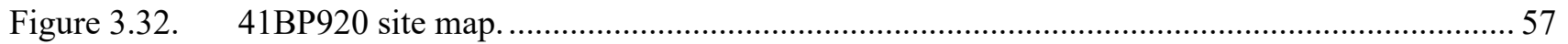

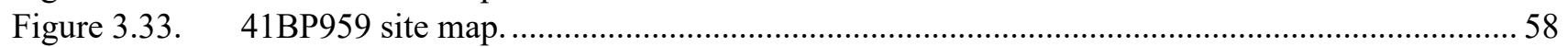

Figure 3.34. Overview of site 41BP959 from northwest margin of site, facing east-southeast.................. 61

Figure 3.35. Artifacts and fire-cracked rock from site 41BP959 in ST AE307 at 10-30 cmbs................. 62

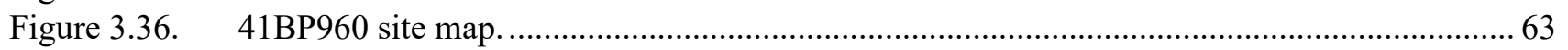

Figure 3.37. Riparian secondary growth along Wilbarger Creek along the western edge of site 41BP960,

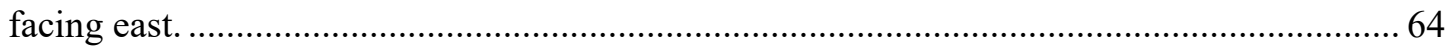

Figure 3.38. BHT 07 profile, golf tees show location of artifacts within possible buried soils.................. 66

Figure 3.39. Artifacts recovered from BHT07 at site 41BP960 (top left: animal bone; bottom left: non-

diagnostic projectile point tip; top right and center: scrapers; bottom right: early-stage biface). 72

Figure 3.40a. Prehistoric ceramics showing exterior surface recovered from AU14 and AU15 at site 41BP960. 
Figure 3.40b. Prehistoric ceramics showing interior surface recovered from AU14 and AU15 at site

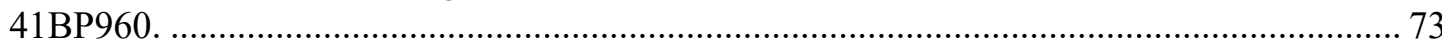

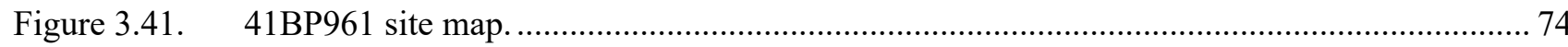

Figure 3.42. Overview of site 41BP961 from BHT 11 location, facing west. .................................... 75

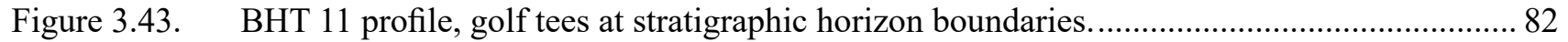

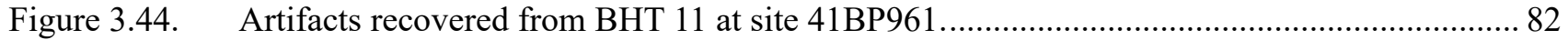

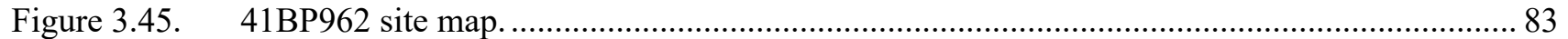

Figure 3.46. Overview of site 41BP962, roadbed in background, facing west....................................... 85

Figure 3.47. Overview of headstones at Hill Cemetery, facing north.................................................... 85

Figure 3.48. Monument within the Hill Cemetery commemorating the Hill, Bragg, Griffin, Storey, and

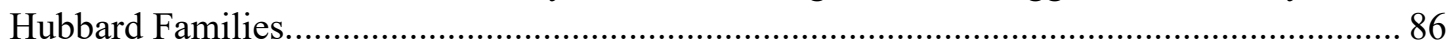

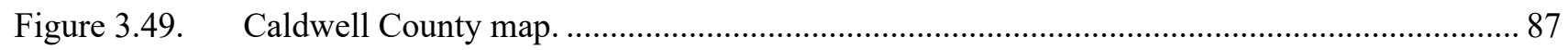

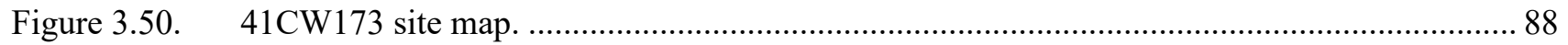

Figure 3.51. Overview of back of main house at 41CW173, facing south........................................... 89

Figure 3.52. Overview of front of main house at site 41CW173, facing north. ..................................... 89

Figure 3.53. Overview of shed outbuilding at 41CW173, facing north............................................ 90

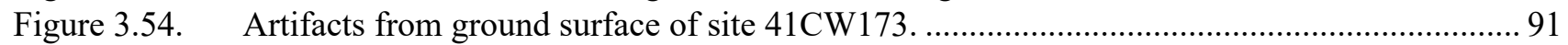

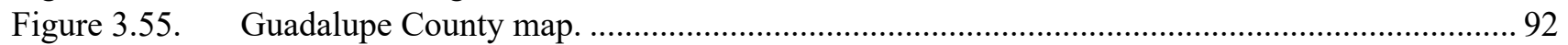

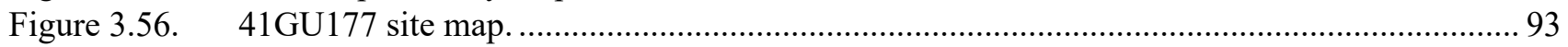

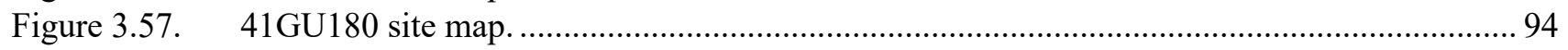

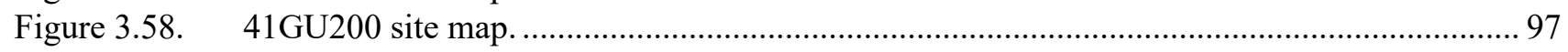

Figure 3.59. Overview of site 41GU200, facing east-southeast. .......................................................... 98

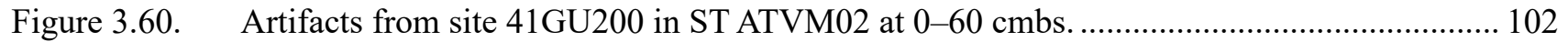

Figure 3.61. Hoffman Cemetery scraping map......................................................................... 103

Figure 3.62. Overview of headstones at the Hoffman Cemetery, facing north.................................... 105

Figure 3.63. Overview of scraping investigations near the Hoffman Cemetery, facing northeast............. 105

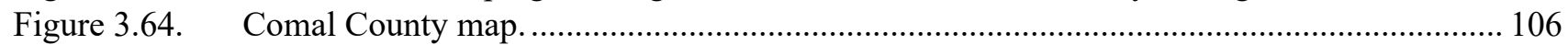

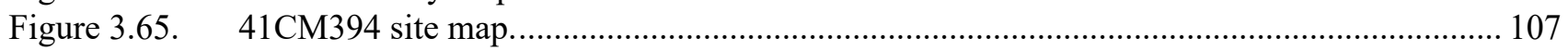

Figure 3.66. Overview of site 41CM394 revisit, facing north.......................................................... 108

Figure 3.67. Artifacts recovered from site 41CM394 revisits. ........................................................... 108

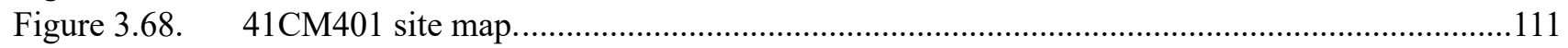

Figure 3.69. Overview of site 41CM401 revisit along southeast margin, facing northeast..................... 112

Figure 3.70. Overview of site 41CM401 revisit along southwest margin, facing northwest................... 112

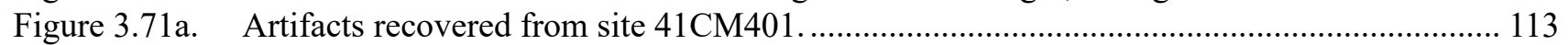

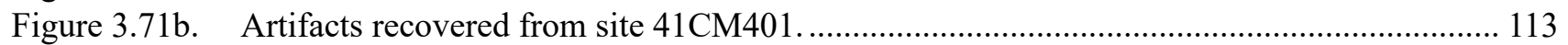

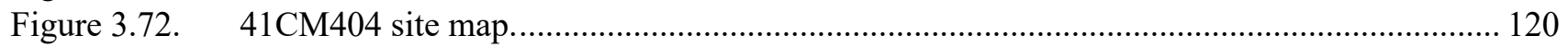

Figure 3.73. Overview of site 41CM404, facing southeast............................................................... 121

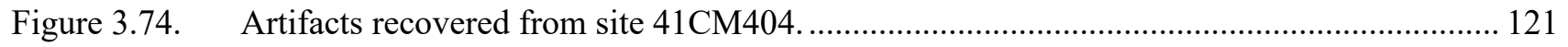

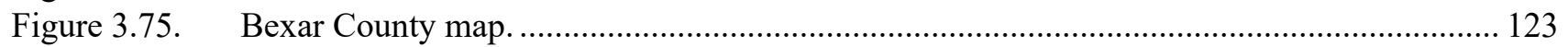

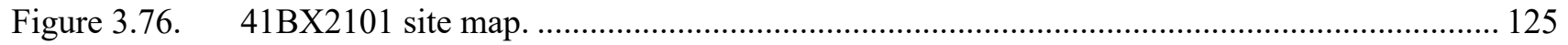

Figure 3.77. Overview of the enclosure at site 41BX1201, facing northwest. .................................... 126

Figure 3.78. Removal of overburden at the site, facing northwest. ................................................. 126

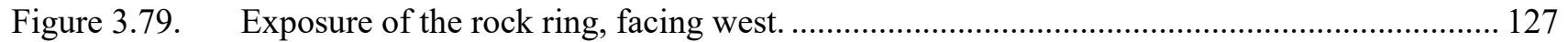

Figure 3.80. Bedrock outcropping at $30 \mathrm{cmbs}$, facing south-southeast. ................................................ 127

Figure 3.81. Limestone cobbles removed during scraping; facing west-northwest. ............................. 128

Figure 3.82. Prehistoric artifacts encountered during the scraping investigations. ................................ 128

Figure 3.83. Overview of the fully exposed rock ring, facing west................................................... 129

Figure 3.84. Second rock ring with plastic and packing tape at its center, facing west.......................... 129

Figure 3.85. Plastic bag encountered at the center of the second stone ring......................................... 130

Figure 3.86. Remains of a small dog encountered below the second rock alignment............................. 130 


\section{Tables}

Table 3.1. 2016-2018 Investigations Overview by County …........................................................ 12

Table 3.2. 2016-2018 Investigations Auger Probe and Backhoe Trench Areas.................................... 12

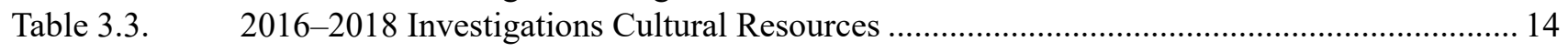

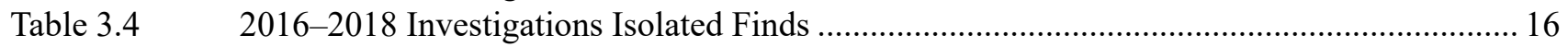

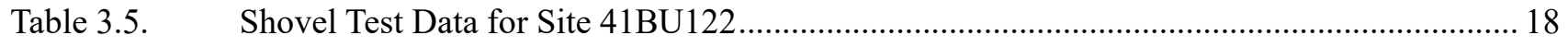

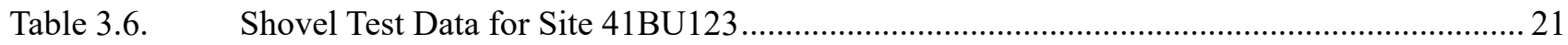

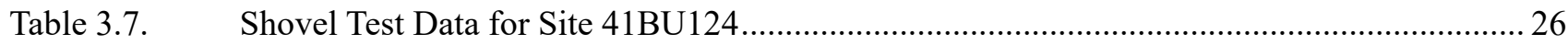

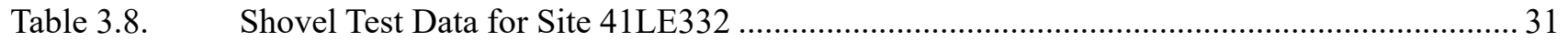

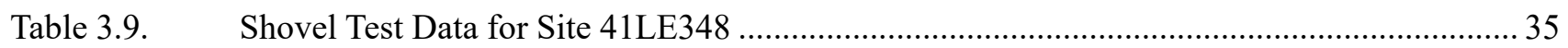

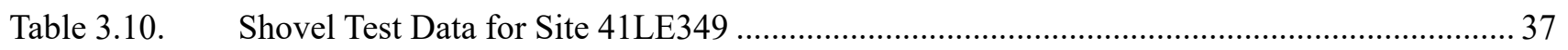

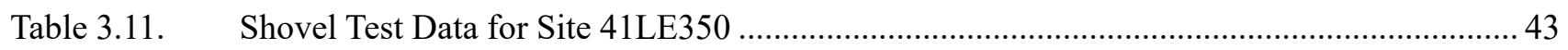

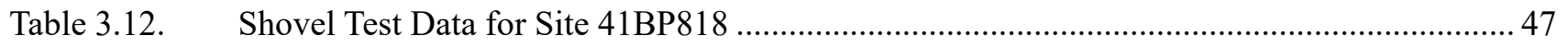

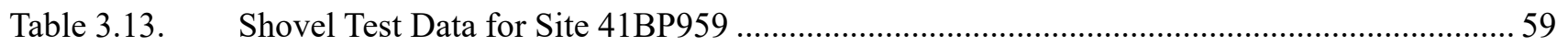

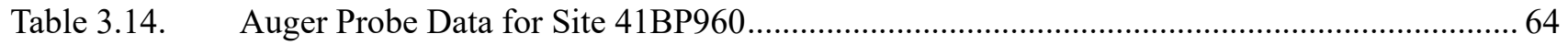

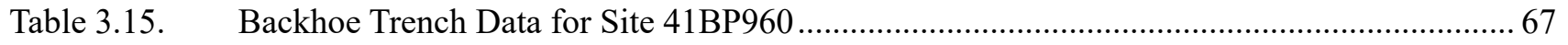

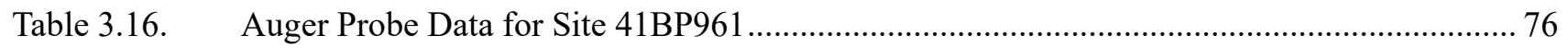

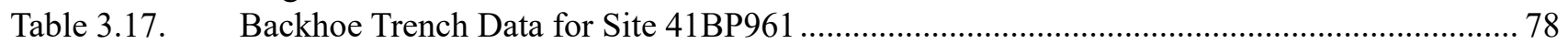

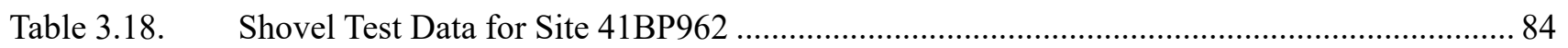

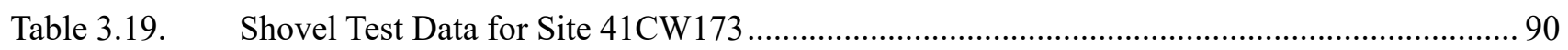

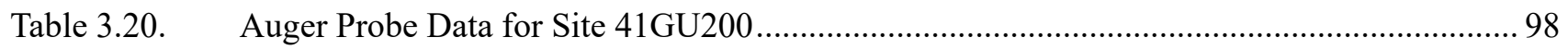

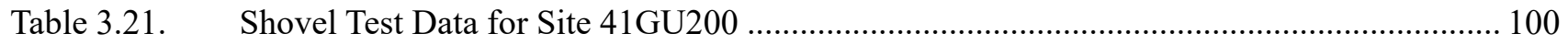

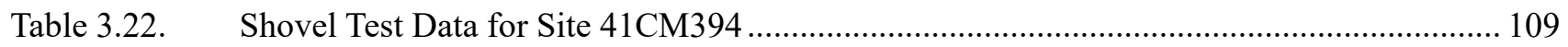

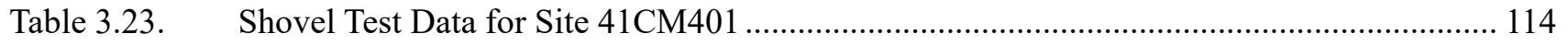

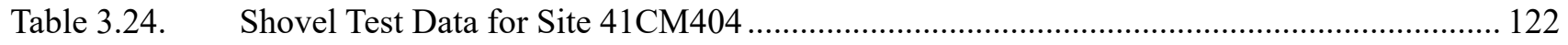

Table 4.1. Cultural Resources Summary and Recommendations...................................................... 132 
This page intentionally left blank. 


\section{Chapter 1 Introduction}

\section{Mercedes C. Cody, B.A., Christina Nielsen, M.A., and Brandon S. Young, M.A., RPA}

On behalf of VRRSP Consultants, LLC, and the Central Texas Regional Water Supply Corporation (CTRWSC), SWCA Environmental Consultants (SWCA) has conducted intensive cultural resources investigations of the Vista Ridge Regional Water Supply Project (Vista Ridge) in Burleson, Lee, Bastrop, Caldwell, Guadalupe, Comal, and Bexar Counties, Texas, since June 2015 (Figures 1.1a and 1.1b). The project will involve installation of a 140.2-mile-long, 60-inch-diameter water pipeline from Deanville, Burleson County, Texas, to north-central San Antonio, Bexar County, Texas. The area of potential effects (APE) will consist of the proposed centerline alignment and an 85-foot-wide corridor for temporary and permanent construction easements; however, SWCA surveyed a 100-foot-wide corridor to allow for minor shifts in the alignment.

Investigations were conducted to comply with Section 106 of the National Historic Preservation Act (NHPA) (54 USC 306108) and its implementing regulations (36 Code of Federal Regulations [CFR] 800), in anticipation of a Nationwide Permit 12 from the U.S. Army Corps of Engineers (USACE) in accordance with Section 404 of the Clean Water Act. In addition, the work is subject to compliance with the Antiquities Code of Texas under Texas Antiquities Permit No. 7295, as the Vista Ridge Project will be ultimately owned by the CTRWSC, a political subdivision of the State of Texas. Furthermore, all human burials in the state of Texas are protected by law, as per the Texas Health and Safety Code Section 711 General Provisions Relating to Cemeteries and the Texas Administrative Code Title 13, THC, Chapter 22 Cemeteries, Sections 22.1 through 22.6. If human burials are encountered in the Project Area and the remains are determined to be Native American, they will be handled in accordance with procedures established through coordination with the THC; work in the affected area would only resume per THC authorization.

\section{SUMMARY OF INVESTIGATIONS}

\section{5}

SWCA conducted a thorough background literature review and intensive field investigations within a 100-foot-wide corridor on available parcels of the previous 139.45-mile project area; due to alignment shifts and reroutes since the initial surveys, the alignment is now 140.2 miles in length. From June to December 23,2015 , SWCA conducted field investigations to inventory known and previously unidentified cultural resources within the project area. Approximately 24.42 miles was not surveyed based on the results of the background review and extensive disturbances as confirmed by vehicular survey. Of the remaining 115.03 miles, 101.8 miles were investigated using intensive pedestrian survey with shovel testing and limited backhoe trenching. By December 23, 2015, there remained approximately 13.23 miles requiring survey due to parcels being unavailable as a result of landowner restrictions or part of newly adopted reroutes. Additional mileage, which includes rerouted areas that are no longer part of the December 8, 2015 alignment, were also surveyed. Approximately 1,792 shovel tests were excavated during the 2015 investigations. The survey was also augmented with limited backhoe trenching at select locations along the proposed alignment.

Based on soil and geology, SWCA identified five stream crossings with the potential for intact, deeply buried archaeological deposits that could not be adequately assessed with standard shovel testing survey methodology. Following pedestrian investigations of two of the stream crossings, SWCA encountered very narrow floodplains with shallow terraces and these crossings were determined to not warrant additional mechanical investigations. Conversely, the pedestrian investigations determined that one previously unidentified crossing would require backhoe trench investigations. A total of 21 backhoe trenches were excavated within four of the identified stream crossings. Three of the 21 backhoe trenches encountered cultural materials; however, two of the positive backhoe trenches were recorded as isolated finds and did not warrant 


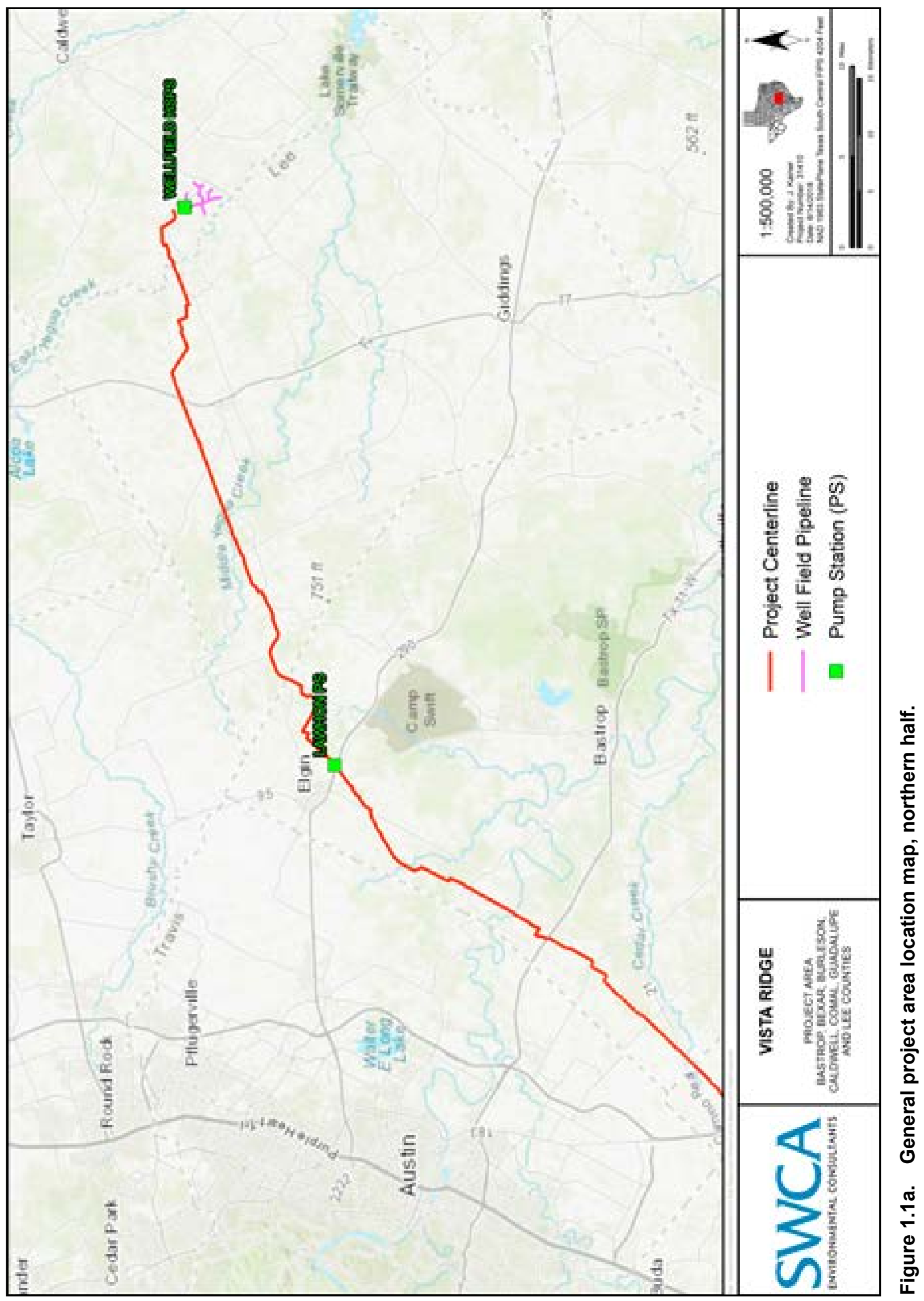




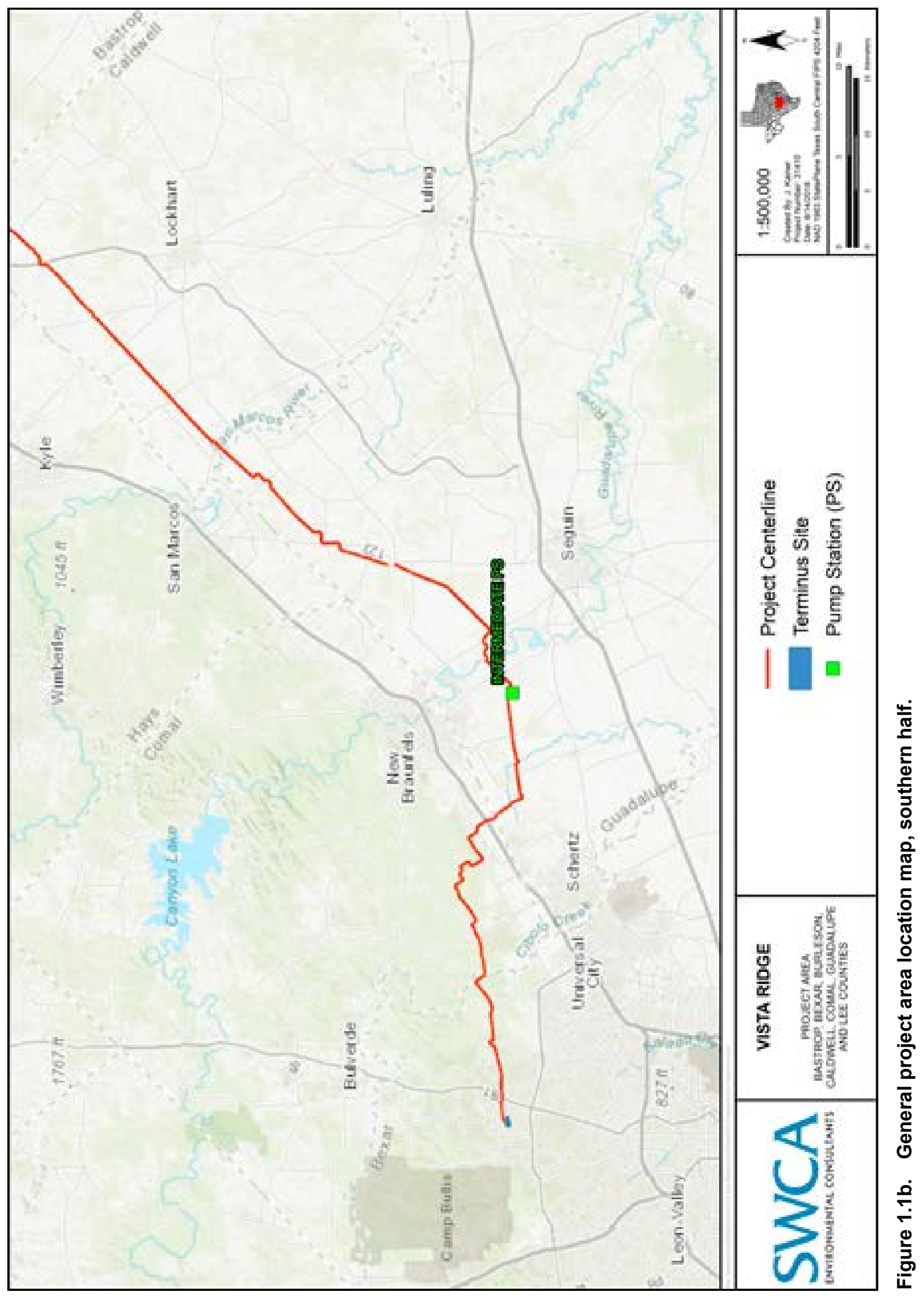


documentation as archaeological sites. The remaining two positive backhoe trenches were excavated within the boundaries of newly documented archaeological site $41 \mathrm{GU} 177$.

Following the completion of survey investigations along accessible portions of the proposed pipeline alignment from June through December 23, 2015, SWCA prepared a draft report (Acuña et al. 2016) of the results of investigations to date and submitted it to the Texas Historical Commission (THC) on January 27, 2016, for review and comments. SWCA identified and recorded 59 cultural resources during the 2015 survey efforts for the Vista Ridge Project. Of the 59 resources, seven were isolated finds that did not warrant formal site recording or require additional investigations. The remaining 52 cultural resources included 34 prehistoric sites, 13 historic sites, and five multi-component sites with both prehistoric and historic materials. In addition to newly recorded resources, SWCA revisited two previously recorded archaeological sites and documented two cemeteries (Acuña et al. 2016).

Of the 52 recorded sites, seven (i.e., 41LE332, 41BP917, 41BP920, 41GU177, 41GU180, 41CM395, and 41BX2101) were recommended as having UNDETERMINED eligibility for inclusion to the National Register of Historic Places (NRHP) or for State Antiquities Landmark (SAL) designation and, as such, required avoidance or significance testing. Of the two previously recorded sites, only one was recommended for avoidance, due to the presence of a historic-age cemetery. Additionally, the previous investigations recommended avoidance of the two documented cemeteries. The remaining 45 cultural resources were recommended as NOT ELIGIBLE for nomination to the NRHP or for designation as SALs and no further cultural resources investigations or avoidance was warranted (Acuña et al. 2016).

Overall, the prehistoric sites not recommended for avoidance or significance testing (i.e., 41LE333-335, 41LE336, 41BP915-916, 41BP918-919, 41BP922, 41CW163-164, 41CW168, 41CM394, 41CM396-400, 41CM404, 41BX2096-2100, and 41BX2102-2106) had an absence of substantial subsurface deposits and/ or exhibited significant horizontal and vertical disturbances from erosion and/or mechanical impacts from agricultural activities, vegetation clearing, two-track roads, and general land clearing and improvements. Based on these conditions, the sites could not provide new or important data concerning regional prehistory (Acuña et al. 2016).

In terms of historic sites with structures and/or structural remains (i.e., 41BU115, 41CW162, 41GU176, 41GU179-181, 41CM391, and 41CM393) the integrity of the structures or structural remains has been compromised by modifications and age (e.g., dilapidation of structures or dismantling of stonewalls). However, because site 41 GU180 contained a house and associated structures, it was recommended for additional investigations in the form of archival research to determine eligibility. Those sites with historic artifact scatters but no structures or structural remains (i.e., 41BP921, 41BP923, 41CW165-169, 41GU178, and 41CM401) have been impacted by erosion and land use and do not exhibit horizontal or vertical integrity. Given these conditions, it was the opinion of SWCA that those resources could not contribute new or important data to local and regional history. Following review of the January 2016 draft report, the THC concurred on February 18, 2016, with SWCA's recommendations that 45 of the sites recorded during survey were NOT ELIGIBLE for nomination to the NRHP or for designation as SALs, and avoidance or additional investigations was warranted at the seven sites recommended as having UNDETERMINED eligibility.

\section{6 то 2018}

Subsequent to THC's review and concurrence with SWCA's draft report recommendations, SWCA completed survey of the remaining 13.23 miles of proposed alignment on all outstanding parcels where right-of-entry (ROE) had been unavailable in 2015. In addition, SWCA surveyed proposed ancillary facilities, including a well field and associated 40-acre pump and water tower facility in Burleson County, two 10- to 15-acre pump stations (one in Bastrop County and one in Guadalupe County), and a 26-acre terminus site at the southern end of the pipeline in Bexar County for integrating the water delivered by the Vista Ridge Project into the City of San Antonio's water system. Moreover, various reroutes and shifts in the pipeline alignment were surveyed during 2016 and 2018. Finally, SWCA conducted investigations at five (i.e., 41LE332, 41BP920, 41GU177, 41GU180, and 41BX2101) of the seven sites recommend as having UNDETERMINED eligibility; the remaining two sites (i.e., 41BP917 and 41CM395) have been avoided by 
project reroutes. Continued investigations at these five sites included:

- hand scraping at site 41BX2101 to determine if a rock ring within a fenced enclosure represented a historical burial;

- additional shovel testing at site 41LE332 to determine if the cultural deposits within a sandy mantle were sufficiently intact to warrant avoidance or test excavations;

- test excavations at sites 41BP920 and 41GU177; and

- $\quad$ archival research for site 41GU180.

Ultimately, test excavations at site $41 \mathrm{GU} 177$ resulted in the need for further data recovery. SWCA conducted data recovery excavations at site $41 \mathrm{GU} 177$ from November 27 to December 21, 2017, and will be documented in a separate report to satisfy the requirements of the Texas Antiquities Permit No. 8231.

Overall, 28 cultural resources were documented or further investigated within the project area during the 2016 to 2018 investigations. Of the 28 resources, seven were isolated finds (i.e., IF08-IF14) that did not warrant formal site recording or require additional investigations. The remaining 21 resources include 12 newly recorded archaeological sites (i.e., 41BU12241BU124, 41LE348-41LE350, 41BP959-41BP962, $41 \mathrm{CW} 173$, and 41GU200) and nine previously recorded sites (i.e., 41LE332, 41BP818, 41BP920, 41GU177, 41GU180, 41CM394, 41CM401, 41CM404, and 41BX2101) initially documented by SWCA during the 2015 investigations or previously recorded prior to the 2015 investigations. The further investigations of the previously recorded sites varied dependent upon recommendations reported in the 2015 initial cultural resources report and included archival research, survey, testing, and/or data recovery excavations. In addition, two cemeteries (the Hill Cemetery and the Hoffman Cemetery) were documented during the 2016 to 2018 investigations. Due to subsequent reroutes, the Hill Cemetery (located within the boundaries of site 41BP818) is now avoided and will not be impacted by the project. Mechanical scraping was conducted adjacent to the Hoffman Cemetery in compliance with the Texas Health and Safety Code; no evidence of interments was identified within the project area.

Of the 21 sites, two sites (i.e., 41BP960 and 41BP961) remain UNDETERMINED regarding their NRHP and SAL eligibility; however, both have currently been avoided by design alignment changes by the Vista Ridge Project. Based on the results of the testing investigations, site 41BP920 has now been determined NOT ELIGIBLE for listing on the NRHP and for designation as a SAL. Site 41 GU177 was determined to be ELIGIBLE for listing on the NRHP and for designation as a SAL and testing and data recovery excavations were conducted at the site. The remaining 18 sites are interpreted to have a low research value and are considered NOT ELIGIBLE for listing on the NRHP or for designation as SALs and no further work or avoidance is recommended.

The following report addresses the results of all survey efforts and additional site investigations by county that occurred during 2016 and 2018. The reader is directed to the initial survey draft report (Acuña et al. 2016) for a complete discussion of the project's environmental setting, previous investigations and known sites within or near the project area, the cultural history of the project area, and the results and recommendations for all investigations completed as of December 23, 2015. The results of test excavations at site 41BP920, test excavations at site $41 \mathrm{GU} 177$, and survey of the 26 -acre project terminus site in San Antonio are presented in separate reports (see Atwood and Ward 2017; Rodriguez et al. 2017; Rodriguez and Young 2018). 
This page intentionally left blank. 


\title{
Chapter 2 Methods
}

\author{
Mercedes C. Cody, B.A., and Christina Nielsen, M.A.
}

The investigations were designed to identify cultural resources in the project area and, to the extent possible, recover sufficient information to evaluate the significance of recorded prehistoric and historic sites. SWCA's investigations included background research and intensive field surveys. The methods and the level of effort used in these investigations were developed in consultation with the THC and in accordance with the Council of Texas Archaeologists (CTA) survey standards.

\section{Field Methods}

The project area traverses both urban and rural settings with varying degrees of archaeological potential. High probability areas are defined as locales that possess or have a statistically higher likelihood of containing intact archaeological deposits. Moderate probability areas have a slightly elevated probability for containing archaeological deposits and are not typically associated with soil and/or stratigraphic integrity (e.g., slopes, uplands, or evident disturbance). Low probability areas are defined as locales where archaeological resources/ sites are likely absent or have low probability to be present (e.g., uplands, evident disturbance, or very recent alluvial floodplains). River drainages, stream settings and terraces, existing archaeological sites, and moderate probability settings were thoroughly explored with subsurface investigations (i.e., shovel testing, auger probing, and/or backhoe trenching).

Although several river and large stream drainages with a high potential to contain cultural resources are traversed, a large portion of the project spans expansive tracts of agricultural fields that have been frequently plowed and terraced or are developed urban/utility areas. Based on the soils and these disturbances, portions of the project area within the Blackland Prairie in Guadalupe and Caldwell Counties, for instance, have a very low potential to contain buried stratified cultural resources, with sites typically limited to surface manifestations of prehistoric artifact scatters or historic materials associated with the late-nineteenth- to midtwentieth-century settlement. Recent investigations conducted by SWCA within Guadalupe County in similar settings suggest that in many areas much of the upper 30 to 40 centimeters $(\mathrm{cm})$ of the surface have been disturbed by significant land clearing and plowing (Acuña et al. 2016; Acuña and Sloan 2014; Ward 2015). The majority of the soils within the project area in Guadalupe and Caldwell Counties are primarily Houston Black clay or Branyon clay. As these soils developed in place from clayey residuum from mudstone and clayey alluvium from mudstone, respectively, they possess limited potential to contain intact buried cultural deposits, particularly prehistoric cultural materials. These soils typically contain cultural resources (prehistoric and historic) that primarily are surface scatters of artifacts with little to no research value, due to poor horizontal integrity and a general lack of cultural features and buried components.

Considering the overall mixed archaeological potential of the project area, SWCA executed a flexible approach where intensive archaeological investigations were tailored to the specific settings encountered across the alignment. River drainages, stream settings and terraces, existing archaeological sites, and moderate probability settings were thoroughly explored with subsurface investigations (i.e., shovel testing, auger probing, and/or backhoe trenching) to THC survey standards. In disturbed and/or upland settings with little to no subsurface potential, SWCA minimized subsurface explorations or excluded survey all together. This also applied to those areas that have been previously surveyed by archaeologists in the last 10 years, per the Texas Archeological Sites Atlas.

\section{SUBSURFACE INVESTIGATIONS}

SWCA's investigations consisted of an intensive pedestrian survey with subsurface investigations within the 100-foot-wide survey corridor. The field survey consisted of teams of SWCA archaeologists walking all of the proposed cultural resources survey areas for the project. Archaeologists examined the ground surface and extensive erosional profiles and exposures along drainages for cultural resources. 
SWCA used three methods of subsurface exploration during the survey: shovel testing, auger probing, and backhoe trenching. SWCA keyed the use of methods to the level of disturbances of the project and the nature of the soils, geology, and topography in a given area. Survey investigations were of sufficient intensity to determine the nature, extent, and, if possible, significance of cultural resources discovered within the proposed project area. Survey efforts met all THC-minimum archaeological survey standards for such projects with exceptions thoroughly documented. In most cases, artifacts were tabulated, analyzed, and documented in the field, but not collected. However, on sites with undetermined eligibility (i.e., 41BP960 and 41BP961) artifacts were collected in the field and will be returned to the landowner after reporting is complete. Following the review and acceptance of the final cultural resources report, all records and photographs will be curated with the Center for Archaeological Research at the University of Texas at San Antonio (CAR-UTSA), per requirements of the $\mathrm{ACT}$.

SWCA archaeologists employ both metric (centimeters and meters) and English units of measurement (inches and feet) when conducting investigations within the Vista Ridge Project area. In compliance with archaeological standard practices, investigations such as shovel tests, auger probes, and backhoe trenches are recorded using metric units. Prehistoric archaeological resources, such as camp sites, features, and artifacts, are also recorded using metric units, whereas historic resources, such as farmsteads and associated historic features, are recorded using English units; no conversions for these measurements are provided.

\section{Shovel Testing}

Shovel testing was not conducted in areas where steep slopes (i.e., greater than 20 percent) were encountered, where impervious substrates (i.e., caliche, concrete, and/or compact gravel) were present, within welldefined surface (i.e., runoff) drainage gullies, where evidence of extensive ground surface disturbance was observed (e.g., terraced agricultural fields), within 5 meters $(\mathrm{m})$ of any identified/marked buried utility markers, or within $5 \mathrm{~m}$ of any paved/graveled road edges.

SWCA primarily used shovel testing when the project crossed upland topography with low potential for deeply buried sites. Archaeologists excavated shovel tests in 20-centimeter $(\mathrm{cm})$ arbitrary levels to $1 \mathrm{~m}$ in depth unless soil characteristics or bedrock precluded reaching that depth. The matrix was screened through $1 / 4$-inch mesh. The location of each shovel test was plotted using a hand-held sub-meter accurate global positioning system (GPS) receiver and was recorded on appropriate project forms in SWCA's field tablets.

Areas with previously recorded sites or other cultural resources identified during the archival research required additional shovel testing to explore the nature of the cultural deposits. For a linear corridor survey, THC survey standards minimally require that for every 100 feet of survey corridor width, 16 shovel tests need to be excavated every mile. For a project of this size (i.e., 140.2 miles), the shovel test investigations would require 2,243 shovel tests. However, as previously mentioned, these standards may be reduced in broad upland areas with shallow soils. If sites were encountered, SWCA excavated a minimum of six shovel tests per site to determine horizontal and vertical extent. If shovel testing could not adequately explore project impacts in soils with potential to contain buried archaeological materials, auger probes and/or backhoe trenches were utilized.

\section{Auger Probes and Backhoe Trenching}

Deeper investigation utilizing hand-excavated auger probe and/or mechanical backhoe trench excavations were conducted at drainages that had characteristics suggesting the potential for containing deeply buried Holocene-aged deposits (i.e., Middle Yegua Creek, Wilbarger Creek, the Colorado River, and the Guadalupe River).

Auger probes were excavated at approximately 50-m intervals, staggered across the proposed alignment to test across the width of the proposed 100-foot-wide survey corridor. All hand auger probes were excavated in 20-cm arbitrary levels to $2 \mathrm{~m}$ in depth, to compact soils, bedrock, or culturally sterile deposits, whichever came first. Matrix from the auger probes were screened through $1 / 4$-inch mesh.

When required, backhoe trenches were placed approximately 200-300 m apart. In larger floodplains, such as those associated with the Guadalupe and Colorado Rivers, backhoe trench intervals were widened. Trench placement was based on the level of disturbance within the project area, the location of buried utilities, the locations of any previously impacted areas, landowner concerns, and the preservation potential for archaeological sites. If a river or stream will be directionally 
drilled, trenches were placed at drill locations and floodplain areas outside the bore ingress/egress locations. Trenches were limited or not excavated between the entry and exit points of the drill.

Backhoe trenches were excavated to a depth sufficient to determine the presence/absence of buried cultural materials and to allow the complete recording of all cultural features and geomorphic information to depths of project impacts. To differentiate the backhoe trenches excavated at different drainages across the project area, the trenches were given a prefix name followed by a number. For example, those trenches excavated at the Colorado River were designated $\mathrm{CO}$, trenches excavated at the San Marcos River were designated $\mathrm{SM}$, etc., followed by the sequential number it was excavated (e.g., CO2 and SM4).

Generally, trenches were $1.8 \mathrm{~m}$ deep, $7 \mathrm{~m}$ long, and 1.5 $\mathrm{m}$ wide. An experienced archaeologist monitored all trenching while excavations were underway. Trench documentation included stratigraphic descriptions for each excavated trench with soil descriptions for each trench containing cultural materials. When applicable, archaeologists mapped and photographed all cultural features encountered during trenching. To quantify artifact density and recovery, a column of soil was excavated and screened down one side of select trenches that contained cultural materials. The columns were roughly $30 \times 30-\mathrm{cm}$ in size, extending from the ground surface to the base of the trench or until soil characteristics or bedrock precluded reaching that depth. Soil from the column was removed in $20-\mathrm{cm}$ levels and screened through $1 / 4$-inch hardware screen mesh.

All Occupational Safety and Health Standards (OSHA) safety protocols were used during backhoe trenching, with SWCA planning to shore and/or step back trenches as appropriate based on depth of excavations, soil characteristics, and field conditions. SWCA thoroughly photographed the entire process. All trenches were backfilled and leveled upon completion of excavation and recording.

SWCA archaeologists defined and recorded all discovered cultural resource sites following standard federal and state guidelines. All sites were mapped in detail with a Trimble hand-held sub-meter accurate GPS unit and plotted on U.S. Geological Survey 7.5-minute topographic maps and appropriate project maps for planning purposes.

\section{SITE EVALUATIONS}

All newly documented archaeological sites were evaluated according to the National Register Criteria for Evaluation (Criteria) as codified in 36 CFR 60.4, which states:

The quality of significance in American history, architecture, archeology, engineering, and culture is present in districts, sites, buildings, structures, and objects that possess integrity of location, design, setting, materials, workmanship, feeling, and association and

$(\alpha)$ that are associated with events that have made a significant contribution to the broad patterns of our history; or

( $\beta$ ) that are associated with the lives of persons significant in our past; or

$(\chi)$ that embody the distinctive characteristics of a type, period, or method of construction, or that represent the work of a master, or that possess high artistic values, or that represent a significant and distinguishable entity whose components may lack individual distinction; or

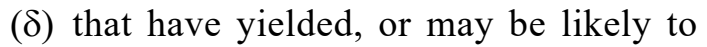
yield, information important in prehistory or history.

Additional evaluations will be made under the ACT 13.26 Rule 26.10 to determine SAL designation eligibility. The ACT criteria states:

The commission shall use one or more of the following criteria when assessing the appropriateness of official landmark designation, and/ or the need for further investigations under the permit process:

(1) the site has the potential to contribute to a better understanding of the prehistory and/ or history of Texas by the addition of new and important information;

(2) the site's archeological deposits and the artifacts within the site are preserved and intact, thereby supporting the research potential or preservation interests of the site; 
(3) the site possesses unique or rare attributes concerning Texas prehistory and/or history;

(4) the study of the site offers the opportunity to test theories and methods of preservation, thereby contributing to new scientific knowledge; and

(5) there is a high likelihood that vandalism and relic collecting has occurred or could occur, and official landmark designation is needed to ensure maximum legal protection, or alternatively, further investigations are needed to mitigate the effects of vandalism and relic collecting when the site cannot be protected.

When evaluating a historic structure under the ACT, the following criteria must be applied:

Buildings, structures, cultural landscapes, and non-archeological sites, objects, and districts may be designated as landmarks, provided that the following conditions are met:

(1) the property fits within at least one of the following criteria:

(A) the property is associated with events that have made a significant contribution to the broad patterns of our history, including importance to a particular cultural or ethnic group;
(B) the property is associated with the lives of persons significant in our past;

$(\mathrm{X})$ the property embodies the distinctive characteristics of a type, period, or method of construction, represents the work of a master, possesses high artistic values, or represents a significant and distinguishable entity whose components may lack individual distinction;

$(\Delta)$ the property has yielded, or may be likely to yield, information important in Texas culture or history;

(2) the property retains integrity at the time of the nomination, as determined by the executive director of the commission; and

(3) for buildings and structures only, the property must be listed in the National Register of Historic Places, either individually, or as a contributing property within a historic district. Contributing status may be determined by the Keeper of the National Register or the executive director of the commission. 


\title{
Chapter 3 Survey Results and Site Descriptions
}

\author{
Mercedes C. Cody, B.A., and Christina Nielsen, M.A.
}

This chapter addresses the results of additional cultural resources investigations conducted by SWCA from January 2016 to June 2018 for the Vista Ridge Project. The 2016 to 2018 investigations follow the 2015 initial cultural resources investigations reported by Acuña et al. (2016). The current alignment as of October 24, 2017, includes new reroutes that were implemented after December 2015. The alignment sheets of the current project area are presented in Appendix A of this report. The alignment sheets depict both the 2015 initial investigations and the 2016 to 2018 additional investigations within the current project corridor. Field data (e.g., shovel tests and sites) depicted outside the current project corridor are from investigations of previously proposed alignments of the project area from 2015 through 2018 that have subsequently been dropped.

\section{Cultural Resources Investigations}

Between 2016 and 2018, SWCA investigated approximately 29.5 miles of the current 140.2-mile-long project corridor and the proposed 6.9-mile-long wellfield pipeline. Investigations consisted of intensive pedestrian survey augmented with shovel testing and hand-excavated auger probes and/or mechanical backhoe trenching in select areas. In addition, SWCA investigated the 25.82-acre terminus site in Bexar County slated for the construction of an integration system (Atwood and Ward 2017).

Overall, 28 cultural resources were documented or further investigated within the project area during the 2016 to 2018 investigations. The 28 resources include seven isolated finds, 15 prehistoric sites, three historic sites, and three multi-component sites with both prehistoric and historic materials. All archaeological sites are discussed in detail in the Cultural Resources section below. In addition, two cemeteries (the Hill Cemetery and the Hoffman Cemetery) were documented during the 2016 to 2018 investigations; the Hill Cemetery is now avoided by the project and mechanical scraping conducted in compliance with the Texas Health and Safety Code adjacent to the Hoffman Cemetery did not identify any interments extending into the proj- ect area. Of note, two additional sites (41BP917 and 41CM395), previously recommended for avoidance in the 2016 report, are no longer within the construction footprint and will be avoided by the Project. These sites were avoided prior to the 2016 to 2018 investigations; therefore, these sites are not included in the cultural resource's totals provided above or in the cultural resource's discussion below.

SWCA's investigations determined that most of the project area is within a rural setting consisting of large, undeveloped parcels of land and agricultural fields with isolated single-family residences or farm/ranch complexes. Beginning in Burleson County, the alignment traverses across a mixture of heavily vegetated, undeveloped parcels; open pastureland; and some agricultural fields. Within Lee County, the alignment intersects a large lignite mine as it parallels Farm-toMarket Road (FM) 696. As the alignment continues southwest through Bastrop County southwest of Elgin, Texas, residential development increases, consisting of large-acre, single-family dwelling parcels and subdivisions. Large-scale agricultural fields are located within the floodplain of the Colorado River and Cedar Creek up to Caldwell County. Within Caldwell County and Guadalupe County, the alignment intersects primarily large-scale agricultural parcels and pastureland in various states of harvest. As the project area enters Comal County, the setting shifts from agricultural tracts to undeveloped, heavily vegetated uplands interspersed with residential parcels. In Bexar County, the alignment begins within a rural, undeveloped setting that is rapidly transitioning to residential and commercial development as it traverses west towards the western project terminus in northern San Antonio.

\section{Pedestrian Survey Investigations}

SWCA excavated 967 shovel tests during the 2016 to 2018 investigations (Appendix B). The THC standards require 16 shovel tests per mile within a 100 -foot corridor, or approximately 472 shovel tests for the 29.5 miles of centerline survey and 110 shovel tests for the 6.9 miles of wellfield pipeline. The additional excavated shovel tests reflect reroutes, site delineations, 
and close-interval shovel testing conducted at site 41GU177. Table 3.1 lists the total mileage within the individual counties, miles reviewed through desktop/ windshield survey, and miles surveyed to date along the current centerline, followed by approximate miles surveyed along the current centerline during the 2016 to 2018 investigations, number of subsurface tests (i.e., shovel tests, auger probes, and backhoe trenches), and number of cultural resources (i.e., sites and isolated finds) identified. Additional areas surveyed between 2016 and 2018 that are no longer within the current project area due to subsequent reroutes are not included in the table totals.

\section{Auger Probe and Backhoe Trench INVESTIGATIONS}

Prior to the 2016 to 2018 additional cultural resources investigations, SWCA identified four stream channel crossings not investigated, or only partially investigated, in 2015 that had characteristics suggesting the potential for containing deeply buried Holocene-aged deposits. These characteristics varied for each of the drainages, but typically included position on the floodplain, previously documented buried soils (i.e., paleosols), and integrity. The stream crossings identified during this review from south to north include the Guadalupe River, the Colorado River, Wilbarger Creek, and Middle Yegua Creek (Table 3.2). Deeper investigation utilizing hand-excavated auger probe and/or mechanical backhoe trench excavations, dependent upon accessibility, were conducted at the identified drainages. The soils and geology for the overall project as well as those specific to the more prominent drainages (i.e., Colorado and Guadalupe Rivers) are discussed in the initial survey report (Acuña et al. 2016).

SWCA excavated a total of 81 auger probes and 85 backhoe trenches at the above-mentioned crossing locations during the 2016 to 2018 investigations (Appendix C). These investigations included the excavation of 15 auger probes and 46 backhoe trenches

Table 3.1. 2016-2018 Investigations Overview by County

\begin{tabular}{|c|c|c|c|c|c|c|c|c|c|}
\hline \multicolumn{4}{|c|}{ Project Data } & \multicolumn{6}{|c|}{ 2016-2018 Investigations } \\
\hline County & $\begin{array}{c}\text { Total } \\
\text { Mileage }\end{array}$ & $\begin{array}{c}\text { Desktop/ } \\
\text { Windshield } \\
\text { Review Mileage }\end{array}$ & $\begin{array}{l}\text { Surveyed } \\
\text { Mileage to } \\
\text { Date }\end{array}$ & $\begin{array}{l}\text { Approx. } \\
\text { Surveyed } \\
\text { Mileage* }^{*}\end{array}$ & $\begin{array}{l}\text { No. of } \\
\text { Shovel } \\
\text { Tests }\end{array}$ & $\begin{array}{l}\text { No. of } \\
\text { Auger } \\
\text { Probes }\end{array}$ & $\begin{array}{l}\text { No. of } \\
\text { BHTs }\end{array}$ & $\begin{array}{l}\text { No. of } \\
\text { Sites }\end{array}$ & $\begin{array}{l}\text { No. of } \\
\text { Isolated } \\
\text { Finds }\end{array}$ \\
\hline Burleson & 3.6 & 0.2 & 3.4 & 1.5 & $216^{\star *}$ & 0 & 0 & 3 & 1 \\
\hline Lee & 25.8 & 4.9 & 20.9 & 2.8 & 132 & 0 & 2 & 4 & 0 \\
\hline Bastrop & 36.4 & 1.5 & 34.9 & 20.1 & 409 & 72 & 72 & 6 & 4 \\
\hline Caldwell & 20.7 & 4.6 & 16.1 & 0.4 & 12 & 0 & 0 & 1 & 0 \\
\hline Guadalupe & 32.3 & 15.5 & 16.7 & 1.1 & 115 & 24 & 11 & 3 & 1 \\
\hline Comal & 12.6 & 0.2 & 12.4 & 2.5 & 58 & 0 & 0 & 3 & 0 \\
\hline Bexar & 8.9 & 1.8 & 7.1 & 1.2 & 25 & 0 & 0 & 1 & 1 \\
\hline Totals & 140.2 & 28.8 & 111.4 & 29.5 & 967 & 96 & 85 & 21 & 7 \\
\hline
\end{tabular}

${ }^{*}$ Approximate surveyed mileage only includes mileage for the current centerline; no offline surveyed areas are included.

**Includes shovel tests excavated along the approximately 6.9-mile-long wellfield pipeline alignment not included in the survey mileage above

Table 3.2. 2016-2018 Investigations Auger Probe and Backhoe Trench Areas

\begin{tabular}{lllll}
\hline BHT Area & Drainage/ Crossing & No. of Auger Tests & $\begin{array}{l}\text { No. of Backhoe } \\
\text { Trenches }\end{array}$ & Cultural Resources Identified \\
\hline Area 1 & Guadalupe River & 24 & 11 & $41 G$ 200 \\
\hline Area 2 & Colorado River & 15 & 46 & None \\
\hline Area 3 & Wilbarger Creek & 42 & 26 & $41 \mathrm{BP} 960$ and 41BP961 \\
\hline Area 4 & Middle Yegua Creek & 0 & 2 & None \\
\hline
\end{tabular}


along the broad Colorado River floodplain in Bastrop County; 42 auger probes and 26 backhoe trenches along Wilbarger Creek in Bastrop County; 24 auger probes and 11 backhoe trenches along the Guadalupe River located in Guadalupe County; and two backhoe trenches just north of the confluence of Middle Yegua and Cross Creeks located in Lee County (see Table 3.2). Fifteen additional auger probes were excavated within the project area at less-pronounced drainage crossings and/or within archaeological sites to test for deep subsurface cultural materials. In addition, column sampling was selectively conducted on several of these backhoe trenches (Appendix C). Specifically, this sampling was utilized when in proximity to a previously recorded site, when cultural materials were observed during the pedestrian survey, or when cultural materials were observed during profile inspection.

A total of three archaeological sites (i.e., 41BP960, 41BP961, and 41GU200) were newly identified during the auger probe and backhoe trench investigation; the results for these investigations are presented in the cultural resources descriptions section below. In addition, auger probe and/or backhoe trench investigations were also conducted at previously recorded archaeological sites $41 \mathrm{BP} 920$ and $41 \mathrm{GU} 177$. Both sites were identified during the initial 2015 investigations and were recommended for further evaluation (i.e., significance testing and/or data recovery). The auger probe and/or backhoe trench data for these cultural resources are presented within their respective significance testing reports (Rodriguez and Young 2018; Nielsen et al. 2018). All remaining auger probes and backhoe trenches excavated during the 2016 to 2018 investigations were negative for cultural materials (Appendix C).

In general, the auger probe and backhoe trench profiles exhibited successive horizons of gradually lighter colored silt loam deposits that graded into clay loam or clay with clear-gradual lower boundaries. The auger probes and backhoe trenches contained between three and nine stratigraphic layers at each crossing. At the Colorado River and Wilbarger Creek, the horizons had a friable consistency and subangular blocky structure, which graded into a massive, structureless horizon with increasing calcium carbonate inclusions and an extremely firm consistency. In contrast, at the Guadalupe River, the horizons had a friable to firm consistency and subangular blocky structure, which graded into a fine, weak, structureless horizon with increasing limestone gravel and pebble inclusions and a friable to loose consistency.

Broadly defined, the deposits observed during the backhoe trenching along the project corridor varied from north to south. North of the San Marcos River as the project area shifts northeastward away from the Edwards Plateau, the deposits become siltier with more evident calcium carbonate development. The drainages at the southern end, including the San Marcos and Guadalupe Rivers, had broad floodplains with alluvial terraces composed of deep, calcareous clay loams and clays. These deposits appeared to have more evident input from the limestone dominated uplands of the Edwards Plateau that is positioned upstream from the project area. Accordingly, the deposits further north are older and exhibit more soil development, while the deposits at the southern end appear to contain younger, more recent soil development.

\section{Cultural Resources}

Overall, 28 cultural resources were documented or further investigated within the project area during the 2016 to 2018 investigations. Of the 28 resources, seven were isolated finds (i.e., IF08-IF14) that did not warrant formal site recording or require additional investigations. The remaining 21 resources include 12 newly recorded archaeological sites (i.e., 41BU12241BU124, 41LE348-41LE350, 41BP959-41BP962, $41 \mathrm{CW} 173$, and 41GU200), and nine previously recorded sites (i.e., 41LE332, 41BP818, 41BP920, 41GU177, 41GU180, 41CM394, 41CM401, 41CM404, and 41BX2101) initially documented by SWCA during the 2015 investigations or previously recorded prior to the 2015 investigations (Tables 3.3 and 3.4). The further investigations of the previously recorded sites varied dependent upon recommendations reported in the 2015 initial cultural resources report and included archival research, survey, testing, and/or data recovery excavations. In addition, two cemeteries (the Hill Cemetery and the Hoffman Cemetery) were documented during the 2016-2018 investigations. Due to subsequent reroutes, the Hill Cemetery (located within the boundaries of site 41BP818) is now avoided and will not be impacted by the project. Mechanical scraping was conducted adjacent to the Hoffman cemetery; no interments were identified within the project area. Based on the results of the testing investigations, site 41BP920 has now been recommended as NOT ELIGIBLE for listing on the NRHP or for designation as a SAL (Rodriguez and Young 2018). 


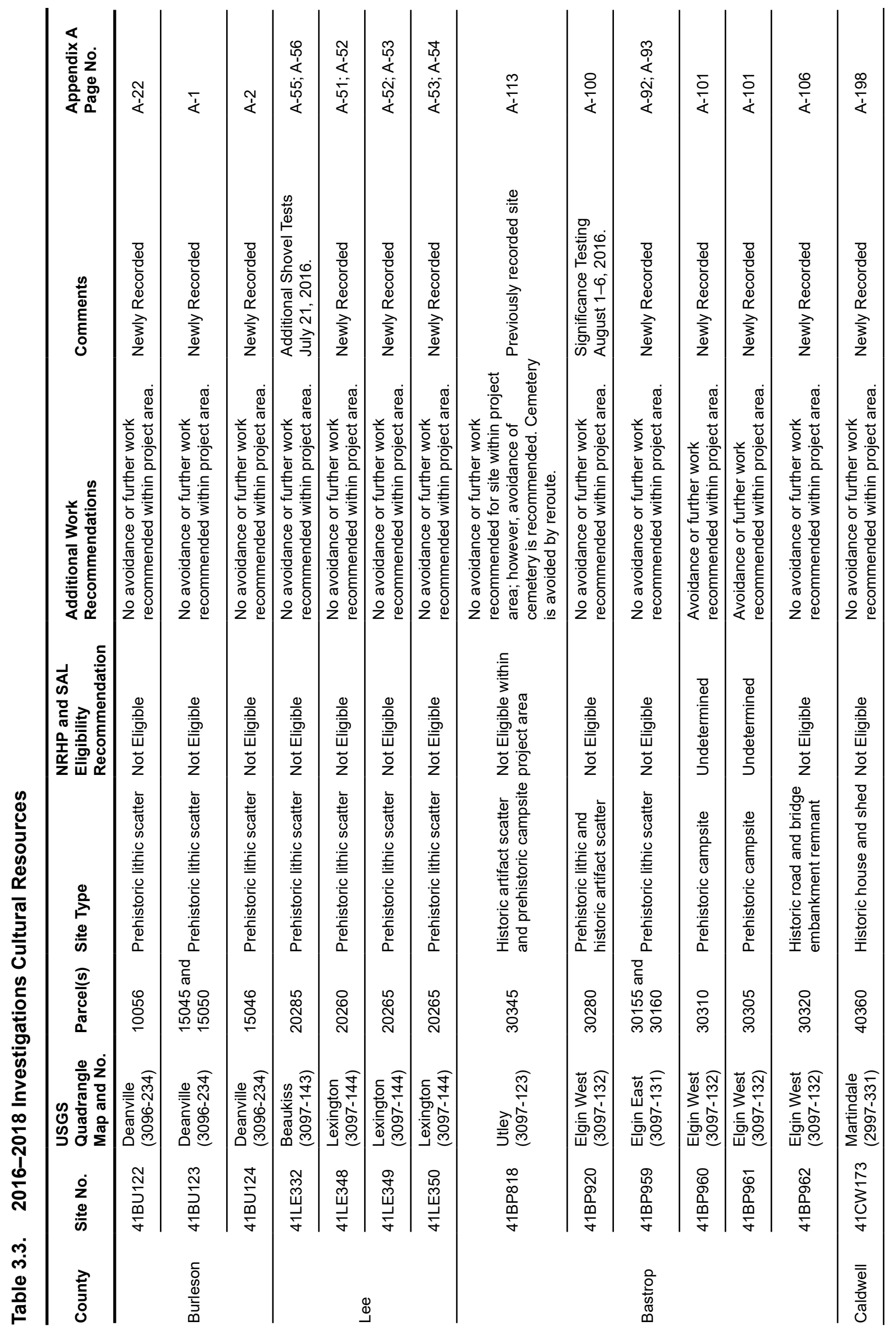




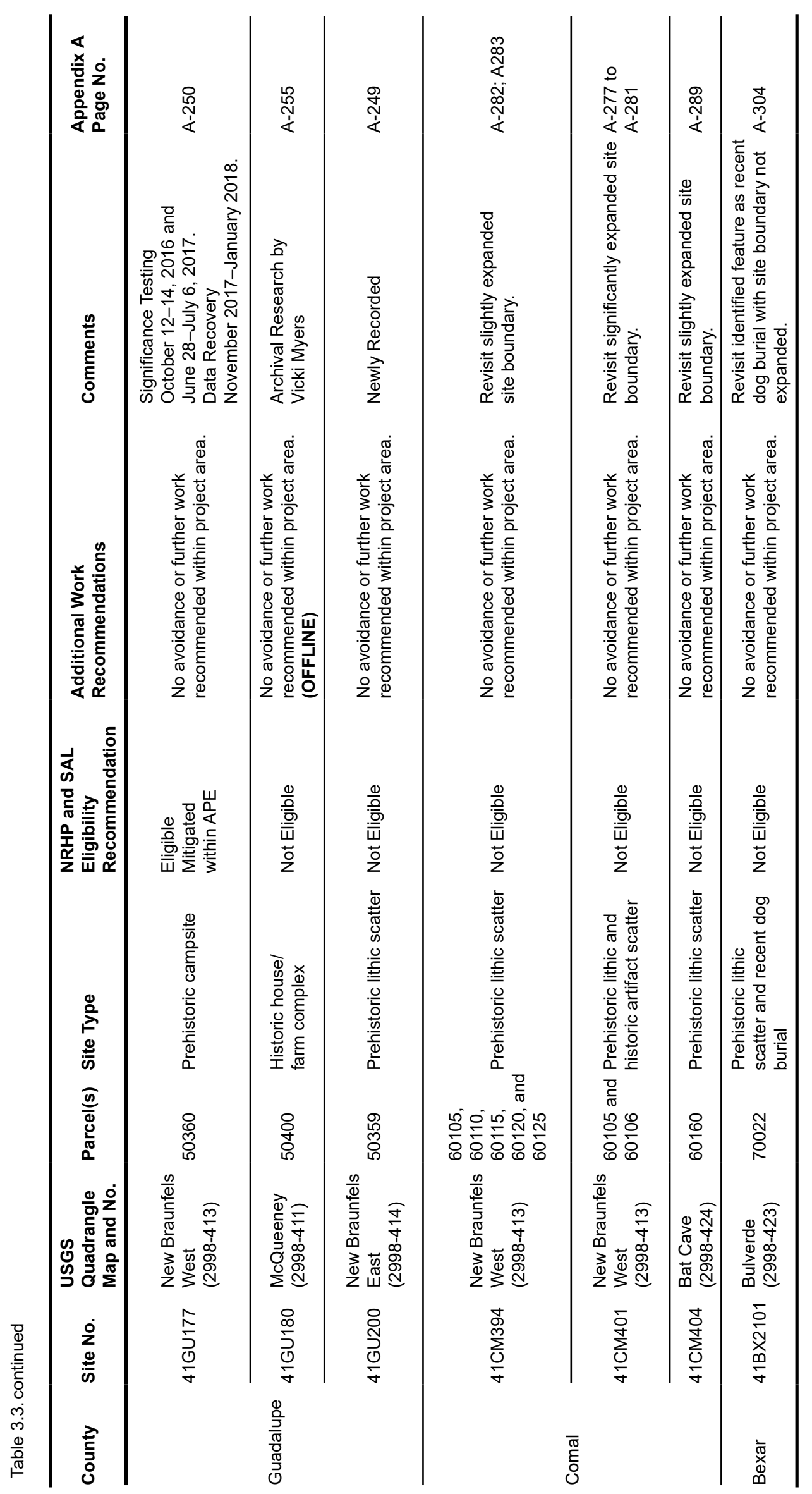




\section{Table 3.4 2016-2018 Investigations Isolated Finds}

\begin{tabular}{|c|c|c|c|c|c|c|c|c|}
\hline County & $\begin{array}{l}\text { Isolated } \\
\text { Find No. }\end{array}$ & $\begin{array}{l}\text { USGS } \\
\text { Quadrangle } \\
\text { Map and No. }\end{array}$ & Parcel(s) & Description & $\begin{array}{l}\text { NRHP and SAL } \\
\text { Eligibility } \\
\text { Recommendations }\end{array}$ & $\begin{array}{l}\text { SWCA } \\
\text { Recommendations }\end{array}$ & Comments & $\begin{array}{l}\text { Appendix A } \\
\text { Sheet No. }\end{array}$ \\
\hline Burleson & IF09 & $\begin{array}{l}\text { Deanville } \\
(3096-234)\end{array}$ & 15081 & $\begin{array}{l}\text { Historic } \\
\text { porcelain } \\
\text { fragment (1) } \\
\text { and } \\
\text { whiteware } \\
\text { fragment (1) }\end{array}$ & Not Eligible & $\begin{array}{l}\text { No avoidance } \\
\text { or further work } \\
\text { recommended within } \\
\text { project area. }\end{array}$ & $\begin{array}{l}\text { On ground } \\
\text { surface }\end{array}$ & A-11 \\
\hline \multirow{4}{*}{ Bastrop } & IF08 & $\begin{array}{l}\text { Elgin East } \\
(3097-131)\end{array}$ & 30019 & $\begin{array}{l}\text { Prehistoric } \\
\text { secondary } \\
\text { flake (1) }\end{array}$ & Not Eligible & $\begin{array}{l}\text { No avoidance } \\
\text { or further work } \\
\text { recommended within } \\
\text { project area. }\end{array}$ & $\begin{array}{l}\text { Within ST } \\
\text { BKM05 } \\
\text { between 0-50 } \\
\text { cmbs }\end{array}$ & A-76 \\
\hline & IF10 & $\begin{array}{l}\text { Webberville } \\
(3097-214)\end{array}$ & 30370 & $\begin{array}{l}\text { Prehistoric } \\
\text { tertiary flake } \\
\text { (1) }\end{array}$ & Not Eligible & $\begin{array}{l}\text { No avoidance } \\
\text { or further work } \\
\text { recommended within } \\
\text { project area. }\end{array}$ & $\begin{array}{l}\text { Within ST } \\
\text { MFR06 } \\
\text { between 0-10 } \\
\text { cmbs }\end{array}$ & $A-134$ \\
\hline & IF13 & $\begin{array}{l}\text { Elgin East } \\
(3097-131)\end{array}$ & 30065 & $\begin{array}{l}\text { Prehistoric } \\
\text { tertiary flakes } \\
(2)\end{array}$ & Not Eligible & $\begin{array}{l}\text { No avoidance } \\
\text { or further work } \\
\text { recommended within } \\
\text { project area. }\end{array}$ & $\begin{array}{l}\text { Within } \\
\text { ST VM09 } \\
\text { between } \\
30-40 \mathrm{cmbs}\end{array}$ & A-83 \\
\hline & IF14 & $\begin{array}{l}\text { Elgin East } \\
(3097-131)\end{array}$ & 30065 & $\begin{array}{l}\text { Prehistoric } \\
\text { tertiary flake } \\
\text { (1) }\end{array}$ & Not Eligible & $\begin{array}{l}\text { No avoidance } \\
\text { or further work } \\
\text { recommended within } \\
\text { project area. }\end{array}$ & $\begin{array}{l}\text { Within } \\
\text { ST JIS10 } \\
\text { between 0-10 } \\
\text { cmbs }\end{array}$ & A-83 \\
\hline Guadalupe & IF12 & $\begin{array}{l}\text { San Marcos } \\
\text { South } \\
(2997-332)\end{array}$ & 50085 & $\begin{array}{l}\text { Prehistoric } \\
\text { primary flake } \\
\text { (1) }\end{array}$ & Not Eligible & $\begin{array}{l}\text { No avoidance } \\
\text { or further work } \\
\text { recommended within } \\
\text { project area. }\end{array}$ & $\begin{array}{l}\text { Within } \\
\text { ST JIS06 } \\
\text { between } \\
10-20 \mathrm{cmbs}\end{array}$ & $A-214$ \\
\hline Bexar & IF11 & $\begin{array}{l}\text { Bat Cave } \\
(2998-424)\end{array}$ & 70015 & $\begin{array}{l}\text { Prehistoric } \\
\text { crude biface } \\
\text { (1), modified } \\
\text { flake (1), and } \\
\text { primary flake } \\
\text { (1) }\end{array}$ & Not Eligible & $\begin{array}{l}\text { No avoidance } \\
\text { or further work } \\
\text { recommended within } \\
\text { project area. }\end{array}$ & $\begin{array}{l}\text { On ground } \\
\text { surface }\end{array}$ & A-299 \\
\hline
\end{tabular}

Of the 21 sites, two sites (i.e., 41BP960 and 41BP961) are UNDETERMINED regarding NRHP and SAL eligibility; however, both have currently been avoided by design alignment changes by the Vista Ridge Project. Site 41GU177 was determined to be ELIGIBLE for listing on the NRHP and for designation as a SAL; testing and data recovery excavations were conducted at the site and the results will be presented in a separate report (Nielsen et al. 2019). The remaining 18 sites are interpreted to have a low research value and are considered NOT ELIGIBLE for listing on the NRHP or for designation as SALs and no further work or avoidance is recommended. The results reported in this chapter are organized by county, beginning in Burleson County and concluding in Bexar County in northern San Antonio, Texas.

\section{BURLESON COUNTY}

Three cultural resource sites and one isolated find were newly recorded in Burleson County (Figure 3.1; see Table 3.3). All three sites (i.e., 41BU122-41BU124) consist of prehistoric lithic scatters. The isolated find (i.e., IF09) consists of historic porcelain and whiteware sherd fragments and was not recorded as an archaeological site (Appendix A:11; see Table 3.4). SWCA recommends all three of the newly recorded archaeological sites (i.e., 41BU122-41BU124) as NOT ELIGIBLE for listing in the NRHP or for designation as SALs. No avoidance strategy or further work is recommended for the portions of these sites within the project corridor. 


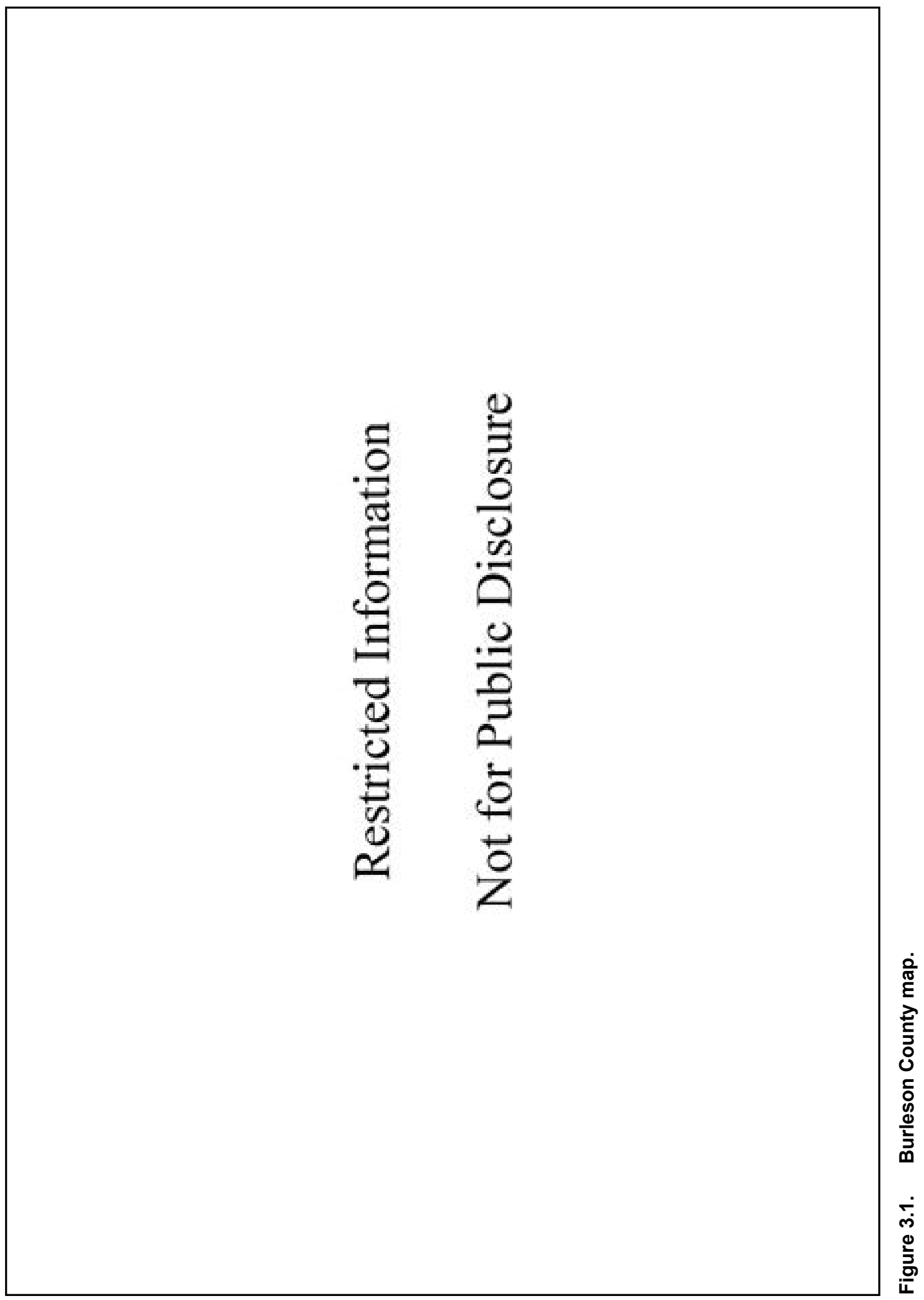




\section{BU122}

Site 41BU122 is a deeply buried subsurface prehistoric lithic scatter of unknown temporal or cultural affiliation located approximately 0.87 mile northwest of the FM 696 and County Road (CR) 324 intersection in northwestern Burleson County, Texas (Figure 3.2; Appendix $\mathrm{A}: 22)$. The site is situated along a forested upland terrace approximately $150 \mathrm{~m}$ east of East Yegua Creek (Figure 3.3). Vegetation consists of dense hardwood forest with thick secondary undergrowth coupled with open areas along a network of two-track roads on the property. Ground surface visibility was poor within the forested areas but approached 100 percent along the two-track that traverses the northern half of the site. Site 41BU122 is located on privately owned land used for ranching and oil and gas activities. Disturbances observed within the site include erosion, vegetation clearing, fence lines, two-track roads and nearby oil and gas activities.

Site 41BU122 measures approximately $30 \mathrm{~m}$ north/ south by $45 \mathrm{~m}$ east/west within the project corridor, based on artifact distribution and landforms; however, the site may extend beyond the project area to the north and south. No cultural materials were observed along the ground surface despite good visibility along bordering and adjacent two-track roads.
SWCA excavated a total of six shovel tests (i.e., KH51-53 and MCC166-168) to delineate the site at approximately $25-\mathrm{m}$ intervals, of which two (i.e., KH51 and MCC167) contained subsurface cultural materials (Table 3.5). Shovel tests typically revealed deep brown (7.5YR 5/4) sandy loam with 1-5 percent gravel and pebble inclusions. Shovel tests near the site terminated at depth (i.e., $100 \mathrm{cmbs}$ ), while shovel tests toward the southwest terminated at strong brown (7.5YR 5/8) sandy clay or clay between 35 and $60 \mathrm{cmbs}$. Cultural materials identified include one secondary chert flake, nine tertiary chert flakes, and one chert biface between 20 and $80 \mathrm{cmbs}$ (Figure 3.4). No temporally diagnostic artifacts or cultural features were observed on the ground surface of within the excavated shovel tests.

\section{BU122 SUMMARY}

Site 41BU122 consists of a low-density, deeply buried prehistoric lithic scatter of primarily debitage located from 20 to $80 \mathrm{cmbs}$. The site has a low density of artifacts and lacks temporally diagnostic artifacts or cultural features. Based on these data, it is SWCA's opinion that site 41BU122 does not have the potential to yield information important to the prehistory of the region. As such, SWCA recommends site 41BU122 as NOT ELIGIBLE for listing on the NRHP or for designation as a SAL. No further work or avoidance strategy

Table 3.5. Shovel Test Data for Site 41BU122

\begin{tabular}{|c|c|c|c|c|c|c|c|c|c|}
\hline $\begin{array}{l}\text { Shovel } \\
\text { Test No. }\end{array}$ & Level & $\begin{array}{l}\text { Depth } \\
\text { (cmbs) }\end{array}$ & $\begin{array}{l}\text { Munsell } \\
\text { Soil Value }\end{array}$ & $\begin{array}{l}\text { Munsell } \\
\text { Soil Color }\end{array}$ & $\begin{array}{l}\text { Soil } \\
\text { Texture }\end{array}$ & $\begin{array}{l}\text { Inclusion } \\
\text { Percentage }\end{array}$ & $\begin{array}{l}\text { Inclusion } \\
\text { Type }\end{array}$ & Cultural Materials & $\begin{array}{l}\text { Comments/ } \\
\text { Reason for } \\
\text { Termination }\end{array}$ \\
\hline KH51 & 1 & $0-100$ & 7.5YR 5/4 & brown & $\begin{array}{l}\text { Sandy } \\
\text { Loam }\end{array}$ & $1-5 \%$ & Pebbles & $\begin{array}{l}\text { 1: Biface }[50-60 \mathrm{cmbs}], 9 \text { : } \\
\text { Flake (tertiary) } \\
\text { [3 at } 20-30 \mathrm{cmbs}, 2 \text { at } 50- \\
60 \mathrm{cmbs} \text {, and } 4 \text { at } 70-80 \\
\text { cmbs]. }\end{array}$ & $\begin{array}{l}\text { Terminated at } \\
\text { depth. }\end{array}$ \\
\hline \multirow{2}{*}{ KH52 } & 1 & $0-50$ & 10YR 5/4 & $\begin{array}{l}\text { yellowish } \\
\text { brown }\end{array}$ & $\begin{array}{l}\text { Sandy } \\
\text { Loam }\end{array}$ & $1-5 \%$ & $\begin{array}{l}\text { Pebbles, } \\
\text { Roots }\end{array}$ & None & - \\
\hline & 2 & $50-60$ & 7.5YR 5/8 & $\begin{array}{l}\text { strong } \\
\text { brown }\end{array}$ & $\begin{array}{l}\text { Sandy } \\
\text { Clay }\end{array}$ & $1-5 \%$ & None & None & $\begin{array}{l}\text { Terminated at } \\
\text { compact soil. }\end{array}$ \\
\hline KH53 & 1 & $0-100$ & 7.5YR 5/4 & brown & $\begin{array}{l}\text { Sandy } \\
\text { Loam }\end{array}$ & $1-5 \%$ & None & None & $\begin{array}{l}\text { Terminated at } \\
\text { depth. }\end{array}$ \\
\hline \multirow{2}{*}{ MCC166 } & 1 & $0-25$ & $7.5 Y R 5 / 3$ & brown & $\begin{array}{l}\text { Sandy } \\
\text { Loam }\end{array}$ & $1-5 \%$ & Gravels & None & - \\
\hline & 2 & $25-35$ & 7.5YR 5/8 & $\begin{array}{l}\text { strong } \\
\text { brown }\end{array}$ & Clay & & & None & $\begin{array}{l}\text { Terminated at } \\
\text { basal clay. }\end{array}$ \\
\hline MCC167 & 1 & $0-100$ & $7.5 Y R 5 / 3$ & brown & $\begin{array}{l}\text { Sandy } \\
\text { Loam }\end{array}$ & $1-5 \%$ & Gravels & $\begin{array}{l}\text { 1: Flake (secondary) [50- } \\
60 \mathrm{cmbs}]\end{array}$ & $\begin{array}{l}\text { Terminated at } \\
\text { depth. }\end{array}$ \\
\hline \multirow{2}{*}{ MCC168 } & 1 & $0-50$ & $7.5 Y R$ 5/3 & brown & $\begin{array}{l}\text { Sandy } \\
\text { Loam }\end{array}$ & $1-5 \%$ & Gravels & None & - \\
\hline & 2 & $50-60$ & 7.5YR 5/8 & $\begin{array}{l}\text { strong } \\
\text { brown }\end{array}$ & Clay & - & - & None & $\begin{array}{l}\text { Terminated at } \\
\text { basal clay. }\end{array}$ \\
\hline
\end{tabular}




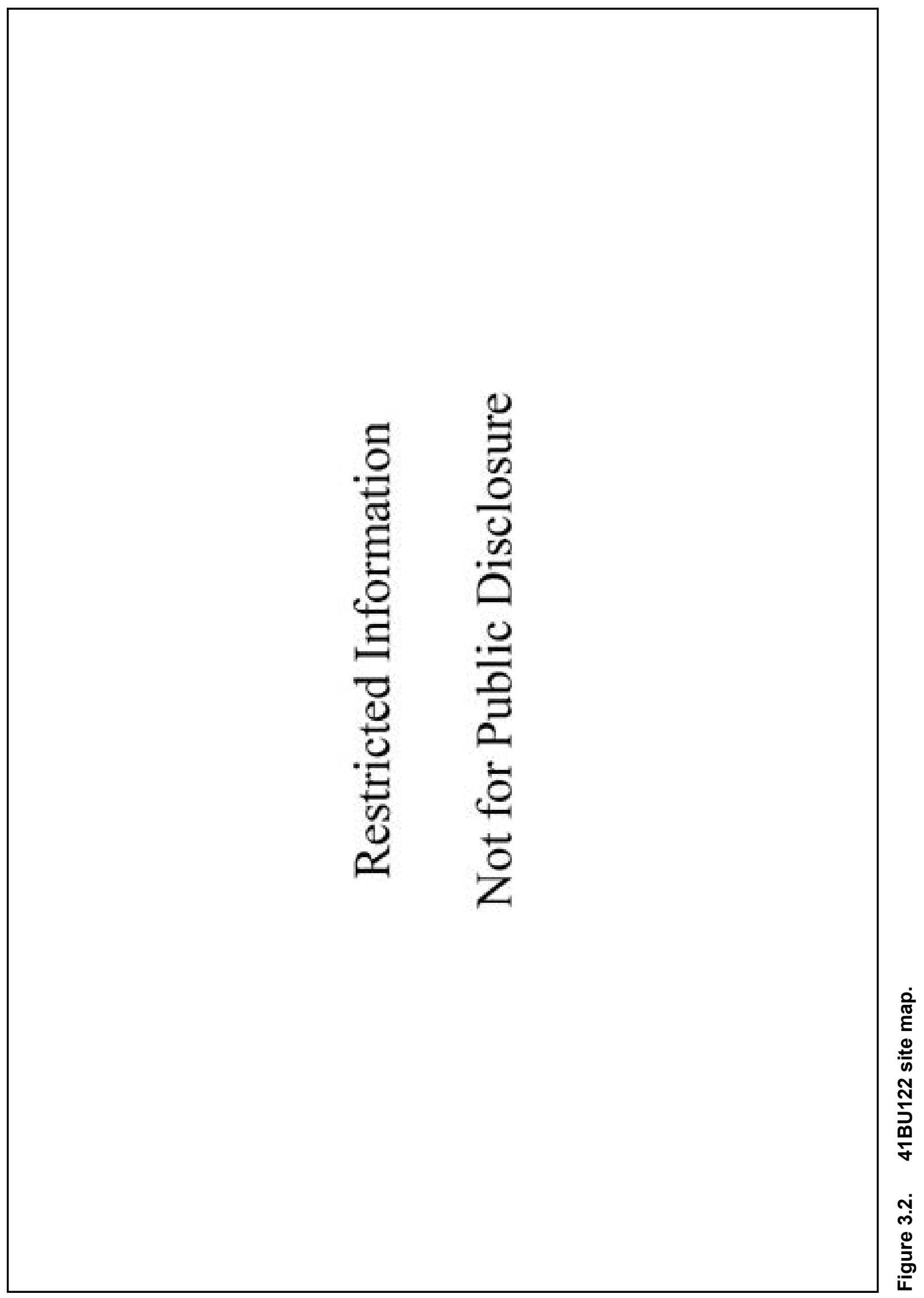




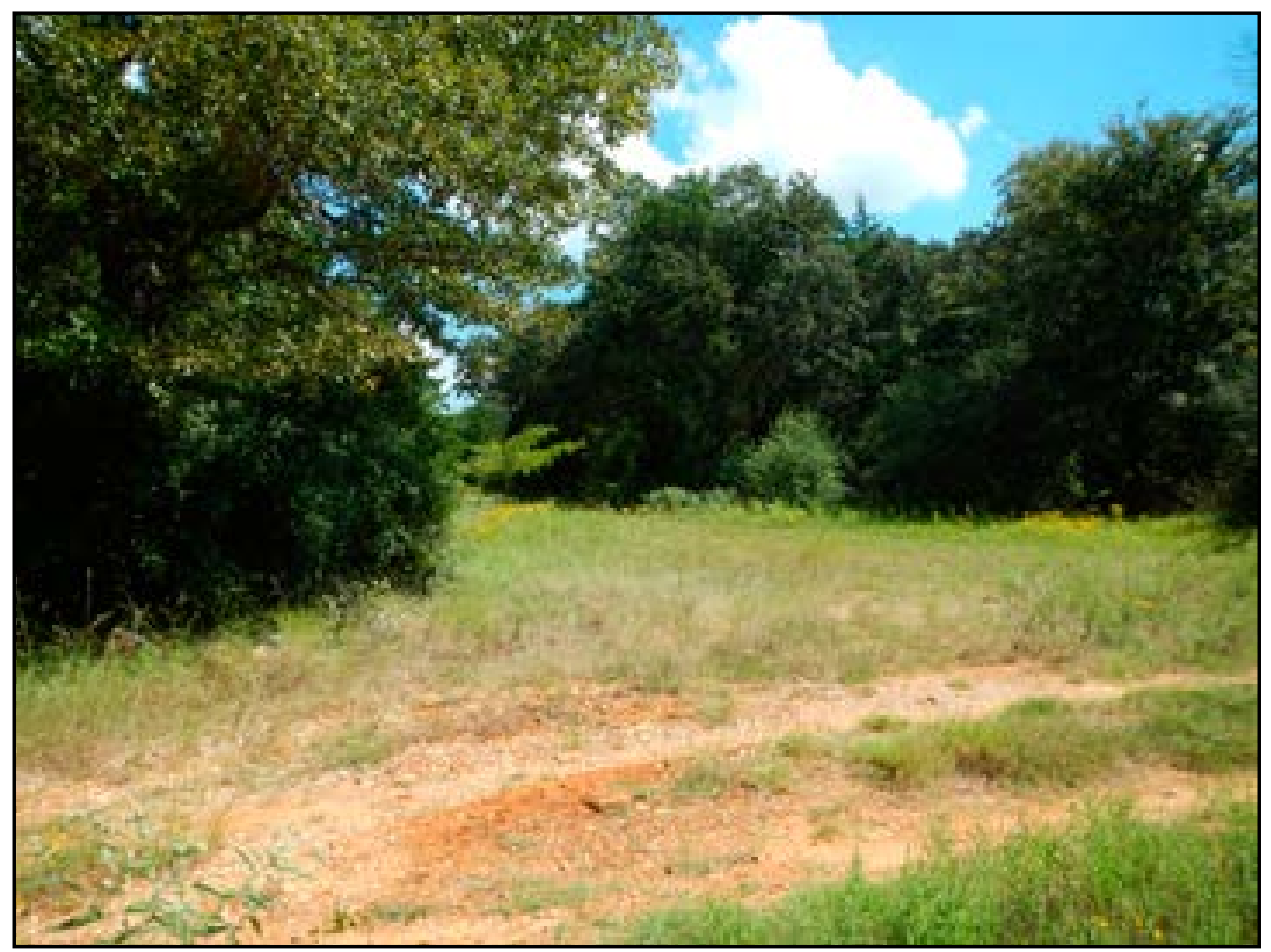

Figure 3.3. Overview of site 41BU122, facing east-northeast.

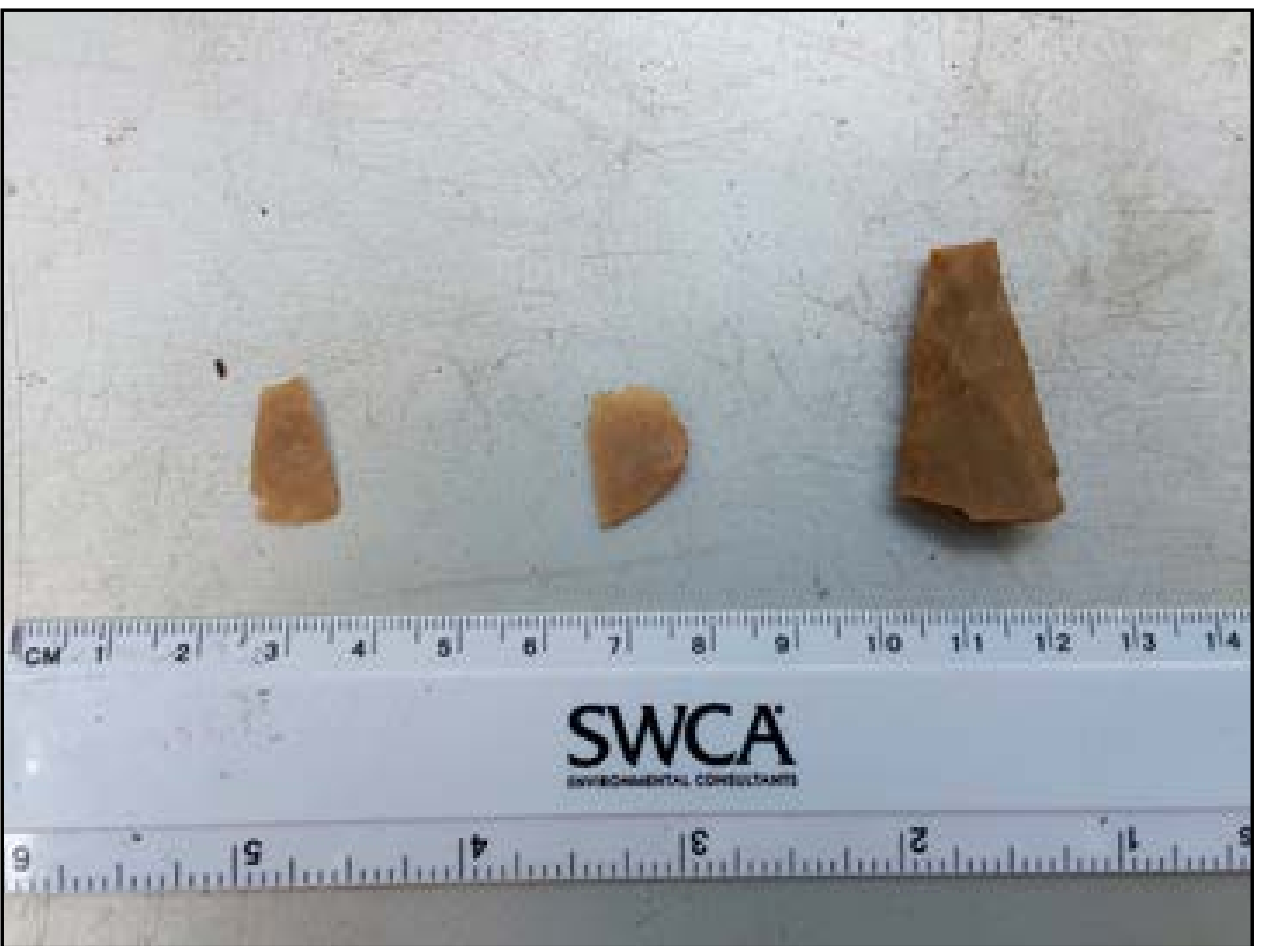

Figure 3.4. Biface and flakes from site 41BU122 in ST KH51 between 20-80 cmbs. 
is recommended for the portions of site $41 \mathrm{BU} 122$ within the project area.

\section{BU123}

Site 41BU123 is a possible Late Prehistoric surficial lithic scatter located along a fence line between two parcels approximately 1 mile southeast of CR 367 and 1.27 miles southwest of the State Highway (SH) 21 and FM 696 intersection in northwestern Burleson County, Texas (Figure 3.5; Appendix A:1). The site is situated within cleared ranch land along an upland terrace overlooking Buffalo Creek located approximately $150 \mathrm{~m}$ to the north (Figure 3.6). Vegetation in the area consists of sparse, short grasses and scattered juniper and scrub affording approximately 90 percent ground surface visibility and a robust riparian zone along the creek to the north. Site 41BU123 is located on privately owned land used for agricultural and ranching activities. Disturbances observed within the site include erosion, vegetation clearing, fence lines, two-track roads, and nearby land modification for stock ponds.

Site 41BU123 measures approximately $37 \mathrm{~m}$ north/ south by $26 \mathrm{~m}$ east/west within the project area based on the distribution of surface artifacts. The artifact assemblage observed consists of five secondary and four tertiary reduction flakes, two modified flakes, one possible perforator, one possible groundstone, and one arrow point midsection, likely a Perdiz point (Figures 3.7 and 3.8). The presence of the arrow point suggests a Late Prehistoric component. Raw material consists of chert except for the possible groundstone.

SWCA excavated a total of five shovel tests (i.e., AE14, CS14-15, DPR13, and MCC216) to delineate the site at approximately $25-\mathrm{m}$ intervals, none of which contained subsurface cultural materials (Table 3.6). Additional survey shovel tests to the east and southeast were also negative for cultural materials. Shovel tests typically revealed deep brown (7.5YR 4/3) to very dark brown (7.5YR 2.5/3) sandy clay loam with 1-5 percent gravel and pebble inclusions. Shovel tests near Buffalo Creek, north of the site terminated at depth (i.e., $100 \mathrm{cmbs}$ ), while shovel tests toward the southwest terminated at red $(2.5 \mathrm{YR} 5 / 8)$ or yellowish red (5YR 4/6) clay between 30 and $60 \mathrm{cmbs}$. Due to project constraints, the site was not fully delineated to the west or southwest, as investigations were not permitted outside the project ROW.

Table 3.6. Shovel Test Data for Site 41BU123

\begin{tabular}{|c|c|c|c|c|c|c|c|c|c|}
\hline $\begin{array}{l}\text { Shovel } \\
\text { Test No. }\end{array}$ & Level & $\begin{array}{l}\text { Depth } \\
\text { (cmbs) }\end{array}$ & $\begin{array}{l}\text { Munsell So } \\
\text { Value }\end{array}$ & $\begin{array}{l}\text { il Munsell Soil } \\
\text { Color }\end{array}$ & $\begin{array}{l}\text { Soil } \\
\text { Texture }\end{array}$ & $\begin{array}{l}\text { Inclusion } \\
\text { Percentage }\end{array}$ & $\begin{array}{l}\text { Inclusion } \\
\text { Type }\end{array}$ & $\begin{array}{l}\text { Cultural } \\
\text { Materials }\end{array}$ & $\begin{array}{l}\text { Comments/ } \\
\text { Reason for Termination }\end{array}$ \\
\hline \multirow[t]{2}{*}{ AE14 } & 1 & $0-35$ & 7.5YR 3/4 & dark brown & $\begin{array}{l}\text { Sandy Cla } \\
\text { Loam }\end{array}$ & $\mathrm{y}_{1-5 \%}$ & Gravels & None & - \\
\hline & 2 & $35-50$ & $5 Y R$ Y/6 & yellowish red & Clay & $1-5 \%$ & Redox & None & Terminated at basal clay. \\
\hline \multirow{3}{*}{ CS15 } & 1 & $0-30$ & 7.5YR $4 / 3$ & brown & $\begin{array}{l}\text { Sandy } \\
\text { Loam }\end{array}$ & $1-5 \%$ & Pebbles & None & - \\
\hline & 2 & $30-50$ & 10YR 4/4 & $\begin{array}{l}\text { dark yellowish } \\
\text { brown }\end{array}$ & $\begin{array}{l}\text { Sandy Cla } \\
\text { Loam }\end{array}$ & & - & None & - \\
\hline & 3 & $50-60$ & 10YR 4/6 & $\begin{array}{l}\text { dark yellowish } \\
\text { brown }\end{array}$ & Sandy Cla & y $1-5 \%$ & $\begin{array}{l}\text { Iron oxide } \\
\text { mottling }\end{array}$ & None & Terminated at basal clay. \\
\hline \multirow{2}{*}{ DPR12 } & 1 & $0-40$ & 7.5YR $2.5 / 3$ & very dark brown & $\begin{array}{l}\text { Sandy Cla } \\
\text { Loam }\end{array}$ & & - & None & - \\
\hline & 2 & $40-100$ & 10YR 4/4 & $\begin{array}{l}\text { dark yellowish } \\
\text { brown }\end{array}$ & \multicolumn{2}{|c|}{$\begin{array}{l}\text { Sandy Clay } \\
\text { Loam }\end{array}$} & - & None & Terminated at depth. \\
\hline DPR13 & 1 & $0-30$ & $2.5 Y R 5 / 8$ & red & Clay & - & - & None & Terminated at basal clay. \\
\hline MCC216 & 1 & $0-30$ & 7.5YR 5/6 & strong brown & \multicolumn{2}{|c|}{ Sandy Clay- } & - & None & \\
\hline
\end{tabular}




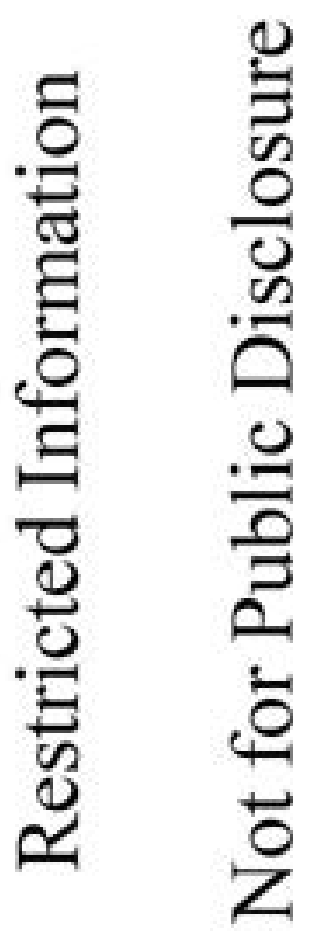

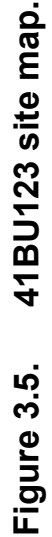




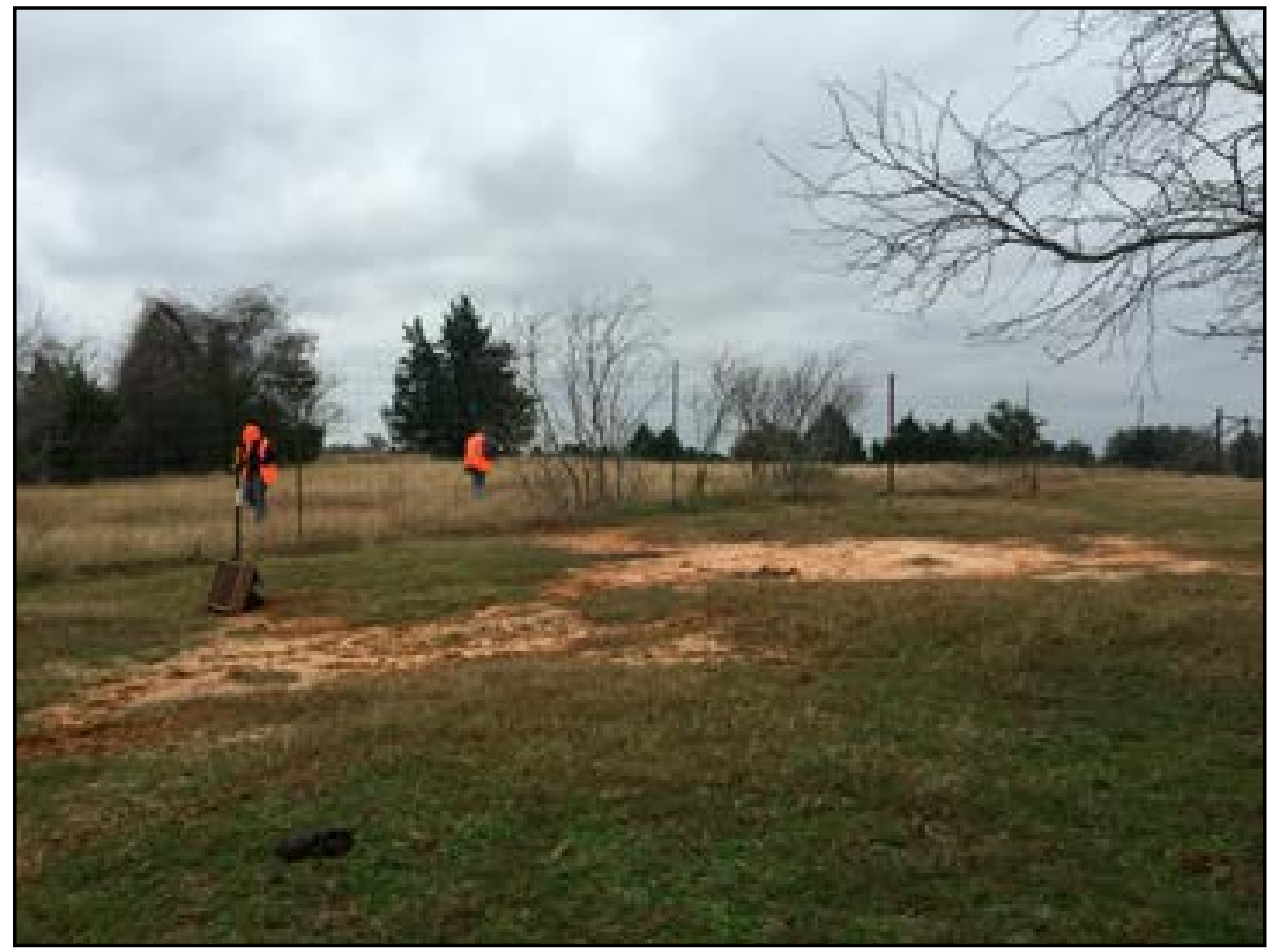

Figure 3.6. Overview of site 41BU123, facing southeast.

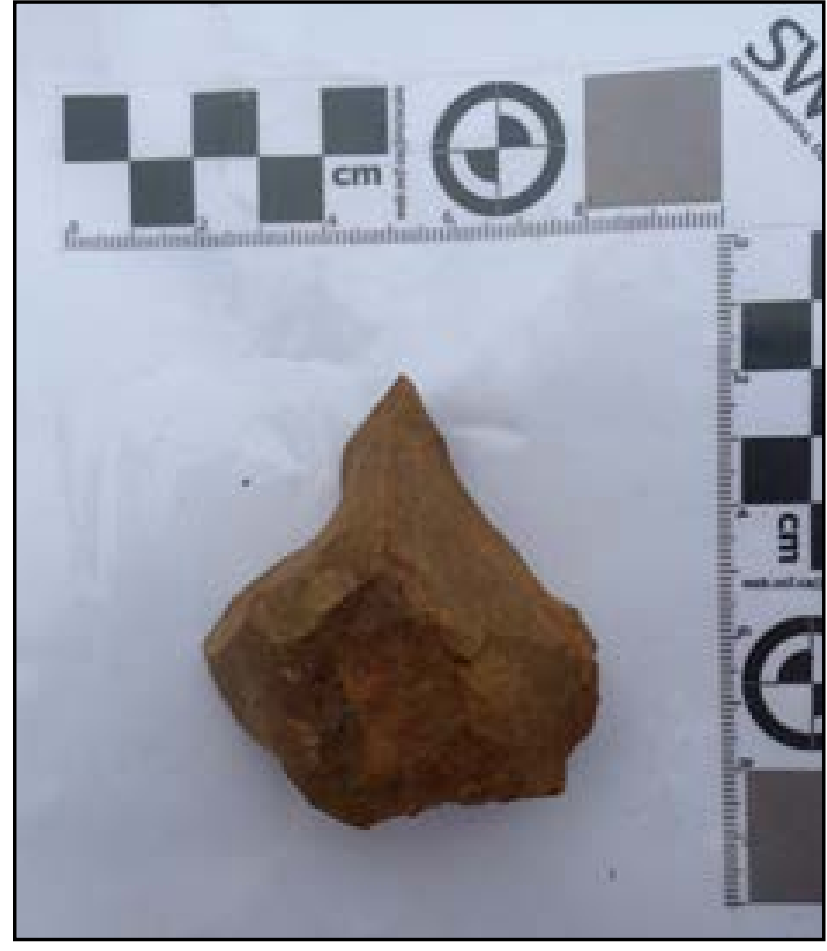

Figure 3.7. Possible perforator from ground surface of site 41BU123.

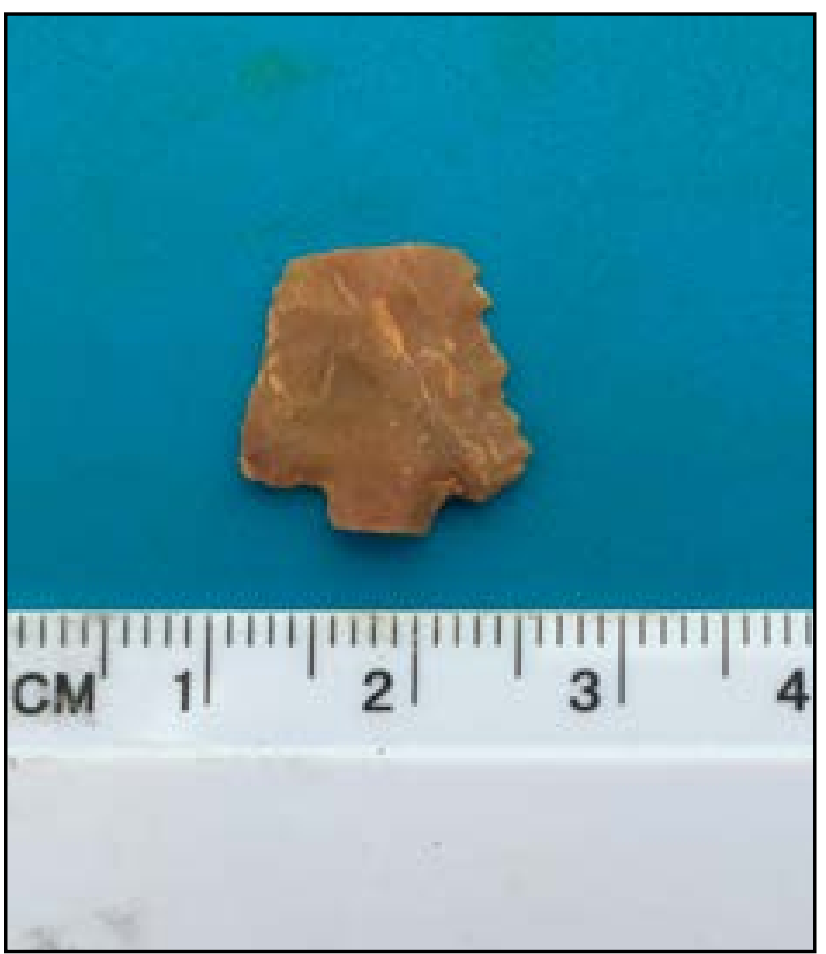

Figure 3.8. Possible Perdiz arrow point midsection from ground surface of site 41BU123. 


\section{A1BU123 SUMMARY}

Site 41BU123 consists of a small surficial prehistoric lithic scatter of flakes and tools. The site has a low density of artifacts, lacks cultural features or temporally diagnostic artifacts with the exception of the arrow point midsection, and lacks deposition. Based on these data, it is SWCA's opinion that site 41BU123 does not have the potential to yield information important to the prehistory of the region. As such, SWCA recommends site 41BU123 as NOT ELIGIBLE for listing on the NRHP or for designation as a SAL. No further work or avoidance strategy is recommended for site 41BU123 within the project area.

\section{BU124}

Site 41BU124 is a deeply buried, subsurface prehistoric lithic scatter of unknown temporal or cultural affiliation located approximately 0.70 mile southeast of CR 367 and 1.13 miles southwest of the SH 21 and FM 696 intersection in northwestern Burleson County, Texas (Figure 3.9; Appendix A:2). The site is situated within an open, grassy pasture on an upland terrace overlooking Buffalo Creek $115 \mathrm{~m}$ to the south (Figure 3.10). Vegetation in the area consists of short grasses within the pasture and a robust mixed hardwood riparian zone along the creek to the south. Ground surface visibility was poor due to grass cover and averaged $0-5$ percent. Site 41BU124 is located on privately owned land used for agricultural and ranching activities. Disturbances include erosion, vegetation clearing, plowing, fence lines, two-track roads, and nearby land modification for stock ponds.

Site 41BU124 measures approximately $78 \mathrm{~m}$ northwest/southeast by $30 \mathrm{~m}$ northeast/southwest within the project area based on artifact distributions within shovel tests; however, the site may extend beyond the project area to the east and west. Due to the poor ground surface visibility, no cultural materials were observed along the ground surface.

SWCA excavated a total of six shovel tests (i.e., AE203-205, CS40, and MCC247-248) to delineate the site at approximately $25-\mathrm{m}$ intervals, two of which (CS40 and MCC247) contained subsurface cultural materials (Table 3.7). Cultural materials recovered consist of one chert secondary reduction flake in shovel test MCC 247 between 70 and $80 \mathrm{cmbs}$ and one utilized chert flake in shovel test CS40 between 90 and $100 \mathrm{cmbs}$ (Figures 3.11 and 3.12). In addition, charcoal chunks likely representing recent burning events were also encountered in shovel test MCC247 between 0 and $70 \mathrm{cmbs}$ above the level containing the secondary flake. Shovel tests typically revealed brown (7.5YR 5/4) sandy clay loam with $1-5$ percent gravel and pebble inclusions. Shovel tests near Buffalo Creek, north of the site, terminated at depth (i.e., 100 cmbs), while shovel tests toward the northern edge of the site terminated at compacted brown (7.5YR 5/3) or yellowish red (5YR 4/6) sandy clay between 60 and $80 \mathrm{cmbs}$. Due to project constraints, the site was not fully delineated to the east or west, as investigations were not permitted outside the project ROW.

\section{A1BU124 SUMMARY}

Site 41BU124 consists of a small, very low density buried prehistoric lithic scatter of debitage containing cultural material from 70 to $100 \mathrm{cmbs}$. The site has a very low quantity of artifacts and lacks temporally diagnostic artifacts or cultural features. Based on these data, site 41BU124 does not have the potential to yield information important to the prehistory of the region. As such, SWCA recommends site 41BU124 as NOT ELIGIBLE for the NRHP or for designation as a SAL. No further work or avoidance strategy is recommended for site 41BU124 within the project area.

\section{LEE COUNTY}

Three cultural resource sites were newly recorded and one previously recorded cultural resource site was revisited during further investigations in Lee County (Figure 3.13; see Table 3.3). The three newly recorded archaeological sites (i.e., 41LE348-41LE350) consist of prehistoric lithic scatters. The previously recorded archaeological site (i.e., 41LE332) consists of a prehistoric lithic scatter that was recommended for avoidance or further testing during the 2015 investigations. SWCA recommends all four sites as NOT ELIGIBLE for listing in the NRHP or SAL designation. No avoidance strategy or further work is recommended for the portions of these sites within the project corridor.

\section{LE332}

Site 41LE332 is a surface and subsurface prehistoric lithic scatter of unknown temporal or cultural affiliation situated on an upland slope overlooking the confluence of Middle Yegua Creek and Pin Oak Branch in northwestern Lee County, Texas (Figure 3.14; Appendix A:55-56). The site was originally recorded during the initial 2015 investigations. Vegetation within the site area consists of moderately dense oak trees with a 


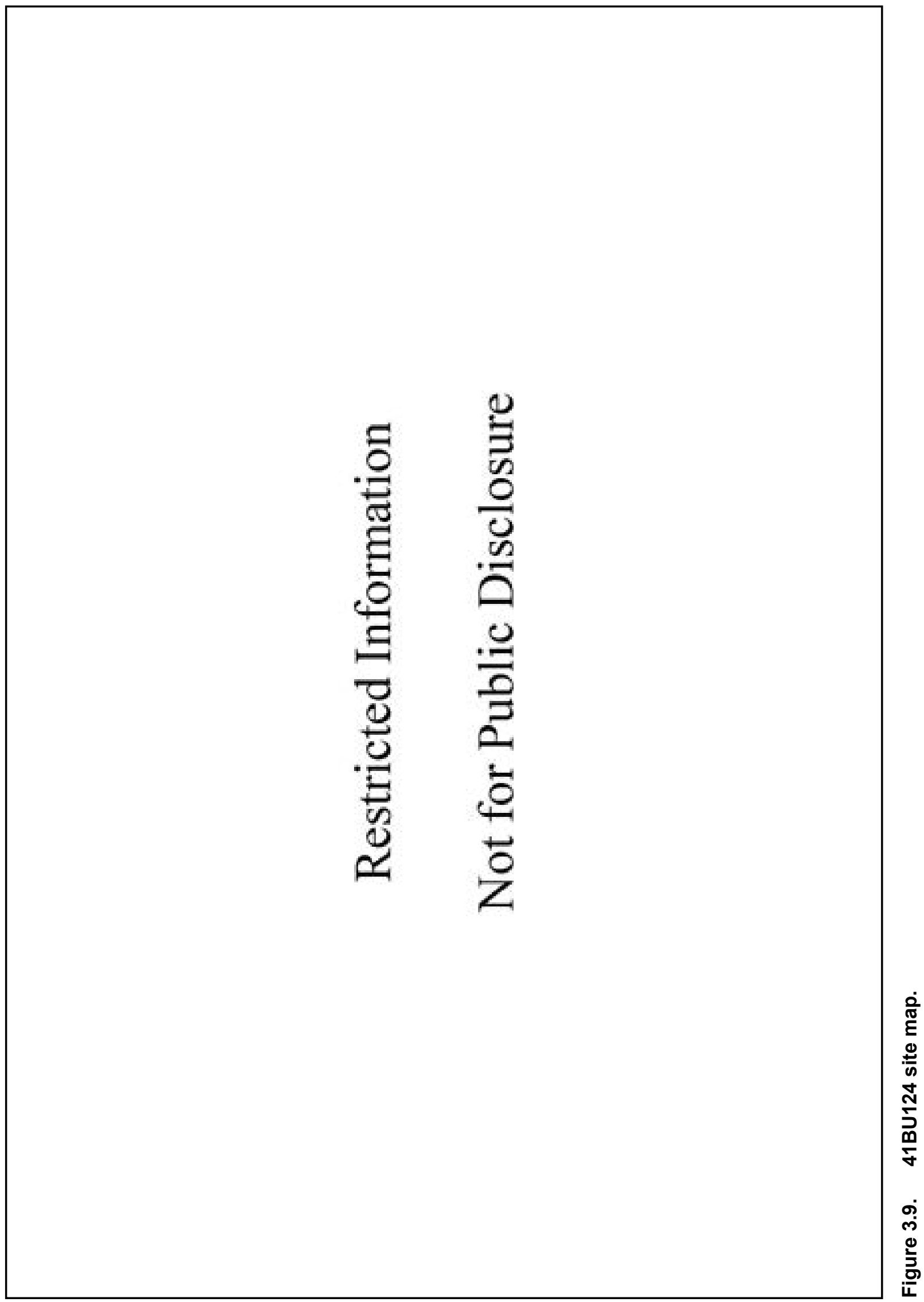




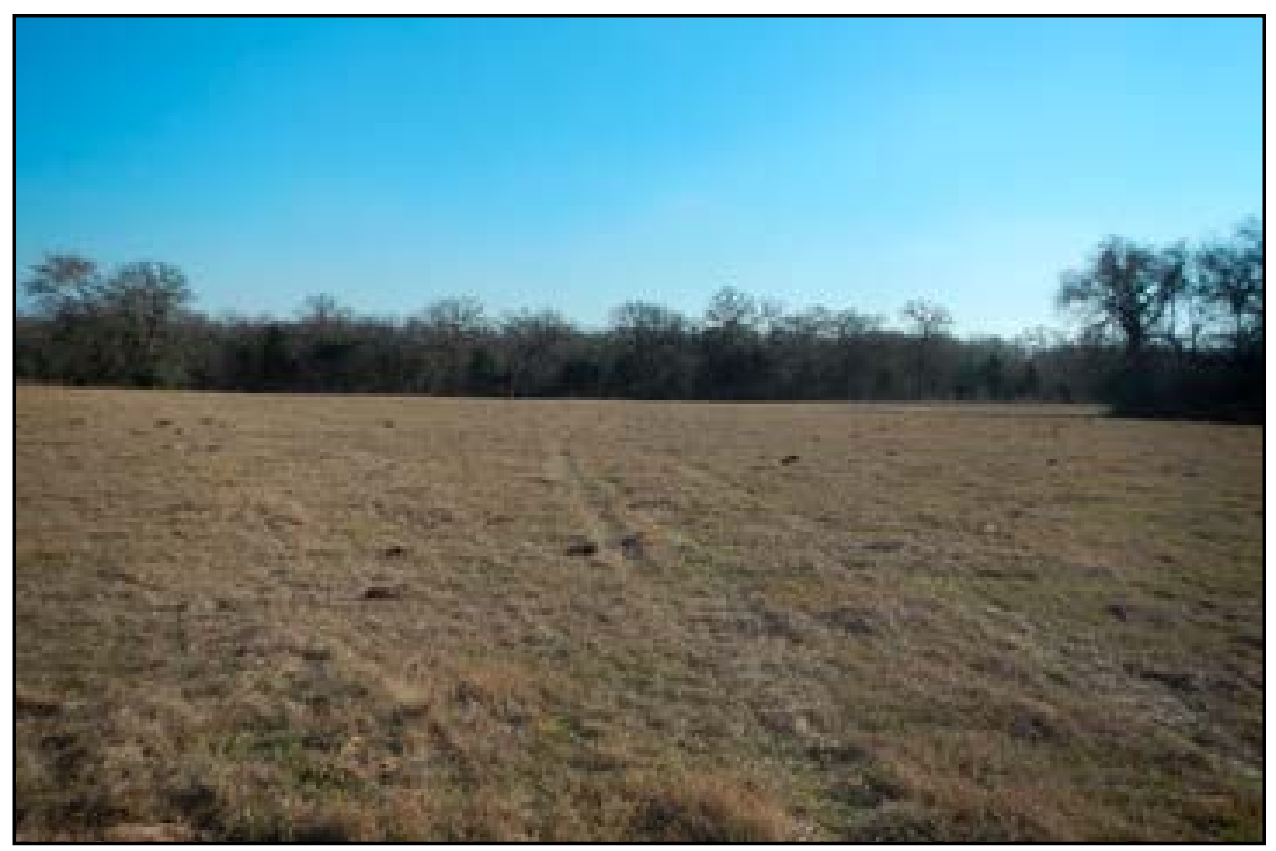

Figure 3.10. Overview of site 41BU124, facing southeast.

Table 3.7. Shovel Test Data for Site 41BU124

\begin{tabular}{|c|c|c|c|c|c|c|c|c|c|}
\hline $\begin{array}{l}\text { Shovel } \\
\text { Test No. }\end{array}$ & Level & $\begin{array}{l}\text { Depth } \\
\text { (cmbs) }\end{array}$ & $\begin{array}{l}\text { Munsell Soil } \\
\text { Value }\end{array}$ & $\begin{array}{l}\text { Munsell } \\
\text { Soil Color }\end{array}$ & $\begin{array}{l}\text { Soil } \\
\text { Texture }\end{array}$ & $\begin{array}{l}\text { Inclusion } \\
\text { Percentage }\end{array}$ & $\begin{array}{l}\text { Inclusion } \\
\text { Type }\end{array}$ & $\begin{array}{l}\text { Cultural } \\
\text { Materials }\end{array}$ & $\begin{array}{l}\text { Comments/ } \\
\text { Reason for } \\
\text { Termination }\end{array}$ \\
\hline AE203 & 1 & $0-70$ & 7.5YR 5/4 & brown & $\begin{array}{l}\text { Loamy } \\
\text { Sand }\end{array}$ & - & - & None & $\begin{array}{l}\text { Terminated at compact } \\
\text { soil. }\end{array}$ \\
\hline \multirow{2}{*}{ AE204 } & 1 & $0-60$ & 7.5YR 4/6 & $\begin{array}{l}\text { strong } \\
\text { brown }\end{array}$ & $\begin{array}{l}\text { Sandy Clay } \\
\text { Loam }\end{array}$ & $5-10 \%$ & $\begin{array}{l}\text { Gravels, } \\
\text { Pebbles }\end{array}$ & None & - \\
\hline & 2 & $60-80$ & 7.5YR 5/3 & brown & $\begin{array}{l}\text { Sandy Clay } \\
\text { Loam }\end{array}$ & $1-5 \%$ & $\begin{array}{l}\text { Gravels, } \\
\text { Pebbles }\end{array}$ & None & $\begin{array}{l}\text { Terminated at compact } \\
\text { soil. }\end{array}$ \\
\hline \multirow{2}{*}{ AE205 } & 1 & $0-40$ & 7.5YR 4/4 & brown & $\begin{array}{l}\text { Sandy } \\
\text { Loam }\end{array}$ & - & - & None & - \\
\hline & 2 & $40-60$ & 5YR 4/6 & $\begin{array}{l}\text { yellowish } \\
\text { red }\end{array}$ & Sandy Clay & - & - & None & $\begin{array}{l}\text { Terminated at basal } \\
\text { clay. }\end{array}$ \\
\hline CS40 & 1 & $0-100$ & 7.5YR 4/3 & brown & $\begin{array}{l}\text { Loamy } \\
\text { Sand }\end{array}$ & $1-5 \%$ & Gravels & $\begin{array}{l}\text { 1: Flake } \\
\text { (utilized) } \\
{[90-100} \\
\text { cmbs]. }\end{array}$ & Terminated at depth. \\
\hline \multirow{2}{*}{ MCC247 } & 1 & $0-70$ & 7.5YR 4/4 & brown & $\begin{array}{l}\text { Sandy } \\
\text { Loam }\end{array}$ & $10-20 \%$ & $\begin{array}{l}\text { Charcoal } \\
\text { chunks } \\
\text { likely from } \\
\text { recent } \\
\text { burning } \\
\text { events }\end{array}$ & None & - \\
\hline & 2 & $70-100$ & 7.5YR 5/4 & brown & $\begin{array}{l}\text { Sandy } \\
\text { Loam }\end{array}$ & - & - & $\begin{array}{l}\text { 1: Flake } \\
\text { (secondary) } \\
{[70-80} \\
\text { cmbs]. }\end{array}$ & Terminated at depth. \\
\hline \multirow{2}{*}{ MCC248 } & 1 & $0-60$ & 7.5YR 5/4 & brown & $\begin{array}{l}\text { Sandy } \\
\text { Loam }\end{array}$ & - & - & None & - \\
\hline & 2 & $60-70$ & 10YR 6/3 & pale brown & $\begin{array}{l}\text { Sandy } \\
\text { Loam }\end{array}$ & - & - & None & $\begin{array}{l}\text { Terminated at water } \\
\text { table. }\end{array}$ \\
\hline
\end{tabular}




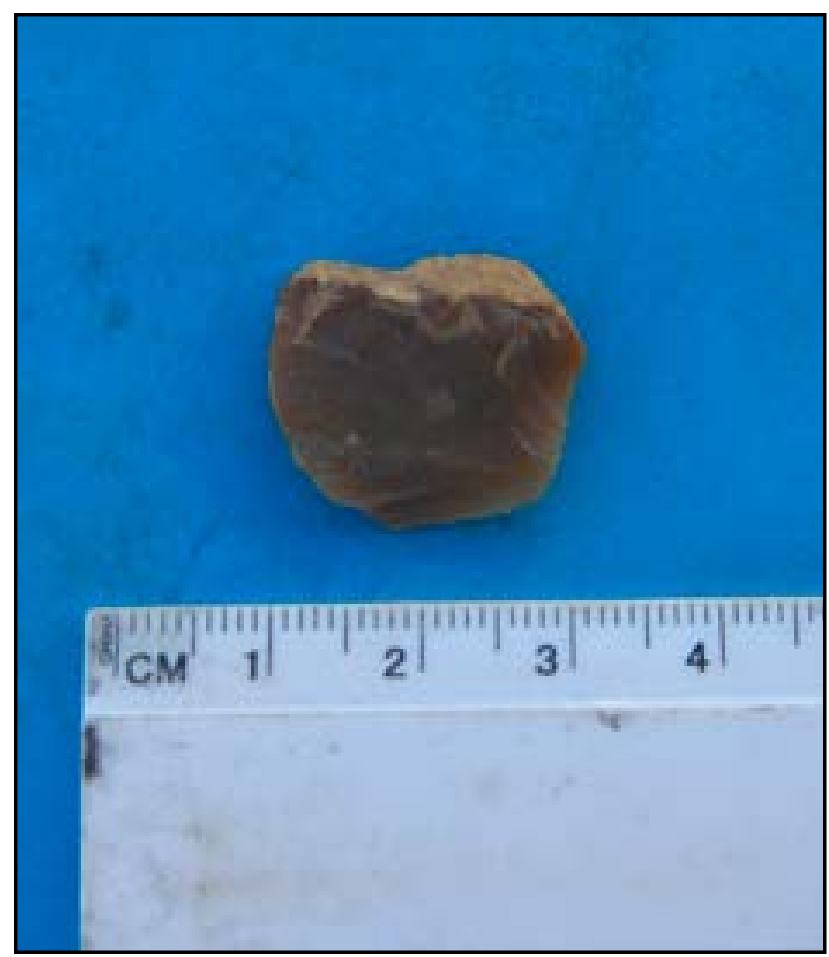

Figure 3.11. Secondary flake from site 41BU124 in ST MCC247 at 70-80 cmbs

light to moderate grass and shrub undergrowth, which afforded 35 to 100 percent ground surface visibility (Figure 3.15). The site is on private property used for hunting recreation activities, and disturbances observed include an existing underground water line and a two-track road utilized for hunting recreation access. SWCA's 2015 initial investigations recommended site 41LE332 as having an UNDETERMINED eligibility for listing in the NRHP or SAL designation and avoidance or further testing was recommended to explore the buried component of the site (Acuña et al. 2016). SWCA revisited the site in 2016 and excavated additional shovel tests to determine the quantity and context of the buried artifacts at the site.

Site 41LE332 measures $240 \mathrm{~m}$ southwest/northeast by $30 \mathrm{~m}$ northwest/southeast within the project corridor based on artifact distribution and landforms surrounding the site; however, the site likely extends beyond the project area to the northwest and southeast. Site boundaries were determined by ground surface inspection and shovel testing for subsurface cultural deposits within the project area boundaries. Cultural materials observed during ground surface inspection in 2015 and 2016 consist of approximately 20 chert tertiary reduction flakes, one fragment of reddish-gray

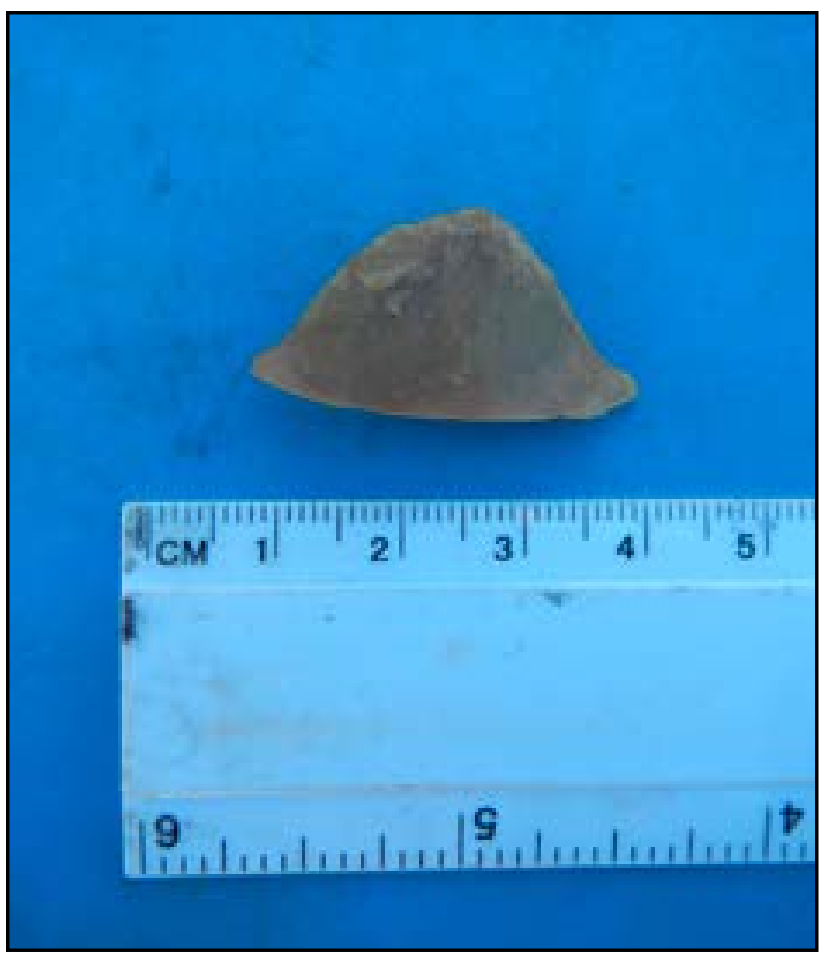

Figure 3.12. Utilized flake from site 41BU124 in ST CS40 at 90-100 cmbs.

quartzite with ground facets on one face, and one tabular slab (measuring $10 \times 15 \times 4 \mathrm{~cm}$ ) of brown chert with a smooth, uniform cortex.

In 2015, SWCA excavated six shovel tests (i.e., MN175-178 and MS144-145) at approximately 25-m intervals to delineate the site, of which three (i.e., MN175-176 and MS144) were positive for cultural materials, consisting of four chert tertiary reduction flakes from $0-30 \mathrm{cmbs}$ and one tertiary flake from 90-100 cmbs (Table 3.8). In 2016, SWCA excavated 11 additional shovel tests (i.e., KH5-10 and MCC75-79) at approximately $10-$ to $15-\mathrm{m}$ intervals to further test the site, with three (i.e., KH6 and MCC77-78) of these positive for cultural materials containing five chert tertiary reduction flakes from 20-60 cmbs (Figure 3.16). Shovel tests typically revealed grayish brown (10YR $5 / 2$ ) to light brownish gray (10YR 6/2) sand or sandy loam with $1-5$ percent gravel and pebble inclusions. Shovel tests in the central and eastern portion of the site terminated at depth (i.e., $100 \mathrm{cmbs}$ ), while shovel tests toward the western edge of the site terminated at compacted reddish yellow (7.5YR 6/8) sandy clay or bedrock between 10 and $70 \mathrm{cmbs}$. 


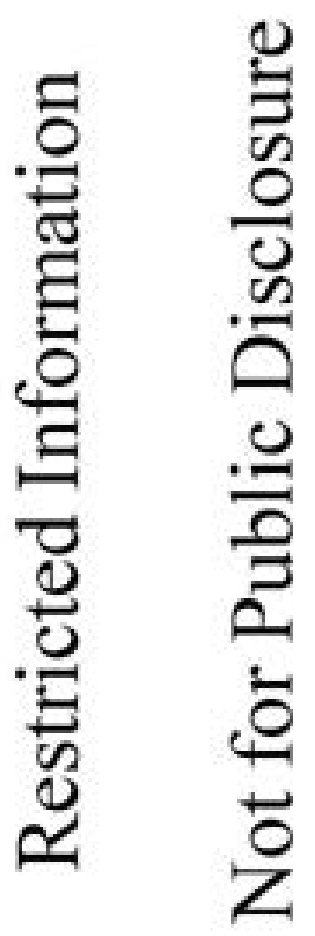

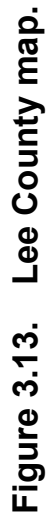




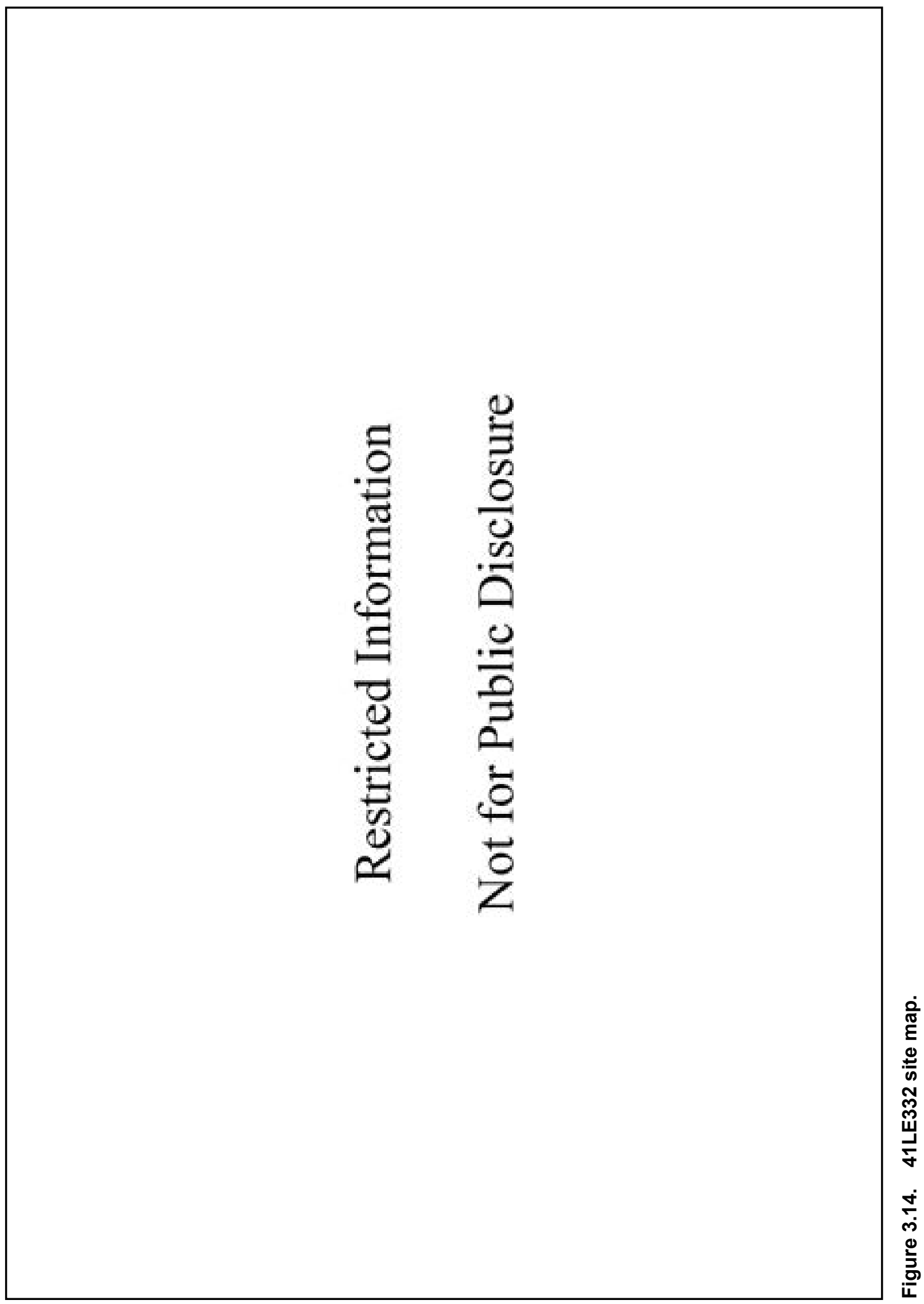




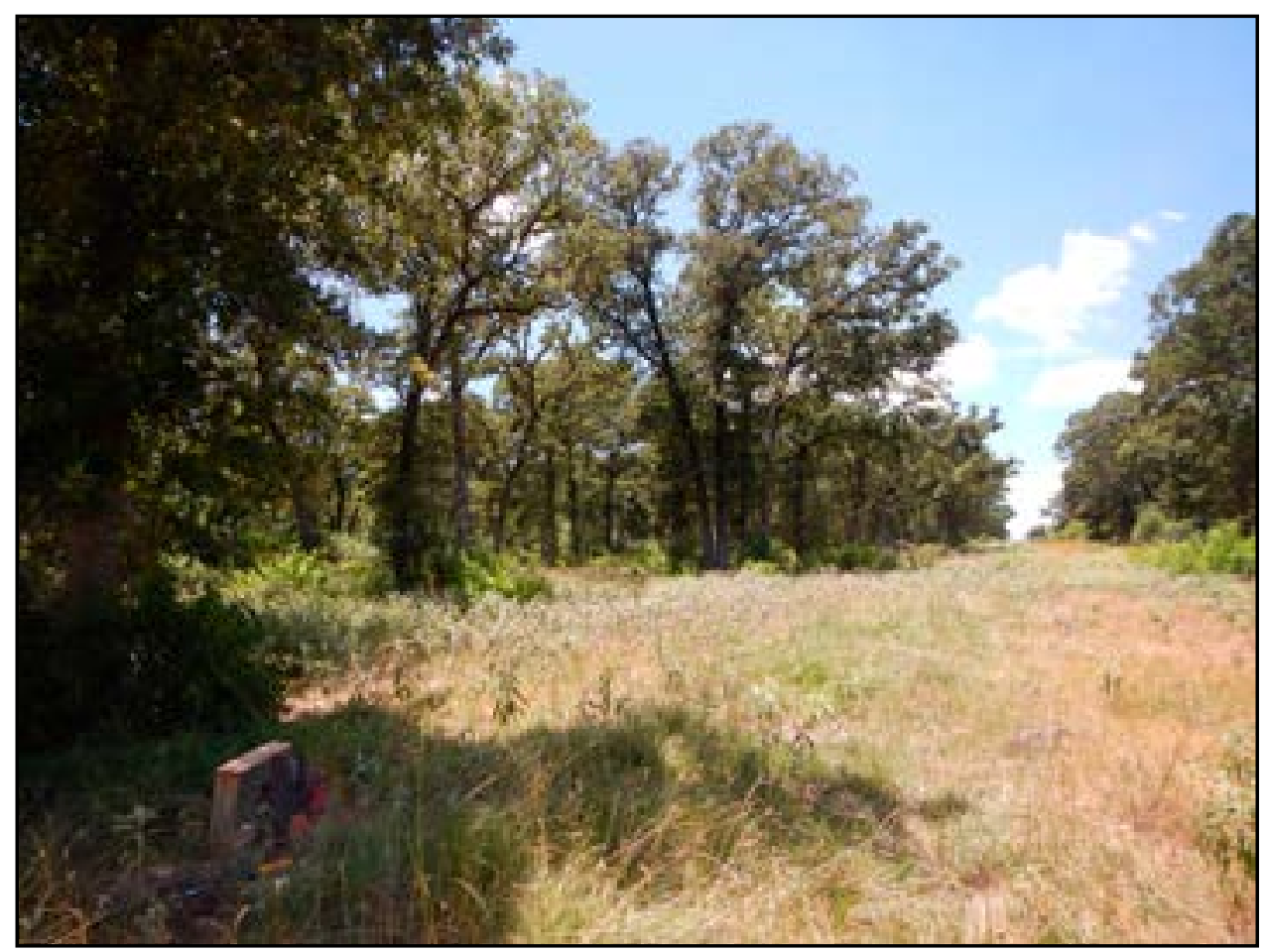

Figure 3.15. Overview of site 41LE332, facing southwest.

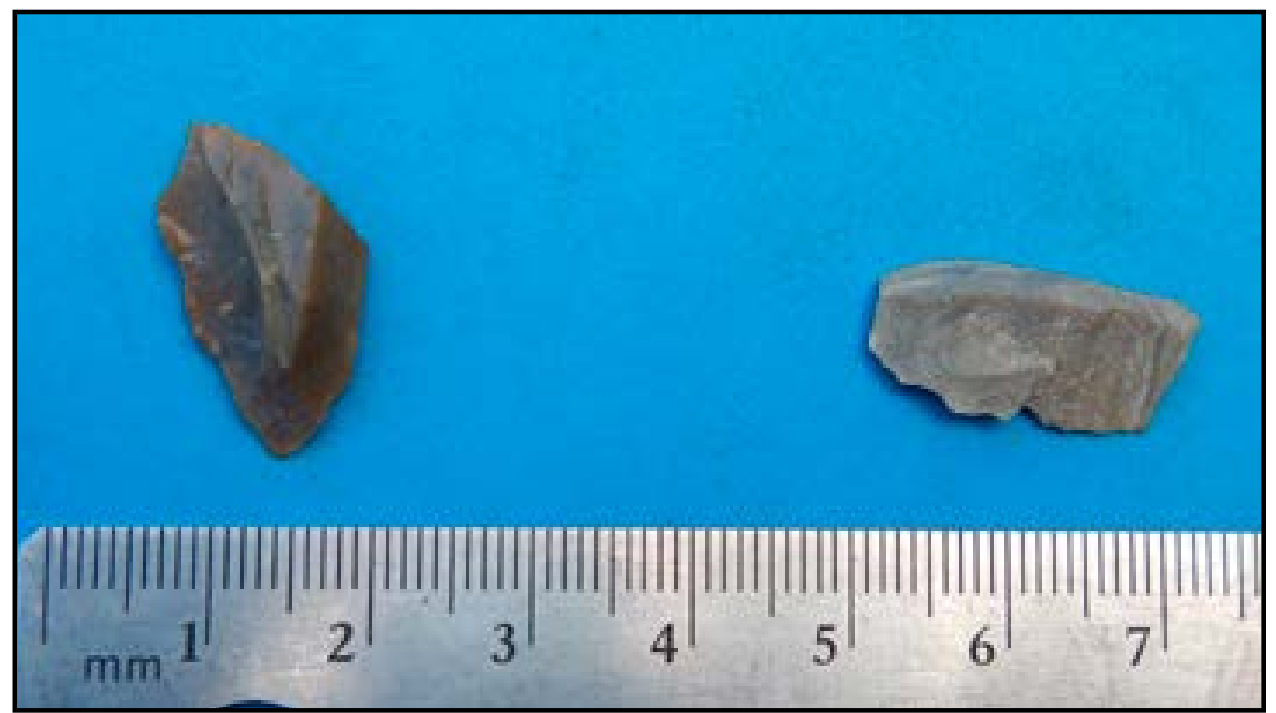

Figure 3.16. Tertiary flakes from site 41LE332 in ST MCC78 at 20-60 cmbs. 
Table 3.8. Shovel Test Data for Site 41LE332

\begin{tabular}{|c|c|c|c|c|c|c|c|c|c|}
\hline $\begin{array}{l}\text { Shovel } \\
\text { Test No. }\end{array}$ & Level & $\begin{array}{l}\text { Depth } \\
\text { (cmbs) }\end{array}$ & $\begin{array}{l}\text { Munsell } \\
\text { Soil Value }\end{array}$ & $\begin{array}{l}\text { Munsell } \\
\text { Soil Color }\end{array}$ & $\begin{array}{l}\text { Soil } \\
\text { Texture }\end{array}$ & $\begin{array}{l}\text { Inclusion } \\
\text { Percentage }\end{array}$ & Inclusion Type & Cultural Materials & $\begin{array}{l}\text { Comments/ } \\
\text { Reason for } \\
\text { Termination }\end{array}$ \\
\hline \multicolumn{10}{|c|}{2015 Initial Cultural Resources Investigations } \\
\hline MN175 & 1 & $0-100$ & 10YR 5/2 & $\begin{array}{l}\text { Grayish } \\
\text { brown }\end{array}$ & Sand & $1-5 \%$ & Gravels & $\begin{array}{l}\text { 3: Flakes (tertiary) } \\
\text { [2 at } 0-10 \mathrm{cmbs} \\
\text { and } 1 \text { at } 20-30 \\
\text { cmbs] }\end{array}$ & $\begin{array}{l}\text { Terminated at } \\
\text { depth. }\end{array}$ \\
\hline \multirow{2}{*}{ MN176 } & 1 & $0-60$ & 10YR 5/2 & $\begin{array}{l}\text { Grayish } \\
\text { brown }\end{array}$ & Sand & $1-5 \%$ & Gravels & $\begin{array}{l}\text { 1: Flake (tertiary) } \\
{[0-10 \mathrm{cmbs}]}\end{array}$ & - \\
\hline & 2 & $60-70$ & 7.5YR 6/8 & $\begin{array}{l}\text { Reddish } \\
\text { Yellow }\end{array}$ & $\begin{array}{l}\text { Sandy } \\
\text { Clay }\end{array}$ & - & - & None & $\begin{array}{l}\text { Terminated at basal } \\
\text { clay. }\end{array}$ \\
\hline MN177 & 1 & $0-33$ & 10YR 5/1 & Gray & $\begin{array}{l}\text { Sandy } \\
\text { Loam }\end{array}$ & $1-5 \%$ & Gravels & None & $\begin{array}{l}\text { Terminated at basal } \\
\text { clay. }\end{array}$ \\
\hline MN178 & 1 & $0-100$ & 10YR 5/1 & Gray & Sand & - & - & None & $\begin{array}{l}\text { Terminated at basal } \\
\text { clay. }\end{array}$ \\
\hline MS144 & 1 & $0-100$ & 10YR 5/4 & $\begin{array}{l}\text { Yellowish } \\
\text { brown }\end{array}$ & Sand & $1-5 \%$ & Gravels & $\begin{array}{l}\text { 1: Flake (tertiary) } \\
\text { [90-100 cmbs] }\end{array}$ & Terminated at depth \\
\hline MS145 & 1 & $0-10$ & 10YR 5/4 & $\begin{array}{l}\text { Yellowish } \\
\text { brown }\end{array}$ & Sand & $10-20 \%$ & $\begin{array}{l}\text { Gravels, Large } \\
\text { Rock Fragments }\end{array}$ & None & $\begin{array}{l}\text { Terminated at } \\
\text { bedrock. }\end{array}$ \\
\hline \multicolumn{10}{|c|}{ 2016-2018 Additional Cultural Resources Investigations } \\
\hline \multirow{2}{*}{$\mathrm{KH} 5$} & 1 & $0-10$ & 10YR 5/2 & $\begin{array}{l}\text { grayish } \\
\text { brown }\end{array}$ & Sand & $1-5 \%$ & Pebbles & None & - \\
\hline & 2 & $10-100$ & 10YR 7/3 & $\begin{array}{l}\text { very pale } \\
\text { brown }\end{array}$ & Sand & $1-5 \%$ & Pebbles & None & $\begin{array}{l}\text { Terminated at } \\
\text { depth. }\end{array}$ \\
\hline \multirow[t]{2}{*}{ KH6 } & 1 & $0-10$ & 10YR 6/2 & $\begin{array}{l}\text { light } \\
\text { brownish } \\
\text { gray }\end{array}$ & Sand & $1-5 \%$ & Pebbles & None & - \\
\hline & 2 & $10-100$ & 10YR 8/2 & $\begin{array}{l}\text { very pale } \\
\text { brown }\end{array}$ & Sand & $1-5 \%$ & $\begin{array}{l}\text { Pebbles, Petrified } \\
\text { wood }\end{array}$ & 2: Flake (tertiary) & $\begin{array}{l}\text { Terminated at } \\
\text { depth. }\end{array}$ \\
\hline $\mathrm{KH} 7$ & 1 & $0-100$ & 10YR 8/2 & $\begin{array}{l}\text { very pale } \\
\text { brown }\end{array}$ & Sand & $1-5 \%$ & $\begin{array}{l}\text { Pebbles, Petrified } \\
\text { wood }\end{array}$ & None & $\begin{array}{l}\text { Terminated at } \\
\text { depth. }\end{array}$ \\
\hline \multirow{2}{*}{$\mathrm{KH} 8$} & 1 & $0-30$ & 10YR 8/2 & $\begin{array}{l}\text { very pale } \\
\text { brown }\end{array}$ & Sand & $1-5 \%$ & $\begin{array}{l}\text { Pebbles, Petrified } \\
\text { wood }\end{array}$ & None & - \\
\hline & 2 & $30-50$ & 7.5YR 6/6 & $\begin{array}{l}\text { reddish } \\
\text { yellow }\end{array}$ & $\begin{array}{l}\text { Sandy } \\
\text { Clay }\end{array}$ & $5-10 \%$ & $\begin{array}{l}\text { Cobbles, Gravels, } \\
\text { Pebbles }\end{array}$ & None & $\begin{array}{l}\text { Terminated at basal } \\
\text { clay. }\end{array}$ \\
\hline \multirow[b]{2}{*}{$\mathrm{KH} 9$} & 1 & $0-10$ & 10YR 8/2 & $\begin{array}{l}\text { very pale } \\
\text { brown }\end{array}$ & Sand & $5-10 \%$ & Gravels, Pebbles & None & - \\
\hline & 2 & $10-40$ & 7.5YR 6/6 & $\begin{array}{l}\text { reddish } \\
\text { yellow }\end{array}$ & Sand & $>20 \%$ & $\begin{array}{l}\text { Cobbles, Gravels, } \\
\text { Decomposing } \\
\text { bedrock }\end{array}$ & None & $\begin{array}{l}\text { Terminated at } \\
\text { decomposing } \\
\text { bedrock. }\end{array}$ \\
\hline $\mathrm{KH} 10$ & 1 & $0-100$ & 10YR 8/2 & $\begin{array}{l}\text { very pale } \\
\text { brown }\end{array}$ & Sand & - & Pebbles & None & $\begin{array}{l}\text { Terminated at } \\
\text { depth. }\end{array}$ \\
\hline MCC75 & 1 & $0-100$ & 10YR 6/2 & $\begin{array}{l}\text { light } \\
\text { brownish } \\
\text { gray }\end{array}$ & Sand & $1-5 \%$ & Pebbles & None & $\begin{array}{l}\text { Terminated at } \\
\text { depth. }\end{array}$ \\
\hline \multirow[t]{2}{*}{ MCC76 } & 1 & $0-35$ & 10YR 6/2 & $\begin{array}{l}\text { light } \\
\text { brownish } \\
\text { gray }\end{array}$ & Sand & $1-5 \%$ & Gravels, Pebbles & None & - \\
\hline & 2 & $35-100$ & 10YR 6/3 & pale brown & Sand & $1-5 \%$ & Gravels, Pebbles & None & $\begin{array}{l}\text { Terminated at } \\
\text { depth. }\end{array}$ \\
\hline
\end{tabular}


Table 3.8. continued

\begin{tabular}{|c|c|c|c|c|c|c|c|c|c|}
\hline $\begin{array}{l}\text { Shovel } \\
\text { Test No. }\end{array}$ & Level & $\begin{array}{l}\text { Depth } \\
\text { (cmbs) }\end{array}$ & $\begin{array}{l}\text { Munsell } \\
\text { Soil Value }\end{array}$ & $\begin{array}{l}\text { Munsell } \\
\text { Soil Color }\end{array}$ & $\begin{array}{l}\text { Soil } \\
\text { Texture }\end{array}$ & $\begin{array}{l}\text { Inclusion } \\
\text { Percentage }\end{array}$ & Inclusion Type & Cultural Materials & $\begin{array}{l}\text { Comments/ } \\
\text { Reason for } \\
\text { Termination }\end{array}$ \\
\hline MCC77 & 1 & $0-40$ & 10YR 6/2 & $\begin{array}{l}\text { light } \\
\text { brownish } \\
\text { gray }\end{array}$ & Sand & $5-10 \%$ & Gravels, Pebbles & $\begin{array}{l}\text { 1: Flake (tertiary) } \\
{[20-40 \mathrm{cmbs} .]}\end{array}$ & - \\
\hline MCC77 & 2 & $40-60$ & 7.5YR 5/8 & $\begin{array}{l}\text { strong } \\
\text { brown }\end{array}$ & $\begin{array}{l}\text { Sandy } \\
\text { Clay }\end{array}$ & - & - & None & $\begin{array}{l}\text { Terminated at basal } \\
\text { clay. }\end{array}$ \\
\hline \multirow{3}{*}{ MCC78 } & 1 & $0-30$ & 10YR 6/2 & $\begin{array}{l}\text { light } \\
\text { brownish } \\
\text { gray }\end{array}$ & Sand & $1-5 \%$ & Gravels, Pebbles & $\begin{array}{l}\text { 1: Flake (tertiary) } \\
{[20-40 \mathrm{cmbs} .]}\end{array}$ & - \\
\hline & 2 & $30-60$ & 7.5YR 5/8 & $\begin{array}{l}\text { strong } \\
\text { brown }\end{array}$ & $\begin{array}{l}\text { Sandy } \\
\text { Loam }\end{array}$ & $1-5 \%$ & Gravels, Pebbles & $\begin{array}{l}\text { 1: Flake (tertiary) } \\
{[40-60 \mathrm{cmbs} .]}\end{array}$ & - \\
\hline & 3 & $60-100$ & 10YR 6/3 & pale brown & $\begin{array}{l}\text { Sandy } \\
\text { Loam }\end{array}$ & - & - & None & $\begin{array}{l}\text { Terminated at } \\
\text { depth. }\end{array}$ \\
\hline \multirow{2}{*}{ MCC79 } & 1 & $0-45$ & 10YR 5/2 & $\begin{array}{l}\text { grayish } \\
\text { brown }\end{array}$ & Sand & $5-10 \%$ & Gravels, Pebbles & None & - \\
\hline & 2 & $45-50$ & 7.5YR 5/8 & $\begin{array}{l}\text { strong } \\
\text { brown }\end{array}$ & $\begin{array}{l}\text { Sandy } \\
\text { Clay }\end{array}$ & - & - & None & $\begin{array}{l}\text { Terminated at basal } \\
\text { clay. }\end{array}$ \\
\hline
\end{tabular}

No temporally diagnostic artifacts or cultural features were observed. All artifacts were recovered within the sand and sandy loam, and there was no evidence of a buried soil. Due to project constraints, the site was not fully delineated to the northwest or southeast, as investigations were not permitted outside the project ROW. Due to a shift of the project corridor since the original recording and revisit of the site, the northwestern portion and southeastern margin of the site are now outside the project area boundaries.

\section{LE332 SUMMARY}

Site 41LE332 consists of a low density, buried prehistoric lithic scatter of debitage containing cultural material from the ground surface to $100 \mathrm{cmbs}$. The site has a relatively low density of artifacts and lacks temporally diagnostic artifacts or cultural features. Based on these data, site 41LE332 does not have the potential to yield information important to the prehistory of the region. As such, SWCA recommends site 41LE332 as NOT ELIGIBLE for the NRHP or for designation as a SAL. No further work or avoidance strategy is recommended for site 41LE332 within the project area.

\section{LE348}

Site 41LE348 is a deeply buried subsurface prehistoric lithic scatter of unknown temporal or cultural affiliation located north of FM 696, approximately 3.0 miles northeast of Blue in northwestern Lee County, Texas (Figure 3.17; Appendix A:51-52). The site is situated in a wide-open, grassy pasture on a rolling upland plain between an ephemeral tributary of Middle Yegua Creek to the east, and a wide, shallow swale to the west (Figures 3.18 and 3.19). Vegetation consists of short grasses with a scattering of mixed hardwood forest to the east along the riparian zone of the ephemeral drainage. Ground surface visibility was poor due to grass cover. Site $41 \mathrm{LE} 348$ is located on privately owned land used for agricultural and ranching activities. Disturbances include a water pipeline that runs west-southwest to east-northeast along the northern edge of the site. Additionally, disturbances to the area include erosion, numerous gopher burrows, vegetation clearing, plowing, fence lines, and nearby land modification for stock ponds.

Site 41LE348 is a diffuse, buried prehistoric lithic scatter of debitage that measures approximately 30 $\mathrm{m}$ northwest/southeast by $155 \mathrm{~m}$ northeast/southwest within the project corridor based on subsurface artifact distribution and landforms to the east and west; however, the site likely extends beyond the project area to the northwest and southeast. No cultural materials were observed along the ground surface due to poor visibility.

SWCA excavated 10 shovel tests (i.e., XBAD01-05 and $\mathrm{XMC01-05)}$ at approximately 25-m intervals to delineate the site, of which five (i.e., XBAD01$\mathrm{XBA} 02, \mathrm{XMC02}$, and XMC04-05) were positive for cultural materials from near surface to a maximum depth of $100 \mathrm{cmbs}$ (Table 3.9). Cultural materials recovered included five secondary and 25 tertiary 


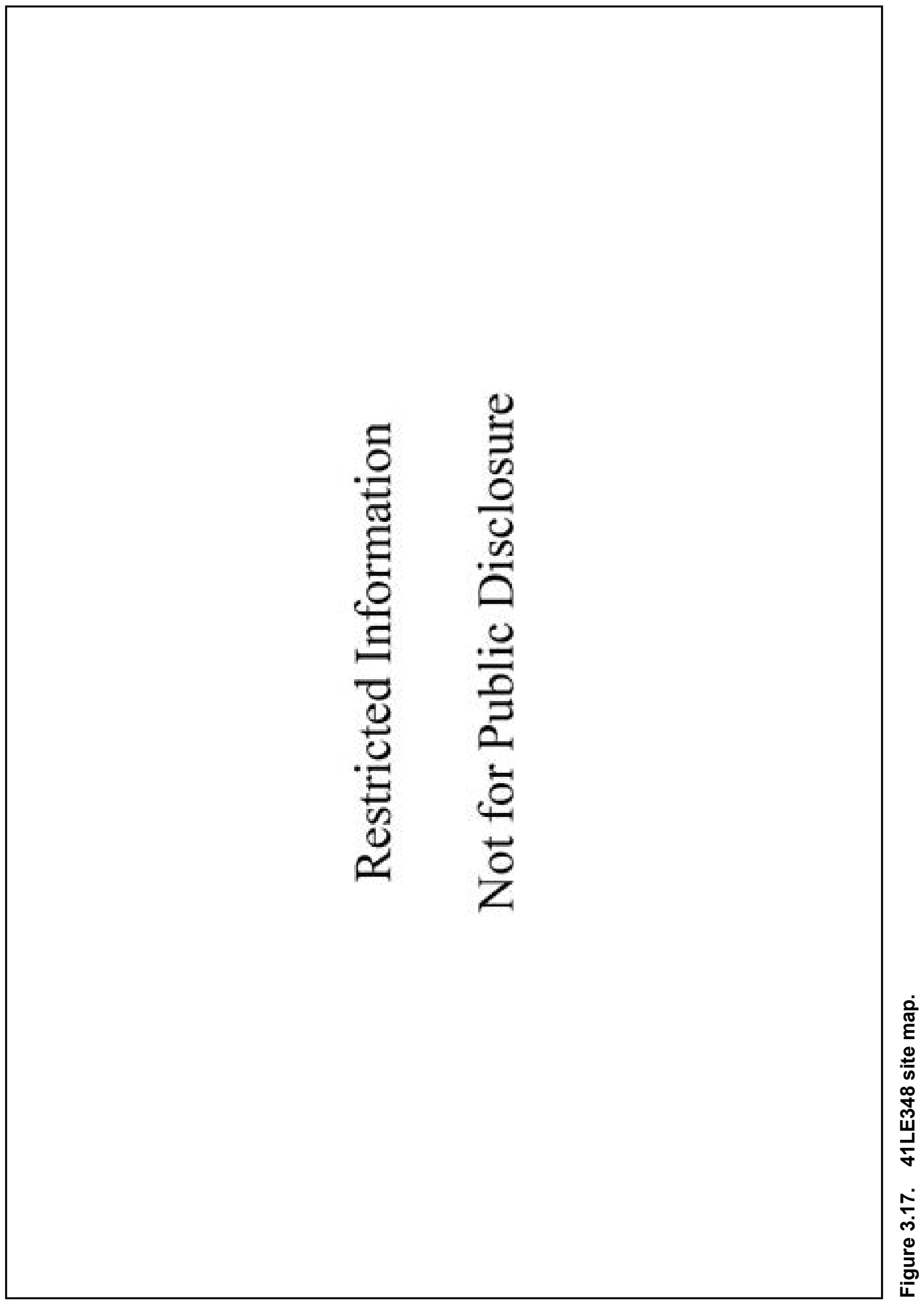




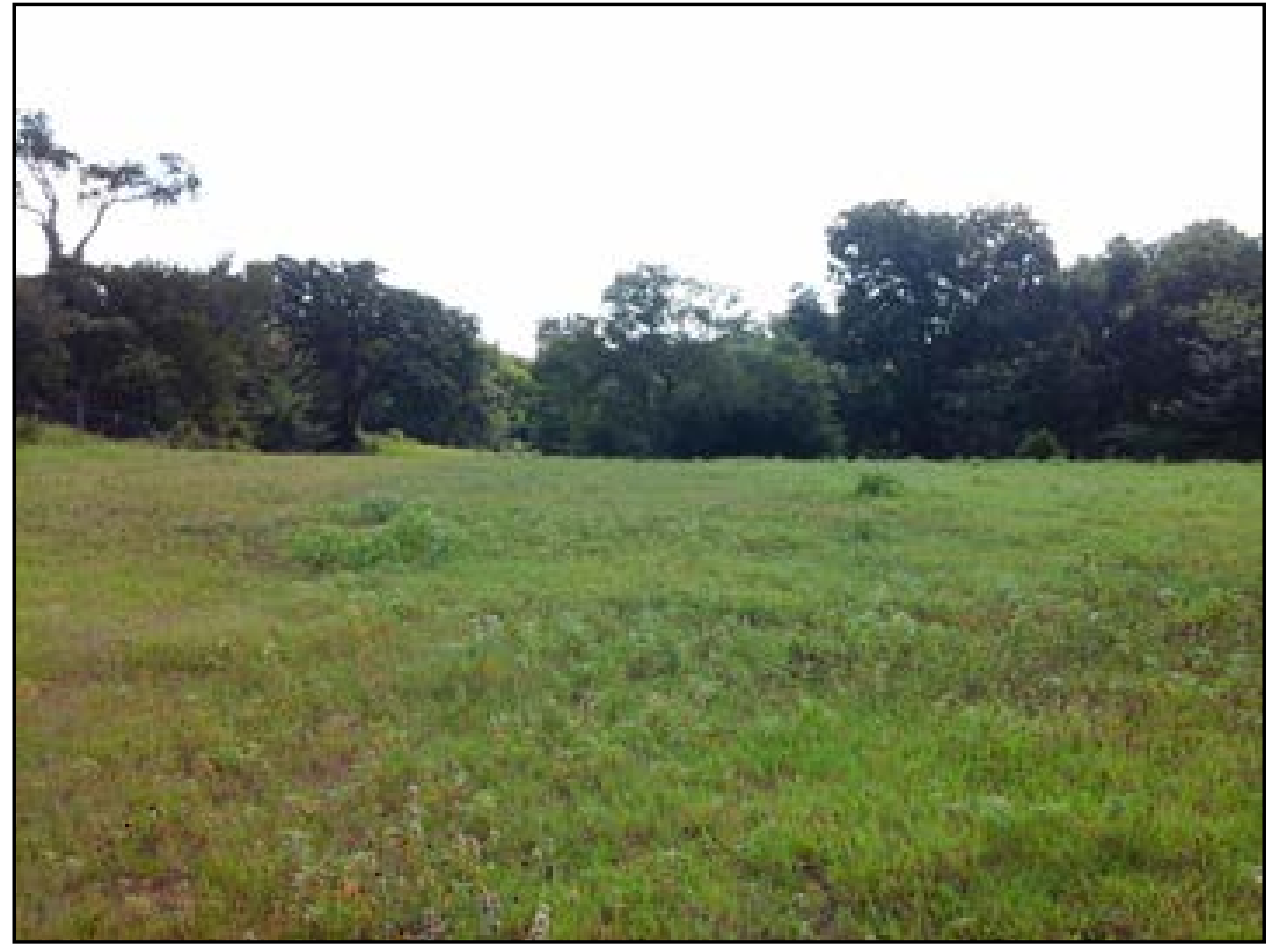

Figure 3.18. Overview of site 41LE348, facing east.

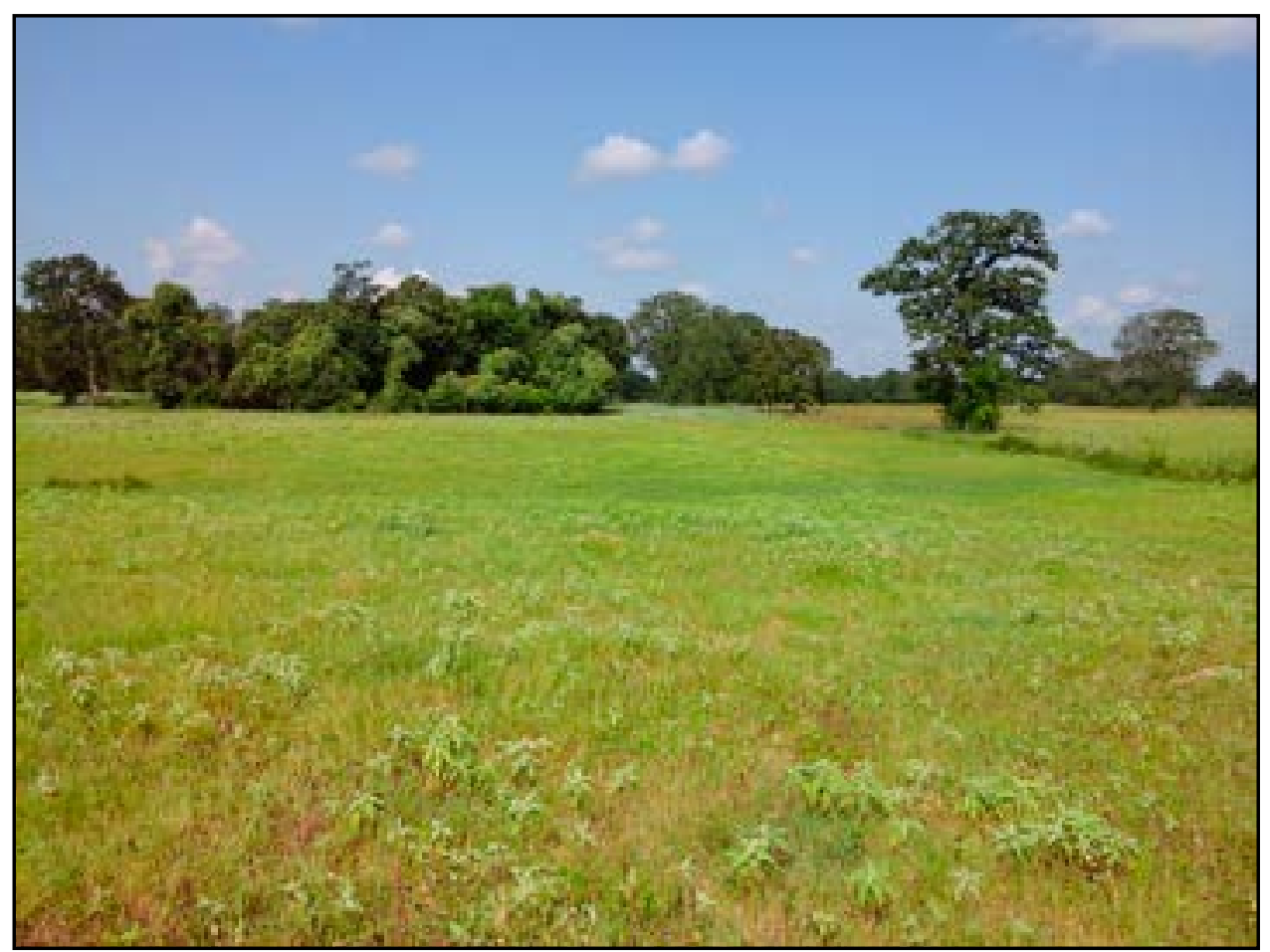

Figure 3.19. Overview of site 41LE348, facing west. Note noticeable swale in background. 
Table 3.9. Shovel Test Data for Site 41LE348

\begin{tabular}{|c|c|c|c|c|c|c|c|c|c|}
\hline $\begin{array}{l}\text { Shovel } \\
\text { Test No. }\end{array}$ & Level & $\begin{array}{l}\text { Depth } \\
\text { (cmbs) }\end{array}$ & $\begin{array}{l}\text { Munsell } \\
\text { Soil Value }\end{array}$ & $\begin{array}{l}\text { Munsell Soil } \\
\text { Color }\end{array}$ & $\begin{array}{l}\text { Soil } \\
\text { Texture }\end{array}$ & $\begin{array}{l}\text { Inclusion } \\
\text { Percentage }\end{array}$ & $\begin{array}{l}\text { Inclusion } \\
\text { Type }\end{array}$ & Cultural Materials & $\begin{array}{l}\text { Comments/ } \\
\text { Reason for } \\
\text { Termination }\end{array}$ \\
\hline \multirow{5}{*}{ XBAD01 } & 1 & $0-20$ & 10YR 4/4 & $\begin{array}{l}\text { dark yellowish } \\
\text { brown }\end{array}$ & Sand & - & - & $\begin{array}{l}\text { 1: Flake (secondary), } \\
\text { 3: Flake (tertiary). }\end{array}$ & - \\
\hline & 2 & $20-40$ & 10YR 4/4 & $\begin{array}{l}\text { dark yellowish } \\
\text { brown }\end{array}$ & Sand & - & - & 2: Flake (tertiary). & - \\
\hline & 3 & $40-60$ & 10YR 4/4 & $\begin{array}{l}\text { dark yellowish } \\
\text { brown }\end{array}$ & Sand & - & - & $\begin{array}{l}\text { 1: Flake (secondary), } \\
\text { 1: Flake (tertiary). }\end{array}$ & - \\
\hline & 4 & $60-80$ & 10YR $4 / 4$ & $\begin{array}{l}\text { dark yellowish } \\
\text { brown }\end{array}$ & Sand & - & - & None & - \\
\hline & 5 & $80-100$ & 10YR 4/4 & $\begin{array}{l}\text { dark yellowish } \\
\text { brown }\end{array}$ & Sand & - & - & 1: Flake (secondary). & $\begin{array}{l}\text { Terminated at } \\
\text { depth. }\end{array}$ \\
\hline \multirow{5}{*}{ XBAD02 } & 1 & $0-20$ & 10YR $4 / 4$ & $\begin{array}{l}\text { dark yellowish } \\
\text { brown }\end{array}$ & Sand & - & - & 1: Flake (tertiary). & - \\
\hline & 2 & $20-40$ & 10YR $4 / 4$ & $\begin{array}{l}\text { dark yellowish } \\
\text { brown }\end{array}$ & Sand & - & - & None & - \\
\hline & 3 & $40-60$ & 10YR 5/4 & yellowish brown & Sand & - & - & None & - \\
\hline & 4 & $60-80$ & 10YR 5/4 & yellowish brown & Sand & - & - & 1: Flake (tertiary). & - \\
\hline & 5 & $80-90$ & 5YR 5/4 & reddish brown & $\begin{array}{l}\text { Sandy } \\
\text { Clay }\end{array}$ & - & - & None & $\begin{array}{l}\text { Terminated at } \\
\text { basal clay. }\end{array}$ \\
\hline \multirow{2}{*}{ XBAD03 } & 1 & $0-60$ & 10YR 4/4 & $\begin{array}{l}\text { dark yellowish } \\
\text { brown }\end{array}$ & Sand & - & - & None & - \\
\hline & 2 & $60-70$ & 10YR 4/4 & $\begin{array}{l}\text { dark yellowish } \\
\text { brown }\end{array}$ & $\begin{array}{l}\text { Sandy } \\
\text { Clay }\end{array}$ & $10-20 \%$ & Mottles & None & $\begin{array}{l}\text { Terminated at } \\
\text { basal clay. }\end{array}$ \\
\hline \multirow{2}{*}{ XBAD04 } & 1 & $0-20$ & 10YR 4/4 & $\begin{array}{l}\text { dark yellowish } \\
\text { brown }\end{array}$ & Sand & & & None & - \\
\hline & 2 & $20-50$ & 10YR 5/6 & yellowish brown & Sand & $>20 \%$ & Mottles & None & $\begin{array}{l}\text { Terminated at } \\
\text { hydric soils. }\end{array}$ \\
\hline XBAD05 & 1 & $0-40$ & 10YR 4/4 & $\begin{array}{l}\text { dark yellowish } \\
\text { brown }\end{array}$ & $\begin{array}{l}\text { Sandy } \\
\text { Clay }\end{array}$ & $10-20 \%$ & Mottles & None & $\begin{array}{l}\text { Terminated at } \\
\text { basal clay. }\end{array}$ \\
\hline \multirow[t]{2}{*}{ XMC01 } & 1 & $0-25$ & 10YR 6/3 & pale brown & $\begin{array}{l}\text { Sandy } \\
\text { Loam }\end{array}$ & $>20 \%$ & $\begin{array}{l}\text { Clay } \\
\text { subsoil } \\
\text { nodules }\end{array}$ & None & - \\
\hline & 2 & $25-30$ & 5YR 5/3 & reddish brown & $\begin{array}{l}\text { Sandy } \\
\text { Clay }\end{array}$ & - & - & None & $\begin{array}{l}\text { Terminated at } \\
\text { basal clay. }\end{array}$ \\
\hline \multirow{4}{*}{$\mathrm{XMC02}$} & 1 & $0-20$ & 10YR 5/3 & brown & Sand & $1-5 \%$ & Gravels & 2: Flake (tertiary). & - \\
\hline & 2 & $20-40$ & 10YR 5/3 & brown & Sand & $1-5 \%$ & Gravels & $\begin{array}{l}\text { 1: Flake (secondary), } \\
\text { 2: Flake (tertiary). }\end{array}$ & - \\
\hline & 3 & $40-60$ & 10YR 5/3 & brown & Sand & $1-5 \%$ & Gravels & None & - \\
\hline & 4 & $60+$ & 5YR 4/2 & $\begin{array}{l}\text { dark reddish } \\
\text { gray }\end{array}$ & $\begin{array}{l}\text { Sandy } \\
\text { Clay }\end{array}$ & - & - & None & $\begin{array}{l}\text { Terminated at } \\
\text { basal clay. }\end{array}$ \\
\hline $\mathrm{XMC03}$ & 1 & $0-30$ & 10YR 4/1 & dark gray & Sand & $5-10 \%$ & $\begin{array}{l}\text { Redox } \\
\text { staining }\end{array}$ & None & $\begin{array}{l}\text { Terminated at } \\
\text { water table. }\end{array}$ \\
\hline
\end{tabular}


Table 3.9. continued

\begin{tabular}{|c|c|c|c|c|c|c|c|c|c|}
\hline $\begin{array}{l}\text { Shovel } \\
\text { Test No. }\end{array}$ & Level & $\begin{array}{l}\text { Depth } \\
\text { (cmbs) }\end{array}$ & $\begin{array}{l}\text { Munsell } \\
\text { Soil Value }\end{array}$ & $\begin{array}{l}\text { Munsell Soil } \\
\text { Color }\end{array}$ & $\begin{array}{l}\text { Soil } \\
\text { Texture }\end{array}$ & $\begin{array}{l}\text { Inclusion } \\
\text { Percentage }\end{array}$ & $\begin{array}{l}\text { Inclusion } \\
\text { Type }\end{array}$ & Cultural Materials & $\begin{array}{l}\text { Comments/ } \\
\text { Reason for } \\
\text { Termination }\end{array}$ \\
\hline \multirow{4}{*}{ XMC04 } & 1 & $0-20$ & 10YR 5/4 & yellowish brown & Sand & $>20 \%$ & Pebbles & 6: Flake (tertiary). & $\begin{array}{l}\text { Likely disturbed } \\
\text { by existing } \\
\text { water line. }\end{array}$ \\
\hline & 2 & $20-40$ & 10YR 5/4 & yellowish brown & Sand & $>20 \%$ & Pebbles & $\begin{array}{l}\text { 1: Flake (secondary), } \\
\text { 4: Flake (tertiary). }\end{array}$ & $\begin{array}{l}\text { Likely disturbed } \\
\text { by existing } \\
\text { water line. }\end{array}$ \\
\hline & 3 & $40-60$ & 10YR 5/4 & yellowish brown & Sand & $5-10 \%$ & Pebbles & 2: Flake (tertiary). & $\begin{array}{l}\text { Likely disturbed } \\
\text { by existing } \\
\text { water line. }\end{array}$ \\
\hline & 4 & $60-100$ & 10YR 5/4 & yellowish brown & Sand & $5-10 \%$ & Pebbles & None & $\begin{array}{l}\text { Terminated at } \\
\text { depth. }\end{array}$ \\
\hline \multirow{3}{*}{ XMC05 } & 1 & $0-20$ & 7.5YR 5/4 & brown & Sand & $1-5 \%$ & Pebbles & None & - \\
\hline & 2 & $20-40$ & 7.5YR 5/4 & brown & Sand & $1-5 \%$ & Pebbles & 1: Flake (tertiary). & - \\
\hline & 3 & $40-80$ & 10YR 5/2 & grayish brown & Sand & $1-5 \%$ & $\begin{array}{l}\text { Organics } \\
\text { (decayed } \\
\text { root) }\end{array}$ & None & $\begin{array}{l}\text { Terminated at } \\
\text { water table. }\end{array}$ \\
\hline
\end{tabular}

reduction flakes of chert and petrified wood (Figure 3.20). No temporally diagnostic artifacts or cultural features were observed. Shovel tests typically revealed dark yellowish brown (10YR 4/4) to brown (10YR 5/3) sand or sandy loam with variable amounts of gravel and pebble inclusions. Shovel tests terminated at depth (i.e., $100 \mathrm{cmbs}$ ) or at basal clay or water table between 30 and $90 \mathrm{cmbs}$. Due to project constraints, the site was not fully delineated to the northwest or southeast, as investigations were not permitted outside the project ROW. Due to a shift of the project corridor since the original recording of the site, the northwestern portion of the site is now outside the project area boundaries.

\section{LE348 SUMMARY}

Site 41LE348 consists of a diffuse, buried prehistoric lithic scatter containing cultural materials from the near surface to $100 \mathrm{cmbs}$. The site has a relatively low density of artifacts and lacks temporally diagnostic artifacts or cultural features. Overall, site 41LE348 does not have the potential to yield information important to the prehistory of the region. As such, SWCA recommends site $41 \mathrm{LE} 348$ as NOT ELIGIBLE for the NRHP or for designation as a SAL. No further work or avoidance strategy is recommended for site 41 LE348 within the project area.

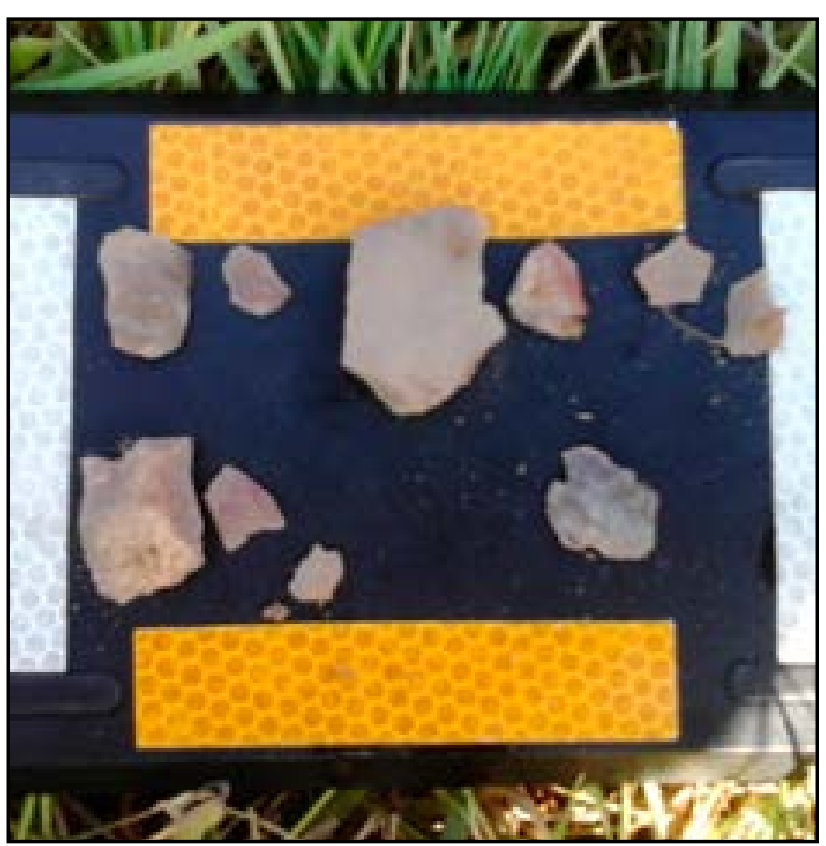

Figure 3.20. Flakes recovered from site 41LE348 in ST XBAD01 at 0-100 cmbs. 


\section{LE349}

Site 41LE349 is a low density, buried prehistoric lithic scatter of unknown temporal or cultural affiliation located just east of a private roughly north/south-trending two-track road off of FM 696 approximately 2.5 miles northeast of Blue in northwestern Lee County, Texas (Figure 3.21; Appendix A:52-53). The site is situated in an open, grassy pasture on a level upland plain approximately $150 \mathrm{~m}$ northeast of Middle Yegua Creek and its confluence with Cross Creek (Figure 3.22). Vegetation surrounding the site consists of short grasses and mixed hardwood forest along the riparian zones of the two creeks. Ground surface visibility was obscured due to grass cover. Site 41LE349 is located on privately owned land used for agricultural and ranching activities. Disturbances include a water pipeline that runs west-southwest to east-northeast along the northern edge of the site. Additionally, disturbances to the area include erosion, numerous gopher burrows, vegetation clearing, plowing, fence lines, and nearby land modification for stock ponds.

Site 41LE349 measures approximately 30 m northwest/ southeast by $289 \mathrm{~m}$ northeast/southwest within the project corridor based on subsurface artifact distribution and prominent landforms; however, the site likely extends beyond the project area to the northwest and southeast. No cultural materials were observed along the ground surface due to poor visibility.

SWCA excavated 13 shovel tests (i.e., XBAD08-14 and XMC09-13) at approximately 25-m intervals to delineate the site, of which six (i.e., XBAD12-13, XMC08-09, and XMC11-12) were positive for cultural materials from $20 \mathrm{cmbs}$ to a maximum depth of $100 \mathrm{cmbs}$ (Table 3.10). Cultural materials recovered included three primary, one secondary, and nine tertiary reduction flakes of chert and petrified wood, as well as one fire-cracked rock fragment (Figure 3.23).
No temporally diagnostic artifacts or intact cultural features were observed. Shovel tests typically revealed dark yellowish brown (10YR 4/4) or strong brown (7.5YR 4/6) sand and most terminated at depth (i.e., $100 \mathrm{cmbs}$ ). Due to project constraints, the site was not fully delineated to the northwest or southeast, as investigations were not permitted outside the project ROW. Due to a shift of the project corridor since the original recording of the site, the northwestern portion of the site is now outside the project area boundaries.

\section{LE349 SUMMARY}

Site 41LE349 consists of a diffuse, buried prehistoric lithic scatter of mainly debitage with very limited firecracked rock from the near surface to $100 \mathrm{cmbs}$. The site has a low density of artifacts and lacks temporally diagnostic artifacts or intact cultural features. Overall, site 41LE349 does not have the potential to yield information important to the prehistory of the region. As such, SWCA recommends site 41LE349 as NOT ELIGIBLE for the NRHP or for designation as a SAL. No further work or avoidance strategy is recommended for site 41LE349 within the project area.

\section{LE350}

Site 41LE350 is a diffuse, buried prehistoric lithic scatter of unknown temporal or cultural affiliation located approximately 0.82 mile northwest of the FM 696 and Private Road 7009 intersection approximately 2.0 miles northeast of Blue in northwestern Lee County, Texas (Figure 3.24; Appendix A:53-54). The site is situated along the lower slope of an undulating upland bisected by a tributary roughly trending north/ south approximately $100 \mathrm{~m}$ south of its confluence with Middle Yegua Creek (Figure 3.25). The eastern boundary is defined at the start of the Middle Yegua Creek floodplain and associated wetland. Vegetation consists of short grasses with a mixed hardwood forest to the north and east along the riparian zone of

Table 3.10. Shovel Test Data for Site 41LE349

\begin{tabular}{llllllll}
\hline $\begin{array}{l}\text { Shovel } \\
\text { Test No. }\end{array}$ & $\begin{array}{l}\text { Devth } \\
\text { (cmbs) }\end{array}$ & $\begin{array}{l}\text { Munsell } \\
\text { Soil Value }\end{array}$ & $\begin{array}{l}\text { Munsell Soil } \\
\text { Color }\end{array}$ & $\begin{array}{l}\text { Soil } \\
\text { Texture }\end{array}$ & $\begin{array}{l}\text { Inclusion } \\
\text { Percentage }\end{array}$ & $\begin{array}{l}\text { Inclusion } \\
\text { Type }\end{array}$ & $\begin{array}{l}\text { Cultural } \\
\text { Materials }\end{array}$ \\
\hline XBAD08 1 & $0-100$ & 10YR 4/4 & $\begin{array}{l}\text { dark yellowish } \\
\text { brown } \\
\text { Reason for } \\
\text { Termination }\end{array}$ & Sand & - & None \\
\hline XBAD09 1 & $0-100$ & 10YR 4/4 & $\begin{array}{l}\text { dark yellowish } \\
\text { brown }\end{array}$ & Sand & - & Terminated at depth. \\
\hline XBAD10 1 & $0-100$ & 10YR 4/4 & $\begin{array}{l}\text { dark yellowish } \\
\text { brown }\end{array}$ & Sand & - & None & Terminated at depth. \\
\hline
\end{tabular}


Table 3.10. continued

\begin{tabular}{|c|c|c|c|c|c|c|c|c|c|}
\hline $\begin{array}{l}\text { Shovel } \\
\text { Test No. }\end{array}$ & Level & $\begin{array}{l}\text { Depth } \\
\text { (cmbs) }\end{array}$ & $\begin{array}{l}\text { Munsell } \\
\text { Soil Value }\end{array}$ & $\begin{array}{l}\text { Munsell Soil } \\
\text { Color }\end{array}$ & $\begin{array}{l}\text { Soil } \\
\text { Texture }\end{array}$ & $\begin{array}{l}\text { Inclusion } \\
\text { Percentage }\end{array}$ & $\begin{array}{l}\text { Inclusion } \\
\text { Type }\end{array}$ & $\begin{array}{l}\text { Cultural } \\
\text { Materials }\end{array}$ & $\begin{array}{l}\text { Comments/ } \\
\text { Reason for } \\
\text { Termination }\end{array}$ \\
\hline XBAD11 & 1 & $0-100$ & 10YR 4/4 & $\begin{array}{l}\text { dark yellowish } \\
\text { brown }\end{array}$ & Sand & - & - & None & Terminated at depth. \\
\hline \multirow{5}{*}{ XBAD12 } & 1 & $0-20$ & 10YR 4/4 & $\begin{array}{l}\text { dark yellowish } \\
\text { brown }\end{array}$ & Sand & $1-5 \%$ & Pebbles & None & - \\
\hline & 2 & $20-40$ & 10YR 4/4 & $\begin{array}{l}\text { dark yellowish } \\
\text { brown }\end{array}$ & Sand & $1-5 \%$ & Pebbles & $\begin{array}{l}\text { 2: Flake } \\
\text { (primary). }\end{array}$ & - \\
\hline & 3 & $40-60$ & 10YR 4/4 & $\begin{array}{l}\text { dark yellowish } \\
\text { brown }\end{array}$ & Sand & $1-5 \%$ & Pebbles & None & - \\
\hline & 4 & $60-80$ & 10YR 4/4 & $\begin{array}{l}\text { dark yellowish } \\
\text { brown }\end{array}$ & Sand & $1-5 \%$ & Pebbles & $\begin{array}{l}\text { 2: Flake } \\
\text { (tertiary). }\end{array}$ & - \\
\hline & 5 & $80-100$ & 10YR 4/4 & $\begin{array}{l}\text { dark yellowish } \\
\text { brown }\end{array}$ & Sand & $1-5 \%$ & Pebbles & None & Terminated at depth. \\
\hline \multirow{5}{*}{ XBAD13 } & 1 & $0-20$ & 10YR 4/4 & $\begin{array}{l}\text { dark yellowish } \\
\text { brown }\end{array}$ & Sand & - & - & None & - \\
\hline & 2 & $20-40$ & 10YR 4/4 & $\begin{array}{l}\text { dark yellowish } \\
\text { brown }\end{array}$ & Sand & - & - & $\begin{array}{l}\text { 1: Flake } \\
\text { (secondary), } \\
\text { 1: Flake } \\
\text { (tertiary). }\end{array}$ & - \\
\hline & 3 & $40-60$ & 10YR 4/4 & $\begin{array}{l}\text { dark yellowish } \\
\text { brown }\end{array}$ & Sand & - & - & None & - \\
\hline & 4 & $60-80$ & 10YR 4/4 & $\begin{array}{l}\text { dark yellowish } \\
\text { brown }\end{array}$ & Sand & - & - & $\begin{array}{l}\text { 1: Flake } \\
\text { (tertiary). }\end{array}$ & - \\
\hline & 5 & $80-100$ & 10YR 4/4 & $\begin{array}{l}\text { dark yellowish } \\
\text { brown }\end{array}$ & Sand & - & - & None & Terminated at depth. \\
\hline \multirow{2}{*}{ XBAD14 } & 1 & $0-90$ & 10YR 3/6 & $\begin{array}{l}\text { dark yellowish } \\
\text { brown }\end{array}$ & Sand & - & - & None & - \\
\hline & 2 & $90-100$ & 10YR 3/6 & $\begin{array}{l}\text { dark yellowish } \\
\text { brown }\end{array}$ & Sand & $5-10 \%$ & Pebbles & None & Terminated at depth. \\
\hline \multirow{4}{*}{ XMC08 } & 1 & $0-40$ & 7.5YR 5/6 & strong brown & Sand & - & - & None & - \\
\hline & 2 & $40-60$ & 7.5YR 5/6 & strong brown & Sand & - & - & $\begin{array}{l}\text { 1: Flake } \\
\text { (tertiary). }\end{array}$ & - \\
\hline & 3 & $60-80$ & 7.5YR 5/6 & strong brown & Sand & - & - & $\begin{array}{l}\text { 1: Flake } \\
\text { (tertiary). }\end{array}$ & - \\
\hline & 4 & $80-100$ & $7.5 Y R$ 5/6 & strong brown & Sand & - & - & None & Terminated at depth. \\
\hline \multirow{3}{*}{ XMC09 } & 1 & $0-40$ & 7.5YR 5/6 & strong brown & Sand & - & - & None & - \\
\hline & 2 & $40-60$ & 7.5YR 5/6 & strong brown & Sand & - & - & $\begin{array}{l}\text { 2: Flake } \\
\text { (tertiary). }\end{array}$ & - \\
\hline & 3 & $60-100$ & 7.5YR 5/6 & strong brown & Sand & - & - & None & Terminated at depth. \\
\hline XMC10 & 1 & $0-100$ & 7.5YR 5/6 & strong brown & Sand & $5-10 \%$ & Pebbles & None & Terminated at depth. \\
\hline \multirow{3}{*}{ XMC11 } & 1 & $0-40$ & 7.5YR 5/6 & strong brown & Sand & - & - & None & - \\
\hline & 2 & $40-60$ & 7.5YR 5/6 & strong brown & Sand & - & - & $\begin{array}{l}\text { 1: Flake } \\
\text { (tertiary). }\end{array}$ & - \\
\hline & 3 & $60-80$ & 7.5YR 5/6 & strong brown & Sand & - & - & $\begin{array}{l}\text { 1: Fire cracked } \\
\text { rock. }\end{array}$ & Terminated at depth. \\
\hline \multirow[b]{2}{*}{ XMC12 } & 1 & $0-90$ & $7.5 Y R$ 5/6 & strong brown & Sand & - & - & None & - \\
\hline & 2 & $90-100$ & 7.5YR 5/6 & strong brown & Sand & - & - & $\begin{array}{l}\text { 1: Flake } \\
\text { (primary). }\end{array}$ & Terminated at depth. \\
\hline XMC13 & 1 & $0-20$ & $5 Y R 4 / 4$ & reddish brown & $\begin{array}{l}\text { Sandy } \\
\text { Clay }\end{array}$ & - & - & None & $\begin{array}{l}\text { Terminated at basal } \\
\text { clay. }\end{array}$ \\
\hline
\end{tabular}




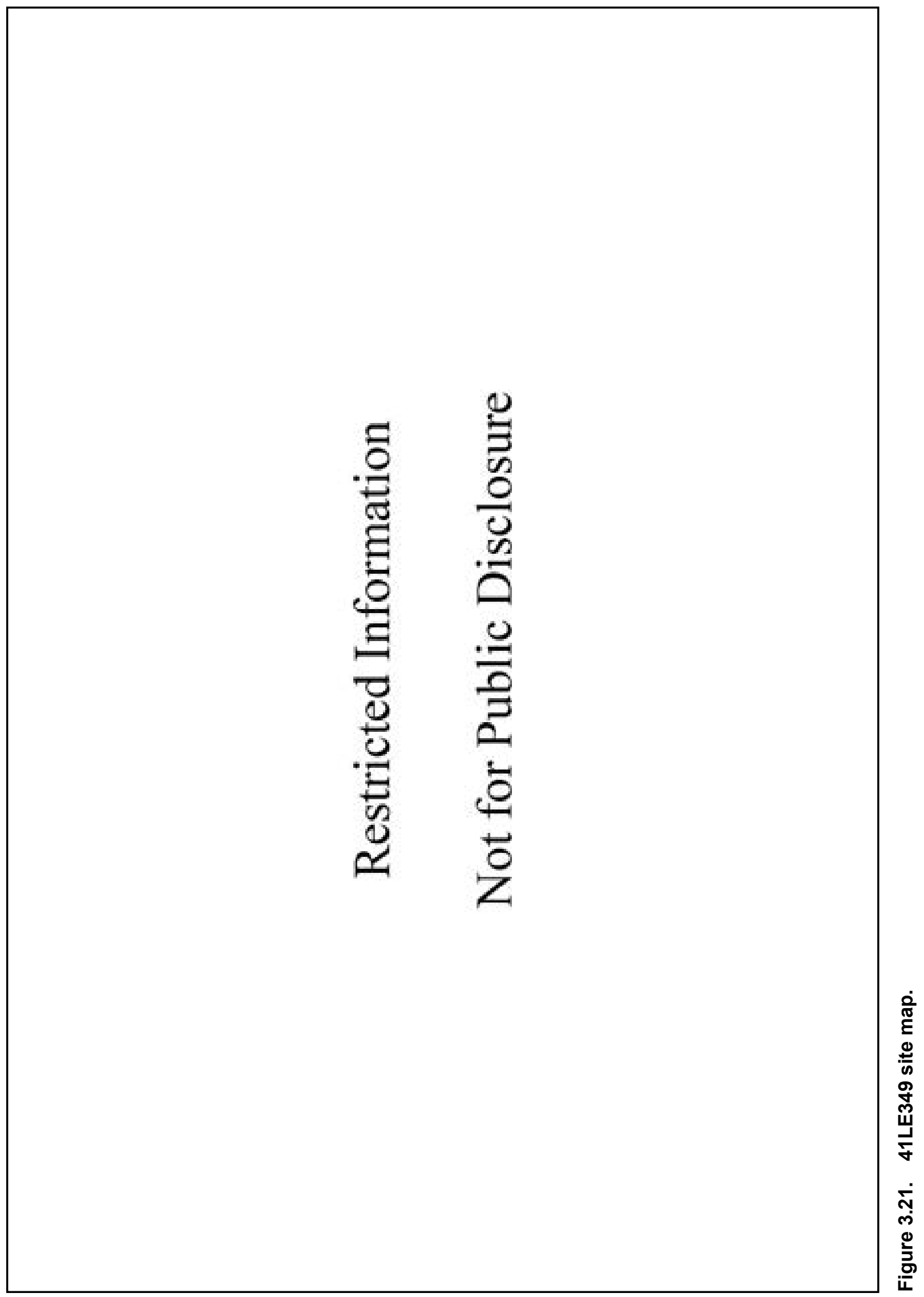




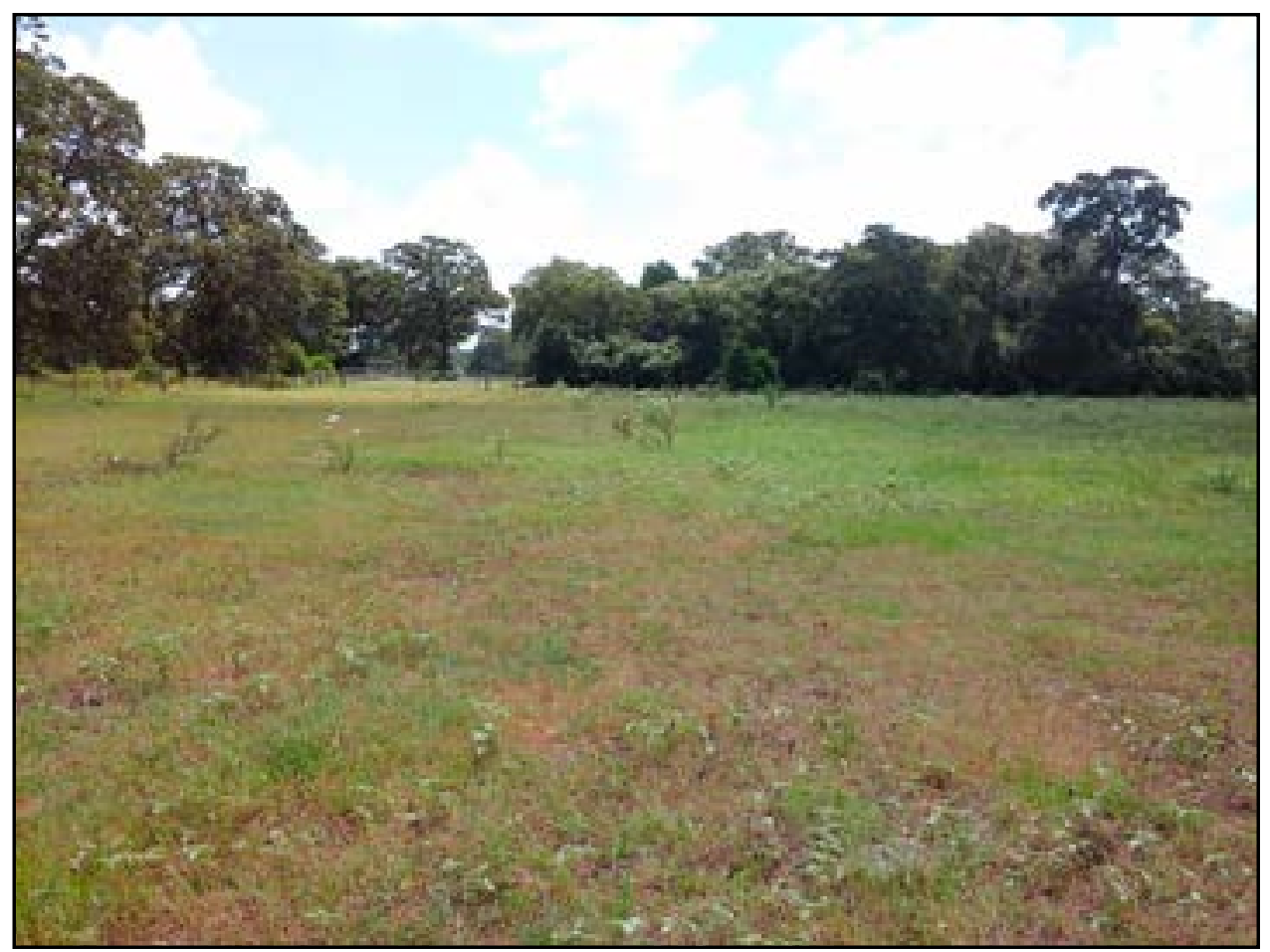

Figure 3.22. Overview of site 41LE349, facing east.

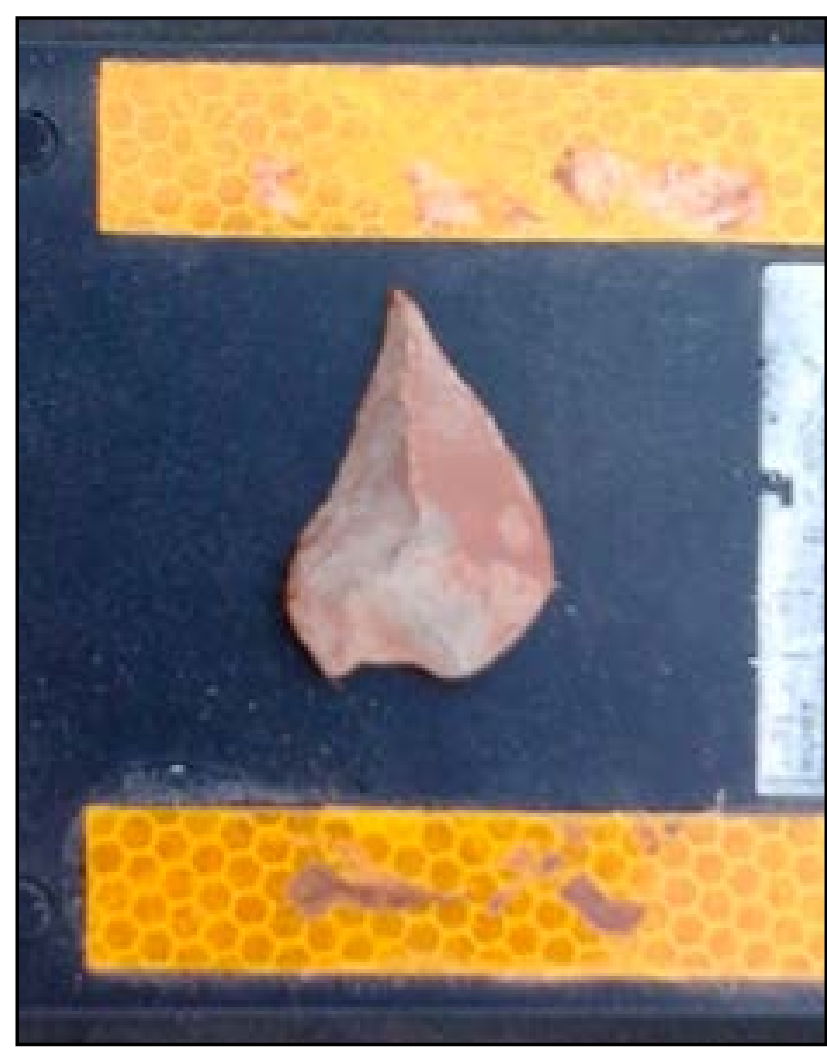

Figure 3.23. Primary flake from site 41 LE349 in ST XMC12 at 90-100 cmbs. the drainage and creek. Ground surface visibility was poor due to grass cover. Site 41LE350 is located on privately owned land used for agricultural and ranching activities. Disturbances include erosion, vegetation clearing, fence lines, two-track roads, and nearby land modification for stock ponds.

Site 41LE350 measures approximately $30 \mathrm{~m}$ northwest/ southeast by $315 \mathrm{~m}$ northeast/southwest within the project corridor based on subsurface artifact distribution and landforms surrounding the site; however, the site may extend beyond the project area to the northwest and southeast. No cultural materials were observed along the ground surface due to poor visibility.

SWCA excavated 10 shovel tests (i.e., AE507-512 and CS206-209) at approximately 50-m intervals to delineate the site, of which five (i.e., AE508, AE510, and CS206-208) were positive for cultural materials from near surface to a maximum depth of $80 \mathrm{cmbs}$ (Table 3.11). Cultural materials recovered included two primary flakes, seven secondary flakes, 25 tertiary reduction flakes, two fragments of chert shatter, two probable fire-cracked rocks, and one charcoal fragment (Figures 3.26 and 3.27). No temporally diagnostic artifacts or intact cultural features were observed. Shovel 


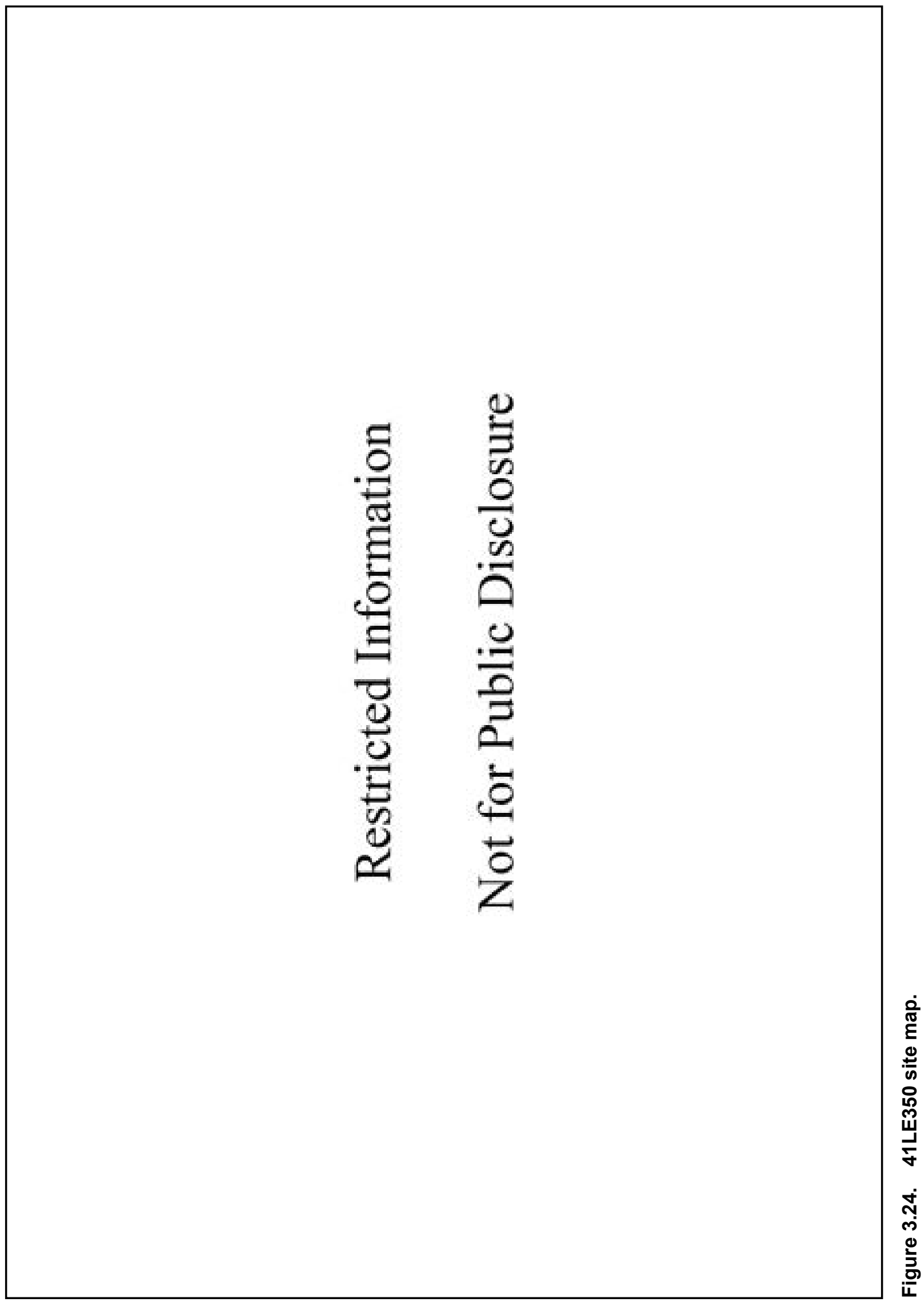




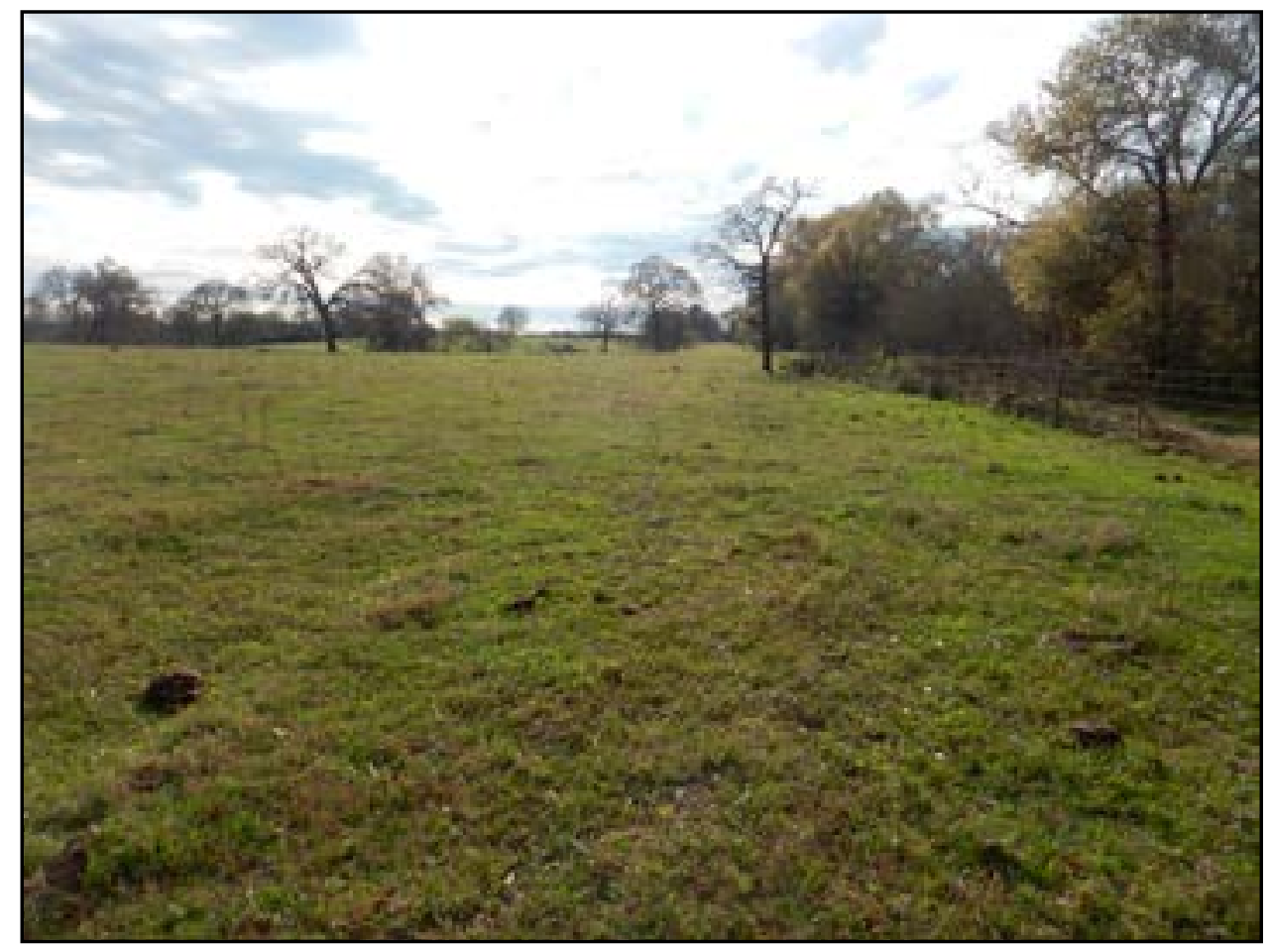

Figure 3.25. Overview of site 41LE350 from shove test AE512, facing west.

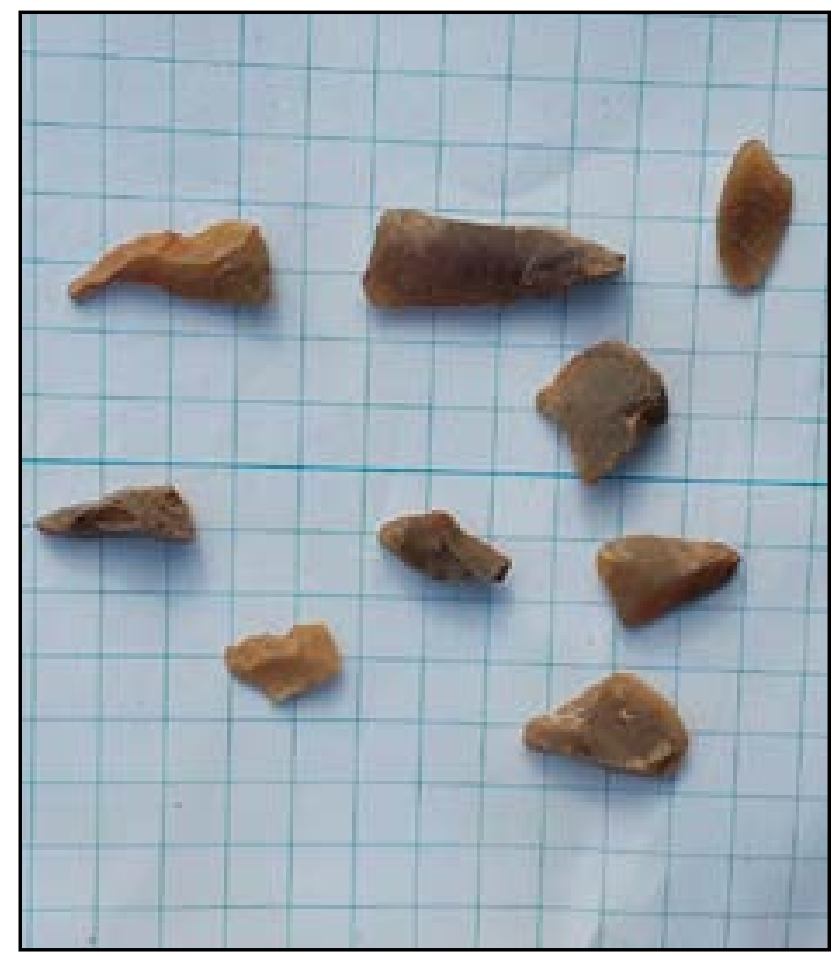

Figure 3.26. Flakes from site 41LE350 in ST CS208 at $0-50$ cmbs.

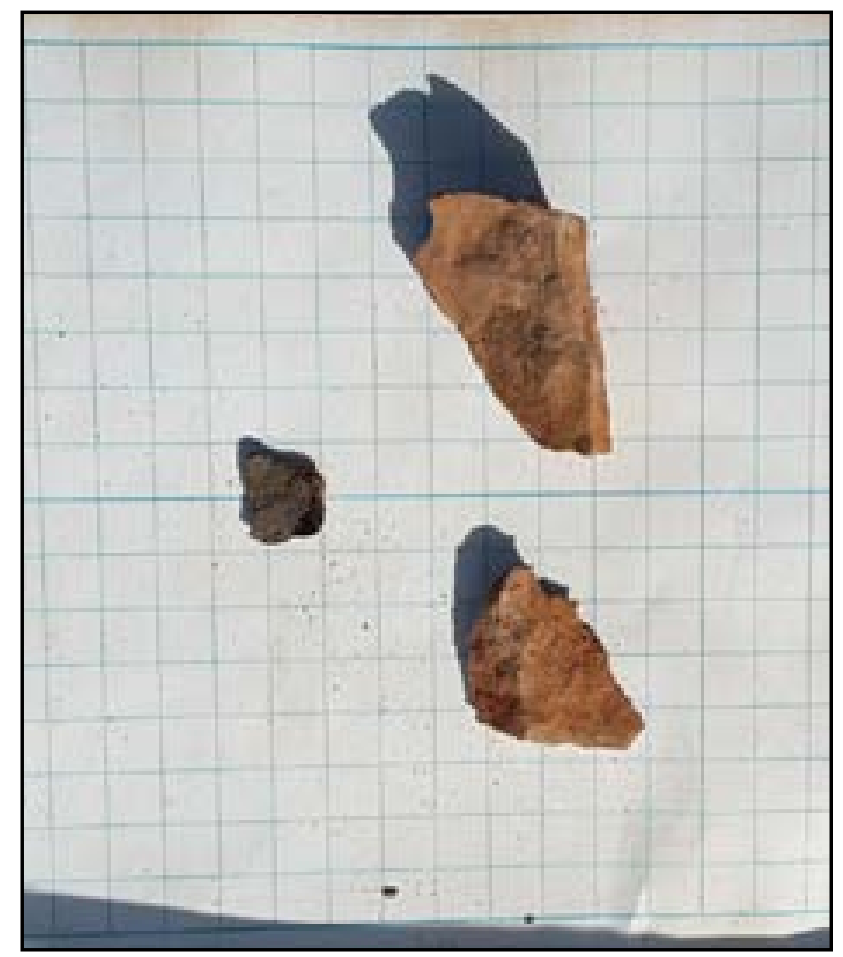

Figure 3.27. Charcoal and possible fire-cracked rock from site 41 LE350 in ST CS207 at $0-80 \mathrm{cmbs}$. 
Table 3.11. Shovel Test Data for Site 41LE350

\begin{tabular}{|c|c|c|c|c|c|c|c|c|c|}
\hline $\begin{array}{l}\text { Shovel } \\
\text { Test No. }\end{array}$ & Level & $\begin{array}{l}\text { Depth } \\
\text { (cmbs) }\end{array}$ & $\begin{array}{l}\text { Munsell Soil } \\
\text { Value }\end{array}$ & $\begin{array}{l}\text { Munsell Soil } \\
\text { Color }\end{array}$ & $\begin{array}{l}\text { Soil } \\
\text { Texture }\end{array}$ & $\begin{array}{l}\text { Inclusion } \\
\text { Percentage }\end{array}$ & $\begin{array}{l}\text { Inclusion } \\
\text { Type }\end{array}$ & Cultural Materials & $\begin{array}{l}\text { Comments/ } \\
\text { Reason for } \\
\text { Termination }\end{array}$ \\
\hline \multirow{2}{*}{ AE507 } & 1 & $0-60$ & 7.5YR 5/4 & brown & \multicolumn{2}{|c|}{ Sandy Loam 1-5\% } & $\begin{array}{l}\text { Gravels, } \\
\text { Pebbles }\end{array}$ & None & \\
\hline & 2 & $60-75$ & 7.5YR 4/6 & strong brown & \multicolumn{2}{|l|}{$\begin{array}{l}\text { Sandy Clay } \\
\text { Loam }\end{array}$} & Mottles & None & $\begin{array}{l}\text { Terminated at } \\
\text { basal clay. }\end{array}$ \\
\hline AE508 & 1 & $0-100$ & 7.5YR 4/4 & brown & \multicolumn{2}{|c|}{ Sandy Loam 1-5\% } & $\begin{array}{l}\text { Gravels, } \\
\text { Pebbles }\end{array}$ & $\begin{array}{l}\text { 1: Flake (secondary) } \\
\text { [10-20 cmbs], } \\
\text { 2: Flake (tertiary) } \\
\text { [10-20 cmbs and } 50- \\
60 \mathrm{cmbs}]\end{array}$ & $\begin{array}{l}\text { Terminated at } \\
\text { depth. }\end{array}$ \\
\hline \multirow{2}{*}{ AE509 } & 1 & $0-30$ & 7.5YR 4/4 & brown & \multicolumn{2}{|c|}{ Sandy Loam 1-5\% } & Pebbles & None & - \\
\hline & 2 & $30-50$ & 5YR 5/8 & yellowish red & \multicolumn{2}{|c|}{ Sandy Clay - } & - & None & $\begin{array}{l}\text { Terminated at } \\
\text { basal clay. }\end{array}$ \\
\hline AE510 & 1 & $0-100$ & 7.5YR 5/4 & brown & \multicolumn{2}{|c|}{ Sandy Loam 1-5\% } & $\begin{array}{l}\text { Gravels, } \\
\text { Pebbles }\end{array}$ & $\begin{array}{l}\text { 3: Flake (tertiary), } \\
2: \text { Shatter [ } 1 \text { tertiary } \\
\text { flake and } 1 \text { shatter } \\
10-20 \mathrm{cmbs} \text {; } 1 \text { tertiary } \\
\text { flake and } 1 \text { shatter } \\
20-30 \mathrm{cmbs} \text {; } 1 \text { tertiary } \\
\text { flake } 30-40 \mathrm{cmbs} \text {. }\end{array}$ & $\begin{array}{l}\text { Terminated at } \\
\text { depth. }\end{array}$ \\
\hline AE511 & - & - & - & - & - & - & - & None & $\begin{array}{l}\text { Not Excavated } \\
\text { due to wetland/ } \\
\text { water table at } \\
\text { surface. }\end{array}$ \\
\hline AE512 & 1 & $0-100$ & 7.5YR 4/4 & brown & \multicolumn{2}{|c|}{ Sandy Loam 1-5\% } & $\begin{array}{l}\text { Gravels, } \\
\text { Pebbles }\end{array}$ & None & $\begin{array}{l}\text { Terminated at } \\
\text { depth. }\end{array}$ \\
\hline CS206 & 1 & $0-100$ & 7.5YR 4/4 & brown & $\begin{array}{l}\text { Loamy } \\
\text { Sand }\end{array}$ & $5-10 \%$ & $\begin{array}{l}\text { Cobbles, } \\
\text { Gravels, } \\
\text { Pebbles }\end{array}$ & 2: Flake (tertiary). & $\begin{array}{l}\text { Terminated at } \\
\text { depth. }\end{array}$ \\
\hline \multirow[t]{2}{*}{ CS207 } & 1 & $0-80$ & 7.5YR 4/3 & brown & $\begin{array}{l}\text { Loamy } \\
\text { Sand }\end{array}$ & $5-10 \%$ & $\begin{array}{l}\text { Cobbles, } \\
\text { Pebbles }\end{array}$ & $\begin{array}{l}\text { 1: Flake (primary), } \\
\text { 2: Flake (secondary), } \\
\text { 9: Flake (tertiary), } \\
\text { 2: FCR, and 1: } \\
\text { Charcoal Fragment. }\end{array}$ & - \\
\hline & 2 & $80-100$ & 5YR 5/8 & yellowish red & Sandy Clay & - & - & None & $\begin{array}{l}\text { Terminated at } \\
\text { depth. }\end{array}$ \\
\hline \multirow[t]{2}{*}{ CS208 } & 1 & $0-50$ & 7.5YR 4/3 & brown & $\begin{array}{l}\text { Loamy } \\
\text { Sand }\end{array}$ & $5-10 \%$ & $\begin{array}{l}\text { Cobbles, } \\
\text { Pebbles }\end{array}$ & $\begin{array}{l}\text { 1: Flake (primary), } \\
\text { 4: Flake (secondary), } \\
\text { 9: Flake (tertiary). }\end{array}$ & - \\
\hline & 2 & $50-60$ & 5YR 5/8 & yellowish red & Sandy Clay & - & - & None & $\begin{array}{l}\text { Terminated at } \\
\text { depth. }\end{array}$ \\
\hline \multirow{2}{*}{ CS209 } & 1 & $0-45$ & 7.5YR 4/3 & brown & \multicolumn{2}{|c|}{ Sandy Loam- } & - & None & - \\
\hline & 2 & $45-100$ & 7.5YR 6/2 & pinkish gray & $\begin{array}{l}\text { Loamy } \\
\text { Sand }\end{array}$ & - & - & None & $\begin{array}{l}\text { Terminated at } \\
\text { depth. }\end{array}$ \\
\hline
\end{tabular}


tests typically revealed brown (7.5YR 5/4) sandy loam overlying strong brown (7.5YR 4/6) sandy clay loam; although most terminated at depth (i.e., $100 \mathrm{cmbs}$ ), two shovel tests (i.e., AE507 and AE509) encountered compacted, impassible clays between 50 and $75 \mathrm{cmbs}$. All artifacts were encountered within the sandy loam layer. Due to project constraints, the site was not fully delineated to the northwest or southeast, as investigations were not permitted outside the project ROW. Due to a shift of the project corridor since the original recording of the site, the northwestern portion of the site is now outside the project area boundaries.

\section{LE350 SUMMARY}

Site 41LE350 consists of a buried, low density prehistoric lithic scatter from the near surface to $80 \mathrm{cmbs}$. The site lacks temporally diagnostic artifacts or intact cultural features. Overall, site 41LE350 does not have the potential to yield information important to the prehistory of the region. As such, SWCA recommends site 41LE350 as NOT ELIGIBLE for the NRHP or for designation as a SAL. No further work or avoidance strategy is recommended for site 41LE350 within the project area.

\section{BASTROP COUNTY}

Four cultural resource sites and four isolated finds were newly recorded, and two previously recorded cultural resource sites were revisited during further investigations in Bastrop County (Figure 3.28; see Table 3.3). The previously recorded archaeological sites consist of a multicomponent historic artifact scatter and prehistoric campsite (i.e., 41BP818) and a multicomponent artifact scatter (i.e., 41BP920) recorded and recommended for avoidance or further testing during the 2015 efforts. Site 41BP920 was revisited for significance testing during the 2016 and 2018 additional investigations and is reported in a separate report (Rodriguez and Young 2018). The isolated finds (i.e., IF08, IF10, IF13, and IF14) consist of prehistoric secondary and tertiary reduction flakes, none of which were recorded as archaeological sites (Appendix A: 76, 83, and 34; see Table 3.4). The newly recorded archaeological sites consist of one prehistoric lithic scatter (41BP959), two prehistoric campsites (i.e., 41BP960 and 41BP961), and one historic road and bridge embankment (i.e., 41BP962). In addition, one cemetery (the Hill Cemetery) was documented within the project area within the boundaries of site 41BP818.
Two of the newly recorded archaeological sites (i.e., 41BP960 and 41BP961) are recommended as having an UNDETERMINED eligibility for listing on the NRHP or for SAL designation; both have currently been avoided by design alignment changes by the Vista Ridge Project. Based on the results of the testing investigations, site 41BP920 has now been determined NOT ELIGIBLE for listing on the NRHP or for designation as a SAL (Rodriguez and Young 2018). SWCA recommends the remaining three archaeological sites (i.e., 41BP818, 41BP959, and 41BP962) in Bastrop County as NOT ELIGIBLE for listing on the NRHP or for SAL designation. No avoidance strategy or further work is recommended for these sites within the project corridor. The Hill Cemetery is now avoided and will not be impacted by the project. In addition, no further work is required or recommended to comply with the Texas Health and Safety code.

\section{$41 B P 818$}

Site 41BP818 is a prehistoric lithic scatter in northwest Bastrop County. The site was originally recorded in 2007 by PBS\&J during the FM 969 Project (Appendix A:113) (THC 2018). The site was described as a prehistoric lithic scatter of an unknown temporal affiliation consisting of flakes, cultural shatter, and fire-cracked rock. The 2007 investigations recommended the site as NOT ELIGIBLE for listing and no further work was recommended (THC 2018).

The site is located on an upland formation overlooking an unnamed tributary of the Colorado River $220 \mathrm{~m}$ to the southwest (Figure 3.29). The site is in an open agricultural field bordered by FM 969 to the north and an active quarry to the south. A large spoil pile overlaps the southern boundary of the site, and the western site boundary is defined by a property fence line. The Hill Cemetery, discussed below, is located at the center of the site and northwest of the active quarry.

SWCA archaeologists revisited site 41BP818 and expanded the original site boundary to the south; this expansion includes a prehistoric lithic scatter with a historic artifact component and the Hill Cemetery. The new dimensions of the site measure 170 m northeast/ southwest by $150 \mathrm{~m}$ northwest/southeast, but the site likely extends to the northwest and southeast, beyond the project boundaries. Site boundaries were determined by ground surface inspection, shovel testing for subsurface cultural deposits, and project area boundaries. 


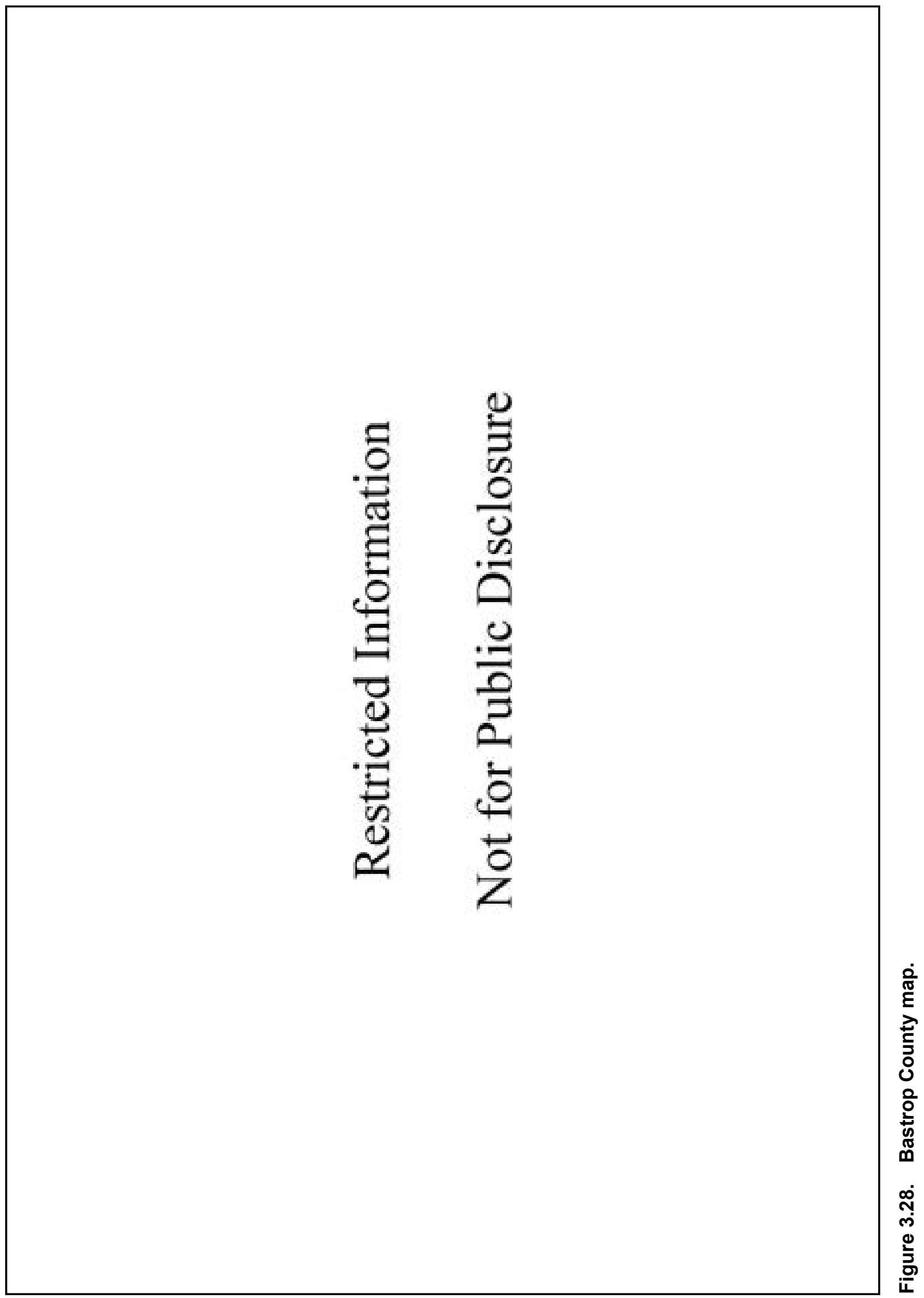




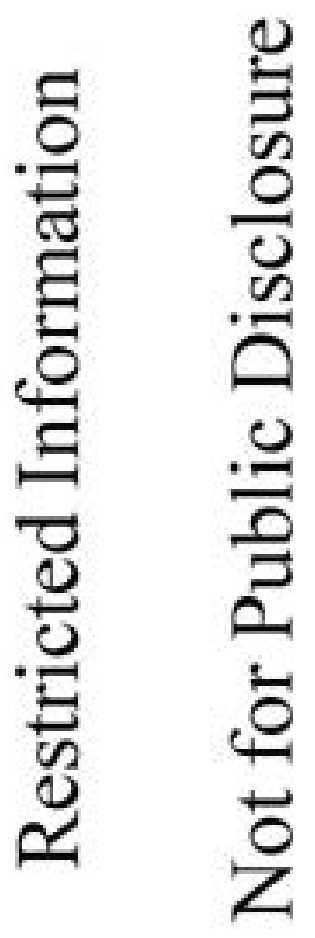

$\frac{0}{0}$
$\frac{1}{E}$
$\frac{0}{0}$
0
$\infty$
$\frac{0}{0}$
0
$\frac{0}{8}$

ลั

N

은

흔 
SWCA excavated 25 shovel tests (i.e., AY22-26, BM39, DR418-423, BD01-09, MN414-415, and PO01-03) within the site boundaries, of which 23 (i.e., AY22-25, AY26, BD01-04, BD06-08, BM39, DR418-23, MN414, and PO01-03) were positive for subsurface cultural materials from the ground surface to $60 \mathrm{cmbs}$ (Table 3.12). Shovel tests typically revealed dark brown (7.5YR 3/4) sandy clay loam to light yellowish brown (10YR 6/4) overlying yellowish red (5YR 5/8) sandy clay loam; most terminated at compacted, impassible clays between 50 and $80 \mathrm{cmbs}$.

Cultural materials consist of: one historic earthenware sherd; 5-10 colorless glass fragments; 5-10 brown glass fragments; $10-15$ aqua glass fragments; $20-40$ milk glass fragments; one temporally non-diagnostic projectile point; $20-40$ bifaces; $10-20$ scrapers; $10-20$ modified flakes; 500-700 burned rock fragments; 50 100 primary flakes; $75-150$ secondary flakes; $200-400$ tertiary flakes; and 300-600 cultural shatter fragments.

A review of aerial imagery indicates the northern half of the site was artificially terraced between 2009 and 2011 and has undergone repeated agricultural plowing since that time. Additional disturbances include construction activities associated with the active quarry on the southeastern site boundary; the quarrying also appears to have begun around the same time as the agricultural activities (Figure 3.30). In addition, a large spoil pile overlaps the southern boundary of the site, and the western site boundary is defined by a property fence line (Figures 3.31a and 3.31b).

\section{BP818 SUMMARY}

Overall, revisit investigations of site 41BP818 determined that the site consists of a prehistoric lithic scatter and historic artifact scatter with the Hill Cemetery at its center. Pedestrian survey and extensive shovel testing throughout the site determined that although a dense assemblage of artifacts is present, no diagnostic artifacts or intact cultural features associated with the prehistoric component or historic artifact component are present on site. In addition, pervasive disturbances (e.g., quarrying, agricultural plowing and artificial terracing) have reduced the potential for intact, cultural features to be present within the portions of the site in the project area. Due to its lack of potential research

Table 3.12. Shovel Test Data for Site 41BP818

\begin{tabular}{|c|c|c|c|c|c|c|c|c|}
\hline $\begin{array}{l}\text { Shovel } \\
\text { Test No. }\end{array}$ & Level & $\begin{array}{l}\text { Depth } \\
\text { (cmbs) }\end{array}$ & $\begin{array}{l}\text { Munsell } \\
\text { Soil Value }\end{array}$ & $\begin{array}{l}\text { Munsell Soil } \\
\text { Color }\end{array}$ & $\begin{array}{l}\text { Inclusion } \\
\text { Percentage }\end{array}$ & Inclusion Type & Cultural Materials & $\begin{array}{l}\text { Comments/ } \\
\text { Reason for } \\
\text { Termination }\end{array}$ \\
\hline \multirow[t]{2}{*}{ AY22 } & 1 & $0-50$ & 7.5YR 3/4 & dark brown & $\begin{array}{l}\text { Sandy Clay >20\% } \\
\text { Loam }\end{array}$ & $\begin{array}{l}\text { Cobbles, Gravels, } \\
\text { Pebbles }\end{array}$ & $\begin{array}{l}\text { 14: Flake } \\
\text { (secondary), Flake } \\
\text { (tertiary), Other } \\
\text { Prehistoric }\end{array}$ & - \\
\hline & 2 & $50-60$ & 5YR 5/8 & yellowish red & $\begin{array}{l}\text { Sandy Clay }>20 \% \\
\text { Loam }\end{array}$ & $\begin{array}{l}\text { Cobbles, Gravels, } \\
\text { Large Rock Frags, } \\
\text { Pebbles }\end{array}$ & $\begin{array}{l}\text { No cultural } \\
\text { material } \\
\text { encountered. }\end{array}$ & $\begin{array}{l}\text { Terminated at } \\
\text { gravel impass. }\end{array}$ \\
\hline \multirow{5}{*}{ AY23 } & 1 & $0-10$ & 7.5YR 3/4 & dark brown & $\begin{array}{l}\text { Sandy Clay >20\% } \\
\text { Loam }\end{array}$ & $\begin{array}{l}\text { Cobbles, Gravels, } \\
\text { Pebbles }\end{array}$ & $\begin{array}{l}\text { 6: Flake } \\
\text { (secondary), } \\
\text { Flake (tertiary), } \\
\text { Other Prehistoric } \\
\text { [3 tertiary, } 1 \\
\text { secondary, } 2 \\
\text { shatter] }\end{array}$ & - \\
\hline & 2 & $10-20$ & 7.5YR 3/4 & dark brown & $\begin{array}{l}\text { Sandy Clay }>20 \% \\
\text { Loam }\end{array}$ & $\begin{array}{l}\text { Cobbles, Gravels, } \\
\text { Pebbles }\end{array}$ & $\begin{array}{l}\text { 4: Flake (tertiary) } \\
\text { [3 tertiary, } 1 \\
\text { shatter] }\end{array}$ & - \\
\hline & 3 & $20-30$ & 7.5YR 3/4 & dark brown & $\begin{array}{l}\text { Sandy Clay >20\% } \\
\text { Loam }\end{array}$ & $\begin{array}{l}\text { Cobbles, Gravels, } \\
\text { Pebbles }\end{array}$ & 3: Flake (tertiary) & - \\
\hline & 4 & $30-40$ & 7.5YR 3/4 & dark brown & $\begin{array}{l}\text { Sandy Clay }>20 \% \\
\text { Loam }\end{array}$ & $\begin{array}{l}\text { Cobbles, Gravels, } \\
\text { Pebbles }\end{array}$ & 3: Flake (tertiary) & - \\
\hline & 5 & $40-50$ & 5YR 5/8 & yellowish red & Sandy Clay $>20 \%$ & Cobbles, Gravels & $\begin{array}{l}\text { No cultural } \\
\text { material } \\
\text { encountered. }\end{array}$ & $\begin{array}{l}\text { Terminated at } \\
\text { basal clay. }\end{array}$ \\
\hline
\end{tabular}


Table 3.12. continued

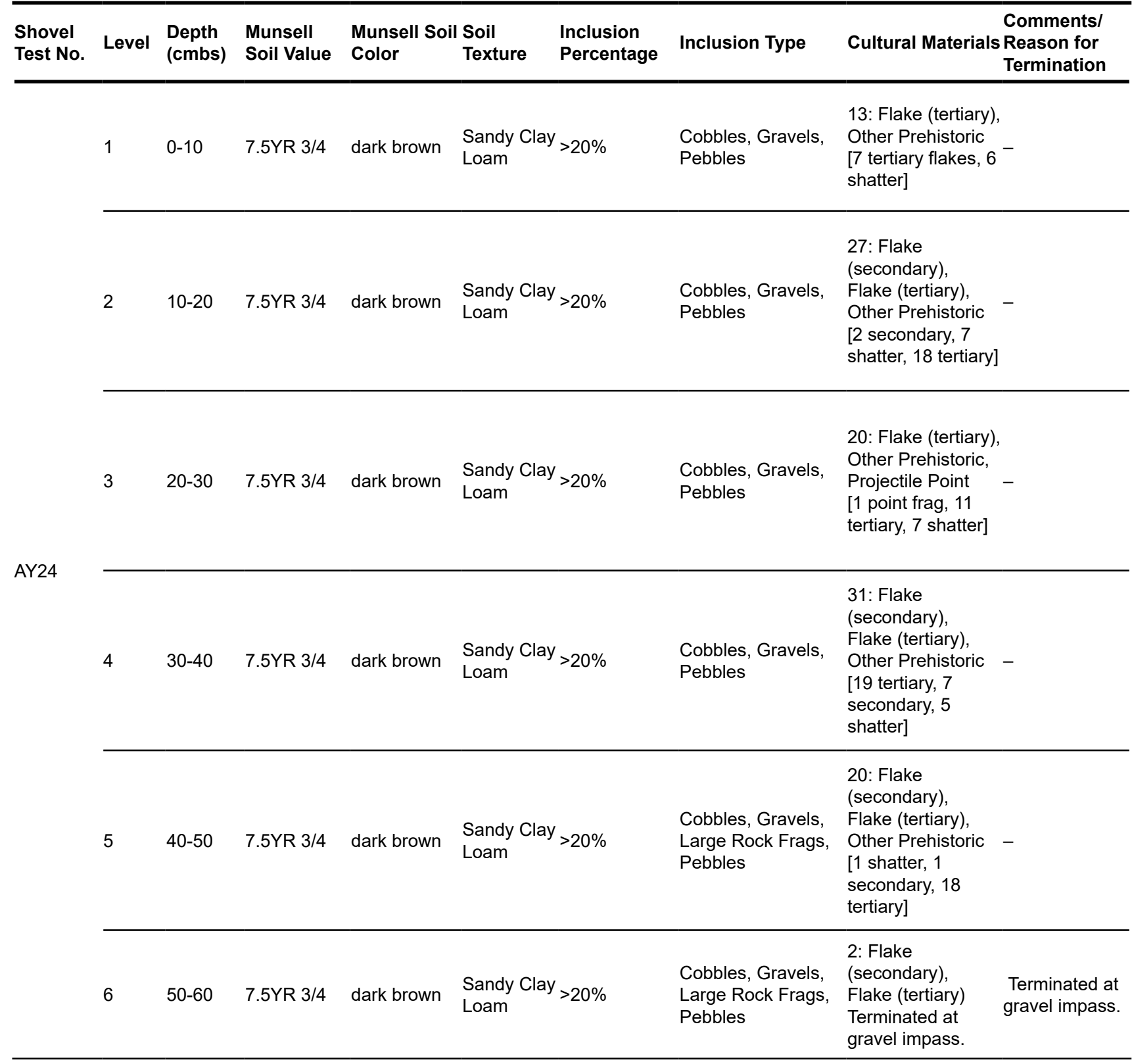


Table 3.12. continued

\begin{tabular}{|c|c|c|c|c|c|c|c|c|c|}
\hline $\begin{array}{l}\text { Shovel } \\
\text { Test No. }\end{array}$ & Level & $\begin{array}{l}\text { Depth } \\
\text { (cmbs) }\end{array}$ & $\begin{array}{l}\text { Munsell } \\
\text { Soil Value }\end{array}$ & $\begin{array}{l}\text { Munsell Soil } \\
\text { Color }\end{array}$ & $\begin{array}{l}\text { Soil } \\
\text { Texture }\end{array}$ & $\begin{array}{l}\text { Inclusion } \\
\text { Percentage }\end{array}$ & Inclusion Type & Cultural Materials & $\begin{array}{l}\text { Comments/ } \\
\text { Reason for } \\
\text { Termination }\end{array}$ \\
\hline \multirow{5}{*}{ AY25 } & 1 & $0-10$ & 7.5YR 4/4 & brown & $\begin{array}{l}\text { Sandy Clay } \\
\text { Loam }\end{array}$ & $>20 \%$ & $\begin{array}{l}\text { Cobbles, Gravels, } \\
\text { Pebbles }\end{array}$ & $\begin{array}{l}\text { 8: Flake (tertiary), } \\
\text { Other Prehistoric } \\
\text { [4 tertiary, } 4 \\
\text { shatter] }\end{array}$ & - \\
\hline & 2 & $10-20$ & 7.5YR 4/4 & brown & $\begin{array}{l}\text { Sandy Clay } \\
\text { Loam }\end{array}$ & $>20 \%$ & $\begin{array}{l}\text { Cobbles, Gravels, } \\
\text { Pebbles }\end{array}$ & $\begin{array}{l}\text { 17: Flake } \\
\text { (secondary), } \\
\text { Flake (tertiary), } \\
\text { Other Prehistoric } \\
\text { [9 tertiary, } 1 \\
\text { secondary, } 7 \\
\text { shatter] }\end{array}$ & - \\
\hline & 3 & $20-30$ & 7.5YR 4/4 & brown & $\begin{array}{l}\text { Sandy Clay } \\
\text { Loam }\end{array}$ & $>20 \%$ & $\begin{array}{l}\text { Cobbles, Gravels, } \\
\text { Pebbles }\end{array}$ & $\begin{array}{l}\text { 9: Flake (tertiary), } \\
\text { Other Prehistoric } \\
\text { [8 tertiary, } 1 \\
\text { shatter] }\end{array}$ & - \\
\hline & 4 & $30-40$ & 7.5YR 4/4 & brown & $\begin{array}{l}\text { Sandy Clay } \\
\text { Loam }\end{array}$ & $>20 \%$ & $\begin{array}{l}\text { Cobbles, Gravels, } \\
\text { Pebbles }\end{array}$ & $\begin{array}{l}\text { 4: Flake (tertiary), } \\
\text { Other Prehistoric } \\
\text { [3 tertiary, } 1 \\
\text { shatter] }\end{array}$ & - \\
\hline & 5 & $40-50$ & 7.5YR 4/4 & brown & $\begin{array}{l}\text { Sandy Clay } \\
\text { Loam }\end{array}$ & $>20 \%$ & $\begin{array}{l}\text { Cobbles, Gravels, } \\
\text { Large Rock Frags, } \\
\text { Pebbles }\end{array}$ & $\begin{array}{l}\text { 4: Flake } \\
\text { (tertiary), Other } \\
\text { Prehistoric [3 } \\
\text { tertiary, } 1 \text { shatter] } \\
\text { Terminated at } \\
\text { gravel impass. }\end{array}$ & $\begin{array}{l}\text { Terminated at } \\
\text { gravel impass. }\end{array}$ \\
\hline \multirow{2}{*}{ AY26 } & 1 & $0-40$ & 7.5YR 3/4 & dark brown & $\begin{array}{l}\text { Sandy Clay } \\
\text { Loam }\end{array}$ & $10-20 \%$ & Gravels, Pebbles & $\begin{array}{l}\text { 2: Flake (tertiary) } \\
\text { [0-15 cmbs } 2 \\
\text { flakes] }\end{array}$ & - \\
\hline & 2 & $40-45$ & 5YR 5/8 & yellowish red & Clay Loam & $1-5 \%$ & Gravels, Pebbles & $\begin{array}{l}\text { No cultural } \\
\text { material } \\
\text { encountered. }\end{array}$ & $\begin{array}{l}\text { Terminated at } \\
\text { basal clay. }\end{array}$ \\
\hline \multirow{6}{*}{ BD01 } & 1 & $0-10$ & 10YR 6/4 & $\begin{array}{l}\text { light } \\
\text { yellowish } \\
\text { brown }\end{array}$ & $\begin{array}{l}\text { Sandy } \\
\text { Loam }\end{array}$ & $>20 \%$ & $\begin{array}{l}\text { Cobbles, Gravels, } \\
\text { Pebbles }\end{array}$ & $\begin{array}{l}\text { 3: Flake } \\
\text { (secondary), Flake } \\
\text { (tertiary) }\end{array}$ & \\
\hline & 2 & $10-20$ & 10YR 6/4 & $\begin{array}{l}\text { light } \\
\text { yellowish } \\
\text { brown }\end{array}$ & $\begin{array}{l}\text { Sandy } \\
\text { Loam }\end{array}$ & $>20 \%$ & $\begin{array}{l}\text { Cobbles, Gravels, } \\
\text { Pebbles }\end{array}$ & $\begin{array}{l}\text { 5: Flake } \\
\text { (secondary), Flake } \\
\text { (tertiary) }\end{array}$ & - \\
\hline & 3 & $20-30$ & 10YR 6/4 & $\begin{array}{l}\text { light } \\
\text { yellowish } \\
\text { brown }\end{array}$ & $\begin{array}{l}\text { Sandy } \\
\text { Loam }\end{array}$ & $>20 \%$ & $\begin{array}{l}\text { Cobbles, Gravels, } \\
\text { Pebbles }\end{array}$ & $\begin{array}{l}\text { 1: Flake } \\
\text { (secondary) }\end{array}$ & - \\
\hline & 4 & $40-50$ & 10YR 6/4 & $\begin{array}{l}\text { light } \\
\text { yellowish } \\
\text { brown }\end{array}$ & $\begin{array}{l}\text { Sandy } \\
\text { Loam }\end{array}$ & $>20 \%$ & Gravels, Pebbles & $\begin{array}{l}\text { 1: Flake } \\
\text { (secondary) }\end{array}$ & - \\
\hline & 5 & $40-50$ & 10YR 6/4 & $\begin{array}{l}\text { light } \\
\text { yellowish } \\
\text { brown }\end{array}$ & $\begin{array}{l}\text { Sandy } \\
\text { Loam }\end{array}$ & $>20 \%$ & Gravels, Pebbles & $\begin{array}{l}\text { 1: Flake } \\
\text { (secondary) }\end{array}$ & - \\
\hline & 6 & $50-60$ & 10YR 6/4 & $\begin{array}{l}\text { light } \\
\text { yellowish } \\
\text { brown }\end{array}$ & $\begin{array}{l}\text { Sandy } \\
\text { Loam }\end{array}$ & $>20 \%$ & Gravels, Pebbles & $\begin{array}{l}\text { 3: Flake } \\
\text { (secondary), Flake } \\
\text { (tertiary) }\end{array}$ & $\begin{array}{l}\text { Terminated at } \\
\text { depth. }\end{array}$ \\
\hline
\end{tabular}


Table 3.12. continued

\begin{tabular}{|c|c|c|c|c|c|c|c|c|c|}
\hline $\begin{array}{l}\text { Shovel } \\
\text { Test No. }\end{array}$ & Level & $\begin{array}{l}\text { Depth } \\
\text { (cmbs) }\end{array}$ & $\begin{array}{l}\text { Munsell } \\
\text { Soil Value }\end{array}$ & $\begin{array}{l}\text { Munsell Soil } \\
\text { Color }\end{array}$ & $\begin{array}{l}\text { Soil } \\
\text { Texture }\end{array}$ & $\begin{array}{l}\text { Inclusion } \\
\text { Percentage }\end{array}$ & Inclusion Type & Cultural Materials & $\begin{array}{l}\text { Comments/ } \\
\text { Season for } \\
\text { Termination }\end{array}$ \\
\hline \multirow{6}{*}{ BD02 } & 1 & $0-10$ & 10YR 6/4 & $\begin{array}{l}\text { light } \\
\text { yellowish } \\
\text { brown }\end{array}$ & $\begin{array}{l}\text { Sandy } \\
\text { Loam }\end{array}$ & $5-10 \%$ & Pebbles & 6: Flake (tertiary) & - \\
\hline & 2 & $10-20$ & 10YR 6/4 & $\begin{array}{l}\text { light } \\
\text { yellowish } \\
\text { brown }\end{array}$ & $\begin{array}{l}\text { Sandy } \\
\text { Loam }\end{array}$ & $5-10 \%$ & Pebbles & 2: Flake (tertiary) & - \\
\hline & 3 & $20-30$ & 10YR 6/4 & $\begin{array}{l}\text { light } \\
\text { yellowish } \\
\text { brown }\end{array}$ & $\begin{array}{l}\text { Sandy } \\
\text { Loam }\end{array}$ & $5-10 \%$ & Pebbles & 1: Flake (tertiary) & - \\
\hline & 4 & $30-40$ & 10YR 6/4 & $\begin{array}{l}\text { light } \\
\text { yellowish } \\
\text { brown }\end{array}$ & $\begin{array}{l}\text { Sandy } \\
\text { Loam }\end{array}$ & $5-10 \%$ & Pebbles & $\begin{array}{l}\text { 2: Flake } \\
\text { (secondary), Flake } \\
\text { (tertiary) }\end{array}$ & - \\
\hline & 5 & $40-50$ & $5 Y R$ 4/6 & yellowish red & $\begin{array}{l}\text { Sandy Clay } \\
\text { Loam }\end{array}$ & $1-$ & - & $\begin{array}{l}\text { No cultural } \\
\text { material } \\
\text { encountered. }\end{array}$ & - \\
\hline & 6 & $50-60$ & 5YR 4/6 & yellowish red & $\begin{array}{l}\text { Sandy Clay } \\
\text { Loam }\end{array}$ & 1 & - & $\begin{array}{l}\text { No cultural } \\
\text { material } \\
\text { encountered. }\end{array}$ & $\begin{array}{l}\text { Terminated at } \\
\text { basal clay. }\end{array}$ \\
\hline \multirow{6}{*}{$\mathrm{BD03}$} & 1 & $0-10$ & 10YR 6/4 & $\begin{array}{l}\text { light } \\
\text { yellowish } \\
\text { brown }\end{array}$ & $\begin{array}{l}\text { Sandy } \\
\text { Loam }\end{array}$ & $10-20 \%$ & Pebbles & $\begin{array}{l}\text { 18: Flake } \\
\text { (secondary), Flake } \\
\text { (tertiary) }\end{array}$ & \\
\hline & 2 & $10-20$ & 10YR 6/4 & $\begin{array}{l}\text { light } \\
\text { yellowish } \\
\text { brown }\end{array}$ & $\begin{array}{l}\text { Sandy } \\
\text { Loam }\end{array}$ & $10-20 \%$ & Pebbles & $\begin{array}{l}\text { 4: Flake } \\
\text { (secondary), Flake } \\
\text { (tertiary) }\end{array}$ & \\
\hline & 3 & $20-30$ & 10YR 6/4 & $\begin{array}{l}\text { light } \\
\text { yellowish } \\
\text { brown }\end{array}$ & $\begin{array}{l}\text { Sandy } \\
\text { Loam }\end{array}$ & $10-20 \%$ & Pebbles & $\begin{array}{l}\text { 2: Flake } \\
\text { (secondary), Flake } \\
\text { (tertiary) }\end{array}$ & \\
\hline & 4 & $30-40$ & 10YR 6/4 & $\begin{array}{l}\text { light } \\
\text { yellowish } \\
\text { brown }\end{array}$ & $\begin{array}{l}\text { Sandy } \\
\text { Loam }\end{array}$ & $10-20 \%$ & Pebbles & $\begin{array}{l}\text { 2: Core, Flake } \\
\text { (tertiary) }\end{array}$ & - \\
\hline & 5 & $40-50$ & 5YR 4/6 & yellowish red & $\begin{array}{l}\text { Sandy Clay } \\
\text { Loam }\end{array}$ & & - & $\begin{array}{l}\text { No cultural } \\
\text { material } \\
\text { encountered. }\end{array}$ & - \\
\hline & 6 & $50-60$ & $5 Y R$ 4/6 & yellowish red & $\begin{array}{l}\text { Sandy Clay } \\
\text { Loam }\end{array}$ & '- & - & $\begin{array}{l}\text { No cultural } \\
\text { material } \\
\text { encountered. }\end{array}$ & $\begin{array}{l}\text { Terminated at } \\
\text { basal clay. }\end{array}$ \\
\hline \multirow{6}{*}{ BD04 } & 1 & $0-10$ & 10YR 6/4 & $\begin{array}{l}\text { light } \\
\text { yellowish } \\
\text { brown }\end{array}$ & Silt & $5-10 \%$ & Pebbles & 1: Flake (tertiary) & - \\
\hline & 2 & $10-20$ & 10YR 6/4 & $\begin{array}{l}\text { light } \\
\text { yellowish } \\
\text { brown }\end{array}$ & $\begin{array}{l}\text { Sandy } \\
\text { Loam }\end{array}$ & $5-10 \%$ & Pebbles & $\begin{array}{l}\text { No cultural } \\
\text { material } \\
\text { encountered. }\end{array}$ & - \\
\hline & 3 & $20-25$ & 10YR 6/4 & $\begin{array}{l}\text { light } \\
\text { yellowish } \\
\text { brown }\end{array}$ & $\begin{array}{l}\text { Sandy } \\
\text { Loam }\end{array}$ & $5-10 \%$ & Pebbles & $\begin{array}{l}\text { No cultural } \\
\text { material } \\
\text { encountered. }\end{array}$ & - \\
\hline & 4 & $25-40$ & 5YR 4/6 & yellowish red & $\begin{array}{l}\text { Sandy Clay } \\
\text { Loam }\end{array}$ & & - & $\begin{array}{l}\text { No cultural } \\
\text { material } \\
\text { encountered. }\end{array}$ & - \\
\hline & 5 & $40-50$ & 5YR 4/6 & yellowish red & $\begin{array}{l}\text { Sandy Clay } \\
\text { Loam }\end{array}$ & & - & $\begin{array}{l}\text { No cultural } \\
\text { material } \\
\text { encountered. }\end{array}$ & - \\
\hline & 6 & $50-60$ & 5YR 4/6 & yellowish red & $\begin{array}{l}\text { Sandy Clay } \\
\text { Loam }\end{array}$ & 1 & - & $\begin{array}{l}\text { No cultural } \\
\text { material } \\
\text { encountered. }\end{array}$ & $\begin{array}{l}\text { Terminated at } \\
\text { basal clay. }\end{array}$ \\
\hline
\end{tabular}


Table 3.12. continued

\begin{tabular}{|c|c|c|c|c|c|c|c|c|c|}
\hline $\begin{array}{l}\text { Shovel } \\
\text { Test No. }\end{array}$ & Level & $\begin{array}{l}\text { Depth } \\
\text { (cmbs) }\end{array}$ & $\begin{array}{l}\text { Munsell } \\
\text { Soil Value }\end{array}$ & $\begin{array}{l}\text { Munsell Soil } \\
\text { Color }\end{array}$ & $\begin{array}{l}\text { Soil } \\
\text { Texture }\end{array}$ & $\begin{array}{l}\text { Inclusion } \\
\text { Percentage }\end{array}$ & Inclusion Type & Cultural Materials & $\begin{array}{l}\text { Comments/ } \\
\text { Reason for } \\
\text { Termination }\end{array}$ \\
\hline \multirow{9}{*}{ BD06 } & 1 & $0-10$ & 10YR 6/4 & $\begin{array}{l}\text { light } \\
\text { yellowish } \\
\text { brown }\end{array}$ & $\begin{array}{l}\text { Sandy } \\
\text { Loam }\end{array}$ & $5-10 \%$ & Pebbles & $\begin{array}{l}\text { 13: Flake } \\
\text { (secondary), Flake - } \\
\text { (tertiary) }\end{array}$ & \\
\hline & 2 & $10-20$ & 10YR 6/4 & $\begin{array}{l}\text { light } \\
\text { yellowish } \\
\text { brown }\end{array}$ & $\begin{array}{l}\text { Sandy } \\
\text { Loam }\end{array}$ & $5-10 \%$ & Pebbles & $\begin{array}{l}\text { 2: Flake } \\
\text { (secondary), Flake - } \\
\text { (tertiary) }\end{array}$ & \\
\hline & 3 & $20-30$ & 10YR 6/4 & $\begin{array}{l}\text { light } \\
\text { yellowish } \\
\text { brown }\end{array}$ & $\begin{array}{l}\text { Sandy } \\
\text { Loam }\end{array}$ & $5-10 \%$ & Pebbles & 4: Flake (tertiary) & - \\
\hline & 4 & $30-40$ & 10YR 6/4 & $\begin{array}{l}\text { light } \\
\text { yellowish } \\
\text { brown }\end{array}$ & $\begin{array}{l}\text { Sandy } \\
\text { Loam }\end{array}$ & $5-10 \%$ & Pebbles & $\begin{array}{l}\text { 19: Flake } \\
\text { (primary), Flake } \\
\text { (secondary), Flake } \\
\text { (tertiary) }\end{array}$ & \\
\hline & 5 & $40-50$ & 10YR 6/4 & $\begin{array}{l}\text { light } \\
\text { yellowish } \\
\text { brown }\end{array}$ & $\begin{array}{l}\text { Sandy } \\
\text { Loam }\end{array}$ & $5-10 \%$ & Pebbles & $\begin{array}{l}\text { 11: Flake } \\
\text { (primary), Flake } \\
\text { (secondary), Flake } \\
\text { (tertiary) }\end{array}$ & \\
\hline & 6 & $50-60$ & 10YR 6/4 & $\begin{array}{l}\text { light } \\
\text { yellowish } \\
\text { brown }\end{array}$ & $\begin{array}{l}\text { Sandy } \\
\text { Loam }\end{array}$ & $5-10 \%$ & Pebbles & $\begin{array}{l}\text { 4: Flake } \\
\text { (secondary), Flake- } \\
\text { (tertiary) }\end{array}$ & \\
\hline & 7 & $60-70$ & 10YR 6/4 & $\begin{array}{l}\text { light } \\
\text { yellowish } \\
\text { brown }\end{array}$ & $\begin{array}{l}\text { Sandy } \\
\text { Loam }\end{array}$ & $5-10 \%$ & Pebbles & $\begin{array}{l}\text { 1: Flake } \\
\text { (secondary) }\end{array}$ & - \\
\hline & 8 & $70-75$ & 10YR 6/4 & $\begin{array}{l}\text { light } \\
\text { yellowish } \\
\text { brown }\end{array}$ & $\begin{array}{l}\text { Sandy } \\
\text { Loam }\end{array}$ & $5-10 \%$ & Pebbles & $\begin{array}{l}\text { 2: Flake } \\
\text { (secondary), Flake- } \\
\text { (tertiary) }\end{array}$ & \\
\hline & 9 & $75-90$ & 5YR 4/6 & yellowish red & $\begin{array}{l}\text { Sandy Clay } \\
\text { Loam }\end{array}$ & & - & $\begin{array}{l}\text { No cultural } \\
\text { material } \\
\text { encountered. }\end{array}$ & $\begin{array}{l}\text { Terminated at } \\
\text { depth. }\end{array}$ \\
\hline \multirow{6}{*}{ BD07 } & 1 & $0-10$ & 10YR 6/4 & $\begin{array}{l}\text { light } \\
\text { yellowish } \\
\text { brown }\end{array}$ & $\begin{array}{l}\text { Sandy } \\
\text { Loam }\end{array}$ & $10-20 \%$ & Pebbles & $\begin{array}{l}\text { 1: Flake (utilized) } \\
\text { [Possibly biface } \\
\text { base] }\end{array}$ & - \\
\hline & 2 & $10-20$ & 10YR 6/4 & $\begin{array}{l}\text { light } \\
\text { yellowish } \\
\text { brown }\end{array}$ & $\begin{array}{l}\text { Sandy } \\
\text { Loam }\end{array}$ & $10-20 \%$ & Pebbles & 1: Flake (tertiary) & - \\
\hline & 3 & $20-30$ & 5YR 4/6 & yellowish red & $\begin{array}{l}\text { Sandy Clay } \\
\text { Loam }\end{array}$ & & - & $\begin{array}{l}\text { No cultural } \\
\text { material } \\
\text { encountered. }\end{array}$ & - \\
\hline & 4 & $30-40$ & $5 Y R \quad 4 / 6$ & yellowish red & $\begin{array}{l}\text { Sandy Clay } \\
\text { Loam }\end{array}$ & & - & $\begin{array}{l}\text { No cultural } \\
\text { material } \\
\text { encountered. }\end{array}$ & - \\
\hline & 5 & $40-50$ & 5YR 4/6 & yellowish red & $\begin{array}{l}\text { Sandy Clay } \\
\text { Loam }\end{array}$ & & - & $\begin{array}{l}\text { No cultural } \\
\text { material } \\
\text { encountered. }\end{array}$ & - \\
\hline & 6 & $50-60$ & 5YR 4/6 & yellowish red & $\begin{array}{l}\text { Sandy Clay } \\
\text { Loam }\end{array}$ & & - & $\begin{array}{l}\text { No cultural } \\
\text { material } \\
\text { encountered. }\end{array}$ & $\begin{array}{l}\text { Terminated at } \\
\text { basal clay. }\end{array}$ \\
\hline
\end{tabular}


Table 3.12. continued

\begin{tabular}{|c|c|c|c|c|c|c|c|c|c|}
\hline $\begin{array}{l}\text { Shovel } \\
\text { Test No. }\end{array}$ & Level & $\begin{array}{l}\text { Depth } \\
\text { (cmbs) }\end{array}$ & $\begin{array}{l}\text { Munsell } \\
\text { Soil Value }\end{array}$ & $\begin{array}{l}\text { Munsell Soil } \\
\text { Color }\end{array}$ & $\begin{array}{l}\text { Soil } \\
\text { Texture }\end{array}$ & $\begin{array}{l}\text { Inclusion } \\
\text { Percentage }\end{array}$ & Inclusion Type & Cultural Materials & $\begin{array}{l}\text { Comments/ } \\
\text { Reason for } \\
\text { Termination }\end{array}$ \\
\hline \multirow{6}{*}{ BD08 } & 1 & $0-10$ & 10YR 6/4 & $\begin{array}{l}\text { light } \\
\text { yellowish } \\
\text { brown }\end{array}$ & $\begin{array}{l}\text { Sandy } \\
\text { Loam }\end{array}$ & $1-5 \%$ & Pebbles & 1: Flake (tertiary) & - \\
\hline & 2 & $10-20$ & 10YR 6/4 & $\begin{array}{l}\text { light } \\
\text { yellowish } \\
\text { brown }\end{array}$ & $\begin{array}{l}\text { Sandy } \\
\text { Loam }\end{array}$ & $1-5 \%$ & Pebbles & $\begin{array}{l}\text { No cultural } \\
\text { material } \\
\text { encountered. }\end{array}$ & - \\
\hline & 3 & $20-30$ & 10YR 6/4 & $\begin{array}{l}\text { light } \\
\text { yellowish } \\
\text { brown }\end{array}$ & $\begin{array}{l}\text { Sandy } \\
\text { Loam }\end{array}$ & $1-5 \%$ & Pebbles & $\begin{array}{l}\text { No cultural } \\
\text { material } \\
\text { encountered. }\end{array}$ & - \\
\hline & 4 & $30-40$ & 10YR 6/4 & $\begin{array}{l}\text { light } \\
\text { yellowish } \\
\text { brown }\end{array}$ & $\begin{array}{l}\text { Sandy } \\
\text { Loam }\end{array}$ & - & - & $\begin{array}{l}\text { No cultural } \\
\text { material } \\
\text { encountered. }\end{array}$ & - \\
\hline & 5 & $40-50$ & 5YR 4/6 & yellowish red & $\begin{array}{l}\text { Sandy Clay } \\
\text { Loam }\end{array}$ & & - & $\begin{array}{l}\text { No cultural } \\
\text { material } \\
\text { encountered. }\end{array}$ & - \\
\hline & 6 & $50-60$ & 5YR 6/4 & $\begin{array}{l}\text { light reddish } \\
\text { brown }\end{array}$ & $\begin{array}{l}\text { Sandy Clay } \\
\text { Loam }\end{array}$ & & - & $\begin{array}{l}\text { No cultural } \\
\text { material } \\
\text { encountered. }\end{array}$ & $\begin{array}{l}\text { Terminated at } \\
\text { basal clay. }\end{array}$ \\
\hline \multirow{5}{*}{ BD09 } & 1 & $0-10$ & 10YR 3/2 & $\begin{array}{l}\text { very dark } \\
\text { grayish } \\
\text { brown }\end{array}$ & Clay & - & - & $\begin{array}{l}\text { No cultural } \\
\text { material } \\
\text { encountered. }\end{array}$ & - \\
\hline & 2 & $10-20$ & 10YR 3/2 & $\begin{array}{l}\text { very dark } \\
\text { grayish } \\
\text { brown }\end{array}$ & Clay & - & - & $\begin{array}{l}\text { No cultural } \\
\text { material } \\
\text { encountered. }\end{array}$ & - \\
\hline & 3 & $20-30$ & 10YR 3/2 & $\begin{array}{l}\text { very dark } \\
\text { grayish } \\
\text { brown }\end{array}$ & Clay & - & - & $\begin{array}{l}\text { No cultural } \\
\text { material } \\
\text { encountered. }\end{array}$ & - \\
\hline & 4 & $30-40$ & 10YR 3/2 & $\begin{array}{l}\text { very dark } \\
\text { grayish } \\
\text { brown }\end{array}$ & Clay & - & - & $\begin{array}{l}\text { No cultural } \\
\text { material } \\
\text { encountered. }\end{array}$ & - \\
\hline & 5 & $40-50$ & 10YR 3/2 & $\begin{array}{l}\text { very dark } \\
\text { grayish } \\
\text { brown }\end{array}$ & Clay & - & - & $\begin{array}{l}\text { No cultural } \\
\text { material } \\
\text { encountered. }\end{array}$ & $\begin{array}{l}\text { Terminated at } \\
\text { too saturated. }\end{array}$ \\
\hline BM39 & 1 & $0-70$ & 10YR 5/4 & $\begin{array}{l}\text { yellowish } \\
\text { brown }\end{array}$ & Sandy Clay & & - & 3: Flake (primary) & $\begin{array}{l}\text { Terminated at } \\
\text { soil change. }\end{array}$ \\
\hline \multirow[t]{2}{*}{ DR418 } & 2 & $0-50$ & 10YR 6/6 & $\begin{array}{l}\text { brownish } \\
\text { yellow }\end{array}$ & $\begin{array}{l}\text { Sandy Clay } \\
\text { Loam }\end{array}$ & $5-10 \%$ & $\begin{array}{l}\text { Cobbles, Gravels, } \\
\text { Pebbles }\end{array}$ & $\begin{array}{l}\text { 5: Flake (tertiary), } \\
\text { Other Prehistoric } \\
\text { [2 shatter } 20-40 \\
\text { cmbs, } 3 \text { tertiary } \\
40-50 \mathrm{cmbs}]\end{array}$ & - \\
\hline & 3 & $50-60$ & 5YR 6/6 & $\begin{array}{l}\text { reddish } \\
\text { yellow }\end{array}$ & Sandy Clay & $1-5 \%$ & Pebbles & $\begin{array}{l}\text { No cultural } \\
\text { material } \\
\text { encountered. }\end{array}$ & $\begin{array}{l}\text { Terminated at } \\
\text { basal clay. }\end{array}$ \\
\hline
\end{tabular}


Table 3.12. continued

\begin{tabular}{|c|c|c|c|c|c|c|c|}
\hline $\begin{array}{l}\text { Shovel } \\
\text { Test No. }\end{array}$ & Level & $\begin{array}{l}\text { Depth } \\
\text { (cmbs) }\end{array}$ & $\begin{array}{l}\text { Munsell } \\
\text { Soil Value }\end{array}$ & $\begin{array}{l}\text { Munsell Soil Soil } \\
\text { Color } \quad \text { Texture }\end{array}$ & $\begin{array}{l}\text { Inclusion } \\
\text { Percentage }\end{array}$ & Inclusion Type & $\begin{array}{c}\text { Comments/ } \\
\text { Cultural Materials Reason for } \\
\text { Termination }\end{array}$ \\
\hline
\end{tabular}

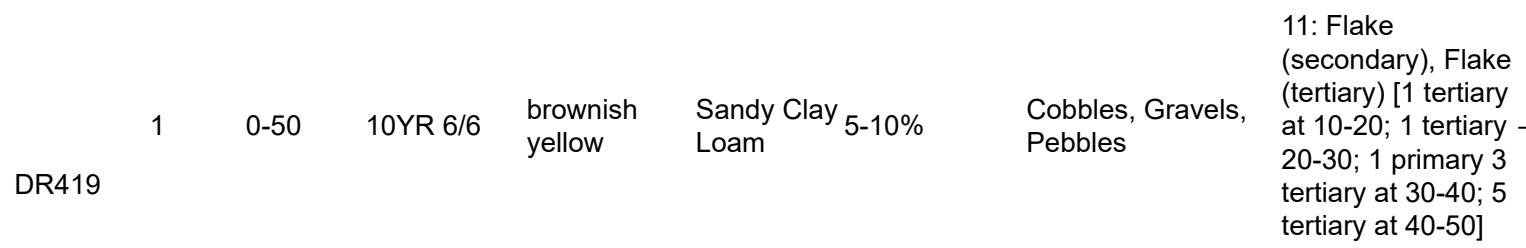

\begin{tabular}{|c|c|c|c|c|c|c|c|c|}
\hline & 2 & $50-60$ & 5YR 6/6 & $\begin{array}{l}\text { reddish } \\
\text { yellow }\end{array}$ & Clay Loam $5-10 \%$ & $\begin{array}{l}\text { Cobbles, Gravels, } \\
\text { Pebbles }\end{array}$ & $\begin{array}{l}\text { No cultural } \\
\text { material } \\
\text { encountered. }\end{array}$ & $\begin{array}{l}\text { Terminated at } \\
\text { basal clay. }\end{array}$ \\
\hline \multirow{2}{*}{ DR420 } & 1 & $0-40$ & 10YR 5/6 & $\begin{array}{l}\text { yellowish } \\
\text { brown }\end{array}$ & $\begin{array}{l}\text { Sandy Clay } 5-10 \% \\
\text { Loam }\end{array}$ & $\begin{array}{l}\text { Cobbles, Gravels, } \\
\text { Pebbles }\end{array}$ & $\begin{array}{l}\text { 1: Flake (tertiary) } \\
\text { [1 tertiary at } 10-20 \\
\text { cmbs] }\end{array}$ & \\
\hline & 2 & $40-45$ & 5YR 6/6 & $\begin{array}{l}\text { reddish } \\
\text { yellow }\end{array}$ & Clay Loam $5-10 \%$ & $\begin{array}{l}\text { Cobbles, Gravels, } \\
\text { Pebbles }\end{array}$ & $\begin{array}{l}\text { No cultural } \\
\text { material } \\
\text { encountered. }\end{array}$ & $\begin{array}{l}\text { Terminated at } \\
\text { basal clay. }\end{array}$ \\
\hline \multirow[t]{2}{*}{ DR421 } & 1 & $0-45$ & 10YR 5/4 & $\begin{array}{l}\text { yellowish } \\
\text { brown }\end{array}$ & $\begin{array}{l}\text { Sandy Clay } 1-5 \% \\
\text { Loam }\end{array}$ & Pebbles & $\begin{array}{l}\text { 4: Flake } \\
\text { (secondary), Flake } \\
\text { (tertiary), Other } \\
\text { Prehistoric [ } 1 \\
\text { tertiary, } 1 \text { shatter } \\
\text { at } 20-30 ; 1 \text { tertiary, } \\
1 \text { shatter at } 30-40]\end{array}$ & - \\
\hline & 2 & $45-55$ & 10YR 4/3 & brown & Clay Loam 1-5\% & Pebbles & $\begin{array}{l}\text { No cultural } \\
\text { material } \\
\text { encountered. }\end{array}$ & $\begin{array}{l}\text { Terminated at } \\
\text { compact soil. }\end{array}$ \\
\hline
\end{tabular}

\begin{tabular}{|c|c|c|c|c|c|c|c|c|}
\hline DR422 & 1 & $0-40$ & 10YR 4/3 & brown & $\begin{array}{l}\text { Sandy Clay } 5-10 \% \\
\text { Loam }\end{array}$ & $\begin{array}{l}\text { Cobbles, Gravels, } \\
\text { Pebbles }\end{array}$ & $\begin{array}{l}\text { 10: Flake (tertiary), } \\
\text { Other Prehistoric } \\
\text { [1 shatter, } 1 \\
\text { tertiary at } 0-20 ; 7 \\
\text { tertiary at } 20-30 ; 1 \\
\text { shatter } 30-40 \text { ] }\end{array}$ & - \\
\hline & 2 & $40-50$ & 5YR 4/4 & $\begin{array}{l}\text { reddish } \\
\text { brown }\end{array}$ & Clay Loam $5-10 \%$ & $\begin{array}{l}\text { Cobbles, Gravels, } \\
\text { Pebbles }\end{array}$ & $\begin{array}{l}\text { No cultural } \\
\text { material } \\
\text { encountered. }\end{array}$ & $\begin{array}{l}\text { Terminated at } \\
\text { basal clay. }\end{array}$ \\
\hline \multirow[t]{2}{*}{ DR423 } & 1 & $0-50$ & 10YR 4/3 & brown & $\begin{array}{l}\text { Sandy Clay } \\
\text { Loam }\end{array}$ & $\begin{array}{l}\text { Cobbles, Gravels, } \\
\text { Pebbles }\end{array}$ & $\begin{array}{l}\text { 15: Flake (tertiary), } \\
\text { Other Prehistoric } \\
\text { [1 secondary, } 1 \\
\text { tertiary, } 1 \text { FCR at } \\
0-20 ; 2 \text { tertiary at } \\
20-30 ; 1 \text { tertiary at } \\
30-40 ; 5 \text { tertiary, } 4 \\
\text { FCR at } 40-50 \text { ] }\end{array}$ & 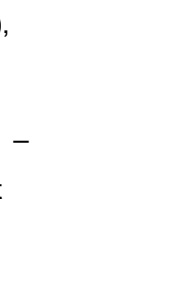 \\
\hline & 2 & $50-55$ & 5YR 4/4 & $\begin{array}{l}\text { reddish } \\
\text { brown }\end{array}$ & Clay Loam $1-5 \%$ & $\begin{array}{l}\text { Cobbles, Gravels, } \\
\text { Pebbles }\end{array}$ & $\begin{array}{l}\text { No cultural } \\
\text { material } \\
\text { encountered. }\end{array}$ & $\begin{array}{l}\text { Terminated at } \\
\text { basal clay. }\end{array}$ \\
\hline
\end{tabular}


Table 3.12. continued

\begin{tabular}{|c|c|c|c|c|c|c|c|c|c|}
\hline $\begin{array}{l}\text { Shovel } \\
\text { Test No. }\end{array}$ & Level & $\begin{array}{l}\text { Depth } \\
\text { (cmbs) }\end{array}$ & $\begin{array}{l}\text { Munsell } \\
\text { Soil Value }\end{array}$ & $\begin{array}{l}\text { Munsell Soil } \\
\text { Color }\end{array}$ & $\begin{array}{l}\text { Soil } \\
\text { Texture }\end{array}$ & $\begin{array}{l}\text { Inclusion } \\
\text { Percentage }\end{array}$ & Inclusion Type & Cultural Materials & $\begin{array}{l}\text { Comments/ } \\
\text { Reason for } \\
\text { Termination }\end{array}$ \\
\hline \multirow[b]{2}{*}{ MN414 } & 1 & $0-45$ & 10YR 5/4 & $\begin{array}{l}\text { yellowish } \\
\text { brown }\end{array}$ & $\begin{array}{l}\text { Sandy } \\
\text { Loam }\end{array}$ & $5-10 \%$ & $\begin{array}{l}\text { Cobbles, Gravels, } \\
\text { Pebbles }\end{array}$ & 2: Flake (tertiary) & \\
\hline & 2 & $45-55$ & 10YR 5/6 & $\begin{array}{l}\text { yellowish } \\
\text { brown }\end{array}$ & \multicolumn{2}{|c|}{ Sandy Clay 5-10\% } & $\begin{array}{l}\text { Cobbles, Gravels, } \\
\text { Pebbles }\end{array}$ & $\begin{array}{l}\text { No cultural } \\
\text { material } \\
\text { encountered. }\end{array}$ & $\begin{array}{l}\text { Terminated at } \\
\text { basal clay. }\end{array}$ \\
\hline MN415 & 1 & $0-45$ & 10YR 3/2 & $\begin{array}{l}\text { very dark } \\
\text { grayish } \\
\text { brown }\end{array}$ & $\begin{array}{l}\text { Sandy Clay } \\
\text { Loam }\end{array}$ & & - & $\begin{array}{l}\text { No cultural } \\
\text { material } \\
\text { encountered. }\end{array}$ & $\begin{array}{l}\text { Terminated at } \\
\text { basal clay. }\end{array}$ \\
\hline \multirow{4}{*}{ PO01 } & 1 & $0-10$ & 10YR 6/4 & $\begin{array}{l}\text { light } \\
\text { yellowish } \\
\text { brown }\end{array}$ & $\begin{array}{l}\text { Sandy } \\
\text { Loam }\end{array}$ & $>20 \%$ & Pebbles & $\begin{array}{l}\text { 3: Flake } \\
\text { (secondary), Flake } \\
\text { (tertiary) }\end{array}$ & \\
\hline & 2 & $10-20$ & 10YR 6/4 & $\begin{array}{l}\text { light } \\
\text { yellowish } \\
\text { brown }\end{array}$ & $\begin{array}{l}\text { Sandy } \\
\text { Loam }\end{array}$ & $>20 \%$ & Pebbles & 1: Core & - \\
\hline & 3 & $20-30$ & 10YR 6/4 & $\begin{array}{l}\text { light } \\
\text { yellowish } \\
\text { brown }\end{array}$ & $\begin{array}{l}\text { Sandy } \\
\text { Loam }\end{array}$ & $>20 \%$ & Cobbles, Pebbles & $\begin{array}{l}\text { 1: Flake } \\
\text { (secondary) }\end{array}$ & - \\
\hline & 4 & $30-40$ & 10YR 6/4 & $\begin{array}{l}\text { light } \\
\text { yellowish } \\
\text { brown }\end{array}$ & $\begin{array}{l}\text { Sandy } \\
\text { Loam }\end{array}$ & $>20 \%$ & Cobbles, Pebbles & 1: Flake (tertiary) & $\begin{array}{l}\text { Terminated } \\
\text { at too many } \\
\text { pebbles to } \\
\text { get the auger } \\
\text { through. }\end{array}$ \\
\hline \multirow{8}{*}{ PO02 } & 1 & $0-10$ & 10YR 6/4 & $\begin{array}{l}\text { light } \\
\text { yellowish } \\
\text { brown }\end{array}$ & $\begin{array}{l}\text { Sandy } \\
\text { Loam }\end{array}$ & $10-20 \%$ & Pebbles & $\begin{array}{l}\text { 2: Flake } \\
\text { (secondary) }\end{array}$ & - \\
\hline & 2 & $10-20$ & 10YR 6/4 & $\begin{array}{l}\text { light } \\
\text { yellowish } \\
\text { brown }\end{array}$ & $\begin{array}{l}\text { Sandy } \\
\text { Loam }\end{array}$ & $10-20 \%$ & Pebbles & 3: Flake (tertiary) & - \\
\hline & 3 & $20-30$ & 10YR 6/4 & $\begin{array}{l}\text { light } \\
\text { yellowish } \\
\text { brown }\end{array}$ & $\begin{array}{l}\text { Sandy } \\
\text { Loam }\end{array}$ & $10-20 \%$ & Pebbles & 1: Flake (tertiary) & - \\
\hline & 4 & $30-40$ & 10YR 6/4 & $\begin{array}{l}\text { light } \\
\text { yellowish } \\
\text { brown }\end{array}$ & $\begin{array}{l}\text { Sandy } \\
\text { Loam }\end{array}$ & $10-20 \%$ & Pebbles & $\begin{array}{l}\text { No cultural } \\
\text { material } \\
\text { encountered. }\end{array}$ & - \\
\hline & 5 & $40-50$ & 5YR 4/6 & yellowish red & $\begin{array}{l}\text { Sandy Clay } \\
\text { Loam }\end{array}$ & $10-20 \%$ & Pebbles & $\begin{array}{l}\text { No cultural } \\
\text { material } \\
\text { encountered. }\end{array}$ & - \\
\hline & 6 & $50-60$ & 5YR 4/6 & yellowish red & $\begin{array}{l}\text { Sandy Clay } \\
\text { Loam }\end{array}$ & $10-20 \%$ & Pebbles & $\begin{array}{l}\text { No cultural } \\
\text { material } \\
\text { encountered. }\end{array}$ & - \\
\hline & 7 & $60-70$ & $5 Y R$ 4/6 & yellowish red & $\begin{array}{l}\text { Sandy Clay } \\
\text { Loam }\end{array}$ & $10-20 \%$ & Pebbles & $\begin{array}{l}\text { No cultural } \\
\text { material } \\
\text { encountered. }\end{array}$ & - \\
\hline & 8 & $70-80$ & 5YR 4/6 & yellowish red & $\begin{array}{l}\text { Sandy Clay } \\
\text { Loam }\end{array}$ & $10-20 \%$ & Pebbles & $\begin{array}{l}\text { No cultural } \\
\text { material } \\
\text { encountered. }\end{array}$ & $\begin{array}{l}\text { Terminated at } \\
\text { basal clay. }\end{array}$ \\
\hline \multirow{3}{*}{ PO03 } & 1 & $0-30$ & 10YR 2/2 & $\begin{array}{l}\text { very dark } \\
\text { brown }\end{array}$ & Silty Clay & - & - & 1: Flake (tertiary) & - \\
\hline & 2 & $30-45$ & 10YR 2/1 & black & Clay Loam & $1-5 \%$ & Gravels & $\begin{array}{l}\text { No cultural } \\
\text { material } \\
\text { encountered. }\end{array}$ & - \\
\hline & 3 & $45-60$ & 10YR 2/1 & black & Clay & $1-5 \%$ & Gravels, Mottles & $\begin{array}{l}\text { No cultural } \\
\text { material } \\
\text { encountered. }\end{array}$ & $\begin{array}{l}\text { Terminated at } \\
\text { compact soil. }\end{array}$ \\
\hline
\end{tabular}




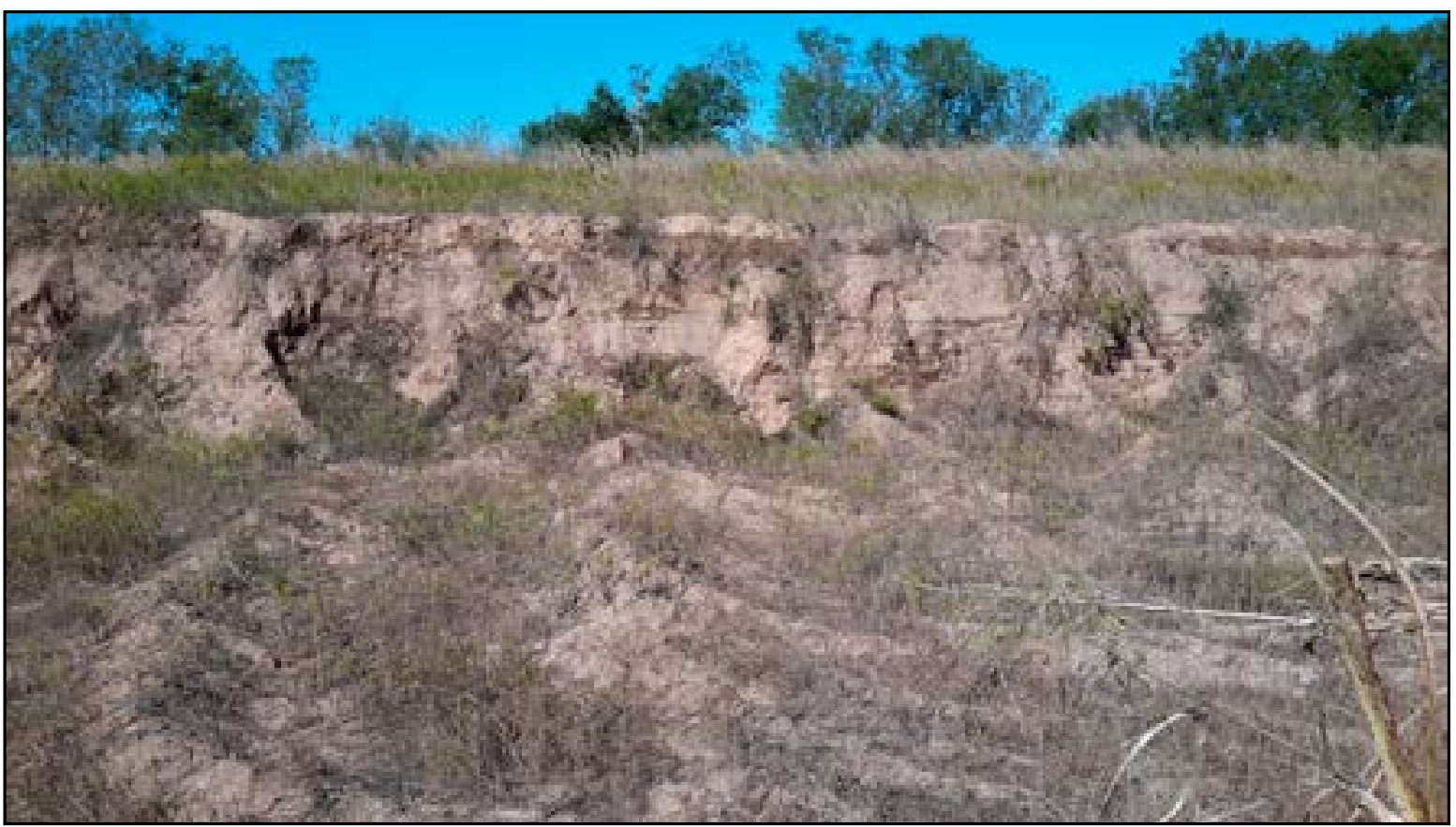

Figure 3.30 Overview of quarrying disturbances at site 41BP818, facing southeast.

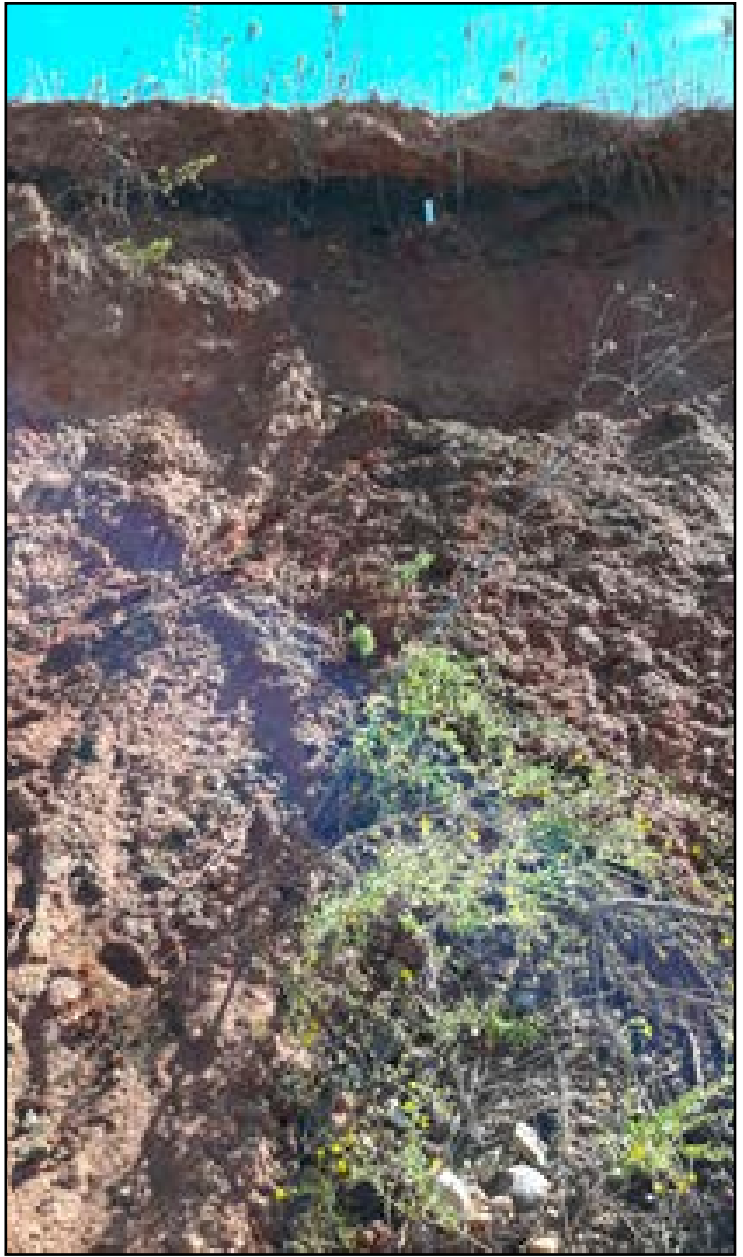

Figure 3.31a Overview of spoil pile disturbances at site 41BP818, facing southeast.

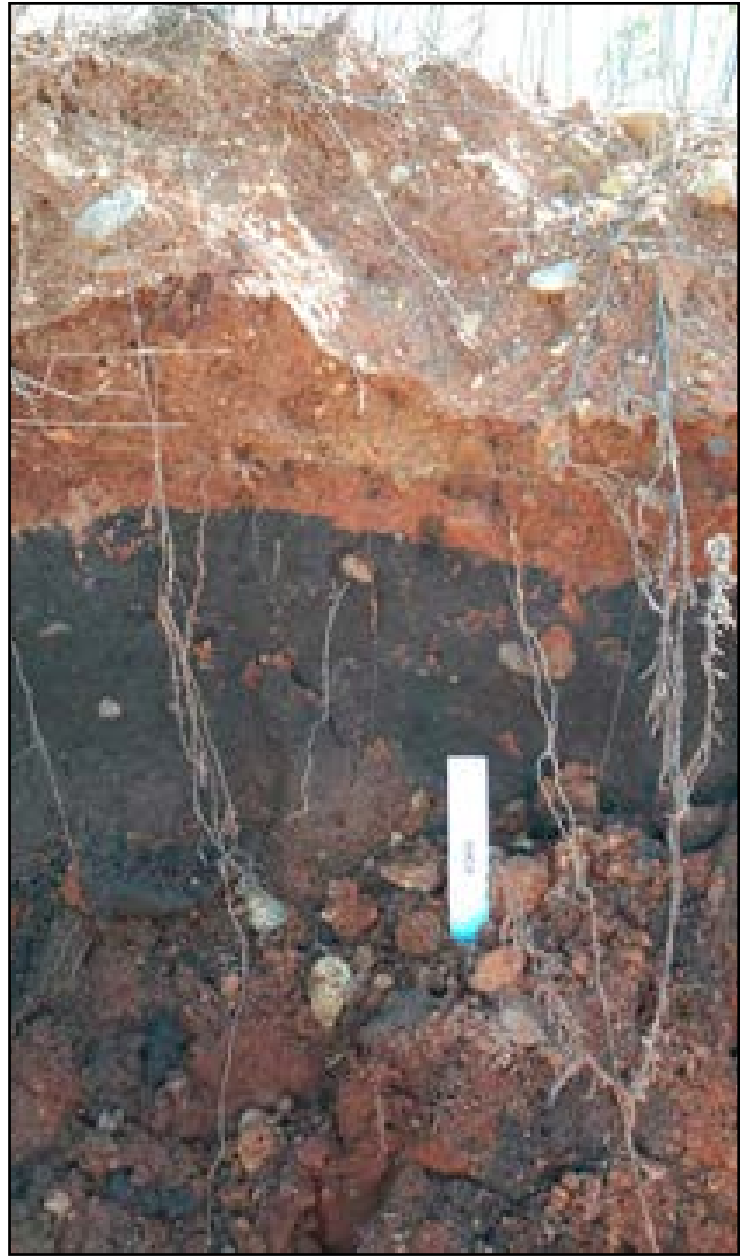

Figure 3.31b Close-up of disturbed soils at site 41BP818. 
value, the prehistoric and historic components of site 41BP818 within the project boundaries are recommended as NOT ELIGIBLE for listing on the NRHP or for designation as a SAL. The Hill Cemetery, discussed below, is avoided by the project and will not be impacted.

\section{BP920}

Site 41BP920 is an early Archaic lithic scatter with a historic component in northwestern Bastrop County. The site was originally recorded during the 2015 initial cultural resources investigations. The site is situated on a generally level upland formation overlooking an unnamed ephemeral tributary of Wilbarger Creek (Figure 3.32; Appendix A:100). After the 2015 investigations, SWCA recommended site 41BP920 for significance testing to determine the site's eligibility for SAL designation or listing on the NRHP due to the presence of buried artifacts, including burned rock that suggested the presence of buried cultural features, and temporally diagnostic projectile points (Acuña et al. 2016).

SWCA revisited the site in 2016 to conduct further testing which consisted of backhoe trenching and $1 \times 1-\mathrm{m}$ hand excavations units; the results of these investigations are presented in a separate report (Rodriguez and Young 2018) and the recommendations are summarized below.

The test investigations indicate that the cultural deposit within the proposed waterline corridor at 41BP920 is a palimpsest consisting of an unknown number of overprinted and mixed occupations encompassing the Late Archaic to the present. The site has been impacted by the removal of an unknown amount of the topsoil from the site, vegetation clearing, and plowing. As a result, neither the surface nor subsurface deposits within the project area are intact, having been displaced and fragmented to varying degrees. Under such circumstances, it is impossible to identify individual site occupations that could potentially contribute new or important data concerning regional prehistory.

Based on these recommendations, SWCA recommended the Vista Ridge Project will not impact cultural deposits eligible for SAL designation or listing on the NRHP within the proposed waterline alignment. However, the parts of the site outside the project area have not been evaluated, so their SAL and NRHP eligibility areas are currently UNDETERMINED. Should the proposed project require design changes that result in impacts to parts of the site outside the currently pro- posed corridor, then additional investigations in those areas would be necessary.

\section{$41 B P 959$}

Site 41BP959 is a buried prehistoric lithic scatter of unknown temporal or cultural affiliation located 0.5 mile east-northeast of the FM 1704 and Monkey Road intersection south of Elgin in northern Bastrop County, Texas (Figure 3.33; Appendix A:92-93). The site is situated along a semi-forested gradually rising upland slope overlooking branches of Little Sandy Creek to the west-southwest and east-southeast. Vegetation consists of open areas with grasses and scattered juniper and scrub in the northeastern half and a robust mixed hardwood riparian zone within the southwestern half approaching the creek (Figure 3.34). Ground surface visibility was poor due to grass cover and leaf litter. Site 41BP959 is located on privately owned land used for ranching and residential activities. Disturbances include transmission line corridors that run northeast to southwest along the northwestern margin and run northwest to southeast traversing the northeastern portion of the site. Additionally, disturbances to the area include erosion, vegetation clearing, fence lines, two-track roads, and nearby land modification for stock ponds.

Site 41BP959 is a diffuse shallow to deeply buried prehistoric lithic scatter of debitage and shatter with few small fire-cracked rocks that measures approximately $243 \mathrm{~m}$ northeast/southwest by $50 \mathrm{~m}$ northwest/ southeast. The site was originally recorded during survey of the project corridor within the parcels and was subsequently revisited and expanded due to a shift of the project corridor since the original recording. As such, the southwestern portion of the site is now outside the project area boundaries, and site dimensions within the current project corridor are approximately $195 \mathrm{~m}$ northeast/southwest by $26 \mathrm{~m}$ northwest/southeast.

Site boundaries were determined by the extent of subsurface cultural deposits within the project area boundaries. No cultural materials were observed along the ground surface due to poor visibility. SWCA excavated 18 shovel tests (i.e., AE307-308, MCC250-252, MCC516-518, MCC520-522, TN516-519, and TN521-523) as part of the survey and to delineate the site, of which nine (i.e., AE307-308, MCC251, MCC517-518, MCC521-522, TN516, and TN523) were positive for cultural materials from near surface to a maximum depth of $80 \mathrm{cmbs}$ (Table 3.13). Cultural 


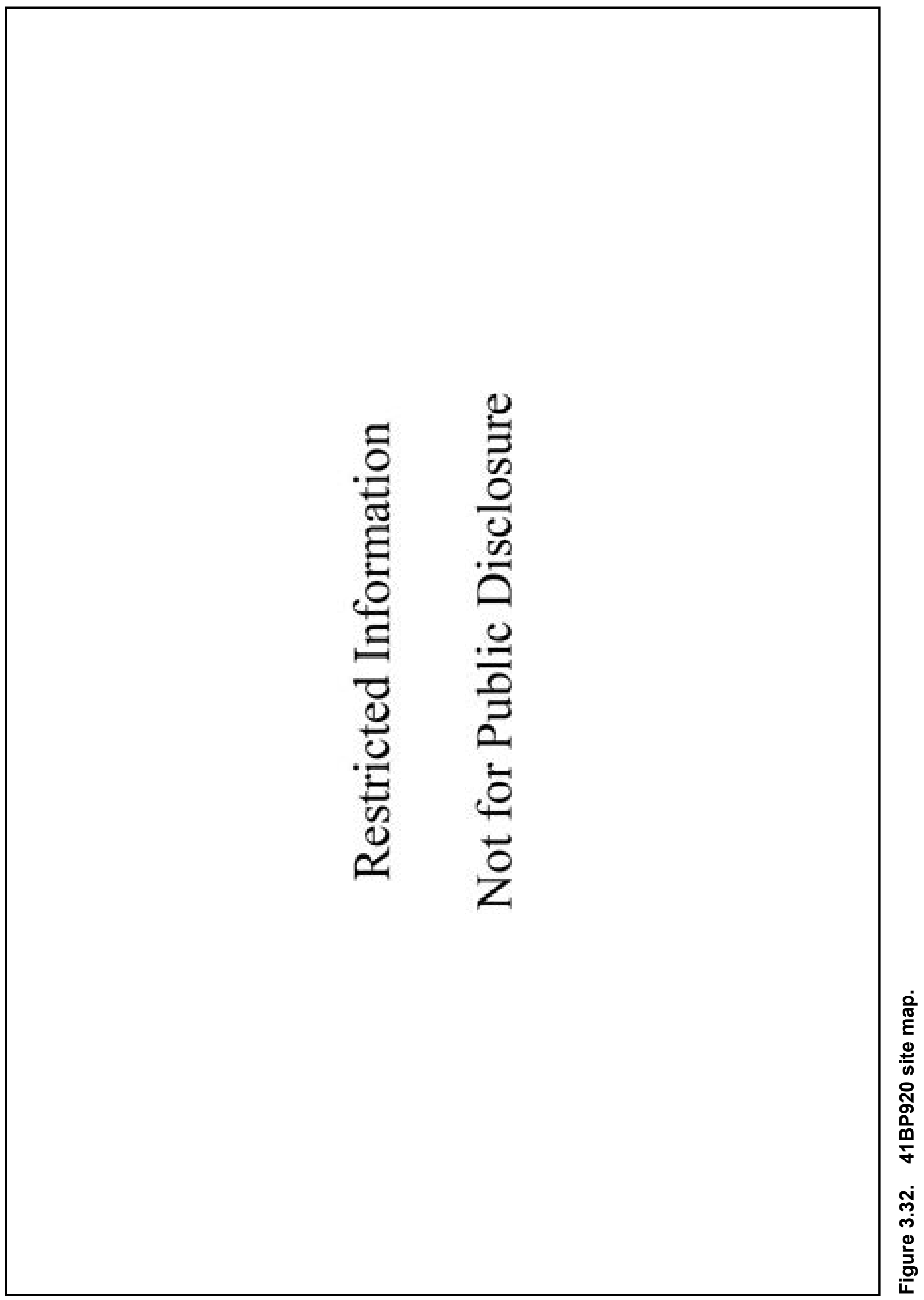




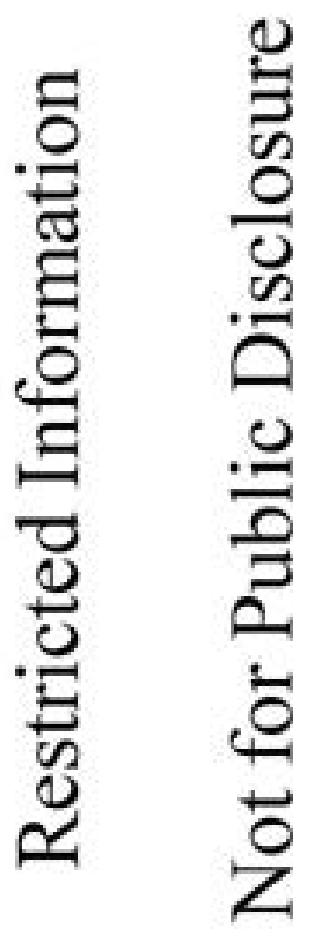

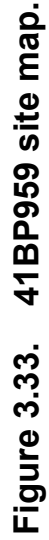


Table 3.13. Shovel Test Data for Site 41BP959

\begin{tabular}{|c|c|c|c|c|c|c|c|c|c|}
\hline $\begin{array}{l}\text { Shovel } \\
\text { Test No. }\end{array}$ & Level & $\begin{array}{l}\text { Depth } \\
\text { (cmbs) }\end{array}$ & $\begin{array}{l}\text { Munsell } \\
\text { Soil Value }\end{array}$ & $\begin{array}{l}\text { Munsell } \\
\text { Soil Color }\end{array}$ & $\begin{array}{l}\text { Soil } \\
\text { Texture }\end{array}$ & $\begin{array}{l}\text { Inclusion } \\
\text { Percentage }\end{array}$ & $\begin{array}{l}\text { Inclusion } \\
\text { Type }\end{array}$ & Cultural Materials & $\begin{array}{l}\text { Comments/ } \\
\text { Reason for Termination }\end{array}$ \\
\hline \multirow{4}{*}{ AE307 } & 1 & $0-10$ & 10YR 5/3 & brown & $\begin{array}{l}\text { Loamy } \\
\text { Sand }\end{array}$ & - & - & None & - \\
\hline & 2 & $10-20$ & 10YR 5/3 & brown & $\begin{array}{l}\text { Loamy } \\
\text { Sand }\end{array}$ & - & - & $\begin{array}{l}\text { 1: Flake (primary), } \\
\text { 7: Flake (tertiary), } \\
\text { 1: Shatter. }\end{array}$ & - \\
\hline & 3 & $20-30$ & 10YR 5/3 & brown & $\begin{array}{l}\text { Loamy } \\
\text { Sand }\end{array}$ & - & - & $\begin{array}{l}\text { 1: Flake (primary), } \\
\text { 3: Flake (tertiary), } \\
\text { 2: FCR. }\end{array}$ & - \\
\hline & 4 & $30-50$ & 10YR 6/2 & $\begin{array}{l}\text { light } \\
\text { brownish } \\
\text { gray }\end{array}$ & Clay & $>20 \%$ & Mottles & None & Terminated at basal clay. \\
\hline \multirow{4}{*}{ AE308 } & 1 & $0-10$ & 10YR 5/3 & brown & $\begin{array}{l}\text { Loamy } \\
\text { Sand }\end{array}$ & - & - & $\begin{array}{l}\text { 1: Flake (tertiary), } \\
\text { 1: Shatter. }\end{array}$ & - \\
\hline & 2 & $10-20$ & 10YR 5/3 & brown & $\begin{array}{l}\text { Loamy } \\
\text { Sand }\end{array}$ & - & - & $\begin{array}{l}\text { 1: Flake (tertiary), } \\
\text { 1: Shatter. }\end{array}$ & - \\
\hline & 3 & $20-30$ & 10YR 5/3 & brown & $\begin{array}{l}\text { Loamy } \\
\text { Sand }\end{array}$ & - & - & None & - \\
\hline & 4 & $30-50$ & 7.5YR 4/4 & brown & $\begin{array}{l}\text { Sandy } \\
\text { Clay }\end{array}$ & $>20 \%$ & Mottles & None & Terminated at basal clay. \\
\hline \multirow{2}{*}{ MCC250 } & 1 & $0-45$ & 7.5YR 5/4 & brown & $\begin{array}{l}\text { Sandy } \\
\text { Loam }\end{array}$ & & & None & - \\
\hline & 2 & $45-55$ & 7.5YR 5/8 & $\begin{array}{l}\text { strong } \\
\text { brown }\end{array}$ & $\begin{array}{l}\text { Sandy } \\
\text { Clay }\end{array}$ & $>20 \%$ & Mottles & None & Terminated at basal clay. \\
\hline \multirow[t]{2}{*}{ MCC251 } & 1 & $0-35$ & 7.5YR 5/4 & brown & $\begin{array}{l}\text { Sandy } \\
\text { Loam }\end{array}$ & & & $\begin{array}{l}\text { 1: Flake } \\
\text { (secondary), } \\
\text { 1: Flake (tertiary). }\end{array}$ & - \\
\hline & 2 & $35-45$ & 7.5YR 5/8 & $\begin{array}{l}\text { strong } \\
\text { brown }\end{array}$ & $\begin{array}{l}\text { Sandy } \\
\text { Clay }\end{array}$ & $>20 \%$ & Mottles & None & Terminated at basal clay. \\
\hline \multirow{2}{*}{ MCC252 } & 1 & $0-30$ & 10YR 5/3 & brown & $\begin{array}{l}\text { Clay } \\
\text { Loam }\end{array}$ & - & - & None & - \\
\hline & 2 & $30-40$ & 7.5YR 5/8 & $\begin{array}{l}\text { strong } \\
\text { brown }\end{array}$ & Clay & - & - & None & Terminated at basal clay. \\
\hline \multirow{2}{*}{ MCC516 } & 1 & $0-25$ & 10YR 5/4 & $\begin{array}{l}\text { yellowish } \\
\text { brown }\end{array}$ & Silt Loam & - & - & None & - \\
\hline & 2 & $25-30$ & 7.5YR 4/6 & $\begin{array}{l}\text { strong } \\
\text { brown }\end{array}$ & Clay & - & - & None & Terminated at basal clay. \\
\hline \multirow[t]{2}{*}{ MCC517 } & 1 & $0-80$ & 10YR 7/3 & $\begin{array}{l}\text { very pale } \\
\text { brown }\end{array}$ & Sand & - & - & $\begin{array}{l}\text { 3: Flake (secondary) } \\
\text { [60-80 cmbs], } \\
\text { Other Prehistoric- } \\
\text { FCR }[20-40 \mathrm{cmbs}] .\end{array}$ & - \\
\hline & 2 & $80-85$ & 7.5YR 5/8 & $\begin{array}{l}\text { strong } \\
\text { brown }\end{array}$ & $\begin{array}{l}\text { Sandy } \\
\text { Clay }\end{array}$ & - & - & None & Terminated at basal clay. \\
\hline \multirow[t]{2}{*}{ MCC518 } & 1 & $0-80$ & 10YR 7/3 & $\begin{array}{l}\text { very pale } \\
\text { brown }\end{array}$ & Sand & - & - & $\begin{array}{l}\text { 4: Flake (tertiary) } \\
\text { [2 at } 20-40 \mathrm{cmbs} \\
\text { and } 2 \text { at } 60-80 \\
\text { cmbs]. }\end{array}$ & - \\
\hline & 2 & $80-85$ & 7.5YR 5/8 & $\begin{array}{l}\text { strong } \\
\text { brown }\end{array}$ & $\begin{array}{l}\text { Sandy } \\
\text { Clay }\end{array}$ & - & - & None & Terminated at basal clay. \\
\hline MCC520 & 1 & $0-10$ & 10YR 5/2 & $\begin{array}{l}\text { grayish } \\
\text { brown }\end{array}$ & $\begin{array}{l}\text { Sandy } \\
\text { Loam }\end{array}$ & $10-20 \%$ & Mottles & None & $\begin{array}{l}\text { Terminated at compact } \\
\text { soil. }\end{array}$ \\
\hline
\end{tabular}


Table 3.13. continued

\begin{tabular}{|c|c|c|c|c|c|c|c|c|c|}
\hline $\begin{array}{l}\text { Shovel } \\
\text { Test No. }\end{array}$ & Level & $\begin{array}{l}\text { Depth } \\
\text { (cmbs) }\end{array}$ & $\begin{array}{l}\text { Munsell } \\
\text { Soil Value }\end{array}$ & $\begin{array}{l}\text { Munsell } \\
\text { Soil Color }\end{array}$ & $\begin{array}{l}\text { Soil } \\
\text { Texture }\end{array}$ & $\begin{array}{l}\text { Inclusion } \\
\text { Percentage }\end{array}$ & $\begin{array}{l}\text { Inclusion } \\
\text { Type }\end{array}$ & Cultural Materials & $\begin{array}{l}\text { Comments/ } \\
\text { Reason for Termination }\end{array}$ \\
\hline \multirow{2}{*}{ MCC521 } & 1 & $0-25$ & 10YR 5/2 & $\begin{array}{l}\text { grayish } \\
\text { brown }\end{array}$ & Sand & - & - & $\begin{array}{l}\text { 1: Other Prehistoric- } \\
\text { Shatter. }\end{array}$ & - \\
\hline & 2 & $25-30$ & 7.5YR 5/8 & $\begin{array}{l}\text { strong } \\
\text { brown }\end{array}$ & Clay & - & - & None & Terminated at basal clay. \\
\hline \multirow[t]{2}{*}{ MCC522 } & 1 & $0-35$ & 10YR 5/2 & $\begin{array}{l}\text { grayish } \\
\text { brown }\end{array}$ & Sand & - & - & $\begin{array}{l}\text { 3: Flake (primary), } \\
\text { Flake (secondary), } \\
\text { Flake (tertiary). }\end{array}$ & - \\
\hline & 2 & $35-40$ & 7.5YR 5/8 & $\begin{array}{l}\text { strong } \\
\text { brown }\end{array}$ & $\begin{array}{l}\text { Sandy } \\
\text { Clay }\end{array}$ & - & - & None & Terminated at basal clay. \\
\hline \multirow{2}{*}{ TN516 } & 1 & $0-50$ & 10YR $5 / 3$ & brown & $\begin{array}{l}\text { Sandy } \\
\text { Loam }\end{array}$ & $1-5 \%$ & Pebbles & $\begin{array}{l}\text { 5: Flake } \\
\text { (secondary), Flake } \\
\text { (tertiary), } \\
\text { Other Prehistoric- } \\
\text { FCR. }\end{array}$ & - \\
\hline & 2 & $50-55$ & 7.5YR 5/8 & $\begin{array}{l}\text { strong } \\
\text { brown }\end{array}$ & $\begin{array}{l}\text { Sandy } \\
\text { Clay } \\
\text { Loam }\end{array}$ & $5-10 \%$ & $\begin{array}{l}\text { Sandstone, } \\
\text { Manganese }\end{array}$ & None & Terminated at basal clay. \\
\hline \multirow[b]{2}{*}{ TN517 } & 1 & $0-50$ & 10YR 5/4 & $\begin{array}{l}\text { yellowish } \\
\text { brown }\end{array}$ & Silt Loam & $1-5 \%$ & Pebbles & None & - \\
\hline & 2 & $50-60$ & $5 Y R 4 / 6$ & $\begin{array}{l}\text { yellowish } \\
\text { red }\end{array}$ & $\begin{array}{l}\text { Silty Clay } \\
\text { Loam }\end{array}$ & $1-5 \%$ & $\begin{array}{l}\text { Pebbles, } \\
\text { Manganese } \\
\text { nodules }\end{array}$ & None & Terminated at basal clay. \\
\hline \multirow[b]{2}{*}{ TN518 } & 1 & $0-50$ & 10YR 5/4 & $\begin{array}{l}\text { yellowish } \\
\text { brown }\end{array}$ & Silt Loam & $1-5 \%$ & Pebbles & None & - \\
\hline & 2 & $50-60$ & $5 Y R 4 / 6$ & $\begin{array}{l}\text { yellowish } \\
\text { red }\end{array}$ & $\begin{array}{l}\text { Silty Clay } \\
\text { Loam }\end{array}$ & $1-5 \%$ & $\begin{array}{l}\text { Pebbles, } \\
\text { Manganese } \\
\text { nodules }\end{array}$ & None & Terminated at basal clay. \\
\hline \multirow[b]{2}{*}{ TN519 } & 1 & $0-30$ & 10YR 5/4 & $\begin{array}{l}\text { yellowish } \\
\text { brown }\end{array}$ & Silt Loam & $1-5 \%$ & Pebbles & None & - \\
\hline & 2 & $30-40$ & $5 Y R 4 / 6$ & $\begin{array}{l}\text { yellowish } \\
\text { red }\end{array}$ & $\begin{array}{l}\text { Silty Clay } \\
\text { Loam }\end{array}$ & $1-5 \%$ & $\begin{array}{l}\text { Pebbles, } \\
\text { Manganese } \\
\text { nodules }\end{array}$ & None & Terminated at basal clay. \\
\hline TN521 & 1 & $0-5$ & 10YR2/1 & black & $\begin{array}{l}\text { Silty Clay } \\
\text { Loam }\end{array}$ & - & - & None & $\begin{array}{l}\text { Terminated at compact } \\
\text { soil. }\end{array}$ \\
\hline TN522 & 1 & $0-10$ & 10YR 6/3 & pale brown & $\begin{array}{l}\text { Silty Clay } \\
\text { Loam }\end{array}$ & $>20 \%$ & Mottles & None & Terminated at basal clay. \\
\hline \multirow{2}{*}{ TN523 } & 1 & $0-75$ & 10YR 6/3 & pale brown & $\begin{array}{l}\text { Sandy } \\
\text { Loam }\end{array}$ & $1-5 \%$ & Pebbles & $\begin{array}{l}\text { 2: Flake (tertiary), } \\
\text { Other Prehistoric- } \\
\text { FCR. }\end{array}$ & - \\
\hline & 1 & $75-80$ & 10YR 5/8 & $\begin{array}{l}\text { yellowish } \\
\text { brown }\end{array}$ & $\begin{array}{l}\text { Sandy } \\
\text { Clay } \\
\text { Loam }\end{array}$ & $5-10 \%$ & $\begin{array}{l}\text { Gravels, } \\
\text { Pebbles }\end{array}$ & None & Terminated at basal clay. \\
\hline
\end{tabular}




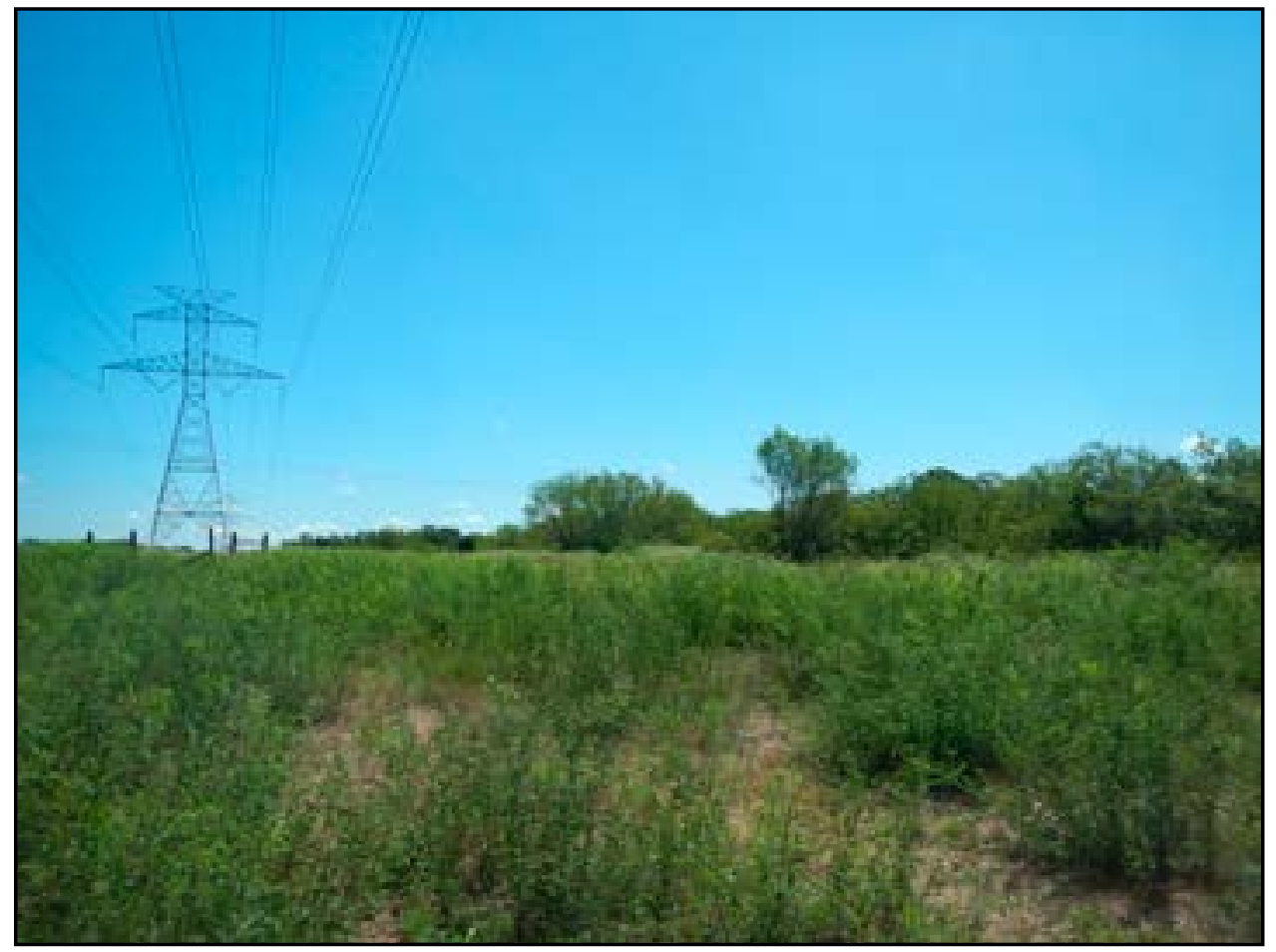

Figure 3.34. Overview of site 41BP959 from northwest margin of site, facing east-southeast.

materials recovered included five primary, 10 secondary, and 21 tertiary reduction flakes and four shatter fragments of chert, along with five small fire-cracked rocks (Figure 3.35). No temporally diagnostic artifacts or cultural features were observed. Shovel tests typically revealed brown (10YR 5/3) to yellowish brown (10YR 5/4) sandy or silty loam overlying compacted yellowish red (5YR 4/6) sandy clay; most terminated at in this compacted substratum between 30 and 80 cmbs. Due to project constraints, the site was not fully delineated to the east and southeast, as investigations were not permitted outside the project ROW, and the site may extend beyond the project area in those directions. Survey of the original and current project corridor resulted in additional negative shovel tests to the northwest, north, northeast, and west of the site.

\section{BP959 SUMMARY}

Site 41BP959 consists of a diffuse shallow to deeply buried prehistoric lithic scatter of mainly debitage and shatter with few fire-cracked rock fragments containing cultural material from the near surface to $80 \mathrm{cmbs}$. The site has a relatively low density of artifacts and lacks temporally diagnostic artifacts or cultural features. Overall, site 41BP959 does not have the potential to yield information important to the prehistory of the region. As such, SWCA recommends site 41BP959 as NOT ELIGIBLE for the NRHP or for designation as a SAL. No further work or avoidance strategy is recommended for site $41 \mathrm{BP} 959$ within the project area.

\section{BP960}

Sites 41BP960 and 41BP961 were initially recorded as one deeply buried prehistoric campsite along the eastern terraces of Wilbarger Creek approximately 0.45 mile east-northeast of the Upper Elgin Road and Hogeye Road intersection in Bastrop County, Texas (Figure 3.36; Appendix A:101). The one site was subsequently split into two sites separated by approximately $90 \mathrm{~m}$ due to an unnamed tributary drainage of Wilbarger Creek running between two discrete cultural deposits. Site 41BP960 is situated along the T2 terrace southwest of the tributary drainage. Vegetation consists of tall, dense hay field within pastures, and mixed wooded and riparian secondary growth along the drainages (Figure 3.37). Ground surface visibility was poor due to the dense vegetation. Site 41BP960 is located on privately owned land used for agricultural and ranching activities. Disturbances include erosion, vegetation clearing, fence lines, two-track roads, and nearby land modification for stock ponds. 


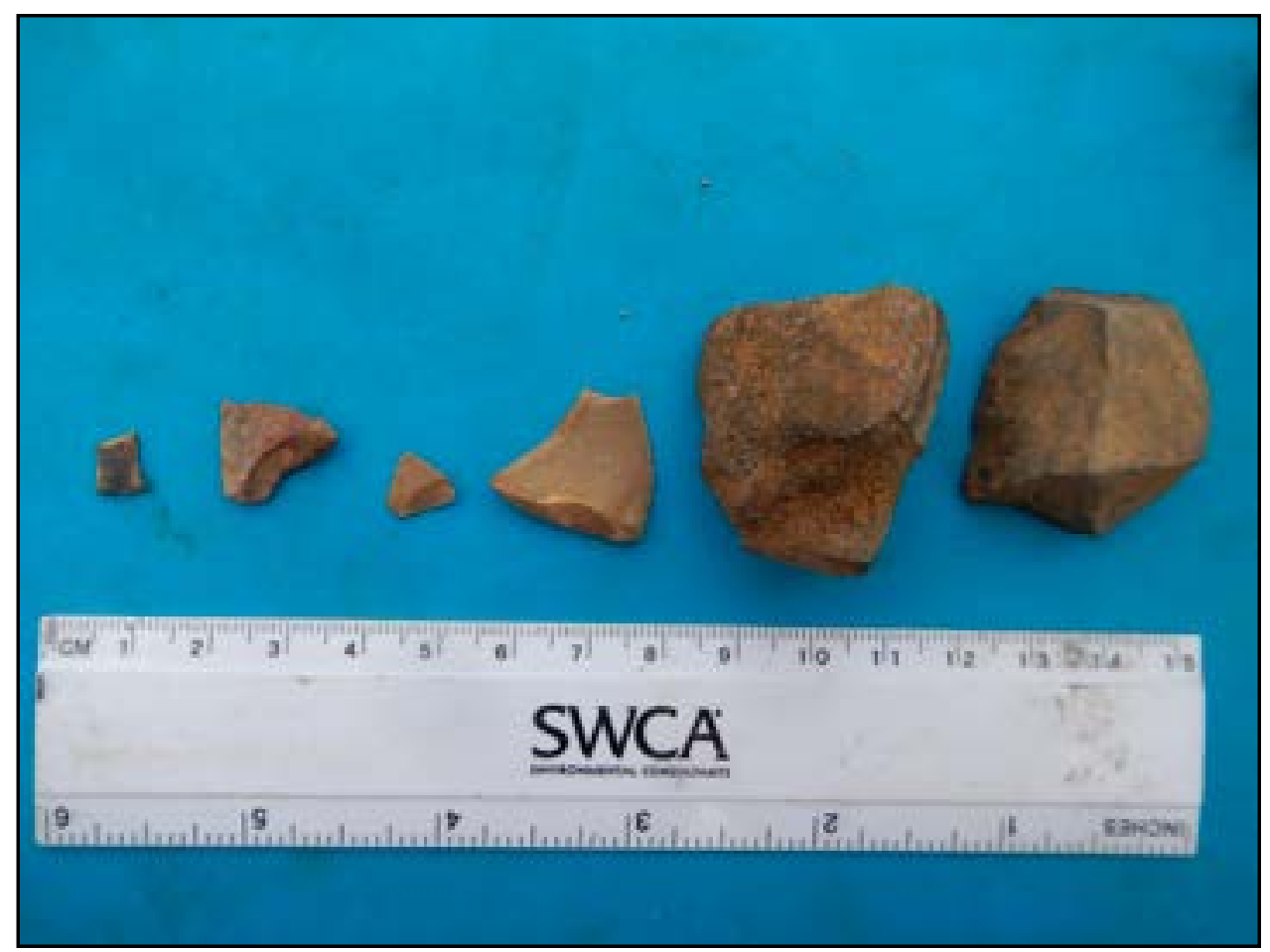

Figure 3.35. Artifacts and fire-cracked rock from site 41BP959 in ST AE307 at $10-30 \mathrm{cmbs}$.

Site 41BP960 is a deeply buried prehistoric campsite with bone-tempered pottery, lithic debitage and tools, and faunal remains that measures approximately 109 $\mathrm{m}$ northeast/southwest by $27 \mathrm{~m}$ northwest/southeast within the project corridor based on artifact distribution and landforms; however, the site may extend beyond the project area to the east and west. Due to the presence of deep alluvial deposits along Wilbarger Creek and the unnamed tributary drainage, site boundaries were determined by intensive systematic excavation of hand auger probes followed by excavation of mechanical backhoe trenches with column sampling in select backhoe trenches. In areas not accessible by the backhoe (i.e., dense trees and other vegetation), only auger probes were excavated. No cultural materials were observed along the ground surface due to the poor visibility.

SWCA excavated 11 auger probes (i.e., AU09-17 and AU33-34) at approximately 50-m intervals to investigate the project corridor and delineate the site, two of which (i.e., AU14-15) were positive for cultural materials from approximately 90 to $100 \mathrm{cmbs}$ (Table 3.14). SWCA also excavated eight backhoe trenches (i.e., BHT01-03 and BHT05-09), of which two (i.e., BHT07 and BHT09) were positive for cultural materi- als from approximately 80 to $100 \mathrm{cmbs}$ (Table 3.15 ). Column samples measuring $50 \times 50$-cm were excavated off the walls of the positive trenches in arbitrary $10-\mathrm{cm}$ levels (Appendix C). In addition, SWCA had previously excavated one shovel test (i.e., DR206) within the site boundary and one shovel test (i.e., AJ07) approximately $30 \mathrm{~m}$ northeast of the site boundary, both of which were negative for cultural materials.

The trenches typically consisted of six to seven strata with alternating horizons of dark grayish brown (10YR $4 / 2)$ or dark gray $(10 \mathrm{YR} 4 / 1)$ clay loam and light yellowish brown (10YR 6/4) or brown (10YR 5/3) sandy clay loam deposits with clear-gradual lower boundaries. The light yellowish brown horizon had a friable to loose consistency crumb structure, while the remaining horizons typically had a firm consistency and subangular blocky structure, which graded into a massive, structureless horizon with increasing calcium carbonate inclusions and an extremely firm consistency. The investigations encountered an upper buried soil between 50 and $115 \mathrm{cmbs}$ containing the cultural materials and a lower buried soil at approximately $180 \mathrm{cmbs}$ and below that contained a mussel shell (Figure 3.38). 


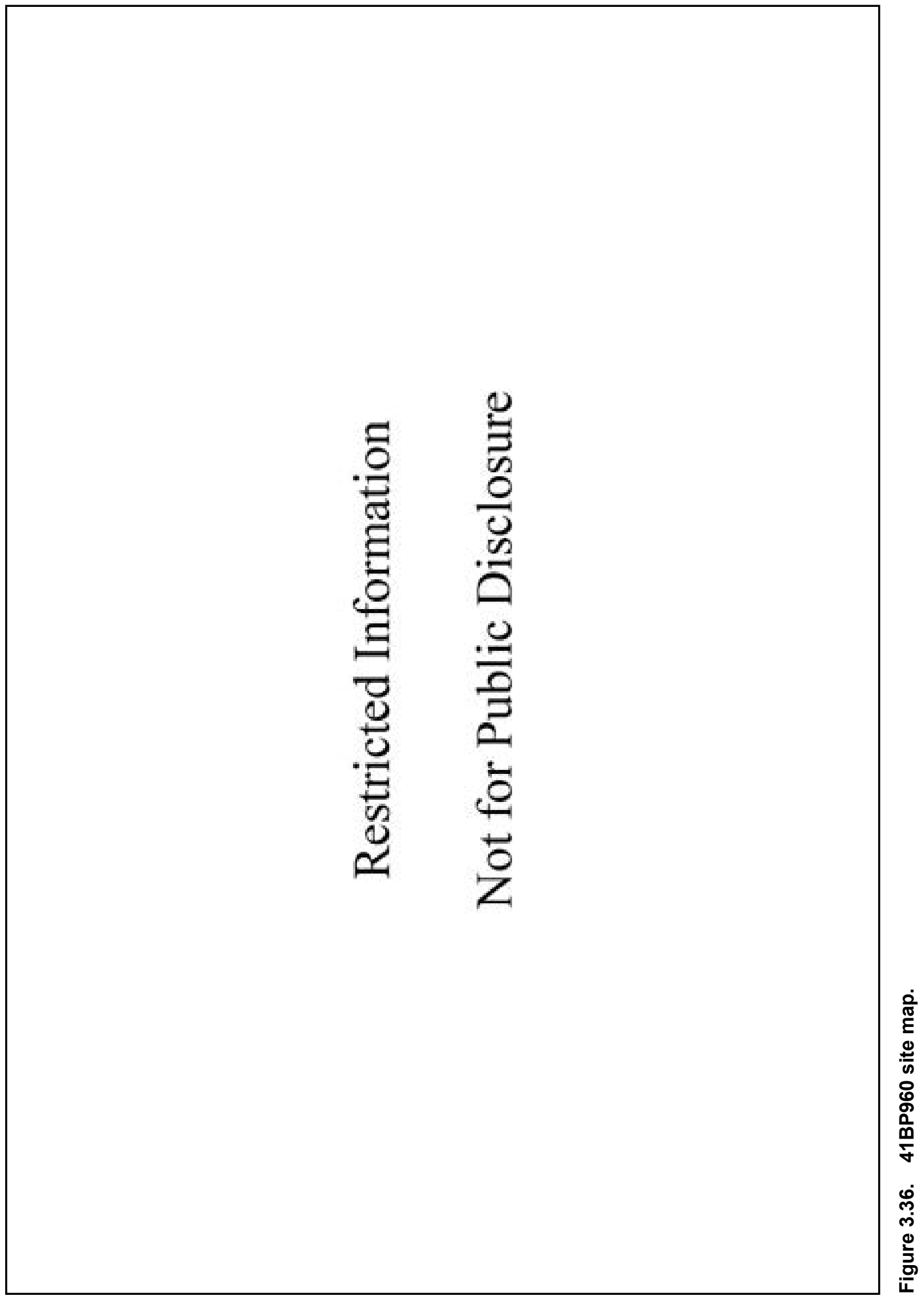




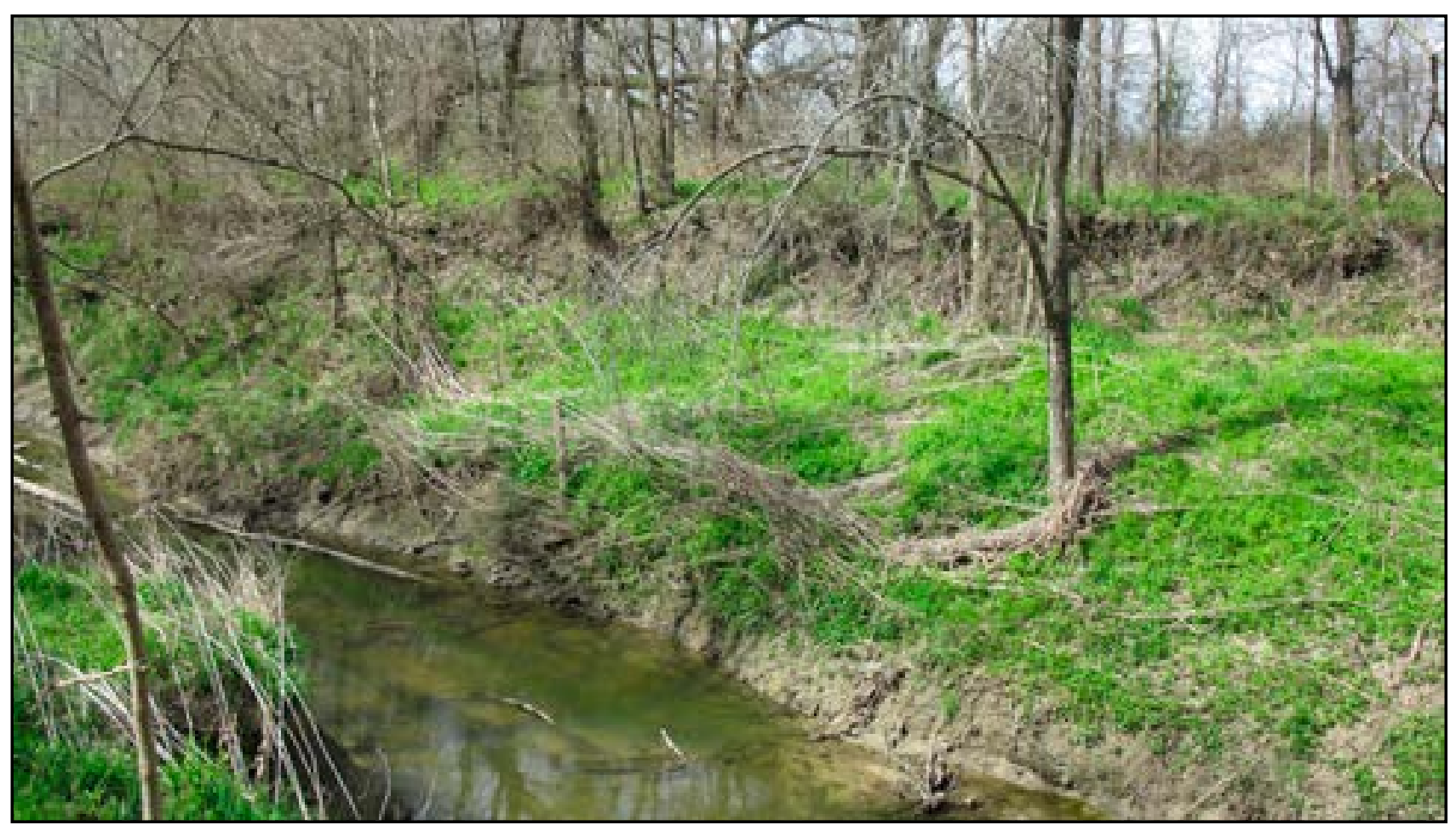

Figure 3.37. Riparian secondary growth along Wilbarger Creek along the western edge of site 41BP960, facing east.

Table 3.14. Auger Probe Data for Site 41BP960

\begin{tabular}{|c|c|c|c|c|c|c|c|c|c|}
\hline $\begin{array}{l}\text { Auger } \\
\text { Probe } \\
\text { No. }\end{array}$ & Level & $\begin{array}{l}\text { Depth } \\
\text { (cmbs) }\end{array}$ & $\begin{array}{l}\text { Munsell } \\
\text { Soil Value }\end{array}$ & $\begin{array}{l}\text { Munsell } \\
\text { Soil Color }\end{array}$ & $\begin{array}{l}\text { Soil } \\
\text { Texture }\end{array}$ & $\begin{array}{l}\text { Inclusion } \\
\text { Percentage }\end{array}$ & $\begin{array}{l}\text { Inclusion } \\
\text { Type }\end{array}$ & $\begin{array}{l}\text { Cultural } \\
\text { Materials }\end{array}$ & $\begin{array}{l}\text { Comments/ } \\
\text { Reason for Termination }\end{array}$ \\
\hline \multirow{4}{*}{ AU09 } & 1 & $0-30$ & 10YR 4/4 & $\begin{array}{l}\text { dark } \\
\text { yellowish } \\
\text { brown }\end{array}$ & Silt Loam & - & - & None & - \\
\hline & 2 & $30-160$ & 10YR 5/6 & $\begin{array}{l}\text { yellowish } \\
\text { brown }\end{array}$ & Silt Loam & - & - & None & - \\
\hline & 3 & $160-170$ & 10YR 6/4 & $\begin{array}{l}\text { light } \\
\text { yellowish } \\
\text { brown }\end{array}$ & $\begin{array}{l}\text { Sandy } \\
\text { Loam }\end{array}$ & $1-5 \%$ & $\begin{array}{l}\text { Calcium } \\
\text { Carbonate, } \\
\text { White } \\
\text { Fungus or } \\
\text { Calcium }\end{array}$ & None & - \\
\hline & 4 & $170-200$ & 10YR 6/3 & pale brown & $\begin{array}{l}\text { Silty Clay } \\
\text { Loam }\end{array}$ & $1-5 \%$ & $\begin{array}{l}\text { Calcium } \\
\text { Carbonate }\end{array}$ & None & Terminated at depth. \\
\hline \multirow{3}{*}{ AU10 } & 1 & $0-65$ & 10YR 4/4 & $\begin{array}{l}\text { dark } \\
\text { yellowish } \\
\text { brown }\end{array}$ & Silt Loam & - & - & None & - \\
\hline & 2 & $65-150$ & 10YR 6/4 & $\begin{array}{l}\text { light } \\
\text { yellowish } \\
\text { brown }\end{array}$ & Silt Loam & - & - & None & - \\
\hline & 3 & $165-200$ & 10YR 3/4 & $\begin{array}{l}\text { dark } \\
\text { yellowish } \\
\text { brown }\end{array}$ & Silty Clay & - & - & None & Terminated at depth. \\
\hline
\end{tabular}


Table 3.14. continued

\begin{tabular}{|c|c|c|c|c|c|c|c|c|c|}
\hline $\begin{array}{l}\text { Auger } \\
\text { Probe } \\
\text { No. }\end{array}$ & Level & $\begin{array}{l}\text { Depth } \\
\text { (cmbs) }\end{array}$ & $\begin{array}{l}\text { Munsell } \\
\text { Soil Value }\end{array}$ & $\begin{array}{l}\text { Munsell } \\
\text { Soil Color }\end{array}$ & $\begin{array}{l}\text { Soil } \\
\text { Texture }\end{array}$ & $\begin{array}{l}\text { Inclusion } \\
\text { Percentage }\end{array}$ & $\begin{array}{l}\text { Inclusion } \\
\text { Type }\end{array}$ & $\begin{array}{l}\text { Cultural } \\
\text { Materials }\end{array}$ & $\begin{array}{l}\text { Comments/ } \\
\text { Reason for Termination }\end{array}$ \\
\hline \multirow{3}{*}{ AU11 } & 1 & $0-40$ & 10YR 4/4 & $\begin{array}{l}\text { dark } \\
\text { yellowish } \\
\text { brown }\end{array}$ & Silt Loam & - & - & None & - \\
\hline & 2 & $40-180$ & 10YR 6/4 & $\begin{array}{l}\text { light } \\
\text { yellowish } \\
\text { brown }\end{array}$ & Silt Loam & - & - & None & - \\
\hline & 3 & $180-200$ & 10YR 3/4 & $\begin{array}{l}\text { dark } \\
\text { yellowish } \\
\text { brown }\end{array}$ & Silty Clay & - & - & None & Terminated at depth. \\
\hline \multirow{3}{*}{ AU12 } & 1 & $0-40$ & 10YR 4/4 & $\begin{array}{l}\text { dark } \\
\text { yellowish } \\
\text { brown }\end{array}$ & Silt Loam & - & - & None & - \\
\hline & 2 & $40-150$ & 10YR 5/6 & $\begin{array}{l}\text { yellowish } \\
\text { brown }\end{array}$ & Silt Loam & - & - & None & - \\
\hline & 3 & $150-200$ & 10YR 6/4 & $\begin{array}{l}\text { light } \\
\text { yellowish } \\
\text { brown }\end{array}$ & $\begin{array}{l}\text { Sandy } \\
\text { Loam }\end{array}$ & $1-5 \%$ & $\begin{array}{l}\text { Calcium } \\
\text { Carbonate, } \\
\text { White } \\
\text { Fungus or } \\
\text { Calcium }\end{array}$ & None & - \\
\hline \multirow{3}{*}{ AU13 } & 1 & $0-40$ & 10YR 4/4 & $\begin{array}{l}\text { dark } \\
\text { yellowish } \\
\text { brown }\end{array}$ & Loam & - & - & None & - \\
\hline & 2 & $0-150$ & 10YR 5/4 & $\begin{array}{l}\text { yellowish } \\
\text { brown }\end{array}$ & $\begin{array}{l}\text { Silty Clay } \\
\text { Loam }\end{array}$ & - & - & None & - \\
\hline & 3 & $150-200$ & 10YR 6/4 & $\begin{array}{l}\text { light } \\
\text { yellowish } \\
\text { brown }\end{array}$ & $\begin{array}{l}\text { Silty Clay } \\
\text { Loam }\end{array}$ & $1-5 \%$ & $\begin{array}{l}\text { Calcium } \\
\text { Carbonate }\end{array}$ & None & Terminated at depth. \\
\hline \multirow{3}{*}{ AU14 } & 1 & $0-80$ & 10YR 4/2 & $\begin{array}{l}\text { dark grayish } \\
\text { brown }\end{array}$ & Clay Loam & - & - & None & - \\
\hline & 2 & $80-120$ & 10YR 4/1 & dark gray & Clay Loam & $1-5 \%$ & Snail Shell & $\begin{array}{l}\text { 1: Ceramic } \\
\text { (prehistoric) } \\
\text { [shell } \\
\text { tempered } \\
\text { pottery with } \\
\text { burnished } \\
\text { exterior } \\
\text { at } 90-100 \\
\mathrm{cmbs} \text { ] }\end{array}$ & - \\
\hline & 3 & $120-180$ & 10YR 5/2 & $\begin{array}{l}\text { grayish } \\
\text { brown }\end{array}$ & Silt Loam & $1-5 \%$ & $\begin{array}{l}\text { Calcium } \\
\text { Carbonate }\end{array}$ & None & Terminated at depth. \\
\hline \multirow{4}{*}{ AU15 } & 1 & $0-30$ & 10YR 4/3 & brown & Clay Loam & - & - & None & - \\
\hline & 2 & $30-80$ & 10YR 5/2 & $\begin{array}{l}\text { grayish } \\
\text { brown }\end{array}$ & Clay Loam & - & - & None & - \\
\hline & 3 & $80-120$ & 10YR 4/2 & $\begin{array}{l}\text { dark grayish } \\
\text { brown }\end{array}$ & Clay Loam & $1-5 \%$ & Snail Shell & $\begin{array}{l}\text { 1: Ceramic } \\
\text { (prehistoric) }\end{array}$ & \\
\hline & 4 & $120-180$ & 10YR 5/4 & $\begin{array}{l}\text { yellowish } \\
\text { brown }\end{array}$ & Silt Loam & $1-5 \%$ & $\begin{array}{l}\text { Calcium } \\
\text { Carbonate }\end{array}$ & None & Terminated at depth. \\
\hline \multirow{4}{*}{ AU16 } & 1 & 30 & 10YR 4/1 & dark gray & Clay Loam & $1-5 \%$ & Roots & None & - \\
\hline & 2 & $30-80$ & 10YR 5/2 & $\begin{array}{l}\text { grayish } \\
\text { brown }\end{array}$ & Clay Loam & $1-5 \%$ & None & None & - \\
\hline & 3 & $80-120$ & 10YR 4/1 & dark gray & Clay Loam & $1-5 \%$ & None & None & - \\
\hline & 4 & $120-165$ & 10YR 5/3 & brown & $\begin{array}{l}\text { Silty Clay } \\
\text { Loam }\end{array}$ & $1-5 \%$ & $\begin{array}{l}\text { Calcium } \\
\text { Carbonate }\end{array}$ & None & Terminated at depth. \\
\hline
\end{tabular}


Table 3.14. continued

\begin{tabular}{|c|c|c|c|c|c|c|c|c|c|}
\hline $\begin{array}{l}\text { Auger } \\
\text { Probe } \\
\text { No. }\end{array}$ & Level & $\begin{array}{l}\text { Depth } \\
\text { (cmbs) }\end{array}$ & $\begin{array}{l}\text { Munsell } \\
\text { Soil Value }\end{array}$ & $\begin{array}{l}\text { Munsell } \\
\text { Soil Color }\end{array}$ & $\begin{array}{l}\text { Soil } \\
\text { Texture }\end{array}$ & $\begin{array}{l}\text { Inclusion } \\
\text { Percentage }\end{array}$ & $\begin{array}{l}\text { Inclusion } \\
\text { Type }\end{array}$ & $\begin{array}{l}\text { Cultural } \\
\text { Materials }\end{array}$ & $\begin{array}{l}\text { Comments/ } \\
\text { Reason for Termination }\end{array}$ \\
\hline \multirow{3}{*}{$\mathrm{AU} 17$} & 1 & $0-30$ & 10YR 4/2 & $\begin{array}{l}\text { dark grayish } \\
\text { brown }\end{array}$ & Clay Loam & - & - & None & - \\
\hline & 2 & $30-120$ & 10YR 5/2 & $\begin{array}{l}\text { grayish } \\
\text { brown }\end{array}$ & Clay Loam & - & - & None & - \\
\hline & 3 & $120-150$ & 10YR 5/3 & brown & $\begin{array}{l}\text { Silty Clay } \\
\text { Loam }\end{array}$ & $1-5 \%$ & $\begin{array}{l}\text { Calcium } \\
\text { Carbonate }\end{array}$ & None & Terminated at depth. \\
\hline \multirow{3}{*}{ AU33 } & 1 & $0-35$ & 10YR 4/2 & $\begin{array}{l}\text { dark grayish } \\
\text { brown }\end{array}$ & Silty Clay & - & - & None & - \\
\hline & 2 & $35-110$ & 10YR 5/2 & $\begin{array}{l}\text { grayish } \\
\text { brown }\end{array}$ & $\begin{array}{l}\text { Silty Clay } \\
\text { Loam }\end{array}$ & - & - & None & - \\
\hline & 3 & $110-200$ & 10YR 5/3 & brown & Silt Loam & $1-5 \%$ & $\begin{array}{l}\text { Calcium } \\
\text { Carbonate }\end{array}$ & None & Terminated at depth. \\
\hline \multirow{4}{*}{ AU34 } & 1 & $0-35$ & 10YR 4/2 & $\begin{array}{l}\text { dark grayish } \\
\text { brown }\end{array}$ & Silty Clay & - & - & None & - \\
\hline & 2 & $35-120$ & 10YR 5/2 & $\begin{array}{l}\text { grayish } \\
\text { brown }\end{array}$ & $\begin{array}{l}\text { Silty Clay } \\
\text { Loam }\end{array}$ & - & - & None & - \\
\hline & 3 & $120-150$ & 10YR 5/3 & brown & Silt Loam & $1-5 \%$ & $\begin{array}{l}\text { Calcium } \\
\text { Carbonate }\end{array}$ & None & - \\
\hline & 4 & $150-200$ & 10YR 4/1 & dark gray & $\begin{array}{l}\text { Silty Clay } \\
\text { Loam }\end{array}$ & $5-10 \%$ & $\begin{array}{l}\text { Calcium } \\
\text { Carbonate }\end{array}$ & None & Terminated at depth. \\
\hline
\end{tabular}

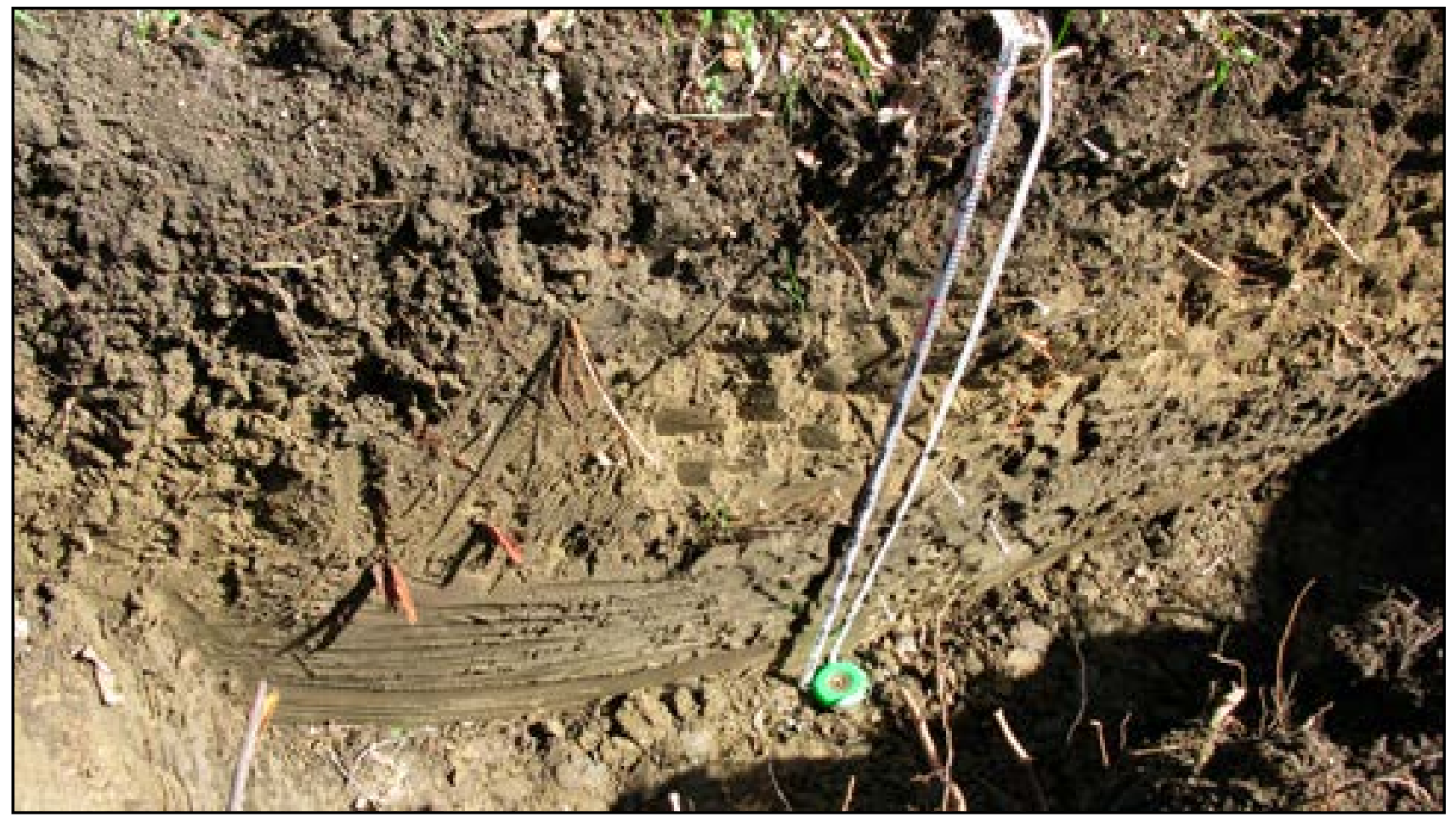

Figure 3.38. BHT 07 profile, golf tees show location of artifacts within possible buried soils. 


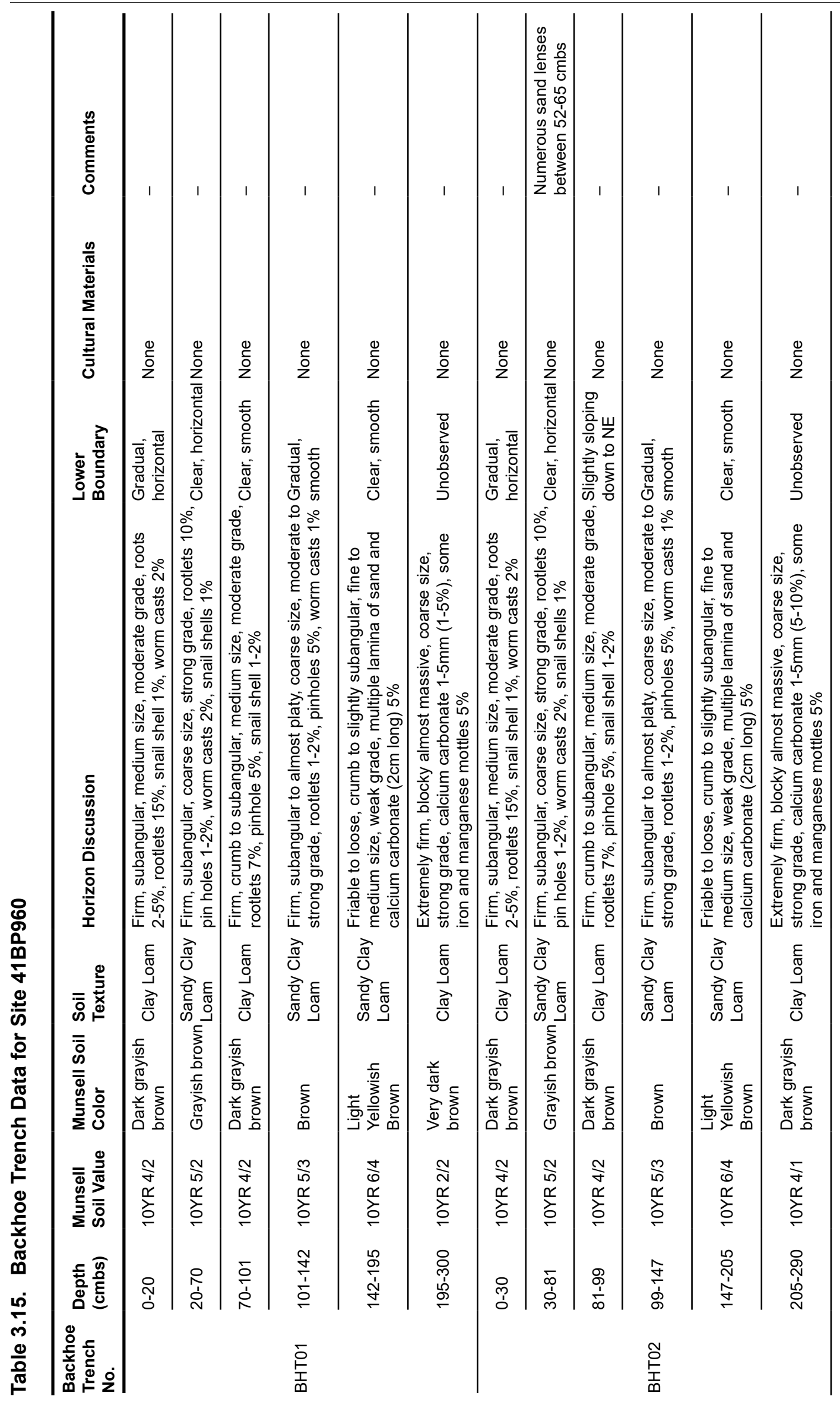




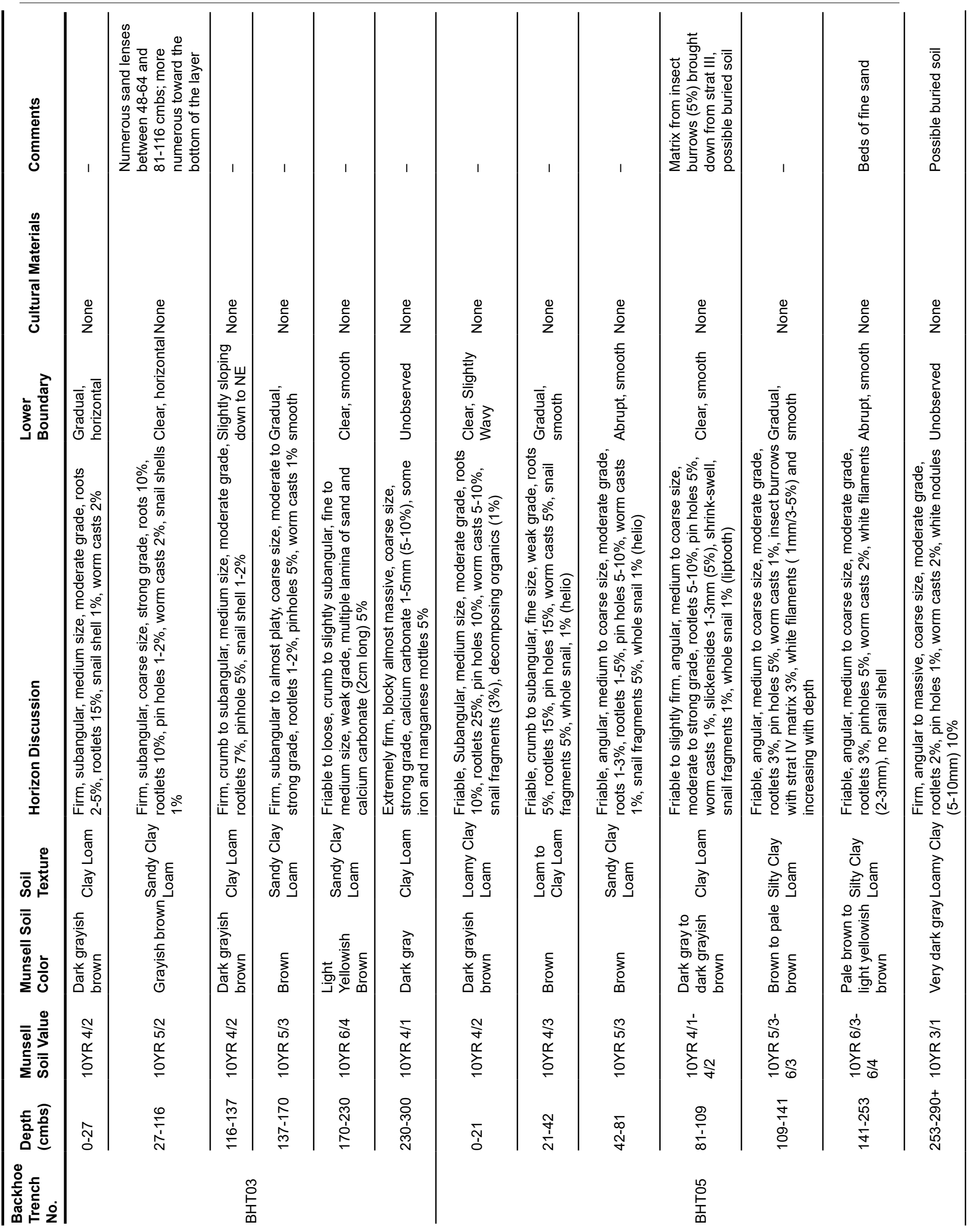




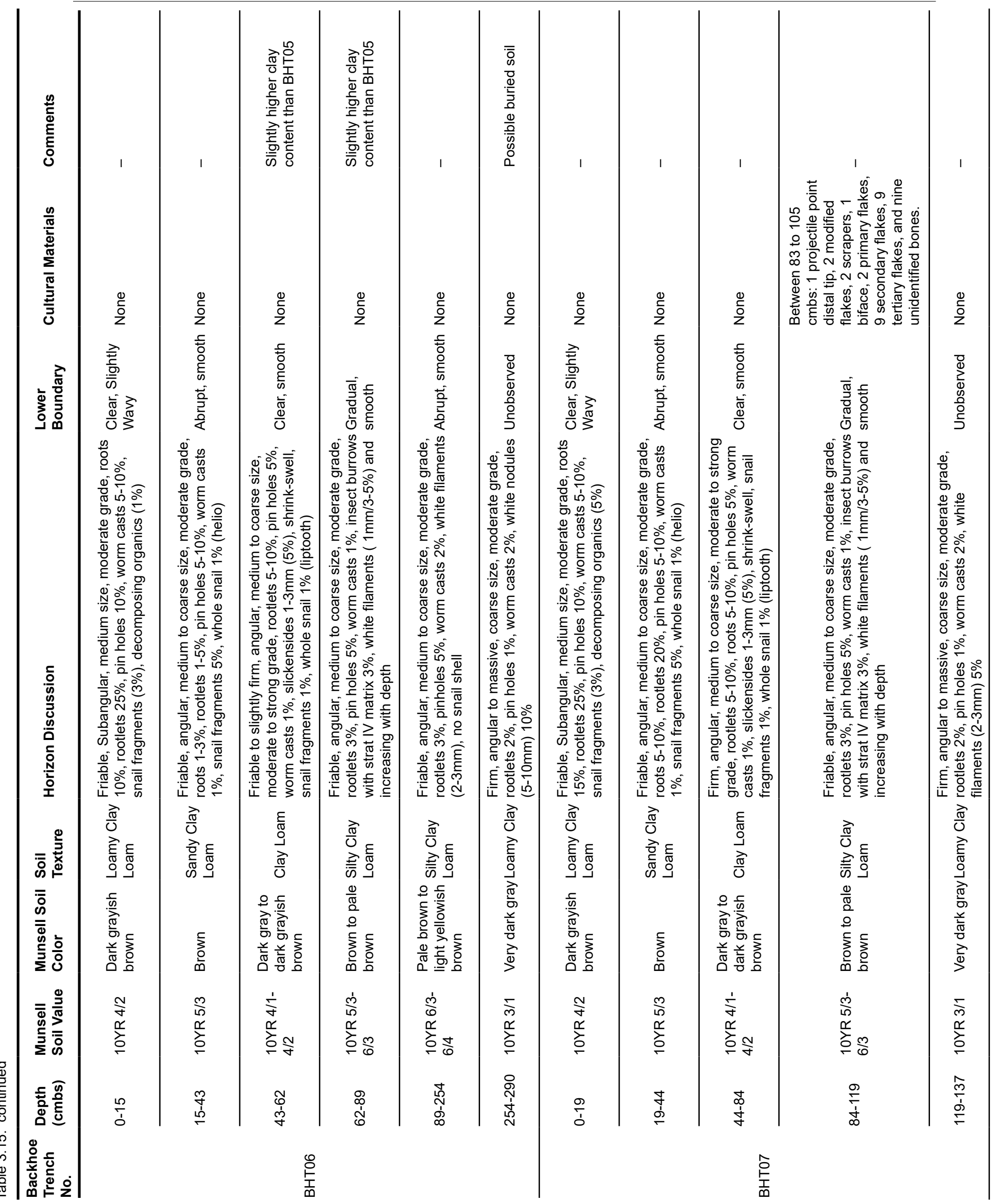




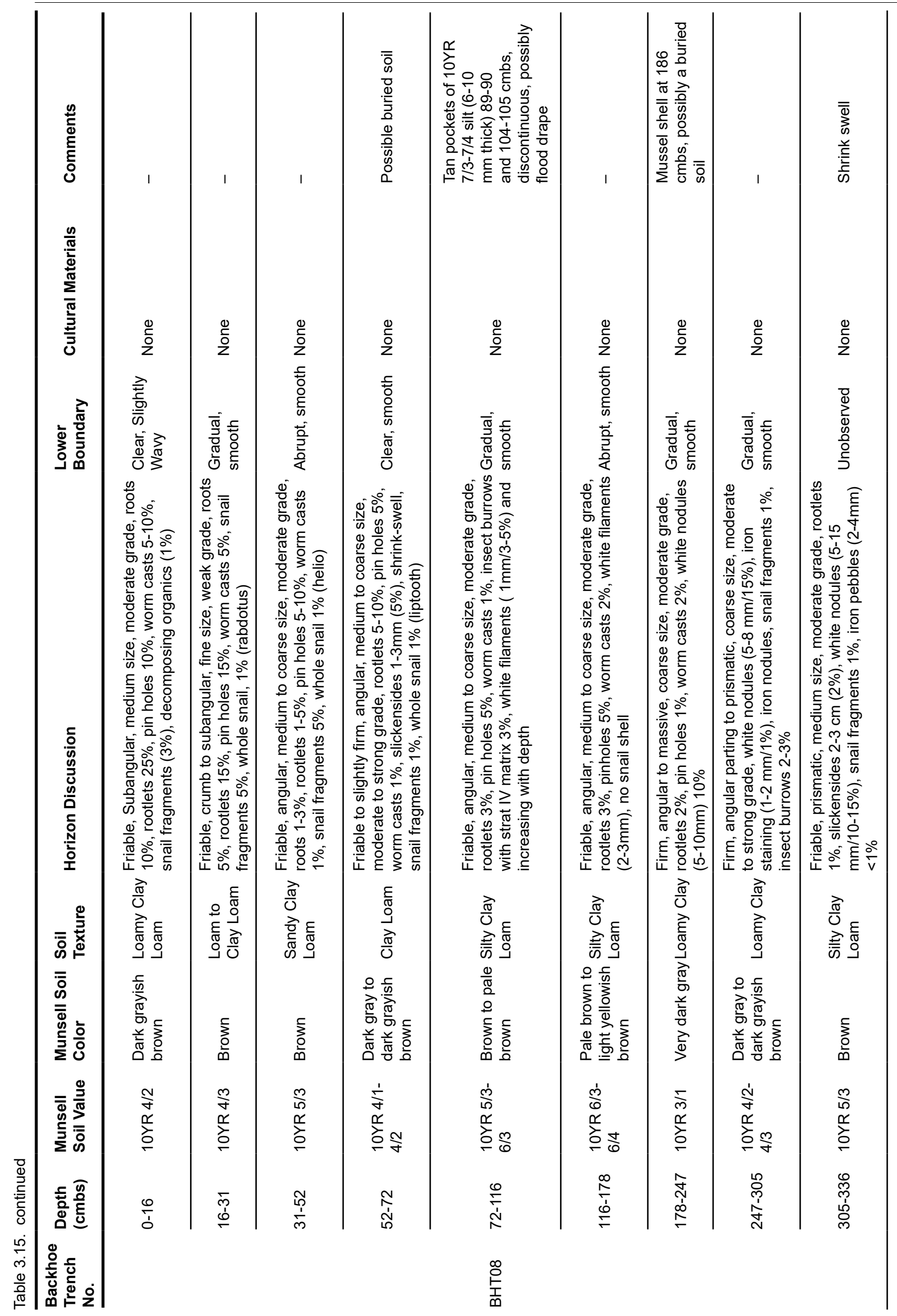




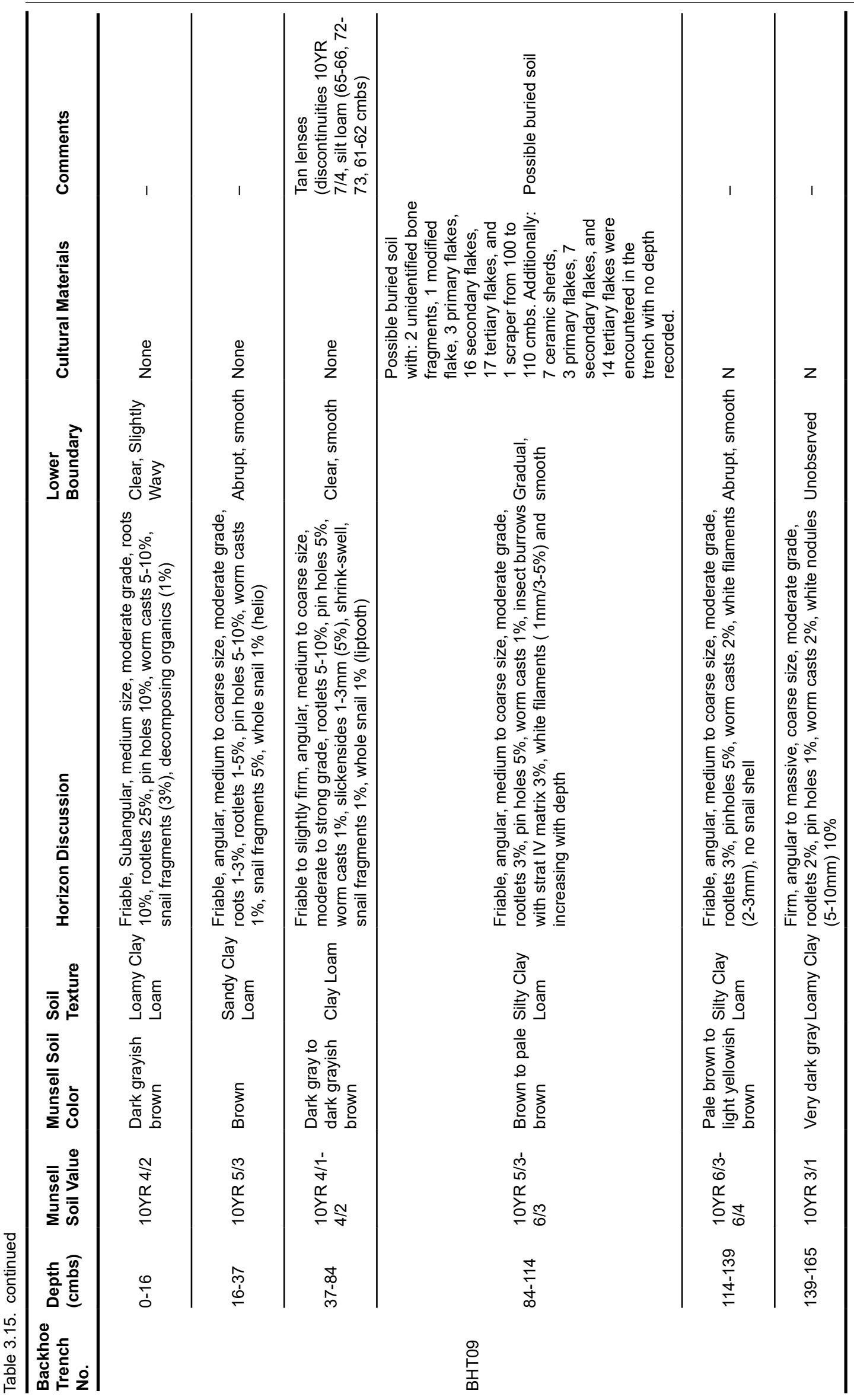


Cultural materials observed include prehistoric ceramic sherds, lithic debitage and tools, fire-cracked chert, and faunal remains. The two positive auger probes (i.e., AU14 and AU15) each recovered one ceramic sherd between $90-100 \mathrm{cmbs}$ and $80-120 \mathrm{cmbs}$, respectively. BHT07 contained a distal top of a non-diagnostic projectile point, two scrapers, two modified flakes, one early-stage biface, 20 chert flakes (nine tertiary, nine secondary, and two primary), and nine fragments of non-diagnostic animal bone; artifacts were recovered from between 85 and 105 cmbs. The column sample excavated on the edge of BHT07 was also positive for cultural material. Materials encountered consisted of five tertiary flakes and a possible fired quartzite rock recovered from between 83 and $105 \mathrm{cmbs}$ (Appendix C). BHT09 encountered seven prehistoric ceramic sherds, one modified flake, 60 chert flakes (31 tertiary, 23 secondary, and 6 primary), and two non-diagnostic animal bones; artifacts were recovered from between 100 and 110 cmbs (Figure 3.39). BHT09's column sample was positive for cultural material including 20 chert flakes (17 tertiary, two secondary, and one primary), two fragments of non-diagnostic animal bone, and a single ceramic sherd; artifacts were recovered from between 89 and $101 \mathrm{cmbs}$ (Appendix C). The thickness of the ceramic sherds recovered from the site range from 5.4 to $6.3 \mathrm{~mm}$. Four of the sherds are burnished with a red slip (2.5YR 4/8) applied to both surfaces. Six of the sherds are burnished with a possible self-slip consistent with the color of the paste. The paste is a strong brown (7.5YR 5/6) color and is the same for all of the sherds. Some of the sherds were fired unevenly and contain a dark yellowish brown (10YR 3/4) core or cortex. All of the sherds contain bone temper, although one (from AU15) also contains some coarse sand temper. All of the sherds are body fragments from indeterminate vessel types. One of the sherds (from AU14) exhibits a rubified and worn interior typical of cooking vessels when the interior slip is removed from repeated stirring or boiling revealing the underlying paste (Figure 3.40). Another sherd (from AU15) exhibits two possible faint fingernail punctations along the exterior surface. The presence of these ceramic sherds with burnished surface treatment, buff colored paste, red slip, and bone temper may indicate an occupation attributed to the Leon Plain or Doss Redware ceramic assemblage, which dates from A.D. 1300 to 1700 and is associated with the Late Prehistoric Toyah Phase (Boyd 2012; Perttula et al. 1995; Texas Beyond History 2018).

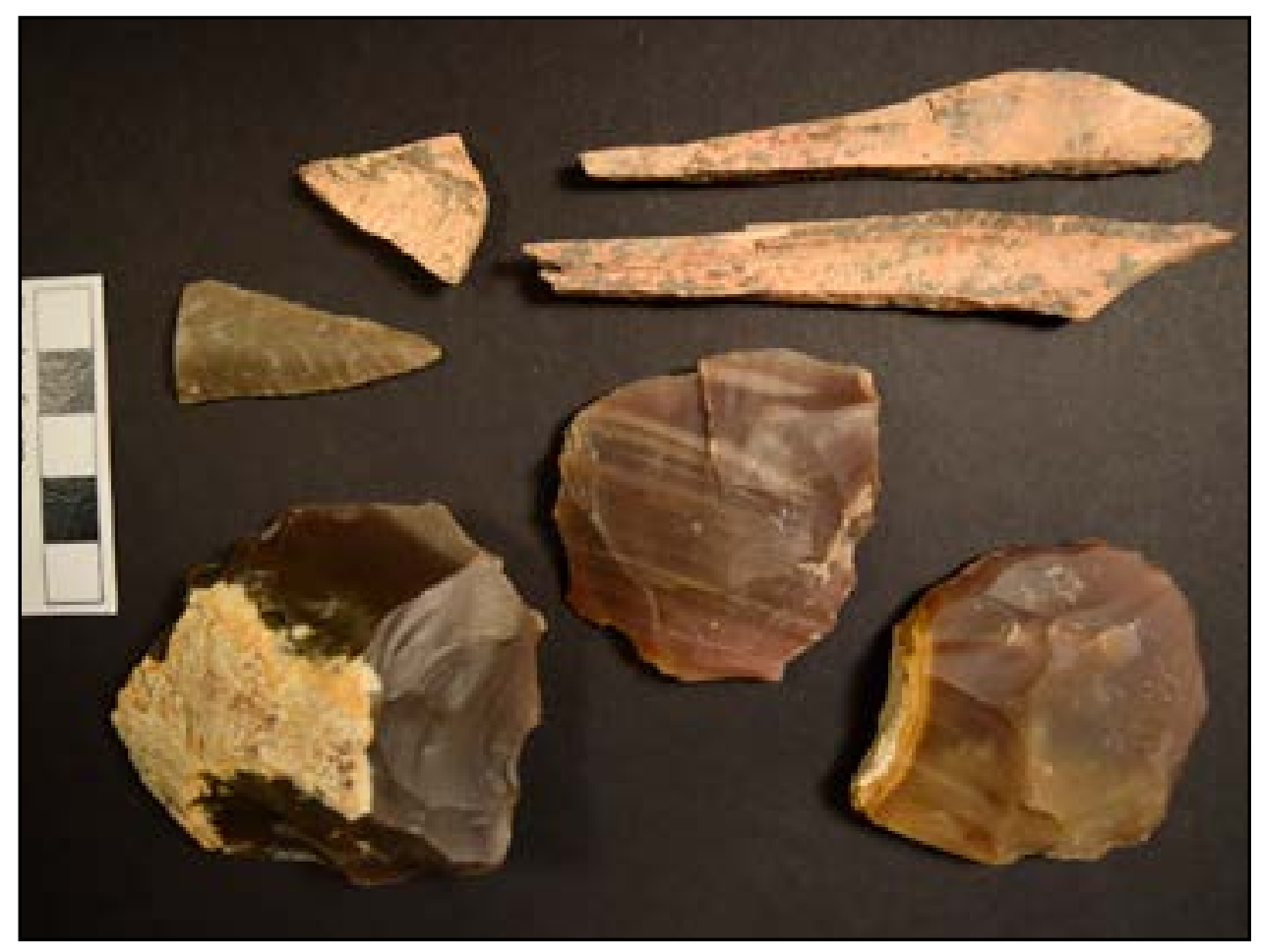

Figure 3.39. Artifacts recovered from BHT07 at site 41BP960 (top left: animal bone; bottom left: non-diagnostic projectile point tip; top right and center: scrapers; bottom right: early-stage biface). 


\section{BP960 SUMMARY}

Site 41BP960 is a deeply buried prehistoric campsite containing an upper and lower buried soil with bonetempered pottery, lithic debitage and tools, and faunal remains. The site contains temporally diagnostic prehistoric ceramics indicating a Late Prehistoric Toyah Phase cultural affiliation. Lithic debitage and tools, and well-preserved faunal remains recovered within discrete stratified intact cultural deposits suggest the potential for intact cultural features and additional temporally diagnostic artifacts to be recovered from the unexcavated portions of the site. Based on these data, site 41BP960 has the potential to contribute new and important information to the understanding of regional prehistory, including the Late Prehistoric Toyah Phase that also extended into the historic era (circa A.D. 1540 to 1700). As such, avoidance of the site or significance testing is recommended to determine the site's eligibility for SAL designation or listing on the NRHP. SWCA conducted backhoe trenching along a reroute approximately $60 \mathrm{~m}$ to the east of the site and determined that site 41BP960 does not extend into these areas; the site is now being avoided by these design alignment changes.

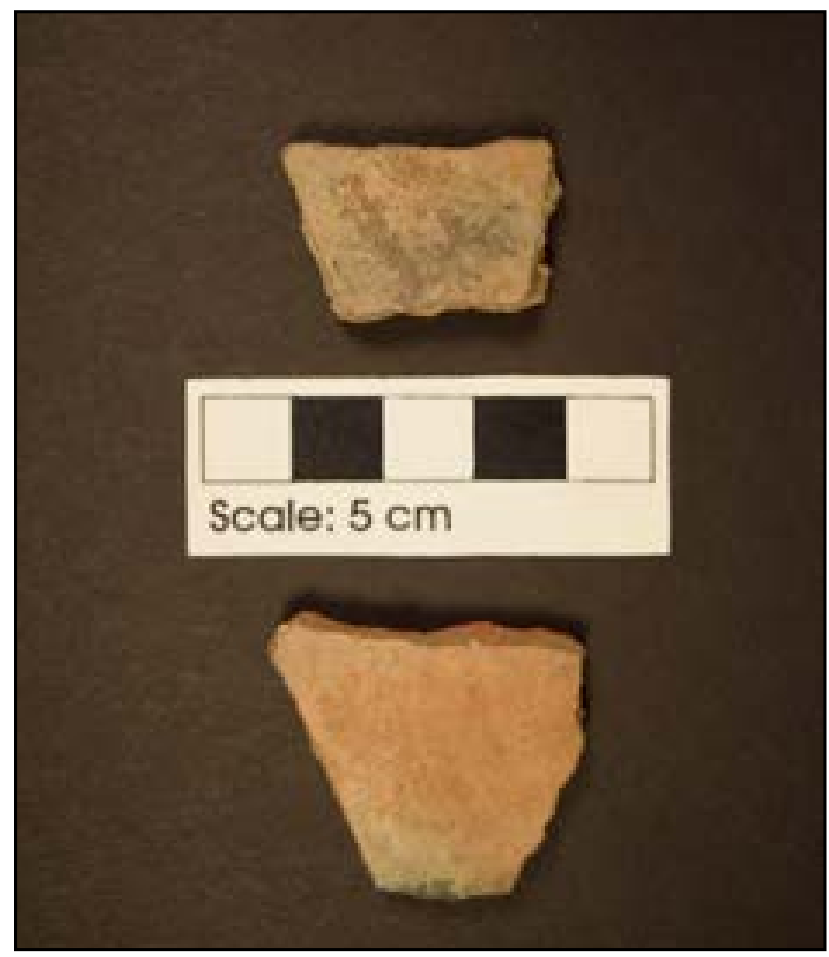

Figure 3.40a. Prehistoric ceramics showing exterior surface recovered from AU14 and AU15 at site 41BP960.

\section{BP961}

Site 41BP961 is situated along the T2 terrace situated northeast of the tributary drainage and consists of open pasture and hay fields along the riparian zones of the waterways (Figure 3.41; Appendix A:101). Vegetation consists of tall, dense hay field within pastures, and mixed wooded and riparian secondary growth along the drainages. Ground surface visibility was poor due to the dense vegetation. Site 41BP961 is located on privately owned land used for agricultural and ranching activities. Disturbances include erosion, vegetation clearing, fence lines, two-track roads, and nearby land modification for stock ponds.

Site 41BP961 is also a deeply buried prehistoric campsite of unknown temporal or cultural affiliation with lithic debitage and tools, fire-cracked chert/rock, and red ochre that measures approximately $180 \mathrm{~m}$ northeast/southwest by $27 \mathrm{~m}$ northwest/southeast within the project corridor based on artifact distribution and landforms; however, the site may extend beyond the project area to the southeast and northwest. Similar to site 41BP960, intensive systematic excavation of hand auger probes was conducted followed by excavation of mechanical backhoe trenches with selective column

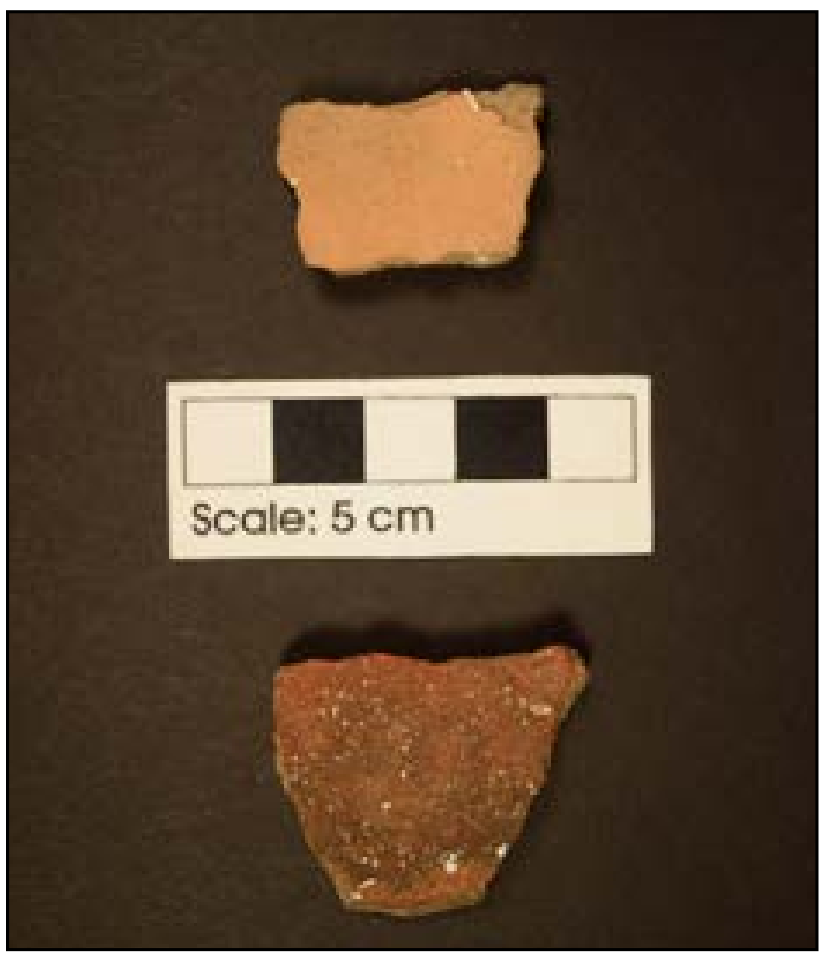

Figure 3.40b. Prehistoric ceramics showing interior surface recovered from AU14 and AU15 at site 41BP960. 


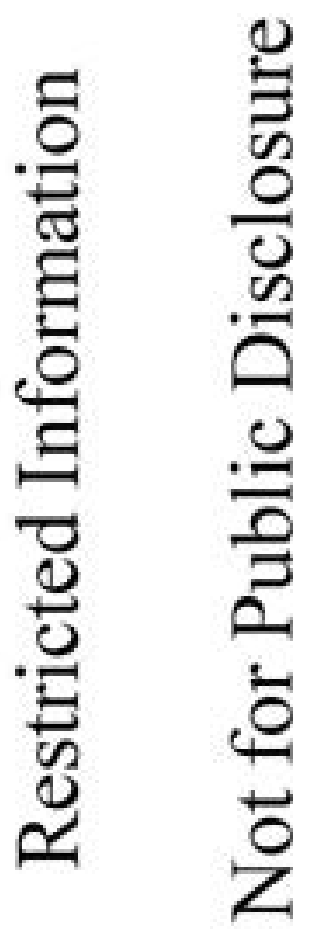

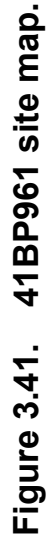


sampling. No cultural materials were observed along the ground surface due to poor visibility.

SWCA excavated 11 auger probes (i.e., AU04-08 and AU34-39) at approximately 50-m intervals to investigate the project corridor and delineate the site, of which three (i.e., AU35 and AU37-38) were positive for cultural materials from 0 to $170 \mathrm{cmbs}$ (Table 3.16). SWCA also excavated seven backhoe trenches (i.e., BHT04 and BHT10-15), of which six (i.e., BHT04 and BHT10-14) were positive for cultural materials from 20 to $150 \mathrm{cmbs}$ (Table 3.17). Column samples measuring $50 \times 50-\mathrm{cm}$ were excavated off the walls of the positive trenches in arbitrary 10-cm levels (Appendix C). In addition, SWCA had previously excavated two shovel tests (i.e., DR207 and AJ08) approximately $10 \mathrm{~m}$ and $20 \mathrm{~m}$ northwest, respectively, and one shovel test (i.e., AJ07) approximately $50 \mathrm{~m}$ southwest of the site, all of which were negative for cultural materials.

The trenches typically consisted of four to seven strata with alternating horizons of dark grayish brown (10YR $4 / 2)$ to dark gray (10YR 4/1) clay loam and light yellowish brown (10YR 6/4), pale brown (10YR 6/3), or brown (10YR 5/3) silty or sandy clay loam deposits with clear-gradual lower boundaries. The horizons typically had a friable consistency and subangular blocky structure, which graded into a massive, structureless horizon with increasing calcium carbonate inclusions and an extremely firm consistency. The investigations encountered an upper buried soil from approximately 80 to $120 \mathrm{cmbs}$, a second lower buried soil at approximately $140 \mathrm{cmbs}$ and below, and a shallow cultural horizon situated above the buried soils between 0 and $50 \mathrm{cmbs}$ containing the cultural materials observed during the investigations (Figure 3.42).

Cultural materials observed included lithic debitage and few flake tools of chert, fire-cracked chert/rock, and a red ochre fragment. The positive auger probes recovered a piece of fire-cracked chert (within AU35) at approximately $110 \mathrm{cmbs}$ within the upper buried soil, an in situ chert tertiary reduction flake (within AU37) in old alluvium at a depth of 160 to $170 \mathrm{cmbs}$ within the lower encountered buried soil, and a chert secondary reduction flake (within AU38) between 0 and $30 \mathrm{cmbs}$ within a cultural horizon situated above the two buried soils observed. The six positive backhoe trenches (i.e., BHT04 and BHT10-BHT14) recovered 19 chert flakes (15 tertiary, three secondary and one primary), one fragment of chert thermal shatter, and fire-cracked chert/rock, all within the buried soils identified above (Figure 3.43; Appendix C). In total the six positive backhoe trenches recovered 108 chert flakes (64 tertiary, 35 secondary, and nine primary), two

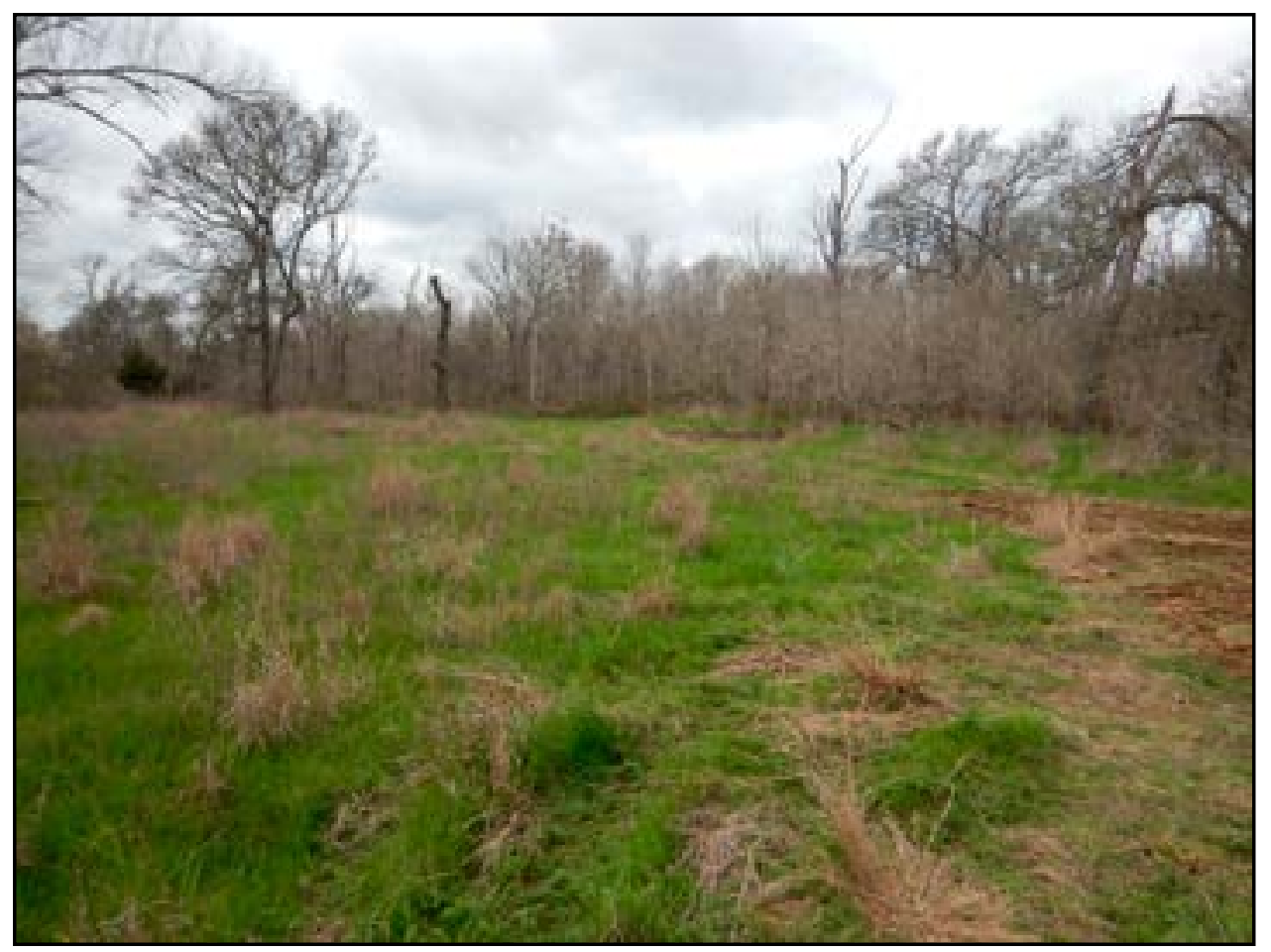

Figure 3.42. Overview of site 41BP961 from BHT 11 location, facing west. 
Table 3.16. Auger Probe Data for Site 41BP961

\begin{tabular}{|c|c|c|c|c|c|c|c|c|c|}
\hline $\begin{array}{l}\text { Auger } \\
\text { Probe } \\
\text { No. }\end{array}$ & Level & $\begin{array}{l}\text { Depth } \\
\text { (cmbs) }\end{array}$ & $\begin{array}{l}\text { Munsell } \\
\text { Soil Value }\end{array}$ & $\begin{array}{l}\text { Munsell } \\
\text { Soil Color }\end{array}$ & $\begin{array}{l}\text { Soil } \\
\text { Texture }\end{array}$ & $\begin{array}{l}\text { Inclusion } \\
\text { Percentage }\end{array}$ & $\begin{array}{l}\text { Inclusion } \\
\text { Type }\end{array}$ & $\begin{array}{l}\text { Cultural } \\
\text { Materials }\end{array}$ & $\begin{array}{l}\text { Comments/ } \\
\text { Reason for Termination }\end{array}$ \\
\hline \multirow[b]{2}{*}{ AU04 } & 1 & $0-130$ & 10YR 5/4 & $\begin{array}{l}\text { yellowish } \\
\text { brown }\end{array}$ & $\begin{array}{l}\text { Silty Clay } \\
\text { Loam }\end{array}$ & - & - & None & - \\
\hline & 2 & $130-200$ & 10YR 4/4 & $\begin{array}{l}\text { dark } \\
\text { yellowish } \\
\text { brown }\end{array}$ & $\begin{array}{l}\text { Clay } \\
\text { Loam }\end{array}$ & - & - & None & Terminated at depth. \\
\hline \multirow[b]{2}{*}{ AU05 } & 1 & $0-140$ & 10YR 5/2 & $\begin{array}{l}\text { grayish } \\
\text { brown }\end{array}$ & $\begin{array}{l}\text { Clay } \\
\text { Loam }\end{array}$ & - & - & None & - \\
\hline & 2 & $140-170$ & 10YR 5/6 & $\begin{array}{l}\text { yellowish } \\
\text { brown }\end{array}$ & $\begin{array}{l}\text { Clay } \\
\text { Loam }\end{array}$ & $10-20 \%$ & $\begin{array}{l}\text { Calcium } \\
\text { Carbonate, } \\
\text { Gravels, } \\
\text { Pebbles, } \\
\text { Iron } \\
\text { concretions }\end{array}$ & None & Terminated at depth. \\
\hline \multirow[b]{2}{*}{ AU06 } & 1 & $0-40$ & 10YR 5/2 & $\begin{array}{l}\text { grayish } \\
\text { brown }\end{array}$ & $\begin{array}{l}\text { Clay } \\
\text { Loam }\end{array}$ & - & - & None & - \\
\hline & 2 & $40-110$ & 10YR 5/6 & $\begin{array}{l}\text { yellowish } \\
\text { brown }\end{array}$ & $\begin{array}{l}\text { Clay } \\
\text { Loam }\end{array}$ & $10-20 \%$ & $\begin{array}{l}\text { Calcium } \\
\text { Carbonate, } \\
\text { Gravels, } \\
\text { Pebbles, } \\
\text { Iron } \\
\text { concretions }\end{array}$ & None & Terminated at depth. \\
\hline \multirow[b]{2}{*}{ AU07 } & 1 & $0-140$ & 10YR 5/2 & $\begin{array}{l}\text { grayish } \\
\text { brown }\end{array}$ & $\begin{array}{l}\text { Clay } \\
\text { Loam }\end{array}$ & - & - & None & - \\
\hline & 2 & $140-160$ & 10YR 5/6 & $\begin{array}{l}\text { yellowish } \\
\text { brown }\end{array}$ & $\begin{array}{l}\text { Clay } \\
\text { Loam }\end{array}$ & $10-20 \%$ & $\begin{array}{l}\text { Calcium } \\
\text { Carbonate, } \\
\text { Gravels, } \\
\text { Pebbles, } \\
\text { Iron } \\
\text { concretions }\end{array}$ & None & Terminated at depth. \\
\hline \multirow{4}{*}{ AU08 } & 1 & $0-40$ & 10YR 4/4 & $\begin{array}{l}\text { dark } \\
\text { yellowish } \\
\text { brown }\end{array}$ & Silt Loam & - & - & None & - \\
\hline & 2 & $40-120$ & 10YR 5/6 & $\begin{array}{l}\text { yellowish } \\
\text { brown }\end{array}$ & Silt Loam & - & - & None & - \\
\hline & 3 & $120-170$ & 10YR 6/4 & $\begin{array}{l}\text { light } \\
\text { yellowish } \\
\text { brown }\end{array}$ & $\begin{array}{l}\text { Sandy } \\
\text { Loam }\end{array}$ & $1-5 \%$ & $\begin{array}{l}\text { Calcium } \\
\text { Carbonate, } \\
\text { White } \\
\text { Fungus or } \\
\text { Calcium }\end{array}$ & None & - \\
\hline & 4 & $170-200$ & 10YR 6/3 & pale brown & $\begin{array}{l}\text { Silty Clay } \\
\text { Loam }\end{array}$ & $1-5 \%$ & $\begin{array}{l}\text { Calcium } \\
\text { Carbonate }\end{array}$ & None & Terminated at depth. \\
\hline \multirow{4}{*}{ AU34 } & 1 & $0-35$ & 10YR 4/2 & $\begin{array}{l}\text { dark } \\
\text { grayish } \\
\text { brown }\end{array}$ & Silty Clay & - & - & None & - \\
\hline & 2 & $35-120$ & 10YR 5/2 & $\begin{array}{l}\text { grayish } \\
\text { brown }\end{array}$ & $\begin{array}{l}\text { Silty Clay } \\
\text { Loam }\end{array}$ & - & - & None & - \\
\hline & 3 & $120-150$ & 10YR 5/3 & brown & Silt Loam & $1-5 \%$ & $\begin{array}{l}\text { Calcium } \\
\text { Carbonate }\end{array}$ & None & - \\
\hline & 4 & $150-200$ & 10YR 4/1 & dark gray & $\begin{array}{l}\text { Silty Clay } \\
\text { Loam }\end{array}$ & $5-10 \%$ & $\begin{array}{l}\text { Calcium } \\
\text { Carbonate }\end{array}$ & None & Terminated at depth. \\
\hline
\end{tabular}


Table 3.16. continued

\begin{tabular}{|c|c|c|c|c|c|c|c|c|c|}
\hline $\begin{array}{l}\text { Auger } \\
\text { Probe } \\
\text { No. }\end{array}$ & Level & $\begin{array}{l}\text { Depth } \\
\text { (cmbs) }\end{array}$ & $\begin{array}{l}\text { Munsell } \\
\text { Soil Value }\end{array}$ & $\begin{array}{l}\text { Munsell } \\
\text { Soil Color }\end{array}$ & $\begin{array}{l}\text { Soil } \\
\text { Texture }\end{array}$ & $\begin{array}{l}\text { Inclusion } \\
\text { Percentage }\end{array}$ & $\begin{array}{l}\text { Inclusion } \\
\text { Type }\end{array}$ & $\begin{array}{l}\text { Cultural } \\
\text { Materials }\end{array}$ & $\begin{array}{l}\text { Comments/ } \\
\text { Reason for Termination }\end{array}$ \\
\hline \multirow{4}{*}{ AU35 } & 1 & $0-40$ & 10YR 4/2 & $\begin{array}{l}\text { dark } \\
\text { grayish } \\
\text { brown }\end{array}$ & Silty Clay & - & - & None & - \\
\hline & 2 & $40-90$ & 10YR 5/2 & $\begin{array}{l}\text { grayish } \\
\text { brown }\end{array}$ & $\begin{array}{l}\text { Silty Clay } \\
\text { Loam }\end{array}$ & - & - & None & - \\
\hline & 3 & $90-120$ & 10YR 4/1 & dark gray & $\begin{array}{l}\text { Silty Clay } \\
\text { Loam }\end{array}$ & - & - & $\begin{array}{l}\text { 1: Other } \\
\text { Prehistoric-FCC } \\
\text { found [110 cmbs] }\end{array}$ & \\
\hline & 4 & $120-160$ & 10YR 5/3 & brown & Silt Loam & $1-5 \%$ & $\begin{array}{l}\text { Calcium } \\
\text { Carbonate }\end{array}$ & None & Terminated at depth. \\
\hline \multirow{3}{*}{ AU36 } & 1 & $0-40$ & 10YR 4/2 & $\begin{array}{l}\text { dark } \\
\text { grayish } \\
\text { brown }\end{array}$ & Silty Clay & - & - & None & - \\
\hline & 2 & $40-90$ & 10YR 5/2 & $\begin{array}{l}\text { grayish } \\
\text { brown }\end{array}$ & $\begin{array}{l}\text { Silty Clay } \\
\text { Loam }\end{array}$ & - & - & None & - \\
\hline & 3 & $90-165$ & 10YR 5/3 & brown & $\begin{array}{l}\text { Silty Clay } \\
\text { Loam }\end{array}$ & $1-5 \%$ & $\begin{array}{l}\text { Calcium } \\
\text { Carbonate }\end{array}$ & None & Terminated at depth. \\
\hline \multirow{5}{*}{ AU37 } & 1 & $0-60$ & 10YR 4/1 & dark gray & Silty Clay & - & - & None & - \\
\hline & 2 & $40-90$ & 10YR 5/2 & $\begin{array}{l}\text { grayish } \\
\text { brown }\end{array}$ & $\begin{array}{l}\text { Silty Clay } \\
\text { Loam }\end{array}$ & - & - & None & - \\
\hline & 3 & $90-140$ & 10YR 4/1 & dark gray & Silty Clay & - & - & None & - \\
\hline & 4 & $140-180$ & 10YR 4/1 & dark gray & Silty Clay & $1-5 \%$ & $\begin{array}{l}\text { Calcium } \\
\text { Carbonate }\end{array}$ & $\begin{array}{l}\text { 1: Flake (tertiary) } \\
{[160-170 \mathrm{cmbs}]}\end{array}$ & . \\
\hline & 5 & $180-200$ & 10YR 5/3 & brown & $\begin{array}{l}\text { Silty Clay } \\
\text { Loam }\end{array}$ & $5-10 \%$ & $\begin{array}{l}\text { Calcium } \\
\text { Carbonate }\end{array}$ & None & Terminated at depth. \\
\hline \multirow{3}{*}{ AU38 } & 1 & $0-50$ & 10YR 4/2 & $\begin{array}{l}\text { dark } \\
\text { grayish } \\
\text { brown }\end{array}$ & Silty Clay & - & - & $\begin{array}{l}\text { 1: Flake } \\
\text { (secondary) }\end{array}$ & - \\
\hline & 2 & $50-100$ & 10YR 5/2 & $\begin{array}{l}\text { grayish } \\
\text { brown }\end{array}$ & $\begin{array}{l}\text { Silty Clay } \\
\text { Loam }\end{array}$ & - & - & None & - \\
\hline & 3 & $100-150$ & 10YR 5/3 & brown & $\begin{array}{l}\text { Silty Clay } \\
\text { Loam }\end{array}$ & $5-10 \%$ & $\begin{array}{l}\text { Calcium } \\
\text { Carbonate }\end{array}$ & None & Terminated at depth. \\
\hline \multirow{4}{*}{ AU39 } & 1 & $0-40$ & 10YR 4/1 & dark gray & Silty Clay & - & - & None & - \\
\hline & 2 & $40-100$ & 10YR 5/2 & $\begin{array}{l}\text { grayish } \\
\text { brown }\end{array}$ & $\begin{array}{l}\text { Silty Clay } \\
\text { Loam }\end{array}$ & - & - & None & - \\
\hline & 3 & $100-140$ & 10YR 4/1 & dark gray & Loam & - & - & None & - \\
\hline & 4 & $140-200$ & 10YR 5/3 & brown & Silt Loam & - & - & None & Terminated at depth. \\
\hline
\end{tabular}




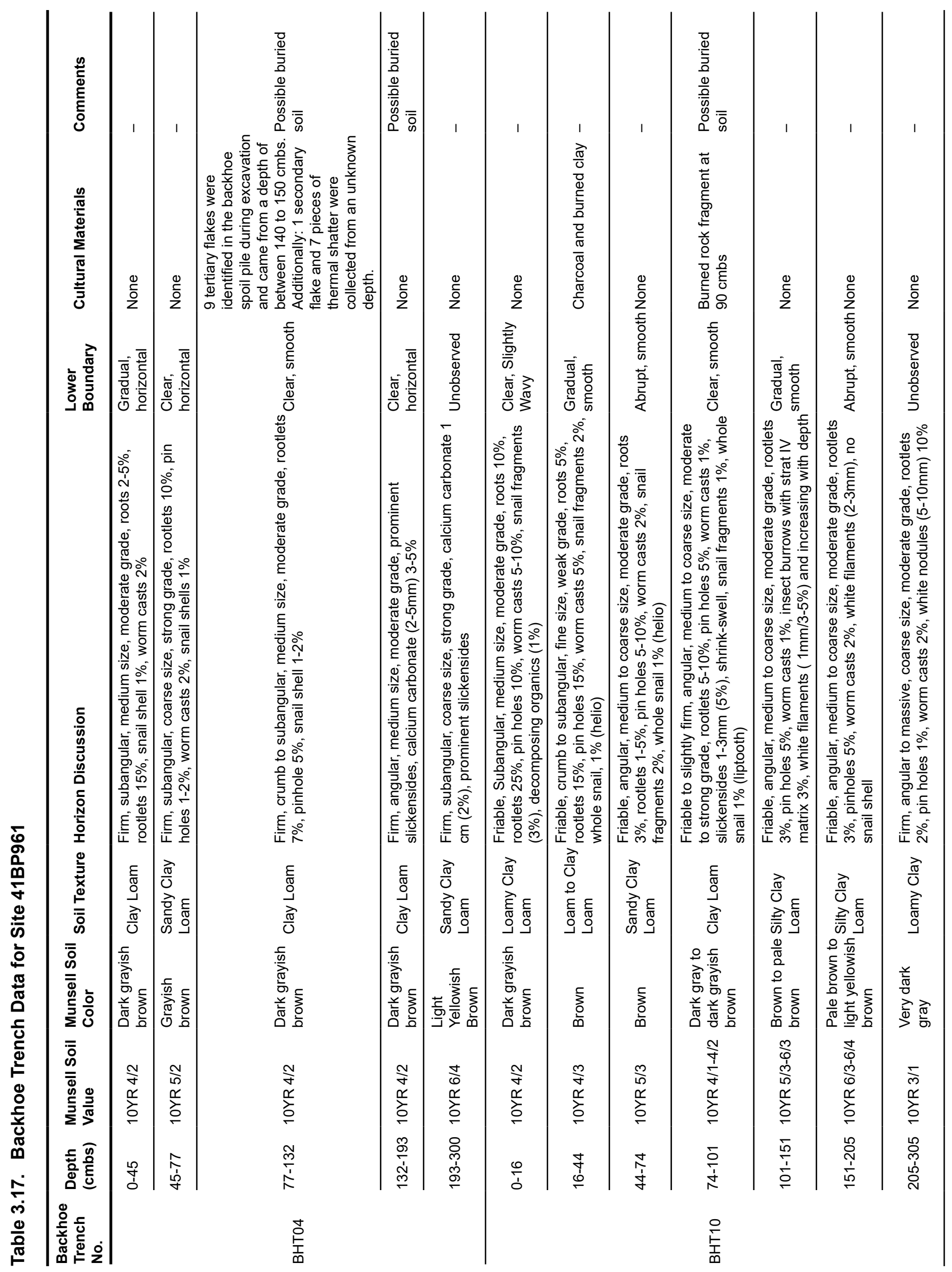




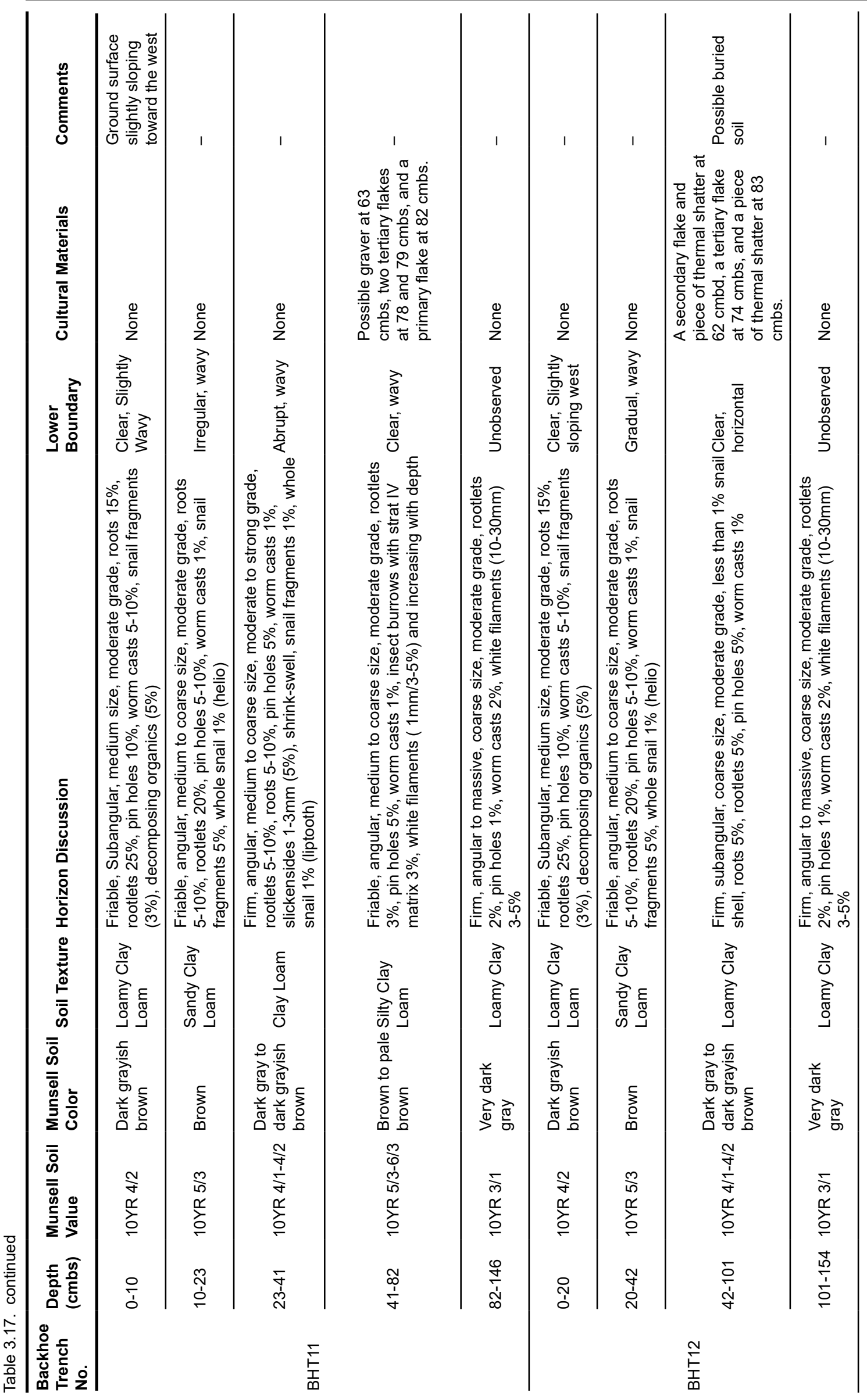




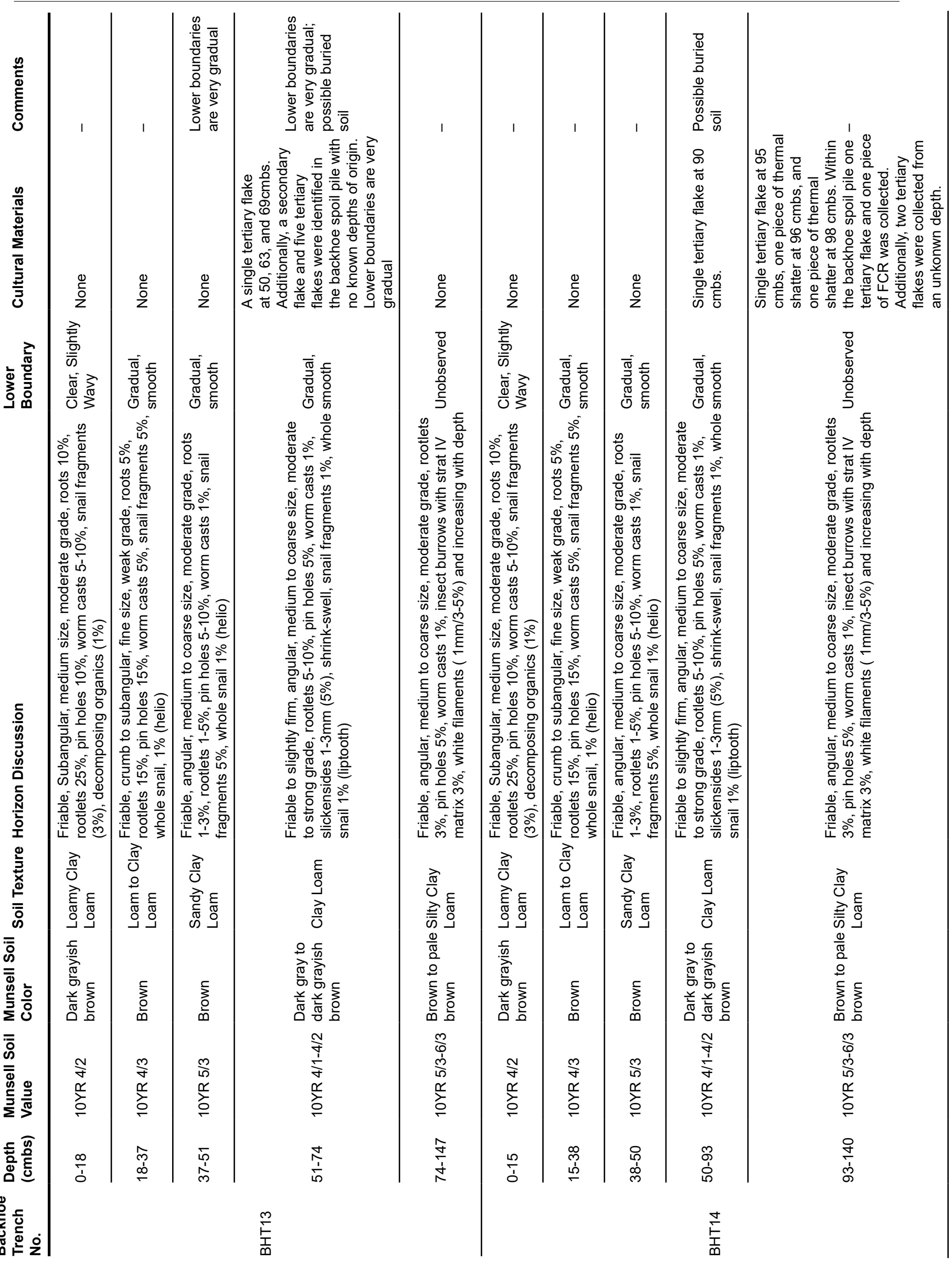




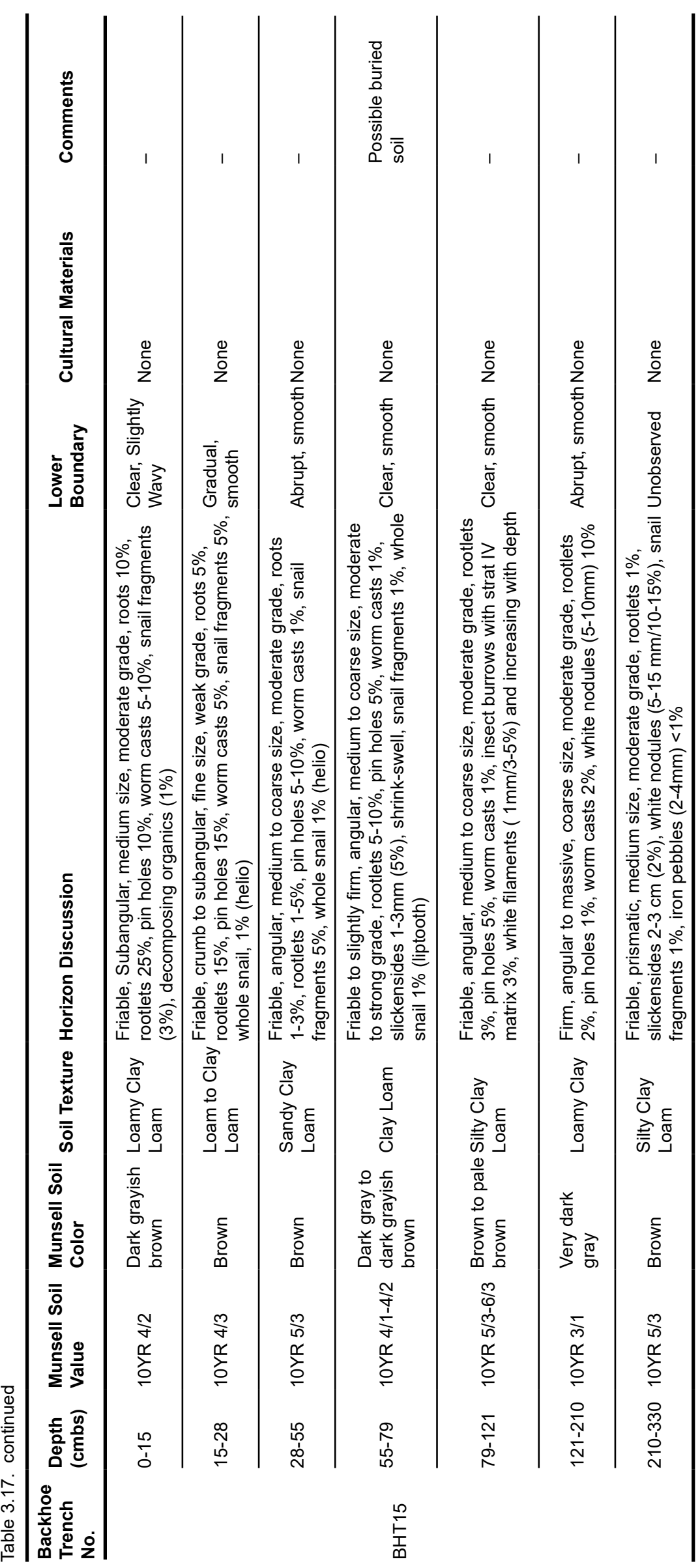




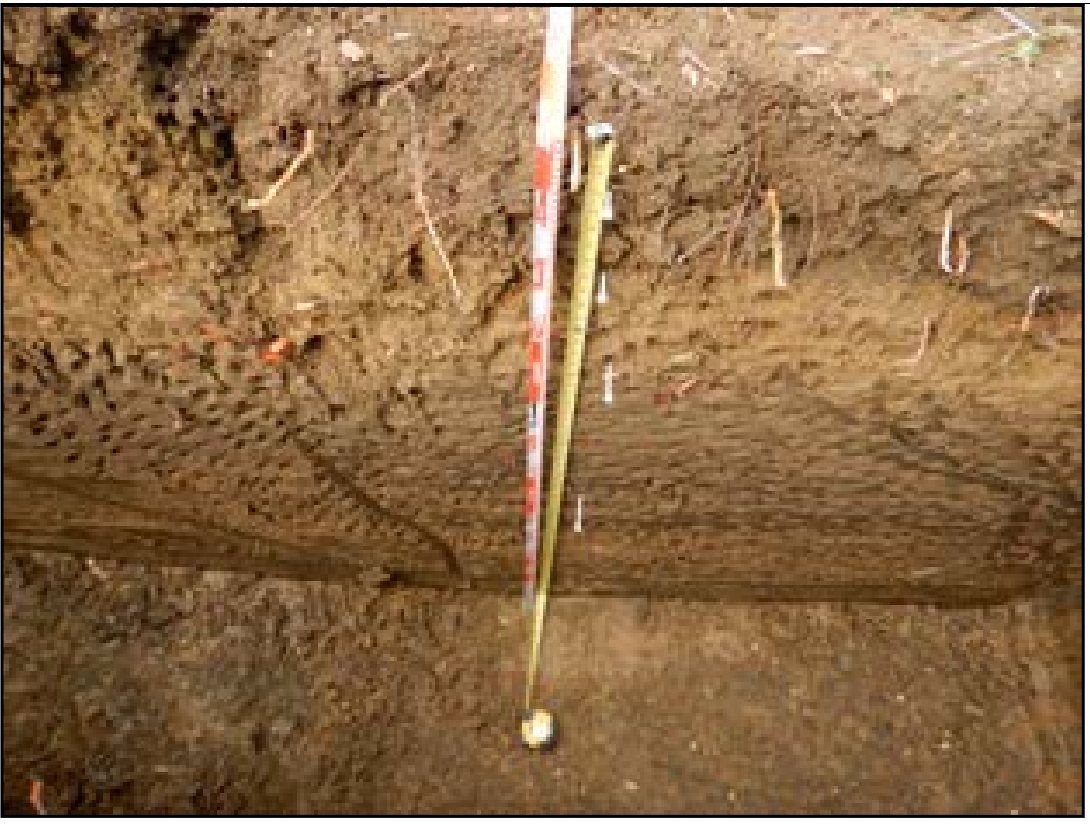

Figure 3.43. BHT 11 profile, golf tees at stratigraphic horizon boundaries.

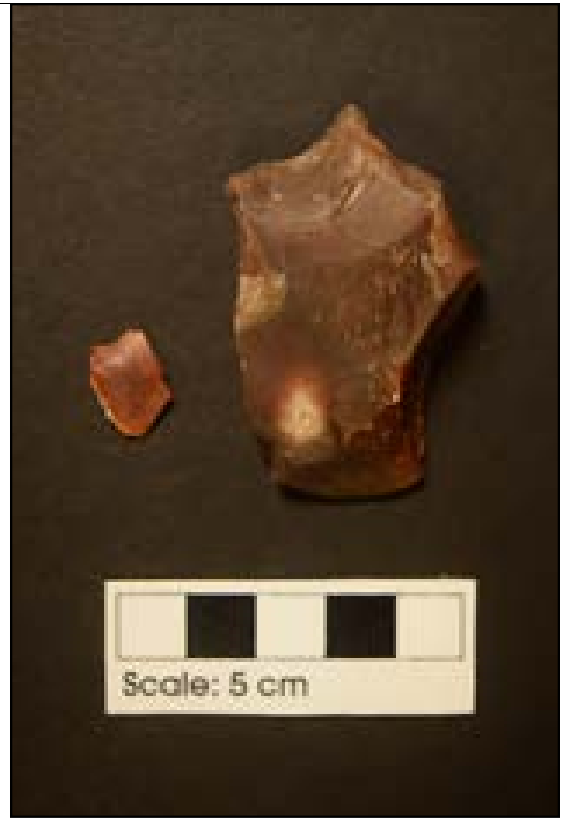

Figure 3.44. Artifacts recovered from $\mathrm{BHT} 11$ at site 41BP961. pieces of fire-cracked rock, 11 pieces of thermally altered chert shatter, three modified flakes, three scrapers, one biface, two fragments of unidentified bone, seven ceramic sherds, one possible graver, and charcoal and burned clay fragments. The column samples excavated off of BHT04 and BHT14 were also positive for cultural material. The column sample at BHT04 identified two pieces of thermal shatter and three tertiary chert flakes from between 79 and $100 \mathrm{cmbs}$. The BHT14 column sample encountered a single secondary flake at $97 \mathrm{cmbs}$ (Appendix C).

\section{BP961 SUMMARY}

Site 41BP961 is a deeply buried prehistoric campsite containing an upper and lower buried soil with a shallower cultural horizon above the two buried soils. The site contains lithic debitage and tools, fire-cracked chert/rock, and red ochre within discrete stratified intact cultural deposits, suggesting the potential for intact cultural features to be present within the site. Based on these data, site 41BP961 has the potential to contribute new and important information to the understanding of regional prehistory. As such, avoidance of the site or significance testing is recommended to determine the site's eligibility for SAL designation or listing on the NRHP. SWCA conducted backhoe trenching along a reroute approximately $20 \mathrm{~m}$ to the east of the site and determined that site 41BP961 does not extend into these areas; the site is now being avoided by these design alignment changes.

\section{BP962}

Site 41BP962 is a historic-age remnant of a raised roadbed and approach to a no longer extant bridge over Dry Creek. The roadbed is located approximately 75 feet west of the existing Upper Elgin River Road and approximately 1.1 miles northeast of its intersection with CR 416 (Figure 3.45; Appendix A:106). Vegetation at the site consists predominately of mesquite trees with some oak and briar and the fence line parallel to Upper Elgin River Road is cleared with medium to tall grass (Figure 3.46). Ground surface visibility was approximately 0-20 percent across the site.

A review of historic topographic maps suggests site 41BP962 may represent the original bridge crossing over Dry Creek depicted on the 1904 Bastrop map, although an exact alignment cannot be determined. No other depiction of Upper Elgin River Road matches the alignment of site 41BP962. The raised roadbed is approximately 150 feet long, 60 feet wide, and approximately $10-15$ feet tall (see Figure 3.46). The structure is oriented approximately 16 degrees east and may have 


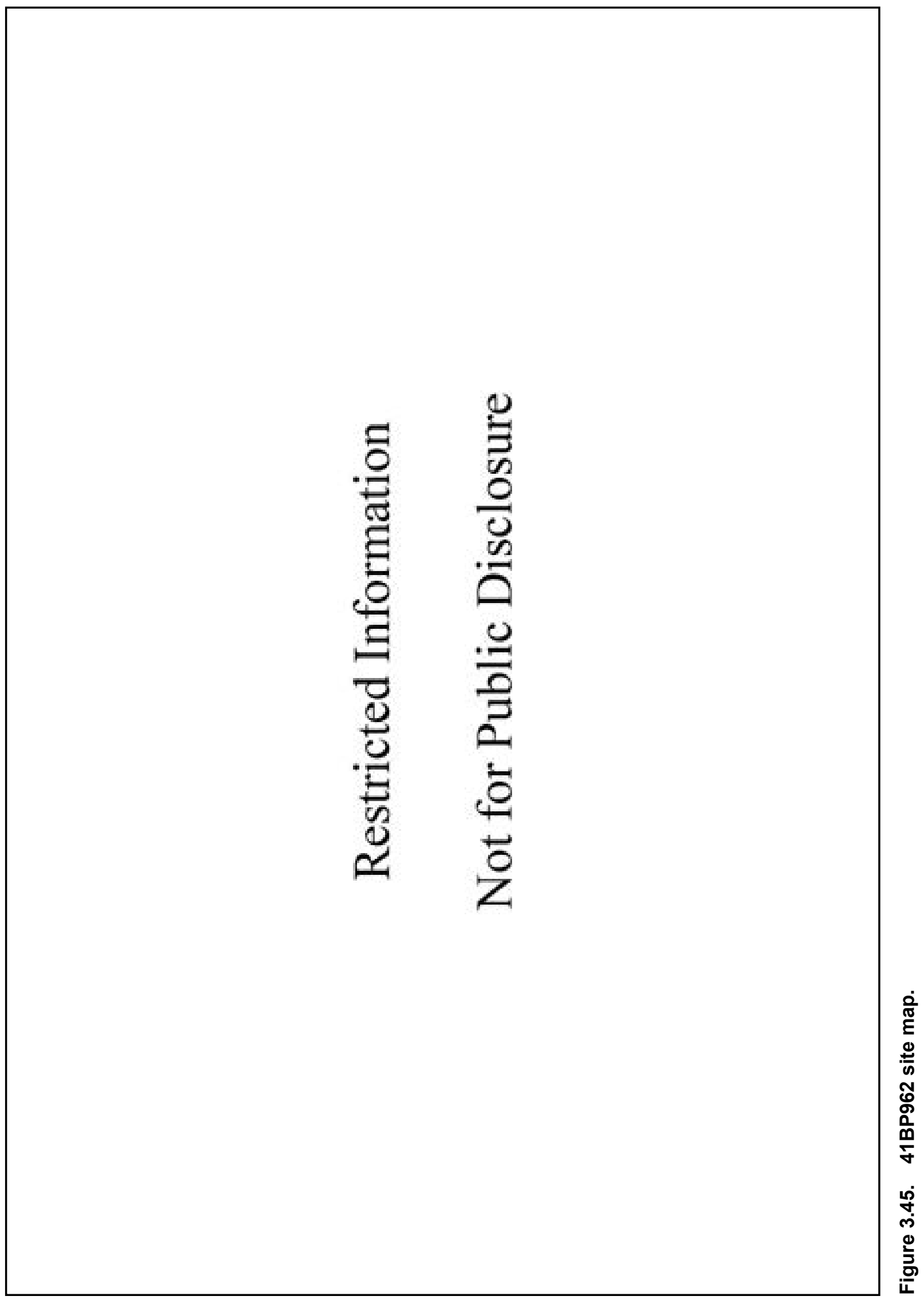


Table 3.18. Shovel Test Data for Site 41BP962

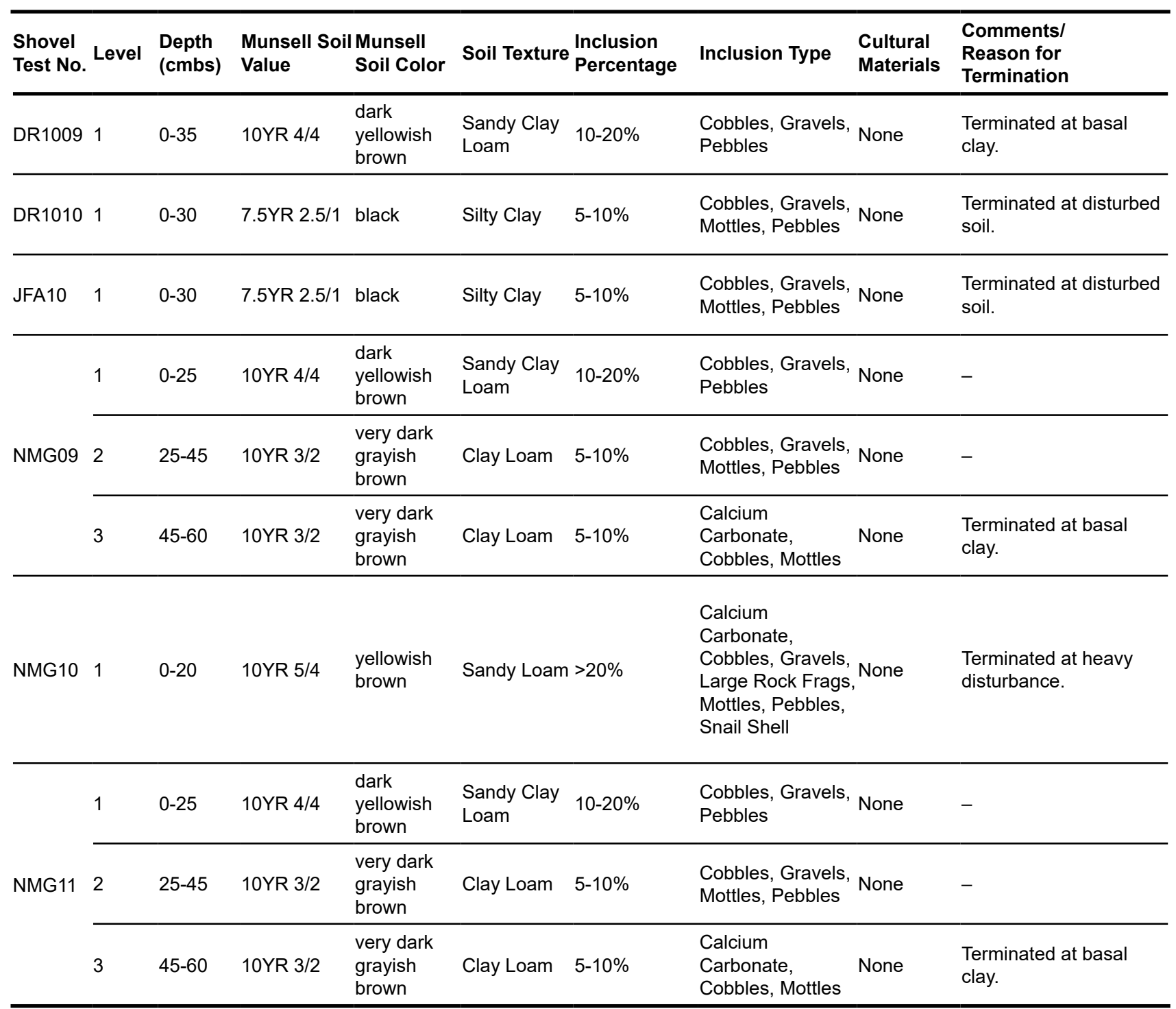

once met up with the current roadway to the south. No bridge remains were located at the site.

Six shovel tests (i.e., DR1009-1010, JFA10, and NMG09-11) were excavated on site, all of which were negative for cultural materials (Table 3.18). Shovel tests typically revealed dark yellowish brown (10YR 4/4) sandy clay loam or black (7.5YR 2.5/1) silty clay and terminated at compacted, disturbed soils with 5-20 percent mottles between 30 and $60 \mathrm{cmbs}$.

\section{BP962 SUMMARY}

Site 41BP962 is a historic-age remnant of a raised roadbed and bridge approach located on the west bank of Dry Creek approximately 75 feet west of Upper
Elgin Road, and may be depicted on historic topographic maps dating to the early twentieth century. Six shovel tests, all negative for cultural materials, were excavated within the project corridor near the road bed and no cultural materials were identified along the ground surface. Overall, site 41BP962 does not have the potential to yield information important to the history of the region. Due to the lack of diagnostic material or intact cultural features, SWCA recommends site 41BP962 as NOT ELIGIBLE for the NRHP or for designation as a SAL. No further work or avoidance strategy is recommended for site 41BP962 within the project area. 


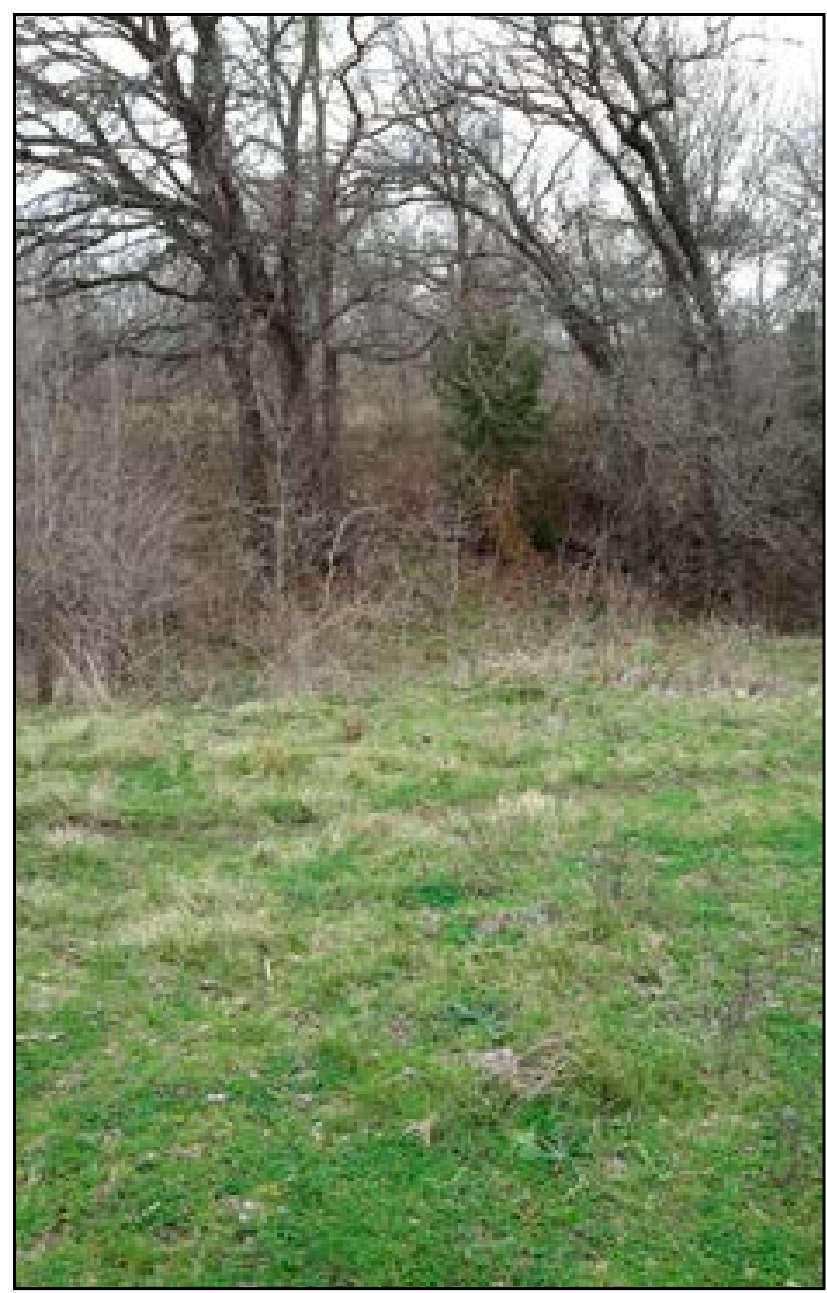

\section{Hill Cemetery}

The Hill Cemetery is a multiple family, historic-age cemetery, located within site 41BP818 approximately $70 \mathrm{~m}$ southeast of FM 696 in northwestern Bastrop County (see Figure 3.29; Appendix A:113). The cemetery measures approximately $20 \times 20 \mathrm{~m}$ and overlooks an unnamed tributary of the Colorado River approximately $230 \mathrm{~m}$ to the southwest. A post and barbed wire fence forms the boundaries of the cemetery. A plowed agricultural field is north and east of the cemetery boundary, and an active quarry is to the southeast. Vegetation consists of overgrown grasses, small shrubs, and mixed hardwood trees.

Field investigations identified 9 to 12 grave markers in various stages of deterioration and collapse (Figure 3.47). The markers range from 1885 to 1895 and represent individuals from the Hill, Bragg, Griffin, Storey, and Hubbard Families; a monument is erected within the cemetery commemorating the five families represented (Figure 3.48). Avoidance of the cemetery with a 75-foot buffer was recommended; subsequently, the project alignment was rerouted to the east and the cemetery will not be impacted by the current project.

Figure 3.46. Overview of site 41BP962, roadbed in background, facing west.

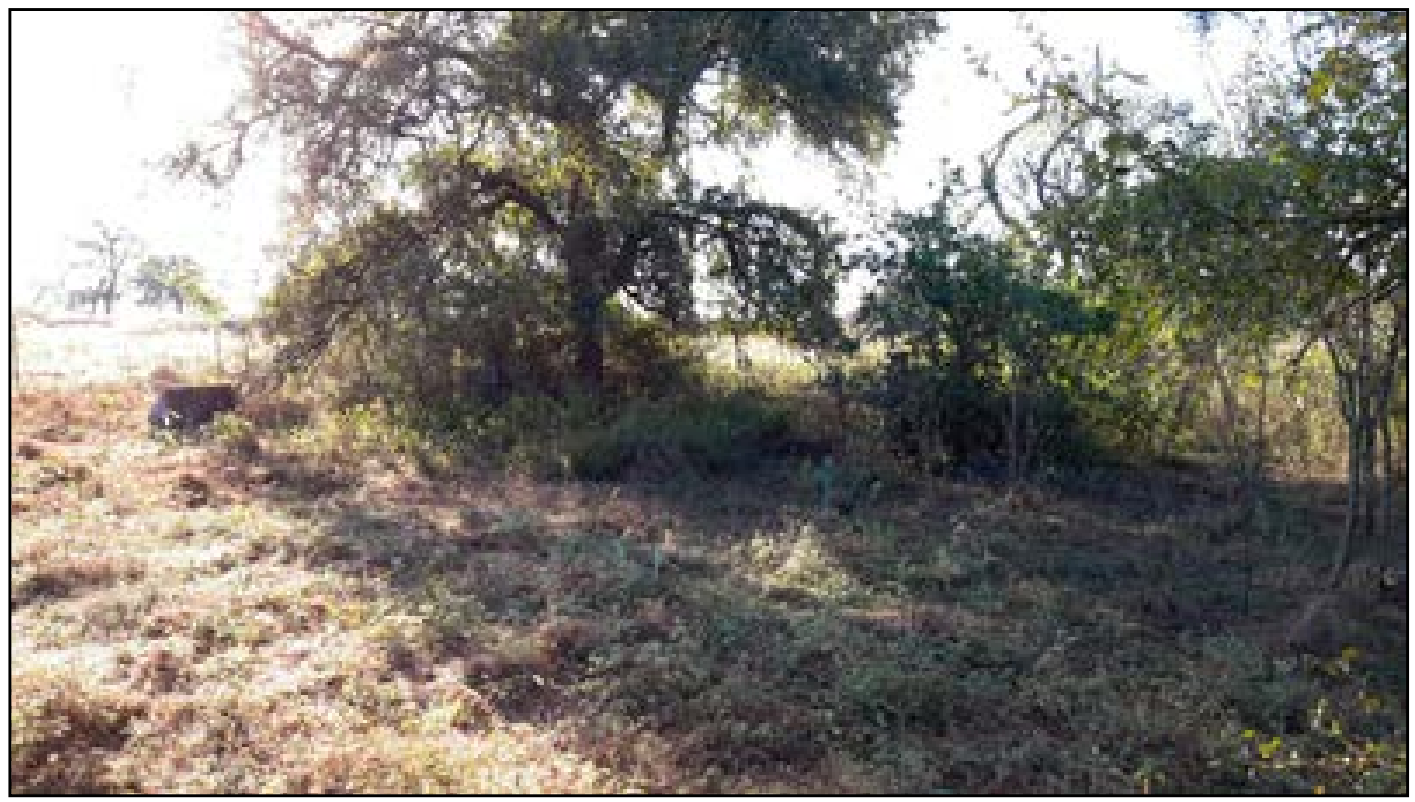

Figure 3.47. Overview of headstones at Hill Cemetery, facing north. 


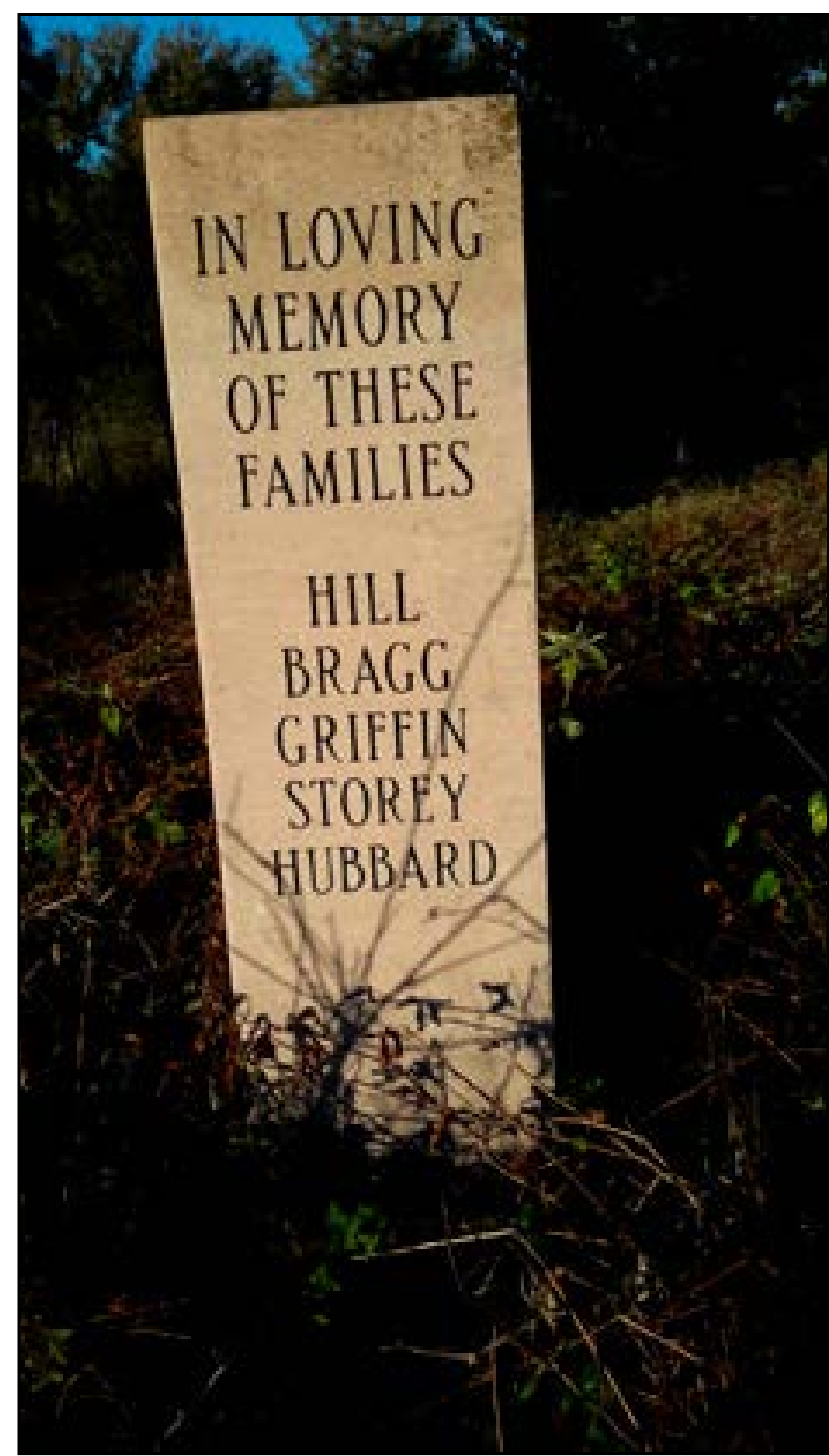

Figure 3.48. Monument within the Hill Cemetery commemorating the Hill, Bragg, Griffin, Storey, and Hubbard Families.

\section{Caldwell County}

One cultural resource site was newly recorded in Caldwell County (Figure 3.49; see Table 3.3). The archaeological site (i.e., 41CW173) consists of a historical house and shed with a sparse artifact scatter. SWCA recommends site $41 \mathrm{CW} 173$ as NOT ELIGIBLE for listing in the NRHP or for SAL designation. No avoidance strategy or further work is recommended for the site.

\section{$41 C W 173$}

Site $41 \mathrm{CW} 173$ is an early to mid-twentieth century house and associated shed outbuilding located along
NW River Road along the western margin of Caldwell County, Texas (Figure 3.50; Appendix A:198). The site is situated on a prominent rocky ridge on a flat terrace which slopes steeply to the southwest towards the immediately adjacent San Marcos River. Vegetation consists primarily of short grasses with a few hickory and oak trees, and ground surface visibility was fairly high within areas of erosion. Site 41CW173 is located on privately owned land. The general area consists of cultivated fields or open pastures and has been disturbed through agricultural plowing and erosion caused by flooding events. The historic-age main house and shed, as well as other modern structures within the parcel, are used as a motorcycle repair shop, and the area is littered with motorcycle parts, tires, and household debris.

Site $41 \mathrm{CW} 173$ consists of a historic-age house (Feature F01), a shed outbuilding (Feature F02), and associated historic artifact scatter measuring approximately 265 feet northeast/southwest by 130 feet northwest/ southeast. Both structures are depicted on the 1964 San Marcos USGS 7.5-minute topographic quadrangle map within the site area (USGS 2018). Additionally, two structures are depicted near the site area on the 1919 San Marcos USGS topographic quadrangle map; however, due to the large scale of the map, it is unclear if these are the same two structures (Foster et al. 2006).

The main house (F01) has very few windows, a peaked roof, is covered with corrugated metal, and is constructed with a pier and beam foundation (Figure 3.51). A small dilapidated front porch is in the front of the house facing southeast (Figure 3.52). Behind the main house is a small wooden shed outbuilding (F02), which is also of pier and beam construction (Figure 3.53). The shed has a corrugated metal roof and is made of wood panels. A modern wooden porch has been constructed in front of the shed. The house and outbuildings are both in poor condition. Just west of the wooden shed is a smaller storage shed constructed of a mixture of wood paneling and sheet metal and a large metal storage container is located just southwest of the storage shed; the storage shed and container are not historic-age.

In addition, a very sparse historic artifact scatter of whiteware sherds and fragmented aqua and green glass was observed on the surface mixed with modern debris (Figure 3.54). Six shovel tests (MRC100-105) were excavated in the vicinity of the structures, none of which contained cultural materials (Table 3.19). Shovel tests 


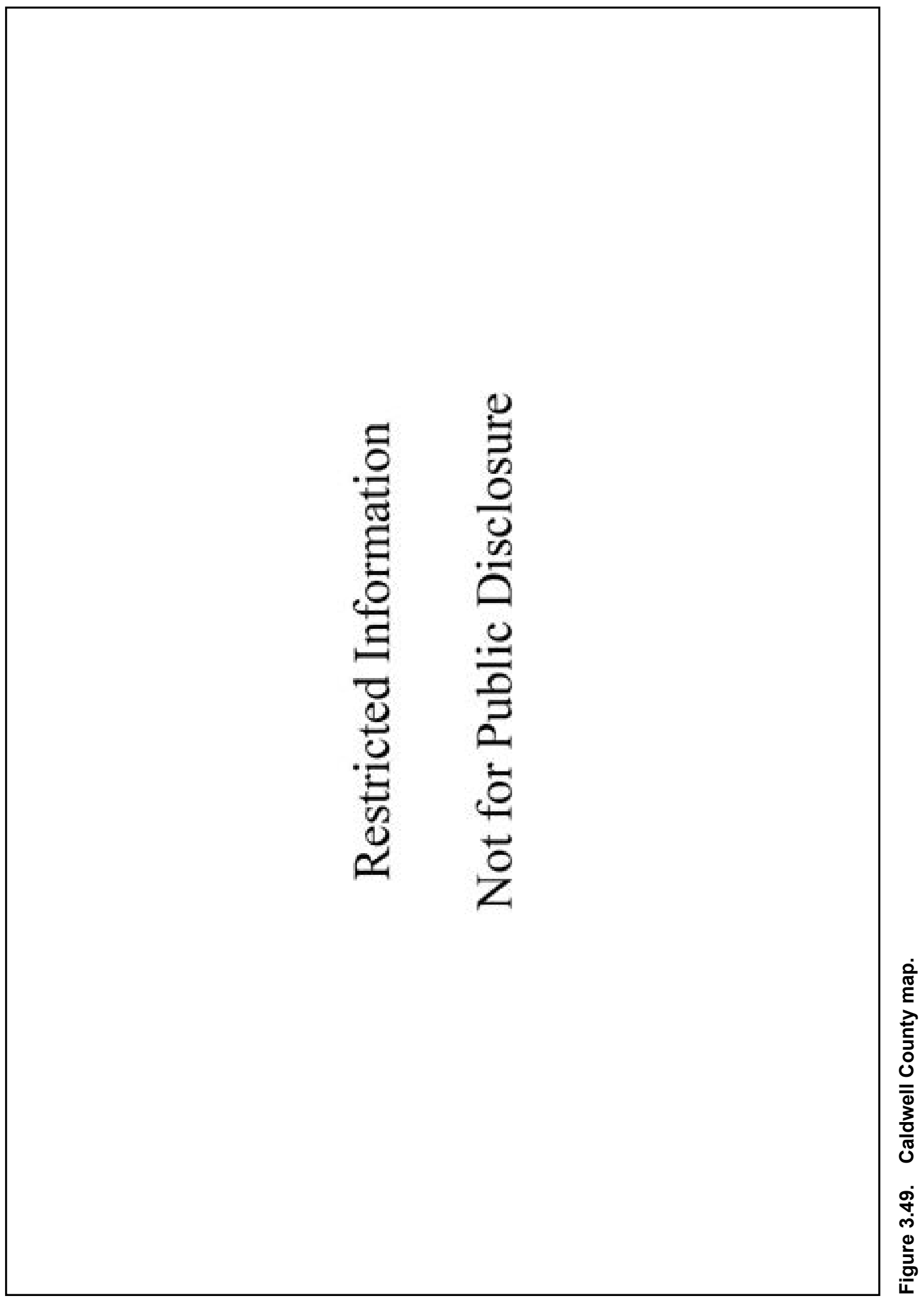




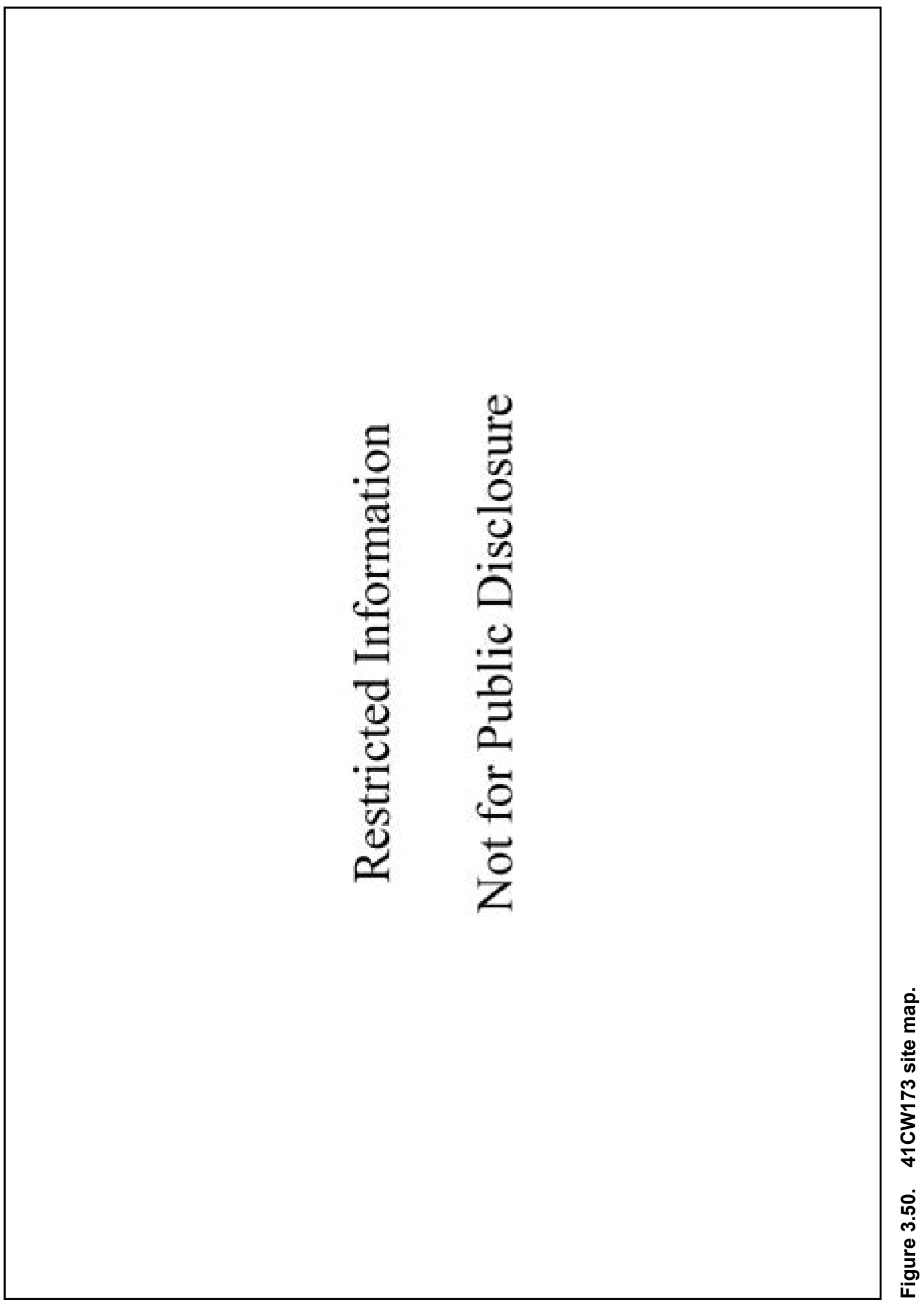




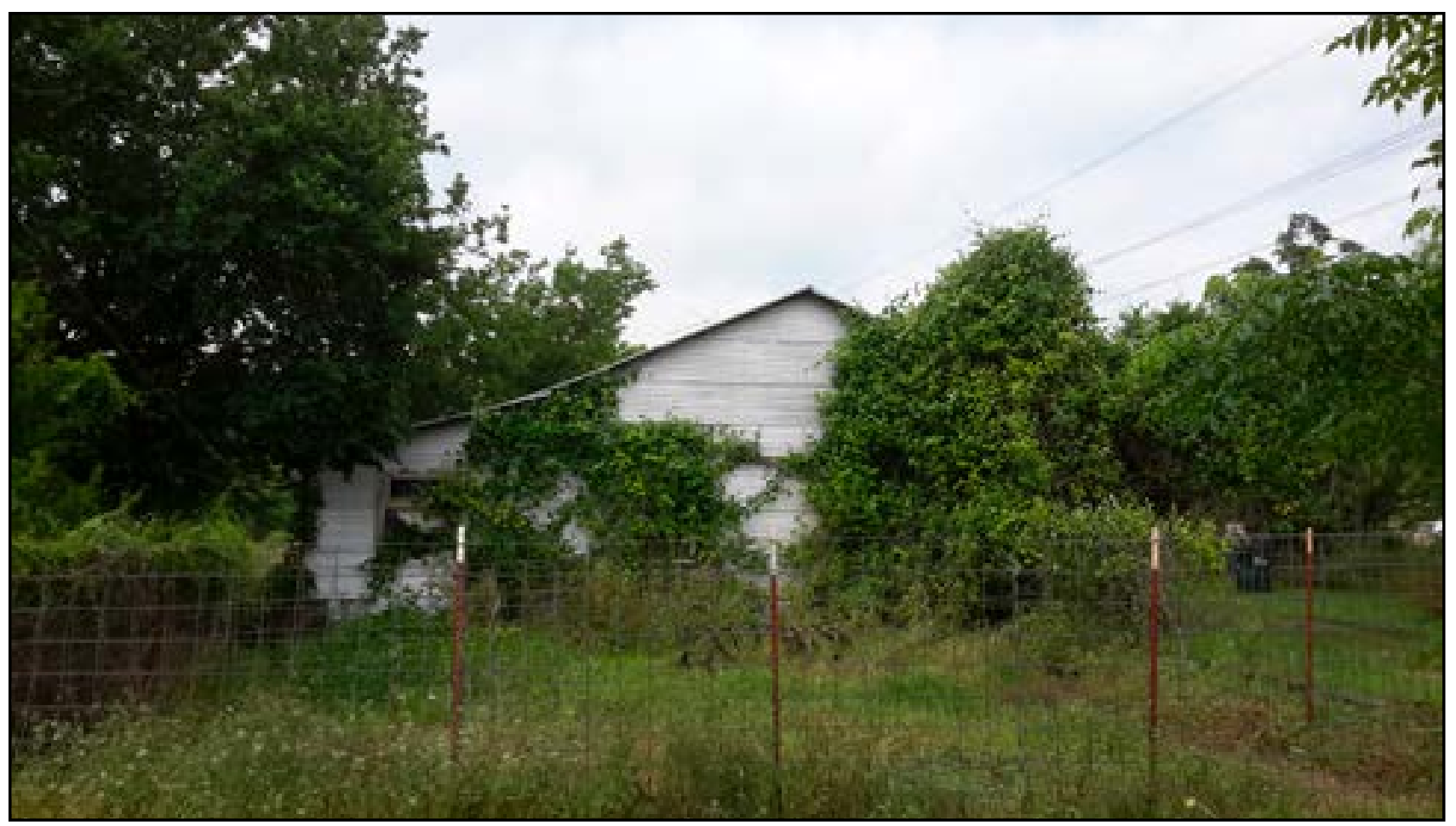

Figure 3.51. Overview of back of main house at 41CW173, facing south.

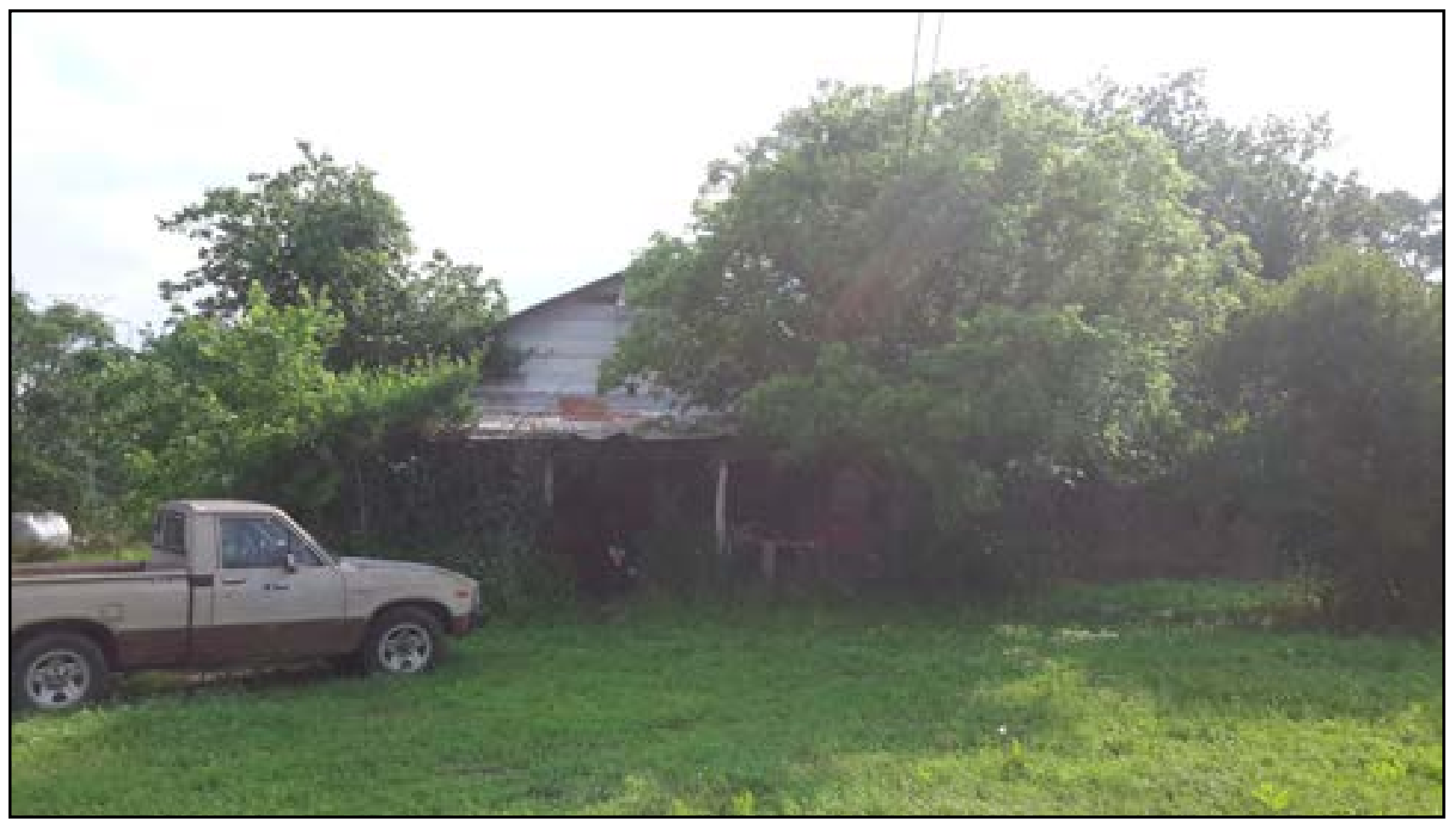

Figure 3.52. Overview of front of main house at site 41CW173, facing north. 


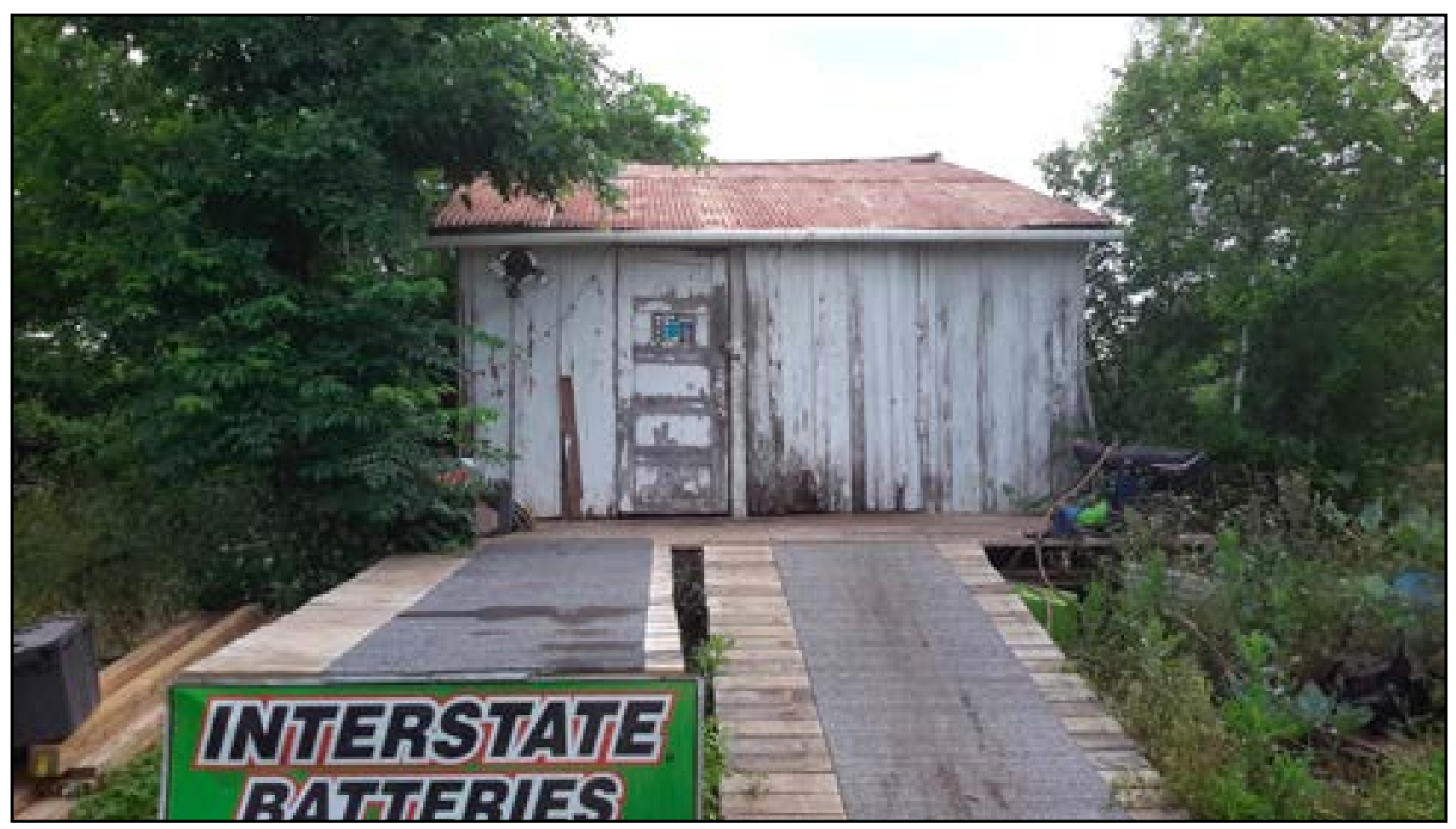

Figure 3.53. Overview of shed outbuilding at 41CW173, facing north.

typically revealed very dark grayish brown (10YR 3/2) silt loam with dense introduced gravels; all terminated at compacted, disturbed gravel lenses at $10 \mathrm{cmbs}$.

\section{CW173 SUMMARY}

41CW173 consists of an early- to mid-twentiethcentury main house and shed outbuilding that has been heavily altered for use as a motorcycle repair shop. Despite the modern alterations, the structures are in disrepair. The site lacks buried cultural material and although some possible historic-age whiteware sherds and glass were observed on the ground surface, these were sparse and scattered. Due to the lack of integrity and poor condition, coupled with a very sparse surficial artifact scatter, site $41 \mathrm{CW} 173$ has generally low research value and is recommended as NOT ELIGIBLE for the NRHP or for designation as a SAL. Due to a shift of the project corridor since the original recording of the site, the resource is no longer within the project area boundaries and will not be impacted by the project.

Table 3.19. Shovel Test Data for Site 41CW173

\begin{tabular}{|c|c|c|c|c|c|c|c|c|}
\hline $\begin{array}{l}\text { Shovel } \\
\text { Test No. Level }\end{array}$ & $\begin{array}{l}\text { Depth } \\
\text { (cmbs) }\end{array}$ & $\begin{array}{l}\text { Munsell } \\
\text { Soil Value }\end{array}$ & $\begin{array}{l}\text { Munsell Soil } \\
\text { Color }\end{array}$ & $\begin{array}{l}\text { Soil } \\
\text { Texture }\end{array}$ & $\begin{array}{l}\text { Inclusion } \\
\text { Percentage }\end{array}$ & $\begin{array}{l}\text { Inclusion } \\
\text { Type }\end{array}$ & $\begin{array}{l}\text { Cultural } \\
\text { Materials }\end{array}$ & $\begin{array}{l}\text { Comments/ } \\
\text { Reason for Termination }\end{array}$ \\
\hline MRC100 1 & $0-10$ & 10YR 3/2 & $\begin{array}{l}\text { very dark } \\
\text { grayish brown }\end{array}$ & silt loam & $>20 \%$ & Gravels & None & $\begin{array}{l}\text { Terminated at disturbance- } \\
\text { dense introduced gravels. }\end{array}$ \\
\hline MRC101 1 & $0-10$ & 10YR 3/2 & $\begin{array}{l}\text { very dark } \\
\text { grayish brown }\end{array}$ & silt loam & $>20 \%$ & Gravels & None & $\begin{array}{l}\text { Terminated at disturbance- } \\
\text { dense introduced gravels. }\end{array}$ \\
\hline MRC102 1 & $0-10$ & 10YR 3/2 & $\begin{array}{l}\text { very dark } \\
\text { grayish brown }\end{array}$ & silt loam & $>20 \%$ & Gravels & None & $\begin{array}{l}\text { Terminated at disturbance- } \\
\text { dense introduced gravels. }\end{array}$ \\
\hline MRC103 1 & $0-10$ & 10YR 3/2 & $\begin{array}{l}\text { very dark } \\
\text { grayish brown }\end{array}$ & silt loam & $>20 \%$ & Gravels & None & $\begin{array}{l}\text { Terminated at disturbance- } \\
\text { dense introduced gravels. }\end{array}$ \\
\hline MRC104 1 & $0-10$ & 10YR 3/2 & $\begin{array}{l}\text { very dark } \\
\text { grayish brown }\end{array}$ & silt loam & $>20 \%$ & Gravels & None & $\begin{array}{l}\text { Terminated at disturbance- } \\
\text { dense introduced gravels. }\end{array}$ \\
\hline MRC105 1 & $0-10$ & 10YR 3/2 & $\begin{array}{l}\text { very dark } \\
\text { grayish brown }\end{array}$ & silt loam & $>20 \%$ & Gravels & None & $\begin{array}{l}\text { Terminated at disturbance- } \\
\text { dense introduced gravels. }\end{array}$ \\
\hline
\end{tabular}




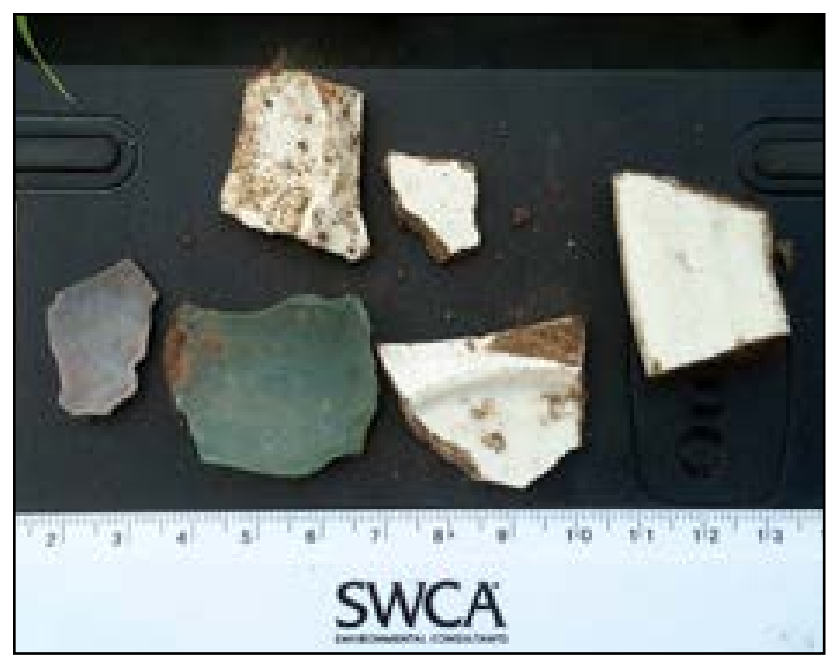

Figure 3.54. Artifacts from ground surface of site $41 \mathrm{CW} 173$.

\section{GUADALUPE COUNTY}

One cultural resource site and one isolated find were newly recorded and two previously recorded cultural resource sites were revisited and/or further investigated in Guadalupe County (Figure 3.55; see Table 3.3) The newly recorded archaeological site (i.e., 41GU200) consists of a prehistoric lithic scatter. The isolated find (i.e, IF12) consists of a single prehistoric lithic primary reduction flake that was not recorded as an archaeological site (Appendix A:214; see Table 3.4). Testing and data recovery investigations were conducted at the previously recorded prehistoric campsite (i.e., 41GU177), while archival research was conducted for the historic farm complex (i.e., 41GU180), based on recommendations from the 2015 initial cultural resources investigations.

One of the previously recorded archaeological sites (i.e., 41GU177) is recommended as ELIGIBLE for listing on the NRHP and for SAL designation. SWCA recommends avoidance or further investigations for the portions of the site which were not further investigated and mitigated. SWCA recommends the remaining two archaeological sites (i.e., 41GU180 and 41GU200) in Guadalupe County as NOT ELIGIBLE for listing on the NRHP or for SAL designation. No avoidance strategy or further work is recommended for these remaining two sites within the project corridor.

\section{GU177}

Site 41 GU177 is a multicomponent campsite containing components deposited intermittently from the approximate Late Archaic to Transitional Archaic periods through Late Prehistoric times located in northwestern Guadalupe County. The site is on the western high bank of the Guadalupe River, with a 30- to 40-foot vertical drop to the river bottom to the east and gently sloping (2-5 percent slope) terrain to the west (Figure 3.56; Appendix A:250). The site was originally recorded during the 2015 initial cultural resources investigations.

Ultimately, the 2015 investigations revealed intact prehistoric subsurface cultural materials and a buried cultural feature in the northeastern/eastern portion of the site. Given the apparent integrity of the cultural deposit and the depth of observed artifacts, SWCA recommended that a phase of test excavations was warranted to better explore the cultural deposits through hand excavations and to determine if the cultural deposits retained sufficient integrity to warrant SAL designation. SWCA revisited the site in 2016 to conduct further testing under Permit No. 7295 which consisted of backhoe trenching and $1 \times 1-\mathrm{m}$ hand excavations units (Appendix D; Rodriguez et al. 2017). Following completion of the limited testing excavations, and consultation with the THC, it was determined that there was sufficient evidence to recommend that portions of the site warranted SAL designation and either avoidance or data recovery excavations.

In 2017, SWCA conducted close interval shovel testing and additional backhoe trenching at the site to better determine the nature, depth, and extent of its cultural deposits (i.e., was there more than one temporal component represented) and to ultimately refine the proposed data recovery areas. Based on the results of the phased investigations at the site, SWCA refined the location and extent of potential data recovery efforts, focusing on the more significant and intact parts of the site identified during the various investigations that would be impacted by construction-related activities. Data recovery excavations conducted under Permit No. 8231 at 41 GU1277 began the last week of November 2017 and extended through December 28, 2017. The analysis and reporting for the data recovery investigations are ongoing and will be presented in a separate report (Nielsen et al. 2019).

\section{GU180}

Site $41 \mathrm{GU} 180$ is a historic farmstead situated on a generally level upland terrace of Long Creek approximately $400 \mathrm{~m}$ northwest overlooking an unnamed drainage to the east in northwest Guadalupe County, Texas (Figure 3.57; Appendix A:255). Vegetation on site consists of heavily overgrown mesquite and mixed 


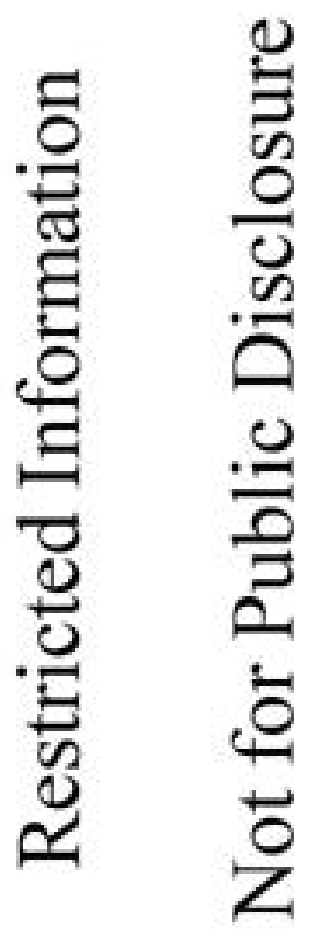

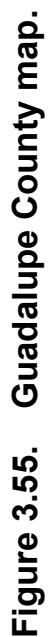




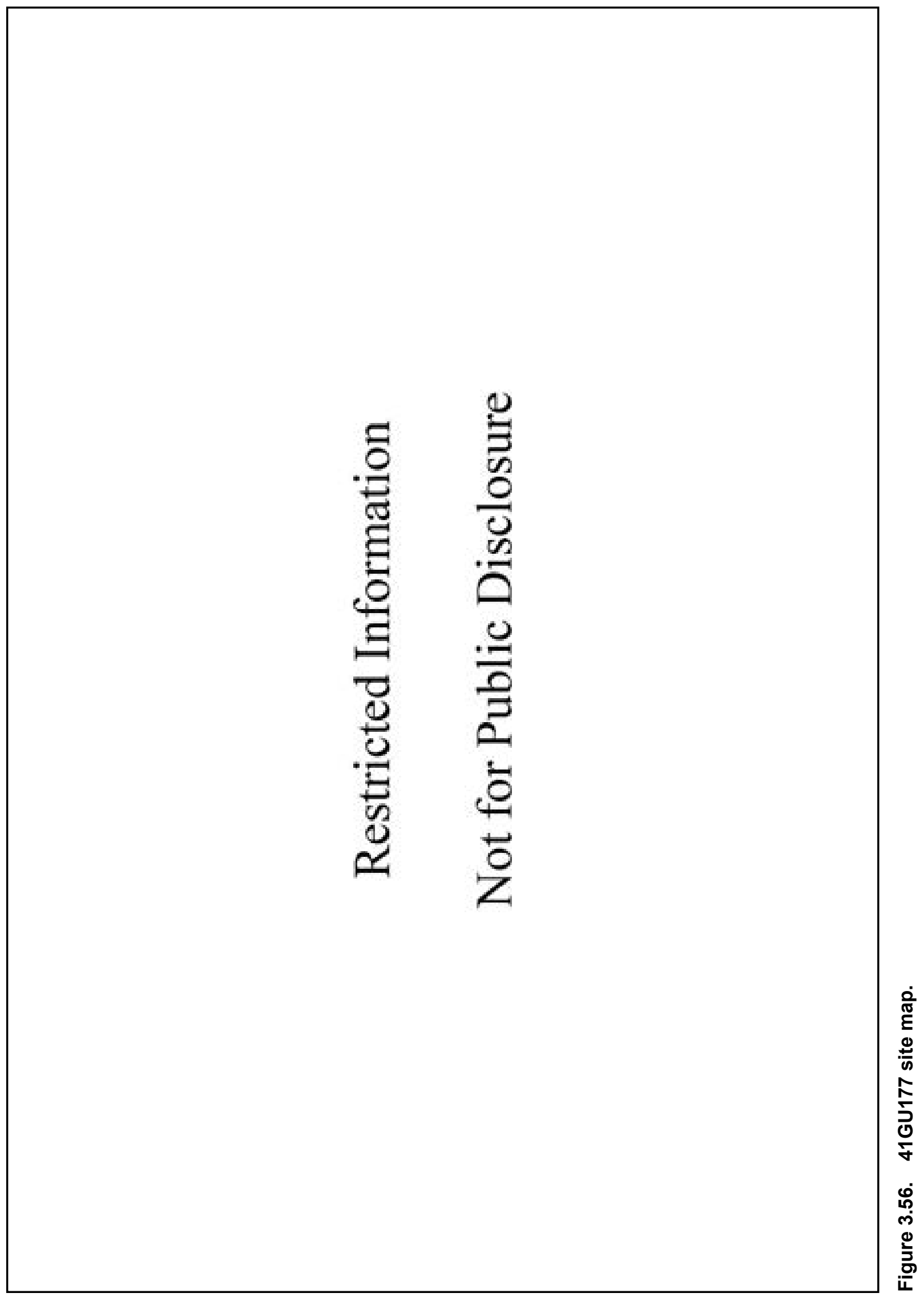




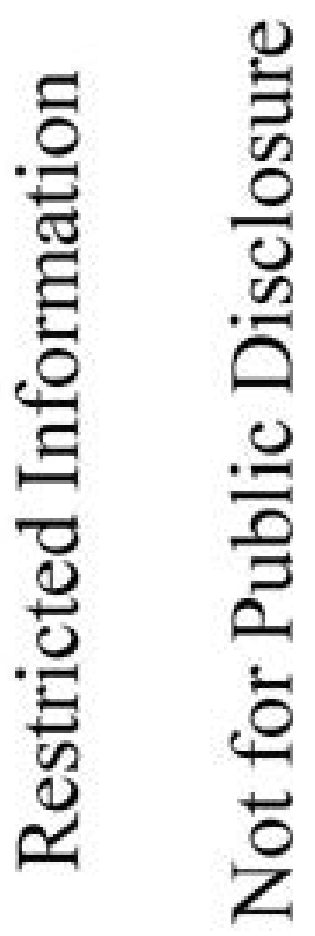

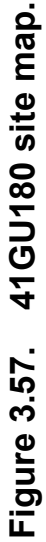


thorny bramble, vines, grasses, and cacti, which afforded 0 to 10 percent ground surface visibility. The site is on private property and has been impacted by erosion, vegetation clearing, plowing, and cattle ranching.

Site 41 GU180 was originally recorded by SWCA in 2015 as a historic farmstead that measures 5 m northwest/southeast by $30 \mathrm{~m}$ northeast/southwest within the project corridor. Visual inspection revealed a historic farmstead containing seven structures and an associated scatter of historic artifacts consisting of yellow and white/gray brick, corrugated metal fragments, miscellaneous wood fragments, and spools of barbed wire. The seven cultural features found at 41GU180 include a stone-lined well (HR01), the main house (HR02), a metal cistern (HR03), a dilapidated barn (HR04), a board and batten siding shed (HR05), five vertical concrete footings (HR06), and a second dilapidated board and batten barn (HR07). All shovel tests excavated within the site area were negative for cultural materials and encountered pre-Holocene clay at or near the surface.

SWCA's 2015 initial investigations recommended site 41GU180 as NOT ELIGIBLE for the listing in the NRHP under Criterion D or for designation a

$\mathrm{s}$ a SAL, since the remains of the structures and the associated surficial scatter of construction materials does not have the potential to yield significant, new information on turn-of-the-century homesteads in the area. However, further archival and deed research was recommended to determine if the site is ELIGIBLE for NRHP listing under Criterion A or B as it is currently unknown if site $41 \mathrm{GU} 180$ is associated with important events or persons. As such, avoidance of the site, pending further archival research, was recommended.

SWCA's architectural historian Victoria Myers, M.A., conducted archival and deed research for site $41 \mathrm{GU} 180$. Research of the county deed records did not locate the original acquisition for the property in which site 41GU180 is located. Archival research indicated that the property was associated with the Altwein and Jensch families in the late nineteenth century and with the Hoffman/Zipp family throughout the twentieth century. In 1959, the parcel was sold to the current owner and her husband. Additional archival research was conducted by Nesta Anderson from Pape Dawson.

Deed research was able to determine that in 1898 , the Altweins conveyed the 65 -acre subject tract to their son Fritz (Guadalupe County Deed Records [GCDR]
1898:14:16). The 1900 Guadalupe County census notes Fritz as a 27-year-old farmer living in Precinct 2 of Guadalupe County with his wife Frieda (25) and children Erna (2) and Edward (7 months). The census notes Fritz owned the property he was living on, suggesting he would have been living on the subject parcel.

The Altweins only retained the property for 6 years, conveying it to Otto Jensch in 1904 (GCDR 1904:24:511). Otto in return only kept the property for 2 years, conveying it to Albert Altwein in 1906 (GCDR 1906:28:248). The Jensch family, which in the 1910 Guadalupe County Census consisted of Otto (30), his wife Ida (29), and their daughter Elsie (5), may have lived on the property, but given their short period of ownership, likely lived elsewhere.

Albert Altwein owned the property for 3 years, conveying it to Meta Hoffman with a vendor's lien in 1909 (GCDR 1909:33:137). Albert appears in the 1900 census as a 21-year-old farm laborer living in his father William's household. William (60) was a farmer who lived with his daughters Emma (23) and Meda (18) and sons Henry (22), Albert, and Arthur (14). It is uncertain if William and his family lived on the property, but if so it was only for a brief time.

Meta Hoffman appears in the 1910 Guadalupe County census as a 32-year-old farmer who had mortgaged her property. Her household included her sons Herbert (9) and Adolph (1) as well as her daughters Hertha (7), Irma (5), and Thelma (3). The family lived in Justice Precinct \#2. In 1914, Meta married Robert Zipp (Guadalupe County Marriage Records [GCMR] 1914:7:274). The 1920 Guadalupe County census shows Robert (45) and Meta (41) living on Schumansville-New Braunfels Road in Justice Precinct 2. Their household includes Robert's daughters from his first marriage, Ruby (17) and Cora (13), and Meta's children from her first marriage, Hertha (17), Thelma (13), and Otto (10). Robert and Meta's children Mary (4) and Margarite (8 months) were also living in the household. The couple owned the property they lived on free of mortgage. The 1930 Guadalupe County census shows them continuing to live on Schumansville Road, suggesting they likely lived on the subject parcel.

Meta Zipp died in 1956, at which time her probated will notes that her land assets consist of a 65 -acre tract of land on which she resided at the time of her death (Guadalupe County Probate Minutes [GCPM] 1956:10:553-562). Meta's children inherited the 
property and kept it in the family until 1959, when they conveyed it to the Veteran's Land Board (GCDR 1959:326:225). The Veterans Land Board conveyed it to Howard A. Altenhof within a month (GCDR 1959:326:226), and the Altenhof family continues to own the land today.

Although the site likely dates to the late nineteenth century, it is unclear whether the Altwein family lived on the property or whether they could have had tenants that may have occupied the property. The Altwein family is significant to the local area and Official Texas Historical Marker No. 12797 for the Altwein Family indicates that the cemetery associated with the family still exists in the area. The cemetery, which is definitively tied to the family and has information potential under Criterion D, is a better association with the Altweins than the potential association between the family and site 41GU180; however, the cemetery is not located within the current project area. For this reason, site $41 \mathrm{GU} 180$ is recommended NOT ELIGIBLE for NRHP listing under Criteria A and B.

As Meta (Hoffman) Zipp lived on the 65-acre property, it is likely that $41 \mathrm{GU} 180$ is associated with her occupation. According to the Handbook of Texas, the Zipp family was associated with Zipp or Zippville, Texas, a village established in the early 1900s near Seguin. It is unlikely the subject tract was part of this community, as Zipp is approximately 2 miles west of Seguin (Jasinski 2010) and site 41GU180 is about 17 miles northwest of Seguin. As a result, although the Zipp family may have been important at the local level in Guadalupe County, the Zipp community is a better representation of the family's association with the area. As a result, site $41 \mathrm{GU} 180$ is recommended not eligible for NRHP listing under Criteria A or B.

\section{GU180 SUMMARY}

$41 \mathrm{GU} 180$ is a historic farmstead with seven features: a well (HR01), house (HR02), cistern (HR03), barn (HR04), shed (HR05), five vertical concrete footings (HR06), and a second barn (HR07). Based on SWCA's 2015 initial investigations, site $41 \mathrm{GU} 180$ was recommended as NOT ELIGIBLE for the listing in the NRHP under Criterion D or for designation as a SAL. Although of historic age, the condition of the house and associated structures have diminished much of the historic integrity required for NRHP eligibility and it is therefore recommended NOT ELIGIBLE for listing in the NRHP. In addition, archival research during the
2016 to 2018 investigations did not indicate any link to historically significant persons or events that would trigger considerations under NRHP Criterion A or B. SWCA recommends that the portion of site $41 \mathrm{GU} 180$ within the project corridor cannot provide information important to the regional history and no further work or avoidance is recommended. Due to project design changes, the site is no longer within the project area and will not be affected by the current project.

\section{GU200}

Site $41 \mathrm{GU} 200$ consists of a shallow to moderately buried subsurface prehistoric lithic scatter of unknown temporal or cultural affiliation situated along Waterway Pass approximately 0.3 mile west of its intersection with Canal Lane, which begins at State Highway (SH) 46 approximately 1.0 mile northeast (Figure 3.58; Appendix A:249). The site is situated along a semi-forested terrace with residential development approximately 0.14 mile east and 0.09 mile north of the Guadalupe River (Figure 3.59). Vegetation consists of patches of hardwood forest interspersed among residential properties and two-track roads leading to them. Ground surface visibility is poor within the semi-forested area within the center of the site and 100 percent along Waterway Pass and the other two-track roads leading to residences and bounding the site. Site 41 GU200 is located on privately owned land used for residential as well as agricultural activities. Disturbances include erosion, vegetation clearing, fence lines, two-track roads, and residential development.

Site 41 GU200 measures approximately 174 m northwest/southeast by $30 \mathrm{~m}$ north/south within the project corridor based on subsurface artifact distribution; however, the site may extend beyond the project area. No cultural materials were observed along the ground surface. Twelve auger probes (i.e., ATJFA03, ATJFA05, ATJIS03-04, ATJIS06, ATMCC02, ATMFV02-04, and ATVM02-04) were excavated at approximately 15- to 30-m intervals to delineate the site, of which four (i.e., ATJIS03, ATJIS06, ATMFV04, and ATVM02) were positive for cultural materials mostly between 30 and $60 \mathrm{cmbs}$, with the exception of one probe (i.e., ATJIS06) with contained one flake between 180 and $190 \mathrm{cmbs}$ (Table 3.20). SWCA also excavated 16 shovel tests (i.e., CXS05-08, JIS11-13, MCC554-556, MFV12-14, and VM12-14) interspersed amongst the auger probes to further investigate the site, with one (i.e., JIS12) positive for cultural materials (Table 


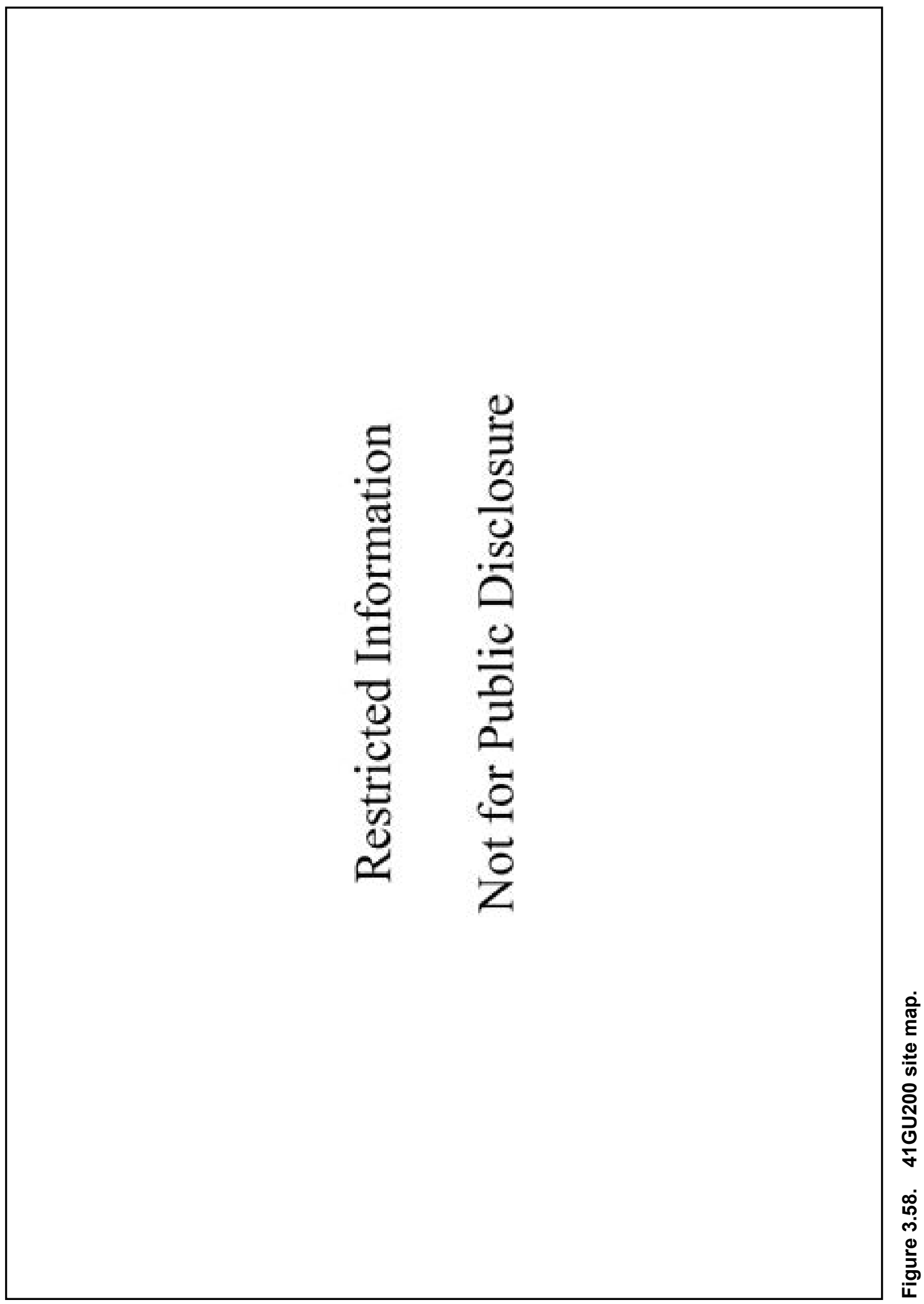




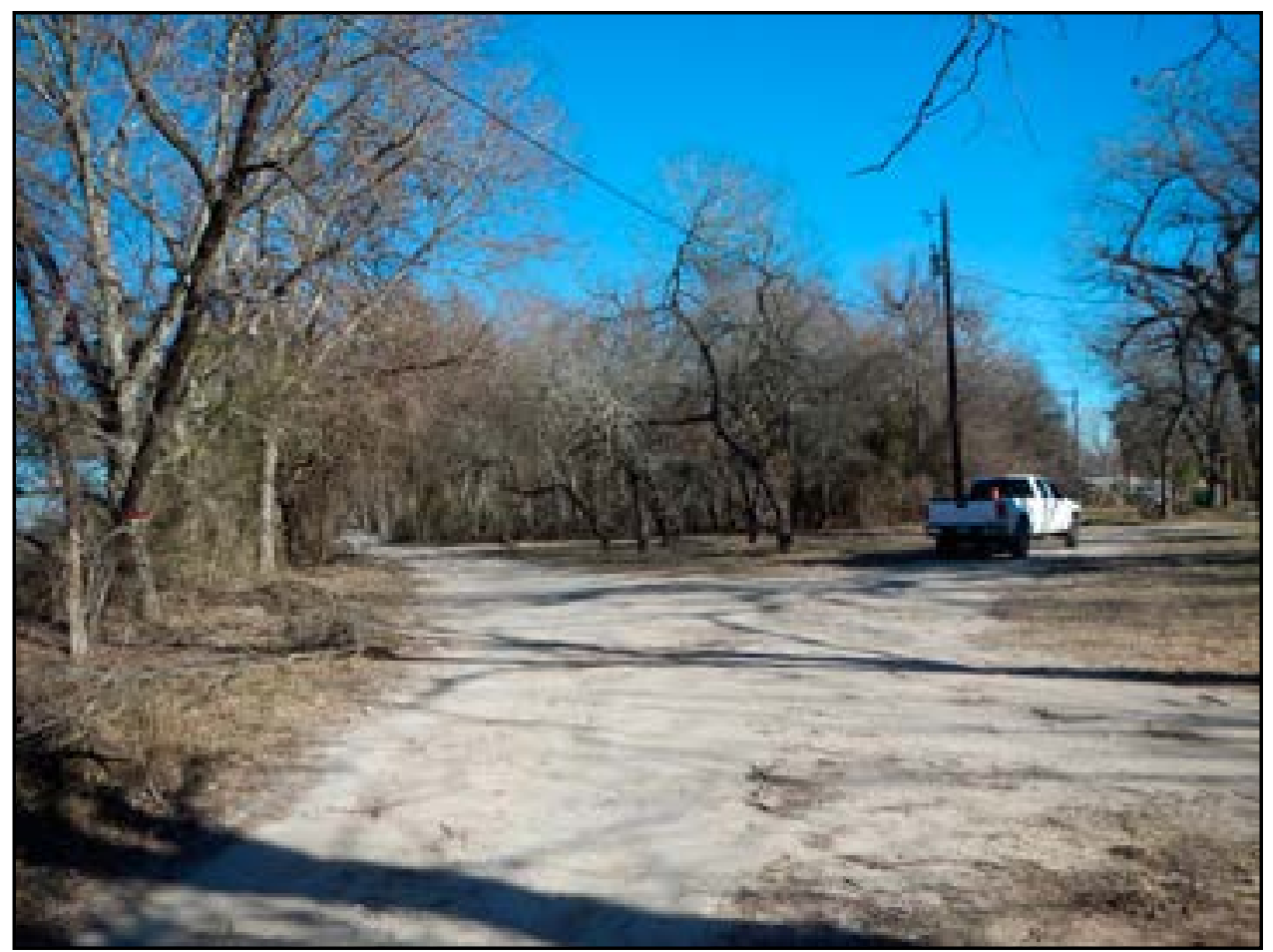

Figure 3.59. Overview of site 41GU200, facing east-southeast.

Table 3.20. Auger Probe Data for Site 41GU200

\begin{tabular}{|c|c|c|c|c|c|c|c|c|c|}
\hline $\begin{array}{l}\text { Auger } \\
\text { Probe No. }\end{array}$ & Level & $\begin{array}{l}\text { Depth } \\
\text { (cmbs) }\end{array}$ & $\begin{array}{l}\text { Munsell } \\
\text { Soil Value }\end{array}$ & $\begin{array}{l}\text { Munsell Soil } \\
\text { Color }\end{array}$ & $\begin{array}{l}\text { Soil } \\
\text { Texture }\end{array}$ & $\begin{array}{l}\text { Inclusion } \\
\text { Percentage }\end{array}$ & $\begin{array}{l}\text { Inclusion } \\
\text { Type }\end{array}$ & $\begin{array}{l}\text { Cultural } \\
\text { Materials }\end{array}$ & $\begin{array}{l}\text { Comments/ } \\
\text { Reason for } \\
\text { Termination }\end{array}$ \\
\hline \multirow{3}{*}{ ATJFA03 } & 1 & $0-110$ & 10YR 3/2 & $\begin{array}{l}\text { very dark grayish } \\
\text { brown }\end{array}$ & $\begin{array}{l}\text { Silty Clay } \\
\text { Loam }\end{array}$ & $1-5 \%$ & Snail Shell & None & - \\
\hline & 2 & $110-150$ & 10YR 4/2 & $\begin{array}{l}\text { dark grayish } \\
\text { brown }\end{array}$ & $\begin{array}{l}\text { Silty Clay } \\
\text { Loam }\end{array}$ & $1-5 \%$ & Snail Shell & None & - \\
\hline & 3 & $150-200$ & 10YR 6/4 & $\begin{array}{l}\text { light yellowish } \\
\text { brown }\end{array}$ & $\begin{array}{l}\text { Sandy Clay } \\
\text { Loam }\end{array}$ & $1-5 \%$ & Snail Shell & None & Terminated at depth. \\
\hline \multirow{3}{*}{ ATJFA05 } & 1 & $0-110$ & 10YR 3/2 & $\begin{array}{l}\text { very dark grayish } \\
\text { brown }\end{array}$ & $\begin{array}{l}\text { Silty Clay } \\
\text { Loam }\end{array}$ & $1-5 \%$ & Snail Shell & None & - \\
\hline & 2 & $110-150$ & 10YR 4/2 & $\begin{array}{l}\text { dark grayish } \\
\text { brown }\end{array}$ & $\begin{array}{l}\text { Silty Clay } \\
\text { Loam }\end{array}$ & $1-5 \%$ & Snail Shell & None & - \\
\hline & 3 & $150-200$ & 10YR 6/4 & $\begin{array}{l}\text { light yellowish } \\
\text { brown }\end{array}$ & $\begin{array}{l}\text { Sandy Clay } \\
\text { Loam }\end{array}$ & $1-5 \%$ & Snail Shell & None & Terminated at depth. \\
\hline \multirow[b]{3}{*}{ ATJIS03 } & 1 & $0-55$ & 10YR 2/2 & very dark brown & Silt Loam & - & - & None & - \\
\hline & 2 & $55-110$ & 10YR 5/3 & brown & $\begin{array}{l}\text { Sandy } \\
\text { Loam }\end{array}$ & - & - & None & - \\
\hline & 3 & $110-210$ & 10YR $7 / 4$ & pale red & Sand & $1-5 \%$ & $\begin{array}{l}\text { Pebbles, } \\
\text { Snail Shell }\end{array}$ & $\begin{array}{l}\text { 1: Flake } \\
\text { (tertiary) } \\
\text { [approx } \\
180-190 \\
\text { cmbs] }\end{array}$ & Terminated at depth. \\
\hline \multirow{2}{*}{ ATJIS04 } & 1 & $0-45$ & 10YR 4/2 & $\begin{array}{l}\text { dark grayish } \\
\text { brown }\end{array}$ & Silt Loam & - & - & None & - \\
\hline & 2 & $45-210$ & 10YR 6/4 & $\begin{array}{l}\text { light yellowish } \\
\text { brown }\end{array}$ & $\begin{array}{l}\text { Loamy } \\
\text { Sand }\end{array}$ & $1-5 \%$ & $\begin{array}{l}\text { Pebbles, } \\
\text { Snail Shell }\end{array}$ & None & Terminated at depth. \\
\hline
\end{tabular}


Table 3.20. continued

\begin{tabular}{|c|c|c|c|c|c|c|c|c|c|}
\hline $\begin{array}{l}\text { Auger } \\
\text { Probe No. }\end{array}$ & Level & $\begin{array}{l}\text { Depth } \\
\text { (cmbs) }\end{array}$ & $\begin{array}{l}\text { Munsell } \\
\text { Soil Value }\end{array}$ & $\begin{array}{l}\text { Munsell Soil } \\
\text { Color }\end{array}$ & $\begin{array}{l}\text { Soil } \\
\text { Texture }\end{array}$ & $\begin{array}{l}\text { Inclusion } \\
\text { Percentage }\end{array}$ & $\begin{array}{l}\text { Inclusion } \\
\text { Type }\end{array}$ & $\begin{array}{l}\text { Cultural } \\
\text { Materials }\end{array}$ & $\begin{array}{l}\text { Comments/ } \\
\text { Reason for } \\
\text { Termination }\end{array}$ \\
\hline \multirow[b]{3}{*}{ ATJIS06 } & 1 & $0-30$ & 10YR 4/3 & brown & Silt Loam & - & - & None & - \\
\hline & 2 & $30-50$ & 10YR 5/3 & brown & $\begin{array}{l}\text { Sandy } \\
\text { Loam }\end{array}$ & - & - & None & - \\
\hline & 3 & $50-210$ & 10YR 6/4 & $\begin{array}{l}\text { light yellowish } \\
\text { brown }\end{array}$ & Sand & $1-5 \%$ & Pebbles & $\begin{array}{l}\text { 1: Flake } \\
\text { (tertiary) } \\
\text { [approx } 60 \\
\text { cmbs] }\end{array}$ & Terminated at depth. \\
\hline \multirow{2}{*}{ ATMCC02 } & 1 & $0-80$ & 10YR 4/2 & $\begin{array}{l}\text { dark grayish } \\
\text { brown }\end{array}$ & Silt Loam & $1-5 \%$ & Snail Shell & None & - \\
\hline & 2 & $80-200$ & 10YR 6/4 & $\begin{array}{l}\text { light yellowish } \\
\text { brown }\end{array}$ & $\begin{array}{l}\text { Sandy Clay } \\
\text { Loam }\end{array}$ & $1-5 \%$ & Snail Shell & None & Terminated at depth. \\
\hline \multirow[t]{2}{*}{ ATMFV02 } & 1 & $0-100$ & 10YR 4/2 & $\begin{array}{l}\text { dark grayish } \\
\text { brown }\end{array}$ & Silt Loam & $1-5 \%$ & $\begin{array}{l}\text { Calcium } \\
\text { Carbonate, } \\
\text { Snail Shell }\end{array}$ & None & - \\
\hline & 2 & $100-200$ & 10YR 6/4 & $\begin{array}{l}\text { light yellowish } \\
\text { brown }\end{array}$ & Silt Loam & $1-5 \%$ & $\begin{array}{l}\text { Calcium } \\
\text { Carbonate }\end{array}$ & None & Terminated at depth. \\
\hline \multirow{3}{*}{ ATMFV03 } & 1 & $0-80$ & 10YR 2/2 & very dark brown & Silt Loam & $1-5 \%$ & $\begin{array}{l}\text { Snail Shell, } \\
\text { Common } \\
\text { Roots and } \\
\text { Rootlets }\end{array}$ & None & - \\
\hline & 2 & $80-100$ & 10YR 3/3 & dark brown & Silt Loam & $1-5 \%$ & $\begin{array}{l}\text { Snail Shell, } \\
\text { Common } \\
\text { Roots and } \\
\text { Rootlets }\end{array}$ & None & - \\
\hline & 3 & $100-200$ & 10YR 6/6 & brownish yellow & Silt Loam & $1-5 \%$ & $\begin{array}{l}\text { Snail Shell, } \\
\text { Common } \\
\text { Roots and } \\
\text { Rootlets }\end{array}$ & None & Terminated at depth. \\
\hline \multirow[t]{2}{*}{ ATMFV04 } & 1 & $0-60$ & $2.5 Y R \quad 4 / 3$ & reddish brown & Silt Loam & $5-10 \%$ & $\begin{array}{l}\text { Snail Shell, } \\
\text { Common } \\
\text { Roots and } \\
\text { Worms }\end{array}$ & $\begin{array}{l}\text { 1: Flake } \\
\text { (tertiary) } \\
\text { [approx } 30 \\
\text { cmbs] }\end{array}$ & - \\
\hline & 2 & $60-200$ & $2.5 Y R$ 7/6 & light red & Silt Loam & $1-5 \%$ & $\begin{array}{l}\text { Snail Shell, } \\
\text { Roots }\end{array}$ & None & Terminated at depth. \\
\hline \multirow[t]{2}{*}{ ATVM02 } & 1 & $0-60$ & 10YR 4/3 & brown & $\begin{array}{l}\text { Silty Clay } \\
\text { Loam }\end{array}$ & $1-5 \%$ & Snail Shell & $\begin{array}{l}\text { 2: Flake } \\
\text { (tertiary) } \\
\text { [approx } 30- \\
40 \text { cmbs] }\end{array}$ & - \\
\hline & 2 & $60-210$ & 10YR 7/4 & very pale brown & $\begin{array}{l}\text { Sandy Clay } \\
\text { Loam }\end{array}$ & $1-5 \%$ & Snail Shell & None & Terminated at depth. \\
\hline \multirow{3}{*}{ ATVM03 } & 1 & $0-60$ & 10YR 4/3 & brown & $\begin{array}{l}\text { Sandy } \\
\text { Loam }\end{array}$ & $1-5 \%$ & Snail Shell & None & - \\
\hline & 2 & $60-180$ & 10YR 6/4 & $\begin{array}{l}\text { light yellowish } \\
\text { brown }\end{array}$ & Silt & $1-5 \%$ & Snail Shell & None & - \\
\hline & 3 & $180-210$ & 10YR 6/4 & $\begin{array}{l}\text { light yellowish } \\
\text { brown }\end{array}$ & $\begin{array}{l}\text { Silty Clay } \\
\text { Loam }\end{array}$ & $1-5 \%$ & Snail Shell & None & Terminated at depth. \\
\hline \multirow{2}{*}{ ATVM04 } & 1 & $0-80$ & 10YR 4/3 & brown & $\begin{array}{l}\text { Silty Clay } \\
\text { Loam }\end{array}$ & $1-5 \%$ & Snail Shell & None & - \\
\hline & 2 & $80-200$ & 10YR 7/4 & very pale brown & $\begin{array}{l}\text { Silty Clay } \\
\text { Loam }\end{array}$ & $1-5 \%$ & Snail Shell & None & Terminated at depth. \\
\hline
\end{tabular}


Table 3.21. Shovel Test Data for Site 41GU200

\begin{tabular}{|c|c|c|c|c|c|c|c|c|c|}
\hline $\begin{array}{l}\text { Shovel } \\
\text { Test No. }\end{array}$ & Level & $\begin{array}{l}\text { Depth } \\
\text { (cmbs) }\end{array}$ & $\begin{array}{l}\text { Munsell } \\
\text { Soil Value }\end{array}$ & $\begin{array}{l}\text { Munsell Soil } \\
\text { Color }\end{array}$ & Soil Texture & $\begin{array}{l}\text { Inclusion } \\
\text { Percentage }\end{array}$ & $\begin{array}{l}\text { Inclusion } \\
\text { Type }\end{array}$ & $\begin{array}{l}\text { Cultural } \\
\text { Materials }\end{array}$ & $\begin{array}{l}\text { Comments/ } \\
\text { Reason for } \\
\text { Termination }\end{array}$ \\
\hline \multirow{2}{*}{ CXS05 } & 1 & $0-25$ & 10YR $2 / 2$ & very dark brown & Clay Loam & $10-20 \%$ & Snail Shell & None & - \\
\hline & 2 & $25-100$ & 10YR 5/4 & yellowish brown & $\begin{array}{l}\text { Sandy Clay } \\
\text { Loam }\end{array}$ & $10-20 \%$ & Snail Shell & None & Terminated at depth. \\
\hline \multirow{2}{*}{ CXS06 } & 1 & $0-35$ & 10YR 2/2 & very dark brown & Sandy Loam & $10-20 \%$ & Snail Shell & None & - \\
\hline & 2 & $35-100$ & 10YR 5/4 & yellowish brown & $\begin{array}{l}\text { Sandy Clay } \\
\text { Loam }\end{array}$ & $10-20 \%$ & $\begin{array}{l}\text { Pebbles, } \\
\text { Snail Shell }\end{array}$ & None & Terminated at depth. \\
\hline \multirow{2}{*}{ CXS07 } & 1 & $0-50$ & 10YR 3/2 & $\begin{array}{l}\text { very dark grayish } \\
\text { brown }\end{array}$ & Sandy Loam & $10-20 \%$ & $\begin{array}{l}\text { Pebbles, } \\
\text { Snail Shell }\end{array}$ & None & - \\
\hline & 2 & $50-100$ & 10YR 5/4 & yellowish brown & $\begin{array}{l}\text { Sandy Clay } \\
\text { Loam }\end{array}$ & $5-10 \%$ & $\begin{array}{l}\text { Pebbles, } \\
\text { Snail Shell }\end{array}$ & None & Terminated at depth. \\
\hline \multirow{2}{*}{ CXS08 } & 1 & $0-70$ & 10YR 2/2 & very dark brown & Sandy Loam & $5-10 \%$ & Snail Shell & None & - \\
\hline & 2 & $70-100$ & 10YR 5/4 & yellowish brown & $\begin{array}{l}\text { Sandy Clay } \\
\text { Loam }\end{array}$ & $5-10 \%$ & $\begin{array}{l}\text { Pebbles, } \\
\text { Snail Shell }\end{array}$ & None & Terminated at depth. \\
\hline \multirow{4}{*}{ JIS11 } & 1 & $0-30$ & 10YR 3/2 & $\begin{array}{l}\text { very dark grayish } \\
\text { brown }\end{array}$ & Loamy Sand & $1-5 \%$ & Snail Shell & None & - \\
\hline & 2 & $30-60$ & 10YR $4 / 3$ & brown & Loamy Sand & $1-5 \%$ & Snail Shell & None & - \\
\hline & 3 & $60-80$ & 10YR 5/4 & yellowish brown & Sand & $1-5 \%$ & Snail Shell & None & - \\
\hline & 4 & $80-100$ & 10YR 6/4 & $\begin{array}{l}\text { light yellowish } \\
\text { brown }\end{array}$ & Sand & $5-10 \%$ & $\begin{array}{l}\text { Calcium } \\
\text { Carbonate, } \\
\text { Snail Shell }\end{array}$ & None & Terminated at depth. \\
\hline \multirow{4}{*}{ JIS12 } & 1 & $0-30$ & 10YR 3/2 & $\begin{array}{l}\text { very dark grayish } \\
\text { brown }\end{array}$ & Loamy Sand & $1-5 \%$ & $\begin{array}{l}\text { Pebbles, } \\
\text { Snail Shell }\end{array}$ & None & - \\
\hline & 2 & $30-60$ & 10YR 4/3 & brown & Loamy Sand & $1-5 \%$ & $\begin{array}{l}\text { Pebbles, } \\
\text { Snail Shell }\end{array}$ & $\begin{array}{l}\text { 1: Flake } \\
\text { (secondary) }\end{array}$ & - \\
\hline & 3 & $60-80$ & 10YR 5/4 & yellowish brown & Sand & $1-5 \%$ & Snail Shell & None & - \\
\hline & 4 & $80-100$ & 10YR 6/4 & $\begin{array}{l}\text { light yellowish } \\
\text { brown }\end{array}$ & Sand & $1-5 \%$ & Snail Shell & None & Terminated at depth. \\
\hline \multirow{4}{*}{ JIS13 } & 1 & $0-10$ & 10YR $3 / 3$ & dark brown & Sandy Loam & $1-5 \%$ & Snail Shell & None & - \\
\hline & 2 & $20-50$ & 10YR 5/6 & yellowish brown & Loamy Sand & $1-5 \%$ & Snail Shell & None & - \\
\hline & 3 & $50-90$ & 10YR 4/3 & brown & Loamy Sand & $1-5 \%$ & Snail Shell & None & - \\
\hline & 4 & $90-100$ & 10YR $6 / 3$ & pale brown & Sand & & & None & Terminated at depth. \\
\hline \multirow{3}{*}{ MCC554 } & 1 & $0-60$ & 10YR 4/2 & $\begin{array}{l}\text { dark grayish } \\
\text { brown }\end{array}$ & Silt Loam & $1-5 \%$ & Snail Shell & None & - \\
\hline & 2 & $60-85$ & 10YR 5/4 & yellowish brown & Silt Loam & $1-5 \%$ & Snail Shell & None & - \\
\hline & 3 & $85-100$ & 10YR 6/4 & $\begin{array}{l}\text { light yellowish } \\
\text { brown }\end{array}$ & $\begin{array}{l}\text { Sandy Clay } \\
\text { Loam }\end{array}$ & $1-5 \%$ & Snail Shell & None & Terminated at depth. \\
\hline \multirow{3}{*}{ MCC555 } & 1 & $0-60$ & 10YR 4/2 & $\begin{array}{l}\text { dark grayish } \\
\text { brown }\end{array}$ & Silt Loam & $1-5 \%$ & $\begin{array}{l}\text { Pebbles, } \\
\text { Snail Shell }\end{array}$ & None & - \\
\hline & 2 & $60-85$ & 10YR 5/4 & yellowish brown & Sandy Loam & $1-5 \%$ & $\begin{array}{l}\text { Pebbles, } \\
\text { Snail Shell }\end{array}$ & None & - \\
\hline & 3 & $85-100$ & 10YR 6/4 & $\begin{array}{l}\text { light yellowish } \\
\text { brown }\end{array}$ & $\begin{array}{l}\text { Sandy Clay } \\
\text { Loam }\end{array}$ & & & None & Terminated at depth. \\
\hline
\end{tabular}


Table 3.21. continued

\begin{tabular}{|c|c|c|c|c|c|c|c|c|c|}
\hline $\begin{array}{l}\text { Shovel } \\
\text { Test No. }\end{array}$ & Level & $\begin{array}{l}\text { Depth } \\
\text { (cmbs) }\end{array}$ & $\begin{array}{l}\text { Munsell } \\
\text { Soil Value }\end{array}$ & $\begin{array}{l}\text { Munsell Soil } \\
\text { Color }\end{array}$ & Soil Texture & $\begin{array}{l}\text { Inclusion } \\
\text { Percentage }\end{array}$ & $\begin{array}{l}\text { Inclusion } \\
\text { Type }\end{array}$ & $\begin{array}{l}\text { Cultural } \\
\text { Materials }\end{array}$ & $\begin{array}{l}\text { Comments/ } \\
\text { Reason for } \\
\text { Termination }\end{array}$ \\
\hline \multirow{3}{*}{ MCC556 } & 1 & $0-10$ & 10YR 4/2 & $\begin{array}{l}\text { dark grayish } \\
\text { brown }\end{array}$ & Sandy Loam & $1-5 \%$ & Pebbles & None & - \\
\hline & 2 & $10-45$ & 10YR 6/4 & $\begin{array}{l}\text { light yellowish } \\
\text { brown }\end{array}$ & Sandy Loam & $1-5 \%$ & Pebbles & None & - \\
\hline & 3 & $45-100$ & 10YR 7/4 & very pale brown & Sandy Loam & $1-5 \%$ & Pebbles & None & Terminated at depth. \\
\hline \multirow{2}{*}{ MFV12 } & 1 & $0-50$ & 10YR 3/3 & dark brown & Silt Loam & $10-20 \%$ & $\begin{array}{l}\text { Gravels, } \\
\text { Pebbles, } \\
\text { Snail Shell, } \\
\text { Common } \\
\text { Roots and } \\
\text { Rootlets }\end{array}$ & None & - \\
\hline & 2 & $50-60$ & 10YR 3/6 & $\begin{array}{l}\text { dark yellowish } \\
\text { brown }\end{array}$ & Silt Loam & $10-20 \%$ & $\begin{array}{l}\text { Gravels, } \\
\text { Pebbles, } \\
\text { Snail Shell, } \\
\text { Common } \\
\text { Roots and } \\
\text { Rootlets }\end{array}$ & None & $\begin{array}{l}\text { Terminated at large } \\
\text { root at } 60 .\end{array}$ \\
\hline \multirow[t]{2}{*}{ MFV13 } & 1 & $0-40$ & 10YR 3/3 & dark brown & Silty Clay & $10-20 \%$ & $\begin{array}{l}\text { Gravels, } \\
\text { Pebbles, } \\
\text { Snail Shell, } \\
\text { Roots and } \\
\text { worms }\end{array}$ & None & - \\
\hline & 2 & $40-70$ & 10YR 4/3 & brown & Silty Clay & $10-20 \%$ & $\begin{array}{l}\text { Gravels, } \\
\text { Pebbles, } \\
\text { Snail Shell, } \\
\text { Roots }\end{array}$ & None & $\begin{array}{l}\text { Terminated at } \\
\text { impenetrable root. }\end{array}$ \\
\hline \multirow{3}{*}{ MFV14 } & 1 & $1-30$ & 10YR 4/3 & brown & Sandy Loam & $5-10 \%$ & $\begin{array}{l}\text { Cobbles, } \\
\text { Gravels, } \\
\text { Snail Shell }\end{array}$ & None & - \\
\hline & 2 & $30-80$ & 10YR 4/4 & $\begin{array}{l}\text { dark yellowish } \\
\text { brown }\end{array}$ & Sandy Loam & $10-20 \%$ & $\begin{array}{l}\text { Gravels, } \\
\text { Pebbles, } \\
\text { Snail Shell, } \\
\text { Roots }\end{array}$ & None & - \\
\hline & 3 & $80-100$ & 10YR 5/4 & yellowish brown & Sandy Loam & $5-10 \%$ & $\begin{array}{l}\text { Gravels, } \\
\text { Pebbles, } \\
\text { Roots }\end{array}$ & None & Terminated at depth. \\
\hline \multirow{2}{*}{ VM12 } & 1 & $0-55$ & 10YR 3/2 & $\begin{array}{l}\text { very dark grayish } \\
\text { brown }\end{array}$ & Sandy Loam & $1-5 \%$ & Snail Shell & None & \\
\hline & 2 & $55-100$ & 10YR 5/4 & yellowish brown & $\begin{array}{l}\text { Sandy Clay } \\
\text { Loam }\end{array}$ & $1-5 \%$ & $\begin{array}{l}\text { Pebbles, } \\
\text { Snail Shell }\end{array}$ & None & Terminated at depth. \\
\hline \multirow{3}{*}{ VM13 } & 1 & $0-20$ & 10YR 3/3 & dark brown & Sandy Loam & & $\begin{array}{l}\text { Pebbles, } \\
\text { Snail Shell }\end{array}$ & None & - \\
\hline & 2 & $20-95$ & 10YR 5/3 & brown & $\begin{array}{l}\text { Sandy Clay } \\
\text { Loam }\end{array}$ & $1-5 \%$ & $\begin{array}{l}\text { Pebbles, } \\
\text { Snail Shell }\end{array}$ & None & - \\
\hline & 3 & $95-100$ & 10YR 7/1 & light gray & $\begin{array}{l}\text { Sandy Clay } \\
\text { Loam }\end{array}$ & $1-5 \%$ & Pebbles & None & Terminated at depth. \\
\hline \multirow{2}{*}{ VM14 } & 1 & $0-55$ & 10YR 3/2 & $\begin{array}{l}\text { very dark grayish } \\
\text { brown }\end{array}$ & Sandy Loam & $1-5 \%$ & Snail Shell & None & - \\
\hline & 2 & $55-100$ & 10YR 5/4 & yellowish brown & $\begin{array}{l}\text { Sandy Clay } \\
\text { Loam }\end{array}$ & $1-5 \%$ & $\begin{array}{l}\text { Pebbles, } \\
\text { Snail Shell }\end{array}$ & None & Terminated at depth. \\
\hline
\end{tabular}


3.21). Cultural materials recovered were very sparse and included one secondary reduction flake and five tertiary reduction flakes of fine-grained chert (Figure 3.60). No temporally diagnostic artifacts or cultural features were observed.

Auger probes and shovel tests typically revealed dark grayish brown (10YR 4/2) silt loam overlying light yellowish brown (10YR 6/4) silt loam to very pale brown (10YR 7/4) silty clay loam with pebble, gravel, and calcium carbonate inclusions. Shovel tests and auger probes terminated at depth (i.e., $100 \mathrm{cmbs}$ for shovel tests and $200 \mathrm{cmbs}$ for auger probes).

\section{GU200 SUMMARY}

Site 41 GU200 consists of a diffuse, shallow to moderately buried prehistoric lithic scatter of debitage containing cultural materials predominantly between 30 and $60 \mathrm{cmbs}$. The site has a very low density of artifacts, lacks temporally diagnostic artifacts or cultural features, and is situated within a disturbed residential development setting. Overall, site 41GU200 does not have the potential to yield information important to the prehistory of the region. As such, SWCA recommends site $41 G U 200$ as NOT ELIGIBLE for the NRHP or for designation as a SAL. No further work or avoidance strategy is recommended for the portion of site $41 \mathrm{GU} 200$ within the project area.

\section{HoffMan Cemetery Scraping}

SWCA identified a family cemetery plot (the Hoffman Cemetery) on the western edge of the survey corridor adjacent to parcel 50360, approximately 0.7 mile northeast of FM 725 (Figure 3.61; Appendix A:250). The fenced-in cemetery contains at least three interments of the Hoffman family, the previous landowners (Figure 3.62). A post and barbed-wire fence forms the boundaries of the cemetery. A residence and open pasture are west and southwest of the cemetery boundary, the Guadalupe River is 0.7 mile to the northeast, and wooded ranchland surrounds the rest of the cemetery. Vegetation consists of overgrown grasses, small shrubs, and mixed hardwood trees. The cemetery was not fully recorded, as it is located outside of the current project area; however, scraping along the edge of the family burial plot was recommended to verify there were no additional interments outside its current fence line.

The cemetery scraping was conducted in November 2017 prior to the data recovery investigations for site $41 \mathrm{GU} 177$, which is just east of the cemetery. Mechanical excavations were conducted to a depth sufficient to determine the presence/absence of interments and buried cultural materials (i.e., 6 feet). The mechanical scraping involved gradually removing strips of soil until reaching a depth unlikely to contain burials or

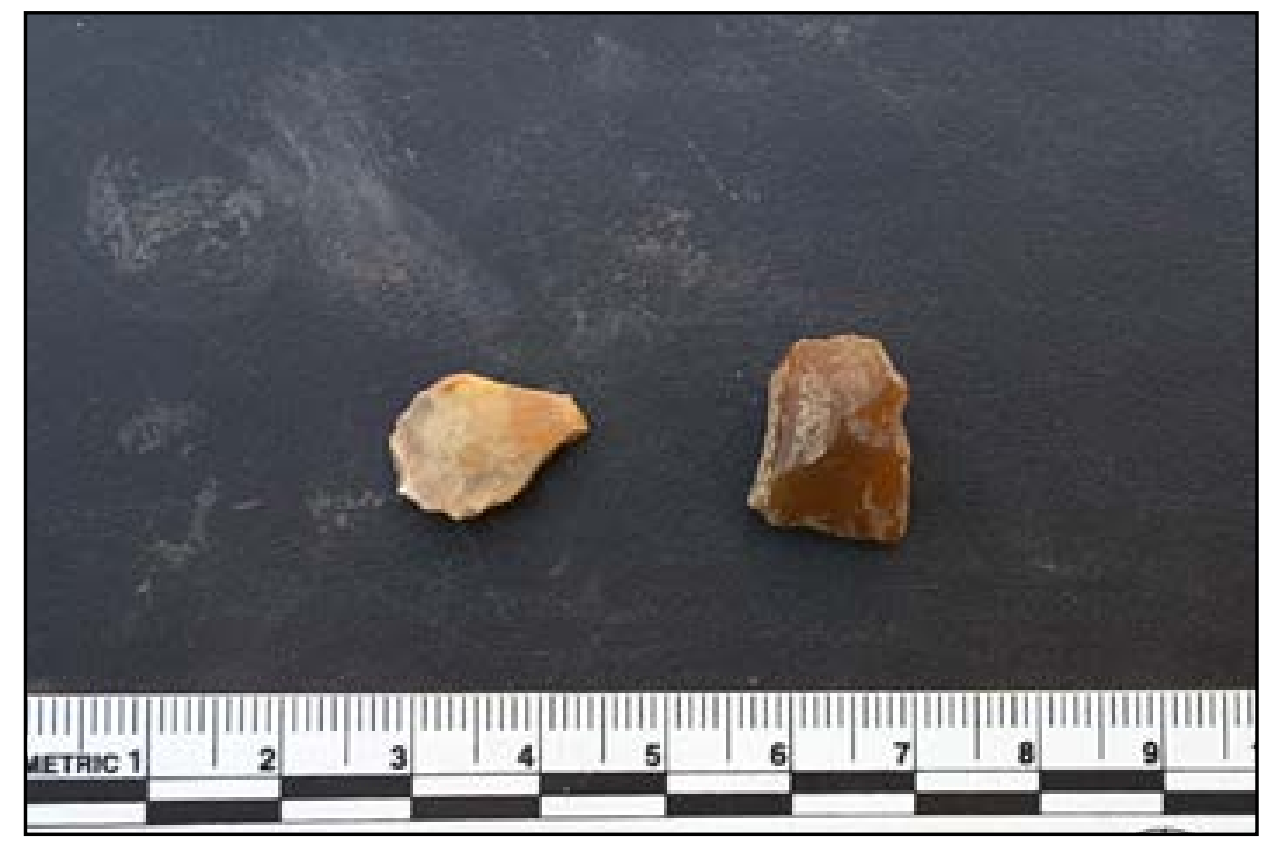

Figure 3.60. Artifacts from site 41GU200 in ST ATVM02 at 0-60 cmbs. 


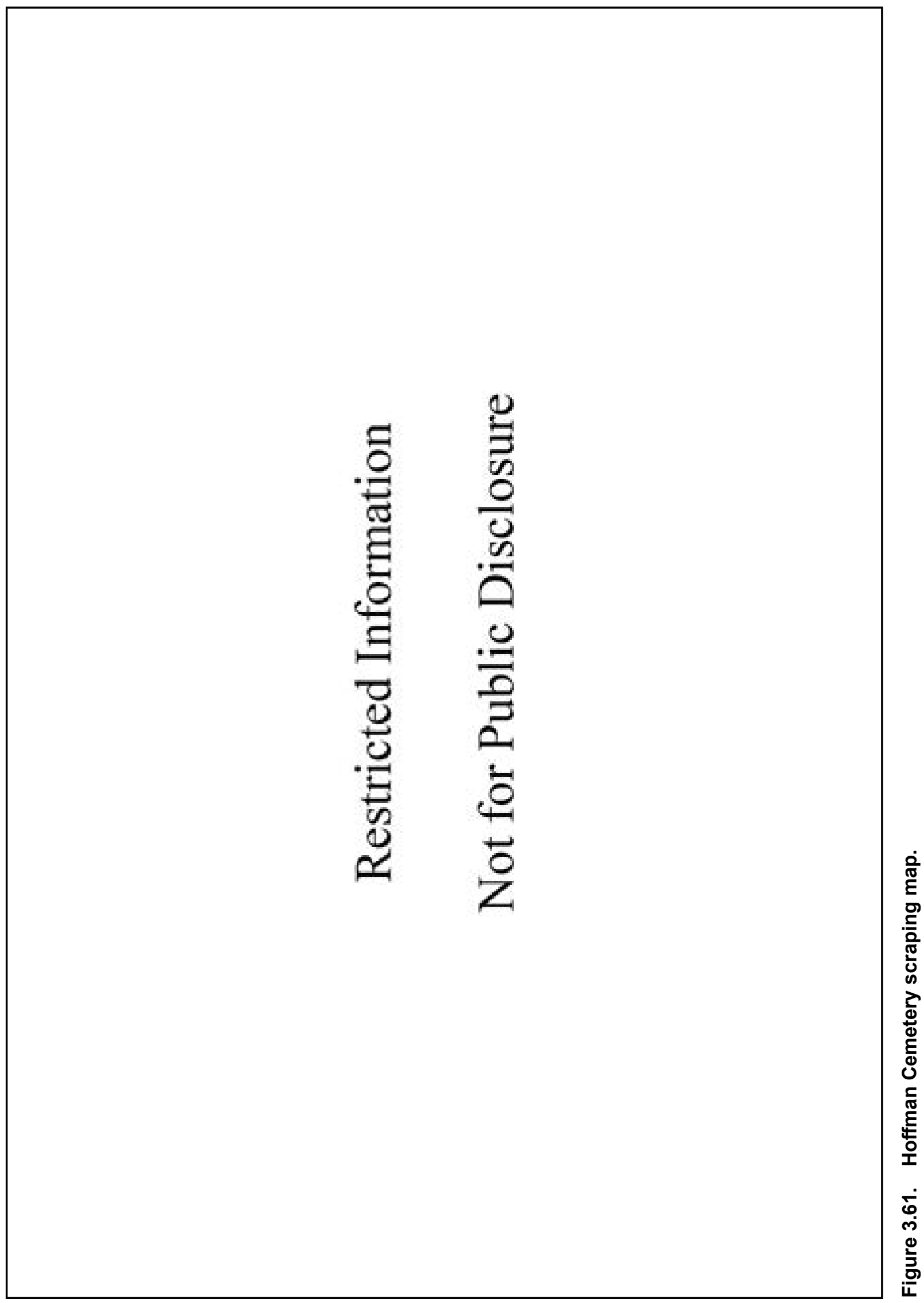


bedrock, whichever came first. Trenches were excavated parallel to the cemetery fence line within an approximately $40 \times 40$-foot-wide area. An experienced archeologist and bioarcheologist monitored all trenching while excavations proceeded. Once the trench was excavated to depth, an SWCA archeologist scraped representative profiles, checking for anomalies that could indicate graves (Figure 3.63). The scraping revealed a temporary grave marker identified approximately 1.5 $m$ east of the cemetery fence line in the upper $10 \mathrm{~cm}$ of unconsolidated sandy sediments. No other associated artifacts or indications of graves were identified, and the marker is inferred to be displaced from its original context within the cemetery. Excluding the temporary grave marker, no human remains and/or burial shafts were identified during the scraping investigations. Upon completion of excavation, each trench was backfilled and returned as closely as possible to their original surface contours. SWCA performed all work in accordance with OSHA regulations (29 CFR 1926).

\section{Comal County}

Three previously recorded cultural resource sites were revisited and further investigated within Comal County (Figure 3.64; see Table 3.3). The three previously recorded archaeological sites consist of two prehistoric lithic scatters (i.e., 41CM394 and 41CM404) and one multicomponent artifact scatter (i.e, 41CM401). SWCA recommends all three sites as NOT ELIGIBLE for listing on the NRHP or for SAL designation. No avoidance strategy or further work is recommended for the portion of these three sites within the project corridor.

\section{CM394}

Site 41CM394 is a shallowly buried prehistoric lithic scatter of unknown temporal or cultural affiliation situated on an upland formation approximately 0.5 mile north of Dry Comal Creek in southern Comal County, Texas (Figure 3.65; Appendix A:282-283). The site was originally recorded during the 2015 initial cultural resources investigations and SWCA revisited the site during the 2016 to 2018 investigations for reroute surveys. SWCA's 2015 initial investigations recommended site 41CM394 as NOT ELIGIBLE for listing in the NRHP or SAL designation with no avoidance or further work warranted due to shallow deposits, lack of temporally diagnostic artifacts or cultural features, and significant disturbances in the area (Acuña et al. 2016).
Vegetation on site consists of secondary juniper and mixed hardwood growth with short to tall grasses, which afforded 70 to 100 percent ground surface visibility with exposed bedrock and concentrations of limestone gravels, cobbles, and large rocks along the ground surface (Figure 3.66). The site is on privately owned land used for land modification, agricultural and residential purposes. Land disturbances observed include erosion, vegetation clearing, fence lines, twotrack roads, and a transmission line corridor with two exiting overhead transmission lines.

Site 41CM394 initially measured $2.5 \mathrm{~km}$ long by 30 $\mathrm{m}$ wide, oriented southwest/northeast then southeast and, in plan, appears " $L$ " shaped based on results of the 2015 initial investigations. The revisit of the site in 2018 resulted in a small extension that measures 235 $\mathrm{m}$ long by $27 \mathrm{~m}$ wide oriented northwest/southeast creating a " $\mathrm{T}$ " shape at its intersection approximately $520 \mathrm{~m}$ southwest of the bend in the "L" shape. All site measurements are within the project corridor at the time of investigations based on surface and subsurface artifact distributions; however, the site likely extends beyond the project area in all directions.

Cultural materials observed during ground surface inspection in 2015 and 2018 consist of approximately 65 cores; 30 modified flakes; 140 primary, 25 secondary, and 150 tertiary reduction flakes; and 20 burned limestone rock fragments (Figure 3.67). All lithic materials observed were composed of chert material types with the exception of the burned rock fragments.

In 2015, SWCA excavated 30 shovel tests (i.e., DR7983, KS100-107, KS120-121, RW73-77, RW300-308, and RW321) to delineate the site, of which only one (i.e., RW300) was positive for cultural materials consisting of two chert secondary reduction flakes at a maximum depth of $10 \mathrm{cmbs}$ immediately atop bedrock (Table 3.22). In 2018, SWCA excavated two additional shovel tests (i.e., MCC588 and MXR19) to delineate the site; both were negative for cultural materials (see Table 3.22). No temporally diagnostic artifacts or cultural features were observed. Shovel tests typically revealed dark brown (7.5YR 3/4) to dark reddish brown (5YR 3/2) clay loam with over 20 percent gravel, cobble, and rock inclusions overlying bedrock between 5 and $25 \mathrm{cmbs}$. Due to project constraints, the site was not fully delineated in all directions, as investigations were not permitted outside the project ROW. Due to a shift of the project corridor since the original recording 


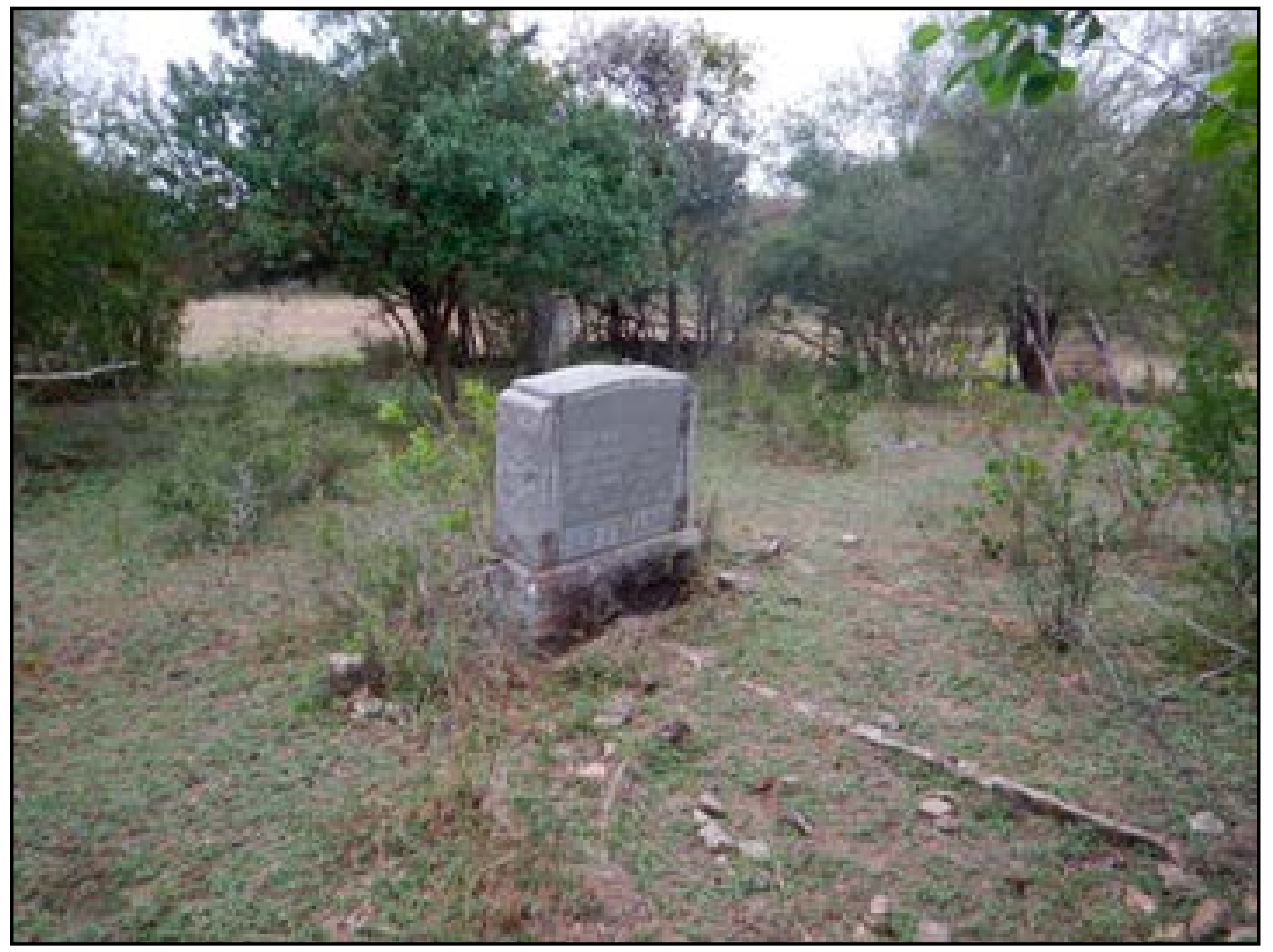

Figure 3.62. Overview of headstones at the Hoffman Cemetery, facing north.

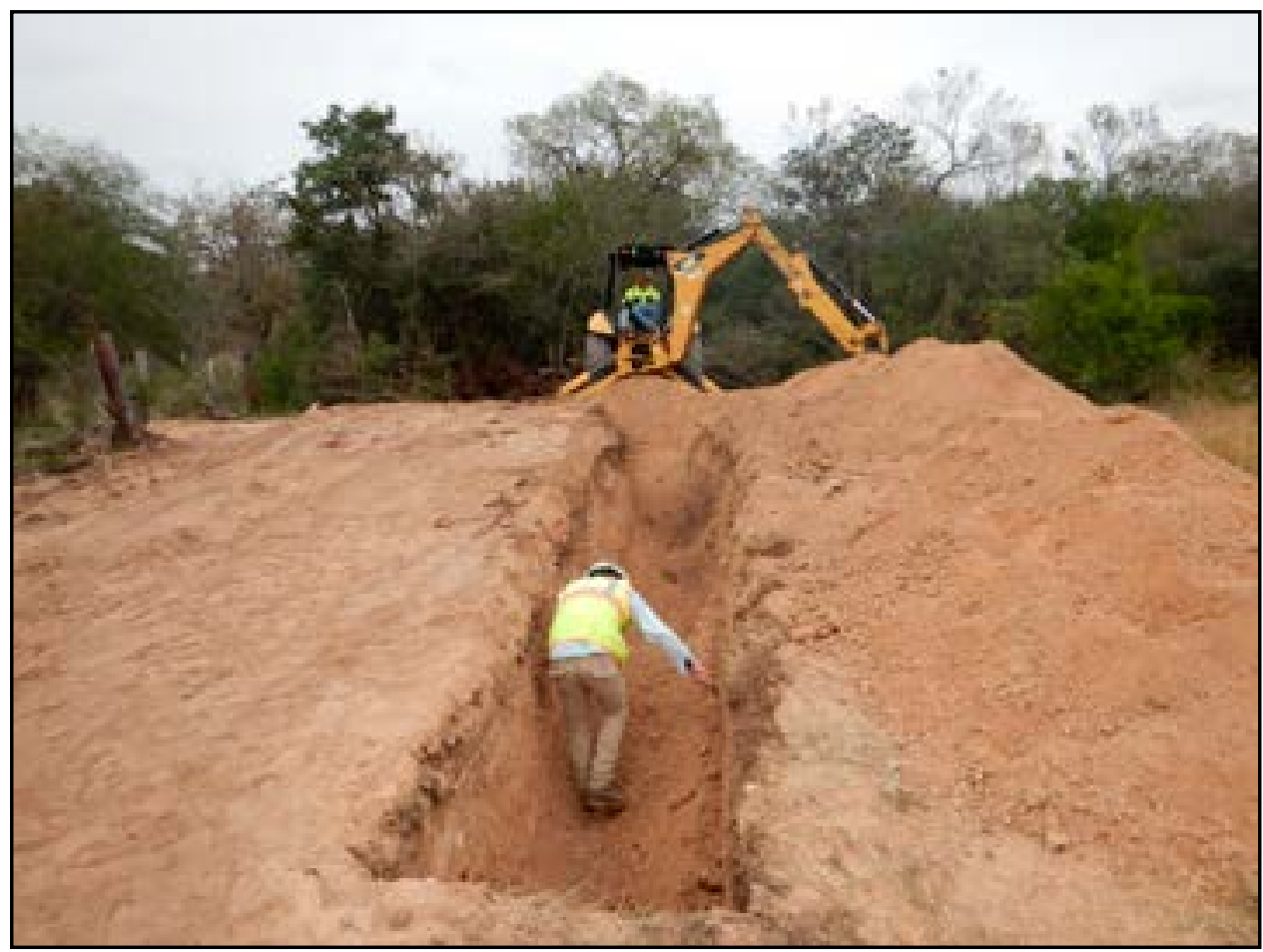

Figure 3.63. Overview of scraping investigations near the Hoffman Cemetery, facing northeast. 


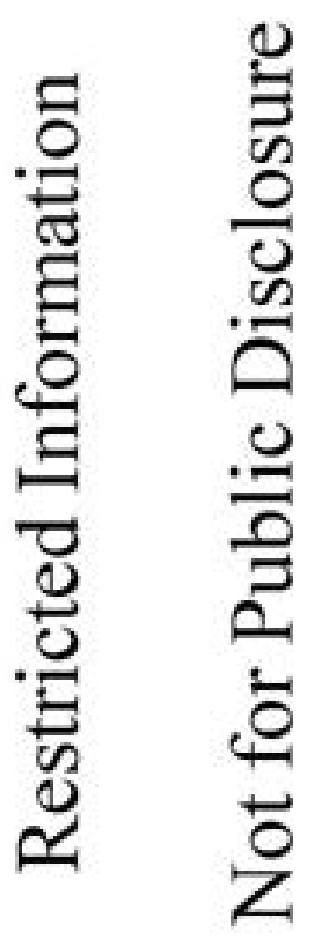

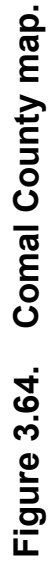




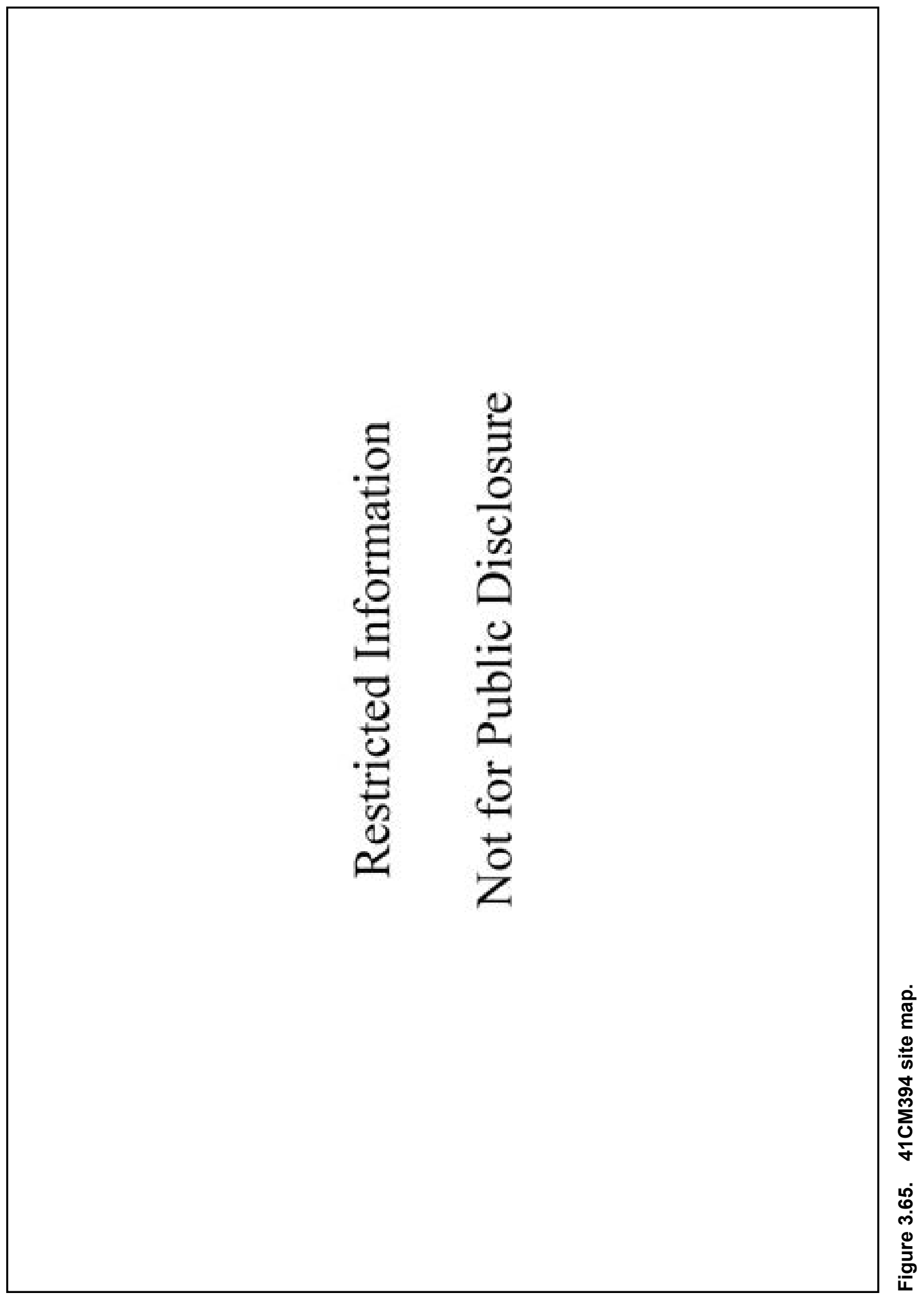




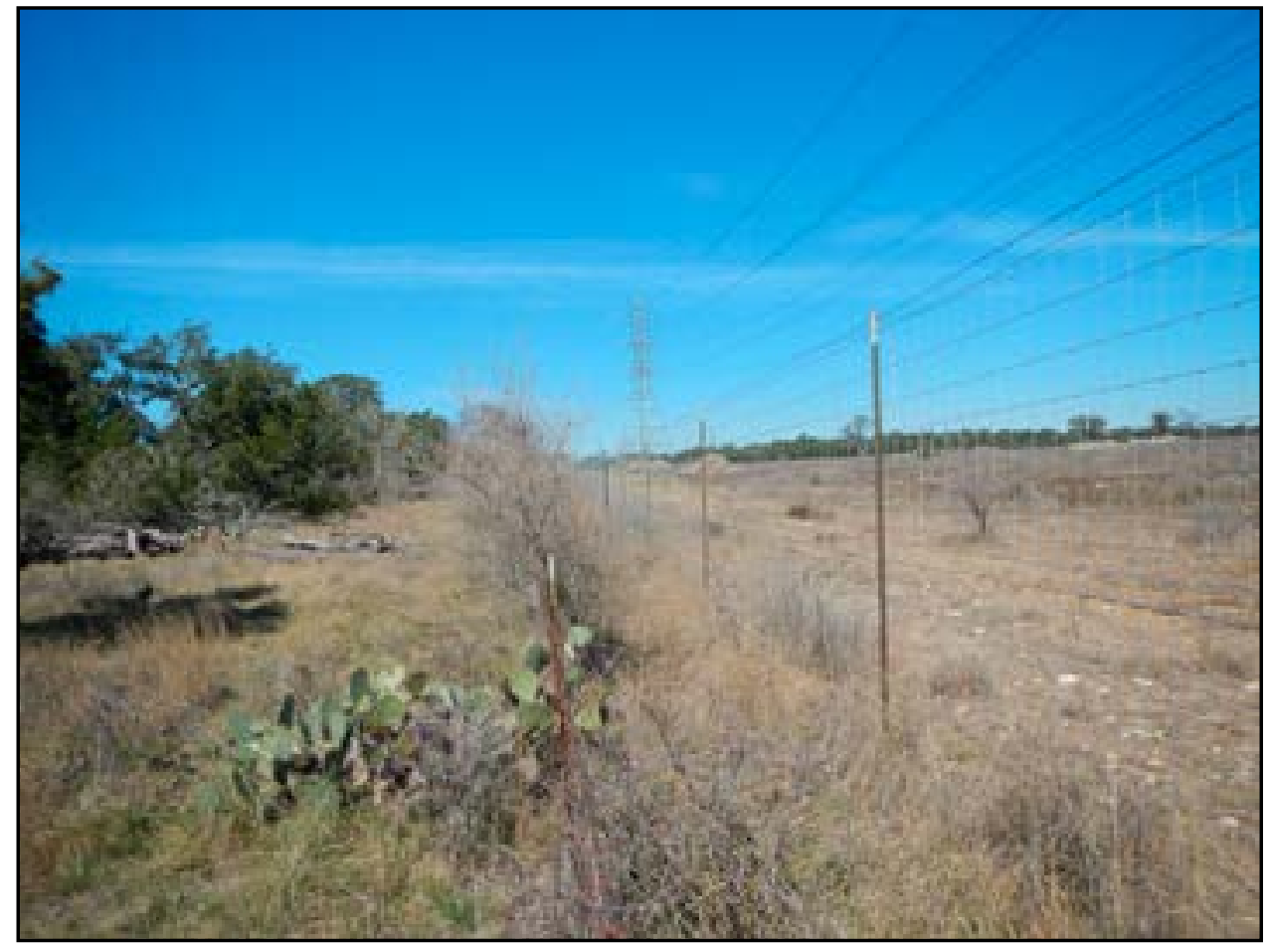

Figure 3.66. Overview of site $41 \mathrm{CM} 394$ revisit, facing north.

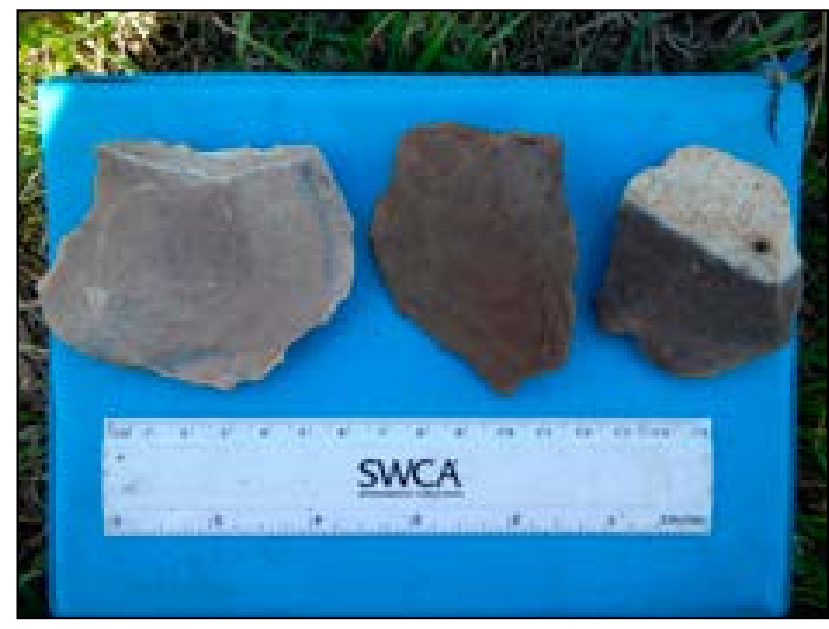

Figure 3.67. Artifacts recovered from site 41 CM394 revisits. of the site, the majority of the site is now outside the project area boundaries.

\section{CM394 SUMMARY}

Site $41 \mathrm{CM} 394$ consists of a prehistoric lithic scatter of unknown temporal and cultural affiliation with shallow soil deposits and a low potential for containing subsurface cultural material. The site lacks subsurface cultural deposition and temporally diagnostic artifacts or cultural features, and has been significantly disturbed by agricultural, residential, and modern development in the area. Overall, site 41CM394 does not have the potential to yield information important to the prehistory of the region. As such, SWCA recommends site 41CM394 as NOT ELIGIBLE for the NRHP or for designation as a SAL. No further work or avoidance strategy is recommended for site 41CM394 within the project area. However, because the site likely extends in all directions beyond the project area, should the alignment shift, additional investigations would be necessary. 
Table 3.22. Shovel Test Data for Site 41CM394

\begin{tabular}{|c|c|c|c|c|c|c|c|c|}
\hline $\begin{array}{l}\text { Shovel } \\
\text { Test No. }\end{array}$ & Level & $\begin{array}{l}\text { Depth } \\
\text { (cmbs) }\end{array}$ & $\begin{array}{l}\text { Munsell } \\
\text { Soil Value }\end{array}$ & $\begin{array}{l}\text { Munsell Soil } \\
\text { Color }\end{array}$ & $\begin{array}{l}\text { Inclusion } \\
\text { Percentage }\end{array}$ & Inclusion Type & $\begin{array}{l}\text { Cultural } \\
\text { Materials }\end{array}$ & $\begin{array}{l}\text { Comments/ } \\
\text { Reason for Termination }\end{array}$ \\
\hline \multicolumn{9}{|c|}{2015 Initial Cultural Resources Investigations } \\
\hline DR79 & 1 & $0-10$ & 10YR 4/4 & $\begin{array}{l}\text { dark } \\
\text { yellowish } \\
\text { brown }\end{array}$ & Clay Loam >20\% & $\begin{array}{l}\text { Calcium } \\
\text { Carbonate, } \\
\text { Cobbles, Gravels }\end{array}$ & None & Terminated at bedrock. \\
\hline DR80 & 1 & $0-5$ & 10YR 4/4 & $\begin{array}{l}\text { dark } \\
\text { yellowish } \\
\text { brown }\end{array}$ & Clay Loam >20\% & & None & Terminated at bedrock. \\
\hline DR81 & 1 & $0-10$ & 10YR 4/4 & $\begin{array}{l}\text { dark } \\
\text { yellowish } \\
\text { brown }\end{array}$ & Clay Loam >20\% & & None & Terminated at bedrock. \\
\hline DR82 & 1 & $0-10$ & 10YR 4/4 & $\begin{array}{l}\text { dark } \\
\text { yellowish } \\
\text { brown }\end{array}$ & Clay Loam >20\% & & None & Terminated at bedrock. \\
\hline DR83 & 1 & $0-5$ & 10YR 4/4 & $\begin{array}{l}\text { dark } \\
\text { yellowish } \\
\text { brown }\end{array}$ & Clay Loam >20\% & & None & Terminated at bedrock. \\
\hline KS100 & 1 & $0-5$ & 10YR 3/3 & dark brown & Clay Loam $10-20 \%$ & Gravels & None & Terminated at bedrock. \\
\hline KS101 & 1 & $0-5$ & 10YR 3/3 & dark brown & Clay Loam $10-20 \%$ & Gravels & None & Terminated at bedrock. \\
\hline KS102 & 1 & $0-5$ & 10YR 3/3 & dark brown & Clay Loam $10-20 \%$ & Gravels & None & Terminated at bedrock. \\
\hline KS103 & 1 & $0-15$ & 10YR 3/4 & dark brown & Clay Loam 10-20\% & $\begin{array}{l}\text { Gravels, 10YR } \\
5 / 3 \text { mottles }\end{array}$ & None & Terminated at bedrock. \\
\hline KS104 & 1 & $0-5$ & 10YR 3/3 & dark brown & Clay Loam 5\% & Gravels & None & Terminated at bedrock. \\
\hline KS105 & 1 & $0-5$ & 10YR 3/3 & dark brown & Clay Loam 5\% & Gravels & None & Terminated at bedrock. \\
\hline KS106 & 1 & $0-5$ & 10YR 3/3 & dark brown & Clay Loam 5\% & Gravels & None & Terminated at bedrock. \\
\hline KS107 & 1 & $0-5$ & 10YR 3/3 & dark brown & Clay Loam 5\% & Gravels & None & Terminated at bedrock. \\
\hline KS120 & 1 & $0-5$ & 5YR 2.5/2 & $\begin{array}{l}\text { dark reddish } \\
\text { brown }\end{array}$ & Clay Loam 10-20\% & $\begin{array}{l}\text { Cobbles, } \\
\text { Gravels, Large } \\
\text { Rock Frags }\end{array}$ & None & Terminated at bedrock. \\
\hline KS121 & 1 & $0-5$ & 5YR 2.5/2 & $\begin{array}{l}\text { dark reddish } \\
\text { brown }\end{array}$ & Clay Loam 10-20\% & $\begin{array}{l}\text { Cobbles, } \\
\text { Gravels, Large } \\
\text { Rock Frags }\end{array}$ & None & Terminated at bedrock. \\
\hline RW73 & 1 & $0-10$ & 7.5YR 3/4 & dark brown & Clay Loam 10-20\% & Cobbles, Gravels & None & Terminated at bedrock. \\
\hline RW74 & 1 & $0-10$ & 7.5YR 3/4 & dark brown & Clay Loam 10-20\% & Cobbles, Gravels & None & Terminated at bedrock. \\
\hline RW75 & 1 & $0-10$ & 7.5YR 3/4 & dark brown & Clay Loam 10-20\% & Cobbles, Gravels & None & Terminated at bedrock. \\
\hline RW76 & 1 & $0-10$ & 7.5YR 3/4 & dark brown & Clay Loam 10-20\% & Cobbles, Gravels & None & Terminated at bedrock. \\
\hline RW77 & 1 & $0-10$ & 7.5YR 3/4 & dark brown & Clay Loam 10-20\% & Cobbles, Gravels & None & Terminated at bedrock. \\
\hline RW300 & 1 & $0-10$ & $5 Y R 3 / 2$ & $\begin{array}{l}\text { dark reddish } \\
\text { brown }\end{array}$ & Clay Loam >20\% & $\begin{array}{l}\text { Cobbles, } \\
\text { Gravels, Large } \\
\text { Rock Frags }\end{array}$ & $\begin{array}{l}\text { 2: Flake } \\
\text { (secondary) }\end{array}$ & Terminated at bedrock. \\
\hline RW301 & 1 & $0-10$ & $5 Y R 3 / 2$ & $\begin{array}{l}\text { dark reddish } \\
\text { brown }\end{array}$ & Clay Loam >20\% & $\begin{array}{l}\text { Cobbles, } \\
\text { Gravels, Large } \\
\text { Rock Frags }\end{array}$ & None & Terminated at bedrock. \\
\hline RW302 & 1 & $0-10$ & $5 Y R 3 / 2$ & $\begin{array}{l}\text { dark reddish } \\
\text { brown }\end{array}$ & Clay Loam >20\% & $\begin{array}{l}\text { Cobbles, } \\
\text { Gravels, Large } \\
\text { Rock Frags }\end{array}$ & None & Terminated at bedrock. \\
\hline RW303 & 1 & $0-10$ & $5 Y R 3 / 2$ & $\begin{array}{l}\text { dark reddish } \\
\text { brown }\end{array}$ & Clay Loam >20\% & $\begin{array}{l}\text { Cobbles, } \\
\text { Gravels, Large } \\
\text { Rock Frags }\end{array}$ & None & Terminated at bedrock. \\
\hline
\end{tabular}


Table 3.22. continued

\begin{tabular}{|c|c|c|c|c|c|c|c|c|c|}
\hline $\begin{array}{l}\text { Shovel } \\
\text { Test No. }\end{array}$ & Level & $\begin{array}{l}\text { Depth } \\
\text { (cmbs) }\end{array}$ & $\begin{array}{l}\text { Munsell } \\
\text { Soil Value }\end{array}$ & $\begin{array}{l}\text { Munsell Soil } \\
\text { Color }\end{array}$ & $\begin{array}{l}\text { il Soil } \\
\text { Texture }\end{array}$ & $\begin{array}{l}\text { Inclusion } \\
\text { Percentage }\end{array}$ & Inclusion Type & $\begin{array}{l}\text { Cultural } \\
\text { Materials }\end{array}$ & $\begin{array}{l}\text { Comments/ } \\
\text { Reason for Termination }\end{array}$ \\
\hline RW304 & 1 & $0-10$ & 5YR 3/2 & $\begin{array}{l}\text { dark reddish } \\
\text { brown }\end{array}$ & Clay Loam & $>20 \%$ & $\begin{array}{l}\text { Cobbles, } \\
\text { Gravels, Large } \\
\text { Rock Frags }\end{array}$ & None & Terminated at bedrock. \\
\hline RW305 & 1 & $0-10$ & $5 Y R 3 / 2$ & $\begin{array}{l}\text { dark reddish } \\
\text { brown }\end{array}$ & Clay Loam & $>20 \%$ & $\begin{array}{l}\text { Cobbles, } \\
\text { Gravels, Large } \\
\text { Rock Frags }\end{array}$ & None & Terminated at bedrock. \\
\hline RW306 & 1 & $0-10$ & 5YR 3/2 & $\begin{array}{l}\text { dark reddish } \\
\text { brown }\end{array}$ & Clay Loam & $>20 \%$ & $\begin{array}{l}\text { Cobbles, } \\
\text { Gravels, Large } \\
\text { Rock Frags }\end{array}$ & None & Terminated at bedrock. \\
\hline RW307 & 1 & $0-10$ & 5YR 3/2 & $\begin{array}{l}\text { dark reddish } \\
\text { brown }\end{array}$ & Clay Loam & $>20 \%$ & $\begin{array}{l}\text { Cobbles, } \\
\text { Gravels, Large } \\
\text { Rock Frags }\end{array}$ & None & Terminated at bedrock. \\
\hline RW308 & 1 & $0-10$ & $5 Y R 3 / 2$ & $\begin{array}{l}\text { dark reddish } \\
\text { brown }\end{array}$ & Clay Loam & $>20 \%$ & $\begin{array}{l}\text { Cobbles, } \\
\text { Gravels, Large } \\
\text { Rock Frags }\end{array}$ & None & Terminated at bedrock. \\
\hline RW321 & 1 & $0-10$ & $5 Y R 2.5 / 2$ & $\begin{array}{l}\text { dark reddish } \\
\text { brown }\end{array}$ & Clay Loam & $>20 \%$ & $\begin{array}{l}\text { Cobbles, } \\
\text { Gravels, Large } \\
\text { Rock Frags }\end{array}$ & None & Terminated at bedrock. \\
\hline \multicolumn{10}{|c|}{ 2016-2018 Additional Cultural Resources Investigations } \\
\hline MCC588 & 1 & $0-25$ & 10YR $3 / 3$ & dark brown & $\begin{array}{l}\text { Silty Clay } \\
\text { Loam }\end{array}$ & $10-20 \%$ & Gravels & None & Terminated at bedrock. \\
\hline MXR19 & 1 & $0-25$ & 10YR $3 / 3$ & dark brown & $\begin{array}{l}\text { Silty Clay } \\
\text { Loam }\end{array}$ & $10-20 \%$ & Gravels & None & Terminated at bedrock. \\
\hline
\end{tabular}

\section{CM401}

Site 41CM401 is shallowly buried multicomponent prehistoric and historic artifact scatter situated on an upland formation that steeply slopes up from erosional drainages, then gently slopes down due south towards the lower terraces of Dry Comal Creek (Figure 3.68; Appendix A:277-281). The site was originally recorded during SWCA's 2015 investigations and is located in southern Comal County, Texas. Vegetation on site consists of tall grasses, weeds, and shrubs in open pasture fields with sporadic clusters of oak and other mixed hardwood trees, which afforded 50 to 100 percent ground surface visibility with exposed bedrock and dense concentrations of gravely clay along the ground surface (Figure 3.69). Site 41CM401 is located within privately owned land used for mining operations along with associated infrastructure as well as cattle ranching and farming, and disturbances observed include erosion, vegetation clearing, land modification, fence lines, two-track roads, and a railroad track along the southern boundary (Figure 3.70). SWCA's 2015 initial investigations recommended site 41CM401 as
NOT ELIGIBLE for listing in the NRHP or for SAL designation with no avoidance or further work warranted due to shallow deposits, lack of temporally diagnostic artifacts or cultural features, and significant disturbances in the area (Acuña et al. 2016).

Site 41CM401 initially measured $780 \mathrm{~m}$ northwest/ southeast by $30 \mathrm{~m}$ northeast/southwest based on the results of the 2015 initial investigations. The revisit of the site in 2018 resulted in a significant extension that measures $2,784 \mathrm{~m}$ long by $27 \mathrm{~m}$ wide, starting from the previous southeastern margin trending northeast/ southwest, then southeast/northwest, and then southwest/northeast creating an incomplete square shape missing one segment for the entire site boundary. All site measurements are within the project corridor at the time of investigations based on artifact distributions; however, the site likely extends beyond the project area in all directions.

Cultural materials observed during ground surface inspection in 2015 and 2018 consist of approximately 150 prehistoric chert cores, seven prehistoric chert 


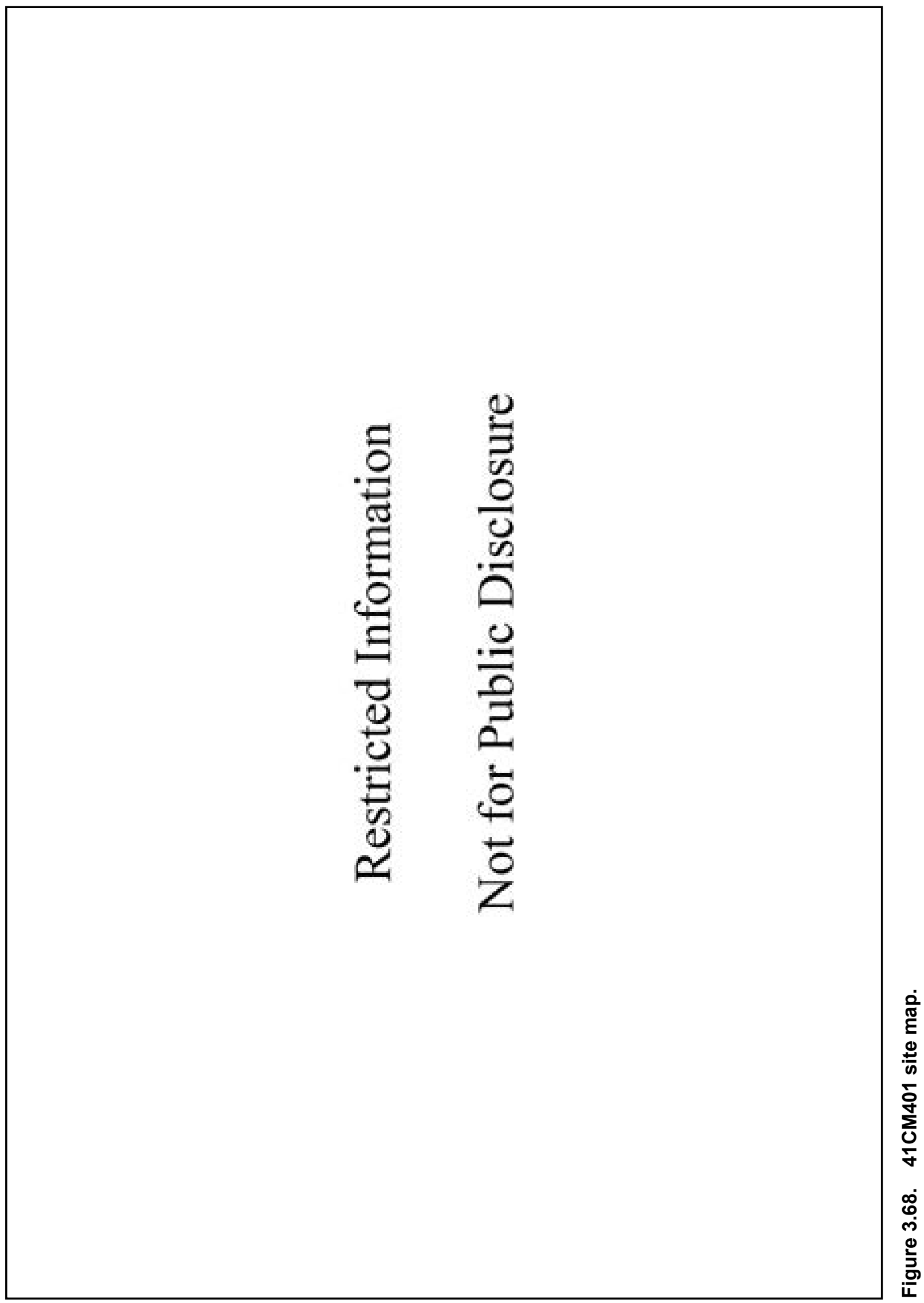




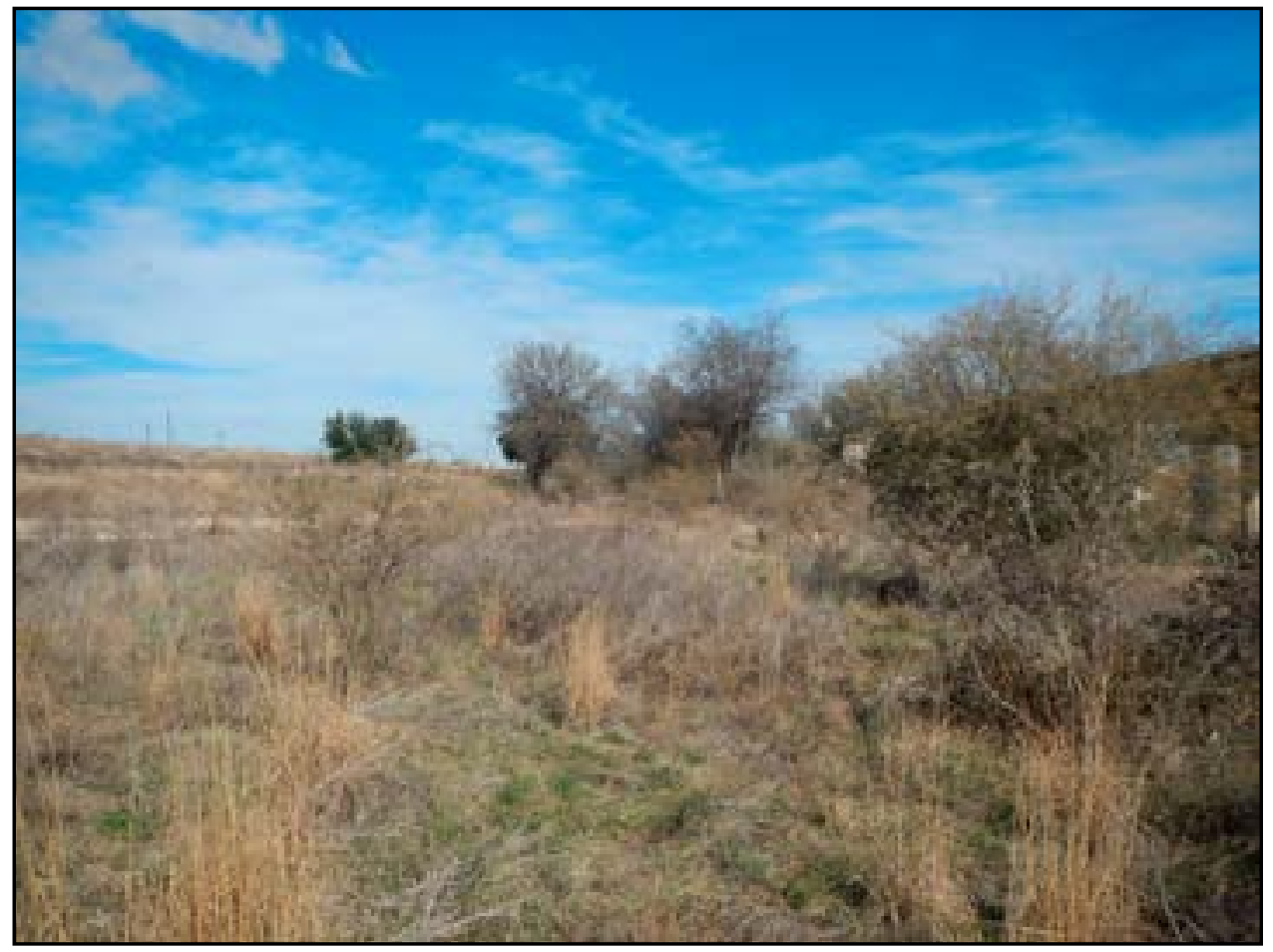

Figure 3.69. Overview of site $41 \mathrm{CM} 401$ revisit along southeast margin, facing northeast.

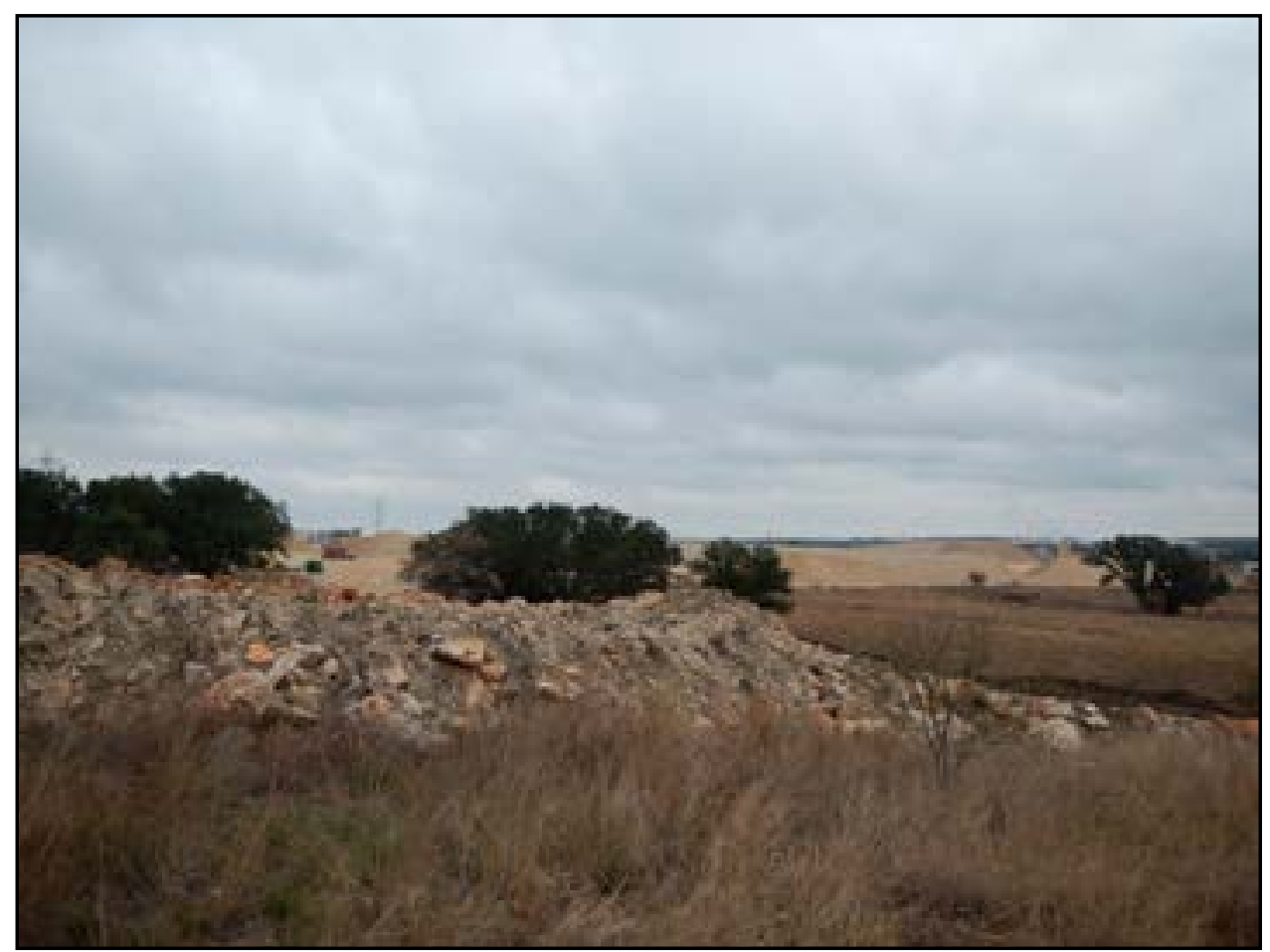

Figure 3.70. Overview of site 41CM401 revisit along southwest margin, facing northwest. 
bifaces, 500 prehistoric chert primary reduction flakes, 900 prehistoric chert secondary reduction flakes, 600 prehistoric chert tertiary reduction flakes, 1,200 pieces of chert cultural shatter, four porcelain sherds, 14 whiteware sherds, 20 crockery fragments, six milk glass fragments, three blue glass fragments, three cobalt blue glass fragments, five amethyst glass fragments, four green glass fragments, 10 aqua glass fragments, 25 brown glass fragments, six solarized glass fragments, 15 colorless glass fragments, 20 miscellaneous metal fragments, and one metal spoon (Figures 3.71a-3.71b). Although the artifacts are not clearly diagnostic (i.e., identifiable makers marks or brands), general manufacturing dates suggest an age from the early twentieth century onward. Amethystcolored glass was caused by the addition of magnesium to the glass production process. When magnesium glass is exposed to ultraviolet radiation, it turns a purple or amethyst color. In the United States, magnesium ceased to be added to glass after the start of World War I (about 1917) when the main source of magnesium, Germany, was cut off (Kendrick 1966:59-61 in IMACS 2001). Aqua-colored glass occurs due to iron impurities found in most sand. Aqua glass was generally common before the 1920s when it was largely replaced by colorless glass, with the exception of Coca-Cola bottles and Ball fruit jars (Munsey 1970). No other diagnostic artifacts or cultural features were observed; however, SWCA observed a cattle barn, likely dating to the early to mid-twentieth century, immediately adjacent to the southern boundary of the site.

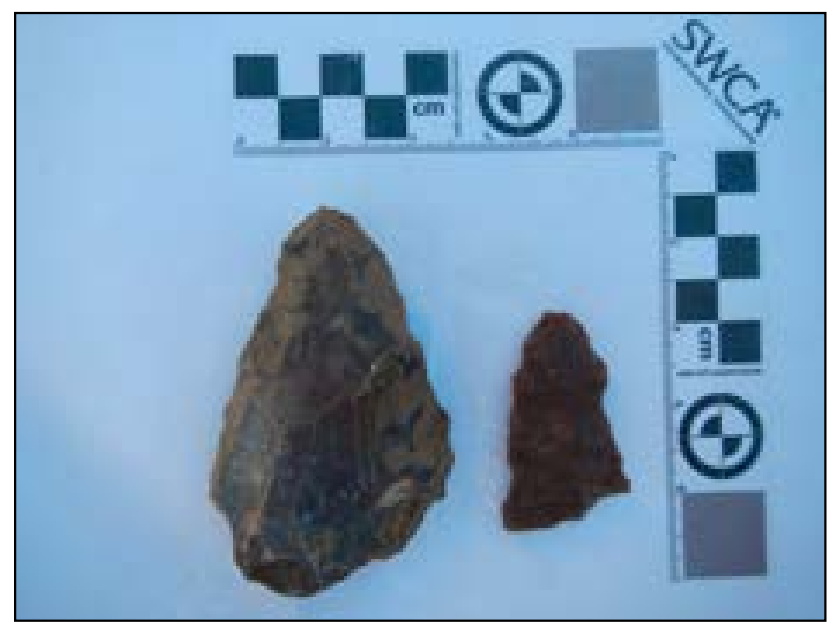

Figure 3.71a. Artifacts recovered from site $41 \mathrm{CM} 401$.
In 2015, SWCA excavated eight shovel tests (i.e., KS108-11 and RW309-12) to delineate the site and all were negative for subsurface cultural materials (Table 3.23). In 2018, SWCA excavated an additional 28 shovel tests to further delineate the site (i.e., JFA07-13, JIS01-5, MCC543-548, MFV01-05, VM01-05), of which nine (i.e., JIS02, JIS04, MCC547, MFV01-04, VM03, and VM05) were positive for cultural materials between 0 and $60 \mathrm{cmbs}$, although the majority of artifacts were recovered from $0-25 \mathrm{cmbs}$. Prehistoric cultural materials recovered include one core, one complete biface, one biface fragment, five chert primary reduction flakes, two chert secondary reduction flakes, four chert tertiary reduction flakes, and one chert shatter fragment. Historic cultural materials include one amber bottle base and one colorless bottle glass fragment (see Table 3.23). No temporally diagnostic artifacts or cultural features were observed within these later shovel tests.

Shovel tests varied, but typically revealed very dark brown (10YR 2/2) to reddish brown (5YR 5/3) clay loam with 5 percent to greater than 20 percent cobble, gravel, and large rock fragment inclusions overlying compacted, impassible clays or bedrock between 15 and $70 \mathrm{cmbs}$. Due to project constraints, the site was not fully delineated in all directions, as investigations were not permitted outside the project ROW. Due to a shift of the project corridor since the original recording of the site, the originally recorded portion of the site is now outside the project area boundaries.

Archival research conducted in 2018 and 2019 indicates that site $41 \mathrm{CM} 401$ is located on two tracts of land

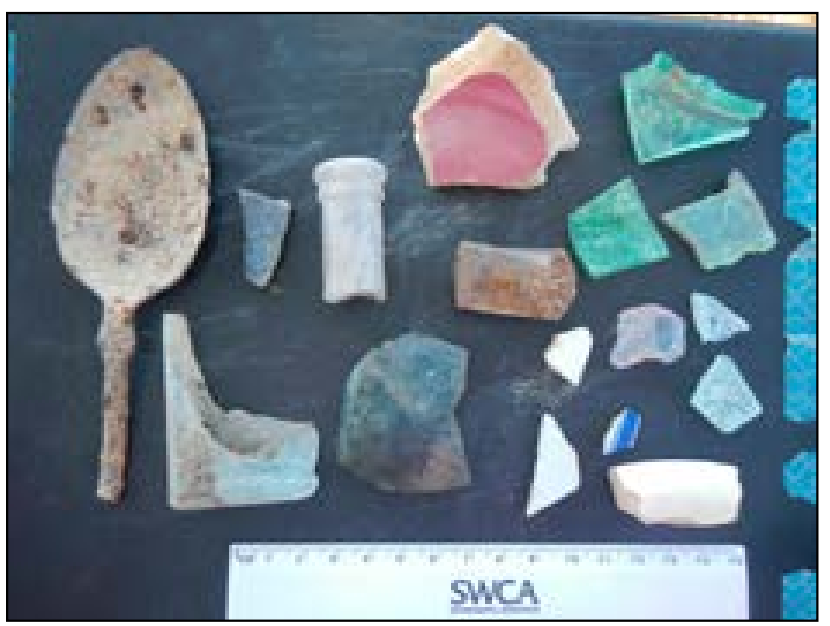

Figure 3.71b. Artifacts recovered from site 41CM401. 
Table 3.23. Shovel Test Data for Site 41CM401

\begin{tabular}{|c|c|c|c|c|c|c|c|c|c|}
\hline $\begin{array}{l}\text { Shovel } \\
\text { Test No. }\end{array}$ & Level & $\begin{array}{l}\text { Depth } \\
\text { (cmbs) }\end{array}$ & $\begin{array}{l}\text { Munsell } \\
\text { Soil Value }\end{array}$ & $\begin{array}{l}\text { Munsell Soil } \\
\text { Color }\end{array}$ & $\begin{array}{l}\text { Soil } \\
\text { Texture }\end{array}$ & $\begin{array}{l}\text { Inclusion } \\
\text { Percentage }\end{array}$ & Inclusion Type & $\begin{array}{l}\text { Cultural } \\
\text { Materials }\end{array}$ & $\begin{array}{l}\text { Comments/ } \\
\text { Reason for } \\
\text { Termination }\end{array}$ \\
\hline \multicolumn{10}{|c|}{2015 Initial Cultural Resources Investigations } \\
\hline RW309 & 1 & $0-10$ & 10YR 5/4 & $\begin{array}{l}\text { yellowish } \\
\text { brown }\end{array}$ & $\begin{array}{l}\text { Sandy } \\
\text { Clay Loam }\end{array}$ & $>20 \%$ & $\begin{array}{l}\text { Cobbles, Gravels, } \\
\text { Large Rock } \\
\text { Fragments }\end{array}$ & None & Terminated at bedrock \\
\hline RW310 & 1 & $0-10$ & 10YR 5/4 & $\begin{array}{l}\text { yellowish } \\
\text { brown }\end{array}$ & $\begin{array}{l}\text { Sandy } \\
\text { Clay Loam }\end{array}$ & $>20 \%$ & $\begin{array}{l}\text { Cobbles, Gravels, } \\
\text { Large Rock } \\
\text { Fragments }\end{array}$ & None & Terminated at bedrock \\
\hline RW311 & 1 & $0-15$ & 10YR 2/1 & black & Clay Loam & $5-10 \%$ & Cobbles & None & $\begin{array}{l}\text { Terminated at basal } \\
\text { clay. }\end{array}$ \\
\hline RW312 & 1 & $0-15$ & 10YR 2/1 & black & Clay Loam & $5-10 \%$ & Cobbles & None & $\begin{array}{l}\text { Terminated at basal } \\
\text { clay. }\end{array}$ \\
\hline KS108 & 1 & $0-10$ & 10YR 5/4 & $\begin{array}{l}\text { yellowish } \\
\text { brown }\end{array}$ & $\begin{array}{l}\text { Sandy } \\
\text { Clay Loam }\end{array}$ & $>20 \%$ & $\begin{array}{l}\text { Cobbles, Gravels, } \\
\text { Large Rock } \\
\text { Fragments }\end{array}$ & None & Terminated at bedrock \\
\hline KS109 & 1 & $0-10$ & 10YR 5/4 & $\begin{array}{l}\text { yellowish } \\
\text { brown }\end{array}$ & $\begin{array}{l}\text { Sandy } \\
\text { Clay Loam }\end{array}$ & $>20 \%$ & $\begin{array}{l}\text { Cobbles, Gravels, } \\
\text { Large Rock } \\
\text { Fragments }\end{array}$ & None & Terminated at bedrock \\
\hline KS110 & 1 & $0-15$ & 10YR 2/1 & black & Clay Loam & $5-10 \%$ & Cobbles & None & $\begin{array}{l}\text { Terminated at basal } \\
\text { clay. }\end{array}$ \\
\hline KS111 & 1 & $0-15$ & 10YR 2/1 & black & Clay Loam & $5-10 \%$ & Cobbles & None & $\begin{array}{l}\text { Terminated at basal } \\
\text { clay. }\end{array}$ \\
\hline \multicolumn{10}{|c|}{ 2016-2018 Additional Cultural Resources Investigations } \\
\hline JFA07 & 1 & $0-5$ & 10YR 2/2 & $\begin{array}{l}\text { very dark } \\
\text { brown }\end{array}$ & Silty Clay & $>20 \%$ & $\begin{array}{l}\text { Gravels, Mottles, } \\
\text { Pebbles }\end{array}$ & None & Terminated at bedrock \\
\hline JFA08 & 1 & $0-30$ & 5YR 3/2 & $\begin{array}{l}\text { dark reddish } \\
\text { brown }\end{array}$ & $\begin{array}{l}\text { Silty Clay } \\
\text { Loam }\end{array}$ & $5-10 \%$ & Cobbles, Pebbles & None & Terminated at bedrock \\
\hline JFA09 & 1 & $1-15$ & 5YR 3/2 & $\begin{array}{l}\text { dark reddish } \\
\text { brown }\end{array}$ & $\begin{array}{l}\text { Silty Clay } \\
\text { Loam }\end{array}$ & $10-20 \%$ & $\begin{array}{l}\text { Cobbles, Mottles, } \\
\text { Pebbles }\end{array}$ & None & Terminated at bedrock \\
\hline JFA10 & 1 & $0-15$ & 10YR 2/2 & $\begin{array}{l}\text { very dark } \\
\text { brown }\end{array}$ & $\begin{array}{l}\text { Silty Clay } \\
\text { Loam }\end{array}$ & $5-10 \%$ & Cobbles, Pebbles & None & Terminated at bedrock \\
\hline JFA11 & 1 & $0-30$ & 10YR 2/2 & $\begin{array}{l}\text { very dark } \\
\text { brown }\end{array}$ & $\begin{array}{l}\text { Silty Clay } \\
\text { Loam }\end{array}$ & $>20 \%$ & Cobbles, Pebbles & None & Terminated at bedrock \\
\hline \multirow[b]{2}{*}{ JFA12 } & 1 & $0-30$ & 10YR 2/2 & $\begin{array}{l}\text { very dark } \\
\text { brown }\end{array}$ & Clay & $5-10 \%$ & Cobbles, Pebbles & None & - \\
\hline & 2 & $30-50$ & 10YR 3/6 & $\begin{array}{l}\text { dark } \\
\text { yellowish } \\
\text { brown }\end{array}$ & Clay & $5-10 \%$ & Cobbles, Pebbles & None & $\begin{array}{l}\text { Terminated at basal } \\
\text { clay. }\end{array}$ \\
\hline JFA13 & 1 & $0-30$ & $5 Y R 3 / 2$ & $\begin{array}{l}\text { dark reddish } \\
\text { brown }\end{array}$ & $\begin{array}{l}\text { Silty Clay } \\
\text { Loam }\end{array}$ & $5-10 \%$ & Cobbles, Pebbles & None & Terminated at bedrock \\
\hline JIS01 & 1 & $0-30$ & 10YR 4/4 & $\begin{array}{l}\text { dark } \\
\text { yellowish } \\
\text { brown }\end{array}$ & Clay Loam & $>20 \%$ & $\begin{array}{l}\text { Cobbles, Gravels, } \\
\text { Mottles, Pebbles }\end{array}$ & None & Terminated at bedrock \\
\hline \multirow{3}{*}{ JIS02 } & 1 & $0-5$ & 10YR 4/4 & $\begin{array}{l}\text { dark } \\
\text { yellowish } \\
\text { brown }\end{array}$ & Silt Loam & $10-20 \%$ & Mottles, Pebbles & 1: Biface & - \\
\hline & 2 & $5-20$ & 10YR 2/2 & $\begin{array}{l}\text { very dark } \\
\text { brown }\end{array}$ & Silty Clay & $1-5 \%$ & Pebbles & None & - \\
\hline & 3 & $20-50$ & $5 Y R 3 / 2$ & $\begin{array}{l}\text { dark reddish } \\
\text { brown }\end{array}$ & Silty Clay & $1-5 \%$ & Pebbles & None & Terminated at bedrock \\
\hline JIS03 & 1 & $0-25$ & 10YR 5/8 & $\begin{array}{l}\text { yellowish } \\
\text { brown }\end{array}$ & $\begin{array}{l}\text { Sandy } \\
\text { Clay Loam }\end{array}$ & $1-5 \%$ & Mottles, Pebbles & None & $\begin{array}{l}\text { Terminated at } \\
\text { disturbed. }\end{array}$ \\
\hline
\end{tabular}


Table 3.23. continued

\begin{tabular}{|c|c|c|c|c|c|c|c|c|c|}
\hline $\begin{array}{l}\text { Shovel } \\
\text { Test No. }\end{array}$ & Level & $\begin{array}{l}\text { Depth } \\
\text { (cmbs) }\end{array}$ & $\begin{array}{l}\text { Munsell } \\
\text { Soil Value }\end{array}$ & $\begin{array}{l}\text { Munsell Soil } \\
\text { Color }\end{array}$ & $\begin{array}{l}\text { Soil } \\
\text { Texture }\end{array}$ & $\begin{array}{l}\text { Inclusion } \\
\text { Percentage }\end{array}$ & Inclusion Type & $\begin{array}{l}\text { Cultural } \\
\text { Materials }\end{array}$ & $\begin{array}{l}\text { Comments/ } \\
\text { Reason for } \\
\text { Termination }\end{array}$ \\
\hline JIS04 & 1 & $0-30$ & 10YR 3/1 & $\begin{array}{l}\text { very dark } \\
\text { gray }\end{array}$ & Silty Clay & $5-10 \%$ & $\begin{array}{l}\text { Cobbles, Gravels, } \\
\text { Pebbles }\end{array}$ & $\begin{array}{l}\text { 1: Core, } \\
\text { 1: Flake } \\
\text { (primary), } \\
\text { 1: Flake } \\
\text { (secondary), } \\
\text { 1: Flake } \\
\text { (tertiary), } \\
\text { Amber } \\
\text { bottle base } \\
\text { fragment } \\
\text { [All b/w } 0-10 \\
\text { cmbs] }\end{array}$ & $\begin{array}{l}\text { Terminated at } \\
\text { impenetrable cobbles. }\end{array}$ \\
\hline JIS05 & 1 & $0-70$ & 10YR 3/1 & $\begin{array}{l}\text { very dark } \\
\text { gray }\end{array}$ & Clay & $1-5 \%$ & Pebbles & None & $\begin{array}{l}\text { Terminated at compact } \\
\text { soil. }\end{array}$ \\
\hline MCC543 & 1 & $0-20$ & 10YR 6/6 & $\begin{array}{l}\text { brownish } \\
\text { yellow }\end{array}$ & Clay & $>20 \%$ & Gravels, Mottles & None & Terminated at bedrock. \\
\hline \multirow[b]{2}{*}{ MCC544 } & 1 & $0-10$ & 10YR 6/6 & $\begin{array}{l}\text { brownish } \\
\text { yellow }\end{array}$ & Clay & $>20 \%$ & Gravels, Mottles & None & - \\
\hline & 2 & $10-30$ & 10YR 3/2 & $\begin{array}{l}\text { very dark } \\
\text { grayish } \\
\text { brown }\end{array}$ & $\begin{array}{l}\text { Silty Clay } \\
\text { Loam }\end{array}$ & $>20 \%$ & Gravels & None & Terminated at bedrock. \\
\hline \multirow{2}{*}{ MCC545 } & 1 & $0-15$ & 10YR 4/2 & $\begin{array}{l}\text { dark grayish } \\
\text { brown }\end{array}$ & Clay & $10-20 \%$ & Gravels & None & - \\
\hline & 2 & $15-25$ & 5YR 5/6 & yellowish red & Clay & - & - & None & $\begin{array}{l}\text { Terminated at basal } \\
\text { clay. }\end{array}$ \\
\hline MCC546 & 1 & $0-20$ & 10YR 3/2 & $\begin{array}{l}\text { very dark } \\
\text { grayish } \\
\text { brown }\end{array}$ & Silt Loam & $>20 \%$ & Gravels & None & Terminated at bedrock. \\
\hline MCC547 & 1 & $0-20$ & 10YR 4/2 & $\begin{array}{l}\text { dark grayish } \\
\text { brown }\end{array}$ & $\begin{array}{l}\text { Silty Clay } \\
\text { Loam }\end{array}$ & $>20 \%$ & Gravels & $\begin{array}{l}\text { 1: Flake } \\
\text { (primary), } \\
\text { 1: Flake } \\
\text { (secondary) }\end{array}$ & $\begin{array}{l}\text { Terminated at thick } \\
\text { gravels. }\end{array}$ \\
\hline \multirow{2}{*}{ MCC548 } & 1 & $0-40$ & 10YR 4/2 & $\begin{array}{l}\text { dark grayish } \\
\text { brown }\end{array}$ & $\begin{array}{l}\text { Silty Clay } \\
\text { Loam }\end{array}$ & $10-20 \%$ & Gravels & None & - \\
\hline & 2 & $40-50$ & 7.5YR 5/6 & strong brown & Clay & - & - & None & $\begin{array}{l}\text { Terminated at basal } \\
\text { clay. }\end{array}$ \\
\hline \multirow[b]{2}{*}{ MFV01 } & 1 & $0-6$ & $2.5 Y R 5 / 4$ & $\begin{array}{l}\text { reddish } \\
\text { brown }\end{array}$ & Clay & $>20 \%$ & $\begin{array}{l}\text { Cobbles, Gravels, } \\
\text { Large Rock Frags, } \\
\text { Mottles, Pebbles }\end{array}$ & None & - \\
\hline & 2 & $6-45$ & $2.5 Y R 3 / 2$ & dusky red & Clay & $5-10 \%$ & Cobbles, Pebbles & $\begin{array}{l}\text { 2: Flake } \\
\text { (primary) } \\
\text { [approx } 40 \\
\text { cmbs] }\end{array}$ & Terminated at bedrock. \\
\hline \multirow{2}{*}{ MFV02 } & 1 & $0-15$ & $2.5 Y R 5 / 4$ & $\begin{array}{l}\text { reddish } \\
\text { brown }\end{array}$ & Clay & $>20 \%$ & $\begin{array}{l}\text { Cobbles, Gravels, } \\
\text { Large Rock Frags, } \\
\text { Mottles, Pebbles }\end{array}$ & None & - \\
\hline & 2 & $15-22$ & $2.5 Y R$ 3/1 & $\begin{array}{l}\text { dark reddish } \\
\text { gray }\end{array}$ & Clay & $5-10 \%$ & $\begin{array}{l}\text { Cobbles, Large } \\
\text { Rock Frags, } \\
\text { Pebbles }\end{array}$ & $\begin{array}{l}\text { 1: Flake } \\
\text { (tertiary) }\end{array}$ & $\begin{array}{l}\text { Terminated at large } \\
\text { rock and bedrock. }\end{array}$ \\
\hline
\end{tabular}


Table 3.23. continued

\begin{tabular}{|c|c|c|c|c|c|c|c|c|c|}
\hline $\begin{array}{l}\text { Shovel } \\
\text { Test No. }\end{array}$ & Level & $\begin{array}{l}\text { Depth } \\
\text { (cmbs) }\end{array}$ & $\begin{array}{l}\text { Munsell } \\
\text { Soil Value }\end{array}$ & $\begin{array}{l}\text { Munsell Soil } \\
\text { Color }\end{array}$ & $\begin{array}{l}\text { Soil } \\
\text { Texture }\end{array}$ & $\begin{array}{l}\text { Inclusion } \\
\text { Percentage }\end{array}$ & Inclusion Type & $\begin{array}{l}\text { Cultural } \\
\text { Materials }\end{array}$ & $\begin{array}{l}\text { Comments/ } \\
\text { Reason for } \\
\text { Termination }\end{array}$ \\
\hline \multirow[t]{2}{*}{ MFV03 } & 1 & $0-7$ & $2.5 Y R 5 / 8$ & red & Clay & $10-20 \%$ & $\begin{array}{l}\text { Calcium Carbonate, } \\
\text { Cobbles, Gravels, } \\
\text { Large Rock Frags, } \\
\text { Mottles, Pebbles }\end{array}$ & None & - \\
\hline & 2 & $7-15$ & 2.5YR 3/1 & $\begin{array}{l}\text { dark reddish } \\
\text { gray }\end{array}$ & Clay & $10-20 \%$ & $\begin{array}{l}\text { Cobbles, Gravels, } \\
\text { Large Rock Frags, } \\
\text { Pebbles }\end{array}$ & $\begin{array}{l}\text { 1: Flake } \\
\text { (tertiary) }\end{array}$ & $\begin{array}{l}\text { Terminated at large } \\
\text { boulder and large tree } \\
\text { root. }\end{array}$ \\
\hline MFV04 & 1 & $0-15$ & 2.5YR 3/1 & $\begin{array}{l}\text { dark reddish } \\
\text { gray }\end{array}$ & Clay Loam & $>20 \%$ & $\begin{array}{l}\text { Cobbles, Gravels, } \\
\text { Large Rock Frags, } \\
\text { Pebbles }\end{array}$ & $\begin{array}{l}\text { 1: Flake } \\
\text { (tertiary) }\end{array}$ & $\begin{array}{l}\text { Disturbed ground } \\
\text { at area of shovel } \\
\text { test. Terminated at } \\
\text { impenetrable cobbles. }\end{array}$ \\
\hline MFV05 & 1 & $0-40$ & $2.5 Y R 3 / 1$ & $\begin{array}{l}\text { dark reddish } \\
\text { gray }\end{array}$ & Clay & $1-5 \%$ & Gravels, Pebbles & None & $\begin{array}{l}\text { Terminated at compact } \\
\text { soil. }\end{array}$ \\
\hline \multirow{3}{*}{ VM01 } & 1 & $0-7$ & $2.5 Y R 3 / 2$ & dusky red & Clay & $>20 \%$ & $\begin{array}{l}\text { Gravels, Mottles, } \\
\text { Pebbles, Sand and } \\
\text { organic material like } \\
\text { leaves }\end{array}$ & None & $\begin{array}{l}\text { No cultural material } \\
\text { encountered. }\end{array}$ \\
\hline & 2 & $7-30$ & 10YR 2/2 & $\begin{array}{l}\text { very dark } \\
\text { brown }\end{array}$ & Clay Loam & $5-10 \%$ & $\begin{array}{l}\text { Cobbles, Large } \\
\text { Rock Frags, Snail } \\
\text { Shell }\end{array}$ & None & - \\
\hline & 3 & $30-40$ & 7.5YR 2.5/1 & black & Clay Loam & $5-10 \%$ & Pebbles & None & Terminated at bedrock. \\
\hline \multirow{2}{*}{ VM02 } & 1 & $0-10$ & $2.5 Y R$ 4/6 & red & Clay & $>20 \%$ & $\begin{array}{l}\text { Gravels, Mottles, } \\
\text { Pebbles }\end{array}$ & None & - \\
\hline & 2 & $10-30$ & 10YR 2/2 & $\begin{array}{l}\text { very dark } \\
\text { brown }\end{array}$ & Clay Loam & $5-10 \%$ & $\begin{array}{l}\text { Large Rock Frags, } \\
\text { Pebbles }\end{array}$ & None & Terminated at bedrock. \\
\hline \multirow[b]{2}{*}{ VM03 } & 1 & $0-17$ & $5 Y R 5 / 3$ & $\begin{array}{l}\text { reddish } \\
\text { brown }\end{array}$ & Clay & $>20 \%$ & $\begin{array}{l}\text { Cobbles, Gravels, } \\
\text { Mottles, Pebbles }\end{array}$ & None & - \\
\hline & 2 & $17-25$ & 10YR 2/2 & $\begin{array}{l}\text { very dark } \\
\text { brown }\end{array}$ & Clay Loam & $5-10 \%$ & $\begin{array}{l}\text { Cobbles, Large } \\
\text { Rock Frags }\end{array}$ & $\begin{array}{l}\text { 1: Biface } \\
\text { Fragment, } \\
\text { 4: Shatter. }\end{array}$ & Terminated at bedrock. \\
\hline VM04 & 1 & $0-70$ & 10YR 2/2 & $\begin{array}{l}\text { very dark } \\
\text { brown }\end{array}$ & Clay Loam & $>20 \%$ & Pebbles, Snail Shell & None & $\begin{array}{l}\text { Terminated at } \\
\text { impassable cobbles at } \\
70 \text { cmbs. }\end{array}$ \\
\hline \multirow{3}{*}{ VM05 } & 1 & $0-20$ & 10YR 2/2 & $\begin{array}{l}\text { very dark } \\
\text { brown }\end{array}$ & Clay Loam & $>20 \%$ & $\begin{array}{l}\text { Cobbles, Gravels, } \\
\text { Pebbles, Snail Shell }\end{array}$ & $\begin{array}{l}\text { 1: Flake } \\
\text { (primary), } \\
1 \text { Glass } \\
\text { fragment } \\
{[0-10 \mathrm{cmbs}] .}\end{array}$ & - \\
\hline & 2 & $20-50$ & 10YR 2/2 & $\begin{array}{l}\text { very dark } \\
\text { brown }\end{array}$ & Clay Loam & $>20 \%$ & $\begin{array}{l}\text { Cobbles, Gravels, } \\
\text { Pebbles, Snail Shell }\end{array}$ & None & - \\
\hline & 3 & $50-60$ & 10YR 2/2 & $\begin{array}{l}\text { very dark } \\
\text { brown }\end{array}$ & Clay Loam & $5-10 \%$ & $\begin{array}{l}\text { Cobbles, Gravels, } \\
\text { Pebbles }\end{array}$ & $\begin{array}{l}\text { 1: Core, } \\
\text { 1: Flake } \\
\text { (secondary) }\end{array}$ & Terminated at depth. \\
\hline
\end{tabular}


that were originally out of the Valentine Bennett Survey and the Francisco Rodriguez Survey. The current size of the land tracts comprising the subject property include a 155.7-acre tract of land out of the Valentine Bennett and Francisco Rodriguez surveys and a 291.5acre tract of land out of the Bennett and Rodriguez surveys. Although there is some overlap between these two tracts of land, the majority of the 155.7-acre tract comes from the Bennett survey and the majority of the 291.5 acre tract comes from the Rodriguez survey. These two tracts of land were associated with various different families throughout history.

The 155.7-acre tract was initially part of a larger 213.33-acre tract that Catharina and W.S. Pryor of Tennessee conveyed to Peter Markwardt in 1866 (Comal County Deed Records [CCDR] 1866:H:403). This was the first division of the Bennett survey. Markwardt retained the property until 1880 , when he sold it to his son, Friederich Markwardt (CCDR 1880:O:767).

Prior to his purchase of the property, the 1860 Comal County census indicates that Peter Markwardt and his family, including his 8-year-old son Friederich (Fritz) lived outside New Braunfels. By 1870, the Comal County census shows Peter Markwardt as a resident of Precinct 2. Markwardt was listed as a 69-yearold farmer heading a household containing Carline (sic) (48), Fritz (18), Bernardine (14), Wilhelm (13), Mathilde (11), and Albert (7). The 1880 Comal County census shows Peter Markwardt (79), his wife Caroline (58), and children Wilhelm (23), Mathilde (20), and Albert (17) were still residing in Precinct 2. Both records show that the Markwardts were living next to Wilhelmine Wiederstein and her children, suggesting they could have lived on the subject tract. Fritz (27), their son, and his wife Dorthea (29) were also living next to them in 1880, suggesting they could also have lived on the tract.

By 1898, Fritz and his new wife had conveyed the property to Adolph Jonas (CCDR 1898:Y:31), and the 1900 Comal County Census shows Fritz had remarried and lived in New Braunfels. The 1900 Comal County census also shows that Adolph Jonas was a 38-yearold farmer living with his family in Precinct 2. Jonas was shown as a property owner. He continued to live in Precinct 2 in 1910, when the Comal County Census shows him as a 48-year-old farmer living with his wife Caroline (45), and children Elfreida (18), Olga (15), and Oscar (4). By 1920, Adolph (58), Caroline
(55), and Oscar (19) were living on Bracken Road in Precinct 2.

The 1930 Comal County census indicates that Adolph (68) and Caroline (65) had moved in with Oscar (29), his wife Valesca (24), and their son Woodroe (3) by that time, still living in Precinct 2. Adolph appears to have passed away sometime prior to 1935, when Caroline and her daughters conveyed the subject tract to Oscar (CCDR 1935:64:471). Oscar (38), Valesca (36), and Woodroe (13) were living on a private road in Precinct 1 in the same house where they had lived in 1935, suggesting they could have lived on the property. As the Jonas family continued to keep the property in their possession through the twenty-first century, it is likely site $41 \mathrm{CM} 410$ could be associated with their family.

The 291.5-acre tract included part of the property owned by the Jonas family as described above and also partially consists of a 179-acre tract owned by the Friesenhahn family throughout the late nineteenth and early twentieth centuries. Originally part of the league and labor granted to Francisco Rodriguez and patented by William Bracken in 1847 (GLO 2019), this tract was not subdivided until 1865, when John James (who had obtained the tract directly from William Bracken in 1847) conveyed 603 acres containing the subject tract to Anna Syring (CCDR 1865:H:55). James, who was a well-known surveyor in San Antonio (Strong 2019) did not live on the tract.

Within a few weeks of acquiring the property, Anna Syring conveyed the property to her sons, Andreas Friesenhahn, Nicolaus Friesenhahn, and Heinrich Syring (CCDR 1865:H:61; Comal County 2015). The brothers partitioned the land in 1870 , at which time Heinrich was still a minor. Each party received 179 acres of land, with Nicolaus receiving the westernmost tract, Henrich the middle, and Andreas the eastern tract (CCDR 1870:K:348).

In 1860, the Comal County census shows Anna Luhring (sic) as a 44-year-old farmer who was head of a household containing Andreas Friesenhahn (17), also a farmer, Nicolaus Friesenhahn (15), a waggoner, and Heinrich Luhring (sic) (7). Nicolaus had moved from their mother's household by 1870 , when the 1870 Comal County census shows Anna Syring as a 55-year-old head of household living in Precinct 2 with her son Heinrich (16). Andreas Friesenhahn (32), a farmer, and his wife Polasita (sic) [Placida] (22) also resided in the household at that time. By 1880, Anna 
Syring (63) was living in her son Andreas' household in Precinct 2 of Comal County. As deed research indicates that Nicolaus Friesenhahn owned the portion of the property containing the subject tract, Anna does not appear to have lived on the subject tract.

Nicolaus conveyed his 179-acre tract to his wife Pauline in 1876 along with his entire stock of longhorns and four mares. Pauline kept the property until 1914 when she conveyed it to Joseph Friesenhahn (CCDR 1914:14:525). Both the 1870 and 1880 Comal County census records show that Nicolaus lived in Precinct 2. In 1870, his household consisted of himself (25) and his wife Pauline (20). By 1880, Nicolaus (35), a farmer, headed a household containing his wife Caroline (sic) (28) and children Joseph (9), Marie (6), and Clara (2). By 1900, Nickolaus (sic) (55) was shown to be a farmer who owned the property where he lived. His household included his wife Pauline (44), daughters Regina (19), Paulina (17), Anna (12), and Hedwig (10) as well as his son Edward (15) and a boarder, Louis Lorscheib (49). Henry Syring (45) and his family lived next door, suggesting these families may have lived on the land tracts they received from Anna Syring. The 1910 Comal County census shows Nicolaus and Pauline had moved to New Braunfels by that time.

Joseph Friesenhahn kept the land until 1944 when he conveyed the property to Harry Brotze (CCDR 1944:80:227). He appears in the 1900 Comal County census as a 29-year-old farmer living in Precinct 2. His wife Marie (22) and daughter Olivia (5 months) lived in the household. The family is shown as renting their property. By 1910, Joseph is shown as a propertyowner with a mortgage. He was listed as a 49-year-old farmer heading a household containing his children Olivia (10), Carl (8), Oseda (7), Amalia (6), Christine (3), and Hugo (1). A boarder, 24-year-old Emma Barton, and a servant, 22-year-old Rosa Fey, also lived with the family. By 1920, the Comal County census shows Joseph Friesenhahn (49) as owning his residence on Bracken Road. The household included his wife Emma (35), children Olivia (20), Carl (18), Osida (17), Amalia (16), Christina (12), Hugo (10), Alfred (8), Edmund (7), and Nathalia (5). The 1930 and 1940 Comal County censuses show the family continued to live in Precinct 2, although no road is listed in 1930, and the family is shown to reside on a private road in 1940. As a result, it is unknown whether the family or tenants lived on the subject tract.
The research suggests site $41 \mathrm{CM} 410$ is associated with the Friesenhahn and the Jonas families in the late nineteenth/early twentieth centuries. The Friesenhahns may have played a significant role in local development, as Anna (Friesenhahn) Syring was one of the early settlers in Comal County. She lived outside of New Braunfels. According to early county history, her land was the site of a homestead and cotton and corn mill, which her son Roman took over. The farm was located near Old Nacogdoches Road and FM 482, which is just outside the project area to the northeast (Comal County 2015). This suggests the original homestead may be just outside the current project area. The Jonas family does not appear to have been significant to the development of the local or regional area.

Although site 41CM401 is not eligible under Criterion $\mathrm{D}$, it is likely the site extends outside the current project area. The portion of the site within the project area is recommended not eligible for listing under Criteria $\mathrm{B}$, C, or D. Site 41CM401 is recommended eligible for the NRHP under Criterion A; however, given that deposits likely extend outside the project area, no additional work is recommended for the current project area. Further archival research may be required in the future if the site is impacted outside the current project area.

\section{CM401 SUMMARY}

Site 41CM401 consists of a multicomponent prehistoric and historic artifact scatter with very minimal, shallow subsurface deposits. Temporally diagnostic artifacts encountered include historic ceramic and glass that indicate an early-twentieth-century historic component. No other diagnostic artifacts or cultural features were observed; however, a cattle barn likely dating to the early to mid-twentieth century was observed immediately adjacent to the southern boundary of the site. The site lacks deposition and isolable activity areas and has been significantly disturbed by mining operations and associated infrastructure as well as cattle ranching and farming activities. It is the opinion of SWCA that site 41CM401 does not have the potential to yield information important to the prehistory or history of the region. As such, SWCA recommends site 41CM401 as NOT ELIGIBLE for the NRHP or for designation as a SAL. No further work or avoidance strategy is recommended for site 41CM401 within the project area. However, because the site likely extends in all directions beyond the project area, should the alignment shift, additional investigations would be necessary. 


\section{CM404}

Site 41CM404 is a surficial prehistoric lithic scatter of unknown temporal or cultural affiliation situated on an open field along an upland slope approximately 0.28 mile southeast of Bear Creek and 0.2 miles west of Dry Comal Creek in southern Comal County, Texas (Figure 3.72; Appendix A:289). The site was originally recorded during the initial 2015 cultural resources investigations. Vegetation at the site consists primarily of grasses and sporadic mesquite with moderately dense juniper and oak woods along the northwestern periphery, which afforded nearly 100 percent ground surface visibility with exposed areas of dense limestone cobble and gravel outcrops (Figure 3.73). The site is on privately owned land currently utilized for agricultural purposes and wild game hunting, and disturbances observed include erosion, vegetation clearing, fence lines, and two-track roads. SWCA's 2015 initial investigations recommended site 41CM401 as NOT ELIGIBLE for listing in the NRHP or SAL designation with no avoidance or further work warranted due to shallow deposits, lack of temporally diagnostic artifacts or cultural features, and significant disturbances in the area (Acuña et al. 2016).

Site 41CM404 initially measured $100 \mathrm{~m}$ northeast/ southwest by $85 \mathrm{~m}$ northwest/southeast based on results of the 2015 initial investigations. The revisit of the site in 2017 resulted in a small extension along the southern margin of the original boundary that measures $60 \mathrm{~m}$ northwest/southeast by $20 \mathrm{~m}$ wide northeast/southwest. All site measurements are based on surface artifact distributions. Site boundaries were determined by ground surface inspection and shovel testing for subsurface cultural deposits within the project area boundaries.

Cultural materials observed during ground surface inspection consist of two stone choppers, one unifacial drill, and numerous secondary and tertiary reduction flakes (Figure 3.74). A few scattered burned rocks were also observed around the northwestern end of the site where limestone concentrations were prevalent. All lithic materials observed were composed of chert raw material types with the exception of the burned rock fragments.

In 2015, SWCA excavated six shovel tests (i.e., RW738-741 and SMM83-84) at approximately 20- to 25-m intervals to delineate the site, all of which were negative for cultural materials (Table 3.24). In 2017,
SWCA excavated three shovel tests (i.e., 41RW25202521 and SS15) at approximately $35-\mathrm{m}$ intervals to further delineate the site, all of which were negative for cultural materials (see Table 3.24). No temporally diagnostic artifacts or cultural features were observed. Shovel tests typically revealed dark yellowish brown (10YR 3/4) clay loam with 1-5 percent calcium carbonates and gravel inclusions overlying brown (7.5YR 4/4) clay with 10-20 percent calcium carbonate inclusions; shovel tests terminated at compacted clay or degrading bedrock around $30 \mathrm{cmbs}$. Due to a shift of the project corridor since the original recording of the site, the majority of the site is now outside the project area boundaries.

\section{CM404 SUMMARY}

Site 41CM404 consists of a strictly surficial prehistoric lithic scatter site of unknown temporal and cultural affiliation. The site lacks deposition and temporally diagnostic artifacts or cultural features and has been disturbed by agricultural activities. Based on these data, site 41CM404 does not have the potential to yield information important to the prehistory of the region. As such, SWCA recommends site 41CM404 as NOT ELIGIBLE for the NRHP or for designation as a SAL. No further work or avoidance strategy is recommended for site 41CM404.

\section{BEXAR COUNTY}

One isolated find was newly recorded and one previously recorded cultural resource site was revisited and further investigated in Bexar County (Figure 3.75; see Table 3.3). The previously recorded multicomponent site (i.e, 41BX2101) consists of a prehistoric lithic scatter and historic-aged enclosure with a rock ring recorded and recommended for avoidance or further testing during the 2015 initial investigations and revisited for significance testing of the historic component due to the possibility of a burial during the 2016 to 2018 additional investigations. The isolated find (i.e., IF11) consists of a prehistoric crude biface, modified flake, and primary reduction flake observed along the ground surface and not recorded as an archaeological site (Appendix A:299; see Table 3.4). SWCA recommends the previously recorded archaeological site (i.e., 41BX2101) as NOT ELIGIBLE for listing in the NRHP or SAL designation. No avoidance strategy or further work is recommended this site within the project corridor. 


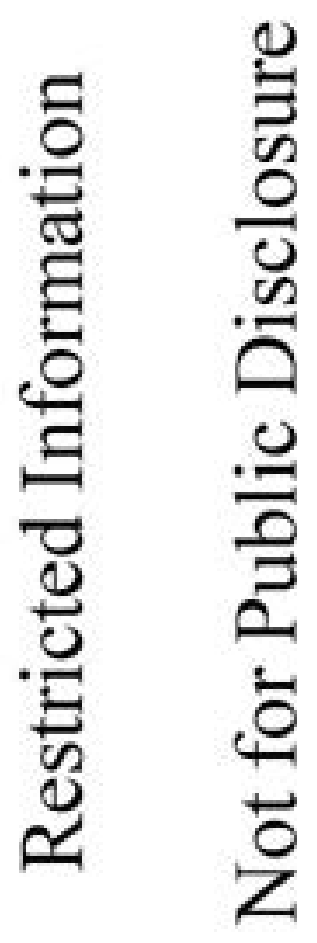

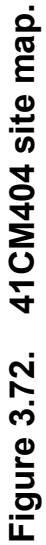




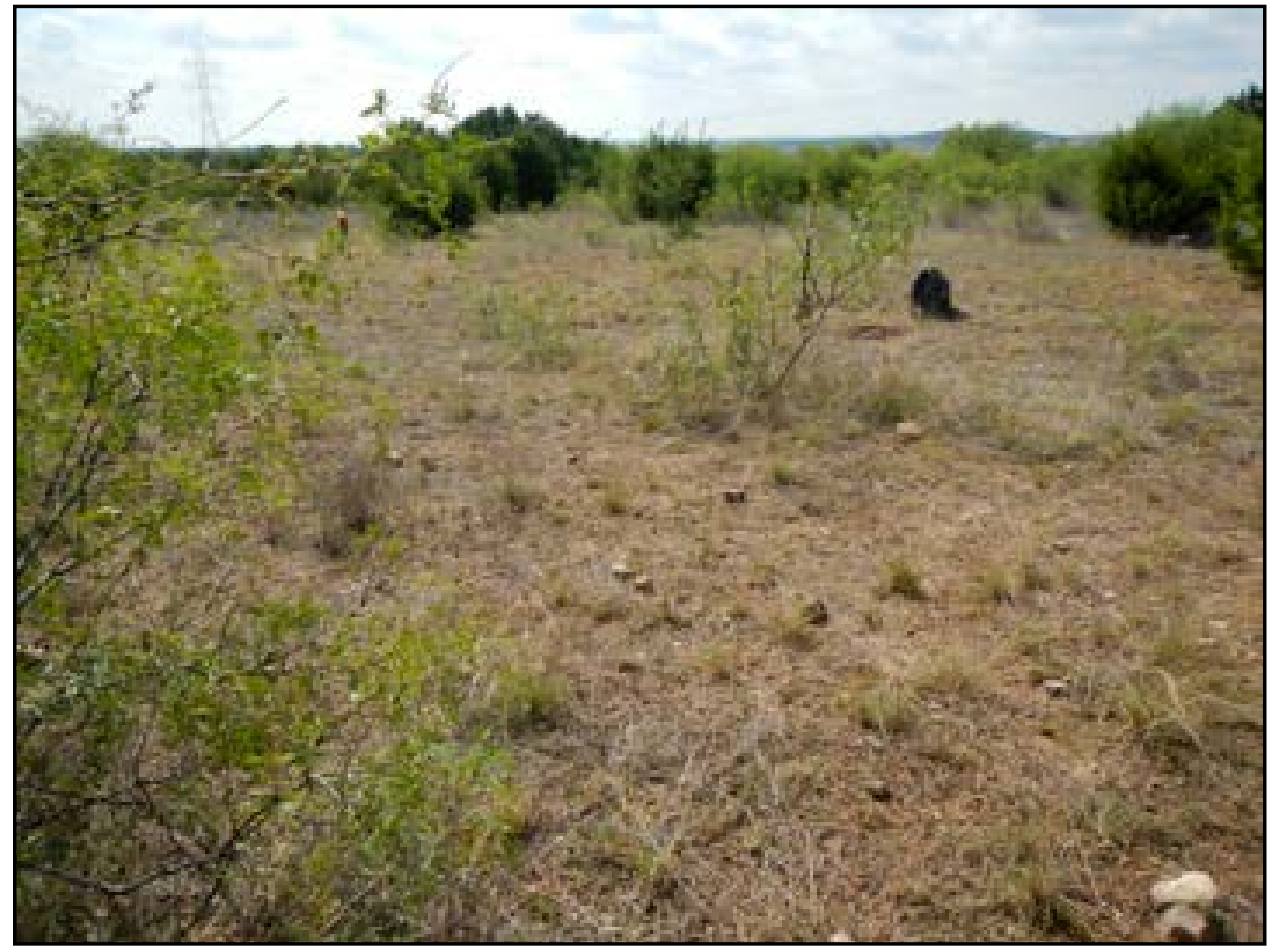

Figure 3.73. Overview of site $41 \mathrm{CM} 404$, facing southeast.

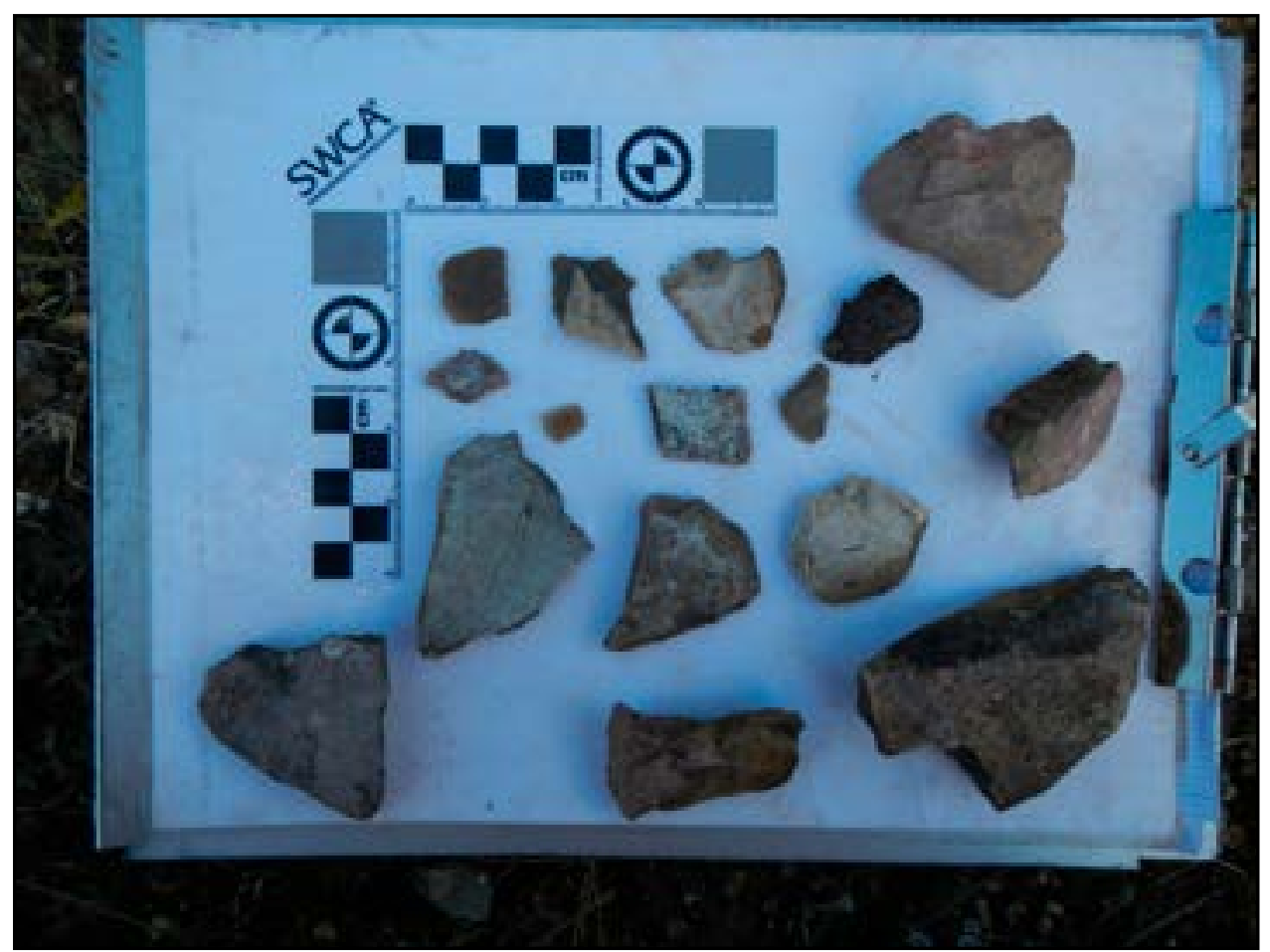

Figure 3.74. Artifacts recovered from site 41CM404. 
Table 3.24. Shovel Test Data for Site 41CM404

\begin{tabular}{|c|c|c|c|c|c|c|c|c|c|}
\hline $\begin{array}{l}\text { Shovel } \\
\text { Test No. }\end{array}$ & Level & $\begin{array}{l}\text { Depth } \\
\text { (cmbs) }\end{array}$ & $\begin{array}{l}\text { Munsell } \\
\text { Soil Value }\end{array}$ & $\begin{array}{l}\text { Munsell Soil } \\
\text { Color }\end{array}$ & $\begin{array}{l}\text { Soil } \\
\text { Texture }\end{array}$ & $\begin{array}{l}\text { Inclusion } \\
\text { Percentage }\end{array}$ & $\begin{array}{l}\text { Inclusion } \\
\text { Type }\end{array}$ & $\begin{array}{l}\text { Cultural } \\
\text { Materials }\end{array}$ & $\begin{array}{l}\text { Comments/ } \\
\text { Reason for Termination }\end{array}$ \\
\hline \multicolumn{10}{|c|}{2015 Initial Cultural Resources Investigations } \\
\hline \multirow[t]{2}{*}{ RW738 } & 1 & $0-25$ & 10YR 3/4 & $\begin{array}{l}\text { Dark yellowish } \\
\text { brown }\end{array}$ & Clay Loam & $1-50 \%$ & $\begin{array}{l}\text { Calcium } \\
\text { Carbonate, } \\
\text { Gravels }\end{array}$ & None & - \\
\hline & 2 & $25-30$ & 7.5YR 4/4 & Brown & Clay & $10-20 \%$ & $\begin{array}{l}\text { Calcium } \\
\text { Carbonate }\end{array}$ & None & Terminated at basal clays. \\
\hline \multirow[t]{2}{*}{ RW739 } & 1 & $0-25$ & 10YR 3/4 & $\begin{array}{l}\text { dark yellowish } \\
\text { brown }\end{array}$ & Clay Loam & $1-5 \%$ & $\begin{array}{l}\text { Calcium } \\
\text { Carbonate, } \\
\text { Gravels }\end{array}$ & None & - \\
\hline & 2 & $25-30$ & 7.5YR 4/4 & brown & Clay & $10-20 \%$ & $\begin{array}{l}\text { Calcium } \\
\text { Carbonate }\end{array}$ & None & Terminated at basal clays. \\
\hline \multirow[t]{2}{*}{ RW740 } & 1 & $0-25$ & 10YR 3/4 & $\begin{array}{l}\text { dark yellowish } \\
\text { brown }\end{array}$ & Clay Loam & $1-5 \%$ & $\begin{array}{l}\text { Calcium } \\
\text { Carbonate, } \\
\text { Gravels }\end{array}$ & None & - \\
\hline & 2 & $25-30$ & 7.5YR 4/4 & brown & Clay & $10-20 \%$ & $\begin{array}{l}\text { Calcium } \\
\text { Carbonate }\end{array}$ & None & Terminated at basal clays. \\
\hline \multirow[t]{2}{*}{ RW741 } & 1 & $0-25$ & 10YR 3/4 & $\begin{array}{l}\text { dark yellowish } \\
\text { brown }\end{array}$ & Clay Loam & $1-5 \%$ & $\begin{array}{l}\text { Calcium } \\
\text { Carbonate, } \\
\text { Gravels }\end{array}$ & None & - \\
\hline & 2 & $25-30$ & 7.5YR 4/4 & brown & Clay & $10-20 \%$ & $\begin{array}{l}\text { Calcium } \\
\text { Carbonate }\end{array}$ & None & Terminated at basal clays. \\
\hline \multirow{2}{*}{ SMM83 } & 1 & $0-15$ & 10YR 4/2 & $\begin{array}{l}\text { dark grayish } \\
\text { brown }\end{array}$ & Clay Loam & $5-10 \%$ & $\begin{array}{l}\text { Cobbles, } \\
\text { pebbles }\end{array}$ & None & - \\
\hline & 2 & $15-30$ & $2.5 Y 6 / 6$ & olive yellow & Clay Loam & $>20 \%$ & $\begin{array}{l}\text { Calcium } \\
\text { Carbonate }\end{array}$ & None & Terminated at basal clays. \\
\hline \multirow{2}{*}{ SMM84 } & 1 & $0-10$ & 10YR 4/3 & brown & Clay Loam & $5-10 \%$ & $\begin{array}{l}\text { Cobbles, } \\
\text { pebbles }\end{array}$ & None & - \\
\hline & 2 & $10-20$ & $2.5 Y 6 / 6$ & olive yellow & Clay Loam & $>20 \%$ & $\begin{array}{l}\text { Calcium } \\
\text { Carbonate }\end{array}$ & None & Terminated at basal clays. \\
\hline \multicolumn{10}{|c|}{ 2016-2018 Additional Cultural Resources Investigations } \\
\hline 41RW2520 & 1 & $0-35$ & 10YR 3/3 & $\begin{array}{l}\text { very dark } \\
\text { brown }\end{array}$ & Clay Loam & $20 \%$ & $\begin{array}{l}\text { Calcium } \\
\text { Carbonate }\end{array}$ & None & Terminated at caliche \\
\hline 41RW2521 & 1 & $0-10$ & 10YR $3 / 3$ & $\begin{array}{l}\text { very dark } \\
\text { brown }\end{array}$ & Clay Loam & $20 \%$ & Cobbles & None & Terminated at bedrock. \\
\hline $41 S S 15$ & 1 & $0-35$ & 10YR 4/2 & $\begin{array}{l}\text { dark grayish } \\
\text { brown }\end{array}$ & $\begin{array}{l}\text { Silty Clay } \\
\text { Loam }\end{array}$ & $>20 \%$ & $\begin{array}{l}\text { Gravels, } \\
\text { Cobbles }\end{array}$ & None & Terminated at bedrock. \\
\hline
\end{tabular}




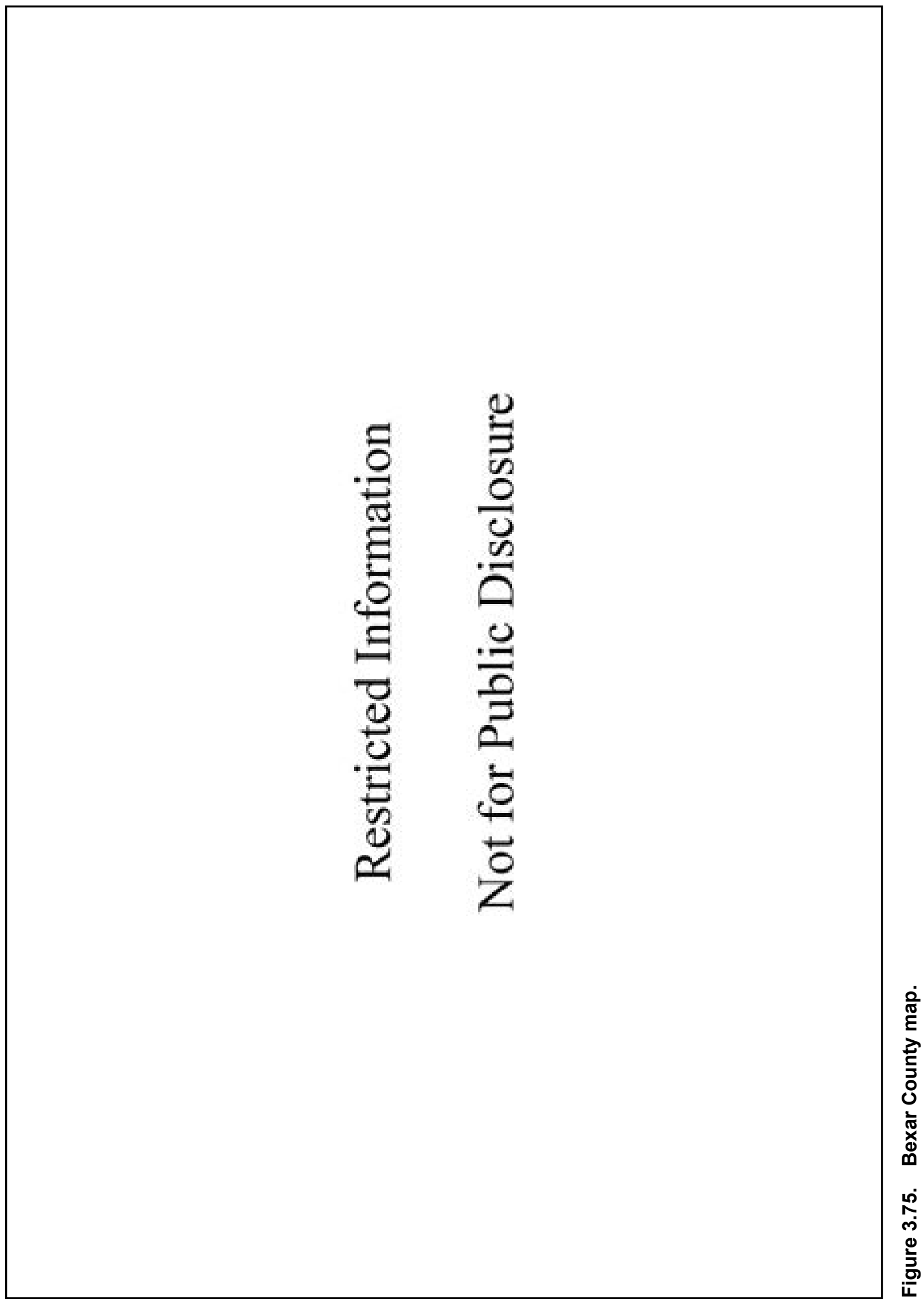




\section{BX2101}

Site 41BX2101 is a multicomponent surficial prehistoric lithic scatter of unknown temporal or cultural affiliation, and a possible historic-age unmarked grave situated along an upland formation that parallels the lower terraces overlooking Elm Waterhole Creek approximately $65 \mathrm{~m}$ north located in northeastern San Antonio, Bexar County, Texas (Figure 3.76; Appendix A:304). SWCA's 2015 initial investigations recommended the prehistoric component as NOT ELIGIBLE for listing in the NRHP or SAL designation with no avoidance or further work warranted (Acuña et al. 2016). However, SWCA recommended the possible historic-age burial/grave as having an UNDETERMINED eligibility for listing in the NRHP or SAL designation and recommended avoidance or further investigations to determine whether the feature was a burial (Acuña et al. 2016).

On July 21 and 22, 2016, SWCA conducted archaeological testing that consisted of visual inspection of the ground surface and controlled hand scraping to efficiently explore the subsurface of the $13 \times 13-\mathrm{m}$ enclosure and rock ring to ensure that no unmarked graves were present. The goal of the work was to expose the subsurface soils for examination and locate evidence of grave shafts, if present, in compliance with the Texas Health and Safety Code. Hand scraping was excavated to a depth sufficient to determine the presence/absence of any grave shafts and allow the complete recording of any features (to eroding bedrock). Within the enclosure, vegetation consisted of leaf litter underlain by short grasses, and juniper trees and roots; ground visibility ranged from 0 to 50 percent (Figure 3.77).

Prior to the investigations, the enclosure was cleared of the overlying vegetation to clearly expose the underlying ground surface and rock ring (Figures 3.78 and 3.79). Once the overburden was removed, the ground surface was examined to identify potential discoloration of the soils, depressions, and any other stone alignments that may indicated potential interments. Examination of the surface did not reveal any markers, depressions, or soils changes. Due to the lack of immediate evidence of possible interments, scraping continued at an interval of $5 \mathrm{cmbs}$ across the area within the enclosure. As the scraping progressed, loose rocks were removed while those that were more securely imbedded to the soils were left until they became loose with each passing.

Scraping of the area continued for six passes reaching a depth of $30 \mathrm{cmbs}$ where bedrock outcropping oc- curred and large flat-limestone cobbles were eroding (Figure 3.80). During the scraping, numerous limestone cobbles ranging in size from 5 to $30 \mathrm{~cm}$ were removed (Figure 3.81). In addition to the removal of limestone cobbles, prehistoric materials were also encountered (Figure 3.82). Cultural materials encountered consisted of primary and secondary flakes. No other cultural materials were encountered, and no evidence of unmarked graves were identified outside of the rock ring. Loose cobbles were removed to determine the shape of the rock ring feature (Figure 3.83). Once the feature was mapped, continued scrapping removed additional cobbles, revealing a second ring (Figure 3.84). The second ring was slightly offset to the east from the original ring and contained some of the initial limestone cobbles encountered within the original ring. Within the center of the additional ring, pieces of packing tape and plastic was observed (see Figure 3.84).

Based on the presence of the plastic bag and packing tape at the center of the feature, it was determined that something was buried within the feature. Rather than scraping the area, soils were excavated using a hand trowel and screened through $1 / 4$-inch mesh. During the excavations, the limestone cobbles were removed, exposing naturally occurring cobbles and an eroded plastic bag with packing tape around it (Figure 3.85). As the excavation progressed, animal bones began to appear within the soils starting at approximately 12 cmbs. The animal bones encountered were identified as a small dog that had been buried (Figure 3.86). The extent of the animal burial reached a depth of $35 \mathrm{cmbs}$ above eroded bedrock.

\section{A1BX2101 SUMMARY}

Site 41BX2101 is a surficial prehistoric lithic scatter located on land that is currently overgrown with forest. The prehistoric component of site 41BX2101 is limited to the ground surface and does not contain any diagnostic cultural material. In addition to the prehistoric component, a $13 \times 13-\mathrm{m}$ historic barbwire enclosure with a rock ring at its north-central portion is present. Investigations of the enclosure and the rock ring revealed that it marked the burial of a family pet (i.e., a small dog). No evidence of other burials within the enclosure were identified. Based on these investigations and the previous 2015 investigations, site 41BX2101 is unlikely to contribute new or important information to local or regional history. As such, site $41 \mathrm{BX} 2101$ is recommended as NOT ELIGIBLE for listing in the NRHP or for SAL designation. No avoidance strategy or further work is recommended for this site within the project corridor. 


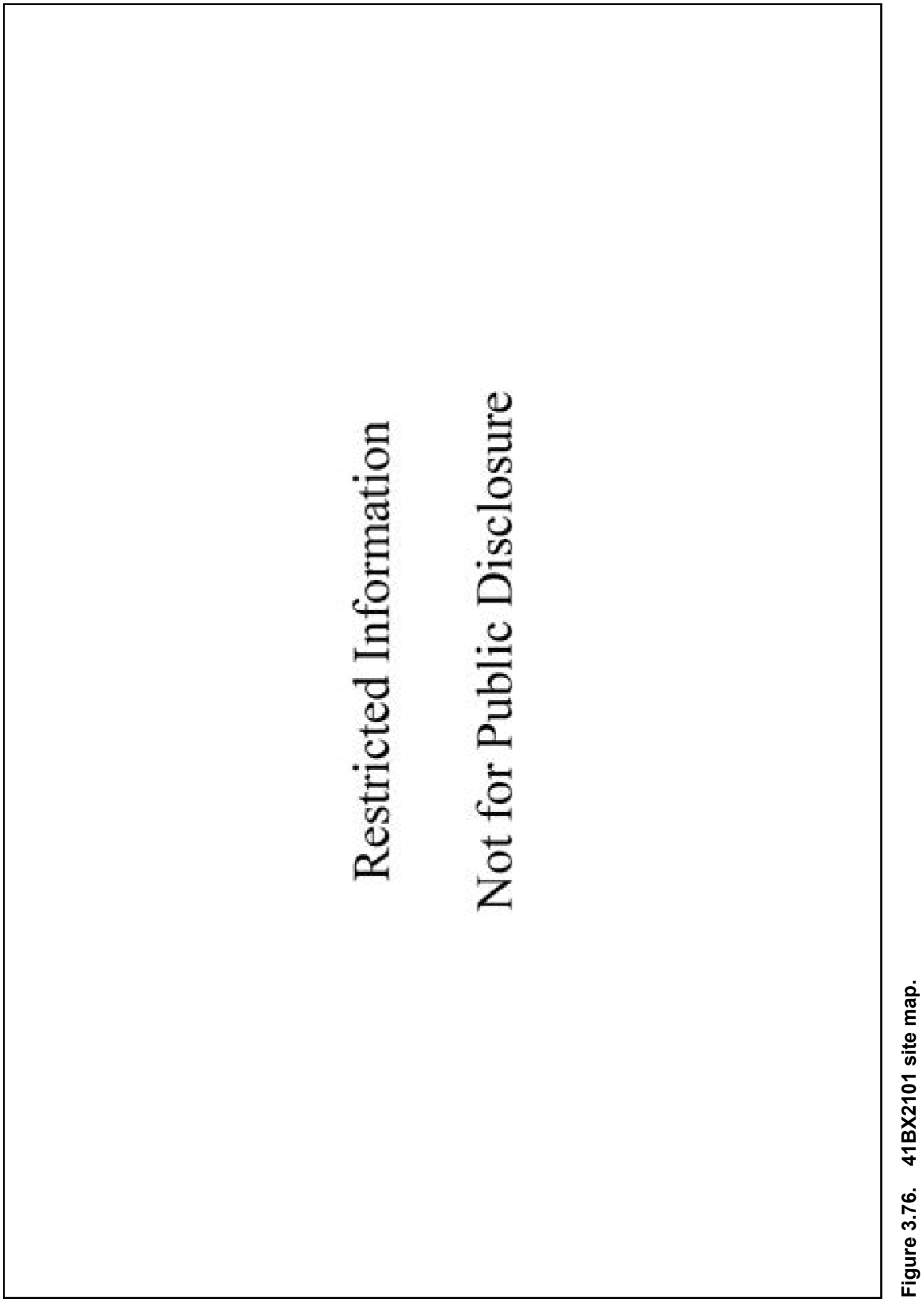




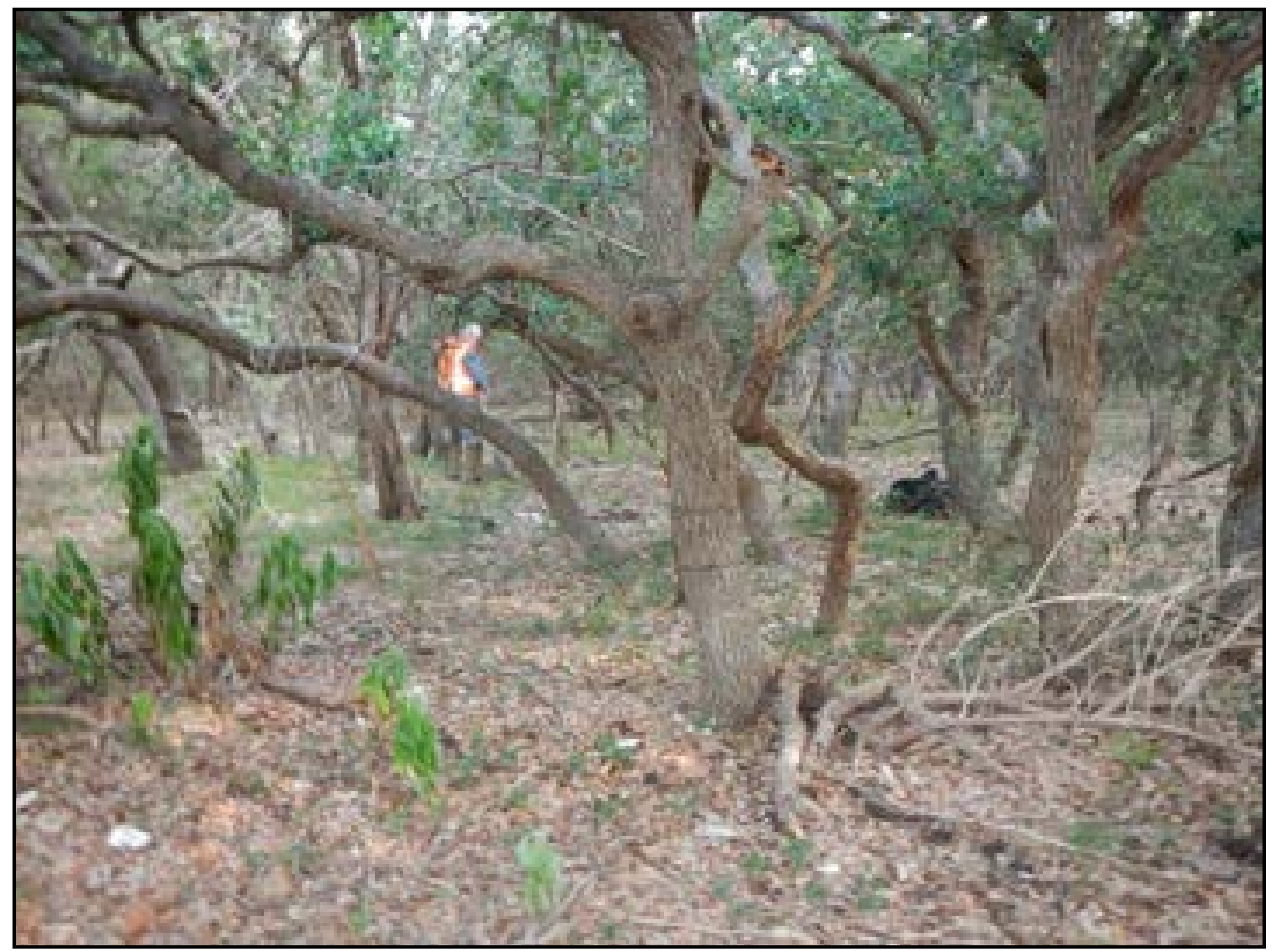

Figure 3.77. Overview of the enclosure at site 41BX1201, facing northwest.

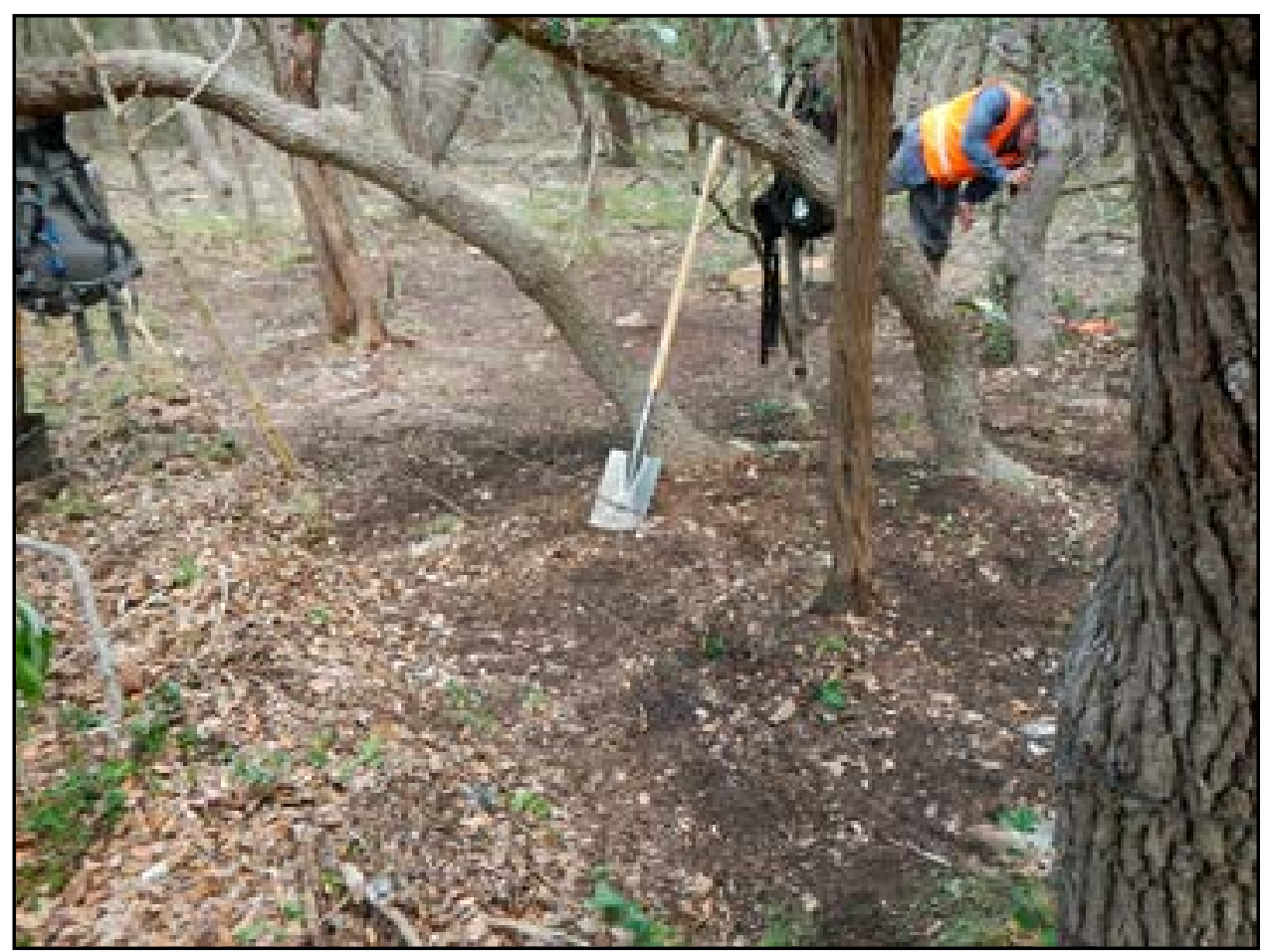

Figure 3.78. Removal of overburden at the site, facing northwest. 


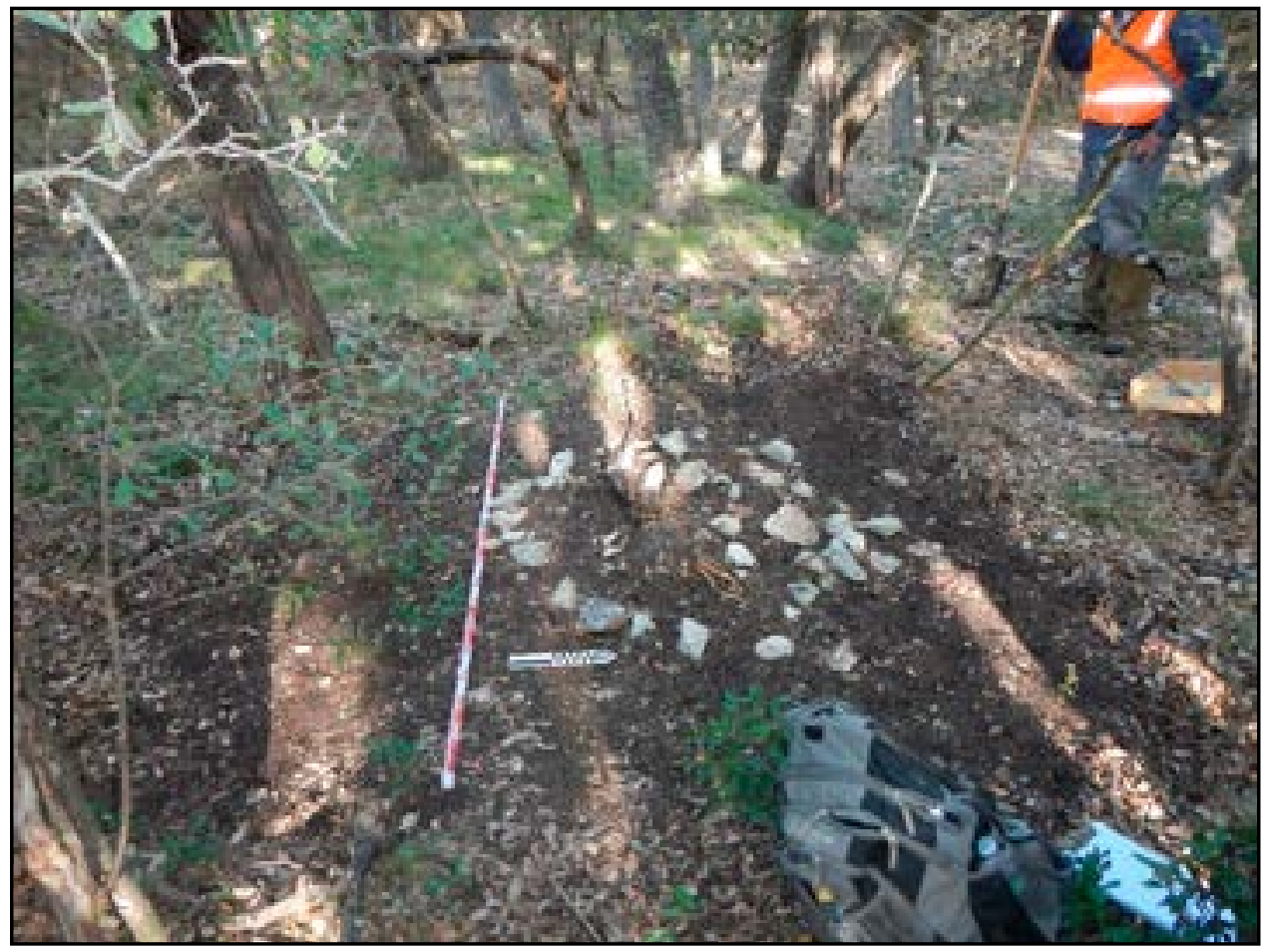

Figure 3.79. Exposure of the rock ring, facing west.

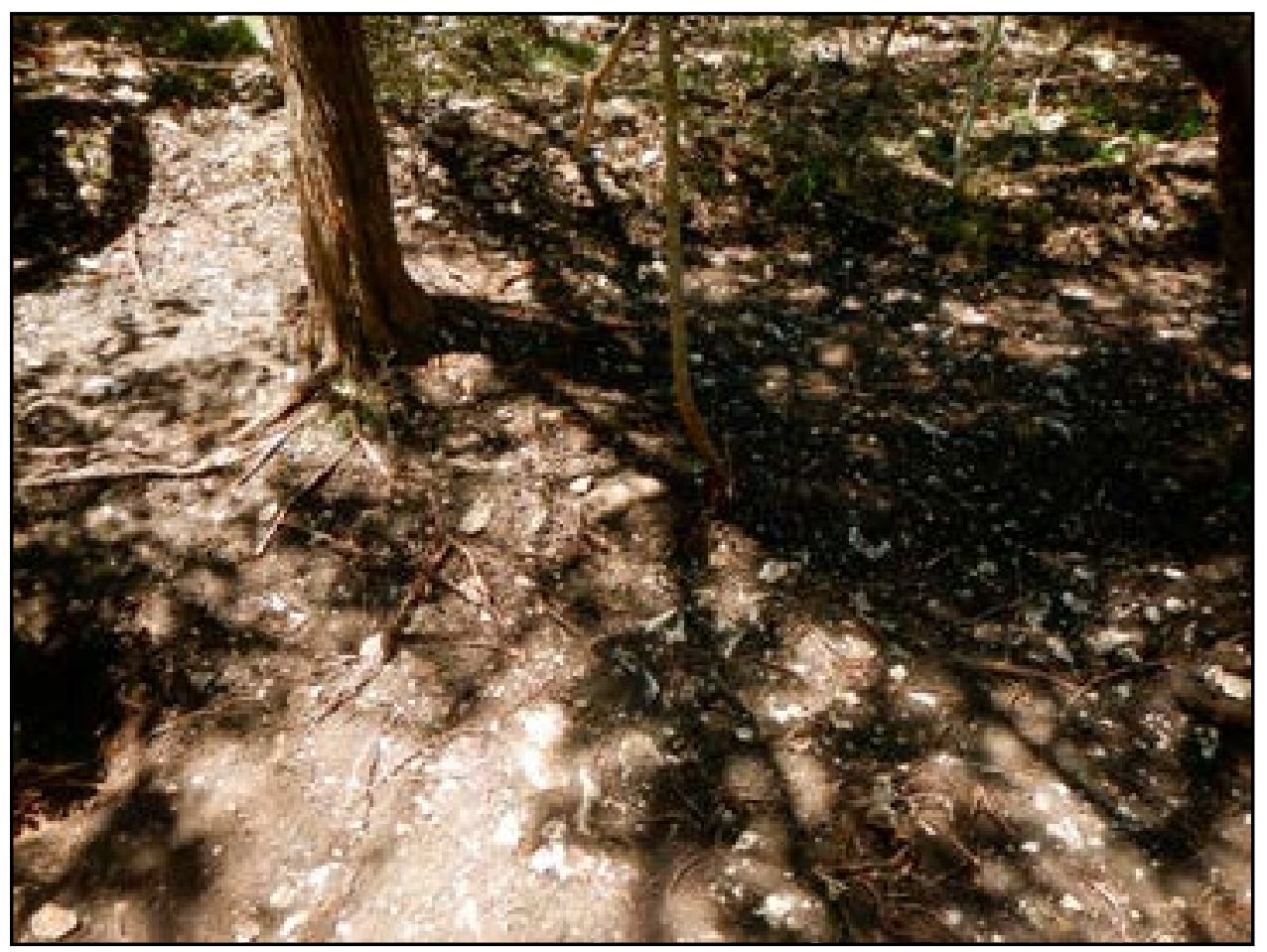

Figure 3.80. Bedrock outcropping at $30 \mathrm{cmbs}$, facing south-southeast. 


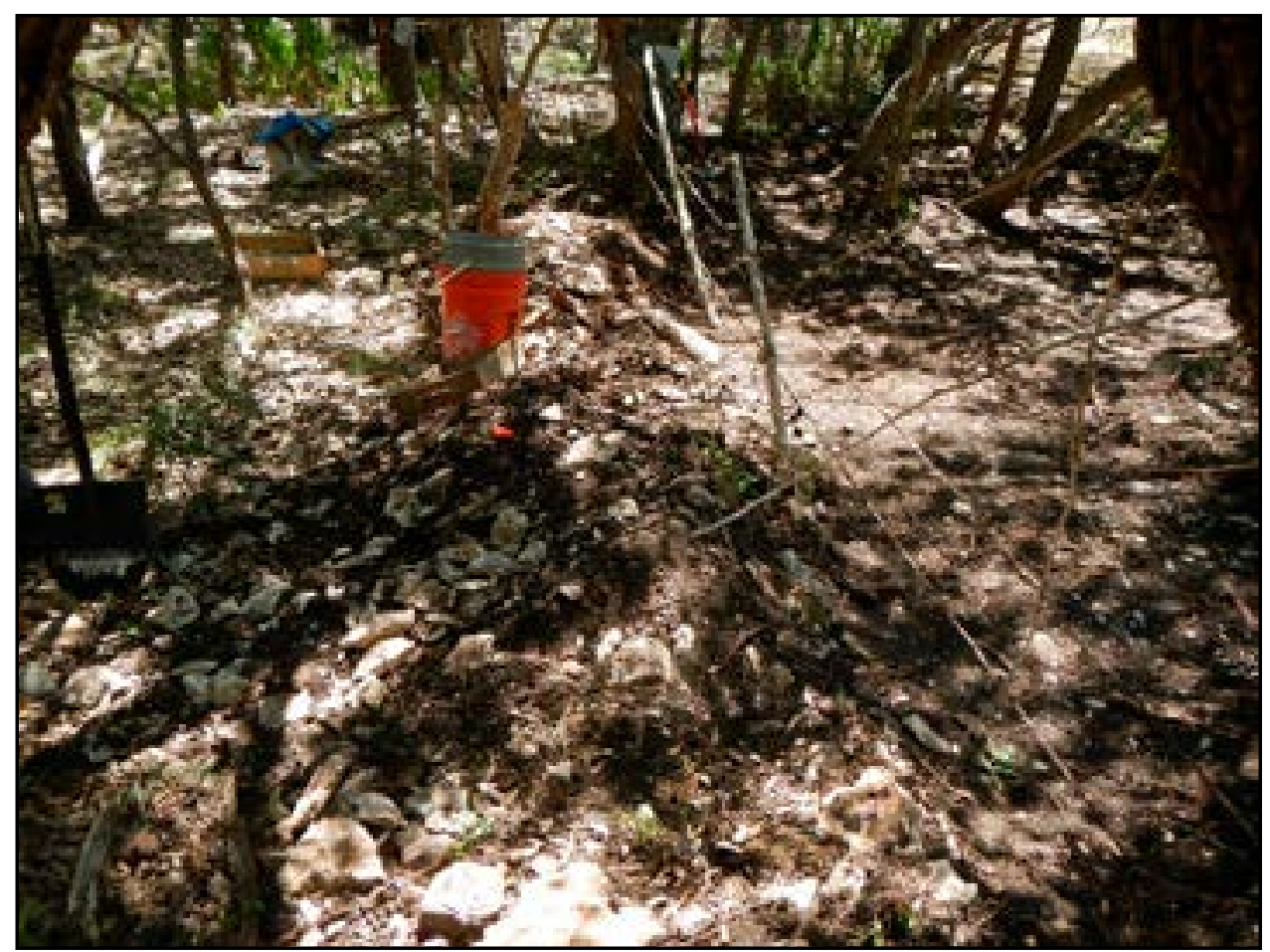

Figure 3.81. Limestone cobbles removed during scraping; facing westnorthwest.

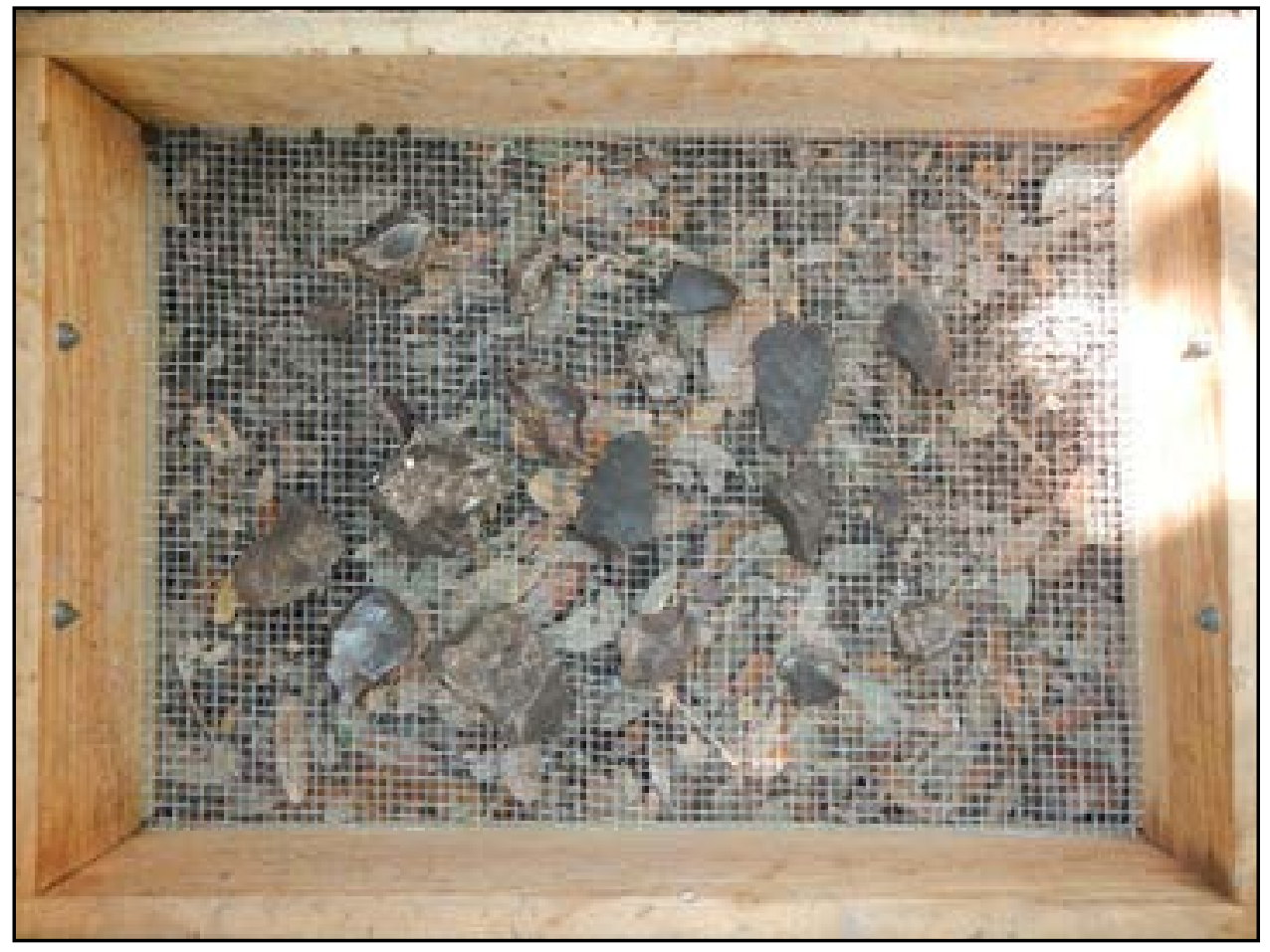

Figure 3.82. Prehistoric artifacts encountered during the scraping investigations. 


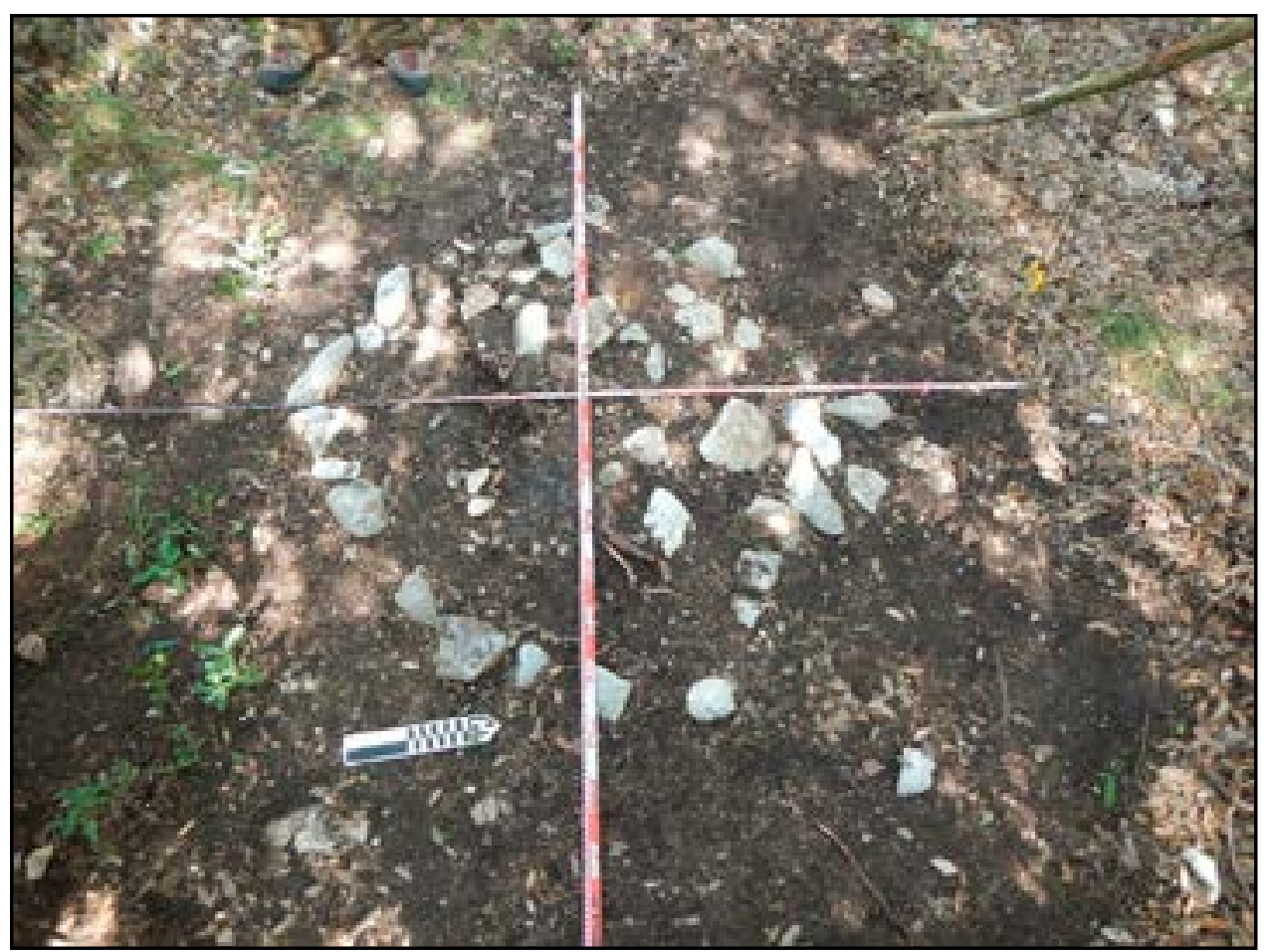

Figure 3.83. Overview of the fully exposed rock ring, facing west.

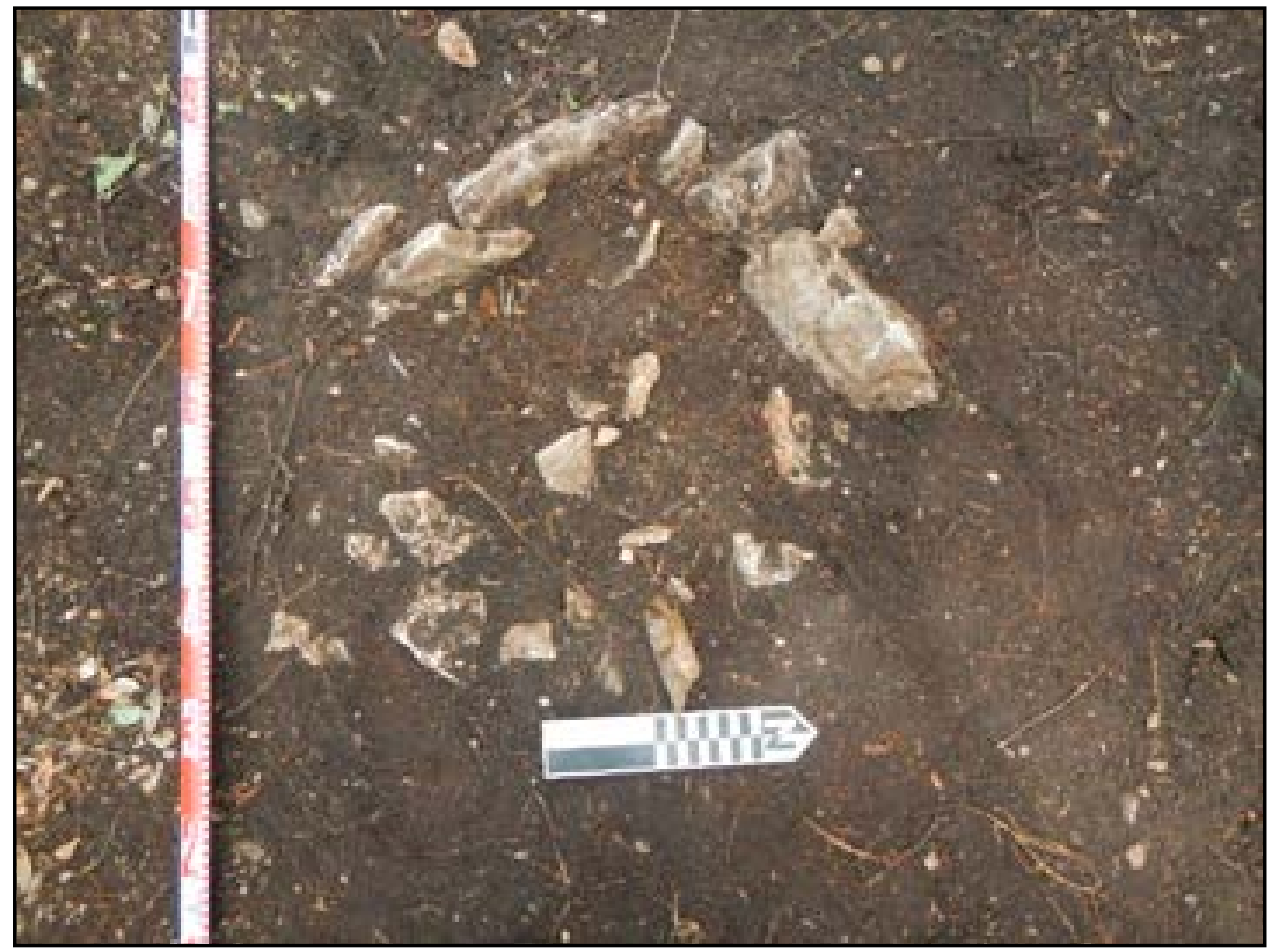

Figure 3.84. Second rock ring with plastic and packing tape at its center, facing west. 


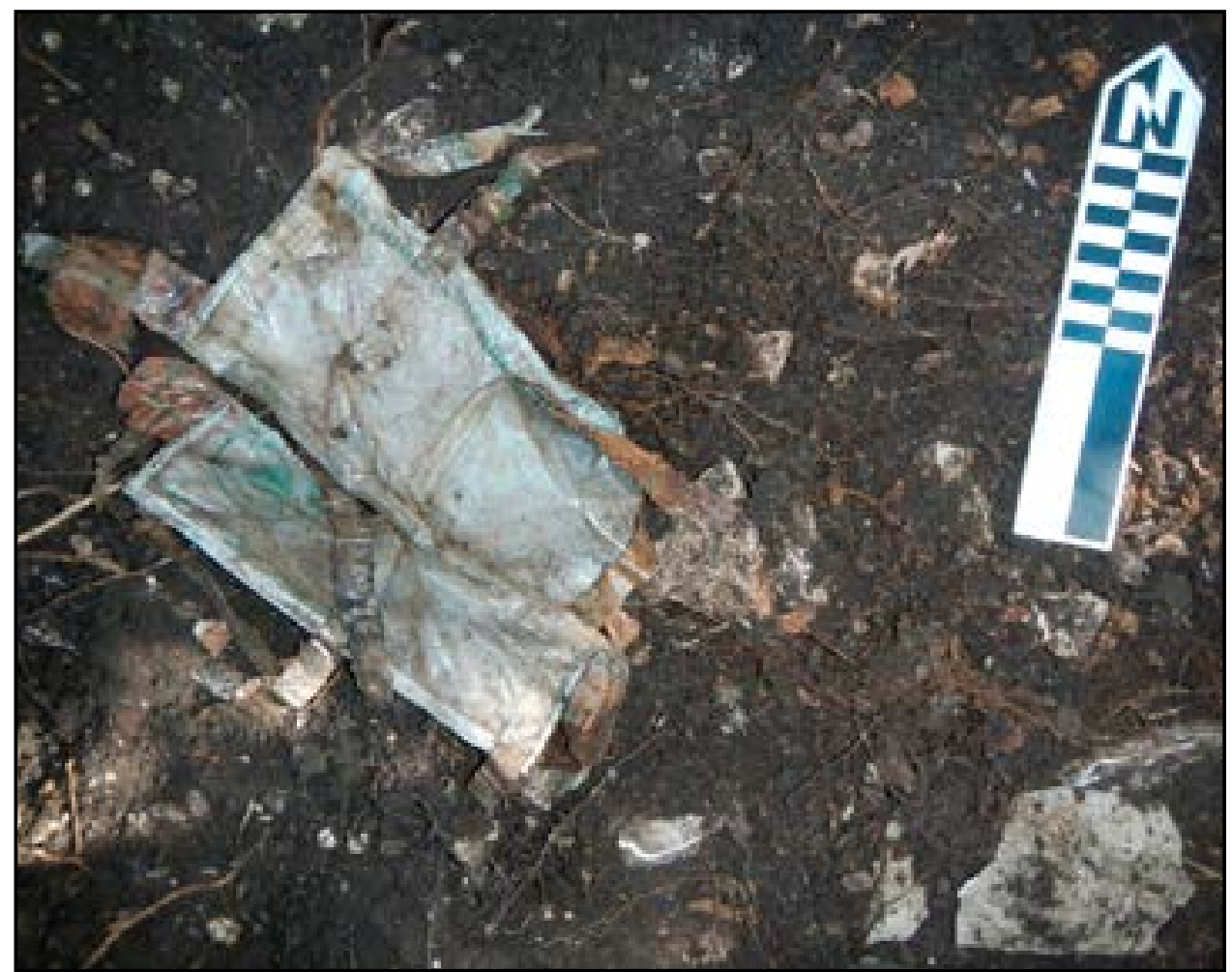

Figure 3.85. Plastic bag encountered at the center of the second stone ring.

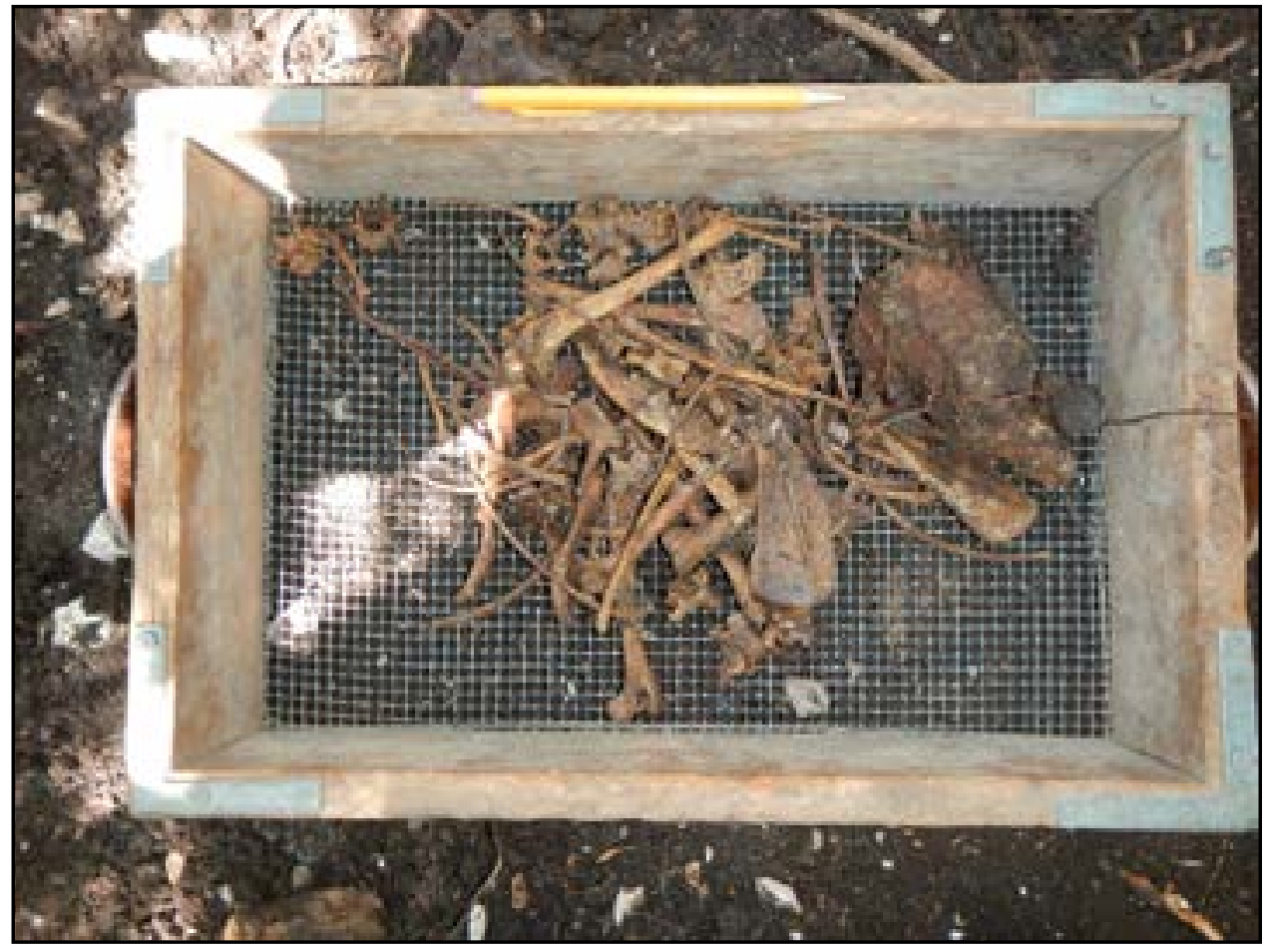

Figure 3.86. Remains of a small dog encountered below the second rock alignment. 


\title{
Chapter 4 Summary and Recommendations
}

\author{
Christina Nielsen, M.A., and Brandon S. Young, M.A., RPA
}

On behalf of VRRSP Consultants, LLC, and CTRWSC, SWCA conducted intensive cultural resources investigations of the Vista Ridge Project in Burleson, Lee, Bastrop, Caldwell, Guadalupe, Comal, and Bexar Counties. The investigations were conducting to comply with Section 106 of the NHPA (54 USC 306108) and its implementing regulations (36 CFR 800), in anticipation of a Nationwide Permit 12 from the USACE in accordance with Section 404 of the Clean Water Act. In addition, the work is subject to compliance with the ACT under Permit No. 7295, as the Vista Ridge Project will be ultimately owned by CTRWSC, a political subdivision of the State of Texas. Any additional work completed for the Vista Ridge Project after the submittal of this addendum report will be reported in subsequent addendum reports.

\section{INVESTIGATIONS SUMMARY}

Between 2016 and 2018, SWCA investigated approximately 29.5 miles of the current 140.2-mile-long project corridor and the proposed 6.9-mile-long wellfield pipeline that was not previously surveyed during the 2015 investigations. Investigations consisted of intensive pedestrian survey augmented with shovel testing and hand-excavated auger probes and/or mechanical backhoe trenching in select areas. In addition, SWCA investigated the 25.82-acre terminus site slated for the construction of an integration system (Atwood and Ward 2017). Additional mileage, which includes rerouted areas that are no longer part of the October 24, 2017 alignment, were also surveyed. SWCA excavated 967 shovel tests, 96 auger probes, and 85 backhoe trenches during the investigations. The following briefly synthesizes the inventory of cultural resources documented during SWCA's investigations and the subsequent recommendations for those resources.

\section{Cultural Resources Summary}

SWCA documented or further investigated 28 cultural resources within the project area during the 2016 to 2018 investigations. Of the 28 resources, seven were isolated finds that did not warrant formal site recording or require additional investigations. The remaining 21 cultural resources include 15 prehistoric sites, three historic sites, and three multi-component sites with prehistoric and historic materials (Table 4.1).

Of the 21 sites, two sites (i.e., 41BP960 and 41BP961) remain UNDETERMINED regarding their NRHP and SAL eligibility; however, both have currently been avoided by design alignment changes by the Vista Ridge Project. Based on the results of the testing investigations, site 41BP920 has now been determined NOT ELIGIBLE for listing on the NRHP or for designation as a SAL. One site (41GU177) was determined to be ELIGIBLE for listing on the NRHP and for designation as a SAL. SWCA conducted testing excavations at 41GU177 under Permit No. 7295 (Rodriguez et al. 2017); data recovery excavations at site $41 \mathrm{GU} 177$ were conducted under Permit No. 8231 and will be presented in a separate report (Nielsen et al. 2019).

The remaining 18 cultural resources sites (see Table 4.1) are considered not eligible for the NRHP or for designation as SALs and no further cultural resources investigations or avoidance are recommended. Based on the results of the testing investigations, site 41BP920 has now been recommended NOT ELIGIBLE for listing on the NRHP and for designation as a SAL (Rodriguez and Young 2018). The remaining prehistoric sites and historic artifact scatters without structural remains not recommended for avoidance or significance testing (i.e., 41BU122-41BU124, 41LE332, 41LE34841LE350, 41BP818, 41BP920, 41BP959, 41GU200, 41CM394, 41CM401, 41CM404, and 41BX2101) have an absence of substantial subsurface deposits and/or exhibit significant horizontal and vertical disturbances from erosion and/or mechanical impacts from agricultural activities, vegetation clearing, two-track roads, and general land clearing and improvements. Based on these conditions, the sites cannot provide new or important data concerning regional prehistory.

In terms of historic sites with structures and/or structural remains (i.e., 41BP962, 41CW173, and 41GU180) the integrity of the structures or structural remains has 
Table 4.1. Cultural Resources Summary and Recommendations

\begin{tabular}{|c|c|c|c|c|}
\hline County & Site No. & Site Type & $\begin{array}{l}\text { NRHP and SAL } \\
\text { Eligibility Recommendation }\end{array}$ & Additional Work Recommendations \\
\hline \multirow{3}{*}{ Burleson } & 41BU122 & Prehistoric lithic scatter & Not Eligible & $\begin{array}{l}\text { No avoidance or further work recommended } \\
\text { within project area. }\end{array}$ \\
\hline & 41BU123 & Prehistoric lithic scatter & Not Eligible & $\begin{array}{l}\text { No avoidance or further work recommended } \\
\text { within project area. }\end{array}$ \\
\hline & 41BU124 & Prehistoric lithic scatter & Not Eligible & $\begin{array}{l}\text { No avoidance or further work recommended } \\
\text { within project area. }\end{array}$ \\
\hline \multirow{4}{*}{ Lee } & 41LE332 & Prehistoric lithic scatter & Not Eligible & $\begin{array}{l}\text { No avoidance or further work recommended } \\
\text { within project area. }\end{array}$ \\
\hline & 41LE348 & Prehistoric lithic scatter & Not Eligible & $\begin{array}{l}\text { No avoidance or further work recommended } \\
\text { within project area. }\end{array}$ \\
\hline & 41LE349 & Prehistoric lithic scatter & Not Eligible & $\begin{array}{l}\text { No avoidance or further work recommended } \\
\text { within project area. }\end{array}$ \\
\hline & 41LE350 & Prehistoric lithic scatter & Not Eligible & $\begin{array}{l}\text { No avoidance or further work recommended } \\
\text { within project area. }\end{array}$ \\
\hline \multirow{6}{*}{ Bastrop } & 41BP818 & $\begin{array}{l}\text { Historic artifact scatter, } \\
\text { prehistoric campsite, and } \\
\text { cemetery }\end{array}$ & Not Eligible within project area & $\begin{array}{l}\text { No avoidance or further work recommended for } \\
\text { site within project area; however, avoidance of } \\
\text { cemetery is recommended. Cemetery is avoided } \\
\text { by reroute. }\end{array}$ \\
\hline & 41BP920 & $\begin{array}{l}\text { Prehistoric lithic and } \\
\text { historic artifact scatter }\end{array}$ & Not Eligible & $\begin{array}{l}\text { No avoidance or further work recommended } \\
\text { within project area. }\end{array}$ \\
\hline & 41BP959 & Prehistoric lithic scatter & Not Eligible & $\begin{array}{l}\text { No avoidance or further work recommended } \\
\text { within project area. }\end{array}$ \\
\hline & 41BP960 & Prehistoric campsite & Undetermined & $\begin{array}{l}\text { Avoidance or further work recommended within } \\
\text { project area. Avoided by reroute. }\end{array}$ \\
\hline & 41BP961 & Prehistoric campsite & Undetermined & $\begin{array}{l}\text { Avoidance or further work recommended within } \\
\text { project area. Avoided by reroute. }\end{array}$ \\
\hline & 41BP962 & $\begin{array}{l}\text { Historic road and bridge } \\
\text { embankment remant }\end{array}$ & Not Eligible & $\begin{array}{l}\text { No avoidance or further work recommended } \\
\text { within project area. }\end{array}$ \\
\hline Caldwell & $41 \mathrm{CW} 173$ & Historic house and shed & Not Eligible & $\begin{array}{l}\text { No avoidance or further work recommended } \\
\text { within project area. }\end{array}$ \\
\hline \multirow{3}{*}{ Guadalupe } & 41GU177 & Prehistoric campsite & Eligible Mitigated within APE & $\begin{array}{l}\text { No avoidance or further work recommended } \\
\text { within project area. }\end{array}$ \\
\hline & $41 \mathrm{GU} 180$ & $\begin{array}{l}\text { Historic house/ } \\
\text { farm complex }\end{array}$ & Not Eligible & $\begin{array}{l}\text { No avoidance or further work recommended } \\
\text { within project area. (OFFLINE) }\end{array}$ \\
\hline & $41 \mathrm{GU} 200$ & Prehistoric lithic scatter & Not Eligible & $\begin{array}{l}\text { No avoidance or further work recommended } \\
\text { within project area. }\end{array}$ \\
\hline \multirow{3}{*}{ Comal } & $41 \mathrm{CM} 394$ & Prehistoric lithic scatter & Not Eligible & $\begin{array}{l}\text { No avoidance or further work recommended } \\
\text { within project area. }\end{array}$ \\
\hline & $41 \mathrm{CM} 401$ & $\begin{array}{l}\text { Prehistoric lithic and } \\
\text { historic artifact scatter }\end{array}$ & Not Eligible & $\begin{array}{l}\text { No avoidance or further work recommended } \\
\text { within project area. }\end{array}$ \\
\hline & $41 \mathrm{CM} 404$ & Prehistoric lithic scatter & Not Eligible & $\begin{array}{l}\text { No avoidance or further work recommended } \\
\text { within project area. }\end{array}$ \\
\hline Bexar & $41 \mathrm{~B} \times 2101$ & $\begin{array}{l}\text { Prehistoric lithic scatter } \\
\text { and recent dog burial }\end{array}$ & Not Eligible & $\begin{array}{l}\text { No avoidance or further work recommended } \\
\text { within project area. }\end{array}$ \\
\hline
\end{tabular}


been compromised by modifications and age (e.g., dilapidation of structures or dismantling of roadway) (see Table 4.1). Given these conditions, it is the opinion of SWCA that these resources cannot contribute new or important data to regional history.

In accordance with 36 CFR 800.4 and the ACT, SWCA has made a reasonable and good faith effort to identify cultural resources within the project area. Portions of site 41 GU177 within the Vista Ridge Project corridor have been mitigated and the results will be presented in a stand-alone report (Nielsen et al. 2019). Two newly recorded sites (41BP960 and 41BP961) are recommended as having UNDETERMINED eligibility for listing on the NRHP or for SAL designation and one site (41GU177) is recommended as ELIGIBLE. The remaining 18 sites are recommended as NOT ELIGIBLE for listing on the NRHP or for SAL designation. It is SWCA's recommendation that the two sites of UNDETERMINED eligibility should be avoided, or subject to further significance testing. No further work or avoidance strategy is recommended for the remaining 18 archaeological sites associated with the Vista Ridge Project. 
134 Chapter 4

This page intentionally left blank. 


\section{REFERENCES}

Acuña, Laura I., Brandon Young, and Rhiana D. Ward

2016 Cultural Resources Investigations of the Vista Ridge Regional Water Supply Project in Burleson, Lee, Bastrop, Caldwell, Guadalupe, Comal and Bexar Counties, Texas. SWCA Cultural Resources Report No. 15-548. Austin, Texas.

Acuña, L. I. and K. Sloan

2014 Cultural Resource Investigations of the Canyon Regional Water Authority Wells Ranch Santa Clara to Wagner Transmission Line Project, Guadalupe County, Texas. SWCA Cultural Resources Report No. 13462. San Antonio, Texas.

Atwood, Kirsten, Ph. D., and Rhiana Ward, M.A.

2017 Cultural Resources Survey of the Proposed Terminus Site for the Vista Ridge Regional Water Supply Project, Bexar County, Texas. SWCA Cultural Resources Report No. 15548. San Antonio, Texas.

Boyd, Douglas K.

2012 What Is Northern Toyah Phase? The Toyah Phenomenon on the Texas Southern Plains. In The Toyah Phase of Central Texas: Late Prehistoric Economic and Social Processes. Edited by Nancy A. Kenmotsu and Douglas K. Boyd, pp. 128-151. Texas A\&M University Press. College Station, Texas.

\section{Comal County}

2015 Comal Settlement. Available at: http:// www.co.comal.tx.us/Historical/Properties/ Comal_Settlement.htm. Accessed July 2019.

Comal County Deed Records (CCDR) 1866-1935 Various volumes.
Foster, T. R., T. Summerville, and T. Brown

2006 The Texas Historic Overlay: A Geographic Information System of Historic Map Images for Planning Transportation Projects in Texas. Prepared for the Texas Department of Transportation by PBS\&J, Austin.

Guadalupe County Deed Records (GCDR) 1845-2017 Various volumes.

Guadalupe County Marriage Records (GCMR)

1914 Robert Zipp and Meta Hoffman, Volume 7, page 274 .

Guadalupe County Probate Minutes (GCPM)

1956 Volume 10, pages 553-562.

Jasinski, Laurie E.

2010 Zipp, Texas. The Handbook of Texas. Available at: http://www.tshaonline.org/ handbook/online/articles/hlz04. Accessed July 2019.

Munsey, Cecil

1970 The Illustrated Guide to Collecting Bottles. Hawthorn Books, Inc., New York.

Nielsen, Christina, Ashley Eyeington, Ken Lawrence, and Brandon S. Young

2019 Draft Report: Date Recovery Excavations at the Snakeskin Bluff Site (41GU177), Guadalupe County, Texas. SWCA Cultural Resource Report No. 19-XXX. Austin, Texas.

Perttula, Timothy K., M. R. Miller, R. A. Ricklis, D. J. Prikryl, and C. Lintz

1995 Prehistoric and Historic Aboriginal Ceramics in Texas. Bulletin of the Texas Archaeological Society 66:175-235. 
Rodriguez, Daniel, Ken Lawrence, and Brandon S. Young

2017 Interim Report: Archaeological Investigations at $41 G U 177$ on the Guadalupe River, Guadalupe County, Texas. SWCA. Austin, Texas.

Rodriguez, Dan, and Brandon S. Young

2018 Draft Report: Site Significance Testing Report of Site 41BP920 on the 140-Mile-Long Vista Ridge Water Pipeline in Bastrop County, Texas. SWCA Cultural Resources Report No. 18-541. Austin, Texas.

Schertz Historical Preservation Committee

2019 Historic Church Bells - Schertz (Comal Settlement Contributors. Remembrances Special Edition Article.

Strong, Berniece

2019 John James. Handbook of Texas Online. Available at: https://tshaonline.org/handbook/ online/articles/fja17. Accessed July 2019.

Texas Beyond History (TBH)

2018 Toyah Culture. Available at: https://www. texasbeyondhistory.net/plateaus/prehistory/ images/toyah.html. Accessed August 3, 2018.
Texas General Land Office (GLO)

2019 Guadalupe County, Abstract 260. File no. 000081, Land Grant Database. Available at: www.glo.texas.gov/history/archives/landgrants/index.cfm. Accessed July 2019.

Texas Historical Commission (THC)

2018 Texas Archeological Site Atlas restricted database. Available at: http://nueces.thc.state. tx.us/. Accessed July 2018.

U.S. Geological Survey (USGS)

2018 The National Geologic Map Database (TopoView). Historical topographic map collection. Available at: http://ngmdb.usgs. gov/maps/TopoView/. Accessed July 2018.

Ward, R.

2015 Cultural Resource Investigations of the Canyon Regional Water Authority Wells Ranch Crystal Clear Transmission Line Project, Guadalupe County, Texas. SWCA Cultural Resources Report No. 14-599. San Antonio, Texas.

Weinert, Willie Mae

2010 Schumansville, $T X$,. The Handbook of Texas Online. Available at: http://www. tshaonline.org/handbook/online/articles/ HLS28. Accessed July 2019. 
Appendix A. Survey Results Maps 
This page intentionally left blank. 
Restricted Information

Not for Public Disclosure 
Restricted Information

Not for Public Disclosure 


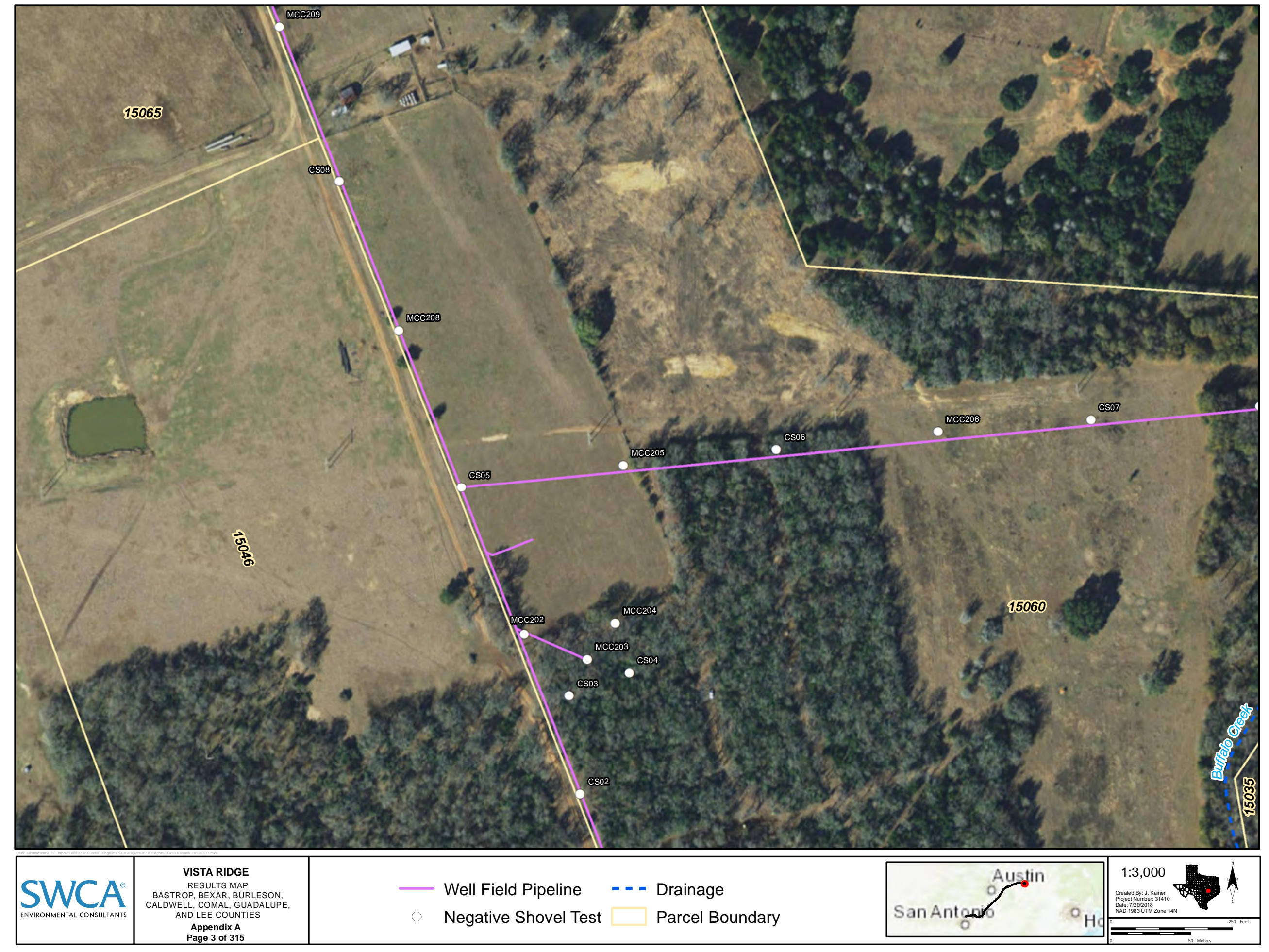




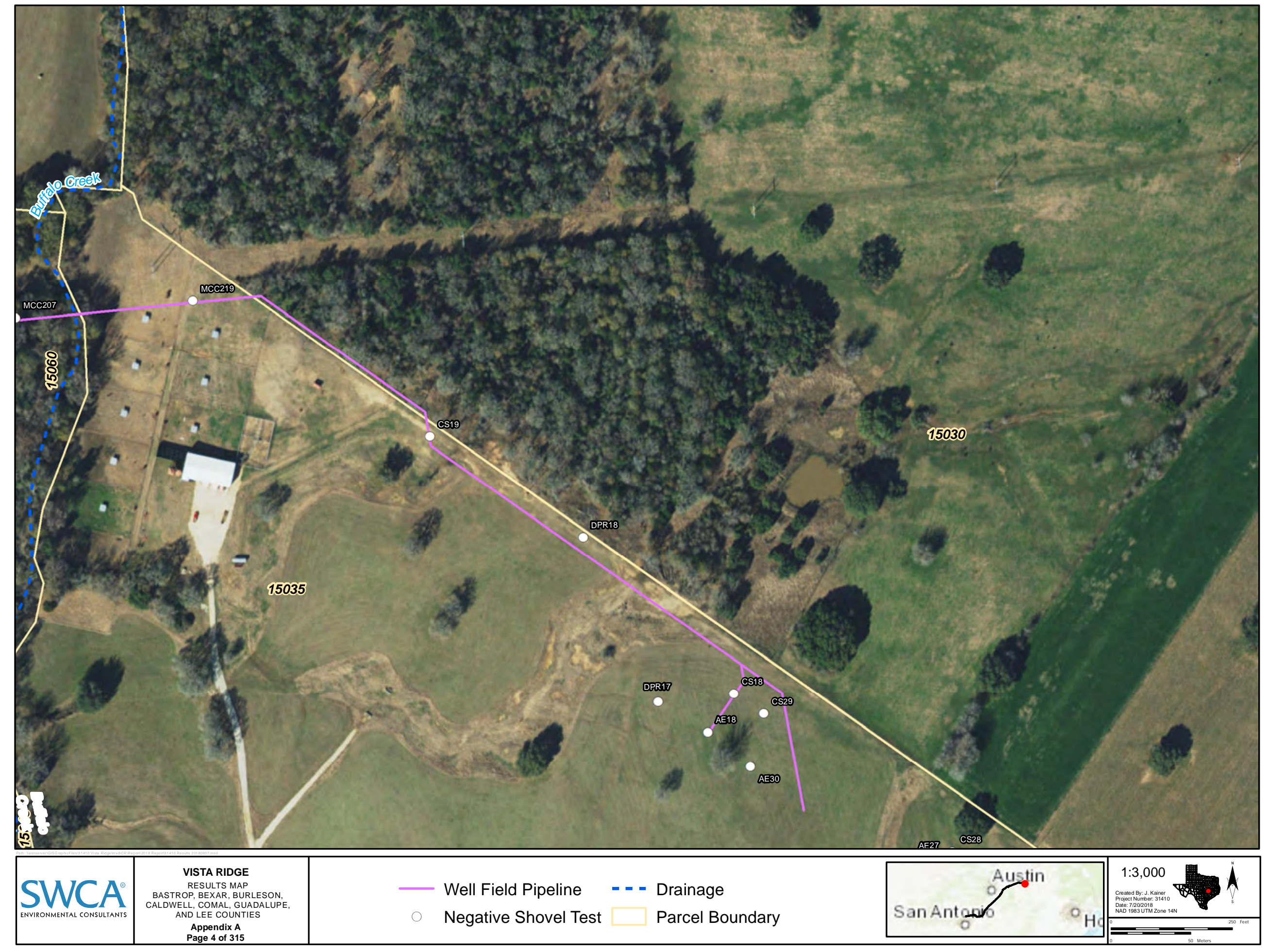




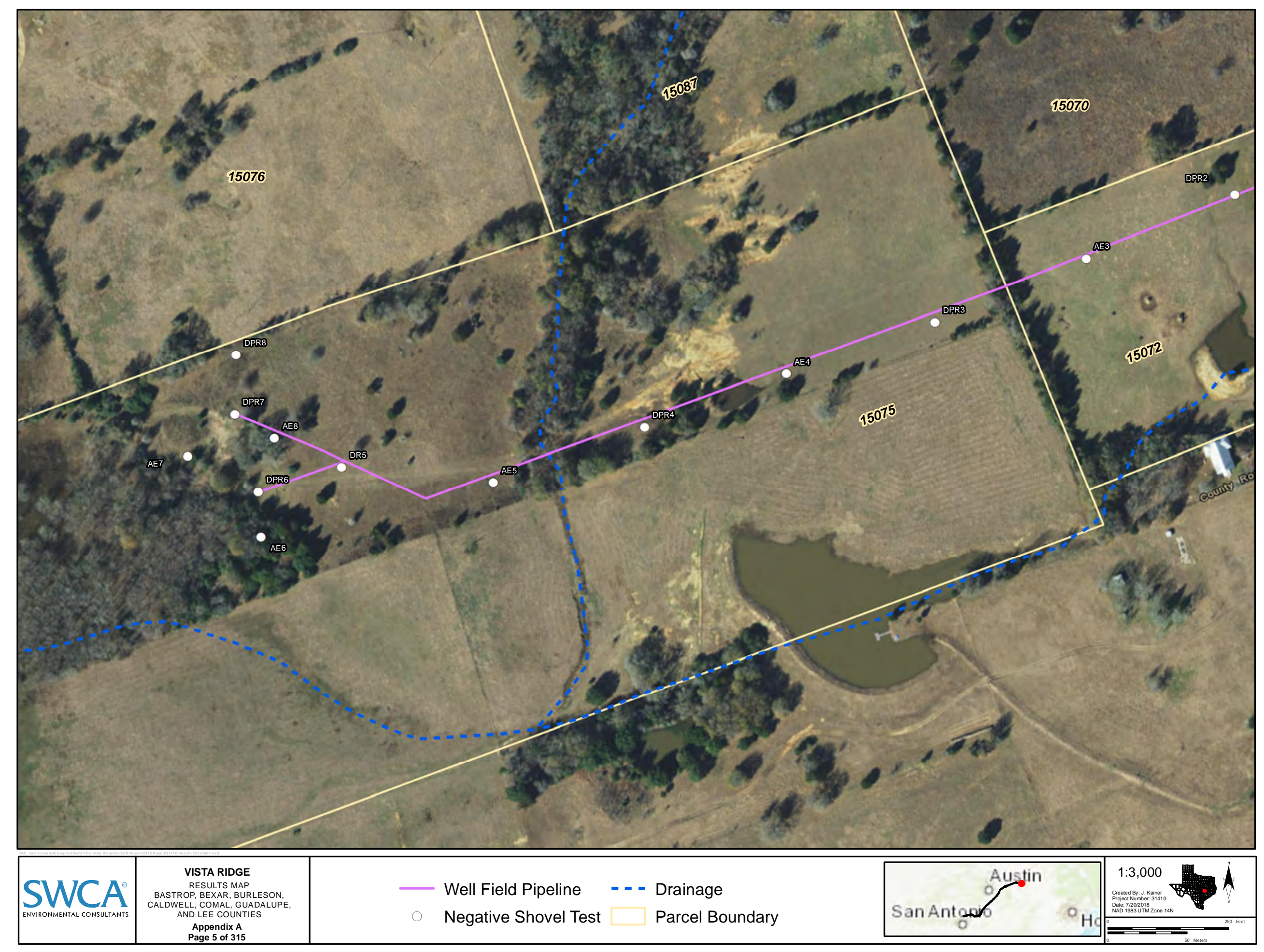




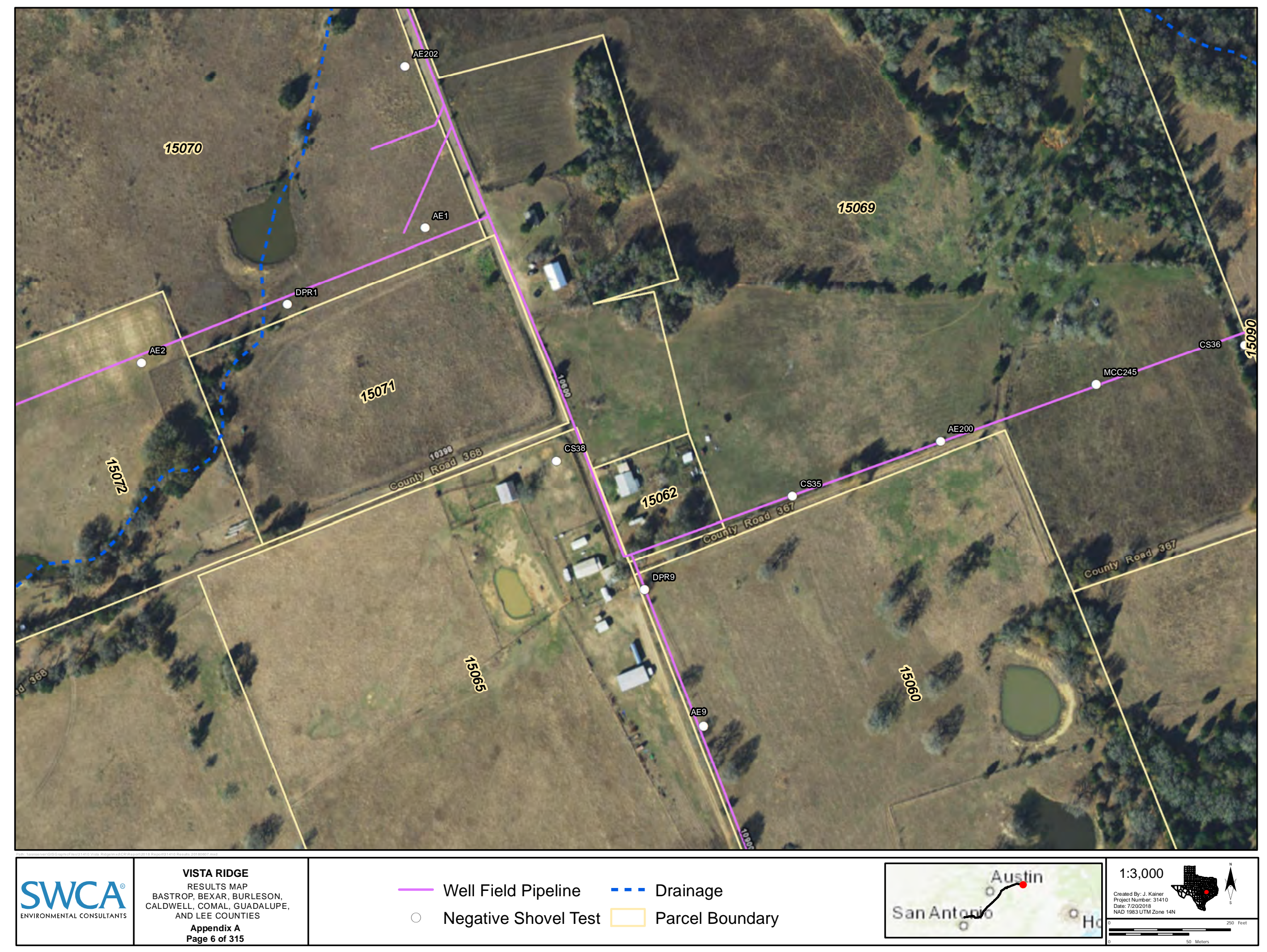




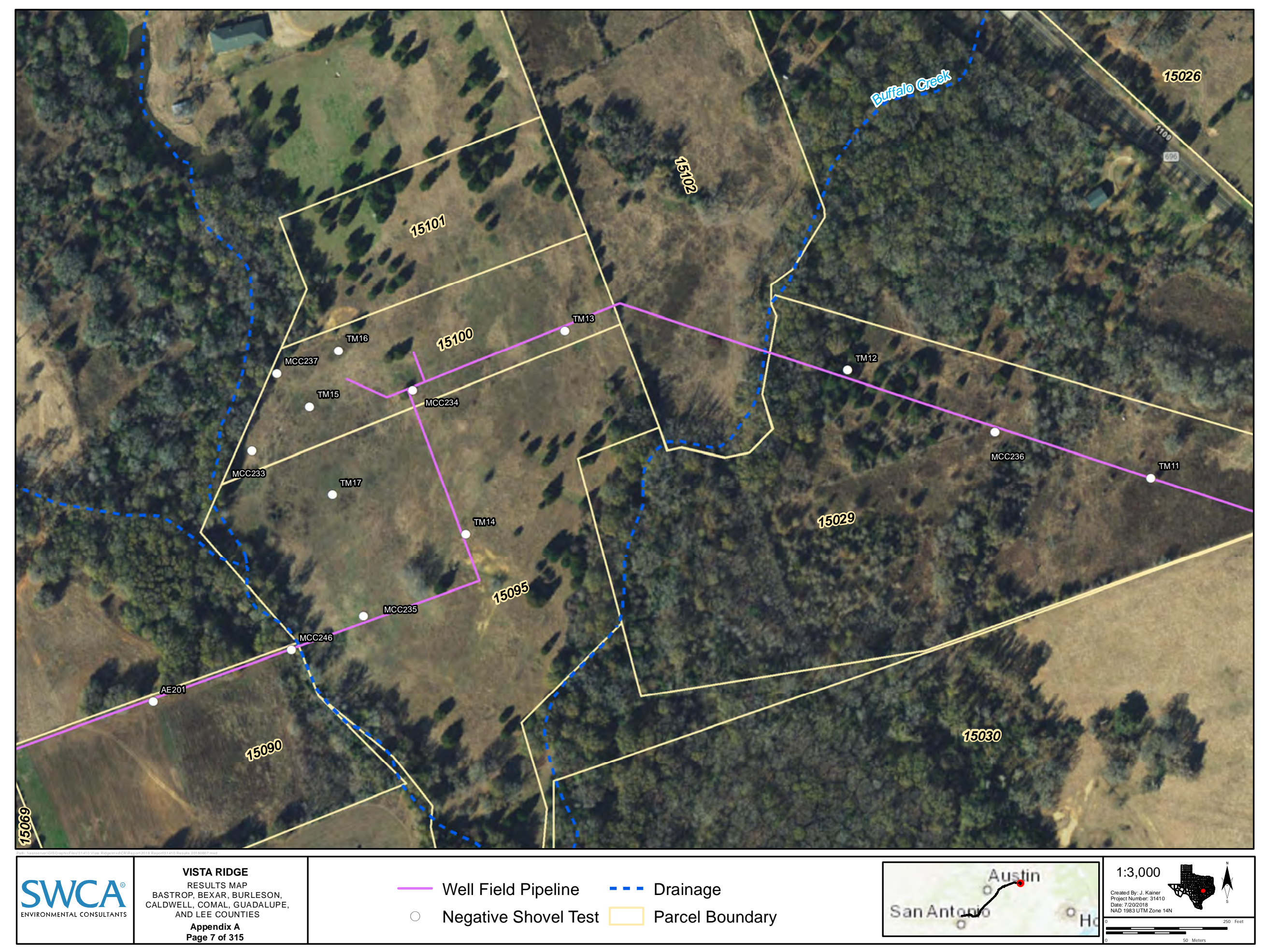




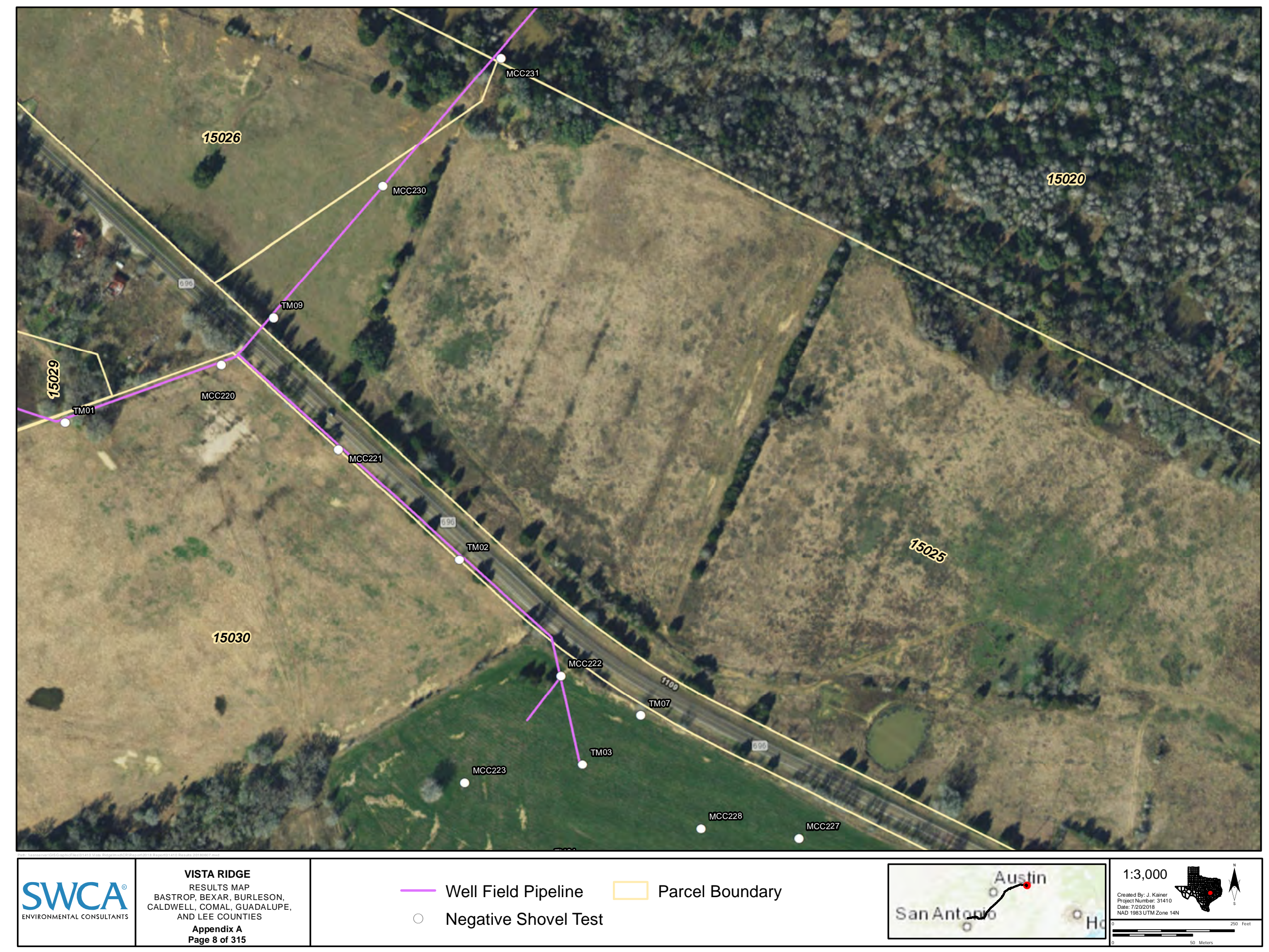




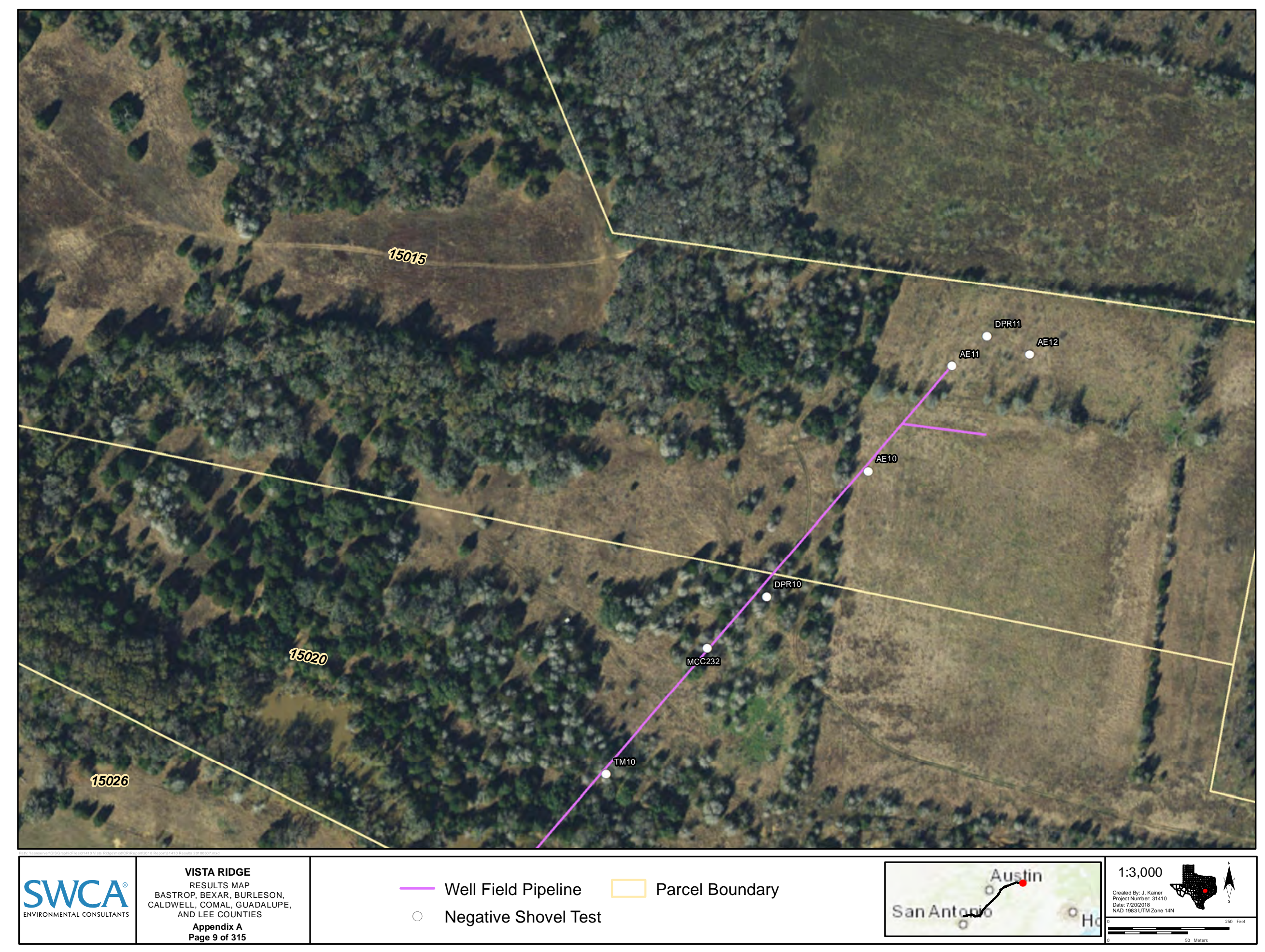




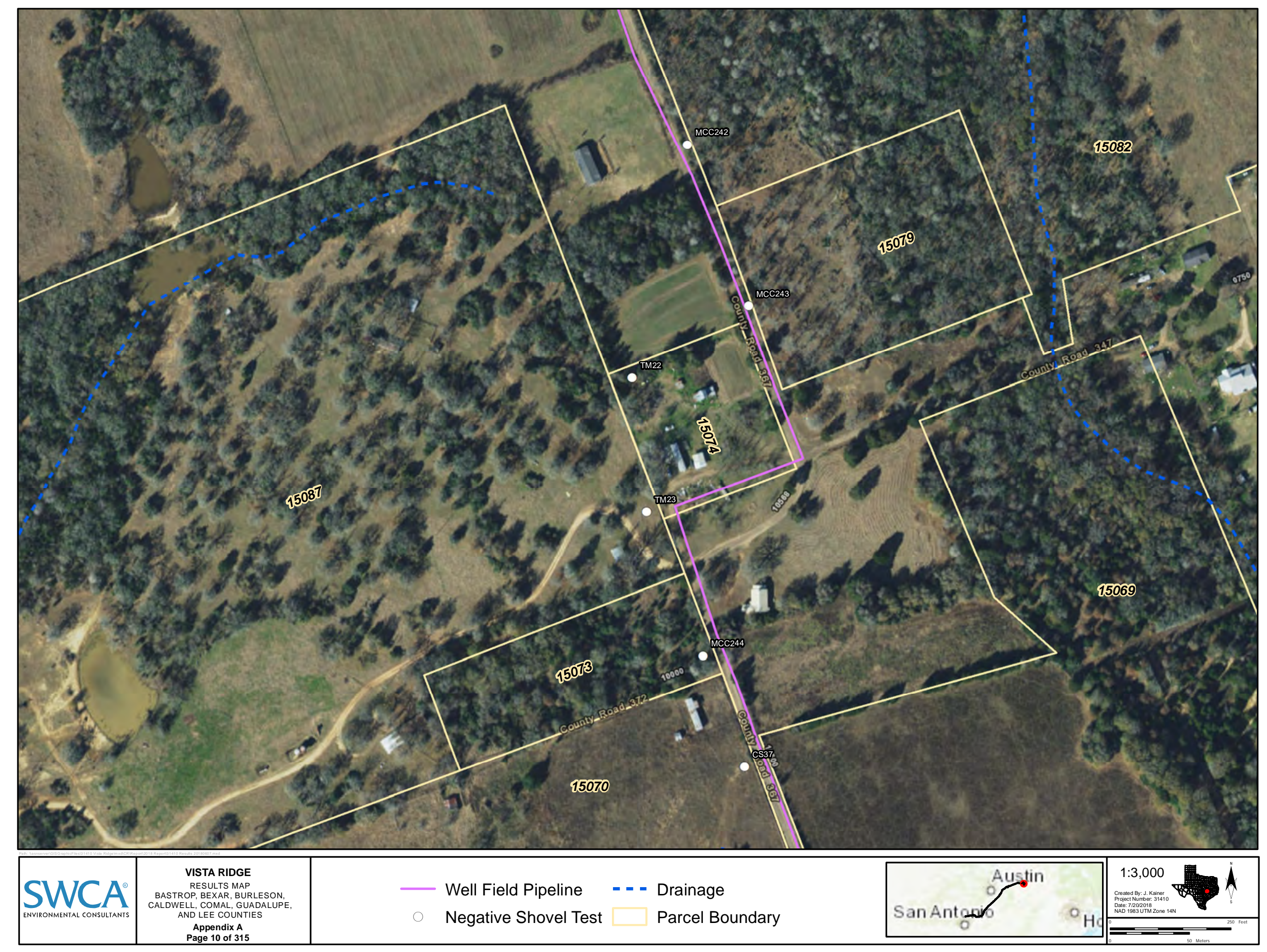




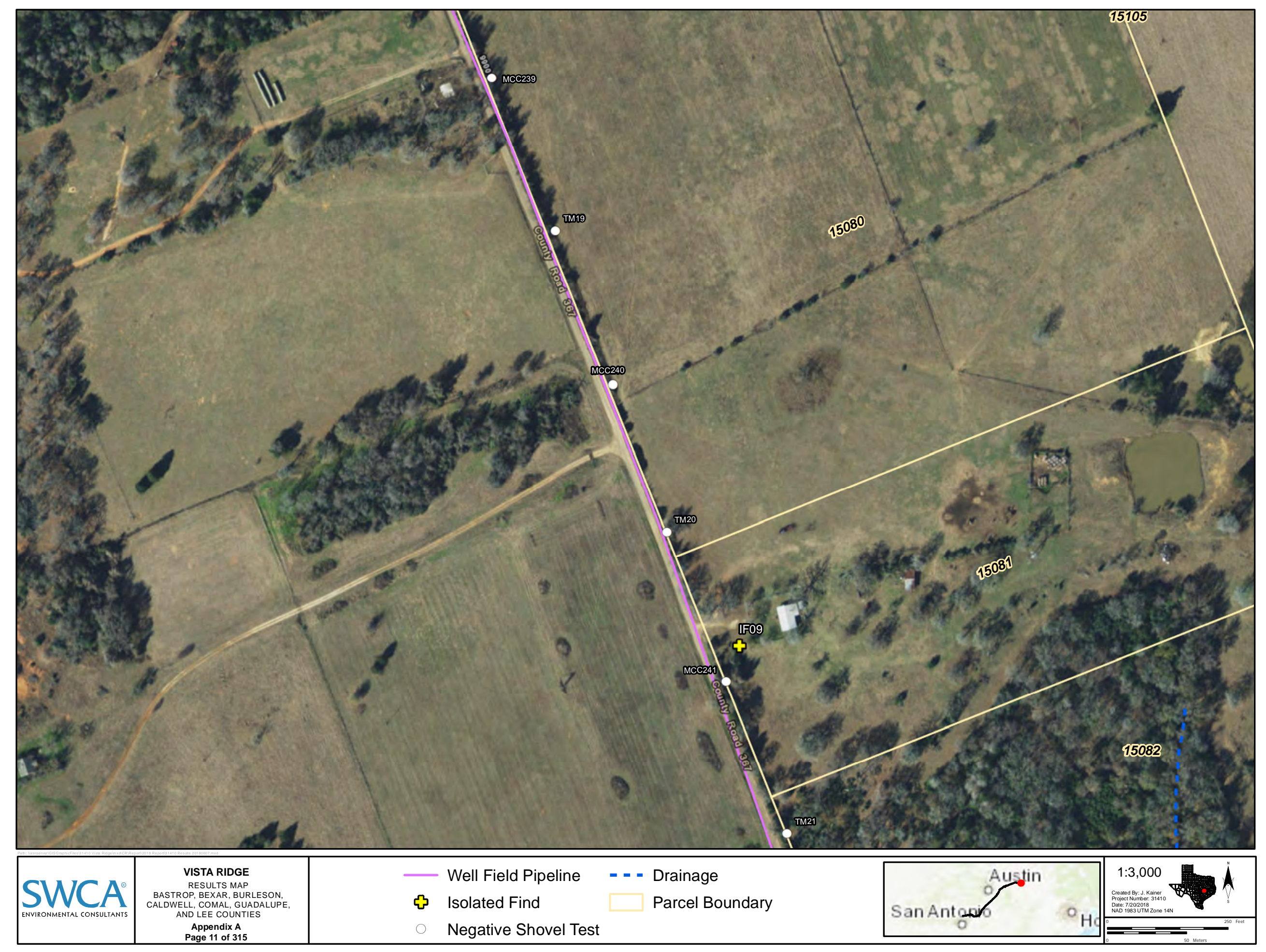




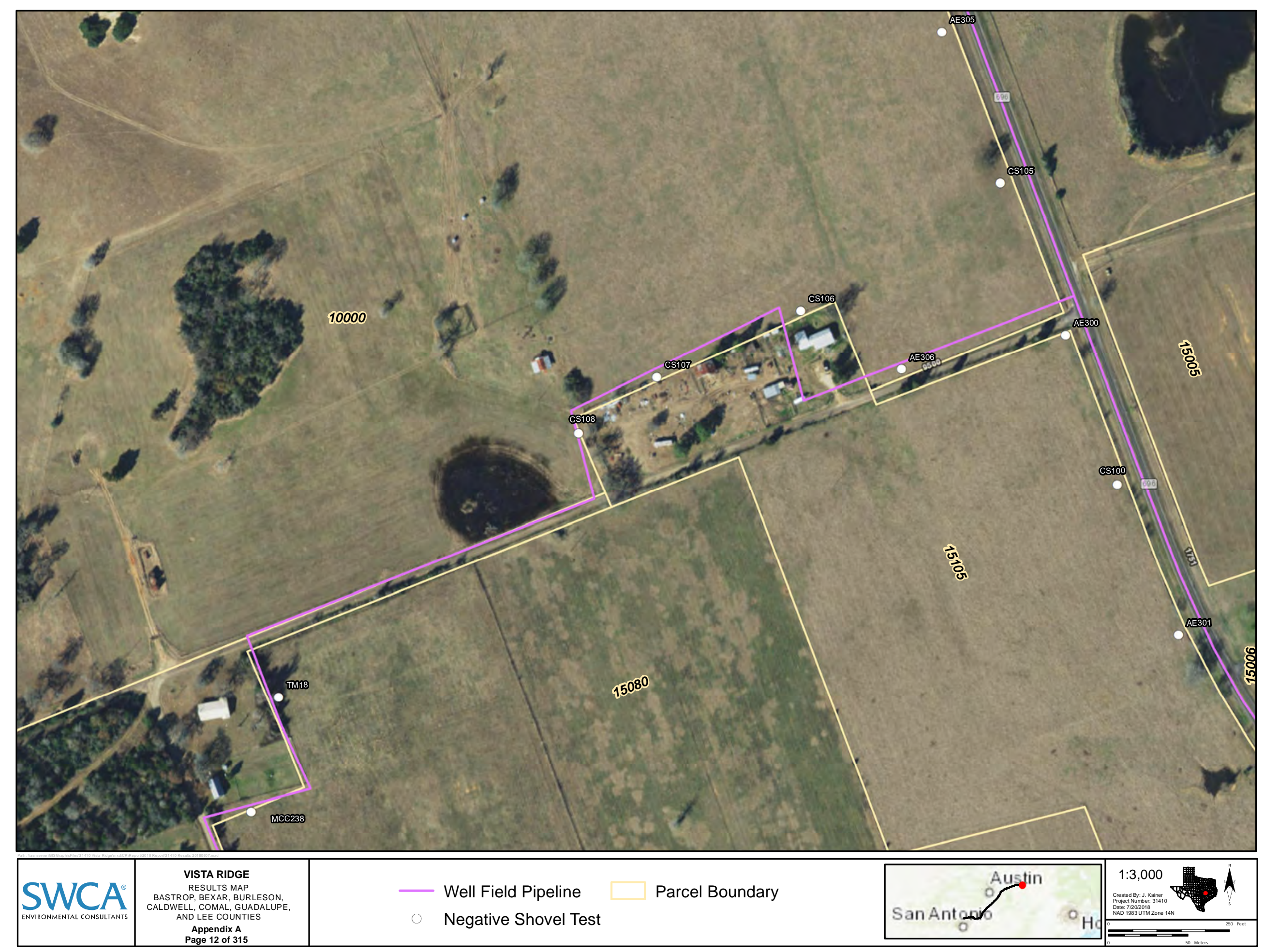




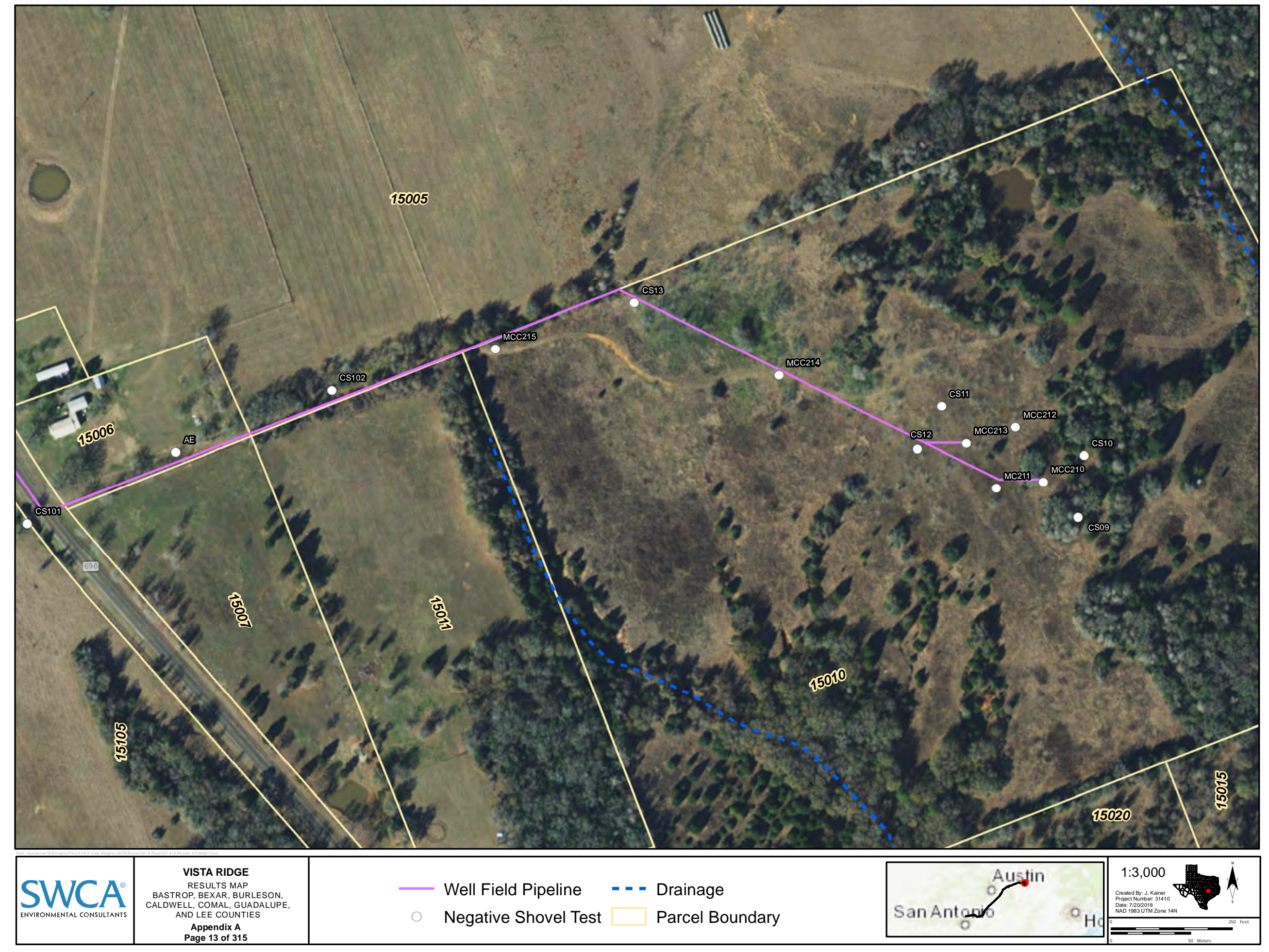




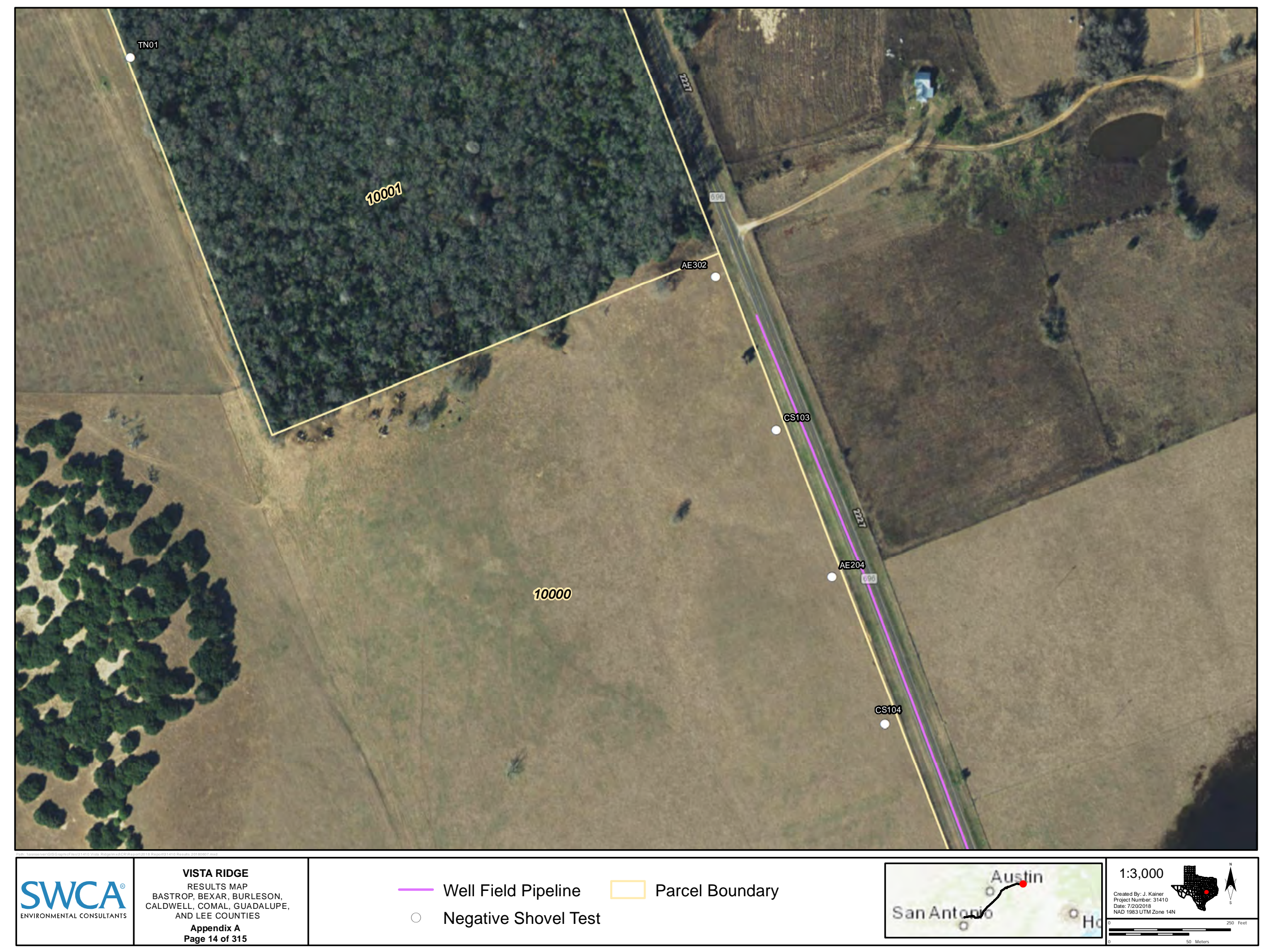




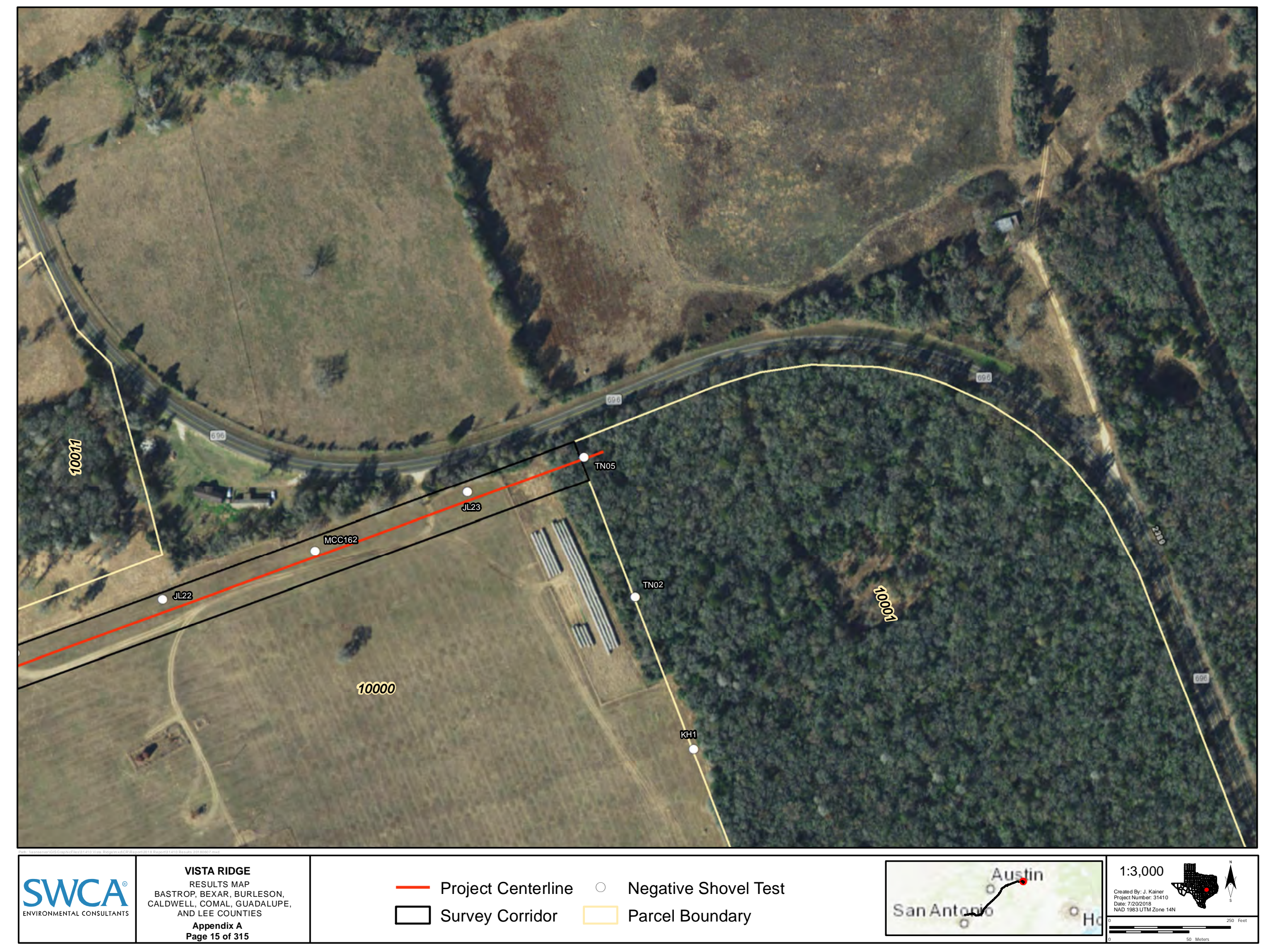




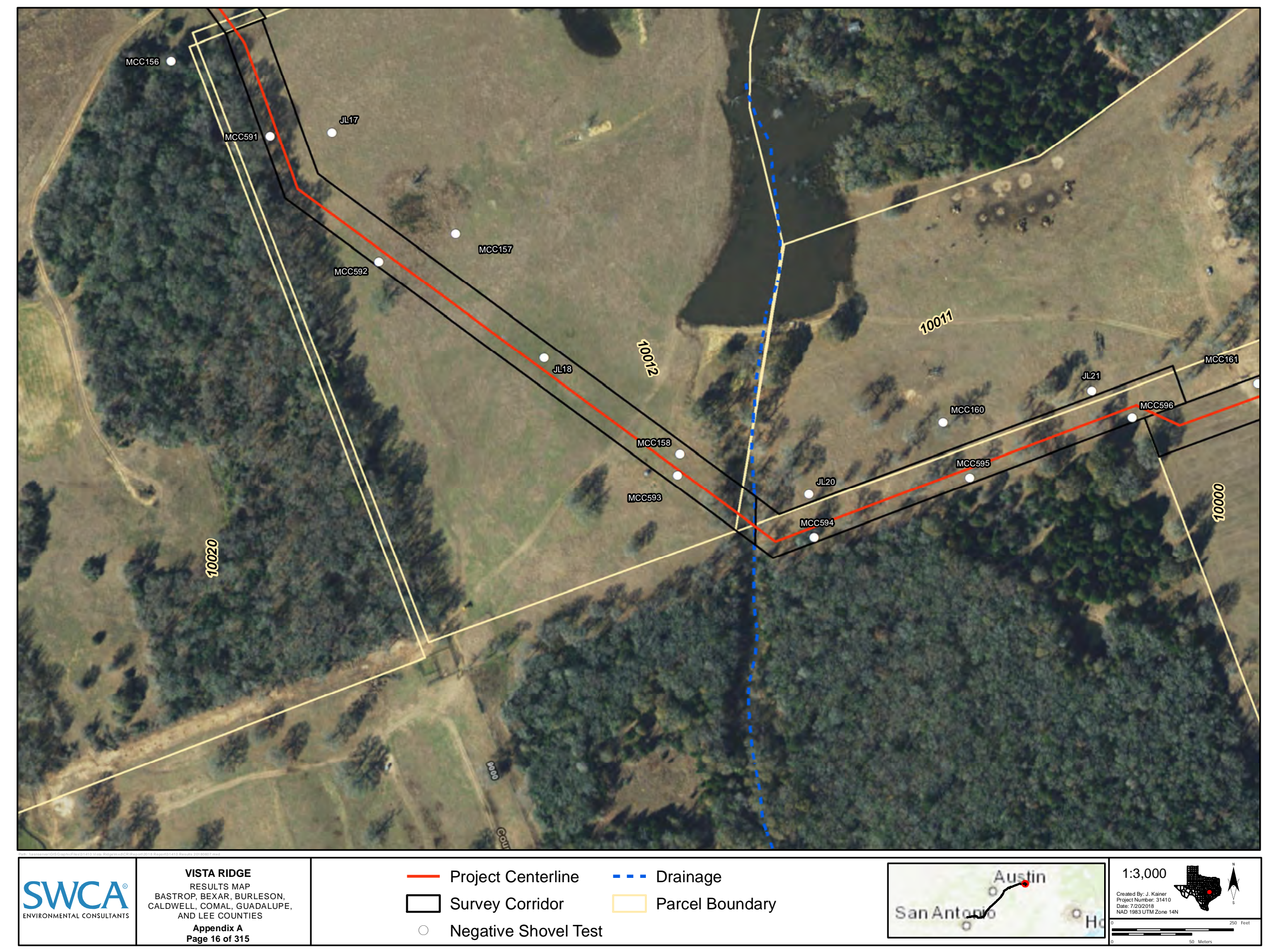




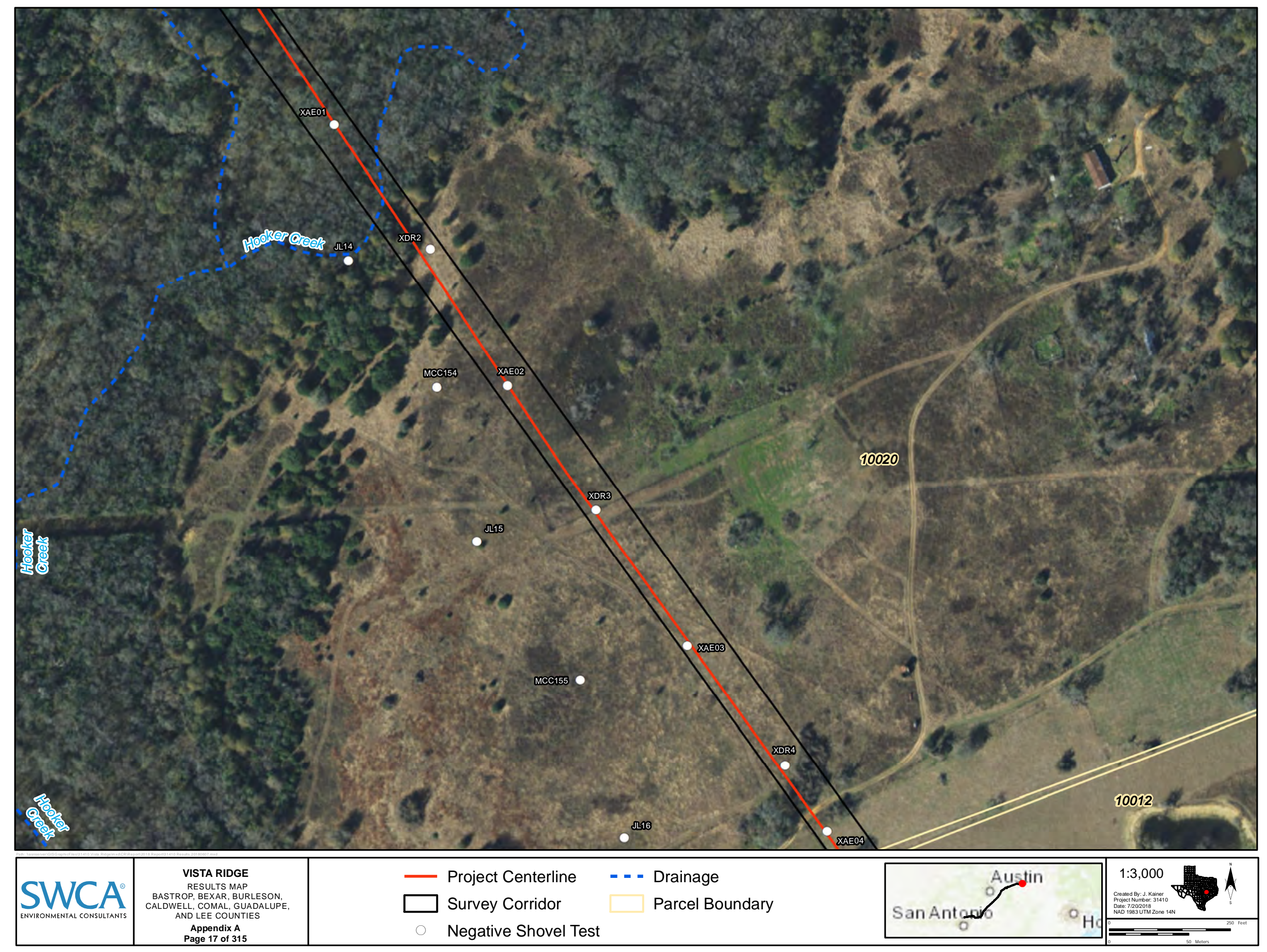




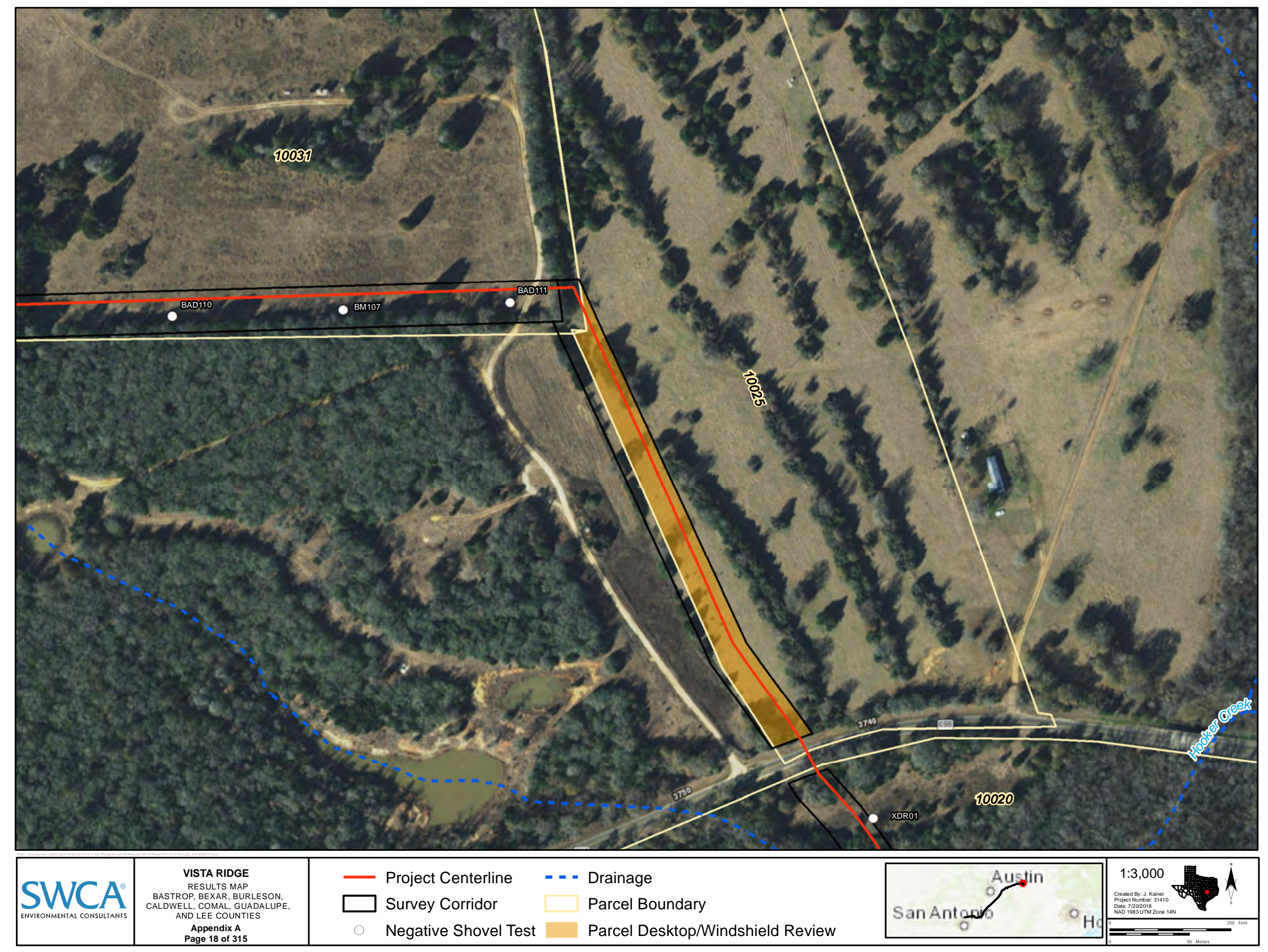




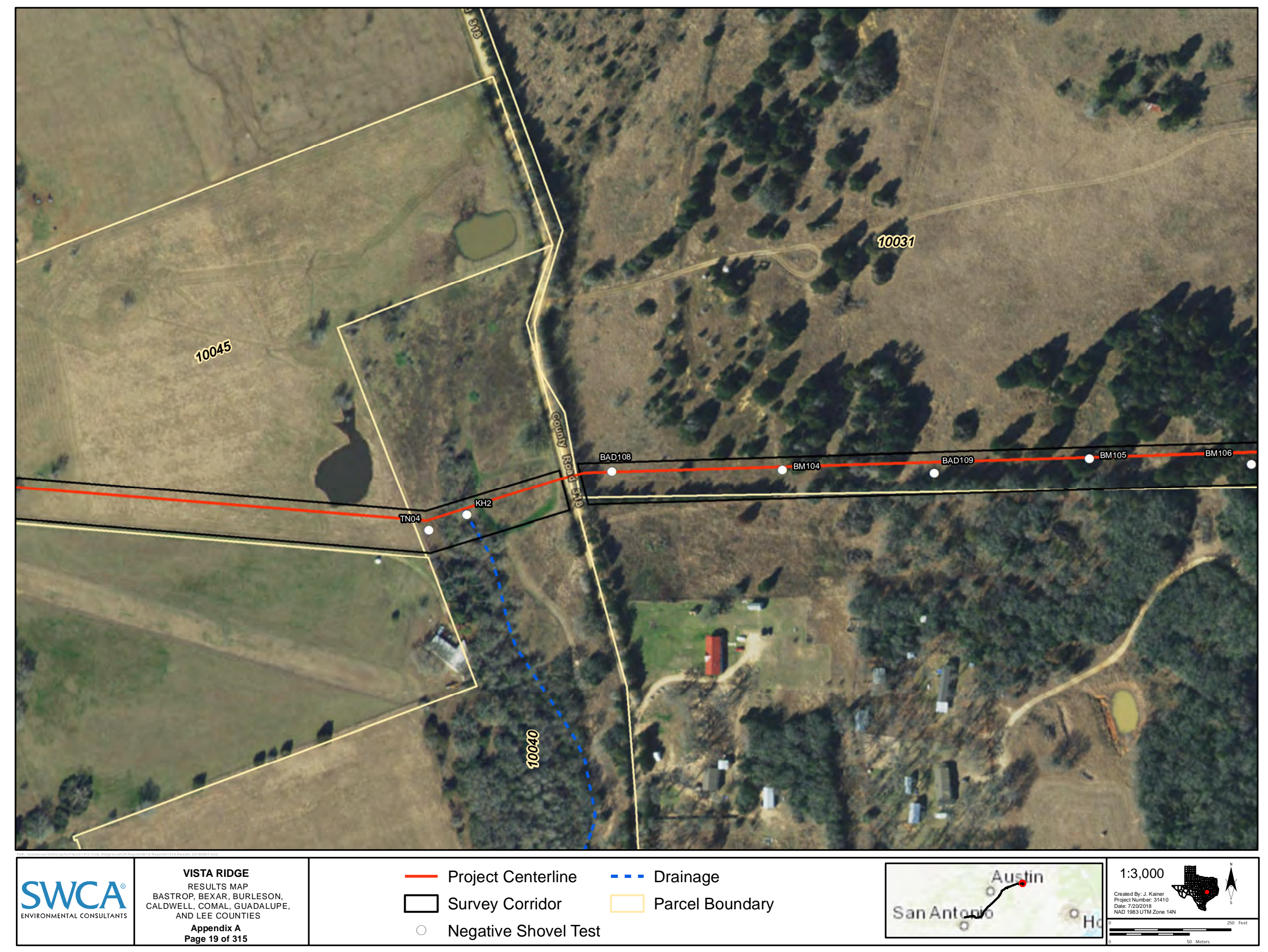




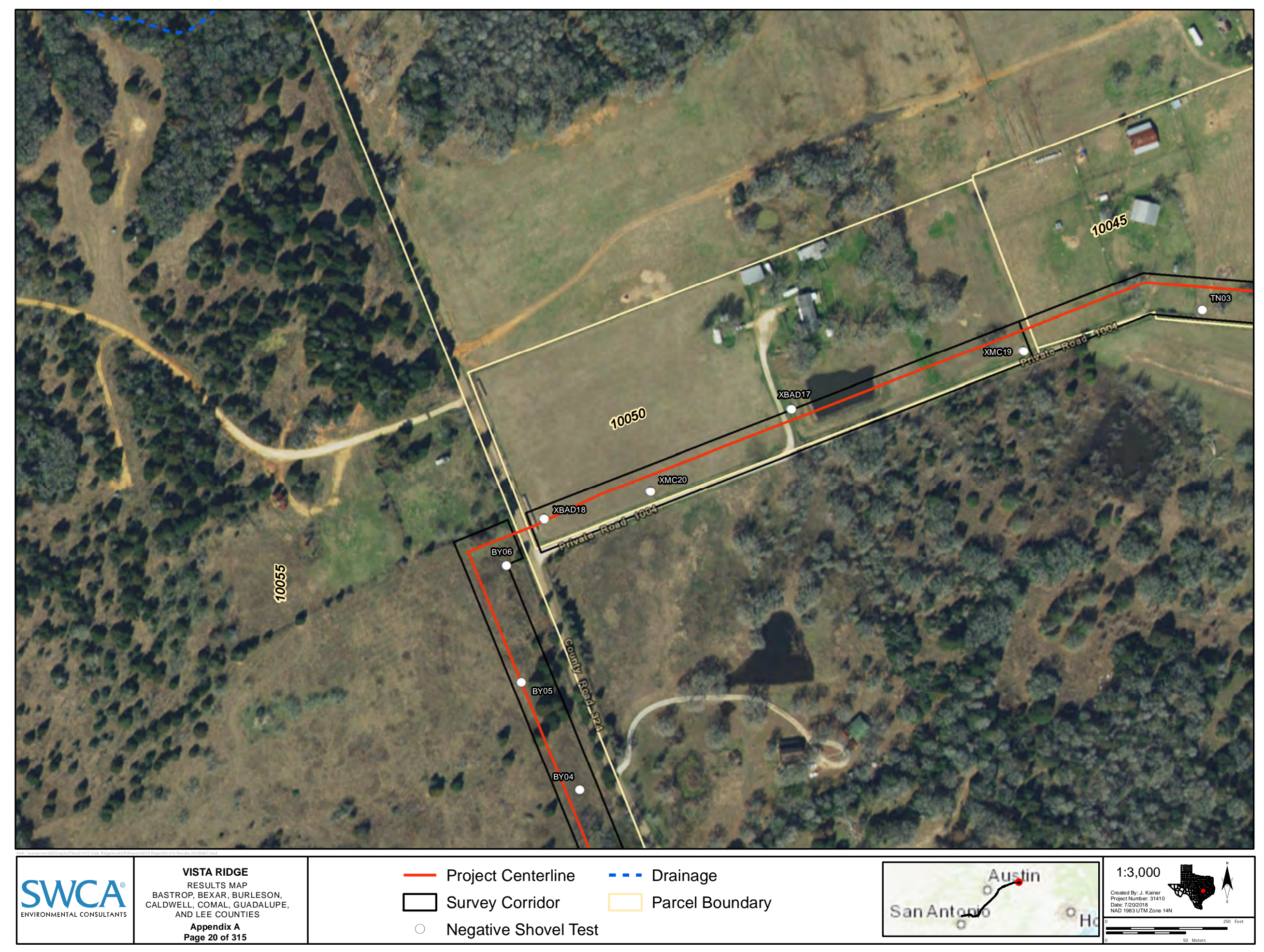


Restricted Information

Not for Public Disclosure 
Restricted Information

Not for Public Disclosure 


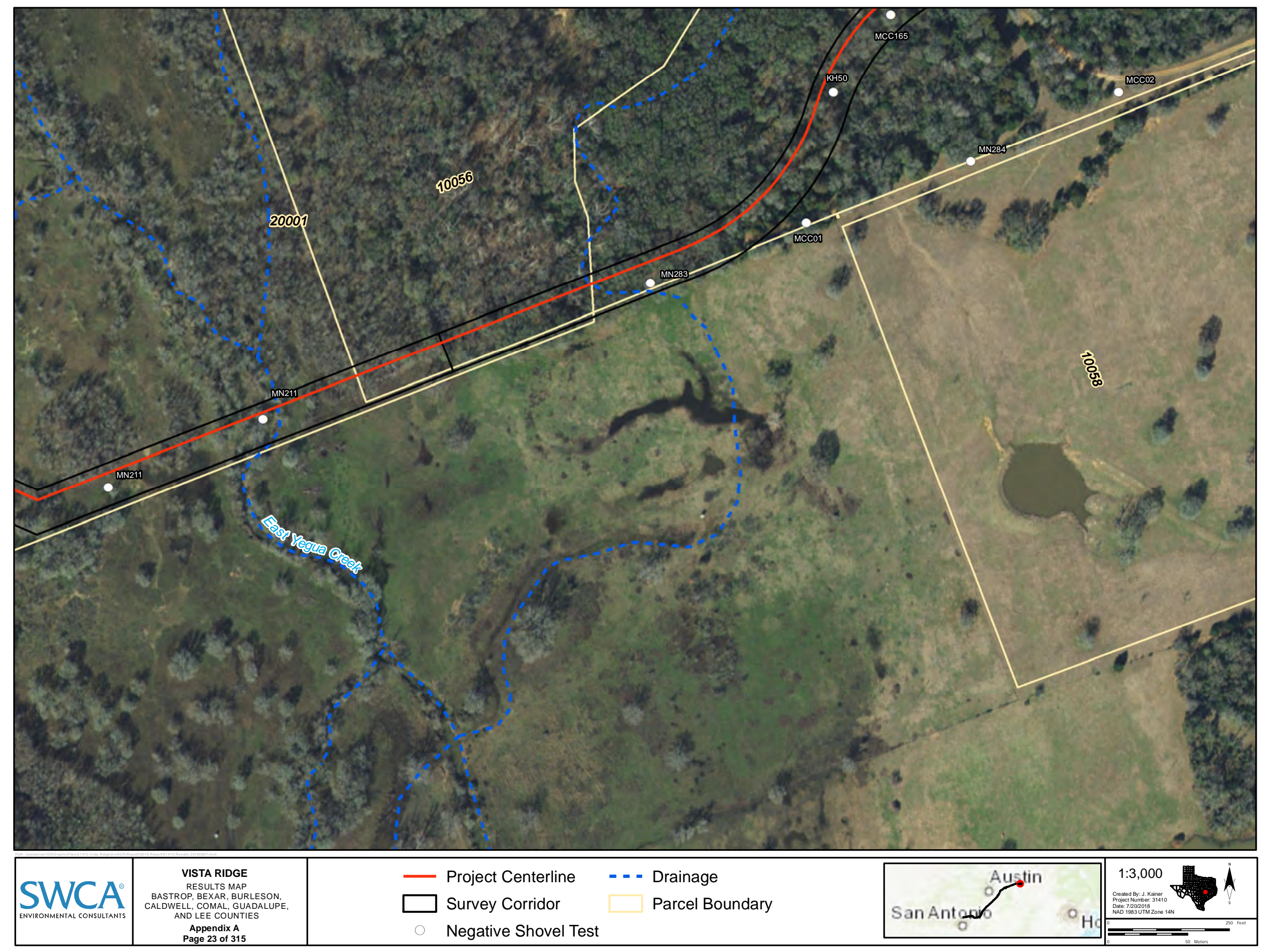


Restricted Information

Not for Public Disclosure 


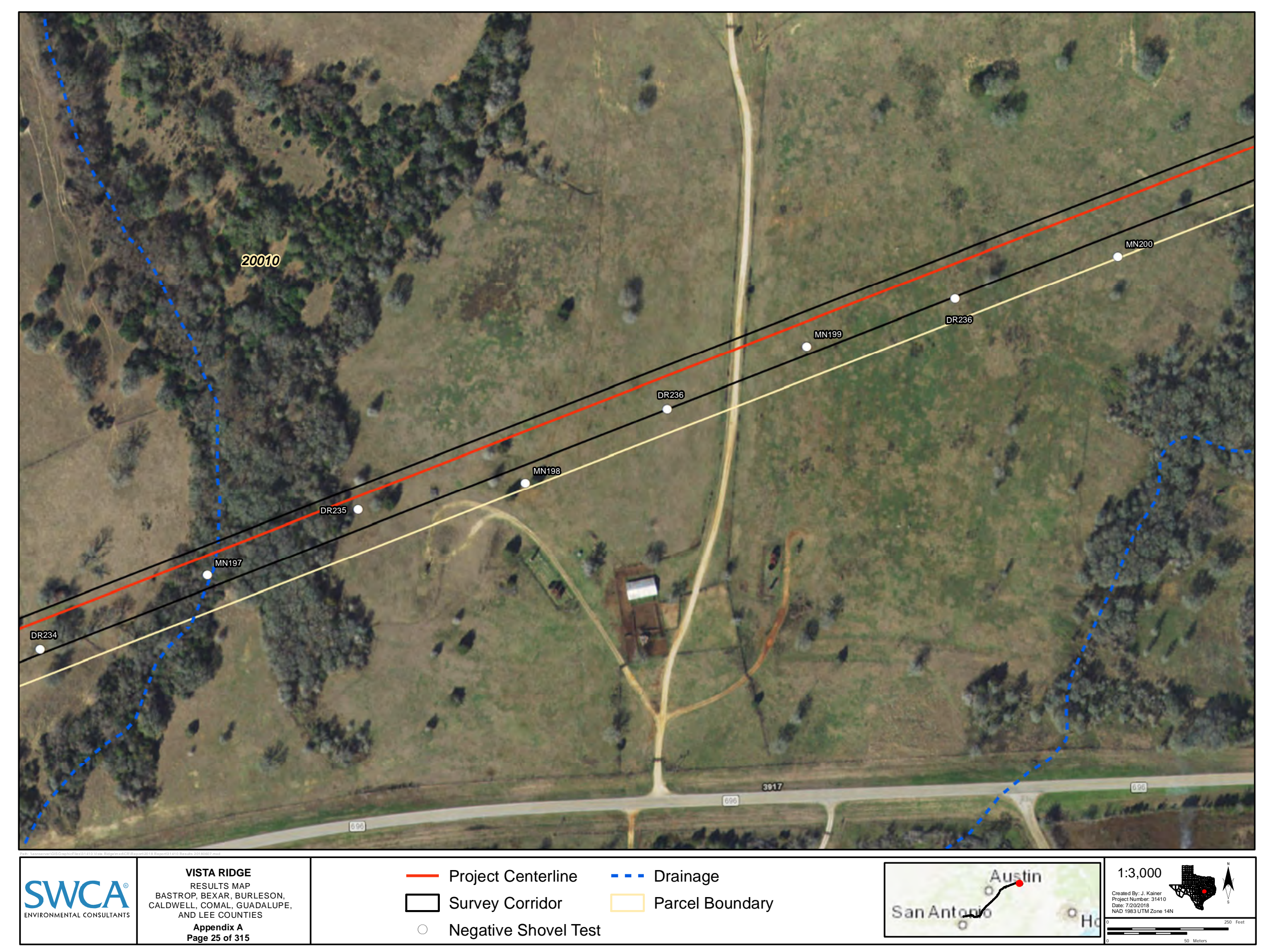




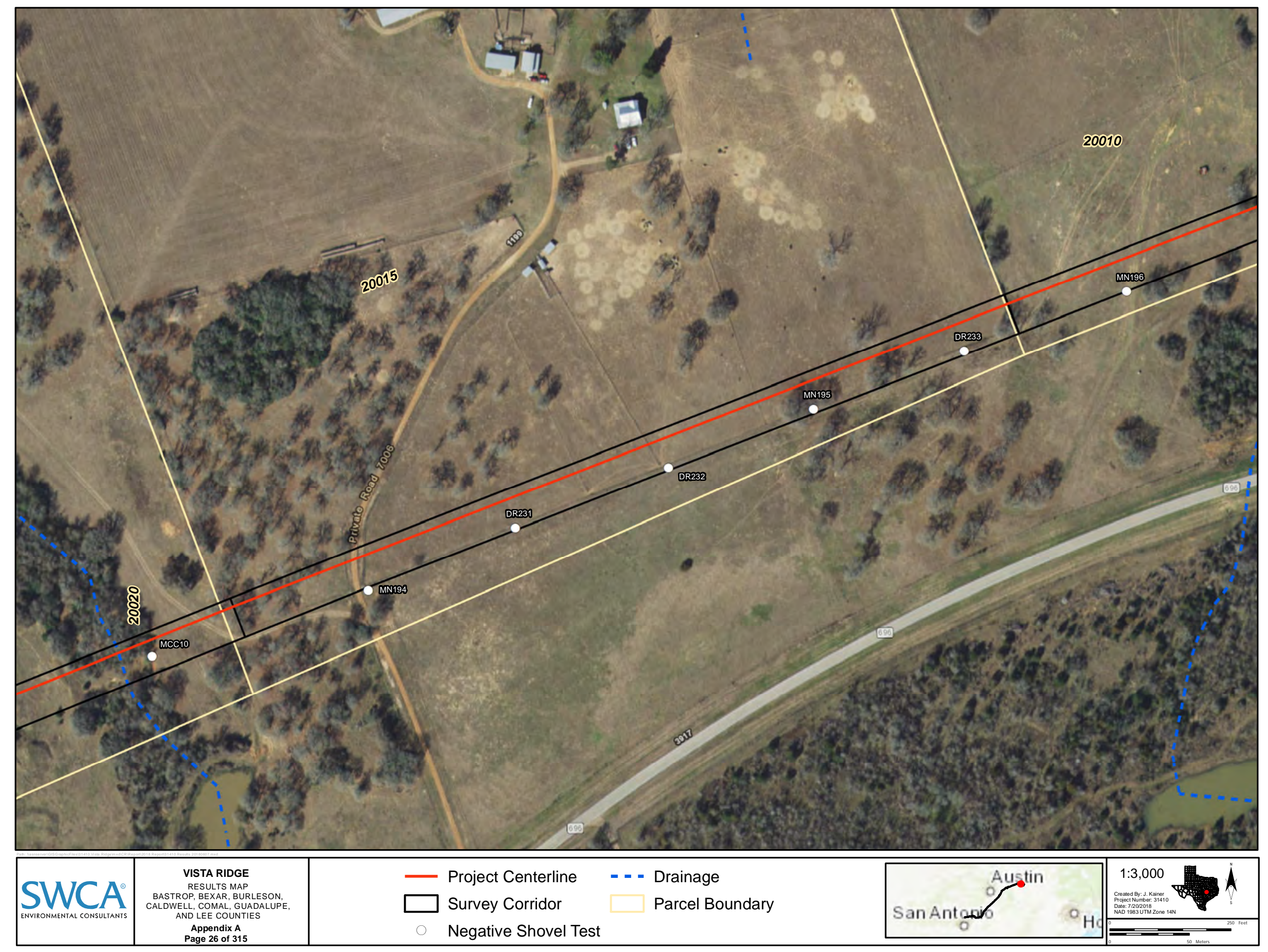


Restricted Information

Not for Public Disclosure 


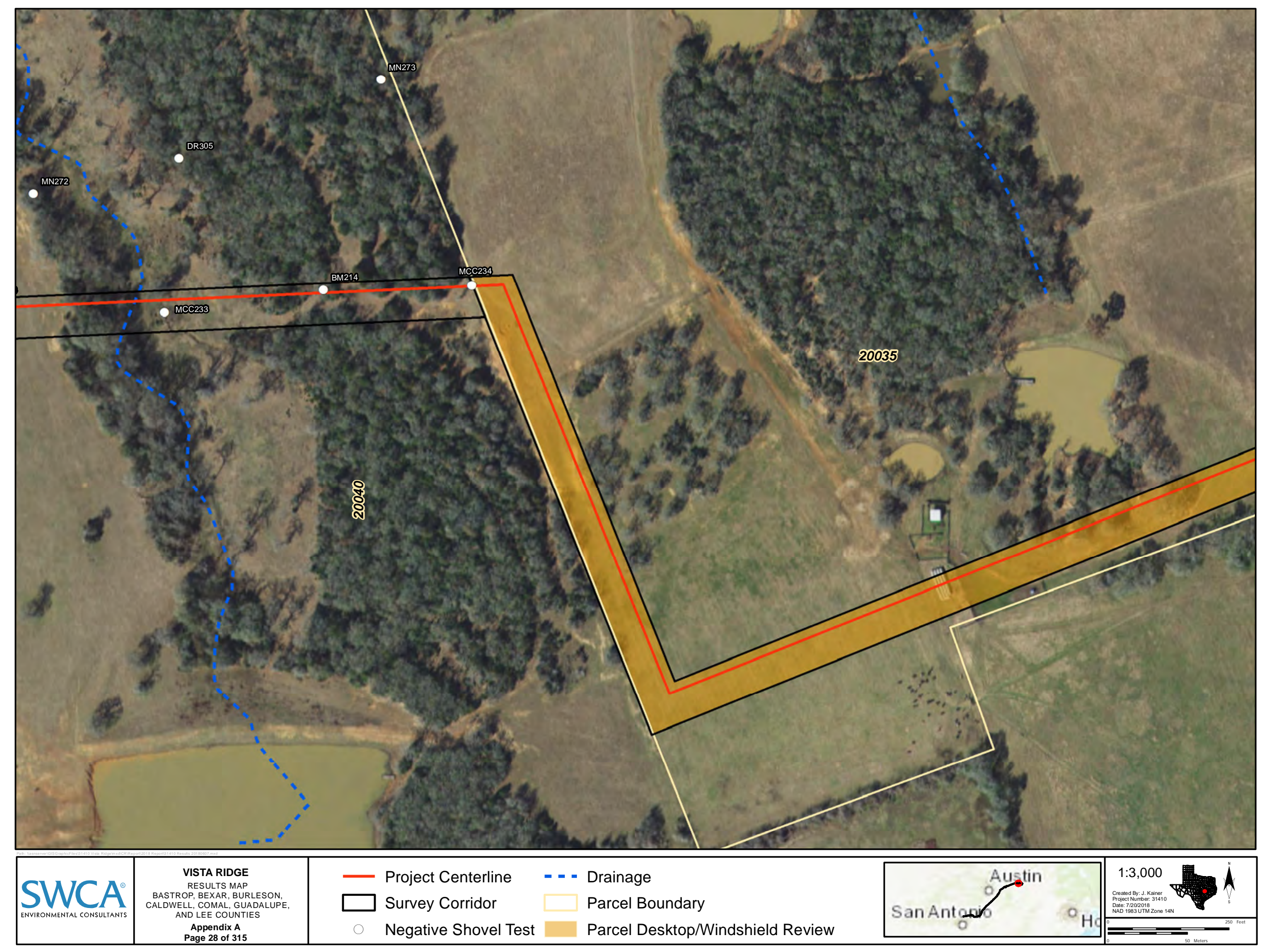




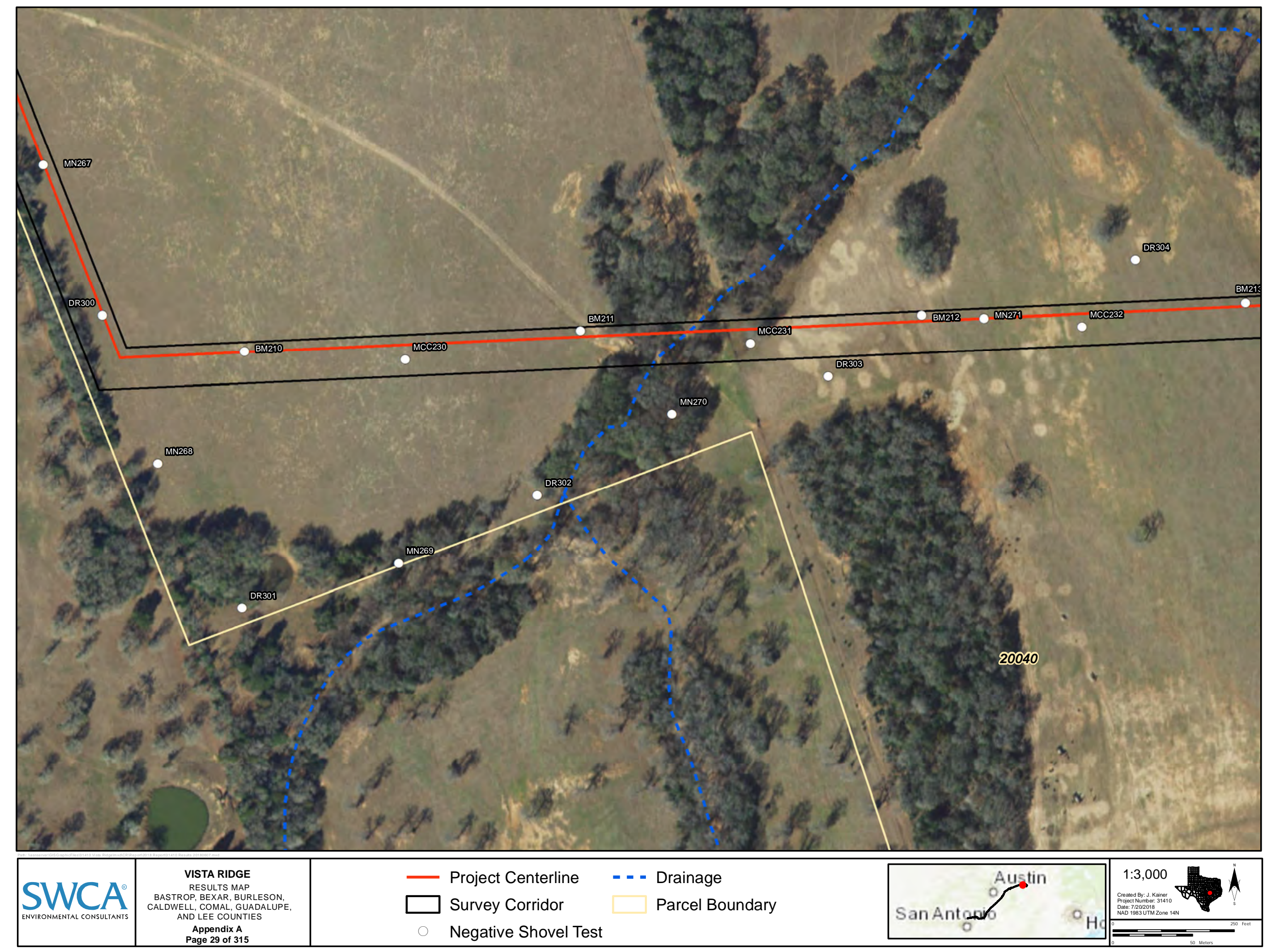




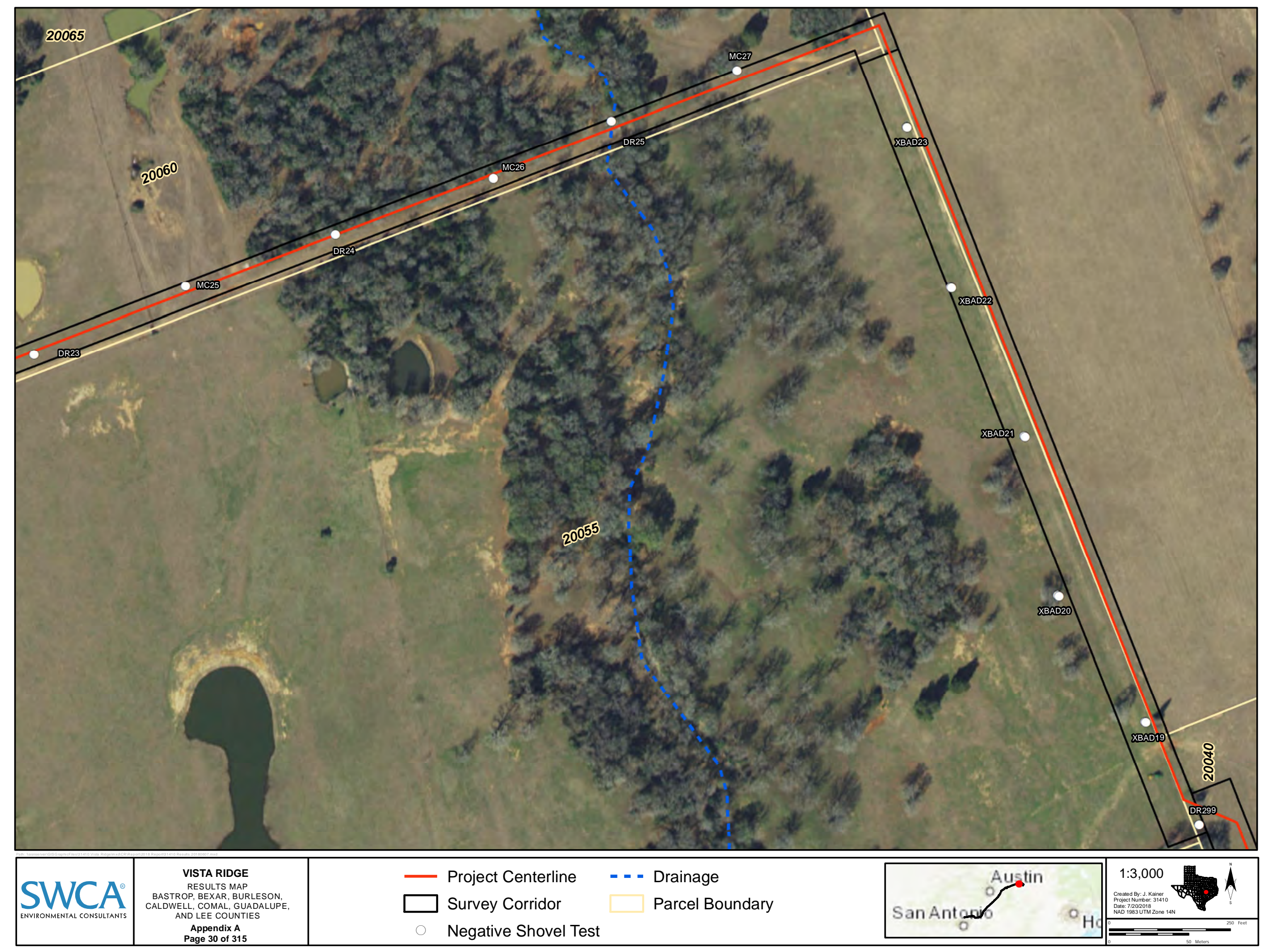




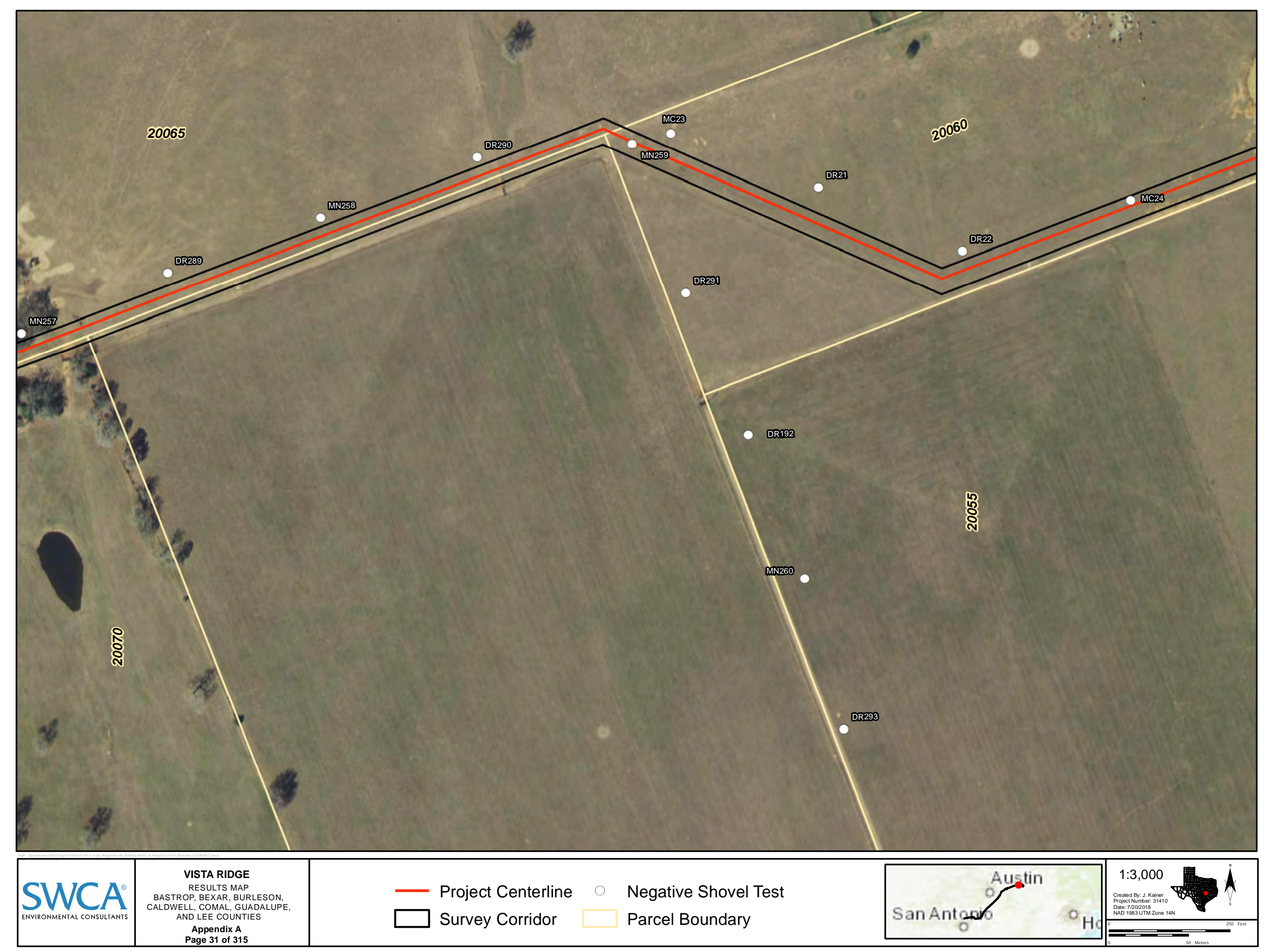




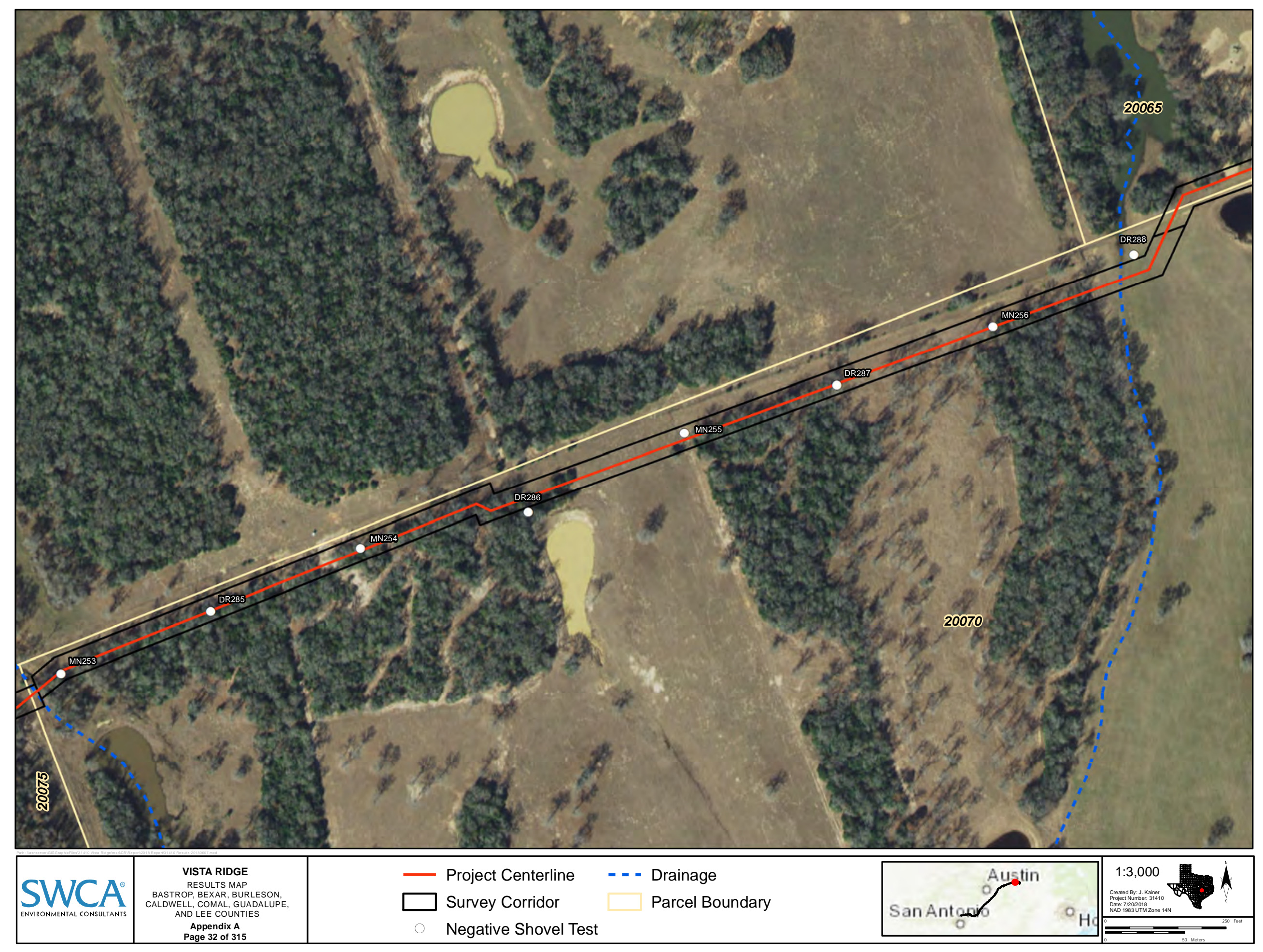




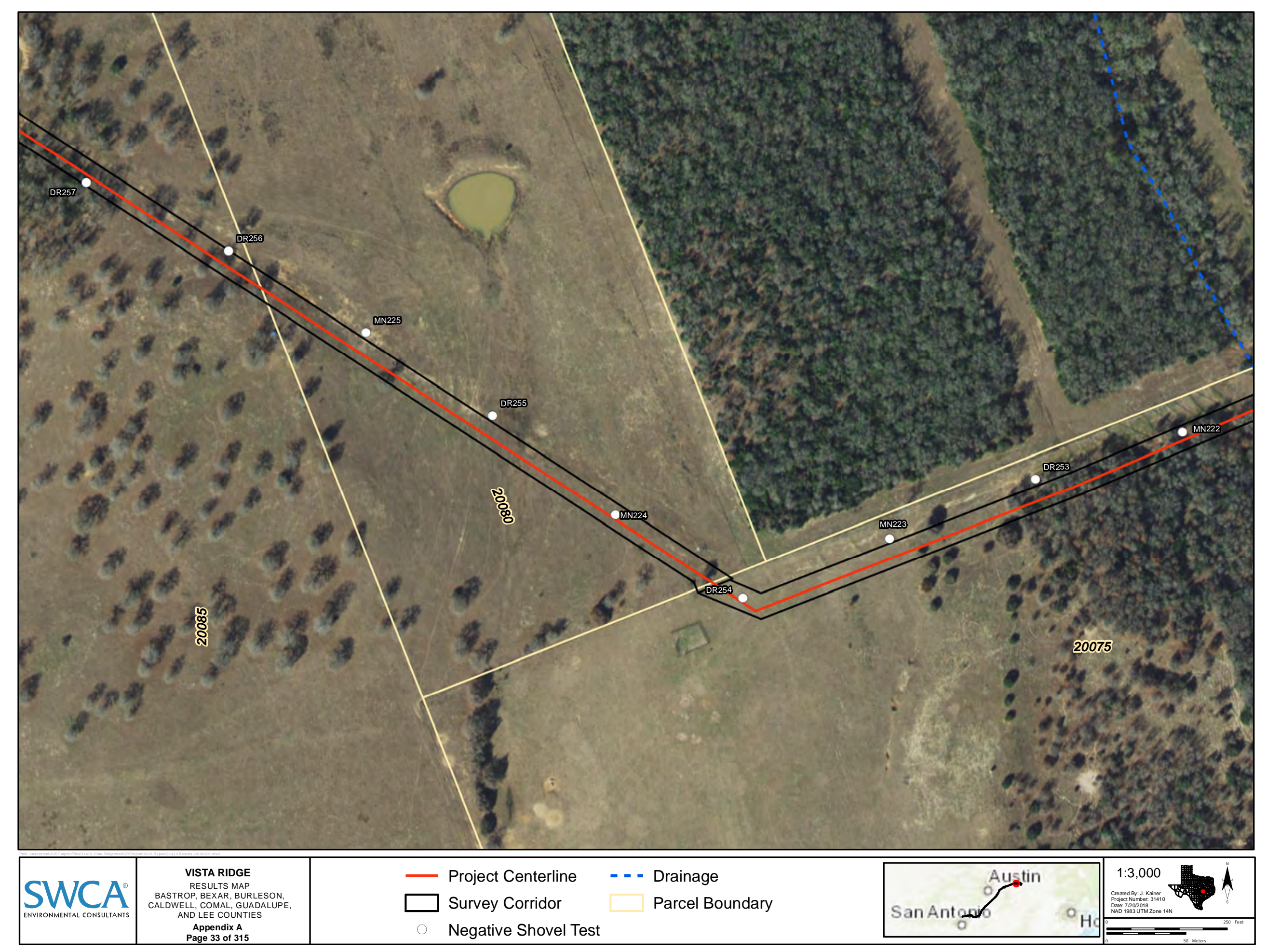




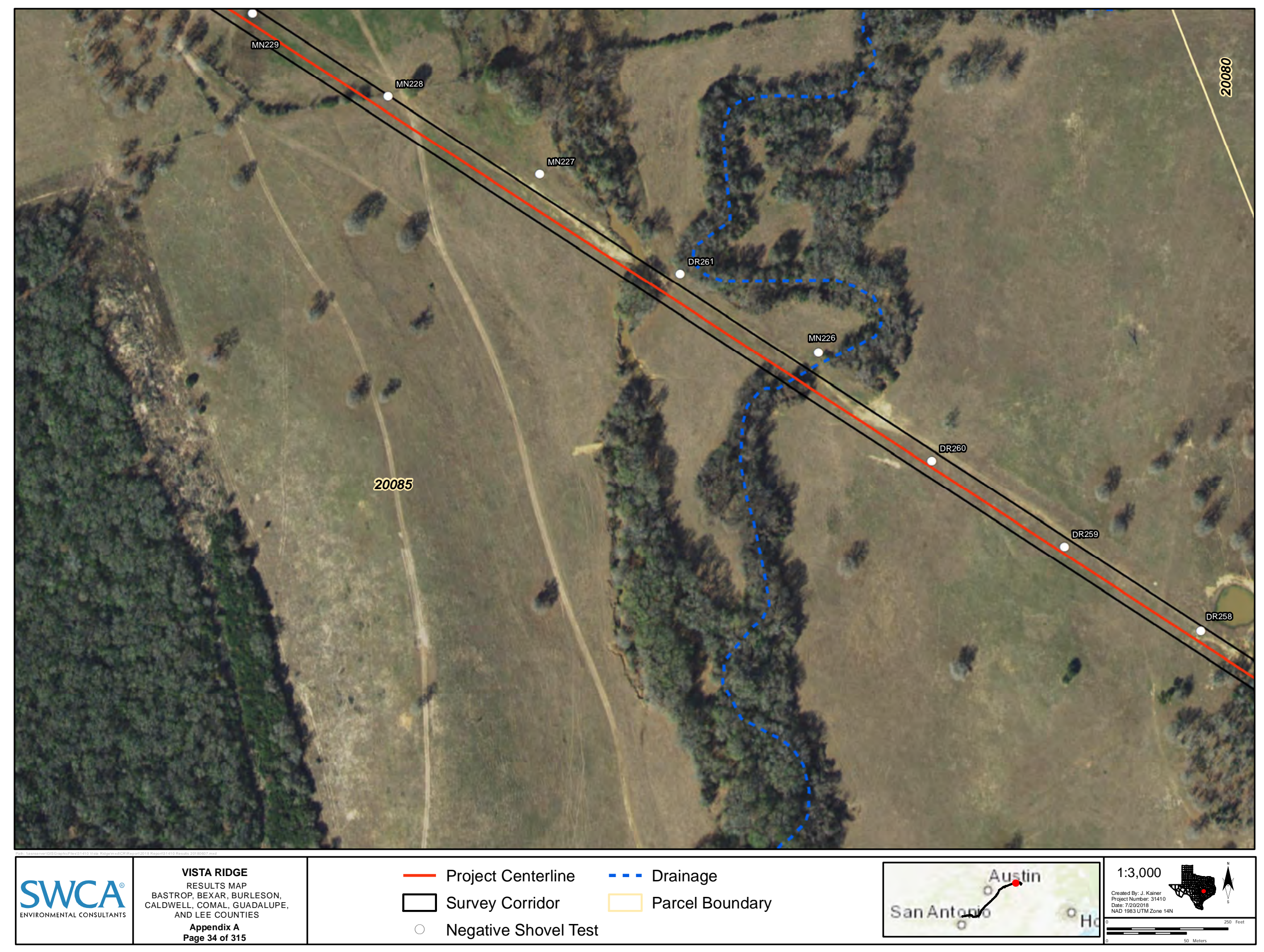


This page has been removed intentionally to protect sensitive

\author{
cultural materials
}

Figure 4. Isolated Find schematic map. 
Restricted Information

Not for Public Disclosure 


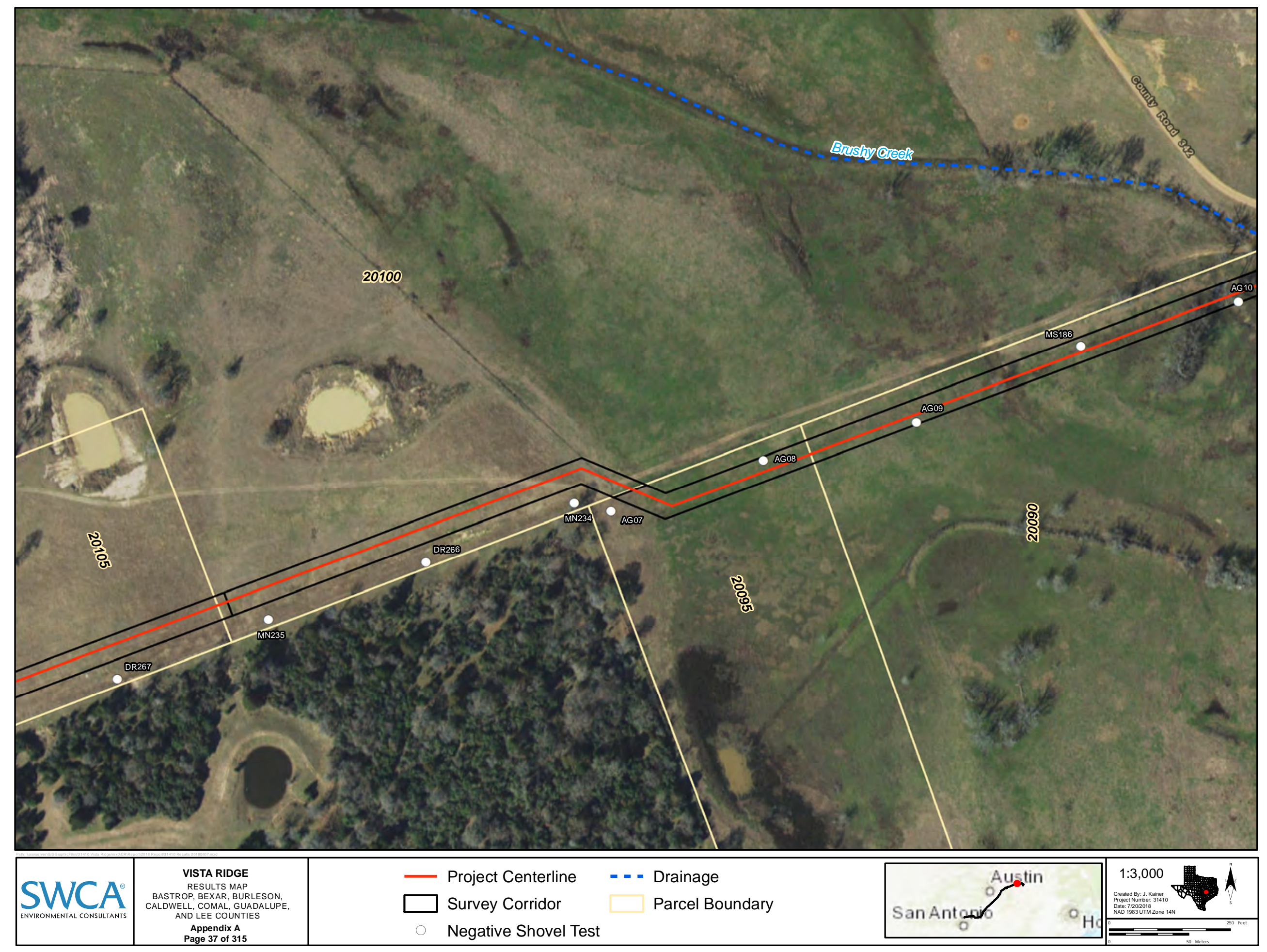




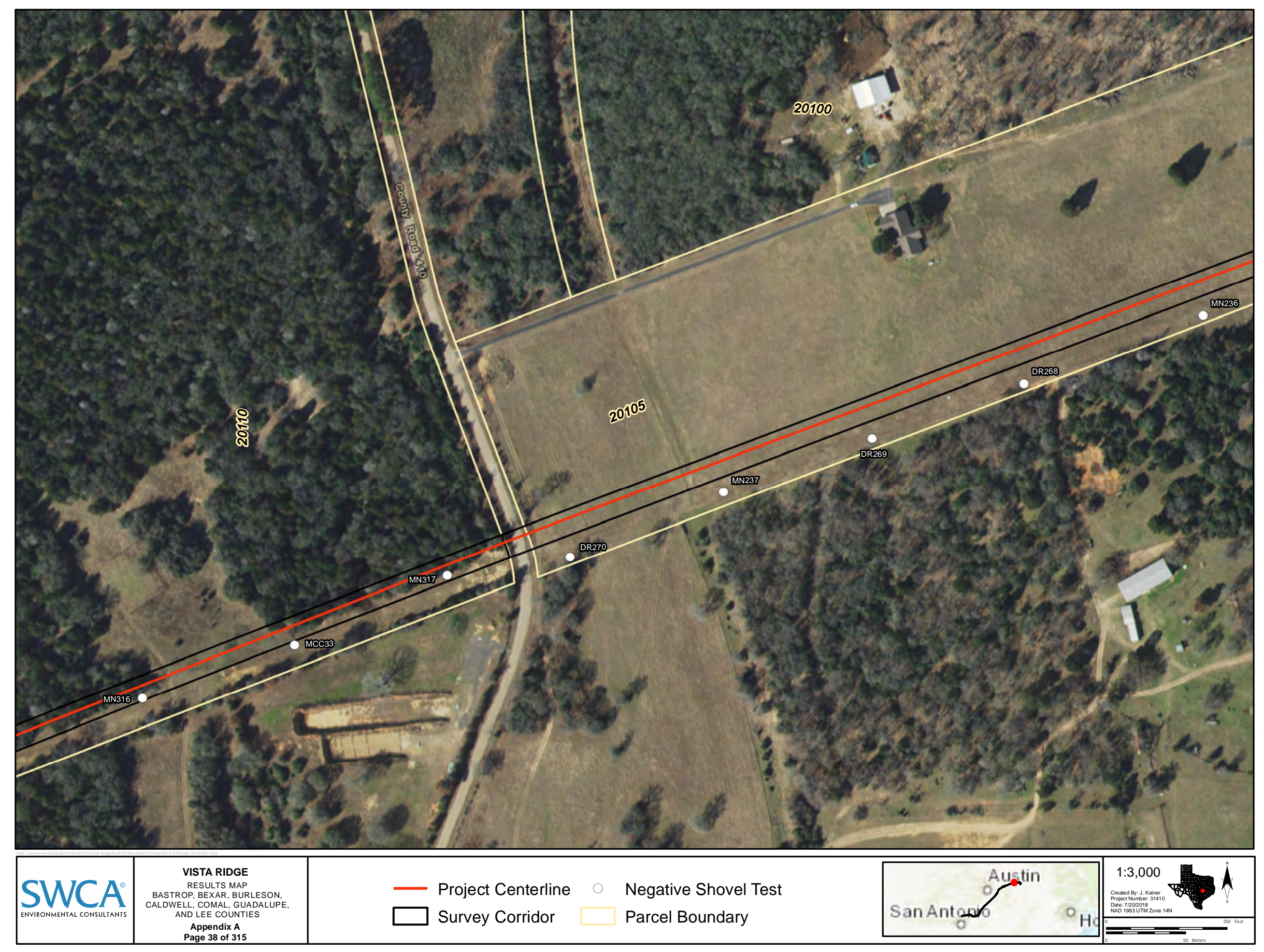




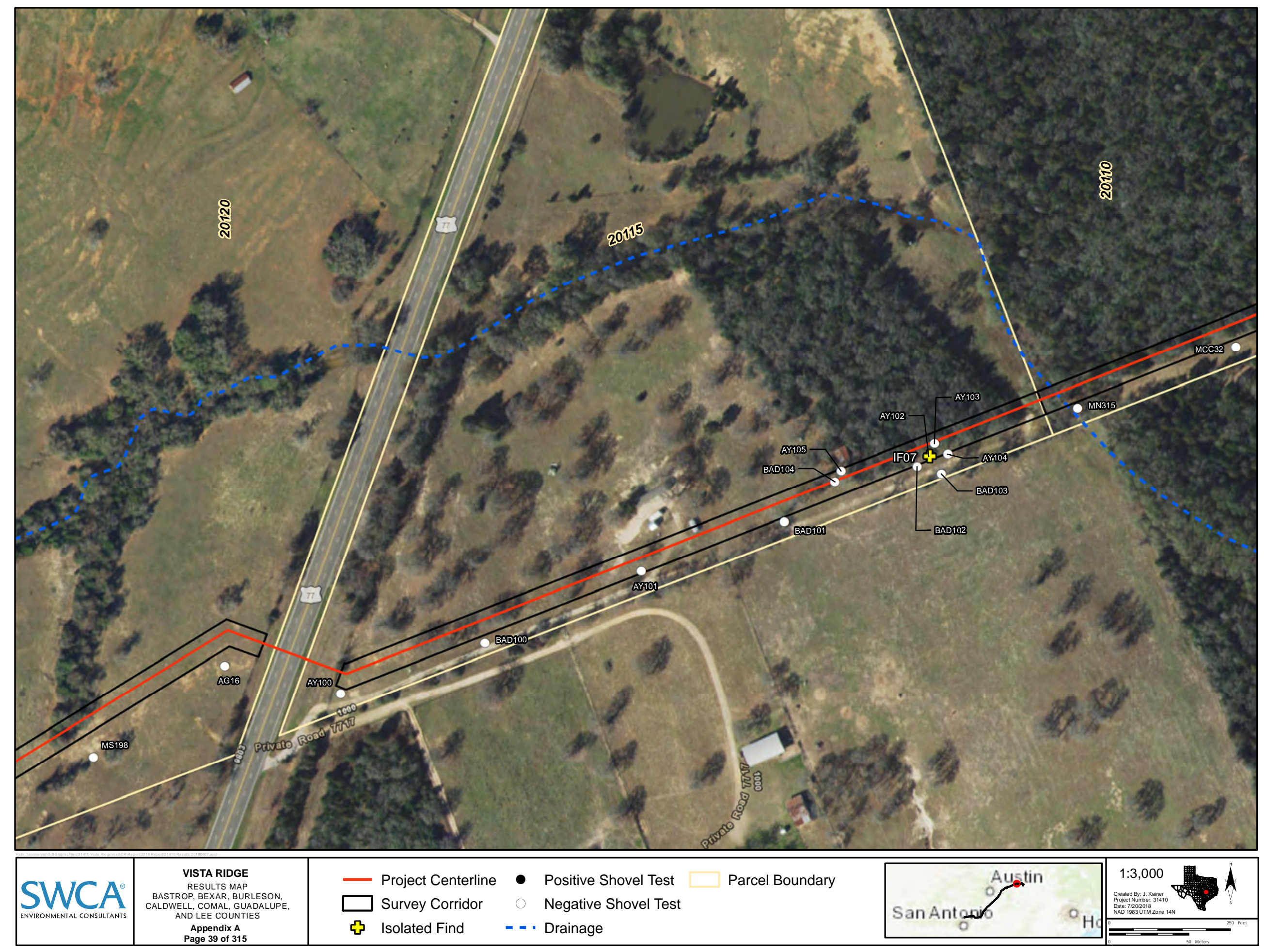




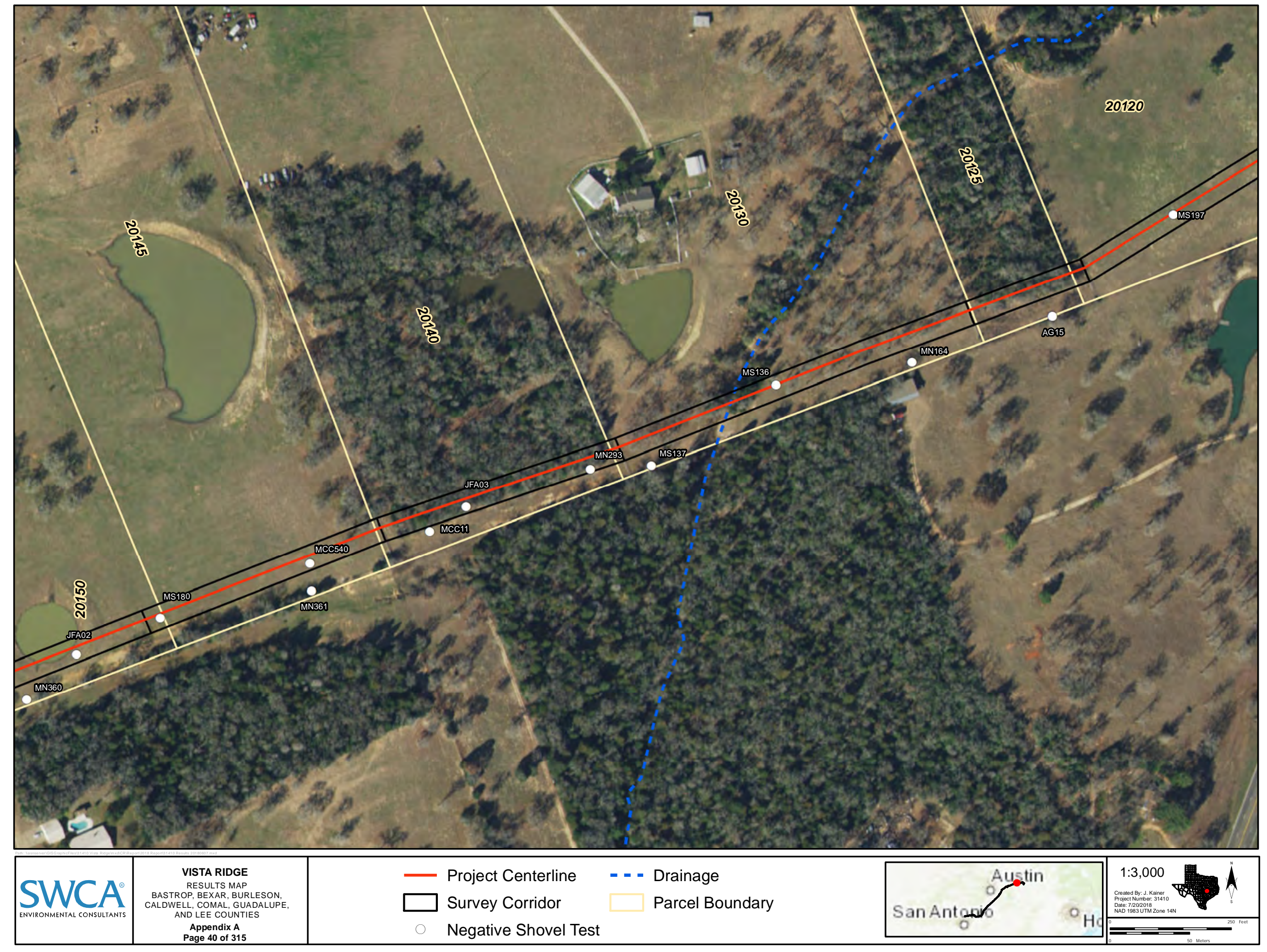




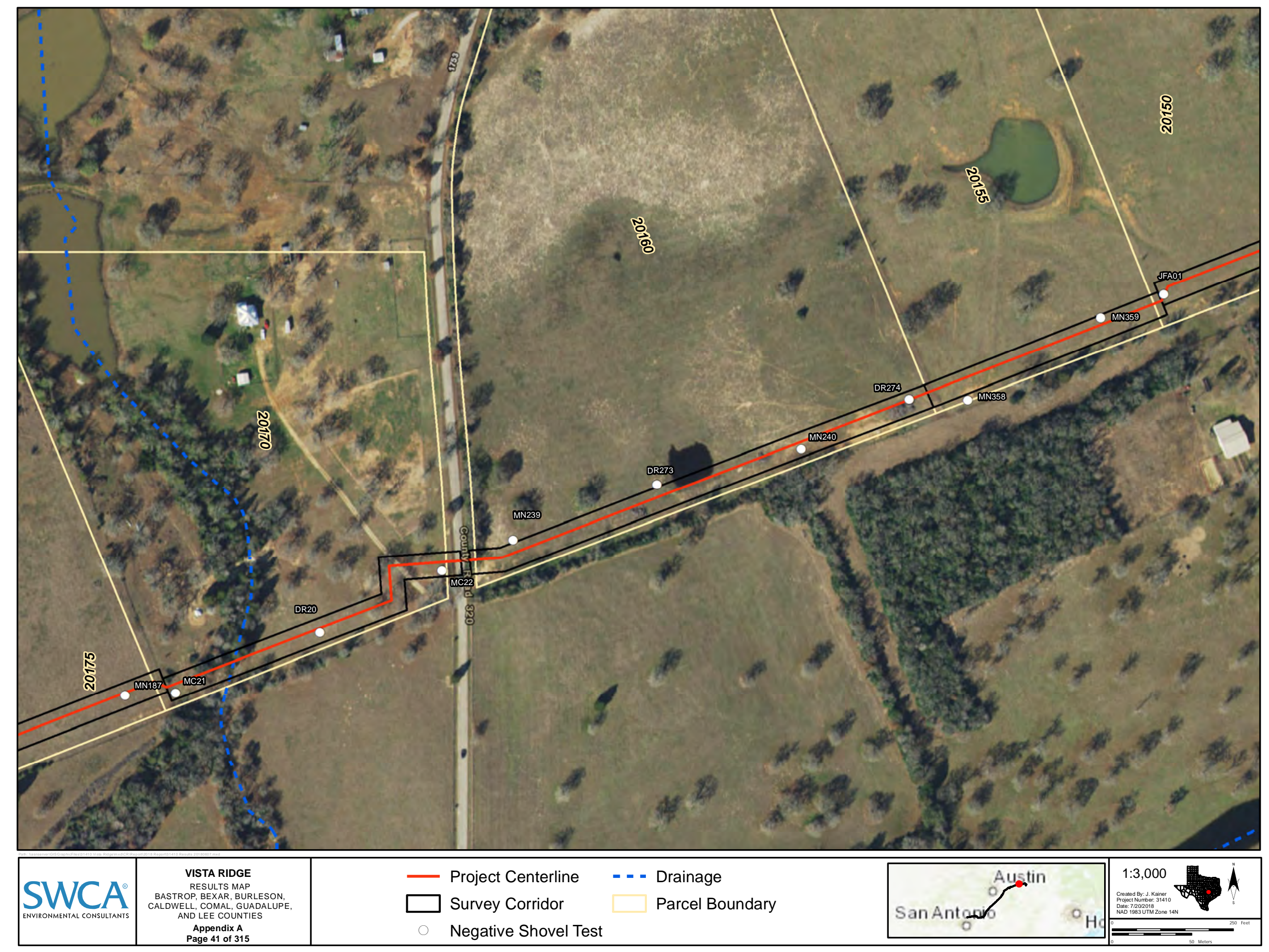




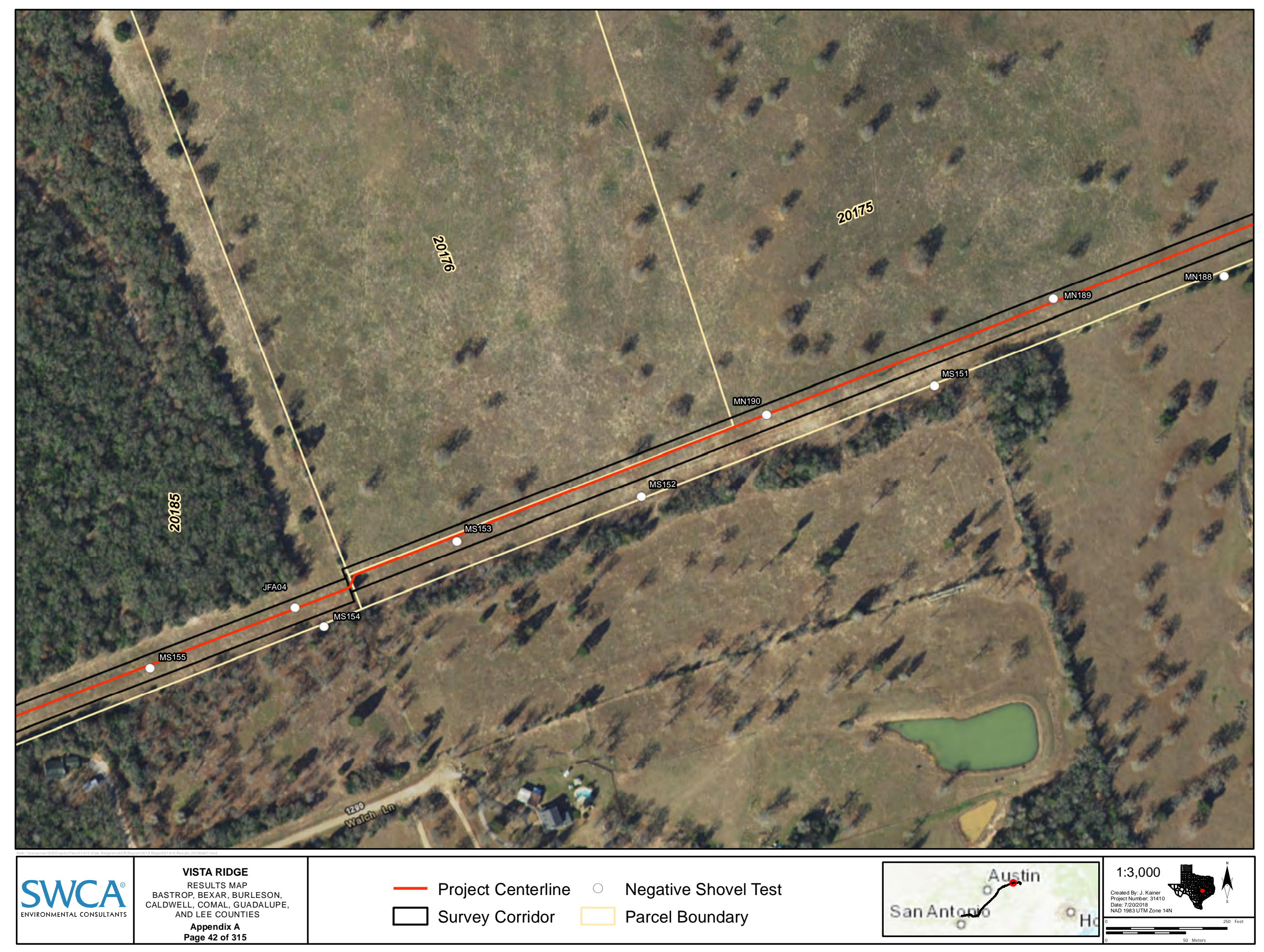




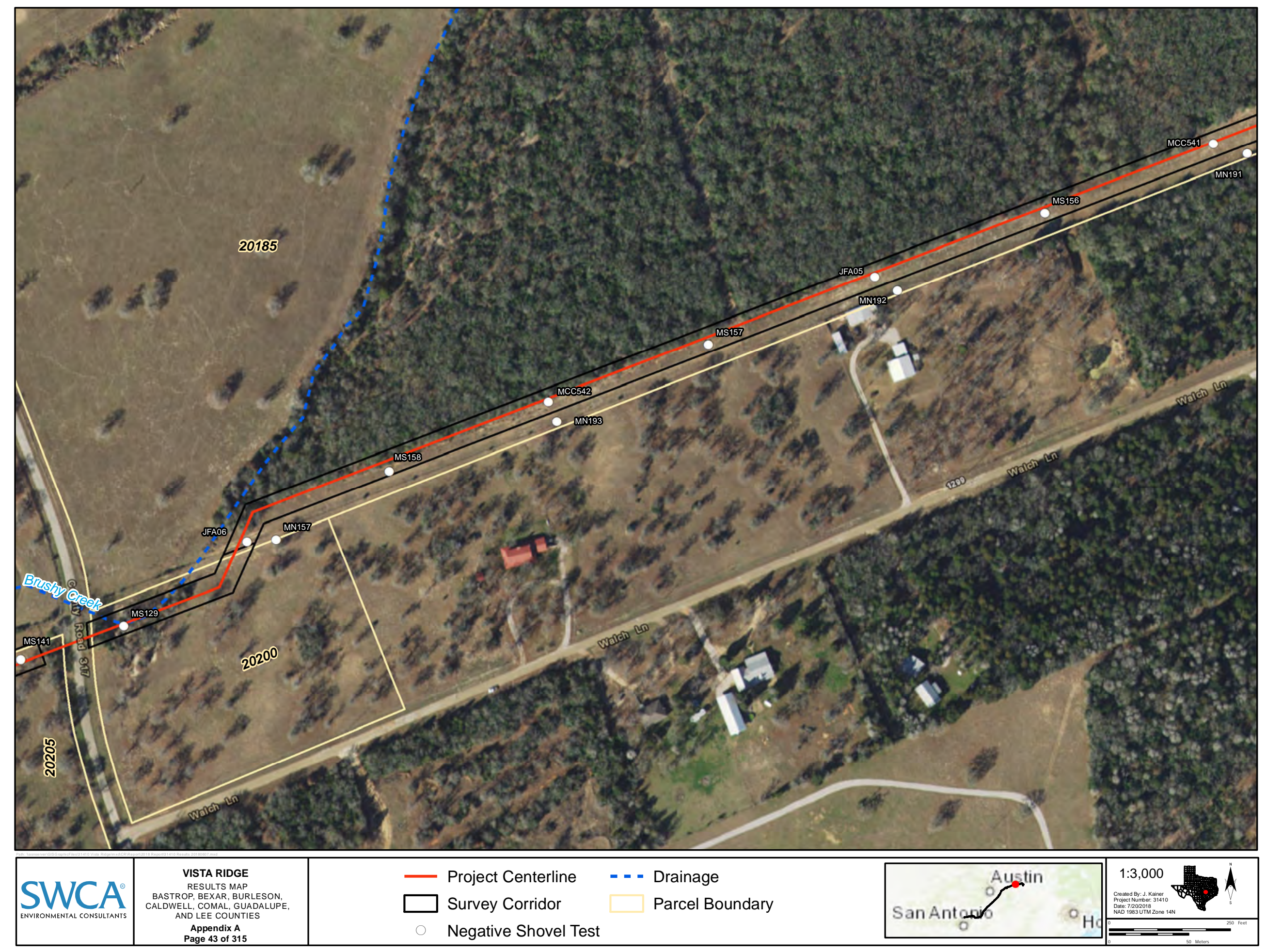




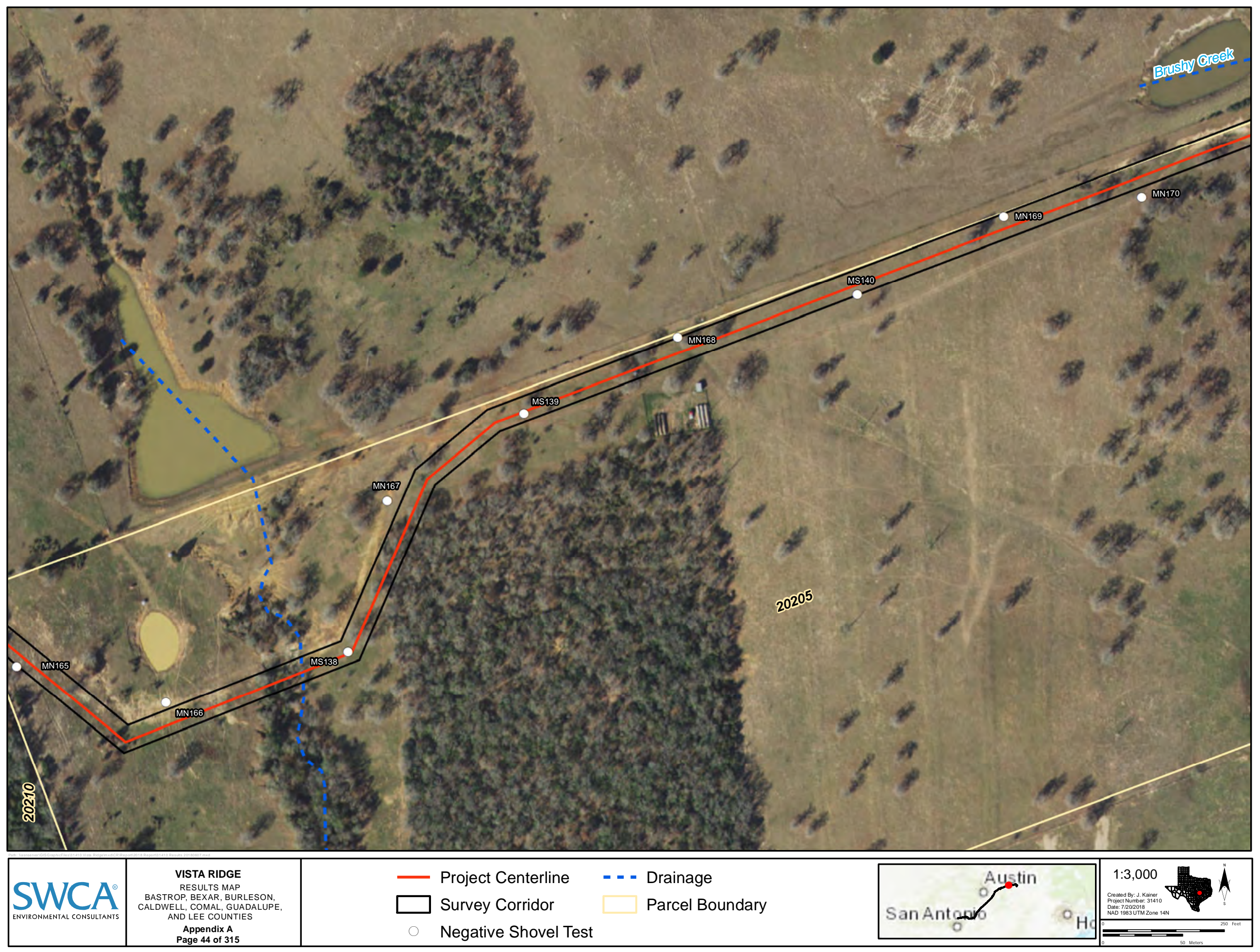




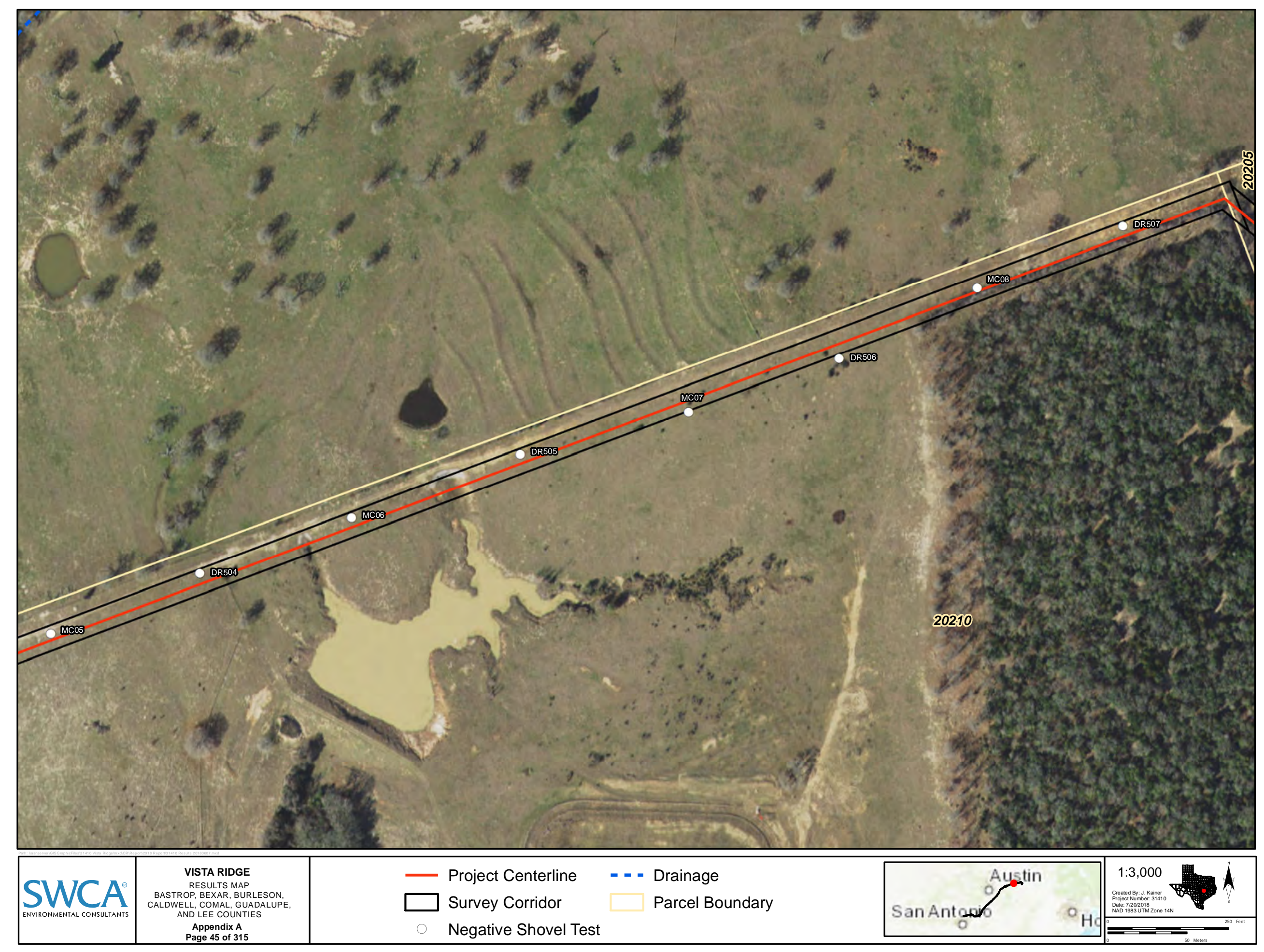




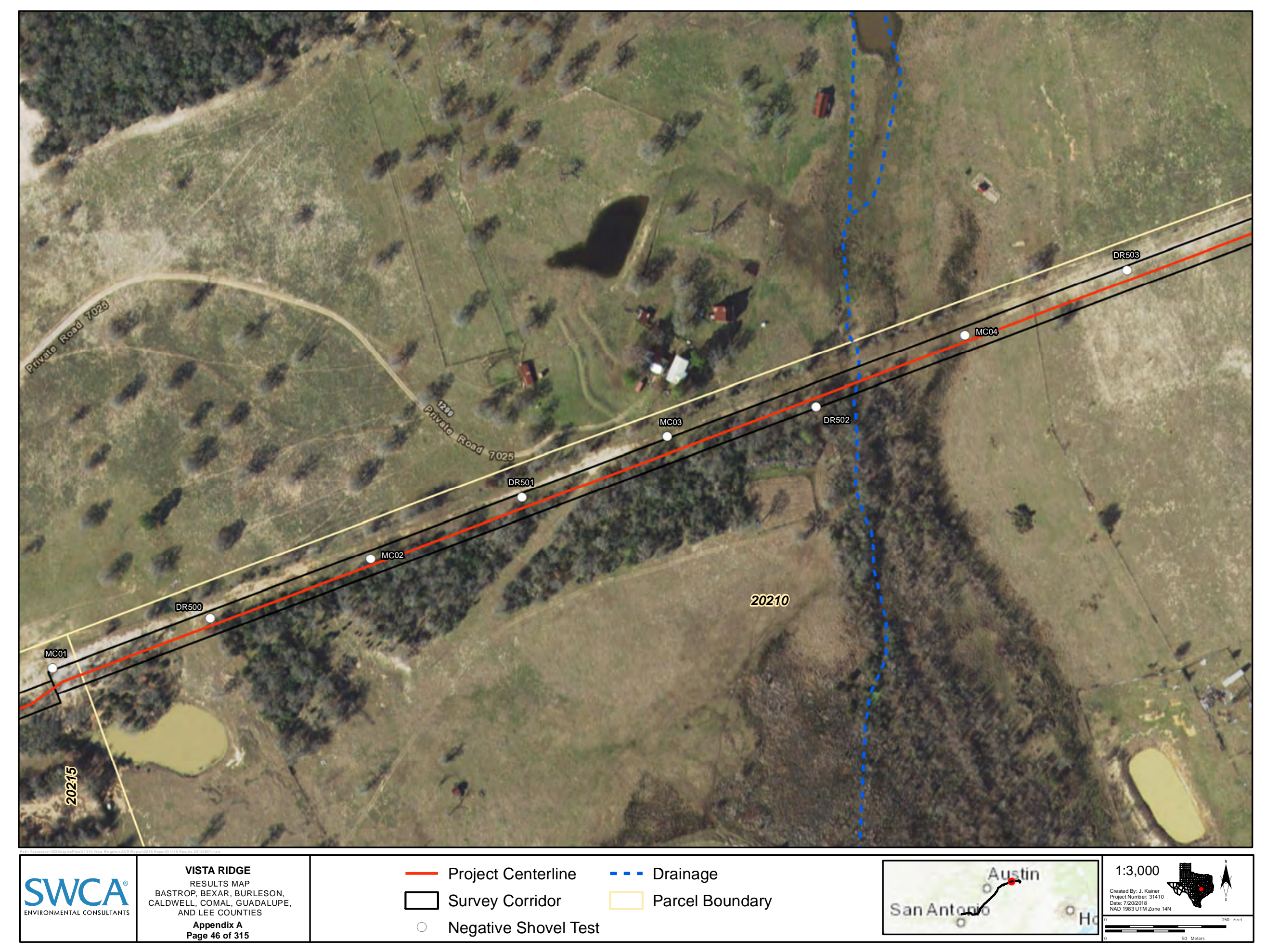




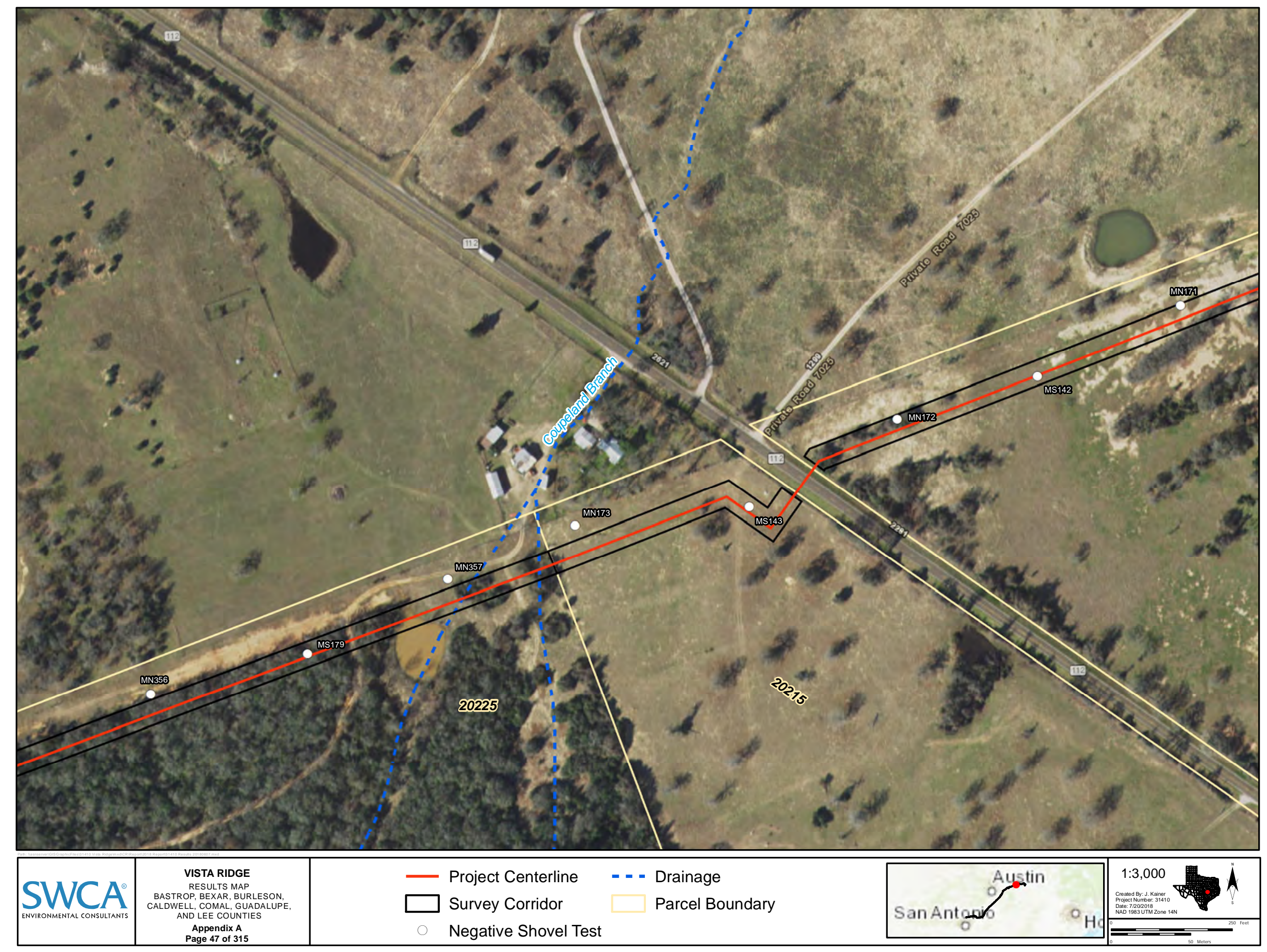




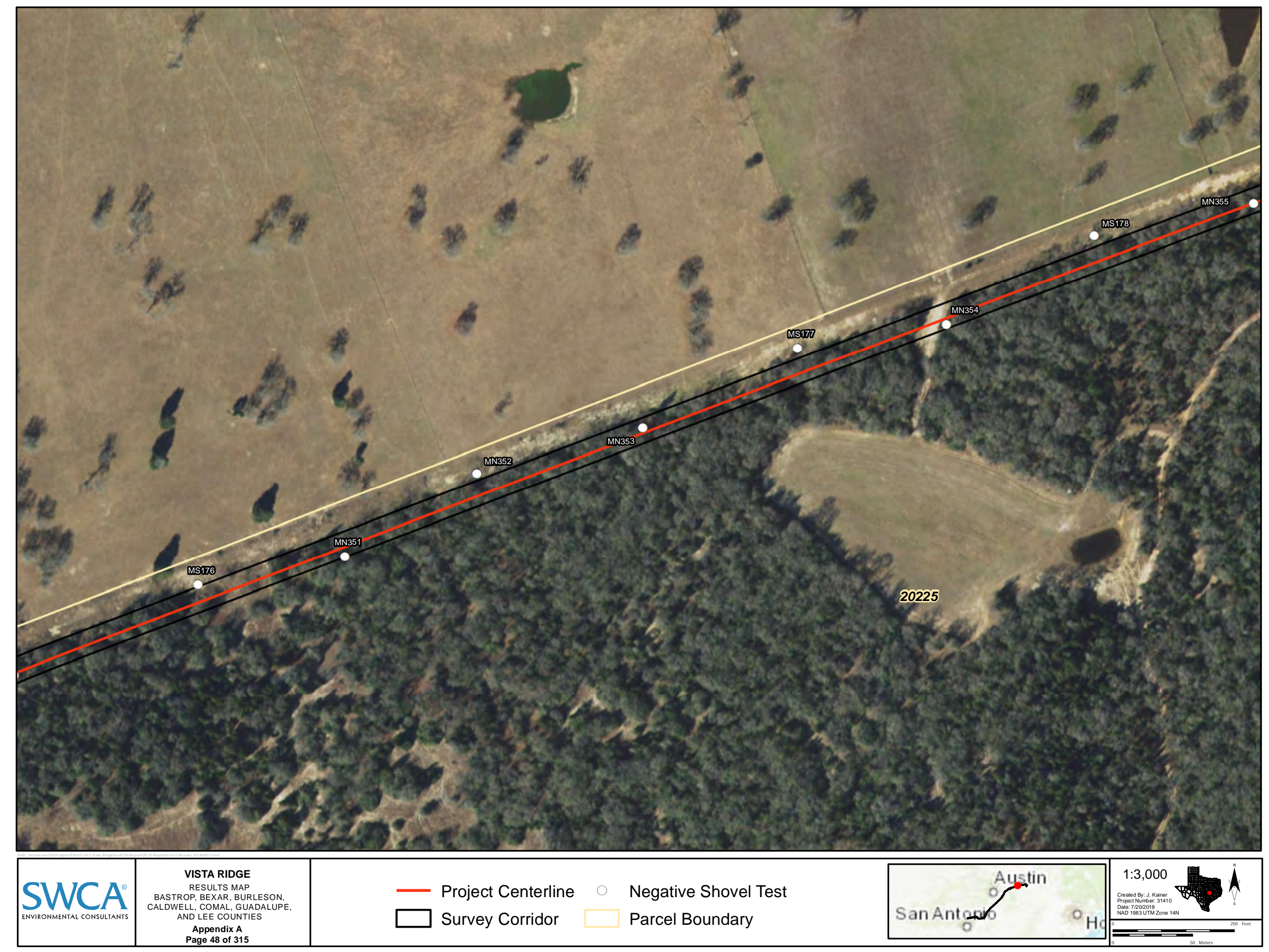




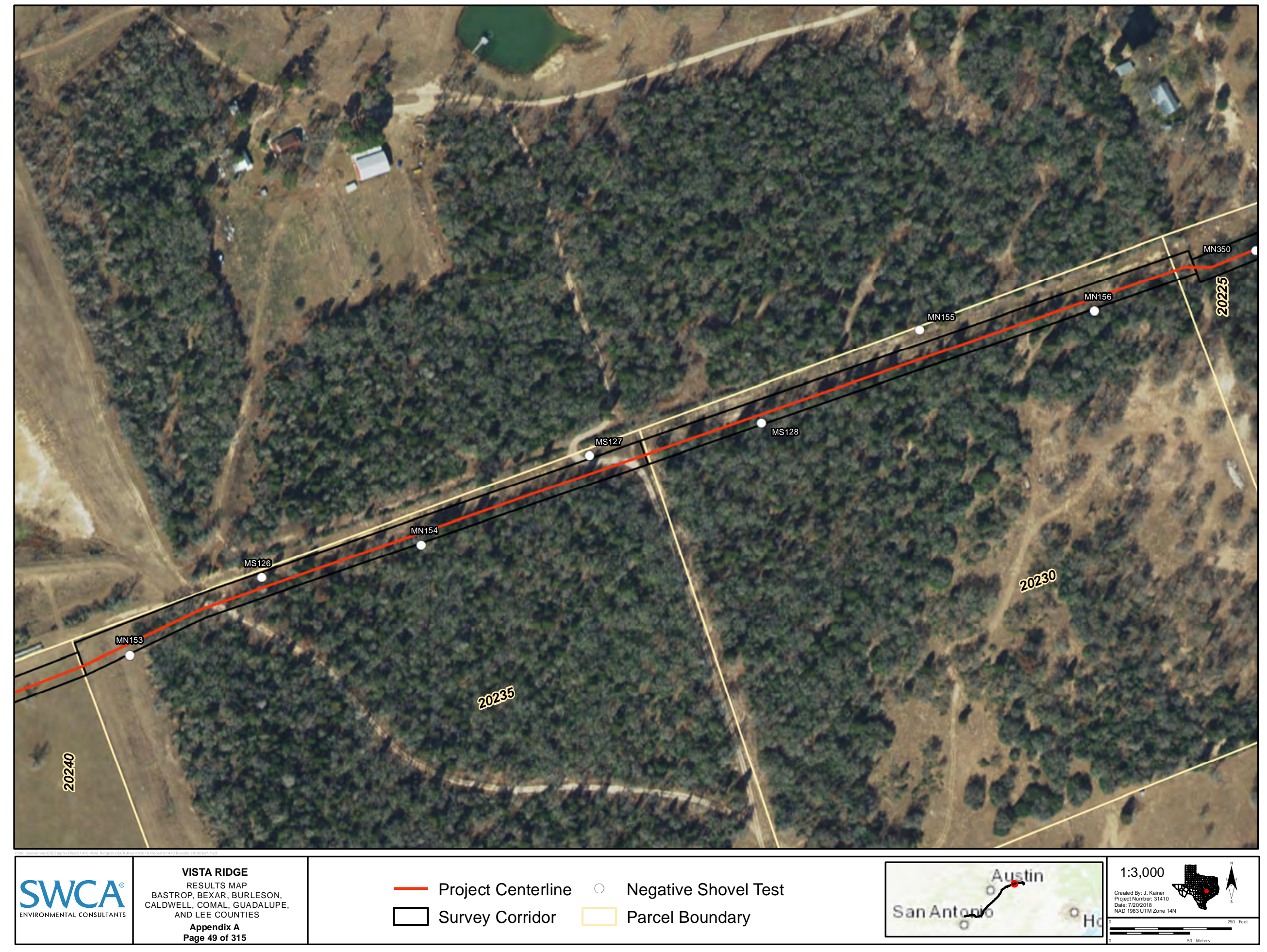




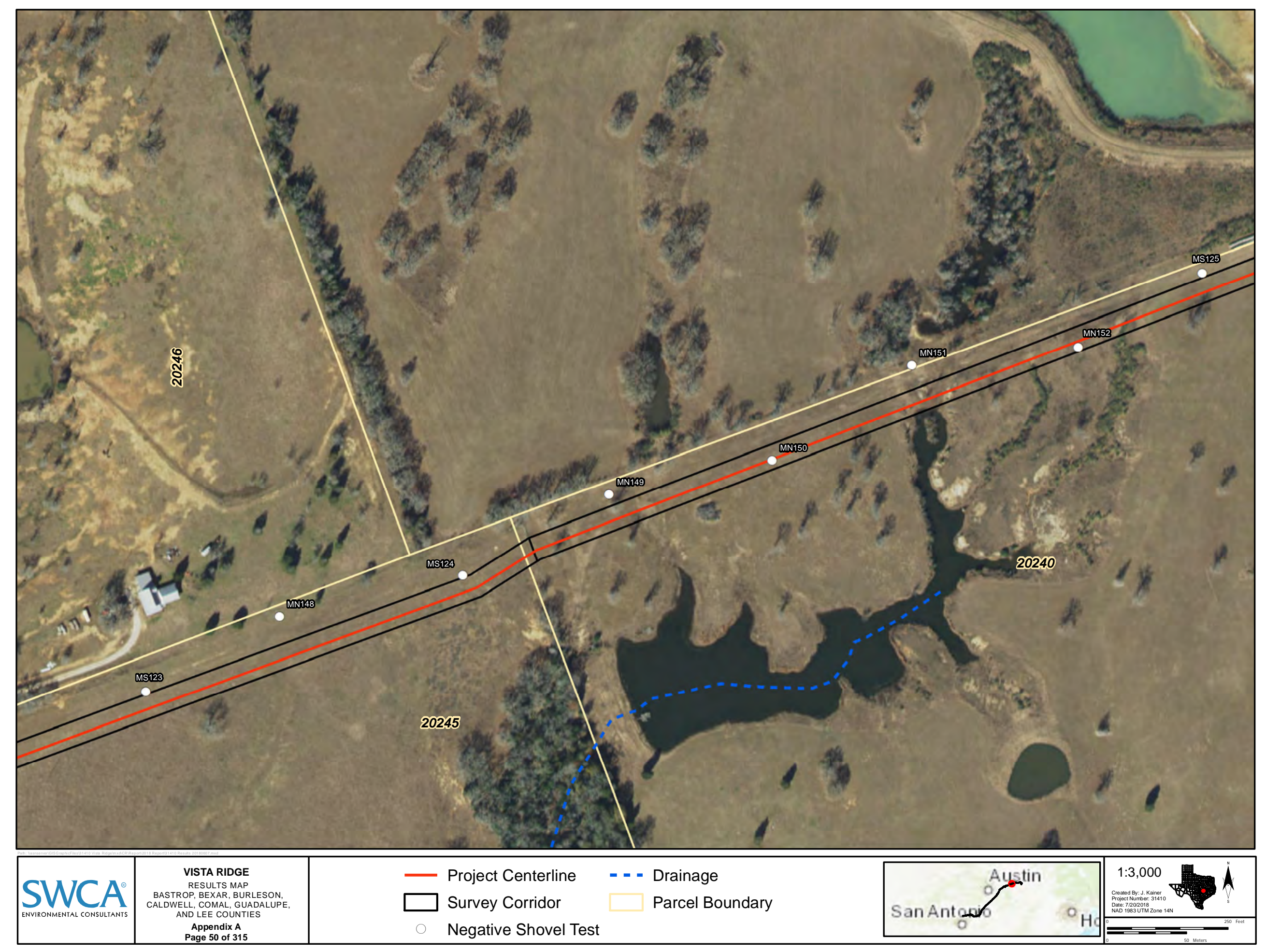


Restricted Information

Not for Public Disclosure 
Restricted Information

Not for Public Disclosure 
Restricted Information

Not for Public Disclosure 
Restricted Information

Not for Public Disclosure 
Restricted Information

Not for Public Disclosure 
Restricted Information

Not for Public Disclosure 


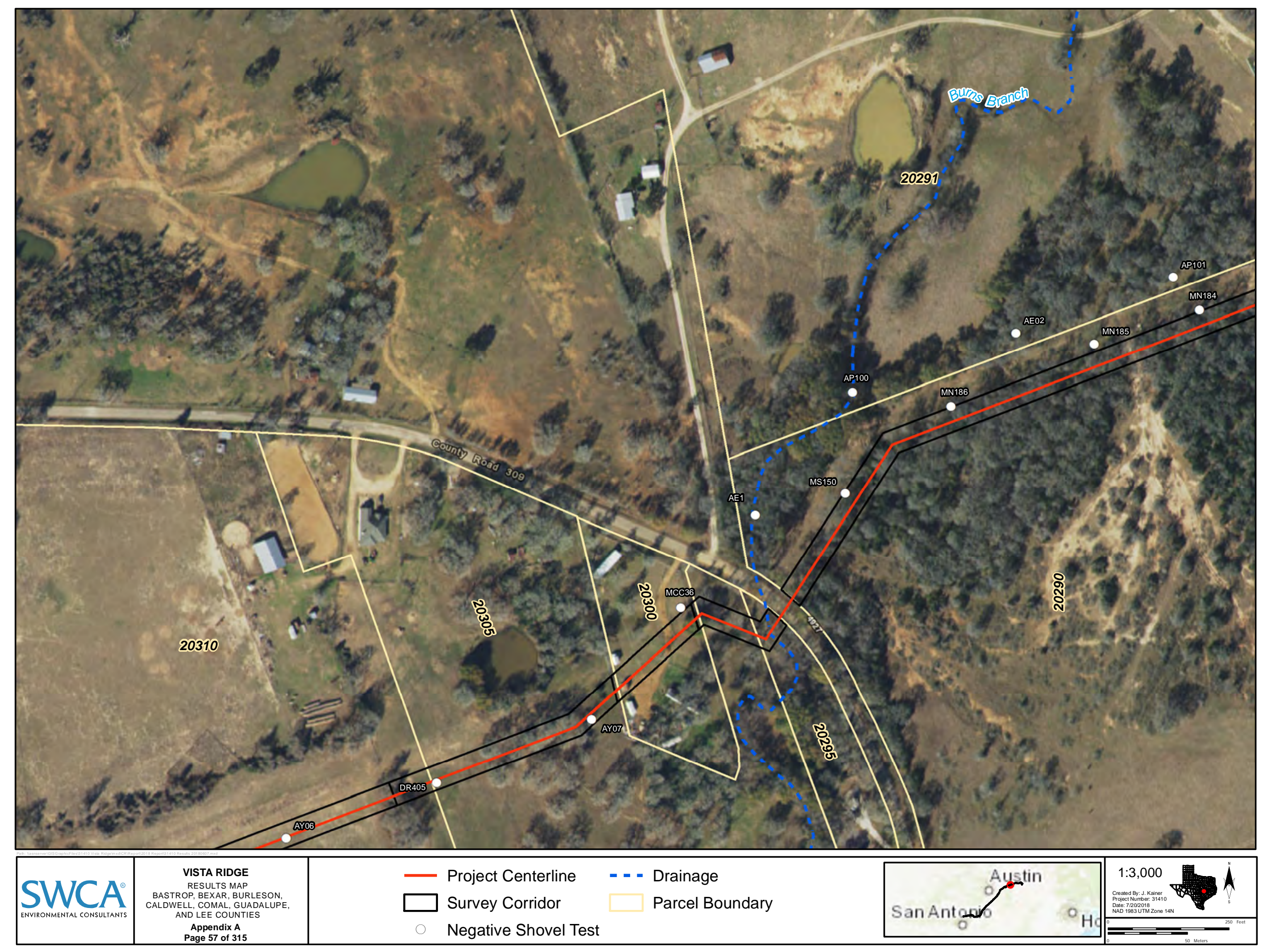




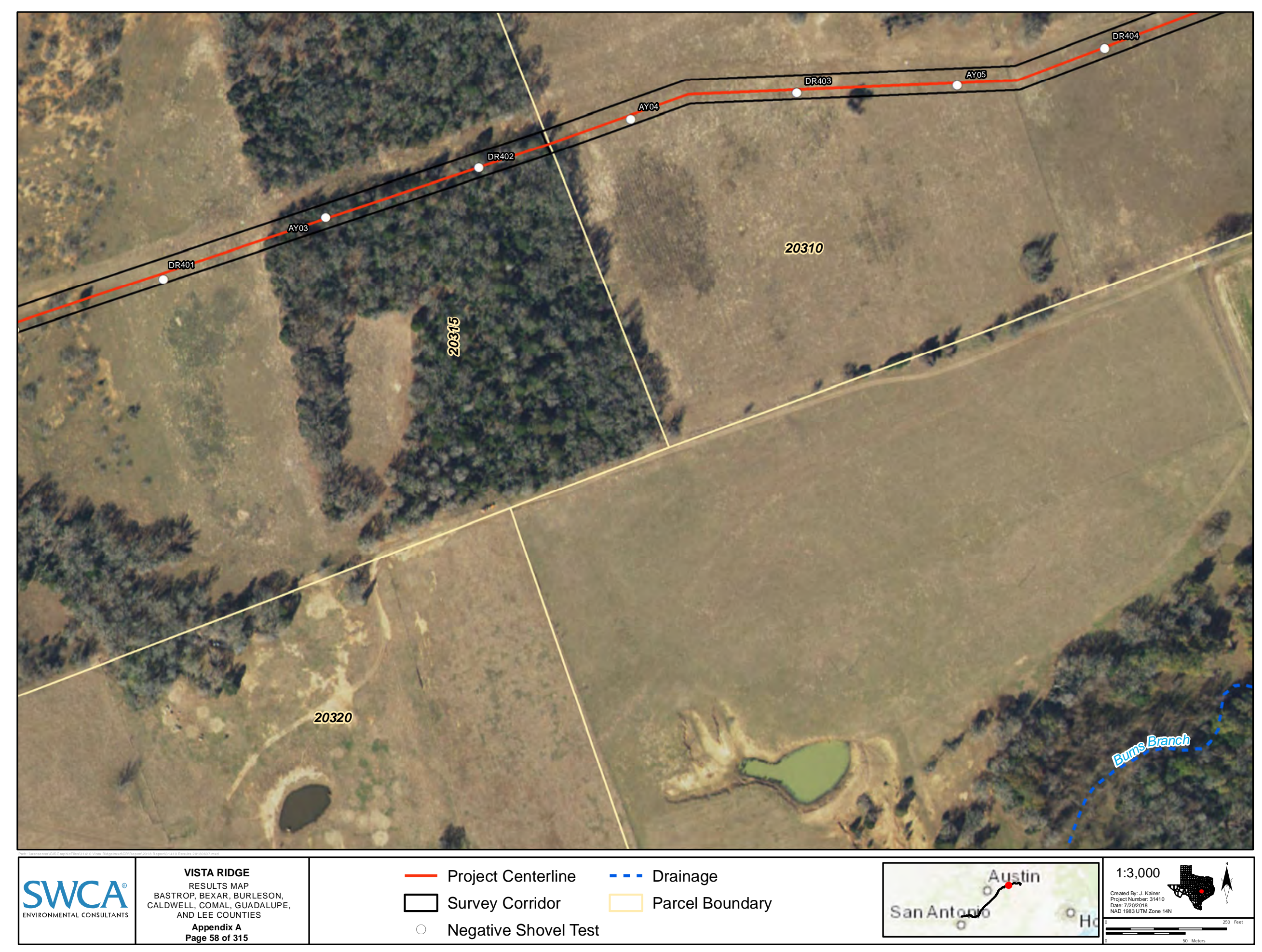




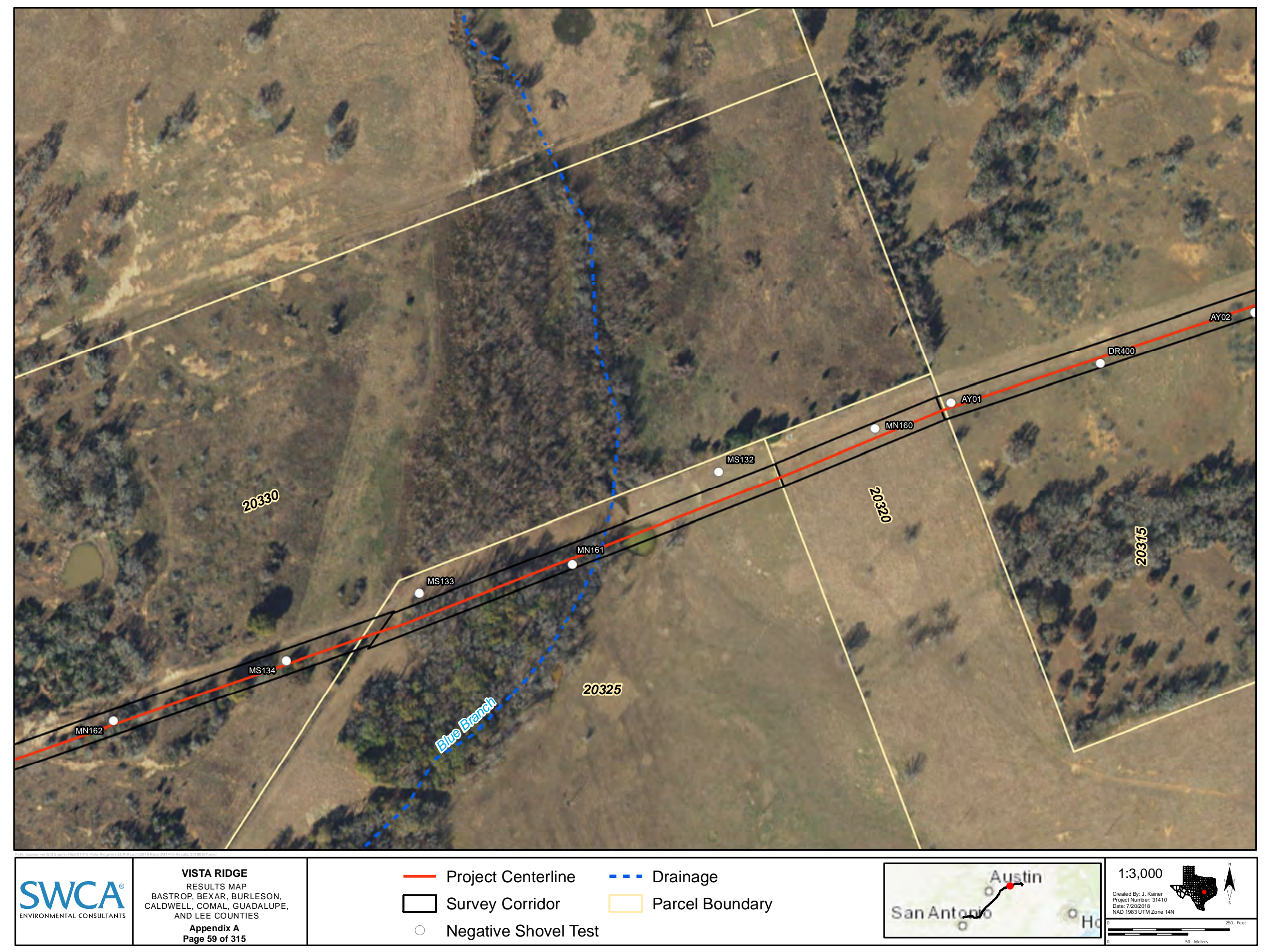




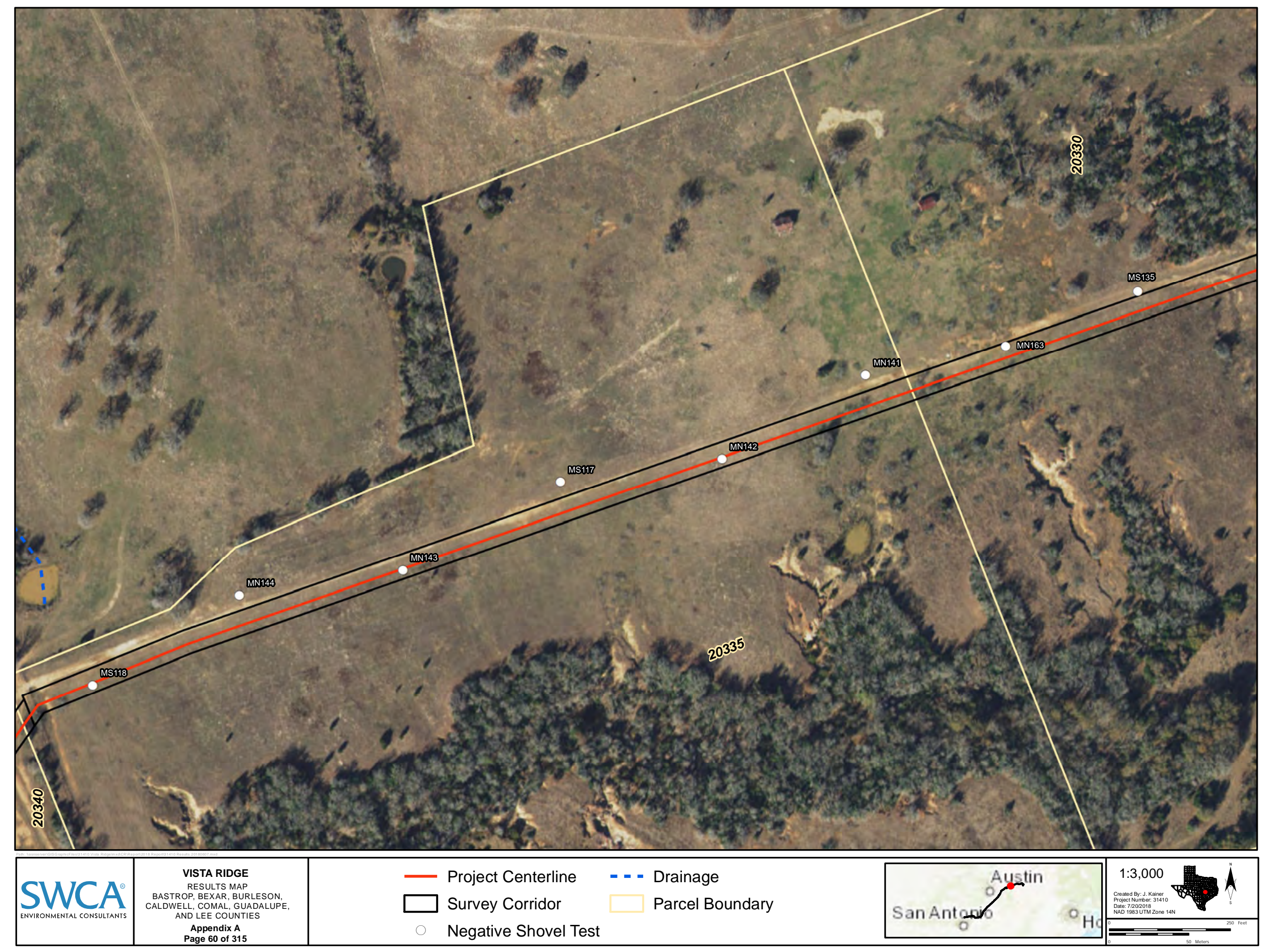




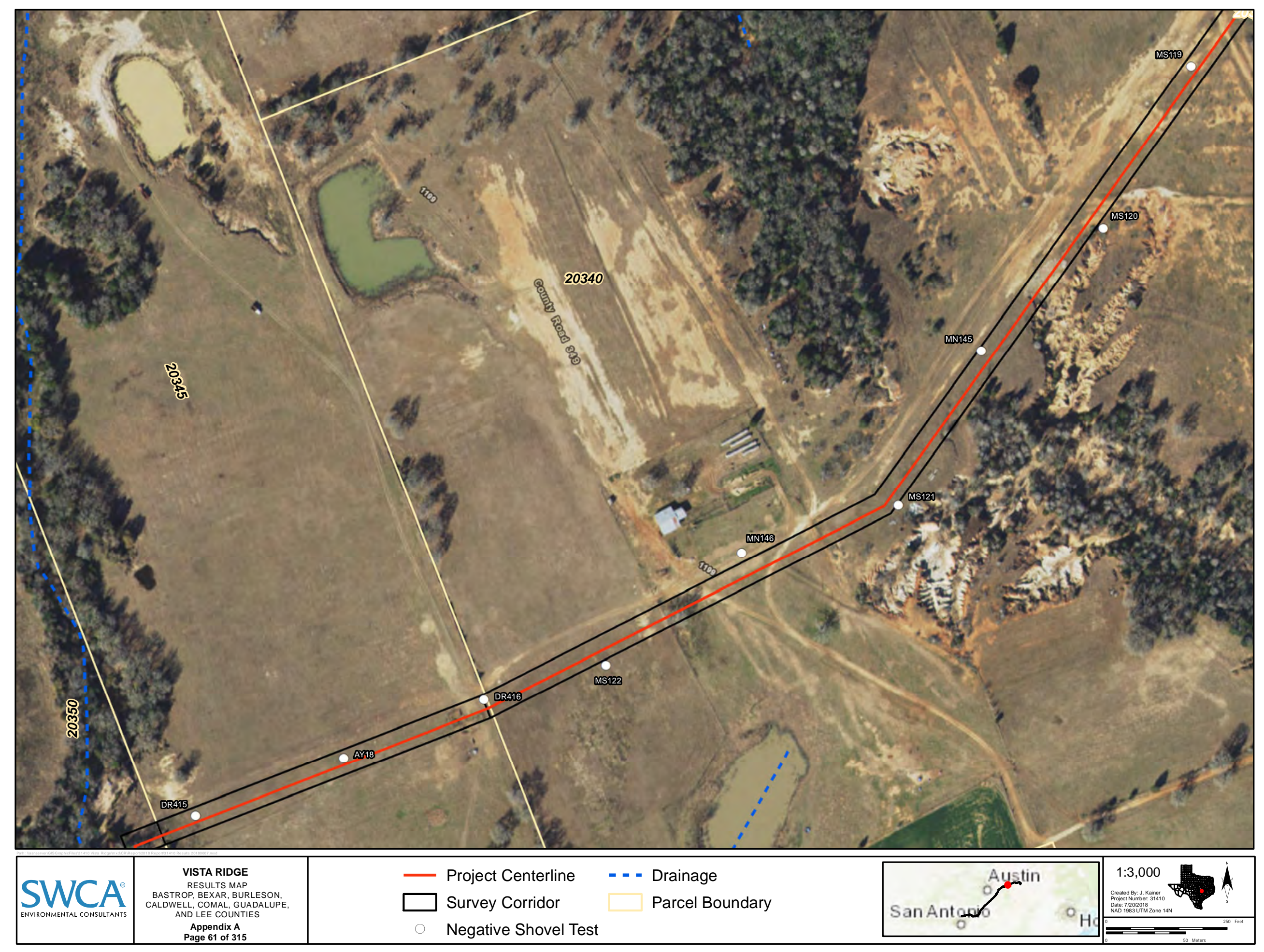




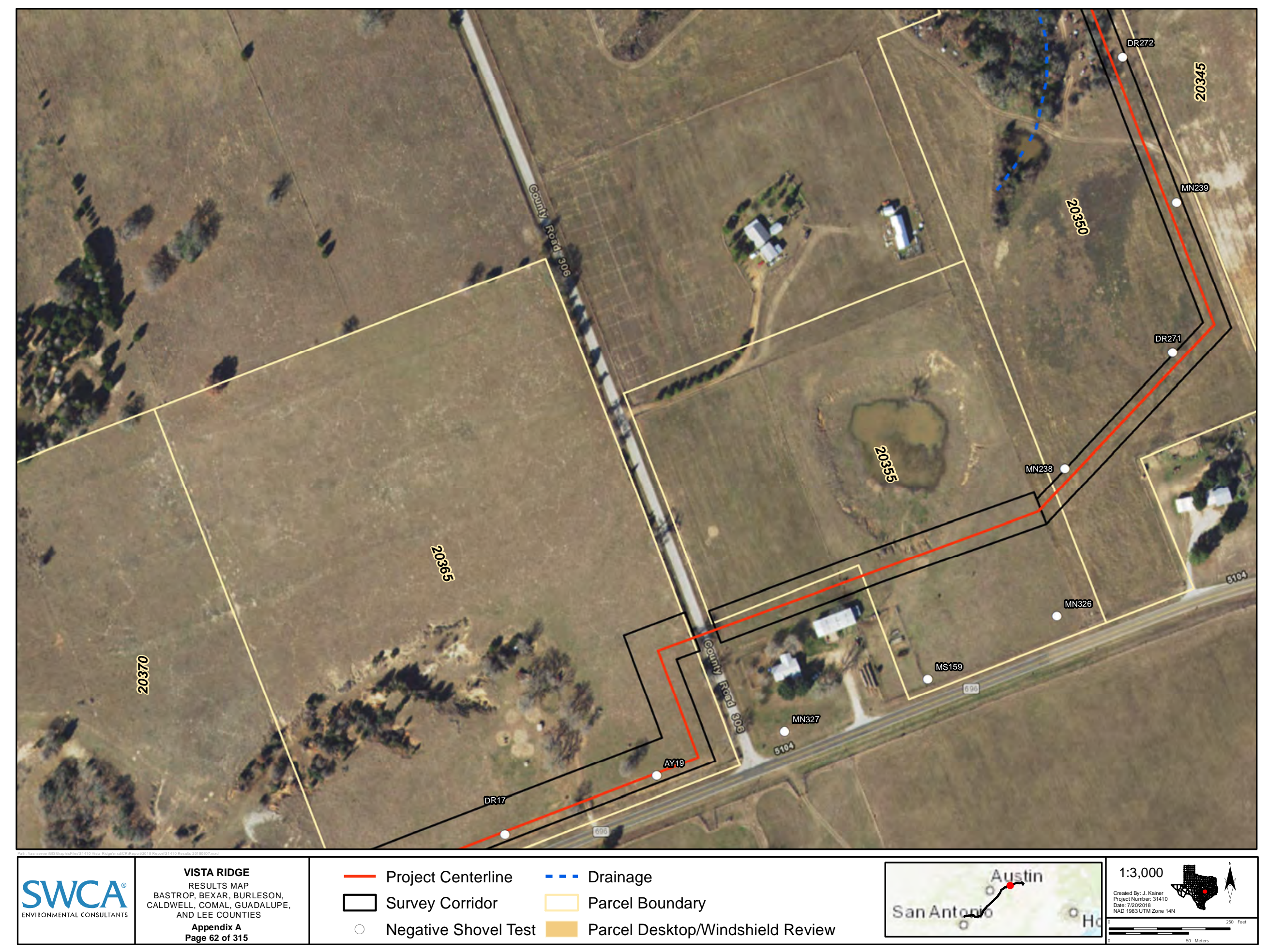




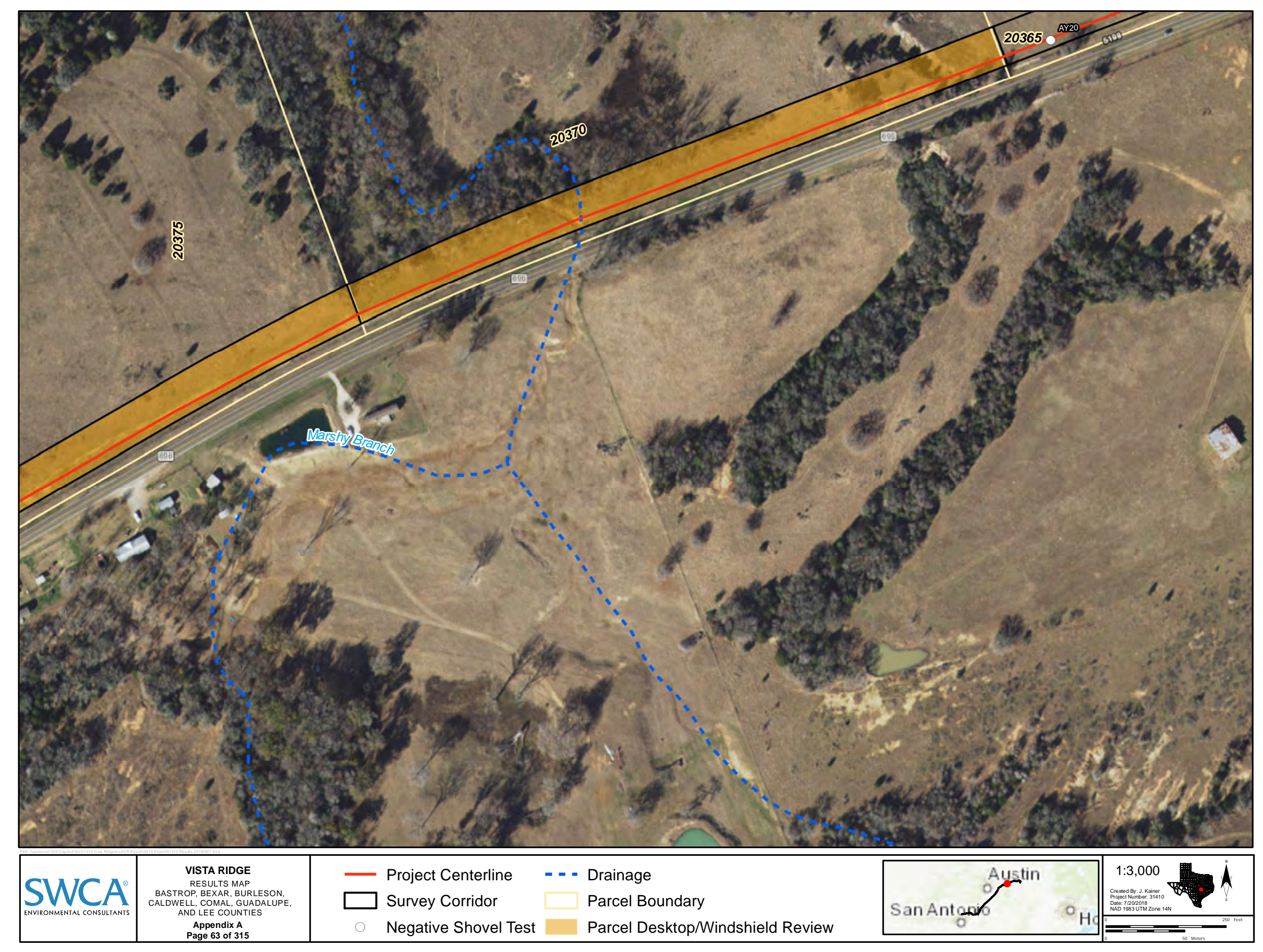




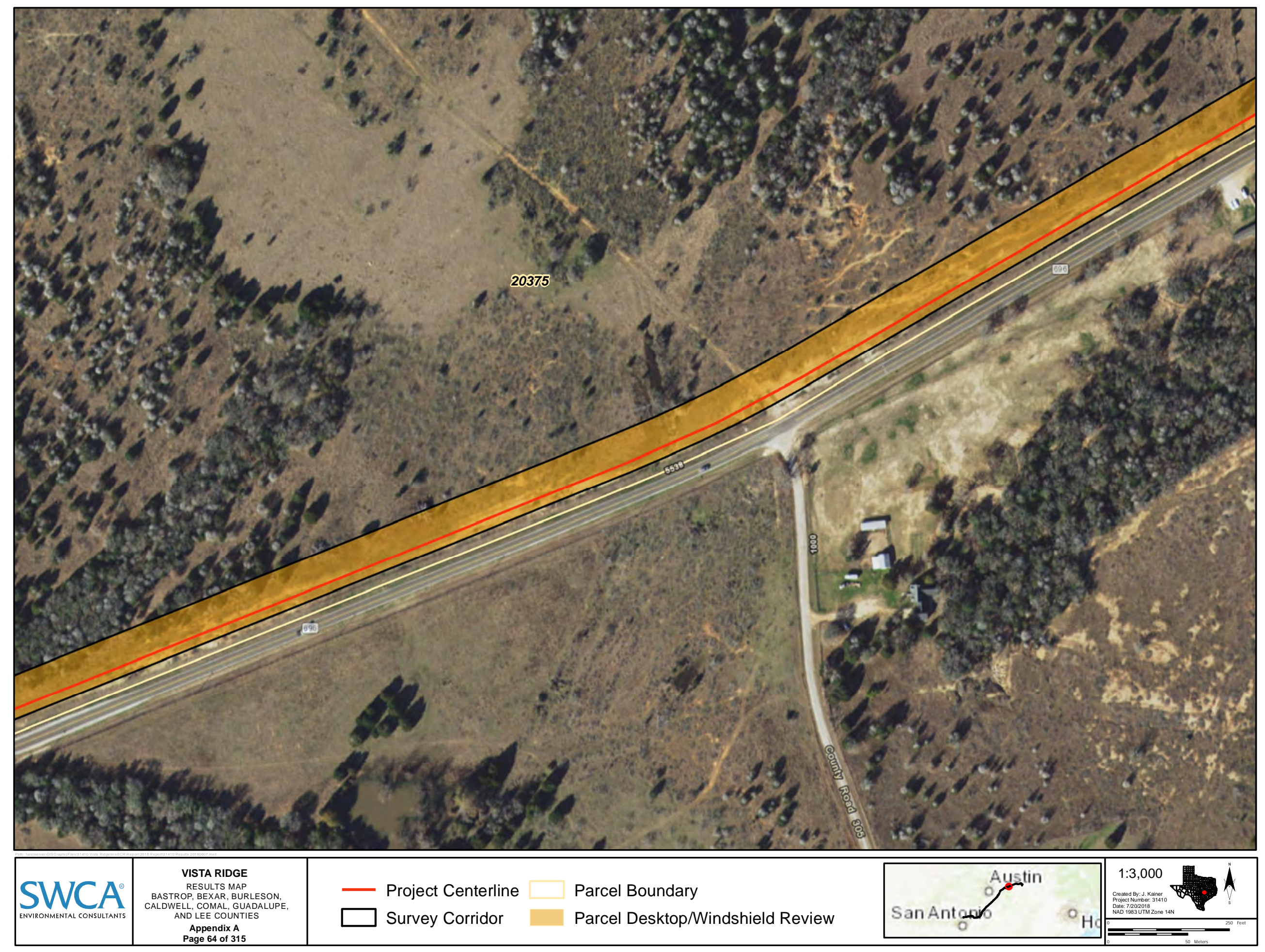




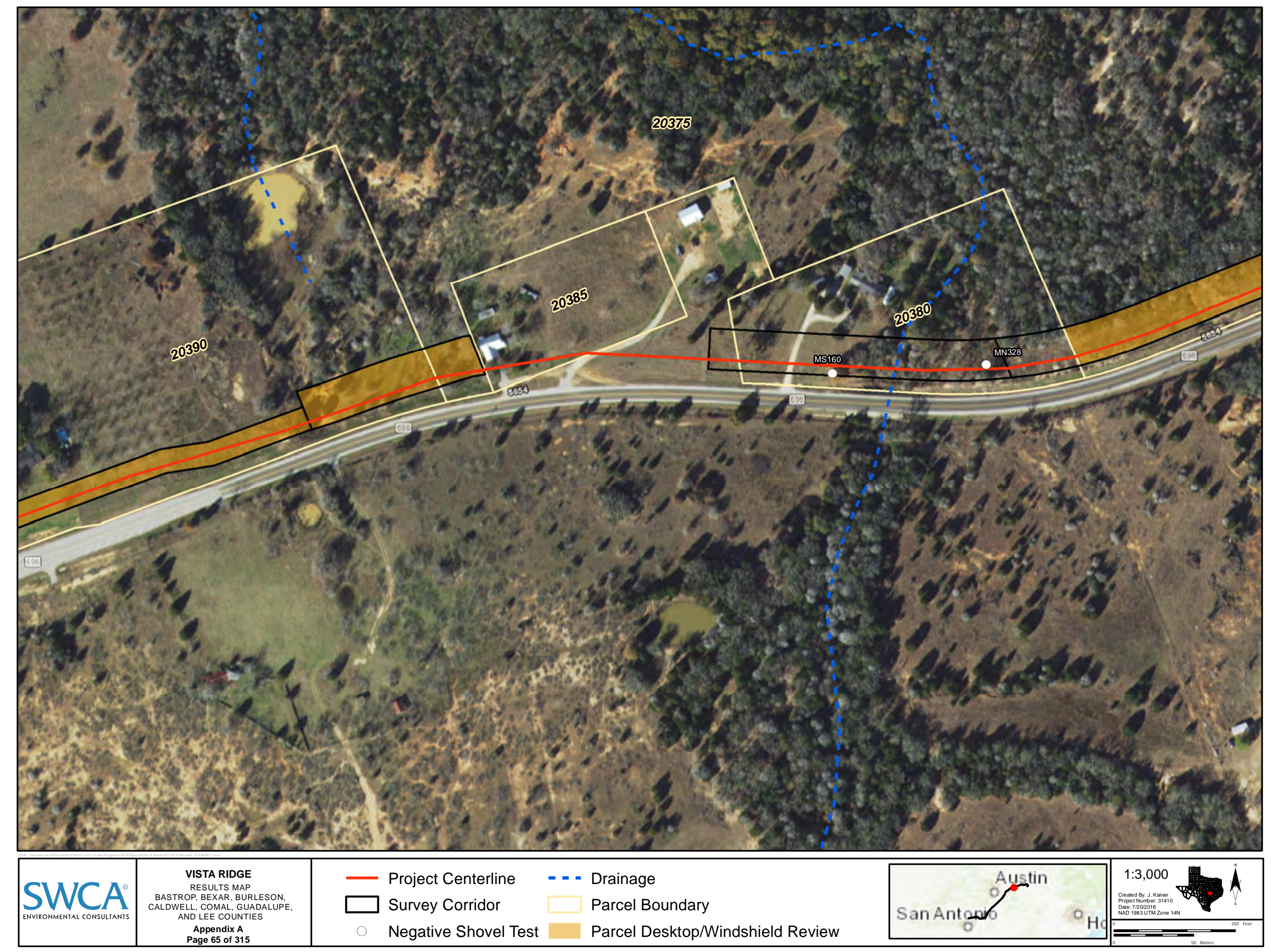




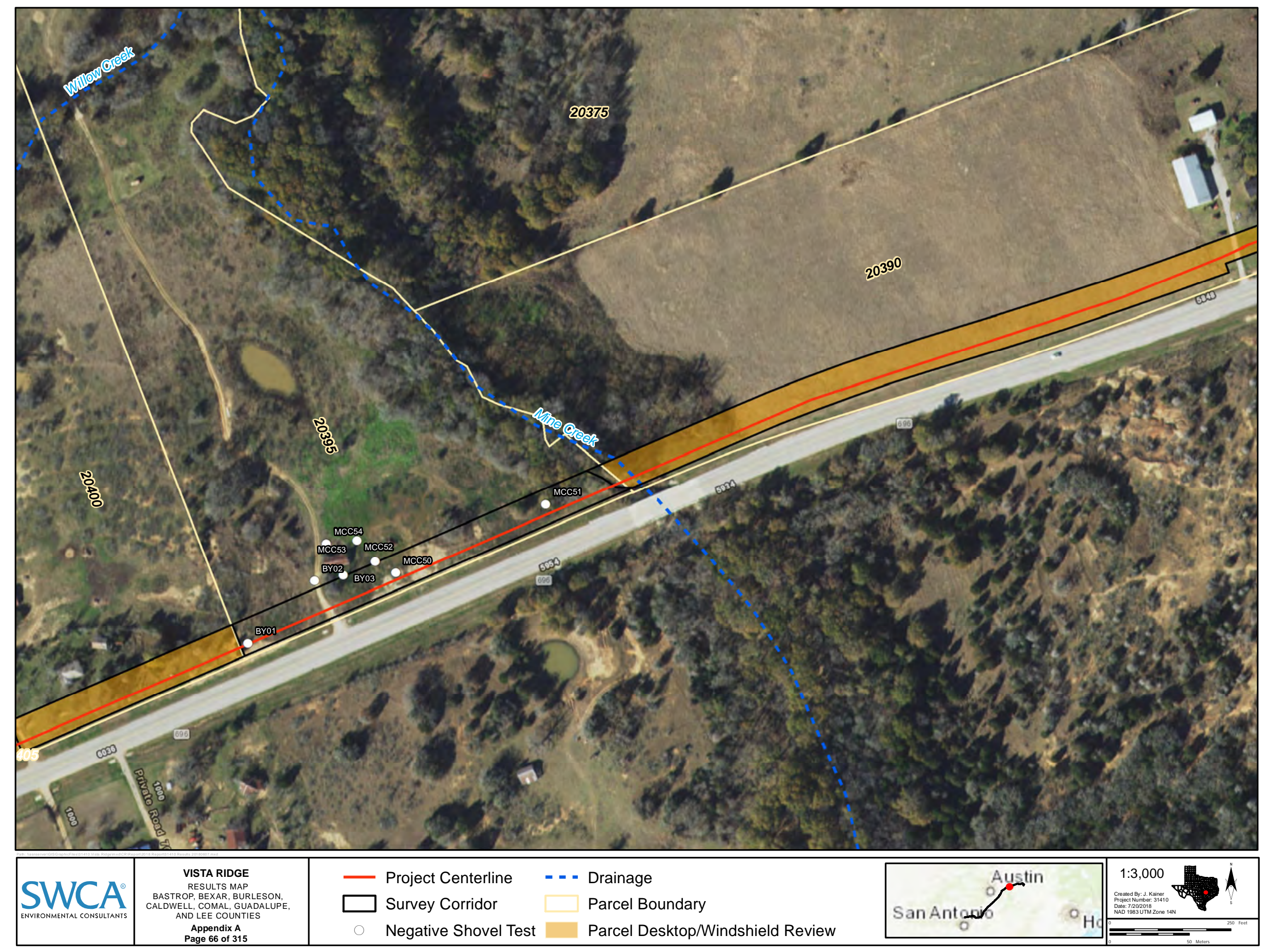




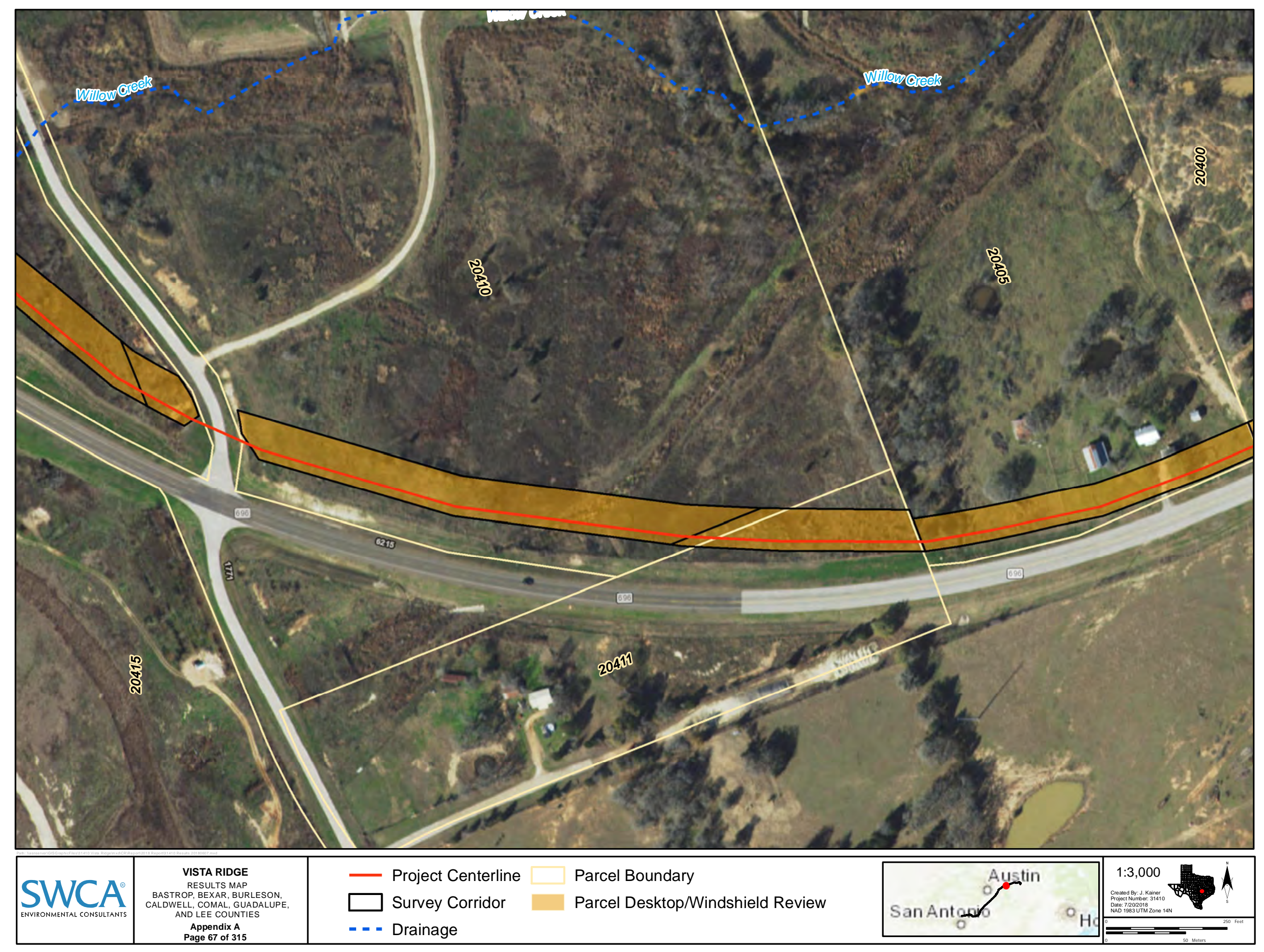




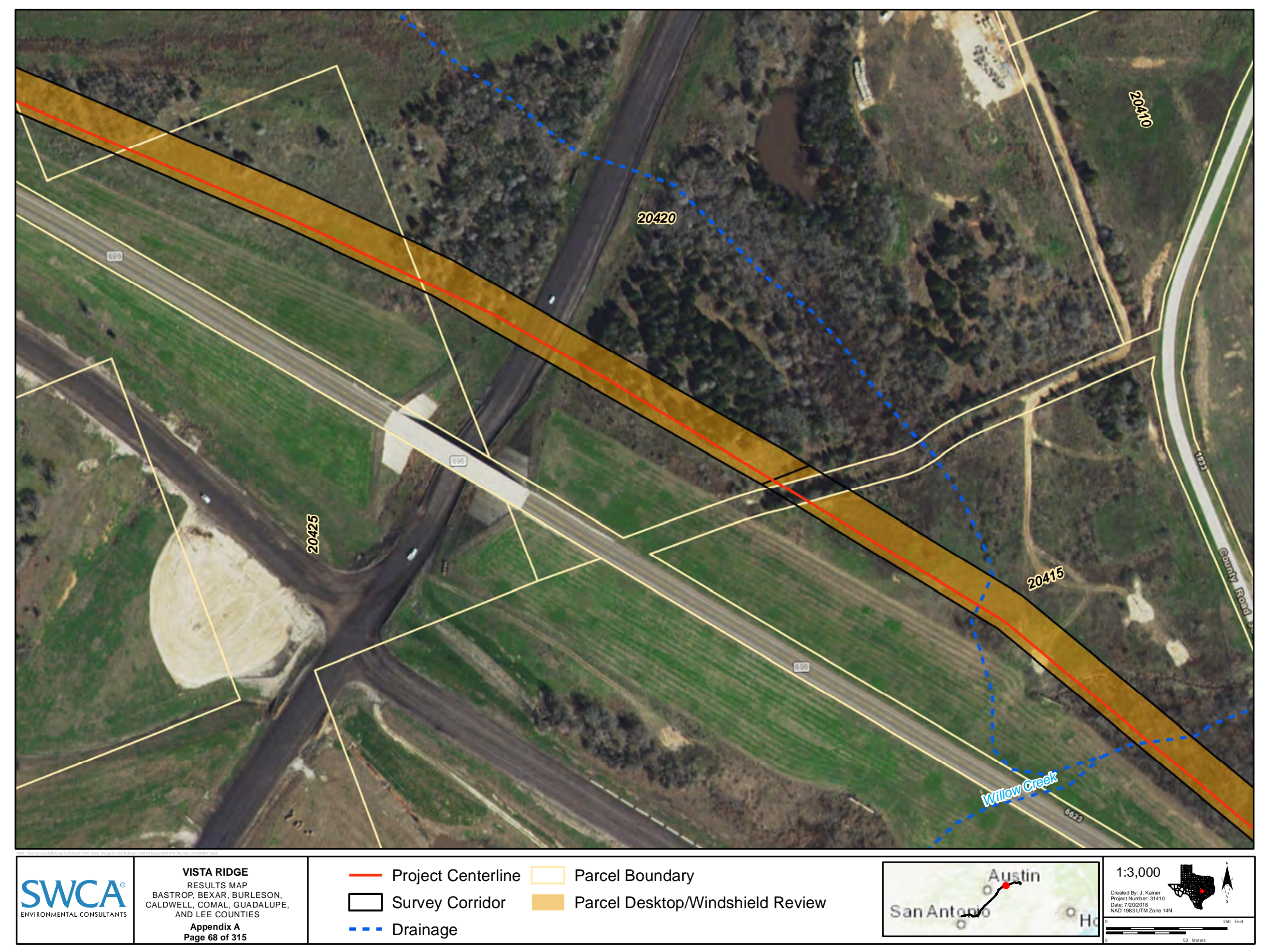




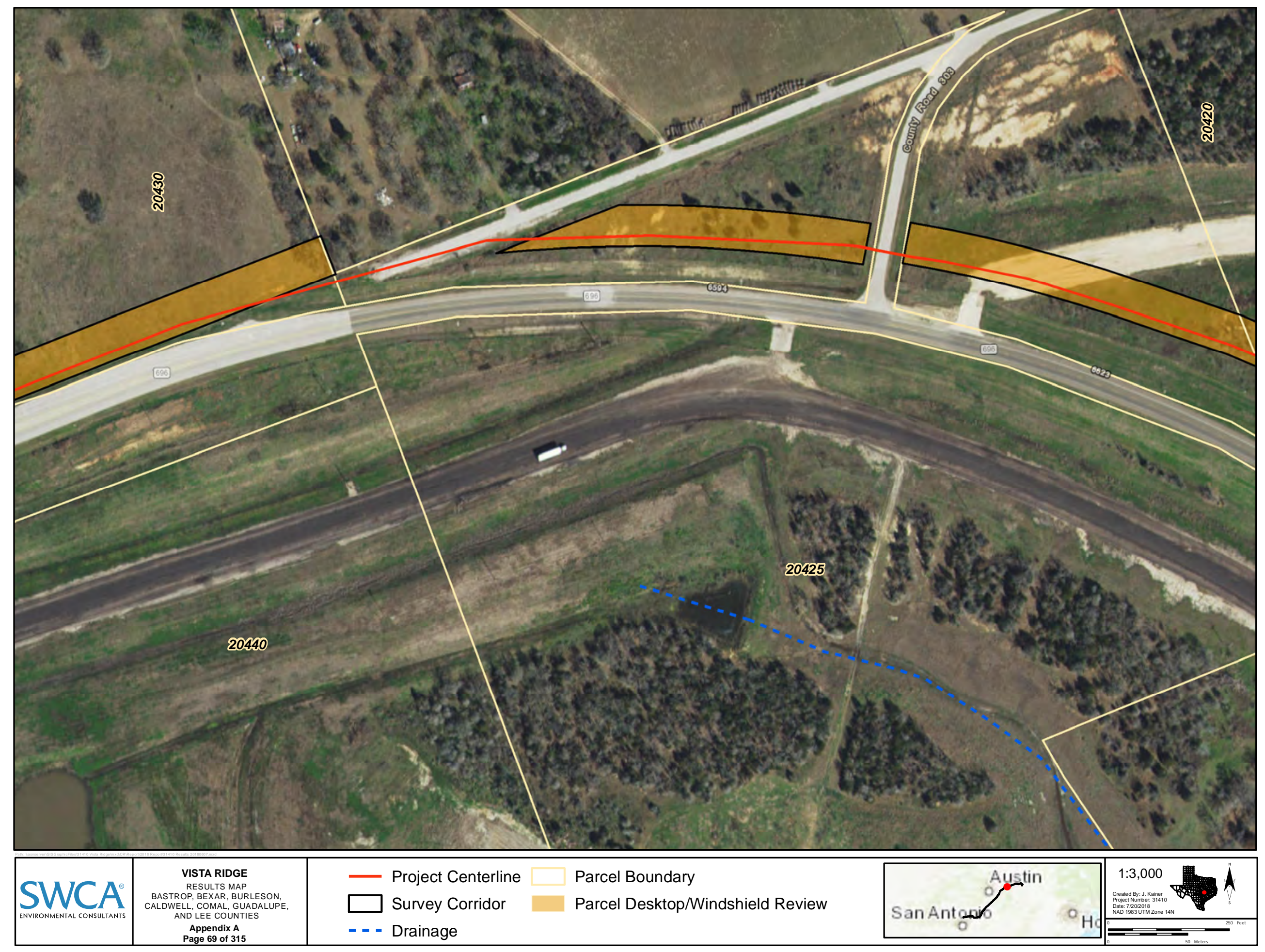




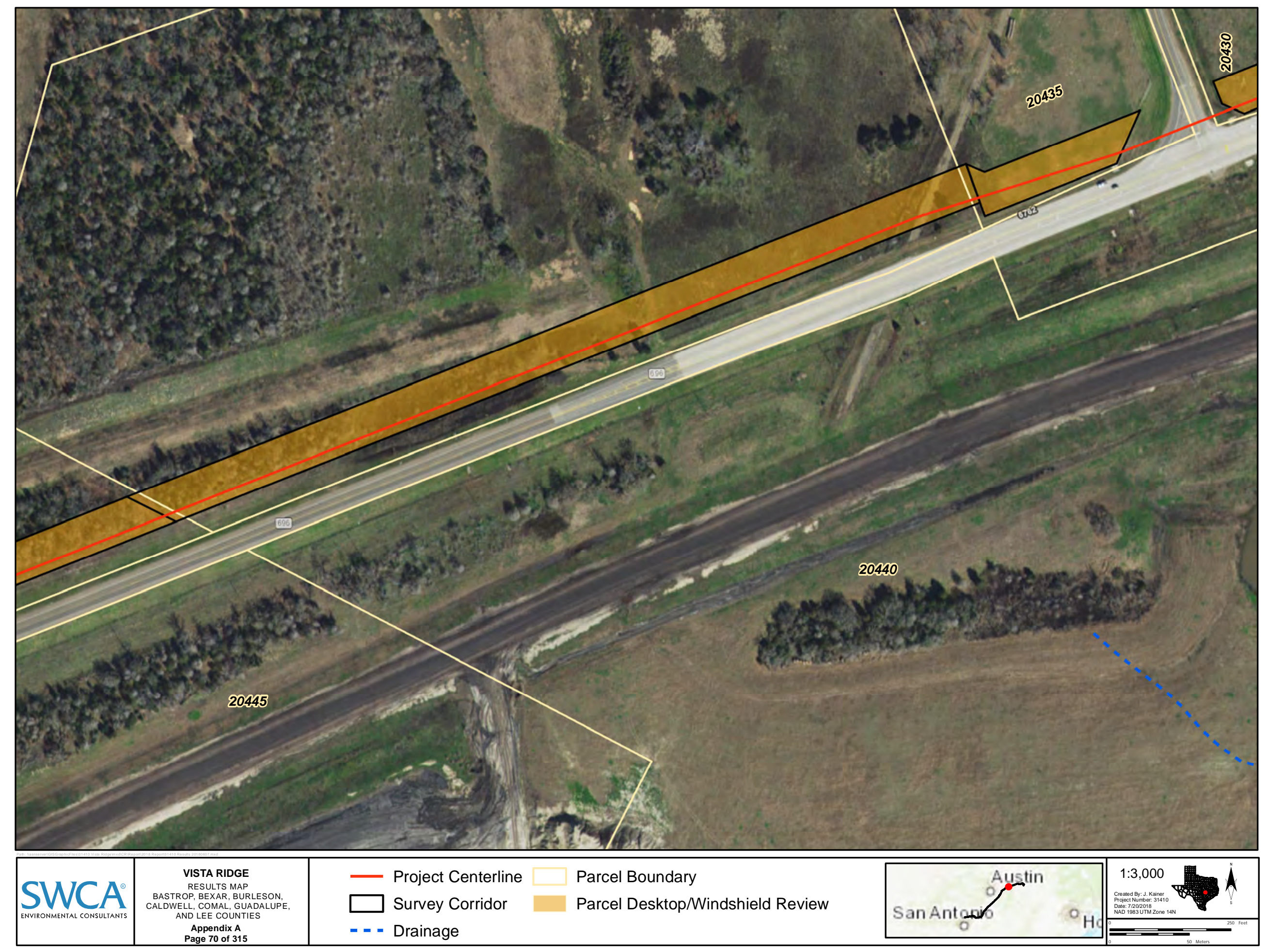




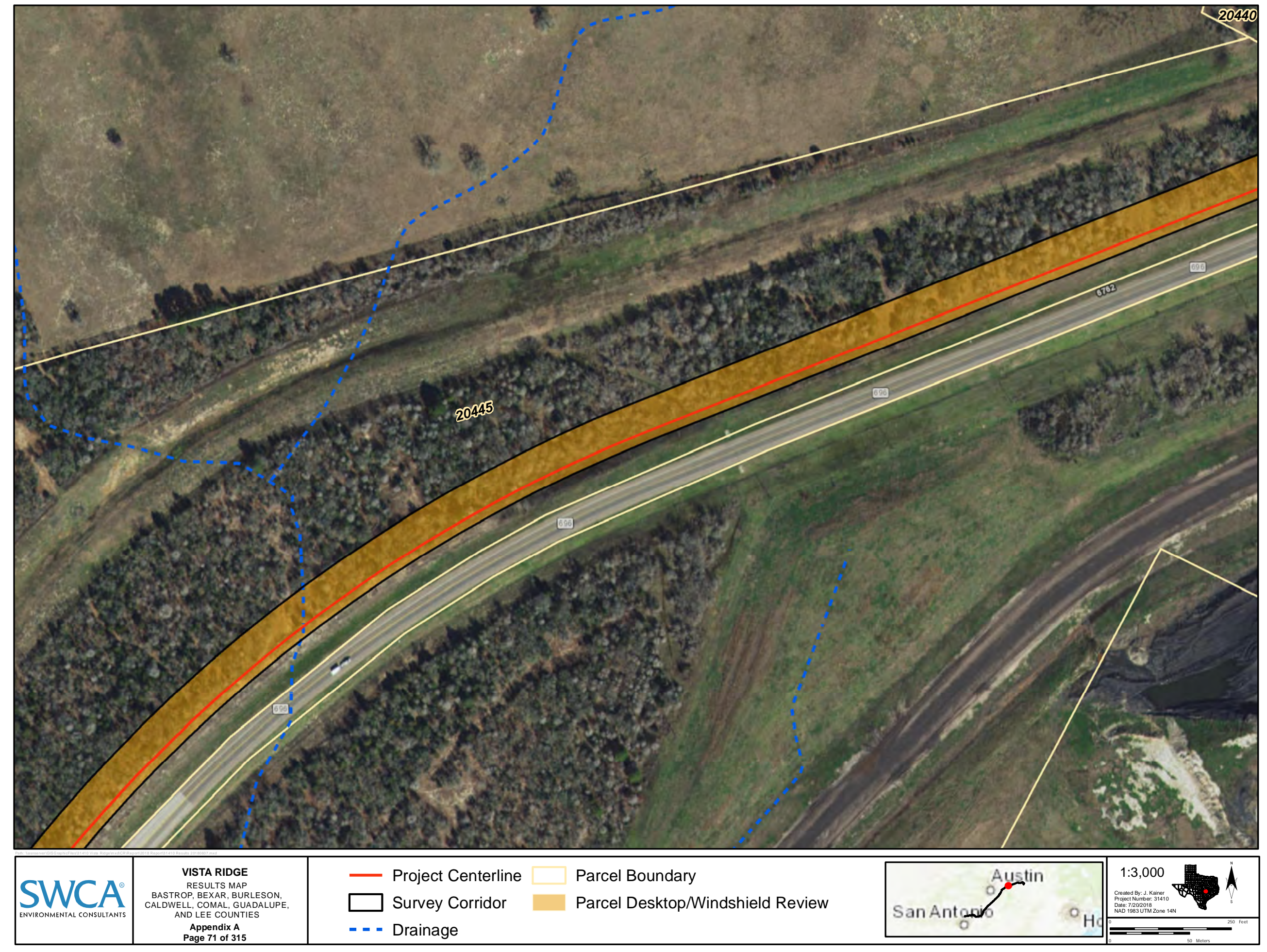




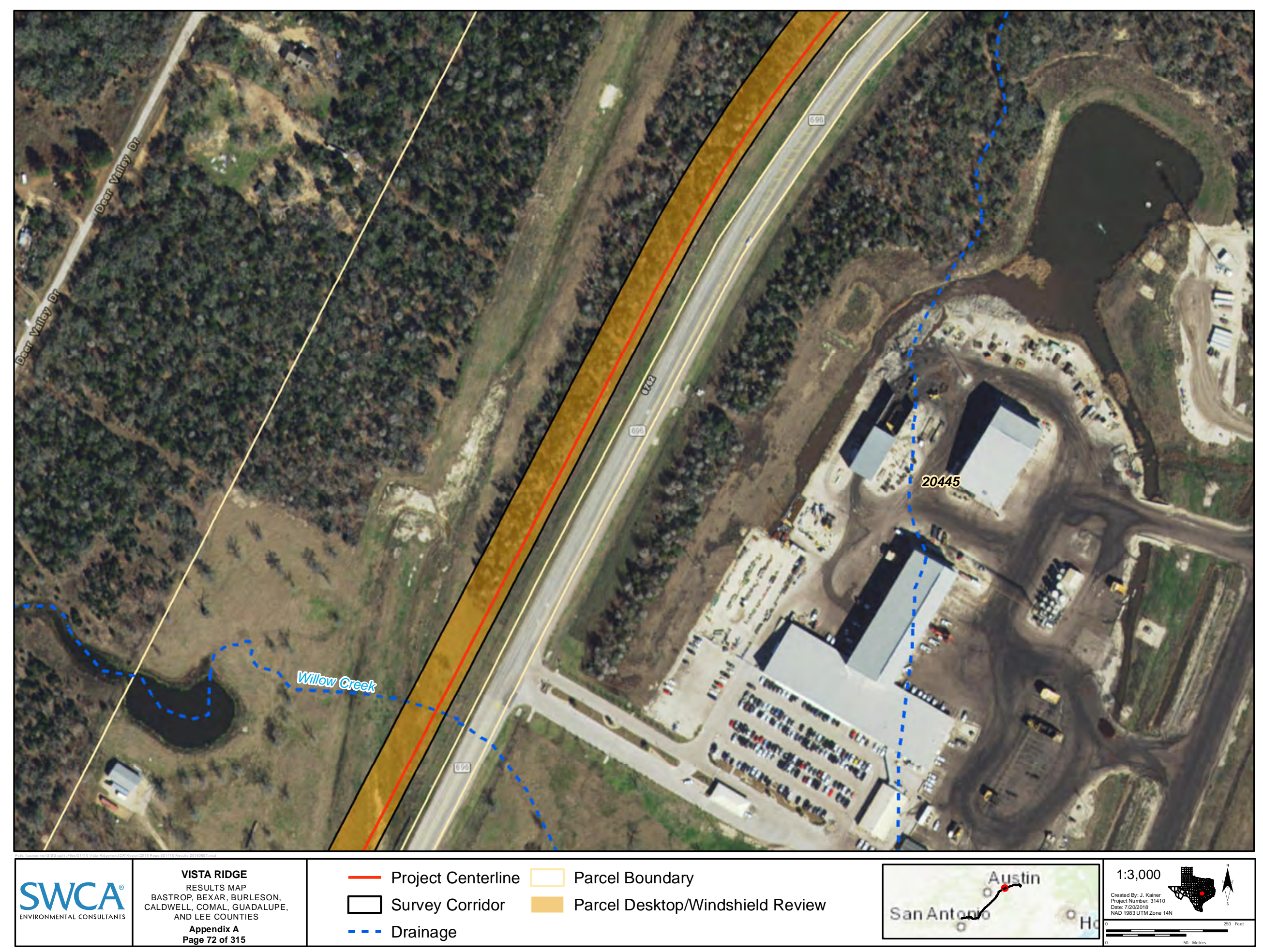




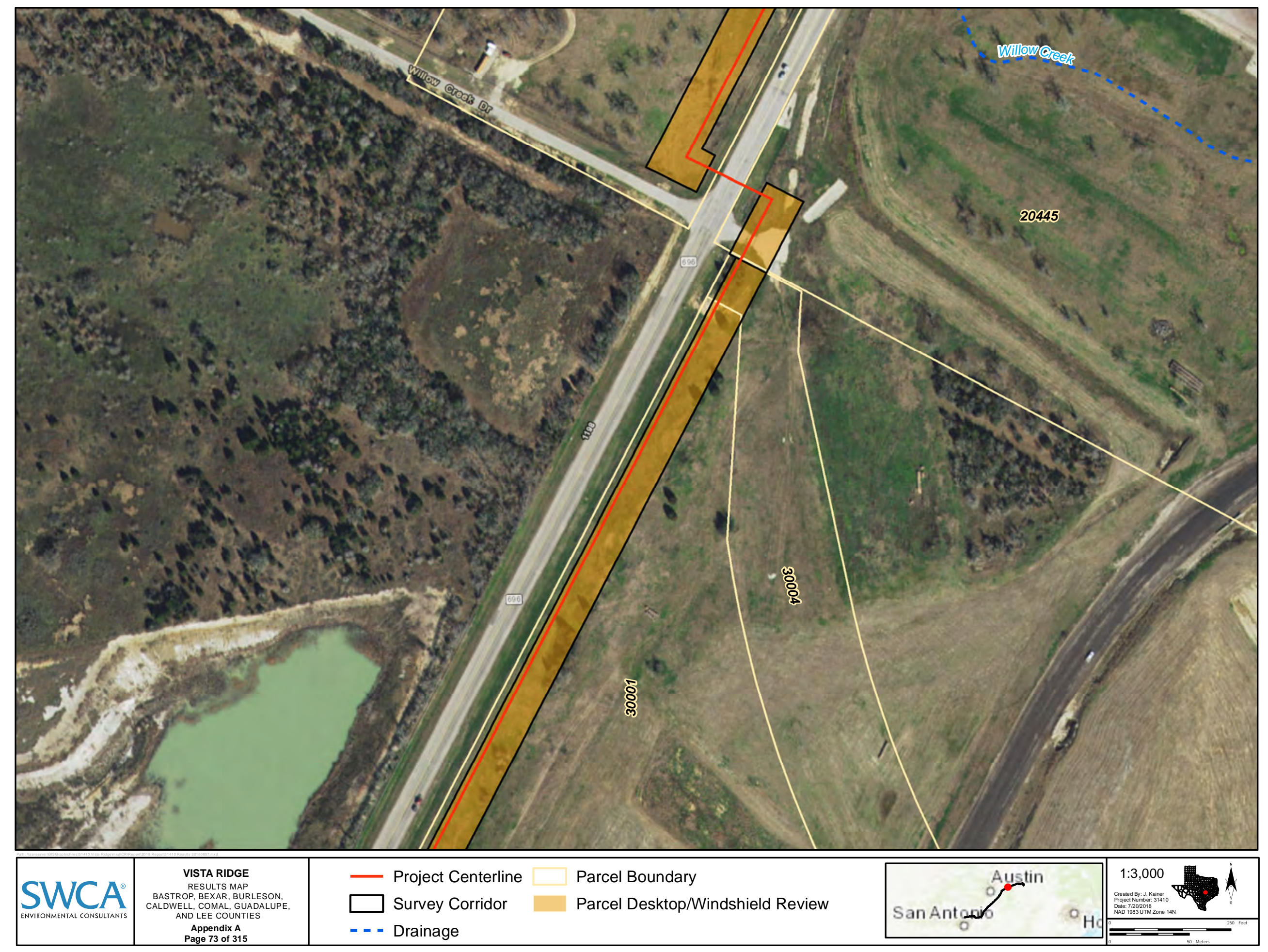




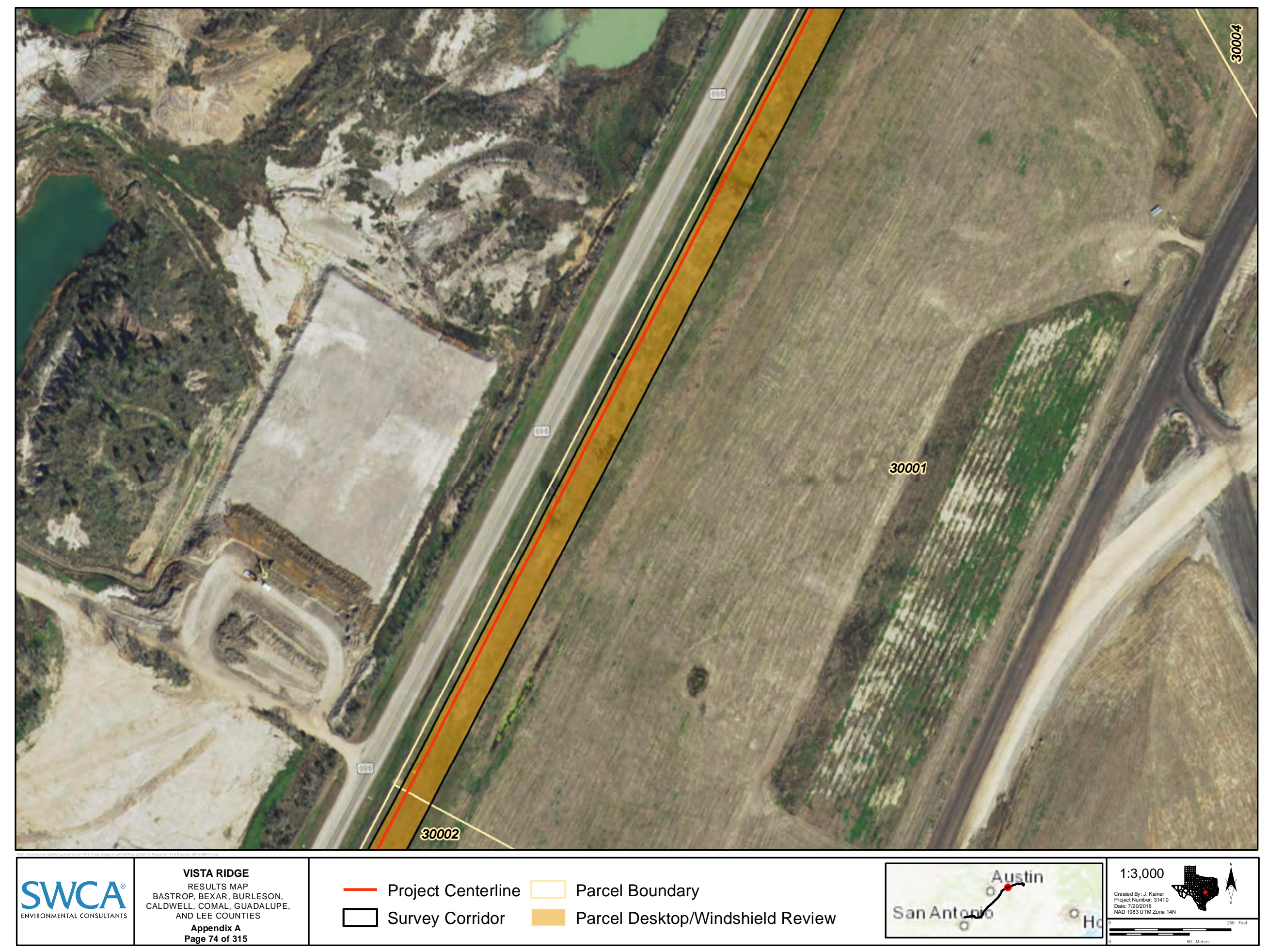




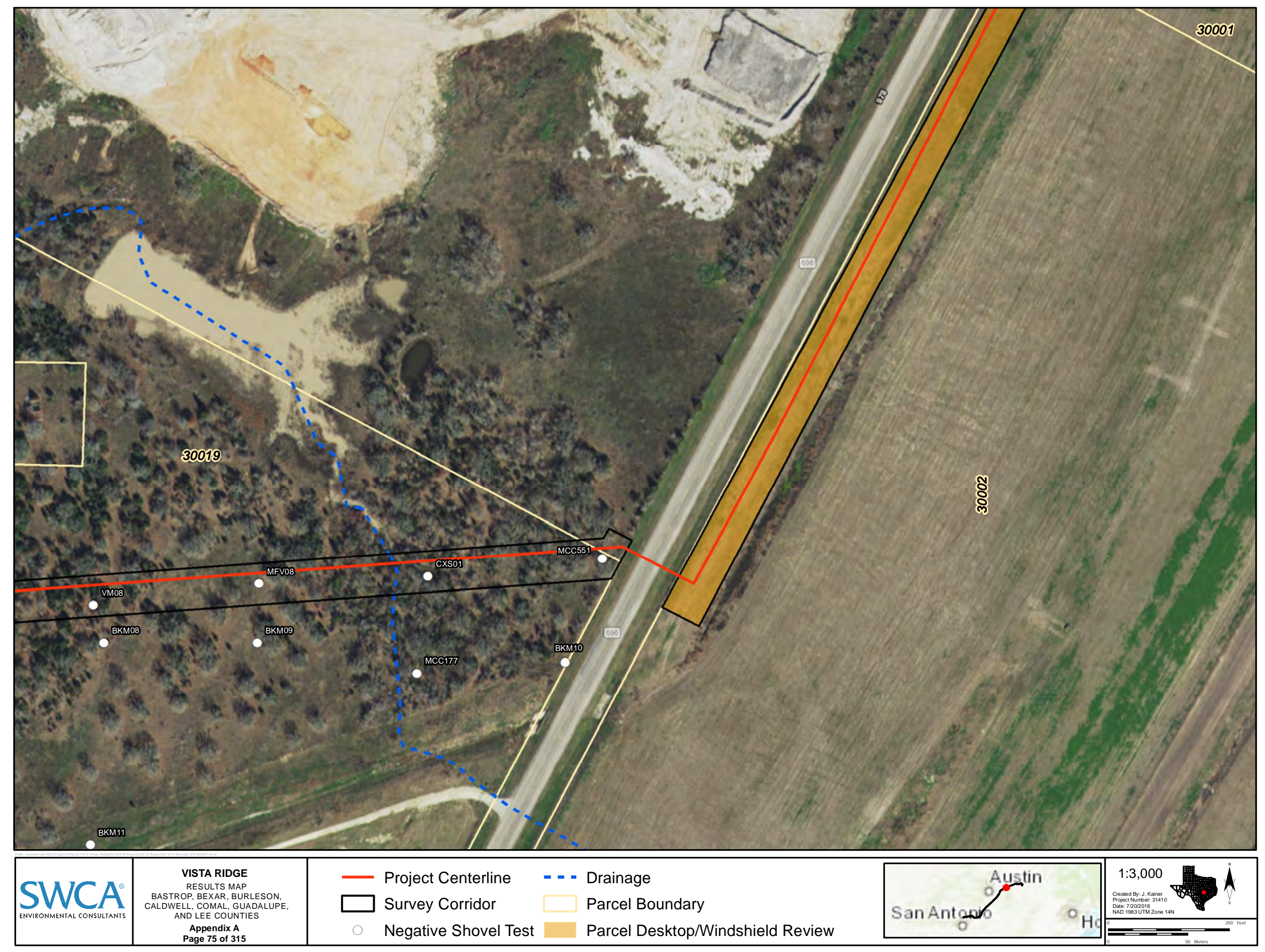




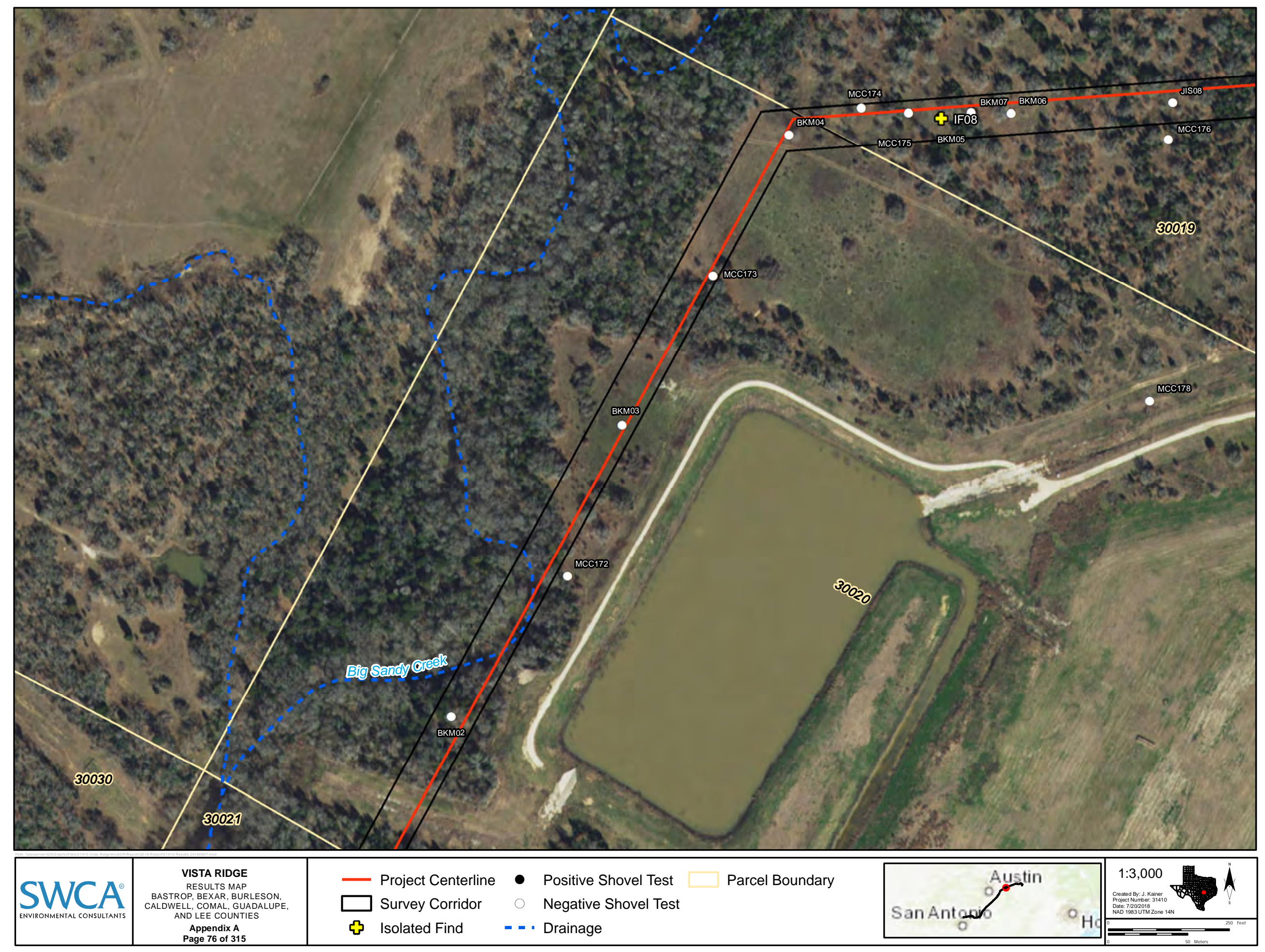




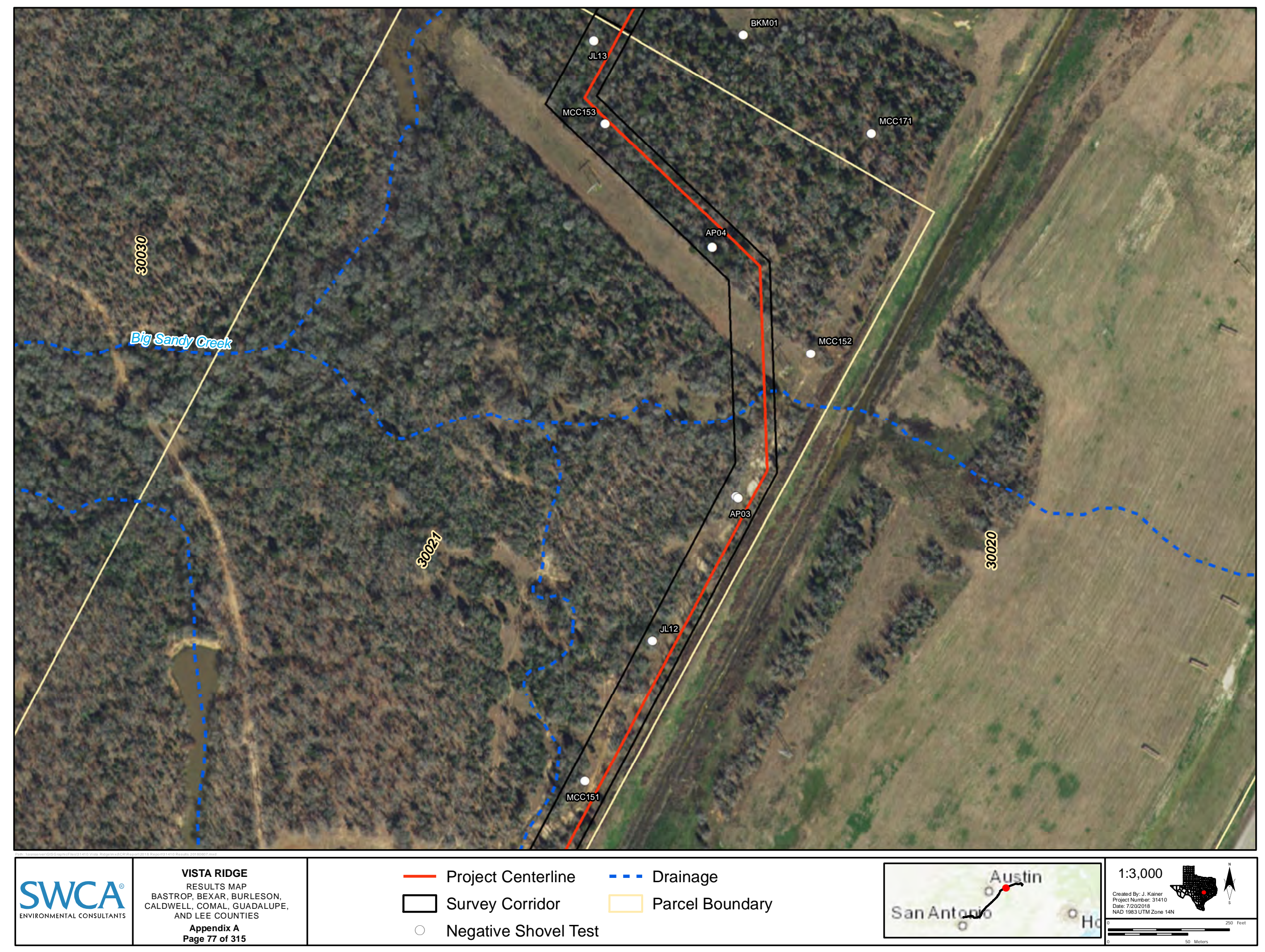




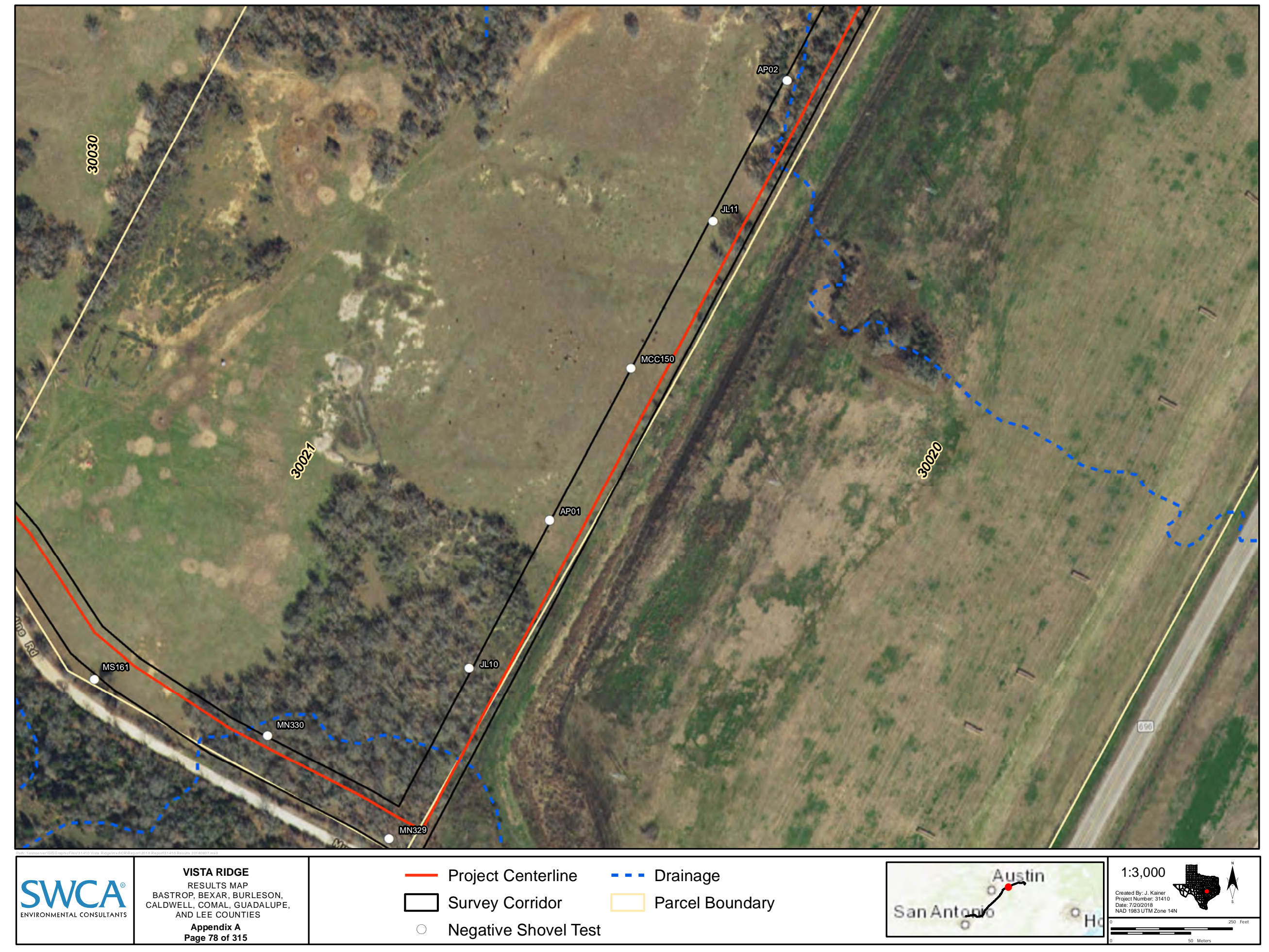




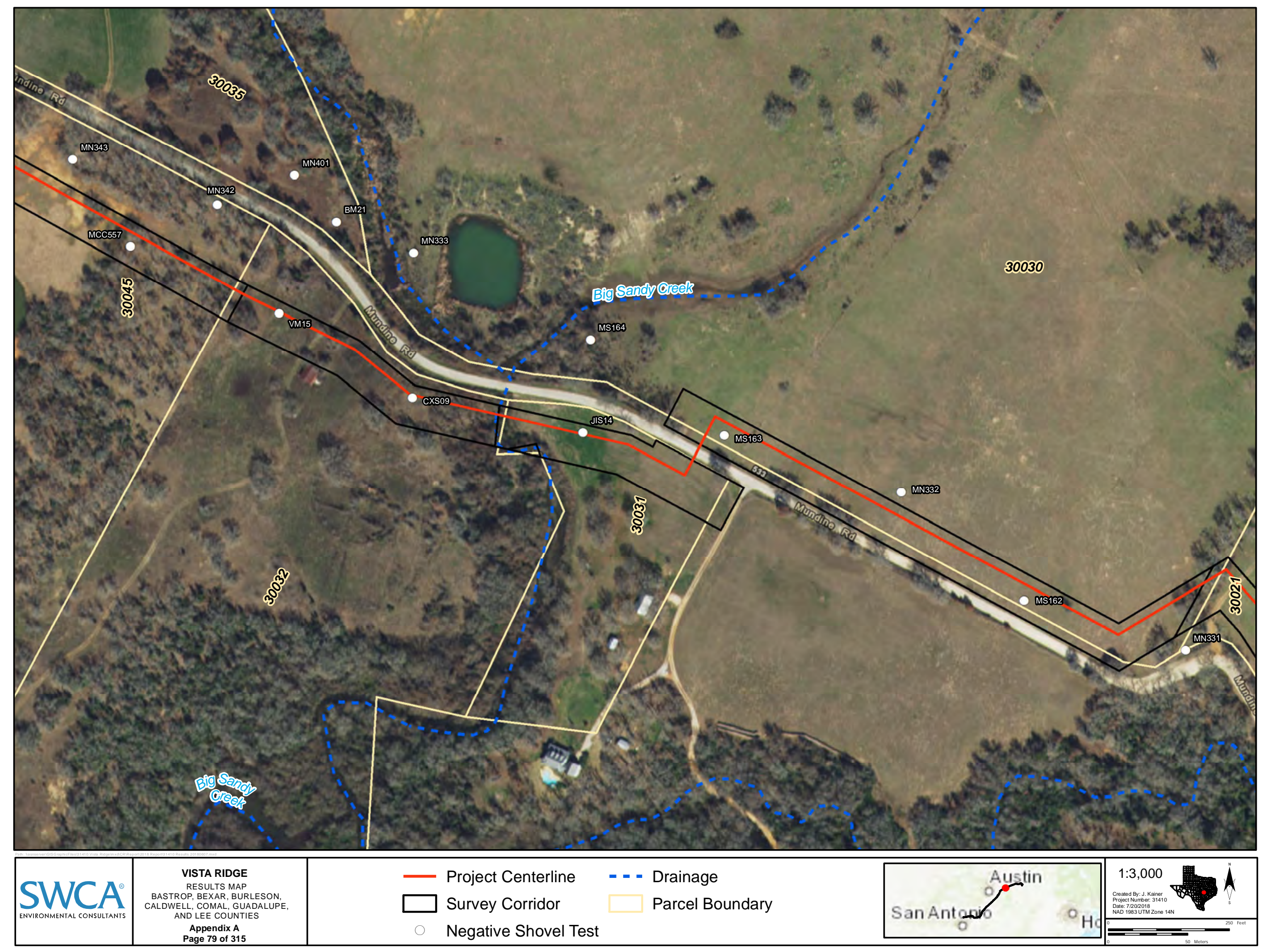




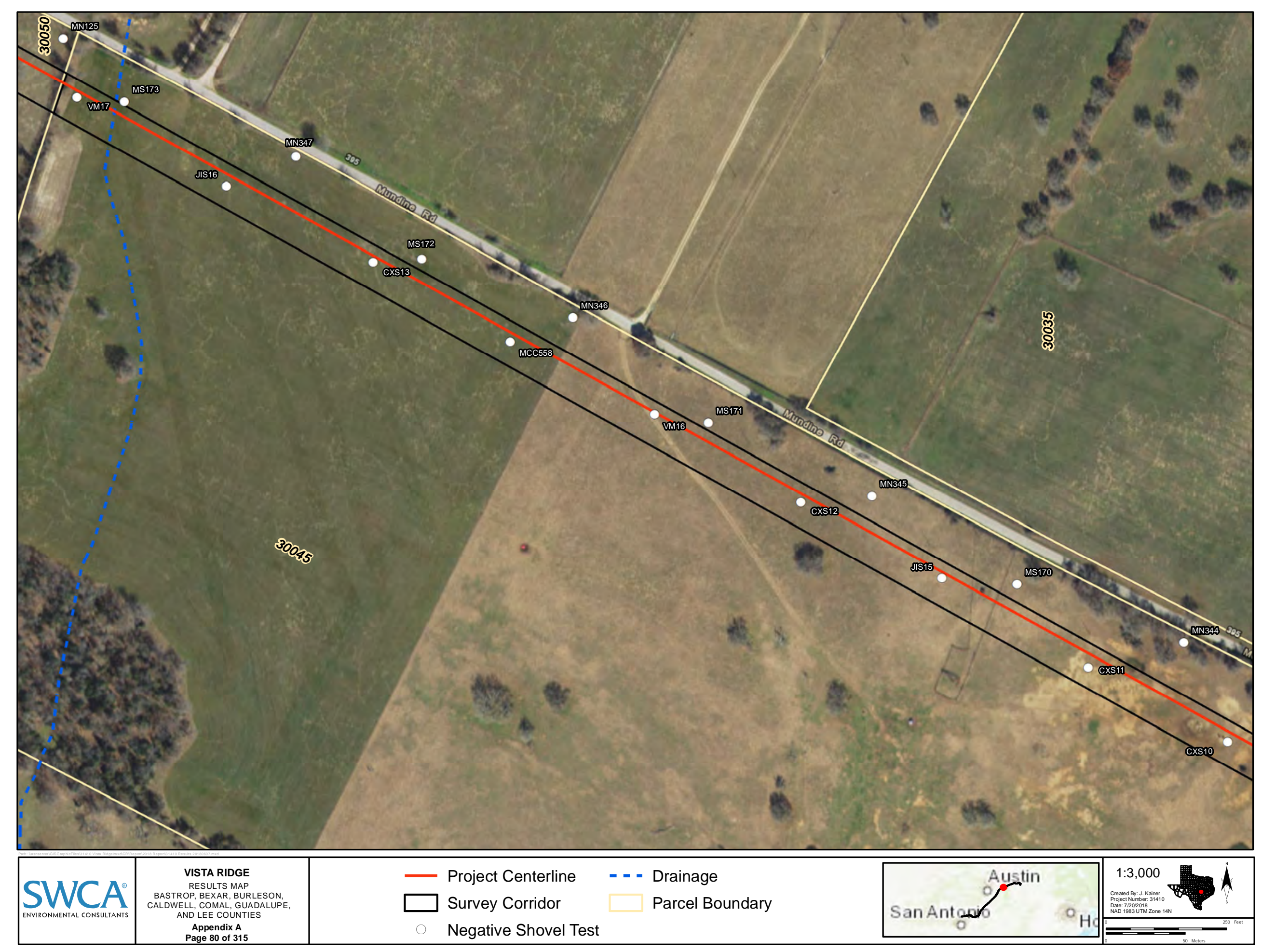


Restricted Information

Not for Public Disclosure 
Restricted Information

Not for Public Disclosure 


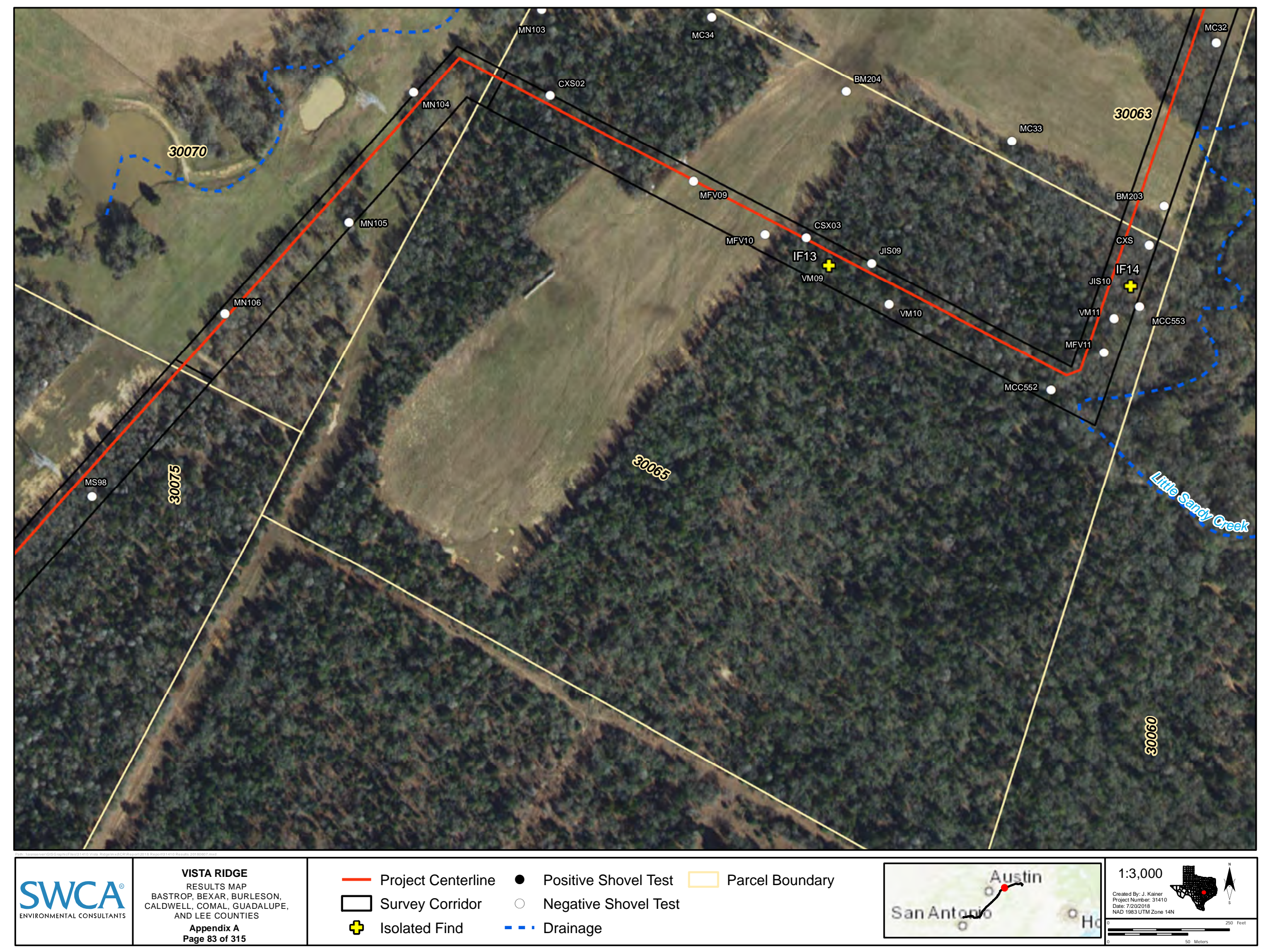




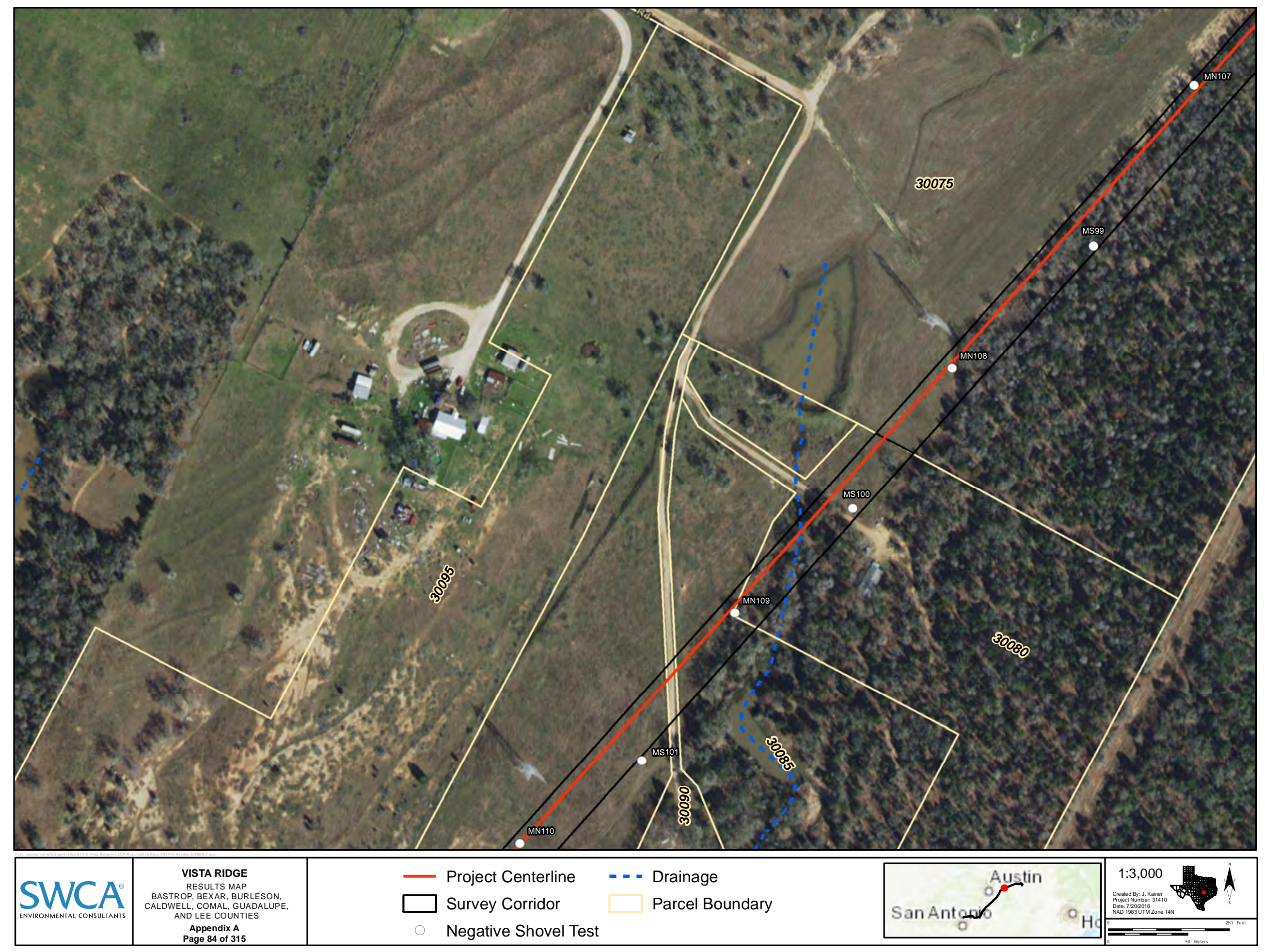




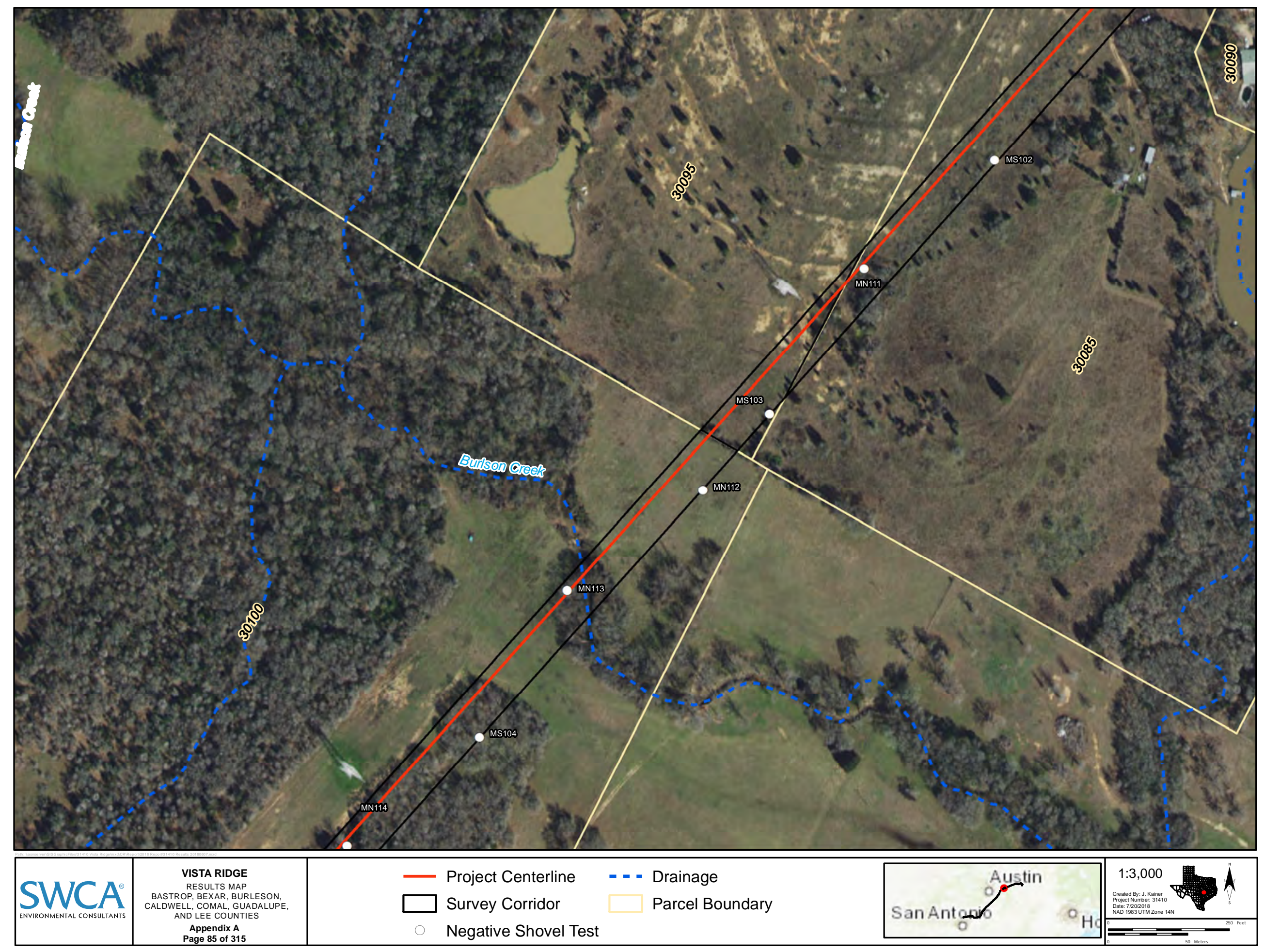




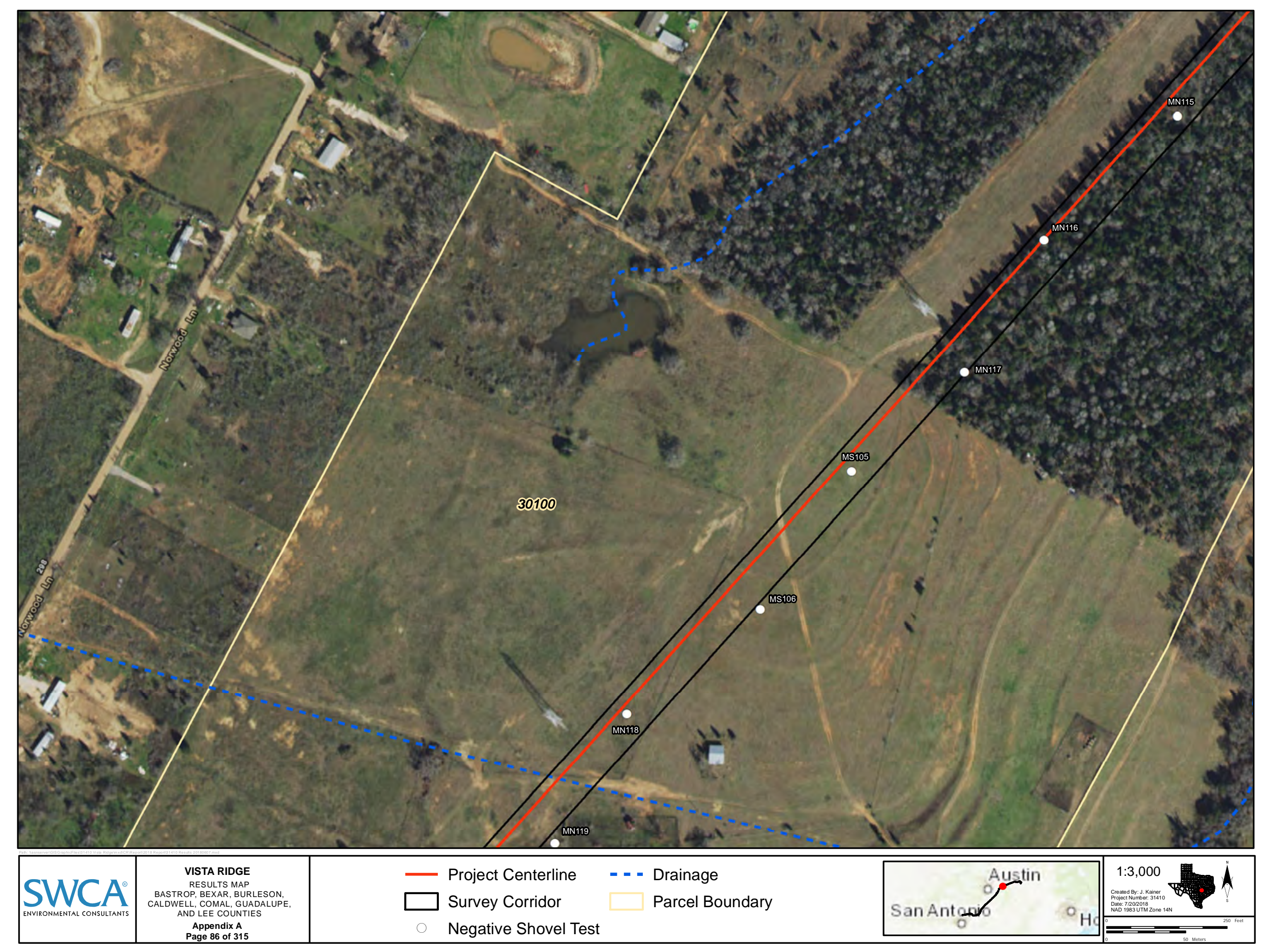




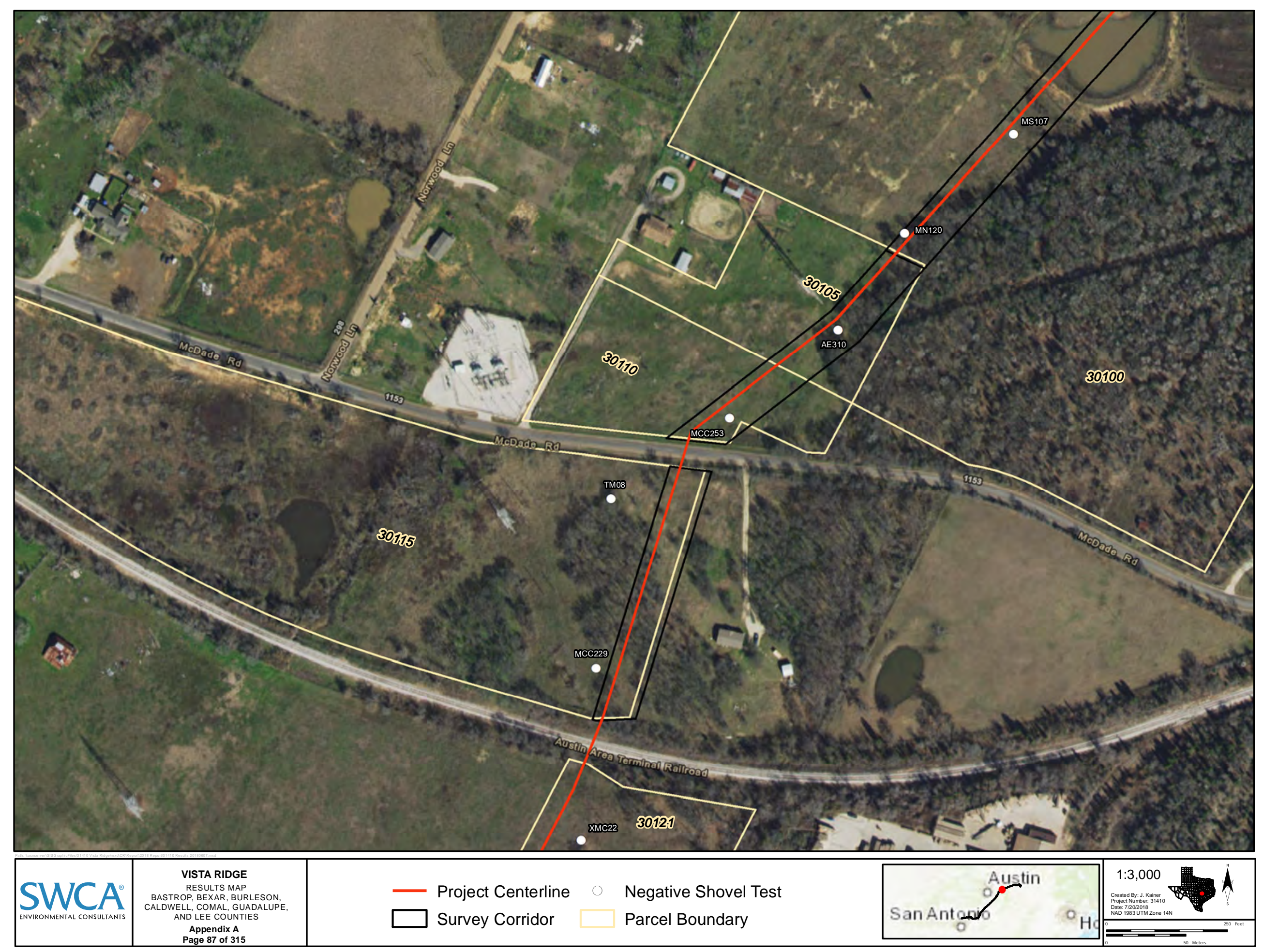




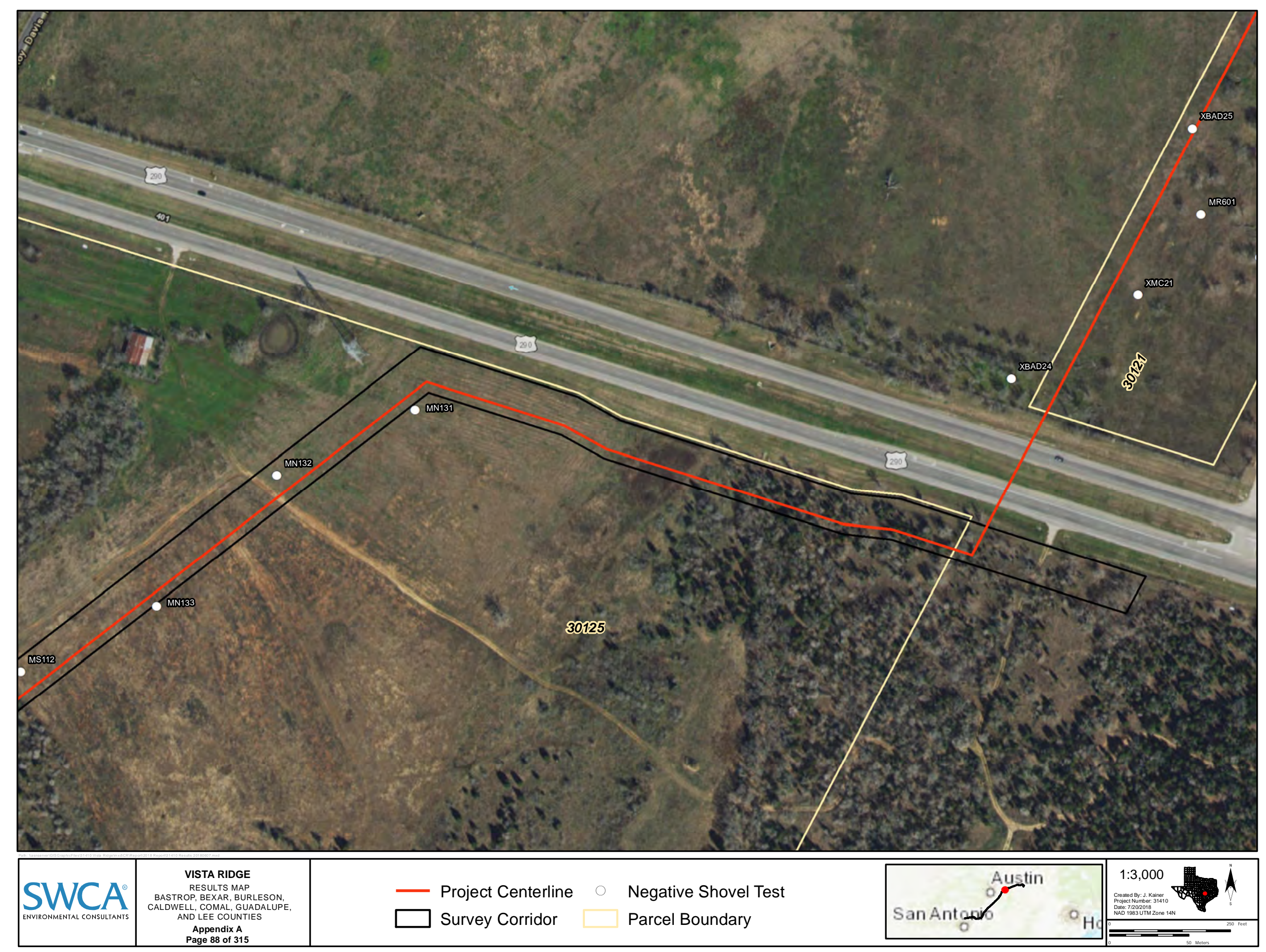




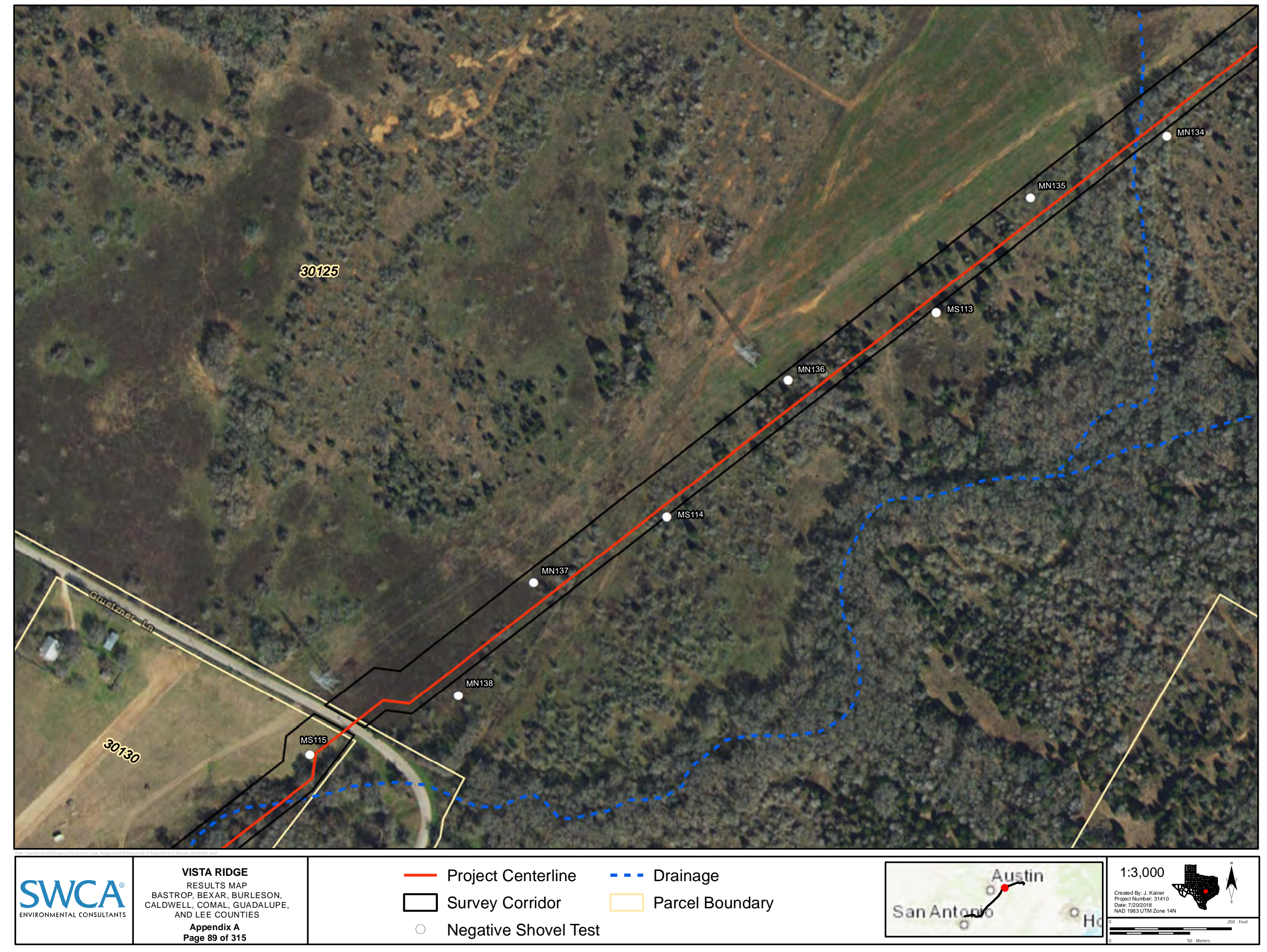




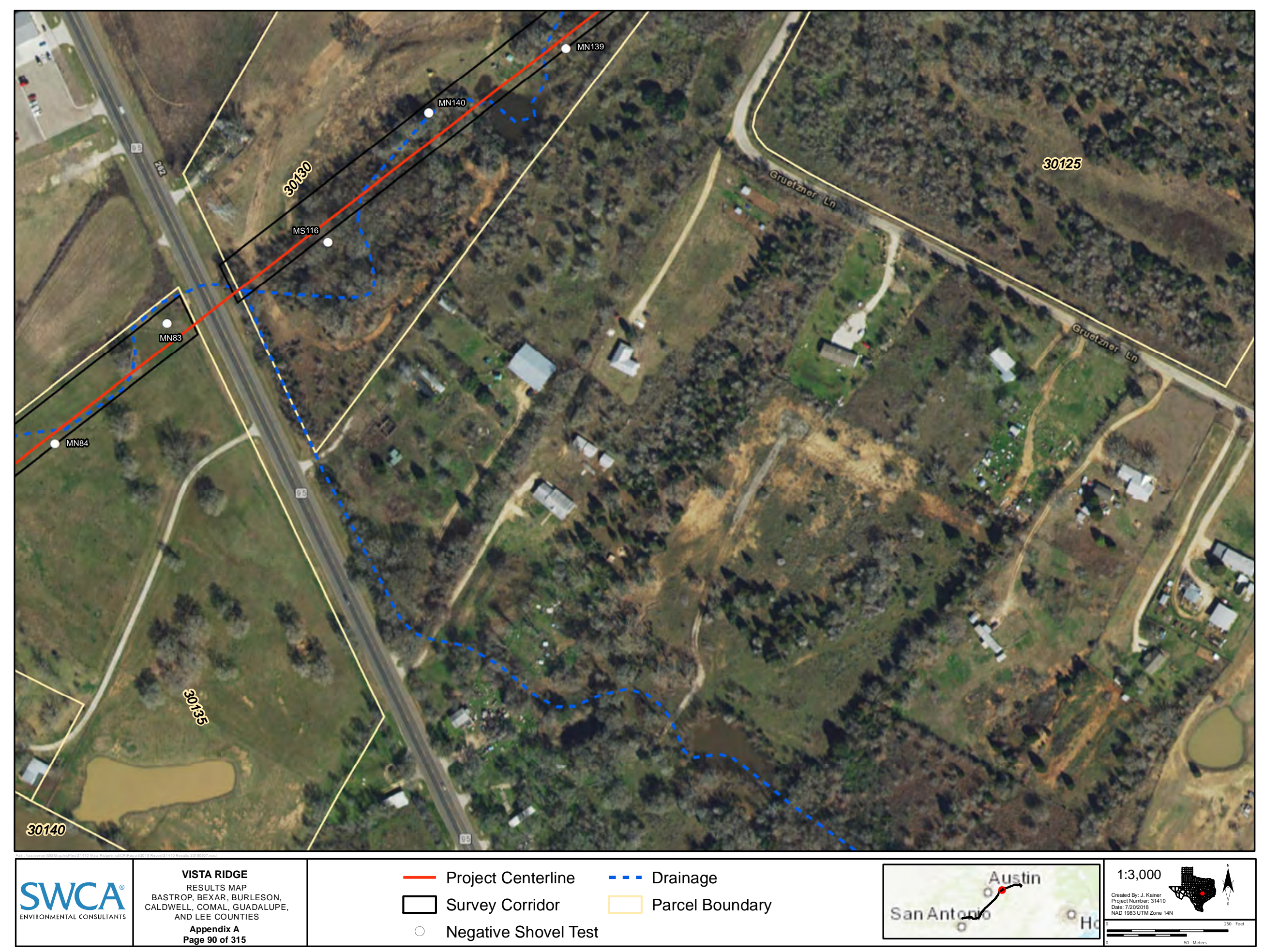




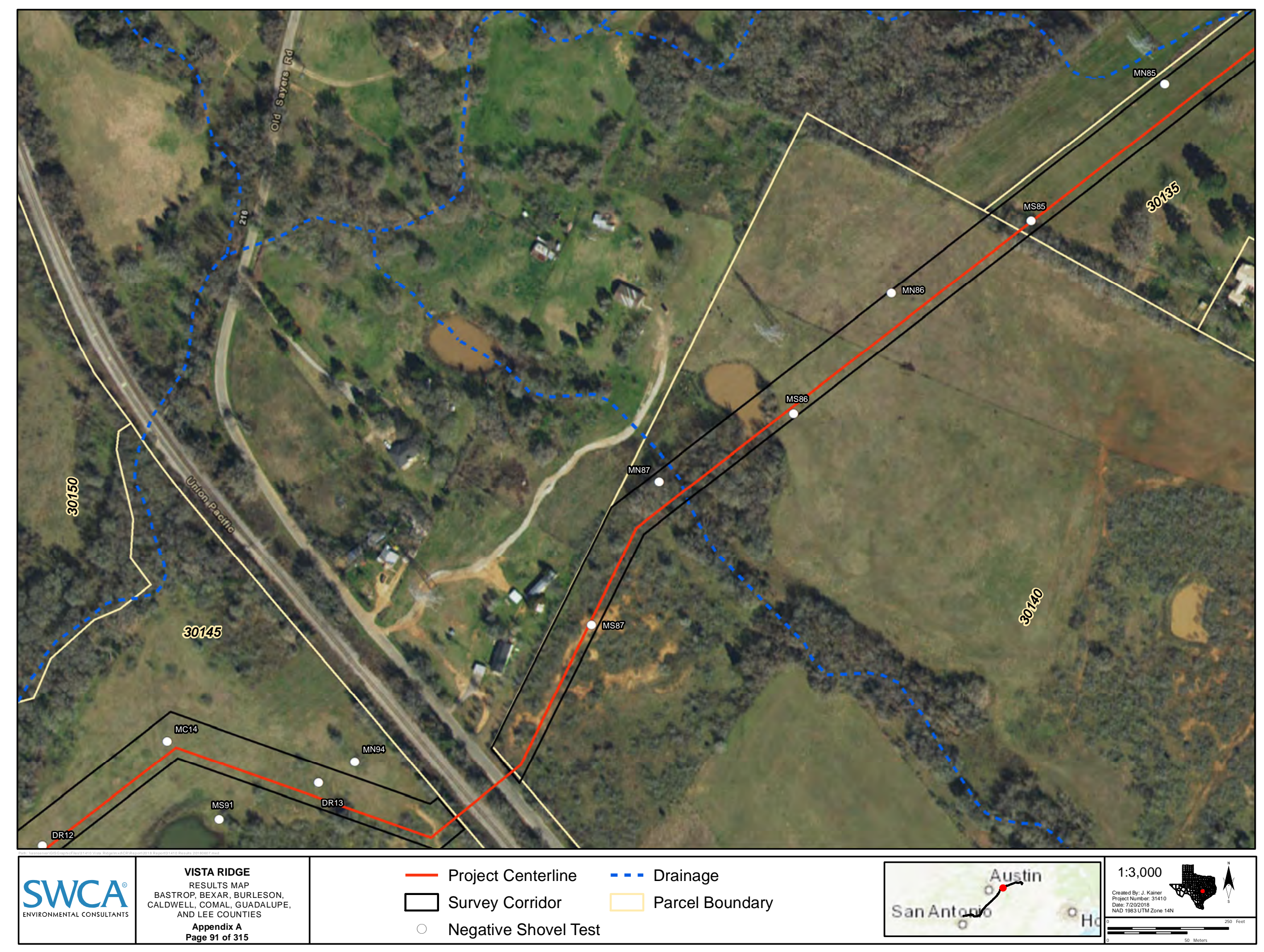


Restricted Information

Not for Public Disclosure 
Restricted Information

Not for Public Disclosure 


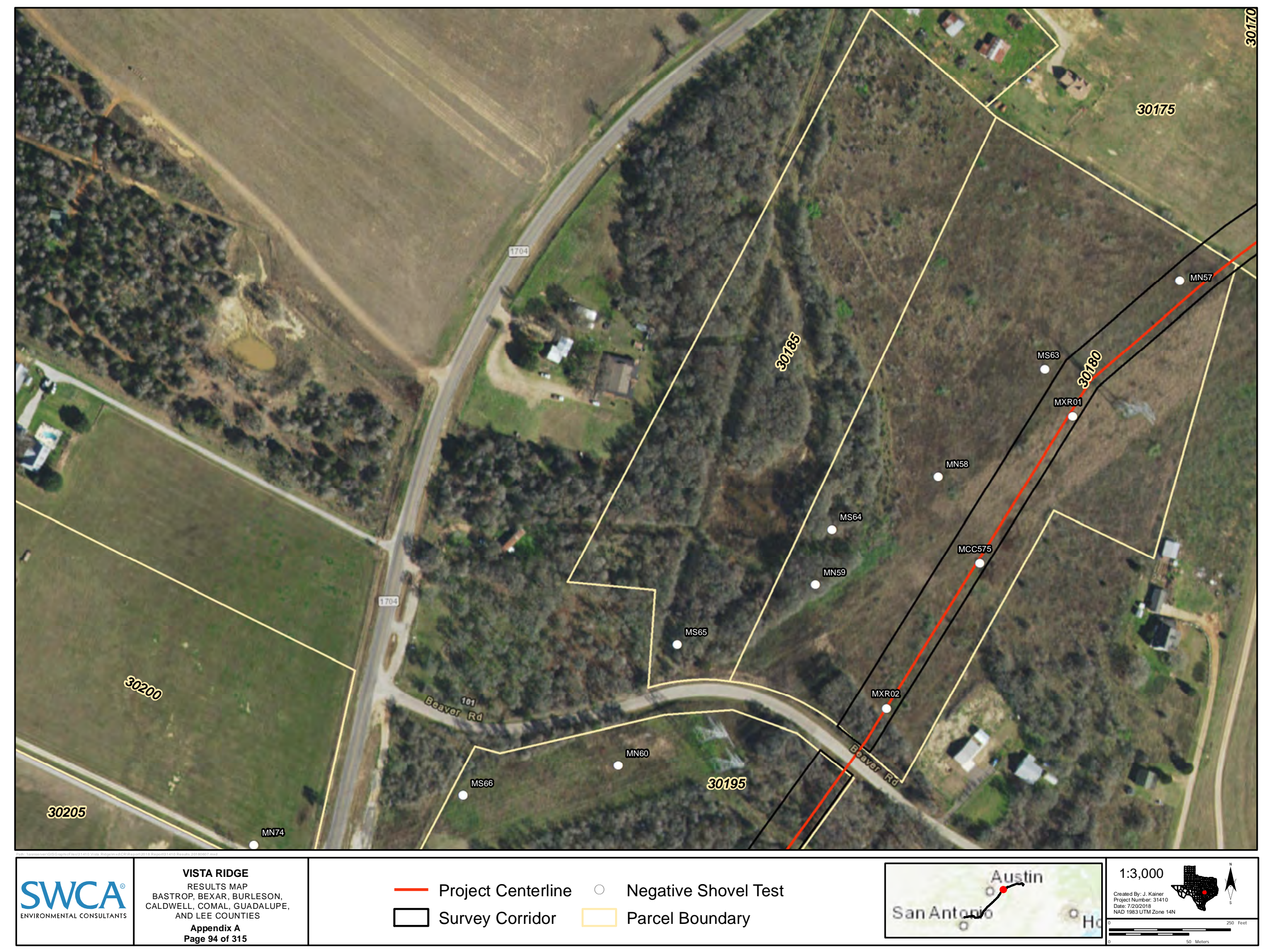




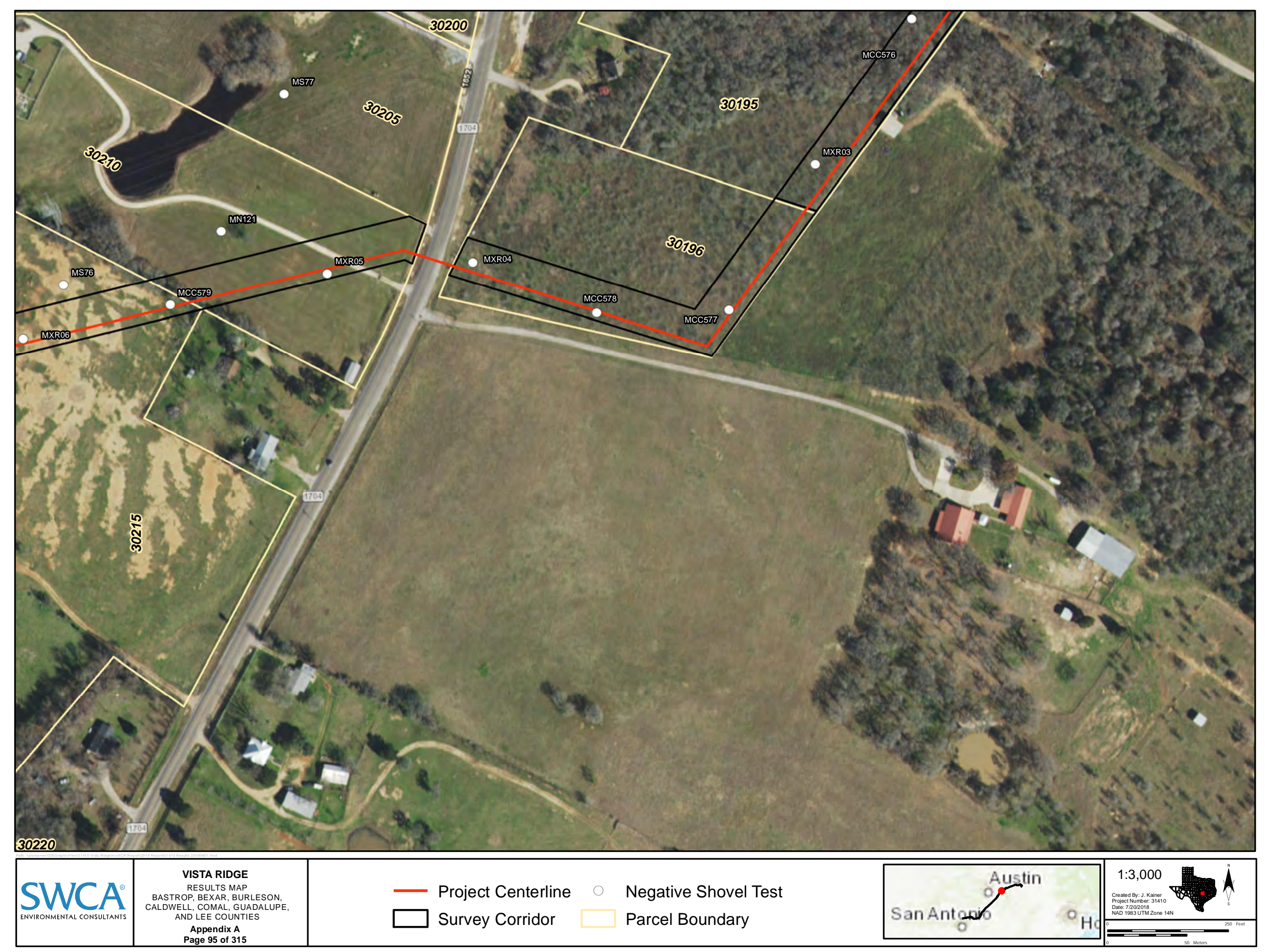




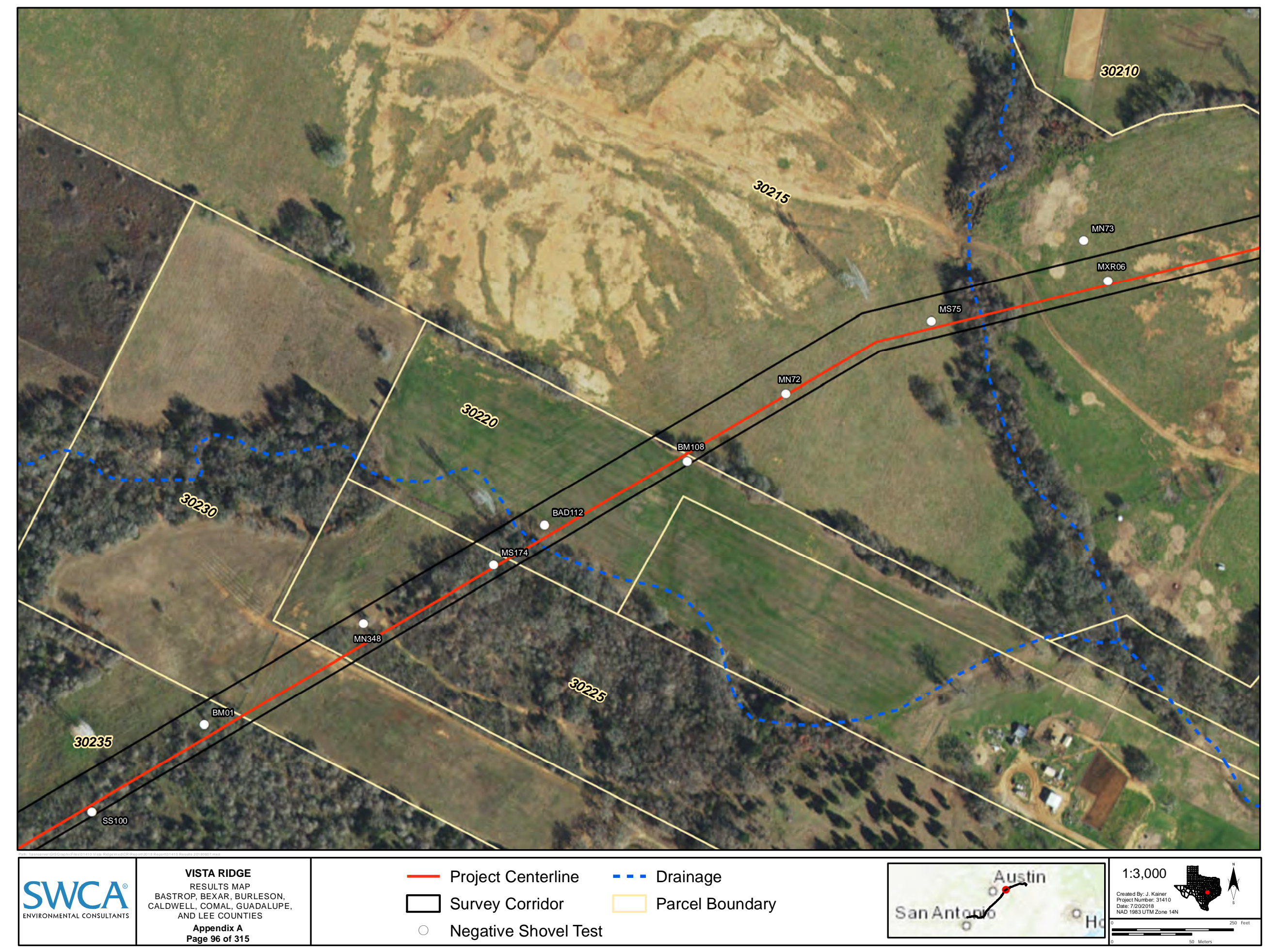




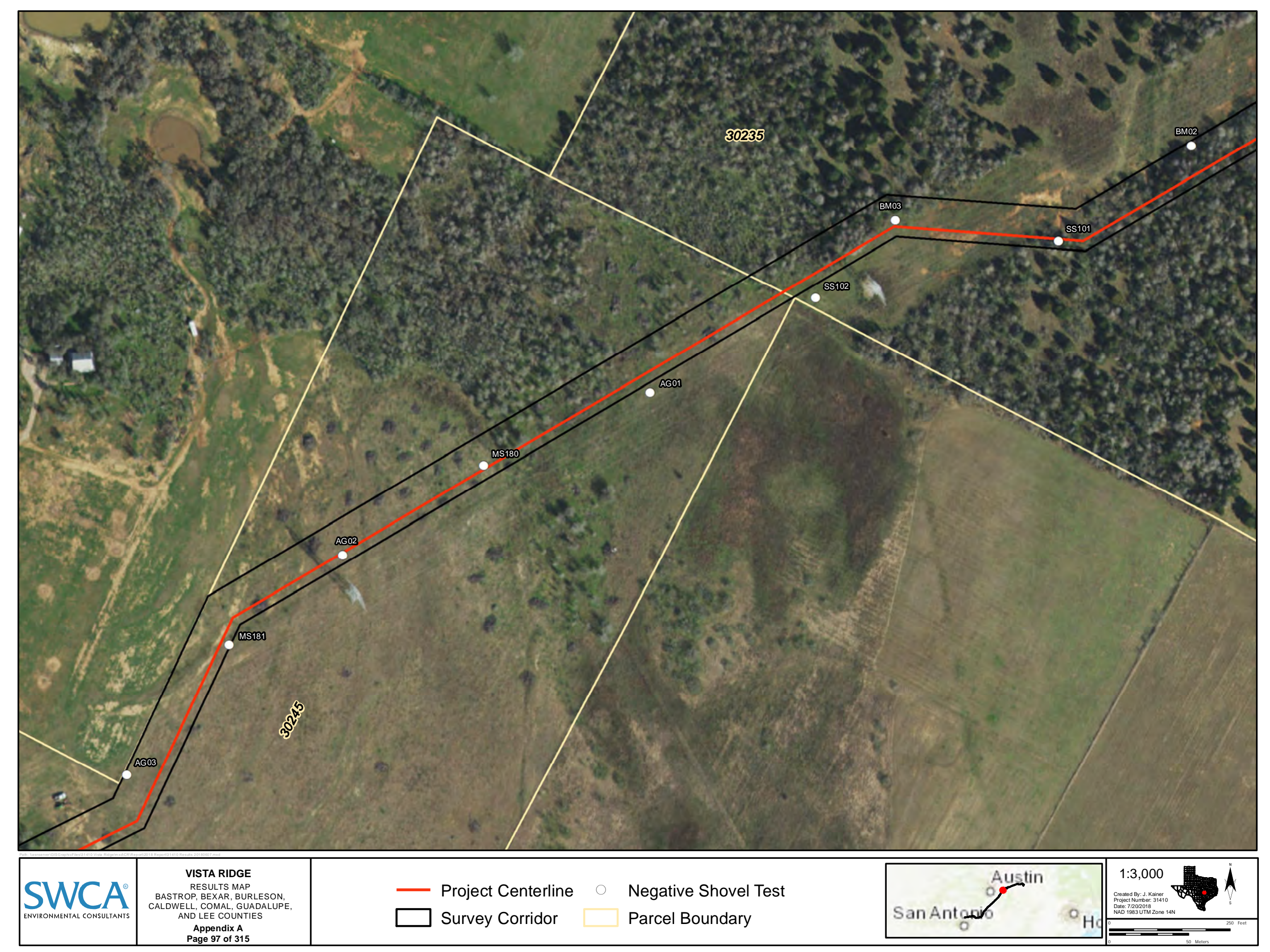




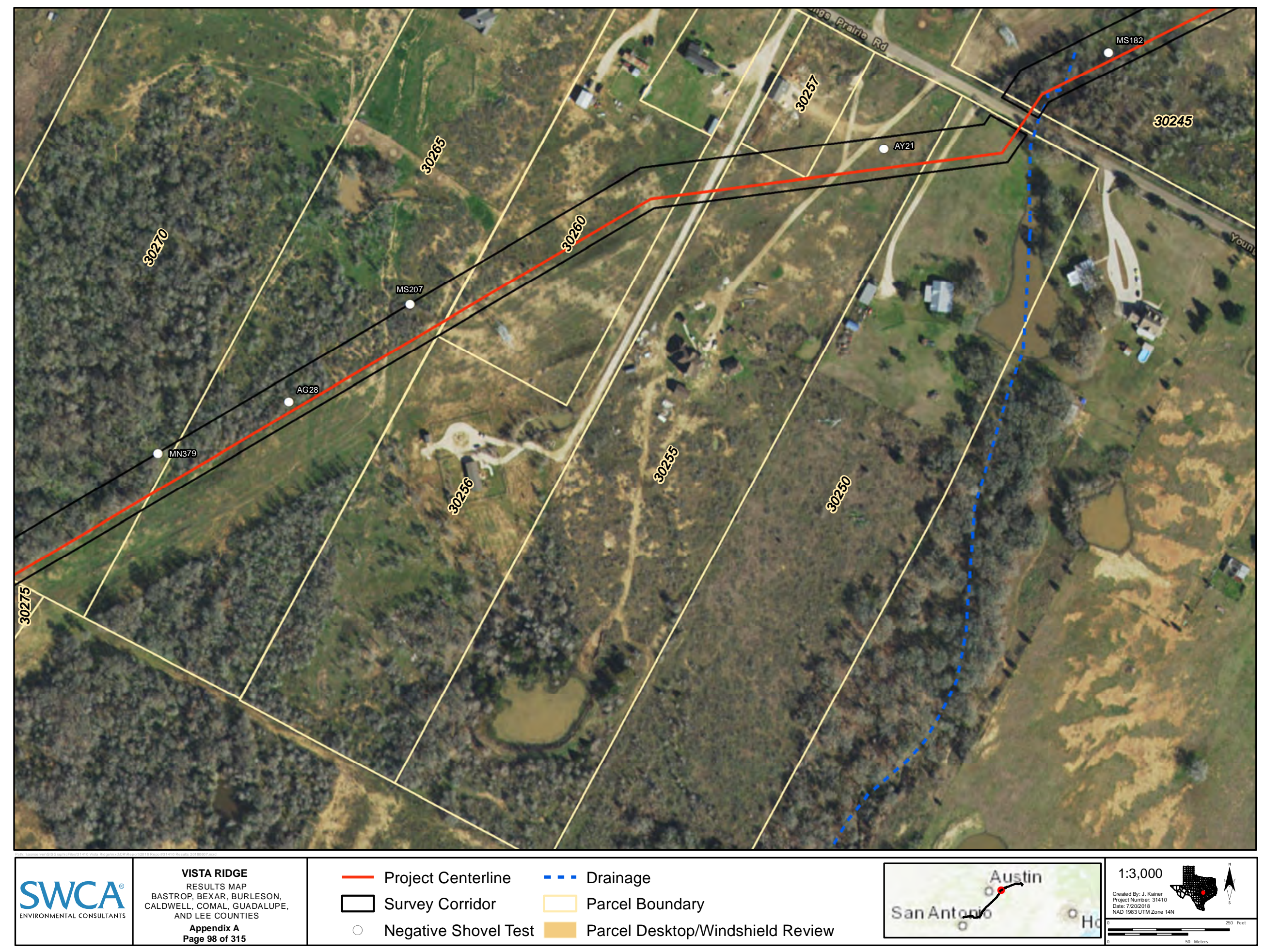


Restricted Information

Not for Public Disclosure 
Restricted Information

Not for Public Disclosure 
Restricted Information

Not for Public Disclosure 


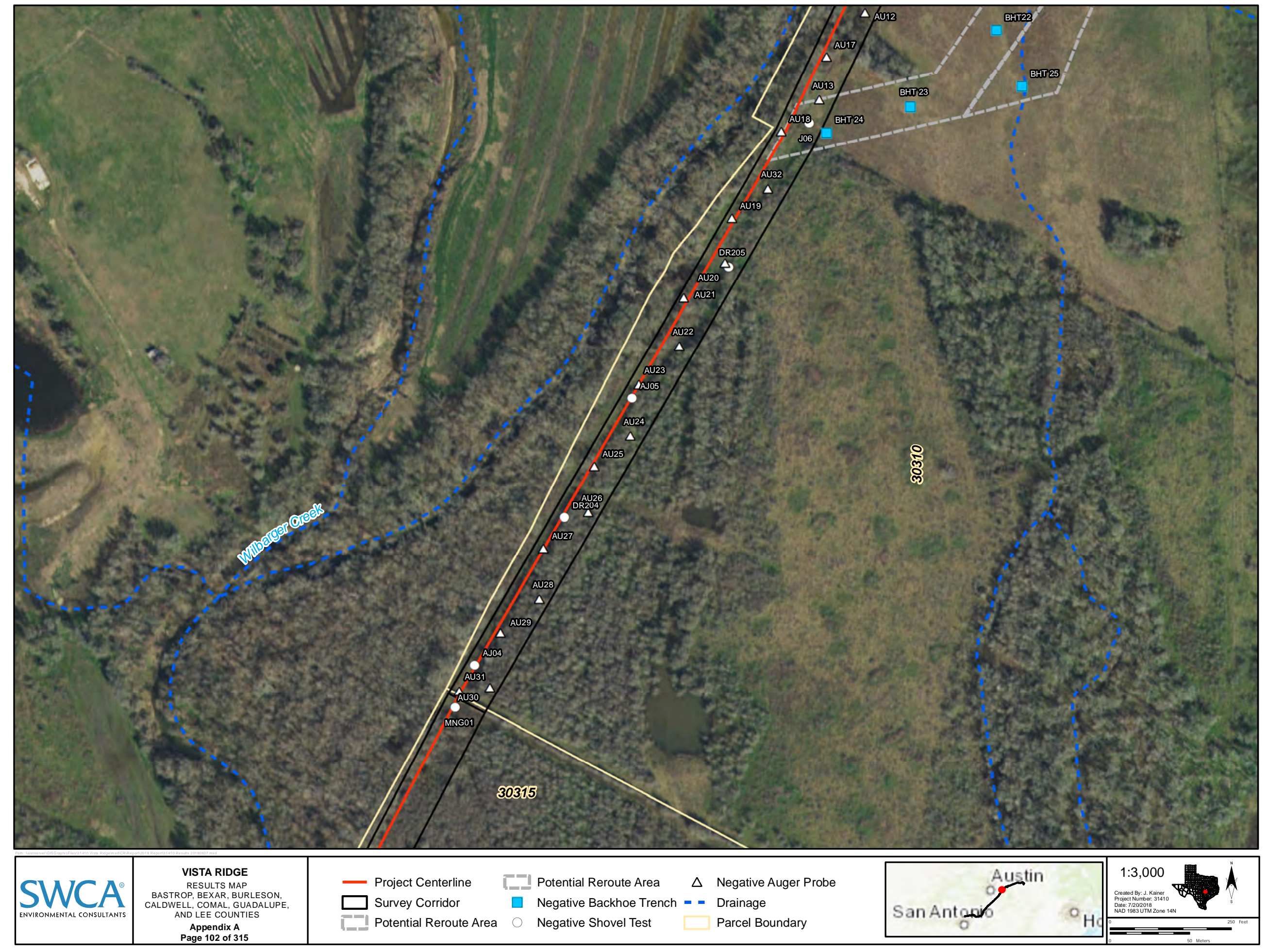




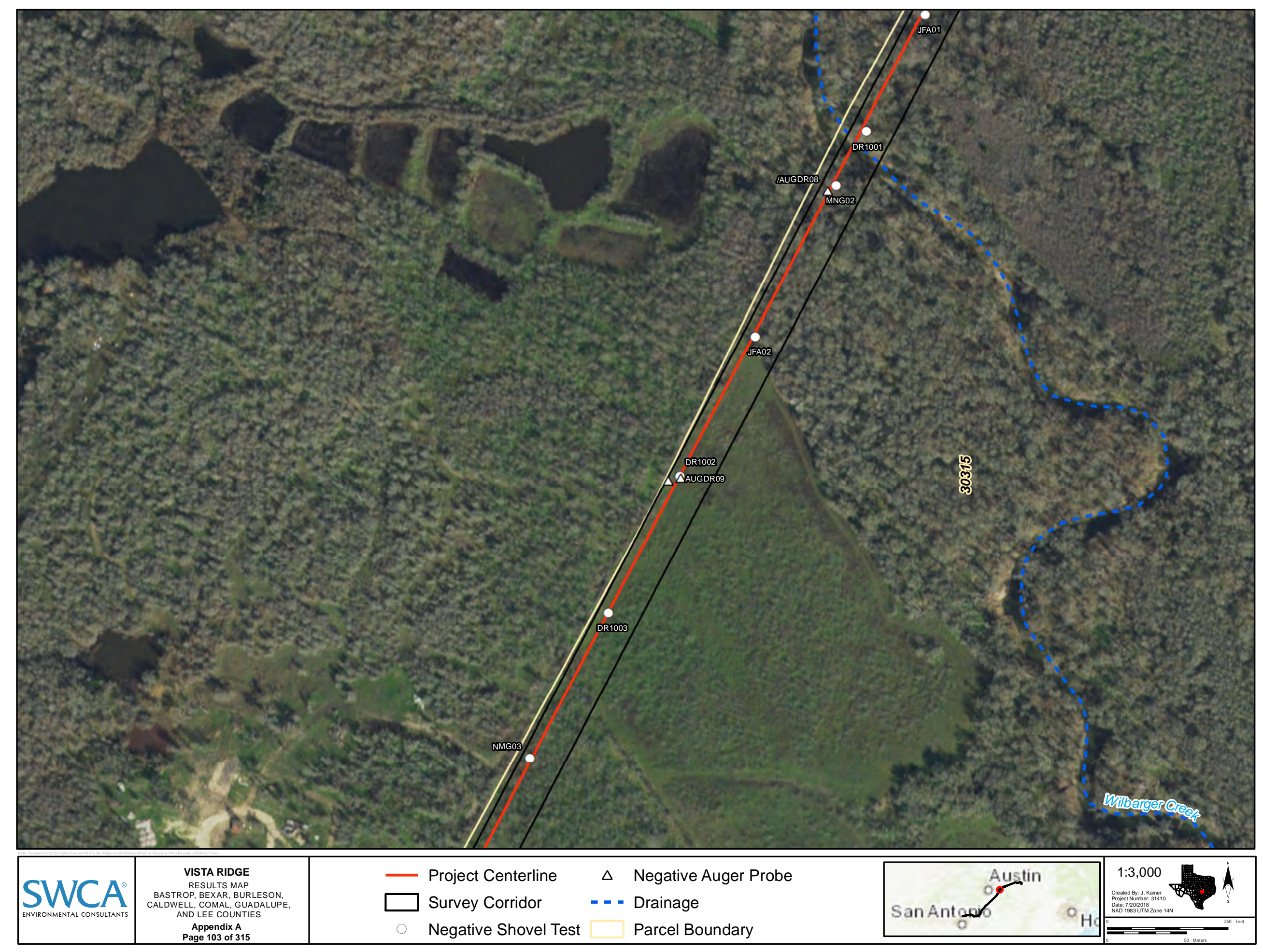




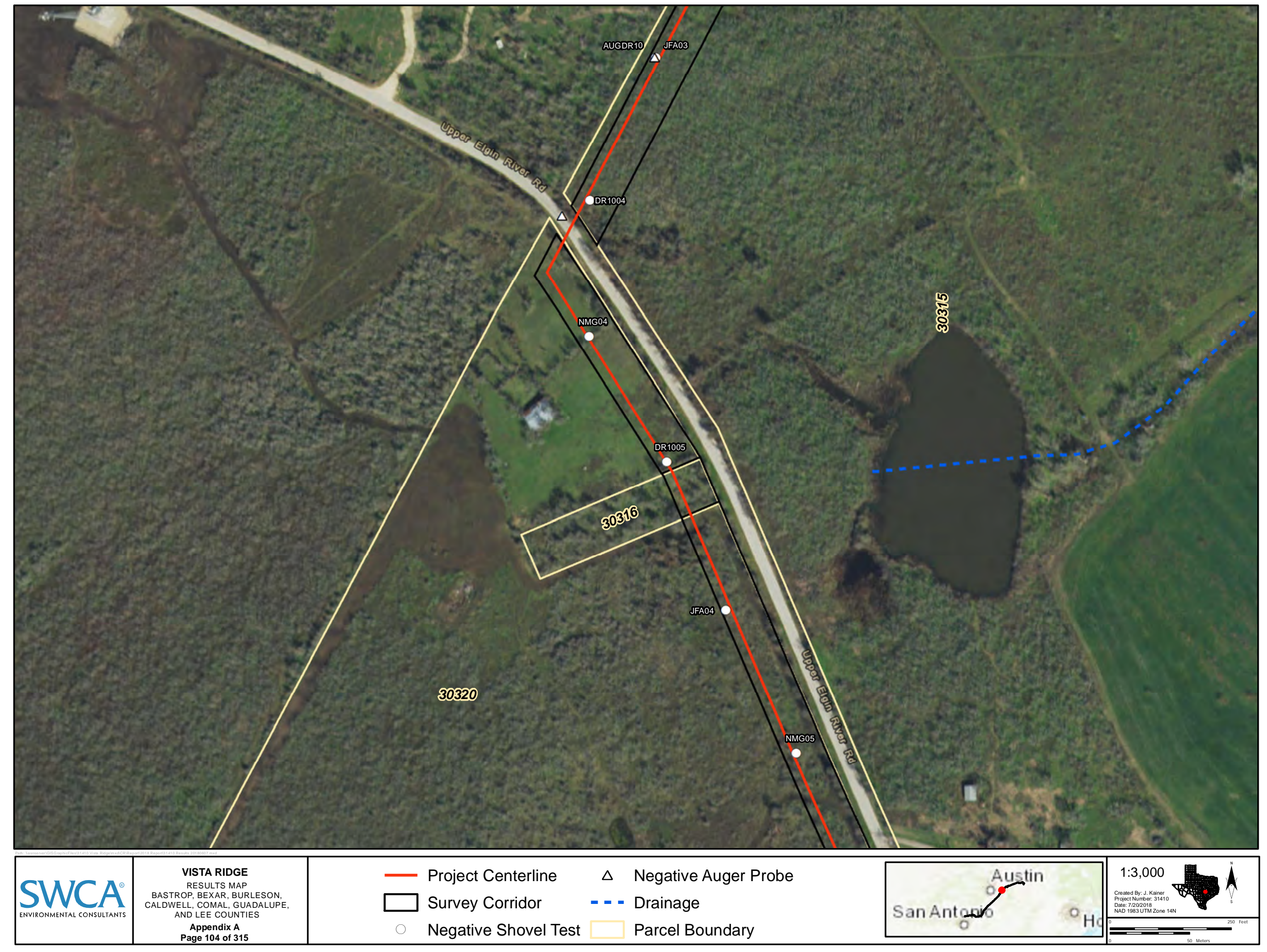




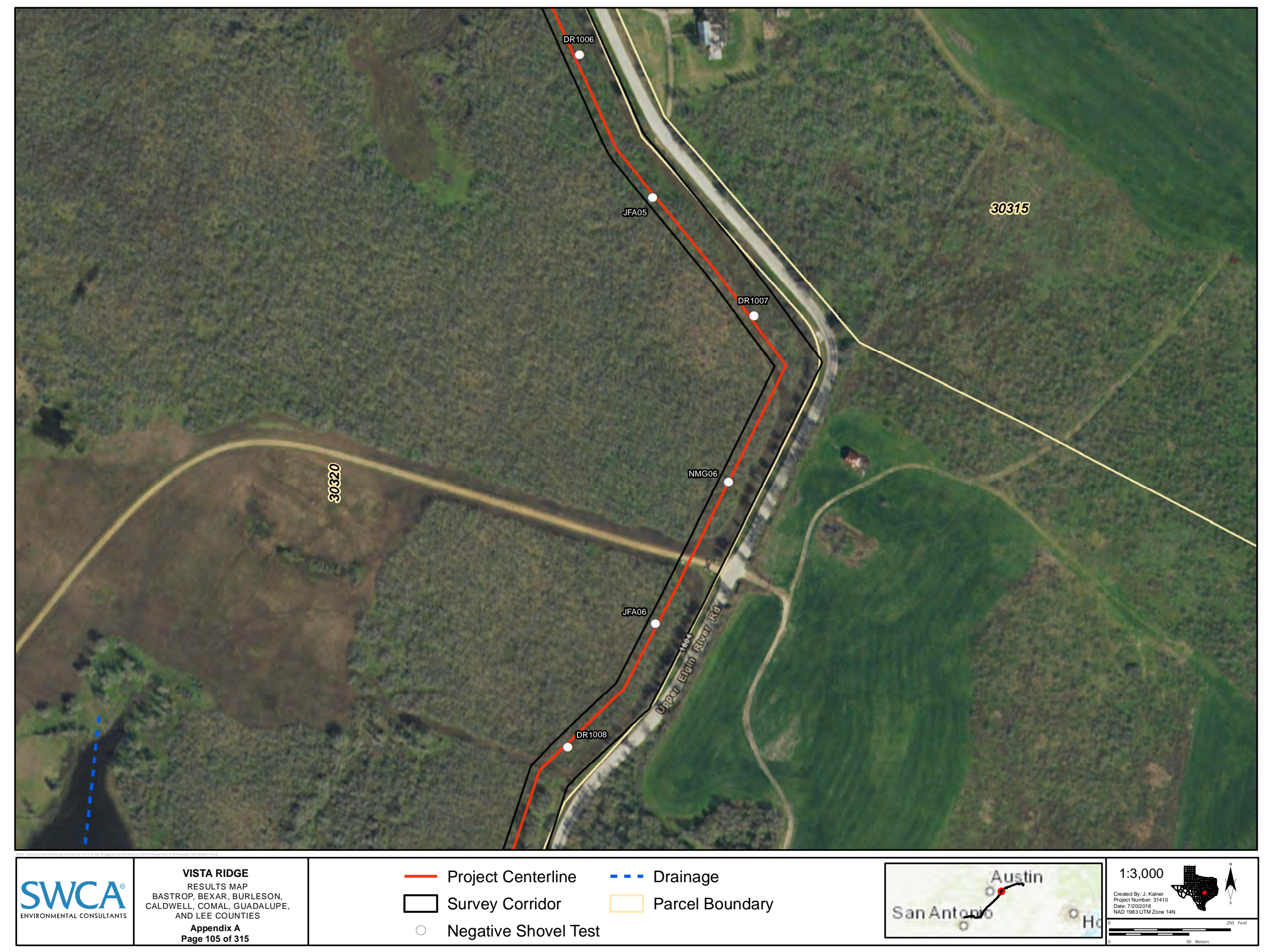


Restricted Information

Not for Public Disclosure 


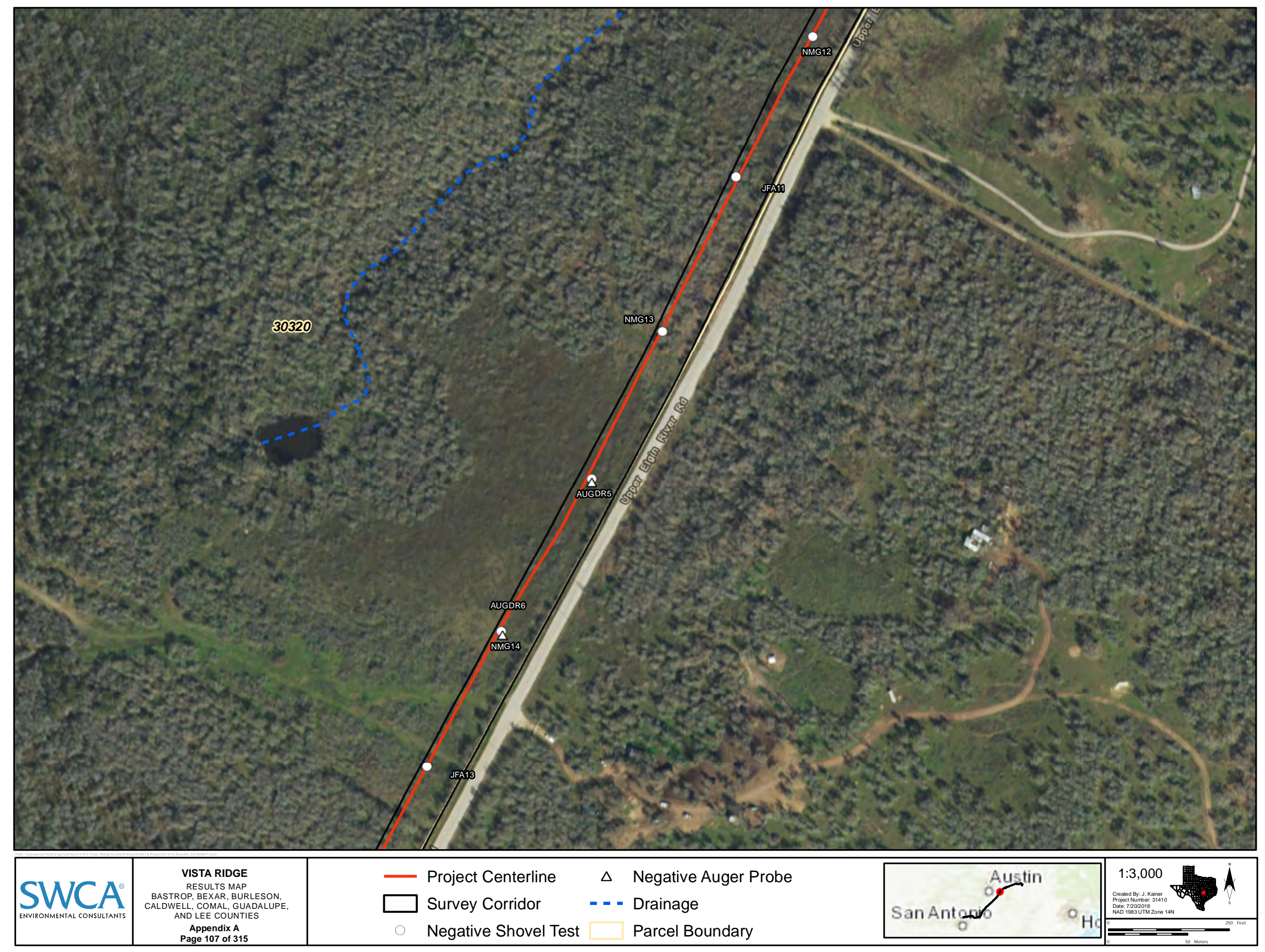




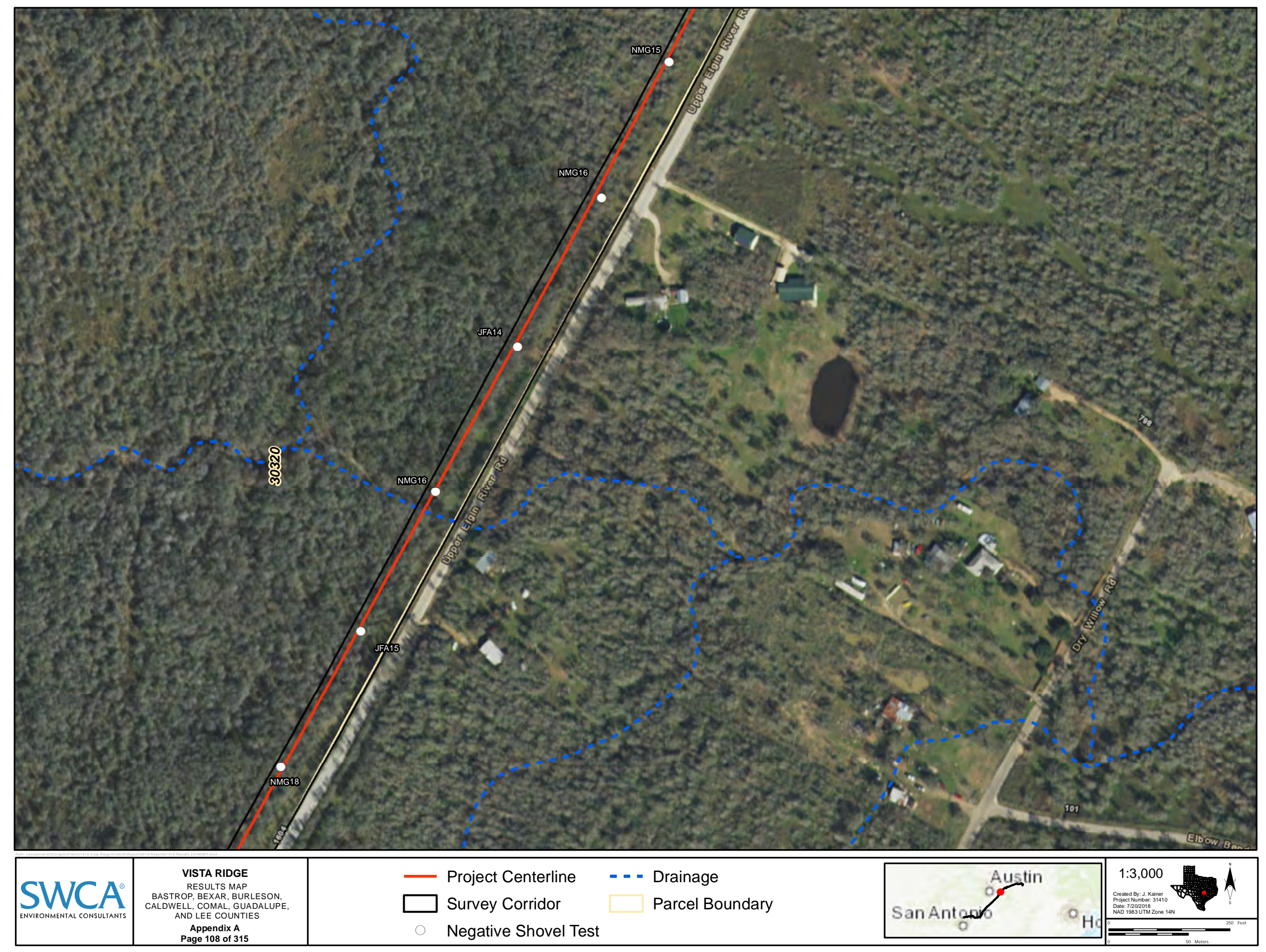




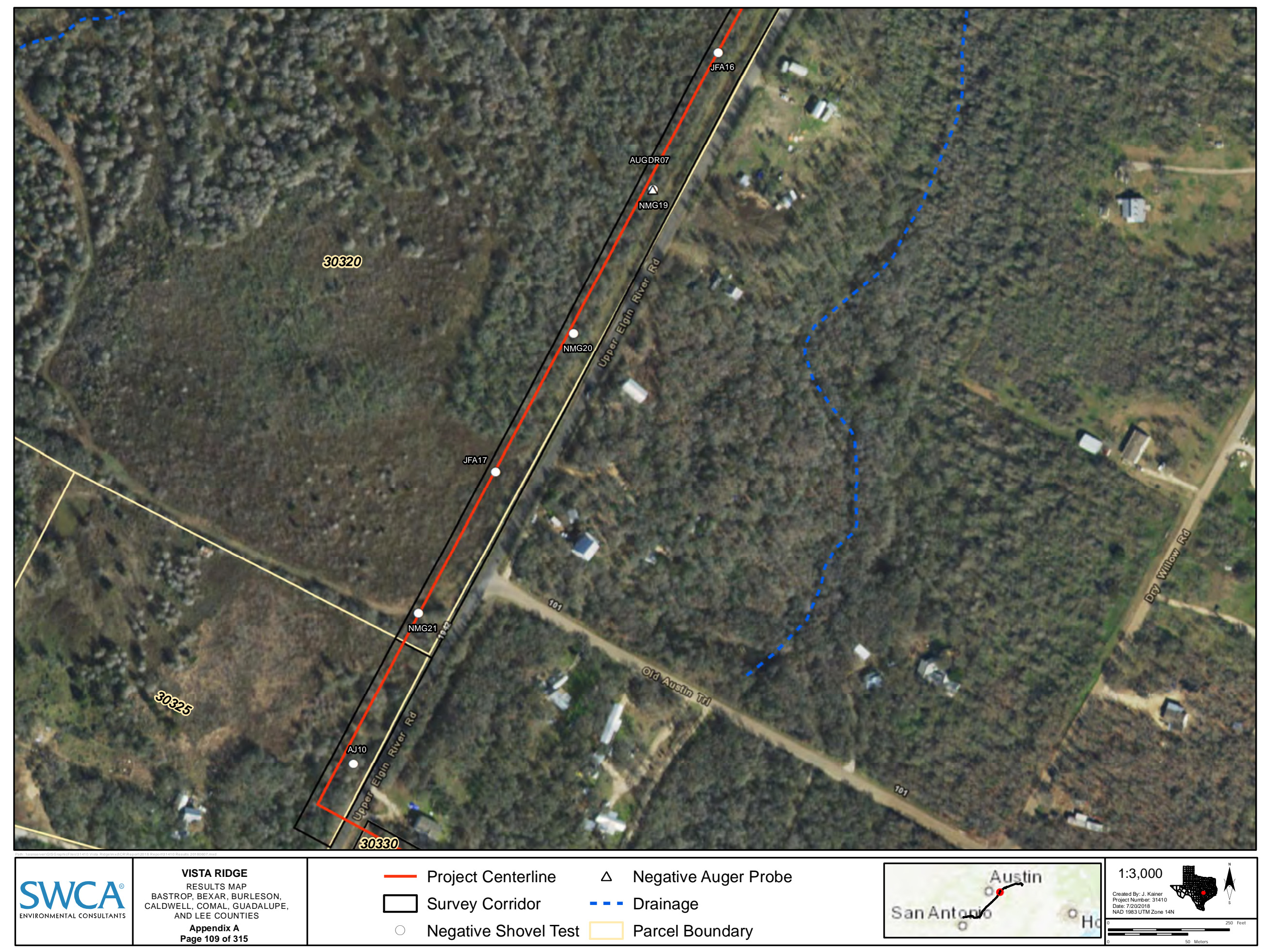




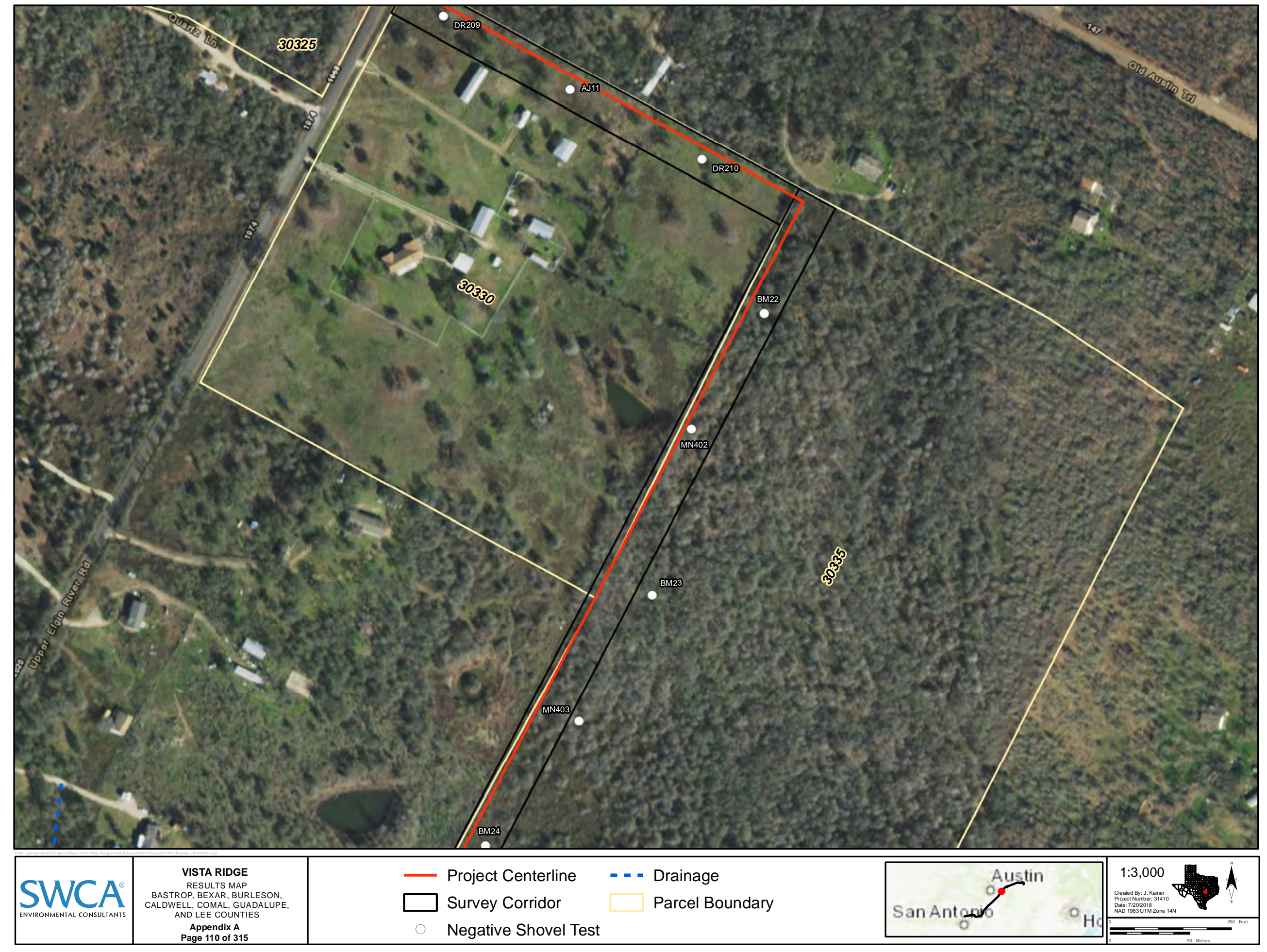




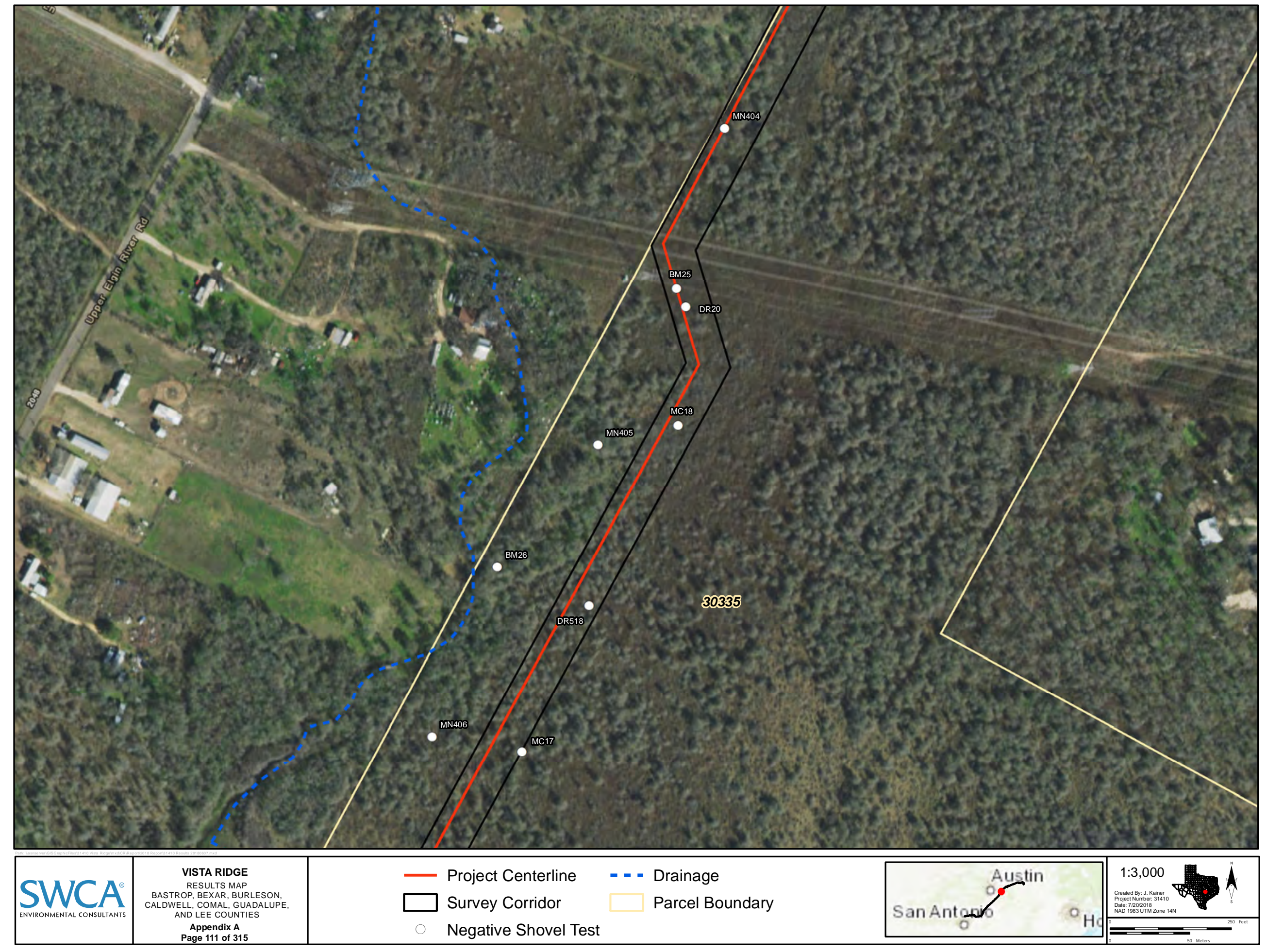




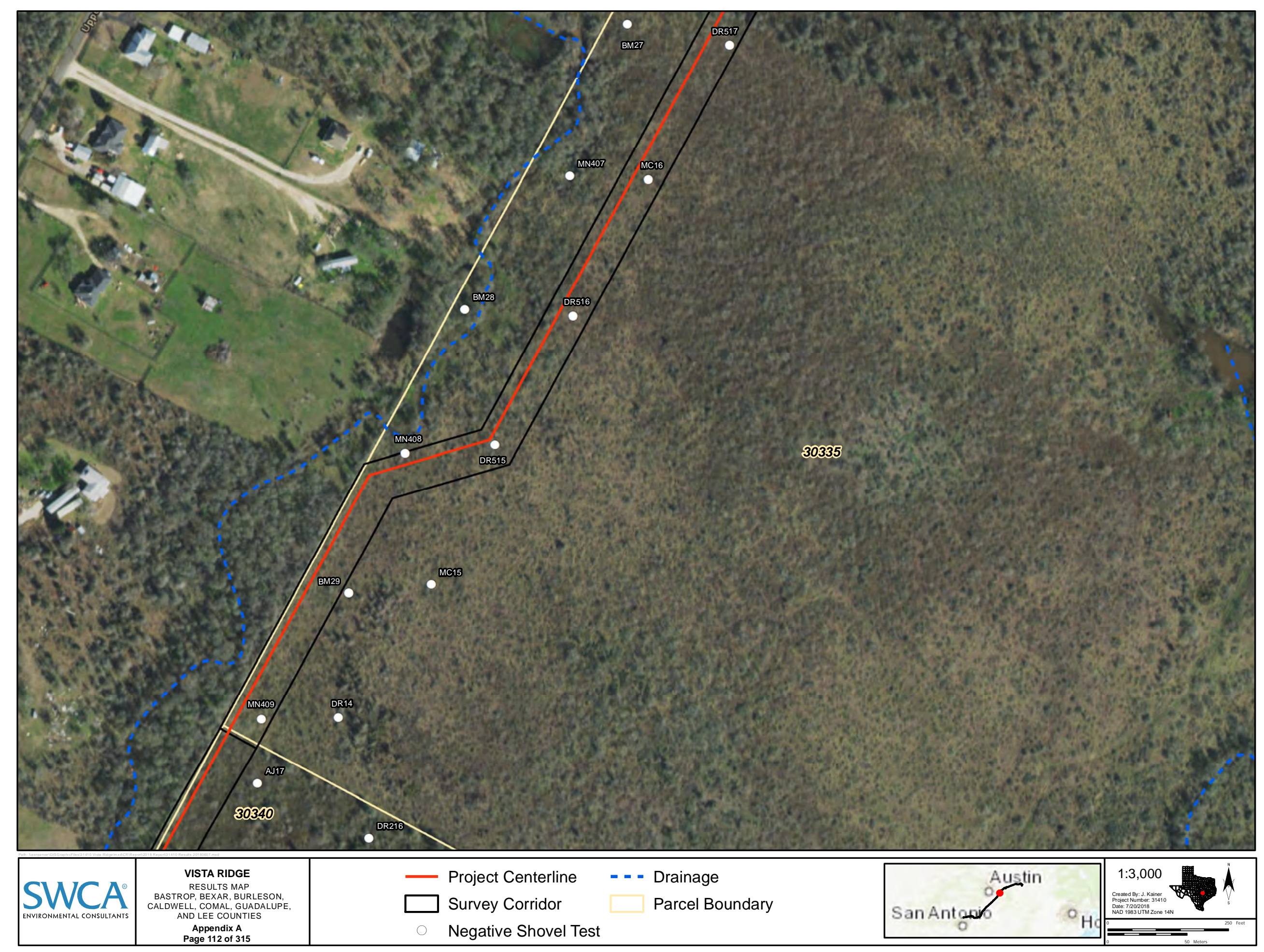


Restricted Information

Not for Public Disclosure 


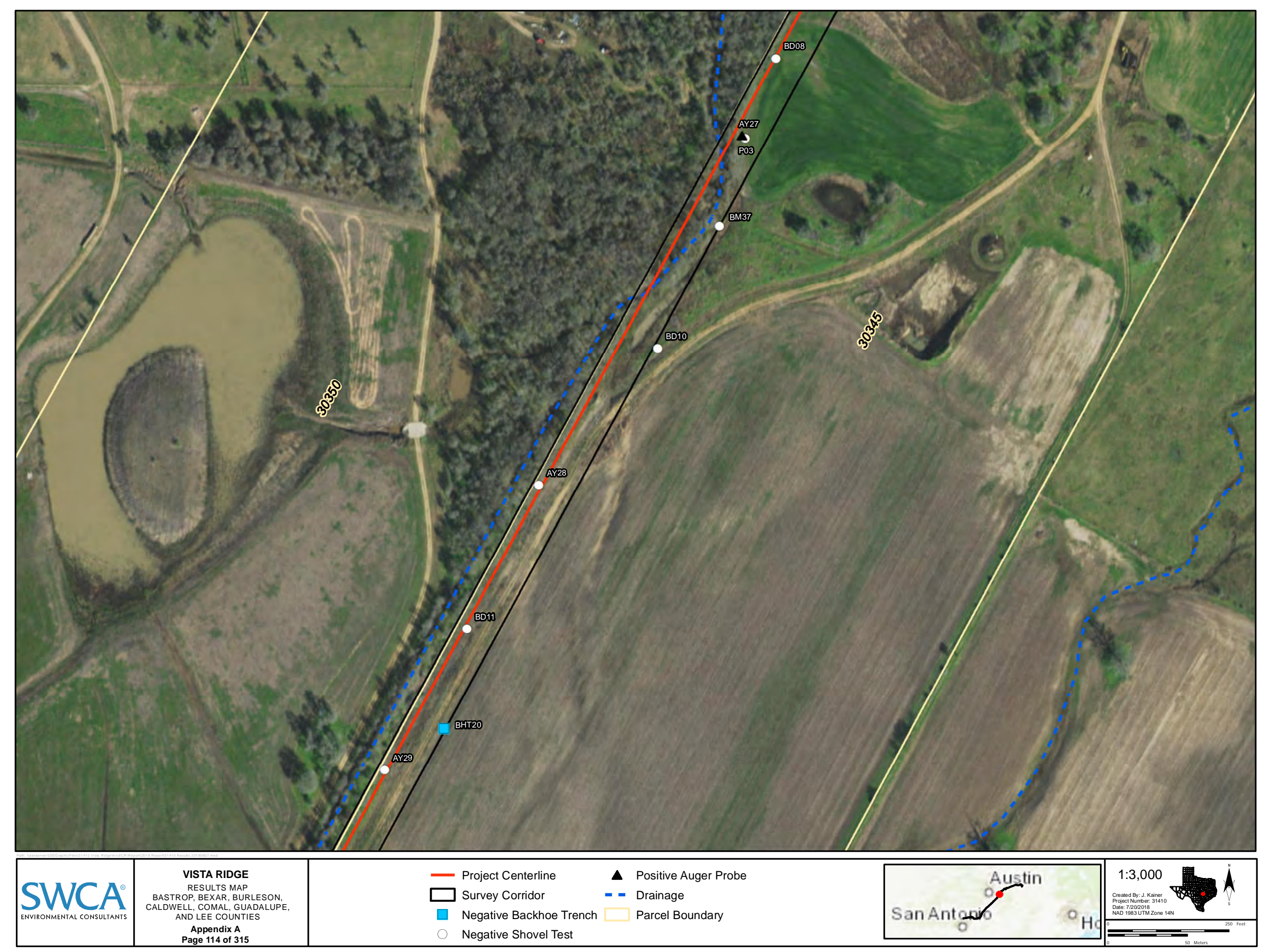




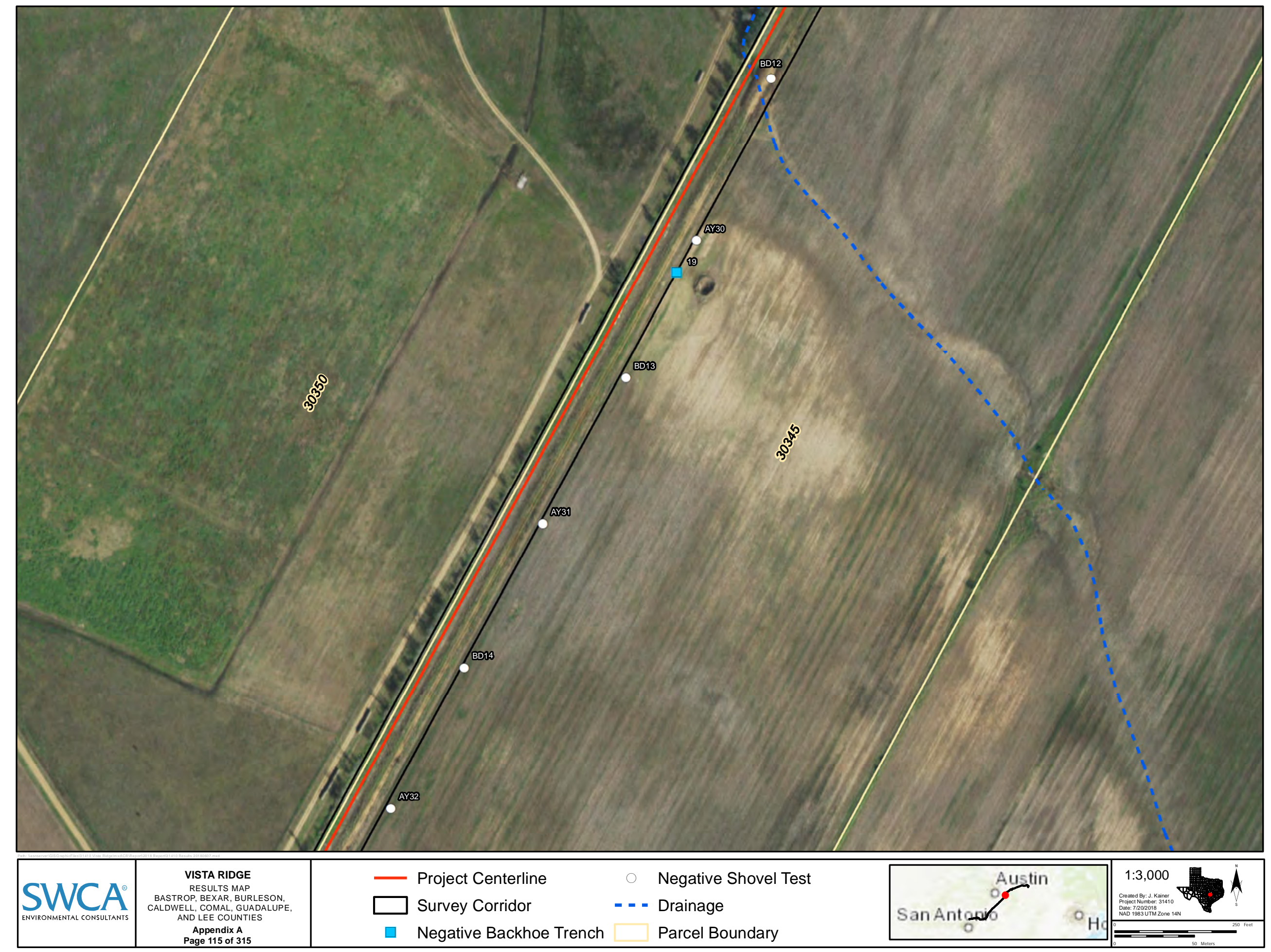




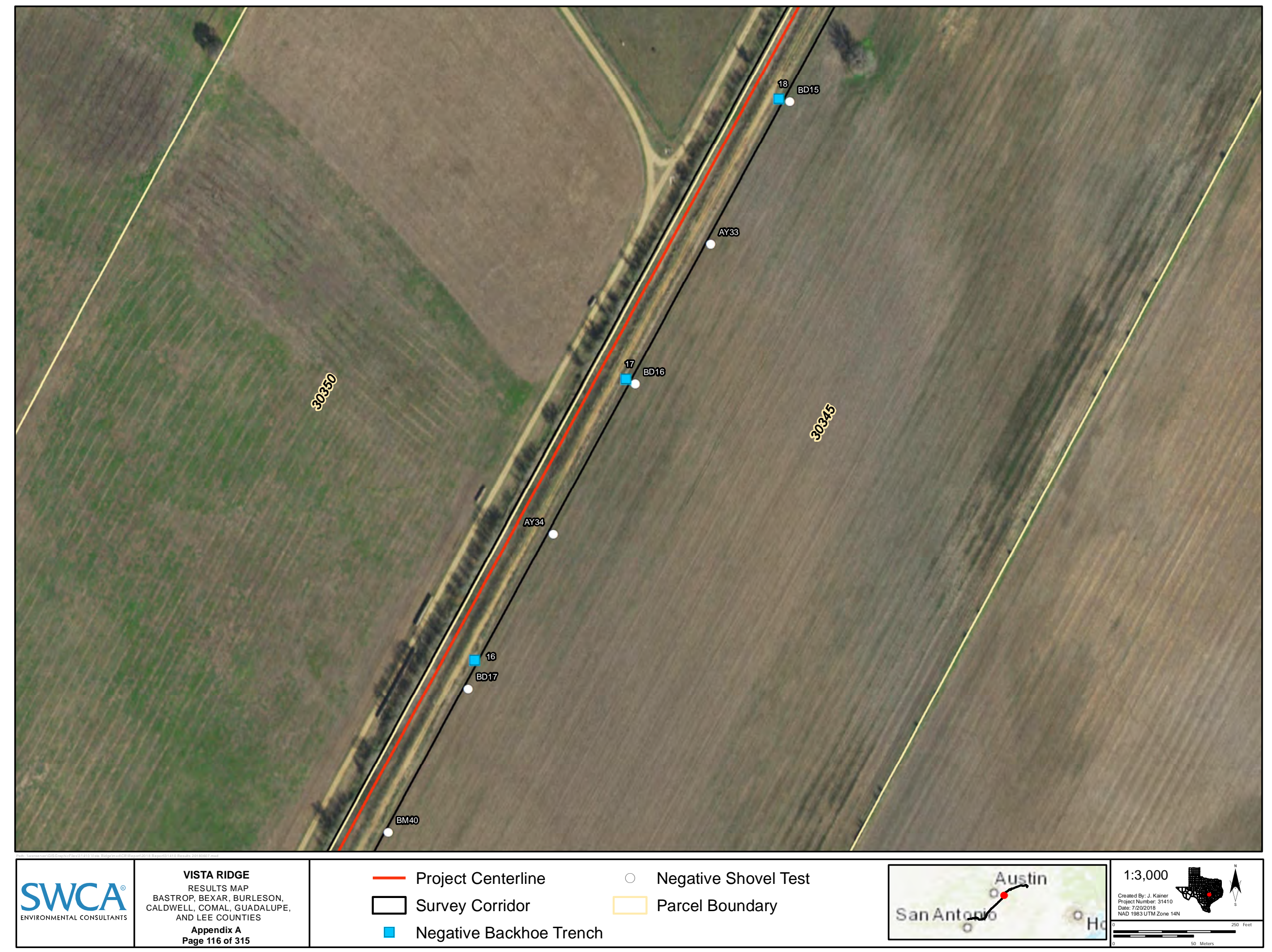




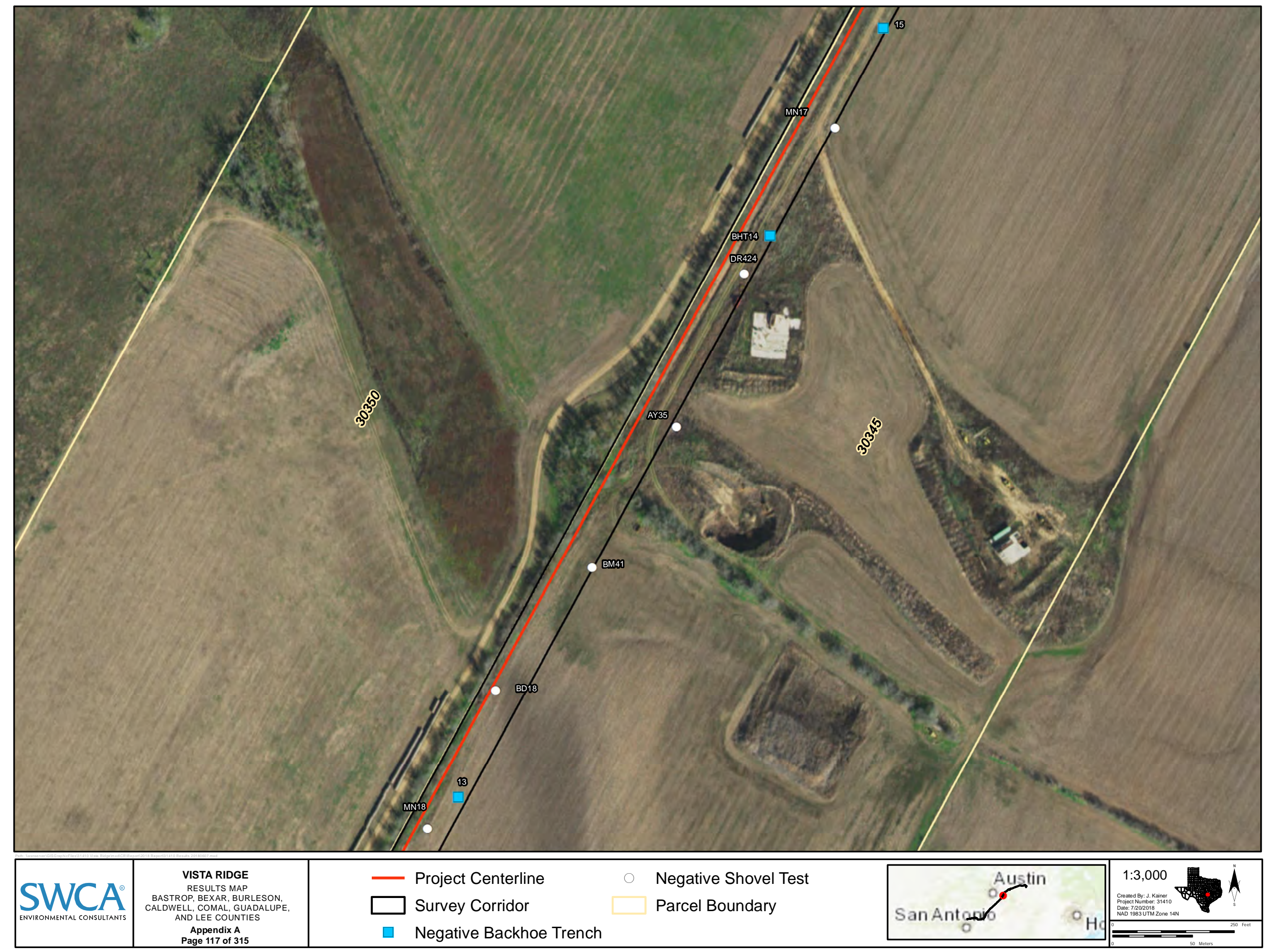




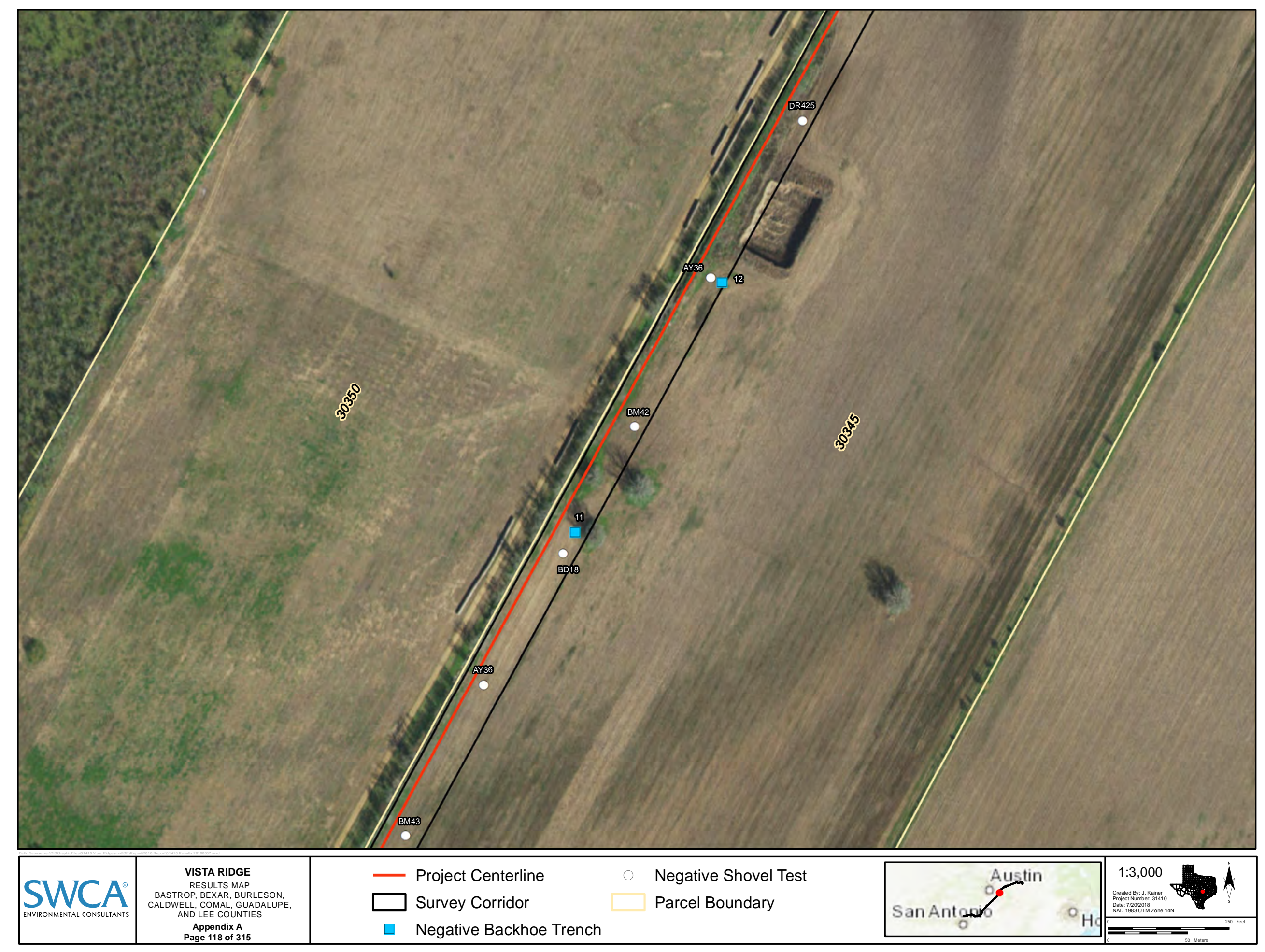




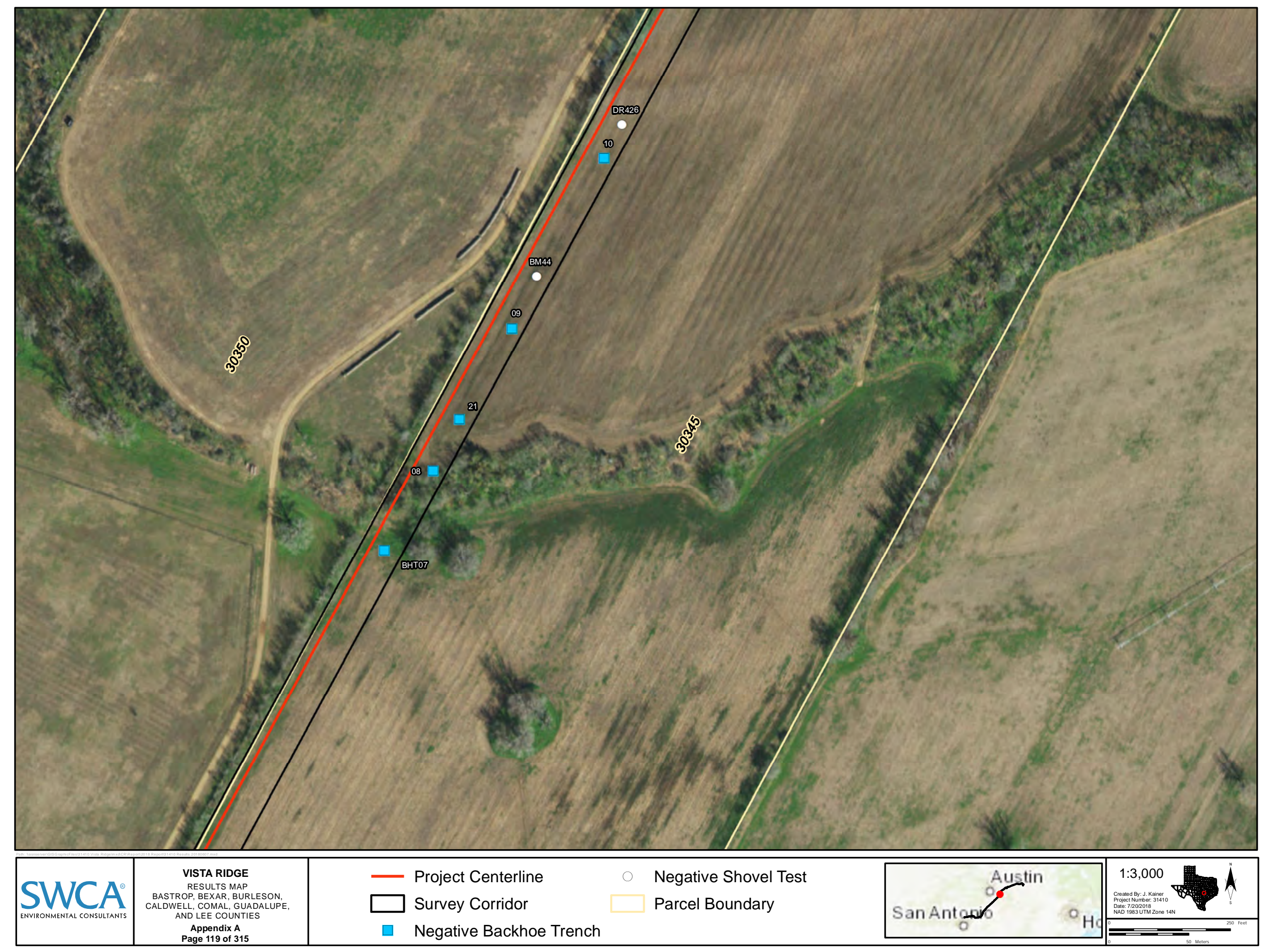




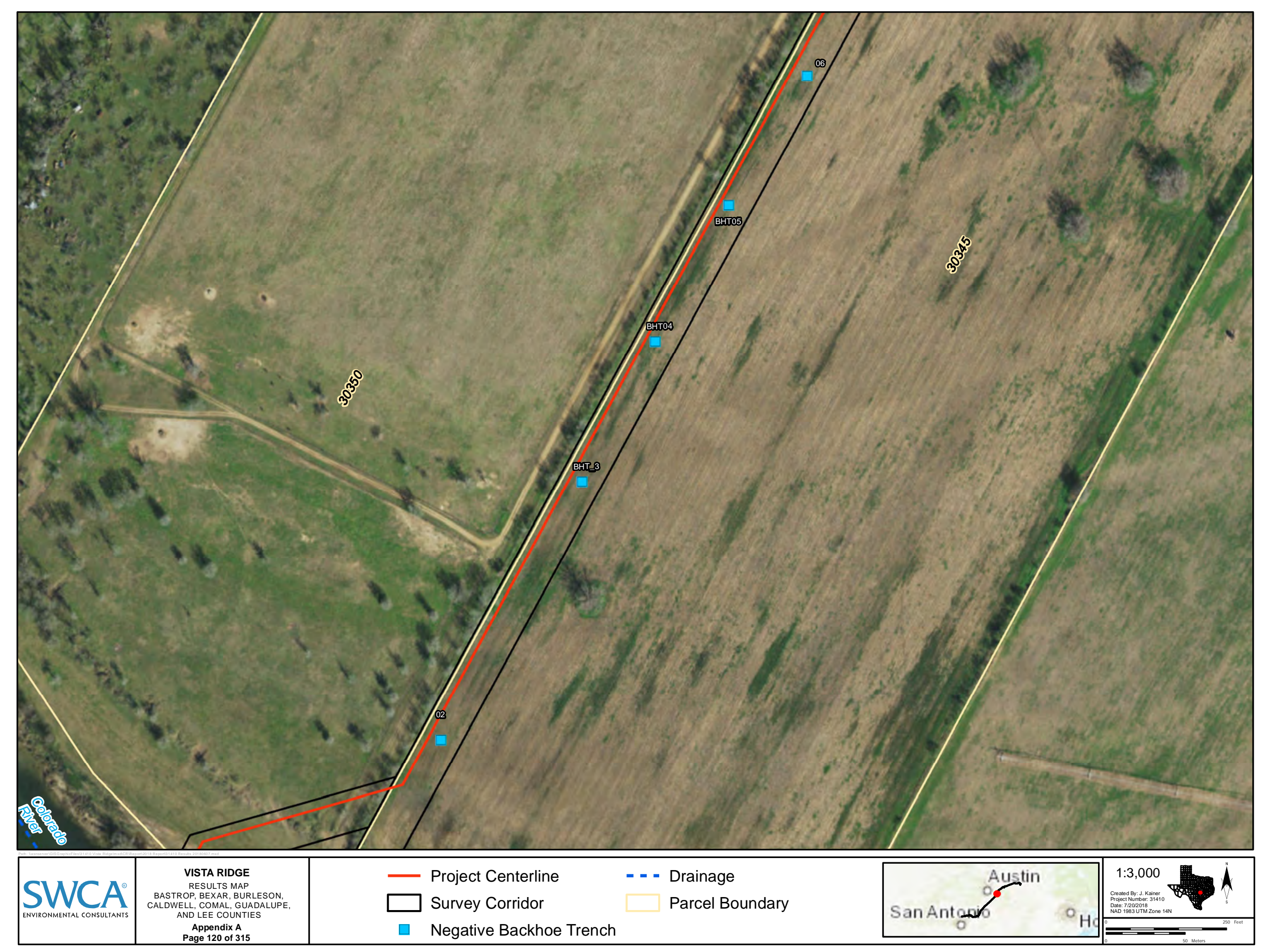




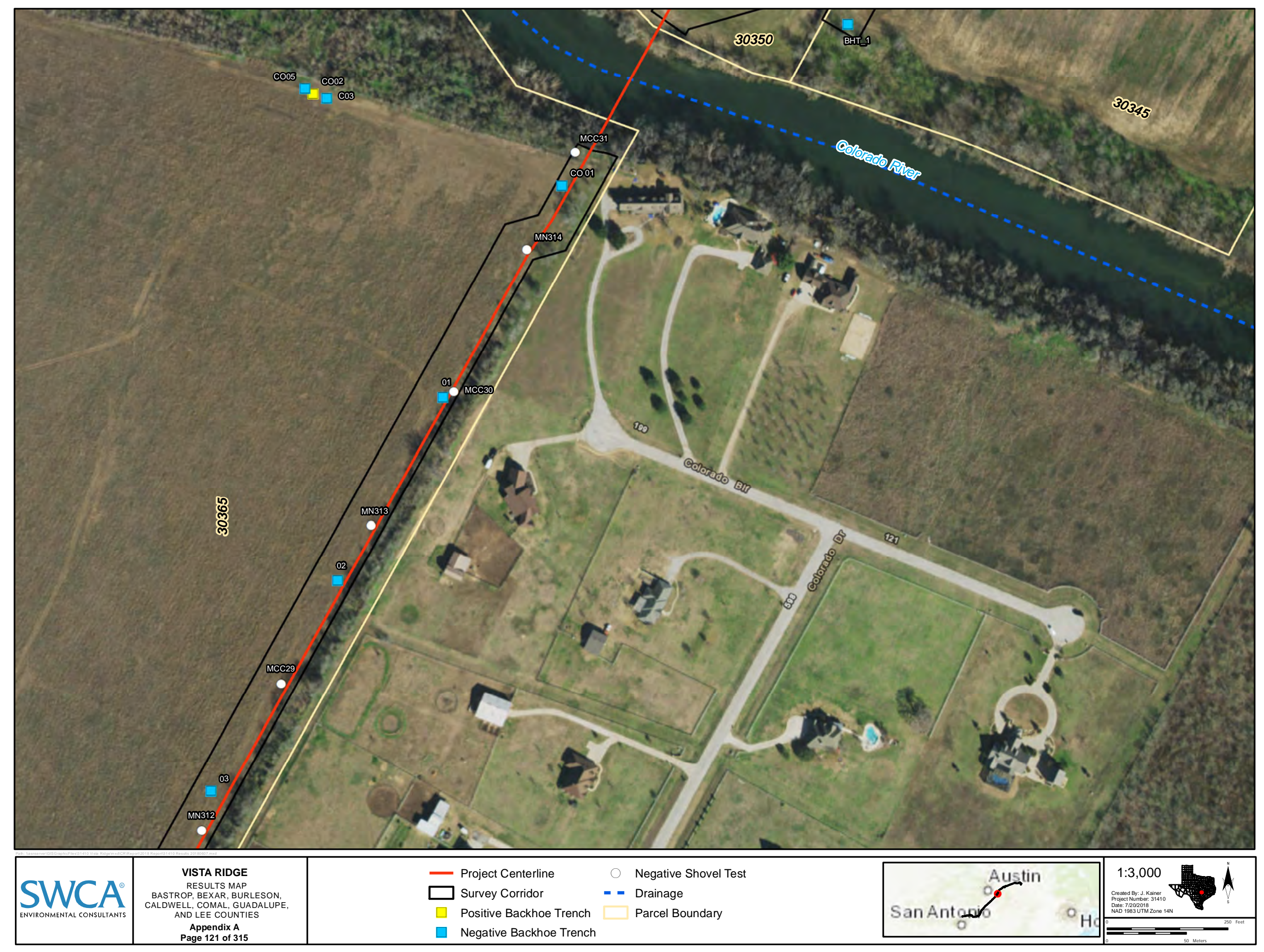




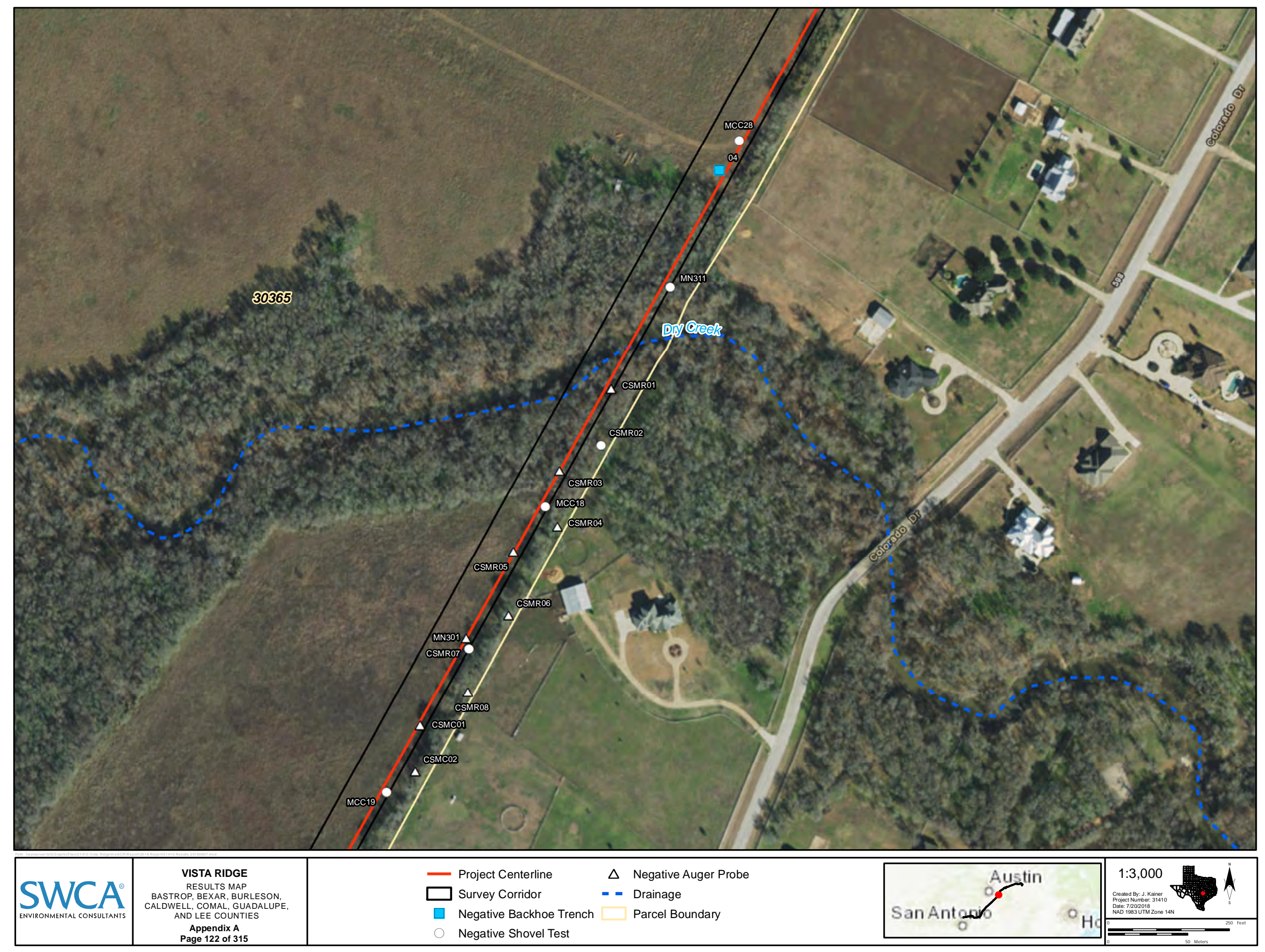




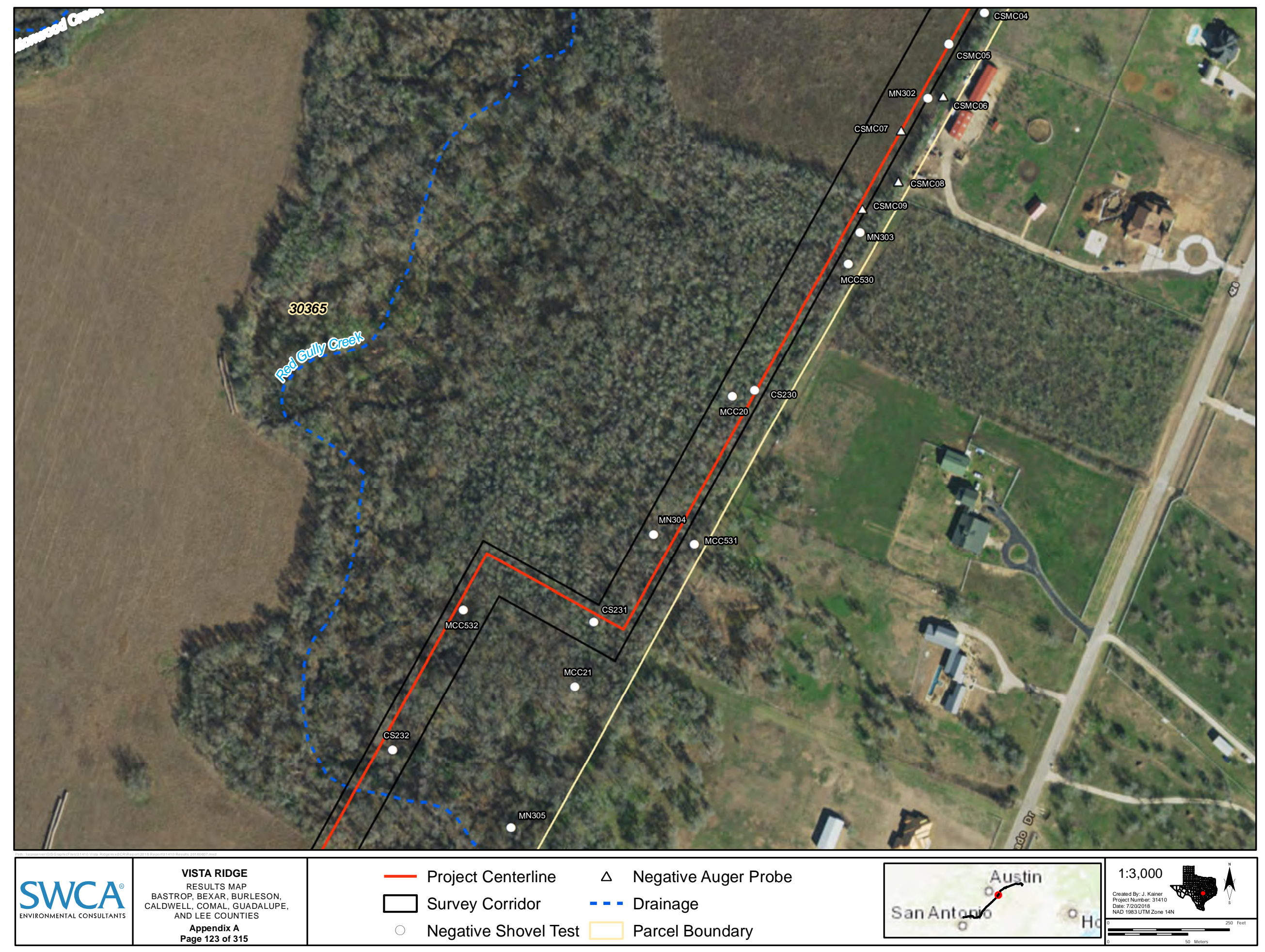




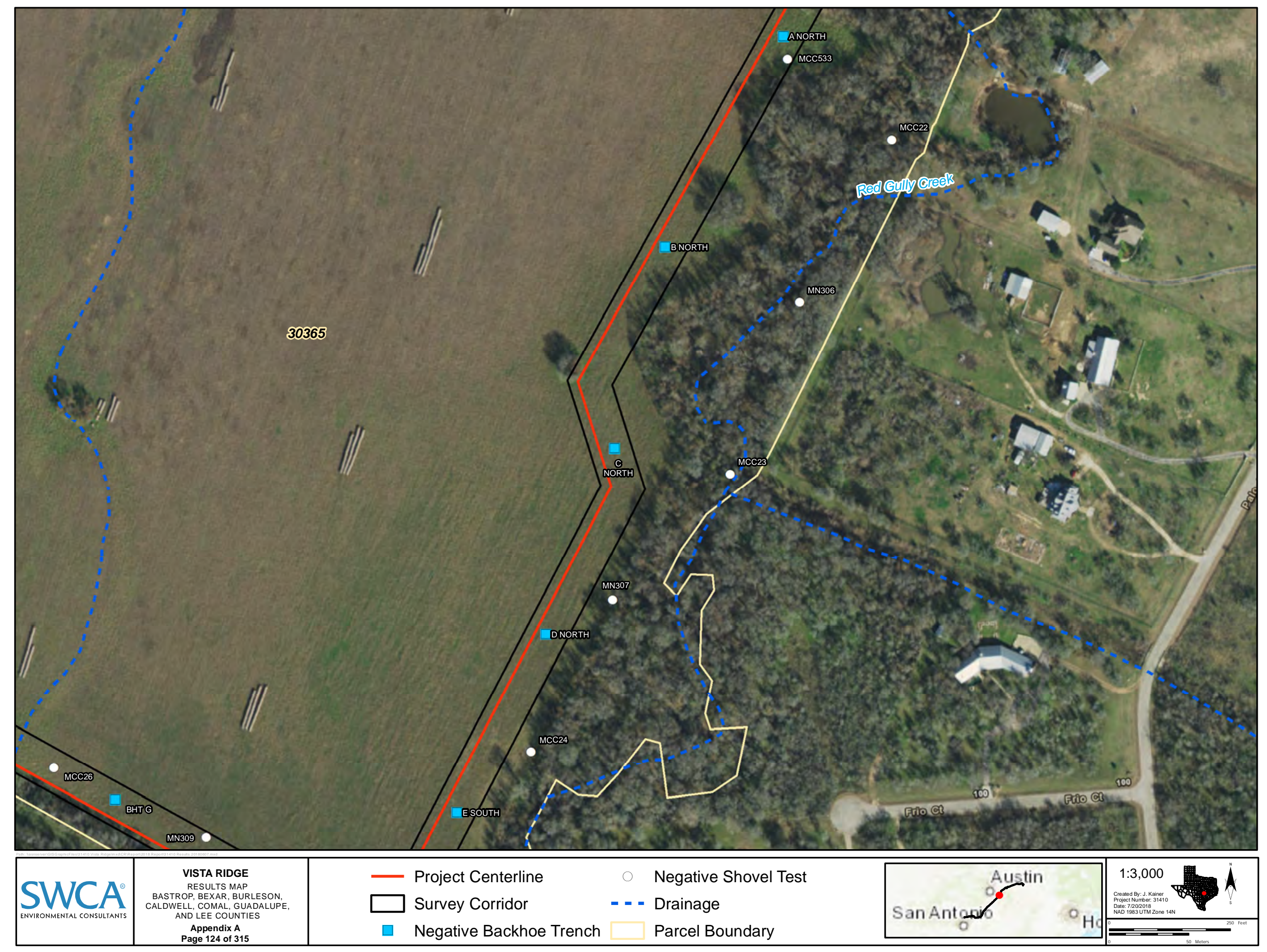




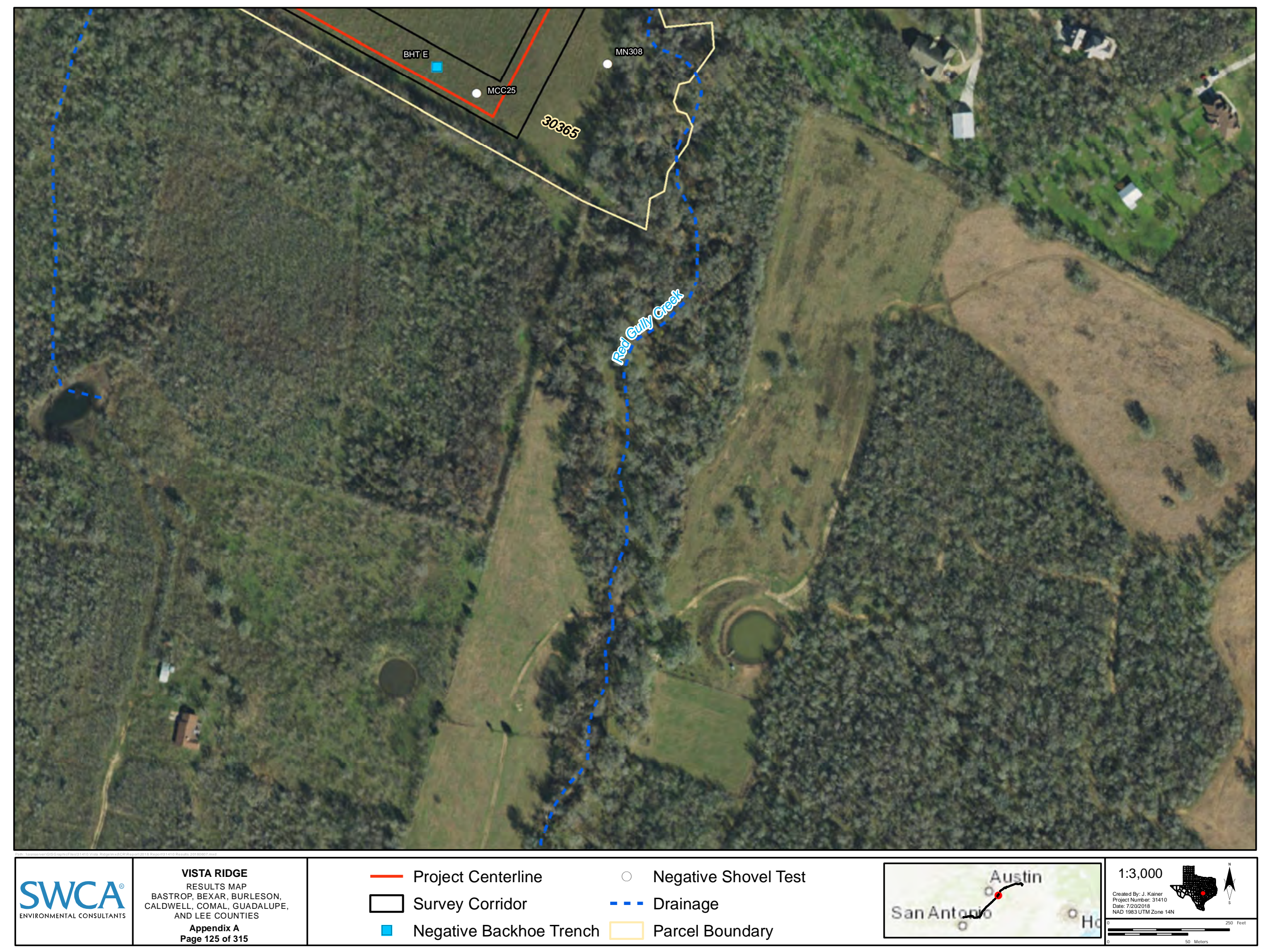




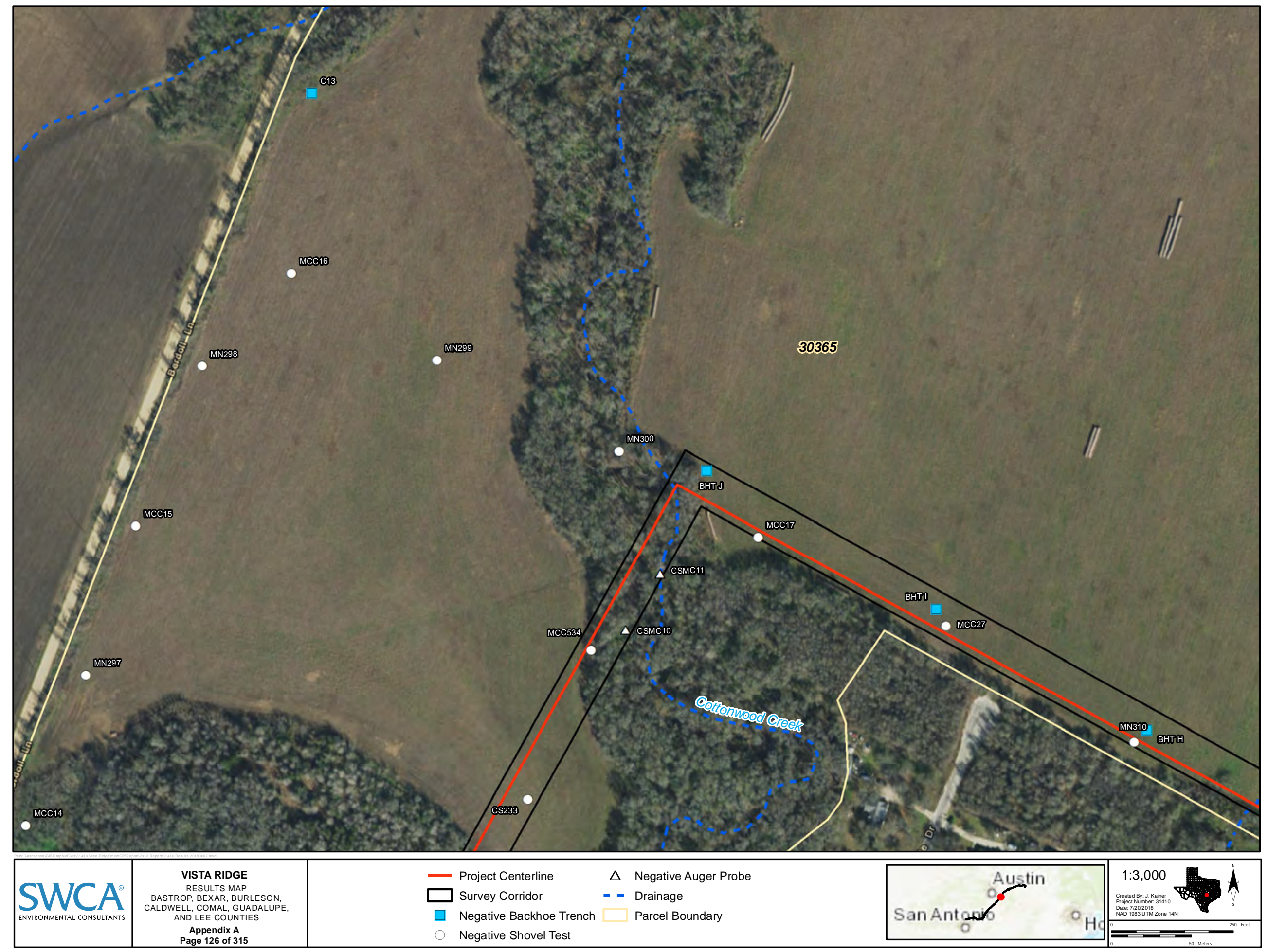




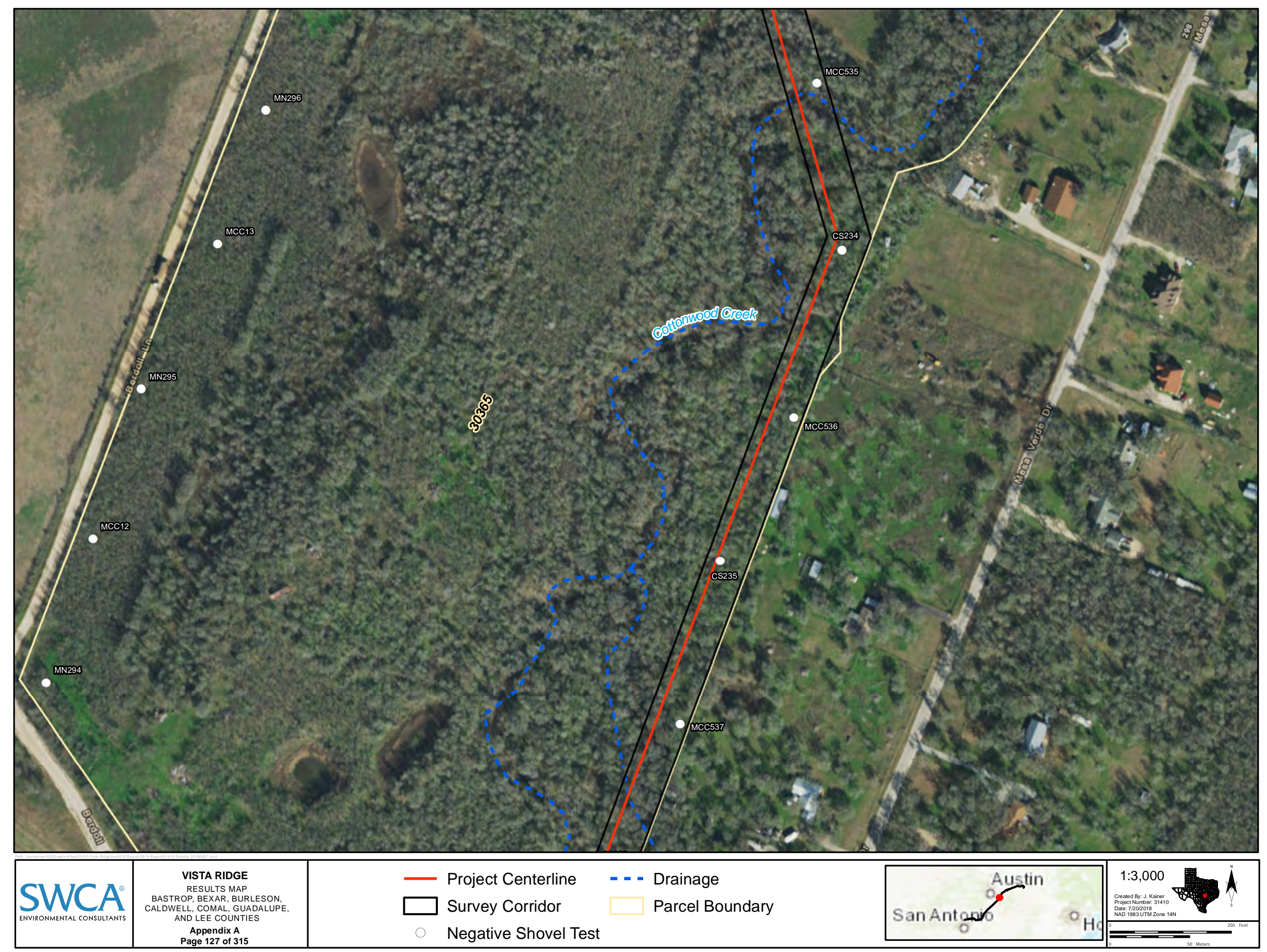




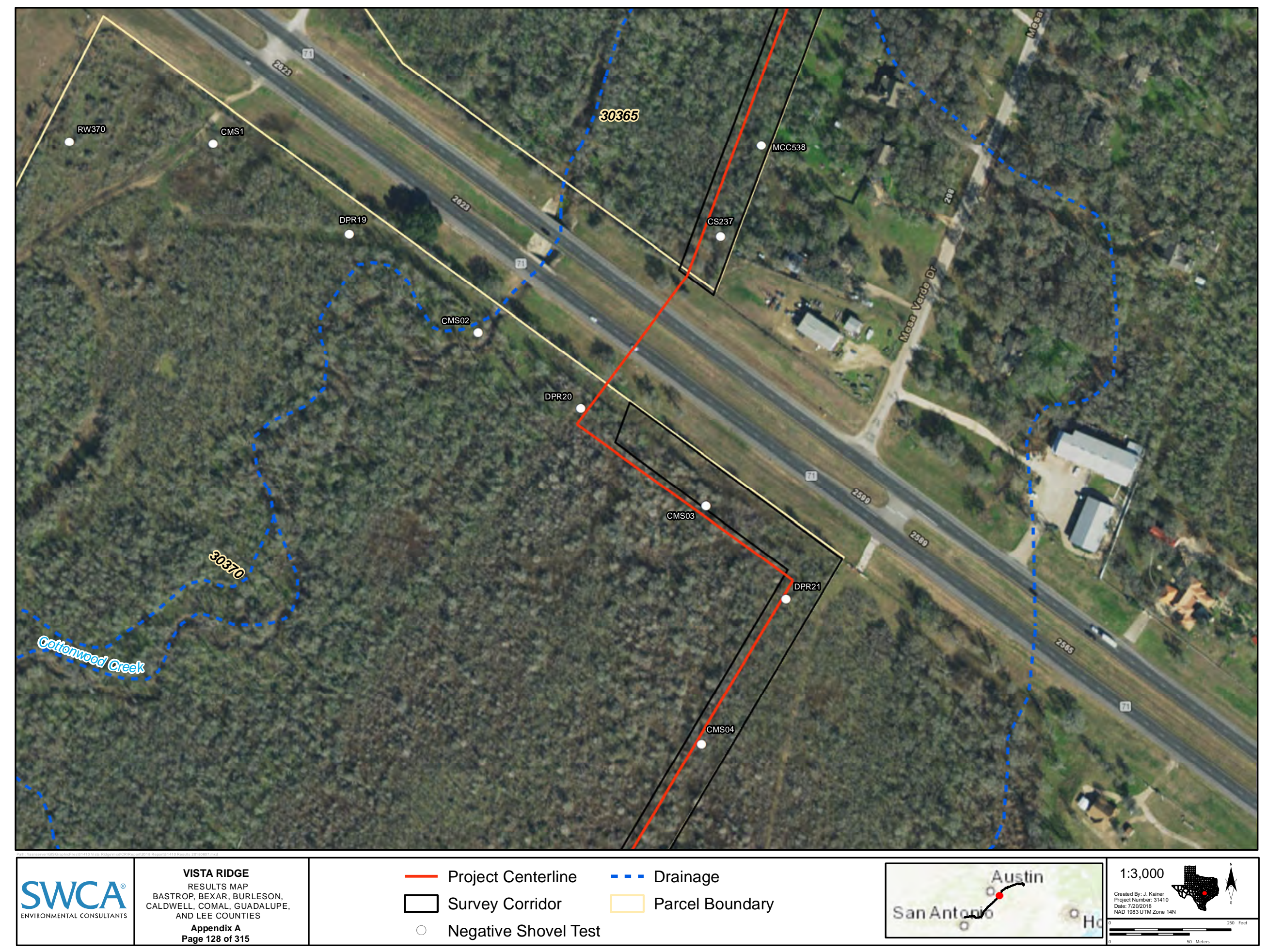




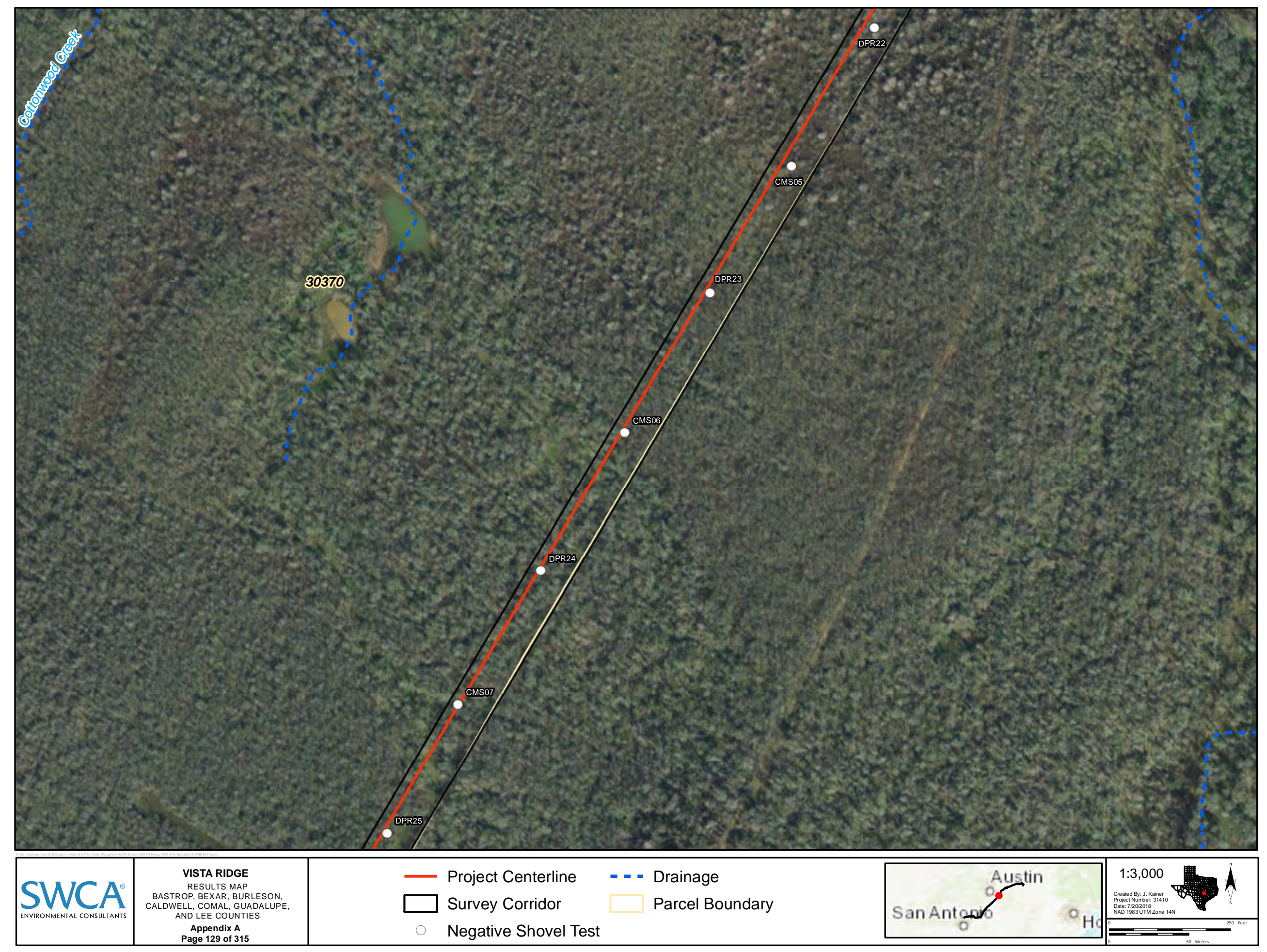




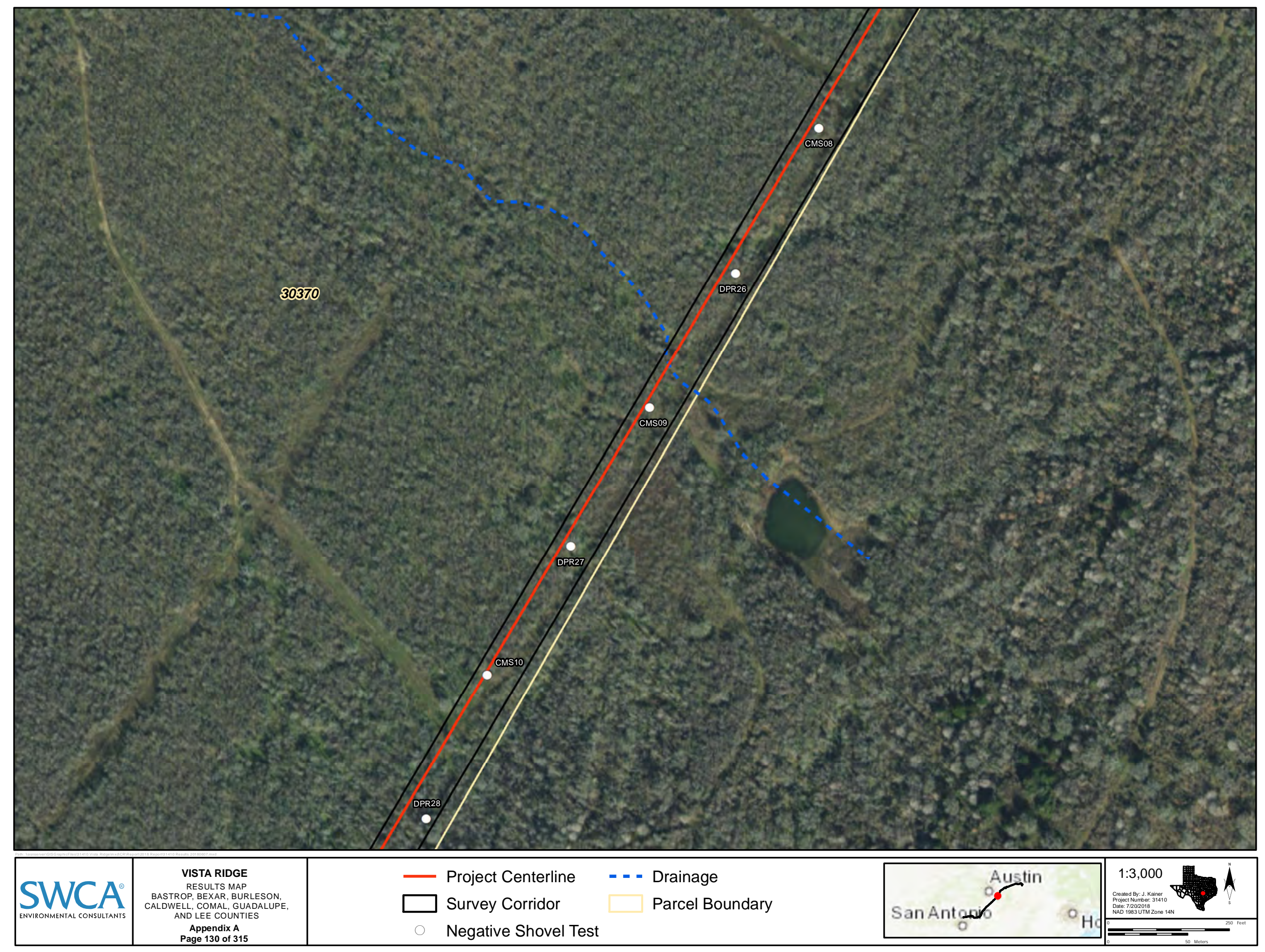




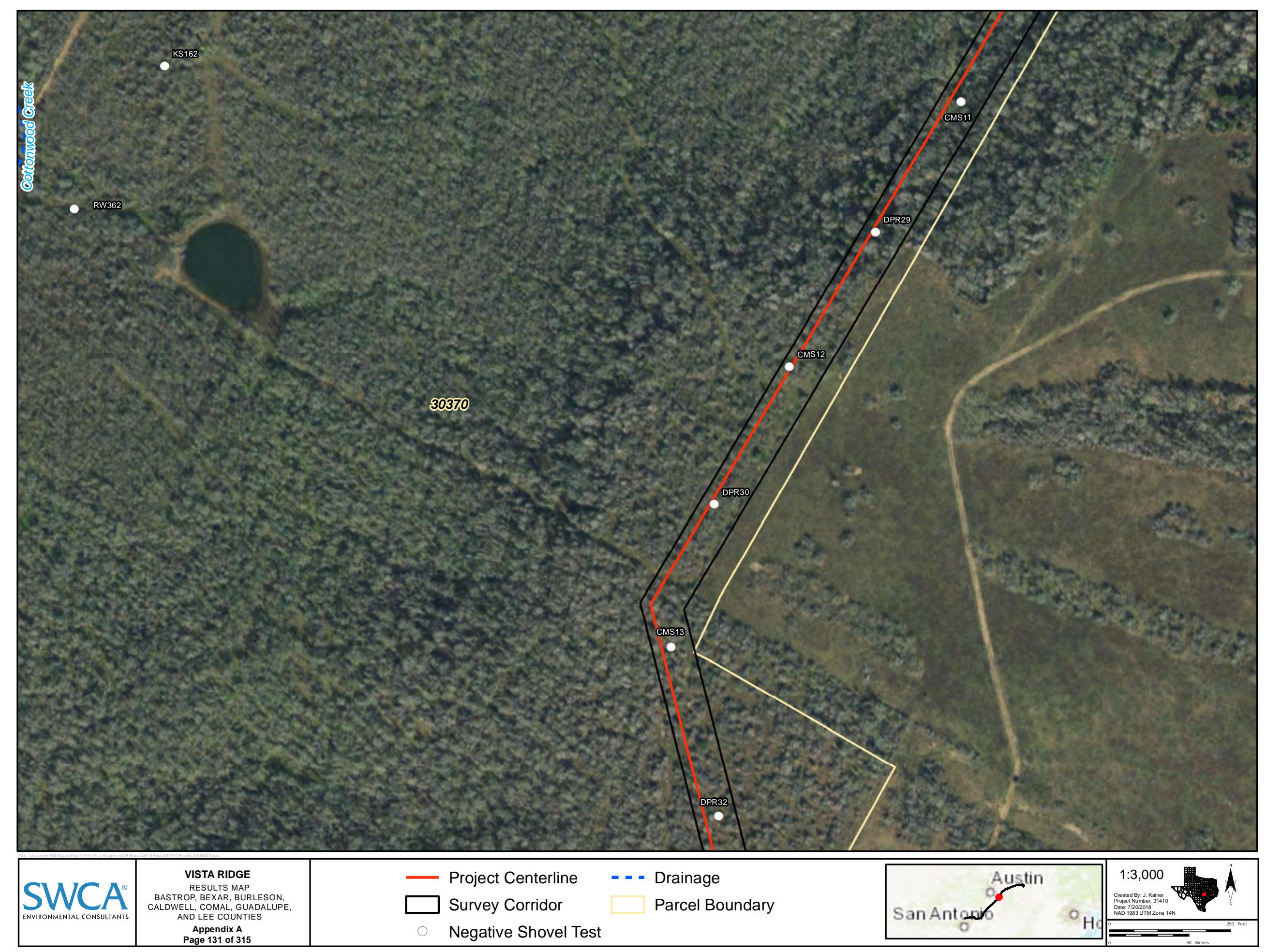




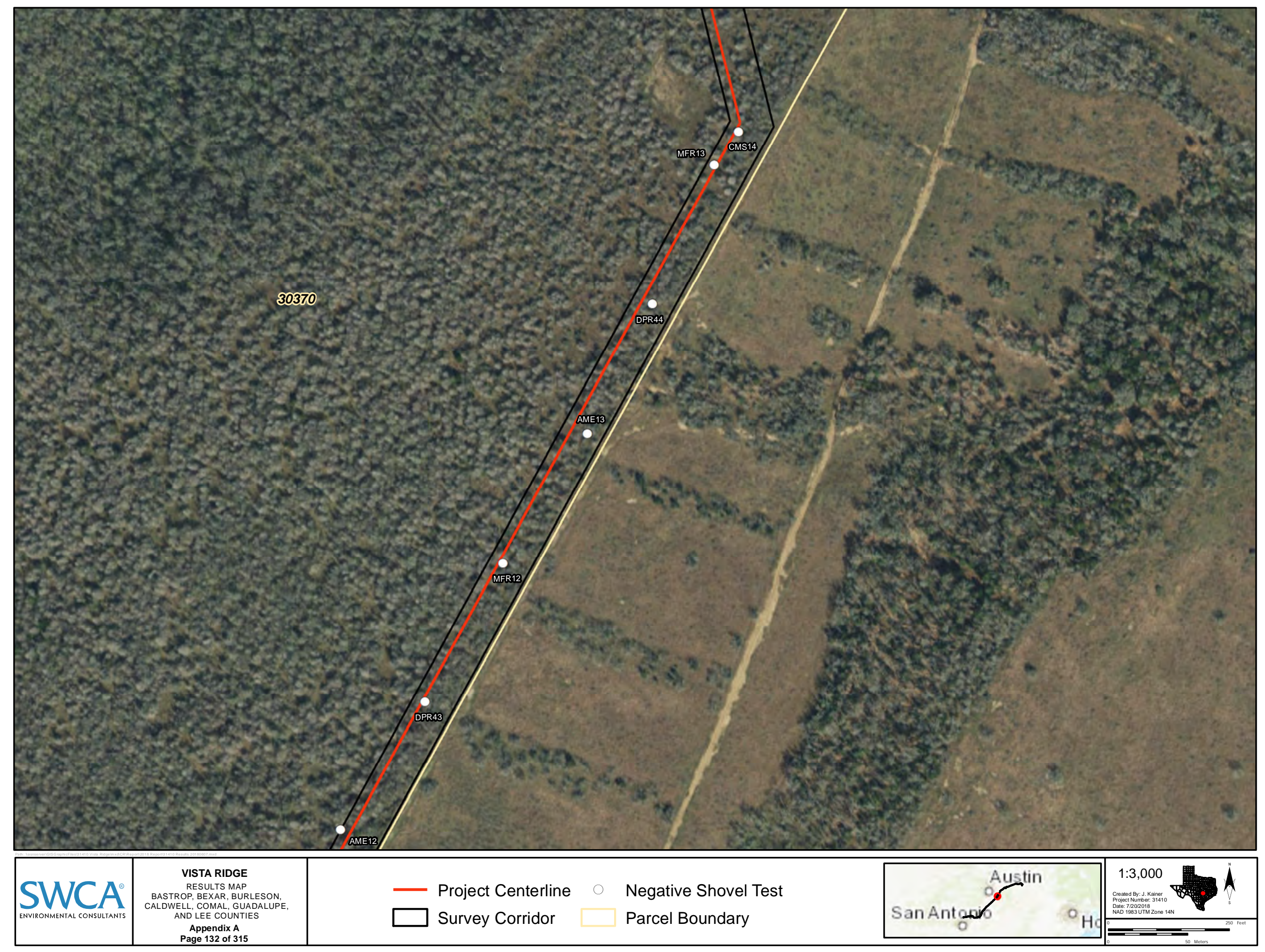




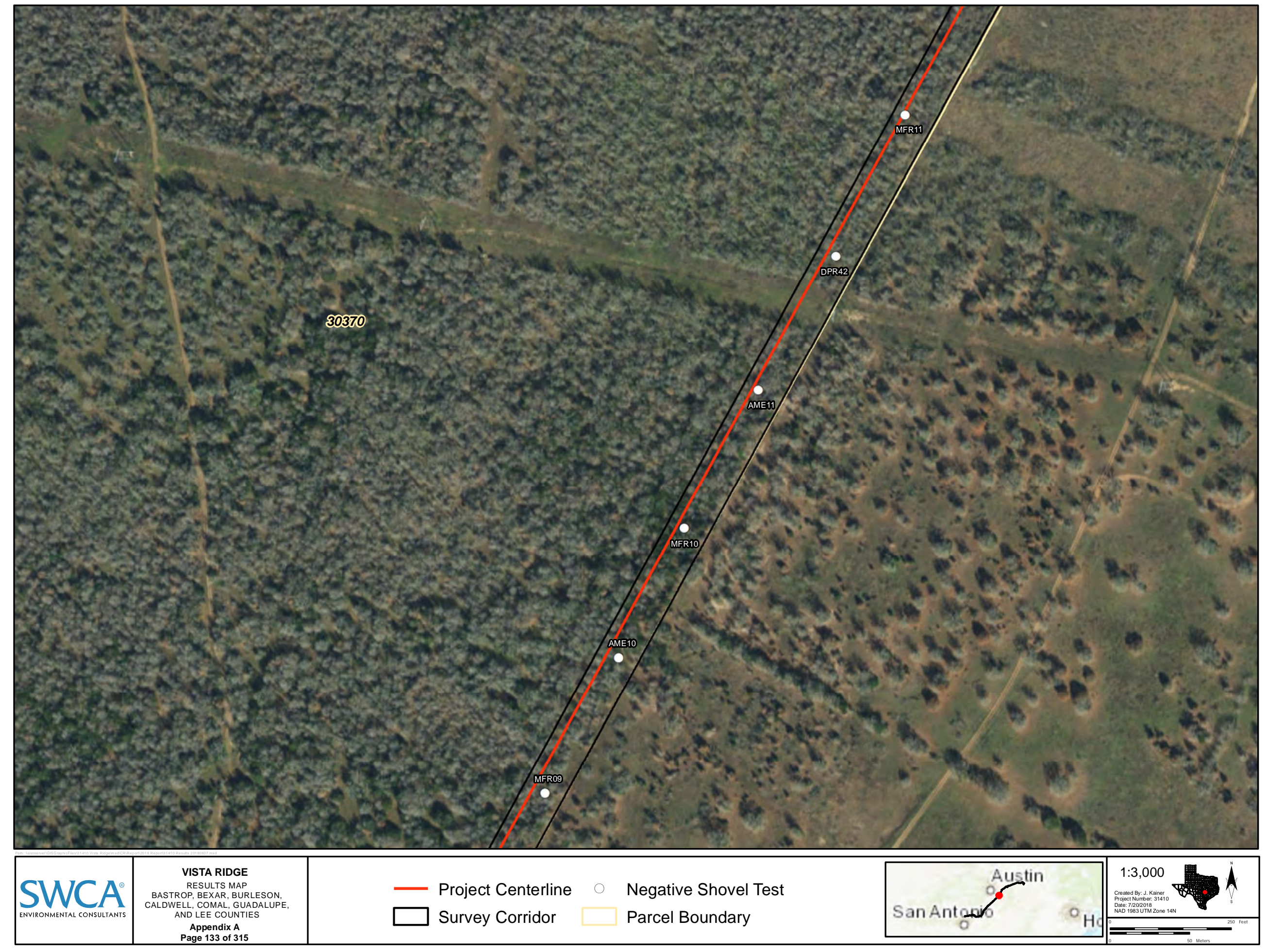




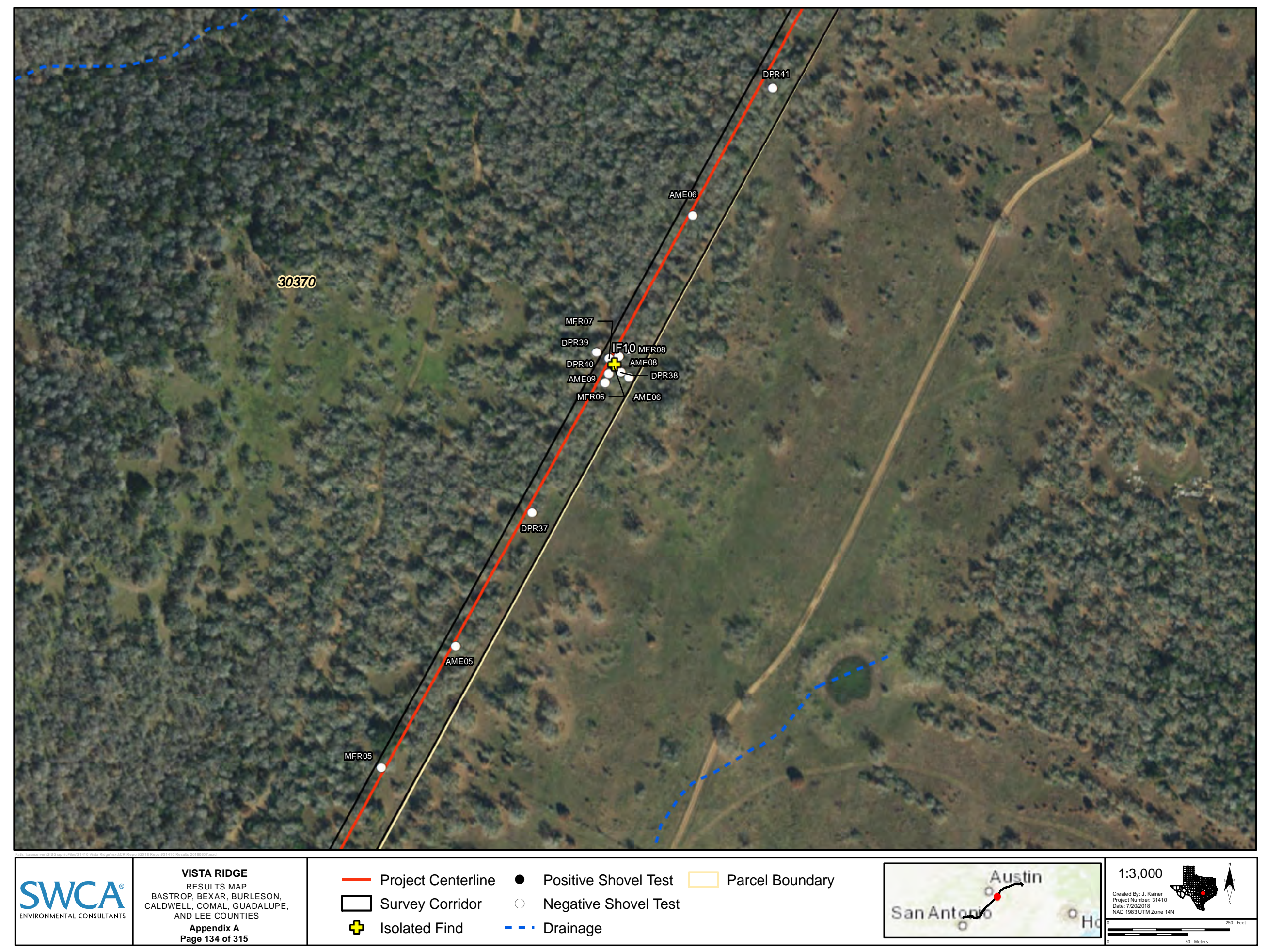




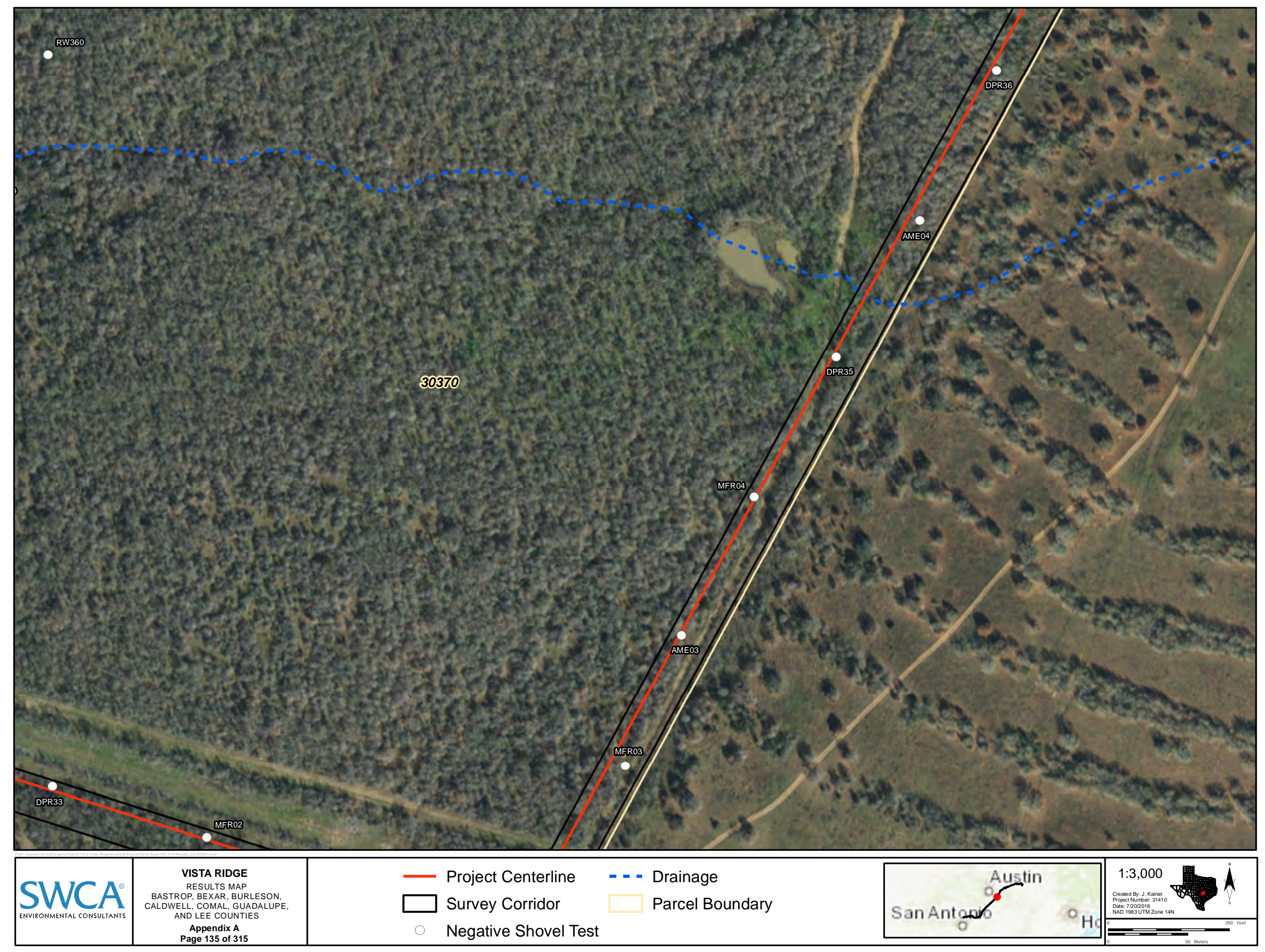




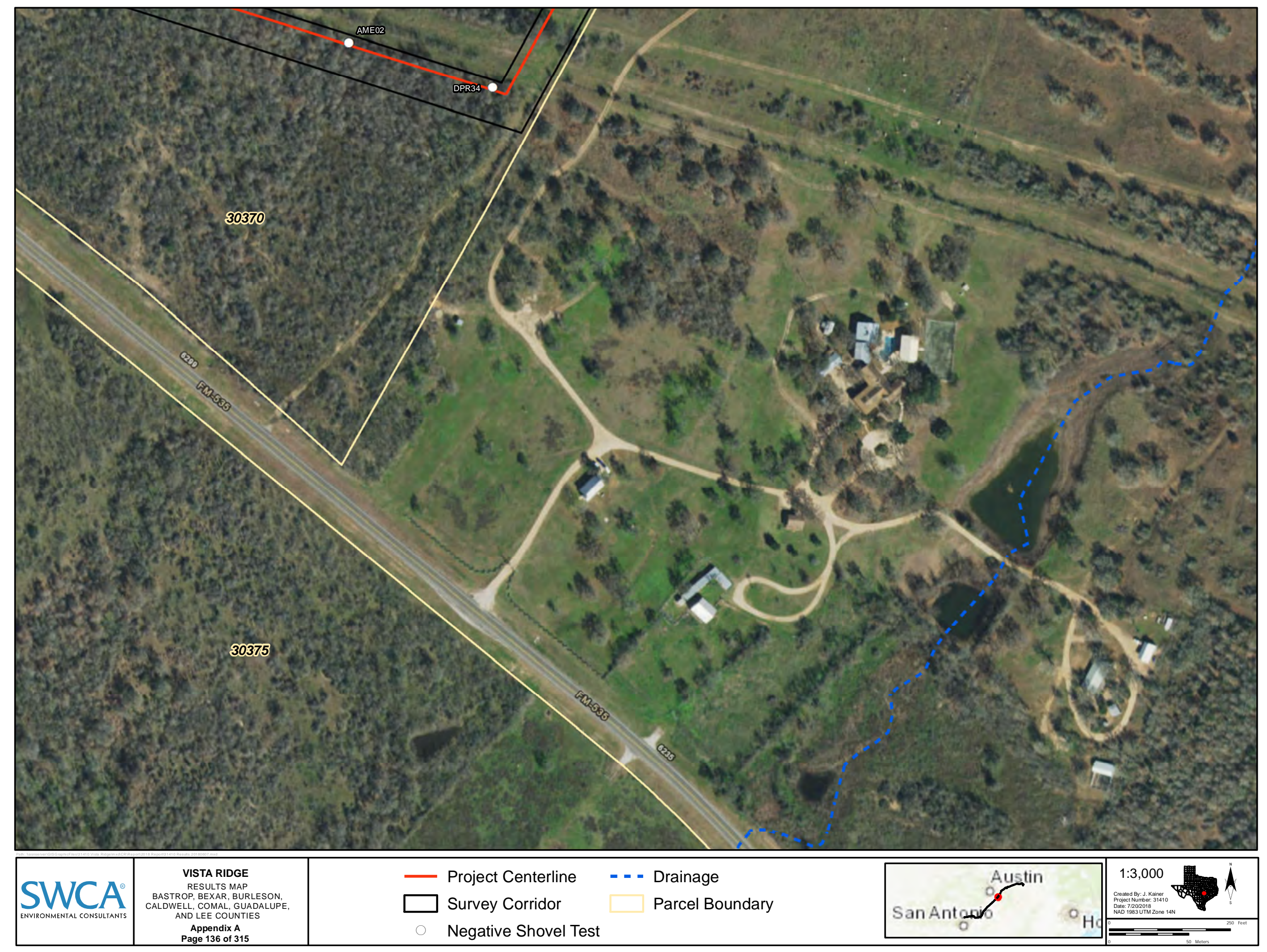




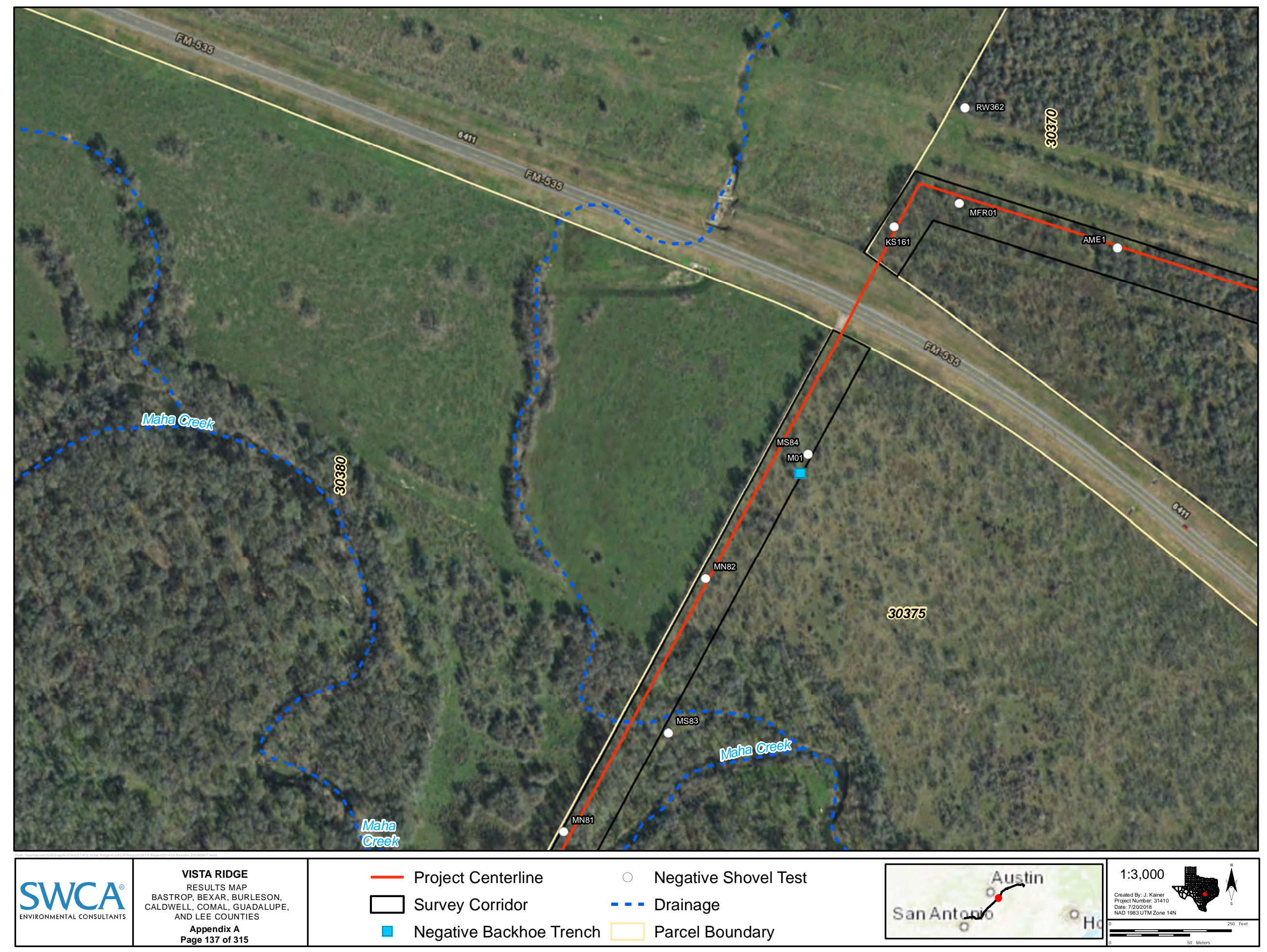




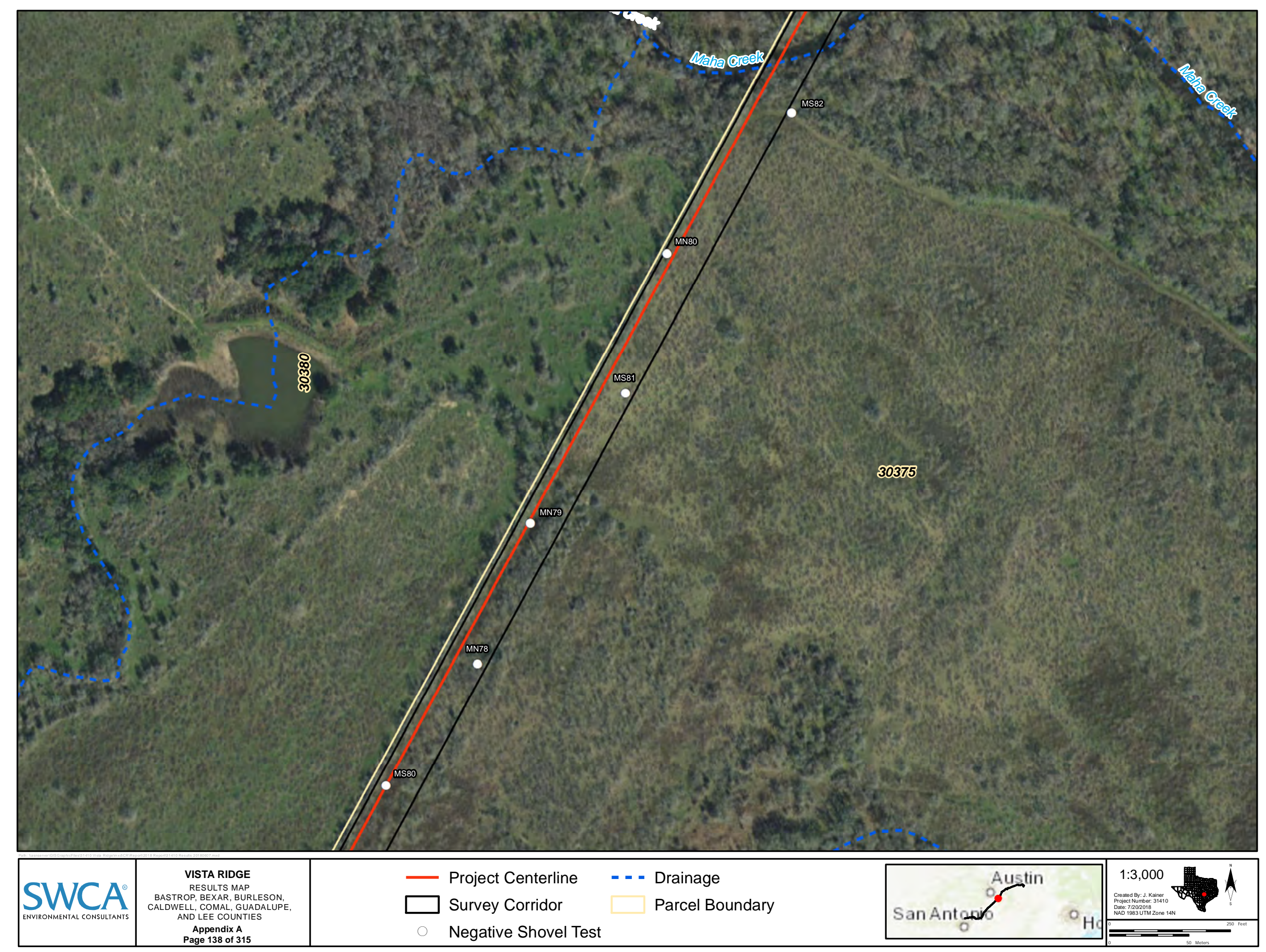




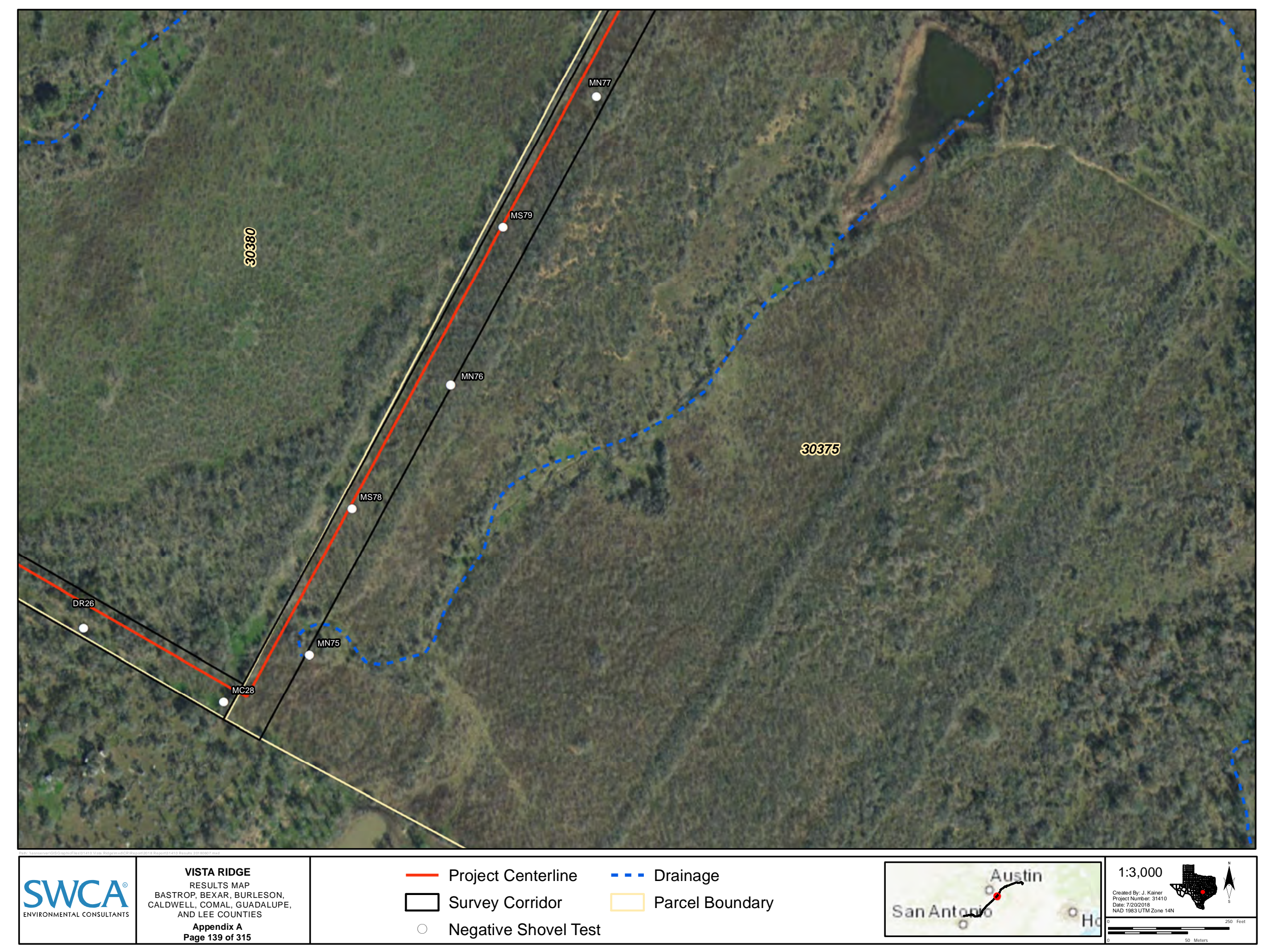




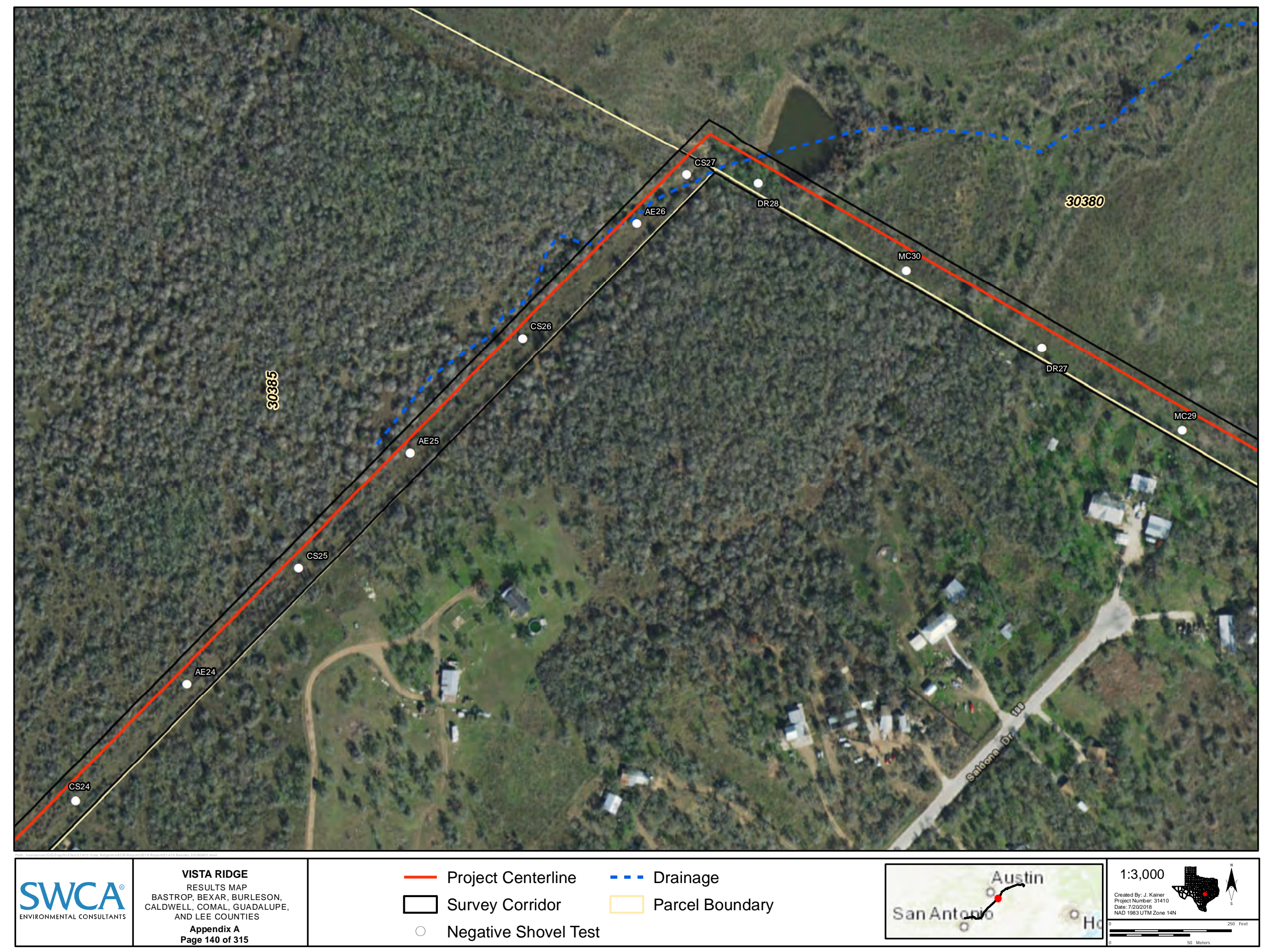




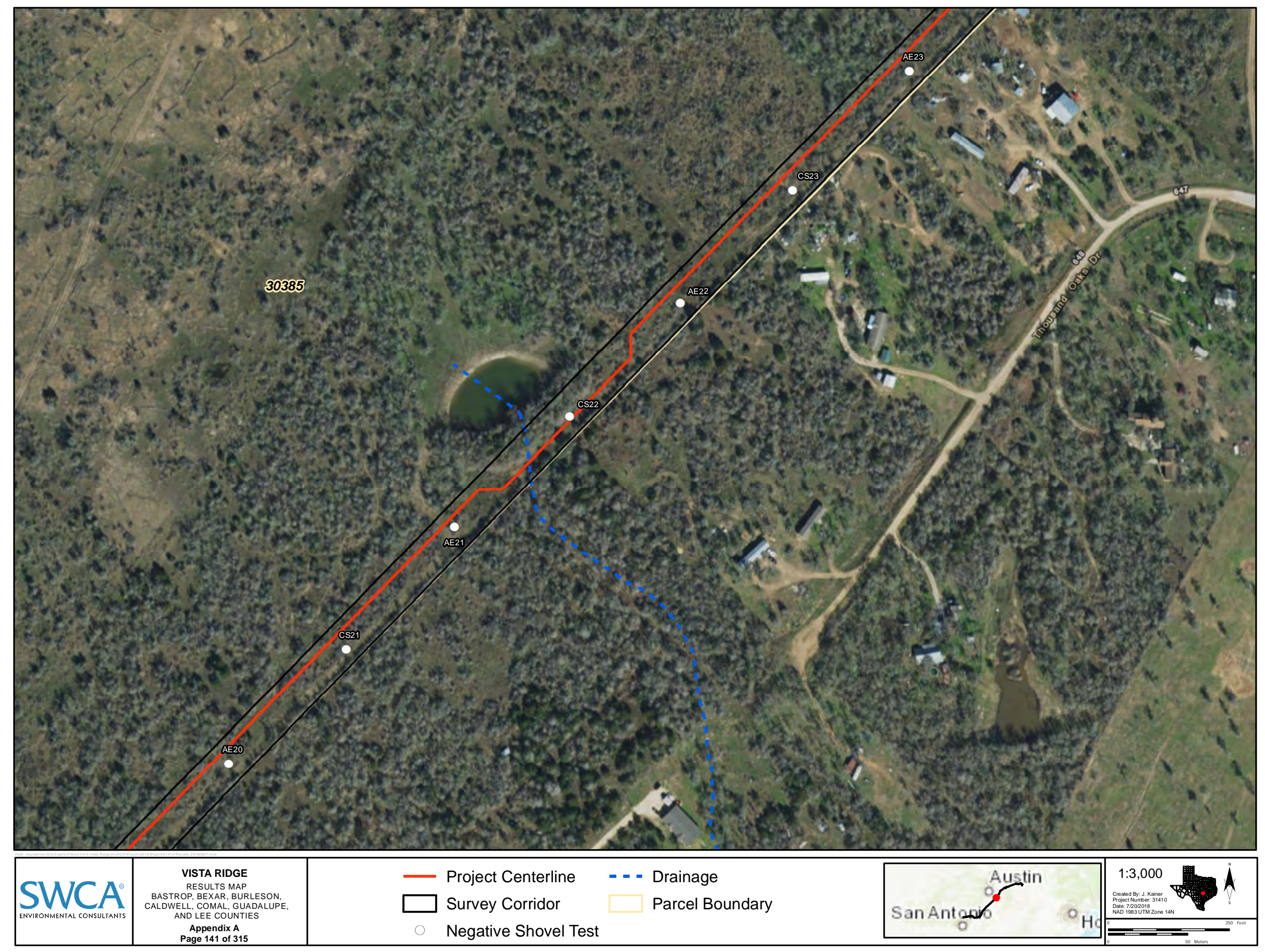




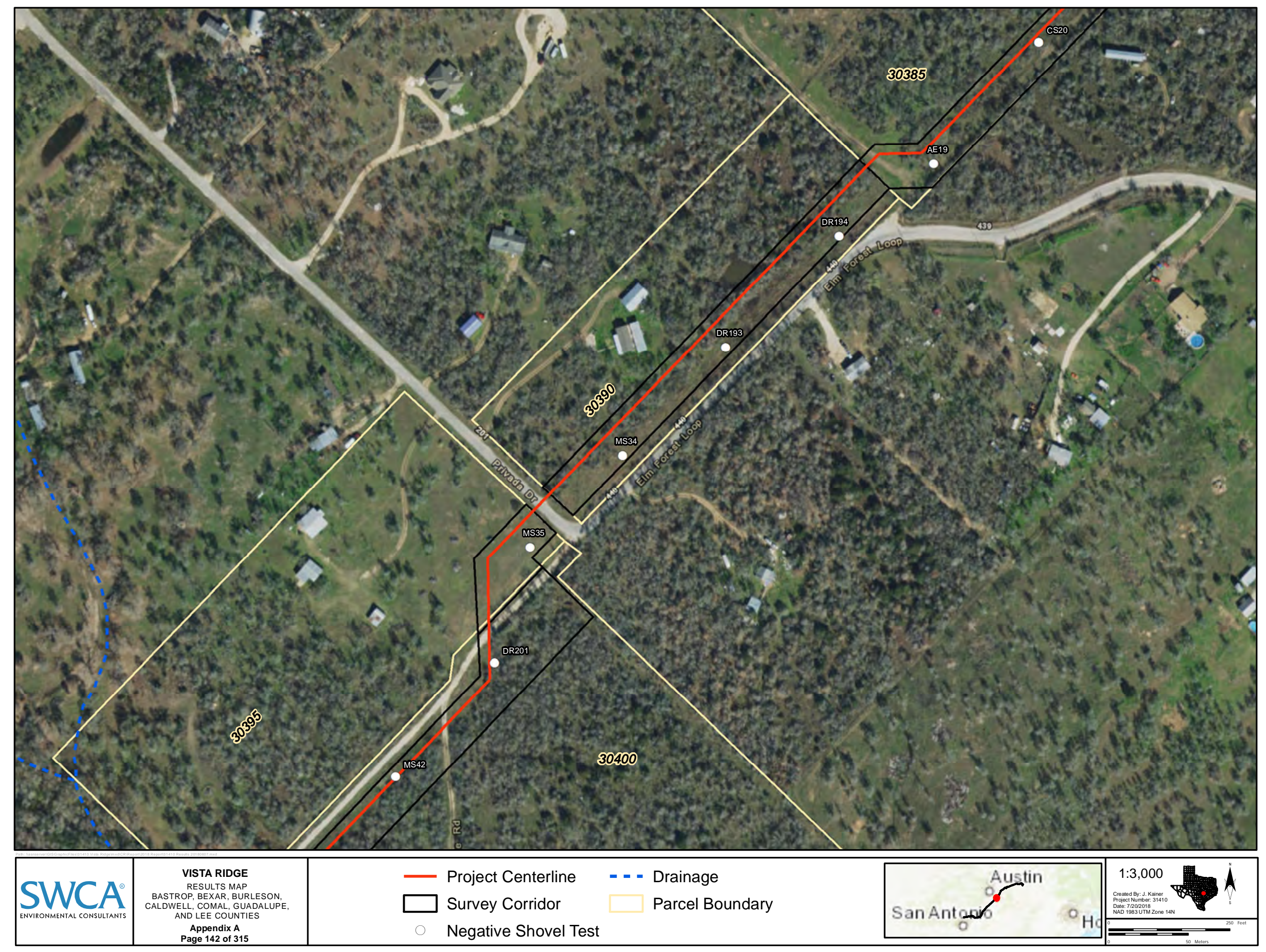




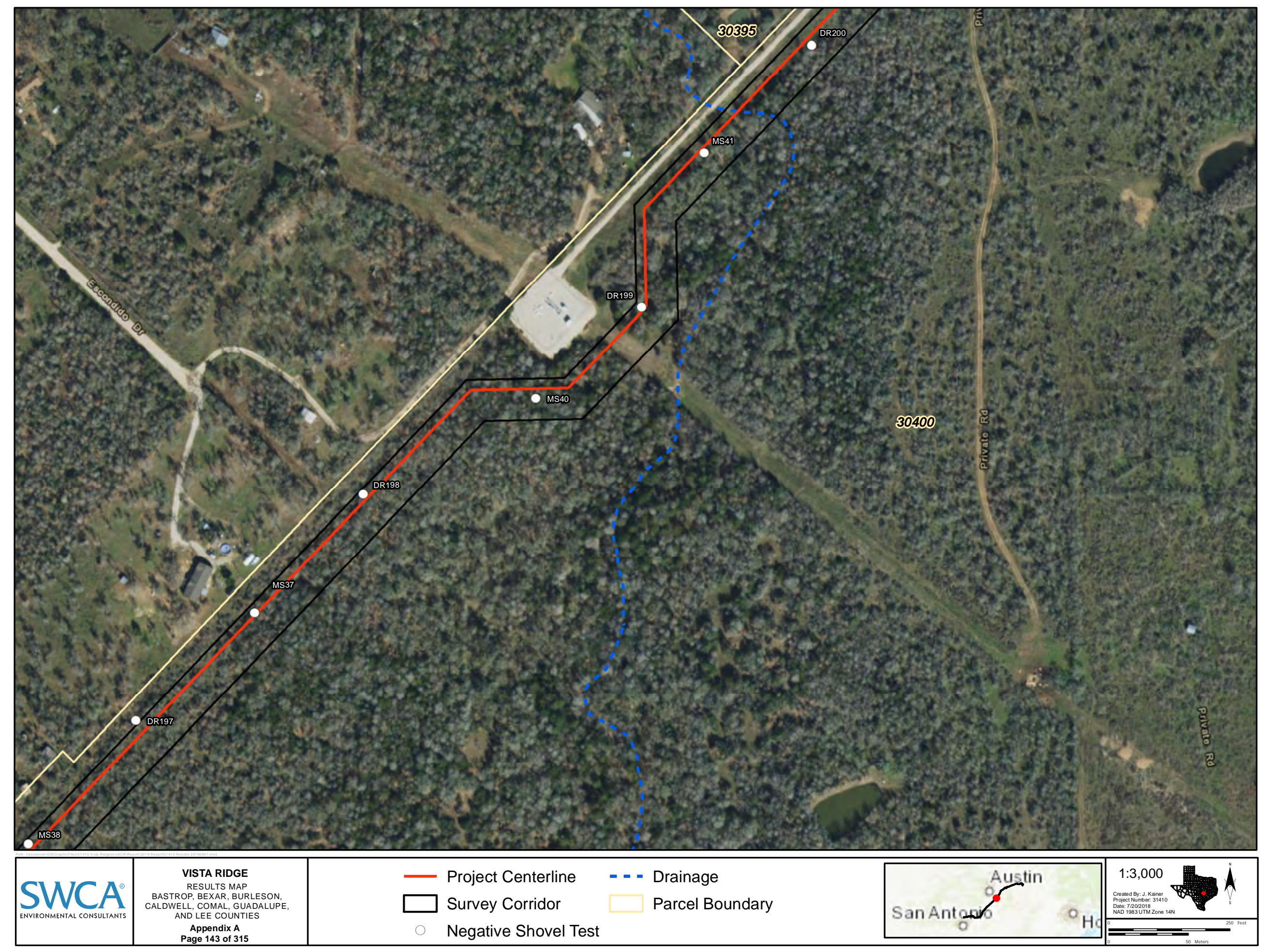




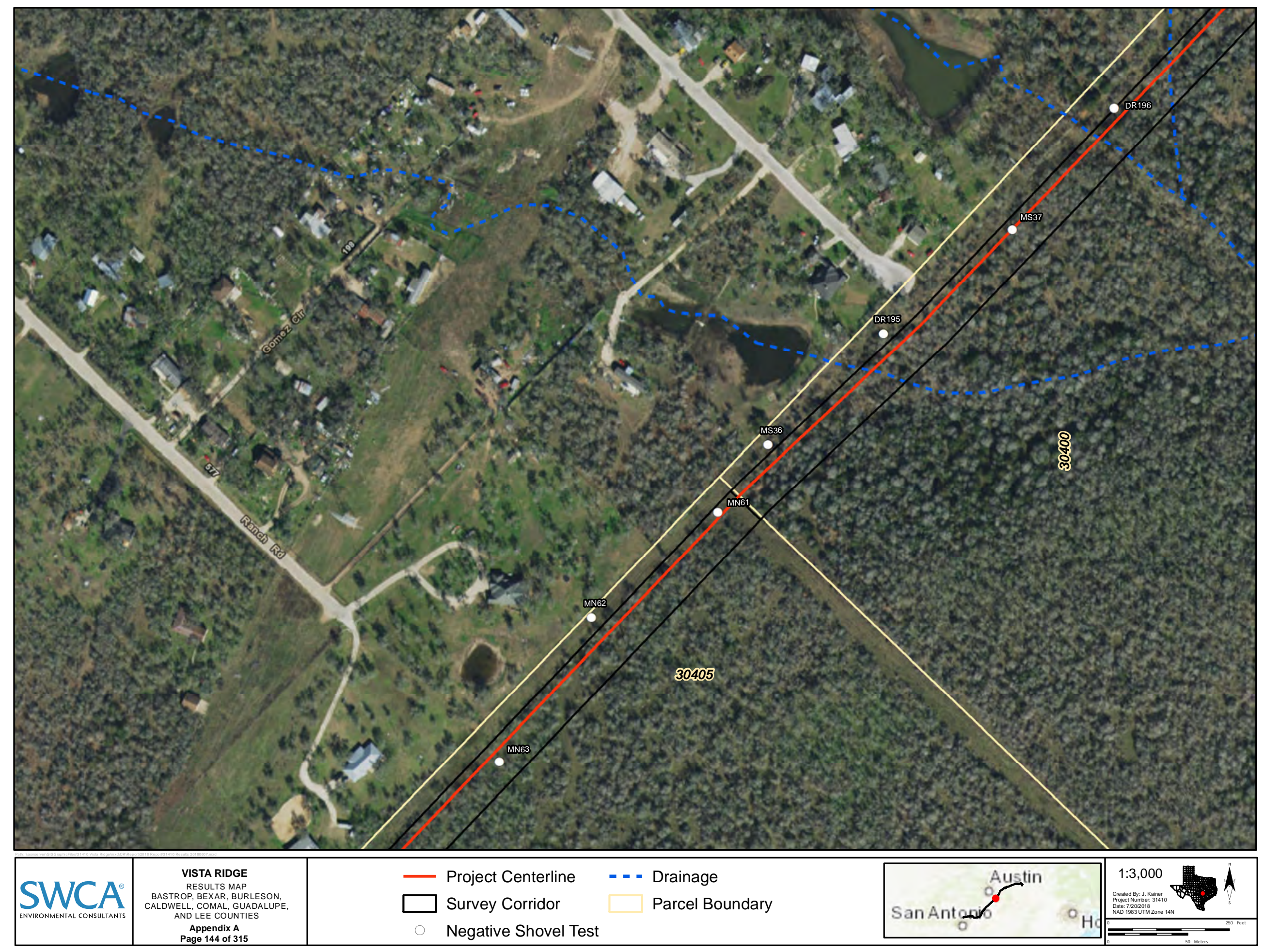


Restricted Information

Not for Public Disclosure 


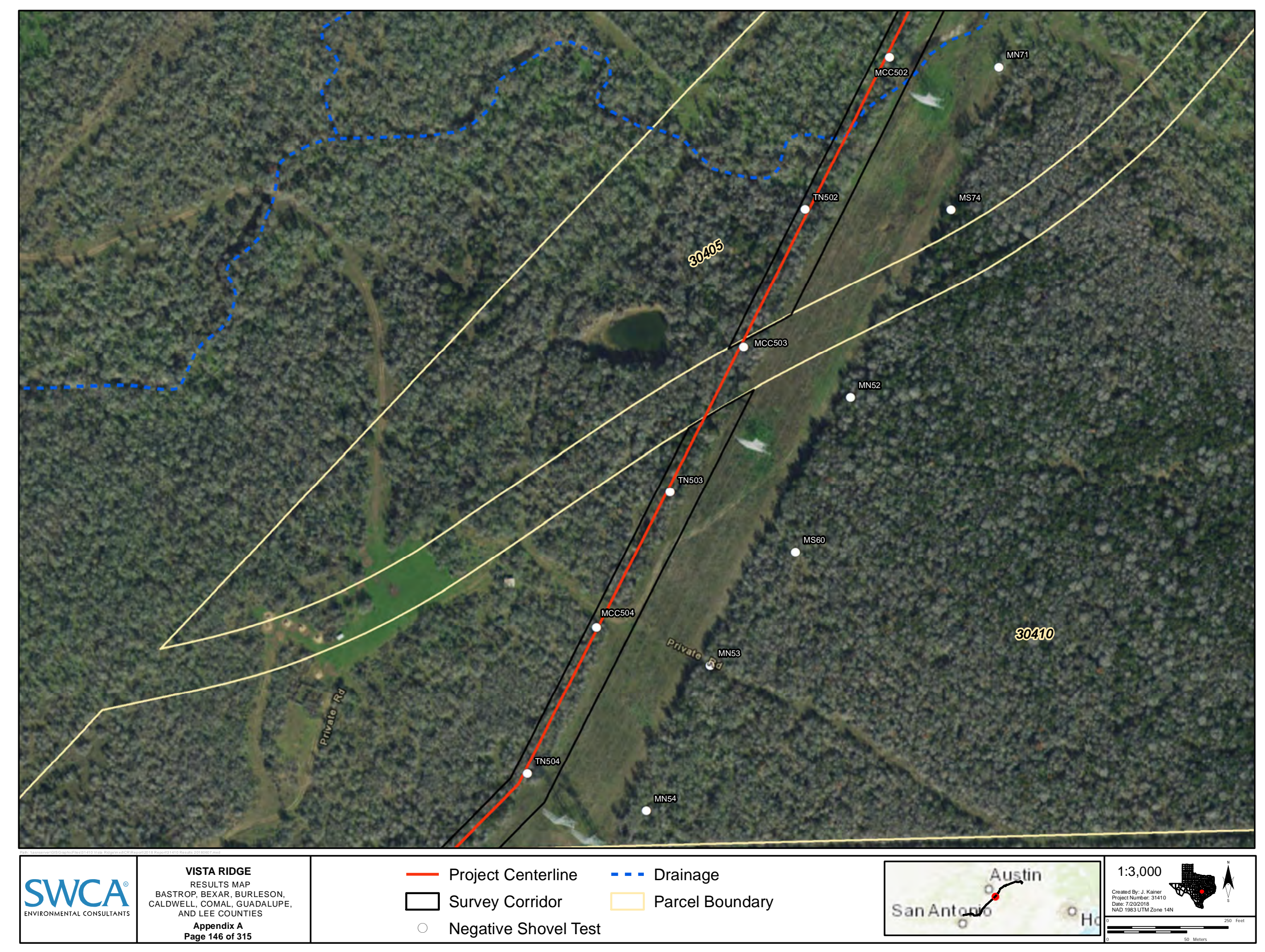




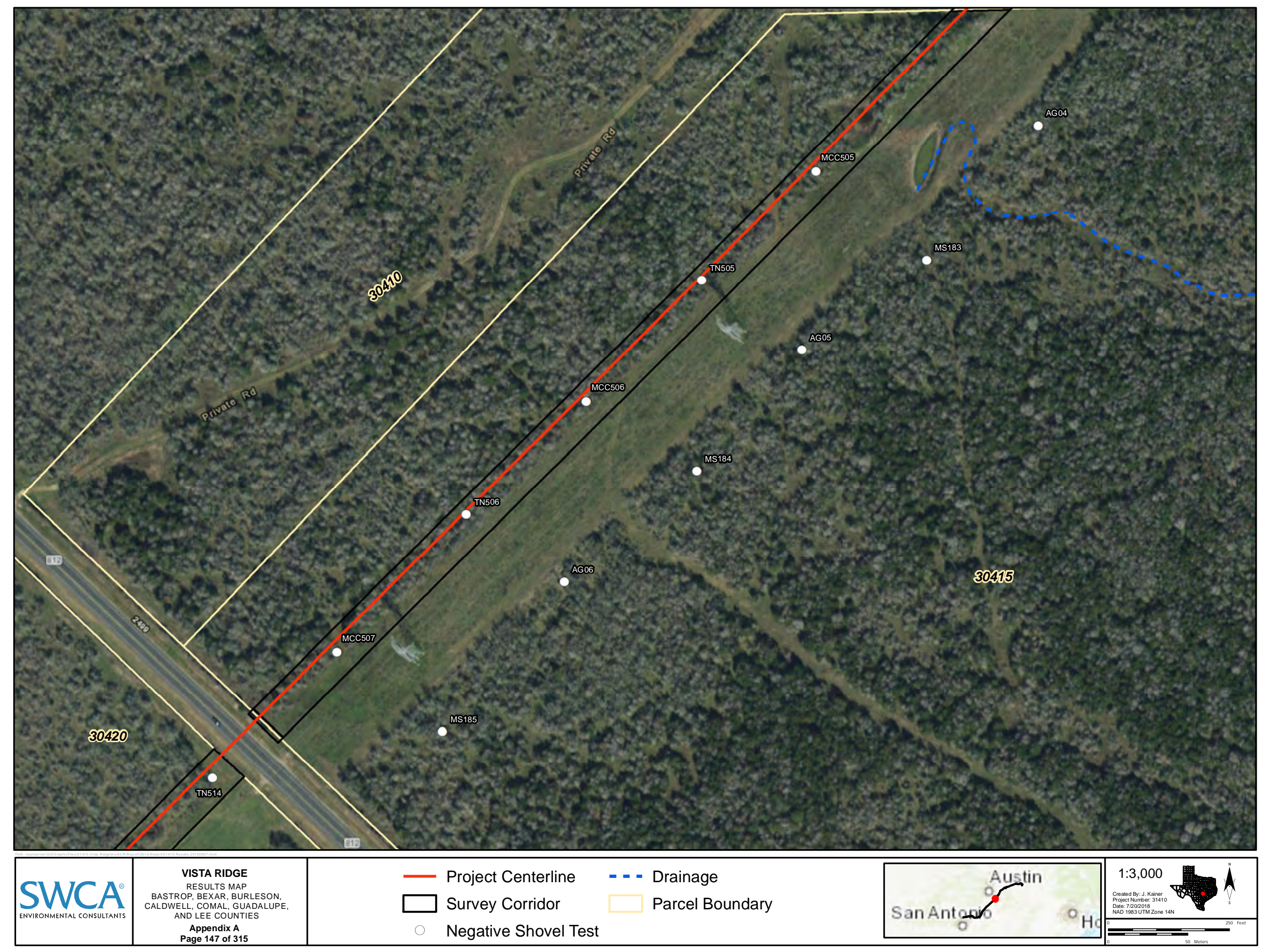




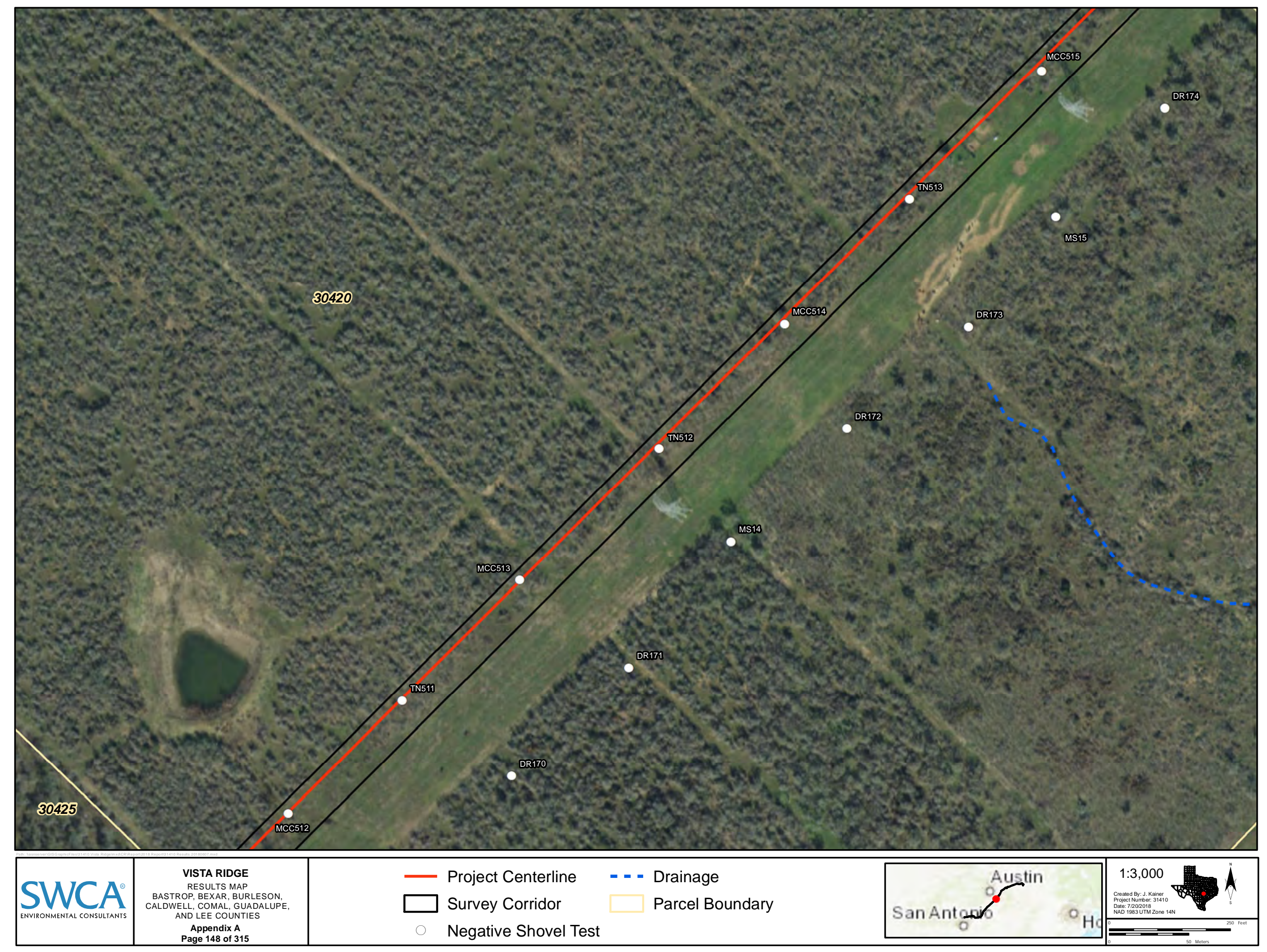


Restricted Information

Not for Public Disclosure 


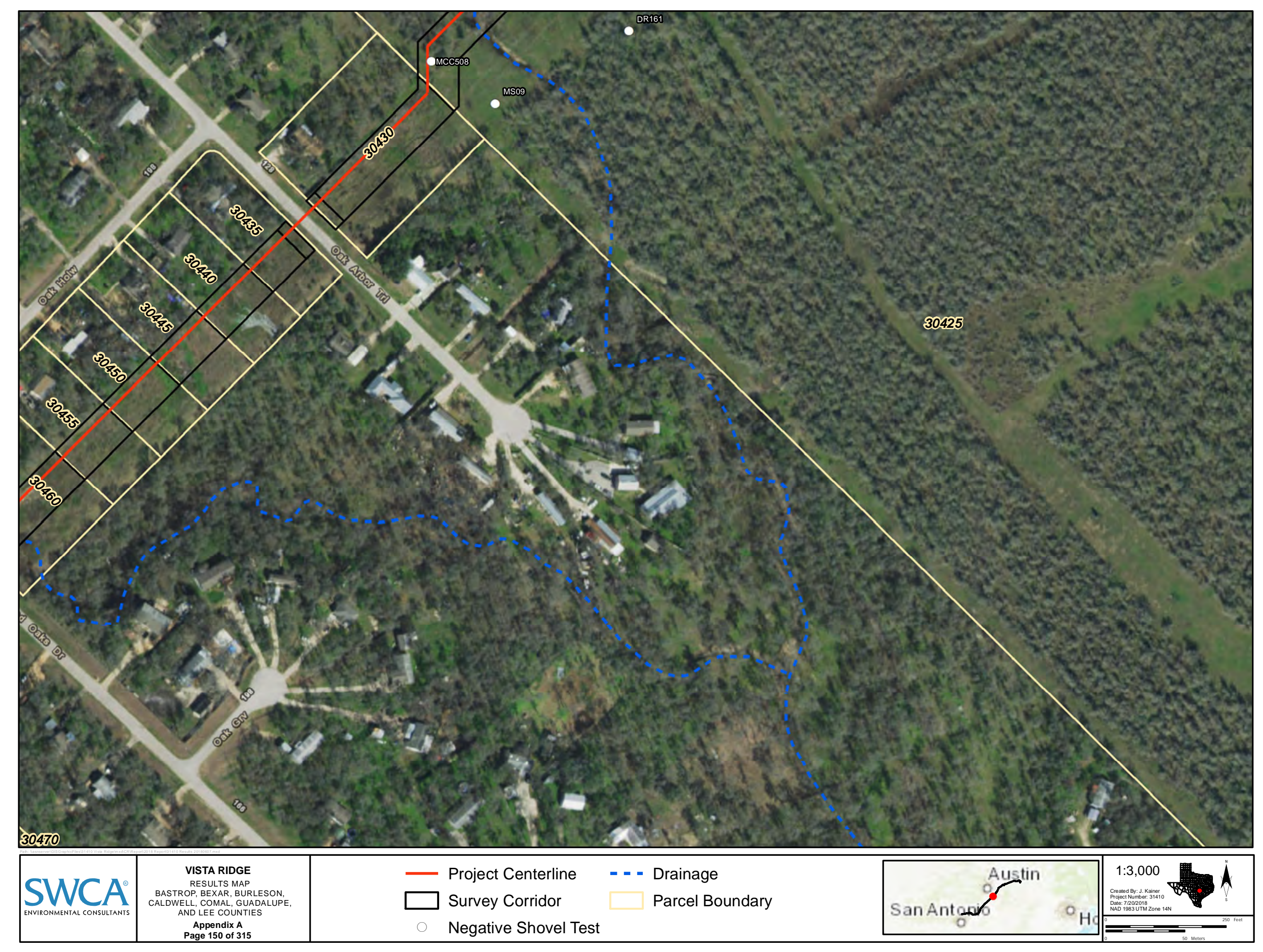




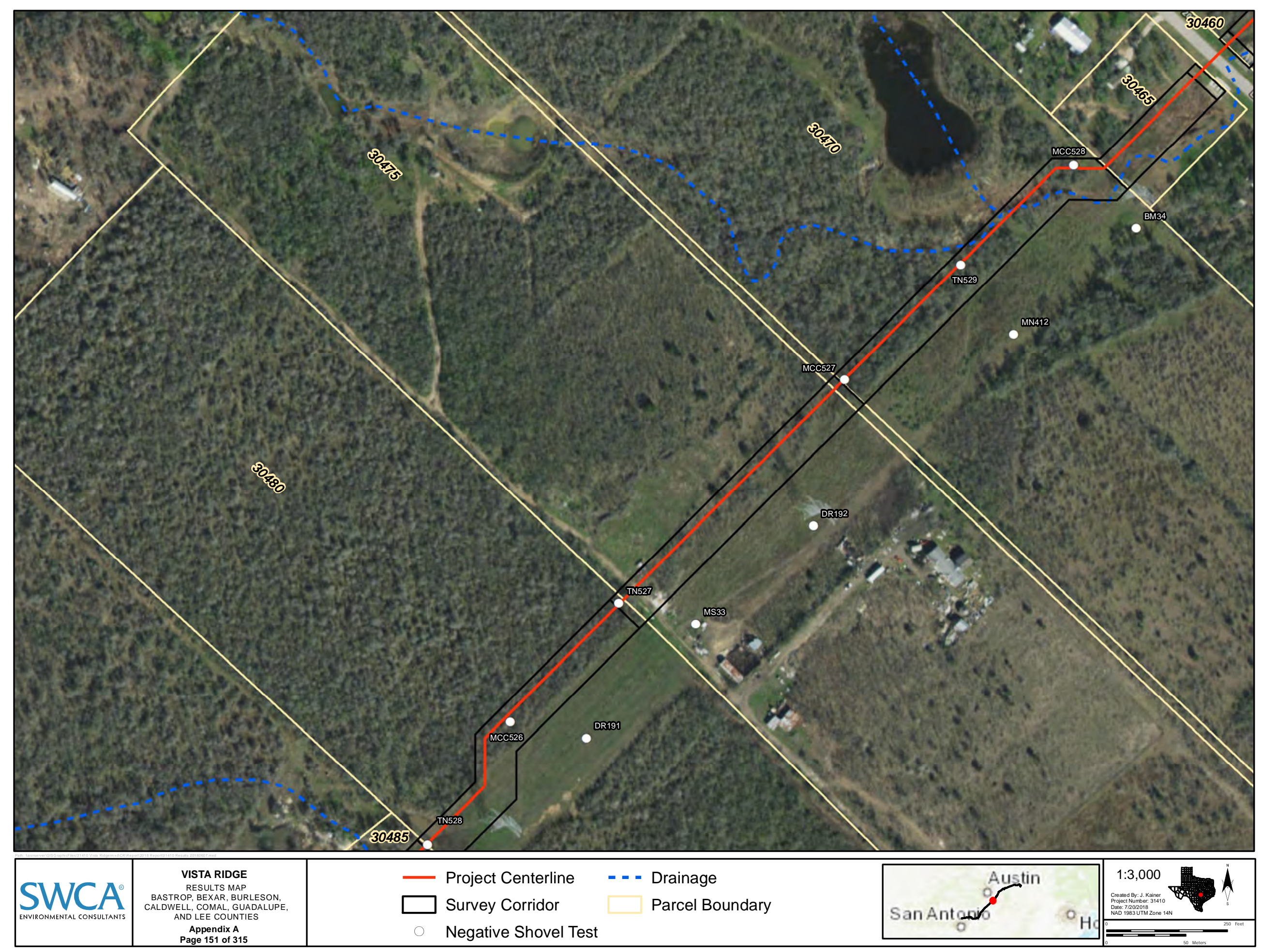




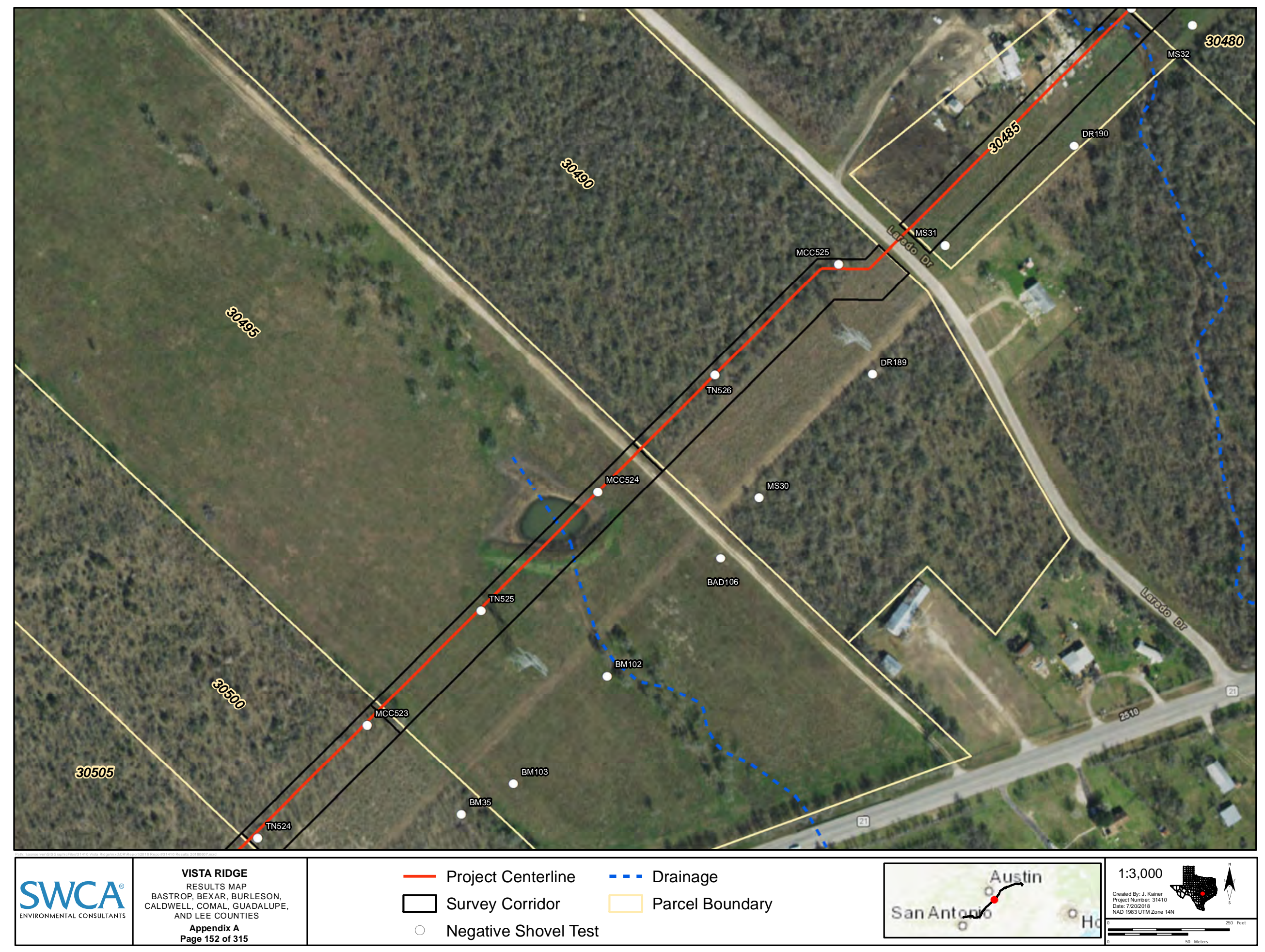


Restricted Information

Not for Public Disclosure 


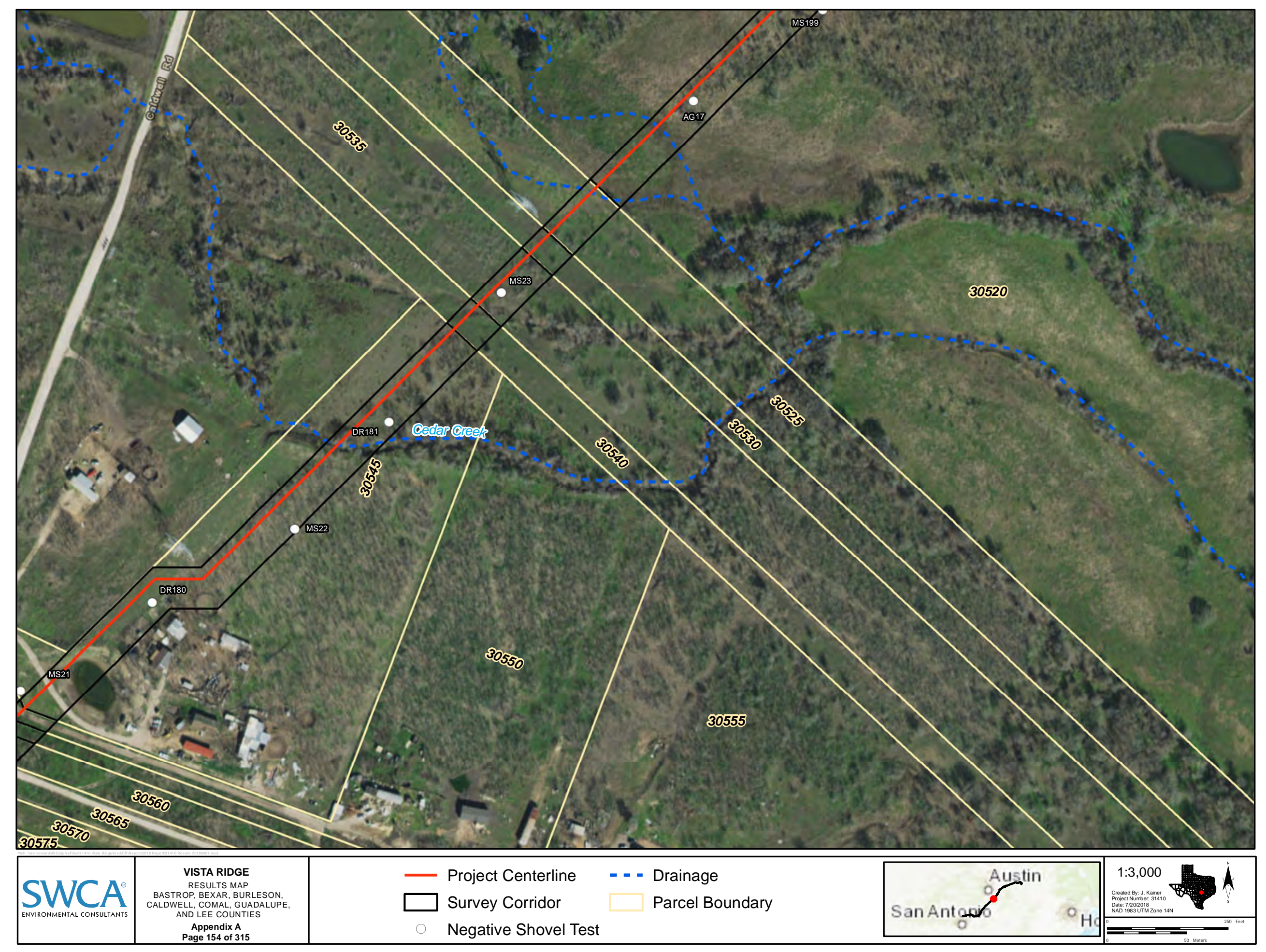




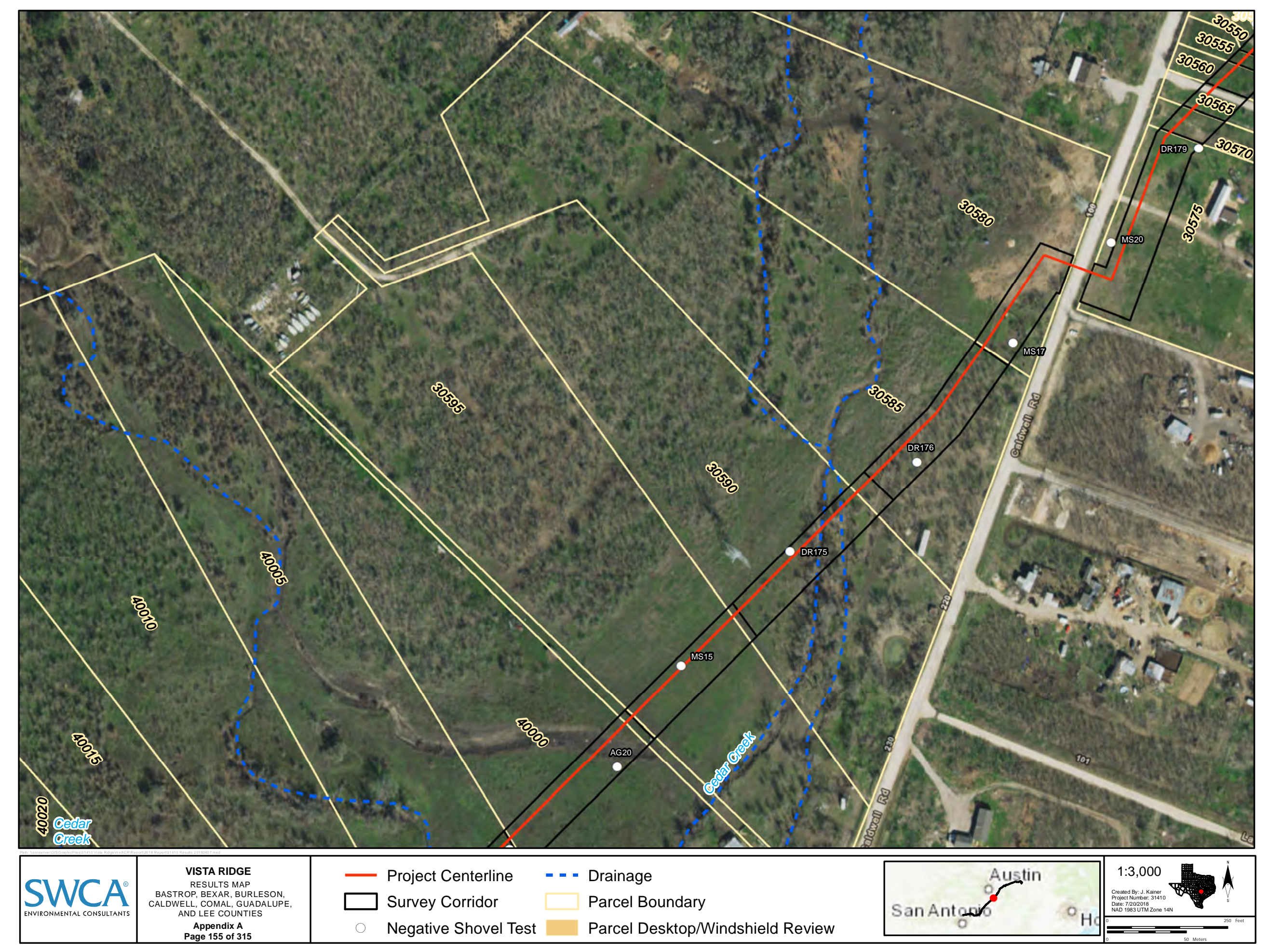




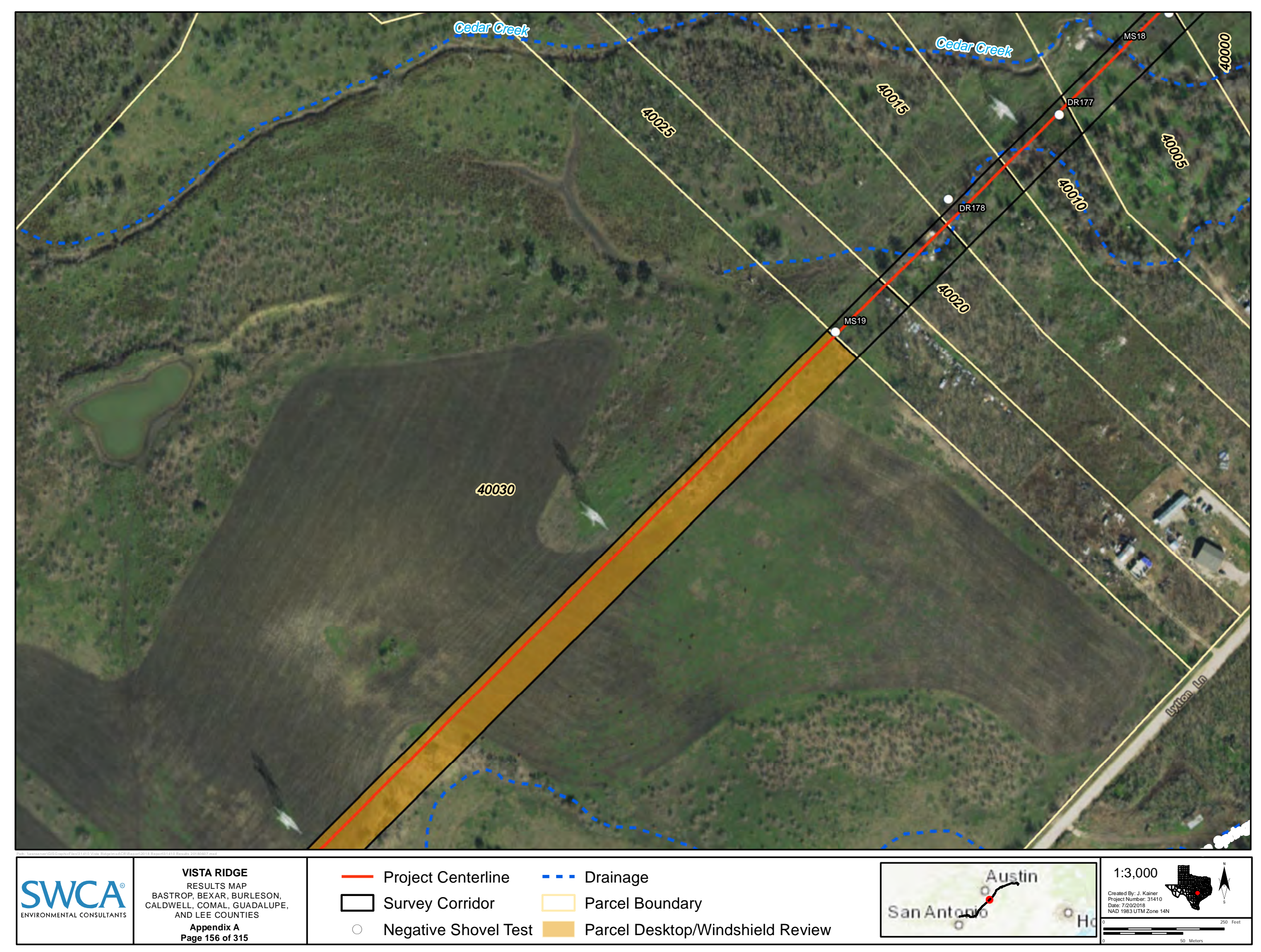




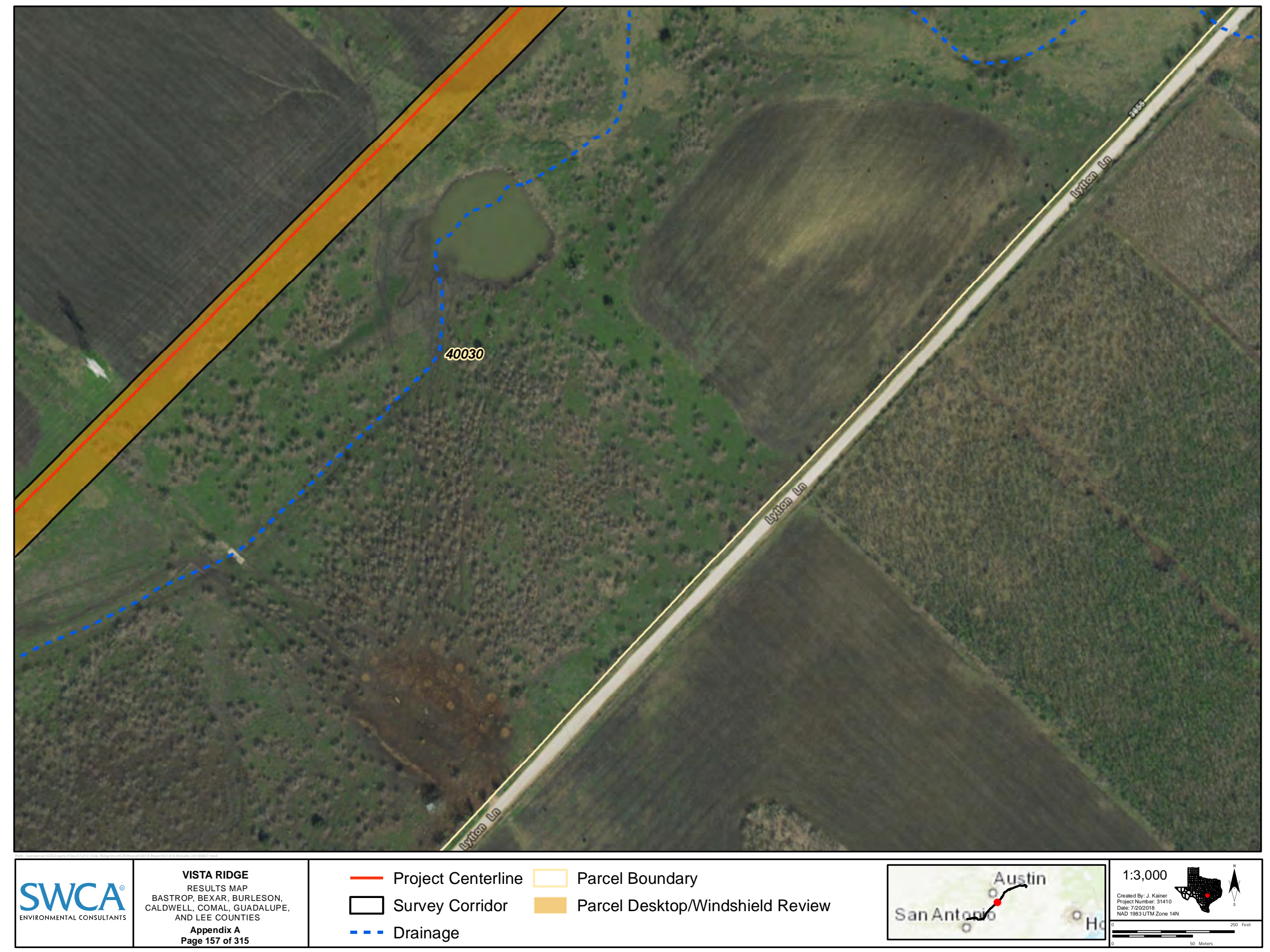




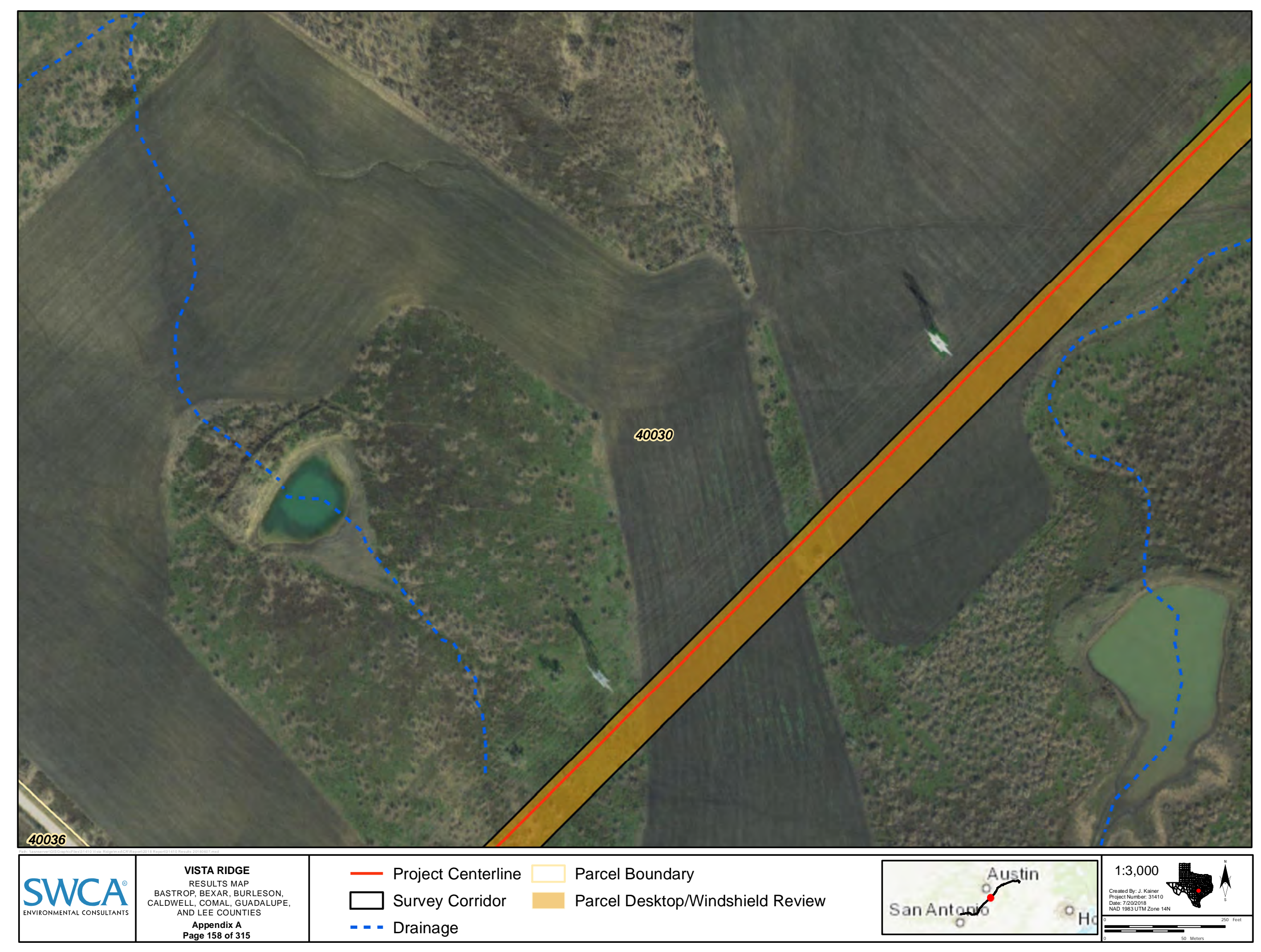




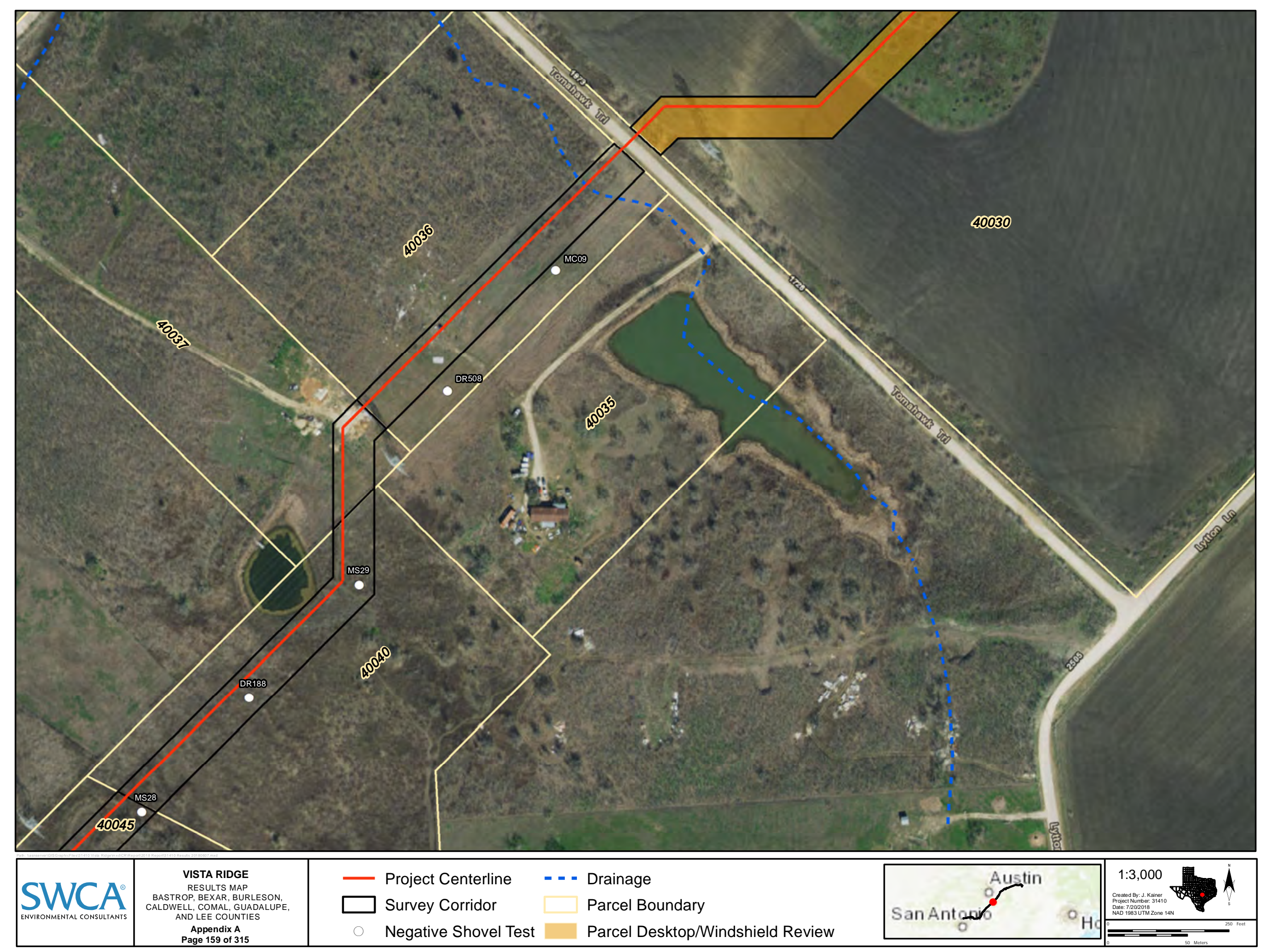




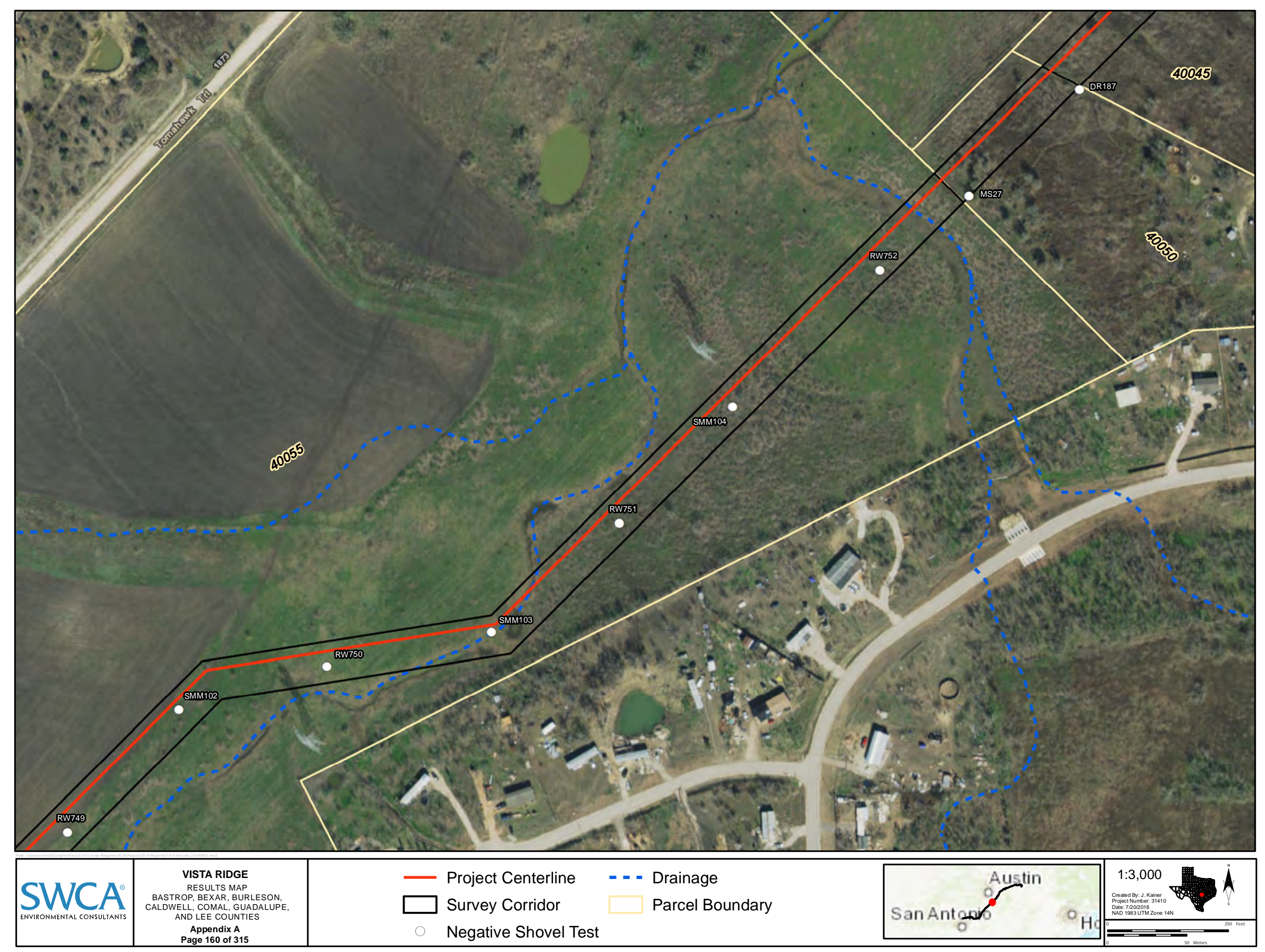




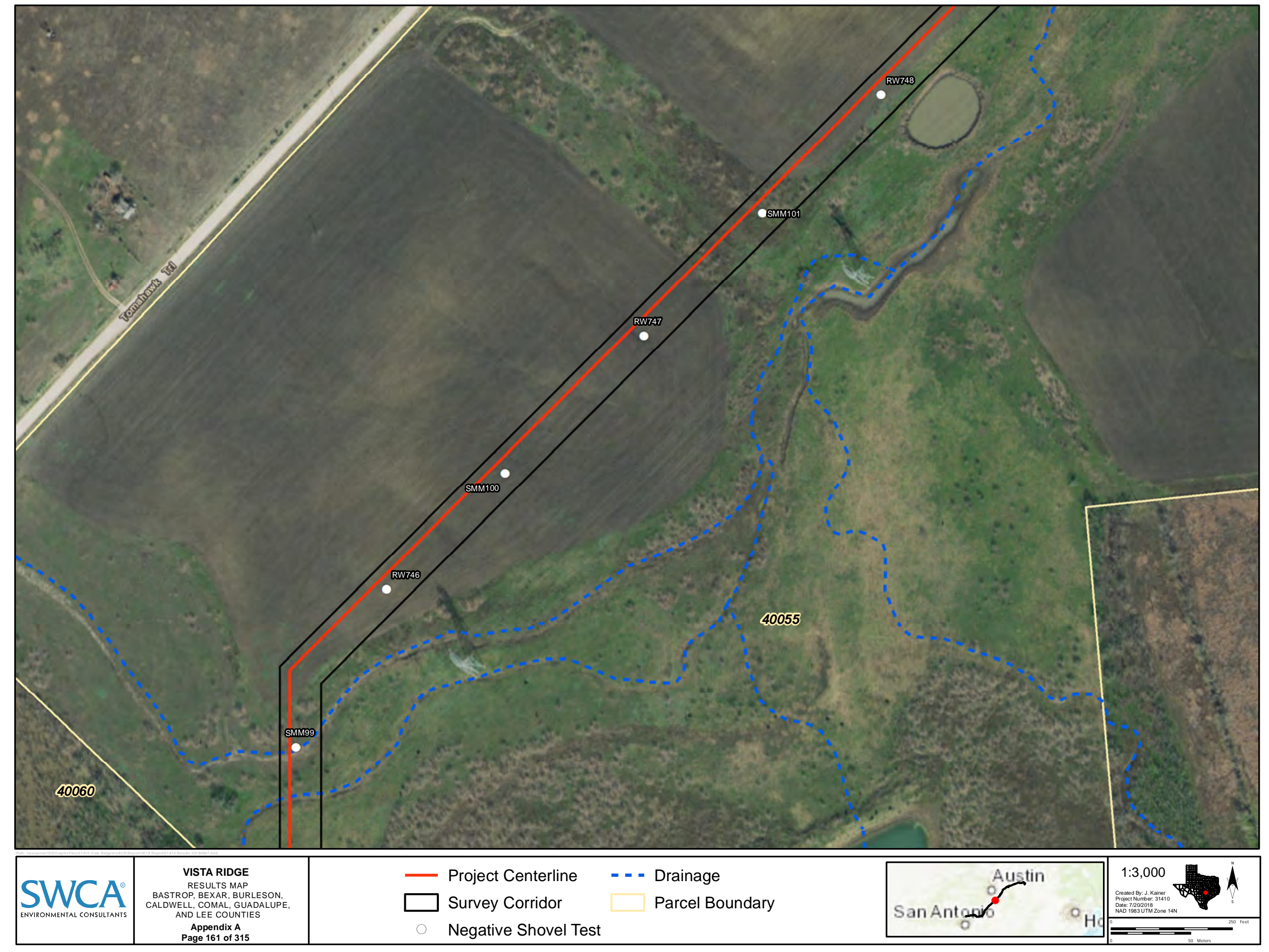




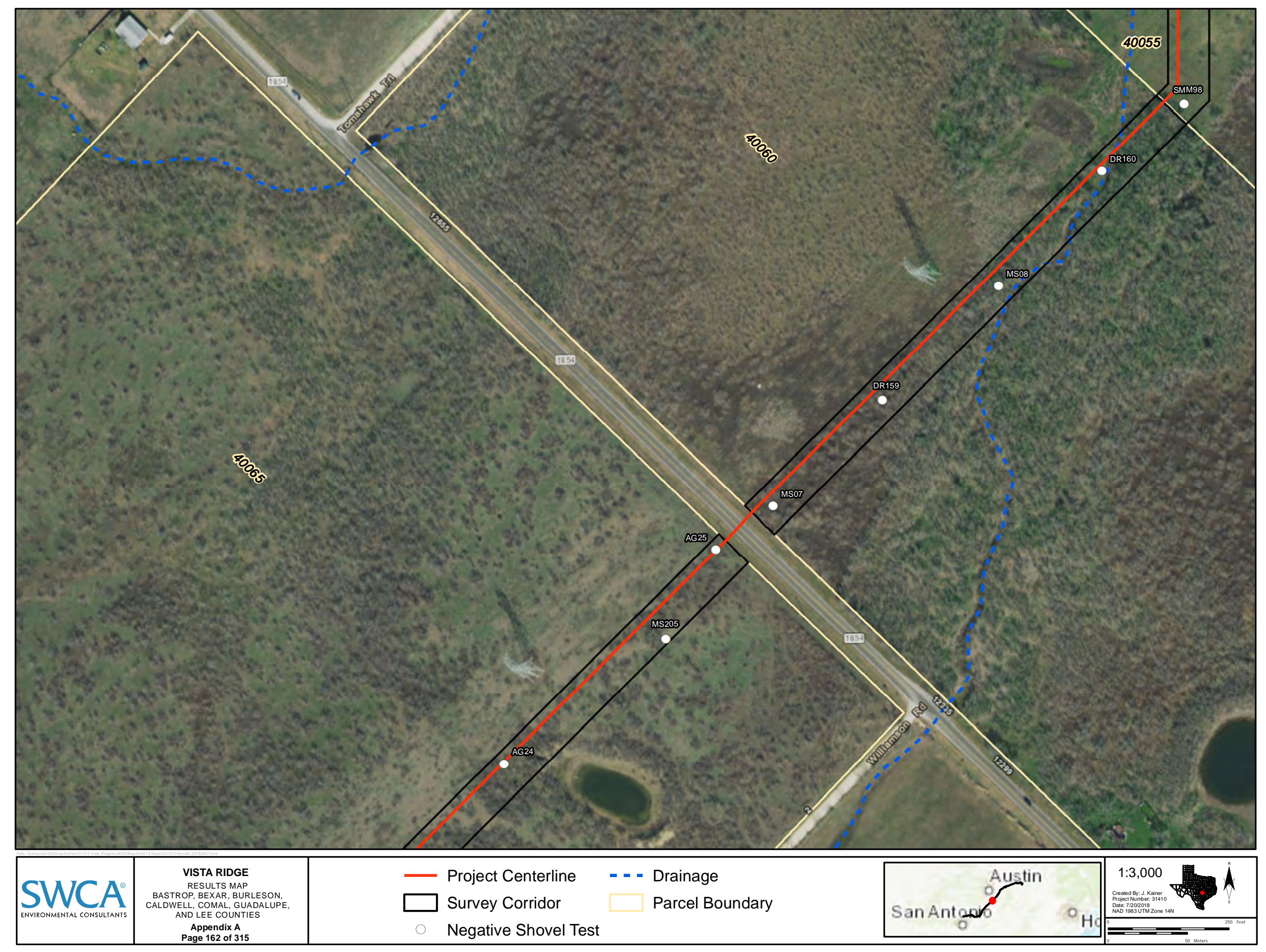




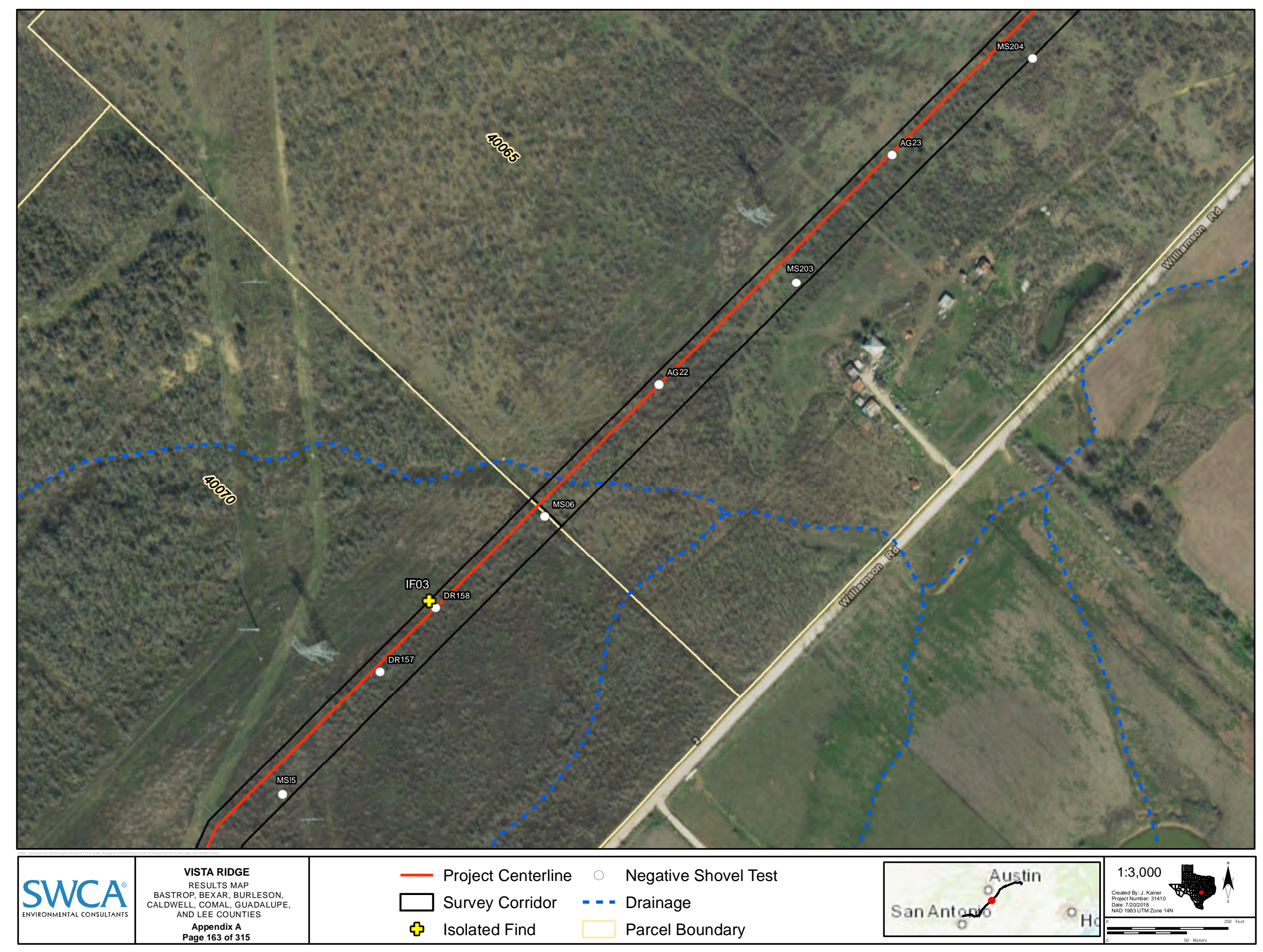




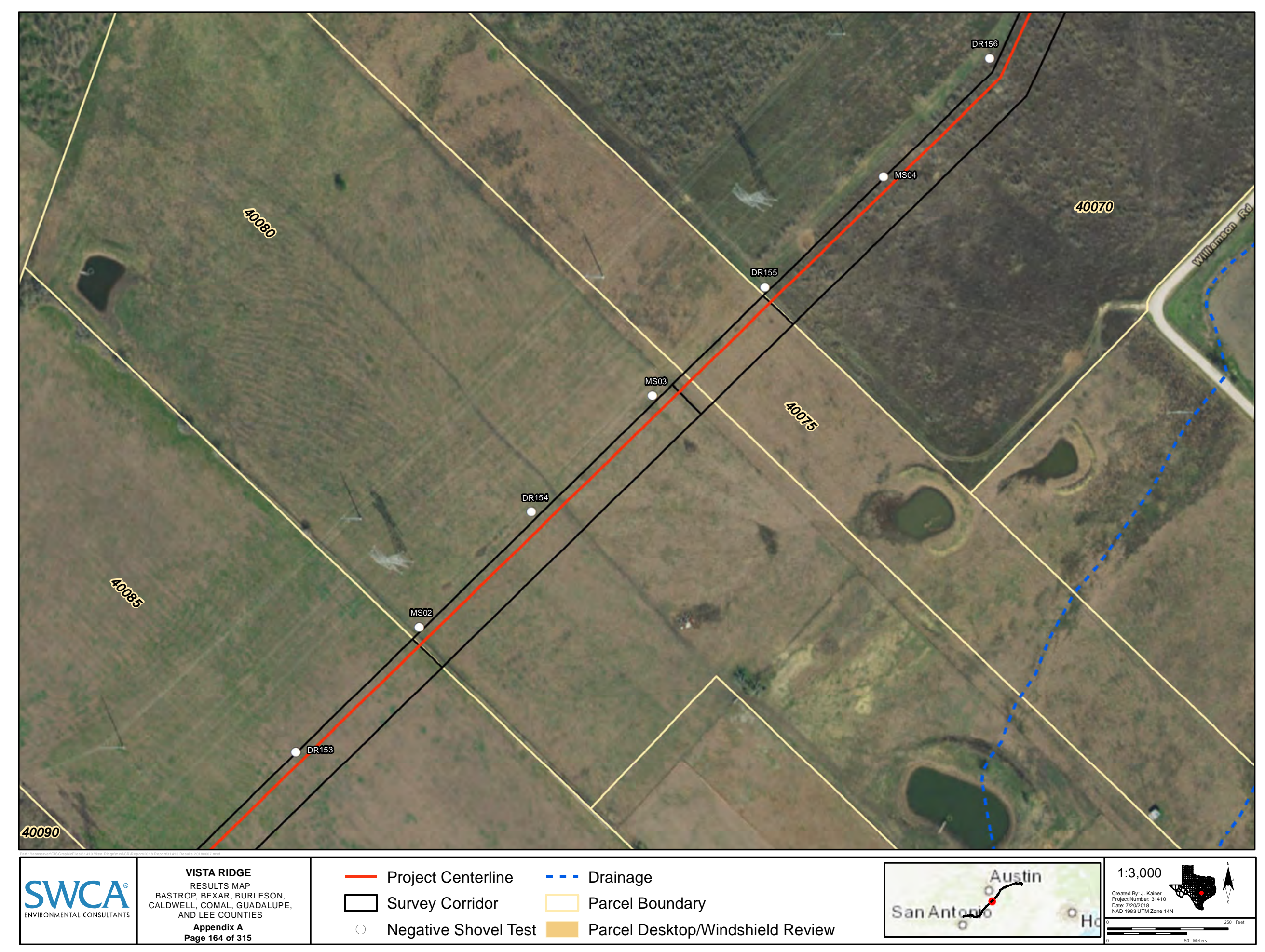


Restricted Information

Not for Public Disclosure 


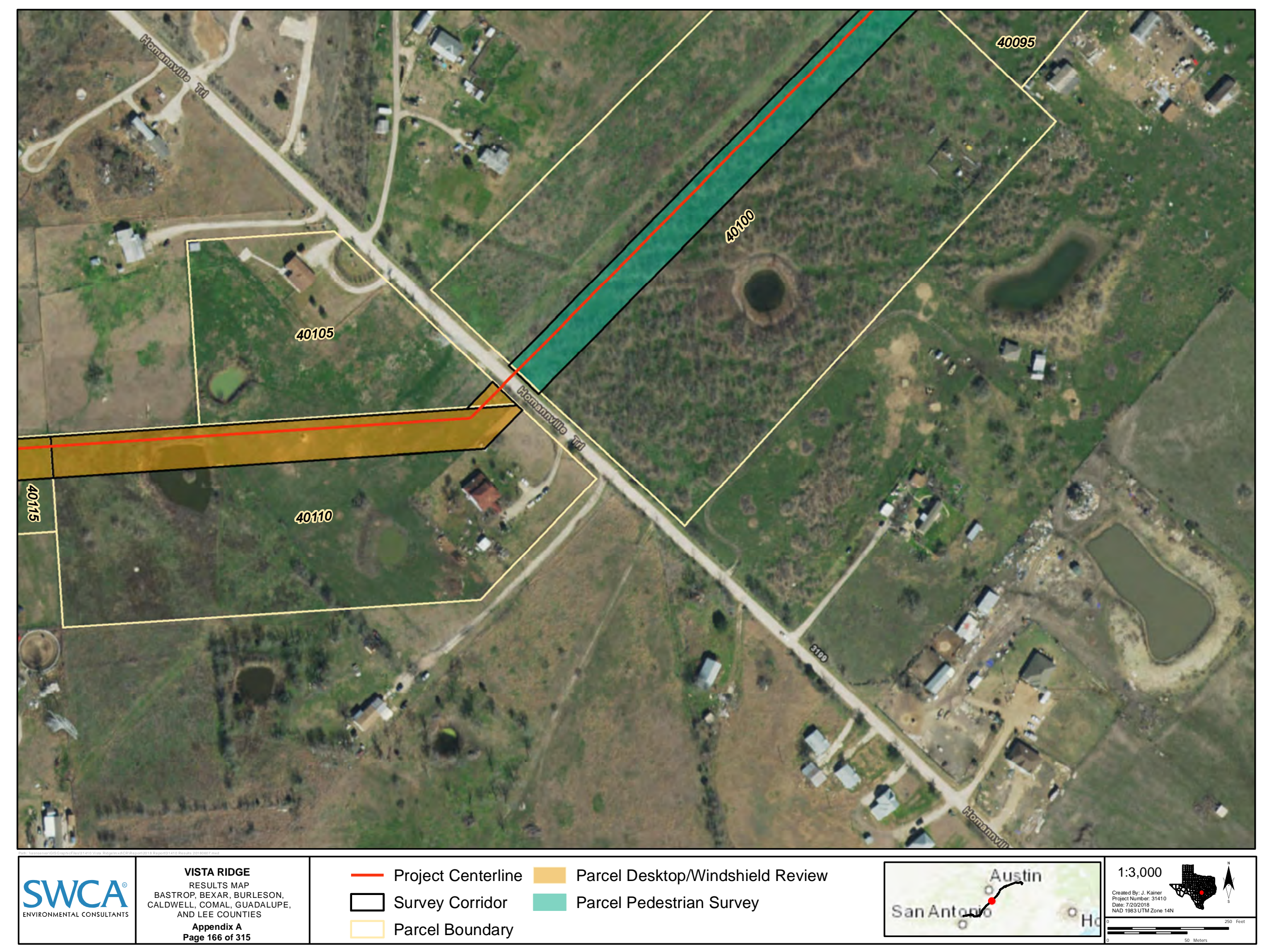




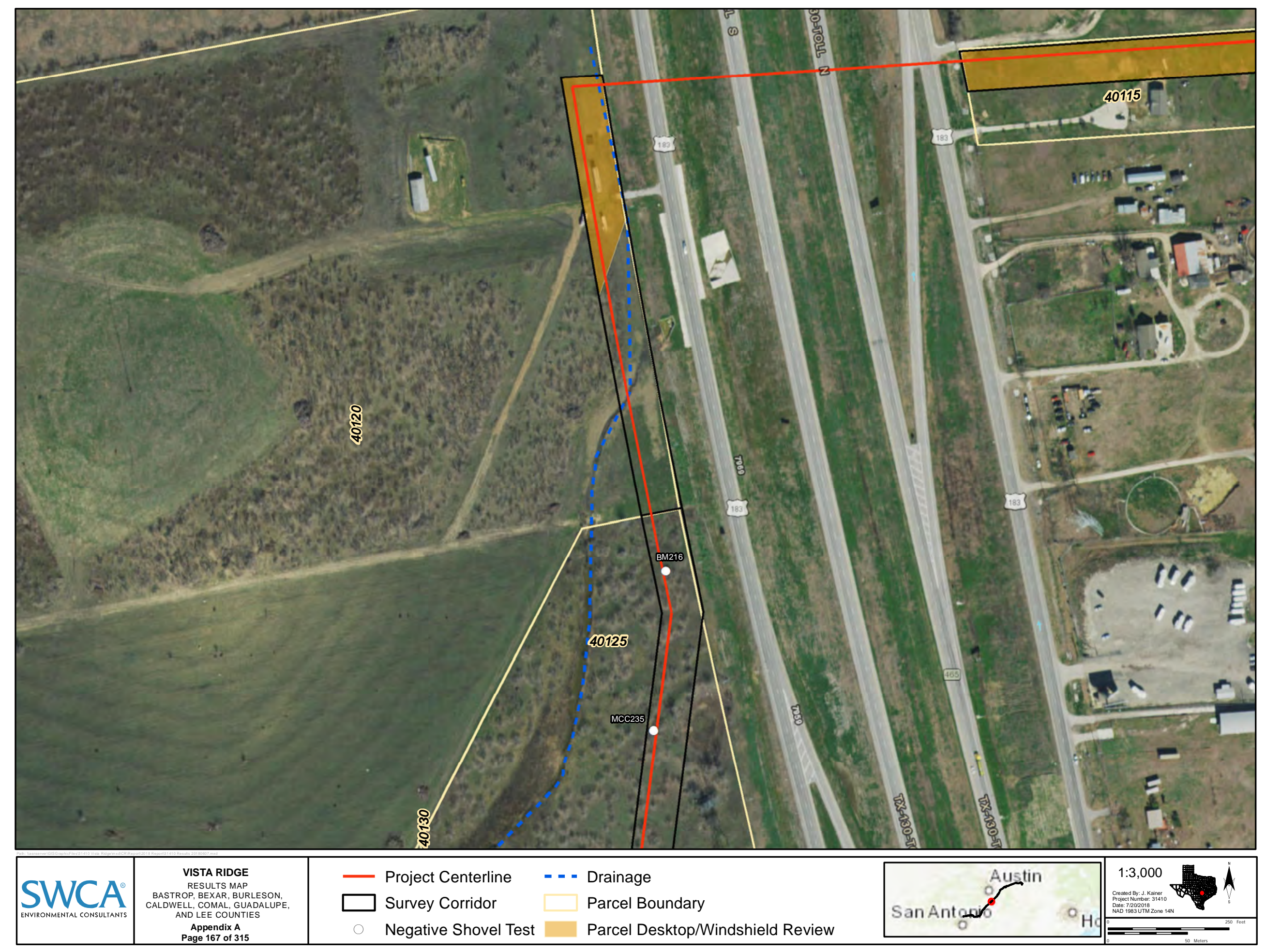




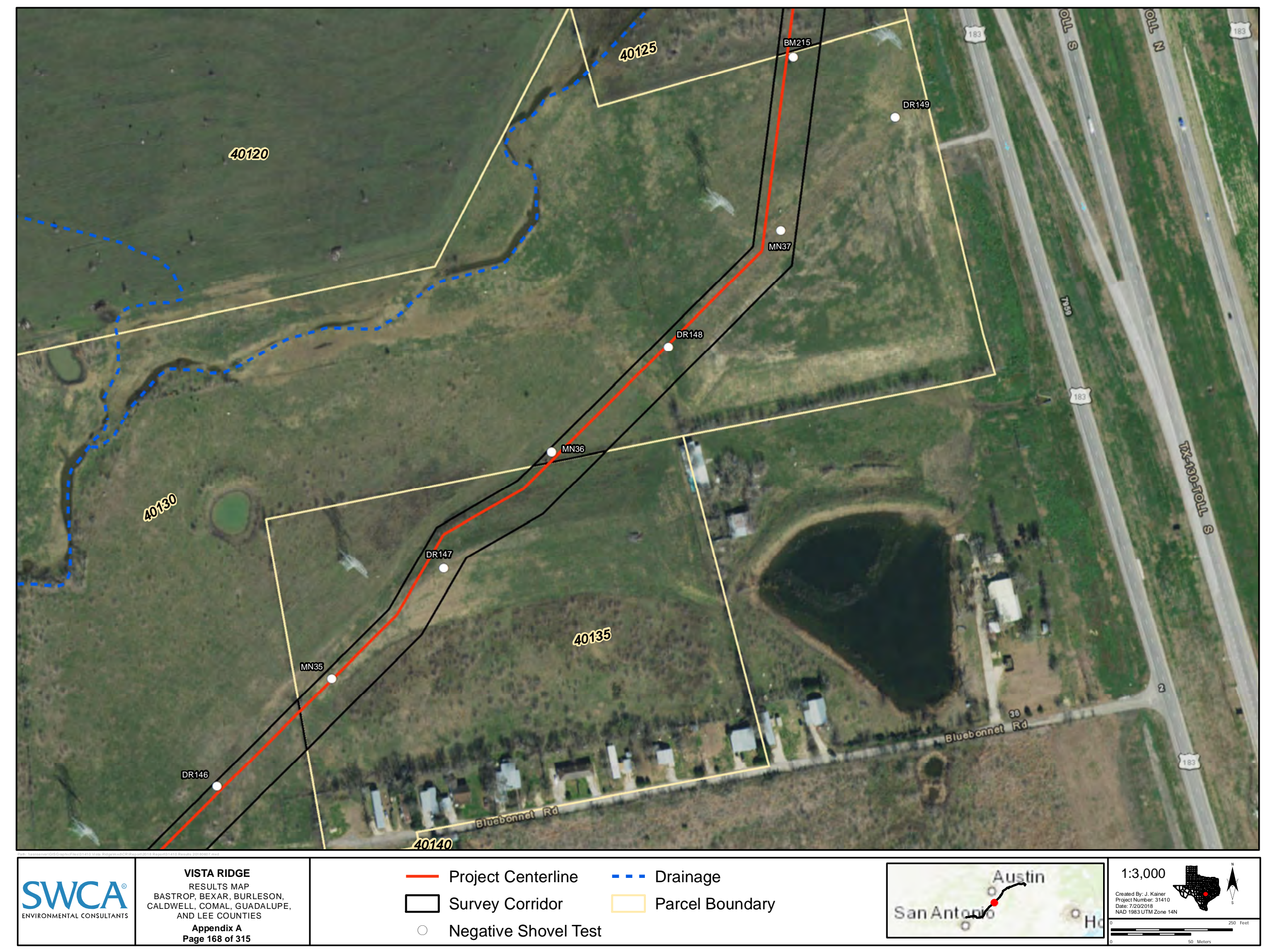




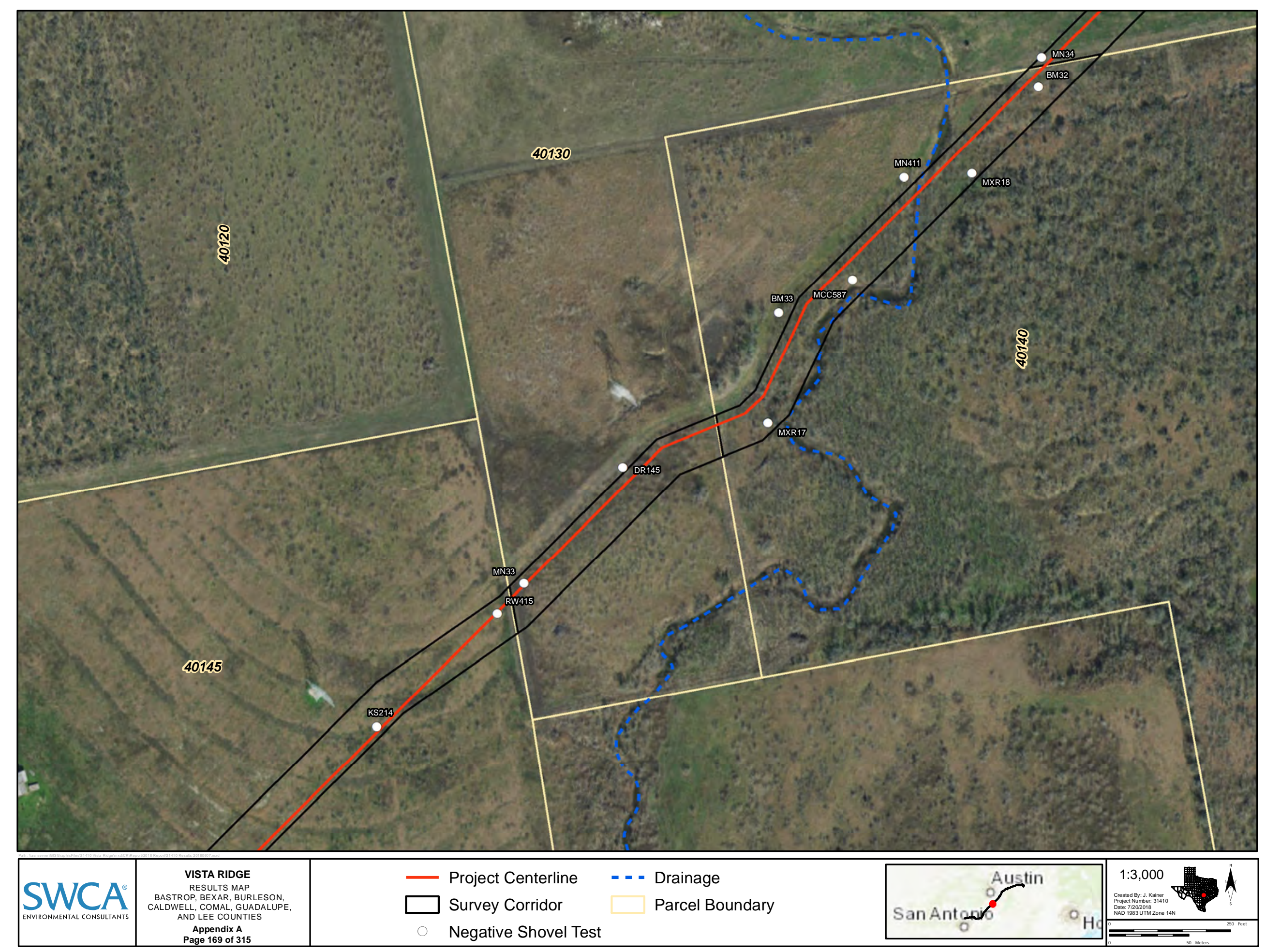




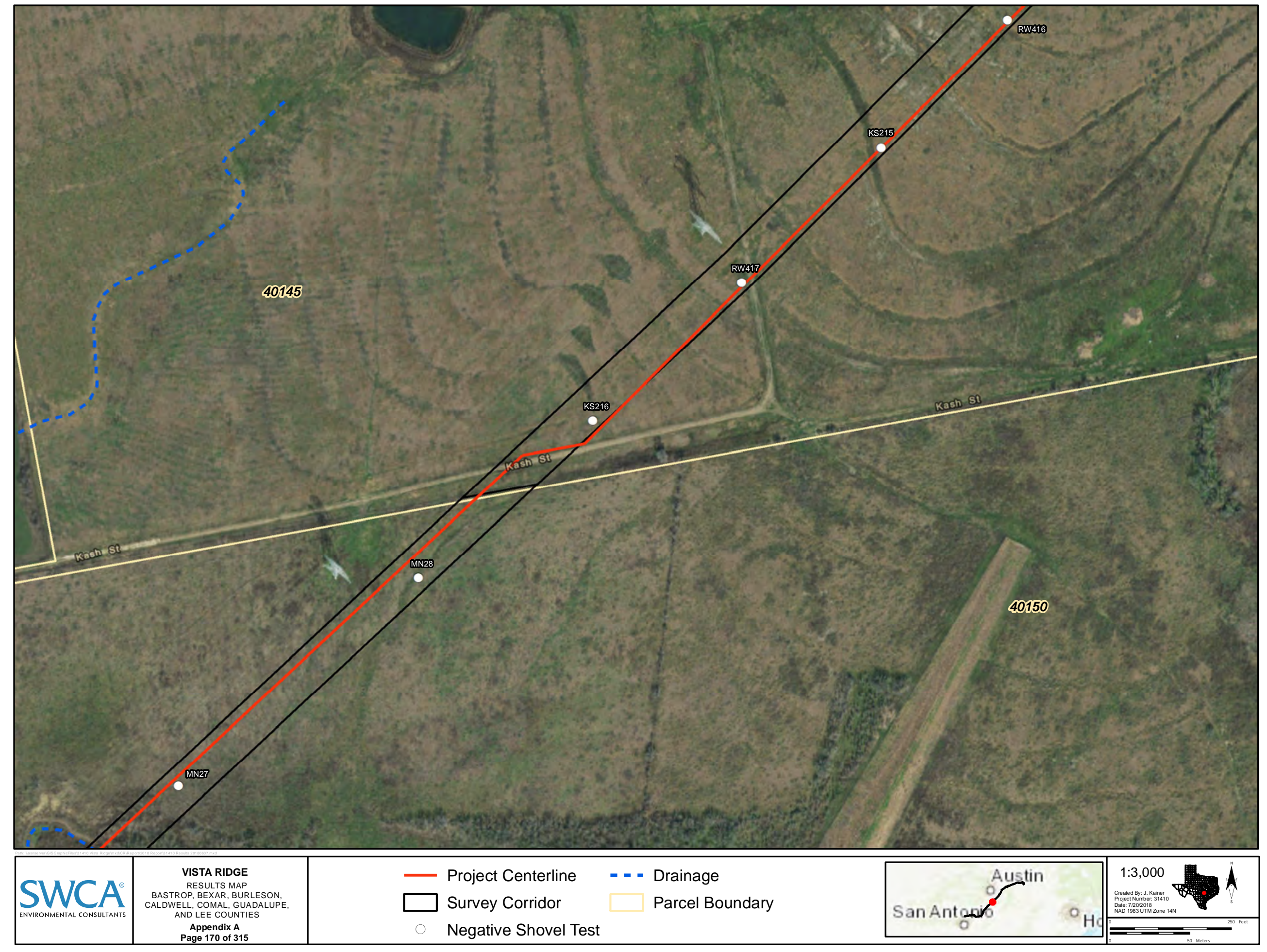




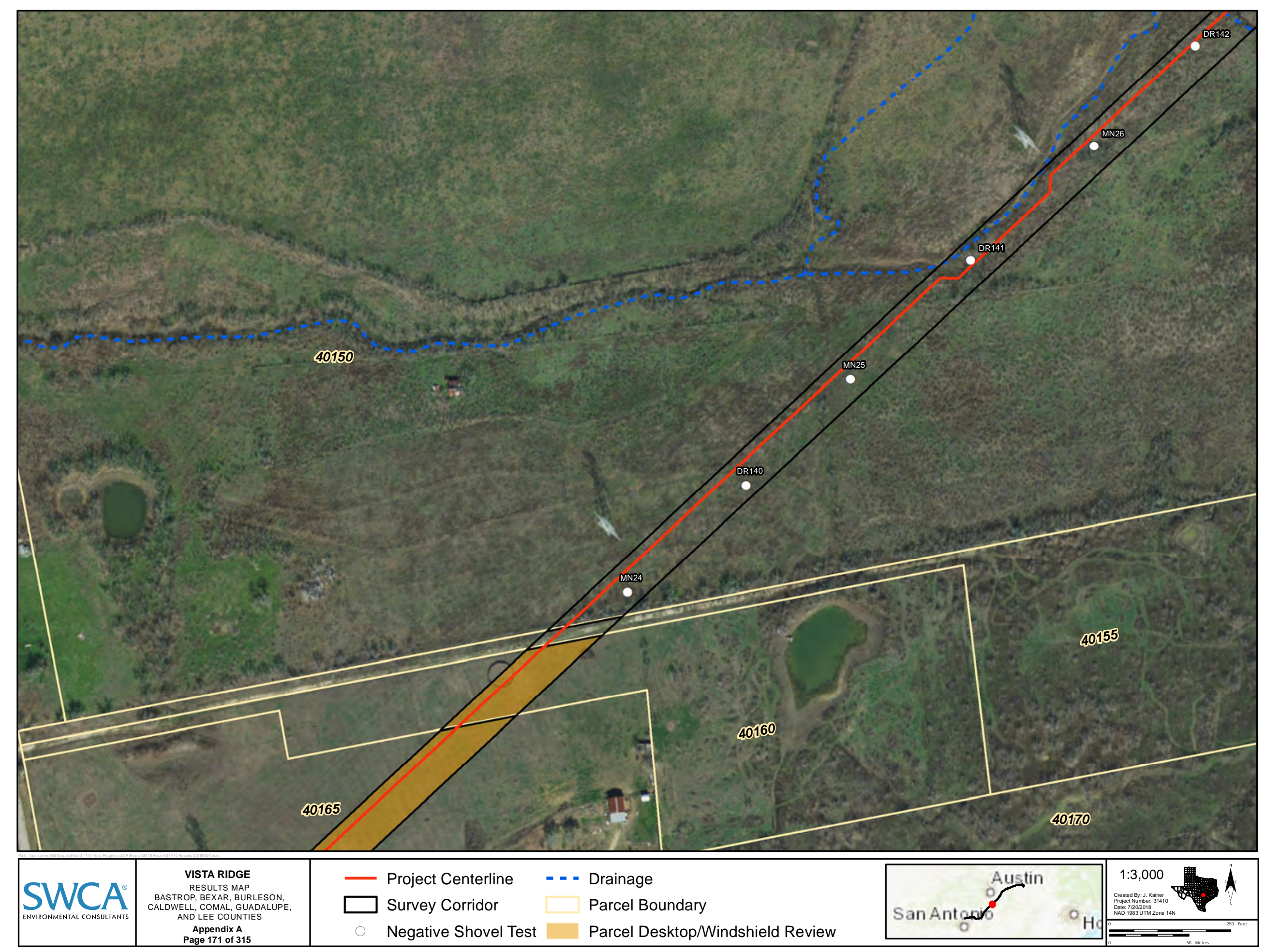




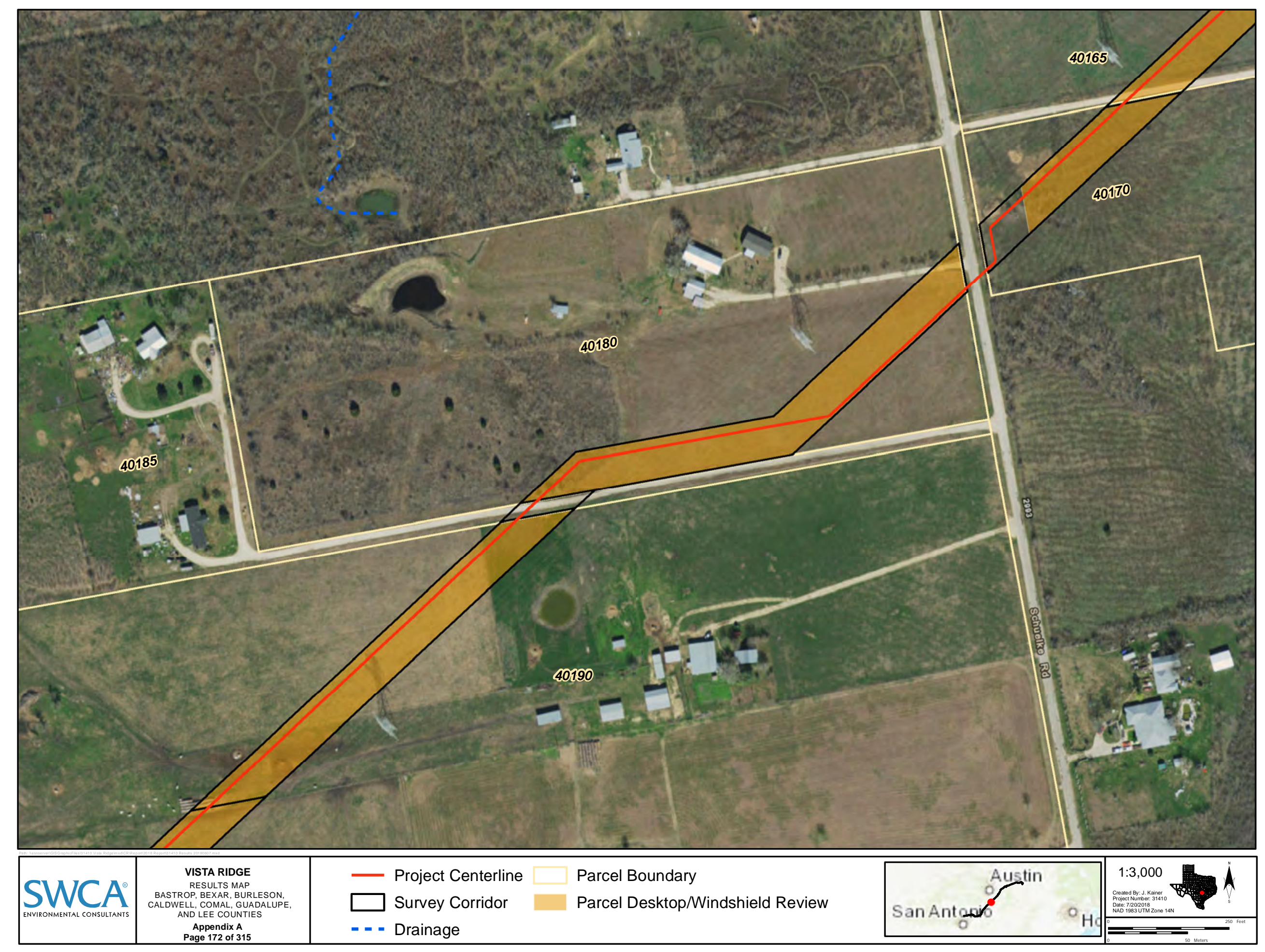




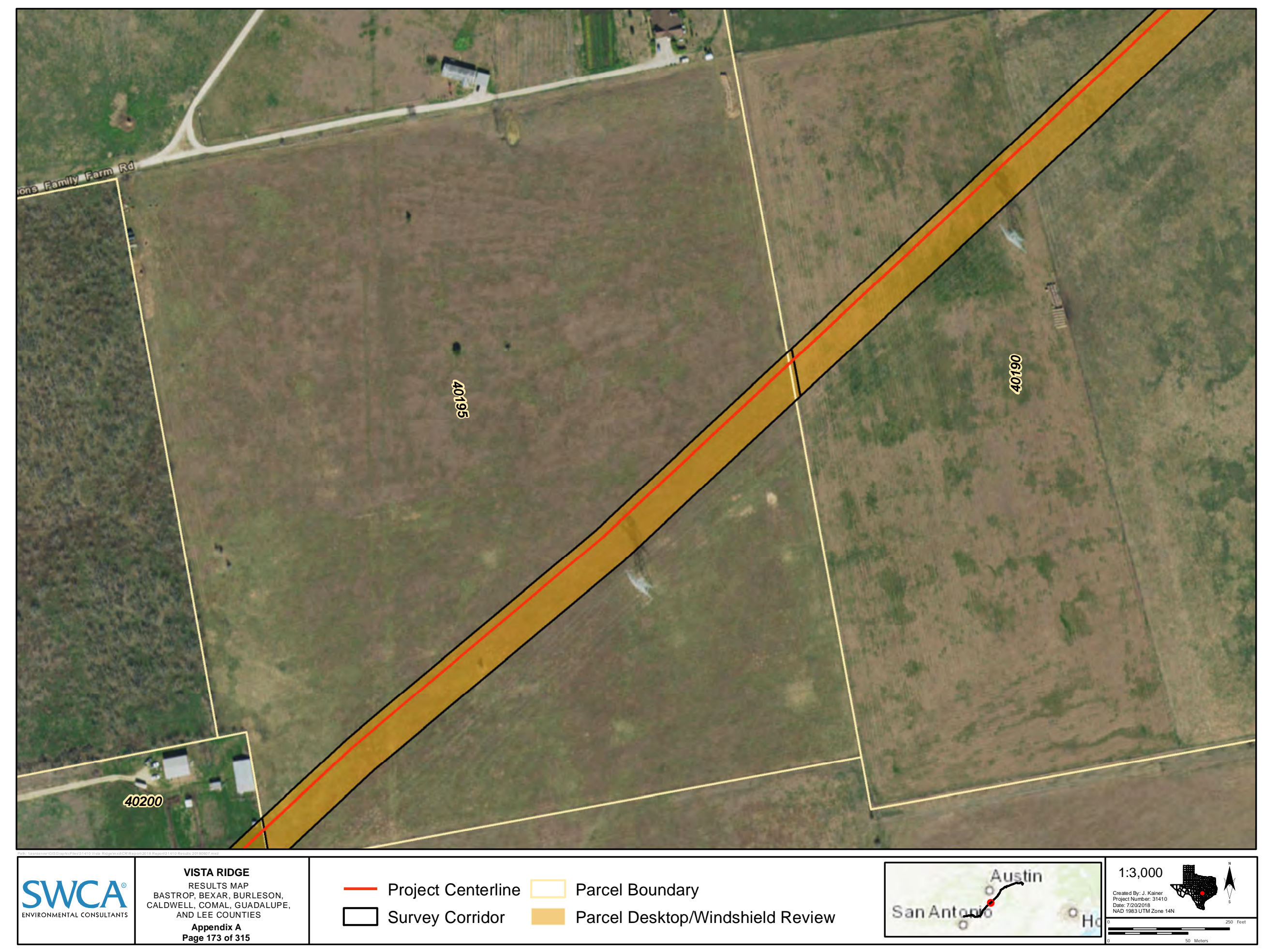




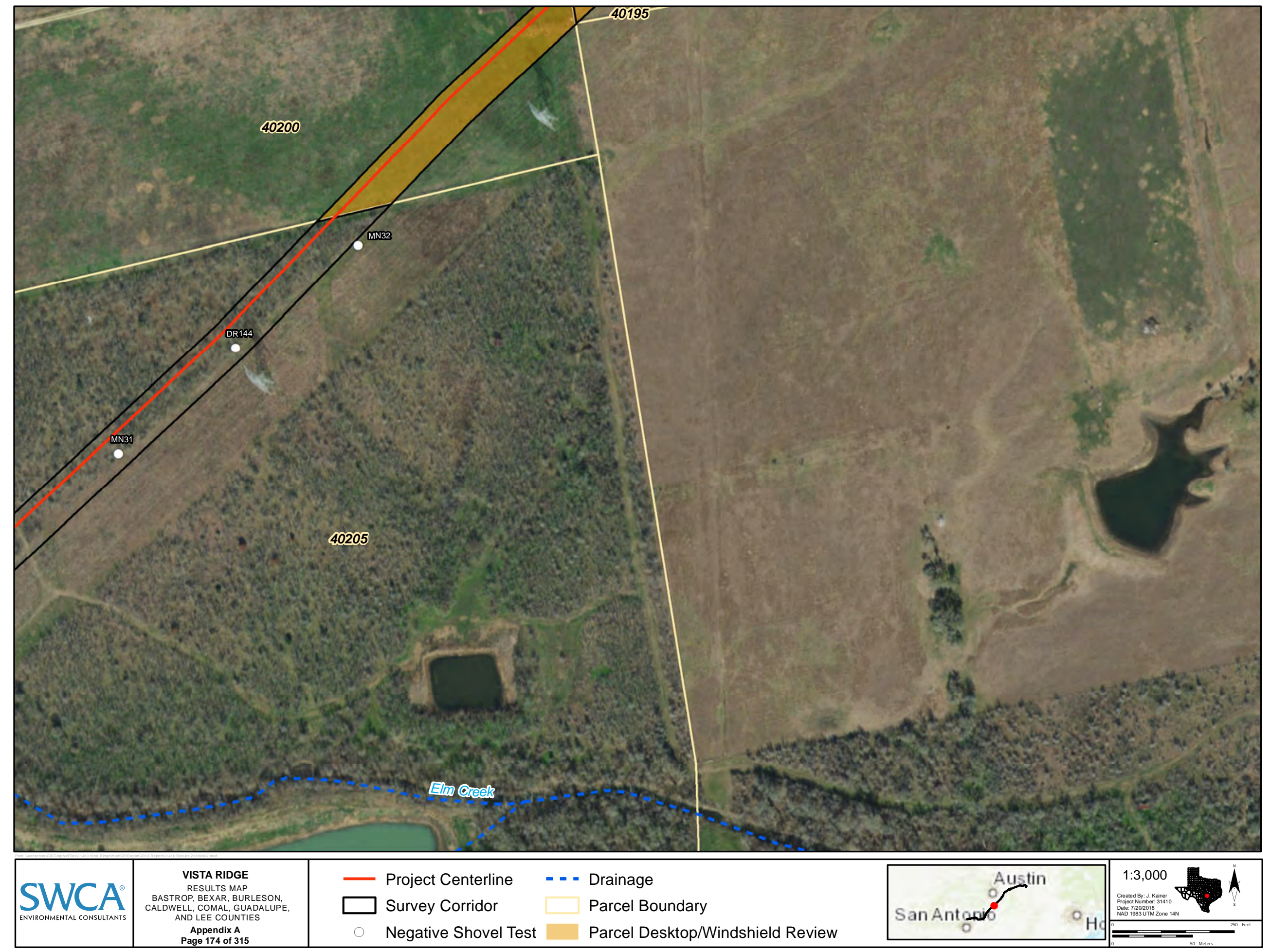


Restricted Information

Not for Public Disclosure 
Restricted Information

Not for Public Disclosure 


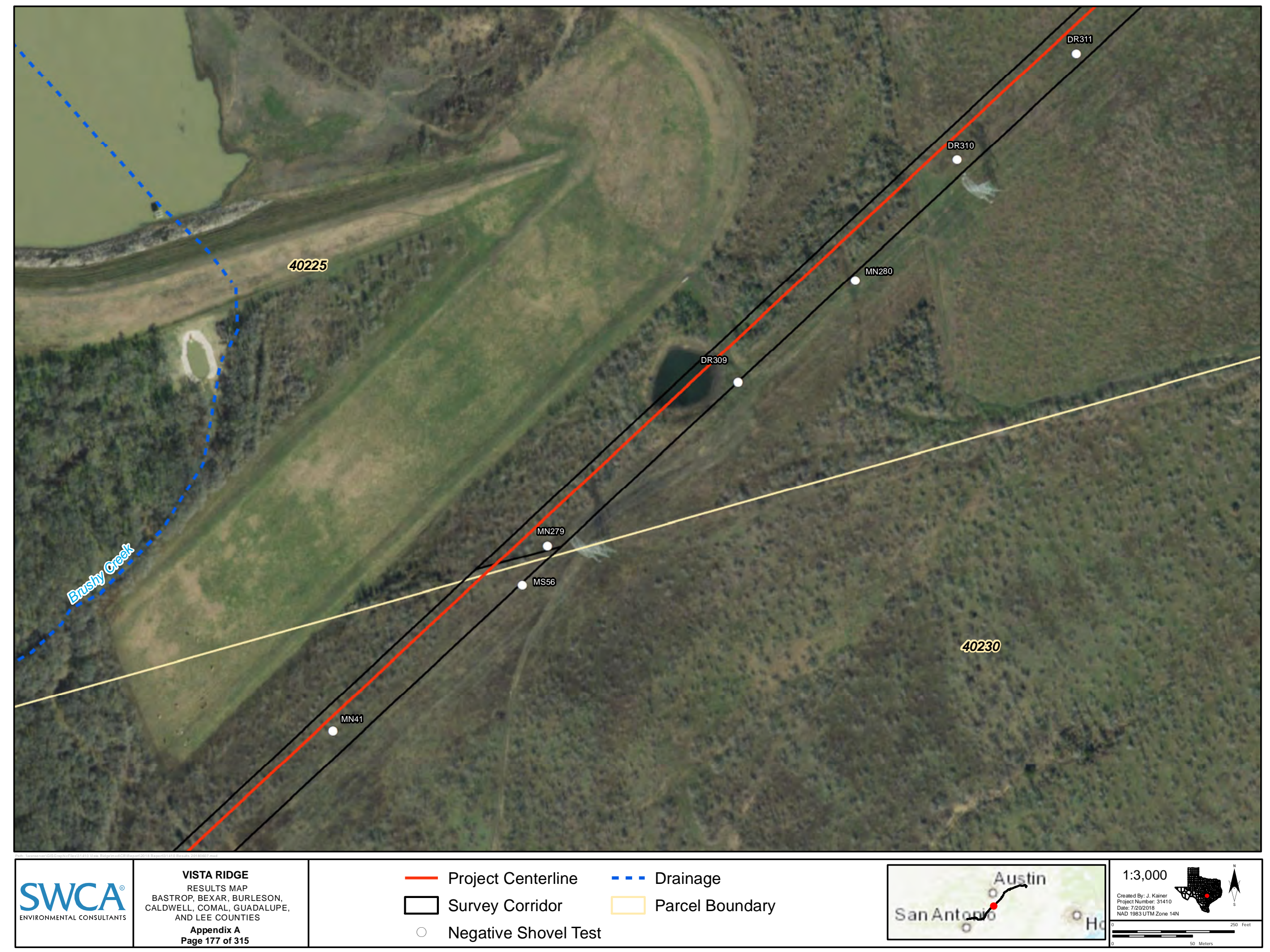




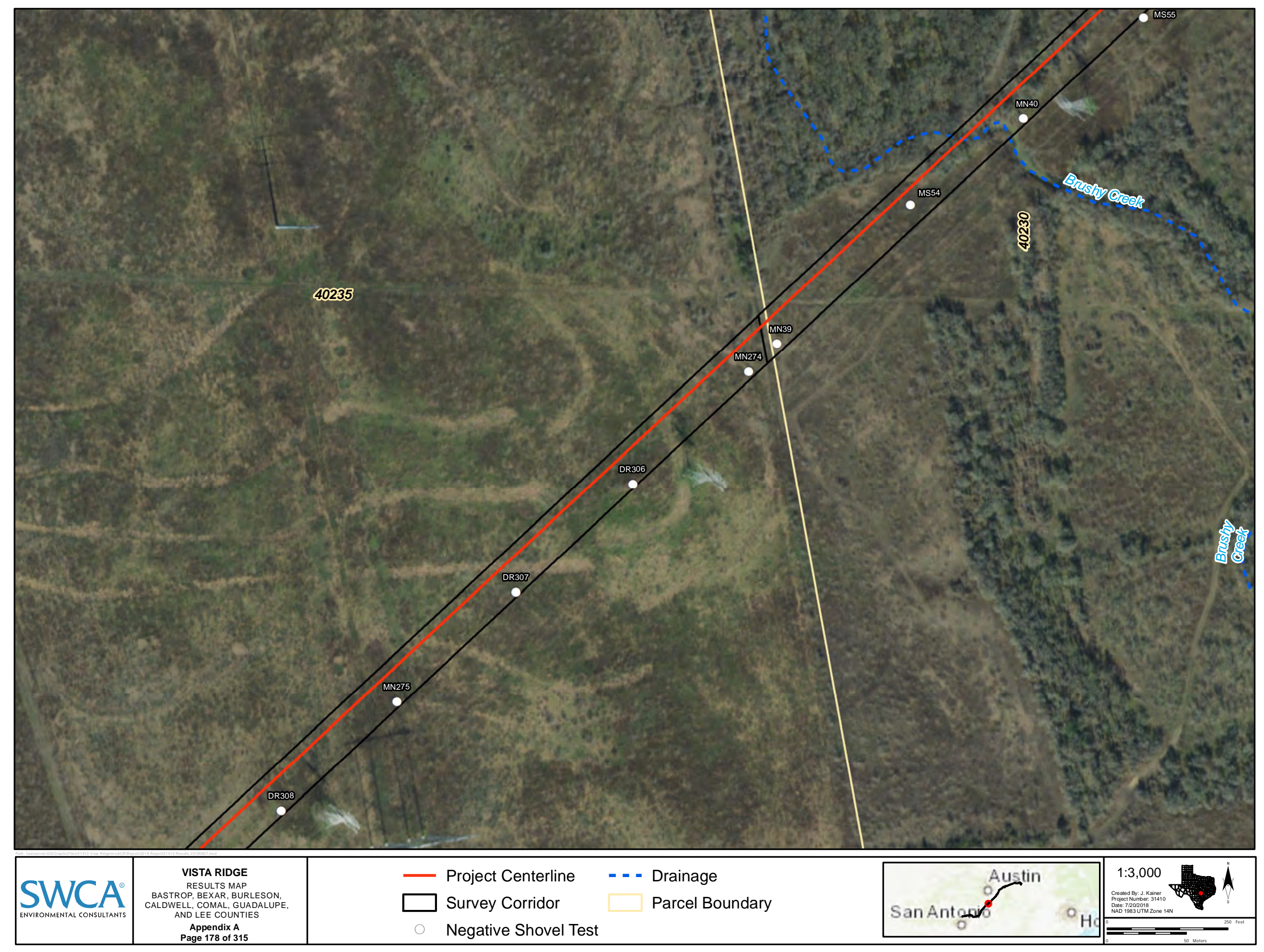


Restricted Information

Not for Public Disclosure 
Restricted Information

Not for Public Disclosure 
Restricted Information

Not for Public Disclosure 


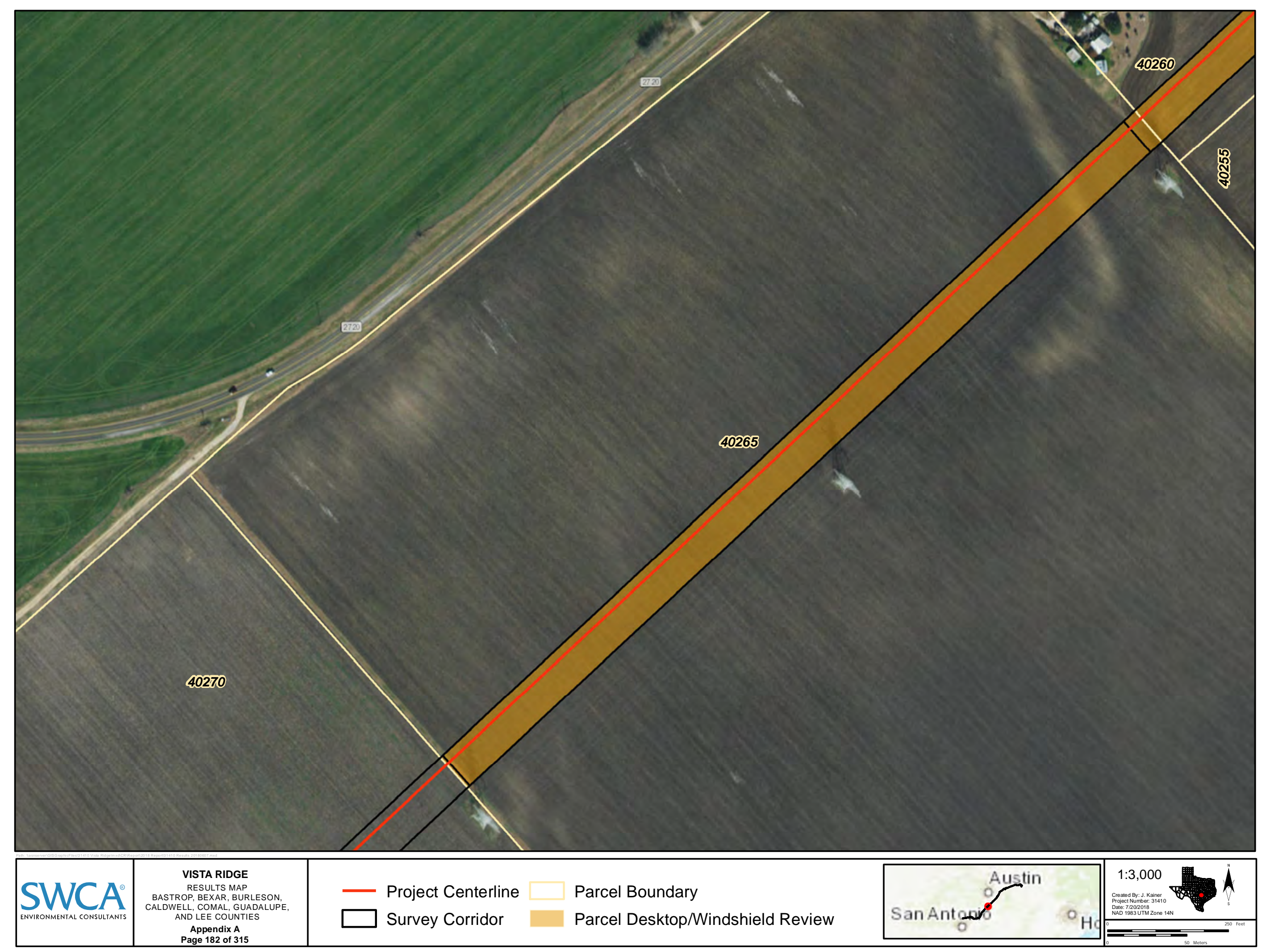




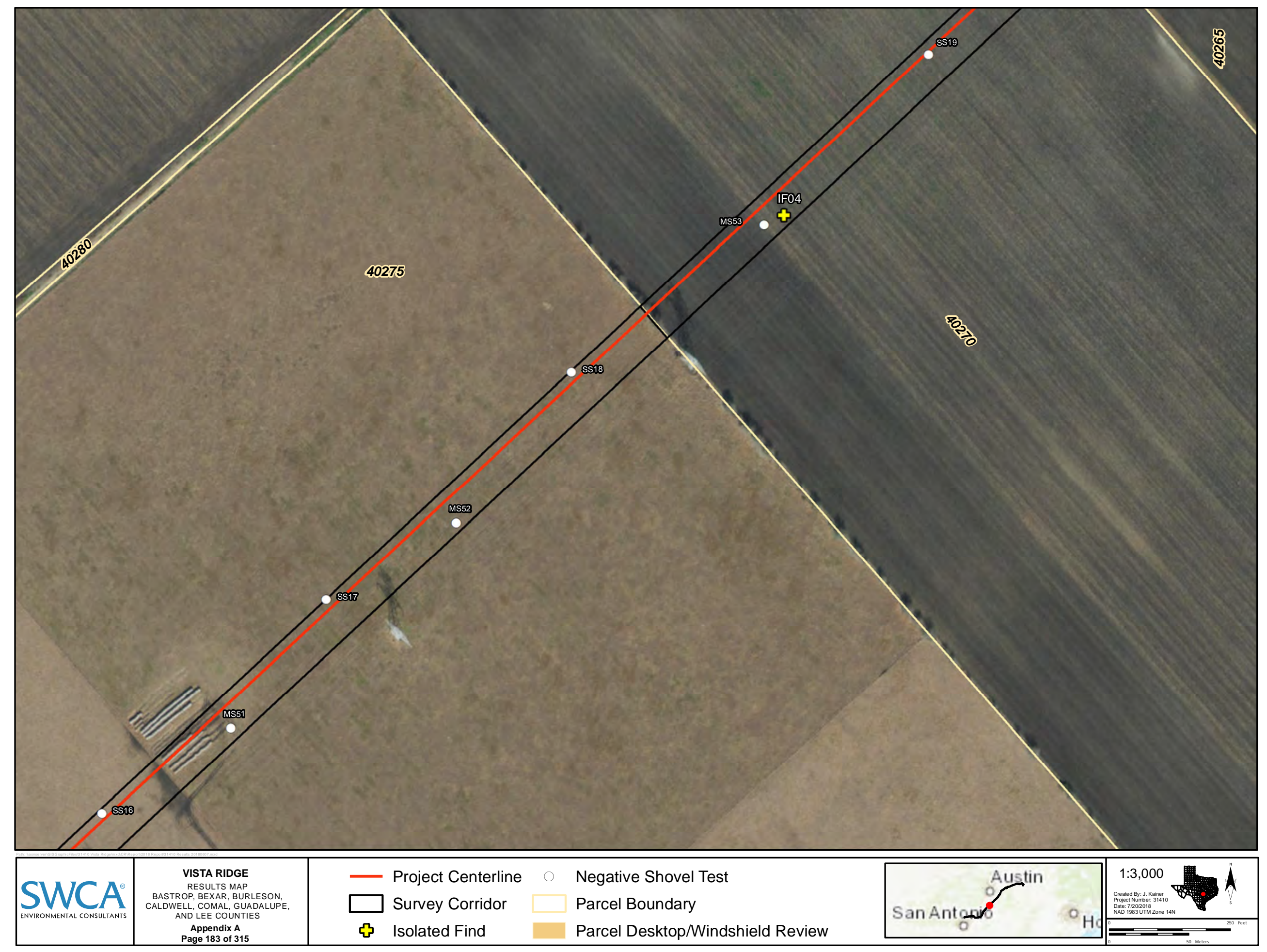




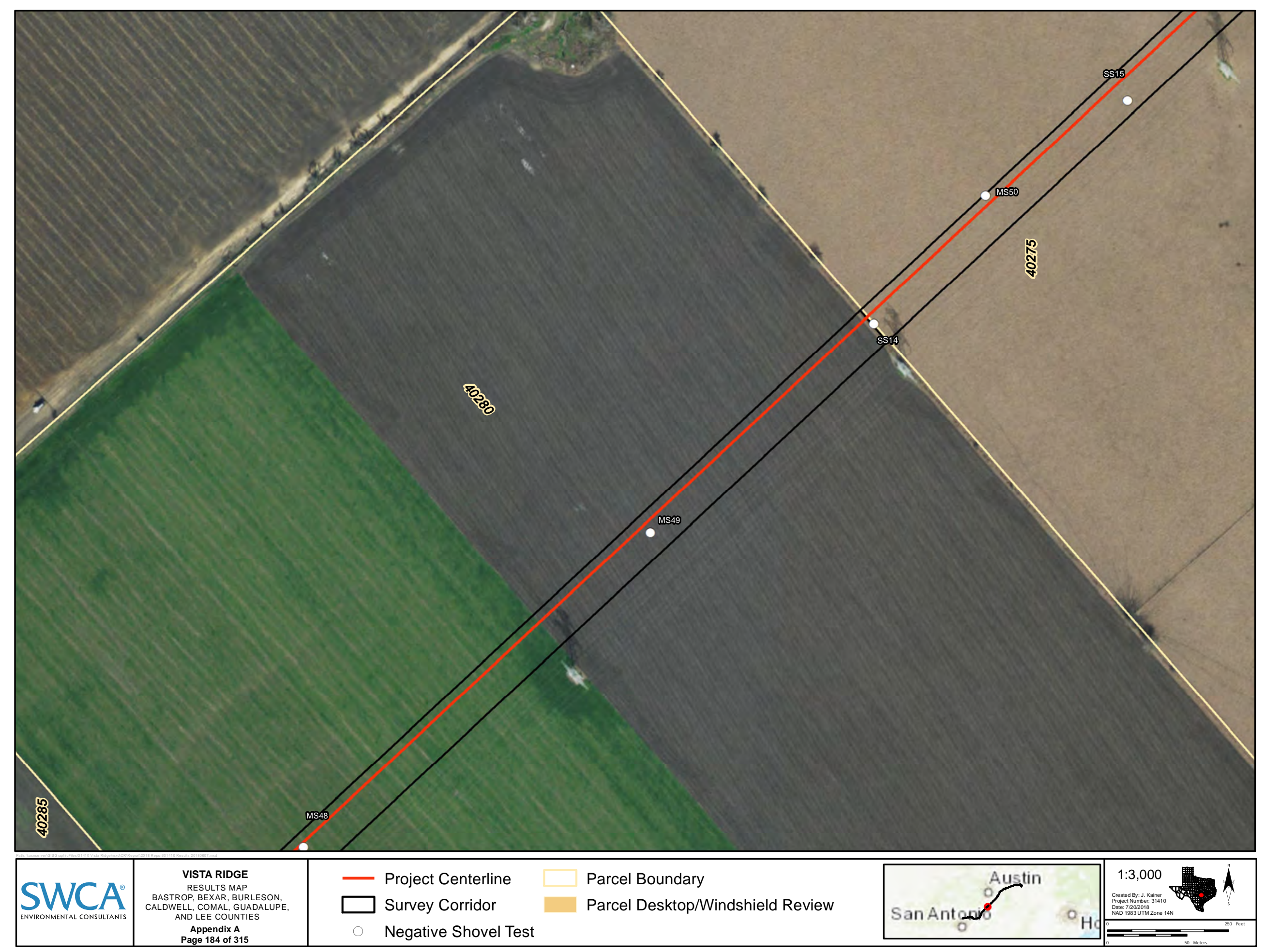




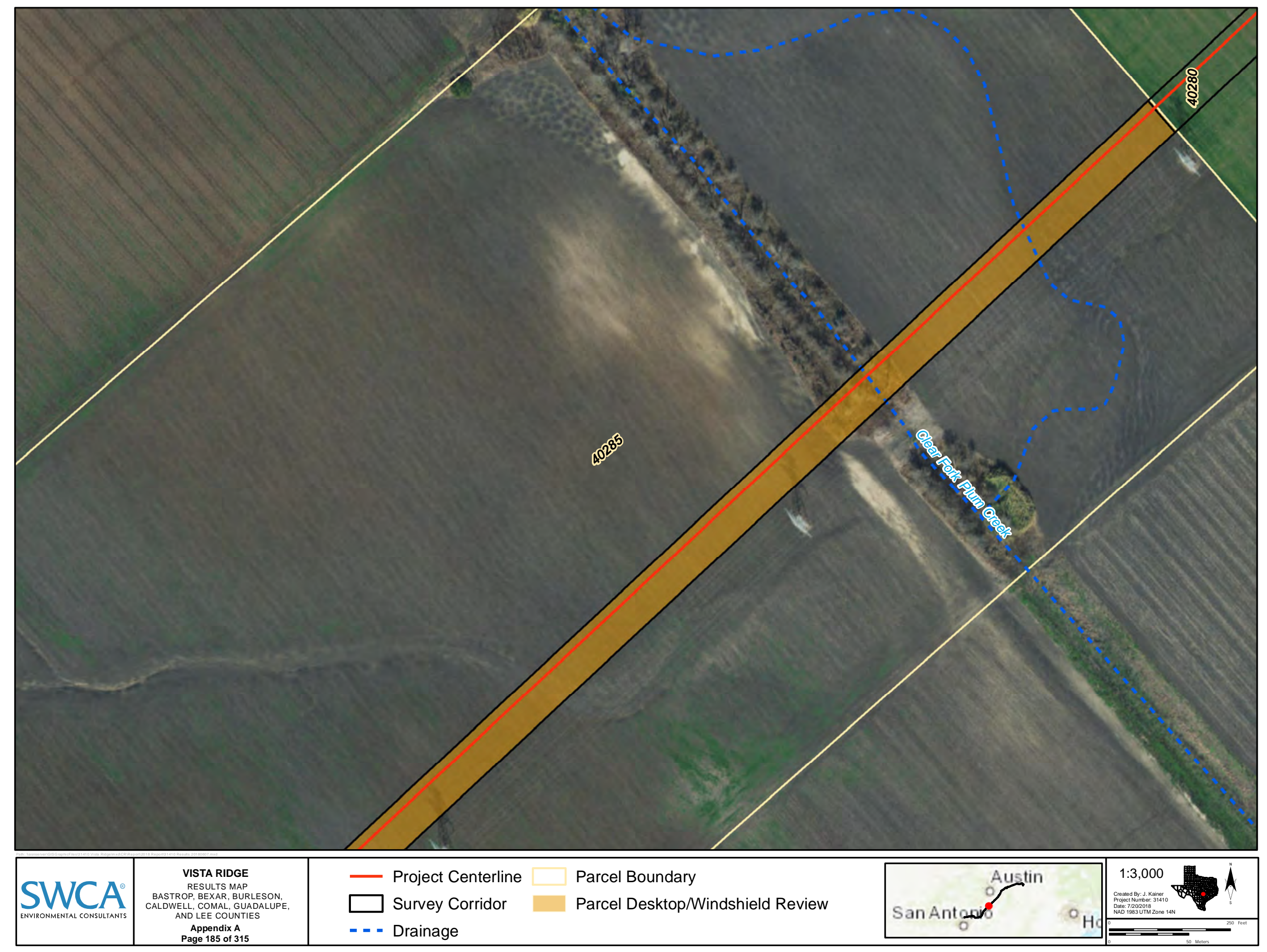




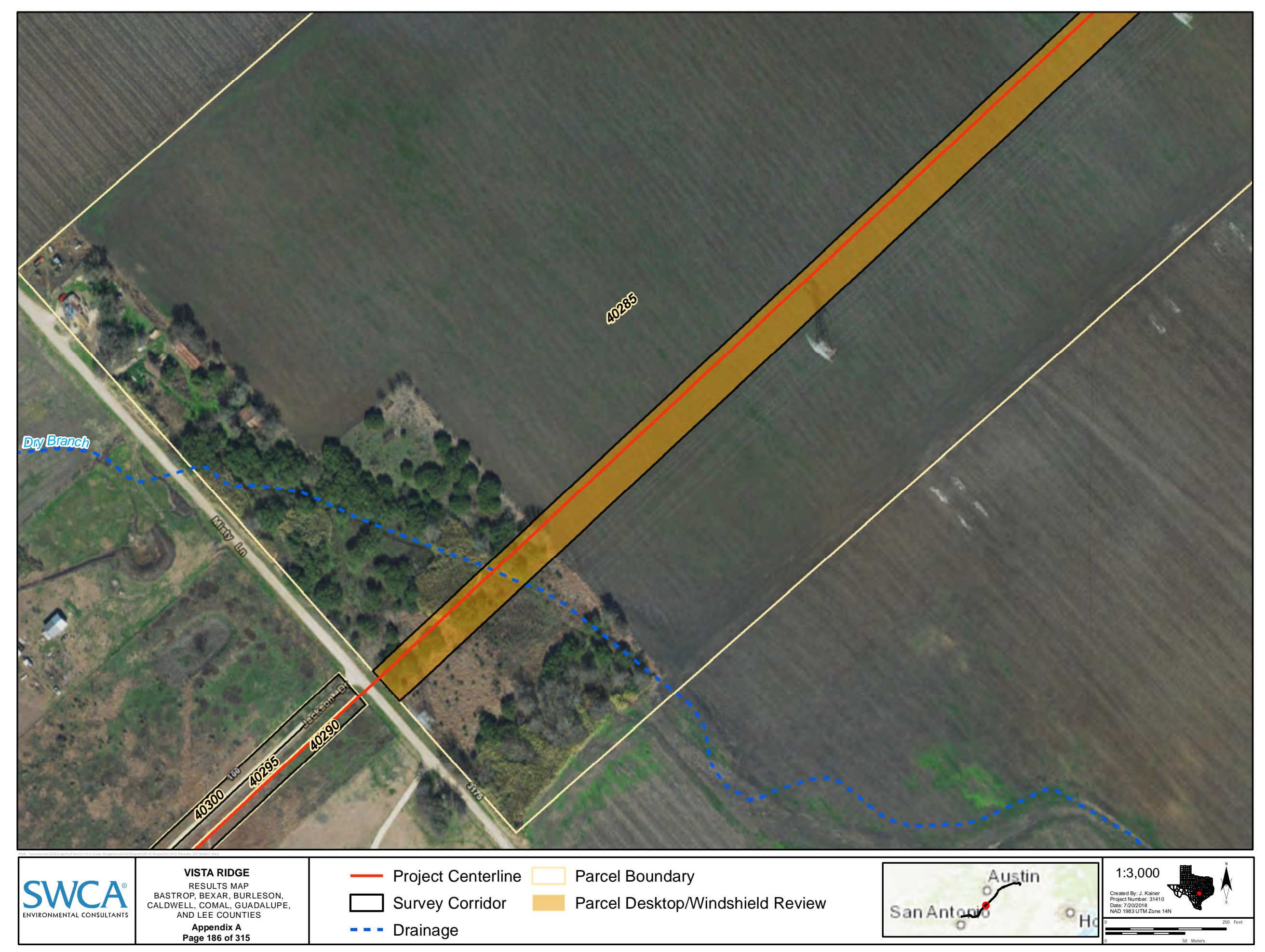




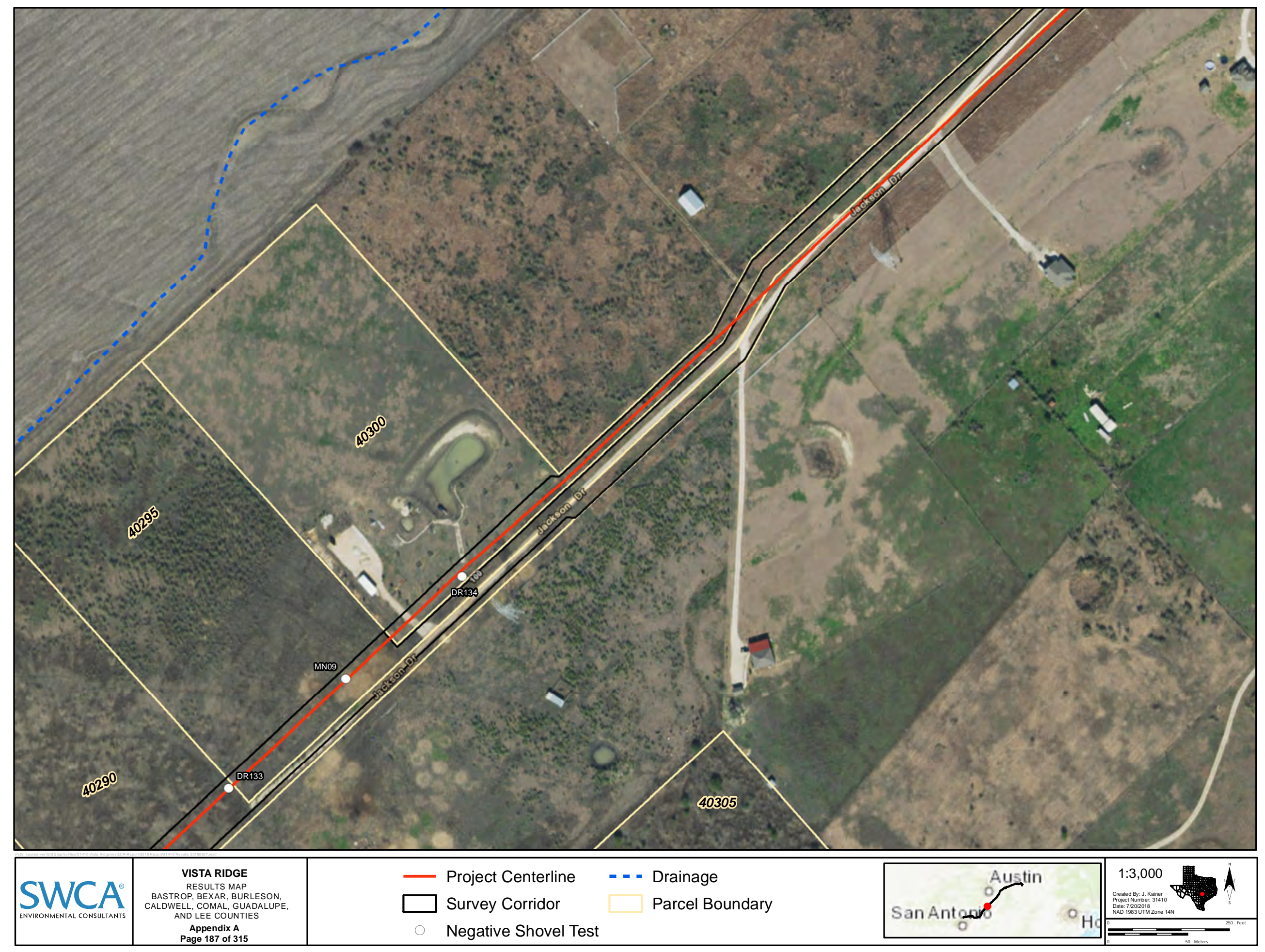


Restricted Information

Not for Public Disclosure 


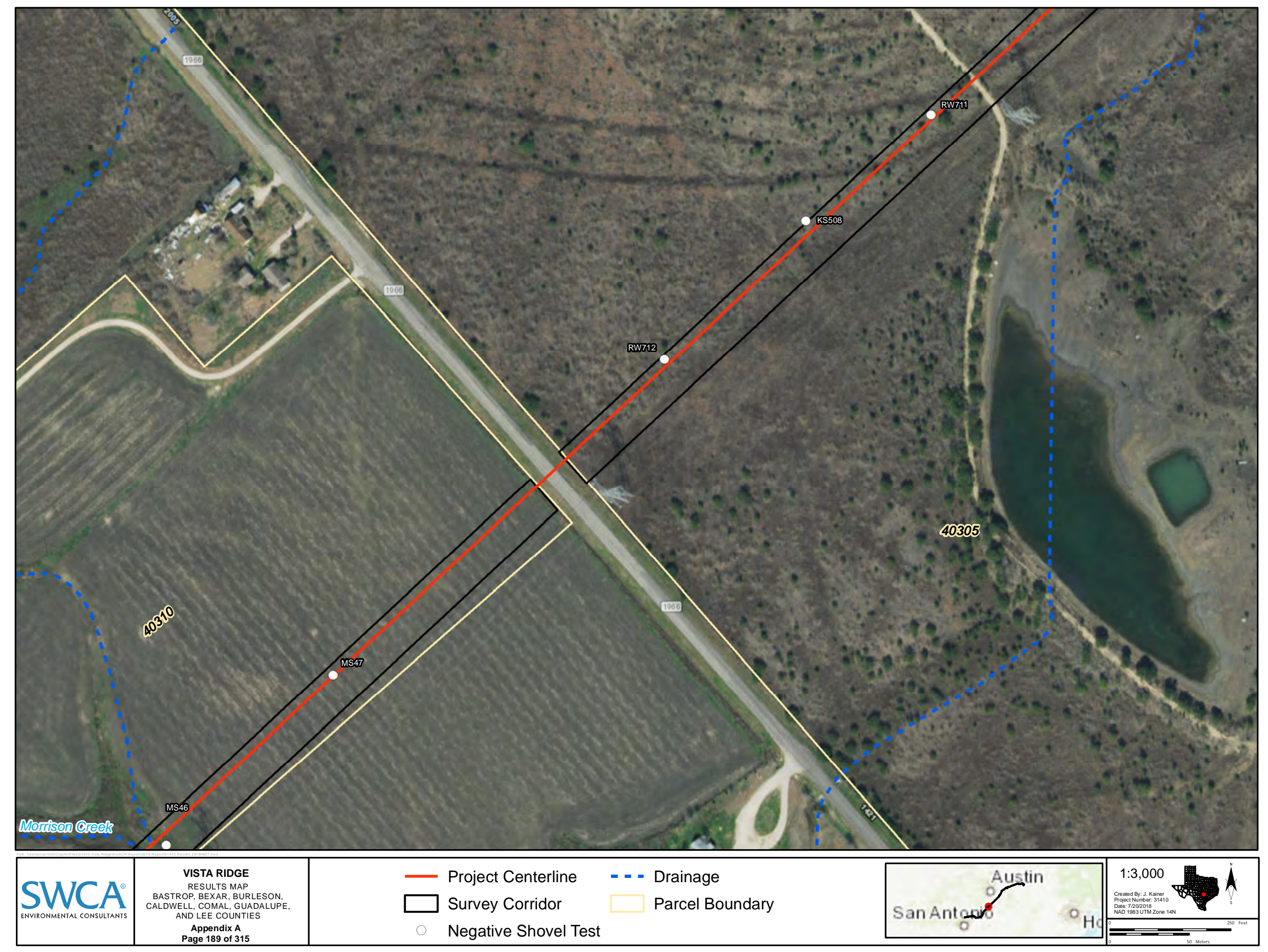


Restricted Information

Not for Public Disclosure 
Restricted Information

Not for Public Disclosure 


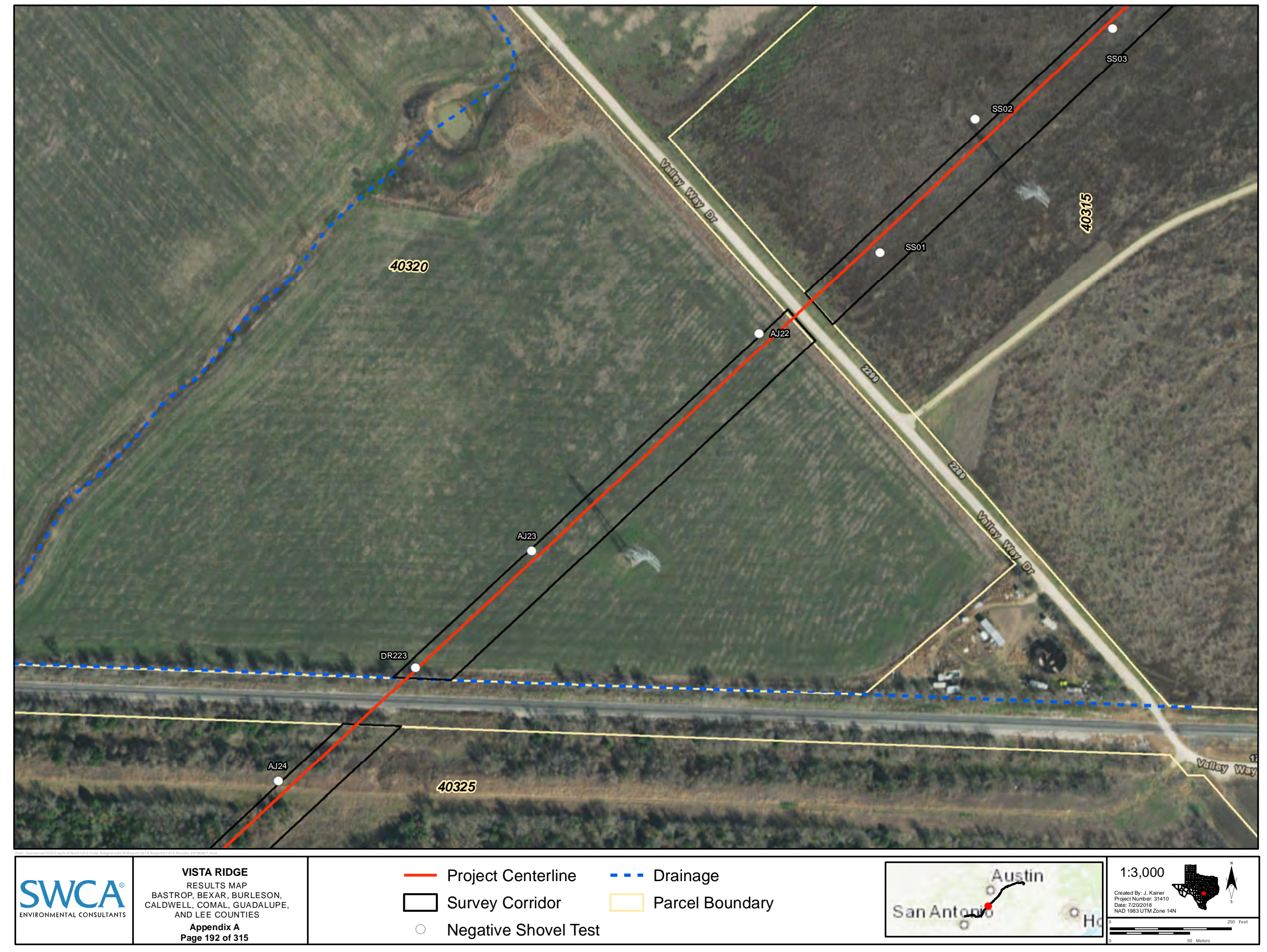




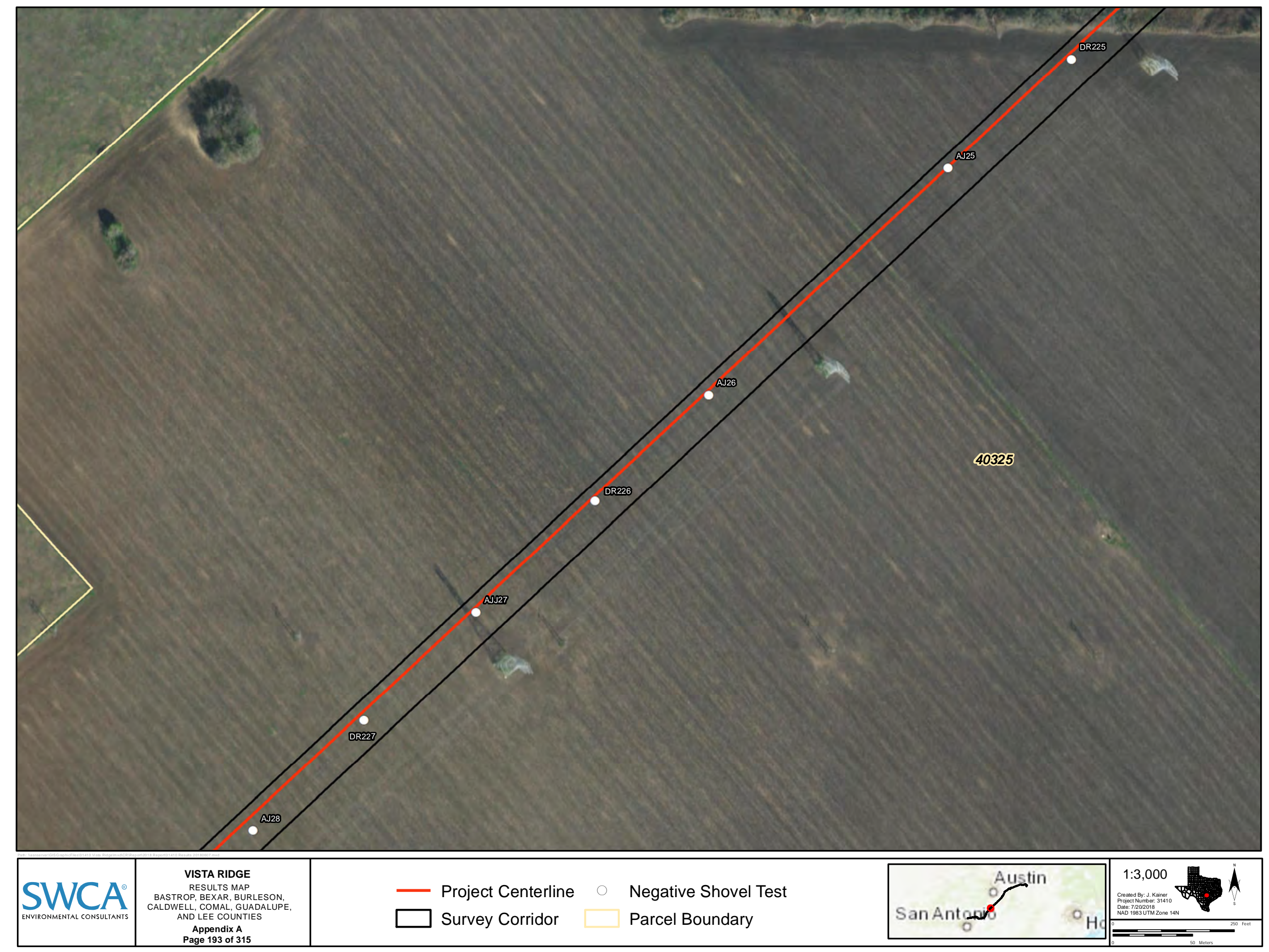




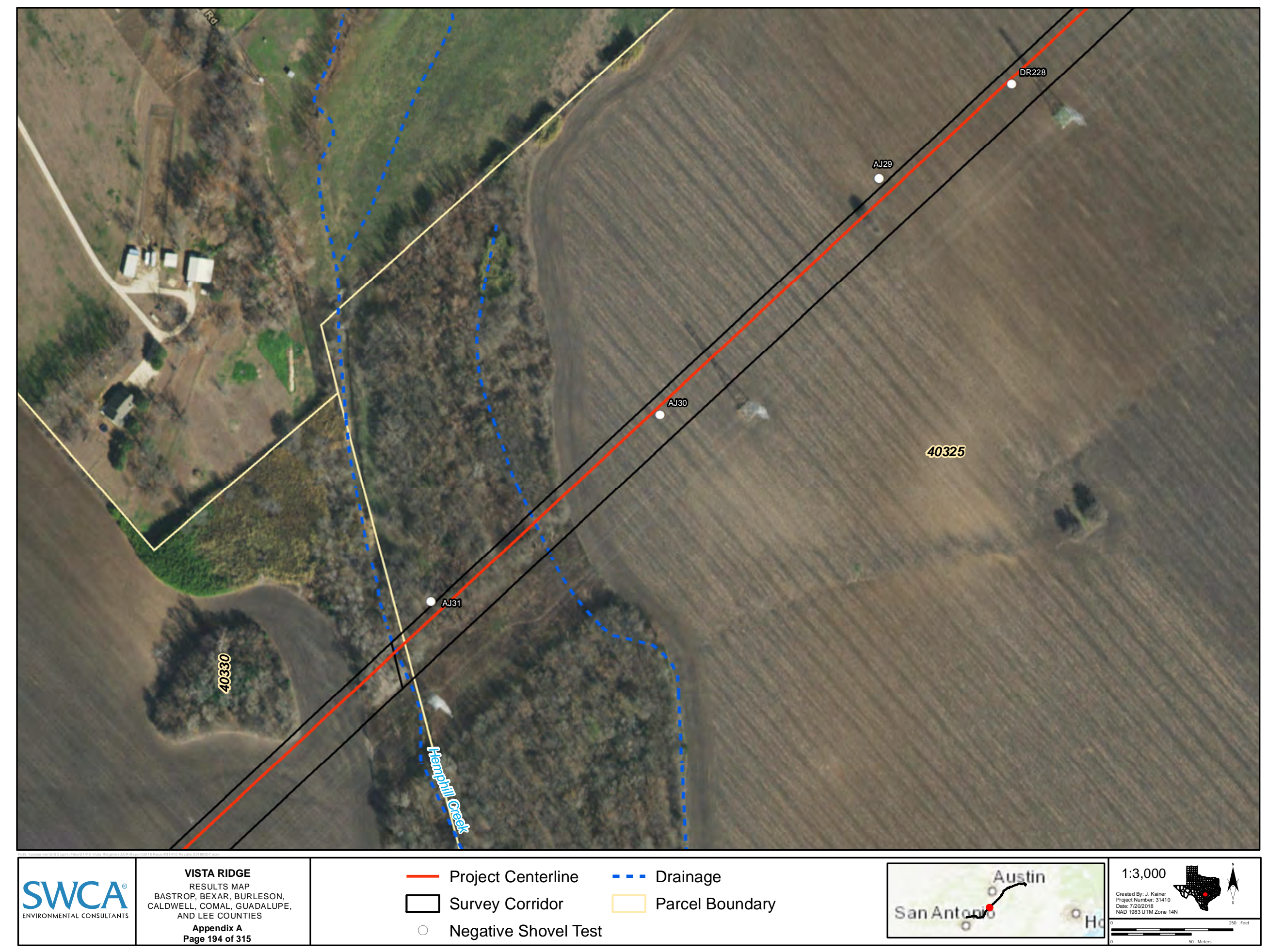




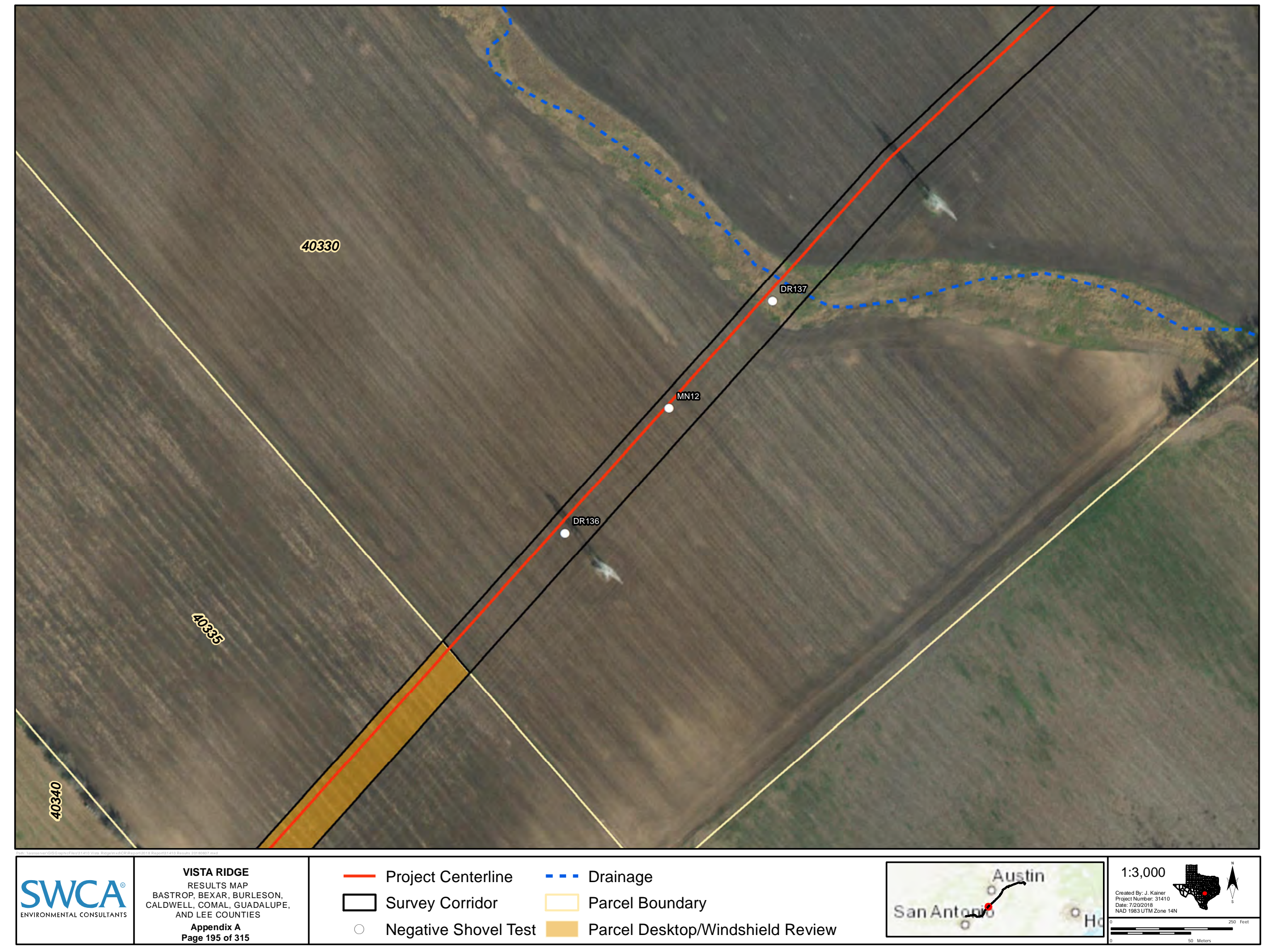




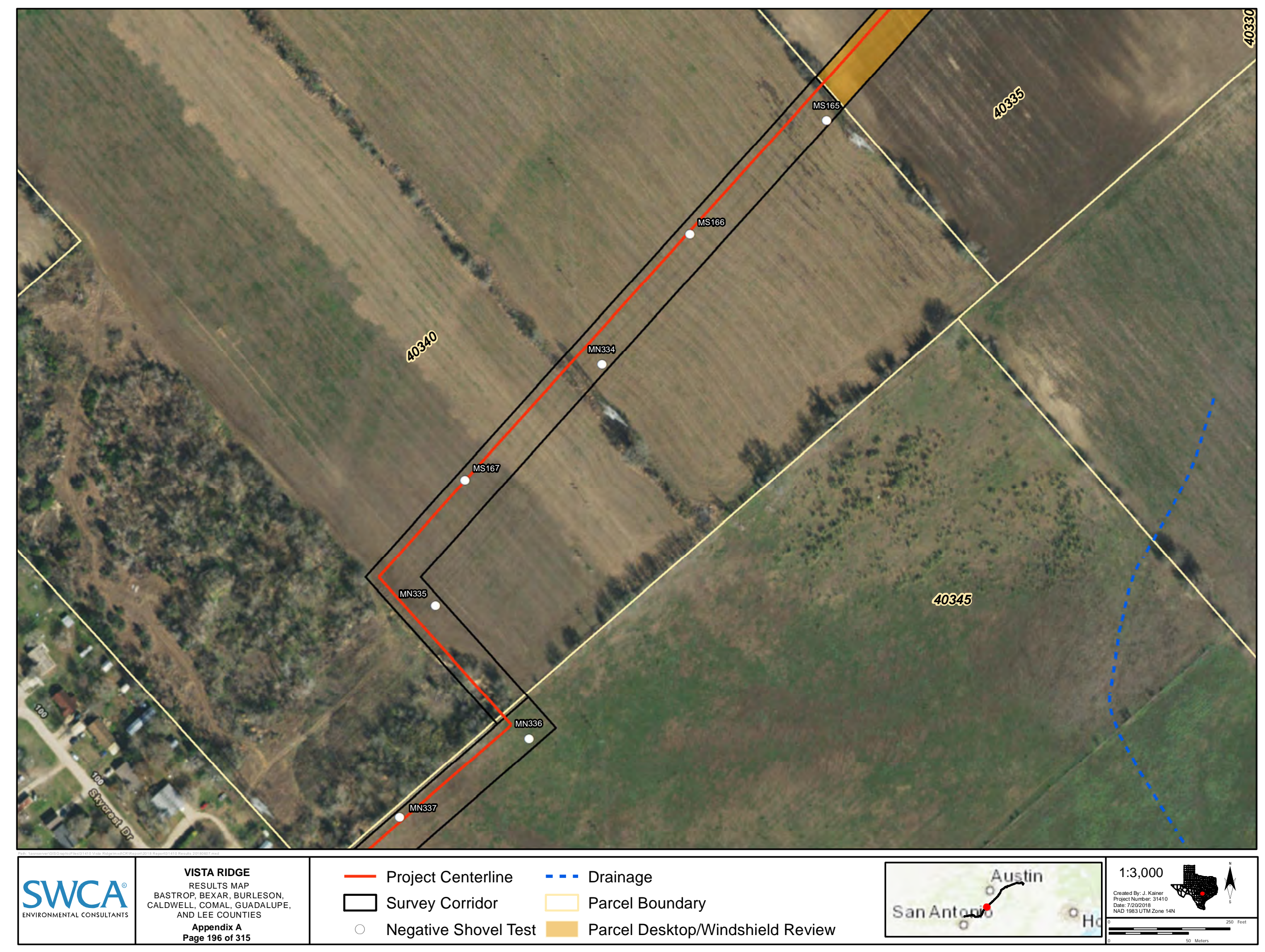




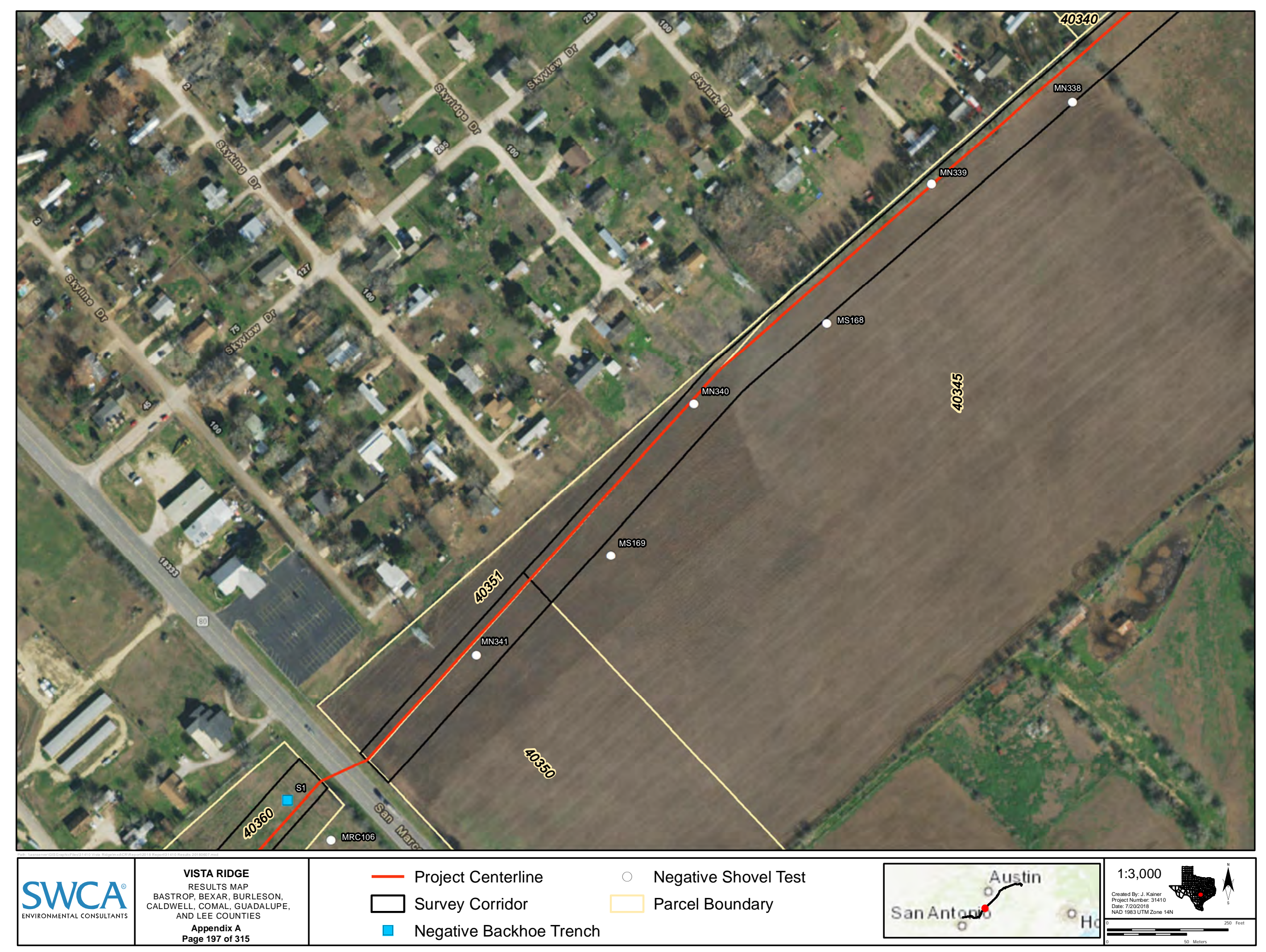




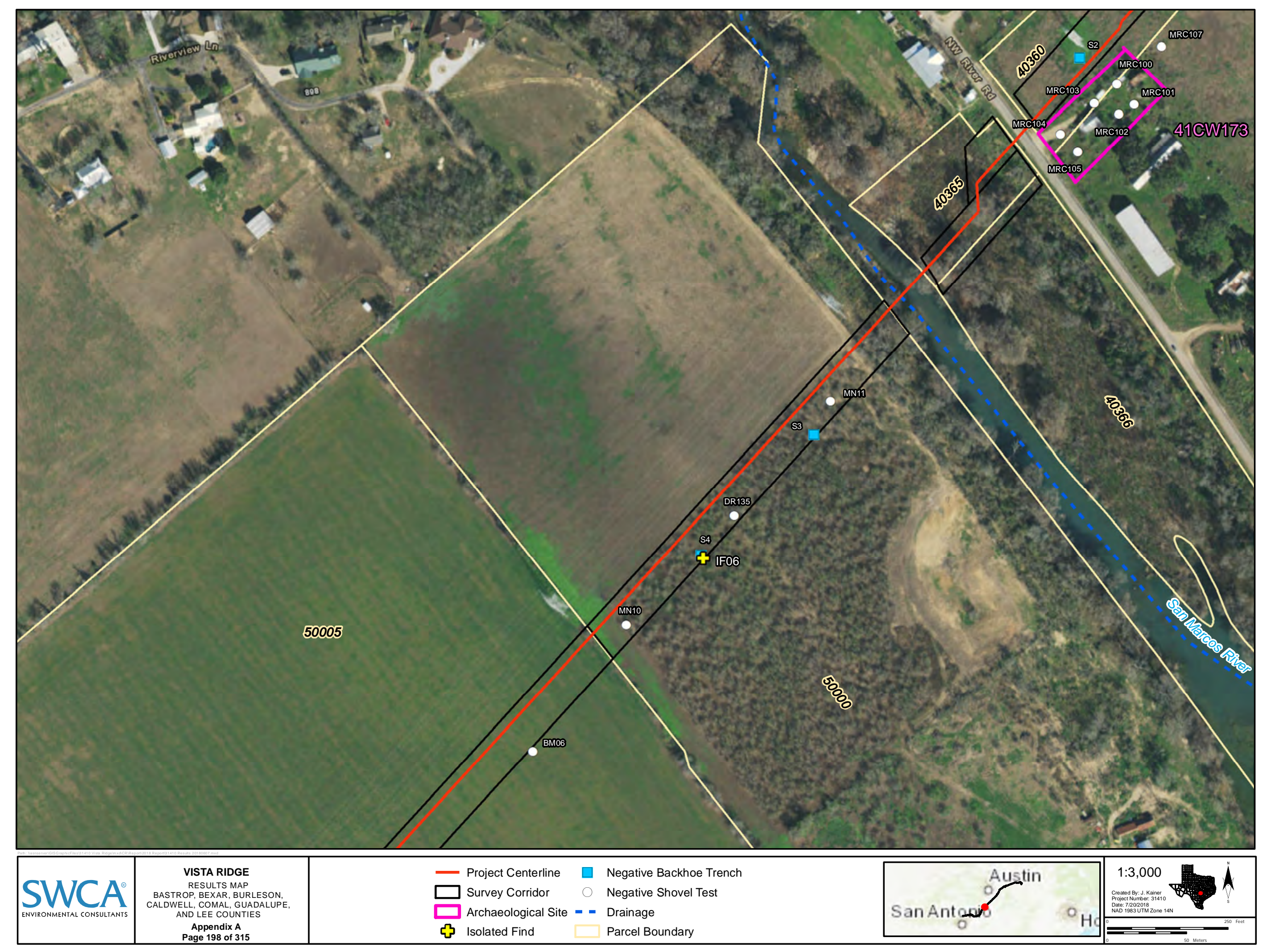




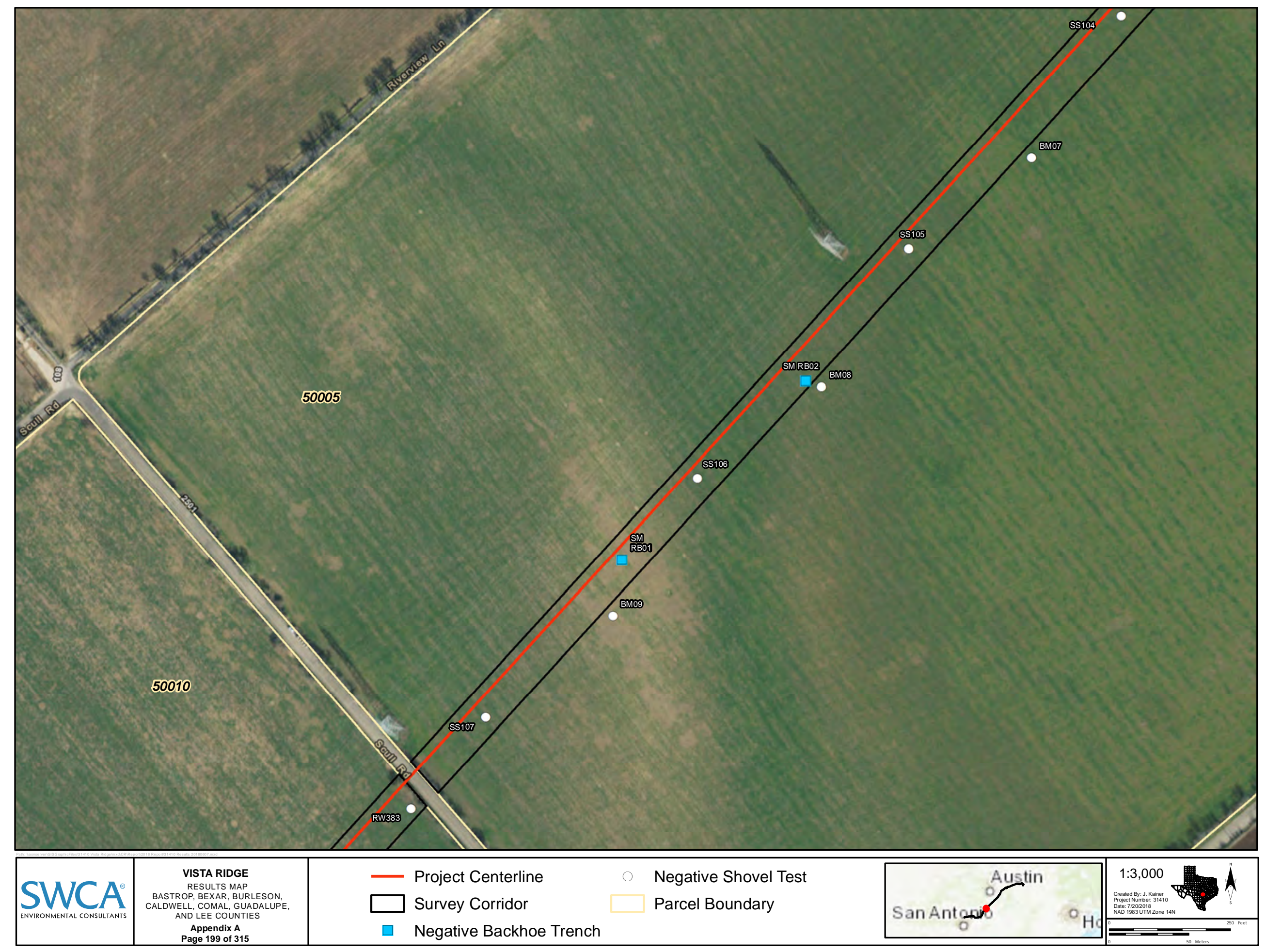




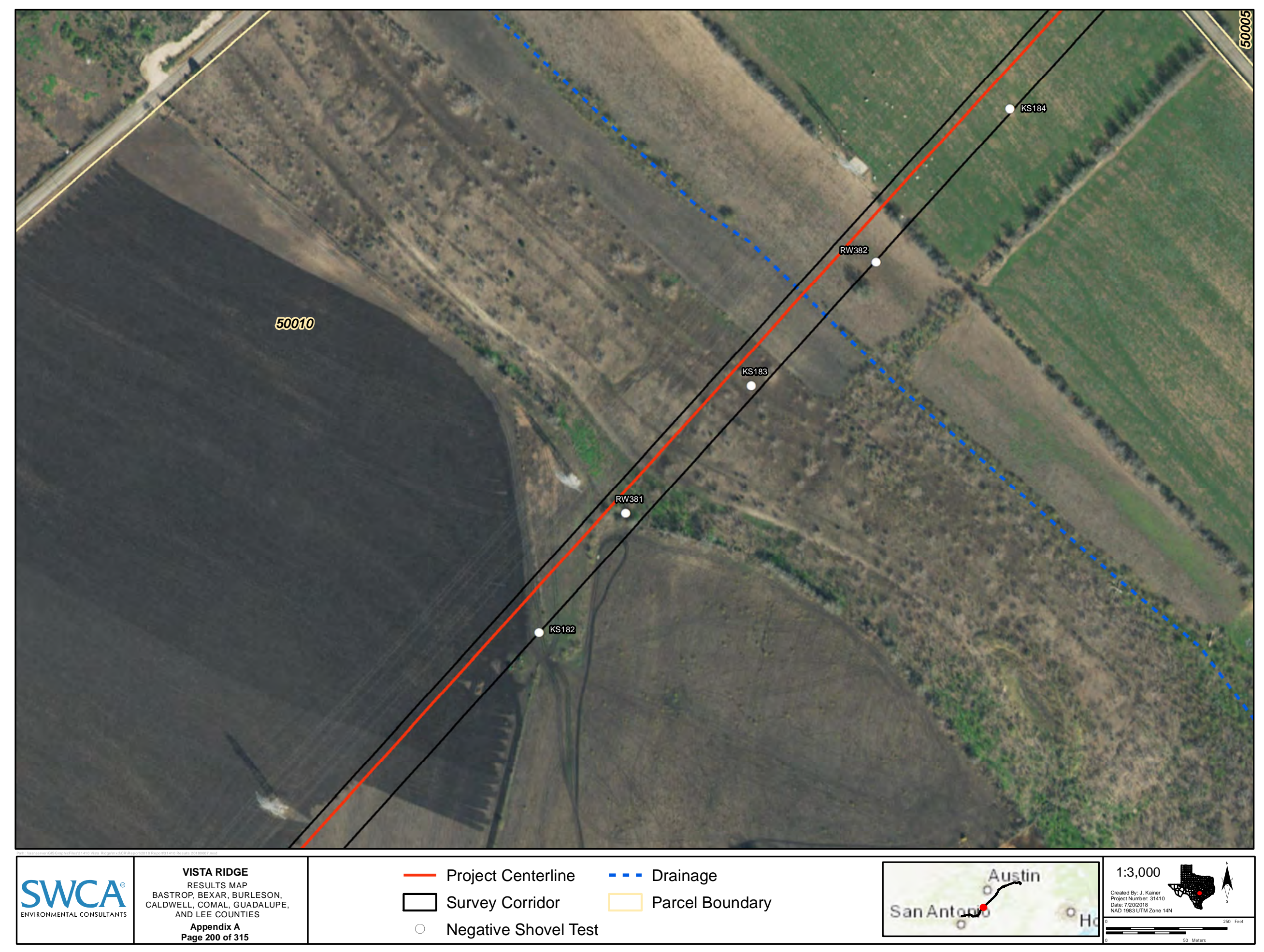




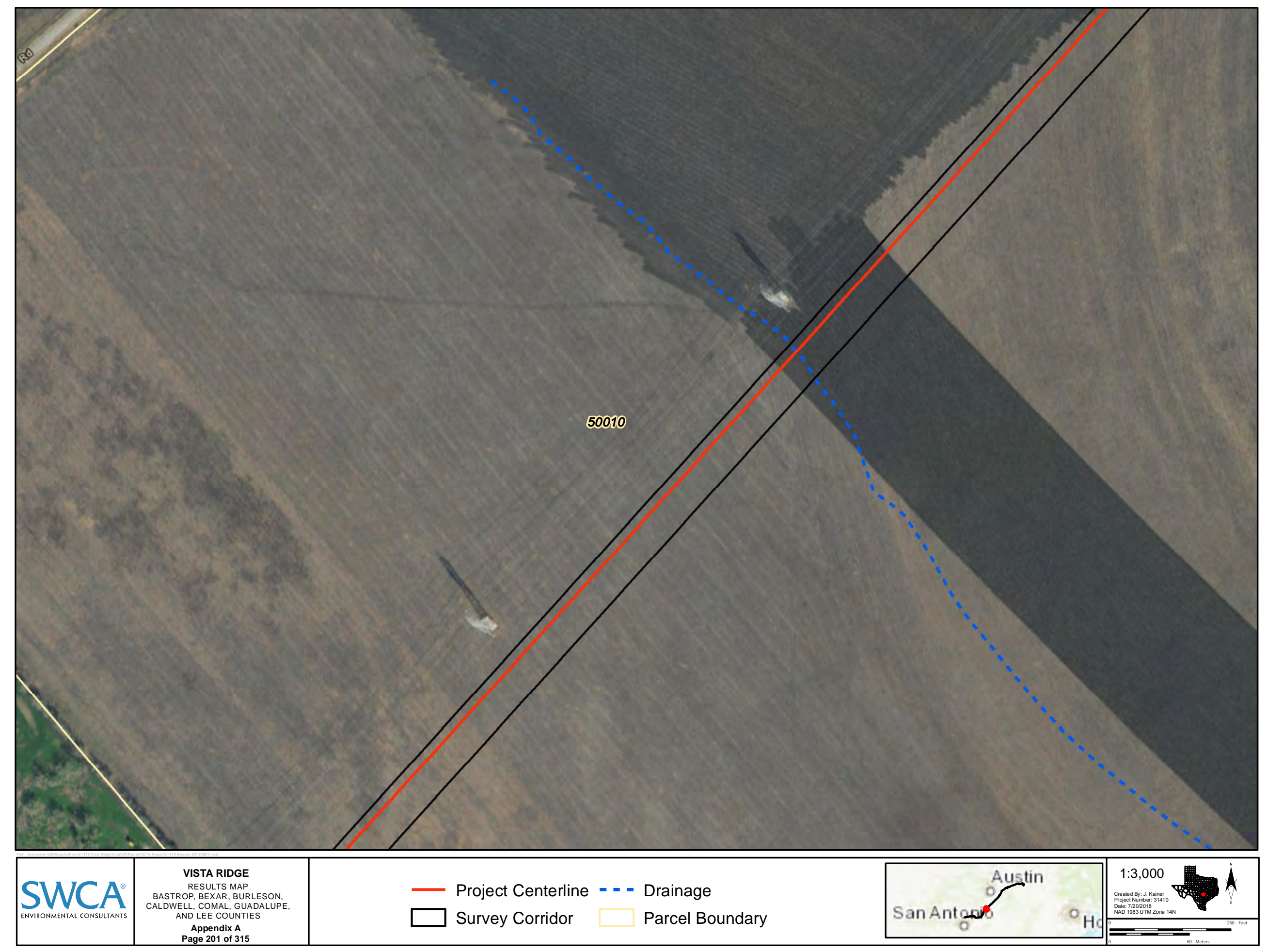




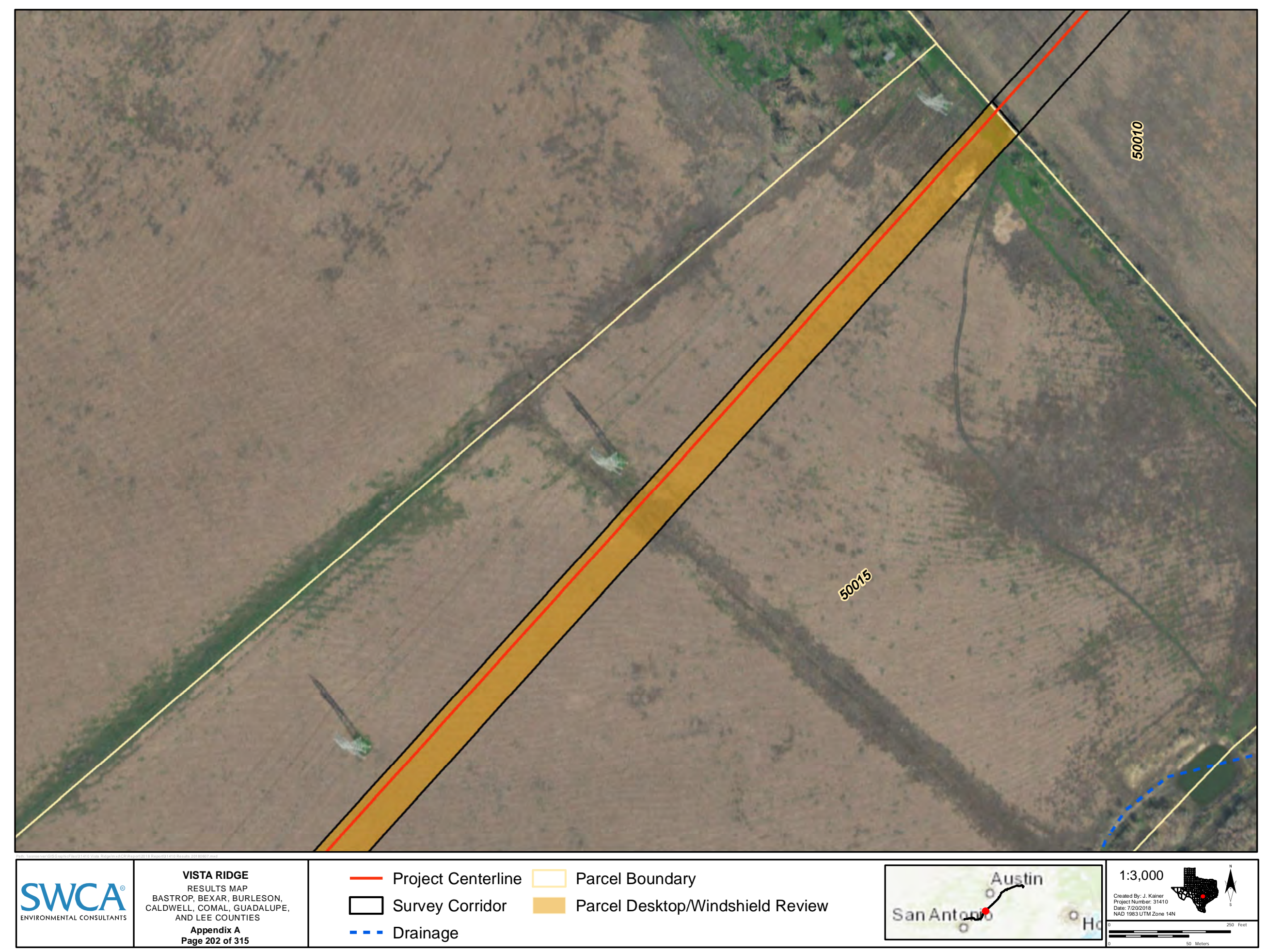




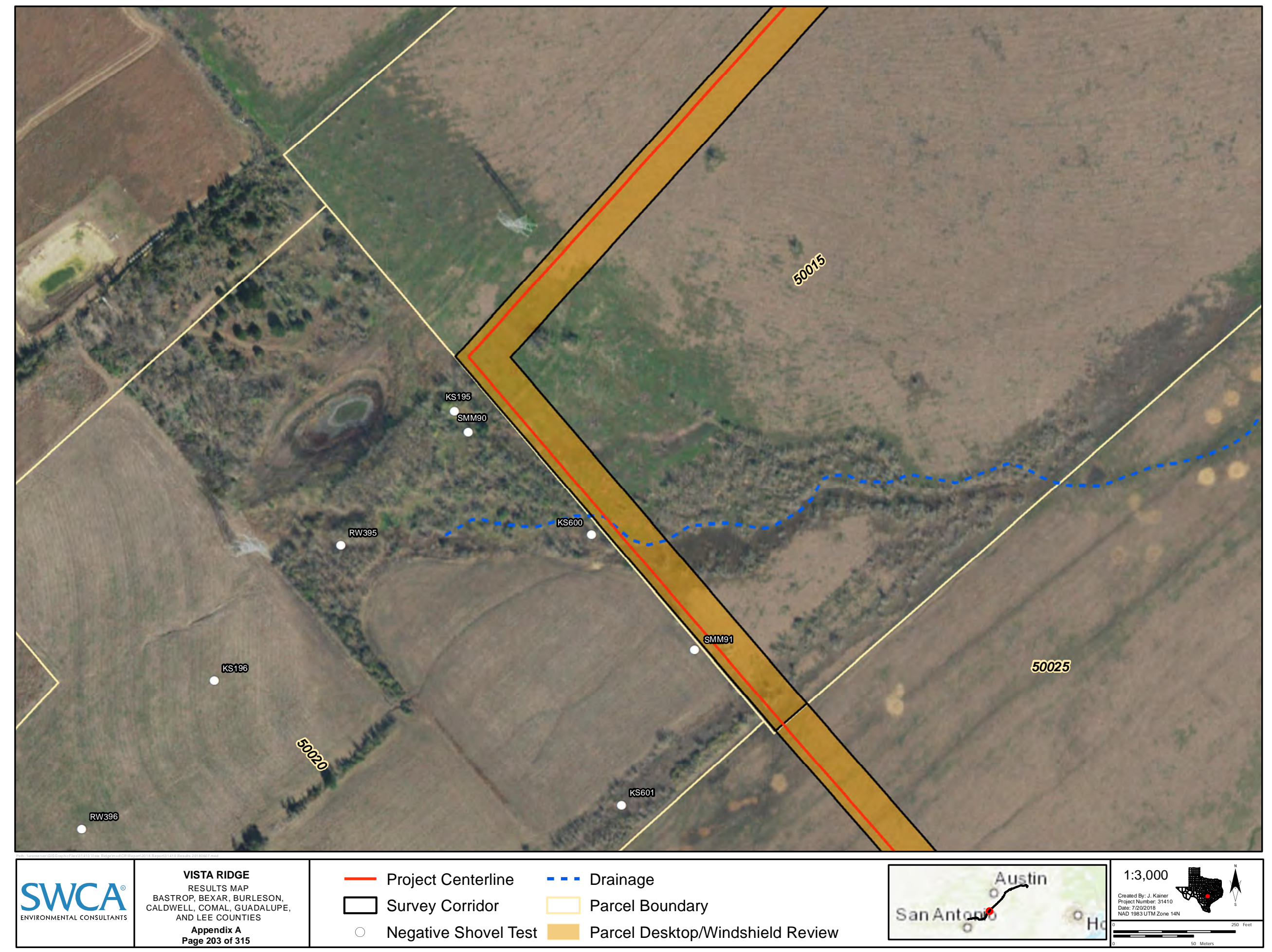


Restricted Information

Not for Public Disclosure 


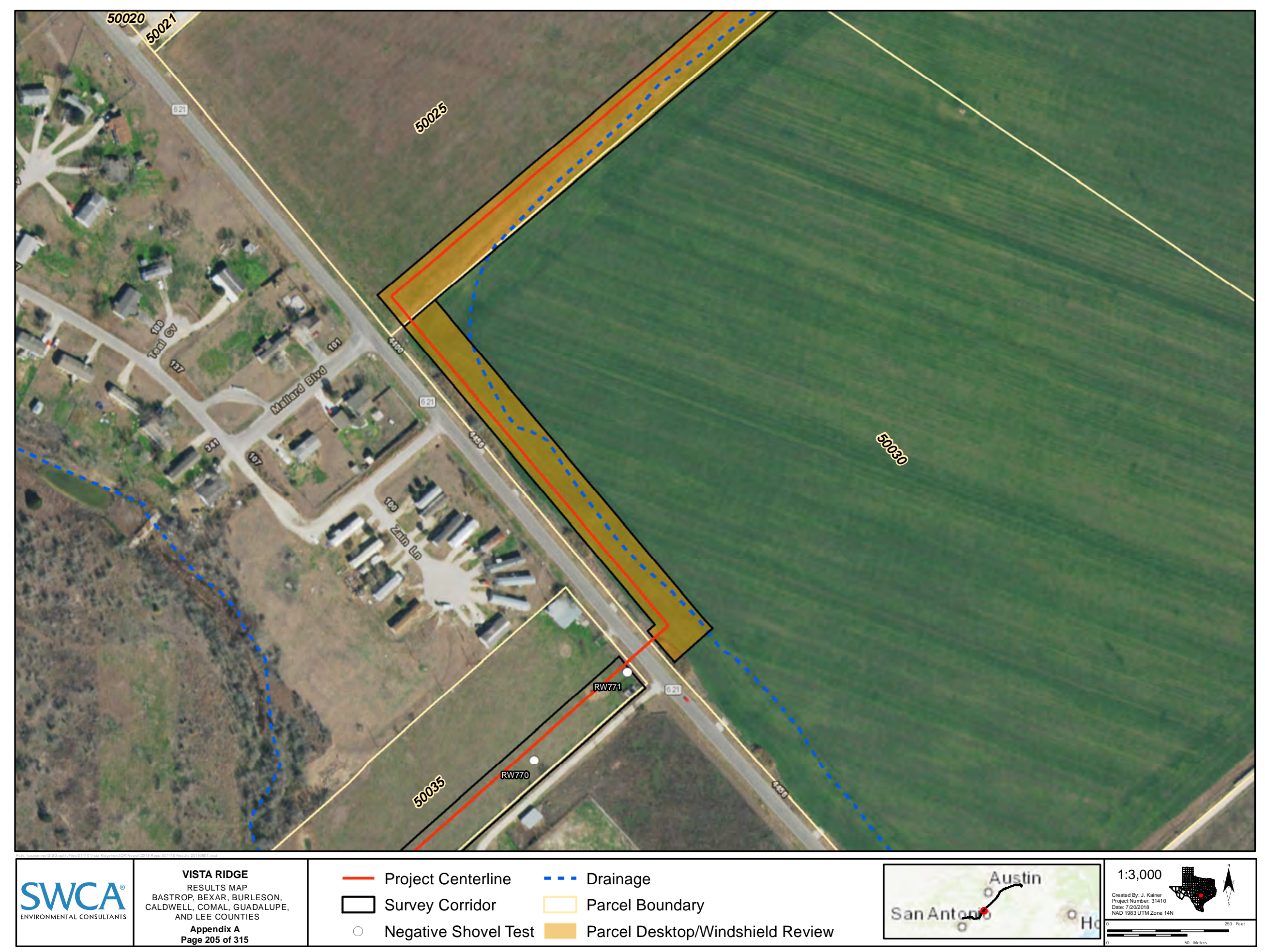




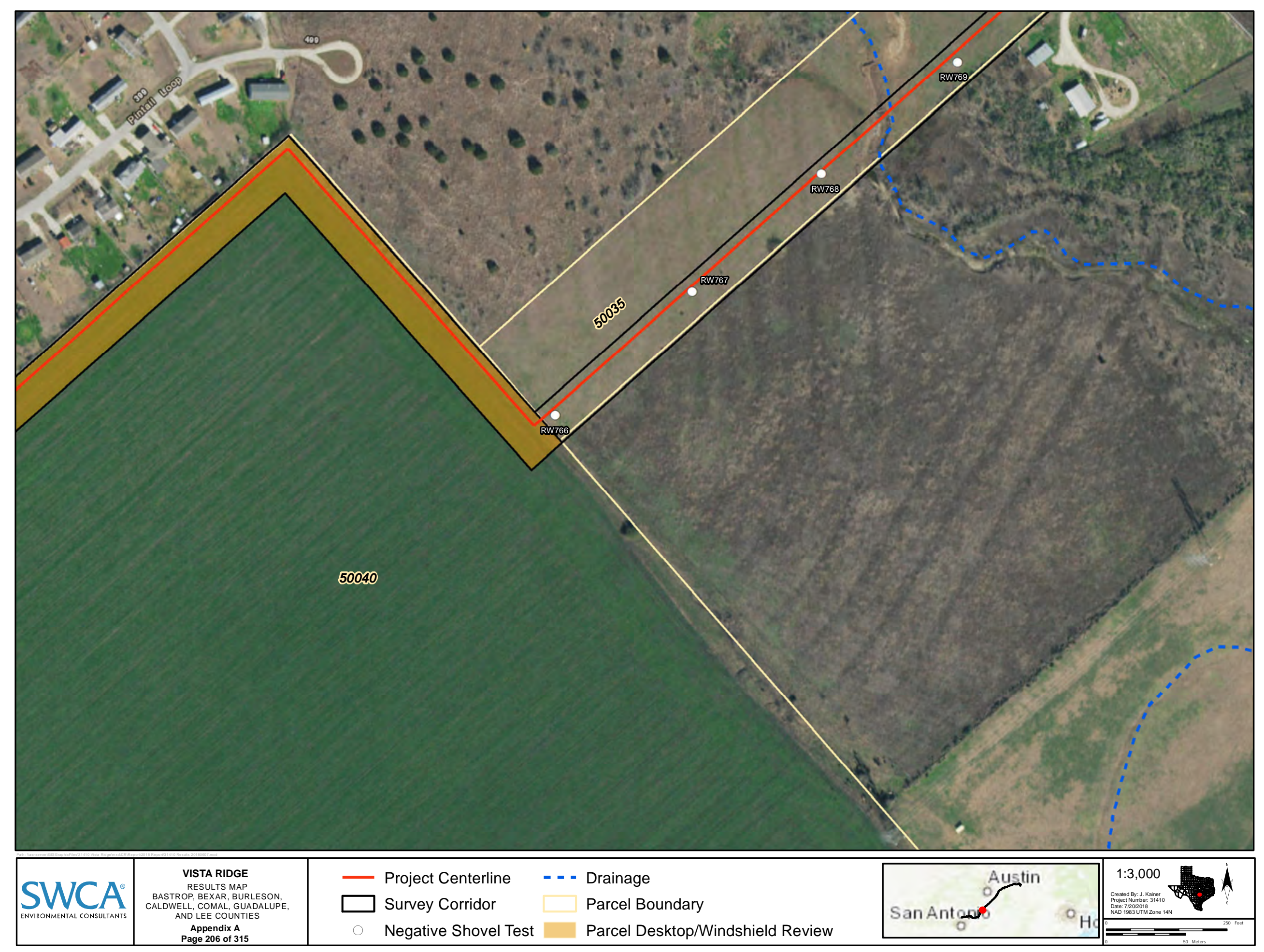




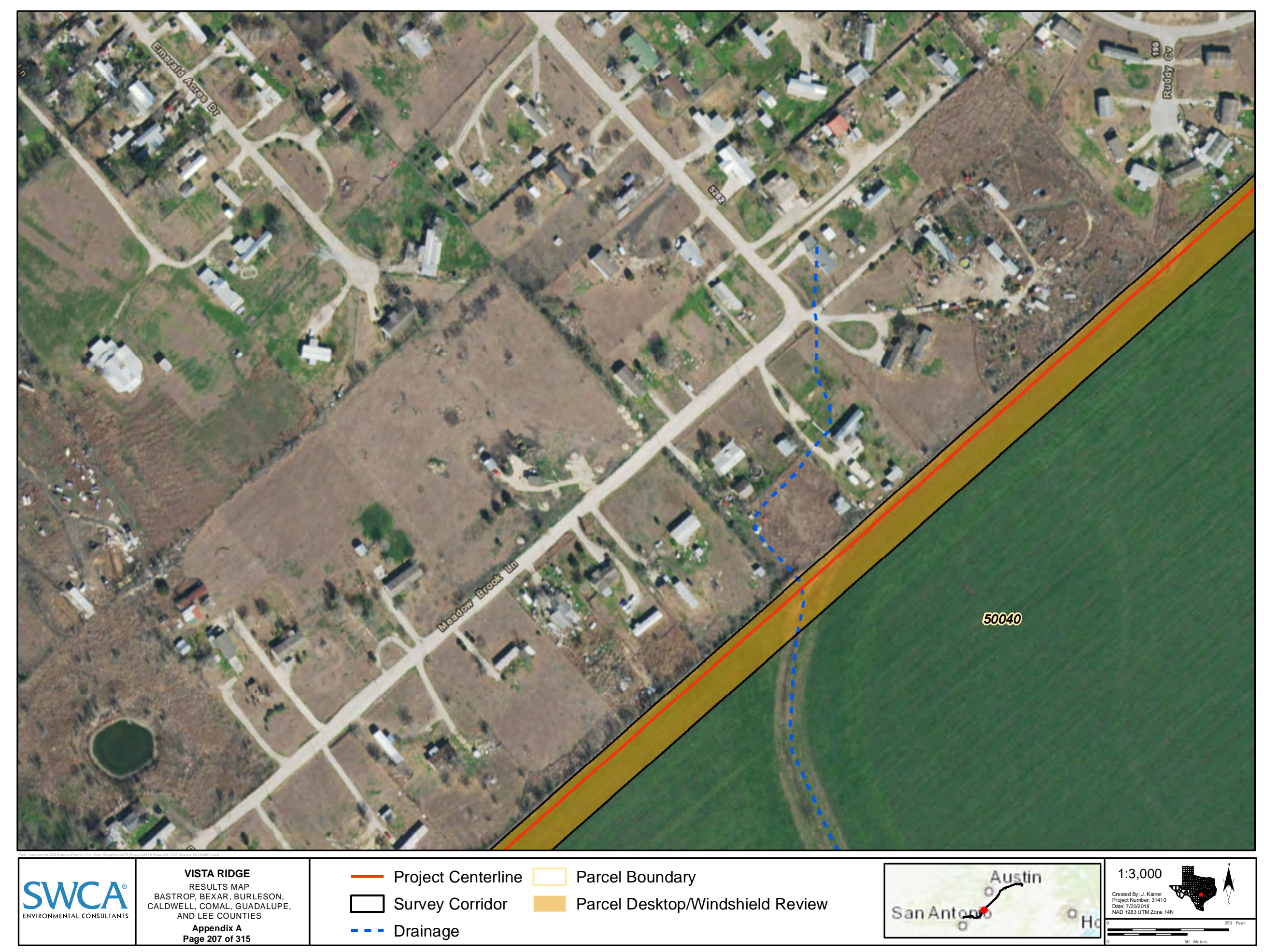




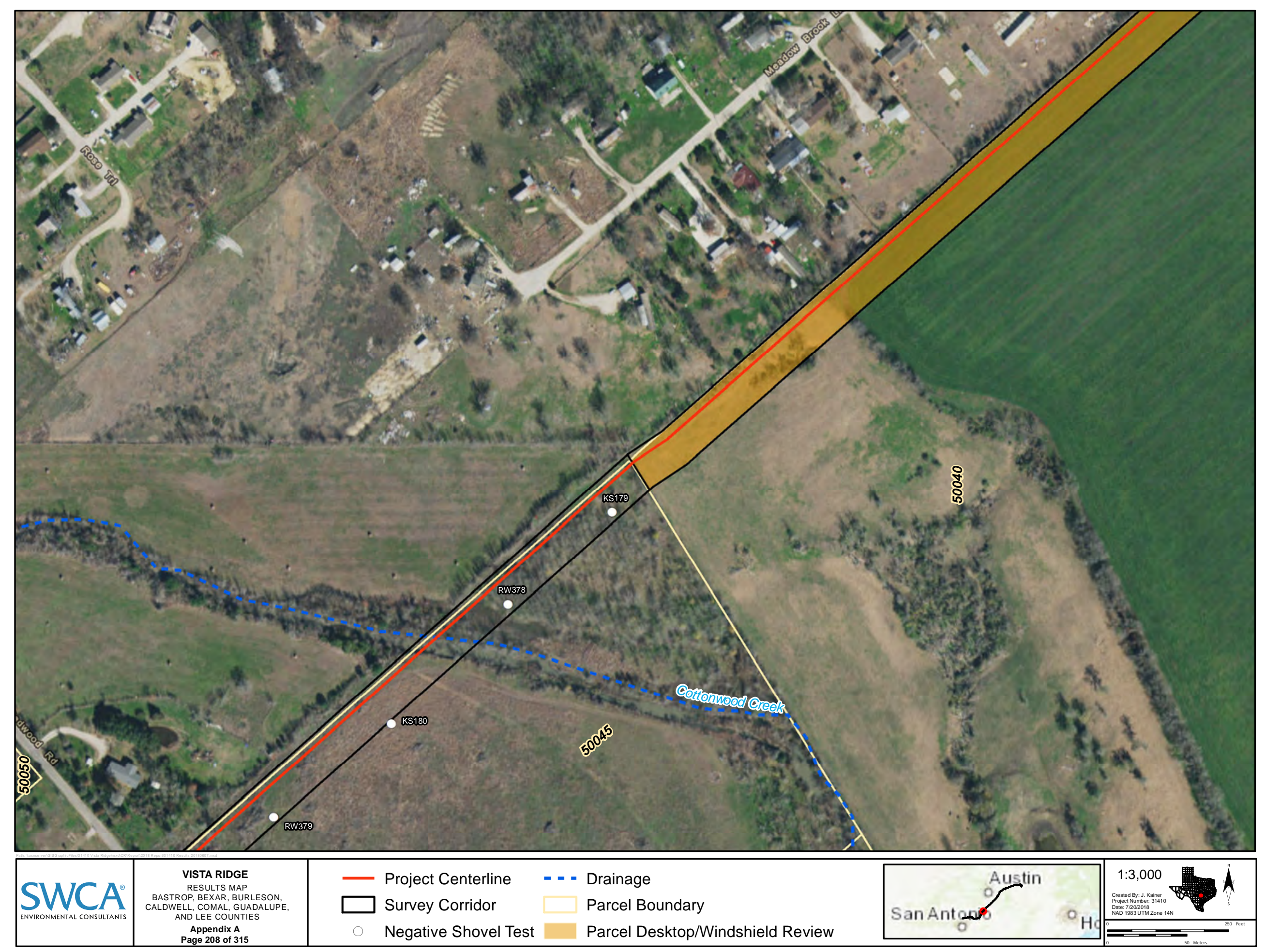




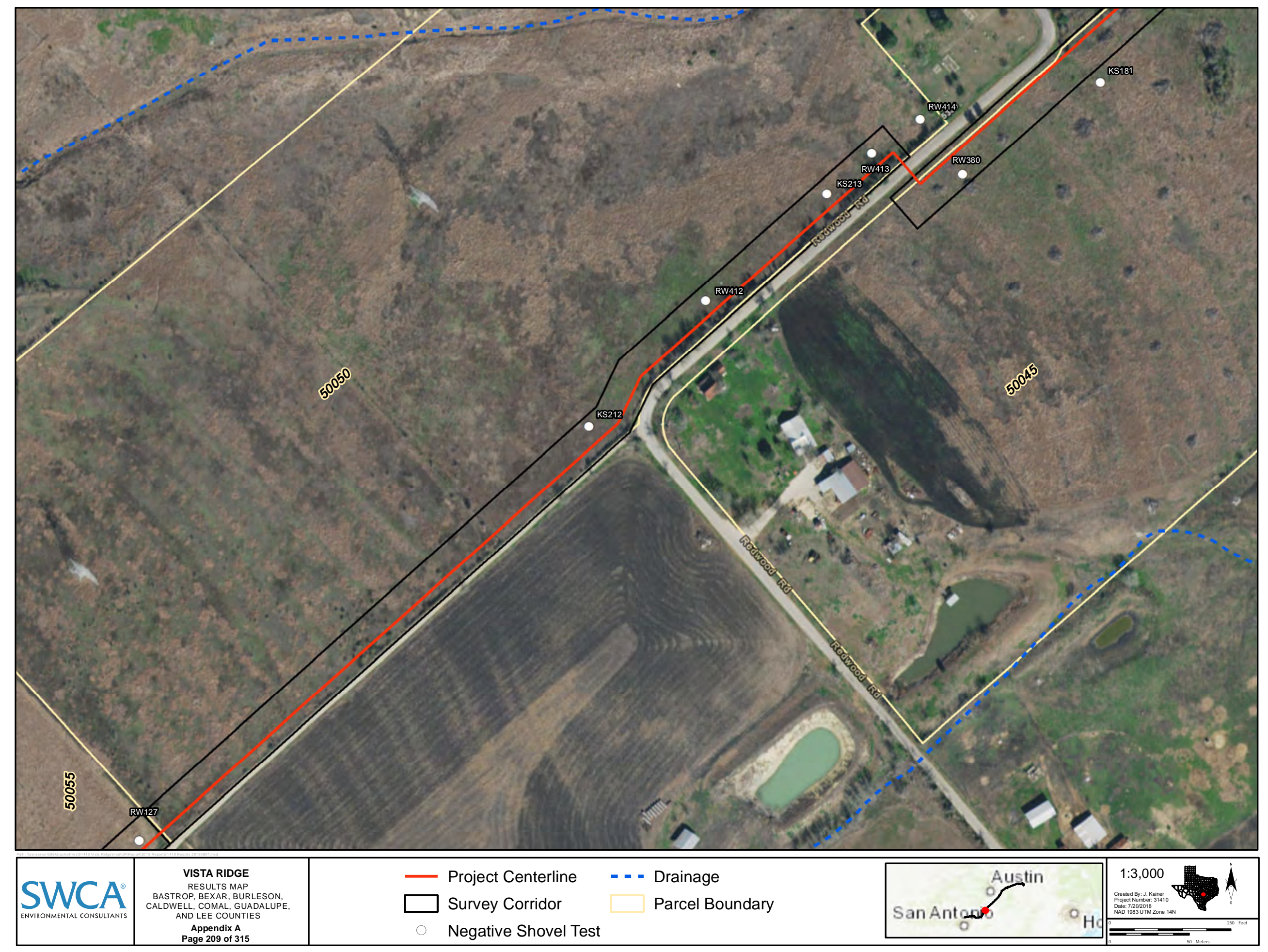




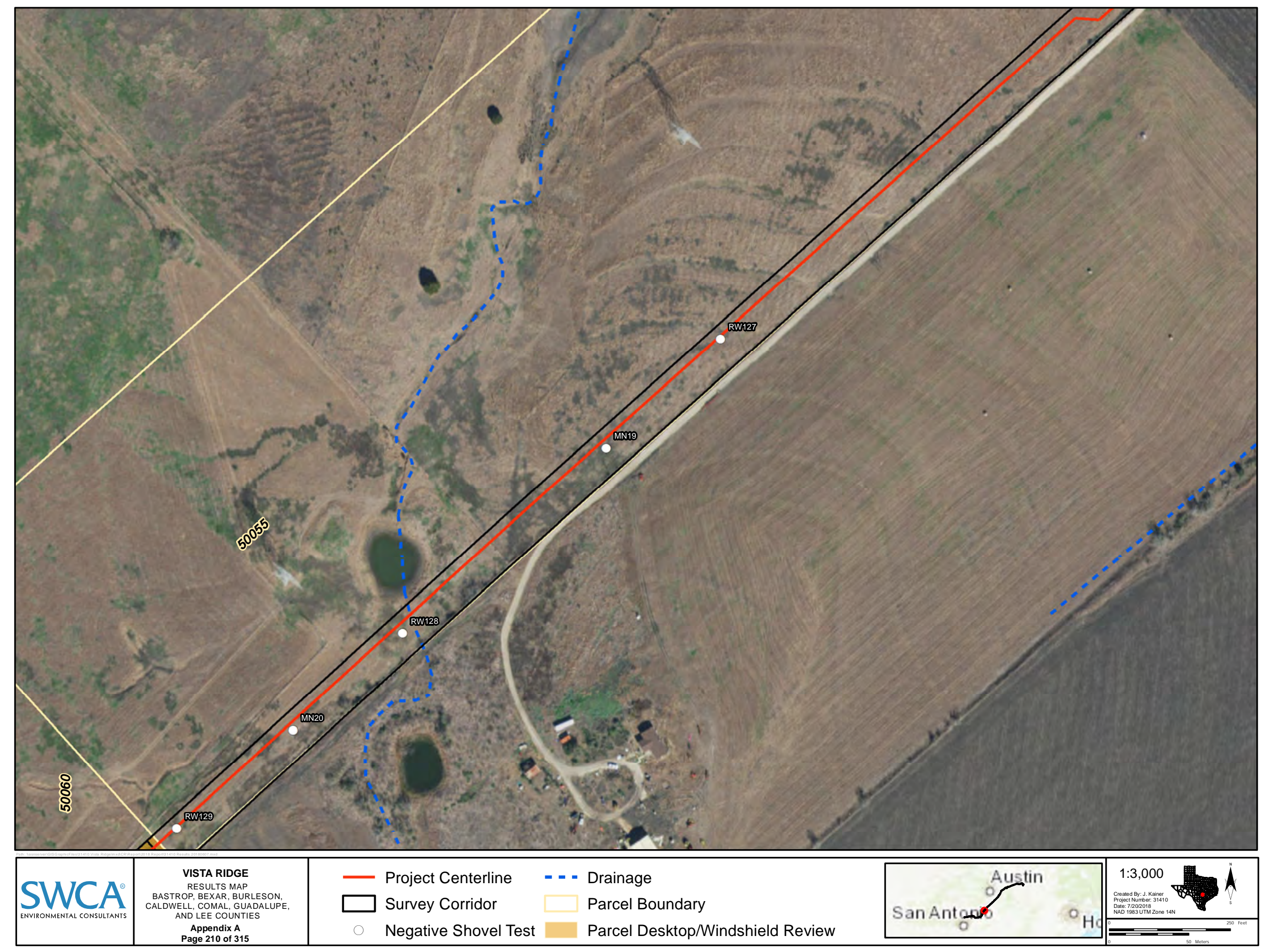




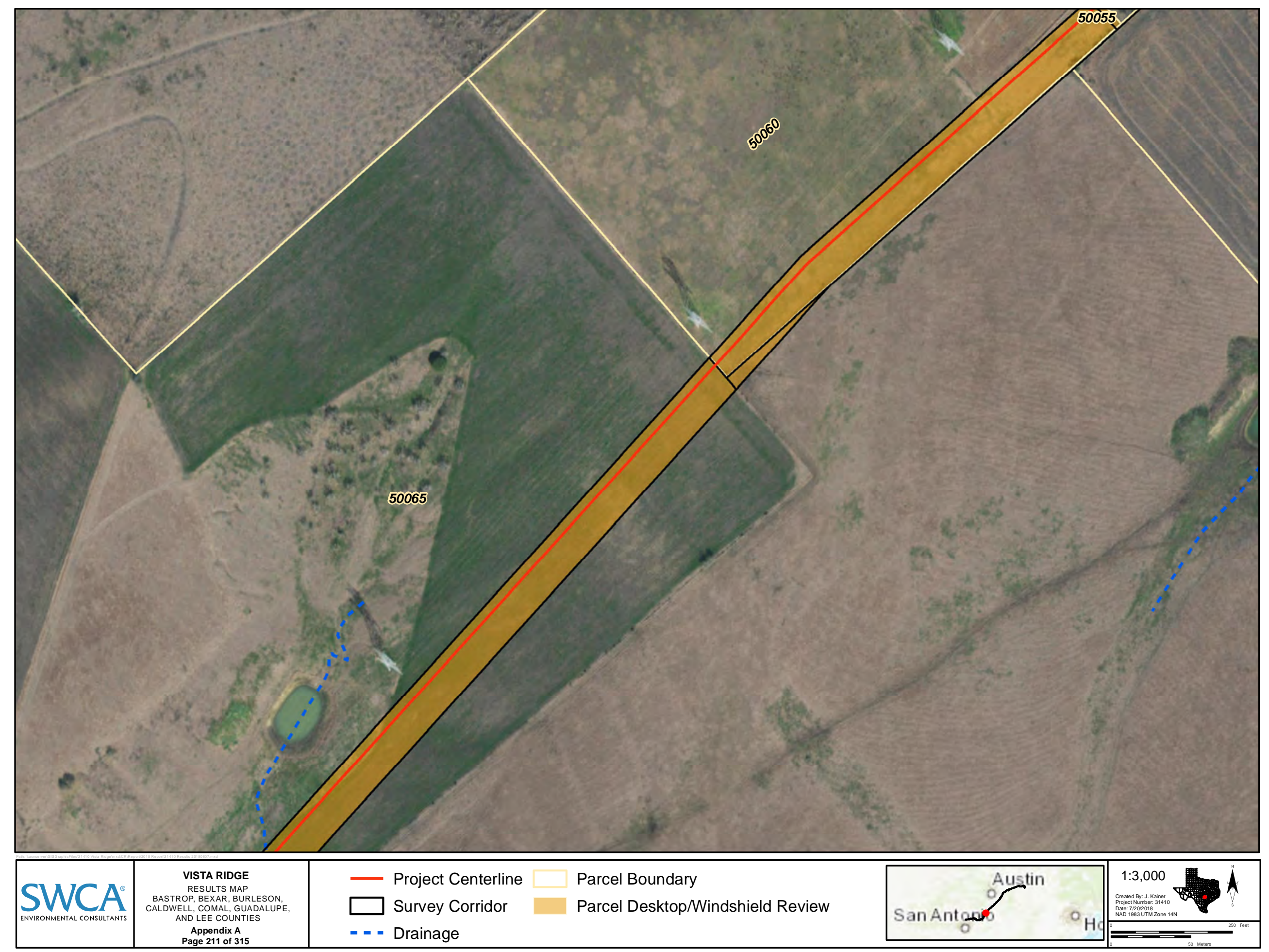




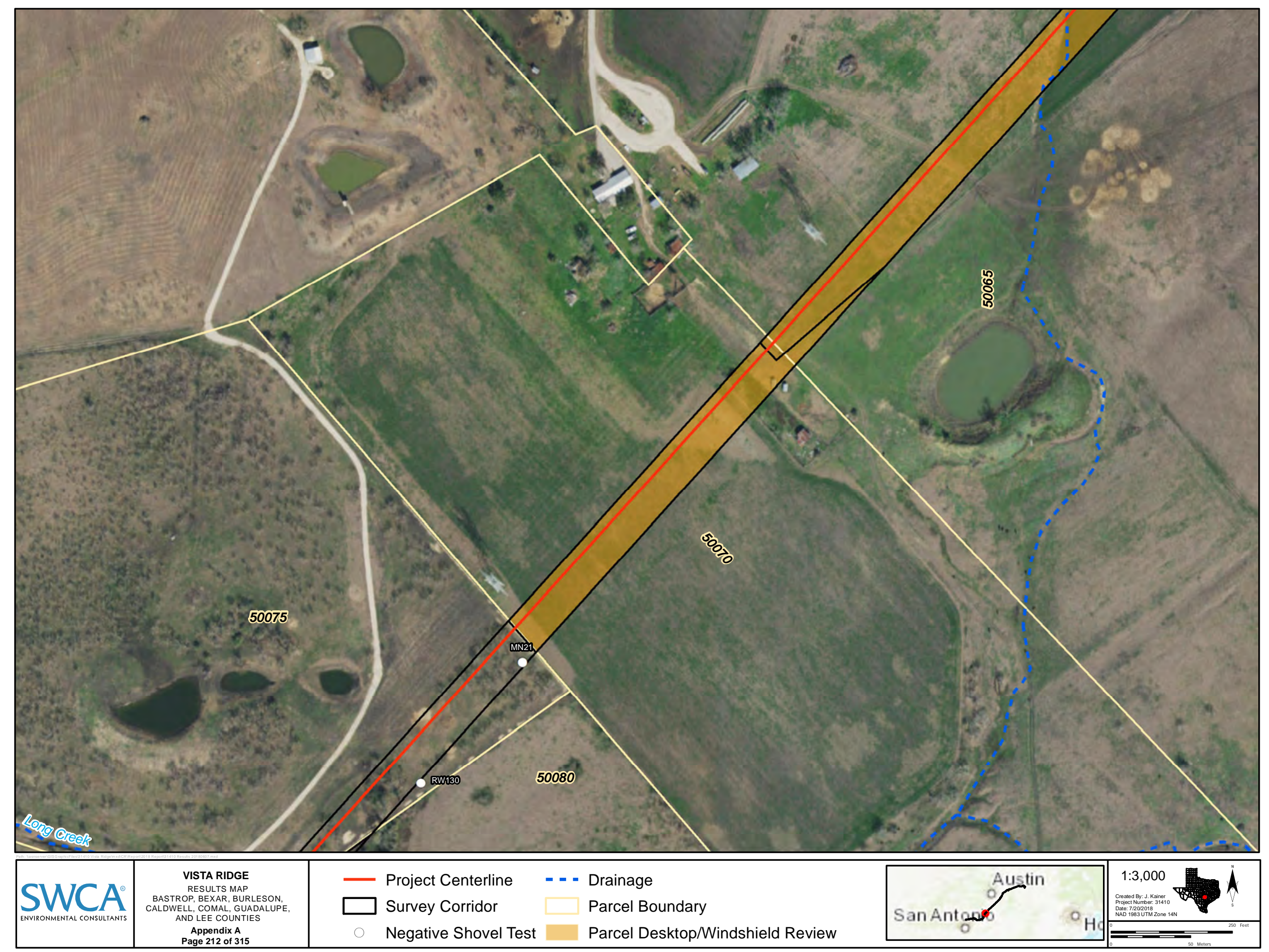




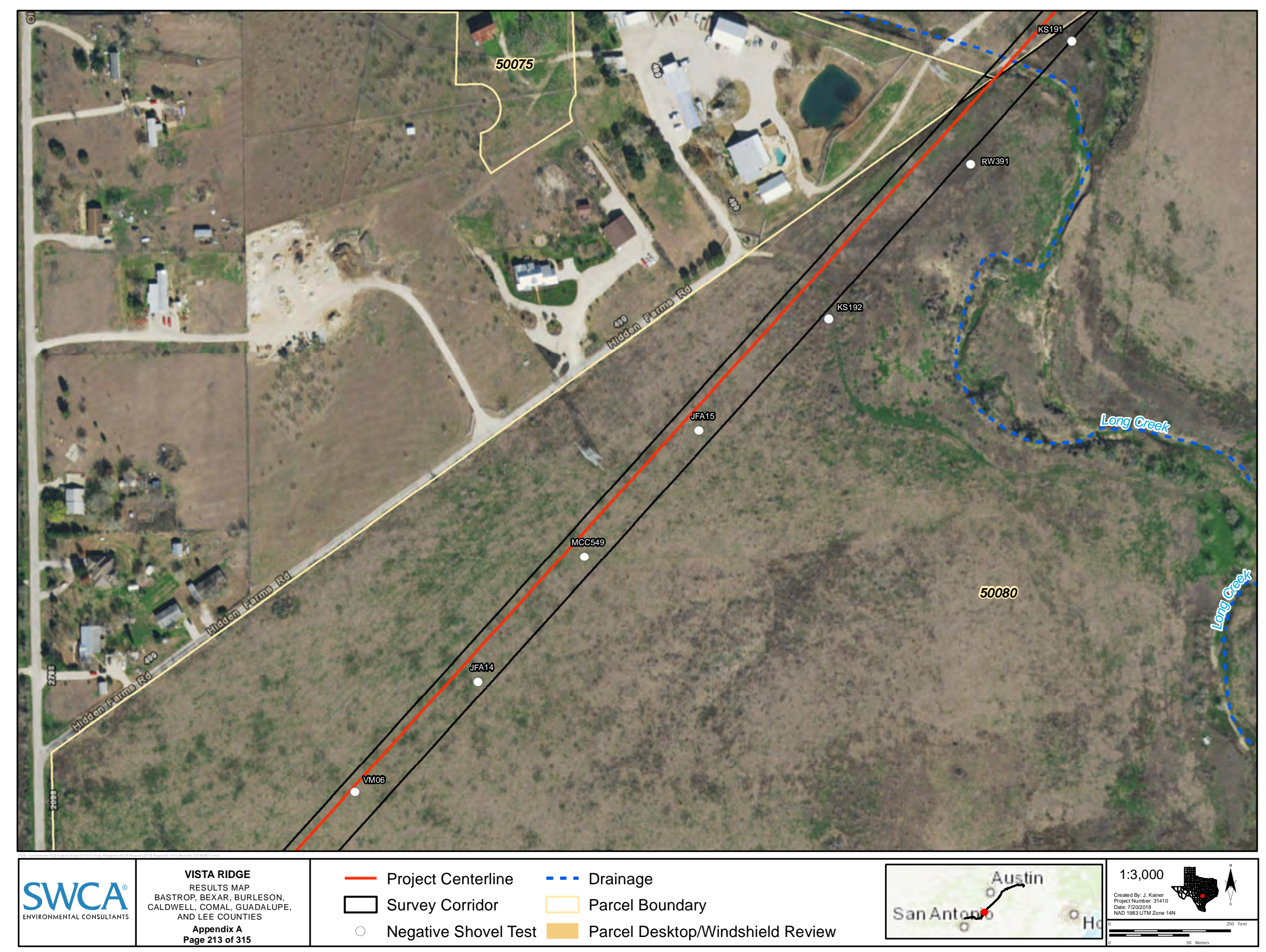




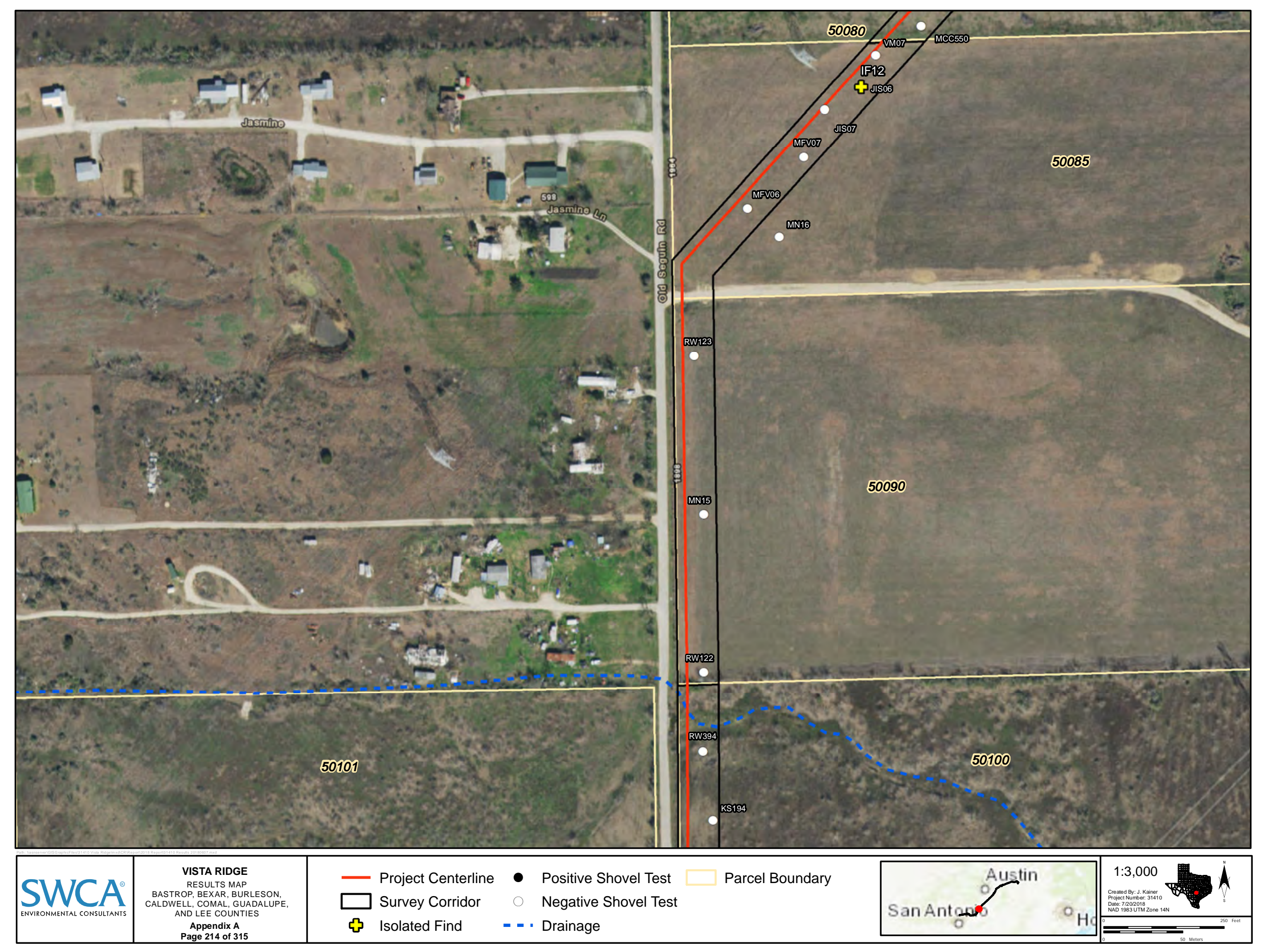




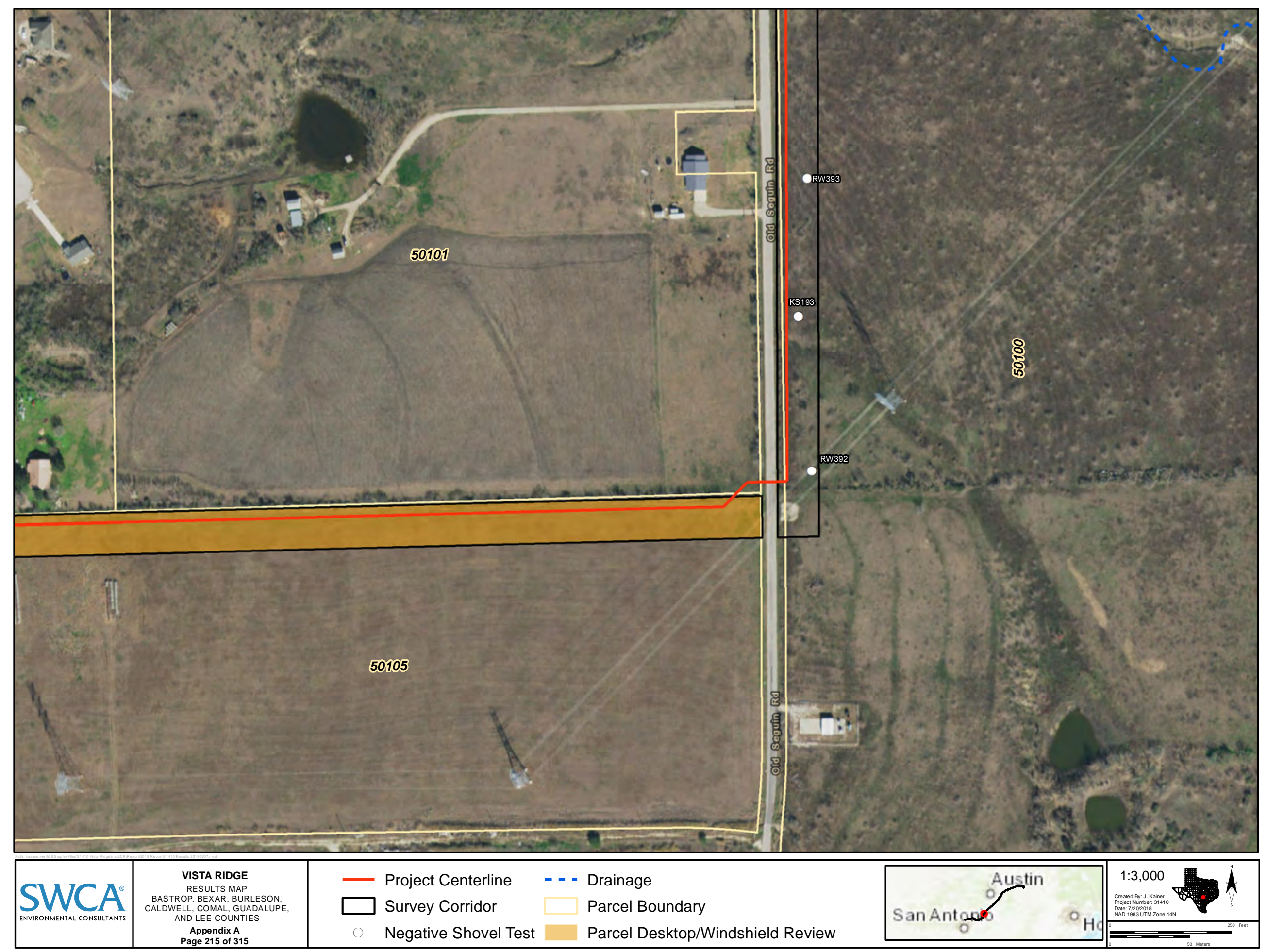




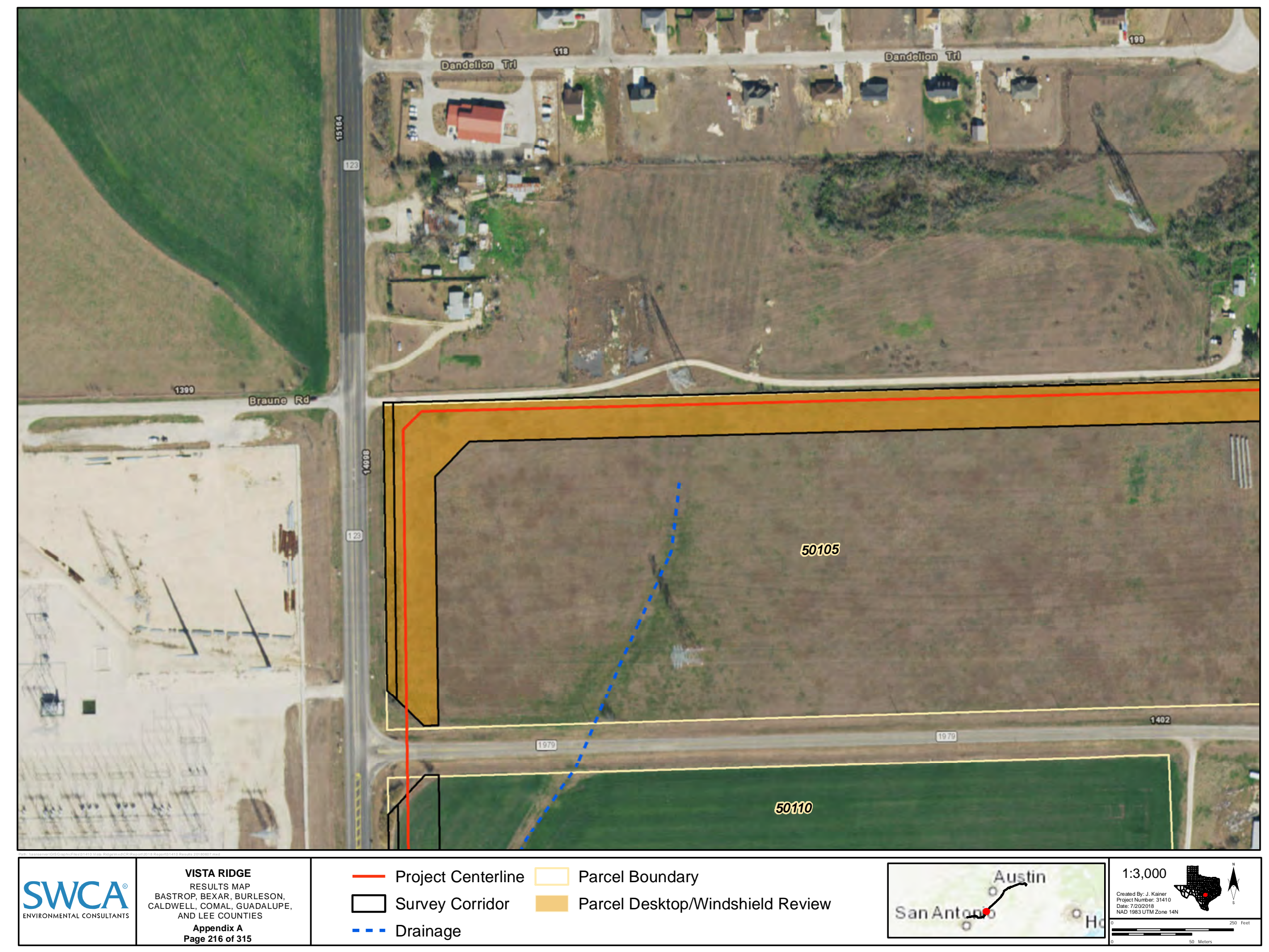




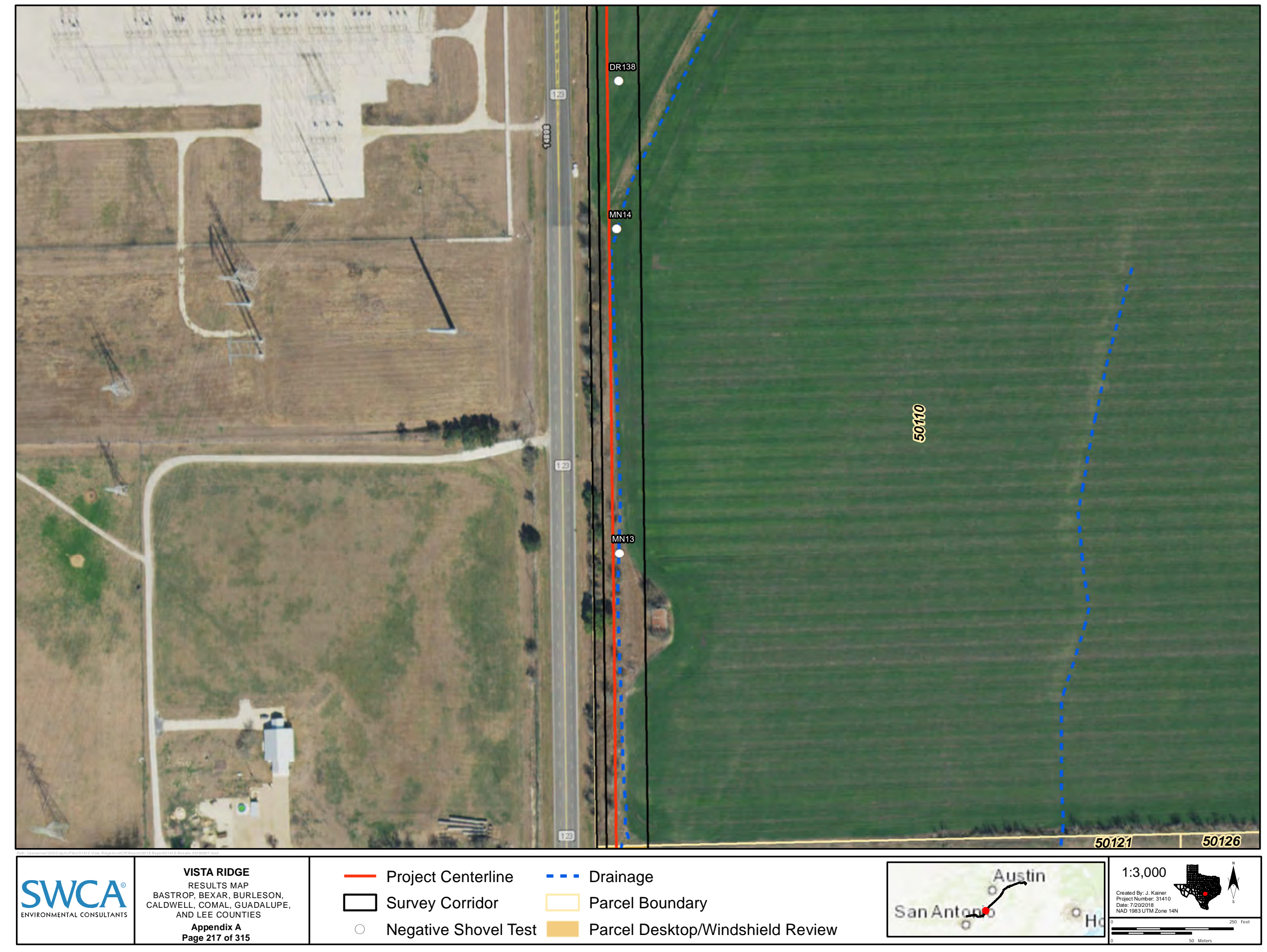




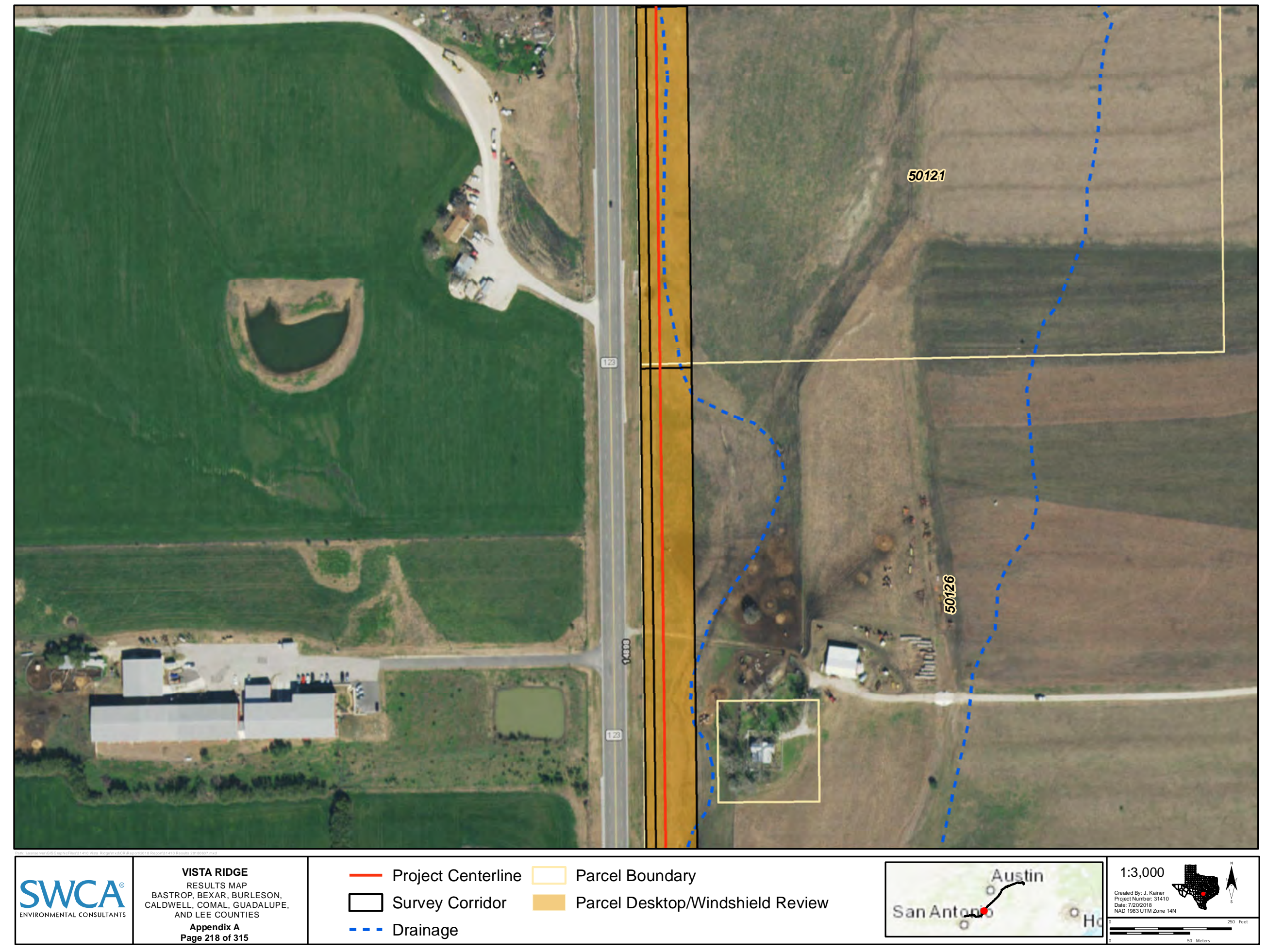




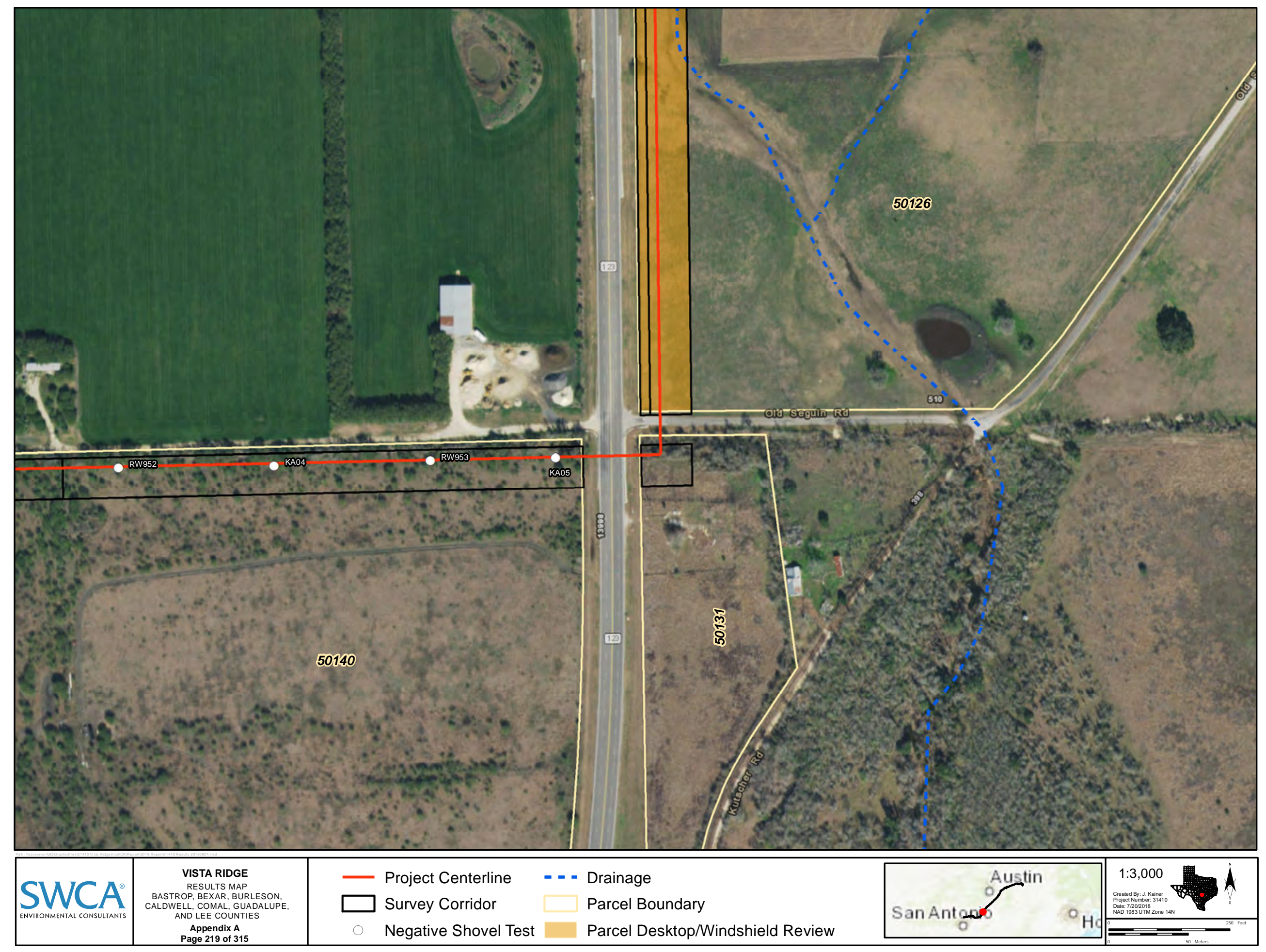




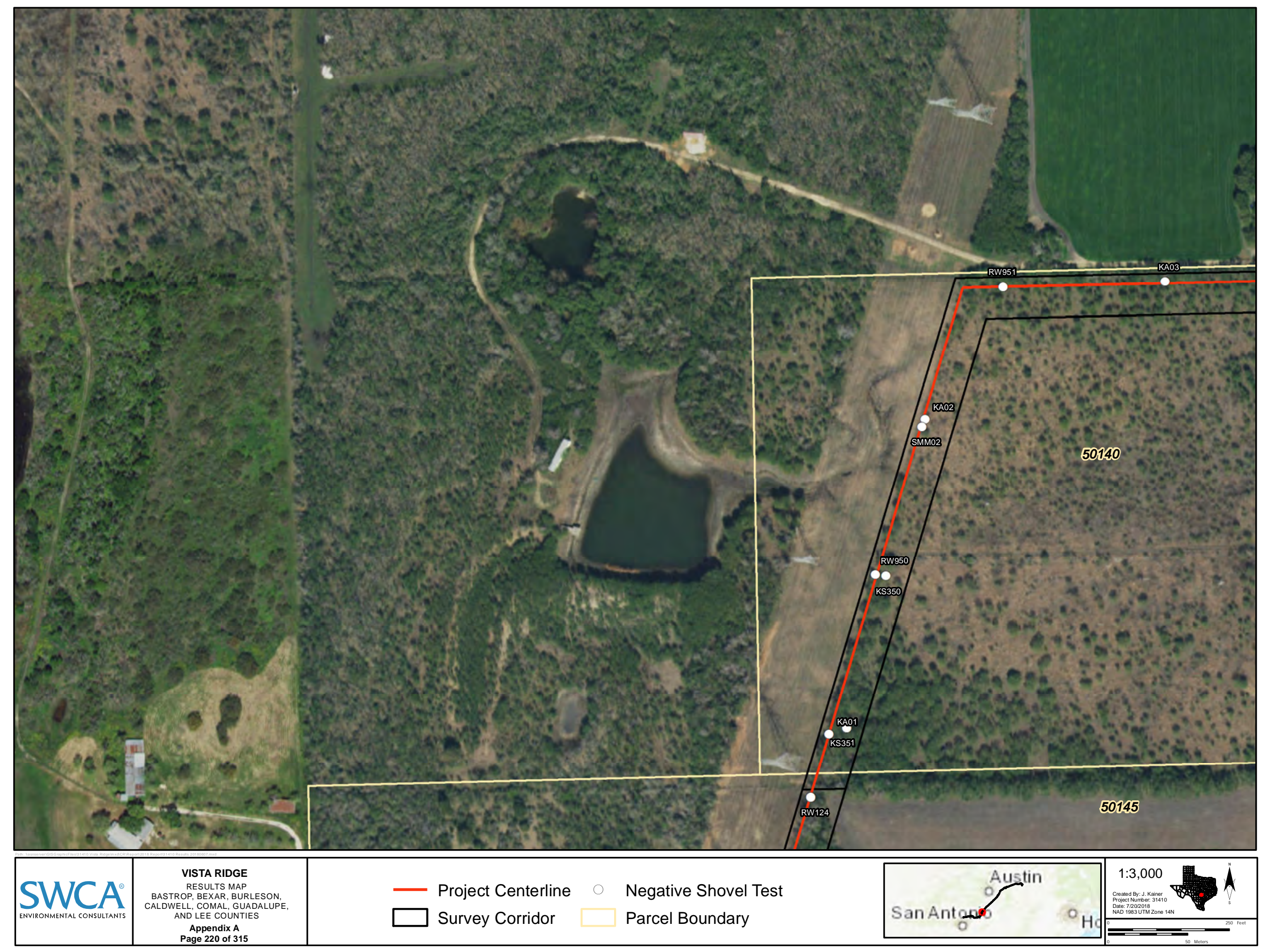




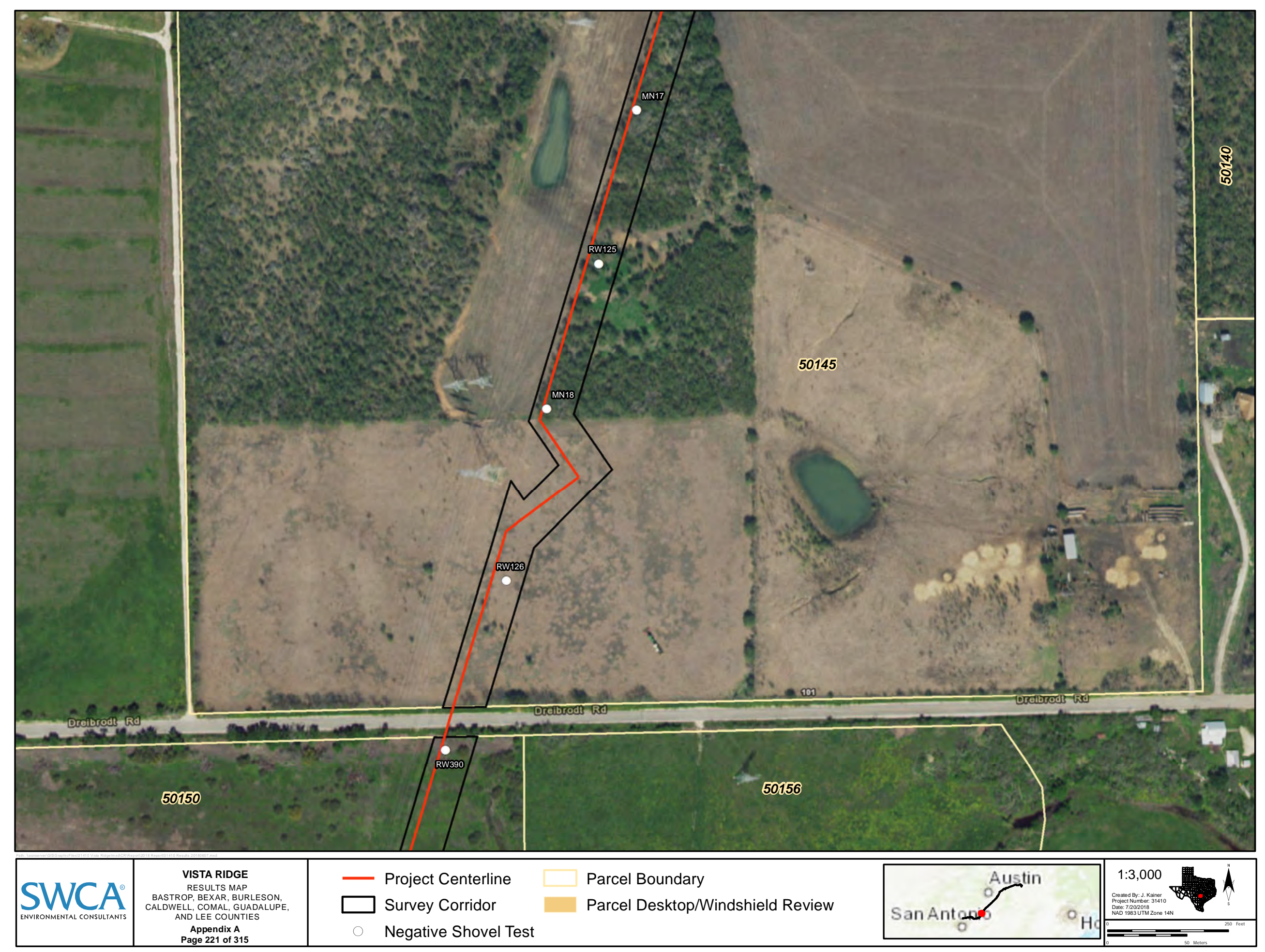




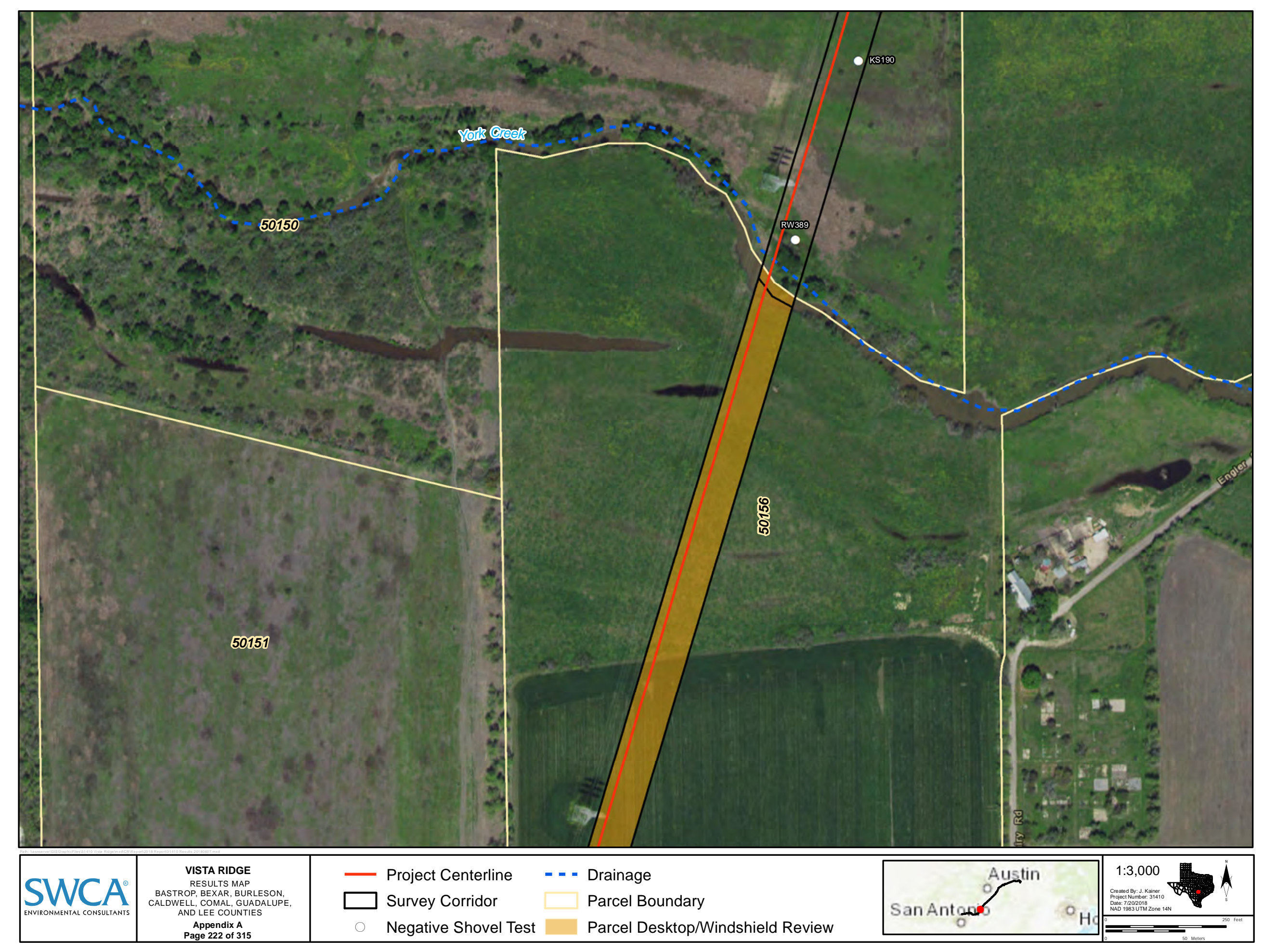




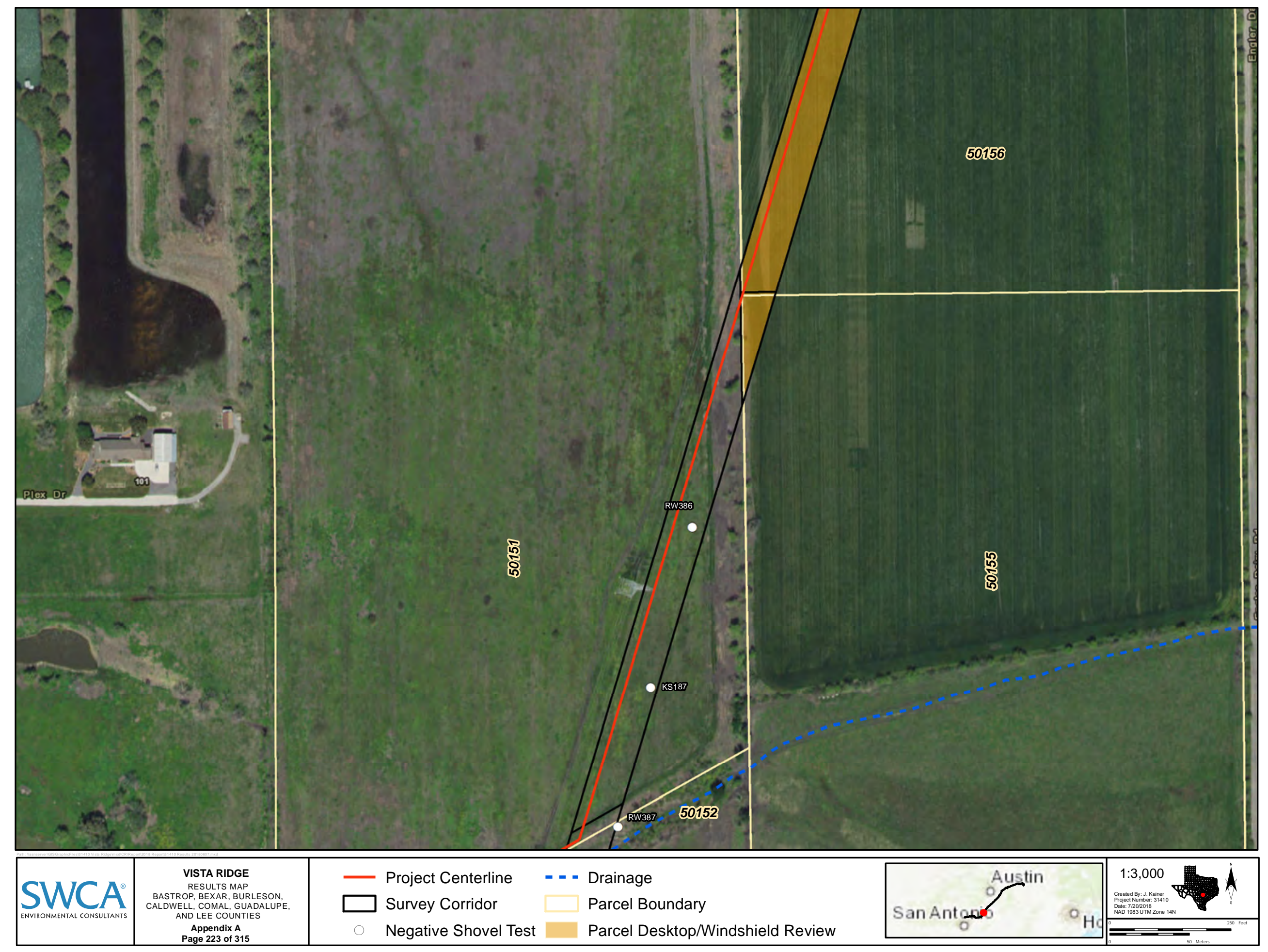




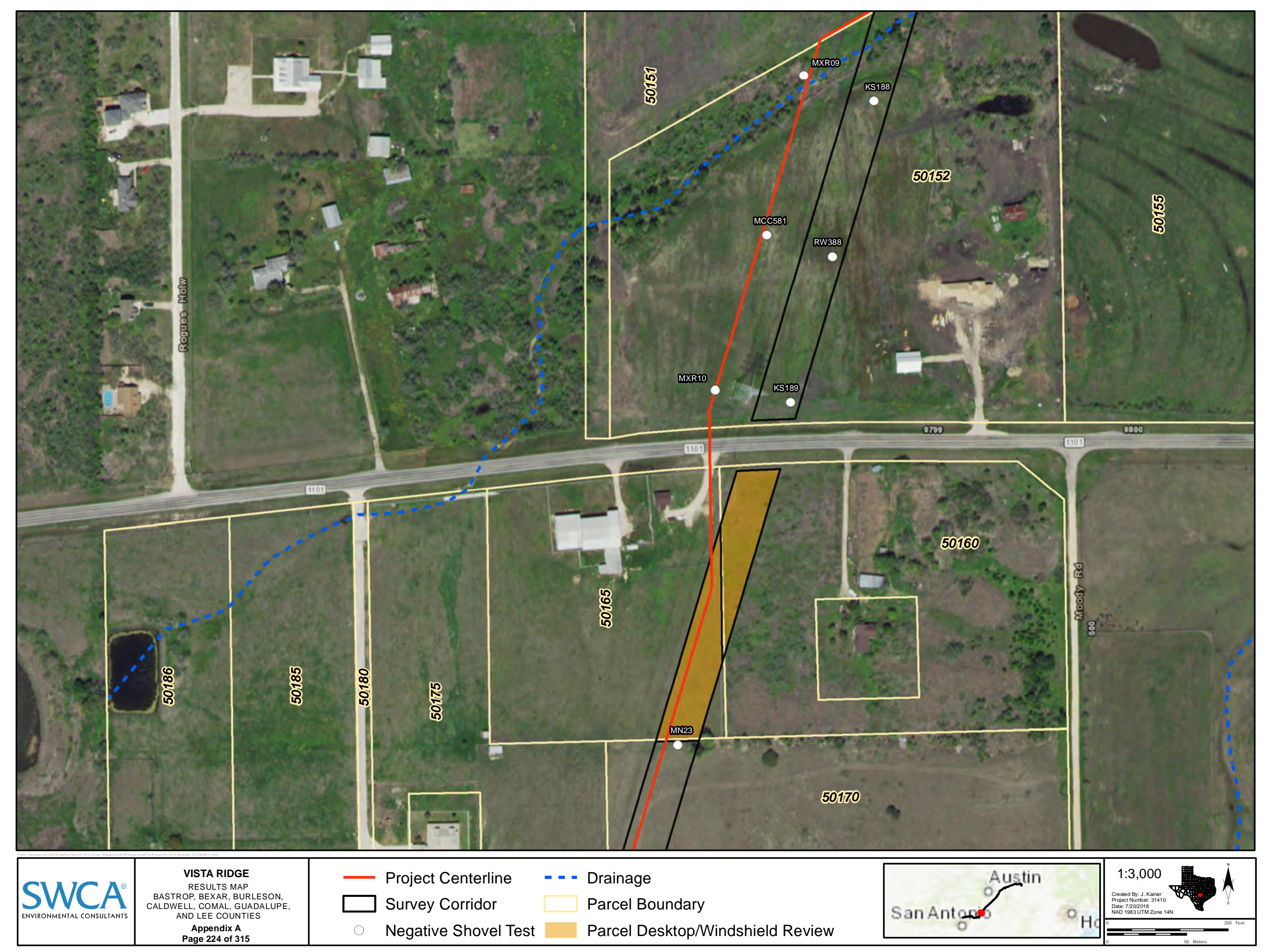




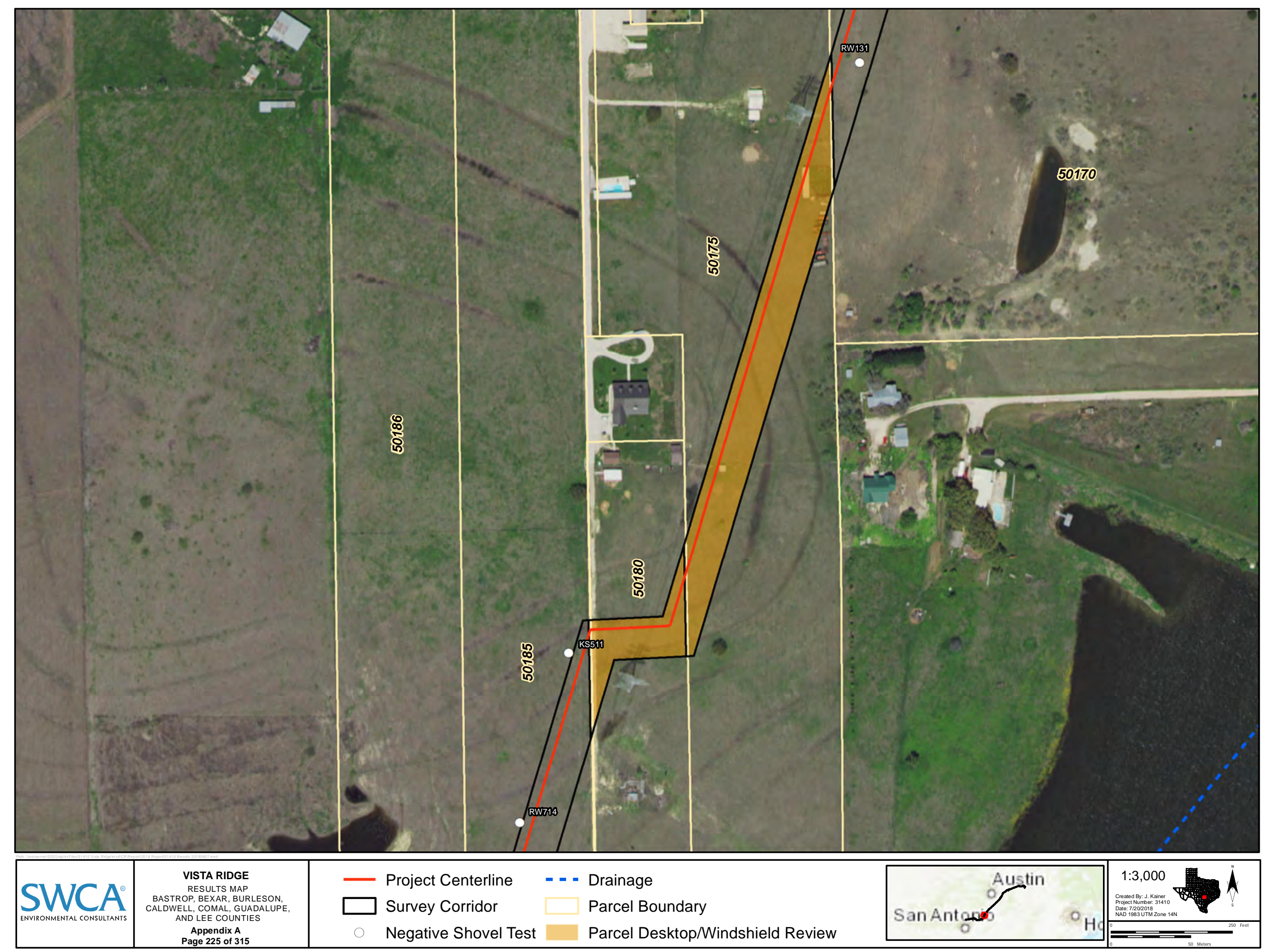




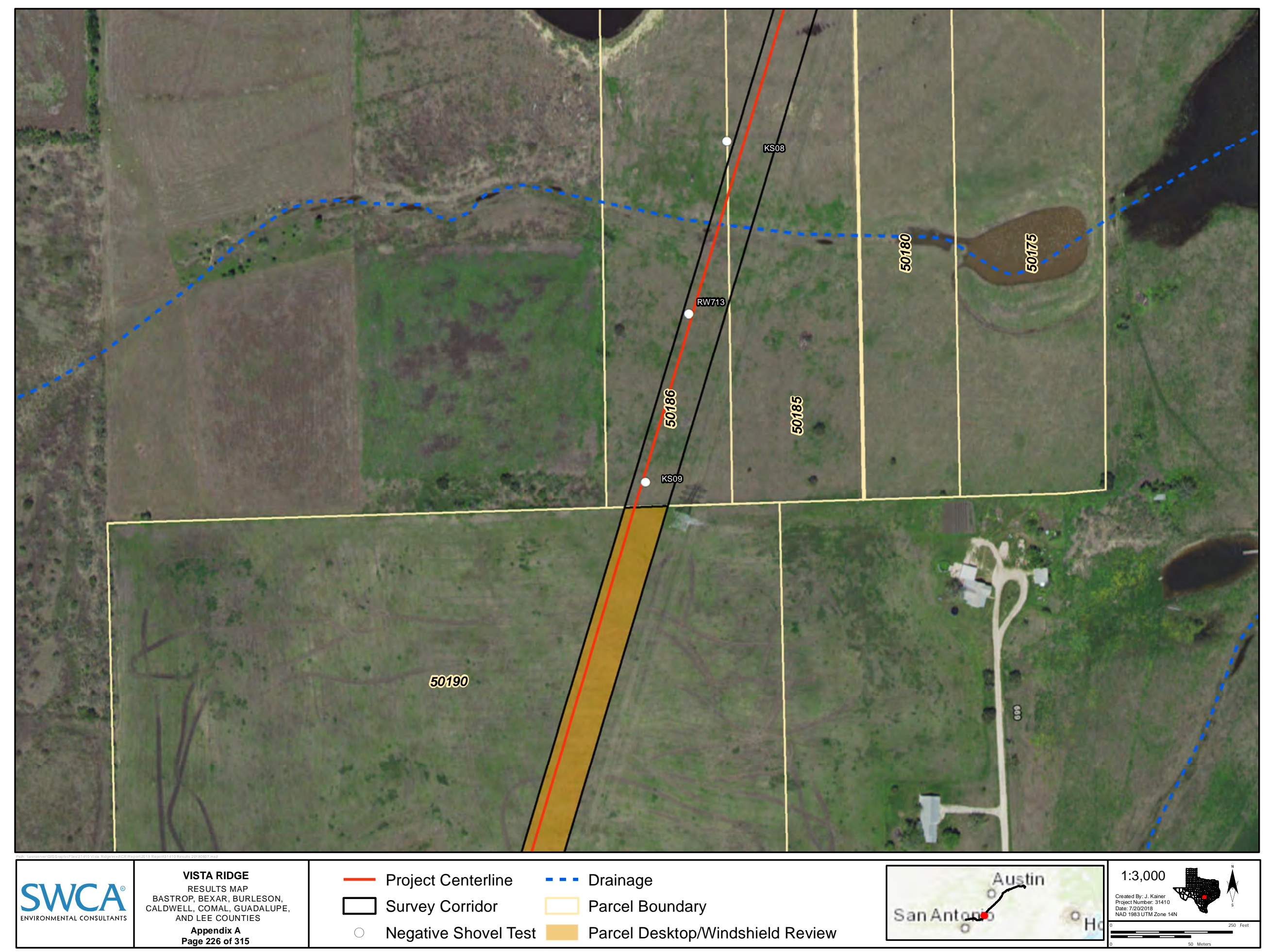




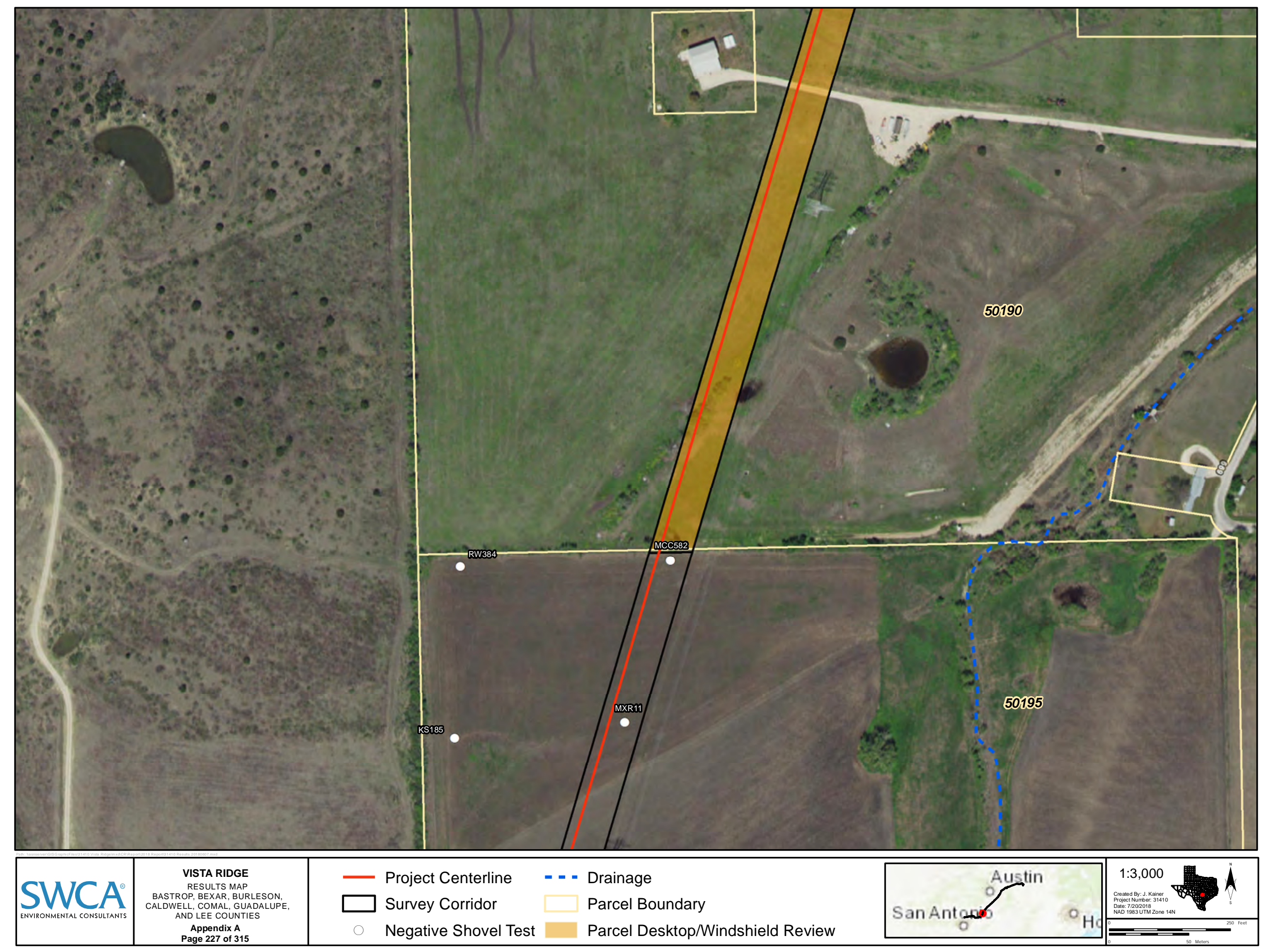




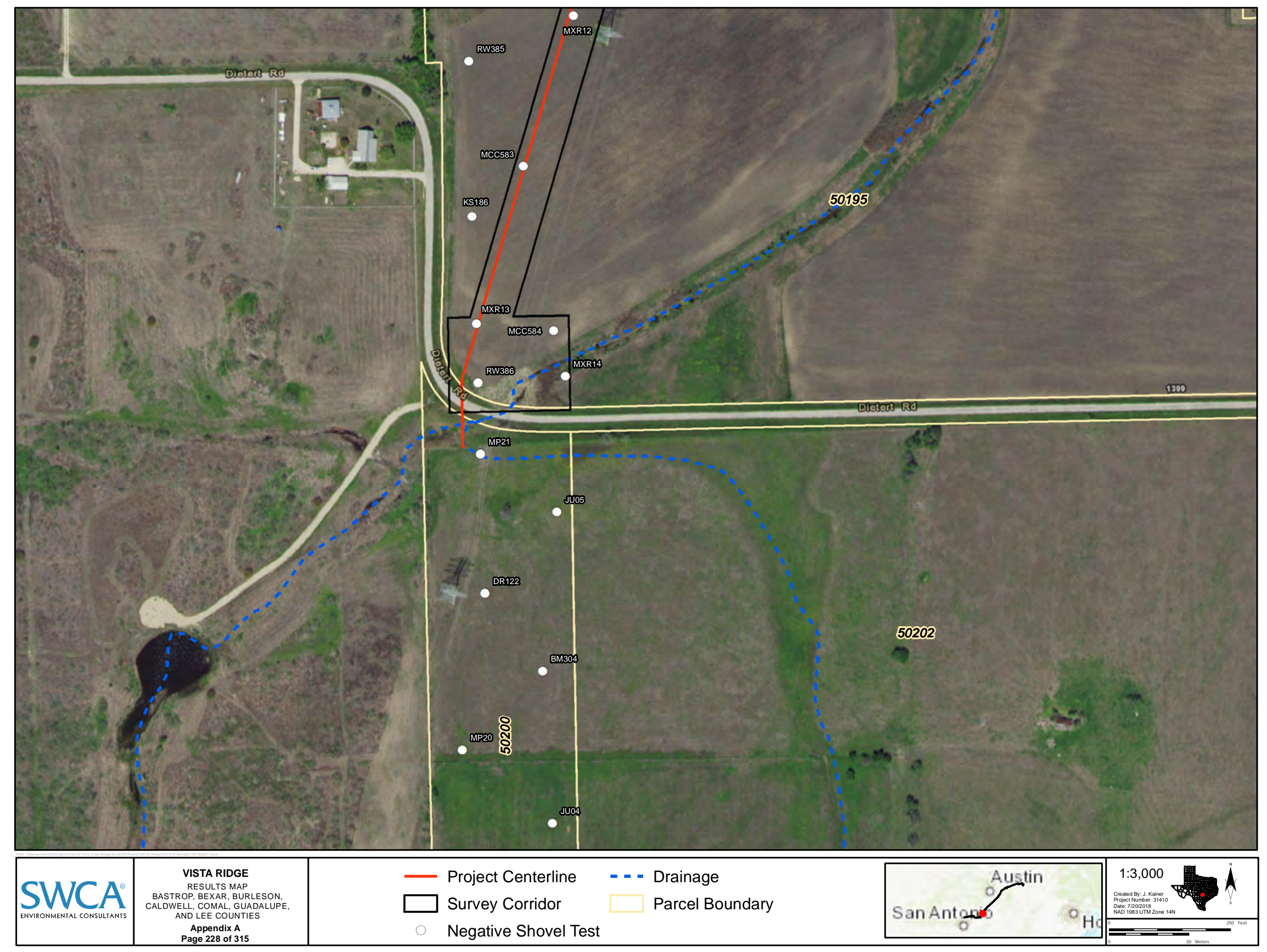




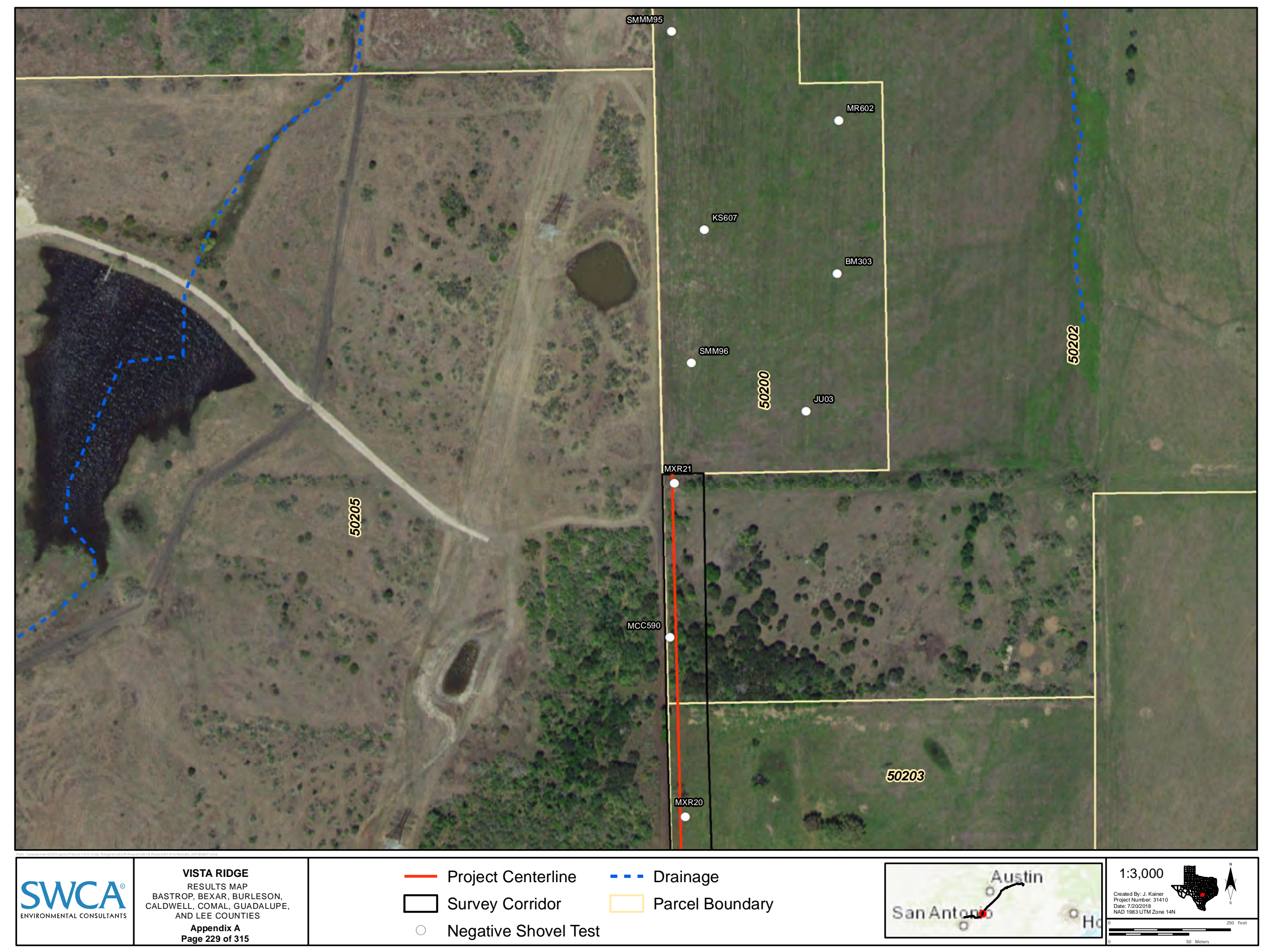




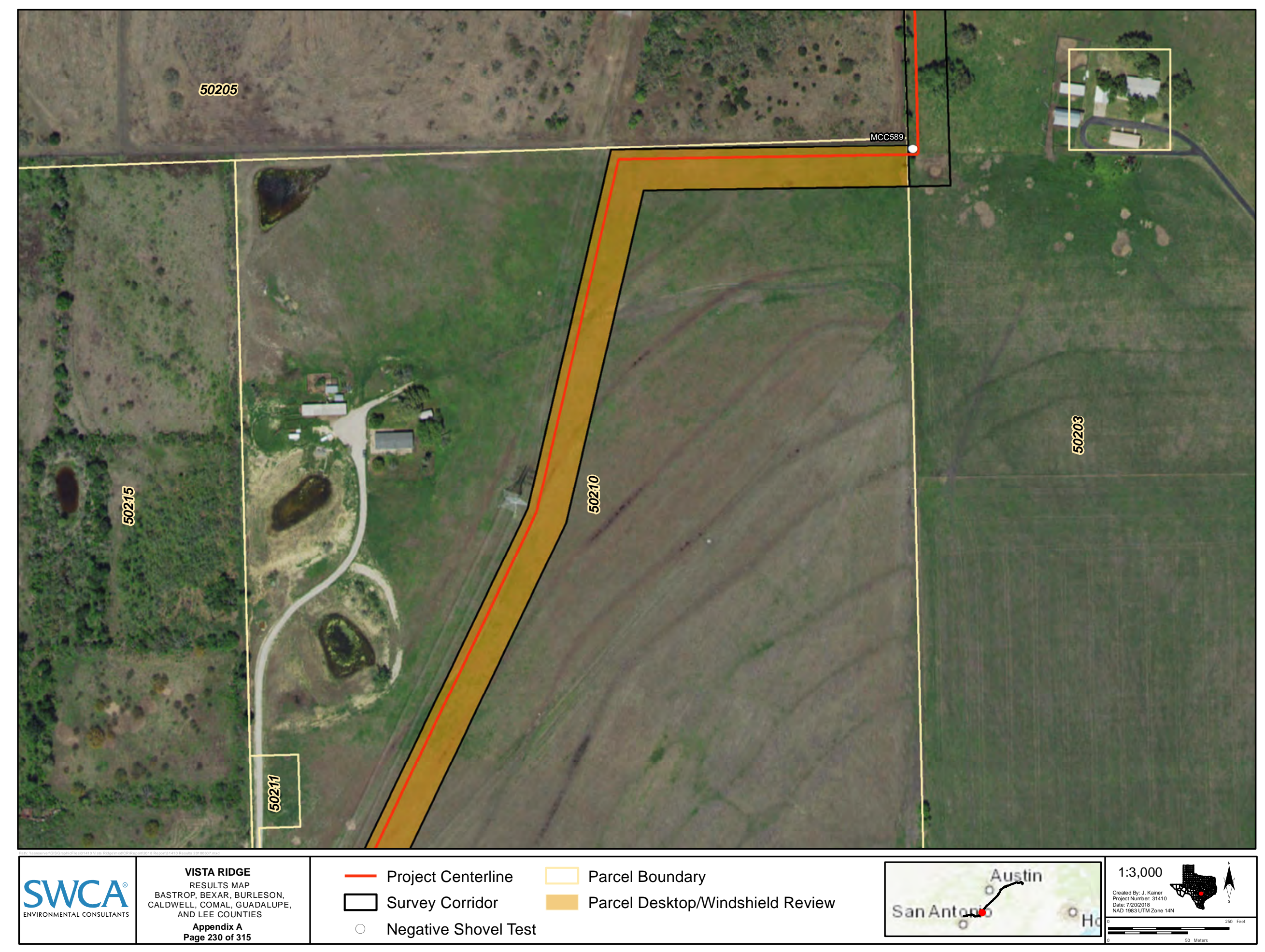




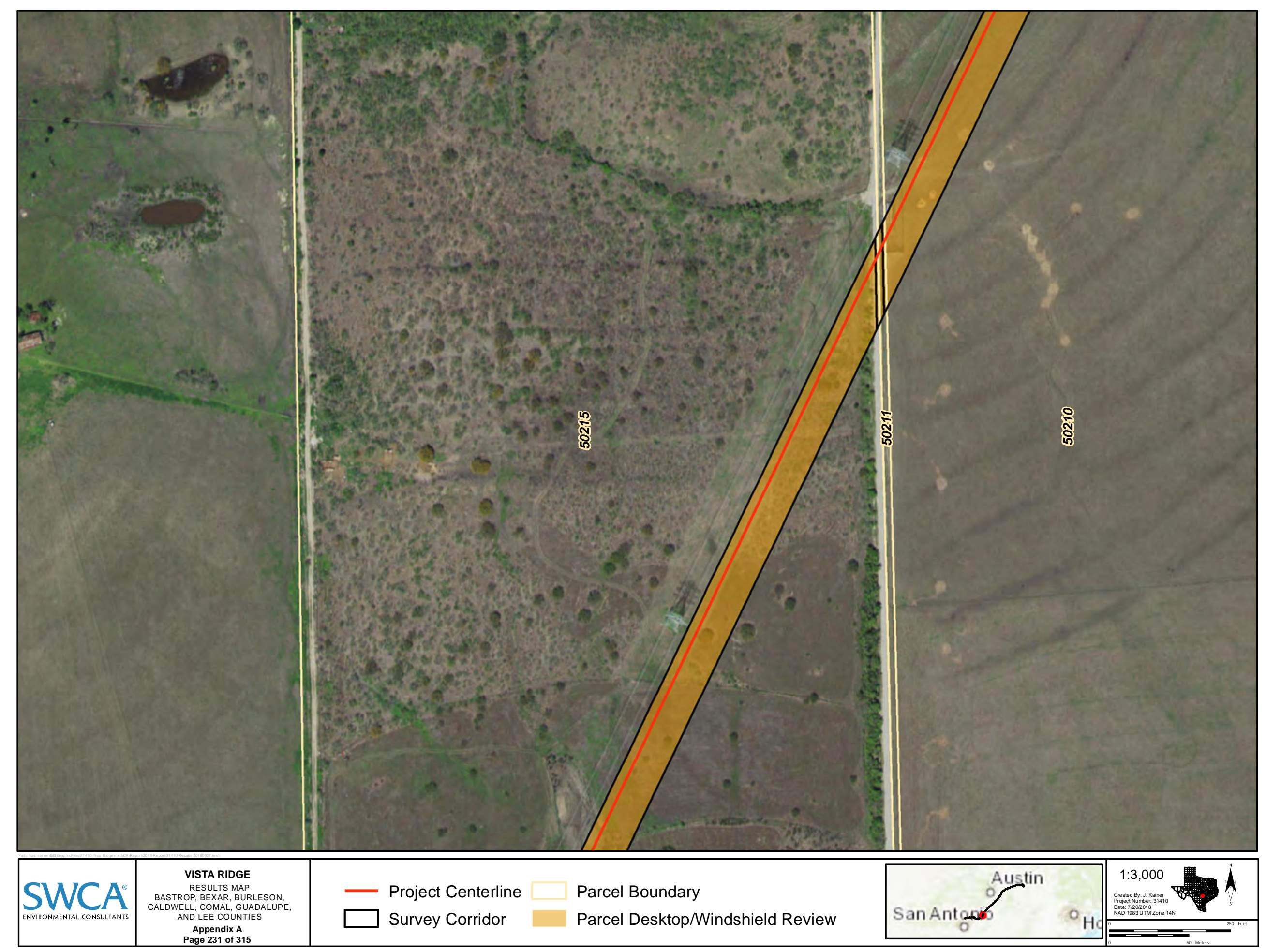




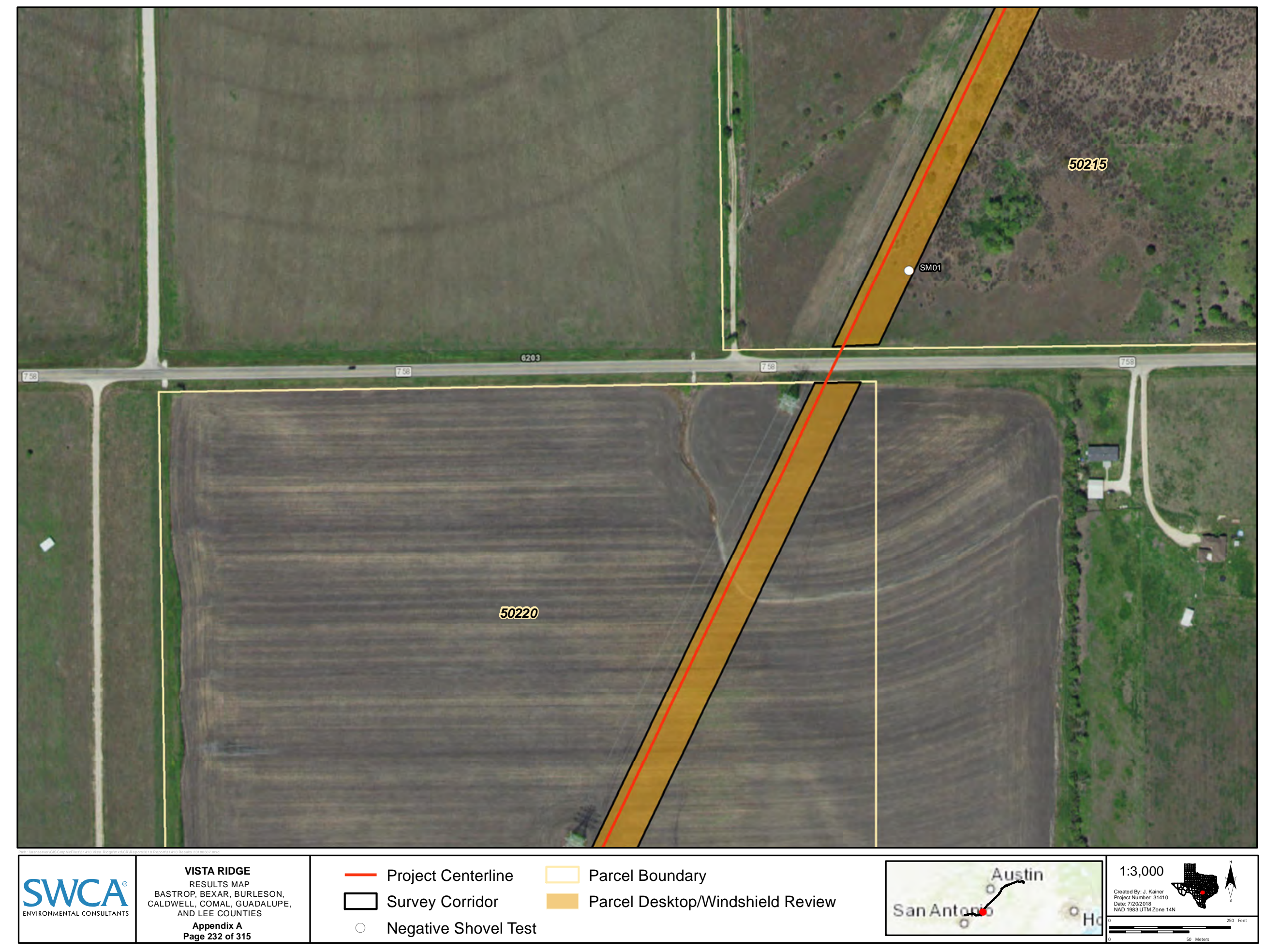




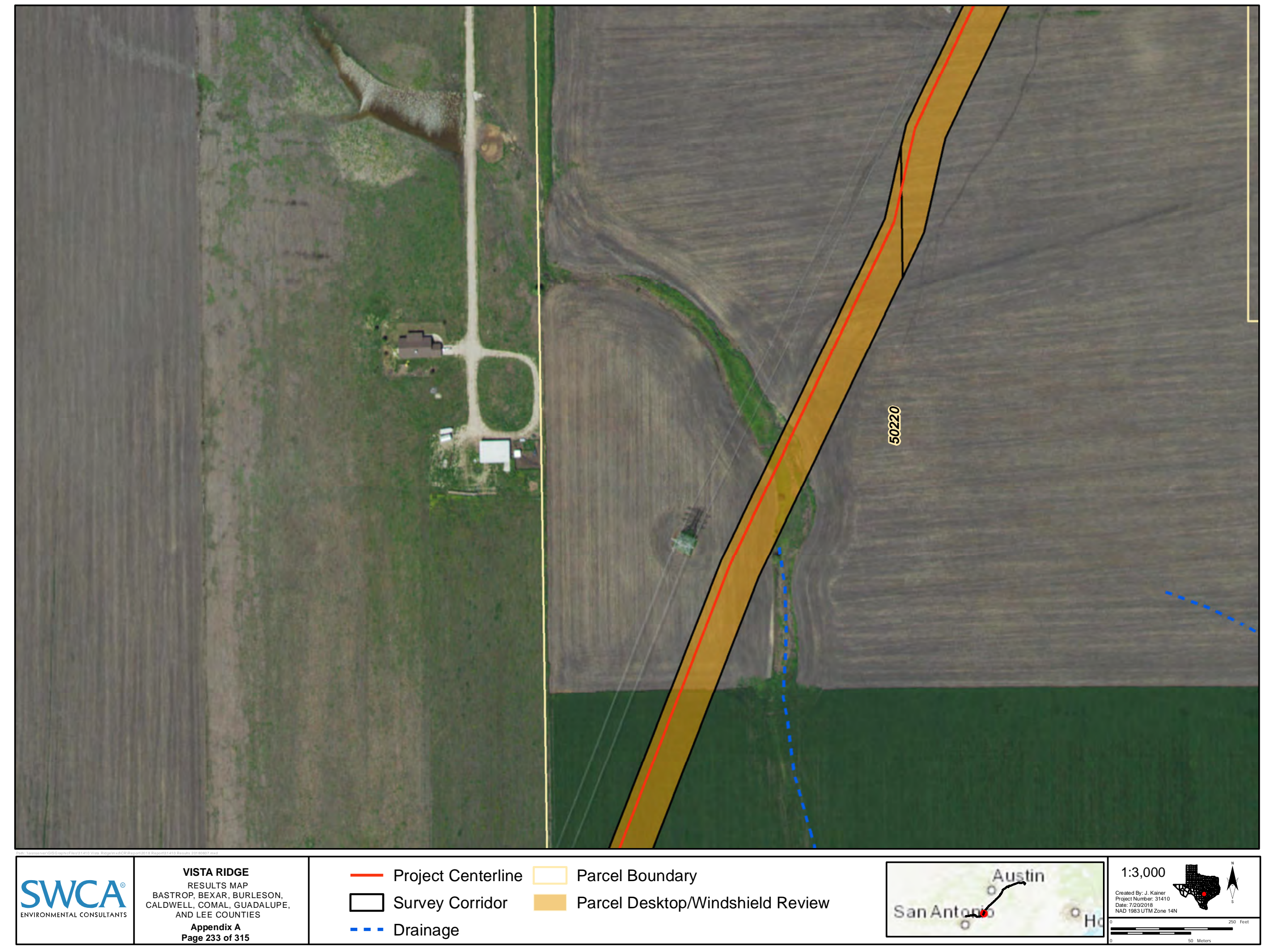




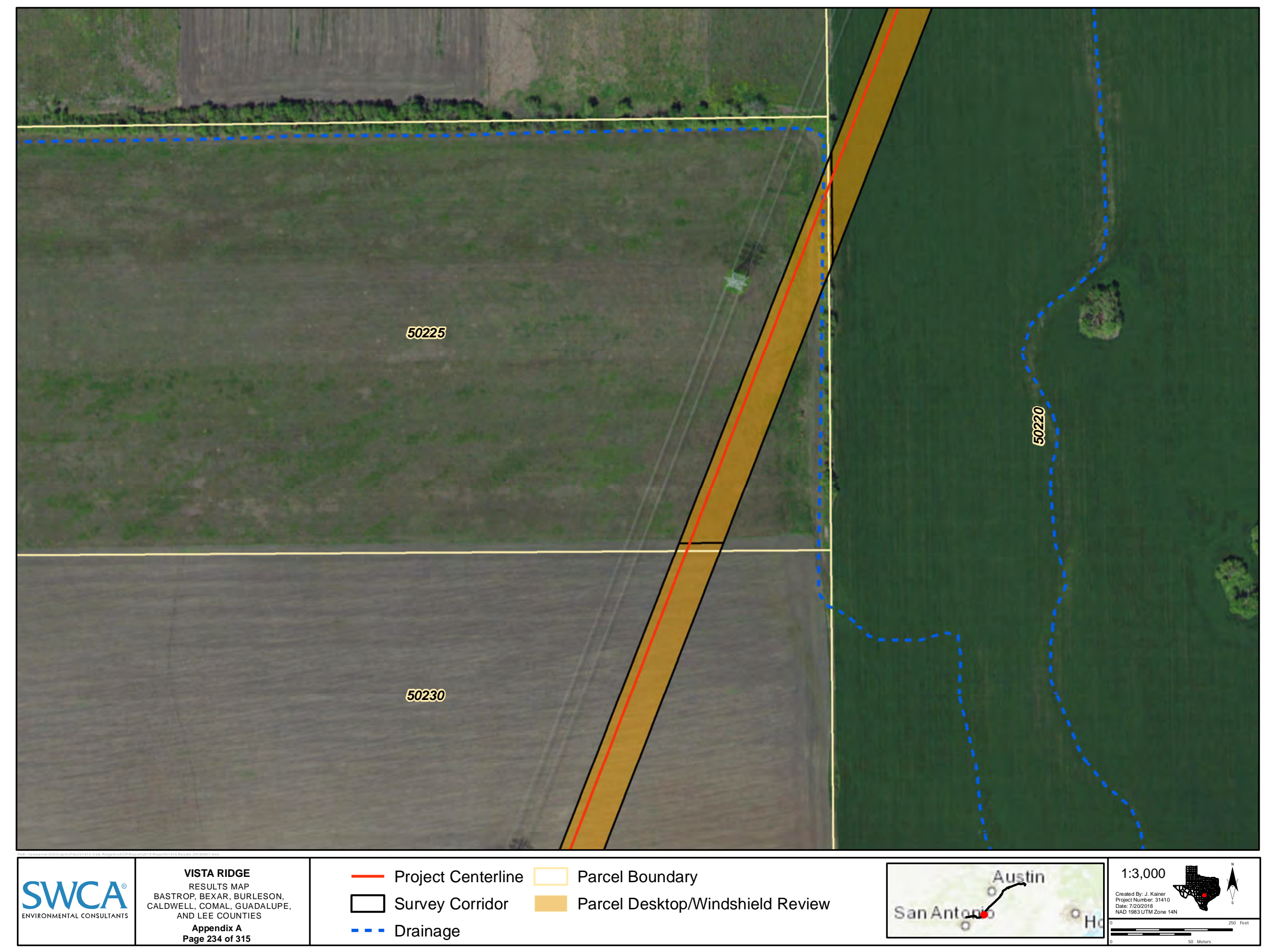




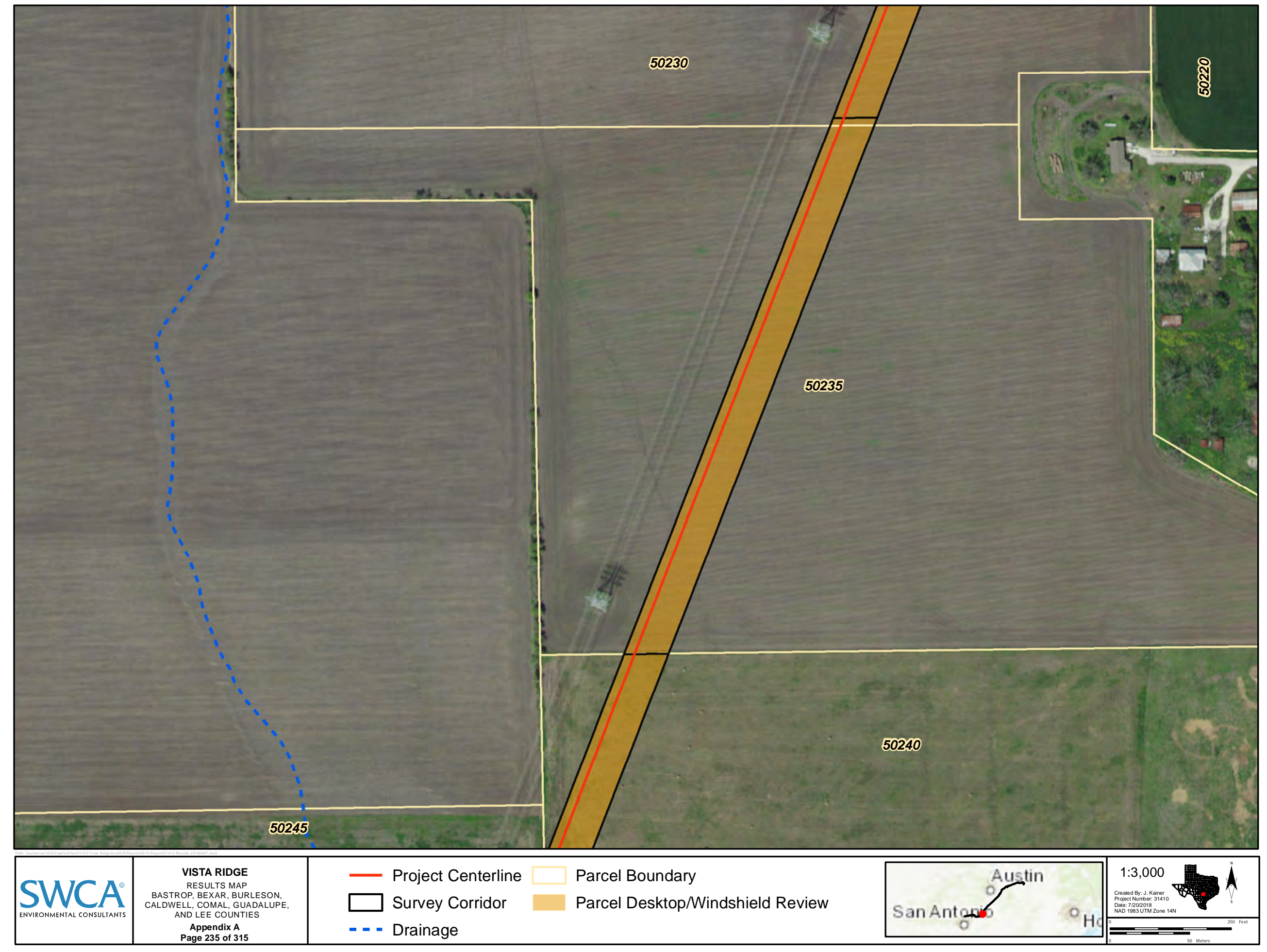




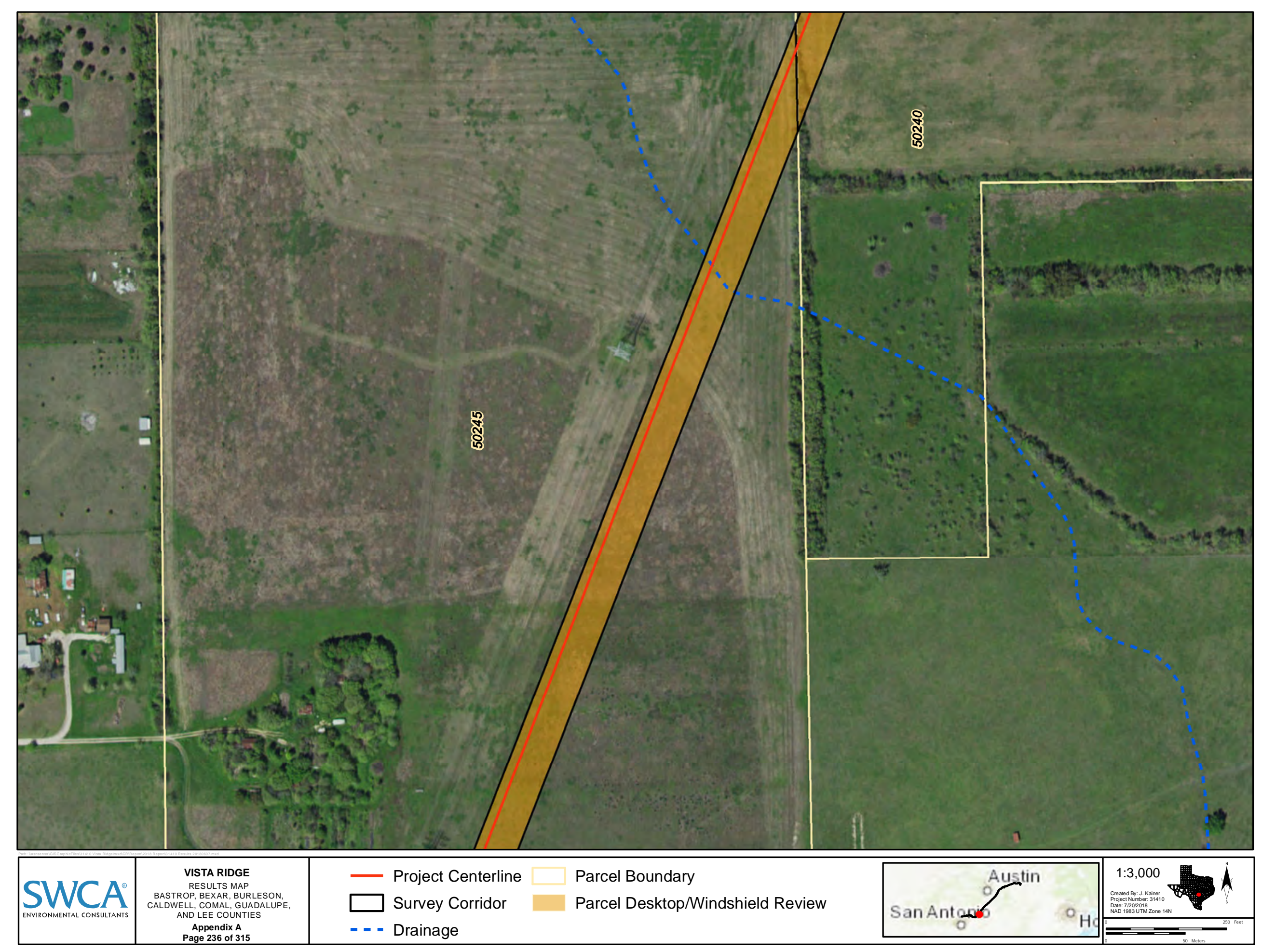




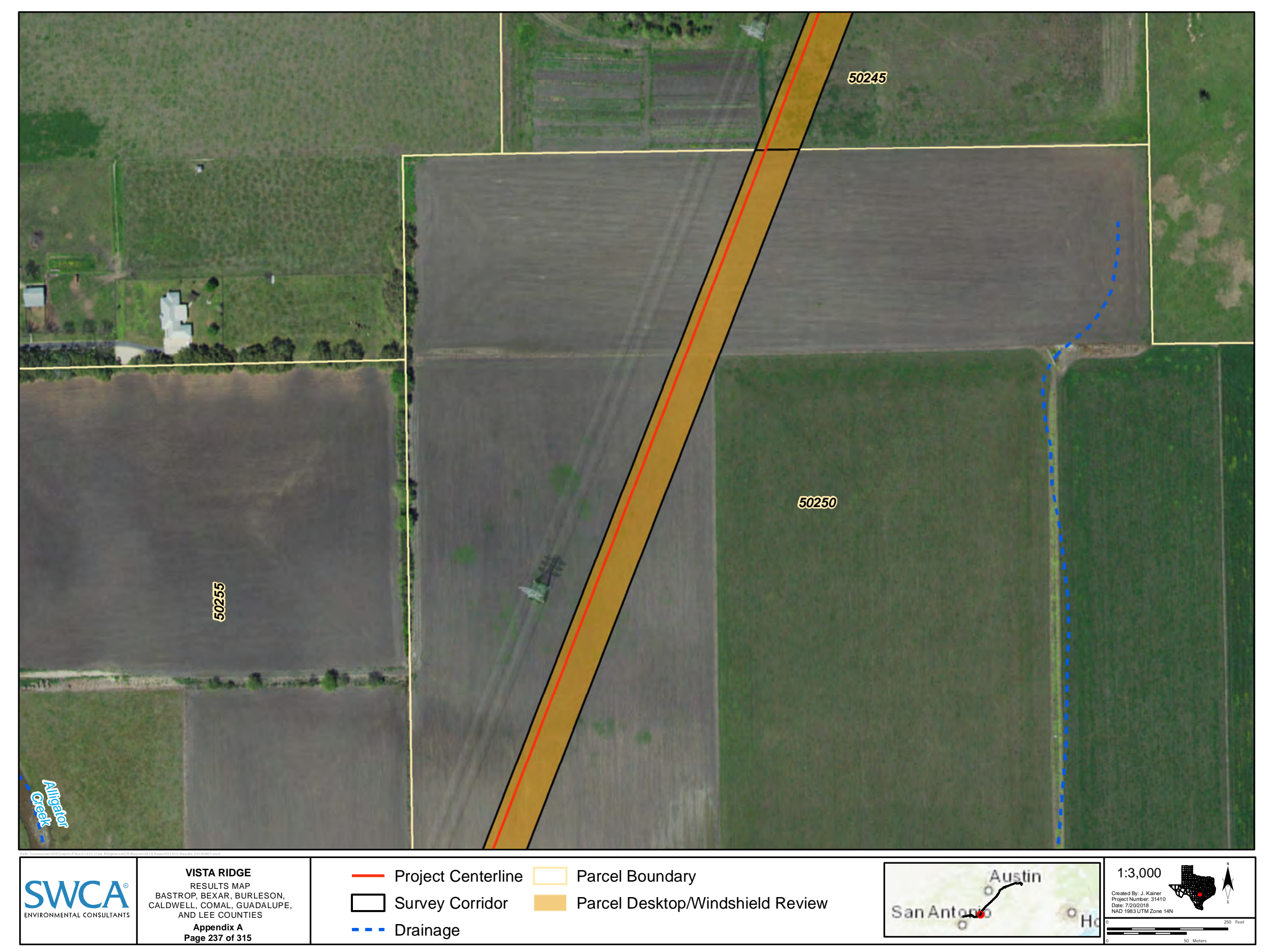




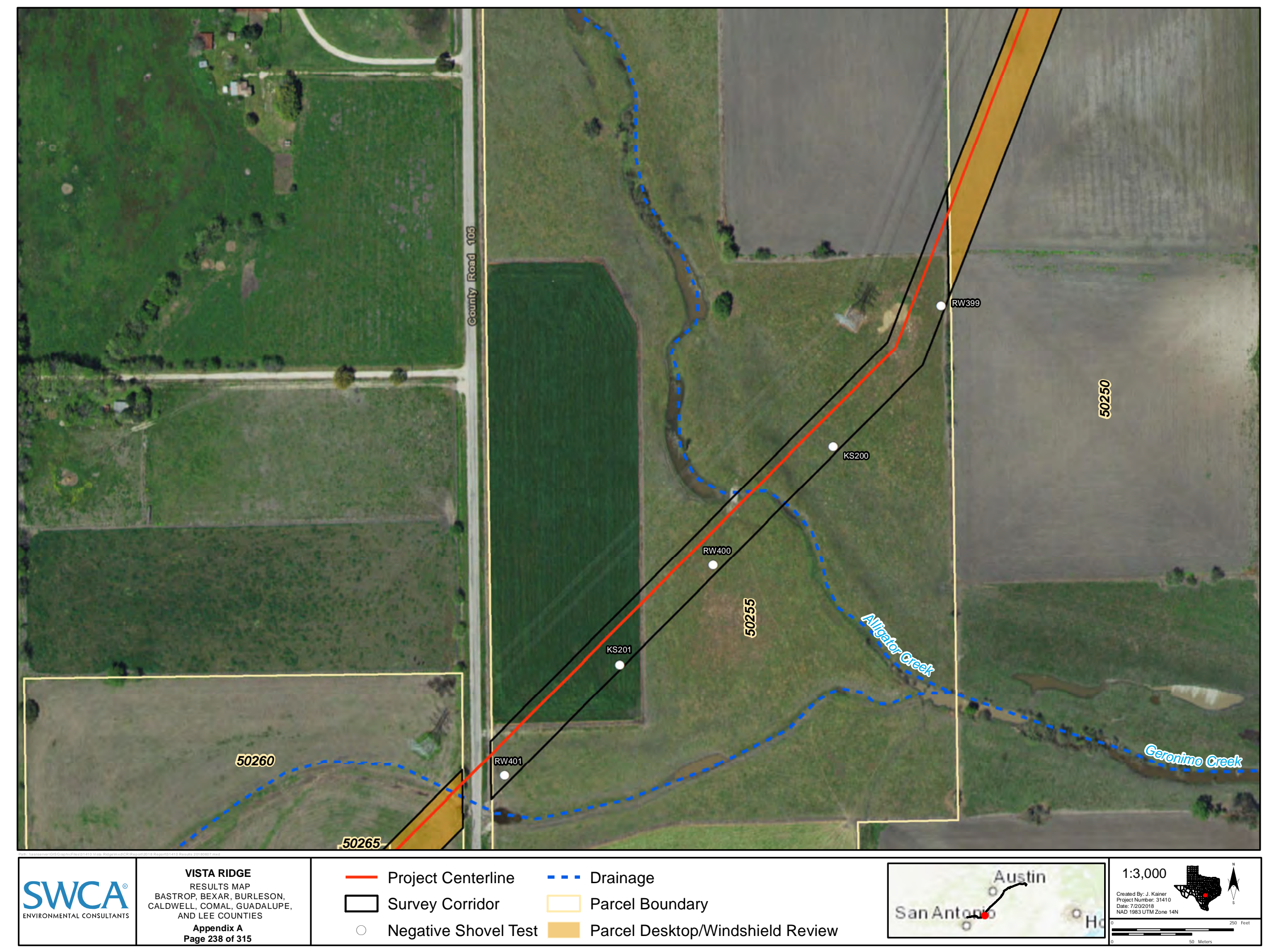




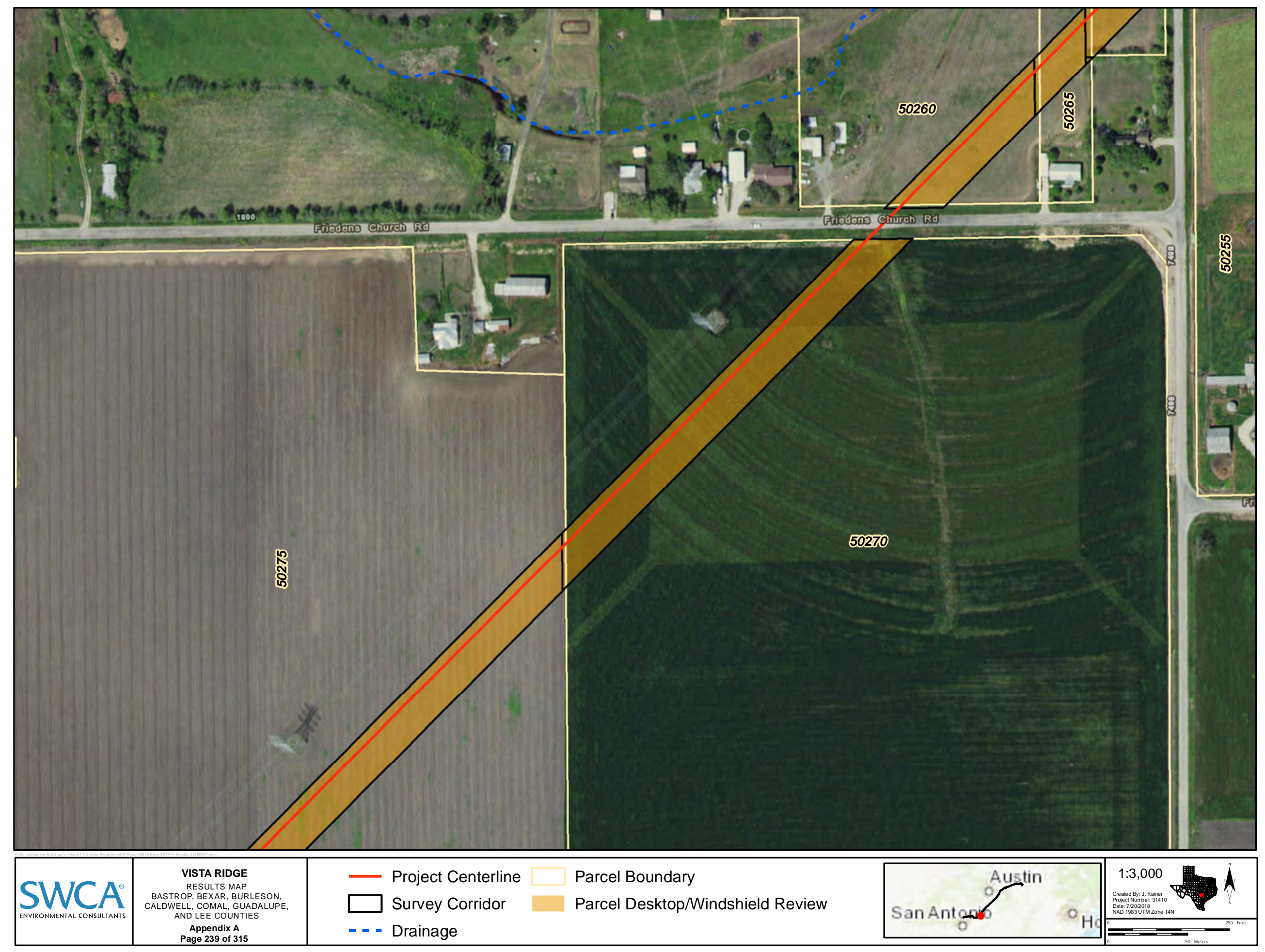




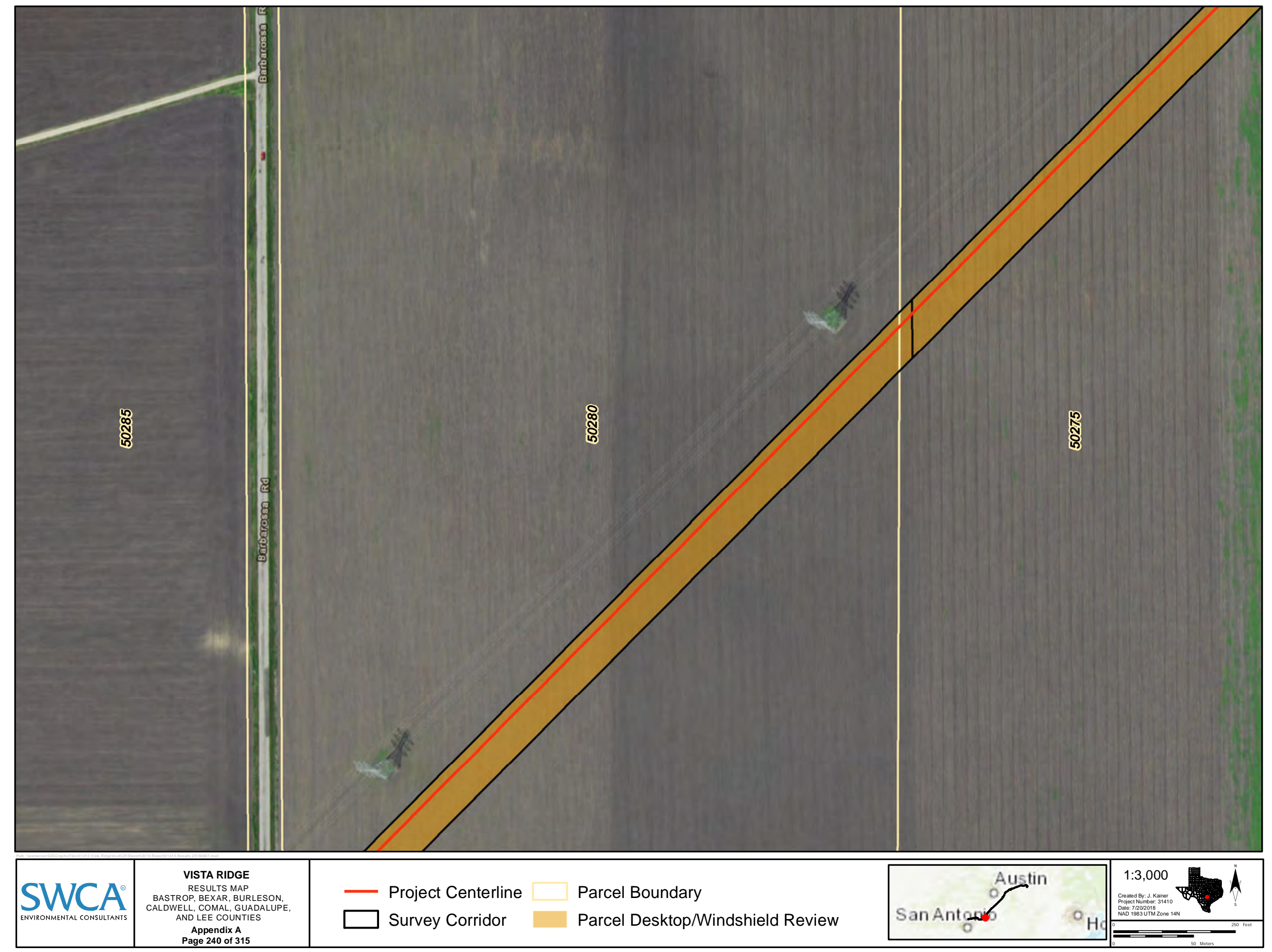




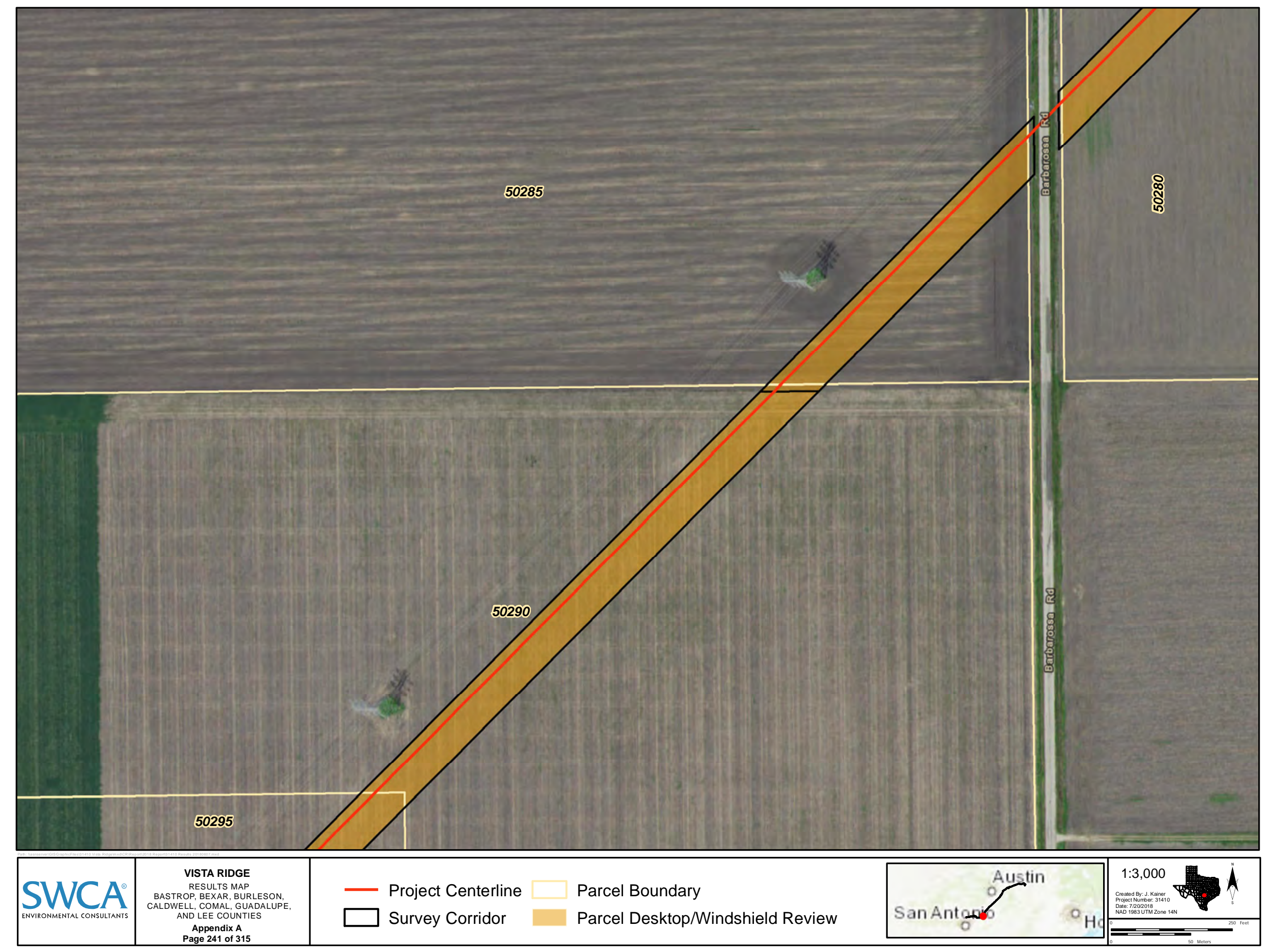




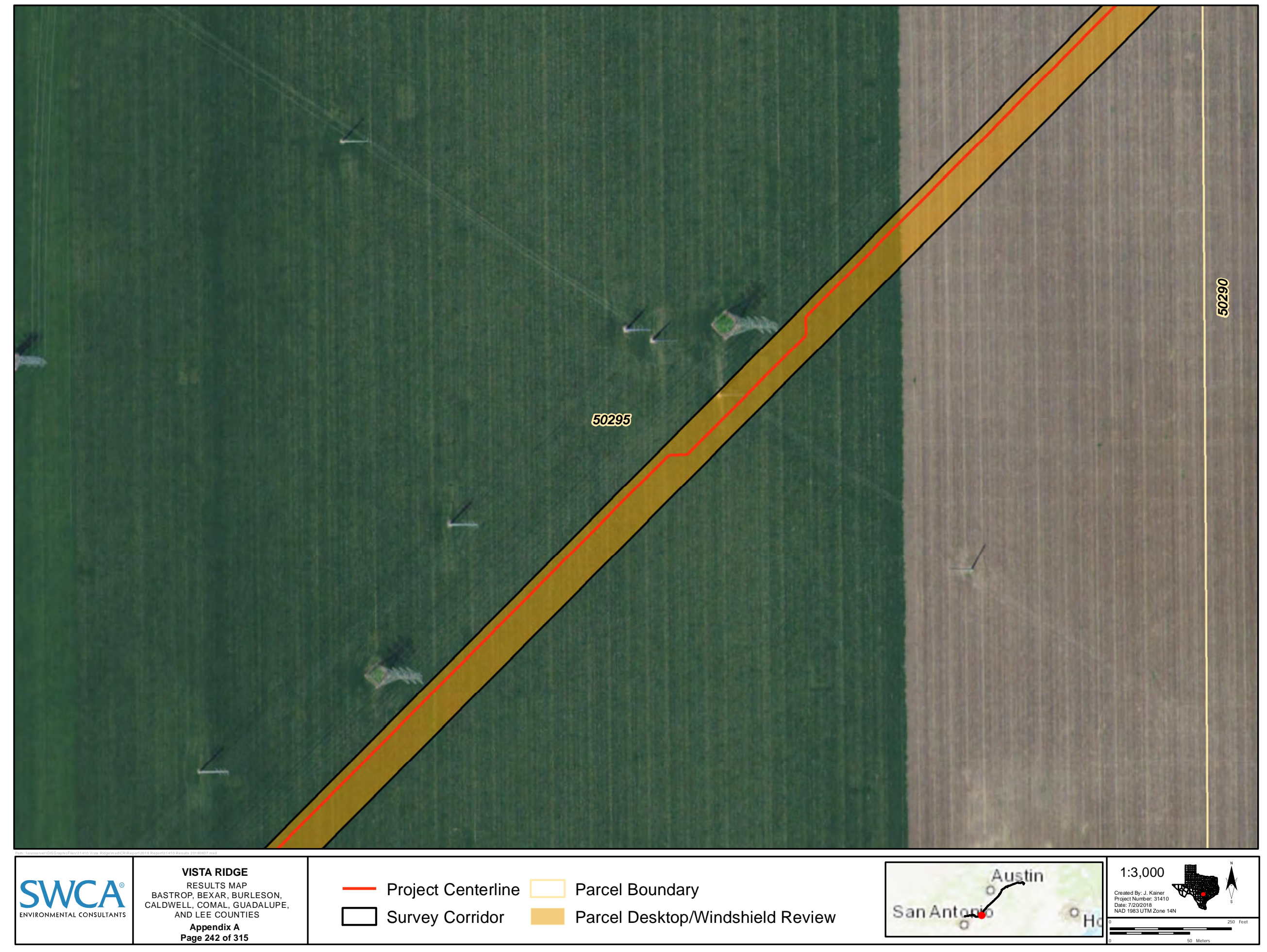




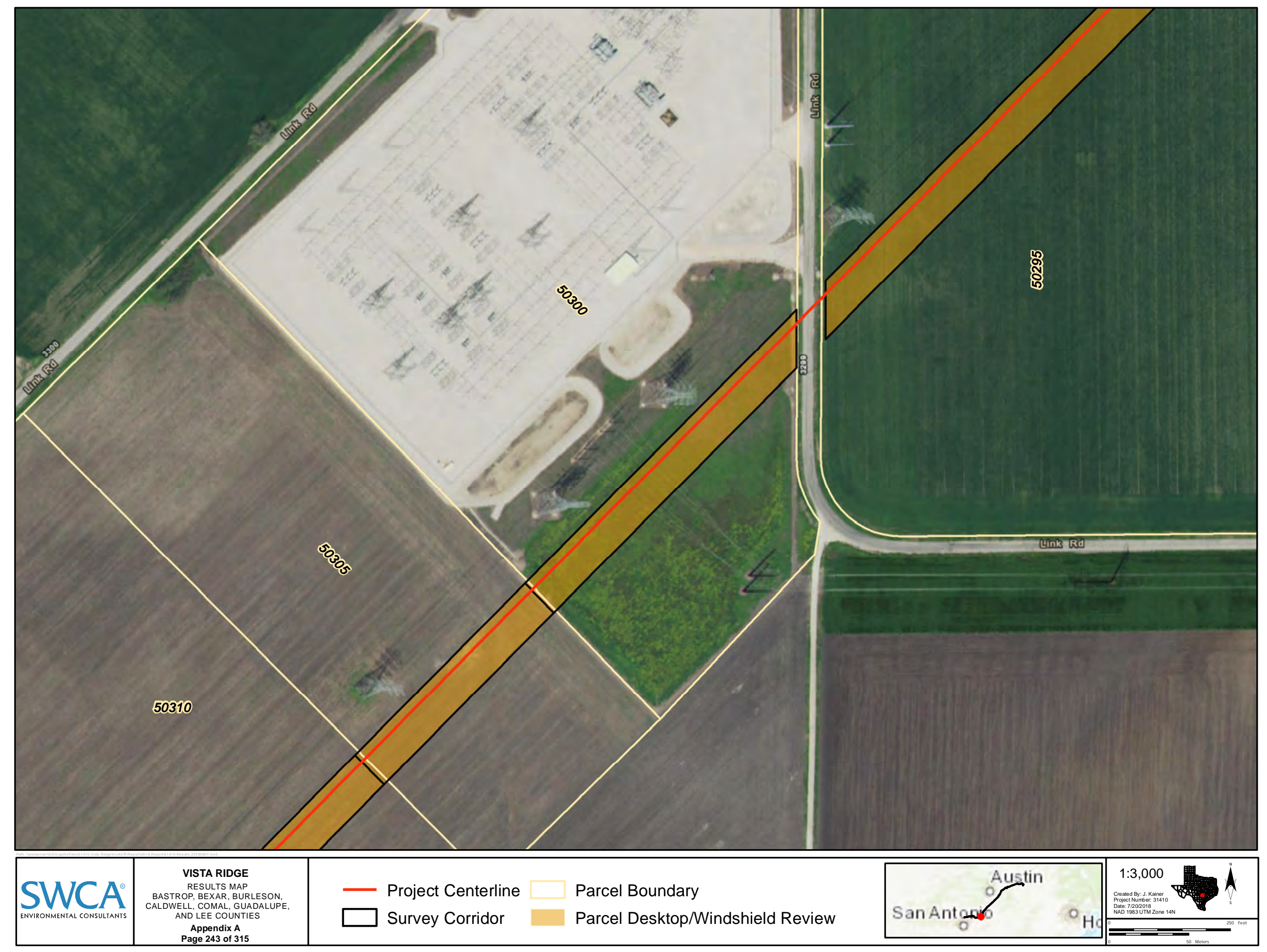




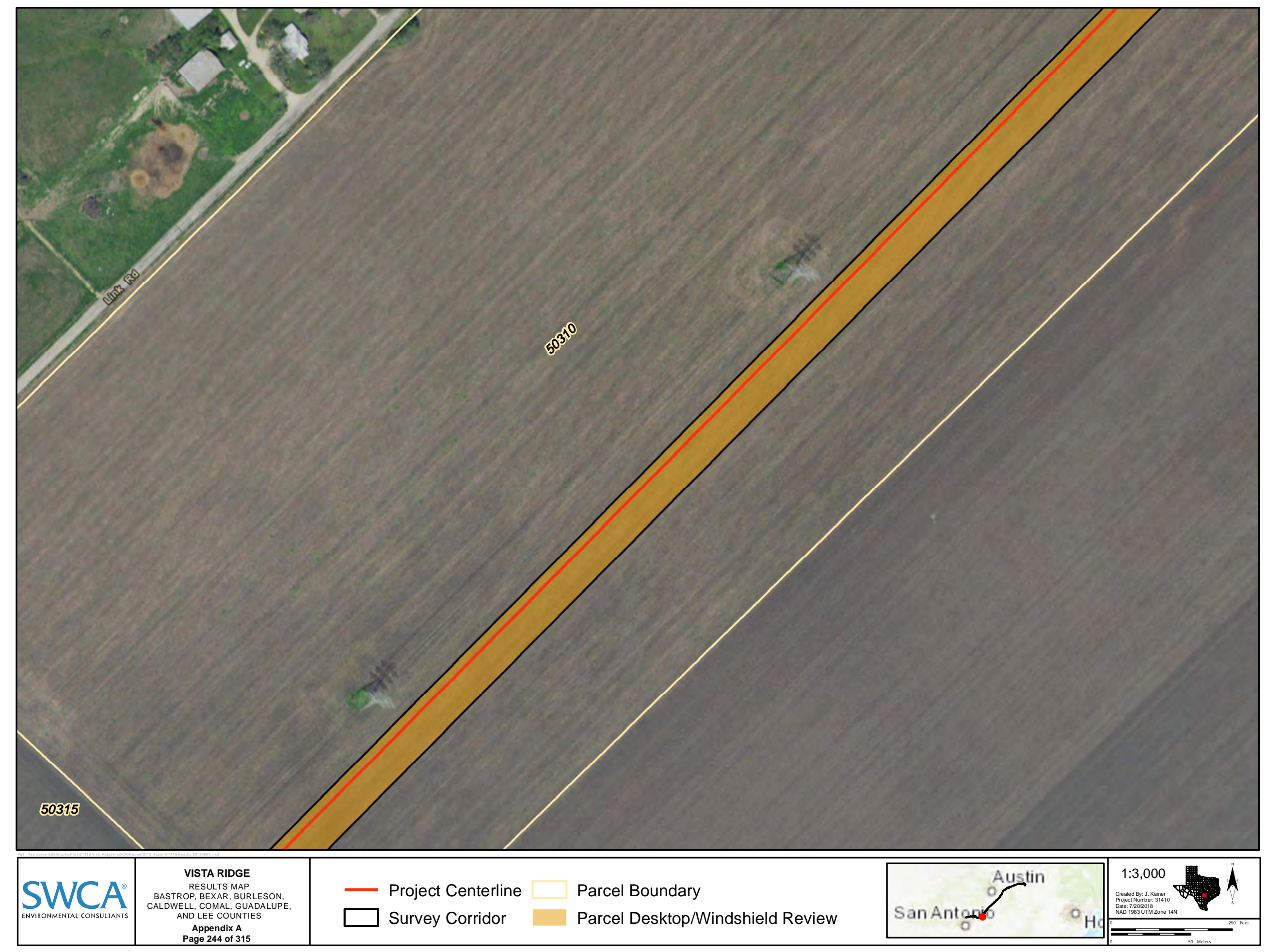




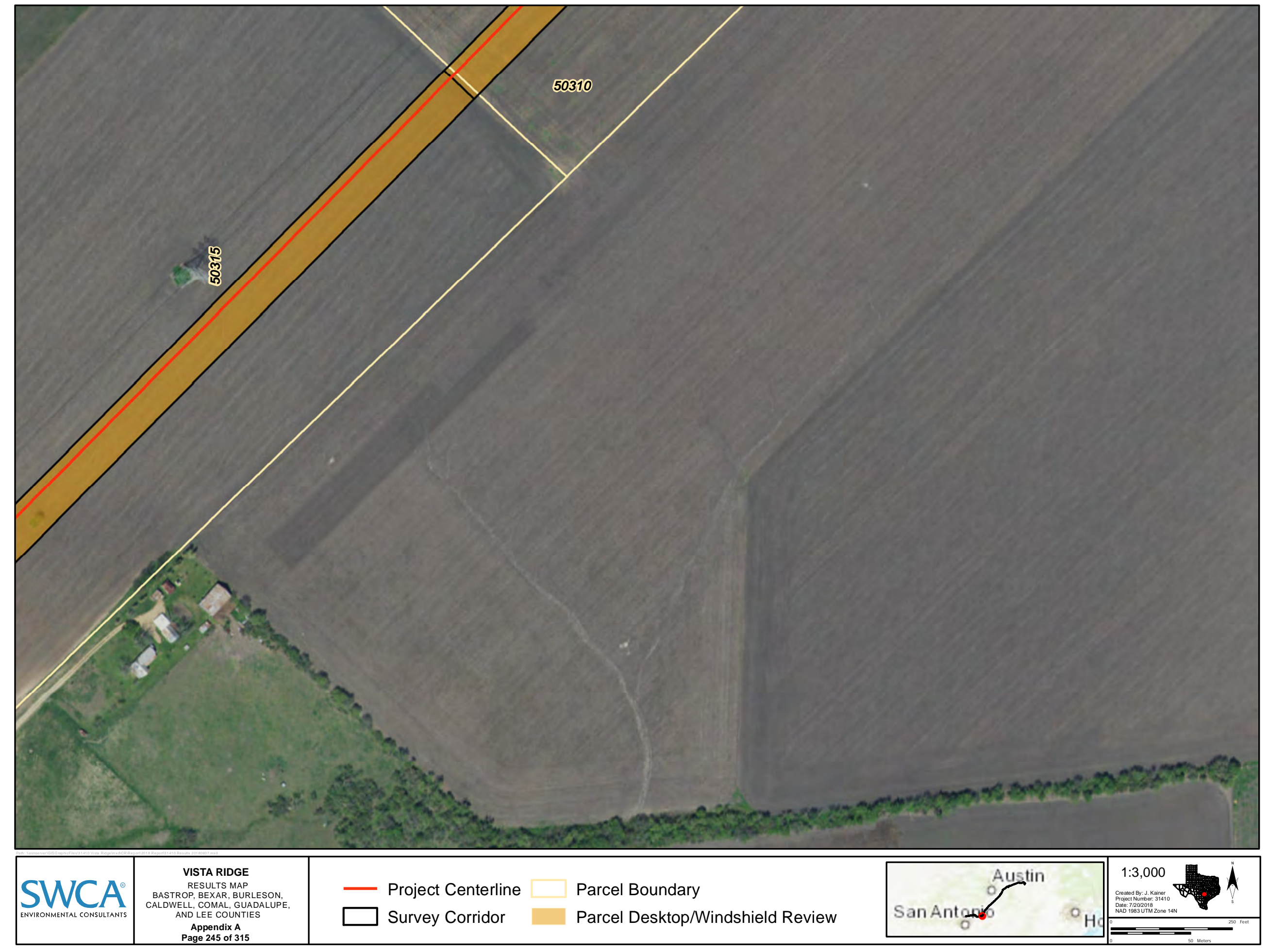




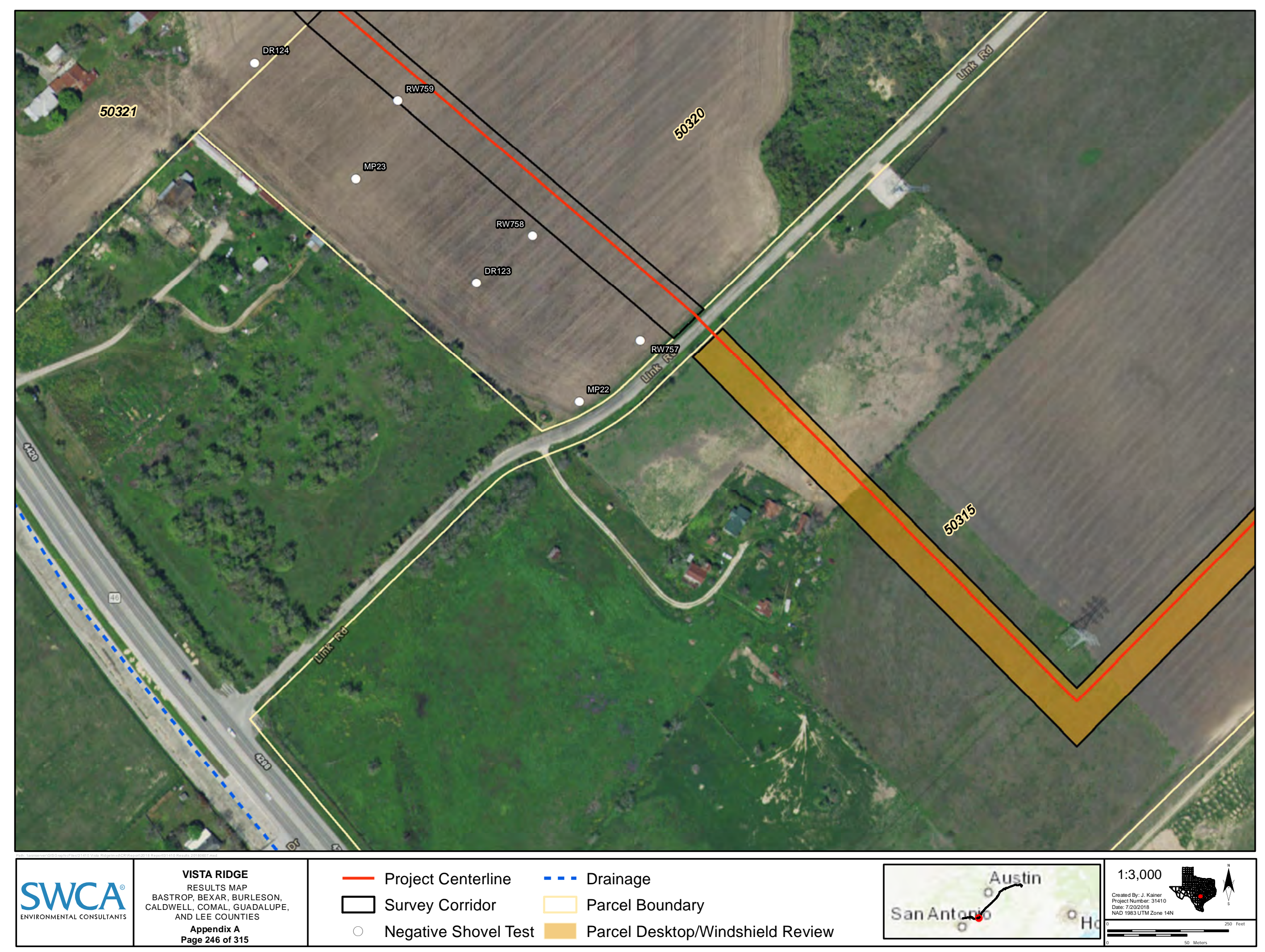


Restricted Information

Not for Public Disclosure 


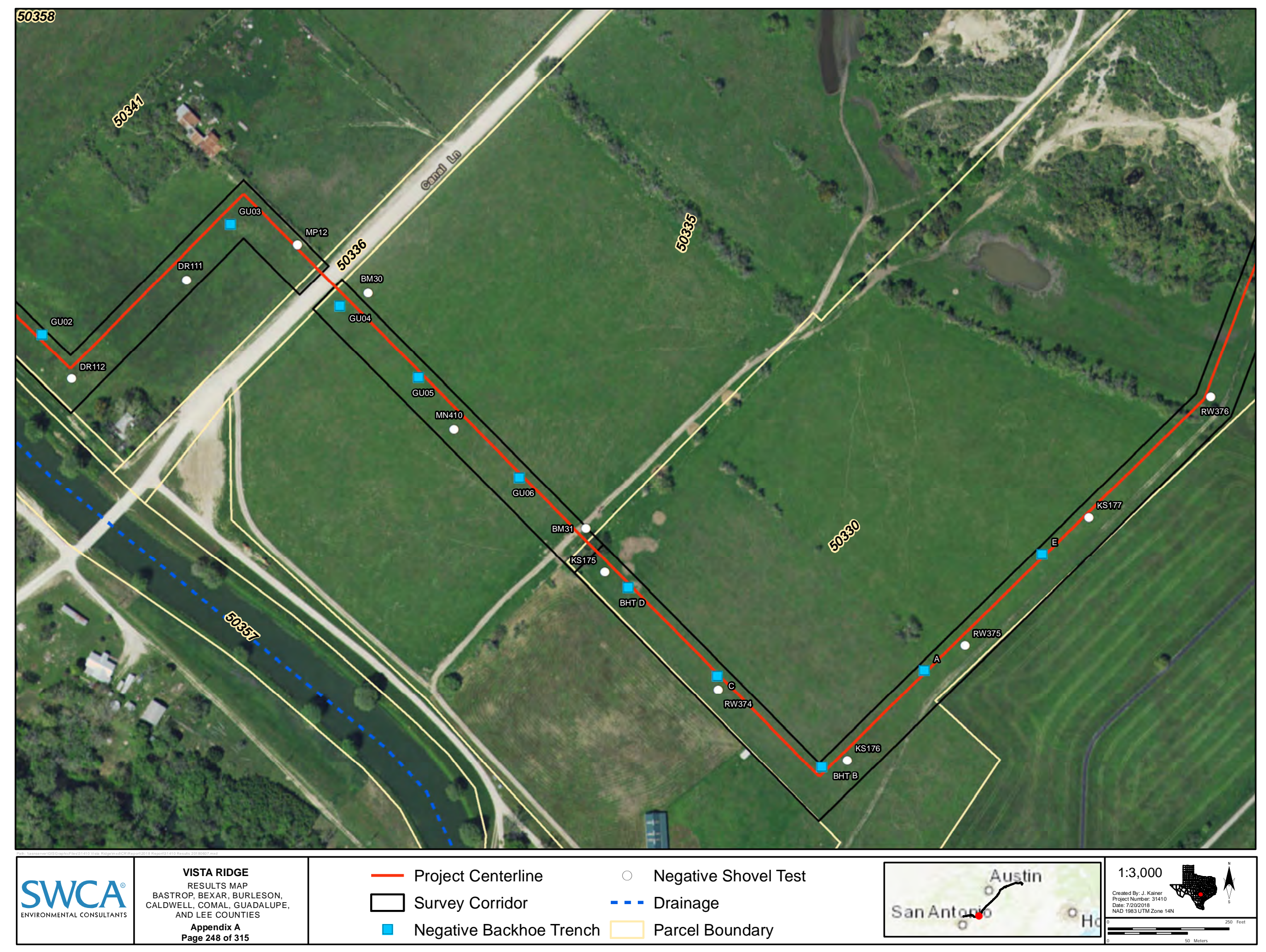


Restricted Information

Not for Public Disclosure 
Restricted Information

Not for Public Disclosure 


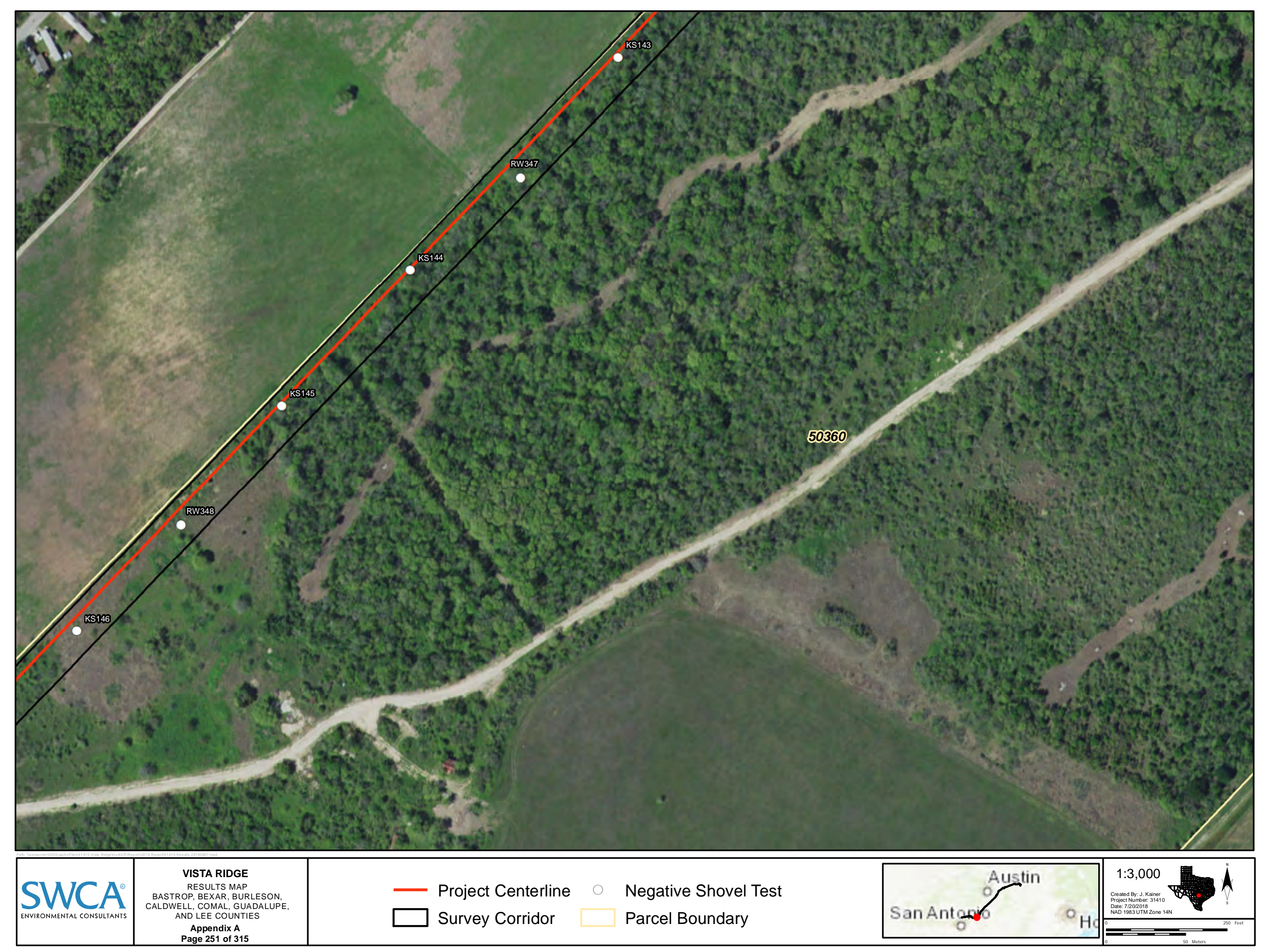




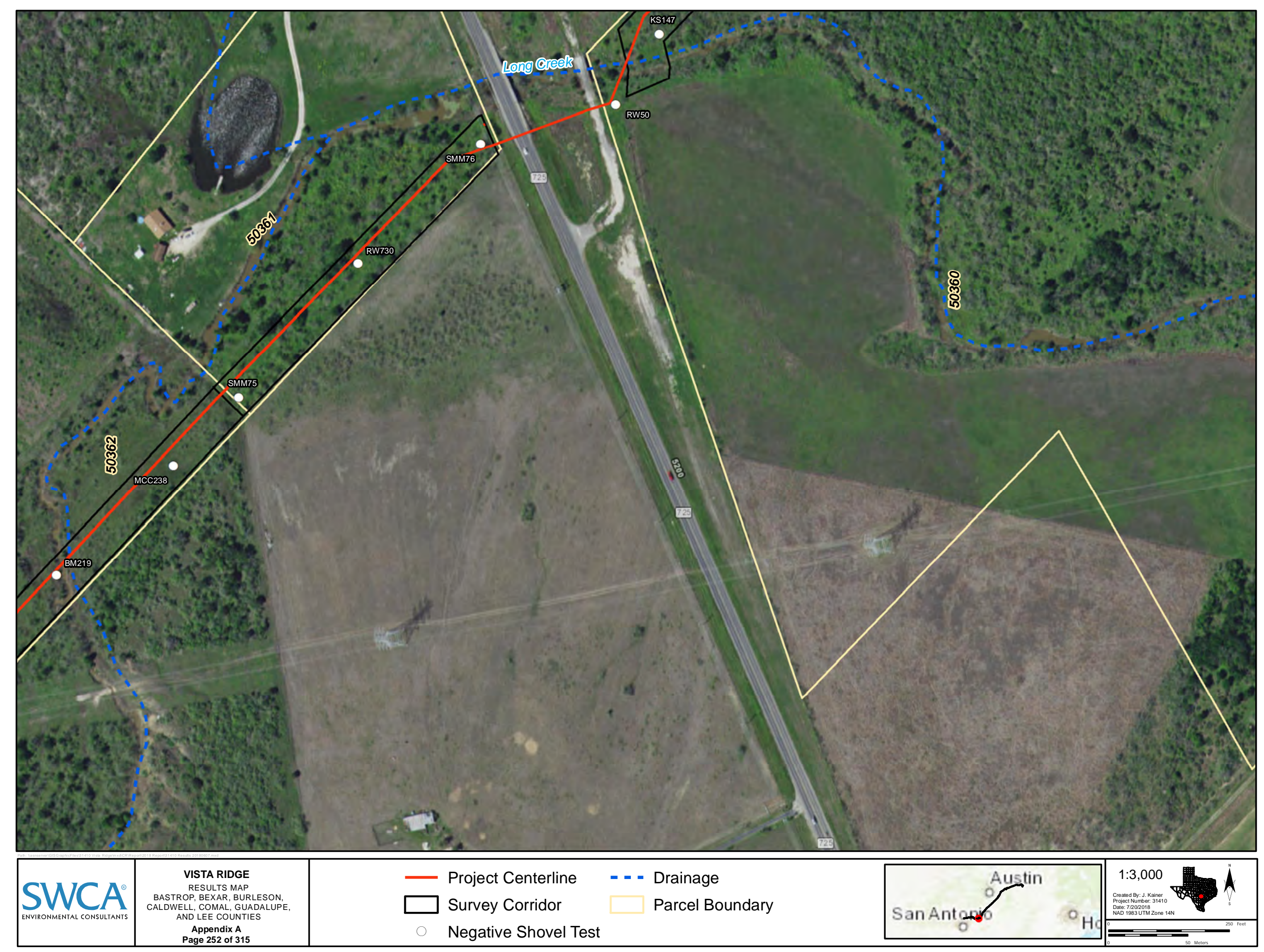




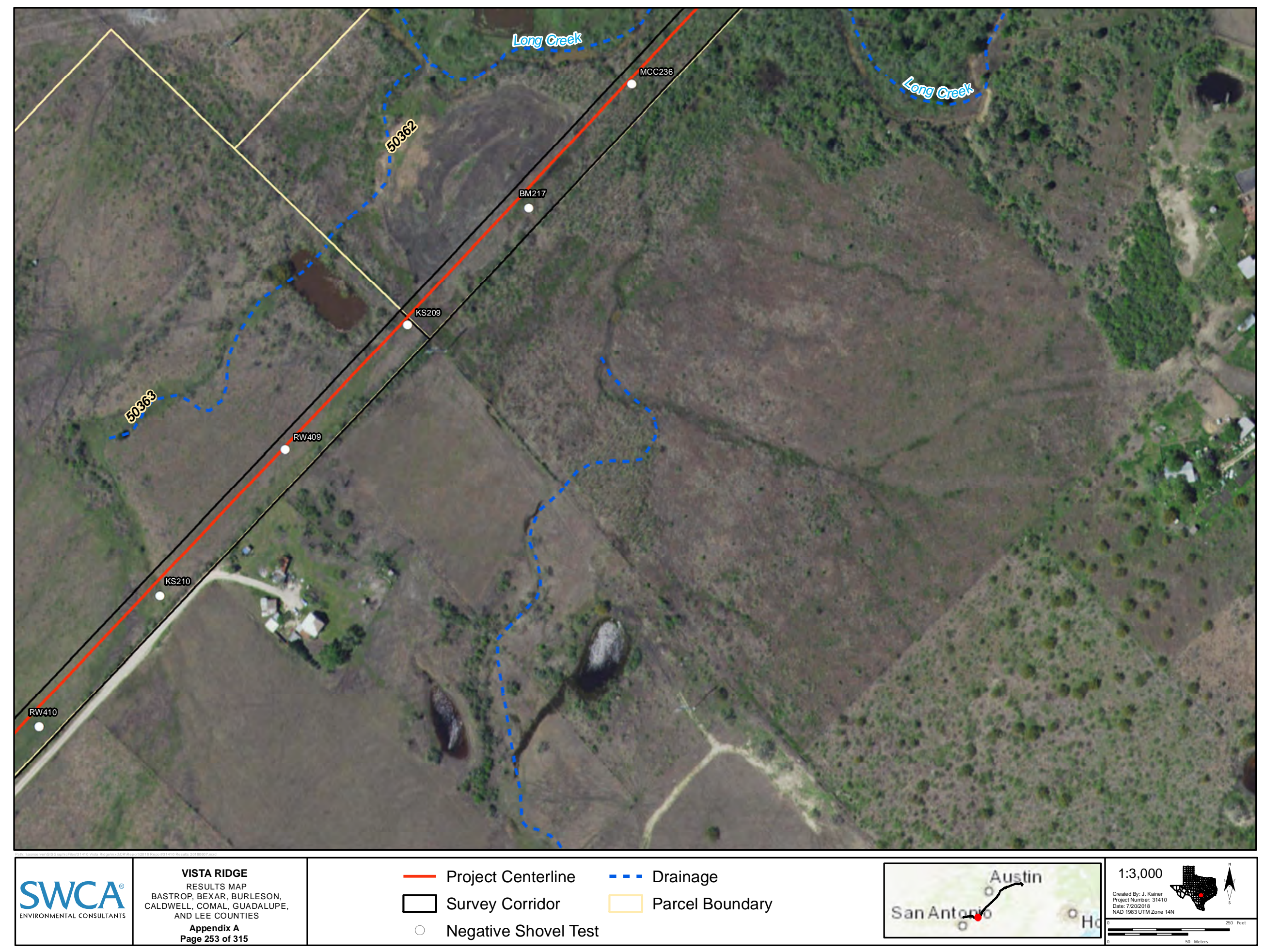




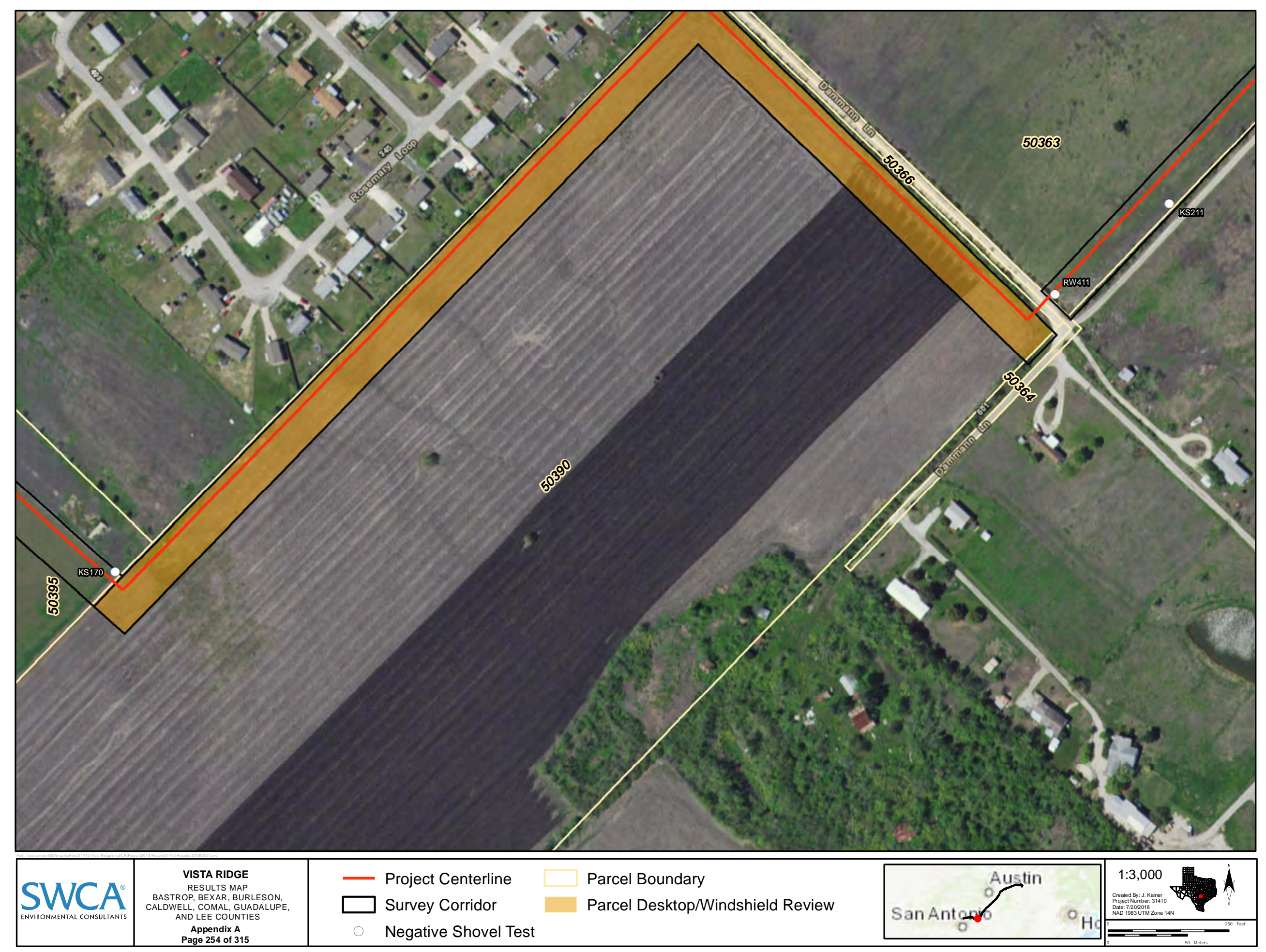


Restricted Information

Not for Public Disclosure 


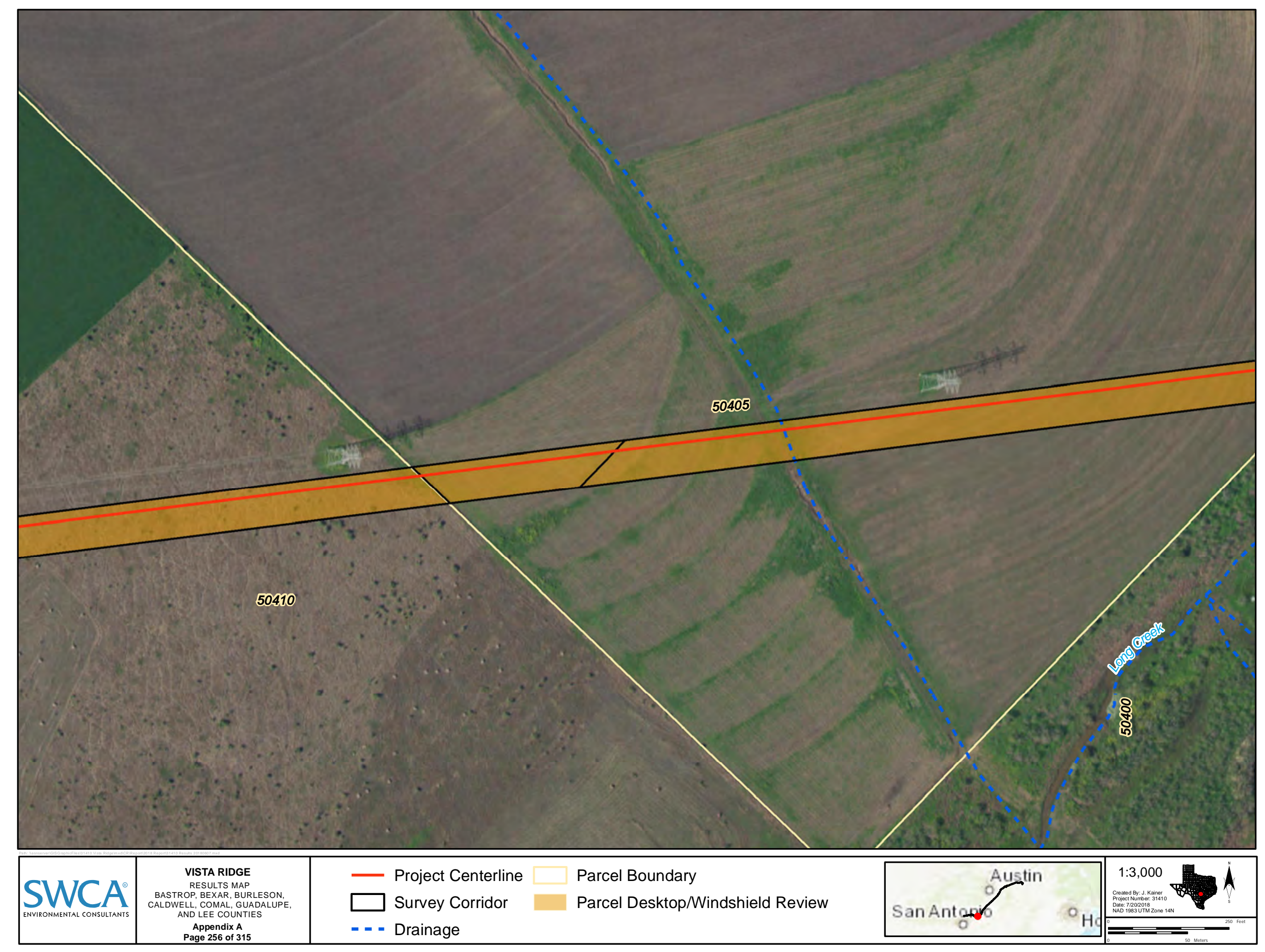




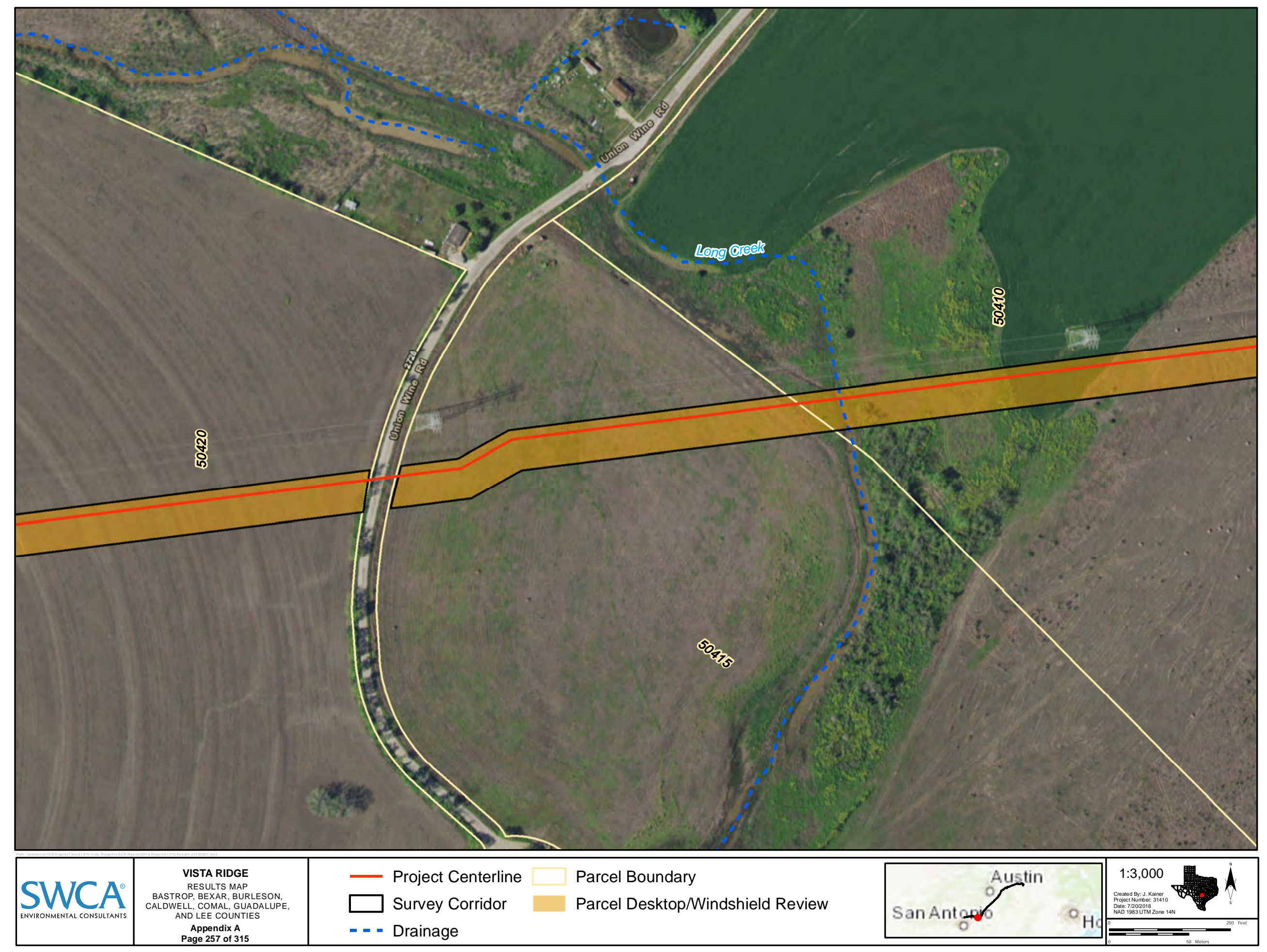




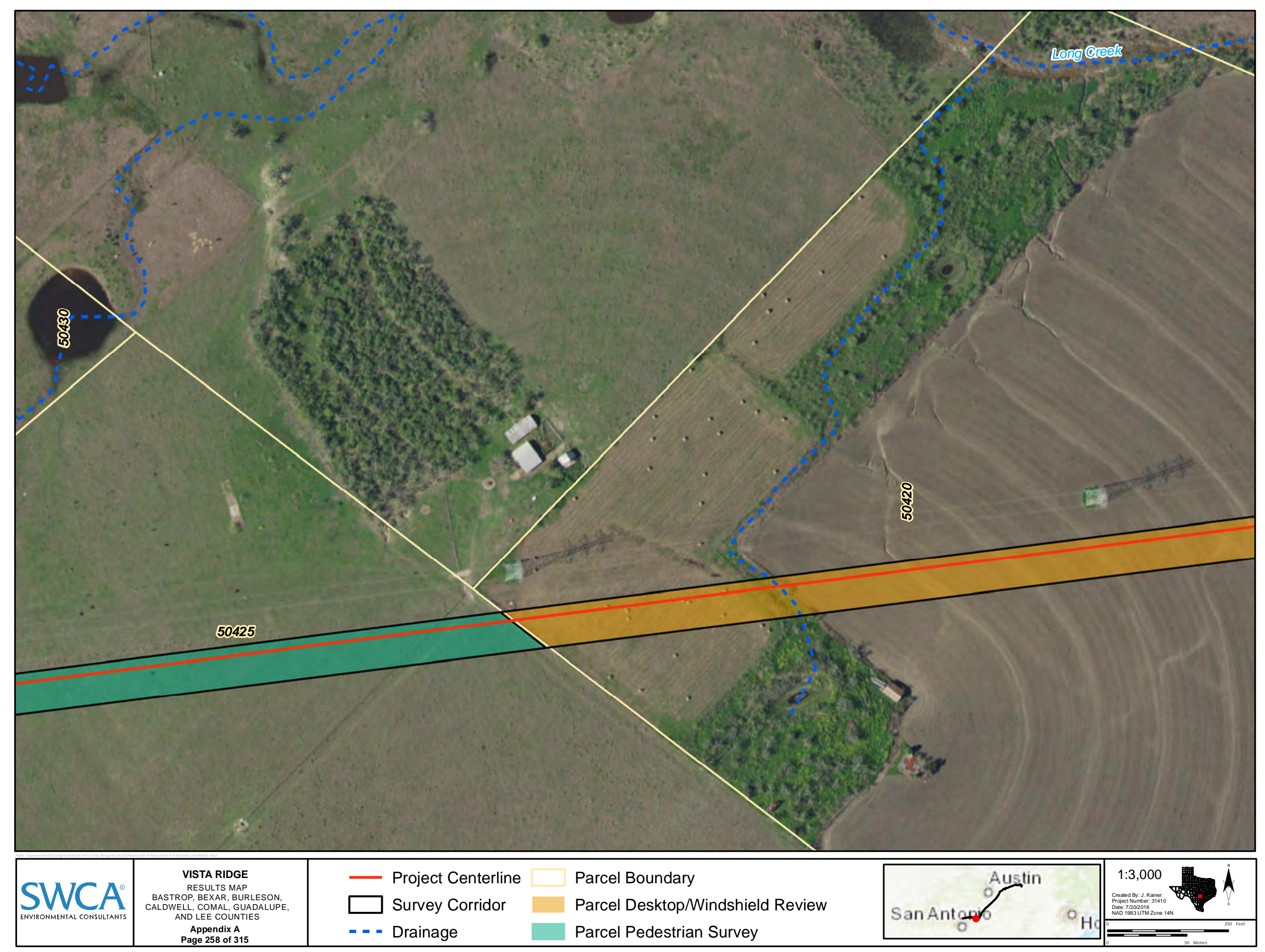


Restricted Information

Not for Public Disclosure 


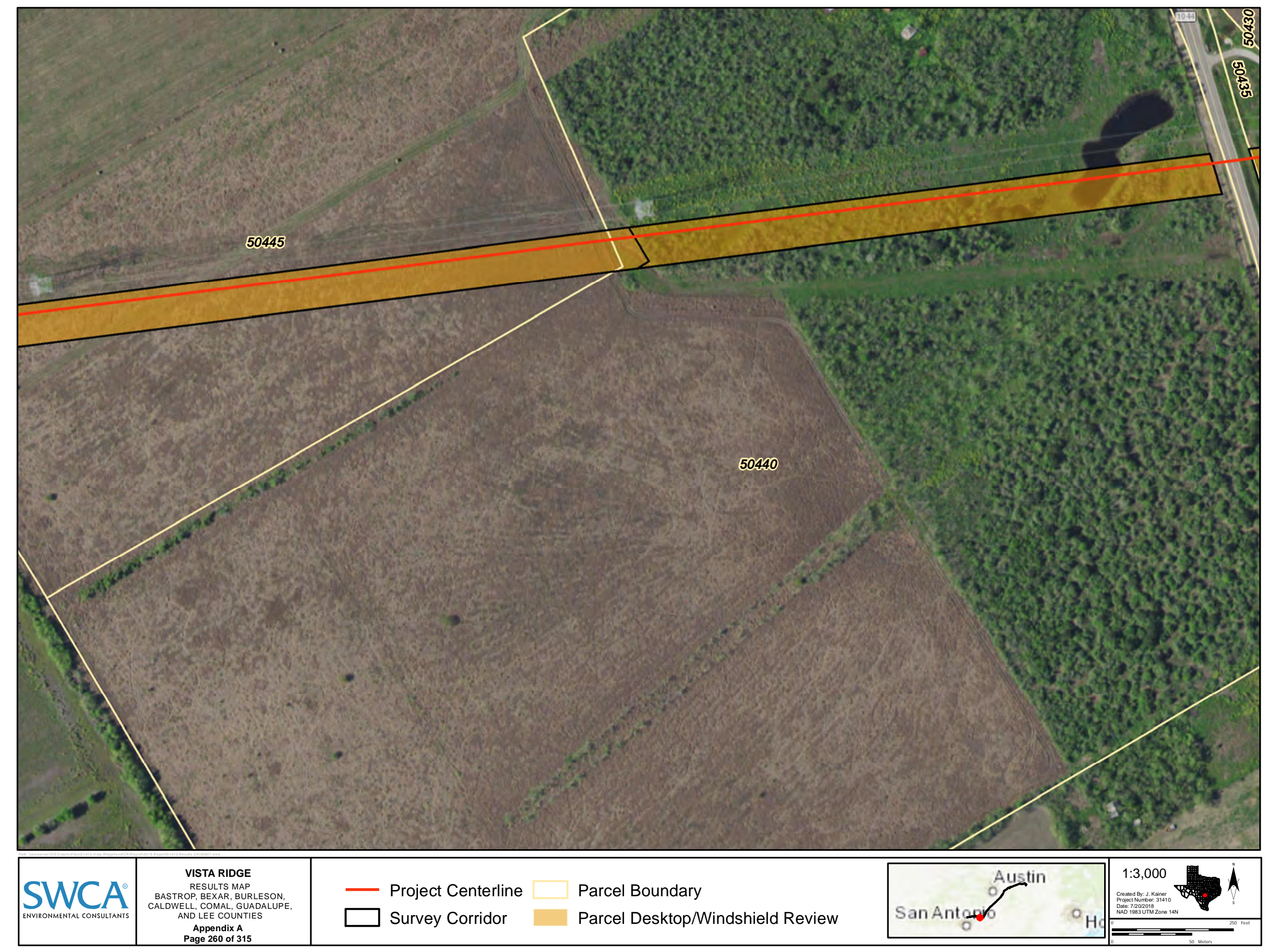




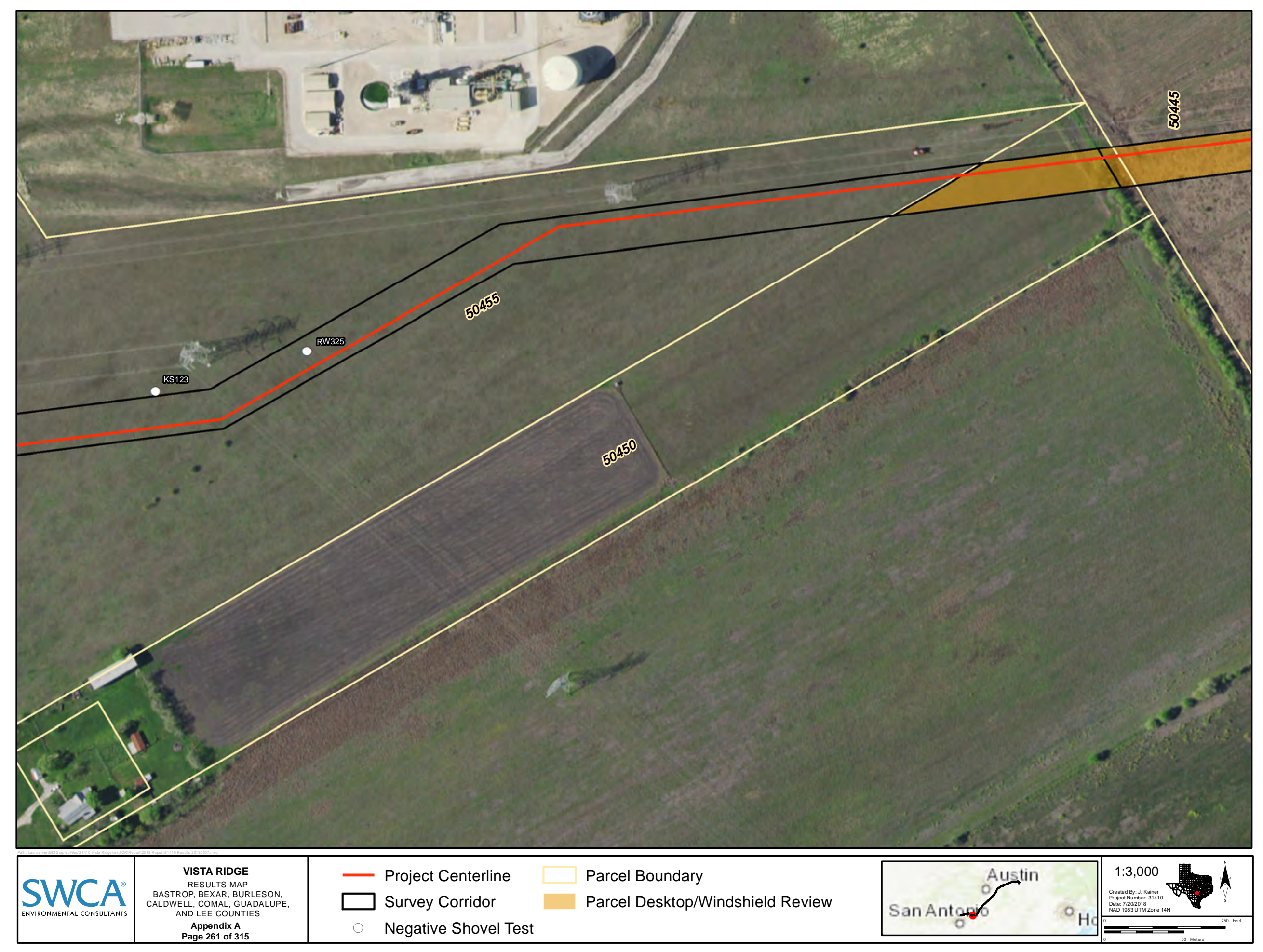




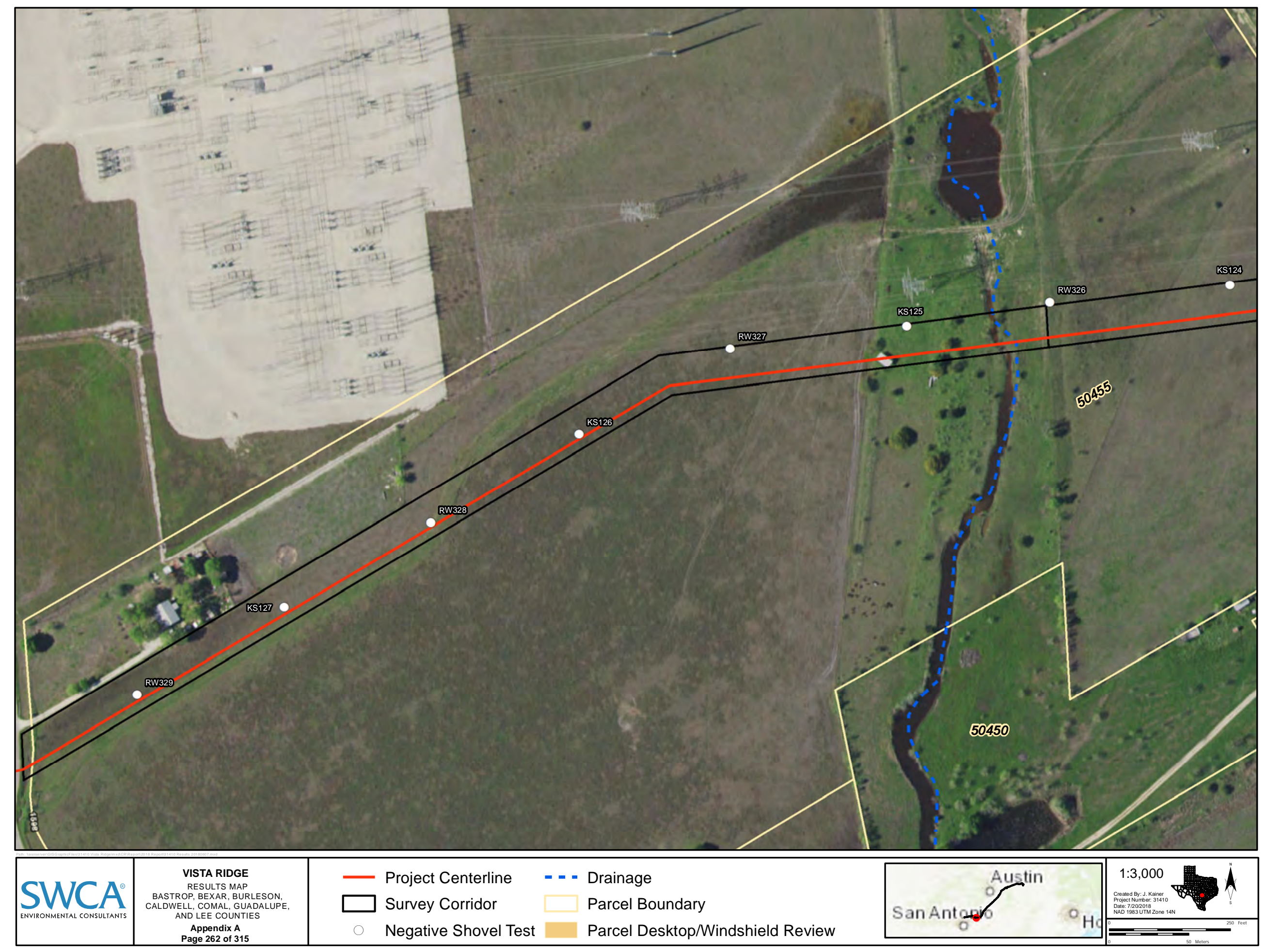




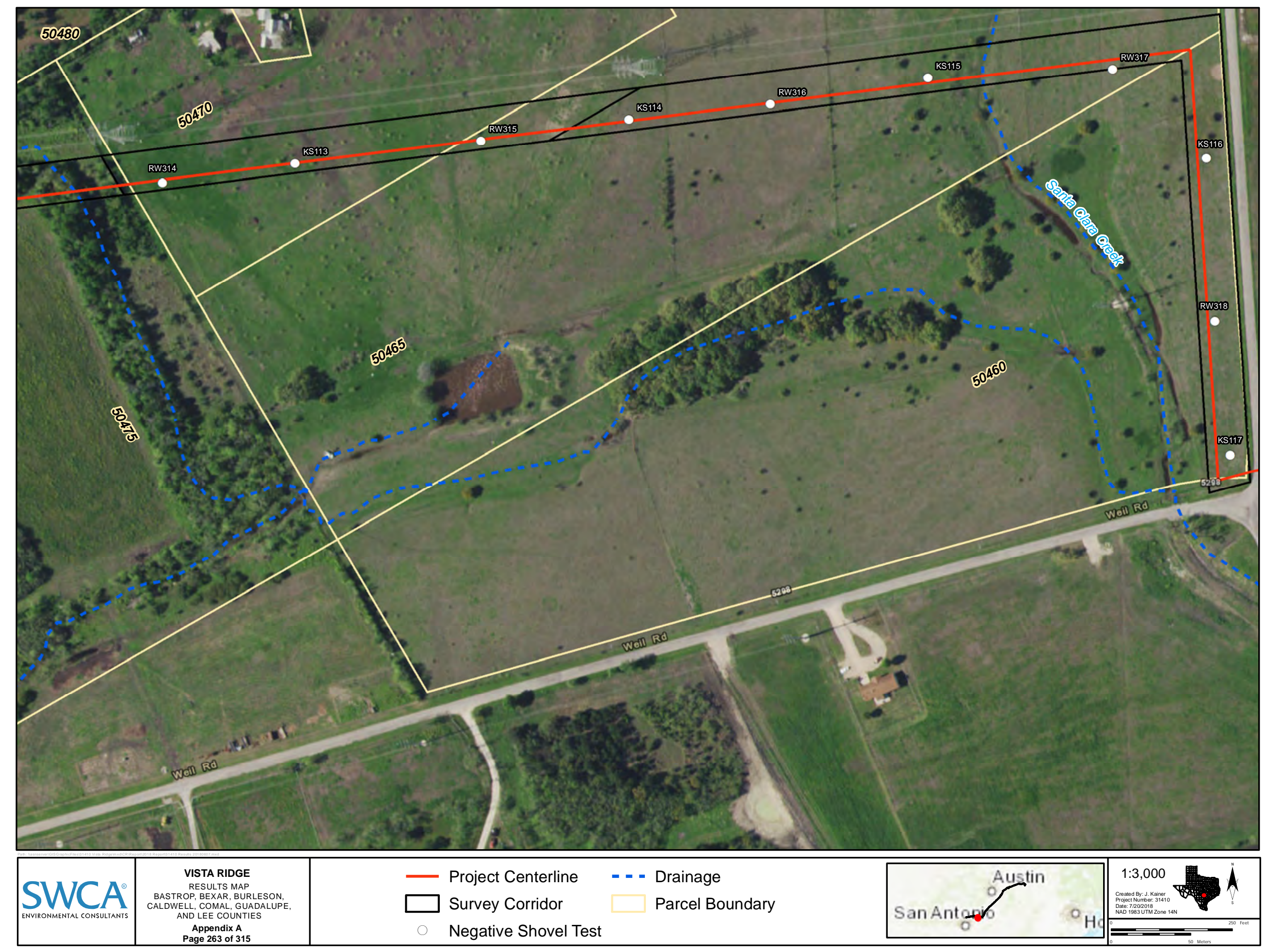




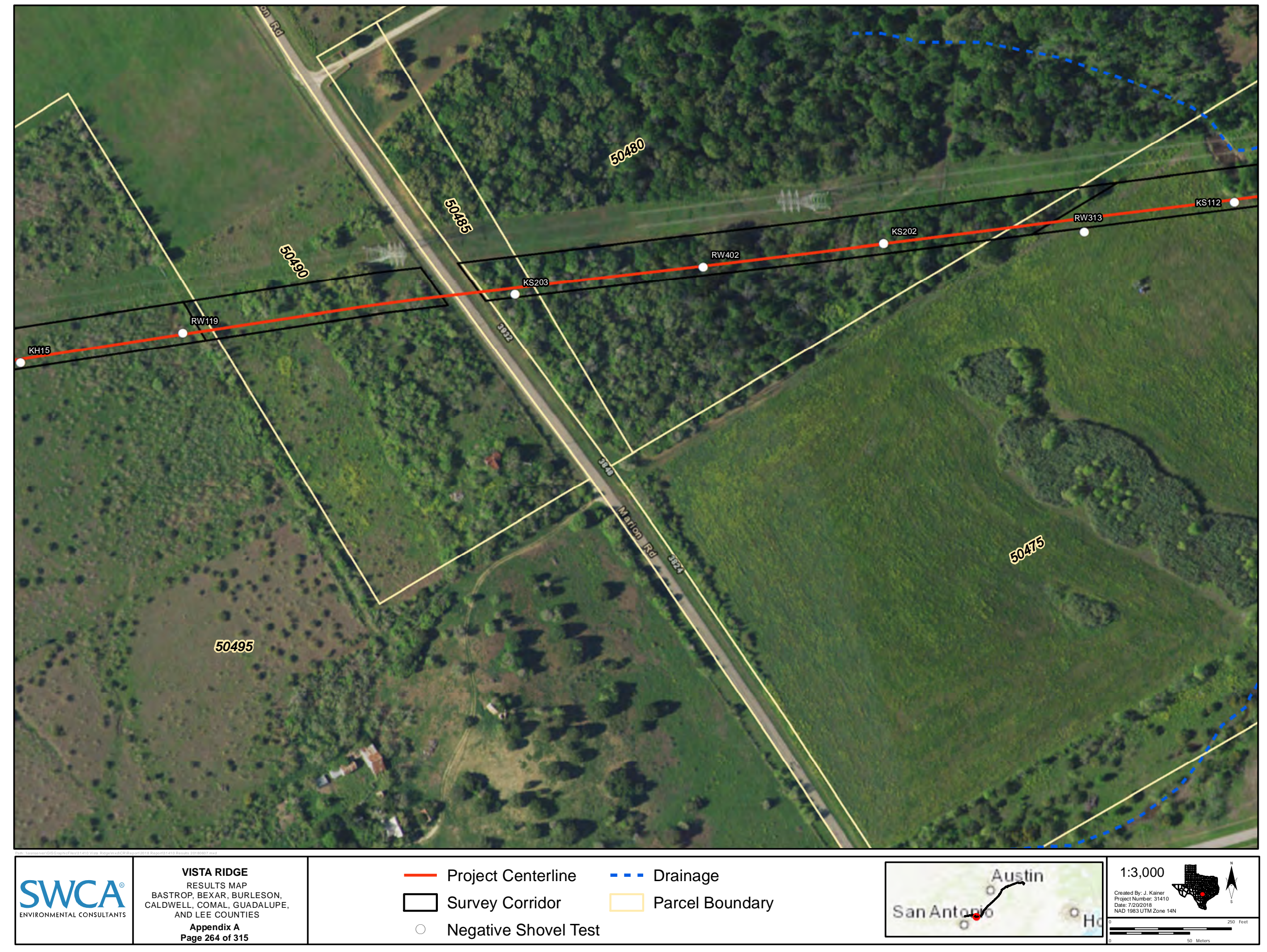




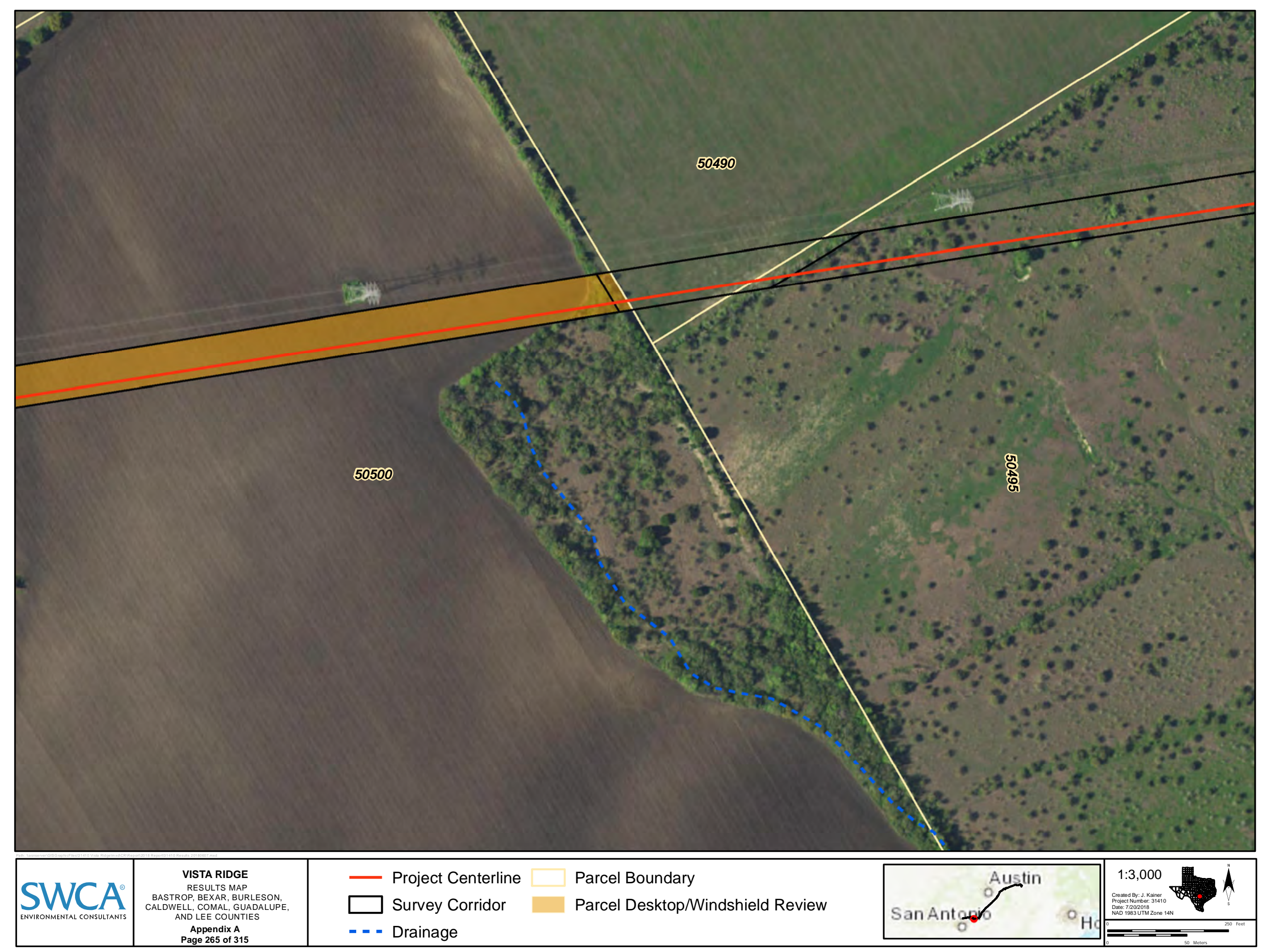




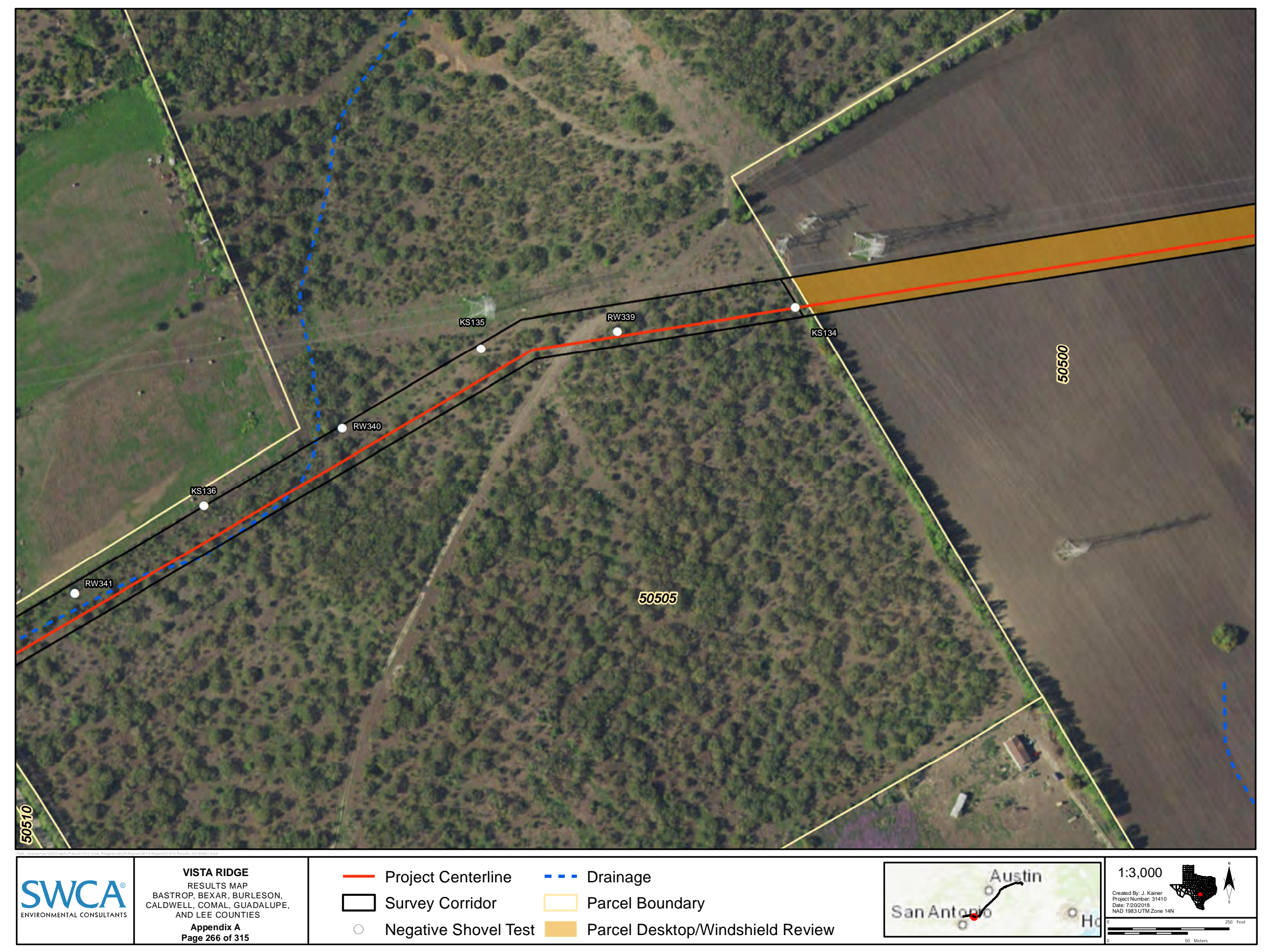




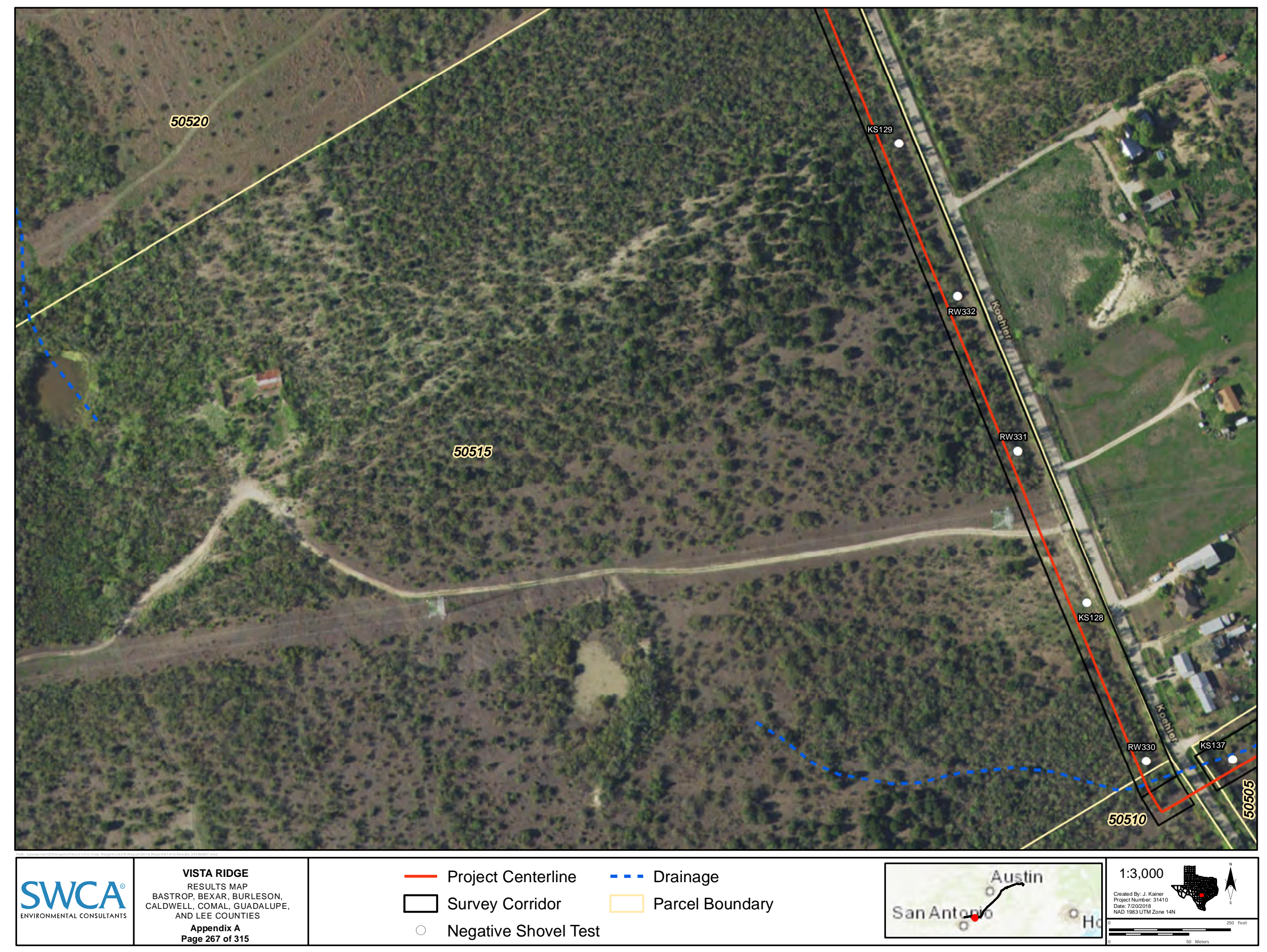




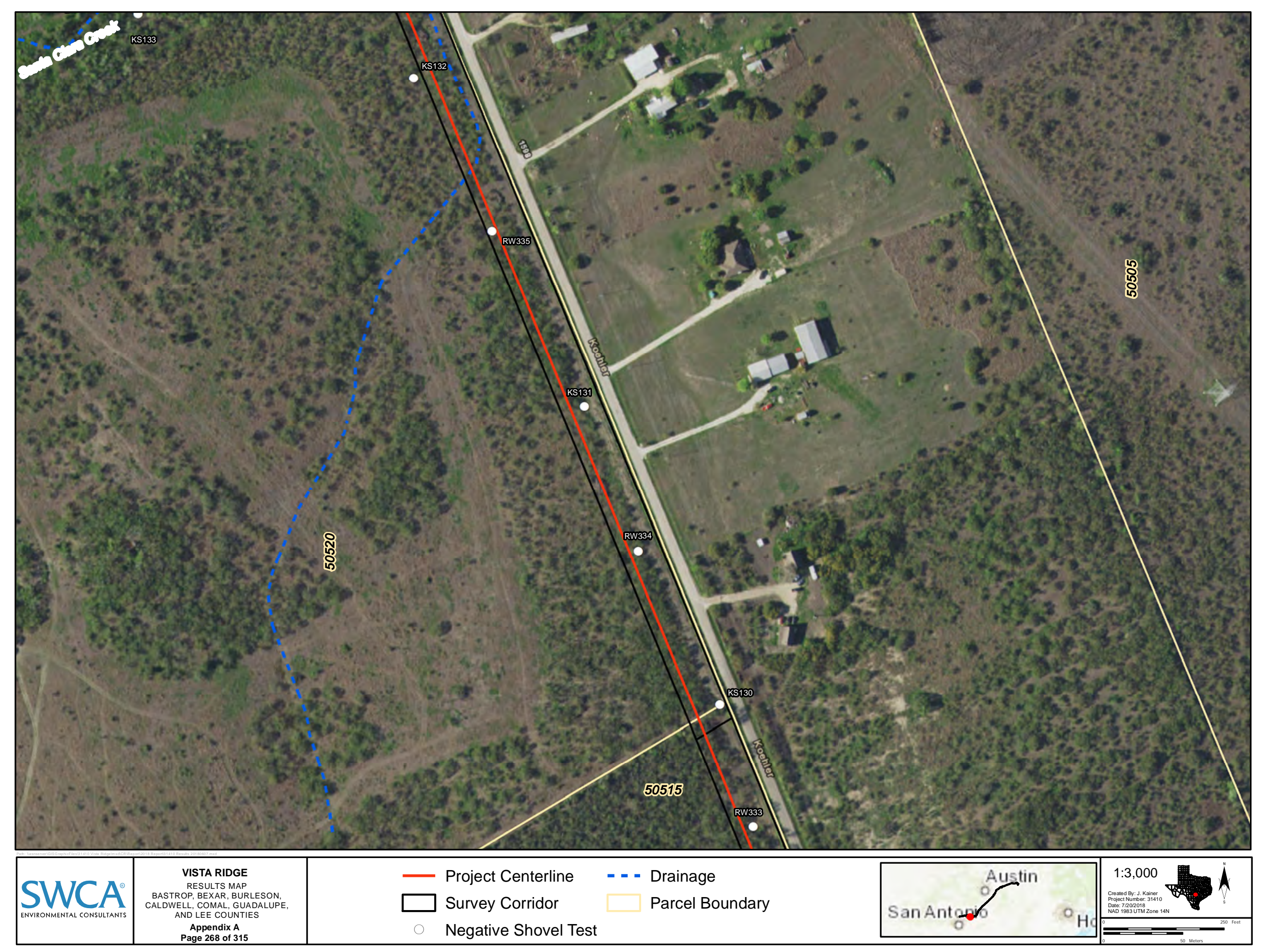




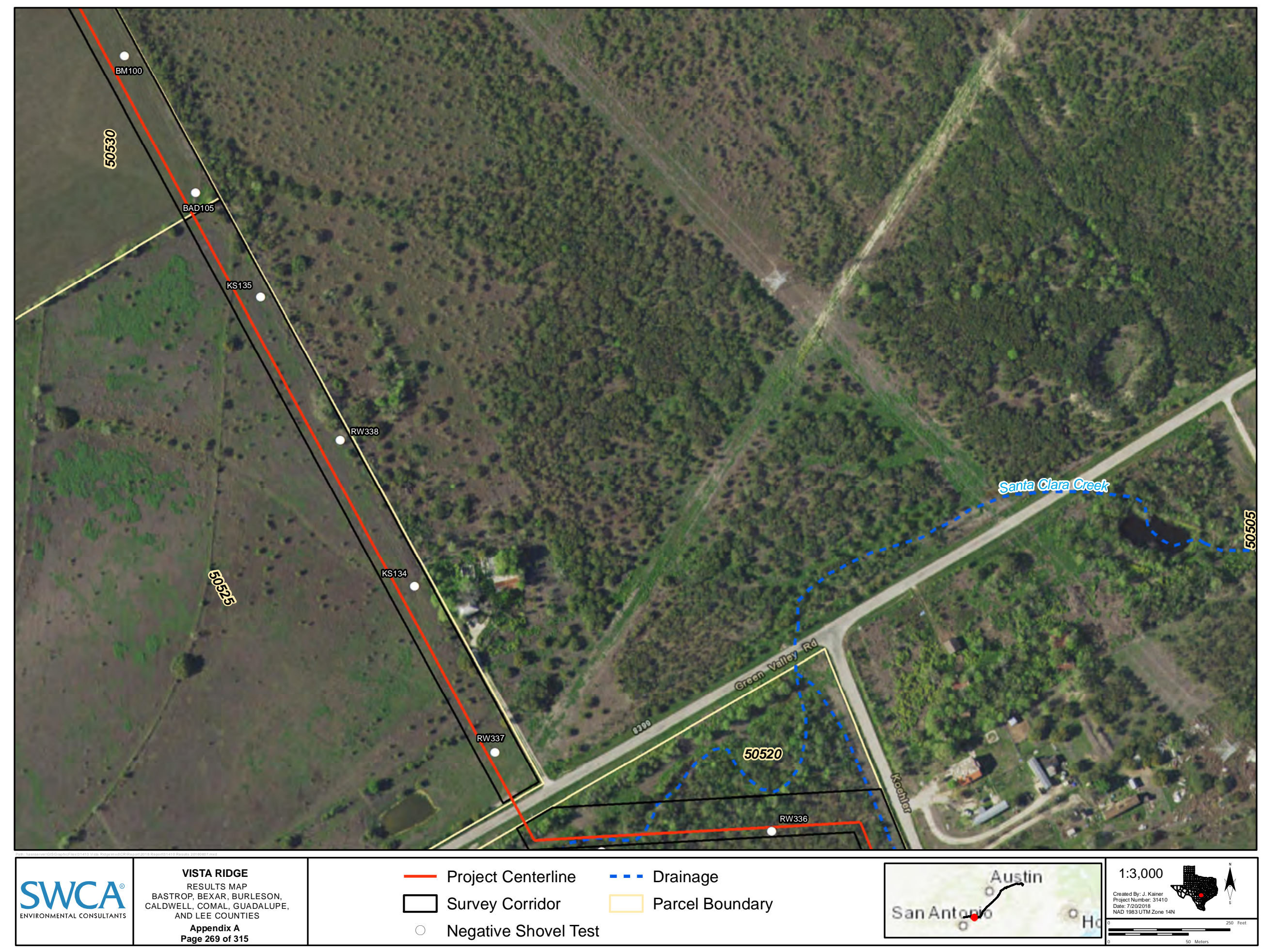




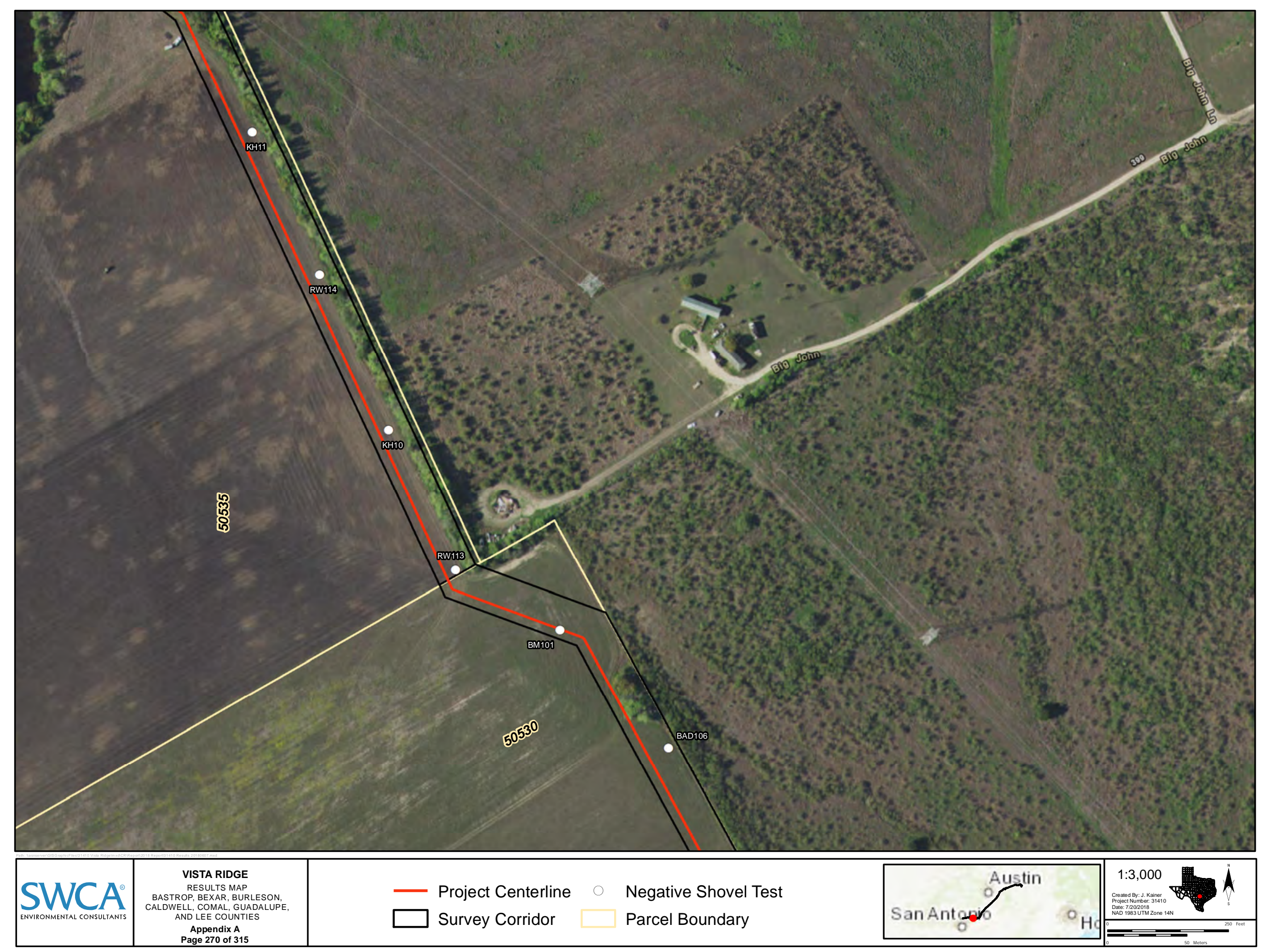


Restricted Information

Not for Public Disclosure 


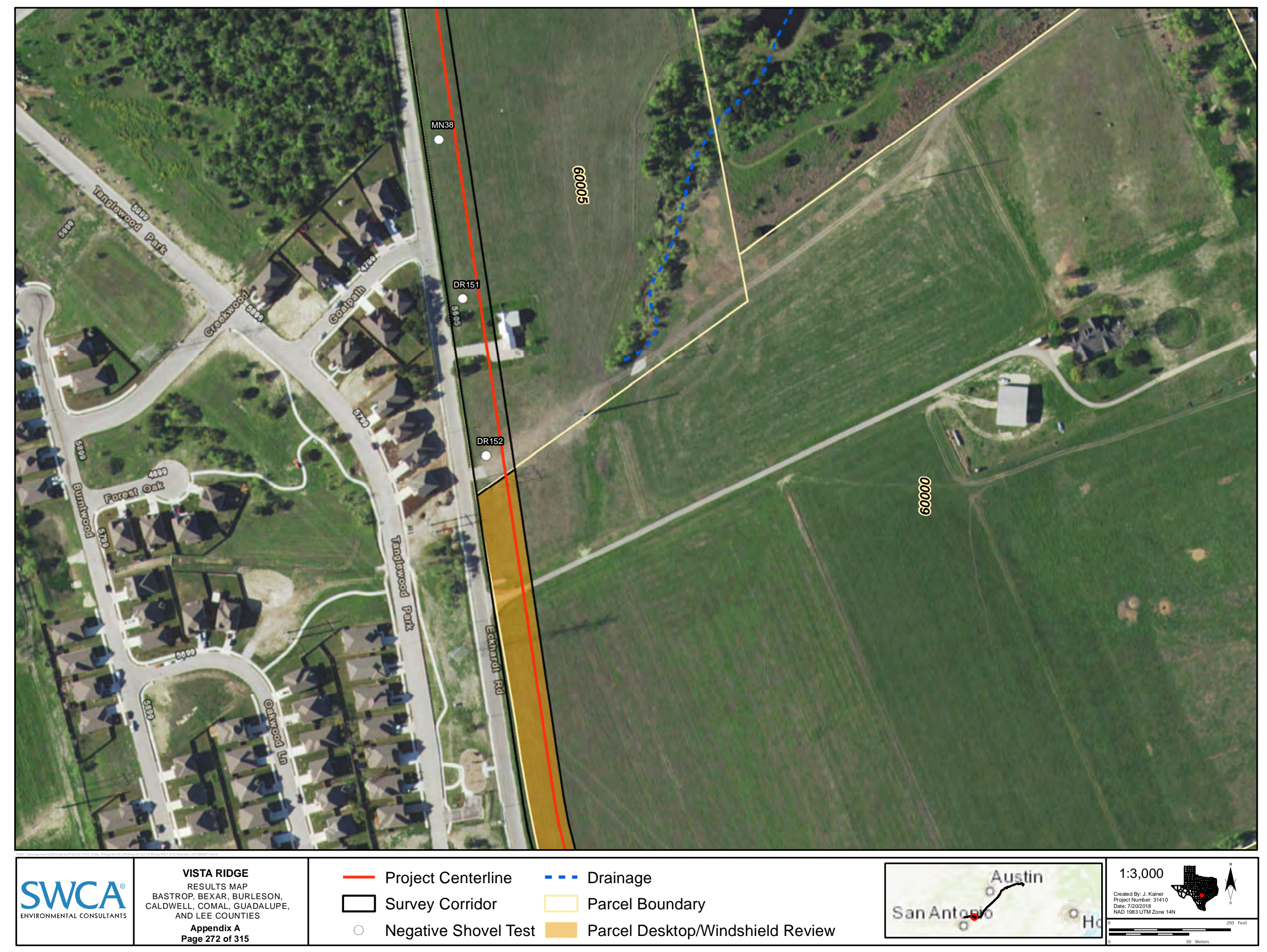




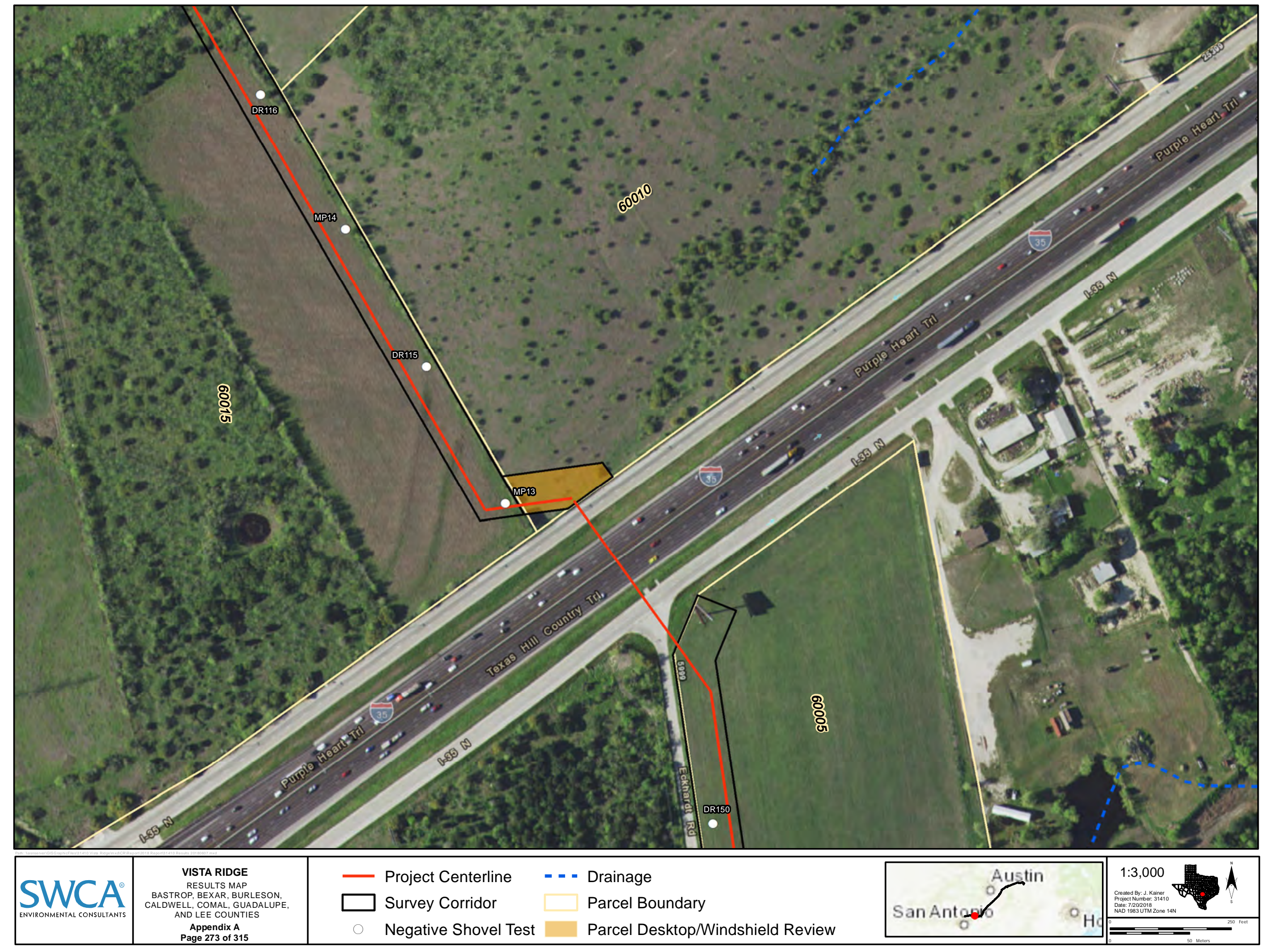




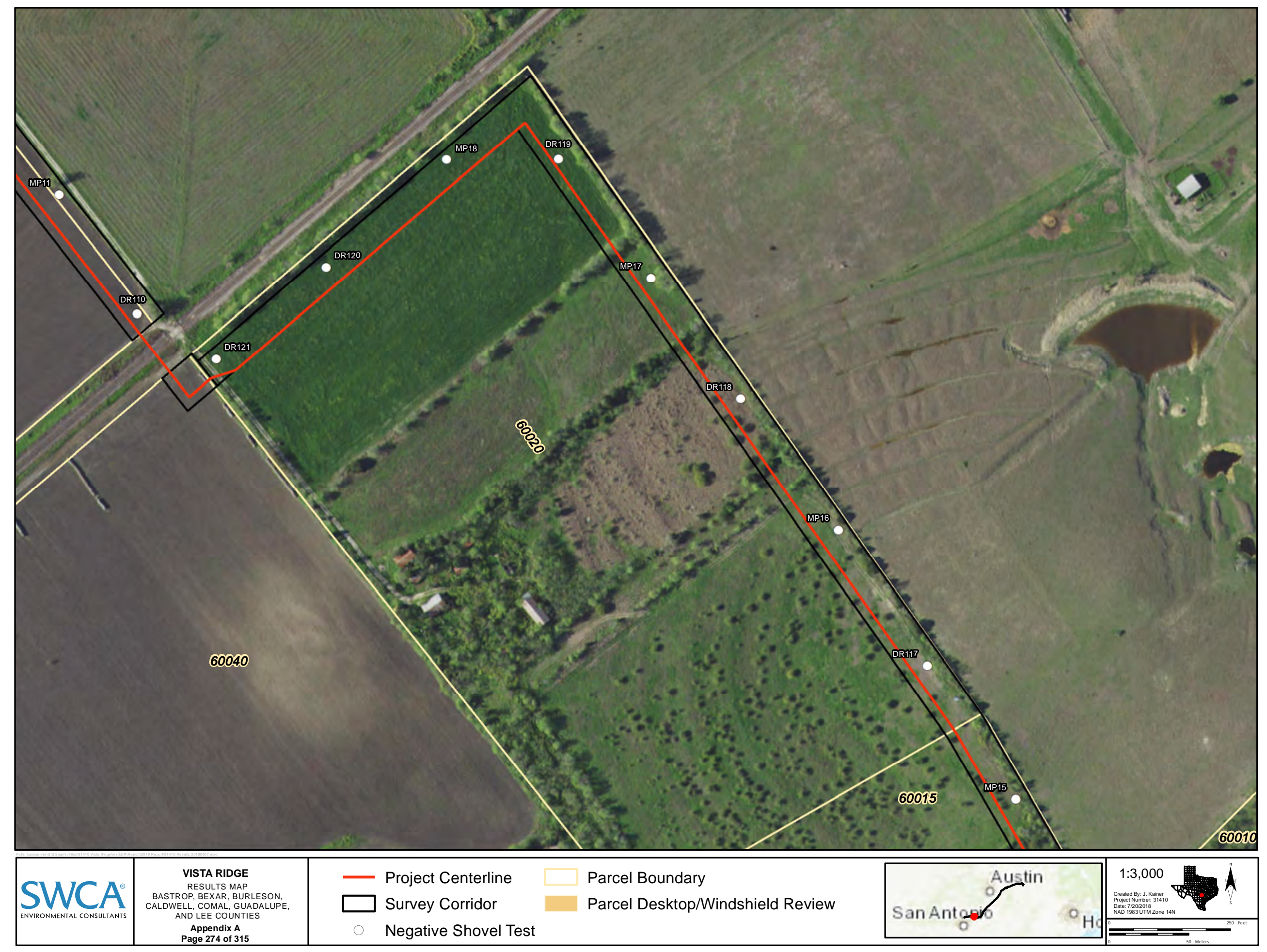


Restricted Information

Not for Public Disclosure 


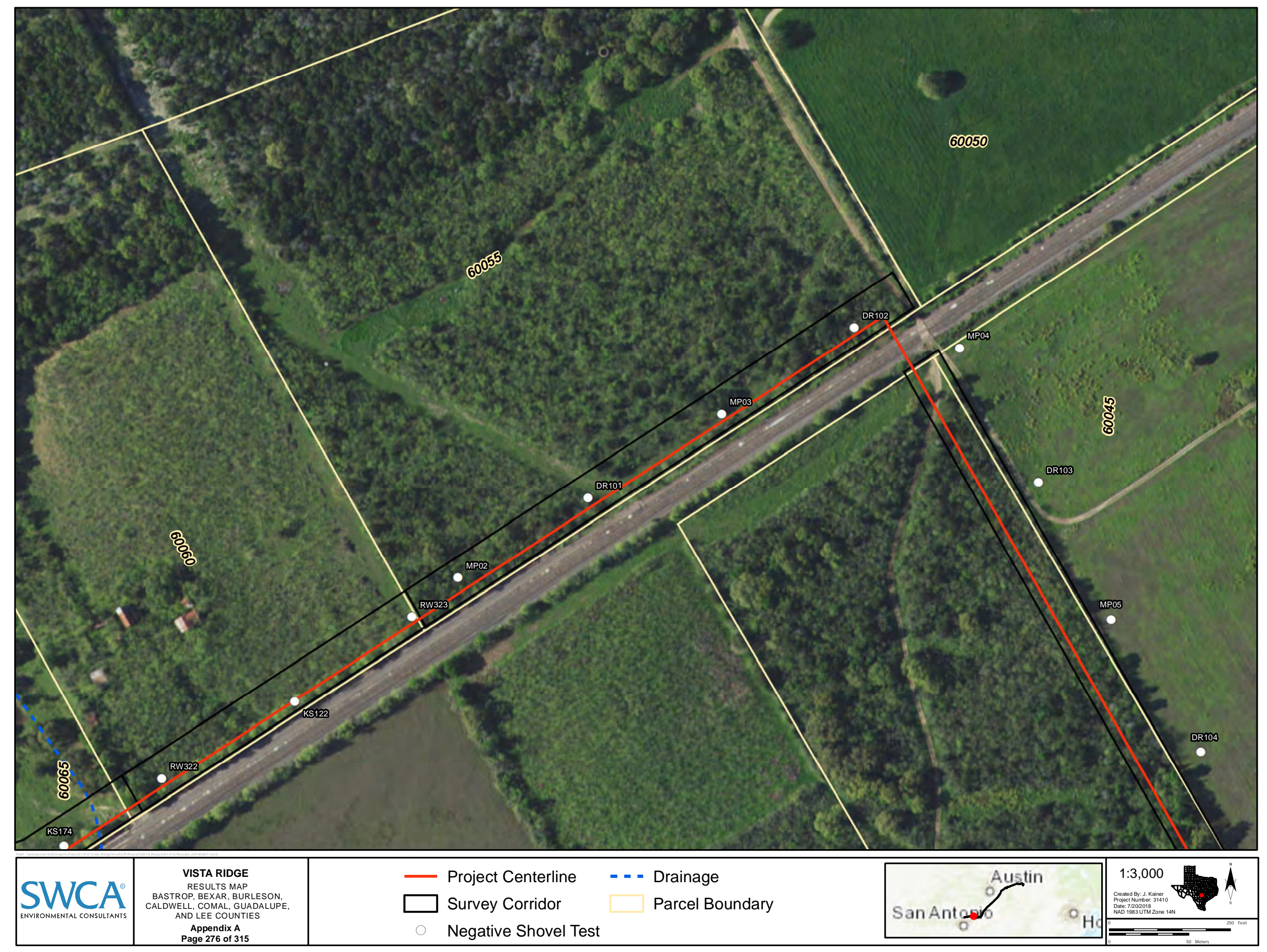


Restricted Information

Not for Public Disclosure 
Restricted Information

Not for Public Disclosure 
Restricted Information

Not for Public Disclosure 
Restricted Information

Not for Public Disclosure 
Restricted Information

Not for Public Disclosure 
Restricted Information

Not for Public Disclosure 
Restricted Information

Not for Public Disclosure 
Restricted Information

Not for Public Disclosure 
Restricted Information

Not for Public Disclosure 
Restricted Information

Not for Public Disclosure 
Restricted Information

Not for Public Disclosure 


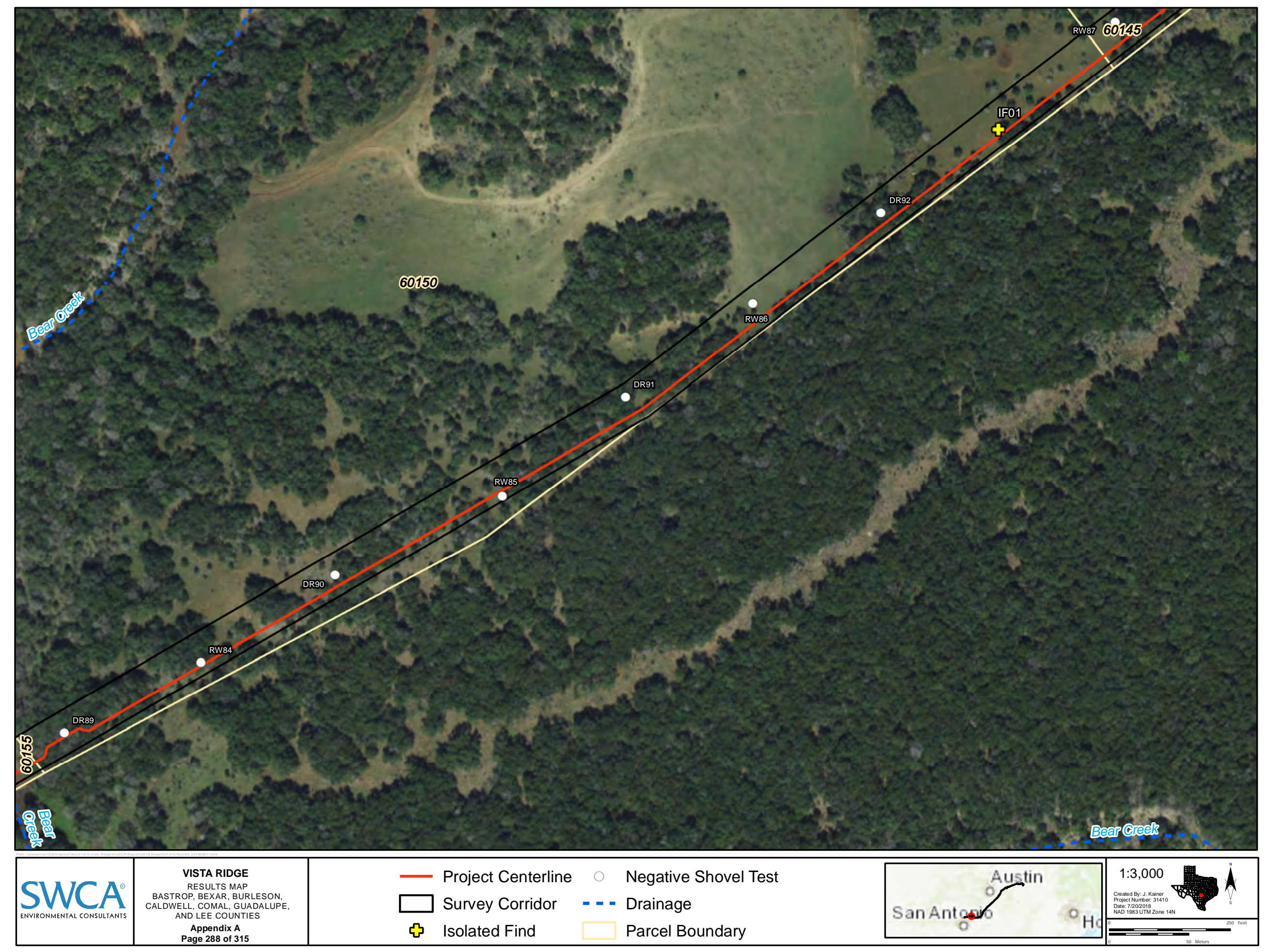


Restricted Information

Not for Public Disclosure 
Restricted Information

Not for Public Disclosure 
Restricted Information

Not for Public Disclosure 
Restricted Information

Not for Public Disclosure 


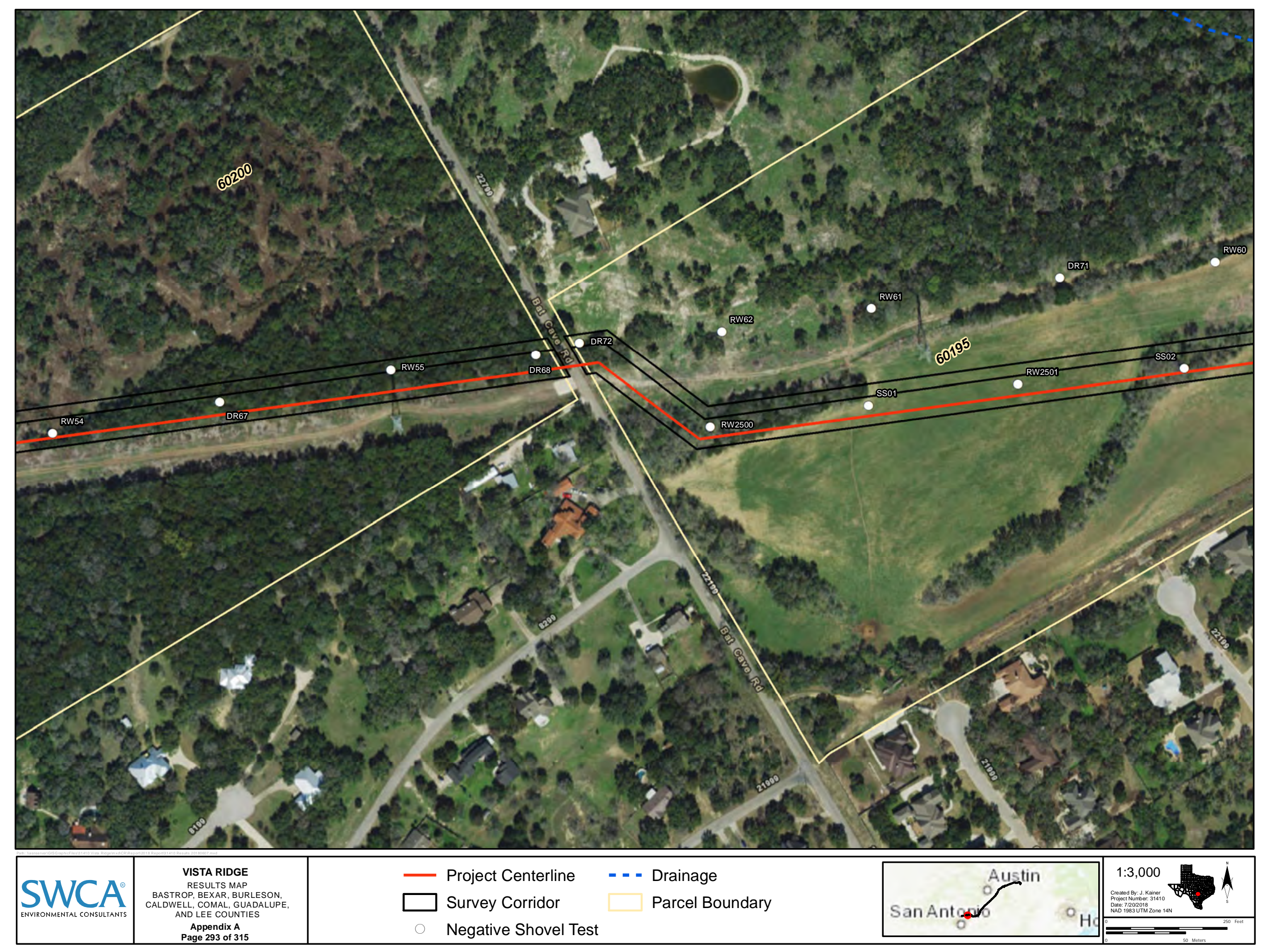




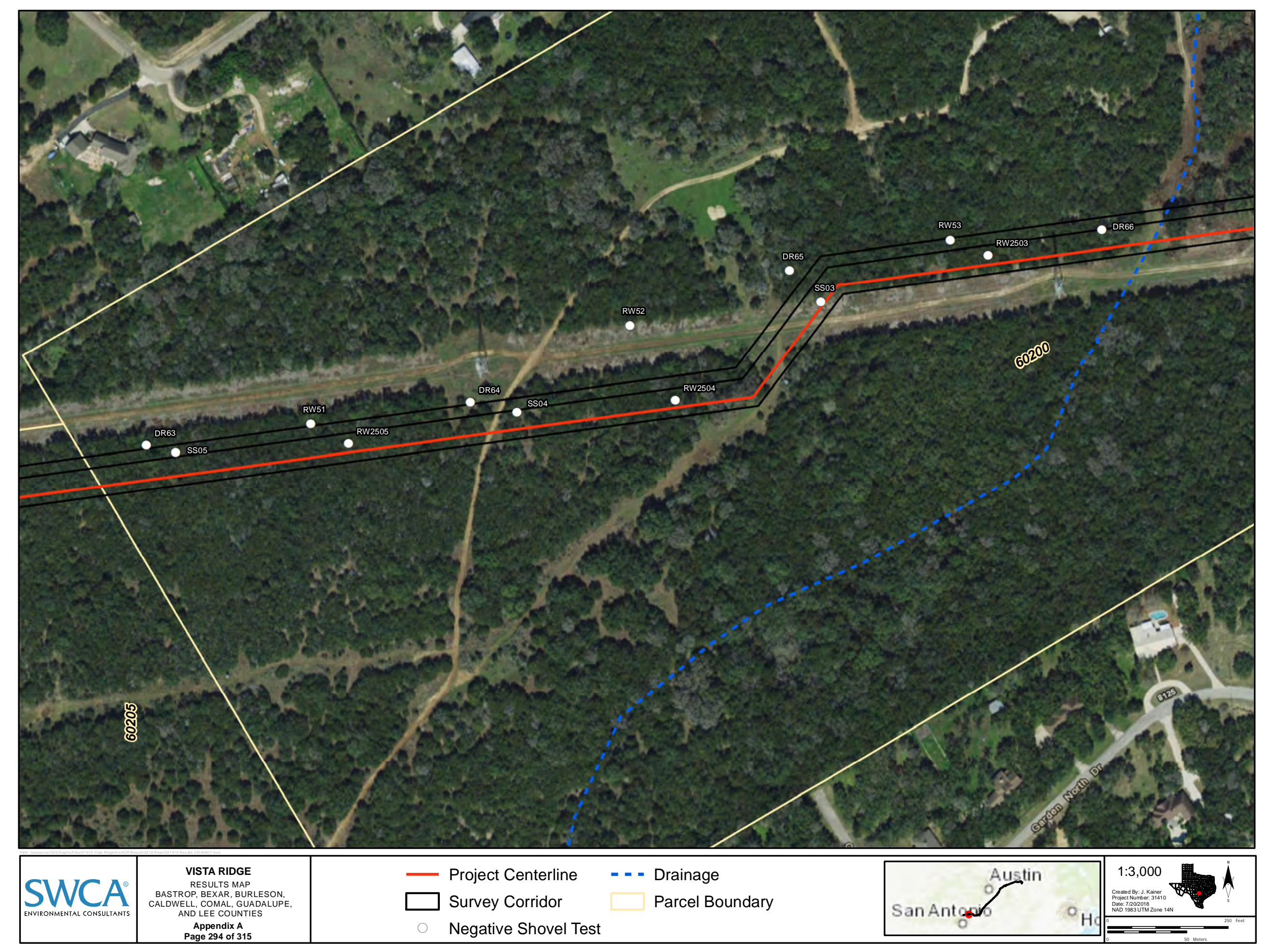


Restricted Information

Not for Public Disclosure 
Restricted Information

Not for Public Disclosure 
Restricted Information

Not for Public Disclosure 
Restricted Information

Not for Public Disclosure 
Restricted Information

Not for Public Disclosure 


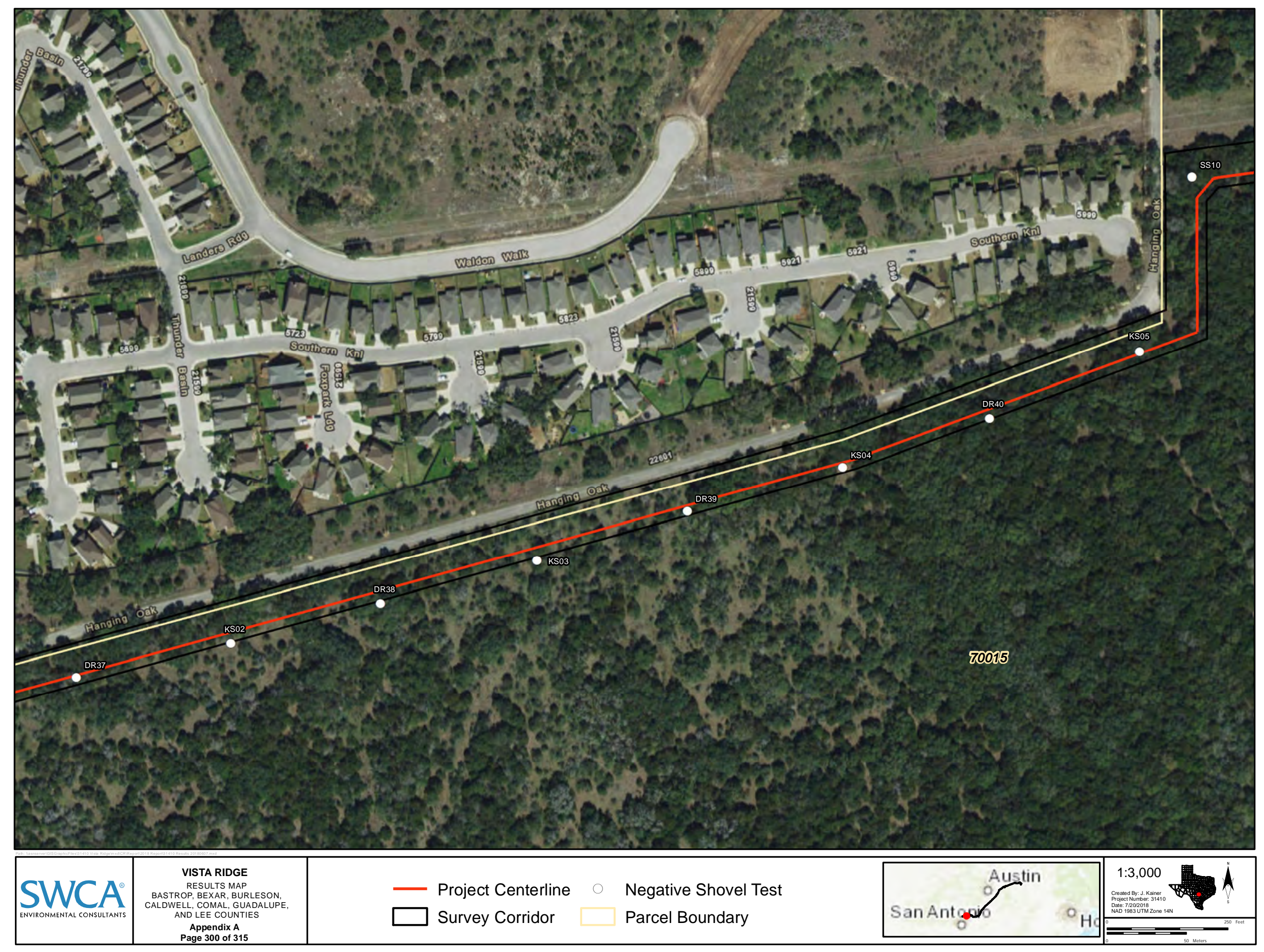




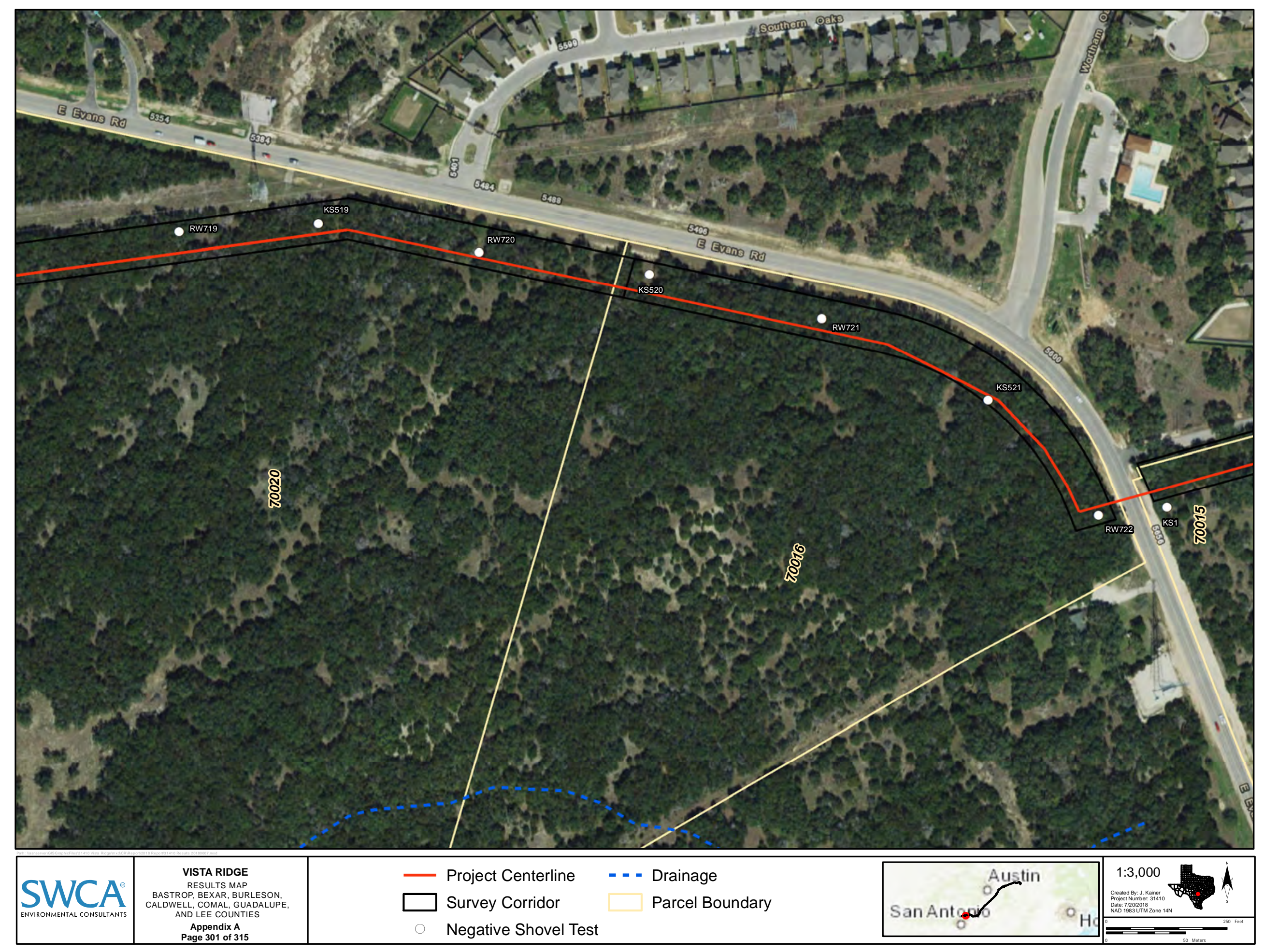




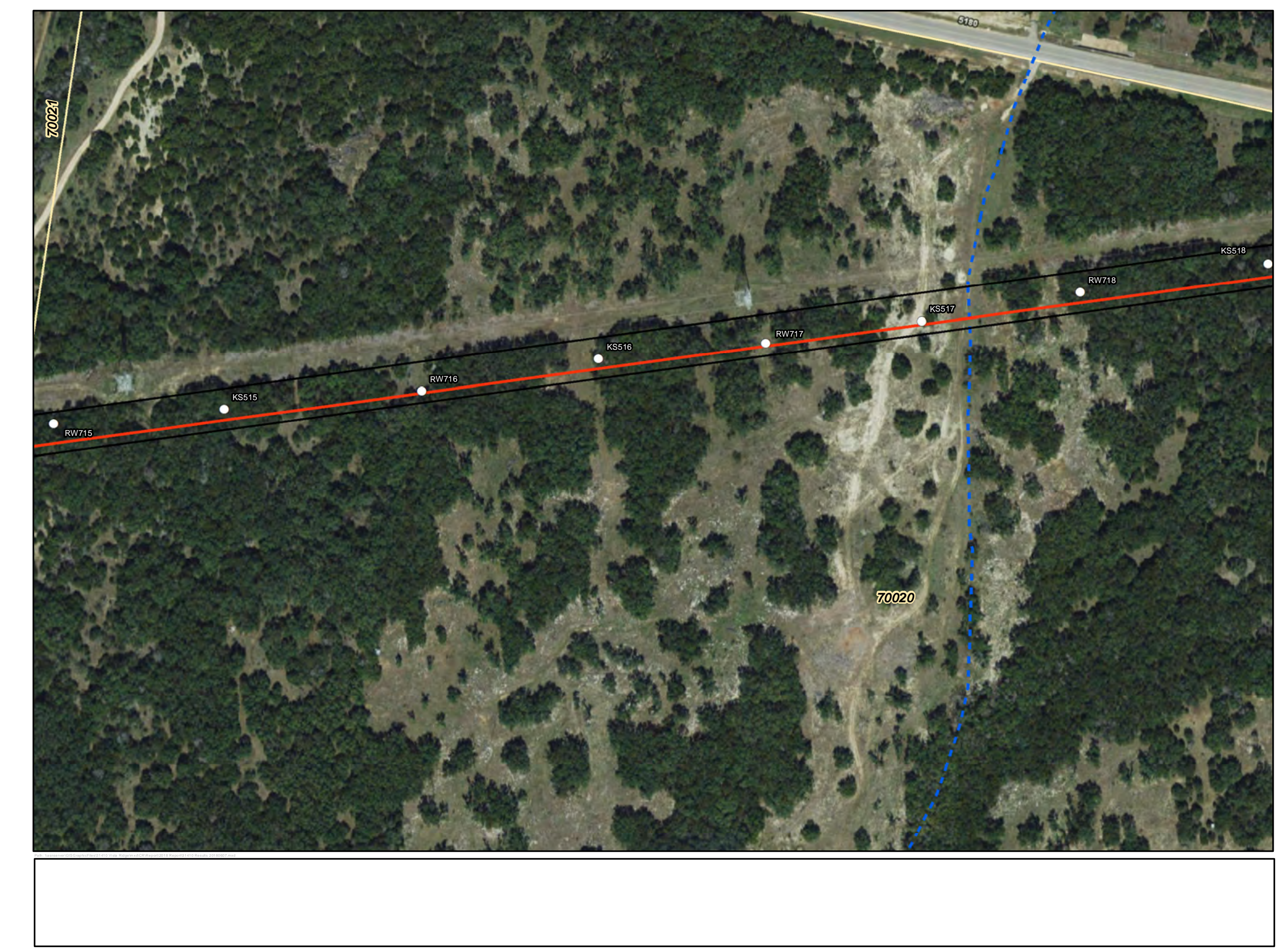




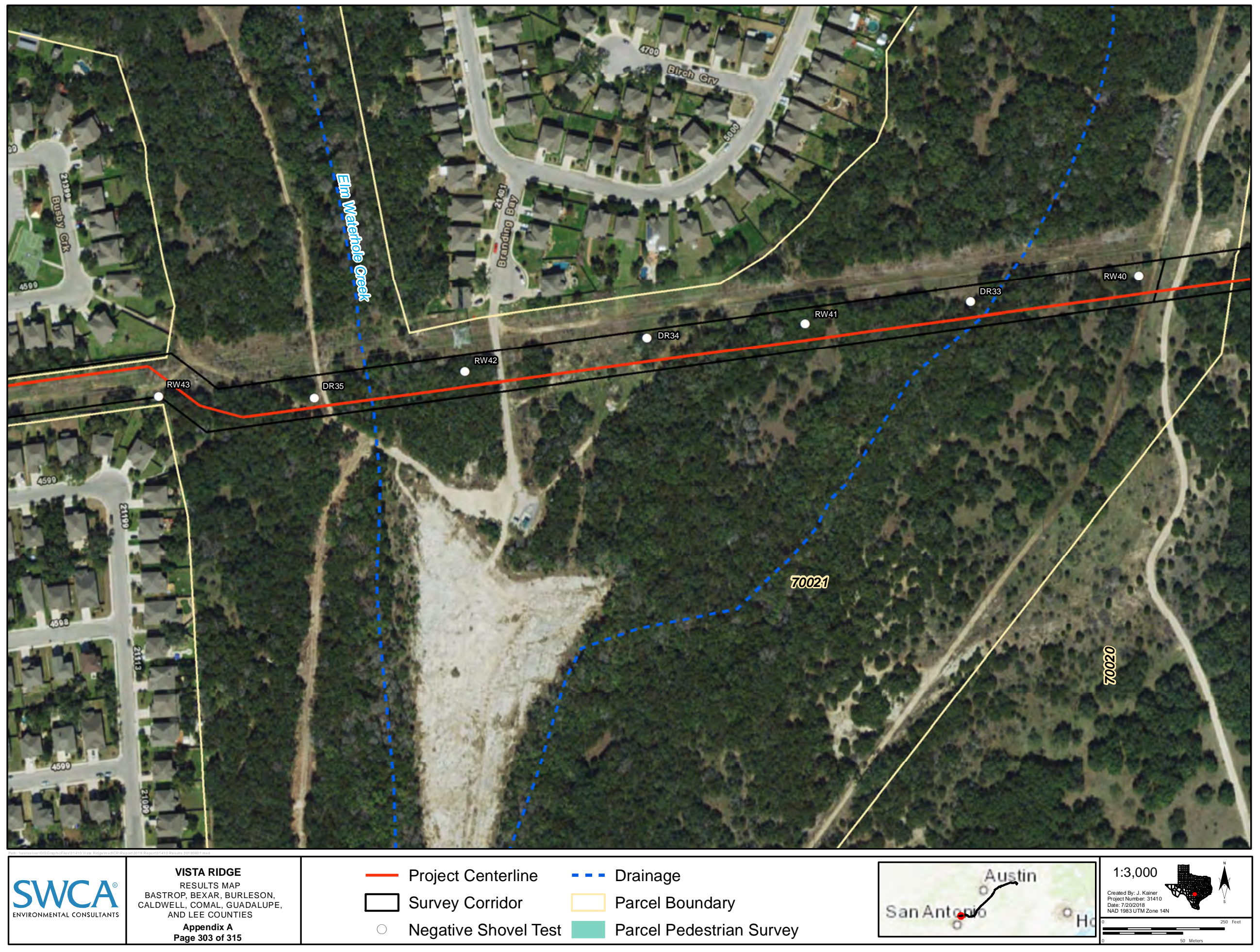


Restricted Information

Not for Public Disclosure 


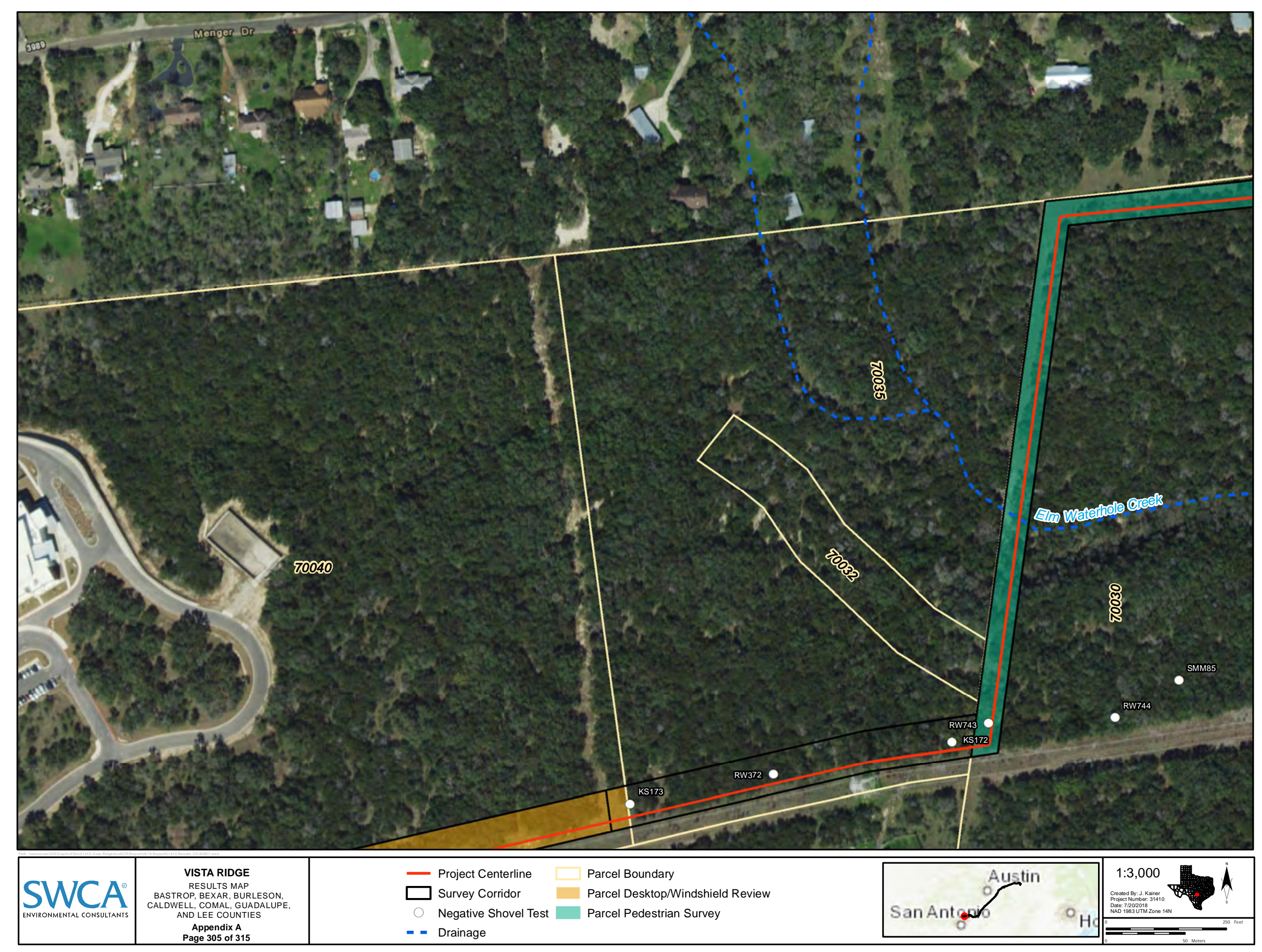




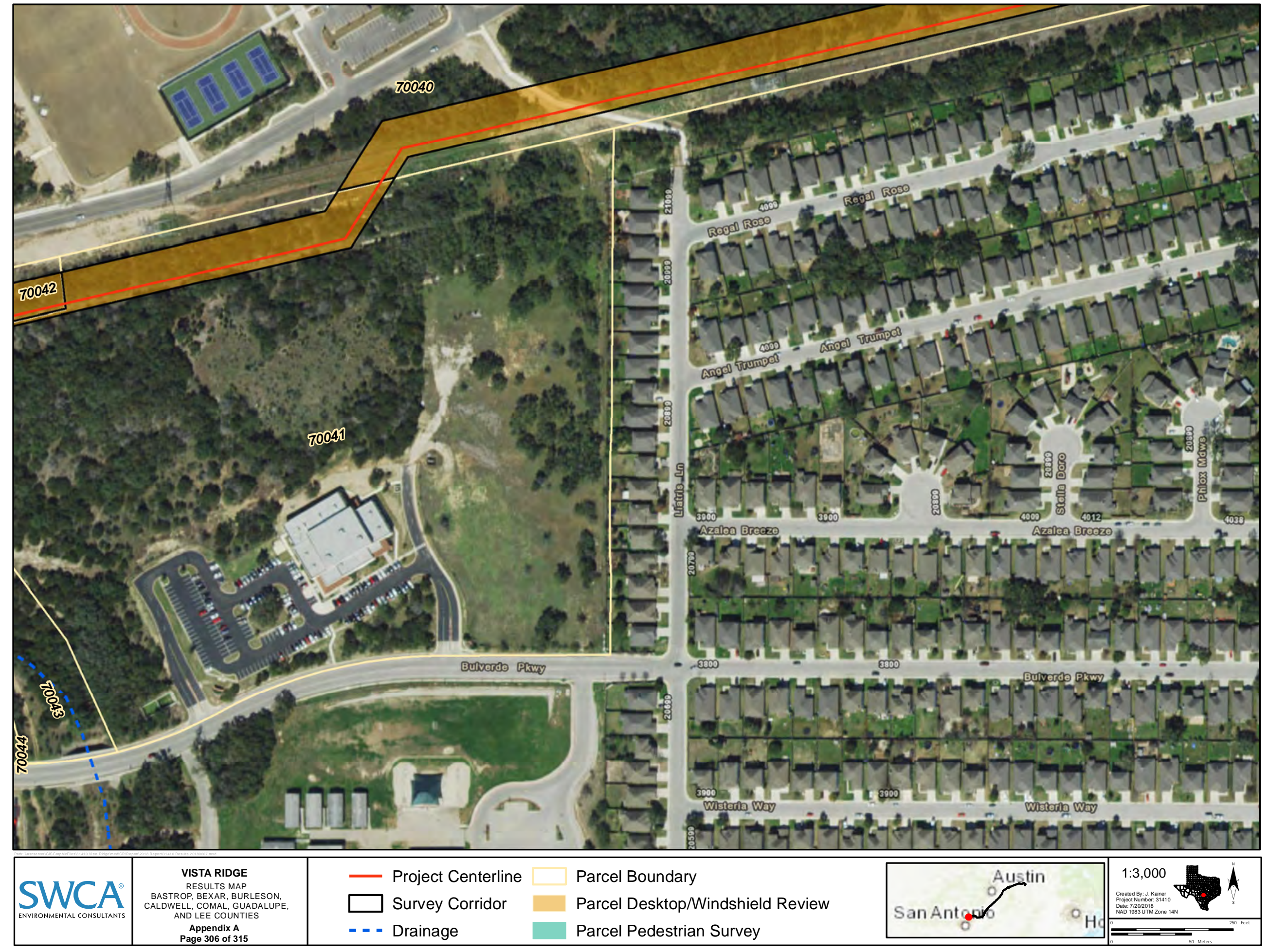


Restricted Information

Not for Public Disclosure 
Restricted Information

Not for Public Disclosure 


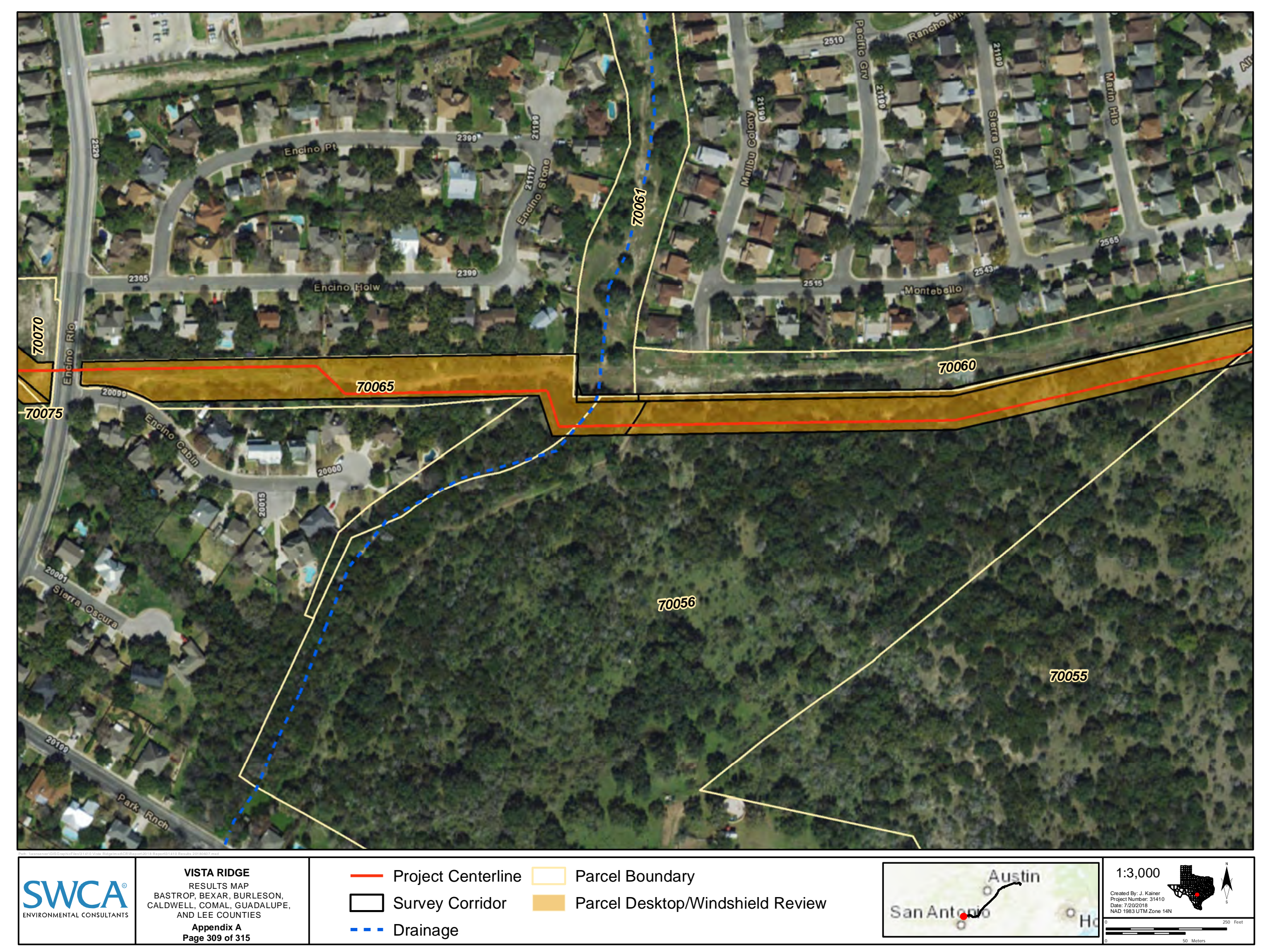




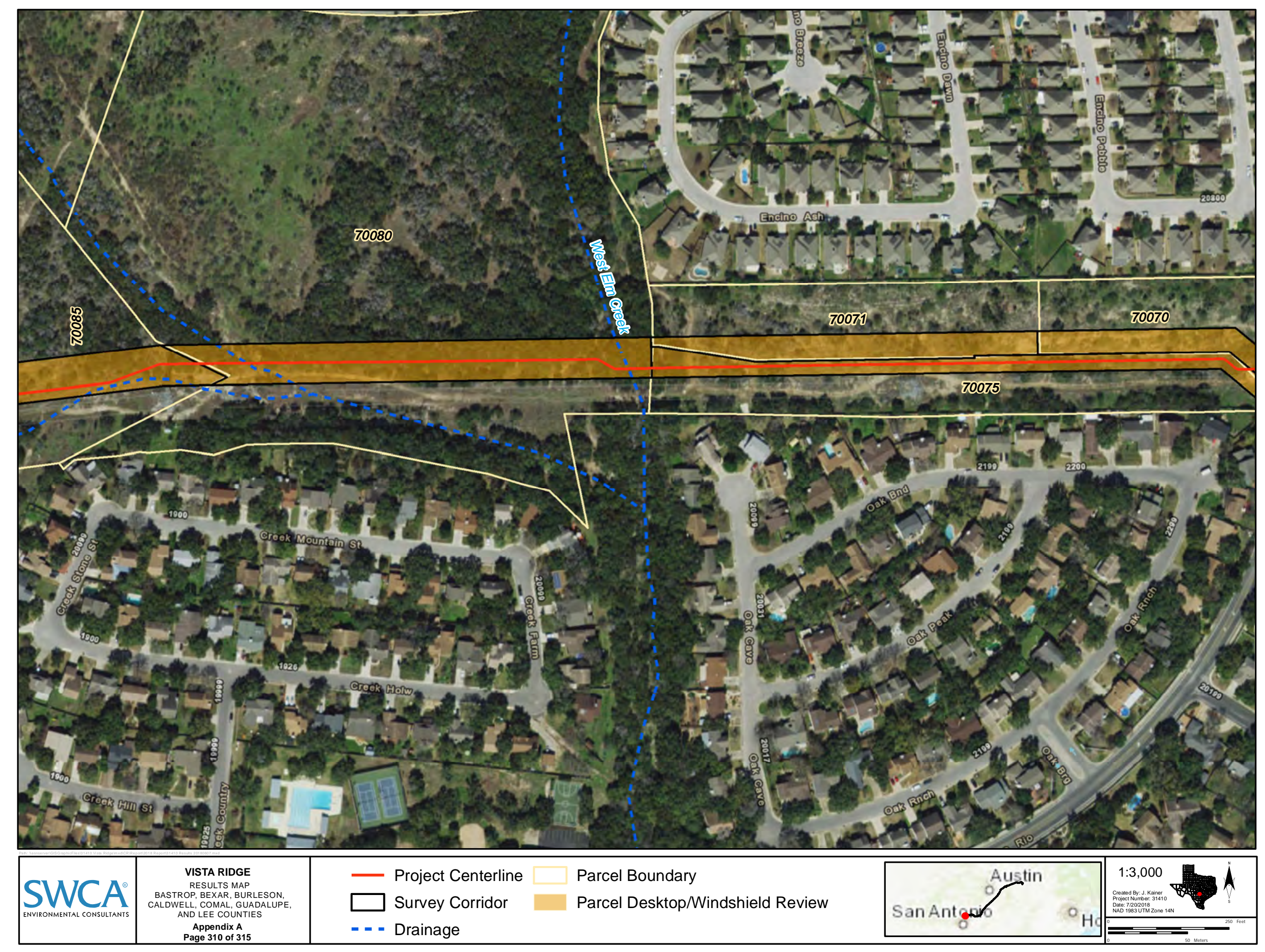


Restricted Information

Not for Public Disclosure 
in $x^{2}$ (

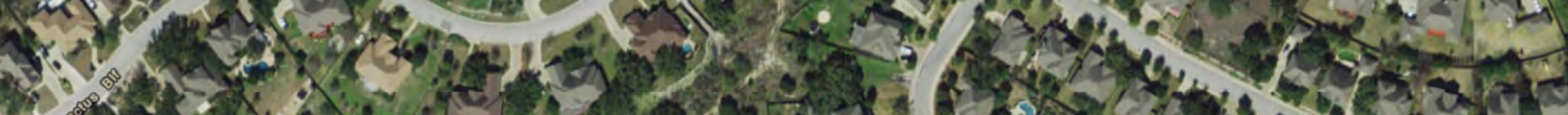

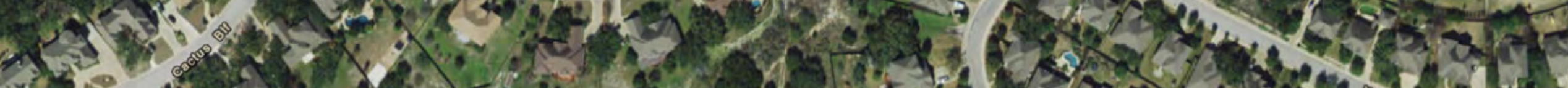

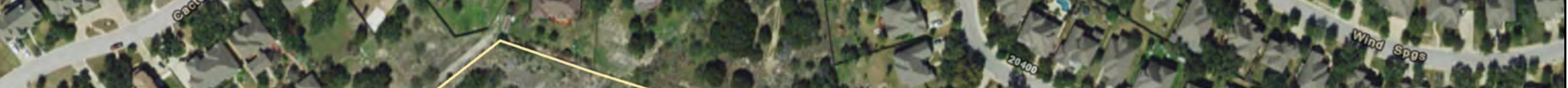

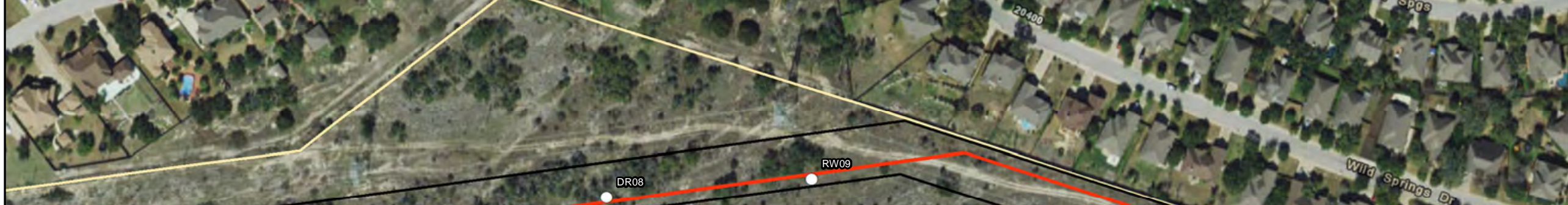

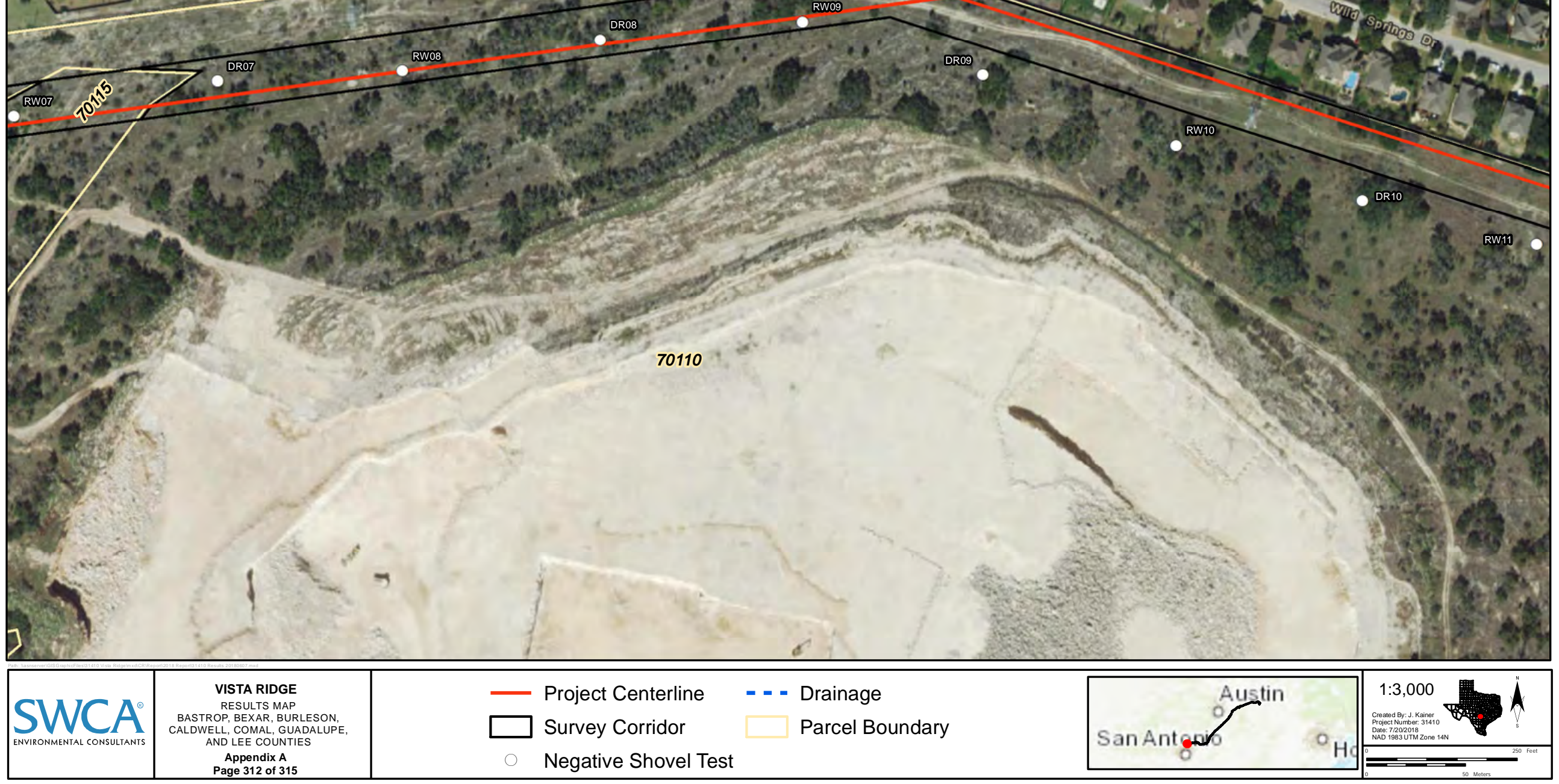


Restricted Information

Not for Public Disclosure 
Restricted Information

Not for Public Disclosure 


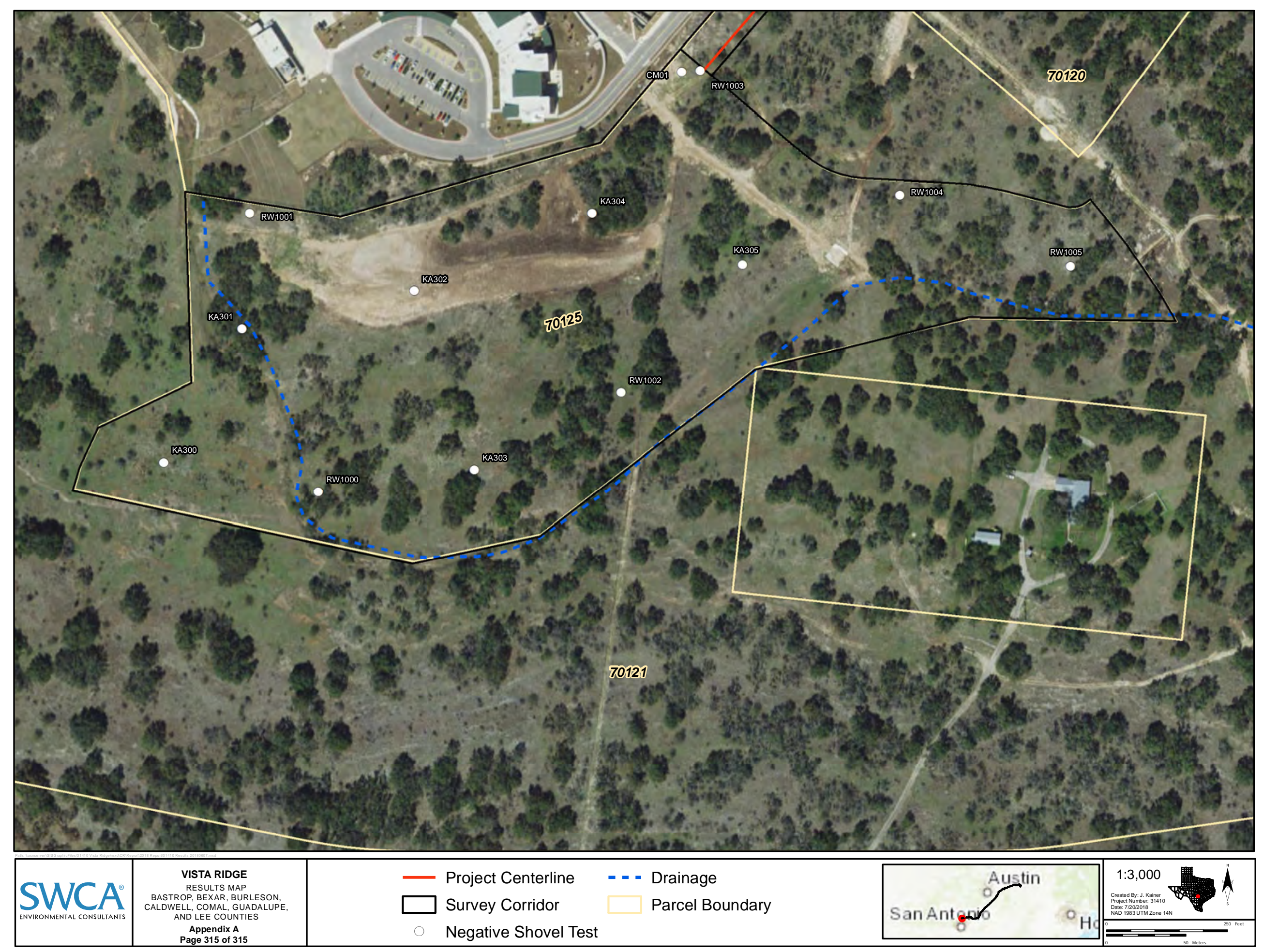


This page intentionally left blank. 
Appendix B. Shovel Test Data 
This page intentionally left blank. 


\begin{tabular}{|c|c|c|c|c|c|c|c|c|c|c|}
\hline Site No. & $\begin{array}{c}\text { Shovel Test } \\
\text { No. }\end{array}$ & Level & $\begin{array}{l}\text { Depth } \\
\text { (cmbs) }\end{array}$ & $\begin{array}{c}\text { Munsell Soil } \\
\text { value }\end{array} \mid$ & $\begin{array}{l}\text { Munsell Soil } \\
\text { Color }\end{array}$ & Soil Texture & $\begin{array}{l}\text { Inclusion } \\
\text { Percentage }\end{array}$ & Inclusion Type & $\begin{array}{c}\text { Positive }(\mathrm{P}) \\
\text { or Negative } \\
\text { (N) }\end{array}$ & Comments/ Reason for Termination \\
\hline \multirow{2}{*}{ NA } & \multirow{2}{*}{ AE01 } & 1 & $0-30$ & 10YR $4 / 4$ & $\begin{array}{c}\text { dark yellowish } \\
\text { brown }\end{array}$ & Sandy Loam & - & - & $\mathrm{N}$ & - \\
\hline & & 2 & $30-45$ & 10YR 5/2 & grayish brown & Sandy Clay Loam & - & - & $\mathrm{N}$ & Terminated at compact soil. \\
\hline $\mathrm{NA}$ & AE01 & 1 & $0-85$ & 7.5YR 5/4 & brown & Sand & - & - & $\mathrm{N}$ & Terminated at compact soil. \\
\hline \multirow[t]{2}{*}{ NA } & \multirow[t]{2}{*}{ AE02 } & 1 & $0-30$ & 10YR $3 / 2$ & $\begin{array}{l}\text { very dark grayish } \\
\text { brown }\end{array}$ & Sandy Clay Loam & - & - & $\mathrm{N}$ & - \\
\hline & & 2 & $30-45$ & $7.5 Y R 6 / 4$ & light brown & Clay & - & - & $\mathrm{N}$ & Terminated at basal clay. \\
\hline \multirow{2}{*}{ NA } & \multirow{2}{*}{ AE02 } & 1 & $0-70$ & 7.5 YR $5 / 4$ & brown & Loamy Sand & 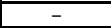 & $\begin{array}{ll}- \\
\end{array}$ & $\mathrm{N}$ & - \\
\hline & & 2 & $70-95$ & 10YR 7/2 & light gray & Sandy Loam & $5-10 \%$ & Redox & $\mathrm{N}$ & Terminated at depth. \\
\hline \multirow{2}{*}{ NA } & \multirow{2}{*}{ AE03 } & 1 & $0-20$ & 10YR 5/3 & brown & $\begin{array}{l}\text { Sandy Loam } \\
\end{array}$ & $\begin{array}{c}- \\
\end{array}$ & $\begin{array}{c}- \\
\end{array}$ & $\mathrm{N}$ & - \\
\hline & & 2 & $20-35$ & $2.5 \mathrm{YR} 4 / 6$ & red & Clay & $10-20 \%$ & Mottles & $\mathrm{N}$ & Terminated at basal clay. \\
\hline & & 1 & $0-35$ & $7.5 Y R 5 / 4$ & brown & Sandy Loam & - & - & $\mathrm{N}$ & - \\
\hline NA & AEUS & 2 & $35-50$ & $7.5 Y R 4 / 6$ & strong brown & Clay Loam & - & - & $\mathrm{N}$ & Terminated at compact soil. \\
\hline NA & AE04 & 1 & $0-100$ & 10YR 5/3 & brown & Sandy Loam & $1-5 \%$ & Gravels & $\mathrm{N}$ & Terminated at depth. \\
\hline & AE04 & 1 & $0-35$ & 7.5 YR $5 / 4$ & brown & Sandy Loam & - & - & $\mathrm{N}$ & - \\
\hline NA & AEO4 & 2 & $35-50$ & $7.5 Y R 4 / 6$ & strong brown & Clay Loam & - & 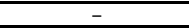 & $\mathrm{N}$ & Terminated at compact soil. \\
\hline $\mathrm{NA}$ & AE05 & 1 & $0-100$ & 10YR 5/3 & brown & Sandy Loam & $1-5 \%$ & Gravels & $\mathrm{N}$ & Terminated at depth. \\
\hline & & 1 & $0-60$ & 7.5 YR $5 / 4$ & brown & Loamy Sand & - & - & $\mathrm{N}$ & - \\
\hline NA & AEUS & 2 & $60-75$ & $7.5 Y R 4 / 6$ & strong brown & Clay & $1-5 \%$ & Redox & $\mathrm{N}$ & Terminated at compact soil. \\
\hline $\mathrm{NA}$ & AE06 & 1 & $0-75$ & 10YR 5/3 & brown & Sandy Loam & $1-5 \%$ & Gravels & $\mathrm{N}$ & Terminated at compact soil. \\
\hline NA & AE06 & 1 & $0-75$ & $7.5 Y R 4 / 4$ & brown & Loamy Sand & $5-10 \%$ & Redox & $\mathrm{N}$ & Terminated at large root. \\
\hline NA & AE07 & 1 & $0-75$ & 10YR 5/3 & brown & $\begin{array}{l}\text { Sandy Loam } \\
\end{array}$ & $1-5 \%$ & Gravels & $\mathrm{N}$ & Terminated at compact soil. \\
\hline NA & AE08 & 1 & $0-30$ & 10YR 4/3 & brown & Sandy Loam & - & - & $\mathrm{N}$ & - \\
\hline NA & AEU8 & 2 & $30-45$ & 7.5 YR $4 / 6$ & strong brown & Clay & - & - & $\mathrm{N}$ & Terminated at basal clay. \\
\hline$N A$ & AE09 & 1 & $0-65$ & 10YR 5/4 & yellowish brown & Sandy Loam & - & - & $\mathrm{N}$ & - \\
\hline NA & AEUS & 2 & $65-75$ & 7.5 YR $4 / 6$ & strong brown & Clay Loam & - & - & $\mathrm{N}$ & Terminated at compact soil. \\
\hline$N A$ & AF10 & 1 & $0-35$ & 10YR 2/2 & very dark brown & Clay Loam & 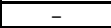 & $\begin{array}{ll}- \\
\end{array}$ & $\mathrm{N}$ & - \\
\hline NA & AEIO & 2 & $35-50$ & 7.5 YR $4 / 6$ & strong brown & Clay & $10-20 \%$ & Mottles, Iron nodules & $\mathrm{N}$ & Terminated at basal clay. \\
\hline NA & AE11 & 1 & $0-55$ & 10YR 2/2 & very dark brown & Clay Loam & $1-5 \%$ & Redox & $\mathrm{N}$ & Terminated at compact soil. \\
\hline NA & $\mathrm{AE} 12$ & 1 & $0-55$ & 10YR 2/2 & very dark brown & Clay Loam & $1-5 \%$ & Redox & $\mathrm{N}$ & Terminated at compact soil. \\
\hline NA & AE13 & 1 & $0-35$ & $7.5 Y R 3 / 4$ & dark brown & Sandy Clay Loam & $1-5 \%$ & Gravels & $\mathrm{N}$ & - \\
\hline & & 2 & $35-50$ & $5 Y$ YR 4/6 & yellowish red & Clay & $1-5 \%$ & Redox & $\mathrm{N}$ & Terminated at basal clay. \\
\hline 41BU123 & AE14 & 1 & $0-35$ & 7.5YR $3 / 4$ & dark brown & Sandy Clay Loam & $1-5 \%$ & Gravels & $\mathrm{N}$ & - \\
\hline & & 2 & $35-50$ & 5 YYR 4/6 & yellowish red & Clay & $1-5 \%$ & Redox & $\mathrm{N}$ & Terminated at basal clay. \\
\hline NA & AE15 & 1 & $0-90$ & 7.5 YR $5 / 4$ & brown & Silt & $1-5 \%$ & Gravels, Pebbles & $\mathrm{N}$ & Terminated at depth. \\
\hline NA & AE16 & 1 & $0-35$ & 7.5YR $3 / 4$ & dark brown & Sandy Clay Loam & $1-5 \%$ & Gravels & $\mathrm{N}$ & - \\
\hline & & 2 & $35-50$ & $5 Y$ YR 4/6 & yellowish red & Clay & $1-5 \%$ & Redox & $\mathrm{N}$ & Terminated at basal clay. \\
\hline $\mathrm{NA}$ & $\mathrm{AE} 17$ & 1 & $0-30$ & 7.5YR 4/6 & strong brown & Clay & $5-10 \%$ & Gravels, Pebbles & $\mathrm{N}$ & Terminated at basal clay. \\
\hline NA & AE18 & 1 & $0-35$ & 10YR $2 / 2$ & very dark brown & Sandy Clay Loam & $1-5 \%$ & Gravels, Pebbles & $\mathrm{N}$ & - \\
\hline & & 2 & $35-50$ & $7.5 Y R 4 / 6$ & strong brown & Clay & $1-5 \%$ & Gravels, Pebbles & $\mathrm{N}$ & Terminated at basal clay. \\
\hline NA & AE19 & 1 & $0-20$ & 10YR $3 / 3$ & dark brown & Silt Loam & $>20 \%$ & Cobbles, Gravels & $\mathrm{N}$ & Terminated at compact soil. \\
\hline $\mathrm{NA}$ & AE20 & 1 & $0-20$ & 10YR 3/3 & dark brown & Silt Loam & $>20 \%$ & Cobbles, Gravels & $\mathrm{N}$ & Terminated at compact soil. \\
\hline & & 1 & $0-20$ & 10YR 2/1 & black & Silt Loam & $>20 \%$ & Cobbles, Gravels & $\mathrm{N}$ & - \\
\hline NA & AE21 & 2 & $20-35$ & 7.5YR $2.5 / 2$ & very dark brown & Silt Loam & $>20 \%$ & Cobbles, Gravels & $\mathrm{N}$ & Terminated at compact soil. \\
\hline NA & AE22 & 1 & $0-30$ & 10YR 2/1 & black & Silt Loam & $5-10 \%$ & Cobbles, Gravels & $\mathrm{N}$ & Terminated at compact soil. \\
\hline NA & AE23 & 1 & $0-20$ & 10YR $4 / 4$ & $\begin{array}{l}\text { dark yellowish } \\
\text { brown }\end{array}$ & Silt Loam & $>20 \%$ & Cobbles, Gravels & $\mathrm{N}$ & Terminated at compact soil. \\
\hline NA & AE24 & 1 & $0-15$ & 7.5 YR $4 / 4$ & brown & Silt Loam & $>20 \%$ & Cobbles, Gravels & $\mathrm{N}$ & Terminated at compact soil. \\
\hline NA & AE25 & 1 & $0-25$ & 10YR 2/1 & black & Silt Loam & $>20 \%$ & Cobbles, Gravels & $\mathrm{N}$ & Terminated at compact soil. \\
\hline NA & AE26 & 1 & $0-20$ & 10YR $3 / 3$ & dark brown & Silt Loam & $>20 \%$ & Cobbles, Gravels & $\mathrm{N}$ & Terminated at compact soil. \\
\hline NA & AE27 & 1 & $0-70$ & 7.5YR $2.5 / 1$ & black & Silty Clay Loam & $>20 \%$ & Mottles & N & Terminated at compact soil. \\
\hline NA & AE28 & 1 & $0-25$ & 7.5 YR $3 / 3$ & dark brown & Sandy Clay Loam & - & - & N & - \\
\hline & & 2 & $25-40$ & 7.5 YR $5 / 8$ & strong brown & Sandy Clay & $10-20 \%$ & Mottles, Pebbles & $\mathrm{N}$ & Terminated at basal clay. \\
\hline NA & AE29 & 1 & $0-25$ & 7.5YR $3 / 3$ & dark brown & Sandy Clay Loam & - & - & $\mathrm{N}$ & - \\
\hline & & 2 & $25-40$ & 7.5 YR $5 / 8$ & strong brown & Sandy Clay & $10-20 \%$ & Mottles, Pebbles & $\mathrm{N}$ & Terminated at basal clay. \\
\hline NA & AE30 & 1 & $0-70$ & 7.5YR $2.5 / 1$ & black & Silty Clay Loam & $>20 \%$ & Mottles & $\mathrm{N}$ & Terminated at compact soil. \\
\hline NA & AE200 & 1 & $0-80$ & 7.5 YR $3 / 4$ & dark brown & Sandy Loam & - & - & $\mathrm{N}$ & - \\
\hline $\mathrm{NA}$ & AEZOU & 2 & $80-100$ & 7.5 YR 4/6 & strong brown & Loamy Sand & - & - & $\mathrm{N}$ & Terminated at depth. \\
\hline & & 1 & $0-25$ & 7.5 YR $3 / 4$ & dark brown & Loamy Sand & - & - & $\mathrm{N}$ & - \\
\hline NA & AE201 & 2 & $25-40$ & $5 Y R 4 / 6$ & yellowish red & Sandy Clay & $5-10 \%$ & $\begin{array}{c}\text { Pebbles, Redox and } \\
\text { manganese }\end{array}$ & $\mathrm{N}$ & Terminated at basal clay. \\
\hline $\mathrm{NA}$ & AE202 & 1 & $0-100$ & $7.5 Y R 4 / 6$ & strong brown & Sand & - & - & $\mathrm{N}$ & Terminated at depth. \\
\hline 41BU124 & AE203 & 1 & $0-70$ & 7.5 YR $5 / 4$ & brown & Loamy Sand & - & - & $\mathrm{N}$ & Terminated at compact soil. \\
\hline & & 1 & $0-60$ & $7.5 Y R 4 / 6$ & strong brown & Sandy Clay Loam & $5-10 \%$ & Gravels, Pebbles & N & - \\
\hline 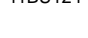 & MLLU & 2 & $60-80$ & $7.5 Y R 5 / 3$ & brown & Sandy Clay Loam & $1-5 \%$ & Gravels, Pebbles & $\mathrm{N}$ & Terminated at compact soil. \\
\hline 41BU124 & AE205 & 1 & $0-40$ & 7.5 YR $4 / 4$ & brown & Sandy Loam & - & - & $\mathrm{N}$ & - \\
\hline & AEZUS & 2 & $40-60$ & 5 YYR 4/6 & yellowish red & Sandy Clay & - & - & $\mathrm{N}$ & Terminated at basal clay. \\
\hline & & 1 & $0-30$ & 7.5 YR $3 / 4$ & dark brown & Loamy Sand & - & - & $\mathrm{N}$ & - \\
\hline NA & AE300 & 2 & $30-50$ & $7.5 Y R 4 / 6$ & strong brown & Sandy Clay Loam & $5-10 \%$ & Gravels, Pebbles & $\mathrm{N}$ & Terminated at basal clay. \\
\hline $\mathrm{NA}$ & $\mathrm{AE} 301$ & 1 & $0-80$ & $7.5 Y R 4 / 6$ & strong brown & Loamy Sand & $1-5 \%$ & Gravels, Pebbles & $\mathrm{N}$ & Terminated at saturated soils. \\
\hline & & 1 & $0-5$ & $7.5 Y R 3 / 4$ & dark brown & Loamy Sand & 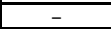 & 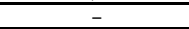 & $\mathrm{N}$ & 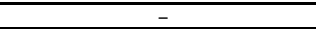 \\
\hline NA & AE302 & 2 & $5-45$ & 5YR 4/6 & yellowish red & Sandy Clay Loam & $5-10 \%$ & $\begin{array}{c}\text { Gravels, Pebbles, } \\
\text { Manganese }\end{array}$ & $\mathrm{N}$ & Terminated at basal clay. \\
\hline $\mathrm{NA}$ & AE303 & 1 & $0-100$ & 10YR $5 / 4$ & yellowish brown & Loamy Sand & $1-5 \%$ & Gravels, Pebbles & $\mathrm{N}$ & Terminated at depth. \\
\hline & & 1 & $0-50$ & 7.5YR $3 / 4$ & dark brown & Loamy Sand & $1-5 \%$ & Gravels, Pebbles & $\mathrm{N}$ & - \\
\hline NA & AE304 & 2 & $50-65$ & 7.5YR $5 / 8$ & strong brown & Sandy Clay Loam & $5-10 \%$ & Gravels, Pebbles & $\mathrm{N}$ & Terminated at compact soil. \\
\hline
\end{tabular}




\begin{tabular}{|c|c|c|c|c|c|c|c|c|c|c|}
\hline Site No. & $\begin{array}{c}\text { Shovel Test } \\
\text { No. }\end{array}$ & Level & $\begin{array}{l}\text { Depth } \\
\text { (cmbs) }\end{array}$ & $\begin{array}{c}\text { Munsell Soil } \\
\text { value }\end{array}$ & $\begin{array}{l}\text { Munsell Soil } \\
\text { Color }\end{array}$ & Soil Texture & $\begin{array}{l}\text { Inclusion } \\
\text { Percentage }\end{array}$ & Inclusion Type & $\begin{array}{l}\text { Positive }(\mathrm{P}) \\
\text { or Negative } \\
(\mathrm{N})\end{array}$ & Comments/ Reason for Termination \\
\hline \multirow{2}{*}{ NA } & \multirow{2}{*}{ AE305 } & 1 & $0-50$ & $7.5 Y R 3 / 4$ & dark brown & Loamy Sand & $1-5 \%$ & Gravels, Pebbles & $\mathrm{N}$ & - \\
\hline & & 2 & $50-65$ & 7.5YR 5/8 & strong brown & Sandy Clay Loam & $5-10 \%$ & Gravels, Pebbles & $\mathrm{N}$ & Terminated at compact soil. \\
\hline NA & AE306 & 1 & $0-65$ & 7.5YR $3 / 4$ & dark brown & Sandy Clay Loam & $1-5 \%$ & Gravels, Pebbles & $\mathrm{N}$ & Terminated at water table. \\
\hline \multirow{4}{*}{ 41BP959 } & \multirow{4}{*}{ AE307 } & 1 & $0-10$ & 10YR $5 / 3$ & brown & Loamy Sand & - & - & $\mathrm{N}$ & - \\
\hline & & 2 & $10-20$ & 10YR 5/3 & brown & Loamy Sand & - & - & Y & $\begin{array}{l}\text { 7: Flake (primary), Flake (tertiary), Other } \\
\text { Prehistoric }\end{array}$ \\
\hline & & 3 & $20-30$ & 10YR $5 / 3$ & brown & Loamy Sand & - & - & Y & $\begin{array}{l}\text { 3: Flake (primary), Flake (tertiary), Other } \\
\text { Prehistoric }\end{array}$ \\
\hline & & 4 & $30-50$ & 10YR 6/2 & light brownish gray & Clay & $>20 \%$ & Mottles & N & Terminated at basal clay. \\
\hline \multirow{4}{*}{ 41BP959 } & \multirow{4}{*}{ AE308 } & 1 & $0-10$ & 10YR $5 / 3$ & brown & Loamy Sand & - & - & $\mathrm{Y}$ & 1: Flake (tertiary), Other Prehistoric \\
\hline & & 2 & $10-20$ & 10 YR $5 / 3$ & brown & Loamy Sand & - & - & $\mathrm{Y}$ & 1: Flake (tertiary), Other Prehistoric \\
\hline & & 3 & $20-30$ & $10 Y R 5 / 3$ & brown & Loamy Sand & - & - & $\mathrm{N}$ & - \\
\hline & & 4 & $30-50$ & $7.5 Y R 4 / 4$ & brown & Sandy Clay & $>20 \%$ & Mottles & $\mathrm{N}$ & Terminated at basal clay. \\
\hline \multirow{4}{*}{ NA } & \multirow{4}{*}{ AE309 } & 1 & $0-10$ & $10 Y R 2 / 2$ & very dark brown & Loamy Sand & - & - & $\mathrm{N}$ & - \\
\hline & & 2 & $10-60$ & 10YR $4 / 4$ & $\begin{array}{c}\text { dark yellowish } \\
\text { brown }\end{array}$ & Loamy Sand & - & - & N & - \\
\hline & & 3 & $60-90$ & 10YR 2/2 & very dark brown & Loamy Sand & - & - & $\mathrm{N}$ & - \\
\hline & & 4 & $90-100$ & 10YR $5 / 2$ & grayish brown & Loamy Sand & $10-20 \%$ & Mottles & $\mathrm{N}$ & Terminated at depth. \\
\hline \multirow{2}{*}{ NA } & \multirow{2}{*}{ AE310 } & 1 & $0-10$ & 10YR 2/2 & very dark brown & Sandy Loam & - & - & $\mathrm{N}$ & - \\
\hline & & 2 & $10-45$ & 10YR $5 / 3$ & brown & Sandy Clay & $>20 \%$ & Mottles, Pebbles & $\mathrm{N}$ & Terminated at basal clay. \\
\hline NA & AE500 & 1 & $0-50$ & 7.5YR $2.5 / 2$ & very dark brown & Clay & $10-20 \%$ & Mottles & N & Terminated at water table. \\
\hline \multirow{3}{*}{ NA } & \multirow{3}{*}{ AE501 } & 1 & $0-55$ & 7.5YR $4 / 4$ & brown & Clay Loam & $>20 \%$ & $\begin{array}{l}\text { Mottles, Redox and } \\
\text { leached gray clay }\end{array}$ & $\mathrm{N}$ & - \\
\hline & & 2 & $55-90$ & 7.5YR $2.5 / 1$ & black & Clay & $10-20 \%$ & Redox in filaments & $\mathrm{N}$ & - \\
\hline & & 3 & $90-100$ & 7.5 YR $5 / 1$ & gray & Clay & $10-20 \%$ & Redox & $\mathrm{N}$ & Terminated at depth. \\
\hline \multirow{3}{*}{ NA } & & 1 & $0-20$ & 7.5 YR $5 / 6$ & strong brown & Sand & $5-10 \%$ & Gravels, Pebbles & $\mathrm{N}$ & - \\
\hline & AE502 & 2 & $20-45$ & 7.5YR 5/1 & gray & Clay Loam & $>20 \%$ & Gravels, Mottles, Pebbles & N & - \\
\hline & & 3 & $45-60$ & 7.5YR 5/1 & gray & Clay & $10-20 \%$ & Redox & $\mathrm{N}$ & Terminated at compact soil. \\
\hline NA & AE503 & 1 & $0-100$ & 7.5YR 4/4 & brown & Loamy Sand & $5-10 \%$ & $\begin{array}{c}\text { Gravels, Pockets of } 5 Y R \\
5 / 8 \text { sandy clay throughout; } \\
\text { subrounded gravels - } \\
\text { sparse }\end{array}$ & $\mathrm{N}$ & Terminated at depth. \\
\hline NA & AE504 & 1 & $0-60$ & 7.5YR $2.5 / 2$ & very dark brown & Clay Loam & $>20 \%$ & Pebbles, Redox; $20-30 \%$ & $\mathrm{~N}$ & Terminated at compact soil. \\
\hline NA & AE505 & 1 & $0-60$ & 7.5YR 4/1 & dark gray & Clay & $>20 \%$ & Redox & $\mathrm{N}$ & Terminated at compact soil. \\
\hline NA & AE506 & 1 & $0-130$ & 7.5 YR $5 / 4$ & brown & Sandy Loam & $5-10 \%$ & $\begin{array}{c}\text { Cobbles, Gravels, } \\
\text { Pebbles }\end{array}$ & $\mathrm{N}$ & Terminated at limestone gravels. \\
\hline & & 1 & $0-60$ & 7.5YR $5 / 4$ & brown & Sandy Loam & $1-5 \%$ & Gravels, Pebbles & $\mathrm{N}$ & - \\
\hline 41LE350 & AE507 & 2 & $60-75$ & 7.5YR 4/6 & strong brown & Sandy Clay Loam & $>20 \%$ & Mottles & N & Terminated at basal clay. \\
\hline 41LE350 & AE508 & 1 & $0-100$ & 7.5YR $4 / 4$ & brown & Sandy Loam & $1-5 \%$ & Gravels, Pebbles & Y & $\begin{array}{l}\text { 2: Flake (secondary), Flake (tertiary) [1 } \\
\text { Secondary flake 10-20; } 1 \text { tertiary flake 20-30; } 1 \\
\text { tertiary flake 50-60] Terminated at depth. }\end{array}$ \\
\hline 41LE350 & AE509 & 1 & $0-30$ & $7.5 Y R 4 / 4$ & brown & Sandy Loam & $1-5 \%$ & Pebbles & $\mathrm{N}$ & - \\
\hline 4ILE350 & AE509 & 2 & $30-50$ & 5YR 5/8 & yellowish red & Sandy Clay & - & - & $\mathrm{N}$ & Terminated at basal clay. \\
\hline 41LE350 & AE510 & 1 & $0-100$ & 7.5YR 5/4 & brown & Sandy Loam & $1-5 \%$ & Gravels, Pebbles & Y & $\begin{array}{l}\text { 3: Flake (tertiary), Other Prehistoric [1 shatter } \\
\text { and } 1 \text { tertiary flake 10-20; } 2 \text { shatter and } 1 \text { tertiary } \\
\text { flake 20-30; } 1 \text { tertiary flake 30-40] Terminated at } \\
\text { depth. }\end{array}$ \\
\hline 41LE350 & AE511 & $\mathrm{n} / \mathrm{a}$ & $\mathrm{n} / \mathrm{a}$ & $\mathrm{n} / \mathrm{a}$ & $\mathrm{n} / \mathrm{a}$ & $\mathrm{n} / \mathrm{a}$ & $\mathrm{n} / \mathrm{a}$ & $\mathrm{n} / \mathrm{a}$ & $\mathrm{n} / \mathrm{a}$ & Not excavated due to inundation. \\
\hline 41LE350 & AE512 & 1 & $0-100$ & $7.5 Y R 4 / 4$ & brown & Sandy Loam & $1-5 \%$ & Gravels, Pebbles & Y & $\begin{array}{l}\text { 2: Flake (secondary), Flake (tertiary) [1 } \\
\text { Secondary flake 10-20; } 1 \text { tertiary flake 20-30; } 1 \\
\text { tertiary flake } 50-60] \text { Terminated at depth. }\end{array}$ \\
\hline NA & AME01 & 1 & $0-10$ & 10YR 2/2 & very dark brown & Clay Loam & $>20 \%$ & Cobbles, Gravels & $\mathrm{N}$ & $\begin{array}{c}\text { No cultural material encountered. Terminated at } \\
\text { compact soil. }\end{array}$ \\
\hline NA & AME01 & 1 & $0-20$ & 10YR 4/3 & brown & Sandy Loam & - & - & $\mathrm{N}$ & - \\
\hline TNA & AIVIEU I & 2 & $20-50$ & 5YR 5/8 & yellowish red & Clay & $10-20 \%$ & Mottles, Redox & $\mathrm{N}$ & Terminated at compact soil. \\
\hline NA & AME02 & 1 & $0-10$ & 10YR 2/2 & very dark brown & Clay Loam & $>20 \%$ & Cobbles, Gravels & $\mathrm{N}$ & Terminated at compact soil. \\
\hline & & 1 & $0-20$ & 10YR $3 / 3$ & dark brown & Sandy Loam & $1-5 \%$ & Gravels, Pebbles & $\mathrm{N}$ & - \\
\hline NA & AME02 & 2 & $20-25$ & 10YR 4/3 & brown & Sandy Loam & - & - & $\mathrm{N}$ & - \\
\hline & & 3 & $25-50$ & 5 YR $5 / 8$ & yellowish red & Clay & $10-20 \%$ & Mottles, Redox & $\mathrm{N}$ & Terminated at compact soil. \\
\hline $\mathrm{NA}$ & AME03 & 1 & $0-30$ & 10YR 2/2 & very dark brown & Clay Loam & $>20 \%$ & Cobbles, Gravels & $\mathrm{N}$ & Terminated at compact soil. \\
\hline & & 1 & $0-20$ & 10YR 4/3 & brown & Sandy Loam & $1-5 \%$ & Gravels, Pebbles & $\mathrm{N}$ & - \\
\hline NA & AME03 & 2 & $20-100$ & 10YR $4 / 6$ & $\begin{array}{l}\text { dark yellowish } \\
\text { brown }\end{array}$ & Loamy Sand & $1-5 \%$ & Gravels, Pebbles & $\mathrm{N}$ & Terminated at depth. \\
\hline NA & AME04 & 1 & $0-30$ & 10YR 2/2 & very dark brown & Clay Loam & $>20 \%$ & Cobbles, Gravels & $\mathrm{N}$ & Terminated at compact soil. \\
\hline & & 1 & $0-20$ & 10YR 4/3 & brown & Sandy Loam & $1-5 \%$ & Gravels, Pebbles & $\mathrm{N}$ & - \\
\hline NA & AME04 & 2 & $20-100$ & 10YR 4/6 & $\begin{array}{c}\text { dark yellowish } \\
\text { brown }\end{array}$ & Loamy Sand & $1-5 \%$ & Gravels, Pebbles & N & Terminated at depth. \\
\hline NA & AME05 & 1 & $0-30$ & 7.5 YR $4 / 6$ & strong brown & Loamy Sand & $>20 \%$ & Cobbles, Gravels & $\mathrm{N}$ & Terminated at compact soil. \\
\hline & & 1 & $0-20$ & 10YR 4/3 & brown & Sandy Loam & $1-5 \%$ & Gravels, Pebbles & $\mathrm{N}$ & - \\
\hline NA & AME05 & 2 & $20-100$ & 10YR $4 / 6$ & $\begin{array}{l}\text { dark yellowish } \\
\text { brown }\end{array}$ & Loamy Sand & $1-5 \%$ & Gravels, Pebbles & $\mathrm{N}$ & Terminated at depth. \\
\hline NA & AME06 & 1 & $0-30$ & 10YR 2/2 & very dark brown & Clay Loam & $>20 \%$ & Cobbles, Gravels & $\mathrm{N}$ & Terminated at compact soil. \\
\hline NA & AME06 & 1 & $0-70$ & 10YR $4 / 3$ & brown & Sandy Loam & $10-20 \%$ & Gravels, Mottles, Pebbles & N & Terminated at compact soil. \\
\hline NA & AME07 & 1 & $0-30$ & 10YR 2/2 & very dark brown & Clay Loam & $>20 \%$ & Cobbles, Gravels & $\mathrm{N}$ & Terminated at compact soil. \\
\hline & & 1 & $0-25$ & $10 \mathrm{YR} 3 / 3$ & dark brown & Sandy Loam & $1-5 \%$ & Gravels, Pebbles & $\mathrm{N}$ & - \\
\hline NA & AME07 & 2 & $25-70$ & 10YR $5 / 4$ & yellowish brown & Sandy Loam & $1-5 \%$ & Gravels, Pebbles & $\mathrm{N}$ & 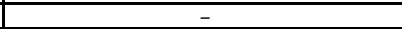 \\
\hline & & 3 & $70-80$ & $10 Y R 4 / 3$ & brown & Clay Loam & $5-10 \%$ & Gravels, Pebbles & $\mathrm{N}$ & Terminated at compact soil. \\
\hline IF10 & AME08 & 1 & $0-30$ & $7.5 Y R 6 / 1$ & gray & Clay Loam & $>20 \%$ & Cobbles, Gravels & $\mathrm{N}$ & Terminated at compact soil. \\
\hline$N A$ & AME08 & 1 & $0-10$ & 10YR $3 / 3$ & dark brown & Sandy Loam & - & - & $\mathrm{N}$ & - \\
\hline NA & AMIEO8 & 2 & $10-35$ & 5YR $5 / 8$ & yellowish red & Clay & $5-10 \%$ & Mottles & $\mathrm{N}$ & Terminated at basal clay. \\
\hline
\end{tabular}




\begin{tabular}{|c|c|c|c|c|c|c|c|c|c|c|}
\hline Site No. & $\begin{array}{c}\text { Shovel Test } \\
\text { No. }\end{array}$ & Level & $\begin{array}{l}\text { Depth } \\
\text { (cmbs) }\end{array}$ & $\begin{array}{c}\text { Munsell Soil } \\
\text { value }\end{array}$ & $\begin{array}{l}\text { Munsell Soil } \\
\text { Color }\end{array}$ & Soil Texture & $\begin{array}{l}\text { Inclusion } \\
\text { Percentage }\end{array}$ & Inclusion Type & $\begin{array}{l}\text { Positive (P) } \\
\text { or Negative } \\
\text { (N) }\end{array}$ & Comments/ Reason for Termination \\
\hline IF10 & AME09 & 1 & $0-30$ & $7.5 Y R 3 / 4$ & dark brown & Sandy Loam & $>20 \%$ & Cobbles, Gravels & $\mathrm{N}$ & Terminated at compact soil. \\
\hline \multirow[t]{2}{*}{ NA } & \multirow[t]{2}{*}{ AME09 } & 1 & $0-55$ & 10YR $4 / 4$ & $\begin{array}{l}\text { dark yellowish } \\
\text { brown }\end{array}$ & Loamy Sand & - & - & $\mathrm{N}$ & - \\
\hline & & 2 & $55-70$ & 10YR 5/8 & yellowish brown & Clay & $5-10 \%$ & Mottles & $\mathrm{N}$ & Terminated at basal clay. \\
\hline NA & AME10 & 1 & $0-30$ & 10YR 2/2 & very dark brown & Clay Loam & $>20 \%$ & Cobbles, Gravels & $\mathrm{N}$ & Terminated at compact soil. \\
\hline \multirow{3}{*}{ NA } & \multirow{3}{*}{ AME10 } & 1 & $0-60$ & 7.5 YR $5 / 4$ & brown & Loamy Sand & $1-5 \%$ & Gravels, Pebbles & $\mathrm{N}$ & - \\
\hline & & 2 & $60-80$ & 7.5 YR $3 / 4$ & dark brown & Sandy Loam & $1-5 \%$ & Gravels, Pebbles & $\mathrm{N}$ & - \\
\hline & & 3 & $80-90$ & 10YR $6 / 1$ & gray & Clay Loam & $5-10 \%$ & Mottles & $\mathrm{N}$ & Terminated at basal clay. \\
\hline NA & AME11 & 1 & $0-30$ & 10YR 2/2 & very dark brown & Clay Loam & $>20 \%$ & Cobbles, Gravels & $\mathrm{N}$ & Terminated at bedrock. \\
\hline NA & AME11 & 1 & $0-10$ & 7.5 YR $6 / 4$ & light brown & Sandy Loam & - & - & $\mathrm{N}$ & Terminated at bedrock. \\
\hline$\overline{N A}$ & AME12 & 1 & $0-30$ & 10YR 2/2 & very dark brown & Clay Loam & $>20 \%$ & Cobbles, Gravels & $\mathrm{N}$ & Terminated at bedrock. \\
\hline \multirow{2}{*}{ NA } & \multirow{2}{*}{ AME12 } & 1 & $0-25$ & 7.5 YR $6 / 4$ & light brown & Loamy Sand & $1-5 \%$ & Gravels & $\mathrm{N}$ & - \\
\hline & & 2 & $25-50$ & 7.5 YR $4 / 6$ & strong brown & Clay & $>20 \%$ & Redox, $20-30$ percent & $\mathrm{N}$ & Terminated at basal clay. \\
\hline \multirow{2}{*}{ NA } & \multirow{2}{*}{ AME13 } & 1 & $0-30$ & 7.5YR $2.5 / 2$ & very dark brown & Clay Loam & $10-20 \%$ & Cobbles, Gravels & $\mathrm{N}$ & - \\
\hline & & 2 & $30-45$ & 5 YYR $4 / 6$ & yellowish red & Clay Loam & $5-10 \%$ & Gravels, Pebbles & $\mathrm{N}$ & Terminated at basal clay. \\
\hline NA & AP01 & 1 & $0-70$ & 10YR $4 / 3$ & brown & Sandy Clay & $1-5 \%$ & None & $\mathrm{N}$ & Terminated at hydric clay. \\
\hline NA & AP02 & 1 & $0-60$ & 7.5 YR $6 / 8$ & reddish yellow & Sandy Loam & $1-5 \%$ & None & $\mathrm{N}$ & Terminated at hydric. \\
\hline NA & AP03 & 1 & $0-25$ & 10YR $4 / 3$ & brown & Sandy Clay & $1-5 \%$ & None & $\mathrm{N}$ & Terminated at hydric. \\
\hline $\mathrm{NA}$ & AP04 & 1 & $0-70$ & 7.5 YR $6 / 6$ & reddish yellow & Sandy Loam & $1-5 \%$ & Pebbles & $\mathrm{N}$ & Terminated at hydric. \\
\hline NA & AP100 & 1 & $0-80$ & 10YR $6 / 4$ & $\begin{array}{l}\text { light yellowish } \\
\text { brown }\end{array}$ & Sandy Loam & $5-10 \%$ & Roots & $\mathrm{N}$ & Terminated at basal clay. \\
\hline NA & AP101 & 1 & $0-20$ & 7.5YR $2.5 / 3$ & very dark brown & Clay & $5-10 \%$ & Roots & $\mathrm{N}$ & Terminated at basal clay. \\
\hline$\overline{N A}$ & AP102 & 1 & $0-70$ & $7.5 Y R 4 / 4$ & brown & Sand & $1-5 \%$ & Gravels & $\mathrm{N}$ & Terminated at basal clay. \\
\hline $\mathrm{NA}$ & AP103 & 1 & $0-50$ & 7.5 YR $4 / 4$ & brown & Sand & $1-5 \%$ & Gravels & $\mathrm{N}$ & Terminated at basal clay. \\
\hline NA & AP104 & 1 & $0-20$ & 7.5YR $2.5 / 3$ & very dark brown & Clay & $5-10 \%$ & Roots & $\mathrm{N}$ & Terminated at basal clay. \\
\hline NA & AP105 & 1 & $0-20$ & 7.5YR $2.5 / 3$ & very dark brown & Clay & $5-10 \%$ & Roots & $\mathrm{N}$ & Terminated at basal clay. \\
\hline$\overline{N A}$ & AP106 & 1 & $0-40$ & $7.5 Y R 4 / 4$ & brown & Sand & $1-5 \%$ & Gravels & $\mathrm{N}$ & Terminated at basal clay. \\
\hline NA & AP107 & 1 & $0-70$ & $7.5 Y R 4 / 4$ & brown & Sand & $1-5 \%$ & Gravels & $\mathrm{N}$ & Terminated at basal clay. \\
\hline NA & BKM01 & 1 & $0-40$ & 10YR $6 / 4$ & $\begin{array}{l}\text { light yellowish } \\
\text { brown }\end{array}$ & Sandy Clay & $1-5 \%$ & Pebbles & N & Terminated at basal clay. \\
\hline NA & BKM02 & 1 & $0-60$ & 10YR $5 / 3$ & brown & Sandy Clay Loam & - & - & $\mathrm{N}$ & Terminated at bedrock. \\
\hline NA & BKM03 & 1 & $0-80$ & 10YR $6 / 3$ & pale brown & Sandy Clay Loam & - & - & $\mathrm{N}$ & Terminated at basal clay. \\
\hline NA & BKM04 & 1 & $0-80$ & 10YR $6 / 3$ & pale brown & Sandy Clay Loam & - & - & N & Terminated at basal clay. \\
\hline IF08 & BKM05 & 1 & $0-50$ & 10YR $7 / 4$ & very pale brown & Silty Clay Loam & $1-5 \%$ & Sandstone rock chunks & Y & 1: Flake (secondary) Terminated at basal clay \\
\hline NA & BKM06 & 1 & $0-50$ & 10YR $6 / 3$ & pale brown & Sandy Clay Loam & $1-5 \%$ & Gravels, Pebbles & N & Terminated at basal clay. \\
\hline NA & BKM07 & 1 & $0-50$ & 10YR $6 / 3$ & pale brown & Sandy Clay Loam & $1-5 \%$ & Gravels, Pebbles & $\mathrm{N}$ & Terminated at basal clay. \\
\hline$\overline{N A}$ & BKM08 & 1 & $0-40$ & 10YR $8 / 6$ & yellow & Sandy Loam & - & - & $\mathrm{N}$ & Terminated at compact soil. \\
\hline NA & BKM09 & 1 & $0-40$ & $10 \mathrm{YR} 8 / 6$ & yellow & Sandy Loam & - & - & $\mathrm{N}$ & Terminated at compact soil. \\
\hline NA & BKM10 & 1 & $0-40$ & 10YR $4 / 6$ & $\begin{array}{l}\text { dark yellowish } \\
\text { brown }\end{array}$ & Sandy Clay Loam & $5-10 \%$ & Gravels, Pebbles & $\mathrm{N}$ & Terminated at bedrock. \\
\hline NA & BKM11 & 1 & $0-25$ & 10YR 4/1 & dark gray & Clay & $>20 \%$ & Mottles & $\mathrm{N}$ & Terminated at compact soil. \\
\hline $\mathrm{NA}$ & BM210 & 1 & $0-100$ & 10YR 6/6 & brownish yellow & Sandy Loam & 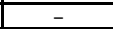 & $\begin{array}{c}- \\
\end{array}$ & $\mathrm{N}$ & Terminated at depth. \\
\hline NA & BM211 & 1 & $0-40$ & 10YR $5 / 6$ & yellowish brown & Sandy Clay Loam & - & - & $\mathrm{N}$ & Terminated at basal clay. \\
\hline NA & BM212 & 1 & $0-40$ & 10YR $4 / 6$ & $\begin{array}{l}\text { dark yellowish } \\
\text { brown }\end{array}$ & Sandy Clay Loam & - & - & $\mathrm{N}$ & Terminated at compact soil. \\
\hline NA & BM213 & 1 & $0-40$ & 10YR $4 / 6$ & $\begin{array}{c}\text { dark yellowish } \\
\text { brown }\end{array}$ & Sandy Clay Loam & - & - & $\mathrm{N}$ & Terminated at compact soil. \\
\hline NA & BM214 & 1 & $0-40$ & 10YR 4/6 & $\begin{array}{l}\text { dark yellowish } \\
\text { brown }\end{array}$ & Sandy Clay Loam & - & - & $\mathrm{N}$ & Terminated at compact soil. \\
\hline $\mathrm{NA}$ & BM215 & 1 & $0-30$ & 10YR 4/1 & dark gray & Clay Loam & - & - & $\mathrm{N}$ & Terminated at basal clay. \\
\hline NA & BM216 & 1 & $0-30$ & 10YR 4/1 & dark gray & Clay Loam & - & - & $\mathrm{N}$ & Terminated at basal clay. \\
\hline NA & BM217 & 1 & $0-60$ & 10YR 4/1 & dark gray & Silty Clay & - & - & $\mathrm{N}$ & Terminated at basal clay. \\
\hline NA & BM218 & 1 & $0-60$ & 10YR 4/1 & dark gray & Silty Clay & - & - & $\mathrm{N}$ & Terminated at basal clay. \\
\hline NA & BM219 & 1 & $0-60$ & 10YR 4/1 & dark gray & Silty Clay & - & - & $\mathrm{N}$ & Terminated at basal clay. \\
\hline NA & BM220 & 1 & $0-50$ & 10YR 3/2 & $\begin{array}{l}\text { very dark grayish } \\
\text { brown }\end{array}$ & Clay Loam & - & - & $\mathrm{N}$ & Terminated at basal clay. \\
\hline NA & BM221 & 1 & $0-50$ & 10YR 3/2 & $\begin{array}{l}\text { very dark grayish } \\
\text { brown }\end{array}$ & Clay Loam & - & - & $\mathrm{N}$ & Terminated at basal clay. \\
\hline NA & BM222 & 1 & $0-50$ & 10YR 3/2 & $\begin{array}{l}\text { very dark grayish } \\
\text { brown }\end{array}$ & Clay Loam & - & - & $\mathrm{N}$ & Terminated at basal clay. \\
\hline NA & BM301 & 1 & $0-50$ & 10YR 4/3 & brown & Clay Loam & - & - & $\mathrm{N}$ & Terminated at basal clay. \\
\hline NA & BM302 & 1 & $0-40$ & 7.5YR $7 / 8$ & reddish yellow & Sandy Clay Loam & - & - & $\mathrm{N}$ & Terminated at bedrock. \\
\hline NA & ВM303 & 1 & $0-40$ & 10YR 3/2 & $\begin{array}{l}\text { very dark grayish } \\
\text { brown }\end{array}$ & Clay Loam & $5-10 \%$ & Cobbles, Gravels & $\mathrm{N}$ & Terminated at bedrock. \\
\hline NA & BM304 & 1 & $0-40$ & 10YR 3/4 & $\begin{array}{l}\text { dark yellowish } \\
\text { brown }\end{array}$ & Clay Loam & $5-10 \%$ & Gravels, Pebbles & $\mathrm{N}$ & Terminated at basal clay. \\
\hline \multirow[b]{2}{*}{ NA } & \multirow[b]{2}{*}{ BY01 } & 1 & $0-5$ & 10YR $7 / 2$ & light gray & Loam & $5-10 \%$ & Pebbles & $\mathrm{N}$ & - \\
\hline & & 2 & 5-35 & 10YR $7 / 2$ & light gray & Sandy Clay Loam & $1-5 \%$ & Pebbles & $\mathrm{N}$ & Terminated at compact soil. \\
\hline \multirow[t]{2}{*}{ NA } & BY01 & 1 & $0-22$ & 10YR $4 / 4$ & $\begin{array}{c}\text { dark yellowish } \\
\text { brown }\end{array}$ & Sandy Loam & $1-5 \%$ & Sandstone frags & $\mathrm{N}$ & - \\
\hline & & 2 & $22-50$ & 10YR 7/2 & light gray & Sandy Loam & $5-10 \%$ & Sandstone frags & $\mathrm{N}$ & Terminated at water table hit. \\
\hline & & 1 & $0-40$ & $10 Y R 5 / 4$ & yellowish brown & Loam & $1-5 \%$ & Gravels, Pebbles & $\mathrm{N}$ & - \\
\hline NA & BY02 & 2 & $40-50$ & 10YR $7 / 3$ & very pale brown & Sandy Clay Loam & $1-5 \%$ & Gravels, Pebbles & N & Terminated at compact clay subsoil. \\
\hline NA & BY02 & 1 & $0-22$ & 10YR $4 / 4$ & $\begin{array}{l}\text { dark yellowish } \\
\text { brown }\end{array}$ & Sandy Loam & $1-5 \%$ & Sandstone fragments & N & - \\
\hline & & 2 & $22-50$ & 10YR $7 / 2$ & light gray & Sandy Loam & $5-10 \%$ & Sandstone fragments & $\mathrm{N}$ & Terminated at water table. \\
\hline NA & BYO3 & 1 & $0-10$ & 10YR $5 / 4$ & yellowish brown & Loam & $1-5 \%$ & Gravels, Pebbles & $\mathrm{N}$ & - \\
\hline NA & BY03 & 2 & $10-50$ & 10YR $5 / 3$ & brown & Sandy Clay & $1-5 \%$ & Pebbles, Grass roots & $\mathrm{N}$ & Terminated at compact soil. \\
\hline
\end{tabular}




\begin{tabular}{|c|c|c|c|c|c|c|c|c|c|c|}
\hline Site No. & $\begin{array}{c}\text { Shovel Test } \\
\text { No. }\end{array}$ & Level & $\begin{array}{l}\text { Depth } \\
\text { (cmbs) }\end{array}$ & $\begin{array}{c}\text { Munsell Soil } \\
\text { value }\end{array} \mid$ & $\begin{array}{l}\text { Munsell Soil } \\
\text { Color }\end{array}$ & Soil Texture & $\begin{array}{l}\text { Inclusion } \\
\text { Percentage }\end{array}$ & Inclusion Type & $\begin{array}{c}\text { Positive (P) } \\
\text { or Negative } \\
\text { (N) }\end{array}$ & Comments/ Reason for Termination \\
\hline \multirow{2}{*}{ NA } & \multirow{2}{*}{ BY03 } & 1 & $0-25$ & 10YR 7/2 & light gray & Sandy Loam & $1-5 \%$ & Grass roots & $\mathrm{N}$ & - \\
\hline & & 2 & $25-35$ & 7.5 YR $5 / 2$ & brown & Sandy Clay & $1-5 \%$ & Grass roots & $\mathrm{N}$ & Terminated at clay subsoil. \\
\hline NA & BY04 & 1 & $0-65$ & 7.5 YR $6 / 4$ & light brown & Sandy Loam & $1-5 \%$ & Grass roots & $\mathrm{N}$ & Terminated at water table. \\
\hline \multirow[b]{2}{*}{ NA } & \multirow[b]{2}{*}{ BY05 } & 1 & $0-30$ & 10YR $5 / 4$ & yellowish brown & Sandy Loam & $5-10 \%$ & Grass and tree roots & $\mathrm{N}$ & - \\
\hline & & 2 & $30-45$ & 7.5YR $4 / 1$ & dark gray & Sandy Loam & $1-5 \%$ & Grass and tree roots & N & $\begin{array}{l}\text { Terminated at wet; dense and sticky matrix at } \\
\text { depth. }\end{array}$ \\
\hline \multirow[t]{2}{*}{ NA } & \multirow[t]{2}{*}{ BY06 } & 1 & $0-75$ & 10YR 6/4 & $\begin{array}{l}\text { light yellowish } \\
\text { brown }\end{array}$ & Sandy Loam & $1-5 \%$ & Grass and tree roots & $\mathrm{N}$ & - \\
\hline & & 2 & $75-80$ & 7.5 YR $6 / 2$ & pinkish gray & Sandy Loam & $5-10 \%$ & Tree roots & $\mathrm{N}$ & Terminated at compact soil. \\
\hline $\mathrm{NA}$ & CM01 & $\mathrm{n} / \mathrm{a}$ & $\mathrm{n} / \mathrm{a}$ & $\mathrm{n} / \mathrm{a}$ & $\mathrm{n} / \mathrm{a}$ & $\mathrm{n} / \mathrm{a}$ & $\mathrm{n} / \mathrm{a}$ & $\mathrm{n} / \mathrm{a}$ & $\mathrm{n} / \mathrm{a}$ & Not excavated due to bedrock at surface \\
\hline NA & CM02 & 1 & $0-10$ & 10YR 3/2 & $\begin{array}{l}\text { very dark grayish } \\
\text { brown }\end{array}$ & Clay Loam & $>20 \%$ & $\begin{array}{l}\text { Gravels, Large Rock } \\
\text { Frags }\end{array}$ & N & Terminated at bedrock. \\
\hline NA & CMS01 & 1 & $0-30$ & 7.5YR 2.5/1 & black & Clay Loam & $10-20 \%$ & Gravels & $\mathrm{N}$ & Terminated at compact soil. \\
\hline NA & CMS02 & 1 & $0-30$ & 7.5YR $2.5 / 2$ & very dark brown & Clay Loam & - & - & N & Terminated at compact soil. \\
\hline NA & $\mathrm{CMS} 03$ & 1 & $0-30$ & 10YR $4 / 2$ & dark grayish brown & Clay Loam & - & - & N & Terminated at compact soil. \\
\hline NA & $\mathrm{CMS} 04$ & 1 & $0-30$ & 10YR $3 / 1$ & very dark gray & Clay & - & - & $\mathrm{N}$ & Terminated at compact soil. \\
\hline $\mathrm{NA}$ & CMS05 & 1 & $0-30$ & 10YR 2/2 & very dark brown & Clay Loam & - & - & $\mathrm{N}$ & Terminated at compact soil. \\
\hline NA & CMS06 & 1 & $0-30$ & 10YR $2 / 2$ & very dark brown & Clay & - & - & $\mathrm{N}$ & Terminated at compact soil. \\
\hline NA & CMS07 & 1 & $0-30$ & 10YR 3/2 & \begin{tabular}{|c|} 
very dark grayish \\
brown
\end{tabular} & Clay Loam & - & - & $\mathrm{N}$ & Terminated at compact soil. \\
\hline NA & CMS09 & 1 & $0-30$ & 10YR $3 / 2$ & $\begin{array}{c}\begin{array}{c}\text { very dark grayish } \\
\text { brown }\end{array} \\
\end{array}$ & Silty Clay & - & - & N & Terminated at compact soil. \\
\hline NA & CMS10 & 1 & $0-20$ & 10YR 2/2 & very dark brown & Clay Loam & $>20 \%$ & Cobbles, Pebbles & $\mathrm{N}$ & Terminated at rock impasse. \\
\hline $\mathrm{NA}$ & CMS11 & 1 & $0-20$ & 10YR 2/2 & very dark brown & Clay Loam & $>20 \%$ & Cobbles, Pebbles & $\mathrm{N}$ & Terminated at rock impasse. \\
\hline NA & CMS12 & 1 & $0-20$ & 10YR 2/2 & very dark brown & Clay Loam & $>20 \%$ & Cobbles, Pebbles & $\mathrm{N}$ & Terminated at rock impasse. \\
\hline NA & CMS13 & 1 & $0-20$ & 10YR 2/2 & very dark brown & Clay Loam & $>20 \%$ & Cobbles, Pebbles & $\mathrm{N}$ & Terminated at rock impasse. \\
\hline NA & CMS14 & 1 & $0-30$ & 7.5YR 2.5/1 & black & Clay Loam & $10-20 \%$ & Cobbles & $\mathrm{N}$ & Terminated at compact soil. \\
\hline NA & CS01 & $\mathrm{n} / \mathrm{a}$ & $\mathrm{n} / \mathrm{a}$ & $\mathrm{n} / \mathrm{a}$ & $\mathrm{n} / \mathrm{a}$ & $\mathrm{n} / \mathrm{a}$ & $\mathrm{n} / \mathrm{a}$ & $\mathrm{n} / \mathrm{a}$ & $\mathrm{n} / \mathrm{a}$ & Not excavated due to inundation. \\
\hline \multirow{2}{*}{ NA } & \multirow{2}{*}{$\mathrm{CSO2}$} & 1 & $0-40$ & 7.5 YR $4 / 3$ & brown & Sand & - & - & $\mathrm{N}$ & - \\
\hline & & 2 & $40-65$ & 7.5 YR $5 / 4$ & brown & Sand & 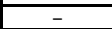 & - & $\mathrm{N}$ & Terminated at bedrock. \\
\hline NA & $\mathrm{CSO}$ & 1 & $0-30$ & $7.5 Y R 4 / 2$ & brown & Sand & - & - & $\mathrm{N}$ & - \\
\hline NA & csos & 2 & $30-40$ & 7.5 YR $5 / 3$ & brown & Sand & - & - & $\mathrm{N}$ & Terminated at hydric sand. \\
\hline & & 1 & $0-25$ & $7.5 \mathrm{YR} 4 / 2$ & brown & Sand & 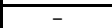 & - & $\mathrm{N}$ & - \\
\hline NA & CS04 & 2 & $25-50$ & 7.5 YR $6 / 4$ & light brown & Sand & - & - & $\mathrm{N}$ & Terminated at bedrock. \\
\hline & & 1 & $0-55$ & 10YR 4/3 & brown & Sand & 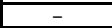 & 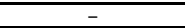 & $\mathrm{N}$ & 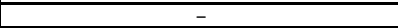 \\
\hline NA & CS05 & 2 & $55-70$ & 10YR $6 / 4$ & $\begin{array}{l}\text { light yellowish } \\
\text { brown }\end{array}$ & Sand & - & - & $\mathrm{N}$ & Terminated at water table. \\
\hline NA & $\operatorname{css} \theta$ & 1 & $0-45$ & 10YR 4/3 & brown & Sand & 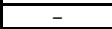 & 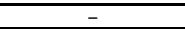 & $\mathrm{N}$ & 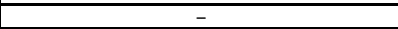 \\
\hline & & 2 & $45-60$ & 7.5 YR $6 / 4$ & light brown & Sand & - & 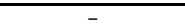 & $\mathrm{N}$ & Terminated at bedrock. \\
\hline $\mathrm{NA}$ & $\operatorname{cs0} 7$ & 1 & $0-50$ & 7.5 YR $4 / 4$ & brown & Sandy Loam & $>20 \%$ & Gravels, Pebbles & $\mathrm{N}$ & - \\
\hline NA & CS07 & 2 & $50-60$ & 7.5 YR $5 / 8$ & strong brown & Sandy Clay & $>20 \%$ & Gravels, Pebbles & $\mathrm{N}$ & Terminated at compact soil. \\
\hline & & 1 & $0-80$ & 10YR $4 / 3$ & brown & Loamy Sand & - & - & $\mathrm{N}$ & 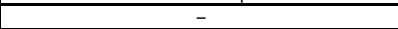 \\
\hline NA & $\operatorname{cs} 08$ & 2 & $80-100$ & 10YR $4 / 6$ & $\begin{array}{l}\text { dark yellowish } \\
\text { brown }\end{array}$ & Loamy Sand & $1-5 \%$ & Gravels & N & Terminated at depth. \\
\hline NA & $\mathrm{csen}$ & 1 & $0-25$ & $7.5 Y R 4 / 4$ & brown & Sandy Loam & $>20 \%$ & Gravels & $\mathrm{N}$ & 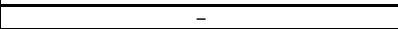 \\
\hline NA & CS09 & 2 & $25-35$ & 5 YR $4 / 6$ & yellowish red & Clay & - & - & $\mathrm{N}$ & Terminated at compact soil. \\
\hline NA & cs10 & 1 & $0-40$ & $7.5 Y R 4 / 4$ & brown & Sandy Loam & $10-20 \%$ & Gravels & $\mathrm{N}$ & - \\
\hline & & 2 & $40-60$ & 10YR 5/6 & yellowish brown & Loamy Sand & $5-10 \%$ & Gravels & $\mathrm{N}$ & Terminated at bedrock. \\
\hline NA & Cs10 & 1 & $0-35$ & 7.5 YR $5 / 6$ & strong brown & Sandy Loam & - & - & $\mathrm{N}$ & - \\
\hline NA & CS10 & 2 & $35-45$ & 5YR $5 / 8$ & yellowish red & Sandy Clay & - & - & $\mathrm{N}$ & Terminated at basal clay. \\
\hline NA & CS11 & 1 & $0-20$ & $7.5 Y R 4 / 4$ & brown & Sandy Loam & $10-20 \%$ & Gravels & $\mathrm{N}$ & - \\
\hline NA & CS11 & 2 & $20-30$ & 5YR $4 / 6$ & yellowish red & Clay & $\begin{array}{llll}- & & & \\
-\end{array}$ & - & $\mathrm{N}$ & Terminated at compact soil. \\
\hline $\mathrm{NA}$ & CS11 & 1 & $0-15$ & $7.5 Y R 4 / 4$ & brown & Sandy Loam & - & - & $\mathrm{N}$ & - \\
\hline & & 2 & $15-25$ & 2.5 YR $4 / 8$ & red & Clay & - & - & $\mathrm{N}$ & Terminated at basal clay. \\
\hline NA & $\mathrm{CS} 12$ & 1 & $0-20$ & $7.5 \mathrm{YR} 4 / 4$ & brown & Sandy Loam & $10-20 \%$ & Gravels & $\bar{N}$ & - \\
\hline NA & CS12 & 2 & $20-30$ & 5YR $4 / 6$ & yellowish red & Clay & $1-5 \%$ & Gravels & $\mathrm{N}$ & Terminated at basal clay. \\
\hline NA & CS13 & 1 & $0-10$ & 7.5 YR $4 / 4$ & brown & Sandy Loam & $10-20 \%$ & Gravels & $\mathrm{N}$ & - \\
\hline NA & CS13 & 2 & $10-30$ & $5 Y R 4 / 6$ & yellowish red & Clay & $1-5 \%$ & Gravels & $\mathrm{N}$ & Terminated at compact soil. \\
\hline & & 1 & $0-40$ & 7.5YR $2.5 / 3$ & very dark brown & Sandy Clay Loam & - & - & $\mathrm{N}$ & - \\
\hline 41BU123 & CS14 & 2 & $40-100$ & 10YR $4 / 4$ & $\begin{array}{l}\text { dark yellowish } \\
\text { brown }\end{array}$ & Sandy Clay Loam & - & - & $\mathrm{N}$ & Terminated at depth. \\
\hline & & 1 & $0-30$ & 7.5 YR $4 / 3$ & brown & Sandy Loam & $1-5 \%$ & Pebbles & $\mathrm{N}$ & - \\
\hline 41BU123 & CS15 & 2 & $30-50$ & 10YR $4 / 4$ & $\begin{array}{l}\text { dark yellowish } \\
\text { brown }\end{array}$ & Sandy Clay Loam & - & - & $\mathrm{N}$ & - \\
\hline & & 3 & $50-60$ & 10YR $4 / 6$ & $\begin{array}{l}\text { dark yellowish } \\
\text { brown }\end{array}$ & Sandy Clay & $1-5 \%$ & Iron oxide mottling & $\mathrm{N}$ & Terminated at basal clay. \\
\hline NA & $\operatorname{cs} 16$ & 1 & $0-45$ & 10YR 4/3 & brown & Loamy Sand & - & - & $\mathrm{N}$ & - \\
\hline & & 2 & $45-100$ & 7.5 YR $4 / 2$ & brown & Loamy Sand & $\begin{array}{c}- \\
\end{array}$ & 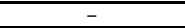 & $\mathrm{N}$ & Terminated at depth. \\
\hline NA & $\mathrm{CS}_{17}$ & 1 & $0-30$ & 7.5 YR $4 / 3$ & brown & Sand & - & 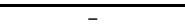 & $\mathrm{N}$ & - \\
\hline NA & CS17 & 2 & $30-50$ & $5 Y R 4 / 6$ & yellowish red & Sandy Clay & - & - & $\mathrm{N}$ & Terminated at compact soil. \\
\hline NA & CS18 & 1 & $0-40$ & 10YR $2 / 2$ & very dark brown & Clay Loam & 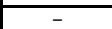 & 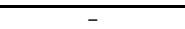 & $\mathrm{N}$ & - \\
\hline NA & CS18 & 2 & $40-50$ & 7.5 YR $4 / 2$ & brown & Clay Loam & 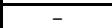 & - & $\mathrm{N}$ & Terminated at compact soil. \\
\hline NA & CS10 & 1 & $0-30$ & 7.5 YR $4 / 4$ & brown & Sand & 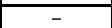 & 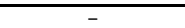 & $\mathrm{N}$ & - \\
\hline NA & CS19 & 2 & $30-40$ & $5 Y R 4 / 6$ & yellowish red & Sandy Clay & - & - & $\mathrm{N}$ & Terminated at basal clay. \\
\hline NA & $\operatorname{cs} 20$ & 1 & $0-15$ & 7.5YR 2.5/2 & very dark brown & Loam & $>20 \%$ & Cobbles, Pebbles & N & Terminated at impenetrable pebble/cobble layer. \\
\hline NA & CS21 & 1 & $0-15$ & 7.5YR $2.5 / 3$ & very dark brown & Loam & $>20 \%$ & Cobbles, Pebbles & $\mathrm{N}$ & Terminated at impenetrable pebble/cobble layer. \\
\hline NA & $\mathrm{CSO}$ & 1 & $0-10$ & 10YR 2/2 & very dark brown & Clay Loam & $>20 \%$ & Pebbles & $\mathrm{N}$ & - \\
\hline NA & CS22 & 2 & $10-20$ & $10 \mathrm{YR} 7 / 3$ & very pale brown & Clay & $>20 \%$ & Pebbles & $\mathrm{N}$ & Terminated at basal clay. \\
\hline NA & $\operatorname{cs} 23$ & 1 & $0-15$ & 7.5YR $2.5 / 3$ & very dark brown & Loam & $>20 \%$ & Cobbles, Pebbles & N & Terminated at impenetrable pebble/cobble layer. \\
\hline NA & $\operatorname{cs} 24$ & 1 & $0-25$ & 7.5YR $2.5 / 2$ & very dark brown & Loam & $5-10 \%$ & Pebbles & $\mathrm{N}$ & Terminated at impenetrable pebble/cobble layer. \\
\hline NA & $\operatorname{cs} 25$ & 1 & $0-15$ & 7.5YR $2.5 / 2$ & very dark brown & Loam & $>20 \%$ & Pebbles & $\mathrm{N}$ & Terminated at impenetrable pebble /cobble layer. \\
\hline
\end{tabular}




\begin{tabular}{|c|c|c|c|c|c|c|c|c|c|c|}
\hline Site No. & $\begin{array}{c}\text { Shovel Test } \\
\text { No. }\end{array}$ & Level & $\begin{array}{l}\text { Depth } \\
\text { (cmbs) }\end{array}$ & $\left|\begin{array}{c}\text { Munsell Soil } \\
\text { value }\end{array}\right|$ & $\begin{array}{l}\text { Munsell Soil } \\
\text { Color }\end{array}$ & Soil Texture & \begin{tabular}{|c|} 
Inclusion \\
Percentage
\end{tabular} & Inclusion Type & $\begin{array}{c}\text { Positive }(P) \\
\text { or Negative } \\
\text { (N) }\end{array}$ & Comments/ Reason for Termination \\
\hline NA & $\operatorname{cs} 26$ & 1 & $0-15$ & 7.5YR $2.5 / 3$ & very dark brown & Loam & $>20 \%$ & Pebbles & $\mathrm{N}$ & Terminated at impenetrable pebble layer. \\
\hline NA & $\operatorname{cs} 27$ & 1 & $0-15$ & 7.5YR $2.5 / 1$ & black & Loam & $>20 \%$ & Pebbles & $\mathrm{N}$ & Terminated at impenetrable pebble layer. \\
\hline \multirow{2}{*}{ NA } & \multirow{2}{*}{$\operatorname{cs} 28$} & 1 & $0-50$ & 7.5YR $2.5 / 3$ & very dark brown & Loam & $10-20 \%$ & Clay from level 2 & $\mathrm{~N}$ & - \\
\hline & & 2 & $50-70$ & 7.5 YR $4 / 2$ & brown & Clay & - & - & $\mathrm{N}$ & Terminated at basal clay. \\
\hline \multirow{2}{*}{ NA } & \multirow{2}{*}{$\operatorname{cs} 29$} & 1 & $0-35$ & 7.5YR $2.5 / 1$ & black & Clay Loam & - & - & $\mathrm{N}$ & - \\
\hline & & 2 & $35-45$ & 5 YYR 5/8 & yellowish red & Sandy Clay & - & - & $\mathrm{N}$ & Terminated at basal clay. \\
\hline $\mathrm{NA}$ & $\operatorname{cs} 35$ & 1 & $0-70$ & 7.5 YR $5 / 4$ & brown & Sand & - & - & $\mathrm{N}$ & Terminated at water table. \\
\hline \multirow{2}{*}{ NA } & CS36 & 1 & $0-25$ & $7.5 Y R 4 / 4$ & brown & Sandy Loam & - & - & $\mathrm{N}$ & 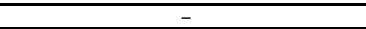 \\
\hline & $\operatorname{cs} 36$ & 2 & $25-35$ & 5YR 4/6 & yellowish red & Sandy Clay & $10-20 \%$ & Pebbles & $\mathrm{N}$ & Terminated at bedrock. \\
\hline & & 1 & $0-80$ & 7.5 YR $5 / 4$ & brown & Sand & $1-5 \%$ & Gravels & $\mathrm{N}$ & - \\
\hline NA & CS37 & 2 & $80-90$ & 7.5 YR $6 / 6$ & reddish yellow & Sandy Clay & $5-10 \%$ & Gravels & $\mathrm{N}$ & Terminated at basal clay. \\
\hline$N A$ & $\operatorname{CS38}$ & 1 & $0-30$ & 7.5 YR $4 / 4$ & brown & Sandy Loam & $1-5 \%$ & Gravels & $\mathrm{N}$ & 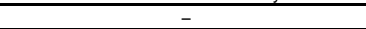 \\
\hline NA & c538 & 2 & $30-40$ & 7.5 YR $6 / 6$ & reddish yellow & Sandy Clay & $5-10 \%$ & Gravels, Pebbles & $\mathrm{N}$ & Terminated at basal clay. \\
\hline & & 1 & $0-60$ & 7.5 YR $4 / 4$ & brown & Sandy Loam & $\begin{array}{ll}- & \\
\end{array}$ & 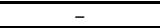 & $\mathrm{N}$ & $\begin{array}{ll}- \\
\end{array}$ \\
\hline NA & $\operatorname{cs} 39$ & 2 & $60-80$ & 7.5 YR $7 / 3$ & pink & Sandy Loam & $5-10 \%$ & Iron oxide & $\mathrm{N}$ & 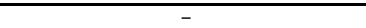 \\
\hline & & 3 & $80-90$ & 7.5 YR $6 / 6$ & reddish yellow & Sandy Clay & - & - & $\mathrm{N}$ & Terminated at basal clay. \\
\hline 41BU124 & CS40 & 1 & $0-100$ & 7.5 YR $4 / 3$ & brown & Loamy Sand & $1-5 \%$ & Gravels & $\bar{Y}$ & 1: Flake (utilized) Terminated at depth. \\
\hline Na & csino & 1 & $0-20$ & 7.5 YR $4 / 4$ & brown & Sandy Loam & $10-20 \%$ & Pebbles & $\mathrm{N}$ & - \\
\hline NA & CSI00 & 2 & $20-30$ & 7.5 YR $5 / 6$ & strong brown & Sandy Clay & - & - & $\mathrm{N}$ & Terminated at basal clay. \\
\hline $\mathrm{NA}$ & CS101 & 1 & $0-100$ & 7.5 YR $3 / 4$ & dark brown & Loamy Sand & - & - & $\mathrm{N}$ & Terminated at depth. \\
\hline NA & CS10? & 1 & $0-60$ & 7.5 YR $3 / 4$ & dark brown & Loamy Sand & $5-10 \%$ & Gravels, Pebbles & $\mathrm{N}$ & - \\
\hline $\mathrm{NA}$ & CS102 & 2 & $60-70$ & 7.5 YR $5 / 6$ & strong brown & Sandy Clay & $5-10 \%$ & Pebbles & $\mathrm{N}$ & Terminated at basal clay. \\
\hline NA & CS103 & 1 & $0-100$ & 7.5 YR $4 / 6$ & strong brown & Sand & $1-5 \%$ & Pebbles & $\mathrm{N}$ & Terminated at depth. \\
\hline$N A$ & CS104 & 1 & $0-70$ & 7.5 YR $5 / 4$ & brown & Sand & $1-5 \%$ & Pebbles & $\mathrm{N}$ & - \\
\hline NA & CS104 & 2 & $70-80$ & 10YR 5/6 & yellowish brown & Sandy Clay & - & - & $\mathrm{N}$ & Terminated at basal clay. \\
\hline & & 1 & $0-20$ & 7.5 YR $4 / 4$ & brown & Sandy Loam & $10-20 \%$ & Pebbles & $\mathrm{N}$ & 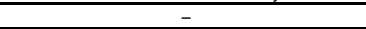 \\
\hline NA & CS105 & 2 & $20-30$ & 7.5 YR $5 / 6$ & strong brown & Sandy Clay & - & - & $\mathrm{N}$ & Terminated at basal clay. \\
\hline NA & cs106 & 1 & $0-50$ & $7.5 Y R 4 / 4$ & brown & Sandy Loam & $\begin{array}{ll}- \\
-\end{array}$ & 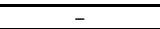 & $\mathrm{N}$ & - \\
\hline NA & CS106 & 2 & $50-60$ & 10YR 5/6 & yellowish brown & Sandy Clay & - & - & $\mathrm{N}$ & Terminated at basal clay. \\
\hline$N A$ & & 1 & $0-50$ & 7.5 YR $4 / 4$ & brown & Sandy Loam & - & - & $\mathrm{N}$ & - \\
\hline NA & CS107 & 2 & $50-60$ & 10 YR $5 / 6$ & yellowish brown & Sandy Clay & - & - & $\bar{N}$ & Terminated at basal clay. \\
\hline$N A$ & CS108 & 1 & $0-50$ & 7.5 YR $4 / 4$ & brown & Sandy Loam & 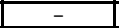 & $\begin{array}{ll}- \\
\end{array}$ & $\mathrm{N}$ & - \\
\hline NA & & 2 & $50-60$ & 10YR 5/6 & yellowish brown & Sandy Clay & - & 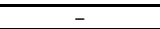 & $\mathrm{N}$ & Terminated at basal clay. \\
\hline NA & CS200 & 1 & $0-50$ & 7.5 YR $4 / 1$ & dark gray & Clay Loam & $\begin{array}{ll}- \\
\end{array}$ & - & $\mathrm{N}$ & Terminated at water table. \\
\hline NA & CS201 & 1 & $0-60$ & 7.5 YR $4 / 1$ & dark gray & Clay Loam & - & - & $\mathrm{N}$ & Terminated at compact soil. \\
\hline NA & CS202 & 1 & $0-20$ & $7.5 Y R \quad 4 / 2$ & brown & Sandy Clay Loam & - & - & $\mathrm{N}$ & - \\
\hline & & 2 & $20-50$ & $7.5 Y R 4 / 1$ & dark gray & Clay & - & - & $\mathrm{N}$ & Terminated at compact soil. \\
\hline $\mathrm{NA}$ & CS203 & 1 & $0-123$ & 7.5 YR $4 / 3$ & brown & Sandy Loam & $5-10 \%$ & Cobbles, Pebbles & $\mathrm{N}$ & Terminated at bedrock. \\
\hline & & 1 & $0-20$ & 7.5YR 4/2 & brown & Sandy Clay Loam & $1-5 \%$ & Gravels, Pebbles & $\mathrm{N}$ & - \\
\hline NA & CS204 & 2 & $20-85$ & $7.5 Y R 4 / 1$ & dark gray & Clay Loam & - & - & $\mathrm{N}$ & - \\
\hline & & 3 & $85-160$ & 7.5 YR $5 / 1$ & gray & Clay & - & - & $\mathrm{N}$ & Terminated at water table. \\
\hline NA & CS205 & 1 & $0-40$ & $7.5 Y R \quad 4 / 1$ & dark gray & Sandy Clay Loam & - & - & $\mathrm{N}$ & - \\
\hline & & 2 & $40-128$ & 7.5 YR $5 / 1$ & gray & Sandy Clay & - & - & $\mathrm{N}$ & Terminated at water table. \\
\hline 41LE350 & CS206 & 1 & $0-100$ & $7.5 Y R 4 / 4$ & brown & Loamy Sand & $5-10 \%$ & $\begin{array}{c}\text { Cobbles, Gravels, } \\
\text { Pebbles }\end{array}$ & $\mathrm{Y}$ & 2: Other Prehistoric Terminated at depth. \\
\hline 41LE350 & CS207 & 1 & $0-80$ & $7.5 Y R 4 / 3$ & brown & Loamy Sand & $5-10 \%$ & Cobbles, Pebbles & Y & $\begin{array}{l}\text { 9: Flake (primary), Flake (secondary), Flake } \\
\text { (tertiary), Other Prehistoric, Other Prehistoric }\end{array}$ \\
\hline & & 2 & $80-100$ & 5 YR $5 / 8$ & yellowish red & Sandy Clay & - & - & $\mathrm{N}$ & Terminated at depth. \\
\hline 41LE350 & CS208 & 1 & $0-50$ & $7.5 \mathrm{YR} 4 / 3$ & brown & Loamy Sand & $5-10 \%$ & Cobbles, Pebbles & $\mathrm{Y}$ & $\begin{array}{c}\text { 9: Flake (primary), Flake (secondary), Flake } \\
\text { (tertiary) }\end{array}$ \\
\hline & & 2 & $50-60$ & 5YR $5 / 8$ & yellowish red & Sandy Clay & - & - & $\mathrm{N}$ & Terminated at depth. \\
\hline 411 E 350 & CS?R० & 1 & $0-45$ & 7.5 YR $4 / 3$ & brown & Sandy Loam & - & - & $\mathrm{N}$ & - \\
\hline 41LE350 & CS209 & 2 & $45-100$ & 7.5 YR $6 / 2$ & pinkish gray & Loamy Sand & - & - & $\mathrm{N}$ & Terminated at depth. \\
\hline NA & CS215 & 1 & $0-45$ & 7.5 YR $4 / 3$ & brown & Sandy Loam & 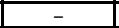 & - & $\mathrm{N}$ & - \\
\hline & & 2 & $45-55$ & 7.5 YR $5 / 6$ & strong brown & Sandy Loam & - & - & $\mathrm{N}$ & Terminated at water table. \\
\hline NA & CS216 & 1 & $0-35$ & 7.5YR $2.5 / 1$ & black & Clay & $1-5 \%$ & Pebbles & $\mathrm{N}$ & Terminated at compact soil. \\
\hline NA & CS217 & 1 & $0-100$ & 7.5 YR $5 / 4$ & brown & Sand & - & - & $\mathrm{N}$ & Terminated at depth. \\
\hline NA & CS218 & 1 & $0-100$ & 7.5 YR $5 / 4$ & brown & Sand & - & - & $\mathrm{N}$ & Terminated at depth. \\
\hline NA & CS219 & 1 & $0-30$ & 7.5 YR 4/2 & brown & Sandy Loam & 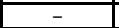 & - & $\mathrm{N}$ & - \\
\hline NA & CS219 & 2 & $30-65$ & 7.5 YR $6 / 1$ & gray & Sandy Clay & $\begin{array}{ll}- & \\
\end{array}$ & - & $\mathrm{N}$ & Terminated at compact soil. \\
\hline NA & CS220 & 1 & $0-100$ & 7.5 YR $6 / 4$ & light brown & Sand & $1-5 \%$ & Gravels & $\mathrm{N}$ & Terminated at depth. \\
\hline $\mathrm{NA}$ & CS221 & 1 & $0-100$ & 7.5 YR $6 / 4$ & light brown & Sand & $1-5 \%$ & Gravels & $\mathrm{N}$ & Terminated at depth. \\
\hline NA & CS222 & 1 & $0-100$ & 7.5 YR $6 / 4$ & light brown & Sand & $1-5 \%$ & Gravels & $\mathrm{N}$ & Terminated at depth. \\
\hline NA & CS223 & 1 & $0-100$ & 7.5 YR $6 / 4$ & light brown & Sand & $1-5 \%$ & Gravels & $\mathrm{N}$ & Terminated at depth. \\
\hline NA & $C S 224$ & 1 & $0-40$ & $7.5 Y R 4 / 4$ & brown & Loamy Sand & $5-10 \%$ & Gravels & $\mathrm{N}$ & 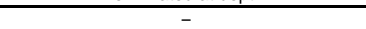 \\
\hline NA & CS224 & 2 & $40-50$ & 2.5 YR $4 / 8$ & red & Clay & - & - & $\mathrm{N}$ & Terminated at basal clay. \\
\hline NA & CS225 & 1 & $0-25$ & 7.5 YR $4 / 6$ & strong brown & Loamy Sand & $>20 \%$ & Gravels, Pebbles & $\mathrm{N}$ & Terminated at bedrock. \\
\hline & & 1 & $0-50$ & 10YR 3/1 & very dark gray & Clay Loam & - & - & $\mathrm{N}$ & - \\
\hline NA & CS230 & 2 & $50-65$ & 10YR $4 / 2$ & dark grayish brown & Clay & $1-5 \%$ & Snail Shell & $\mathrm{N}$ & Terminated at compact soil. \\
\hline & & 1 & $0-40$ & $10 Y R 3 / 1$ & very dark gray & Clay Loam & - & - & $\mathrm{N}$ & - \\
\hline NA & CS231 & 2 & $40-55$ & 10YR $4 / 2$ & dark grayish brown & Clay & - & - & $\mathrm{N}$ & Terminated at compact soil. \\
\hline$N A$ & $\operatorname{cs} 232$ & 1 & $0-45$ & $10 \mathrm{YR} 3 / 3$ & dark brown & Clay Loam & - & - & $\mathrm{N}$ & - \\
\hline & & 2 & $45-100$ & 10YR 5/4 & yellowish brown & Sand & 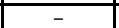 & - & $\mathrm{N}$ & Terminated at depth. \\
\hline NA & CS233 & 1 & $0-50$ & 10YR 3/1 & very dark gray & Clay & - & - & $\mathrm{N}$ & Terminated at compact soil. \\
\hline NA & CS234 & 1 & $0-50$ & 10YR 3/1 & very dark gray & Clay Loam & - & - & $\mathrm{N}$ & Terminated at compact soil. \\
\hline NA & $\mathrm{CSP} 25$ & 1 & $0-40$ & 10YR $2 / 2$ & very dark brown & Clay Loam & - & - & $\mathrm{N}$ & - \\
\hline NA & CS235 & 2 & $40-50$ & 10YR 2/1 & black & Clay & - & - & $\mathrm{N}$ & Terminated at compact soil. \\
\hline NA & $\operatorname{cs} 236$ & 1 & $0-30$ & 10YR 2/2 & very dark brown & Clay Loam & - & - & $\mathrm{N}$ & - \\
\hline & & 2 & $30-40$ & 10YR 2/1 & black & Clay & - & - & $\mathrm{N}$ & Terminated at compact soil. \\
\hline
\end{tabular}




\begin{tabular}{|c|c|c|c|c|c|c|c|c|c|c|}
\hline Site No. & $\begin{array}{l}\text { Shovel Test } \\
\text { No. }\end{array}$ & Level & $\begin{array}{l}\text { Depth } \\
\text { (cmbs) }\end{array}$ & $\begin{array}{c}\text { Munsell Soil } \\
\text { value }\end{array}$ & $\begin{array}{l}\text { Munsell Soil } \\
\text { Color }\end{array}$ & Soil Texture & \begin{tabular}{|l} 
Inclusion \\
Percentage
\end{tabular} & Inclusion Type & $\begin{array}{c}\text { Positive }(\mathrm{P}) \\
\text { or Negative } \\
(\mathrm{N})\end{array}$ & Comments/ Reason for Termination \\
\hline \multirow[t]{2}{*}{ NA } & \multirow[t]{2}{*}{$\operatorname{cs} 237$} & 1 & $0-30$ & 10YR $3 / 2$ & \begin{tabular}{|c|} 
very dark grayish \\
brown
\end{tabular} & Clay Loam & - & - & $\mathrm{N}$ & - \\
\hline & & 2 & $30-40$ & 10YR 2/1 & black & Clay & 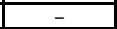 & - & $\mathrm{N}$ & Terminated at compact soil. \\
\hline \multirow[b]{2}{*}{ NA } & \multirow[b]{2}{*}{ CXS01 } & 1 & $0-35$ & 10YR 5/3 & brown & Sandy Loam & 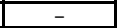 & $\begin{array}{cc}- \\
\end{array}$ & $\mathrm{N}$ & $\begin{array}{ll}- \\
\end{array}$ \\
\hline & & 2 & $35-50$ & 10YR $6 / 1$ & gray & Sandy Clay & $>20 \%$ & Mottles & $\mathrm{N}$ & Terminated at compact soil. \\
\hline \multirow{2}{*}{ NA } & \multirow{2}{*}{ CXS02 } & 1 & $0-50$ & 10YR 5/4 & yellowish brown & Sand & - & - & $\mathrm{N}$ & - \\
\hline & & 2 & $50-60$ & 10YR $6 / 8$ & brownish yellow & Sandy Clay & - & - & $\mathrm{N}$ & Terminated at compact soil. \\
\hline \multirow{2}{*}{ NA } & \multirow{2}{*}{$\mathrm{CXS03}$} & 1 & $0-85$ & 10YR 5/4 & yellowish brown & Sand & $10-20 \%$ & Gravels & $\mathrm{N}$ & $\begin{array}{llll}- & & & 0\end{array}$ \\
\hline & & 2 & $85-95$ & 5YR 4/6 & yellowish red & Sandy Clay & $10-20 \%$ & Gravels & $\mathrm{N}$ & Terminated at compact soil. \\
\hline \multirow{2}{*}{ NA } & \multirow[b]{2}{*}{$\mathrm{CXSO4}$} & 1 & $0-35$ & 10YR $4 / 3$ & brown & Sandy Loam & - & - & $\mathrm{N}$ & - \\
\hline & & 2 & $35-45$ & 10YR 5/1 & gray & Sandy Clay & - & - & $\mathrm{N}$ & Terminated at compact soil. \\
\hline \multirow[b]{2}{*}{ 41GU200 } & \multirow[b]{2}{*}{ CXS05 } & 1 & $0-25$ & 10YR $2 / 2$ & very dark brown & Clay Loam & $10-20 \%$ & Snail Shell & $\mathrm{N}$ & - \\
\hline & & 2 & $25-100$ & 10YR $5 / 4$ & yellowish brown & Sandy Clay Loam & $10-20 \%$ & Snail Shell & $\mathrm{N}$ & Terminated at depth. \\
\hline & & 1 & $0-35$ & 10YR 2/2 & very dark brown & Sandy Loam & $10-20 \%$ & Snail Shell & $\mathrm{N}$ & - \\
\hline 41GU200 & CXS06 & 2 & $35-100$ & 10YR $5 / 4$ & yellowish brown & Sandy Clay Loam & $10-20 \%$ & Pebbles, Snail Shell & $\mathrm{N}$ & Terminated at depth. \\
\hline $41 G U 200$ & $\operatorname{cxs} \Omega 7$ & 1 & $0-50$ & 10YR $3 / 2$ & \begin{tabular}{|c|}
$\begin{array}{c}\text { very dark grayish } \\
\text { brown }\end{array}$ \\
\end{tabular} & Sandy Loam & $10-20 \%$ & Pebbles, Snail Shell & $\mathrm{N}$ & - \\
\hline & & 2 & $50-100$ & 10YR $5 / 4$ & yellowish brown & Sandy Clay Loam & $5-10 \%$ & Pebbles, Snail Shell & $\mathrm{N}$ & Terminated at depth. \\
\hline & & 1 & $0-70$ & 10YR 2/2 & very dark brown & Sandy Loam & $5-10 \%$ & Snail Shell & $\mathrm{N}$ & - \\
\hline 41GU200 & CXS08 & 2 & $70-100$ & 10YR $5 / 4$ & yellowish brown & Sandy Clay Loam & $5-10 \%$ & Pebbles, Snail Shell & $\mathrm{N}$ & Terminated at depth. \\
\hline NA & CXS09 & 1 & $0-30$ & 10YR 5/1 & gray & Clay & $>20 \%$ & Mottles & $\mathrm{N}$ & Terminated at compact soil. \\
\hline NA & CXS10 & 1 & $0-30$ & 10YR 5/1 & gray & Clay & $>20 \%$ & Mottles & $\mathrm{N}$ & Terminated at compact soil. \\
\hline NA & CXS11 & 1 & $0-100$ & 7.5 YR $5 / 4$ & brown & Sand & - & - & $\mathrm{N}$ & Terminated at depth. \\
\hline NA & CXS12 & 1 & $0-100$ & 7.5 YR $5 / 4$ & brown & Sand & - & - & $\mathrm{N}$ & Terminated at depth. \\
\hline NA & CXS13 & 1 & $0-100$ & 7.5 YR $5 / 4$ & brown & Sand & $10-20 \%$ & Gravels, Pebbles & $\mathrm{N}$ & Terminated at depth. \\
\hline NA & DPR01 & 1 & $0-70$ & 10YR $6 / 4$ & $\begin{array}{l}\text { light yellowish } \\
\text { brown }\end{array}$ & Loamy Sand & $1-5 \%$ & Mottles & $\mathrm{N}$ & Terminated at water table. \\
\hline NA & DPR02 & 1 & $0-30$ & 10YR $6 / 4$ & $\begin{array}{l}\text { light yellowish } \\
\text { brown }\end{array}$ & Loamy Sand & - & - & $\mathrm{N}$ & - \\
\hline & & 2 & $30-50$ & 7.5 YR $7 / 3$ & pink & Sandy Clay & $1-5 \%$ & Mottles & $\mathrm{N}$ & Terminated at basal clay. \\
\hline NA & DPR03 & 1 & $0-70$ & 10YR $6 / 4$ & $\begin{array}{l}\text { light yellowish } \\
\text { brown }\end{array}$ & Loamy Sand & $1-5 \%$ & Mottles & $\mathrm{N}$ & Terminated at water table. \\
\hline NA & DPR04 & 1 & $0-70$ & 10YR $6 / 4$ & $\begin{array}{l}\text { light yellowish } \\
\text { brown }\end{array}$ & Loamy Sand & - & - & $\mathrm{N}$ & - \\
\hline & & 2 & $70-80$ & 7.5 YR $7 / 3$ & pink & Sandy Clay & $1-5 \%$ & Mottles & $\mathrm{N}$ & Terminated at basal clay. \\
\hline NA & DPR05 & 1 & $0-30$ & 10YR $6 / 4$ & $\begin{array}{l}\text { light yellowish } \\
\text { brown }\end{array}$ & Loamy Sand & - & - & $\mathrm{N}$ & - \\
\hline & & 2 & $30-50$ & 7.5 YR $7 / 3$ & pink & Sandy Clay & $1-5 \%$ & Mottles & $\mathrm{N}$ & Terminated at basal clay. \\
\hline NA & DPR06 & 1 & $0-30$ & 10YR $6 / 4$ & $\begin{array}{l}\text { light yellowish } \\
\text { brown }\end{array}$ & Loamy Sand & - & - & $\mathrm{N}$ & - \\
\hline & & 2 & $30-50$ & 7.5 YR $7 / 3$ & pink & Sandy Clay & $1-5 \%$ & Mottles & $\mathrm{N}$ & Terminated at basal clay. \\
\hline NA & DPR07 & 1 & $0-30$ & 10YR $6 / 4$ & $\begin{array}{l}\text { light yellowish } \\
\text { brown }\end{array}$ & Loamy Sand & - & - & $\mathrm{N}$ & - \\
\hline & & 2 & $30-50$ & $7.5 Y R 7 / 3$ & pink & Sandy Clay & $1-5 \%$ & Mottles & $\mathrm{N}$ & Terminated at basal clay. \\
\hline NA & DPR08 & 1 & $0-100$ & 10YR $4 / 6$ & $\begin{array}{c}\text { dark yellowish } \\
\text { brown }\end{array}$ & Loamy Sand & - & - & $\mathrm{N}$ & Terminated at depth. \\
\hline NA & DPR09 & 1 & $0-30$ & 10YR $6 / 4$ & $\begin{array}{c}\text { light yellowish } \\
\text { brown }\end{array}$ & Loamy Sand & - & - & $\mathrm{N}$ & - \\
\hline & & 2 & $30-50$ & $7.5 Y R 7 / 3$ & pink & Sandy Clay & $1-5 \%$ & Mottles & $\mathrm{N}$ & Terminated at basal clay. \\
\hline $\mathrm{NA}$ & DPR10 & 1 & $0-40$ & 10YR 3/3 & dark brown & Silty Clay Loam & $5-10 \%$ & Mottles & $\mathrm{N}$ & Terminated at water table. \\
\hline NA & DPR11 & 1 & $0-40$ & 10YR $3 / 3$ & dark brown & Silty Clay Loam & $5-10 \%$ & Mottles & $\mathrm{N}$ & Terminated at water table. \\
\hline & & 1 & $0-40$ & 7.5YR $2.5 / 3$ & very dark brown & Sandy Clay Loam & - & - & $\mathrm{N}$ & - \\
\hline NA & DPR12 & 2 & $40-100$ & 10YR $4 / 4$ & $\begin{array}{c}\text { dark yellowish } \\
\text { brown }\end{array}$ & Sandy Clay Loam & - & - & $\mathrm{N}$ & Terminated at depth. \\
\hline 41BU123 & DPR13 & 1 & $0-30$ & 2.5 YR $5 / 8$ & red & Clay & - & - & $\mathrm{N}$ & Terminated at basal clay. \\
\hline$N A$ & PPB14 & 1 & $0-40$ & 7.5 YR $5 / 4$ & brown & Sandy Loam & 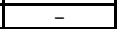 & 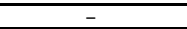 & $\mathrm{N}$ & 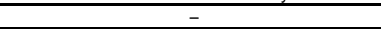 \\
\hline NA & DPR14 & 2 & $40-50$ & 2.5 YR $5 / 8$ & red & Clay & - & - & $\mathrm{N}$ & Terminated at basal clay. \\
\hline Na & א15 & 1 & $0-50$ & 7.5 YR $5 / 4$ & brown & Sandy Loam & - & - & $\mathrm{N}$ & - \\
\hline NA & DPR15 & 2 & $50-60$ & 2.5 YR $5 / 8$ & red & Clay & $\begin{array}{llll}- & & & \\
\end{array}$ & 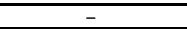 & $\mathrm{N}$ & Terminated at basal clay. \\
\hline NA & DPR16 & 1 & $0-40$ & $7.5 Y R 8 / 3$ & pink & Sandy Clay & $>20 \%$ & Gravels, Pebbles & $\mathrm{N}$ & Terminated at compact soil. \\
\hline & & 1 & $0-40$ & 10YR 6/2 & light brownish gray & Sandy Loam & $1-5 \%$ & Manganese & $\mathrm{N}$ & - \\
\hline TNA & DTRाठठ & 2 & $40-50$ & $5 Y R 6 / 4$ & light reddish brown & Clay Loam & - & - & $\mathrm{N}$ & Terminated at basal clay. \\
\hline NA & DPR19 & 1 & $0-30$ & 7.5YR $2.5 / 1$ & black & Clay Loam & $10-20 \%$ & Gravels & $\mathrm{N}$ & Terminated at compact soil. \\
\hline NA & DPR20 & 1 & $0-30$ & 10YR $4 / 2$ & dark grayish brown & Silt Loam & $1-5 \%$ & Gravels, Pebbles & $\mathrm{N}$ & Terminated at compact soil. \\
\hline NA & DPR21 & 1 & $0-30$ & 10YR 4/2 & dark grayish brown & Silt Loam & $1-5 \%$ & Gravels, Pebbles & $\mathrm{N}$ & Terminated at compact soil. \\
\hline NA & DPR22 & 1 & $0-30$ & 10YR $4 / 2$ & dark grayish brown & Silt Loam & $1-5 \%$ & Gravels, Pebbles & $\mathrm{N}$ & Terminated at compact soil. \\
\hline NA & DPR23 & 1 & $0-35$ & 10YR 5/4 & yellowish brown & Silty Clay Loam & $1-5 \%$ & Cobbles & $\mathrm{N}$ & Terminated at compact soil. \\
\hline NA & DPR24 & 1 & $0-35$ & 10YR $5 / 4$ & yellowish brown & Silty Clay Loam & $1-5 \%$ & Cobbles & $\mathrm{N}$ & Terminated at compact soil. \\
\hline NA & DPR25 & 1 & $0-30$ & 10YR 4/2 & dark grayish brown & Silt Loam & $1-5 \%$ & Gravels, Pebbles & $\mathrm{N}$ & Terminated at compact soil. \\
\hline NA & DPR26 & 1 & $0-30$ & 10YR 4/2 & dark grayish brown & Silt Loam & $1-5 \%$ & Gravels, Pebbles & $\mathrm{N}$ & Terminated at compact soil. \\
\hline NA & DPR27 & 1 & $0-30$ & 10YR $4 / 2$ & dark grayish brown & Silt Loam & $1-5 \%$ & Gravels, Pebbles & $\mathrm{N}$ & Terminated at compact soil. \\
\hline NA & DPR28 & 1 & $0-30$ & 10YR 4/2 & dark grayish brown & Silt Loam & $1-5 \%$ & Gravels, Pebbles & $\mathrm{N}$ & Terminated at compact soil. \\
\hline NA & DPR29 & 1 & $0-10$ & 10YR 5/4 & yellowish brown & Silt Loam & $5-10 \%$ & Cobbles, Pebbles & $\mathrm{N}$ & - \\
\hline NA & DPR29 & 2 & $10-30$ & 10YR $6 / 3$ & pale brown & Clay Loam & $1-5 \%$ & Cobbles & $\mathrm{N}$ & Terminated at basal clay. \\
\hline NA & DPR30 & 1 & $0-40$ & 10YR $3 / 4$ & $\begin{array}{l}\text { dark yellowish } \\
\text { brown }\end{array}$ & Silty Clay Loam & $5-10 \%$ & Cobbles & $\mathrm{N}$ & $\begin{array}{l}\text { Terminated at compact large ( } 15 \mathrm{~cm} \text { diameter) } \\
\text { cobbles. }\end{array}$ \\
\hline
\end{tabular}




\begin{tabular}{|c|c|c|c|c|c|c|c|c|c|c|}
\hline Site No. & $\begin{array}{c}\text { Shovel Test } \\
\text { No. }\end{array}$ & Level & $\begin{array}{l}\text { Depth } \\
\text { (cmbs) }\end{array}$ & $\begin{array}{c}\text { Munsell Soil } \\
\text { value }\end{array}$ & $\begin{array}{l}\text { Munsell Soil } \\
\text { Color }\end{array}$ & Soil Texture & $\begin{array}{c}\text { Inclusion } \\
\text { Percentage }\end{array}$ & Inclusion Type & $\begin{array}{c}\text { Positive (P) } \\
\text { or Negative } \\
\text { (N) }\end{array}$ & Comments/ Reason for Termination \\
\hline NA & DPR31 & 1 & $0-40$ & 10YR $3 / 4$ & $\begin{array}{l}\text { dark yellowish } \\
\text { brown }\end{array}$ & Silty Clay Loam & $5-10 \%$ & Cobbles & $\mathrm{N}$ & $\begin{array}{l}\text { Terminated at compact large ( } 15 \mathrm{~cm} \text { diameter) } \\
\text { cobbles. }\end{array}$ \\
\hline NA & DPR32 & 1 & $0-40$ & 10YR $3 / 4$ & $\begin{array}{c}\text { dark yellowish } \\
\text { brown }\end{array}$ & Silty Clay Loam & $5-10 \%$ & Cobbles & $\mathrm{N}$ & $\begin{array}{c}\text { Terminated at compact large (15 cm diameter) } \\
\text { cobbles. }\end{array}$ \\
\hline NA & DPR33 & 1 & $0-15$ & 10YR $3 / 4$ & $\begin{array}{l}\text { dark yellowish } \\
\text { brown }\end{array}$ & Silty Clay Loam & $5-10 \%$ & $\begin{array}{l}\text { Cobbles, Large Rock } \\
\text { Frags }\end{array}$ & $\mathrm{N}$ & Terminated at compacted large cobble layer. \\
\hline NA & DPR34 & 1 & $0-15$ & 10YR $3 / 4$ & $\begin{array}{l}\text { dark yellowish } \\
\text { brown }\end{array}$ & Silty Clay Loam & $5-10 \%$ & $\begin{array}{l}\text { Cobbles, Large Rock } \\
\text { Frags }\end{array}$ & $\mathrm{N}$ & Terminated at compacted large cobble layer. \\
\hline NA & DPR35 & 1 & $0-40$ & 10YR $3 / 4$ & $\begin{array}{l}\text { dark yellowish } \\
\text { brown }\end{array}$ & Silty Clay Loam & $5-10 \%$ & $\begin{array}{l}\text { Cobbles, Large Rock } \\
\text { Frags }\end{array}$ & $\mathrm{N}$ & Terminated at compacted large cobble layer. \\
\hline \multirow[t]{2}{*}{ NA } & \multirow[t]{2}{*}{ DPR36 } & 1 & $0-20$ & 10YR $6 / 4$ & $\begin{array}{l}\text { light yellowish } \\
\text { brown }\end{array}$ & Sandy Loam & $5-10 \%$ & Cobbles, Pebbles & $\mathrm{N}$ & - \\
\hline & & 2 & $20-30$ & 5YR $5 / 8$ & yellowish red & Sandy Clay & $1-5 \%$ & Cobbles, Pebbles & $\mathrm{N}$ & Terminated at basal clay. \\
\hline NA & DPR37 & 1 & $0-15$ & 10YR $3 / 4$ & $\begin{array}{l}\text { dark yellowish } \\
\text { brown }\end{array}$ & Silty Clay Loam & $5-10 \%$ & $\begin{array}{l}\text { Cobbles, Large Rock } \\
\text { Frags }\end{array}$ & $\mathrm{N}$ & Terminated at compacted large cobble layer. \\
\hline NA & DPR38 & 1 & $0-20$ & 10YR $3 / 4$ & $\begin{array}{l}\text { dark yellowish } \\
\text { brown }\end{array}$ & Silty Clay Loam & $5-10 \%$ & $\begin{array}{l}\text { Cobbles, Large Rock } \\
\text { Frags }\end{array}$ & $\mathrm{N}$ & Terminated at compacted large cobble layer. \\
\hline NA & DPR39 & 1 & $0-8$ & 10YR $3 / 4$ & $\begin{array}{l}\text { dark yellowish } \\
\text { brown }\end{array}$ & Silty Clay Loam & $5-10 \%$ & $\begin{array}{l}\text { Cobbles, Large Rock } \\
\text { Frags }\end{array}$ & $\mathrm{N}$ & Terminated at compacted large cobble layer. \\
\hline NA & DPR40 & 1 & $0-15$ & 10YR $5 / 4$ & yellowish brown & Silty Clay Loam & $10-20 \%$ & $\begin{array}{l}\text { Cobbles, Gravels, } \\
\text { Pebbles }\end{array}$ & $\mathrm{N}$ & $\begin{array}{l}\text { Terminated at compact bed of river gravels and } \\
\text { cobbles. }\end{array}$ \\
\hline NA & DPR41 & 1 & $0-20$ & 10YR $3 / 4$ & $\begin{array}{l}\text { dark yellowish } \\
\text { brown }\end{array}$ & Silty Clay Loam & $5-10 \%$ & $\begin{array}{l}\text { Cobbles, Large Rock } \\
\text { Frags }\end{array}$ & $\mathrm{N}$ & Terminated at compacted large cobble layer. \\
\hline NA & DPR42 & 1 & $0-30$ & 10YR 3/4 & $\begin{array}{c}\text { dark yellowish } \\
\text { brown }\end{array}$ & Silty Clay Loam & $5-10 \%$ & $\begin{array}{l}\text { Cobbles, Large Rock } \\
\text { Frags }\end{array}$ & $\mathrm{N}$ & Terminated at compacted large cobble layer. \\
\hline NA & DPR43 & 1 & $0-15$ & 10YR $3 / 4$ & $\begin{array}{l}\text { dark yellowish } \\
\text { brown }\end{array}$ & Silty Clay Loam & $5-10 \%$ & $\begin{array}{l}\text { Cobbles, Large Rock } \\
\text { Frags }\end{array}$ & $\mathrm{N}$ & Terminated at compacted large cobble layer. \\
\hline NA & DPR44 & 1 & $0-15$ & 10YR $3 / 4$ & $\begin{array}{l}\text { dark yellowish } \\
\text { brown }\end{array}$ & Silty Clay Loam & $5-10 \%$ & $\begin{array}{l}\text { Cobbles, Large Rock } \\
\text { Frags }\end{array}$ & $\mathrm{N}$ & Terminated at compacted large cobble layer. \\
\hline $\mathrm{NA}$ & DR1001 & 1 & $0-100$ & 10YR 5/1 & gray & Silty Clay & - & - & $\mathrm{N}$ & Terminated at depth. \\
\hline \multirow{2}{*}{ NA } & \multirow{2}{*}{ DR1002 } & 1 & $0-60$ & 10YR $5 / 2$ & grayish brown & Silty Clay & $10-20 \%$ & Mottles, Pebbles & $\mathrm{N}$ & - \\
\hline & & 2 & $60-70$ & 10YR $5 / 2$ & grayish brown & Clay & $1-5 \%$ & Pebbles & $\mathrm{N}$ & Terminated at compact soil. \\
\hline \multirow{2}{*}{ NA } & \multirow{2}{*}{ DR1003 } & 1 & $0-60$ & 10YR 5/2 & grayish brown & Silty Clay & $10-20 \%$ & Mottles, Pebbles & $\mathrm{N}$ & - \\
\hline & & 2 & $60-70$ & 10YR 5/2 & grayish brown & Clay & $1-5 \%$ & Pebbles & $\mathrm{N}$ & Terminated at compact soil. \\
\hline \multirow{2}{*}{ NA } & \multirow{2}{*}{ DR1004 } & 1 & $0-30$ & 10YR $3 / 4$ & $\begin{array}{l}\text { dark yellowish } \\
\text { brown }\end{array}$ & Silty Clay Loam & $5-10 \%$ & Cobbles, Pebbles & $\mathrm{N}$ & - \\
\hline & & 2 & $30-40$ & 10YR $5 / 2$ & grayish brown & Silty Clay Loam & $5-10 \%$ & $\begin{array}{l}\text { Calcium Carbonate, } \\
\text { Pebbles }\end{array}$ & $\mathrm{N}$ & Terminated at basal clay. \\
\hline \multirow{2}{*}{ NA } & \multirow{2}{*}{ DR1005 } & 1 & $0-30$ & 10YR $3 / 4$ & $\begin{array}{l}\text { dark yellowish } \\
\text { brown }\end{array}$ & Silty Clay Loam & $5-10 \%$ & Cobbles, Pebbles & $\mathrm{N}$ & - \\
\hline & & 2 & $30-40$ & 10YR $5 / 2$ & grayish brown & Silty Clay Loam & $5-10 \%$ & $\begin{array}{l}\text { Calcium Carbonate, } \\
\text { Pebbles }\end{array}$ & $\mathrm{N}$ & Terminated at basal clay. \\
\hline \multirow{2}{*}{ NA } & \multirow{2}{*}{ DR1006 } & 1 & $0-10$ & 10YR $3 / 4$ & $\begin{array}{c}\text { dark yellowish } \\
\text { brown }\end{array}$ & Silty Clay Loam & $5-10 \%$ & Cobbles, Pebbles & $\mathrm{N}$ & - \\
\hline & & 2 & $10-50$ & 10YR $5 / 2$ & grayish brown & Silty Clay Loam & $5-10 \%$ & $\begin{array}{l}\text { Calcium Carbonate, } \\
\text { Pebbles }\end{array}$ & $\mathrm{N}$ & Terminated at basal clay. \\
\hline \multirow{2}{*}{ NA } & \multirow{2}{*}{ DR1007 } & 1 & $0-30$ & 10YR $3 / 4$ & $\begin{array}{l}\text { dark yellowish } \\
\text { brown }\end{array}$ & Silty Clay Loam & $5-10 \%$ & Cobbles, Pebbles & $\mathrm{N}$ & - \\
\hline & & 2 & $30-40$ & 10YR $5 / 2$ & grayish brown & Silty Clay Loam & $5-10 \%$ & $\begin{array}{l}\text { Calcium Carbonate, } \\
\text { Pebbles }\end{array}$ & $\mathrm{N}$ & Terminated at basal clay. \\
\hline \multirow{3}{*}{ NA } & & 1 & $0-20$ & 10YR 4/1 & dark gray & Silty Clay Loam & $1-5 \%$ & Pebbles & $\mathrm{N}$ & - \\
\hline & DR1008 & 2 & $20-50$ & 10YR 2/1 & black & Silty Clay & $1-5 \%$ & Gravels, Pebbles & $\mathrm{N}$ & - \\
\hline & & 3 & $50-60$ & 10YR 2/1 & black & Clay & $5-10 \%$ & $\begin{array}{l}\text { Pebbles, Very Coarse } \\
\text { grain sand }\end{array}$ & $\mathrm{N}$ & Terminated at compact soil. \\
\hline 41BP961 & DR1009 & 1 & $0-35$ & 10YR $4 / 4$ & $\begin{array}{l}\text { dark yellowish } \\
\text { brown }\end{array}$ & Sandy Clay Loam & $10-20 \%$ & $\begin{array}{l}\text { Cobbles, Gravels, } \\
\text { Pebbles }\end{array}$ & $\mathrm{N}$ & Terminated at compact soil. \\
\hline 41BP961 & DR1010 & 1 & $0-30$ & 7.5YR 2.5/1 & black & Silty Clay & $5-10 \%$ & $\begin{array}{l}\text { Cobbles, Gravels, } \\
\text { Mottles, Pebbles }\end{array}$ & $\mathrm{N}$ & Terminated at disturbed soil. \\
\hline & & 1 & $0-50$ & 10YR 5/6 & yellowish brown & Sandy Loam & - & - & $\mathrm{N}$ & - \\
\hline NA & JFA01 & 2 & $50-65$ & 10YR 5/8 & yellowish brown & Sandy Clay Loam & - & - & $\mathrm{N}$ & - \\
\hline & & 3 & $65-70$ & 10YR $6 / 8$ & brownish yellow & Sandy Clay & - & - & $\mathrm{N}$ & Terminated at basal clay. \\
\hline NA & JFA01 & 1 & $0-65$ & $2.5 Y 4 / 2$ & dark grayish brown & Silty Clay & - & - & $\mathrm{N}$ & Terminated at tree root. \\
\hline$\overline{N A}$ & JFA02 & 1 & $0-10$ & 7.5 YR $5 / 8$ & strong brown & Sandy Clay & $>20 \%$ & Mottles & $\bar{N}$ & Terminated at compact soil. \\
\hline NA & JFA02 & 1 & $0-65$ & 10YR 4/1 & dark gray & Silty Clay & $1-5 \%$ & Pebbles & $\mathrm{N}$ & Terminated at compact soil. \\
\hline NA & JFA03 & 1 & $0-100$ & 10YR $6 / 4$ & $\begin{array}{l}\text { light yellowish } \\
\text { brown }\end{array}$ & Sand & $1-5 \%$ & Pebbles & $\mathrm{N}$ & Terminated at depth. \\
\hline NA & JFA03 & 1 & $0-85$ & 10YR $4 / 1$ & dark gray & Silty Clay & $10-20 \%$ & $\begin{array}{l}\text { Calcium Carbonate, } \\
\text { Cobbles, Pebbles }\end{array}$ & $\mathrm{N}$ & Terminated at compact soil. \\
\hline NA & JFA04 & 1 & $0-100$ & 10YR $6 / 4$ & $\begin{array}{l}\text { light yellowish } \\
\text { brown }\end{array}$ & Sand & $1-5 \%$ & Pebbles & $\mathrm{N}$ & Terminated at depth. \\
\hline $\mathrm{NA}$ & JFA04 & 1 & $0-30$ & 10YR 4/1 & dark gray & Silty Clay & $>20 \%$ & Cobbles, Pebbles & $\mathrm{N}$ & Terminated at compact chert and soil. \\
\hline NA & JFA05 & 1 & $0-100$ & 10YR $6 / 4$ & $\begin{array}{l}\text { light yellowish } \\
\text { brown }\end{array}$ & Sand & $1-5 \%$ & Pebbles & $\mathrm{N}$ & Terminated at depth. \\
\hline NA & JFA05 & 1 & $0-85$ & 10YR $4 / 1$ & dark gray & Silty Clay & $10-20 \%$ & $\begin{array}{l}\text { Calcium Carbonate, } \\
\text { Cobbles, Pebbles }\end{array}$ & $\mathrm{N}$ & Terminated at compact soil. \\
\hline NA & JFA06 & 1 & $0-10$ & 10YR 5/8 & yellowish brown & Sandy Clay & $1-5 \%$ & Pebbles & $\mathrm{N}$ & Terminated at basal clay. \\
\hline NA & JFA06 & 1 & $0-60$ & 10YR $2 / 1$ & black & Silty Clay & - & - & $\mathrm{N}$ & Terminated at compact soil. \\
\hline $41 \mathrm{CM} 401$ & JFA07 & 1 & $0-5$ & 10YR $2 / 2$ & very dark brown & Silty Clay & $>20 \%$ & Gravels, Mottles, Pebbles & $\mathrm{N}$ & Terminated at bedrock. \\
\hline NA & JFA07 & 1 & $0-10$ & 10YR 2/2 & very dark brown & Silt Loam & $>20 \%$ & Cobbles, Pebbles & $\mathrm{N}$ & Terminated at compact chert. \\
\hline $41 \mathrm{CM} 401$ & JFA08 & 1 & $0-30$ & 5YR $3 / 2$ & dark reddish brown & Silty Clay Loam & $5-10 \%$ & Cobbles, Pebbles & $\mathrm{N}$ & Terminated at bedrock. \\
\hline NA & JFA08 & 1 & $0-50$ & 10YR 2/1 & black & Silty Clay & $1-5 \%$ & Pebbles & $\mathrm{N}$ & Terminated at compact soil. \\
\hline 41CM401 & JFA09 & 1 & 1-15 & $5 Y R 3 / 2$ & dark reddish brown & Silty Clay Loam & $10-20 \%$ & Cobbles, Mottles, Pebbles & $\mathrm{N}$ & Terminated at bedrock. \\
\hline $\mathrm{NA}$ & JFA09 & 1 & $0-50$ & 10YR 2/1 & black & Silty Clay & $1-5 \%$ & Pebbles & $\mathrm{N}$ & Terminated at compact soil. \\
\hline 41CM401 & JFA10 & 1 & $0-15$ & 10YR 2/2 & very dark brown & Silty Clay Loam & $5-10 \%$ & Cobbles, Pebbles & $\mathrm{N}$ & Terminated at bedrock. \\
\hline NA & JFA10 & 1 & $0-30$ & 7.5YR $2.5 / 1$ & black & Silty Clay & $5-10 \%$ & $\begin{array}{l}\text { Cobbles, Gravels, } \\
\text { Mottles, Pebbles }\end{array}$ & $\mathrm{N}$ & Terminated at disturbed soil. \\
\hline 41CM401 & JFA11 & 1 & $0-30$ & 10YR 2/2 & very dark brown & Silty Clay Loam & $>20 \%$ & Cobbles, Pebbles & $\mathrm{N}$ & Terminated at bedrock. \\
\hline
\end{tabular}




\begin{tabular}{|c|c|c|c|c|c|c|c|c|c|c|}
\hline Site No. & $\begin{array}{c}\text { Shovel Test } \\
\text { No. }\end{array}$ & Level & $\begin{array}{l}\text { Depth } \\
\text { (cmbs) }\end{array}$ & $\left|\begin{array}{c}\text { Munsell Soil } \\
\text { value }\end{array}\right|$ & $\begin{array}{l}\text { Munsell Soil } \\
\text { Color }\end{array}$ & Soil Texture & $\begin{array}{l}\text { Inclusion } \\
\text { Percentage }\end{array}$ & Inclusion Type & $\begin{array}{l}\text { Positive (P) } \\
\text { or Negative } \\
\text { (N) }\end{array}$ & Comments/ Reason for Termination \\
\hline NA & JFA11 & 1 & $0-45$ & 10YR 5/2 & grayish brown & Silty Clay & $5-10 \%$ & $\begin{array}{l}\text { Calcium Carbonate, } \\
\text { Gravels, Pebbles }\end{array}$ & $\mathrm{N}$ & Terminated at basal clay. \\
\hline \multirow[b]{2}{*}{ 41CM401 } & \multirow[b]{2}{*}{ JFA12 } & 1 & $0-30$ & 10YR 2/2 & very dark brown & Clay & $5-10 \%$ & Cobbles, Pebbles & $\mathrm{N}$ & - \\
\hline & & 2 & $30-50$ & 10YR $3 / 6$ & $\begin{array}{l}\text { dark yellowish } \\
\text { brown }\end{array}$ & Clay & $5-10 \%$ & Cobbles, Pebbles & $\mathrm{N}$ & Terminated at basal clay. \\
\hline 41CM401 & JFA12 & 1 & $0-50$ & 10YR 2/1 & black & Silty Clay & $1-5 \%$ & Pebbles & $\mathrm{N}$ & Terminated at compact soil. \\
\hline \multirow[b]{2}{*}{ 41CM401 } & \multirow[b]{2}{*}{ JFA13 } & 1 & $0-30$ & 10YR 2/2 & very dark brown & Clay & $5-10 \%$ & Cobbles, Pebbles & $\mathrm{N}$ & 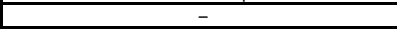 \\
\hline & & 2 & $30-50$ & 10YR 3/6 & $\begin{array}{c}\text { dark yellowish } \\
\text { brown }\end{array}$ & Clay & $5-10 \%$ & Cobbles, Pebbles & $\mathrm{N}$ & Terminated at basal clay. \\
\hline NA & JFA13 & 1 & $0-30$ & 10YR 2/2 & very dark brown & Silt Loam & $>20 \%$ & $\begin{array}{l}\text { Cobbles, Gravels, } \\
\text { Pebbles }\end{array}$ & $\mathrm{N}$ & Terminated at compact chert. \\
\hline $\mathrm{NA}$ & JFA14 & 1 & $0-50$ & 10YR 2/2 & very dark brown & Clay & $1-5 \%$ & Cobbles, Pebbles & $\mathrm{N}$ & Terminated at compact soil. \\
\hline NA & JFA14 & 1 & $0-30$ & 10YR $2 / 2$ & very dark brown & Silt Loam & $>20 \%$ & $\begin{array}{l}\text { Cobbles, Gravels, } \\
\text { Pebbles }\end{array}$ & $\mathrm{N}$ & Terminated at compact chert. \\
\hline NA & JFA15 & 1 & $0-50$ & 10YR $2 / 2$ & very dark brown & Clay & $1-5 \%$ & Cobbles, Pebbles & $\mathrm{N}$ & Terminated at compact soil. \\
\hline NA & JFA15 & 1 & $0-45$ & $2.5 Y 4 / 2$ & dark grayish brown & Silty Clay Loam & $5-10 \%$ & Cobbles, Pebbles & N & Terminated at compact soil. \\
\hline NA & JFA16 & 1 & $0-60$ & $2.5 Y 3 / 2$ & \begin{tabular}{|c|}
$\begin{array}{c}\text { very dark grayish } \\
\text { brown }\end{array}$ \\
\end{tabular} & Silty Clay & $1-5 \%$ & Pebbles & $\mathrm{N}$ & Terminated at compact soil. \\
\hline NA & JFA17 & 1 & $0-60$ & $2.5 Y 3 / 2$ & $\begin{array}{c}\text { very dark grayish } \\
\text { brown }\end{array}$ & Silty Clay & $1-5 \%$ & Pebbles & N & Terminated at compact soil. \\
\hline \multirow{3}{*}{ 41CM401 } & \multirow{3}{*}{ JIS02 } & 1 & $0-5$ & 10YR $4 / 4$ & $\begin{array}{l}\text { dark yellowish } \\
\text { brown }\end{array}$ & Sandy Loam & $10-20 \%$ & Mottles, Pebbles & $P$ & One biface. \\
\hline & & 2 & $5-20$ & 10YR 2/2 & very dark brown & Silty Clay & $1-5 \%$ & Pebbles & $\mathrm{N}$ & - \\
\hline & & 3 & $20-50$ & $5 Y R 3 / 2$ & dark reddish brown & Silty Clay & $1-5 \%$ & Pebbles & N & Terminated at bedrock. \\
\hline $41 \mathrm{CM} 401$ & JIS03 & 1 & $0-25$ & 10YR 5/8 & yellowish brown & Sandy Clay Loam & $1-5 \%$ & Mottles, Pebbles & $\mathrm{N}$ & Terminated at disturbance. \\
\hline $41 \mathrm{CM} 401$ & JIS04 & 1 & $0-30$ & 10YR 3/1 & very dark gray & Silty Clay & $5-10 \%$ & $\begin{array}{l}\text { Cobbles, Gravels, } \\
\text { Pebbles }\end{array}$ & $\mathrm{Y}$ & $\begin{array}{l}\text { 1: Core, Flake (primary), Flake (secondary), } \\
\text { Flake (tertiary), Glass [All artifacts b/w } 0-10 \\
\text { cmbs] Terminated at impenetrable cobbles. }\end{array}$ \\
\hline 41CM401 & JIS05 & 1 & $0-70$ & 10YR 3/1 & very dark gray & Clay & $1-5 \%$ & Pebbles & $\mathrm{N}$ & Terminated at compact soil. \\
\hline IF12 & JIS06 & 1 & $0-40$ & 10YR 2/2 & very dark brown & Clay & $5-10 \%$ & Cobbles, Gravels & Y & $\begin{array}{l}\text { 1: Flake (primary) [Primary flake observed } 10-20 \\
\text { cmbs] Terminated at basal clay. }\end{array}$ \\
\hline NA & JIS07 & 1 & $0-40$ & 10YR 2/2 & very dark brown & Clay & $5-10 \%$ & Cobbles, Gravels & $\mathrm{N}$ & Terminated at basal clay. \\
\hline \multirow{3}{*}{ NA } & \multirow{3}{*}{ JIS08 } & 1 & $0-30$ & $7.5 Y R 4 / 4$ & brown & Sand & $1-5 \%$ & Pebbles & $\mathrm{N}$ & - \\
\hline & & 2 & $30-65$ & 7.5 YR $5 / 6$ & strong brown & Sand & & Pebbles & $\mathrm{N}$ & - \\
\hline & & 3 & $65-80$ & 5YR $5 / 8$ & yellowish red & Sand & $>20 \%$ & $\begin{array}{l}\text { Cobbles, Gravels, } \\
\text { Pebbles }\end{array}$ & $\mathrm{N}$ & Terminated at stream rolled gravel and cobbles. \\
\hline \multirow{3}{*}{ NA } & \multirow{3}{*}{ JIS09 } & 1 & $0-20$ & 10YR 4/3 & brown & Sand & 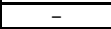 & 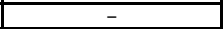 & $\mathrm{N}$ & $\begin{array}{c}- \\
\end{array}$ \\
\hline & & 2 & $20-55$ & 10YR $6 / 6$ & brownish yellow & Sand & - & 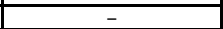 & $\mathrm{N}$ & - \\
\hline & & 3 & $55-100$ & 7.5 YR $6 / 8$ & reddish yellow & Sand & - & - & $\mathrm{N}$ & Terminated at depth. \\
\hline & & 1 & $0-10$ & 10YR $3 / 3$ & dark brown & Sandy Loam & - & - & $\mathrm{Y}$ & 1: Flake (tertiary) \\
\hline IF14 & JIS10 & 2 & $10-50$ & 10YR $7 / 6$ & yellow & Sand & - & - & $\mathrm{Y}$ & $\begin{array}{l}\text { 1: Flake (tertiary) [Tertiary flake observed } \\
\text { approximately } 40-50 \mathrm{cmbs} \text { ] }\end{array}$ \\
\hline & & 3 & $50-70$ & 10YR 6/4 & $\begin{array}{c}\text { light yellowish } \\
\text { brown }\end{array}$ & Sandy Clay & $1-5 \%$ & Mottles & N & Terminated at basal clay. \\
\hline & & 1 & $0-30$ & 10YR 3/2 & $\begin{array}{c}\text { very dark grayish } \\
\text { brown }\end{array}$ & Loamy Sand & $1-5 \%$ & Snail Shell & $\mathrm{N}$ & - \\
\hline 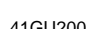 & NS11 & 2 & $30-60$ & 10YR $4 / 3$ & brown & Loamy Sand & $1-5 \%$ & Snail Shell & $\mathrm{N}$ & - \\
\hline $41 G U 200$ & JIS17 & 3 & $60-80$ & 10YR 5/4 & yellowish brown & Sand & $1-5 \%$ & Snail Shell & $\mathrm{N}$ & - \\
\hline & & 4 & $80-100$ & 10YR $6 / 4$ & $\begin{array}{l}\text { light yellowish } \\
\text { brown }\end{array}$ & Sand & $5-10 \%$ & $\begin{array}{c}\begin{array}{c}\text { Calcium Carbonate, Snail } \\
\text { Shell }\end{array} \\
\end{array}$ & $\mathrm{N}$ & Terminated at depth. \\
\hline & & 1 & $0-30$ & 10YR 3/2 & $\begin{array}{c}\text { very dark grayish } \\
\text { brown }\end{array}$ & Loamy Sand & $1-5 \%$ & Pebbles, Snail Shell & $\mathrm{N}$ & - \\
\hline 41G & NS12 & 2 & $30-60$ & 10YR $4 / 3$ & brown & Loamy Sand & $1-5 \%$ & Pebbles, Snail Shell & $\mathrm{Y}$ & 1: Flake (secondary) \\
\hline $41 G U 200$ & JIST2 & 3 & $60-80$ & 10YR 5/4 & yellowish brown & Sand & $1-5 \%$ & Snail Shell & $\mathrm{N}$ & - \\
\hline & & 4 & $80-100$ & 10YR $6 / 4$ & $\begin{array}{l}\text { light yellowish } \\
\text { brown }\end{array}$ & Sand & $1-5 \%$ & Snail Shell & $\mathrm{N}$ & Terminated at depth. \\
\hline & & 1 & $0-10$ & 10YR 3/3 & dark brown & Sandy Loam & $1-5 \%$ & Snail Shell & $\mathrm{N}$ & - \\
\hline $41 G U 200$ & IS13 & 2 & $20-50$ & 10YR 5/6 & yellowish brown & Loamy Sand & $1-5 \%$ & Snail Shell & $\mathrm{N}$ & 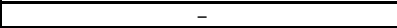 \\
\hline & & 3 & $50-90$ & 10YR 4/3 & brown & Loamy Sand & $1-5 \%$ & Snail Shell & $\mathrm{N}$ & - \\
\hline & & 4 & $90-100$ & 10 YR $6 / 3$ & pale brown & Sand & - & - & $\mathrm{N}$ & Terminated at depth. \\
\hline & & 1 & $0-20$ & 10YR 2/1 & black & Loamy Sand & $5-10 \%$ & Mottles, Charcoal & $\mathrm{N}$ & - \\
\hline$N A$ & IIS14 & 2 & $20-50$ & 10YR 5/6 & yellowish brown & Loamy Sand & - & - & $\mathrm{N}$ & - \\
\hline NA & JIS14 & 3 & $50-90$ & 10YR 4/3 & brown & Sandy Clay & 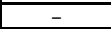 & 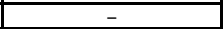 & $\mathrm{N}$ & - \\
\hline & & 4 & $90-100$ & 10YR $5 / 4$ & yellowish brown & Sand & - & 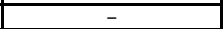 & $\mathrm{N}$ & Terminated at depth. \\
\hline & & 1 & $0-10$ & 10YR $3 / 3$ & dark brown & Sand & - & - & $\mathrm{N}$ & - \\
\hline NA & JIS15 & 2 & $10-30$ & 10YR $4 / 6$ & $\begin{array}{l}\text { dark yellowish } \\
\text { brown }\end{array}$ & Sand & - & - & $\mathrm{N}$ & - \\
\hline & & 3 & $30-40$ & 5 YYR $5 / 8$ & yellowish red & Sandy Clay & - & - & $\mathrm{N}$ & Terminated at basal clay. \\
\hline NA & JIS16 & 1 & $0-10$ & 10YR $4 / 4$ & $\begin{array}{l}\text { dark yellowish } \\
\text { brown }\end{array}$ & Loamy Sand & - & - & $\mathrm{N}$ & - \\
\hline NA & JIS16 & 2 & $10-60$ & 10YR 5/6 & yellowish brown & Sand & - & - & $\mathrm{N}$ & - \\
\hline & & 3 & $60-100$ & 10 YR $6 / 6$ & brownish yellow & Sand & 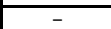 & 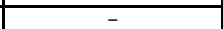 & $\mathrm{N}$ & Terminated at depth. \\
\hline & & 1 & $0-25$ & 10YR $5 / 3$ & brown & Sandy Loam & - & 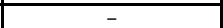 & $\mathrm{N}$ & - \\
\hline NA & JL10 & 2 & $25-45$ & 10YR 4/3 & brown & Sandy Clay & - & 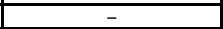 & $\mathrm{N}$ & - \\
\hline & & 3 & $45-55$ & $2.5 Y R 3 / 6$ & dark red & Clay & - & - & $\mathrm{N}$ & Terminated at basal clay. \\
\hline & & 1 & $0-35$ & 10 YR $5 / 3$ & brown & Sandy Loam & - & - & $\mathrm{N}$ & - \\
\hline NA & JL11 & 2 & $35-80$ & 10YR 4/3 & brown & Sandy Loam & - & 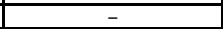 & $\mathrm{N}$ & $\begin{array}{c}- \\
\end{array}$ \\
\hline & & 3 & $80-90$ & 10YR $5 / 1$ & gray & Clay & 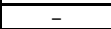 & 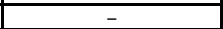 & $\mathrm{N}$ & Terminated at hydric clay. \\
\hline NA & ل12 & 1 & $0-65$ & 7.5 YR $4 / 6$ & strong brown & Sandy Loam & - & - & $\mathrm{N}$ & - \\
\hline & & 2 & $65-75$ & 10YR $5 / 2$ & grayish brown & Sandy Clay & - & $\begin{array}{ll}- \\
\end{array}$ & $\mathrm{N}$ & Terminated at hydric sandy clay. \\
\hline$N A$ & 13 & 1 & $0-75$ & 7.5 YR $5 / 4$ & brown & Sandy Loam & - & - & $\mathrm{N}$ & - \\
\hline NA & JL13 & 2 & $75-85$ & 10YR $7 / 6$ & yellow & Sandy Clay & - & - & $\mathrm{N}$ & Terminated at hydric clay. \\
\hline NA & $\| 14$ & 1 & $0-30$ & 10YR 4/3 & brown & Sandy Loam & $\begin{array}{c}- \\
\end{array}$ & 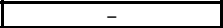 & $\mathrm{N}$ & - \\
\hline NA & JL14 & 2 & $30-40$ & 10YR $7 / 6$ & yellow & Sand & - & - & $\mathrm{N}$ & Terminated at root impasse. \\
\hline & & 1 & $0-35$ & 7.5 YR $5 / 6$ & strong brown & Sandy Loam & - & - & $\mathrm{N}$ & - \\
\hline NA & JL15 & 2 & $35-45$ & $2.5 Y R 3 / 4$ & dark reddish brown & Sandy Clay & - & - & $\mathrm{N}$ & Terminated at basal clay. \\
\hline
\end{tabular}




\begin{tabular}{|c|c|c|c|c|c|c|c|c|c|c|}
\hline Site No. & $\begin{array}{c}\text { Shovel Test } \\
\text { No. }\end{array}$ & Level & $\begin{array}{l}\text { Depth } \\
\text { (cmbs) }\end{array}$ & $\begin{array}{c}\text { Munsell Soil } \\
\text { value }\end{array}$ & $\begin{array}{l}\text { Munsell Soil } \\
\text { Color }\end{array}$ & Soil Texture & $\begin{array}{l}\text { Inclusion } \\
\text { Percentage }\end{array}$ & Inclusion Type & $\begin{array}{c}\text { Positive (P) } \\
\text { or Negative } \\
\text { (N) }\end{array}$ & Comments/ Reason for Termination \\
\hline \multirow{2}{*}{ NA } & \multirow{2}{*}{ JL16 } & 1 & $0-30$ & 10YR $5 / 8$ & yellowish brown & Sandy Loam & - & - & $\mathrm{N}$ & - \\
\hline & & 2 & $30-45$ & $7.5 Y R 4 / 3$ & brown & Sandy Clay & - & - & $\mathrm{N}$ & Terminated at hydric clay at $30 \mathrm{cmbs}$. \\
\hline \multirow{2}{*}{ NA } & \multirow{2}{*}{ JL17 } & 1 & $0-80$ & $7.5 Y R 5 / 4$ & brown & Sandy Loam & - & - & $\mathrm{N}$ & - \\
\hline & & 2 & $80-90$ & $2.5 Y R 3 / 4$ & dark reddish brown & Sandy Clay & - & - & $\mathrm{N}$ & Terminated at basal clay. \\
\hline \multirow{2}{*}{ NA } & \multirow{2}{*}{ JL18 } & 1 & $0-35$ & 7.5 YR $6 / 6$ & reddish yellow & Sandy Loam & - & - & $\mathrm{N}$ & - \\
\hline & & 2 & $35-45$ & $7.5 Y R 6 / 8$ & reddish yellow & Sandy Clay & - & - & $\mathrm{N}$ & Terminated at basal clay. \\
\hline \multirow{2}{*}{ NA } & \multirow{2}{*}{ JL19 } & 1 & $0-90$ & 10YR $4 / 4$ & $\begin{array}{l}\text { dark yellowish } \\
\text { brown }\end{array}$ & Sandy Loam & $1-5 \%$ & Gravels & $\mathrm{N}$ & - \\
\hline & & 2 & $90-100$ & 7.5 YR $4 / 6$ & strong brown & Sandy Clay Loam & - & - & $\mathrm{N}$ & Terminated at depth. \\
\hline \multirow{2}{*}{ NA } & \multirow{2}{*}{ JL20 } & 1 & $0-30$ & $7.5 Y R 4 / 4$ & brown & Sandy Loam & $1-5 \%$ & Pebbles & $\mathrm{N}$ & - \\
\hline & & 2 & $30-40$ & 7.5 YR $5 / 8$ & strong brown & Clay & 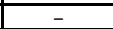 & 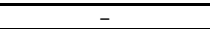 & $\mathrm{N}$ & Terminated at basal clay. \\
\hline & & 1 & $0-25$ & $10 \mathrm{YR} 4 / 3$ & brown & Sandy Loam & - & - & $\mathrm{N}$ & - \\
\hline NA & $\mathrm{JL} 21$ & 2 & $25-65$ & 10YR $6 / 4$ & $\begin{array}{l}\text { light yellowish } \\
\text { brown }\end{array}$ & Sandy Loam & $1-5 \%$ & Mottles & $\mathrm{N}$ & - \\
\hline & & 3 & $65-75$ & 7.5 YR $5 / 8$ & strong brown & Sandy Clay & $1-5 \%$ & Mottles & $\mathrm{N}$ & Terminated at basal clay. \\
\hline NA & $\| 20$ & 1 & $0-60$ & $7.5 Y R 4 / 4$ & brown & Sandy Loam & - & - & $\mathrm{N}$ & - \\
\hline NA & JL22 & 2 & $60-100$ & 7.5 YR $6 / 6$ & reddish yellow & Sandy Loam & - & - & $\mathrm{N}$ & Terminated at depth. \\
\hline & & 1 & $0-40$ & $10 \mathrm{YR} 5 / 3$ & brown & Sandy Loam & - & - & $\mathrm{N}$ & - \\
\hline NA & JL23 & 2 & $40-100$ & 10YR $6 / 4$ & $\begin{array}{l}\text { light yellowish } \\
\text { brown }\end{array}$ & Sandy Loam & - & - & $\mathrm{N}$ & Terminated at depth. \\
\hline NA & JU01 & 1 & $0-30$ & 10YR $3 / 2$ & \begin{tabular}{|c|}
$\begin{array}{c}\text { very dark grayish } \\
\text { brown }\end{array}$ \\
\end{tabular} & Clay Loam & $10-20 \%$ & Gravels, Mottles & $\mathrm{N}$ & Terminated at disturbance. \\
\hline NA & JU02 & 1 & $0-35$ & 10YR $4 / 2$ & dark grayish brown & Silty Clay Loam & $1-5 \%$ & Gravels & $\mathrm{N}$ & Terminated at compact soil. \\
\hline NA & JU03 & 1 & $0-25$ & 10YR 2/1 & black & Clay & $>20 \%$ & Cobbles, Gravels & $\mathrm{N}$ & Terminated at impassable cobbles. \\
\hline NA & $\mathrm{JU} 04$ & 1 & $0-35$ & 10YR $3 / 2$ & \begin{tabular}{|c|}
$\begin{array}{c}\text { very dark grayish } \\
\text { brown }\end{array}$ \\
\end{tabular} & Clay & $1-5 \%$ & Gravels & N & Terminated at compact soil. \\
\hline$\overline{N A}$ & JU05 & 1 & $0-25$ & 10YR 2/1 & black & Clay & $>20 \%$ & Cobbles, Gravels & $\mathrm{N}$ & Terminated at impassable cobbles. \\
\hline NA & KA01 & 1 & $0-47$ & 10YR 4/1 & dark gray & Silty Clay & $10-20 \%$ & Cobbles & $\mathrm{N}$ & Terminated at rock impasse. \\
\hline & & 1 & $0-7$ & $7.5 \mathrm{YR} 3 / 1$ & very dark gray & Silty Clay & $>20 \%$ & Cobbles & $\mathrm{N}$ & - \\
\hline NA & KA02 & 2 & $7-30$ & 10YR $4 / 1$ & dark gray & Silty Clay & $>20 \%$ & $\begin{array}{l}\text { Cobbles, Calcium } \\
\text { Carbonate }\end{array}$ & $\mathrm{N}$ & Terminated at compact soil. \\
\hline & & 1 & $0-7$ & $7.5 Y R 3 / 1$ & very dark gray & Silty Clay & $10-20 \%$ & Cobbles & $\mathrm{N}$ & - \\
\hline NA & KA03 & 2 & $7-30$ & 10YR 4/1 & dark gray & Silty Clay & $>20 \%$ & $\begin{array}{l}\text { Cobbles, Calcium } \\
\text { Carbonate }\end{array}$ & $\mathrm{N}$ & Terminated at compact soil. \\
\hline & & 1 & $0-12$ & $7.5 Y R 3 / 1$ & very dark gray & Silty Clay & $10-20 \%$ & Cobbles & $\mathrm{N}$ & - \\
\hline NA & KA04 & 2 & $12-15$ & 10YR $4 / 1$ & dark gray & Silty Clay & $>20 \%$ & $\begin{array}{l}\text { Cobbles, Calcium } \\
\text { Carbonate }\end{array}$ & $\mathrm{N}$ & Terminated at root impasse. \\
\hline NA & KA05 & 1 & $0-25$ & 10YR 3/1 & very dark gray & Silty Clay & $5-10 \%$ & Gravels & $\mathrm{N}$ & 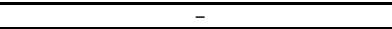 \\
\hline & & 2 & $25-30$ & 7.5 YR $3 / 1$ & very dark gray & Silty Clay & $5-10 \%$ & Gravels & $\mathrm{N}$ & Terminated at compact soil. \\
\hline NA & KA300 & 1 & $0-47$ & 10YR 4/1 & dark gray & Silty Clay & $10-20 \%$ & Cobbles & $\mathrm{N}$ & Terminated at rock impasse. \\
\hline & & 1 & $0-7$ & 7.5 YR $3 / 1$ & very dark gray & Silty Clay & $>20 \%$ & Cobbles & $\mathrm{N}$ & - \\
\hline NA & KA301 & 2 & $7-30$ & 10YR $4 / 1$ & dark gray & Silty Clay & $>20 \%$ & $\begin{array}{l}\text { Cobbles, Calcium } \\
\text { Carbonate }\end{array}$ & $\mathrm{N}$ & Terminated at compact soil. \\
\hline & & 1 & $0-7$ & $7.5 Y R 3 / 1$ & very dark gray & Silty Clay & $10-20 \%$ & Cobbles & $\mathrm{N}$ & - \\
\hline NA & КАЗ302 & 2 & $7-30$ & 10YR $4 / 1$ & dark gray & Silty Clay & $>20 \%$ & $\begin{array}{l}\text { Cobbles, Calcium } \\
\text { Carbonate }\end{array}$ & $\mathrm{N}$ & Terminated at compact soil. \\
\hline & & 1 & $0-12$ & 7.5 YR $3 / 1$ & very dark gray & Silty Clay & $10-20 \%$ & Cobbles & $\mathrm{N}$ & - \\
\hline NA & KA303 & 2 & $12-15$ & 10YR $4 / 1$ & dark gray & Silty Clay & $>20 \%$ & $\begin{array}{l}\text { Cobbles, Calcium } \\
\text { Carbonate }\end{array}$ & N & Terminated at root impasse. \\
\hline NA & KA304 & 1 & $0-25$ & 10YR 3/1 & very dark gray & Silty Clay & $5-10 \%$ & Gravels & $\mathrm{N}$ & - \\
\hline NA & KA304 & 2 & $25-30$ & $7.5 Y R 3 / 1$ & very dark gray & Silty Clay & $5-10 \%$ & Gravels & $\mathrm{N}$ & Terminated at compact soil. \\
\hline NA & KA305 & 1 & $0-50$ & 10YR 4/1 & dark gray & Silty Clay & $10-20 \%$ & Cobbles & $\mathrm{N}$ & Terminated at rock impasse. \\
\hline $\mathrm{NA}$ & KH01 & 1 & $0-100$ & 10YR $8 / 2$ & very pale brown & Sand & $1-5 \%$ & Pebbles & $\mathrm{N}$ & Terminated at depth. \\
\hline NA & KH02 & 1 & $0-100$ & 10YR $8 / 2$ & very pale brown & Sand & $1-5 \%$ & Pebbles & $\mathrm{N}$ & Terminated at depth. \\
\hline 545332 & $K H 05$ & 1 & $0-10$ & $10 Y R 5 / 2$ & grayish brown & Sand & $1-5 \%$ & Pebbles & $\mathrm{N}$ & - \\
\hline 41LE332 & KH05 & 2 & $10-100$ & $10 \mathrm{YR} 7 / 3$ & very pale brown & Sand & $1-5 \%$ & Pebbles & $\mathrm{N}$ & Terminated at depth. \\
\hline - & ( & 1 & $0-10$ & 10YR $6 / 2$ & light brownish gray & Sand & $1-5 \%$ & Pebbles & $\mathrm{N}$ & - \\
\hline & & 2 & $10-100$ & 10YR 8/2 & very pale brown & Sand & $1-5 \%$ & Pebbles, Petrified wood & $\mathrm{Y}$ & 2: Flake (tertiary) Terminated at depth. \\
\hline 41LE332 & KH07 & 1 & $0-100$ & 10YR $8 / 2$ & very pale brown & Sand & $1-5 \%$ & Pebbles, Petrified wood & $\mathrm{N}$ & Terminated at depth. \\
\hline & & 1 & $0-30$ & 10YR $8 / 2$ & very pale brown & Sand & $1-5 \%$ & Pebbles, Petrified wood & $\mathrm{N}$ & - \\
\hline 41LE332 & KH08 & 2 & $30-50$ & 7.5YR 6/6 & reddish yellow & Sandy Clay & $5-10 \%$ & $\begin{array}{c}\text { Cobbles, Gravels, } \\
\text { Pebbles }\end{array}$ & $\mathrm{N}$ & Terminated at basal clay. \\
\hline & & 1 & $0-10$ & 10YR $8 / 2$ & very pale brown & Sand & $5-10 \%$ & Gravels, Pebbles & $\mathrm{N}$ & - \\
\hline 41LE332 & KH09 & 2 & $10-40$ & 7.5 YR $6 / 6$ & reddish yellow & Sand & $>20 \%$ & $\begin{array}{c}\text { Cobbles, Gravels, } \\
\text { Decomposing bedrock }\end{array}$ & $\mathrm{N}$ & Terminated at decomposing bedrock. \\
\hline $41 \mathrm{LE} 332$ & $\mathrm{KH} 10$ & 1 & $0-100$ & 10YR $8 / 2$ & very pale brown & Sand & $1-5 \%$ & Pebbles & $\mathrm{N}$ & Terminated at depth. \\
\hline NA & KH50 & 1 & $0-100$ & 7.5 YR $5 / 4$ & brown & Sandy Loam & - & - & $\mathrm{N}$ & Terminated at depth. \\
\hline 41BU122 & KH51 & 1 & $0-100$ & 7.5YR 5/4 & brown & Sandy Loam & $1-5 \%$ & Pebbles & Y & $\begin{array}{l}\text { 9: Biface, Flake (tertiary) [3 tertiary flakes at } 20- \\
30 \mathrm{~cm} ; 2 \text { tertiary flakes and } 1 \text { biface fragment at } \\
50-60 \mathrm{~cm} \text {; and } 4 \text { tertiary flakes at } 70-80 \mathrm{~cm} \text {. } \\
\text { Terminated at depth. }\end{array}$ \\
\hline 41BU122 & KH52 & 1 & $0-50$ & $10 Y R 5 / 4$ & yellowish brown & Sandy Loam & $1-5 \%$ & Pebbles, Roots & $\mathrm{N}$ & - \\
\hline 41BU122 & KH52 & 2 & $50-60$ & 7.5 YR $5 / 8$ & strong brown & Sandy Clay & - & - & $\mathrm{N}$ & Terminated at compact soil. \\
\hline 41BU122 & KH53 & 1 & $0-100$ & 7.5 YR $5 / 4$ & brown & Sandy Loam & - & - & $\mathrm{N}$ & Terminated at depth. \\
\hline NA & KH54 & 1 & $0-100$ & $10 \mathrm{YR} 7 / 6$ & yellow & Sand & 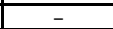 & - & $\mathrm{N}$ & Terminated at depth. \\
\hline NA & $K H 55$ & 1 & $0-60$ & 7.5 YR $5 / 3$ & brown & Sandy Loam & - & - & $\mathrm{N}$ & 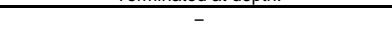 \\
\hline NA & KHS5 & 2 & $60-70$ & 7.5 YR $5 / 8$ & strong brown & Clay & - & - & $\mathrm{N}$ & Terminated at basal clay. \\
\hline NA & MCc50 & 1 & $0-30$ & 7.5YR $5 / 4$ & brown & Sandy Clay Loam & - & - & $\mathrm{N}$ & - \\
\hline & & 2 & $30-50$ & 7.5 YR $5 / 6$ & strong brown & Clay & - & - & $\mathrm{N}$ & Terminated at compact soil. \\
\hline AM & Mcc5 & $\frac{2}{1}$ & $0-60$ & 7.5 YR $5 / 4$ & brown & Sandy Loam & - & - & $\mathrm{N}$ & - \\
\hline NA & MCC51 & 2 & $60-75$ & 10 YR $5 / 2$ & grayish brown & Sandy Loam & - & 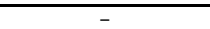 & $\mathrm{N}$ & Terminated at water table. \\
\hline & & 1 & $0-50$ & 7.5 YR $5 / 6$ & strong brown & Sandy Loam & $1-5 \%$ & Gravels & $\mathrm{N}$ & - \\
\hline NA & MCC52 & 2 & $50-80$ & 10YR 6/2 & light brownish gray & Sandy Clay & - & - & $\mathrm{N}$ & Terminated at compact soil. \\
\hline
\end{tabular}




\begin{tabular}{|c|c|c|c|c|c|c|c|c|c|c|}
\hline Site No. & $\begin{array}{c}\text { Shovel Test } \\
\text { No. }\end{array}$ & Level & $\begin{array}{l}\text { Depth } \\
\text { (cmbs) }\end{array}$ & $\begin{array}{c}\text { Munsell Soil } \\
\text { value }\end{array} \mid$ & $\begin{array}{l}\text { Munsell Soil } \\
\text { Color }\end{array}$ & Soil Texture & $\begin{array}{l}\text { Inclusion } \\
\text { Percentage }\end{array}$ & Inclusion Type & $\begin{array}{c}\text { Positive (P) } \\
\text { or Negative } \\
\text { (N) }\end{array}$ & Comments/ Reason for Termination \\
\hline \multirow[b]{2}{*}{ NA } & \multirow[b]{2}{*}{ MCC53 } & 1 & $0-50$ & 7.5 YR $5 / 6$ & strong brown & Sandy Loam & $1-5 \%$ & Gravels & $\mathrm{N}$ & - \\
\hline & & 2 & $50-80$ & 10YR $6 / 2$ & light brownish gray & Sandy Clay & - & - & $\mathrm{N}$ & Terminated at compact soil. \\
\hline \multirow{2}{*}{ NA } & \multirow{2}{*}{ MCC54 } & 1 & $0-50$ & 7.5YR 5/6 & strong brown & Sandy Loam & $1-5 \%$ & Gravels & $\mathrm{N}$ & - \\
\hline & & 2 & $50-80$ & 10YR $6 / 2$ & light brownish gray & Sandy Clay & - & - & $\mathrm{N}$ & Terminated at compact soil. \\
\hline 41LE332 & MCC75 & 1 & $0-100$ & 10YR 6/2 & light brownish gray & Sand & $1-5 \%$ & Pebbles & $\mathrm{N}$ & Terminated at depth. \\
\hline \multirow{2}{*}{ 41LE332 } & \multirow{2}{*}{ MCC76 } & 1 & $0-35$ & 10YR $6 / 2$ & light brownish gray & Sand & $1-5 \%$ & Gravels, Pebbles & $\mathrm{N}$ & - \\
\hline & & 2 & $35-100$ & 10YR 6/3 & pale brown & Sand & $1-5 \%$ & Gravels, Pebbles & $\mathrm{N}$ & Terminated at depth. \\
\hline 41LE332 & MCC77 & 1 & $0-40$ & 10YR 6/2 & light brownish gray & Sand & $5-10 \%$ & Gravels, Pebbles & $\mathrm{Y}$ & 1: Flake (tertiary) [Tertiary flake $20-40 \mathrm{cmbs}$.] \\
\hline & & 2 & $40-60$ & 7.5YR $5 / 8$ & strong brown & Sandy Clay & - & - & $\mathrm{N}$ & Terminated at basal clay. \\
\hline & & 1 & $0-30$ & 10YR $6 / 2$ & light brownish gray & Sand & $1-5 \%$ & Gravels, Pebbles & $\mathrm{Y}$ & 1: Flake (tertiary) [Tertiary flake $20-40 \mathrm{cmbs}$.] \\
\hline 41LE332 & MCC78 & 2 & $30-60$ & 7.5 YR $5 / 8$ & strong brown & Sandy Loam & $1-5 \%$ & Gravels, Pebbles & $\mathrm{Y}$ & 1: Flake (tertiary) [Tertiary flake $40-60 \mathrm{cmbs}$.] \\
\hline & & 3 & $60-100$ & 10YR $6 / 3$ & pale brown & Sandy Loam & - & - & $\mathrm{N}$ & Terminated at depth. \\
\hline 41LE332 & & 1 & $0-45$ & 10YR 5/2 & grayish brown & Sand & $5-10 \%$ & Gravels, Pebbles & $\mathrm{N}$ & - \\
\hline 4ILE332 & IVCCly & 2 & $45-50$ & 7.5 YR $5 / 8$ & strong brown & Sandy Clay & - & - & $\mathrm{N}$ & Terminated at basal clay. \\
\hline & & 1 & $0-30$ & 10YR $5 / 3$ & brown & Sandy Loam & - & - & $\mathrm{N}$ & - \\
\hline NA & MCC150 & 2 & $30-60$ & 10YR 4/3 & brown & Sandy Loam & - & - & $\mathrm{N}$ & - \\
\hline & & 3 & $60-70$ & 5YR $5 / 6$ & yellowish red & Sandy Clay Loam & - & - & $\mathrm{N}$ & Terminated at hydric. \\
\hline NA & MCC151 & 1 & $0-60$ & $7.5 \mathrm{YR} 6 / 6$ & reddish yellow & Sandy Loam & - & - & $\mathrm{N}$ & - \\
\hline TNA & 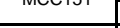 & 2 & $60-65$ & $2.5 \mathrm{YR} 4 / 6$ & red & Clay & $>20 \%$ & Mottles & $\mathrm{N}$ & Terminated at basal clay. \\
\hline NA & MCC152 & 1 & $0-60$ & 7.5YR $5 / 3$ & brown & Sandy Loam & $5-10 \%$ & Gravels & $\mathrm{N}$ & - \\
\hline & & 2 & $60-65$ & $2.5 \mathrm{YR} 4 / 6$ & red & Clay & $>20 \%$ & Mottles & $\mathrm{N}$ & Terminated at basal clay. \\
\hline NA & MCC153 & 1 & $0-55$ & 10YR 4/3 & brown & Sandy Loam & $1-5 \%$ & Gravels & $\mathrm{N}$ & - \\
\hline (1) & 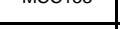 & 2 & $55-65$ & 7.5YR 5/6 & strong brown & Sandy Clay & - & - & $\mathrm{N}$ & Terminated at basal clay. \\
\hline NA & & 1 & $0-40$ & $7.5 Y R 4 / 4$ & brown & Sandy Loam & - & - & $\mathrm{N}$ & - \\
\hline NA & MICC 154 & 2 & $40-50$ & $7.5 Y R 4 / 6$ & strong brown & Clay & - & - & $\mathrm{N}$ & Terminated at basal clay. \\
\hline NA & MCC155 & 1 & $0-65$ & 7.5 YR $4 / 6$ & strong brown & Sandy Loam & - & - & $\mathrm{N}$ & - \\
\hline (1) & & 2 & $65-75$ & $2.5 \mathrm{YR} 4 / 6$ & red & Sandy Clay & - & - & $\mathrm{N}$ & Terminated at basal clay. \\
\hline$N A$ & MCC156 & 1 & $0-70$ & $7.5 Y R 4 / 4$ & brown & Sandy Loam & - & - & $\mathrm{N}$ & - \\
\hline NAT & 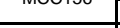 & 2 & $70-100$ & 7.5YR 5/6 & strong brown & Sandy Loam & - & - & $\mathrm{N}$ & Terminated at depth. \\
\hline NA & MCC157 & 1 & $0-65$ & $7.5 \mathrm{YR} 4 / 4$ & brown & Sandy Loam & - & - & $\mathrm{N}$ & - \\
\hline $\mathrm{INA}$ & IVIUCist & 2 & $65-75$ & 7.5 YR $5 / 6$ & strong brown & Sandy Clay & $>20 \%$ & Mottles & $\mathrm{N}$ & Terminated at hydric clay.. \\
\hline NA & MCC158 & 1 & $0-50$ & $7.5 Y R 5 / 4$ & brown & Sandy Loam & $1-5 \%$ & Pebbles & $\mathrm{N}$ & - \\
\hline . & (1900 & 2 & $50-60$ & 7.5YR 5/6 & strong brown & Clay & - & - & $\mathrm{N}$ & Terminated at basal clay. \\
\hline NA & MCC159 & 1 & $0-45$ & 10YR 4/2 & dark grayish brown & Clay & - & - & $\mathrm{N}$ & - \\
\hline & & 2 & $45-55$ & 7.5 YR $6 / 6$ & reddish yellow & Clay & $>20 \%$ & Mottles & $\mathrm{N}$ & Terminated at hydric clay. \\
\hline NA & MCC160 & 1 & $0-40$ & $7.5 Y R 4 / 4$ & brown & Sandy Loam & - & - & $\mathrm{N}$ & - \\
\hline $\mathrm{NAH}$ & IVUCIOU & 2 & $40-50$ & 7.5YR $5 / 8$ & strong brown & Clay & $>20 \%$ & Mottles & $\mathrm{N}$ & Terminated at hydric clay. \\
\hline & & 1 & $0-15$ & 10YR $5 / 3$ & brown & $\begin{array}{l}\text { Sandy Loam } \\
\end{array}$ & - & - & $\mathrm{N}$ & - \\
\hline NA & MCC161 & 2 & $15-60$ & 10YR 5/6 & yellowish brown & Sandy Loam & - & - & $\mathrm{N}$ & - \\
\hline & & 3 & $60-70$ & 7.5 YR $5 / 6$ & strong brown & Clay & - & - & $\mathrm{N}$ & Terminated at basal clay. \\
\hline & & 1 & $0-40$ & 10YR 5/3 & brown & Sandy Loam & - & - & $\mathrm{N}$ & - \\
\hline NA & MCC162 & 2 & $40-100$ & 10YR 6/4 & $\begin{array}{l}\text { light yellowish } \\
\text { brown }\end{array}$ & Sandy Loam & - & - & $\mathrm{N}$ & Terminated at depth. \\
\hline $\mathrm{NA}$ & MCC165 & 1 & $0-100$ & 7.5 YR $5 / 3$ & brown & Sandy Loam & $1-5 \%$ & Gravels & $\mathrm{N}$ & Terminated at depth. \\
\hline 41BU122 & MCC166 & 1 & $0-25$ & $7.5 Y R 5 / 3$ & brown & Sandy Loam & $1-5 \%$ & Gravels & $\mathrm{N}$ & - \\
\hline & & 2 & $25-35$ & 7.5YR 5/8 & strong brown & Clay & - & - & $\mathrm{N}$ & Terminated at basal clay. \\
\hline 41BU122 & MCC167 & 1 & $0-100$ & $7.5 Y R 5 / 3$ & brown & Sandy Loam & $1-5 \%$ & Gravels & $\mathrm{Y}$ & $\begin{array}{l}\text { 1: Flake (secondary) [Secondary flake b/w } 50- \\
60 \mathrm{cmbs} \text {.] Terminated at depth. }\end{array}$ \\
\hline 41BU122 & MCC168 & 1 & $0-50$ & 7.5YR $5 / 3$ & brown & Sandy Loam & $1-5 \%$ & Gravels & $\mathrm{N}$ & - \\
\hline $410012 \angle 2$ & FVUCloo & 2 & $50-60$ & $7.5 Y R 5 / 8$ & strong brown & Clay & - & - & $\mathrm{N}$ & Terminated at basal clay. \\
\hline NA & MCC169 & 1 & $0-40$ & 7.5 YR $5 / 3$ & brown & Sandy Loam & $1-5 \%$ & Gravels & $\mathrm{N}$ & - \\
\hline & & 2 & $40-50$ & 7.5YR 5/8 & strong brown & Sandy Clay & - & - & $\mathrm{N}$ & Terminated at basal clay. \\
\hline NA & MCc170 & 1 & $0-40$ & $7.5 Y R 5 / 3$ & brown & Sandy Loam & $1-5 \%$ & Gravels & $\mathrm{N}$ & - \\
\hline NA & S & 2 & $40-50$ & $7.5 Y R 5 / 8$ & strong brown & Sandy Clay & - & - & $\mathrm{N}$ & Terminated at basal clay. \\
\hline NA & MCC171 & 1 & $0-65$ & 10YR $5 / 3$ & brown & Sandy Loam & $1-5 \%$ & Gravels & $\mathrm{N}$ & - \\
\hline $\mathrm{TNA}$ & MUC-III & 2 & $65-75$ & 5YR 4/6 & yellowish red & Sandy Clay & $\begin{array}{ll}- \\
\end{array}$ & - & $\mathrm{N}$ & Terminated at basal clay. \\
\hline $\mathrm{NA}$ & MCC172 & 1 & $0-100$ & $7.5 Y R 5 / 4$ & brown & Sandy Loam & $1-5 \%$ & Gravels & $\mathrm{N}$ & Terminated at depth. \\
\hline NA & MCC173 & 1 & $0-65$ & 7.5 YR $5 / 4$ & brown & Sandy Loam & - & - & $\mathrm{N}$ & - \\
\hline NA & $\operatorname{IVCC} 173$ & 2 & $65-75$ & 10YR 7/1 & light gray & Sandy Clay & $>20 \%$ & Mottles & $\mathrm{N}$ & Terminated at basal clay. \\
\hline NA & MCC174 & 1 & $0-100$ & 7.5YR 5/4 & brown & Sandy Loam & - & - & $\mathrm{N}$ & Terminated at depth. \\
\hline NA & MCC175 & 1 & $0-100$ & $7.5 Y R 5 / 4$ & brown & Sandy Loam & - & - & $\mathrm{N}$ & Terminated at depth. \\
\hline NA & MCC176 & 1 & $0-65$ & 7.5YR 4/6 & strong brown & Sandy Loam & - & - & $\mathrm{N}$ & - \\
\hline & & 2 & $65-70$ & $2.5 \mathrm{YR} 4 / 6$ & red & Sandy Clay & - & - & $\mathrm{N}$ & Terminated at basal clay. \\
\hline NA & MCC177 & 1 & $0-60$ & 10YR 6/4 & $\begin{array}{c}\text { light yellowish } \\
\text { brown }\end{array}$ & Sandy Loam & - & - & $\mathrm{N}$ & Terminated at compact soil. \\
\hline $\mathrm{NA}$ & MCC178 & 1 & $0-25$ & 10YR 4/1 & dark gray & Clay & $>20 \%$ & Mottles & $\mathrm{N}$ & Terminated at compact soil. \\
\hline NA & MCc201 & 1 & $0-30$ & 10YR 4/3 & brown & Sandy Loam & - & - & $\mathrm{N}$ & - \\
\hline & & 2 & $30-75$ & 7.5YR 5/4 & brown & Sandy Loam & - & - & $\mathrm{N}$ & Terminated at water table. \\
\hline NA & MCс202 & 1 & $0-30$ & 10YR 4/3 & brown & Sandy Loam & - & - & $\mathrm{N}$ & - \\
\hline $\mathrm{TNA}$ & IVICLZOz & 2 & $30-75$ & 7.5 YR $5 / 4$ & brown & Sandy Loam & - & - & $\mathrm{N}$ & Terminated at water table. \\
\hline & & 1 & $0-30$ & 10YR 4/3 & brown & Sandy Loam & - & - & $\mathrm{N}$ & - \\
\hline NA & MCC203 & 2 & $30-75$ & 10YR $6 / 4$ & $\begin{array}{l}\text { light yellowish } \\
\text { brown }\end{array}$ & Sandy Loam & - & - & $\mathrm{N}$ & Terminated at wet hydric soil.. \\
\hline & & 1 & $0-30$ & 10YR 4/3 & brown & Sandy Loam & - & - & $\mathrm{N}$ & - \\
\hline NA & MCC204 & 2 & $30-75$ & 10YR $6 / 4$ & $\begin{array}{l}\text { light yellowish } \\
\text { brown }\end{array}$ & Sandy Loam & - & - & $\mathrm{N}$ & Terminated at wet hydric soil.. \\
\hline & & 1 & $0-30$ & 10YR 4/3 & brown & Sandy Loam & - & - & $\mathrm{N}$ & - \\
\hline NA & MCC205 & 2 & $30-75$ & 10YR $6 / 4$ & $\begin{array}{l}\text { light yellowish } \\
\text { brown }\end{array}$ & Sandy Loam & - & - & $\mathrm{N}$ & Terminated at wet hydric soil.. \\
\hline NA & MCC206 & 1 & $0-45$ & 7.5YR $5 / 3$ & brown & Sandy Loam & - & - & $\mathrm{N}$ & - \\
\hline & & 2 & $45-55$ & 7.5YR $5 / 8$ & strong brown & Sandy Clay & - & - & $\mathrm{N}$ & Terminated at basal clay. \\
\hline
\end{tabular}




\begin{tabular}{|c|c|c|c|c|c|c|c|c|c|}
\hline Site No. & $\begin{array}{c}\text { Shovel Test } \\
\text { No. }\end{array}$ & Level & $\begin{array}{l}\text { Depth } \\
\text { (cmbs) }\end{array}$ & $\begin{array}{c}\text { Munsell Soil } \\
\text { value }\end{array} \mid$ & $\begin{array}{l}\text { Munsell Soil } \\
\text { Color }\end{array}$ & Soil Texture & $\begin{array}{l}\text { Inclusion } \\
\text { Percentage }\end{array}$ & Inclusion Type & $\begin{array}{c}\text { Positive (P) } \\
\text { or Negative } \\
\text { (N) }\end{array}$ \\
\hline & & 1 & $0-30$ & 10YR 4/3 & brown & Sandy Loam & - & - & $\mathrm{N}$ \\
\hline NA & MCC207 & 2 & $30-60$ & 7.5 YR $5 / 6$ & strong brown & Sandy Loam & - & - & $\mathrm{N}$ \\
\hline & & 3 & $60-70$ & 7.5 YR $5 / 6$ & strong brown & Sandy Clay & - & $\begin{array}{lll}- & & \end{array}$ & $\mathrm{N}$ \\
\hline & & 1 & $0-40$ & 7.5 YR $5 / 4$ & brown & Sandy Loam & - & $\begin{array}{lll}- & & \\
\end{array}$ & $\mathrm{N}$ \\
\hline NA & MCC208 & 2 & $40-50$ & 10YR 5/6 & yellowish brown & Sandy Loam & - & - & $\mathrm{N}$ \\
\hline & & 3 & $50-60$ & 7.5 YR $5 / 6$ & strong brown & Sandy Clay & - & - & $\mathrm{N}$ \\
\hline NA & $\mathrm{MCC}>0$ & 1 & $0-30$ & 10YR 4/3 & brown & Sandy Loam & - & - & $\mathrm{N}$ \\
\hline NA & MICCZOU9 & 2 & $30-40$ & 7.5 YR $5 / 6$ & strong brown & Sandy Clay & 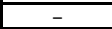 & $\begin{array}{llll}- & & & \\
\end{array}$ & $\mathrm{N}$ \\
\hline NA & $\mathrm{MCC} 10$ & 1 & $0-30$ & 7.5 YR $4 / 3$ & brown & Sandy Loam & $1-5 \%$ & Gravels & $\mathrm{N}$ \\
\hline NA & МICCLZ10 & 2 & $30-40$ & 5 YYR $4 / 6$ & yellowish red & Clay & - & - & $\mathrm{N}$ \\
\hline NA & MCC211 & 1 & $0-30$ & 7.5 YR $4 / 3$ & brown & Sandy Loam & $1-5 \%$ & Gravels & $\mathrm{N}$ \\
\hline NA & MCC211 & 2 & $30-40$ & $5 Y R 4 / 6$ & yellowish red & Clay & - & - & $\mathrm{N}$ \\
\hline $\mathrm{NA}$ & $\mathrm{MCC212}$ & 1 & $0-30$ & 7.5 YR 4/3 & brown & Sandy Loam & $1-5 \%$ & Gravels & $\mathrm{N}$ \\
\hline NA & $1 \mathrm{MLC} 272$ & 2 & $30-40$ & 5YR $4 / 6$ & yellowish red & Clay & $\begin{array}{llll}- & & & \\
\end{array}$ & $\begin{array}{lll}- & & \\
\end{array}$ & $\mathrm{N}$ \\
\hline NA & $\mathrm{MCC213}$ & 1 & $0-30$ & $7.5 Y R 4 / 3$ & brown & Sandy Loam & $1-5 \%$ & Gravels & $\mathrm{N}$ \\
\hline NA & MICLCZ13 & 2 & $30-40$ & 5 YYR $4 / 6$ & yellowish red & Clay & - & $\begin{array}{ll}- \\
\end{array}$ & $\mathrm{N}$ \\
\hline NA & MCC214 & 1 & $0-20$ & $5 Y$ YR $4 / 6$ & yellowish red & Clay & $\begin{array}{llll}- & & & \\
\end{array}$ & 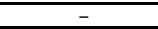 & $\mathrm{N}$ \\
\hline NA & $\mathrm{MCC} 215$ & 1 & $0-45$ & $7.5 Y R 4 / 6$ & strong brown & Sandy Loam & - & - & $\mathrm{N}$ \\
\hline $\mathrm{NA}$ & IVICLCZ15 & 2 & $45-50$ & 5YR 4/6 & yellowish red & Clay & - & - & $\mathrm{N}$ \\
\hline 41BU123 & MCC216 & 1 & $0-30$ & 7.5 YR $5 / 6$ & strong brown & Sandy Clay & - & - & $\mathrm{N}$ \\
\hline NA & MCC217 & 1 & $0-100$ & 10YR 4/3 & brown & Sandy Loam & - & - & $\mathrm{N}$ \\
\hline NA & $\mathrm{CCCO}_{18}$ & 1 & $0-30$ & $10 \mathrm{YR} 4 / 3$ & brown & Sandy Loam & - & - & $\mathrm{N}$ \\
\hline NA & 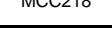 & 2 & $30-40$ & 7.5 YR $5 / 6$ & strong brown & Clay & - & - & $\mathrm{N}$ \\
\hline NA & MCC219 & 1 & $0-100$ & 10YR 4/3 & brown & Sandy Loam & - & - & $\mathrm{N}$ \\
\hline NA & MCC220 & 1 & $0-60$ & 10YR 4/1 & dark gray & Sandy Clay Loam & - & - & N \\
\hline NA & & 1 & $0-50$ & 7.5 YR 4/3 & brown & Sandy Loam & - & - & $\mathrm{N}$ \\
\hline NA & MCC221 & 2 & $50-60$ & 2.5 YR $4 / 8$ & red & Sandy Clay & - & - & $\mathrm{N}$ \\
\hline NA & MCC222 & 1 & $0-30$ & 10YR $4 / 2$ & dark grayish brown & Sandy Loam & - & - & $\mathrm{N}$ \\
\hline & & 2 & $30-40$ & 7.5 YR $5 / 8$ & strong brown & Clay & - & $\begin{array}{lll}- & & \end{array}$ & $\mathrm{N}$ \\
\hline NA & & 1 & $0-35$ & 10YR 4/1 & dark gray & Clay Loam & - & - & $\mathrm{N}$ \\
\hline $\mathrm{NA}$ & MCC223 & 2 & $35-45$ & 7.5 YR $5 / 8$ & strong brown & Clay & - & - & $\mathrm{N}$ \\
\hline & & 1 & $0-35$ & 10YR 4/1 & dark gray & Clay Loam & $\begin{array}{ll}- \\
-\end{array}$ & - & $\mathrm{N}$ \\
\hline NA & MCC224 & 2 & $35-45$ & 7.5 YR $5 / 8$ & strong brown & Clay & - & - & $\mathrm{N}$ \\
\hline NA & MCC225 & 1 & $0-35$ & 10YR 4/1 & dark gray & Clay Loam & - & - & $\mathrm{N}$ \\
\hline NA & $\mathrm{MCC} 225$ & 2 & $35-45$ & 7.5 YR $5 / 8$ & strong brown & Clay & - & - & $\mathrm{N}$ \\
\hline NA & $\mathrm{MCC} 226$ & 1 & $0-35$ & 10YR 4/1 & dark gray & Clay Loam & - & - & $\mathrm{N}$ \\
\hline NA & МИССZZZ & 2 & $35-45$ & 7.5 YR $5 / 8$ & strong brown & Clay & - & $\begin{array}{llll}- & & & \end{array}$ & $\mathrm{N}$ \\
\hline NA & & 1 & $0-35$ & 10YR 4/1 & dark gray & Clay Loam & - & - & $\mathrm{N}$ \\
\hline NA & MCC227 & 2 & $35-45$ & 7.5 YR $5 / 8$ & strong brown & Clay & - & - & $\mathrm{N}$ \\
\hline$N A$ & MCс228 & 1 & $0-35$ & 10YR 4/1 & dark gray & Clay Loam & $\begin{array}{lll}- & & \\
\end{array}$ & $\begin{array}{llll}- & & & \end{array}$ & $\mathrm{N}$ \\
\hline & & 2 & $35-45$ & 7.5YR 5/8 & strong brown & Clay & - & - & $\mathrm{N}$ \\
\hline NA & MCC?29 & 1 & $0-20$ & 10YR 4/1 & dark gray & Clay Loam & $\begin{array}{llll}- & & & \end{array}$ & $\begin{array}{llll}- & & & \end{array}$ & $\mathrm{N}$ \\
\hline NA & MCC229 & 2 & $20-25$ & 7.5 YR $5 / 8$ & strong brown & Clay & - & $\begin{array}{lll}- & & \end{array}$ & $\mathrm{N}$ \\
\hline NA & Мсс2зо & 1 & $0-30$ & 7.5 YR $4 / 6$ & strong brown & Sandy Loam & - & - & $\mathrm{N}$ \\
\hline NA & MCC230 & 2 & $30-40$ & 2.5 YR $4 / 6$ & red & Clay & - & - & $\mathrm{N}$ \\
\hline NA & мсс230 & 1 & $0-80$ & 10YR 5/6 & yellowish brown & Sandy Loam & 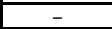 & 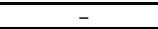 & $\mathrm{N}$ \\
\hline & & 2 & $80-100$ & 10YR $6 / 6$ & brownish yellow & Sandy Loam & 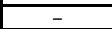 & - & $\mathrm{N}$ \\
\hline NA & MCC231 & 1 & $0-35$ & 7.5 YR $6 / 8$ & reddish yellow & Clay & - & - & $\mathrm{N}$ \\
\hline NA & $\mathrm{MCC} 231$ & 1 & $0-40$ & 10YR 4/3 & brown & Sandy Loam & - & - & $\mathrm{N}$ \\
\hline & & 2 & $40-50$ & 7.5 YR $5 / 8$ & strong brown & Sandy Clay & - & - & $\mathrm{N}$ \\
\hline NA & 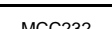 & 1 & $0-40$ & 10YR $3 / 1$ & very dark gray & Clay Loam & $\begin{array}{ll}- & \\
\end{array}$ & 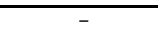 & $\mathrm{N}$ \\
\hline NA & $\mathrm{MCC} 232$ & 2 & $40-50$ & 7.5YR 5/8 & strong brown & Clay & - & - & $\mathrm{N}$ \\
\hline$N A$ & MCс232 & 1 & $0-40$ & 10YR 4/3 & brown & Sandy Loam & - & - & $\mathrm{N}$ \\
\hline NA & MCC232 & 2 & $40-50$ & 7.5 YR $5 / 8$ & strong brown & Sandy Clay & 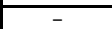 & 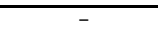 & $\mathrm{N}$ \\
\hline NA & $\mathrm{MCC} 233$ & 1 & $0-55$ & 7.5 YR $5 / 4$ & brown & Sandy Loam & - & 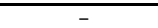 & $\mathrm{N}$ \\
\hline & & 2 & $55-65$ & 7.5 YR $5 / 8$ & strong brown & Clay Loam & - & - & $\mathrm{N}$ \\
\hline NA & $\mathrm{MCC} 233$ & 1 & $0-40$ & 10YR 4/3 & brown & Sandy Loam & $\begin{array}{ll}- \\
-\end{array}$ & - & $\mathrm{N}$ \\
\hline NA & МICCZ33 & 2 & $40-50$ & 7.5YR 5/8 & strong brown & Sandy Clay & $\begin{array}{ll}- \\
-\end{array}$ & 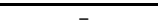 & $\mathrm{N}$ \\
\hline $\mathrm{NA}$ & MCC234 & 1 & $0-60$ & 7.5 YR $4 / 2$ & brown & Sandy Loam & $\begin{array}{llll}- & & & 0\end{array}$ & 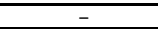 & $\mathrm{N}$ \\
\hline & & 1 & $0-45$ & 10YR 5/3 & brown & Sandy Loam & $\begin{array}{llll}- & & & \end{array}$ & $\begin{array}{lll}- & & \end{array}$ & $\mathrm{N}$ \\
\hline NA & MCC234 & 2 & $45-60$ & 10YR $5 / 6$ & yellowish brown & Sandy Loam & 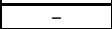 & - & $\mathrm{N}$ \\
\hline & & 3 & $60-65$ & 7.5 YR $5 / 8$ & strong brown & Sandy Clay & $\begin{array}{llll}- & & & \\
\end{array}$ & $\begin{array}{llll}- & & & 0\end{array}$ & $\mathrm{~N}$ \\
\hline NA & $\mathrm{MCC} 235$ & 1 & $0-20$ & $7.5 Y R 4 / 2$ & brown & Sandy Loam & $\begin{array}{lll}- & & \\
\end{array}$ & - & $\mathrm{N}$ \\
\hline INA & VIICULSOS & 2 & $20-30$ & 7.5YR 5/8 & strong brown & Clay & - & - & $\mathrm{N}$ \\
\hline NA & MCC235 & 1 & $0-25$ & 10YR 3/1 & very dark gray & Clay & $>20 \%$ & Cobbles, Gravels & $\mathrm{N}$ \\
\hline NA & MCC236 & 1 & $0-50$ & 7.5 YR $5 / 4$ & brown & Sandy Loam & - & - & $\mathrm{N}$ \\
\hline NA & MCC236 & 1 & $0-45$ & 10YR 3/1 & very dark gray & Clay Loam & - & - & $\mathrm{N}$ \\
\hline $\mathrm{NA}$ & MCC237 & 1 & $0-50$ & 7.5 YR $5 / 4$ & brown & Sandy Loam & - & - & $\mathrm{N}$ \\
\hline NA & MCC237 & 1 & $0-45$ & 10YR $3 / 1$ & very dark gray & Clay Loam & - & - & $\mathrm{N}$ \\
\hline NA & $\mathrm{MCC} 238$ & 1 & $0-70$ & 7.5 YR $5 / 4$ & brown & Sandy Loam & 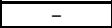 & $\begin{array}{llll}- & & & \\
\end{array}$ & $\mathrm{N}$ \\
\hline NA & $\mathrm{MCC} 238$ & 2 & $70-80$ & 7.5YR 5/8 & strong brown & Sandy Clay & $\begin{array}{ll}- \\
-\end{array}$ & $\begin{array}{lll}- & & \end{array}$ & $\mathrm{N}$ \\
\hline NA & MCC238 & 1 & $0-45$ & 10YR 3/1 & very dark gray & Clay Loam & $\begin{array}{llll}- & & & 0\end{array}$ & $\begin{array}{llll}- & & & \\
\end{array}$ & $\mathrm{N}$ \\
\hline NA & $\mathrm{MCC239}$ & 1 & $0-45$ & 7.5 YR $5 / 4$ & brown & Sandy Loam & 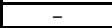 & 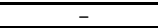 & $\mathrm{N}$ \\
\hline & & 2 & $45-55$ & 7.5 YR $5 / 8$ & strong brown & Sandy Clay & $\begin{array}{lll}- & & \\
\end{array}$ & $\begin{array}{lll}- & & \end{array}$ & $\mathrm{N}$ \\
\hline NA & MCC239 & 1 & $0-45$ & 10YR $3 / 1$ & very dark gray & Clay Loam & $5-10 \%$ & Cobbles, Gravels & $\mathrm{N}$ \\
\hline NA & $\mathrm{MCC} 240$ & 1 & $0-70$ & 7.5 YR $5 / 4$ & brown & Sandy Loam & 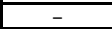 & 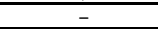 & $\mathrm{N}$ \\
\hline NA & & 2 & $70-80$ & 7.5 YR $5 / 8$ & strong brown & Sandy Clay & - & - & $\mathrm{N}$ \\
\hline NA & MCC241 & 1 & $0-50$ & 7.5 YR $4 / 6$ & strong brown & Sandy Loam & - & $\begin{array}{lll}- & & \end{array}$ & $\mathrm{N}$ \\
\hline NA & $\mathrm{MCC}_{24}$ & 1 & $0-60$ & 7.5 YR $5 / 4$ & brown & Sandy Loam & $\begin{array}{llll}- & & & \end{array}$ & $\begin{array}{llll}- & & & 0\end{array}$ & $\mathrm{~N}$ \\
\hline NA & MCC242 & 2 & $60-70$ & 7.5 YR $5 / 8$ & strong brown & Sandy Clay & - & - & $\mathrm{N}$ \\
\hline$N A$ & & 1 & $0-55$ & 7.5 YR $5 / 4$ & brown & Sandy Loam & - & - & $\mathrm{N}$ \\
\hline NA & MCC243 & 2 & $55-65$ & 7.5 YR $5 / 8$ & strong brown & Sandy Clay & - & - & $\mathrm{N}$ \\
\hline NA & $\mathrm{MCC} 244$ & 1 & $0-60$ & 7.5 YR $5 / 4$ & brown & Sandy Loam & - & - & $\mathrm{N}$ \\
\hline NA & MCC244 & 2 & $60-70$ & 7.5 YR $5 / 8$ & strong brown & Sandy Clay & 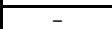 & - & $\mathrm{N}$ \\
\hline NA & MCC245 & 1 & $0-55$ & 7.5 YR $5 / 4$ & brown & Sandy Loam & - & - & $\mathrm{N}$ \\
\hline & MCC245 & 2 & $55-65$ & 7.5 YR $5 / 8$ & strong brown & Sandy Clay & $\begin{array}{ll}- & \\
\end{array}$ & 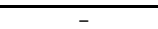 & $\mathrm{N}$ \\
\hline NA & $\mathrm{MCC246}$ & 1 & $0-55$ & 7.5 YR $5 / 4$ & brown & Sandy Loam & $\begin{array}{lll}- \\
\end{array}$ & $\begin{array}{llll}- & & & \end{array}$ & $\mathrm{N}$ \\
\hline & & 2 & $55-65$ & 7.5YR 5/8 & strong brown & Sandy Clay & - & - & $\mathrm{N}$ \\
\hline
\end{tabular}




\begin{tabular}{|c|c|c|c|c|c|c|c|c|c|c|}
\hline Site No. & $\begin{array}{c}\text { Shovel Test } \\
\text { No. }\end{array}$ & Level & $\begin{array}{l}\text { Depth } \\
\text { (cmbs) }\end{array}$ & $\begin{array}{c}\text { Munsell Soil } \\
\text { value }\end{array}$ & $\begin{array}{l}\text { Munsell Soil } \\
\text { Color }\end{array}$ & Soil Texture & $\begin{array}{l}\text { Inclusion } \\
\text { Percentage }\end{array}$ & Inclusion Type & $\begin{array}{l}\text { Positive }(\mathrm{P}) \\
\text { or Negative } \\
(\mathrm{N})\end{array}$ & Comments/ Reason for Termination \\
\hline \multirow{2}{*}{ 41BU124 } & \multirow{2}{*}{ MCC247 } & 1 & $0-70$ & $7.5 Y R 4 / 4$ & brown & Sandy Loam & $10-20 \%$ & $\begin{array}{c}\text { Charcoal chunks likely } \\
\text { from recent burning } \\
\text { events }\end{array}$ & $\mathrm{N}$ & - \\
\hline & & 2 & $70-100$ & 7.5YR $5 / 4$ & brown & Sandy Loam & - & - & Y & $\begin{array}{l}\text { 1: Flake (secondary) [Secondary flake observed } \\
\text { b/w } 70-80 \text { cmbs.] Terminated at depth. }\end{array}$ \\
\hline \multirow{2}{*}{ 41BU124 } & \multirow{2}{*}{ MCC248 } & 1 & $0-60$ & $7.5 Y R 5 / 4$ & brown & Sandy Loam & 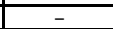 & - & $\mathrm{N}$ & 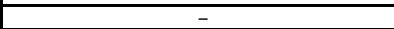 \\
\hline & & 2 & $60-70$ & $10 Y R$ $6 / 3$ & pale brown & Sandy Loam & - & - & $\mathrm{N}$ & Terminated at water table. \\
\hline \multirow{2}{*}{ 41BP959 } & \multirow{2}{*}{ MCC250 } & 1 & $0-45$ & 7.5 YR $5 / 4$ & brown & Sandy Loam & 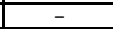 & 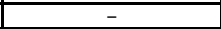 & $\mathrm{N}$ & - \\
\hline & & 2 & $45-55$ & 7.5YR 5/8 & strong brown & Sandy Clay & $>20 \%$ & Mottles & $\mathrm{N}$ & Terminated at basal clay. \\
\hline \multirow{2}{*}{ 41BP959 } & \multirow{2}{*}{ MCC251 } & 1 & $0-35$ & 7.5 YR $5 / 4$ & brown & Sandy Loam & - & - & $\mathrm{Y}$ & 1: Flake (secondary), Flake (tertiary) \\
\hline & & 2 & $35-45$ & $7.5 Y R 5 / 8$ & strong brown & Sandy Clay & $>20 \%$ & Mottles & $\mathrm{N}$ & Terminated at basal clay. \\
\hline \multirow{2}{*}{ 41BP959 } & \multirow{2}{*}{ MCC252 } & 1 & $0-30$ & 10YR $5 / 3$ & brown & Clay Loam & - & - & $\mathrm{N}$ & - \\
\hline & & 2 & $30-40$ & $7.5 Y R 5 / 8$ & strong brown & Clay & - & - & $\mathrm{N}$ & Terminated at basal clay. \\
\hline \multirow{2}{*}{ NA } & \multirow{2}{*}{ MCC253 } & 1 & $0-45$ & 10YR 4/2 & dark grayish brown & Clay Loam & - & - & $\mathrm{N}$ & - \\
\hline & & 2 & $40-50$ & $7.5 Y R 5 / 8$ & strong brown & Clay & - & - & $\mathrm{N}$ & Terminated at basal clay. \\
\hline NA & MCC500 & 1 & $0-15$ & 10YR $5 / 2$ & grayish brown & Silt Loam & $1-5 \%$ & Cobbles, Gravels, Mottles & $\mathrm{N}$ & Terminated at compact soil. \\
\hline NA & MCC501 & 1 & $0-30$ & 10YR 3/1 & very dark gray & Clay & $1-5 \%$ & Cobbles, Gravels & $\mathrm{N}$ & Terminated at compact soil. \\
\hline NA & MCC502 & 1 & $0-30$ & 10YR 3/1 & very dark gray & Clay & $1-5 \%$ & Cobbles, Gravels & $\mathrm{N}$ & Terminated at compact soil. \\
\hline NA & MCC503 & 1 & $0-30$ & 10YR $3 / 1$ & very dark gray & Clay & $1-5 \%$ & Cobbles, Gravels & $\mathrm{N}$ & Terminated at compact soil. \\
\hline NA & MCC504 & 1 & $0-10$ & 10YR 5/2 & grayish brown & Silt & $>20 \%$ & $\begin{array}{c}\text { Cobbles, Gravels, } \\
\text { Pebbles }\end{array}$ & $\mathrm{N}$ & Terminated at thick gravels.. \\
\hline NA & MCC505 & 1 & $0-10$ & 10YR 5/2 & grayish brown & Silt & $>20 \%$ & $\begin{array}{c}\text { Cobbles, Gravels, } \\
\text { Pebbles }\end{array}$ & $\mathrm{N}$ & Terminated at thick gravels.. \\
\hline NA & MCC506 & 1 & $0-10$ & 10YR 5/2 & grayish brown & Silt & $>20 \%$ & $\begin{array}{c}\text { Cobbles, Gravels, } \\
\text { Pebbles }\end{array}$ & $\mathrm{N}$ & Terminated at thick gravels.. \\
\hline NA & MCC507 & 1 & $0-10$ & 10YR 5/2 & grayish brown & Silt & $>20 \%$ & $\begin{array}{c}\text { Cobbles, Gravels, } \\
\text { Pebbles }\end{array}$ & $\mathrm{N}$ & Terminated at thick gravels.. \\
\hline NA & MCC508 & 1 & $0-10$ & 10YR 3/1 & very dark gray & Clay & $>20 \%$ & Cobbles, Gravels & $\mathrm{N}$ & Terminated at compact soil \& thick gravels.. \\
\hline $\mathrm{NA}$ & MCC509 & 1 & $0-10$ & 10YR 3/1 & very dark gray & Clay & $>20 \%$ & Cobbles, Gravels & $\mathrm{N}$ & Terminated at compact soil \& thick gravels.. \\
\hline NA & MCC510 & 1 & $0-10$ & 10YR 3/1 & very dark gray & Clay & $>20 \%$ & Cobbles, Gravels & $\mathrm{N}$ & Terminated at compact soil \& thick gravels.. \\
\hline \multirow{2}{*}{ NA } & MCC511 & 1 & $0-30$ & 10YR 4/1 & dark gray & Clay Loam & $5-10 \%$ & Cobbles, Gravels & $\mathrm{N}$ & - \\
\hline & IVICUST & 2 & $30-35$ & 10YR 3/1 & very dark gray & Clay & - & - & $\mathrm{N}$ & Terminated at compact soil. \\
\hline NA & MCC512 & 1 & $0-10$ & 10YR 3/1 & very dark gray & Clay & $>20 \%$ & Cobbles, Gravels & $\mathrm{N}$ & Terminated at compact soil \& thick gravels.. \\
\hline NA & MCC513 & 1 & $0-5$ & 10YR 5/2 & grayish brown & Silt & $>20 \%$ & $\begin{array}{c}\text { Cobbles, Gravels, } \\
\text { Pebbles }\end{array}$ & $\mathrm{N}$ & Terminated at compact soil \& thick gravels.. \\
\hline NA & MCC514 & 1 & $0-5$ & 10YR 5/2 & grayish brown & Silt & $>20 \%$ & $\begin{array}{c}\text { Cobbles, Gravels, } \\
\text { Pebbles }\end{array}$ & $\mathrm{N}$ & Terminated at compact soil \& thick gravels.. \\
\hline NA & MCC515 & 1 & $0-5$ & 10YR 5/2 & grayish brown & Silt & $>20 \%$ & $\begin{array}{c}\text { Cobbles, Gravels, } \\
\text { Pebbles }\end{array}$ & $\mathrm{N}$ & Terminated at compact soil \& thick gravels.. \\
\hline 41BP959 & MCC516 & 1 & $0-25$ & 10YR 5/4 & yellowish brown & Silt Loam & - & - & $\mathrm{N}$ & - \\
\hline $41 \mathrm{BP} 959$ & IVICC5I6 & 2 & $25-30$ & $7.5 Y R 4 / 6$ & strong brown & Clay & - & - & $\mathrm{N}$ & Terminated at basal clay. \\
\hline 41BP959 & MCC517 & 1 & $0-80$ & 10YR $7 / 3$ & very pale brown & Sand & - & - & Y & $\begin{array}{l}\text { 3: Flake (secondary), Other Prehistoric [Burned } \\
\text { rock } 20-40 \mathrm{cmbs} \& \text { secondary flakes } 60- \\
80 \mathrm{cmbs} \text {.] } \\
\end{array}$ \\
\hline & & 2 & $80-85$ & $7.5 Y R 5 / 8$ & strong brown & Sandy Clay & 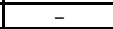 & - & $\mathrm{N}$ & Terminated at basal clay. \\
\hline 41BP959 & MCC518 & 1 & $0-80$ & 10YR $7 / 3$ & very pale brown & Sand & - & - & $\mathrm{Y}$ & $\begin{array}{l}\text { 4: Flake (tertiary) [2 tertiary flakes } 20-40 \mathrm{cmbs} \& \\
2 \text { tertiary flakes } 60-80 \mathrm{cmbs} \text {.] }\end{array}$ \\
\hline & & 2 & $80-85$ & 7.5YR 5/8 & strong brown & Sandy Clay & 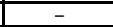 & - & $\mathrm{N}$ & Terminated at basal clay. \\
\hline$N A$ & MCC519 & 1 & $0-5$ & 10YR $4 / 3$ & brown & Silt Loam & - & - & $\mathrm{N}$ & - \\
\hline NA & MICC519 & 2 & $5-10$ & 7.5 YR $5 / 8$ & strong brown & Clay & - & - & $\mathrm{N}$ & Terminated at basal clay. \\
\hline 41BP959 & MCC520 & 1 & $0-10$ & 10YR $5 / 2$ & grayish brown & Sandy Loam & $10-20 \%$ & Mottles & $\mathrm{N}$ & Terminated at compact soil. \\
\hline 41BP959 & MCC521 & 1 & $0-25$ & 10YR 5/2 & grayish brown & Sand & - & - & $\mathrm{Y}$ & 1: Other Prehistoric \\
\hline $41 \mathrm{BP} Y 59$ & MICC 521 & 2 & $25-30$ & $7.5 Y R 5 / 8$ & strong brown & Clay & - & - & $\mathrm{N}$ & Terminated at basal clay. \\
\hline 41BP959 & MCC522 & 1 & $0-35$ & 10YR 5/2 & grayish brown & Sand & - & - & $\mathrm{Y}$ & $\begin{array}{l}\text { 3: Flake (primary), Flake (secondary), Flake } \\
\text { (tertiary) }\end{array}$ \\
\hline & & 2 & $35-40$ & 7.5 YR $5 / 8$ & strong brown & Sandy Clay & - & - & $\mathrm{N}$ & Terminated at basal clay. \\
\hline NA & MCC523 & 1 & $0-25$ & 10YR $3 / 1$ & very dark gray & Clay & $>20 \%$ & $\begin{array}{c}\text { Cobbles, Gravels, } \\
\text { Pebbles }\end{array}$ & $\mathrm{N}$ & Terminated at compact soil \& thick gravels.. \\
\hline NA & MCC524 & 1 & $0-25$ & 10YR 3/1 & very dark gray & Clay & $>20 \%$ & $\begin{array}{c}\text { Cobbles, Gravels, } \\
\text { Pebbles }\end{array}$ & $\mathrm{N}$ & Terminated at compact soil \& thick gravels.. \\
\hline NA & MCC525 & 1 & $0-25$ & 10YR 3/1 & very dark gray & Clay & $>20 \%$ & $\begin{array}{c}\text { Cobbles, Gravels, } \\
\text { Pebbles }\end{array}$ & $\mathrm{N}$ & Terminated at compact soil \& thick gravels.. \\
\hline NA & MCC526 & 1 & $0-35$ & 10YR 3/1 & very dark gray & Clay & $>20 \%$ & $\begin{array}{l}\text { Cobbles, Gravels, } \\
\text { Pebbles }\end{array}$ & $\mathrm{N}$ & Terminated at compact soil \& thick gravels.. \\
\hline $\mathrm{NA}$ & MCC527 & 1 & $0-30$ & $2.5 Y 5 / 6$ & light olive brown & Clay & $>20 \%$ & Mottles & $\mathrm{N}$ & Terminated at compact soil. \\
\hline NA & MCC528 & 1 & $0-30$ & 10YR $5 / 3$ & brown & Silt Loam & $>20 \%$ & $\begin{array}{c}\text { Cobbles, Gravels, } \\
\text { Pebbles }\end{array}$ & $\mathrm{N}$ & Terminated at thick gravels.. \\
\hline NA & MCC530 & 1 & 0-35 & 10YR $3 / 2$ & $\begin{array}{c}\text { very dark grayish } \\
\text { brown }\end{array}$ & Silty Clay Loam & $1-5 \%$ & Snail Shell & $\mathrm{N}$ & - \\
\hline & & 2 & $35-55$ & 10YR $4 / 2$ & dark grayish brown & Clay Loam & $1-5 \%$ & Snail Shell & $\mathrm{N}$ & Terminated at compact soil. \\
\hline NA & MCC531 & 1 & $0-35$ & 10YR $3 / 2$ & $\begin{array}{c}\text { very dark grayish } \\
\text { brown }\end{array}$ & Silty Clay Loam & $1-5 \%$ & Snail Shell & $\mathrm{N}$ & - \\
\hline & & 2 & $35-55$ & 10YR $4 / 2$ & dark grayish brown & Clay Loam & $1-5 \%$ & Snail Shell & $\mathrm{N}$ & Terminated at compact soil. \\
\hline NA & MCC532 & 1 & $0-30$ & 10YR 3/2 & $\begin{array}{c}\text { very dark grayish } \\
\text { brown }\end{array}$ & Silty Clay Loam & $1-5 \%$ & Snail Shell & $\mathrm{N}$ & - \\
\hline & & 2 & $30-50$ & 10YR $4 / 2$ & dark grayish brown & Clay Loam & $1-5 \%$ & Snail Shell & $\mathrm{N}$ & Terminated at compact soil. \\
\hline & & 1 & $0-40$ & 10YR $4 / 2$ & dark grayish brown & Sandy Loam & - & - & $\mathrm{N}$ & - \\
\hline NA & MCC533 & 2 & $50-55$ & 10YR $4 / 4$ & $\begin{array}{c}\text { dark yellowish } \\
\text { brown }\end{array}$ & Sandy Clay Loam & - & - & $\mathrm{N}$ & - \\
\hline & & 3 & $55-60$ & 10YR $3 / 2$ & $\begin{array}{c}\text { very dark grayish } \\
\text { brown }\end{array}$ & Sandy Clay & - & - & $\mathrm{N}$ & Terminated at compact soil. \\
\hline NA & MCC534 & 1 & $0-40$ & $2.5 Y 3 / 2$ & $\begin{array}{c}\text { very dark grayish } \\
\text { brown }\end{array}$ & Clay & - & - & $\mathrm{N}$ & Terminated at compact soil. \\
\hline NA & MCC535 & 1 & $0-30$ & $2.5 Y 2.5 / 1$ & black & Clay Loam & - & - & $\mathrm{N}$ & - \\
\hline & & 2 & $30-35$ & $2.5 Y 2.5 / 1$ & black & Clay & - & - & $\mathrm{N}$ & Terminated at compact soil. \\
\hline
\end{tabular}




\begin{tabular}{|c|c|c|c|c|c|c|c|c|c|c|}
\hline Site No. & $\left|\begin{array}{c}\text { Shovel Test } \\
\text { No. }\end{array}\right|$ & Level & $\begin{array}{l}\text { Depth } \\
\text { (cmbs) }\end{array}$ & $\begin{array}{c}\text { Munsell Soil } \\
\text { value }\end{array}$ & $\begin{array}{l}\text { Munsell Soil } \\
\text { Color }\end{array}$ & Soil Texture & $\begin{array}{l}\text { Inclusion } \\
\text { Percentage }\end{array}$ & Inclusion Type & $\begin{array}{c}\text { Positive }(\mathrm{P}) \\
\text { or Negative } \\
(\mathrm{N})\end{array}$ & Comments/ Reason for Termination \\
\hline NA & MCC536 & 1 & $0-40$ & $2.5 Y 3 / 2$ & \begin{tabular}{|c|}
$\begin{array}{c}\text { very dark grayish } \\
\text { brown }\end{array}$ \\
\end{tabular} & Clay & - & - & $\mathrm{N}$ & Terminated at compact soil. \\
\hline \multirow{2}{*}{ NA } & \multirow{2}{*}{ MCC537 } & 1 & $0-35$ & 10YR 4/2 & dark grayish brown & Silty Clay Loam & - & - & N & - \\
\hline & & 2 & $35-40$ & 10YR $4 / 2$ & dark grayish brown & Clay & - & - & $\mathrm{N}$ & Terminated at compact soil. \\
\hline \multirow{2}{*}{ NA } & \multirow{2}{*}{ MCC538 } & 1 & $0-40$ & 10YR $4 / 2$ & dark grayish brown & Silty Clay Loam & - & - & $\mathrm{N}$ & - \\
\hline & & 2 & $40-45$ & 10YR $4 / 2$ & dark grayish brown & Clay & - & - & $\mathrm{N}$ & Terminated at compact soil. \\
\hline \multirow{2}{*}{ NA } & \multirow{2}{*}{ MCc540 } & 1 & $0-60$ & 10YR 5/6 & yellowish brown & Sandy Loam & - & - & $\mathrm{N}$ & - \\
\hline & & 2 & $60-65$ & $7.5 Y R 5 / 8$ & strong brown & Sandy Clay & - & - & $\mathrm{N}$ & Terminated at basal clay. \\
\hline \multirow{2}{*}{ NA } & \multirow{2}{*}{ MCC541 } & 1 & $0-85$ & 10YR $6 / 3$ & pale brown & Sandy Loam & $\begin{array}{ll}- & \\
\end{array}$ & - & $\mathrm{N}$ & - \\
\hline & & 2 & $85-100$ & 10YR 5/8 & yellowish brown & Sandy Clay & - & - & $\mathrm{N}$ & Terminated at depth. \\
\hline \multirow{2}{*}{ NA } & \multirow{2}{*}{ MCC542 } & 1 & $0-85$ & 10YR 6/3 & pale brown & Sandy Loam & - & - & $\mathrm{N}$ & $\begin{array}{l}- \\
\end{array}$ \\
\hline & & 2 & $85-100$ & 10YR 5/8 & yellowish brown & Sandy Clay & $\begin{array}{c}- \\
\end{array}$ & 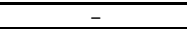 & $\mathrm{N}$ & Terminated at depth. \\
\hline 41CM401 & MCC543 & 1 & $0-20$ & 10YR 6/6 & brownish yellow & Clay & $>20 \%$ & Gravels, Mottles & $\mathrm{N}$ & Terminated at bedrock. \\
\hline \multirow[b]{2}{*}{$41 \mathrm{CM} 401$} & & 1 & $0-10$ & 10YR $6 / 6$ & brownish yellow & Clay & $>20 \%$ & Gravels, Mottles & $\mathrm{N}$ & - \\
\hline & MCC544 & 2 & $10-30$ & 10YR $3 / 2$ & $\begin{array}{c}\begin{array}{c}\text { very dark grayish } \\
\text { brown }\end{array} \\
\end{array}$ & Silty Clay Loam & $>20 \%$ & Gravels & $\mathrm{N}$ & Terminated at bedrock. \\
\hline 41CM401 & MCC545 & 1 & $0-15$ & 10YR 4/2 & dark grayish brown & Clay & $10-20 \%$ & Gravels & $\mathrm{N}$ & - \\
\hline & & 2 & $15-25$ & 5YR 5/6 & yellowish red & Clay & - & - & $\mathrm{N}$ & Terminated at basal clay. \\
\hline $41 \mathrm{CM} 401$ & MCC546 & 1 & $0-20$ & 10YR $3 / 2$ & $\begin{array}{c}\text { very dark grayish } \\
\text { brown }\end{array}$ & Silt Loam & $>20 \%$ & Gravels & $\mathrm{N}$ & Terminated at bedrock. \\
\hline 41CM401 & MCC547 & 1 & $0-20$ & 10YR 4/2 & dark grayish brown & Silty Clay Loam & $>20 \%$ & Gravels & Y & $\begin{array}{l}\text { 1: Flake (primary), Flake (secondary) Terminated } \\
\text { at thick gravels.. }\end{array}$ \\
\hline $41 \mathrm{CM} 401$ & MCC548 & 1 & $0-40$ & 10YR $4 / 2$ & dark grayish brown & Silty Clay Loam & $10-20 \%$ & Gravels & N & - \\
\hline & & 2 & $40-50$ & 7.5 YR $5 / 6$ & strong brown & Clay & - & - & $\mathrm{N}$ & Terminated at basal clay. \\
\hline $\mathrm{NA}$ & MCC549 & 1 & $0-40$ & 10YR 3/1 & very dark gray & Clay & $>20 \%$ & Gravels & $\mathrm{N}$ & Terminated at compact soil. \\
\hline NA & MCC550 & 1 & $0-45$ & 10YR 3/1 & very dark gray & Clay & $10-20 \%$ & Gravels & $\mathrm{N}$ & Terminated at compact soil. \\
\hline & & 1 & $0-50$ & 10YR 5/6 & yellowish brown & Sandy Loam & - & - & $\mathrm{N}$ & - \\
\hline NA & MCC551 & 2 & $50-60$ & 10YR $5 / 2$ & grayish brown & Sandy Clay Loam & $>20 \%$ & Mottles & N & Terminated at compact soil. \\
\hline & & 1 & $0-10$ & 10YR 4/3 & brown & Sandy Loam & $1-5 \%$ & Pebbles & $\mathrm{N}$ & - \\
\hline & & 2 & $10-60$ & 10YR 5/4 & yellowish brown & Sandy Loam & $1-5 \%$ & Pebbles & $\mathrm{N}$ & - \\
\hline NA & MCC552 & 3 & $60-85$ & $10 \mathrm{YR} 7 / 3$ & very pale brown & Sandy Loam & $1-5 \%$ & Pebbles & $\mathrm{N}$ & - \\
\hline & & 4 & $85-100$ & 10YR 5/6 & yellowish brown & Sandy Clay Loam & $10-20 \%$ & Mottles & N & Terminated at depth. \\
\hline & & 1 & $0-10$ & 10YR $3 / 3$ & dark brown & Sandy Loam & - & - & $\mathrm{N}$ & - \\
\hline NA & MCC553 & 2 & $10-35$ & 10YR 5/3 & brown & Sandy Loam & - & - & $\mathrm{N}$ & - \\
\hline & & 3 & $25-35$ & 7.5 YR $5 / 6$ & strong brown & Clay & - & - & $\mathrm{N}$ & Terminated at basal clay. \\
\hline & & 1 & $0-60$ & 10YR $4 / 2$ & dark grayish brown & Silt Loam & $1-5 \%$ & Snail Shell & $\mathrm{N}$ & - \\
\hline $41 \mathrm{GU} 200$ & MCC554 & 2 & $60-85$ & 10YR 5/4 & yellowish brown & Silt Loam & $1-5 \%$ & Snail Shell & $\mathrm{N}$ & - \\
\hline & & 3 & $85-100$ & 10YR $6 / 4$ & $\begin{array}{c}\text { light yellowish } \\
\text { brown }\end{array}$ & Sandy Clay Loam & $1-5 \%$ & Snail Shell & N & Terminated at depth. \\
\hline & & 1 & $0-60$ & 10YR $4 / 2$ & dark grayish brown & Silt Loam & $1-5 \%$ & Pebbles, Snail Shell & N & - \\
\hline $41 \mathrm{GU} 200$ & MCC555 & 2 & $60-85$ & 10YR 5/4 & yellowish brown & Sandy Loam & $1-5 \%$ & Pebbles, Snail Shell & $\mathrm{N}$ & - \\
\hline & & 3 & $85-100$ & 10YR $6 / 4$ & $\begin{array}{c}\text { light yellowish } \\
\text { brown }\end{array}$ & Sandy Clay Loam & - & - & $\mathrm{N}$ & Terminated at depth. \\
\hline & & 1 & $0-10$ & 10YR $4 / 2$ & dark grayish brown & Sandy Loam & $1-5 \%$ & Pebbles & $\mathrm{N}$ & - \\
\hline NA & MCC556 & 2 & $10-45$ & 10YR 6/4 & $\begin{array}{c}\text { light yellowish } \\
\text { brown }\end{array}$ & Sandy Loam & $1-5 \%$ & Pebbles & N & - \\
\hline & & 3 & $45-100$ & 10YR 7/4 & very pale brown & Sandy Loam & $1-5 \%$ & Pebbles & $\mathrm{N}$ & Terminated at depth. \\
\hline NA & MCC557 & 1 & $0-40$ & 5 YY $4 / 4$ & reddish brown & Sandy Loam & $5-10 \%$ & Gravels & $\mathrm{N}$ & - \\
\hline $\mathrm{INA}$ & IVICLSכ) & 2 & $40-50$ & 5YR $5 / 8$ & yellowish red & Sandy Clay & - & - & $\mathrm{N}$ & Terminated at basal clay. \\
\hline NA & MCC558 & 1 & $0-40$ & 5 5YR $4 / 4$ & reddish brown & Sandy Loam & $5-10 \%$ & Gravels & $\mathrm{N}$ & - \\
\hline & & 2 & $40-50$ & 5YR 5/8 & yellowish red & Sandy Clay & - & - & $\mathrm{N}$ & Terminated at basal clay. \\
\hline NA & MCC575 & 1 & $0-40$ & 10YR $4 / 2$ & dark grayish brown & Clay & - & - & N & Terminated at compact soil. \\
\hline NA & MCC576 & 1 & $0-45$ & 10YR $4 / 2$ & dark grayish brown & Silty Clay Loam & $1-5 \%$ & Gravels, Pebbles & $\mathrm{N}$ & - \\
\hline & & 2 & $45-55$ & 7.5 YR $6 / 8$ & reddish yellow & Clay & - & - & $\mathrm{N}$ & Terminated at basal clay. \\
\hline NA & MCC577 & 1 & $0-45$ & 10YR $4 / 2$ & dark grayish brown & Silty Clay Loam & $1-5 \%$ & Gravels, Pebbles & $\mathrm{N}$ & - \\
\hline & & 2 & $45-55$ & $7.5 Y R 6 / 8$ & reddish yellow & Clay & - & - & $\mathrm{N}$ & Terminated at basal clay. \\
\hline NA & MCC578 & 1 & $0-55$ & 10YR $4 / 2$ & dark grayish brown & Silty Clay Loam & $1-5 \%$ & Gravels, Pebbles & $\mathrm{N}$ & - \\
\hline & & 2 & $55-60$ & 7.5 YR $6 / 8$ & reddish yellow & Clay & - & - & $\mathrm{N}$ & Terminated at basal clay. \\
\hline $\mathrm{NA}$ & MCC579 & 1 & $0-10$ & $5 Y R 4 / 6$ & yellowish red & Clay & - & - & $\mathrm{N}$ & Terminated at basal clay. \\
\hline & & 1 & $0-10$ & 10YR 3/1 & very dark gray & Sandy Clay Loam & - & - & N & - \\
\hline NA & MCC580 & 2 & $10-50$ & 10YR $4 / 3$ & brown & Sandy Clay Loam & - & - & N & - \\
\hline & & 3 & $50-60$ & 10YR 6/6 & brownish yellow & Clay & - & - & $\mathrm{N}$ & Terminated at compact soil. \\
\hline $\mathrm{NA}$ & MCC581 & 1 & $0-25$ & 10YR 2/1 & black & Clay & $>20 \%$ & Gravels & $\mathrm{N}$ & Terminated at thick gravels.. \\
\hline NA & MCC582 & 1 & $0-40$ & 10YR 3/1 & very dark gray & Silty Clay Loam & $10-20 \%$ & Gravels & $\mathrm{N}$ & Terminated at compact soil. \\
\hline $\mathrm{NA}$ & MCC583 & 1 & $0-40$ & 10YR 3/1 & very dark gray & Silty Clay Loam & $5-10 \%$ & Gravels & $\mathrm{N}$ & Terminated at compact soil. \\
\hline $\mathrm{NA}$ & MCC584 & 1 & $0-30$ & 10YR 3/1 & very dark gray & \begin{tabular}{|l|} 
Silty Clay Loam \\
\end{tabular} & $5-10 \%$ & Gravels & $\mathrm{N}$ & Terminated at compact soil. \\
\hline NA & MCC585 & 1 & $0-40$ & 10YR $3 / 3$ & dark brown & Clay Loam & $>20 \%$ & $\begin{array}{l}\text { Cobbles, Large Rock } \\
\text { Frags, Mottles }\end{array}$ & N & Terminated at disturbed to $50 \mathrm{cmbs}$. \\
\hline NA & MCC586 & 1 & $0-35$ & $2.5 \mathrm{Y} 4 / 2$ & dark grayish brown & Clay & $1-5 \%$ & Gravels & N & Terminated at compact soil. \\
\hline NA & MCC587 & 1 & $0-25$ & 10YR $3 / 1$ & very dark gray & Clay & $5-10 \%$ & Gravels & $\mathrm{N}$ & Terminated at compact soil. \\
\hline $\begin{array}{l}41 \mathrm{CM} 394 \\
\text { Extension }\end{array}$ & MCC588 & 1 & $0-25$ & 10YR $3 / 3$ & dark brown & Silty Clay Loam & $10-20 \%$ & Gravels & $\mathrm{N}$ & Terminated at bedrock. \\
\hline NA & MCC589 & 1 & $0-20$ & 10YR $3 / 2$ & \begin{tabular}{|c|}
$\begin{array}{c}\text { very dark grayish } \\
\text { brown }\end{array}$ \\
\end{tabular} & Silty Clay Loam & $>20 \%$ & Gravels & N & Terminated at thick gravels.. \\
\hline
\end{tabular}




\begin{tabular}{|c|c|c|c|c|c|c|c|c|c|c|}
\hline Site No. & $\begin{array}{c}\text { Shovel Test } \\
\text { No. }\end{array}$ & Level & $\begin{array}{l}\text { Depth } \\
\text { (cmbs) }\end{array}$ & $\left|\begin{array}{c}\text { Munsell Soil } \\
\text { value }\end{array}\right|$ & $\begin{array}{l}\text { Munsell Soil } \\
\text { Color }\end{array}$ & Soil Texture & \begin{tabular}{|c|} 
Inclusion \\
Percentage
\end{tabular} & Inclusion Type & $\begin{array}{c}\text { Positive }(\mathrm{P}) \\
\text { or Negative } \\
(\mathrm{N})\end{array}$ & Comments/ Reason for Termination \\
\hline NA & MCC590 & 1 & $0-15$ & 10YR $3 / 2$ & $\begin{array}{c}\text { very dark grayish } \\
\text { brown }\end{array}$ & Silty Clay Loam & $>20 \%$ & Gravels & $\mathrm{N}$ & Terminated at thick gravels.. \\
\hline \multirow{2}{*}{ NA } & \multirow{2}{*}{ MCC591 } & 1 & $0-50$ & 10YR 5/6 & yellowish brown & Sandy Loam & - & - & $\mathrm{N}$ & - \\
\hline & & 2 & $50-60$ & 5YR $5 / 8$ & yellowish red & Sandy Clay & $\begin{array}{ll}- & \\
\end{array}$ & - & $\mathrm{N}$ & Terminated at basal clay. \\
\hline \multirow{2}{*}{ NA } & \multirow{2}{*}{ MCC592 } & 1 & $0-50$ & 10YR 5/4 & yellowish brown & Sandy Loam & 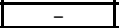 & - & $\mathrm{N}$ & - \\
\hline & & 2 & $50-60$ & 10YR 5/8 & yellowish brown & Sandy Clay & - & - & $\mathrm{N}$ & Terminated at basal clay. \\
\hline \multirow{2}{*}{ NA } & \multirow{2}{*}{ MCC593 } & 1 & $0-35$ & 10YR 5/6 & yellowish brown & Sandy Loam & - & - & $\mathrm{N}$ & - \\
\hline & & 2 & $35-45$ & 5YR $5 / 8$ & yellowish red & Sandy Clay & - & - & $\mathrm{N}$ & Terminated at basal clay. \\
\hline \multirow{2}{*}{ NA } & \multirow{2}{*}{ MCC594 } & 1 & $0-30$ & 10YR 5/6 & yellowish brown & Sandy Loam & $\begin{array}{ll}- & \\
\end{array}$ & - & $\mathrm{N}$ & - \\
\hline & & 2 & $30-40$ & 5YR $5 / 8$ & yellowish red & Sandy Clay & - & - & $\mathrm{N}$ & Terminated at basal clay. \\
\hline \multirow{2}{*}{ NA } & \multirow{2}{*}{ MCC595 } & 1 & $0-50$ & 10YR $5 / 6$ & yellowish brown & Sandy Loam & - & - & $\mathrm{N}$ & - \\
\hline & & 2 & $50-60$ & 5 YR $5 / 8$ & yellowish red & Sandy Clay & - & - & $\mathrm{N}$ & Terminated at basal clay. \\
\hline \multirow{2}{*}{ NA } & \multirow{2}{*}{ MFR01 } & 1 & $0-25$ & 10YR $4 / 3$ & brown & Silt Loam & $1-5 \%$ & $\begin{array}{l}\text { Gravels, Large Rock } \\
\text { Frags }\end{array}$ & $\mathrm{N}$ & - \\
\hline & & 2 & $25-35$ & 7.5YR 5/6 & strong brown & Silty Clay & $5-10 \%$ & $\begin{array}{l}\text { Gravels, Large Rock } \\
\text { Frags }\end{array}$ & $\mathrm{N}$ & Terminated at basal clay. \\
\hline NA & MFR01 & 1 & $0-20$ & 10YR $5 / 2$ & grayish brown & Clay Loam & $>20 \%$ & $\begin{array}{l}\text { Gravels, Large Rock } \\
\text { Frags }\end{array}$ & $\mathrm{N}$ & Terminated at large impassable gravels. \\
\hline NA & MFR02 & 1 & $0-20$ & 10YR 5/2 & grayish brown & Clay Loam & $>20 \%$ & $\begin{array}{l}\text { Gravels, Large Rock } \\
\text { Frags }\end{array}$ & $\mathrm{N}$ & Terminated at large impassable gravels. \\
\hline NA & MFR03 & 1 & $0-20$ & 10YR 5/2 & grayish brown & Clay Loam & $>20 \%$ & $\begin{array}{l}\text { Gravels, Large Rock } \\
\text { Frags }\end{array}$ & $\mathrm{N}$ & Terminated at large impassable gravels. \\
\hline NA & MFR04 & 1 & $0-30$ & 10YR 5/2 & grayish brown & Clay Loam & $>20 \%$ & $\begin{array}{l}\text { Gravels, Large Rock } \\
\text { Frags }\end{array}$ & $\mathrm{N}$ & Terminated at large impassable gravels. \\
\hline NA & MFR05 & 1 & $0-20$ & 10YR 5/2 & grayish brown & Clay Loam & $>20 \%$ & $\begin{array}{l}\text { Gravels, Large Rock } \\
\text { Frags }\end{array}$ & $\mathrm{N}$ & Terminated at large impassable gravels. \\
\hline \multirow{2}{*}{ IF10 } & \multirow{2}{*}{ MFR06 } & 1 & $0-10$ & 10YR 5/2 & grayish brown & Silty Clay Loam & $>20 \%$ & $\begin{array}{c}\text { Cobbles, Gravels, Large } \\
\text { Rock Frags }\end{array}$ & $\mathrm{Y}$ & 1: Flake (tertiary), Other Prehistoric \\
\hline & & 2 & $10-30$ & 10YR 5/2 & grayish brown & Silty Clay Loam & $>20 \%$ & $\begin{array}{c}\text { Cobbles, Gravels, Large } \\
\text { Rock Frags }\end{array}$ & $\mathrm{N}$ & Terminated at impassable dense gravels. \\
\hline NA & MFR07 & 1 & $0-20$ & 10YR 5/2 & grayish brown & Clay Loam & $>20 \%$ & $\begin{array}{c}\text { Gravels, Large Rock } \\
\text { Frags }\end{array}$ & $\mathrm{N}$ & Terminated at large impassable gravels. \\
\hline NA & MFR08 & 1 & $0-20$ & 10YR 5/2 & grayish brown & Clay Loam & $>20 \%$ & $\begin{array}{l}\text { Gravels, Large Rock } \\
\text { Frags }\end{array}$ & $\mathrm{N}$ & Terminated at large impassable gravels. \\
\hline NA & MFR09 & 1 & $0-20$ & 10YR 5/2 & grayish brown & Clay Loam & $>20 \%$ & $\begin{array}{l}\text { Gravels, Large Rock } \\
\text { Frags }\end{array}$ & $\mathrm{N}$ & Terminated at large impassable gravels. \\
\hline NA & MFR10 & 1 & $0-20$ & 10YR $5 / 2$ & grayish brown & Clay Loam & $>20 \%$ & $\begin{array}{l}\text { Gravels, Large Rock } \\
\text { Frags }\end{array}$ & $\mathrm{N}$ & Terminated at large impassable gravels. \\
\hline $\mathrm{NA}$ & MFR11 & 1 & $0-50$ & 10YR 2/1 & black & Clay Loam & 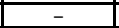 & 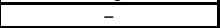 & $\mathrm{N}$ & Terminated at compact soil. \\
\hline NA & MFR12 & 1 & $0-20$ & 10YR $5 / 2$ & grayish brown & Clay Loam & $>20 \%$ & $\begin{array}{l}\text { Gravels, Large Rock } \\
\text { Frags }\end{array}$ & $\mathrm{N}$ & Terminated at large impassable gravels. \\
\hline NA & MFR13 & 1 & $0-20$ & 10YR 5/2 & grayish brown & Clay Loam & $>20 \%$ & $\begin{array}{l}\text { Gravels, Large Rock } \\
\text { Frags } \\
\end{array}$ & $\mathrm{N}$ & Terminated at large impassable gravels. \\
\hline \multirow[t]{2}{*}{$41 \mathrm{CM} 401$} & \multirow[t]{2}{*}{ MFV01 } & 1 & $0-6$ & 2.5 YR $5 / 4$ & reddish brown & Clay & $>20 \%$ & \begin{tabular}{|c|} 
Cobbles, Gravels, Large \\
Rock Frags, Mottles, \\
Pebbles
\end{tabular} & $\mathrm{N}$ & - \\
\hline & & 2 & 6-45 & $2.5 \mathrm{YR} 3 / 2$ & dusky red & Clay & $5-10 \%$ & Cobbles, Pebbles & $\mathrm{Y}$ & $\begin{array}{l}\text { 2: Flake (primary) [Flakes found about } 40 \mathrm{cmbs} \text { ] } \\
\text { Terminated at bedrock. }\end{array}$ \\
\hline \multirow{2}{*}{ 41CM401 } & \multirow{2}{*}{ MFV02 } & 1 & $0-15$ & 2.5YR $5 / 4$ & reddish brown & Clay & $>20 \%$ & \begin{tabular}{|c|} 
Cobbles, Gravels, Large \\
Rock Frags, Mottles, \\
Pebbles \\
\end{tabular} & $\mathrm{N}$ & - \\
\hline & & 2 & $15-22$ & 2.5 YR $3 / 1$ & dark reddish gray & Clay & $5-10 \%$ & $\begin{array}{l}\text { Cobbles, Large Rock } \\
\text { Frags, Pebbles }\end{array}$ & Y & $\begin{array}{l}\text { 1: Flake (tertiary) [Terminated at } 22 \mathrm{cmbs} \text { due to } \\
\text { large rock/bedrock] Terminated at bedrock. }\end{array}$ \\
\hline \multirow[t]{2}{*}{$41 \mathrm{CM} 401$} & \multirow[t]{2}{*}{ MFV03 } & 1 & $0-7$ & 2.5 YR $5 / 8$ & red & Clay & $10-20 \%$ & \begin{tabular}{|c|} 
Calcium Carbonate, \\
Cobbles, Gravels, Large \\
Rock Frags, Mottles, \\
Pebbles \\
\end{tabular} & $\mathrm{N}$ & - \\
\hline & & 2 & 7-15 & 2.5 YR $3 / 1$ & dark reddish gray & Clay & $10-20 \%$ & $\begin{array}{l}\text { Cobbles, Gravels, Large } \\
\text { Rock Frags, Pebbles }\end{array}$ & $\mathrm{Y}$ & $\begin{array}{c}\text { 1: Other Prehistoric [One worm seen in soil] } \\
\text { Terminated at large boulder and large tree root } \\
\text { running through shovel test. }\end{array}$ \\
\hline $41 \mathrm{CM} 401$ & MFV04 & 1 & $0-15$ & 2.5 YR $3 / 1$ & dark reddish gray & Clay Loam & $>20 \%$ & $\begin{array}{l}\text { Cobbles, Gravels, Large } \\
\text { Rock Frags, Pebbles }\end{array}$ & $\mathrm{Y}$ & $\begin{array}{l}\text { 1: Flake (tertiary) [Disturbed ground at area of } \\
\text { ST] Terminated at impenetrable cobbles. }\end{array}$ \\
\hline 41CM401 & MFV05 & 1 & $0-40$ & $2.5 \mathrm{YR} 3 / 1$ & dark reddish gray & Clay & $1-5 \%$ & Gravels, Pebbles & $\mathrm{N}$ & Terminated at compact soil. \\
\hline NA & MFV06 & 1 & $0-45$ & 10YR 2/1 & black & Clay & $10-20 \%$ & \begin{tabular}{|c|} 
Cobbles, Gravels, Large \\
Rock Frags, Pebbles, \\
Earthworms \\
\end{tabular} & $\mathrm{N}$ & Terminated at compact soil. \\
\hline NA & MFV07 & 1 & $0-45$ & 10YR 2/1 & black & Clay & $10-20 \%$ & \begin{tabular}{|c|} 
Cobbles, Gravels, Large \\
Rock Frags, Pebbles, \\
Earthworms
\end{tabular} & $\mathrm{N}$ & Terminated at compact soil. \\
\hline & & 1 & $0-30$ & 10YR 4/3 & brown & Sand & $5-10 \%$ & Gravels, Pebbles & $\mathrm{N}$ & - \\
\hline NA & MFV08 & 2 & $30-50$ & 10YR 5/2 & grayish brown & Sandy Clay & $5-10 \%$ & $\begin{array}{c}\text { Calcium Carbonate, } \\
\text { Gravels, Mottles, Pebbles }\end{array}$ & $\mathrm{N}$ & Terminated at compact disturbed clay. \\
\hline NA & MFYO9 & 1 & $0-5$ & 10YR $4 / 2$ & dark grayish brown & Sand & $1-5 \%$ & $\begin{array}{c}\begin{array}{c}\text { Gravels, Pebbles, Roots } \\
\text { and rootlets }\end{array} \\
\end{array}$ & $\mathrm{N}$ & - \\
\hline & & 2 & 5-90 & 10YR 6/6 & brownish yellow & Sand & $1-5 \%$ & $\begin{array}{c}\text { Cobbles, Gravels, } \\
\text { Pebbles }\end{array}$ & $\mathrm{N}$ & Terminated at depth. \\
\hline NA & MFV10 & 1 & $1-10$ & 10YR $4 / 6$ & $\begin{array}{c}\text { dark yellowish } \\
\text { brown }\end{array}$ & Sand & $1-5 \%$ & Gravels, Pebbles & $\mathrm{N}$ & - \\
\hline & & 2 & $10-60$ & 10YR $5 / 6$ & yellowish brown & Sand & $1-5 \%$ & Gravels, Mottles, Pebbles & $\mathrm{N}$ & Terminated at depth. \\
\hline & & 1 & $0-5$ & 10YR $3 / 1$ & very dark gray & Sand & $10-20 \%$ & $\begin{array}{l}\text { Pebbles, Common roots } \\
\text { and rootlets many large }\end{array}$ & $\mathrm{N}$ & - \\
\hline NA & MFV11 & 2 & $5-55$ & 10YR $5 / 4$ & yellowish brown & Sand & $>20 \%$ & Pebbles, Roots & $\mathrm{N}$ & - \\
\hline & & 3 & $55-60$ & 10YR $6 / 4$ & $\begin{array}{l}\text { light yellowish } \\
\text { brown }\end{array}$ & Sand & $>20 \%$ & Pebbles, Roots & $\mathrm{N}$ & Terminated at hydric soil- feels very wet. \\
\hline
\end{tabular}




\begin{tabular}{|c|c|c|c|c|c|c|c|c|c|c|}
\hline Site No. & $\begin{array}{c}\text { Shovel Test } \\
\text { No. }\end{array}$ & Level & $\begin{array}{l}\text { Depth } \\
\text { (cmbs) }\end{array}$ & $\begin{array}{c}\text { Munsell Soil } \\
\text { value }\end{array}$ & $\begin{array}{l}\text { Munsell Soil } \\
\text { Color }\end{array}$ & Soil Texture & \begin{tabular}{|c|} 
Inclusion \\
Percentage
\end{tabular} & Inclusion Type & \begin{tabular}{|c|}
$\begin{array}{c}\text { Positive }(\mathrm{P}) \\
\text { or Negative } \\
(\mathrm{N})\end{array}$ \\
\end{tabular} & Comments/ Reason for Termination \\
\hline \multirow[t]{2}{*}{$41 \mathrm{GU} 200$} & \multirow[t]{2}{*}{ MFV12 } & 1 & $0-50$ & 10YR $3 / 3$ & dark brown & Silt Loam & $10-20 \%$ & $\begin{array}{l}\text { Gravels, Pebbles, Snail } \\
\text { Shell, Common roots and } \\
\text { rootlets in both levels. } \\
\text { Worms from } 0-30 \mathrm{cmbs}\end{array}$ & $\mathrm{N}$ & - \\
\hline & & 2 & $50-60$ & 10YR $3 / 6$ & $\begin{array}{c}\text { dark yellowish } \\
\text { brown }\end{array}$ & Silt Loam & $10-20 \%$ & \begin{tabular}{|c|} 
Gravels, Pebbles, Snail \\
Shell, Common roots \\
\end{tabular} & $\mathrm{N}$ & Terminated at large root at 60 . \\
\hline \multirow{2}{*}{$41 \mathrm{GU} 200$} & \multirow{2}{*}{ MFV13 } & 1 & $0-40$ & 10YR 3/3 & dark brown & Silty Clay & $10-20 \%$ & $\begin{array}{l}\text { Gravels, Pebbles, Snail } \\
\text { Shell, Roots and worms }\end{array}$ & $\mathrm{N}$ & - \\
\hline & & 2 & $40-70$ & 10YR $4 / 3$ & brown & Silty Clay & $10-20 \%$ & $\begin{array}{l}\text { Gravels, Pebbles, Snail } \\
\text { Shell, Roots. Many larger } \\
\text { as levels increased }\end{array}$ & $\mathrm{N}$ & Terminated at impenetrable root. \\
\hline \multirow{3}{*}{ NA } & \multirow{3}{*}{ MFV14 } & 1 & $1-30$ & 10YR 4/3 & brown & Sandy Loam & $5-10 \%$ & \begin{tabular}{|c|} 
Cobbles, Gravels, Snail \\
Shell
\end{tabular} & $\mathrm{N}$ & - \\
\hline & & 2 & $30-80$ & 10YR 4/4 & $\begin{array}{l}\text { dark yellowish } \\
\text { brown }\end{array}$ & Sandy Loam & $10-20 \%$ & \begin{tabular}{|c|}
$\begin{array}{c}\text { Gravels, Pebbles, Snail } \\
\text { Shell, Roots }\end{array}$ \\
\end{tabular} & $\mathrm{N}$ & - \\
\hline & & 3 & $80-100$ & 10YR 5/4 & yellowish brown & Sandy Loam & $5-10 \%$ & $\begin{array}{l}\text { Gravels, Pebbles, Roots } \\
\text { which increase with size }\end{array}$ & $\mathrm{N}$ & Terminated at depth. \\
\hline $\mathrm{NA}$ & MN06 & 1 & $0-50$ & 10YR 2/1 & black & Clay Loam & $>20 \%$ & Cobbles, Gravels & $\mathrm{N}$ & Terminated at bedrock. \\
\hline \multirow{2}{*}{ NA } & \multirow{2}{*}{ MR01 } & 1 & $0-30$ & 10YR 5/2 & grayish brown & Silty Clay & 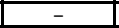 & - & $\mathrm{N}$ & $\begin{array}{lll}- & & \\
\end{array}$ \\
\hline & & 2 & $30-40$ & 10 YR $5 / 3$ & brown & Clay Loam & 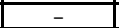 & - & $\mathrm{N}$ & Terminated at basal clay. \\
\hline \multirow[t]{2}{*}{ NA } & \multirow[t]{2}{*}{ MR02 } & 1 & $0-50$ & 10YR $6 / 4$ & $\begin{array}{l}\text { light yellowish } \\
\text { brown }\end{array}$ & Sandy Loam & - & - & $\mathrm{N}$ & - \\
\hline & & 2 & $50-60$ & 10YR 5/6 & yellowish brown & Sandy Clay & $10-20 \%$ & Mottles & $\mathrm{N}$ & Terminated at basal clay. \\
\hline \multirow[t]{2}{*}{ NA } & \multirow[t]{2}{*}{ MR03 } & 1 & $0-50$ & 10YR 6/4 & $\begin{array}{l}\text { light yellowish } \\
\text { brown }\end{array}$ & Sandy Loam & - & - & $\mathrm{N}$ & - \\
\hline & & 2 & $50-60$ & 10 YR $5 / 6$ & yellowish brown & Sandy Clay & $10-20 \%$ & Mottles & $\mathrm{N}$ & Terminated at basal clay. \\
\hline \multirow[t]{2}{*}{ NA } & \multirow[t]{2}{*}{ MR04 } & 1 & $0-50$ & 10YR $6 / 4$ & $\begin{array}{l}\text { light yellowish } \\
\text { brown }\end{array}$ & Sandy Loam & - & - & $\mathrm{N}$ & - \\
\hline & & 2 & $50-60$ & 10YR 5/6 & yellowish brown & Sandy Clay & $10-20 \%$ & Mottles & $\mathrm{N}$ & Terminated at basal clay. \\
\hline $\mathrm{NA}$ & MR05 & 1 & $0-40$ & 10YR 5/3 & brown & Loamy Sand & $\begin{array}{llll}- & & & 0\end{array}$ & 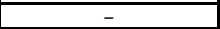 & $\mathrm{N}$ & Terminated at water table. \\
\hline NA & MR06 & 1 & $0-40$ & 10 YR $5 / 3$ & brown & Loamy Sand & - & - & $\mathrm{N}$ & Terminated at water table. \\
\hline NA & MR07 & 1 & $0-40$ & 10 YR $5 / 3$ & brown & Loamy Sand & - & - & $\mathrm{N}$ & Terminated at water table. \\
\hline $\mathrm{NA}$ & MR08 & 1 & $0-100$ & 10YR 5/3 & brown & Sand & - & - & $\mathrm{N}$ & Terminated at depth. \\
\hline NA & MR09 & 1 & $0-100$ & 10YR $6 / 4$ & $\begin{array}{l}\text { light yellowish } \\
\text { brown }\end{array}$ & Sandy Loam & - & - & $\mathrm{N}$ & Terminated at depth. \\
\hline NA & MR10 & 1 & $0-100$ & 10YR $6 / 4$ & $\begin{array}{l}\text { light yellowish } \\
\text { brown }\end{array}$ & Sandy Loam & - & - & $\mathrm{N}$ & Terminated at depth. \\
\hline NA & MR11 & 1 & $0-100$ & 10YR 6/4 & $\begin{array}{l}\text { light yellowish } \\
\text { brown }\end{array}$ & Sandy Loam & - & - & $\mathrm{N}$ & Terminated at depth. \\
\hline NA & MR13 & 1 & $0-100$ & 10YR 6/4 & $\begin{array}{c}\text { light yellowish } \\
\text { brown }\end{array}$ & Sandy Loam & - & - & $\mathrm{N}$ & Terminated at depth. \\
\hline \multirow{2}{*}{ NA } & \multirow{2}{*}{ MR14 } & 1 & $0-10$ & $7.5 Y R 5 / 6$ & strong brown & Sandy Loam & - & - & $\mathrm{N}$ & - \\
\hline & & 2 & $10-30$ & 2.5 YR $4 / 8$ & red & Sandy Clay & - & - & $\mathrm{N}$ & Terminated at basal clay. \\
\hline \multirow{2}{*}{ NA } & MR15 & 1 & $0-10$ & 7.5 YR $5 / 6$ & strong brown & Sandy Loam & - & - & $\mathrm{N}$ & - \\
\hline & MR15 & 2 & $10-30$ & 2.5 YR $4 / 8$ & red & Sandy Clay & - & - & $\mathrm{N}$ & Terminated at basal clay. \\
\hline NA & MR600 & 1 & $0-20$ & 10YR 4/4 & $\begin{array}{l}\text { dark yellowish } \\
\text { brown }\end{array}$ & Silty Clay Loam & - & - & $\mathrm{N}$ & - \\
\hline & & 2 & $20-50$ & 7.5 YR $5 / 4$ & brown & Sandy Clay & $10-20 \%$ & Gravels, Pebbles & $\mathrm{N}$ & Terminated at basal clay. \\
\hline & & 1 & $0-30$ & 10YR 5/2 & grayish brown & Sandy Clay & - & - & $\mathrm{N}$ & 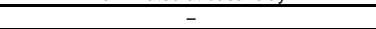 \\
\hline NA & MR601 & 2 & $30-50$ & 10YR $4 / 4$ & $\begin{array}{l}\text { dark yellowish } \\
\text { brown }\end{array}$ & Clay Loam & $1-5 \%$ & Calcium Carbonate & $\mathrm{N}$ & Terminated at compact soil. \\
\hline NA & MR602 & 1 & $0-50$ & 10YR 5/2 & grayish brown & Clay Loam & $10-20 \%$ & $\begin{array}{c}\text { Calcium Carbonate, } \\
\text { Cobbles, Gravels, } \\
\text { Pebbles }\end{array}$ & $\mathrm{N}$ & Terminated at compact soil. \\
\hline $41 \mathrm{CW} 173$ & MRC100 & 1 & $0-10$ & 10YR 2/2 & very dark brown & Clay & $>20 \%$ & Gravels & $\mathrm{N}$ & $\begin{array}{l}\text { Terminated at disturbance. dense introduced } \\
\text { gravels. }\end{array}$ \\
\hline $41 \mathrm{CW} 173$ & MRC101 & 1 & $0-10$ & 10YR 2/2 & very dark brown & Clay & $>20 \%$ & Gravels & $\mathrm{N}$ & $\begin{array}{c}\text { Terminated at disturbance. dense introduced } \\
\text { gravels. }\end{array}$ \\
\hline $41 \mathrm{CW} 173$ & MRC102 & 1 & $0-10$ & 10YR 2/2 & very dark brown & Clay & $>20 \%$ & Gravels & $\mathrm{N}$ & $\begin{array}{l}\text { Terminated at disturbance. dense introduced } \\
\text { gravels. }\end{array}$ \\
\hline $41 \mathrm{CW} 173$ & MRC103 & 1 & $0-10$ & 10YR $2 / 2$ & very dark brown & Clay & $>20 \%$ & Gravels & $\mathrm{N}$ & $\begin{array}{c}\text { Terminated at disturbance. dense introduced } \\
\text { gravels. }\end{array}$ \\
\hline $41 \mathrm{CW} 173$ & MRC104 & 1 & $0-10$ & 10YR 2/2 & very dark brown & Clay & $>20 \%$ & Gravels & $\mathrm{N}$ & $\begin{array}{c}\text { Terminated at disturbance. dense introduced } \\
\text { gravels. }\end{array}$ \\
\hline $41 \mathrm{CW} 173$ & MRC105 & 1 & $0-10$ & 10YR 2/2 & very dark brown & Clay & $>20 \%$ & Gravels & $\mathrm{N}$ & $\begin{array}{c}\text { Terminated at disturbance. dense introduced } \\
\text { gravels. }\end{array}$ \\
\hline NA & MRC106 & 1 & $0-50$ & 10YR 3/4 & $\begin{array}{c}\text { dark yellowish } \\
\text { brown }\end{array}$ & Clay Loam & $1-5 \%$ & Cobbles, Gravels & $\mathrm{N}$ & Terminated at compact soil. \\
\hline NA & MRC107 & 1 & $0-45$ & 10YR 2/2 & very dark brown & Clay & $1-5 \%$ & $\begin{array}{l}\text { Cobbles, Gravels, } \\
\text { Pebbles }\end{array}$ & $\mathrm{N}$ & Terminated at gravel bed. \\
\hline NA & MXR01 & 1 & $0-50$ & 10YR 2/1 & black & Clay Loam & - & - & $\mathrm{N}$ & Terminated at compact soil. \\
\hline NA & MXR02 & 1 & $0-40$ & 10YR $4 / 2$ & dark grayish brown & Silty Clay & - & - & $\mathrm{N}$ & - \\
\hline & & 2 & $40-60$ & 10YR $5 / 8$ & yellowish brown & Clay Loam & - & - & $\mathrm{N}$ & Terminated at basal clay. \\
\hline NA & MXR03 & 1 & $0-40$ & 10YR 4/2 & dark grayish brown & Silty Clay & - & - & $\mathrm{N}$ & - \\
\hline & & 2 & $40-60$ & 10YR 5/8 & yellowish brown & Clay Loam & - & - & $\mathrm{N}$ & Terminated at basal clay. \\
\hline NA & MXR04 & 1 & $0-100$ & 10YR 5/4 & yellowish brown & Loamy Sand & - & - & $\mathrm{N}$ & Terminated at depth. \\
\hline NA & MXR05 & 1 & $0-30$ & 10YR 5/4 & yellowish brown & Silt Loam & - & - & $\mathrm{N}$ & - \\
\hline NA & MXKरण5 & 2 & $30-40$ & 7.5 YR $5 / 6$ & strong brown & Clay Loam & - & - & $\mathrm{N}$ & Terminated at basal clay. \\
\hline NA & MXR06 & 1 & $0-40$ & 10YR $4 / 2$ & dark grayish brown & Silty Clay & - & - & $\mathrm{N}$ & - \\
\hline & & 2 & $40-60$ & 10YR 5/8 & yellowish brown & Clay Loam & - & - & $\mathrm{N}$ & Terminated at basal clay. \\
\hline NA & MXR07 & 1 & $0-40$ & 10YR $4 / 2$ & dark grayish brown & Silty Clay & - & - & $\mathrm{N}$ & - \\
\hline & & 2 & $40-60$ & 10YR 5/8 & yellowish brown & Clay Loam & - & - & $\mathrm{N}$ & Terminated at basal clay. \\
\hline
\end{tabular}




\begin{tabular}{|c|c|c|c|c|c|c|c|c|c|c|}
\hline Site No. & $\begin{array}{c}\text { Shovel Test } \\
\text { No. }\end{array}$ & Level & $\begin{array}{l}\text { Depth } \\
\text { (cmbs) }\end{array}$ & $\begin{array}{c}\text { Munsell Soil } \\
\text { value }\end{array}$ & $\begin{array}{l}\text { Munsell Soil } \\
\text { Color }\end{array}$ & Soil Texture & $\begin{array}{l}\text { Inclusion } \\
\text { Percentage }\end{array}$ & Inclusion Type & $\begin{array}{l}\text { Positive (P) } \\
\text { or Negative } \\
\text { (N) }\end{array}$ & Comments/ Reason for Termination \\
\hline \multirow[t]{2}{*}{ NA } & \multirow[t]{2}{*}{ MXR08 } & 1 & $0-20$ & 10YR 4/4 & $\begin{array}{c}\text { dark yellowish } \\
\text { brown }\end{array}$ & Silty Clay Loam & - & - & $\mathrm{N}$ & - \\
\hline & & 2 & $20-30$ & 10YR 5/8 & yellowish brown & Clay Loam & - & - & $\mathrm{N}$ & Terminated at basal clay. \\
\hline $\mathrm{NA}$ & MXR09 & 1 & $0-40$ & 10YR 2/1 & black & Clay Loam & - & - & $\mathrm{N}$ & Terminated at dense gravels. \\
\hline NA & MXR10 & 1 & $0-10$ & 10YR $4 / 4$ & $\begin{array}{l}\text { dark yellowish } \\
\text { brown }\end{array}$ & Silty Clay Loam & - & - & $\mathrm{N}$ & Terminated at dense gravels. \\
\hline NA & MXR11 & 1 & $0-40$ & 10YR 2/1 & black & Clay Loam & - & - & $\mathrm{N}$ & Terminated at dense gravels. \\
\hline NA & MXR12 & 1 & $0-45$ & 10YR $6 / 4$ & $\begin{array}{l}\text { light yellowish } \\
\text { brown }\end{array}$ & Sandy Loam & - & - & $\mathrm{N}$ & Terminated at depth. \\
\hline NA & MXR13 & 1 & $0-50$ & 10YR 2/1 & black & Clay Loam & - & - & $\mathrm{N}$ & Terminated at dense gravels. \\
\hline NA & MXR14 & 1 & $0-100$ & 10YR $6 / 4$ & $\begin{array}{c}\text { light yellowish } \\
\text { brown }\end{array}$ & Sandy Loam & - & - & $\mathrm{N}$ & Terminated at depth. \\
\hline NA & MXR15 & 1 & $0-50$ & 10YR 3/3 & dark brown & Clay Loam & $>20 \%$ & $\begin{array}{l}\text { Cobbles, Large Rock } \\
\text { Frags, Mottles } \\
\end{array}$ & $\mathrm{N}$ & Terminated at disturbed to $50 \mathrm{cmbs}$. \\
\hline NA & MXR16 & 1 & $0-100$ & 10YR 6/4 & $\begin{array}{l}\text { light yellowish } \\
\text { brown }\end{array}$ & Sandy Loam & - & - & $\mathrm{N}$ & Terminated at depth. \\
\hline NA & MXR17 & 1 & $0-40$ & 10YR 2/1 & black & Clay Loam & - & - & $\mathrm{N}$ & Terminated at dense gravels. \\
\hline NA & MXR18 & 1 & $0-40$ & 10YR 2/1 & black & Clay Loam & - & - & $\mathrm{N}$ & Terminated at dense gravels. \\
\hline $\mathrm{NA}$ & MXR19 & 1 & $0-40$ & 10YR 2/1 & black & Clay Loam & - & - & $\mathrm{N}$ & Terminated at dense gravels. \\
\hline NA & MXR20 & 1 & $0-40$ & 10YR 2/1 & black & Clay Loam & - & - & $\mathrm{N}$ & Terminated at dense gravels. \\
\hline NA & MXR21 & 1 & $0-40$ & 10YR 2/1 & black & Clay Loam & - & - & $\mathrm{N}$ & Terminated at dense gravels. \\
\hline \multirow{5}{*}{ NA } & \multirow{5}{*}{ NMG01 } & 1 & $0-20$ & 10YR $3 / 4$ & $\begin{array}{l}\text { dark yellowish } \\
\text { brown }\end{array}$ & Silty Clay Loam & $1-5 \%$ & Rootless, snail & $\mathrm{N}$ & - \\
\hline & & 2 & $20-40$ & 10YR 3/2 & \begin{tabular}{|c|}
$\begin{array}{c}\text { very dark grayish } \\
\text { brown }\end{array}$ \\
\end{tabular} & Silty Clay Loam & $5-10 \%$ & Root, rootlets, snail & $\mathrm{N}$ & - \\
\hline & & 3 & $40-60$ & 10YR 3/4 & $\begin{array}{c}\text { dark yellowish } \\
\text { brown }\end{array}$ & Silty Clay Loam & $1-5 \%$ & Mottles, Roots, snail & $\mathrm{N}$ & - \\
\hline & & 4 & $60-80$ & 10YR 4/4 & $\begin{array}{c}\text { dark yellowish } \\
\text { brown }\end{array}$ & Silty Clay Loam & $1-5 \%$ & Roots & $\mathrm{N}$ & - \\
\hline & & 5 & $80-100$ & 10YR 5/4 & yellowish brown & Silty Clay Loam & $1-5 \%$ & Mottles, Small roots & $\mathrm{N}$ & Terminated at depth. \\
\hline \multirow{3}{*}{ NA } & \multirow{3}{*}{ NMG02 } & 1 & $0-20$ & 10YR 4/2 & dark grayish brown & Silty Clay Loam & $1-5 \%$ & $\begin{array}{c}\text { Roots, rootlets, leaf litter, } \\
\text { snail }\end{array}$ & $\mathrm{N}$ & - \\
\hline & & 2 & $20-75$ & 10YR 3/2 & $\begin{array}{c}\begin{array}{c}\text { very dark grayish } \\
\text { brown }\end{array} \\
\end{array}$ & Silty Clay Loam & $5-10 \%$ & Roots, snails & $\mathrm{N}$ & - \\
\hline & & 3 & $75-100$ & 10YR 5/4 & yellowish brown & Silty Clay Loam & $1-5 \%$ & Snail Shell & $\mathrm{N}$ & Terminated at depth. \\
\hline \multirow{2}{*}{ NA } & \multirow{2}{*}{ NMG03 } & 1 & $0-50$ & 10YR $3 / 4$ & $\begin{array}{c}\text { dark yellowish } \\
\text { brown }\end{array}$ & Silty Clay Loam & $5-10 \%$ & Cobbles, Pebbles & $\mathrm{N}$ & - \\
\hline & & 2 & $50+$ & 10YR 5/2 & grayish brown & Silty Clay Loam & $5-10 \%$ & $\begin{array}{c}\text { Calcium Carbonate, } \\
\text { Pebbles }\end{array}$ & N & Terminated at basal clay. \\
\hline \multirow{2}{*}{ NA } & \multirow{2}{*}{ NMG04 } & 1 & $0-50$ & 10YR 3/4 & $\begin{array}{l}\text { dark yellowish } \\
\text { brown }\end{array}$ & Silty Clay Loam & $5-10 \%$ & Cobbles, Pebbles & $\mathrm{N}$ & - \\
\hline & & 2 & $50+$ & 10YR 5/2 & grayish brown & Silty Clay Loam & $5-10 \%$ & $\begin{array}{c}\text { Calcium Carbonate, } \\
\text { Pebbles }\end{array}$ & N & Terminated at basal clay. \\
\hline \multirow{2}{*}{ NA } & \multirow{2}{*}{ NMG05 } & 1 & $0-40$ & 10YR 3/4 & $\begin{array}{c}\text { dark yellowish } \\
\text { brown }\end{array}$ & Silty Clay Loam & $5-10 \%$ & Cobbles, Pebbles & $\mathrm{N}$ & - \\
\hline & & 2 & $40-50+$ & 10YR 5/2 & grayish brown & Silty Clay Loam & $5-10 \%$ & $\begin{array}{c}\text { Calcium Carbonate, } \\
\text { Pebbles }\end{array}$ & $\mathrm{N}$ & Terminated at basal clay. \\
\hline \multirow{2}{*}{ NA } & \multirow{2}{*}{ NMG06 } & 1 & $0-40$ & 10YR 3/4 & $\begin{array}{c}\text { dark yellowish } \\
\text { brown }\end{array}$ & Silty Clay Loam & $5-10 \%$ & Cobbles, Pebbles & $\mathrm{N}$ & - \\
\hline & & 2 & $40-50+$ & 10YR 5/2 & grayish brown & Silty Clay Loam & $5-10 \%$ & $\begin{array}{c}\text { Calcium Carbonate, } \\
\text { Pebbles }\end{array}$ & $\mathrm{N}$ & Terminated at basal clay. \\
\hline NA & NMG07 & 1 & $0-40$ & 10YR 3/4 & $\begin{array}{c}\text { dark yellowish } \\
\text { brown }\end{array}$ & Sandy Loam & $>20 \%$ & $\begin{array}{c}\text { Cobbles, Gravels, } \\
\text { Pebbles, Snail Shell }\end{array}$ & N & Terminated at bedrock. \\
\hline \multirow[t]{2}{*}{ NA } & \multirow[t]{2}{*}{ NMG08 } & 1 & $0-20$ & 10YR 4/2 & dark grayish brown & Clay Loam & $5-10 \%$ & $\begin{array}{l}\text { Cobbles, Gravels, } \\
\text { Pebbles, Snail Shell }\end{array}$ & $\mathrm{N}$ & - \\
\hline & & 2 & $20-50$ & 10YR 3/1 & very dark gray & Clay & $1-5 \%$ & Cobbles, Snail Shell & $\mathrm{N}$ & Terminated at compact soil. \\
\hline \multirow{3}{*}{ NA } & \multirow{3}{*}{ NMG09 } & 1 & $0-25$ & 10YR $4 / 4$ & $\begin{array}{l}\text { dark yellowish } \\
\text { brown }\end{array}$ & Sandy Clay Loam & $10-20 \%$ & $\begin{array}{l}\text { Cobbles, Gravels, } \\
\text { Pebbles }\end{array}$ & $\mathrm{N}$ & - \\
\hline & & 2 & $25-45$ & 10YR $3 / 2$ & $\begin{array}{c}\begin{array}{c}\text { very dark grayish } \\
\text { brown }\end{array} \\
\end{array}$ & Clay Loam & $5-10 \%$ & $\begin{array}{l}\text { Cobbles, Gravels, } \\
\text { Mottles, Pebbles }\end{array}$ & $\mathrm{N}$ & - \\
\hline & & 3 & $45-60$ & 10YR 3/2 & \begin{tabular}{|c|}
$\begin{array}{c}\text { very dark grayish } \\
\text { brown }\end{array}$ \\
\end{tabular} & Clay Loam & $5-10 \%$ & $\begin{array}{c}\text { Calcium Carbonate, } \\
\text { Cobbles, Mottles }\end{array}$ & N & Terminated at basal clay. \\
\hline 41BP961 & NMG10 & 1 & $0-20$ & 10YR 5/4 & yellowish brown & Sandy Loam & $>20 \%$ & $\begin{array}{l}\text { Calcium Carbonate, } \\
\text { Cobbles, Gravels, Large } \\
\text { Rock Frags, Mottles, } \\
\text { Pebbles, Snail Shell }\end{array}$ & $\mathrm{N}$ & Terminated at heavy disturbance. \\
\hline \multirow{3}{*}{ NA } & & 1 & $0-25$ & 10YR 4/4 & $\begin{array}{c}\text { dark yellowish } \\
\text { brown }\end{array}$ & Sandy Clay Loam & $10-20 \%$ & $\begin{array}{c}\text { Cobbles, Gravels, } \\
\text { Pebbles }\end{array}$ & $\mathrm{N}$ & - \\
\hline & NMG11 & 2 & $25-45$ & 10YR 3/2 & \begin{tabular}{|c|}
$\begin{array}{c}\text { very dark grayish } \\
\text { brown }\end{array}$ \\
\end{tabular} & Clay Loam & $5-10 \%$ & $\begin{array}{l}\text { Cobbles, Gravels, } \\
\text { Mottles, Pebbles }\end{array}$ & $\mathrm{N}$ & - \\
\hline & & 3 & $45-60$ & 10YR 3/2 & $\begin{array}{c}\text { very dark grayish } \\
\text { brown }\end{array}$ & Clay Loam & $5-10 \%$ & $\begin{array}{c}\text { Calcium Carbonate, } \\
\text { Cobbles, Mottles }\end{array}$ & $\mathrm{N}$ & Terminated at basal clay. \\
\hline NA & NMG12 & 1 & $0-20$ & 10YR $4 / 4$ & $\begin{array}{l}\text { dark yellowish } \\
\text { brown }\end{array}$ & Sandy Loam & $>20 \%$ & $\begin{array}{c}\text { Cobbles, Large Rock } \\
\text { Frags, Pebbles, Rootlets, } \\
\text { leaf litter }\end{array}$ & $\mathrm{N}$ & - \\
\hline & & 2 & $20-40$ & 10YR $3 / 2$ & \begin{tabular}{|c|}
$\begin{array}{c}\text { very dark grayish } \\
\text { brown }\end{array}$ \\
\end{tabular} & Sandy Clay Loam & $>20 \%$ & $\begin{array}{l}\text { Cobbles, Large Rock } \\
\text { Frags, Pebbles }\end{array}$ & $\mathrm{N}$ & Terminated at bedrock. \\
\hline NA & NMG13 & 1 & $0-15$ & 10YR $4 / 4$ & $\begin{array}{c}\text { dark yellowish } \\
\text { brown }\end{array}$ & Sandy Clay Loam & $>20 \%$ & $\begin{array}{l}\text { Cobbles, Large Rock } \\
\text { Frags, Pebbles }\end{array}$ & $\mathrm{N}$ & Terminated at bedrock or dense large cobbles. \\
\hline & & 1 & $0-20$ & 10YR $4 / 2$ & dark grayish brown & Sandy Clay Loam & $>20 \%$ & $\begin{array}{c}\text { Cobbles, Large Rock } \\
\text { Frags, Pebbles, Snail } \\
\text { Shell } \\
\end{array}$ & N & - \\
\hline NA & NMG14 & 2 & $20-30$ & 10YR 3/1 & very dark gray & Clay Loam & $5-10 \%$ & Cobbles, Mottles, Pebbles & $\mathrm{N}$ & - \\
\hline & & 3 & $30-60$ & 10YR 3/1 & very dark gray & Clay & $1-5 \%$ & $\begin{array}{c}\text { Calcium Carbonate, } \\
\text { Gravels }\end{array}$ & $\mathrm{N}$ & Terminated at basal clay. \\
\hline NA & NMG15 & 1 & 0-15 & 10YR $4 / 4$ & $\begin{array}{l}\text { dark yellowish } \\
\text { brown }\end{array}$ & Sandy Clay Loam & $5-10 \%$ & $\begin{array}{l}\text { Cobbles, Large Rock } \\
\text { Frags, Pebbles }\end{array}$ & $\mathrm{N}$ & Terminated at bedrock or dense large cobbles. \\
\hline NA & NMG16 & 1 & $0-15$ & 10YR $4 / 4$ & $\begin{array}{c}\text { dark yellowish } \\
\text { brown }\end{array}$ & Sandy Clay Loam & $5-10 \%$ & $\begin{array}{l}\text { Cobbles, Large Rock } \\
\text { Frags, Pebbles }\end{array}$ & $\mathrm{N}$ & Terminated at bedrock or dense large cobbles. \\
\hline
\end{tabular}




\begin{tabular}{|c|c|c|c|c|c|c|c|c|c|c|}
\hline Site No. & $\begin{array}{c}\text { Shovel Test } \\
\text { No. }\end{array}$ & Level & $\begin{array}{l}\text { Depth } \\
\text { (cmbs) }\end{array}$ & $\begin{array}{c}\text { Munsell Soil } \\
\text { value }\end{array}$ & $\begin{array}{l}\text { Munsell Soil } \\
\text { Color }\end{array}$ & Soil Texture & $\begin{array}{l}\text { Inclusion } \\
\text { Percentage }\end{array}$ & Inclusion Type & $\begin{array}{c}\text { Positive }(\mathrm{P}) \\
\text { or Negative } \\
(\mathrm{N})\end{array}$ & Comments/ Reason for Termination \\
\hline \multirow{2}{*}{ NA } & \multirow{2}{*}{ NMG17 } & 1 & $0-50$ & 10YR $5 / 2$ & grayish brown & Sandy Loam & $10-20 \%$ & $\begin{array}{c}\text { Snail Shell, Decaying } \\
\text { wood }\end{array}$ & $\mathrm{N}$ & - \\
\hline & & 2 & $50-70$ & 10YR $4 / 2$ & dark grayish brown & Sandy Clay Loam & $1-5 \%$ & Mottles, Decaying wood & $\mathrm{N}$ & Terminated at compact soil. \\
\hline \multirow{2}{*}{ NA } & \multirow{2}{*}{ NMG18 } & 1 & $0-20$ & 10YR 4/2 & dark grayish brown & Silty Clay Loam & $>20 \%$ & $\begin{array}{c}\text { Cobbles, Gravels, } \\
\text { Pebbles, Decaying roots, } \\
\text { rootlets }\end{array}$ & $\mathrm{N}$ & - \\
\hline & & 2 & $20-50$ & 10YR 5/4 & yellowish brown & Silty Clay Loam & $10-20 \%$ & \begin{tabular}{|c|} 
Calcium Carbonate, \\
Gravels, Mottles, Pebbles, \\
Snail Shell
\end{tabular} & $\mathrm{N}$ & Terminated at basal clay. \\
\hline \multirow{2}{*}{ NA } & \multirow{2}{*}{ NMG19 } & 1 & $0-20$ & 10YR 4/2 & dark grayish brown & Silty Clay Loam & $>20 \%$ & \begin{tabular}{|c|} 
Cobbles, Gravels, \\
Pebbles, Decaying roots, \\
rootlets
\end{tabular} & $\mathrm{N}$ & - \\
\hline & & 2 & $20-50$ & 10YR 5/4 & yellowish brown & Silty Clay Loam & $10-20 \%$ & $\begin{array}{c}\text { Calcium Carbonate, } \\
\text { Gravels, Mottles, Pebbles, } \\
\text { Snail Shell }\end{array}$ & $\mathrm{N}$ & Terminated at basal clay. \\
\hline NA & NMG20 & 1 & $0-15$ & 10YR $4 / 4$ & $\begin{array}{l}\text { dark yellowish } \\
\text { brown }\end{array}$ & Sandy Clay Loam & $10-20 \%$ & $\begin{array}{l}\text { Cobbles, Large Rock } \\
\text { Frags, Pebbles }\end{array}$ & N & Terminated at bedrock or dense large cobbles. \\
\hline \multirow[b]{2}{*}{ NA } & \multirow[b]{2}{*}{ NMG21 } & 1 & $0-20$ & 10YR $4 / 2$ & dark grayish brown & Sandy Clay Loam & $>20 \%$ & $\begin{array}{l}\text { Cobbles, Gravels, } \\
\text { Pebbles, Snail Shell }\end{array}$ & N & - \\
\hline & & 2 & $20-60$ & 10YR 4/1 & dark gray & Clay Loam & $>20 \%$ & $\begin{array}{c}\text { Calcium Carbonate, } \\
\text { Cobbles, Gravels, } \\
\text { Pebbles, Roots }\end{array}$ & N & Terminated at basal clay. \\
\hline \multirow{2}{*}{ NA } & \multirow{2}{*}{ RW950 } & 1 & $0-30$ & 10YR 2/1 & black & Clay Loam & $1-5 \%$ & Gravels & $\mathrm{N}$ & 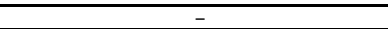 \\
\hline & & 2 & $30-35$ & 10YR 2/1 & black & Clay & $10-20 \%$ & Gravels, Cobbles & $\mathrm{N}$ & Terminated at gravel impasse. \\
\hline NA & RW951 & 1 & $0-30$ & 10YR $2 / 1$ & black & Clay & 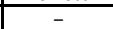 & - & $\mathrm{N}$ & Terminated at compact soil. \\
\hline NA & RW952 & 1 & $0-30$ & 10YR $2 / 1$ & black & Clay & $1-5 \%$ & Gravels & $\mathrm{N}$ & Terminated at compact soil. \\
\hline NA & RW953 & 1 & $0-30$ & 10YR 2/1 & black & Clay & $1-5 \%$ & Gravels & $\mathrm{N}$ & Terminated at compact soil. \\
\hline NA & RW1000 & 1 & $0-10$ & 10YR $3 / 1$ & very dark gray & Clay Loam & - & - & $\mathrm{N}$ & Terminated at bedrock. \\
\hline NA & RW1001 & 1 & $0-20$ & 7.5 YR $3 / 3$ & dark brown & Clay Loam & $1-5 \%$ & Gravels & $\mathrm{N}$ & Terminated at caliche. \\
\hline NA & RW1002 & 1 & $0-15$ & 7.5 YR $3 / 3$ & dark brown & Clay Loam & $1-5 \%$ & Gravels & $\mathrm{N}$ & Terminated at caliche. \\
\hline NA & RW1003 & 1 & $0-10$ & 10YR 2/2 & very dark brown & Clay Loam & - & $-z_{-1}$ & $\mathrm{~N}$ & Terminated at bedrock. \\
\hline \multirow[b]{2}{*}{ NA } & \multirow[b]{2}{*}{ RW1004 } & 1 & $0-10$ & 10YR $3 / 3$ & dark brown & Clay Loam & - & - & $\mathrm{N}$ & - \\
\hline & & 2 & $10-30$ & $7.5 Y R 2.5 / 3$ & very dark brown & Clay & - & - & $\mathrm{N}$ & Terminated at sterile soil. \\
\hline$\overline{N A}$ & RW1005 & 1 & $0-10$ & 10YR 3/3 & dark brown & Clay Loam & $1-5 \%$ & Calcium Carbonate & $\mathrm{N}$ & Terminated at bedrock. \\
\hline NA & RW2500 & 1 & $0-10$ & 10YR $3 / 1$ & very dark gray & Clay Loam & - & - & $\mathrm{N}$ & Terminated at bedrock. \\
\hline NA & RW2501 & 1 & $0-20$ & 7.5 YR $3 / 3$ & dark brown & Clay Loam & $1-5 \%$ & Gravels & $\mathrm{N}$ & Terminated at caliche. \\
\hline NA & RW2502 & 1 & $0-15$ & $7.5 \mathrm{YR} 3 / 3$ & dark brown & Clay Loam & $1-5 \%$ & Gravels & $\mathrm{N}$ & Terminated at caliche. \\
\hline NA & RW2503 & 1 & $0-10$ & 10YR $2 / 2$ & very dark brown & Clay Loam & - & - & $\mathrm{N}$ & Terminated at bedrock. \\
\hline \multirow[b]{2}{*}{ NA } & & 1 & $0-10$ & 10YR $3 / 3$ & dark brown & Clay Loam & - & - & $\mathrm{N}$ & - \\
\hline & RW2504 & 2 & $10-30$ & $7.5 Y R 2.5 / 3$ & very dark brown & Clay & - & - & $\mathrm{N}$ & Terminated at sterile soil. \\
\hline NA & RW2505 & 1 & $0-10$ & 10YR 3/3 & dark brown & Clay Loam & $1-5 \%$ & Calcium Carbonate & $\mathrm{N}$ & Terminated at bedrock. \\
\hline NA & RW2506 & 1 & $0-30$ & 7.5YR $2.5 / 3$ & very dark brown & Clay Loam & $>20 \%$ & Gravels & $\mathrm{N}$ & Terminated at bedrock. \\
\hline & & 1 & $0-20$ & 7.5YR $2.5 / 3$ & very dark brown & Clay & $>20 \%$ & Gravels & $\mathrm{N}$ & - \\
\hline$T N A$ & & 2 & $20-30$ & 2.5 YR $3 / 3$ & dark reddish brown & Clay & - & - & $\mathrm{N}$ & Terminated at bedrock. \\
\hline & 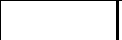 & 1 & $0-20$ & 7.5YR $2.5 / 3$ & very dark brown & Clay & $>20 \%$ & Gravels & $\mathrm{N}$ & - \\
\hline & & 2 & $20-30$ & 2.5 YR $3 / 3$ & dark reddish brown & Clay & - & - & $\mathrm{N}$ & Terminated at bedrock. \\
\hline & & 1 & $0-20$ & 7.5 YR $2.5 / 3$ & very dark brown & Clay & $>20 \%$ & Gravels & $\mathrm{N}$ & - \\
\hline $\mathrm{TNA}$ & nVv 2509 & 2 & $20-30$ & 2.5 YR $3 / 3$ & dark reddish brown & Clay & - & - & $\mathrm{N}$ & Terminated at bedrock. \\
\hline & & 1 & $0-20$ & $7.5 Y R 2.5 / 3$ & very dark brown & Clay & $>20 \%$ & Gravels & $\mathrm{N}$ & - \\
\hline $\mathrm{TNA}$ & RVV 2510 & 2 & $20-30$ & 2.5 YR $3 / 3$ & dark reddish brown & Clay & - & - & $\mathrm{N}$ & Terminated at bedrock. \\
\hline IF11 & RW2511 & 1 & $0-10$ & 10YR 3/3 & dark brown & Clay Loam & $>20 \%$ & Cobbles & $\mathrm{N}$ & Terminated at bedrock. \\
\hline IF11 & RW2512 & 1 & $0-10$ & 10YR $3 / 3$ & dark brown & Clay Loam & $>20 \%$ & Cobbles & $\mathrm{N}$ & Terminated at bedrock. \\
\hline IF11 & RW2513 & 1 & $0-10$ & 10YR $3 / 3$ & dark brown & Clay Loam & $>20 \%$ & Cobbles & $\mathrm{N}$ & Terminated at bedrock. \\
\hline IF11 & RW2514 & 1 & $0-10$ & 10YR $3 / 3$ & dark brown & Clay Loam & $>20 \%$ & Cobbles & $\mathrm{N}$ & Terminated at bedrock. \\
\hline IF11 & RW2515 & 1 & $0-10$ & 10YR $3 / 3$ & dark brown & Clay Loam & $>20 \%$ & Cobbles & $\mathrm{N}$ & Terminated at bedrock. \\
\hline NA & RW2517 & 1 & $0-10$ & 10YR $3 / 3$ & dark brown & Clay Loam & $>20 \%$ & Cobbles & $\mathrm{N}$ & Terminated at bedrock. \\
\hline NA & RW2518 & 1 & $0-5$ & 10YR $3 / 3$ & dark brown & Clay Loam & $>20 \%$ & Cobbles & $\mathrm{N}$ & Terminated at bedrock. \\
\hline NA & RW2519 & 1 & $0-10$ & 10YR $3 / 3$ & dark brown & Clay Loam & $>20 \%$ & Cobbles & $\mathrm{N}$ & Terminated at bedrock. \\
\hline $41 \mathrm{CM} 404$ & BW2520 & 1 & $0-30$ & 10YR $3 / 3$ & dark brown & Clay Loam & $>20 \%$ & Cobbles & $\mathrm{N}$ & - \\
\hline & & 2 & $30-35$ & 10YR $3 / 3$ & dark brown & Clay Loam & $>20 \%$ & Cobbles & $\mathrm{N}$ & Terminated at caliche. \\
\hline$\overline{N A}$ & RW2521 & $\frac{2}{1}$ & $0-10$ & 10YR $3 / 3$ & dark brown & Clay Loam & $>20 \%$ & Cobbles & $\mathrm{N}$ & Terminated at bedrock. \\
\hline NA & SS01 & 1 & $0-35$ & 10YR $5 / 3$ & brown & Silty Clay Loam & $>20 \%$ & Gravels & $\mathrm{N}$ & Terminated at bedrock. \\
\hline NA & SS02 & 1 & $0-30$ & 10YR $3 / 2$ & \begin{tabular}{|c|} 
very dark grayish \\
brown
\end{tabular} & Silty Clay Loam & $1-5 \%$ & Gravels & $\mathrm{N}$ & Terminated at bedrock. \\
\hline NA & $\mathrm{SS} 03$ & 1 & $0-45$ & 10YR 3/2 & $\begin{array}{c}\begin{array}{c}\text { very dark grayish } \\
\text { brown }\end{array} \\
\end{array}$ & Silty Clay Loam & $1-5 \%$ & Gravels & $\mathrm{N}$ & Terminated at bedrock. \\
\hline$\overline{N A}$ & $\mathrm{SS} 04$ & 1 & $0-5$ & 10YR $5 / 3$ & brown & Silty Clay Loam & $>20 \%$ & Gravels & $\mathrm{N}$ & Terminated at bedrock. \\
\hline NA & SS05 & 1 & $0-20$ & 10 YR $5 / 3$ & brown & Silty Clay Loam & $>20 \%$ & Cobbles & $\mathrm{N}$ & Terminated at bedrock. \\
\hline NA & SS06 & 1 & $0-10$ & 7.5YR $2.5 / 2$ & very dark brown & Silty Clay Loam & $10-20 \%$ & Cobbles & $\mathrm{N}$ & Terminated at bedrock. \\
\hline NA & SS07 & 1 & $0-30$ & 7.5YR $2.5 / 2$ & very dark brown & Silty Clay Loam & $>20 \%$ & Cobbles & $\mathrm{N}$ & Terminated at bedrock. \\
\hline NA & SS08 & 1 & $0-16$ & $7.5 Y R 2.5 / 2$ & very dark brown & Silty Clay Loam & $>20 \%$ & Cobbles & $\mathrm{N}$ & Terminated at bedrock. \\
\hline NA & SS09 & 1 & $0-5$ & $7.5 Y R 2.5 / 2$ & very dark brown & Silty Clay Loam & $>20 \%$ & Cobbles & $\mathrm{N}$ & Terminated at bedrock. \\
\hline NA & SS10 & 1 & $0-30$ & 10YR 2/2 & very dark brown & Silty Clay & $>20 \%$ & Cobbles & $\mathrm{N}$ & Terminated at bedrock. \\
\hline NA & SS11 & 1 & $0-25$ & 10YR $2 / 2$ & very dark brown & Silty Clay & $>20 \%$ & Cobbles, Pebbles & $\mathrm{N}$ & Terminated at bedrock. \\
\hline IF11 & SS12 & 1 & $0-10$ & 10YR $2 / 2$ & very dark brown & Silty Clay Loam & $>20 \%$ & Cobbles, Pebbles & $\mathrm{N}$ & Terminated at bedrock. \\
\hline NA & SS13 & 1 & $0-5$ & 10YR $4 / 3$ & brown & Silty Clay Loam & $10-20 \%$ & Cobbles, Gravels & $\mathrm{N}$ & Terminated at bedrock. \\
\hline
\end{tabular}




\begin{tabular}{|c|c|c|c|c|c|c|c|c|c|c|}
\hline Site No. & \begin{tabular}{|} 
Shovel Test \\
No.
\end{tabular} & Level & $\begin{array}{l}\text { Depth } \\
\text { (cmbs) }\end{array}$ & $\begin{array}{c}\text { Munsell Soil } \\
\text { value }\end{array} \mid$ & $\begin{array}{l}\text { Munsell Soil } \\
\text { Color }\end{array}$ & Soil Texture & \begin{tabular}{|l|} 
Inclusion \\
Percentage
\end{tabular} & Inclusion Type & $\begin{array}{c}\text { Positive (P) } \\
\text { or Negative } \\
(\mathrm{N})\end{array}$ & Comments/ Reason for Termination \\
\hline $\mathrm{NA}$ & SS14 & 1 & $0-10$ & 10YR $3 / 3$ & dark brown & Silty Clay Loam & $>20 \%$ & Cobbles, Gravels & $\mathrm{N}$ & Terminated at bedrock. \\
\hline NA & SS15 & 1 & $0-35$ & 10YR $4 / 2$ & dark grayish brown & Silty Clay Loam & $>20 \%$ & Cobbles, Gravels, Mottles & $\mathrm{N}$ & Terminated at bedrock. \\
\hline \multirow[b]{2}{*}{ NA } & \multirow[b]{2}{*}{ TM01 } & 1 & $0-30$ & 7.5YR $5 / 6$ & strong brown & Sandy Loam & - & - & $\mathrm{N}$ & - \\
\hline & & 2 & $30-65$ & 7.5 YR $5 / 6$ & strong brown & Sandy Clay Loam & $5-10 \%$ & Mottles & $\mathrm{N}$ & Terminated at compact soil. \\
\hline NA & TM02 & 1 & $0-40$ & 7.5 YR $4 / 4$ & brown & Sandy Clay Loam & - & - & $\mathrm{N}$ & Terminated at water table. \\
\hline NA & TM03 & 1 & $0-30$ & $7.5 Y R 3 / 4$ & dark brown & Sandy Clay Loam & - & - & $\mathrm{N}$ & Terminated at water table. \\
\hline NA & TM04 & 1 & $0-30$ & 7.5YR $3 / 4$ & dark brown & Sandy Clay Loam & - & - & $\mathrm{N}$ & Terminated at water table. \\
\hline NA & TM05 & 1 & $0-35$ & 7.5YR $3 / 4$ & dark brown & Sandy Clay Loam & - & - & $\mathrm{N}$ & Terminated at water table. \\
\hline NA & TM06 & 1 & $0-50$ & 10YR 2/2 & very dark brown & Sandy Clay Loam & - & - & $\mathrm{N}$ & Terminated at water table. \\
\hline \multirow{2}{*}{ NA } & \multirow{2}{*}{ TM07 } & 1 & $0-30$ & 7.5 YR $3 / 3$ & dark brown & Clay Loam & - & - & $\mathrm{N}$ & - \\
\hline & & 2 & $30-35$ & 7.5 YR $5 / 6$ & strong brown & Clay Loam & $\begin{array}{c}- \\
\end{array}$ & 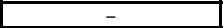 & $\mathrm{N}$ & Terminated at basil clay. \\
\hline $\mathrm{NA}$ & TM08 & 1 & $0-35$ & 10YR 3/1 & very dark gray & Clay Loam & - & - & $\mathrm{N}$ & Terminated at root impasse. \\
\hline $\mathrm{NA}$ & TM09 & 1 & $0-35$ & 7.5 YR $3 / 3$ & dark brown & Clay Loam & - & - & $\mathrm{N}$ & Terminated at water table. \\
\hline $\mathrm{NA}$ & TM10 & 1 & $0-40$ & 10YR 4/1 & dark gray & Clay Loam & - & - & $\mathrm{N}$ & Terminated at compact soil. \\
\hline NA & TM11 & 1 & $0-35$ & 10YR $4 / 4$ & $\begin{array}{c}\text { dark yellowish } \\
\text { brown }\end{array}$ & Sandy Clay Loam & - & - & $\mathrm{N}$ & Terminated at water table. \\
\hline \multirow{2}{*}{ NA } & \multirow{2}{*}{ TM12 } & 1 & $0-30$ & 7.5YR $5 / 4$ & brown & Sandy Loam & $1-5 \%$ & $\begin{array}{c}\text { Large Rock Frags, } \\
\text { Pebbles } \\
\end{array}$ & $\mathrm{N}$ & - \\
\hline & & 2 & $30-55$ & $7.5 Y R 5 / 8$ & strong brown & Sandy Clay Loam & - & - & $\mathrm{N}$ & Terminated at hydric soil. \\
\hline \multirow{2}{*}{ NA } & \multirow{2}{*}{ TM13 } & 1 & $0-10$ & 7.5YR 4/4 & brown & Sandy Loam & $1-5 \%$ & Gravels, Pebbles & $\mathrm{N}$ & - \\
\hline & & 2 & $10-15$ & $7.5 Y R 5 / 8$ & strong brown & Clay & 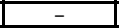 & - & $\mathrm{N}$ & Terminated at basal clay. \\
\hline \multirow{2}{*}{ NA } & \multirow{2}{*}{ TM14 } & 1 & $0-30$ & 7.5YR 4/1 & dark gray & Loamy Sand & - & - & $\mathrm{N}$ & - \\
\hline & & 2 & $30-35$ & 7.5 YR $5 / 8$ & strong brown & Clay & - & - & $\mathrm{N}$ & Terminated at basal clay. \\
\hline \multirow{2}{*}{ NA } & \multirow{2}{*}{ TM15 } & 1 & $0-40$ & $7.5 Y R 4 / 4$ & brown & Sandy Loam & $1-5 \%$ & Gravels, Pebbles & $\mathrm{N}$ & - \\
\hline & & 2 & $40-45$ & 7.5 YR $5 / 8$ & strong brown & Clay & - & - & $\mathrm{N}$ & Terminated at basal clay. \\
\hline & & 1 & $0-40$ & 10YR 5/1 & gray & Sandy Loam & - & - & $\mathrm{N}$ & - \\
\hline NA & TM16 & 2 & $40-45$ & 10YR 6/1 & gray & Sandy Clay Loam & - & - & $\mathrm{N}$ & Terminated at water table. \\
\hline $\mathrm{NA}$ & TM17 & 1 & $0-50$ & 7.5YR 4/4 & brown & Sandy Loam & $1-5 \%$ & Gravels, Pebbles & $\mathrm{N}$ & Terminated at water table. \\
\hline & & 1 & $0-30$ & 7.5 YR $5 / 6$ & strong brown & Sand & $1-5 \%$ & Pebbles & $\mathrm{N}$ & - \\
\hline NA & TM18 & 2 & $30-65$ & 7.5 YR $5 / 8$ & strong brown & Sandy Loam & $1-5 \%$ & Pebbles & $\mathrm{N}$ & - \\
\hline & & 3 & $65-75$ & 7.5 YR $6 / 8$ & reddish yellow & Sandy Loam & $1-5 \%$ & Pebbles & $\mathrm{N}$ & Terminated at water table. \\
\hline & & 1 & $0-15$ & 7.5 YR $5 / 8$ & strong brown & Sandy Loam & $1-5 \%$ & Pebbles & $\mathrm{N}$ & - \\
\hline NA & TM19 & 2 & $15-30$ & 7.5YR 6/6 & reddish yellow & Sandy Clay Loam & $1-5 \%$ & Pebbles & $\mathrm{N}$ & - \\
\hline & & 3 & $30-40$ & 7.5 YR $6 / 8$ & reddish yellow & Clay & - & - & $\mathrm{N}$ & Terminated at hydric soil. \\
\hline NA & TM20 & 1 & $0-35$ & $5 Y R 4 / 6$ & yellowish red & Sandy Loam & $5-10 \%$ & $\begin{array}{c}\text { Cobbles, Gravels, Large } \\
\text { Rock Frags, Pebbles }\end{array}$ & $\mathrm{N}$ & Terminated at large rock frag impasse. \\
\hline & & 1 & $0-30$ & 7.5YR $4 / 4$ & brown & Sandy Loam & $1-5 \%$ & Pebbles & $\mathrm{N}$ & - \\
\hline NA & TM21 & 2 & $30-50$ & 7.5 YR $5 / 6$ & strong brown & Sandy Loam & $1-5 \%$ & Pebbles & $\mathrm{N}$ & - \\
\hline & & 3 & $50-60$ & 7.5YR $5 / 8$ & strong brown & Sandy Clay Loam & $1-5 \%$ & Pebbles & $\mathrm{N}$ & Terminated at hydric soil. \\
\hline $\mathrm{NA}$ & TM22 & 1 & $0-20$ & 7.5 YR $4 / 4$ & brown & Sandy Loam & $\begin{array}{c}- \\
\end{array}$ & 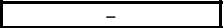 & $\mathrm{N}$ & Terminated at hit asphalt. \\
\hline & & 1 & $0-30$ & 7.5YR 4/4 & brown & Sandy Loam & $1-5 \%$ & & $\mathrm{~N}$ & - \\
\hline NA & TM23 & 2 & $30-45$ & 7.5 YR $5 / 6$ & strong brown & Sandy Loam & $1-5 \%$ & Pebbles & $\mathrm{N}$ & - \\
\hline & & 3 & $45-50$ & 7.5YR $5 / 8$ & strong brown & Sandy Clay Loam & $1-5 \%$ & Pebbles & $\mathrm{N}$ & Terminated at hydric soil. \\
\hline $\mathrm{NA}$ & TN01 & 1 & $0-5$ & 10YR 3/1 & very dark gray & Silt Loam & $1-5 \%$ & Gravels & $\mathrm{N}$ & Terminated at compact soil. \\
\hline NA & TN02 & 1 & $0-30$ & 10YR 3/1 & very dark gray & Silty Clay Loam & - & - & $\mathrm{N}$ & Terminated at compact soil. \\
\hline $\mathrm{NA}$ & TN03 & 1 & $0-10$ & 10YR 3/1 & very dark gray & Silty Clay Loam & $10-20 \%$ & Gravels & $\mathrm{N}$ & Terminated at dense gravel lens. \\
\hline NA & TN04 & 1 & $0-20$ & 10YR $3 / 2$ & $\begin{array}{c}\text { very dark grayish } \\
\text { brown }\end{array}$ & Silty Clay Loam & $5-10 \%$ & Gravels, Mottles & $\mathrm{N}$ & Terminated at basal clay. \\
\hline $\mathrm{NA}$ & TN05 & 1 & $0-30$ & 10YR 3/1 & very dark gray & Silty Clay Loam & - & - & $\mathrm{N}$ & Terminated at compact soil. \\
\hline $\mathrm{NA}$ & TN500 & 1 & $0-5$ & 10YR 3/1 & very dark gray & Silt Loam & $1-5 \%$ & Gravels & $\mathrm{N}$ & Terminated at compact soil. \\
\hline $\mathrm{NA}$ & TN501 & 1 & $0-30$ & 10YR 3/1 & very dark gray & Silty Clay Loam & - & - & $\mathrm{N}$ & Terminated at compact soil. \\
\hline $\mathrm{NA}$ & TN502 & 1 & $0-10$ & 10YR 3/1 & very dark gray & Silty Clay Loam & $10-20 \%$ & Gravels & $\mathrm{N}$ & Terminated at dense gravel lens. \\
\hline NA & TN503 & 1 & $0-20$ & 10YR 3/2 & $\begin{array}{c}\text { very dark grayish } \\
\text { brown }\end{array}$ & Silty Clay Loam & $5-10 \%$ & Gravels, Mottles & $\mathrm{N}$ & Terminated at basal clay. \\
\hline NA & TN504 & 1 & $0-20$ & 10YR 3/2 & $\begin{array}{c}\text { very dark grayish } \\
\text { brown }\end{array}$ & Silty Clay Loam & $5-10 \%$ & Gravels, Mottles & $\mathrm{N}$ & Terminated at basal clay. \\
\hline NA & TN505 & 1 & $0-2$ & 10YR 3/2 & $\begin{array}{c}\text { very dark grayish } \\
\text { brown }\end{array}$ & Silty Clay Loam & $5-10 \%$ & Gravels, Mottles & $\mathrm{N}$ & Terminated at basal clay. \\
\hline NA & TN506 & 1 & $0-5$ & 10YR 3/2 & \begin{tabular}{|c|}
$\begin{array}{c}\text { very dark grayish } \\
\text { brown }\end{array}$ \\
\end{tabular} & Silty Clay Loam & $5-10 \%$ & Gravels, Mottles & $\mathrm{N}$ & Terminated at basal clay. \\
\hline $\mathrm{NA}$ & TN507 & 1 & $0-15$ & 10YR 2/1 & black & Silty Clay Loam & $10-20 \%$ & Gravels & $\mathrm{N}$ & Terminated at compact gravel lens. \\
\hline NA & TN508 & 1 & $0-15$ & 10YR 2/1 & black & Silty Clay Loam & $10-20 \%$ & Gravels & $\mathrm{N}$ & Terminated at compact gravel lens. \\
\hline $\mathrm{NA}$ & TN509 & 1 & $0-15$ & 10YR 2/1 & black & Silty Clay Loam & $10-20 \%$ & Gravels & $\mathrm{N}$ & Terminated at compact gravel lens. \\
\hline NA & TN510 & 1 & $0-15$ & 10YR $3 / 2$ & \begin{tabular}{|c|}
$\begin{array}{c}\text { very dark grayish } \\
\text { brown }\end{array}$ \\
\end{tabular} & Silty Clay Loam & $1-5 \%$ & Gravels, Mottles & $\mathrm{N}$ & Terminated at basal clay. \\
\hline NA & TN511 & 1 & $0-15$ & 10YR 3/2 & \begin{tabular}{|c|}
$\begin{array}{c}\text { very dark grayish } \\
\text { brown }\end{array}$ \\
\end{tabular} & Silty Clay Loam & $1-5 \%$ & Gravels, Mottles & $\mathrm{N}$ & Terminated at basal clay. \\
\hline NA & TN512 & 1 & $0-5$ & 10YR $4 / 2$ & dark grayish brown & Silty Clay Loam & $>20 \%$ & Gravels & $\mathrm{N}$ & Terminated at compact soil. \\
\hline NA & TN513 & 1 & 0-5 & 10YR 4/2 & dark grayish brown & Silty Clay Loam & $>20 \%$ & Gravels & $\mathrm{N}$ & Terminated at compact soil. \\
\hline NA & TN514 & 1 & $0-5$ & 10YR $4 / 2$ & dark grayish brown & Silty Clay Loam & $>20 \%$ & Gravels & $\mathrm{N}$ & Terminated at compact soil. \\
\hline & & 1 & $0-30$ & 10YR $5 / 4$ & yellowish brown & Silt Loam & $1-5 \%$ & Pebbles & $\mathrm{N}$ & - \\
\hline NA & TN515 & 2 & $30-40$ & $5 Y R 4 / 6$ & yellowish red & Silty Clay Loam & $1-5 \%$ & $\begin{array}{c}\text { Pebbles, Manganese } \\
\text { nodules }\end{array}$ & $\mathrm{N}$ & Terminated at basal clay. \\
\hline
\end{tabular}




\begin{tabular}{|c|c|c|c|c|c|c|c|c|c|c|}
\hline Site No. & $\begin{array}{c}\text { Shovel Test } \\
\text { No. }\end{array}$ & Level & $\begin{array}{l}\text { Depth } \\
\text { (cmbs) }\end{array}$ & $\begin{array}{c}\text { Munsell Soil } \\
\text { value }\end{array}$ & $\begin{array}{l}\text { Munsell Soil } \\
\text { Color }\end{array}$ & Soil Texture & \begin{tabular}{|c|} 
Inclusion \\
Percentage
\end{tabular} & Inclusion Type & \begin{tabular}{|c|} 
Positive (P) \\
or Negative \\
(N)
\end{tabular} & Comments/ Reason for Termination \\
\hline \multirow{2}{*}{ 41BP959 } & \multirow{2}{*}{ TN516 } & 1 & $0-50$ & 10YR $5 / 3$ & brown & Sandy Loam & $1-5 \%$ & Pebbles & $\mathrm{Y}$ & $\begin{array}{c}\text { 5: Flake (secondary), Flake (tertiary), Other } \\
\text { Prehistoric }\end{array}$ \\
\hline & & 2 & $50-55$ & $7.5 Y R 5 / 8$ & strong brown & Sandy Clay Loam & $5-10 \%$ & $\begin{array}{c}\text { Sandstone and } \\
\text { manganese }\end{array}$ & $\mathrm{N}$ & Terminated at basal clay. \\
\hline \multirow[b]{2}{*}{ 41BP959 } & \multirow[b]{2}{*}{ TN517 } & 1 & $0-50$ & 10YR 5/4 & yellowish brown & Silt Loam & $1-5 \%$ & Pebbles & $\mathrm{N}$ & - \\
\hline & & 2 & $50-60$ & 5YR $4 / 6$ & yellowish red & Silty Clay Loam & $1-5 \%$ & $\begin{array}{l}\text { Pebbles, Manganese } \\
\text { nodules }\end{array}$ & $\mathrm{N}$ & Terminated at basal clay. \\
\hline \multirow[b]{2}{*}{ 41BP959 } & \multirow[b]{2}{*}{ TN518 } & 1 & $0-50$ & 10YR 5/4 & yellowish brown & Silt Loam & $1-5 \%$ & Pebbles & $\mathrm{N}$ & - \\
\hline & & 2 & $50-60$ & 5YR 4/6 & yellowish red & Silty Clay Loam & $1-5 \%$ & $\begin{array}{c}\text { Pebbles, Manganese } \\
\text { nodules }\end{array}$ & $\mathrm{N}$ & Terminated at basal clay. \\
\hline \multirow[b]{2}{*}{ 41BP959 } & \multirow[b]{2}{*}{ TN519 } & 1 & $0-30$ & 10YR 5/4 & yellowish brown & Silt Loam & $1-5 \%$ & Pebbles & $\mathrm{N}$ & - \\
\hline & & 2 & $30-40$ & $5 Y R 4 / 6$ & yellowish red & Silty Clay Loam & $1-5 \%$ & $\begin{array}{c}\text { Pebbles, Manganese } \\
\text { nodules }\end{array}$ & $\mathrm{N}$ & Terminated at basal clay. \\
\hline $\mathrm{NA}$ & TN520 & 1 & $0-15$ & 10YR 2/1 & black & Silty Clay Loam & - & - & $\mathrm{N}$ & Terminated at compact soil. \\
\hline NA & TN521 & 1 & $0-25$ & 10YR 2/1 & black & Silty Clay Loam & - & - & $\mathrm{N}$ & Terminated at compact soil. \\
\hline 41BP959 & TN522 & 1 & $0-10$ & 10YR $6 / 3$ & pale brown & Silty Clay Loam & $>20 \%$ & Mottles & $\mathrm{N}$ & Terminated at basal clay. \\
\hline \multirow{2}{*}{ 41BP959 } & \multirow{2}{*}{ TN523 } & 1 & $0-75$ & 10YR $6 / 3$ & pale brown & Sandy Loam & $1-5 \%$ & Pebbles & $\mathrm{Y}$ & $\begin{array}{c}\text { 2: Flake (tertiary), Other Prehistoric Terminated } \\
\text { at basal clay. }\end{array}$ \\
\hline & & 1 & $75-80$ & 10YR $5 / 8$ & yellowish brown & Sandy Clay Loam & $5-10 \%$ & Gravels, Pebbles & $\mathrm{N}$ & Terminated at basal clay. \\
\hline NA & TN524 & 1 & $0-5$ & 10YR $4 / 2$ & dark grayish brown & Silt Loam & $10-20 \%$ & Gravels & $\mathrm{N}$ & Terminated at compact soil. \\
\hline $\mathrm{NA}$ & TN525 & 1 & $0-15$ & 10YR 3/1 & very dark gray & Silty Clay Loam & $10-20 \%$ & Gravels & $\mathrm{N}$ & Terminated at compact soil. \\
\hline NA & TN526 & 1 & $0-35$ & 10YR 3/1 & very dark gray & Silty Clay Loam & $10-20 \%$ & Gravels & $\mathrm{N}$ & Terminated at compact soil. \\
\hline NA & TN527 & 1 & $0-5$ & 10YR 3/1 & very dark gray & Silt Loam & $10-20 \%$ & Cobbles, Gravels & $\mathrm{N}$ & Terminated at compact soil. \\
\hline NA & TN528 & $\mathrm{n} / \mathrm{a}$ & $n / a$ & $n / a$ & $\mathrm{n} / \mathrm{a}$ & $\mathrm{n} / \mathrm{a}$ & $\mathrm{n} / \mathrm{a}$ & $\mathrm{n} / \mathrm{a}$ & $n / a$ & Not excavated due to stock pond disturbance \\
\hline $\mathrm{NA}$ & TN529 & 1 & $0-20$ & 10YR 3/1 & very dark gray & Silt Loam & $10-20 \%$ & Cobbles, Gravels & $\mathrm{N}$ & Terminated at compact soil. \\
\hline \multirow{3}{*}{ 41CM401 } & \multirow{3}{*}{ VM01 } & 1 & $0-7$ & 2.5 YR $3 / 2$ & dusky red & Clay & $>20 \%$ & $\begin{array}{c}\text { Gravels, Mottles, Pebbles, } \\
\text { Sand and organic material } \\
\text { like leaves }\end{array}$ & $\mathrm{N}$ & - \\
\hline & & 2 & $7-30$ & 10YR $2 / 2$ & very dark brown & Clay Loam & $5-10 \%$ & $\begin{array}{c}\text { Cobbles, Large Rock } \\
\text { Frags, Snail Shell } \\
\end{array}$ & $\mathrm{N}$ & - \\
\hline & & 3 & $30-40$ & 7.5YR $2.5 / 1$ & black & Clay Loam & $5-10 \%$ & Pebbles & $\mathrm{N}$ & Terminated at bedrock. \\
\hline \multirow[b]{2}{*}{$41 \mathrm{CM} 401$} & \multirow[b]{2}{*}{ VM02 } & 1 & $0-10$ & $2.5 \mathrm{YR} 4 / 6$ & red & Clay & $>20 \%$ & Gravels, Mottles, Pebbles & $\mathrm{N}$ & - \\
\hline & & 2 & $10-30$ & 10YR $2 / 2$ & very dark brown & Clay Loam & $>20 \%$ & $\begin{array}{c}\text { Large Rock Frags, } \\
\text { Pebbles } \\
\end{array}$ & $\mathrm{N}$ & Terminated at bedrock. \\
\hline \multirow{2}{*}{$41 \mathrm{CM} 401$} & VM03 & 1 & $0-17$ & 5 YR $5 / 3$ & reddish brown & Clay & $>20 \%$ & $\begin{array}{l}\text { Cobbles, Gravels, } \\
\text { Mottles, Pebbles }\end{array}$ & $\mathrm{N}$ & - \\
\hline & VMO3 & 2 & $17-25$ & 10YR $2 / 2$ & very dark brown & Clay Loam & $>20 \%$ & $\begin{array}{l}\text { Cobbles, Large Rock } \\
\text { Frags } \\
\end{array}$ & $\mathrm{Y}$ & $\begin{array}{l}\text { 4: Biface, Other Prehistoric Terminated at } \\
\text { bedrock. }\end{array}$ \\
\hline 41CM401 & VM04 & 1 & $0-70$ & 10YR $2 / 2$ & very dark brown & Clay Loam & $>20 \%$ & Pebbles, Snail Shell & $\mathrm{N}$ & Terminated at impassable cobbles at $70 \mathrm{cmbs}$. \\
\hline & & 1 & $0-20$ & 10YR $2 / 2$ & very dark brown & Clay Loam & $>20 \%$ & $\begin{array}{l}\text { Cobbles, Gravels, } \\
\text { Pebbles, Snail Shell }\end{array}$ & $\mathrm{Y}$ & 1: Flake (primary), Glass \\
\hline $41 \mathrm{CM} 401$ & VM05 & 2 & $20-50$ & 10YR 2/2 & very dark brown & Clay Loam & $>20 \%$ & $\begin{array}{l}\text { Cobbles, Gravels, } \\
\text { Pebbles, Snail Shell }\end{array}$ & $\mathrm{N}$ & - \\
\hline & & 3 & $50-60$ & 10YR $2 / 2$ & very dark brown & Clay Loam & $>20 \%$ & $\begin{array}{c}\text { Cobbles, Gravels, } \\
\text { Pebbles }\end{array}$ & $\mathrm{Y}$ & $\begin{array}{c}\text { 1: Core, Core, Flake (secondary) Terminated at } \\
\text { depth. }\end{array}$ \\
\hline NA & vMOG & 1 & $0-30$ & 10YR 2/2 & very dark brown & Clay & $1-5 \%$ & Cobbles, Pebbles & $\mathrm{N}$ & - \\
\hline $\mathrm{TNA}$ & viviod & 2 & $30-40$ & 10YR 3/1 & very dark gray & Clay & $1-5 \%$ & Gravels, Pebbles & $\mathrm{N}$ & Terminated at basal clay. \\
\hline NA & VM07 & 1 & $0-30$ & 10YR 2/2 & very dark brown & Clay & $1-5 \%$ & Cobbles, Pebbles & $\mathrm{N}$ & - \\
\hline $\mathrm{TNA}$ & Viviur & 2 & $30-40$ & 10YR 3/1 & very dark gray & Clay & $1-5 \%$ & Gravels, Pebbles & $\mathrm{N}$ & Terminated at basal clay. \\
\hline$N A$ & VMOP & 1 & $0-70$ & 10YR 5/6 & yellowish brown & Sandy Loam & $5-10 \%$ & Pebbles & $\mathrm{N}$ & - \\
\hline $\mathrm{TNA}$ & VM08 & 2 & $70-80$ & 10YR 7/1 & light gray & Sandy Clay & $10-20 \%$ & Mottles, Pebbles & $\mathrm{N}$ & Terminated at depth. \\
\hline F13 & VMOg & 1 & $0-55$ & 10YR $5 / 3$ & brown & Sandy Clay & $1-5 \%$ & Pebbles & $\bar{Y}$ & 2: Flake (tertiary) [Flakes from $30-40 \mathrm{cmbs}$ ] \\
\hline IF-13 & VMO9 & 2 & $55-60$ & 10YR $5 / 3$ & brown & Sandy Loam & $10-20 \%$ & Mottles, Pebbles & $\mathrm{N}$ & Terminated at basal clay. \\
\hline NA & VM10 & 1 & $0-80$ & 10YR $5 / 3$ & brown & Sandy Loam & $1-5 \%$ & Pebbles & $\mathrm{N}$ & - \\
\hline NA & VM10 & 2 & $80-85$ & 10YR 5/3 & brown & Sandy Clay & $1-5 \%$ & Mottles, Pebbles & $\mathrm{N}$ & Terminated at basal clay. \\
\hline & & 1 & $0-15$ & $10 \mathrm{YR} 5 / 3$ & brown & Sandy Loam & $1-5 \%$ & Pebbles & $\mathrm{N}$ & - \\
\hline NA & VM11 & 2 & $15-65$ & 10YR $5 / 3$ & brown & Sandy Clay Loam & $1-5 \%$ & Pebbles & $\mathrm{N}$ & - \\
\hline & & 3 & $65-80$ & 10YR 7/1 & light gray & Sandy Clay & $10-20 \%$ & Mottles & $\mathrm{N}$ & Terminated at depth. \\
\hline 41G & VM12 & 1 & $0-55$ & 10YR $3 / 2$ & $\begin{array}{l}\text { very dark grayish } \\
\text { brown }\end{array}$ & Sandy Loam & $1-5 \%$ & Snail Shell & $\mathrm{N}$ & - \\
\hline & & 2 & $55-100$ & 10YR 5/4 & yellowish brown & Sandy Clay Loam & $1-5 \%$ & Pebbles, Snail Shell & $\mathrm{N}$ & Terminated at depth. \\
\hline & & 1 & $0-20$ & 10YR $3 / 3$ & dark brown & Sandy Loam & $1-5 \%$ & Pebbles, Snail Shell & $\mathrm{N}$ & - \\
\hline $41 \mathrm{GU} 200$ & VM13 & 2 & $20-95$ & 10YR 5/3 & brown & Sandy Clay Loam & $1-5 \%$ & Pebbles, Snail Shell & $\mathrm{N}$ & - \\
\hline & & 3 & $95-100$ & 10YR $7 / 1$ & light gray & Sandy Clay Loam & $1-5 \%$ & Pebbles & $\mathrm{N}$ & Terminated at depth. \\
\hline 41GU200 & VM14 & 1 & $0-55$ & 10YR 3/2 & $\begin{array}{l}\text { very dark grayish } \\
\text { brown }\end{array}$ & Sandy Loam & $1-5 \%$ & Snail Shell & $\mathrm{N}$ & - \\
\hline & & 2 & $55-100$ & 10YR 5/4 & yellowish brown & Sandy Clay Loam & $1-5 \%$ & Pebbles, Snail Shell & $\mathrm{N}$ & Terminated at depth. \\
\hline NA & VM15 & 1 & $0-60$ & 10YR $4 / 4$ & $\begin{array}{c}\text { dark yellowish } \\
\text { brown }\end{array}$ & Sandy Clay Loam & $5-10 \%$ & Pebbles & $\mathrm{N}$ & - \\
\hline$\pi$ & जivis & 2 & $60-75$ & 10YR $5 / 6$ & yellowish brown & Sandy Clay Loam & $1-5 \%$ & Mottles, Pebbles & $\mathrm{N}$ & Terminated at basal clay. \\
\hline & & 1 & $0-20$ & 10YR 4/3 & brown & Sandy Loam & $1-5 \%$ & Pebbles & $\mathrm{N}$ & - \\
\hline NA & VM16 & 2 & $20-100$ & 10YR $6 / 4$ & $\begin{array}{l}\text { light yellowish } \\
\text { brown }\end{array}$ & Sandy Loam & $1-5 \%$ & Pebbles & $\mathrm{N}$ & Terminated at depth. \\
\hline & & 1 & $0-20$ & 10YR 4/3 & brown & Sandy Loam & $1-5 \%$ & Pebbles & $\mathrm{N}$ & - \\
\hline NA & VM17 & 2 & $20-100$ & 10YR 6/4 & $\begin{array}{c}\text { light yellowish } \\
\text { brown }\end{array}$ & Sandy Loam & $1-5 \%$ & Pebbles & $\mathrm{N}$ & Terminated at depth. \\
\hline
\end{tabular}




\begin{tabular}{|c|c|c|c|c|c|c|c|c|c|c|}
\hline Site No. & $\begin{array}{c}\text { Shovel Test } \\
\text { No. }\end{array}$ & Level & $\begin{array}{l}\text { Depth } \\
\text { (cmbs) }\end{array}$ & $\left|\begin{array}{c}\text { Munsell Soil } \\
\text { value }\end{array}\right|$ & $\begin{array}{l}\text { Munsell Soil } \\
\text { Color }\end{array}$ & Soil Texture & \begin{tabular}{|c|} 
Inclusion \\
Percentage
\end{tabular} & Inclusion Type & \begin{tabular}{|c|}
$\begin{array}{c}\text { Positive }(\mathrm{P}) \\
\text { or Negative } \\
(\mathrm{N})\end{array}$ \\
\end{tabular} & Comments/ Reason for Termination \\
\hline \multirow{3}{*}{ NA } & \multirow{3}{*}{ XAE01 } & 1 & $0-20$ & 7.5YR $2.5 / 2$ & very dark brown & Clay Loam & - & - & $\mathrm{N}$ & - \\
\hline & & 2 & $20-50$ & 7.5 YR $3 / 4$ & dark brown & Sandy Loam & - & - & $\mathrm{N}$ & - \\
\hline & & 3 & $50-80$ & 7.5 YR $5 / 4$ & brown & Sand & $\begin{array}{ll}- & \\
\end{array}$ & - & $\mathrm{N}$ & Terminated at dense roots. \\
\hline \multirow{2}{*}{ NA } & \multirow{2}{*}{ XAE02 } & 1 & $0-50$ & 5 YYR $4 / 6$ & yellowish red & Loamy Sand & $1-5 \%$ & Gravels, Pebbles & $\mathrm{N}$ & - \\
\hline & & 2 & $50-60$ & $2.5 Y R 4 / 6$ & red & Sandy Clay & $\begin{array}{ll}- & \\
-\end{array}$ & - & $\mathrm{N}$ & Terminated at compact soil. \\
\hline \multirow{2}{*}{ NA } & \multirow{2}{*}{ XAE03 } & 1 & $0-30$ & $7.5 Y R 4 / 4$ & brown & Loamy Sand & - & - & $\mathrm{N}$ & - \\
\hline & & 2 & $30-50$ & 7.5 YR $5 / 6$ & strong brown & Sand & - & - & $\mathrm{N}$ & Terminated at compact soil. \\
\hline \multirow{2}{*}{ NA } & \multirow{2}{*}{ XAE04 } & 1 & $0-50$ & 5 YYR $4 / 6$ & yellowish red & Loamy Sand & $1-5 \%$ & Gravels, Pebbles & $\mathrm{N}$ & - \\
\hline & & 2 & $50-60$ & 2.5 YR $4 / 6$ & red & Sandy Clay & - & - & $\mathrm{N}$ & Terminated at compact soil. \\
\hline \multirow{5}{*}{ 41LE348 } & \multirow{5}{*}{ XBAD01 } & 1 & $0-20$ & 10YR $4 / 4$ & $\begin{array}{l}\text { dark yellowish } \\
\text { brown }\end{array}$ & Sand & - & - & Y & 3: Flake (secondary), Flake (tertiary) \\
\hline & & 2 & $20-40$ & 10YR $4 / 4$ & $\begin{array}{l}\text { dark yellowish } \\
\text { brown }\end{array}$ & Sand & - & - & Y & 2: Flake (tertiary) \\
\hline & & 3 & $40-60$ & 10YR $4 / 4$ & $\begin{array}{c}\text { dark yellowish } \\
\text { brown }\end{array}$ & Sand & - & - & $\mathrm{Y}$ & 1: Flake (secondary), Flake (tertiary) \\
\hline & & 4 & $60-80$ & 10YR 4/4 & $\begin{array}{l}\text { dark yellowish } \\
\text { brown }\end{array}$ & Sand & - & - & $\mathrm{N}$ & - \\
\hline & & 5 & $80-100$ & 10YR $4 / 4$ & $\begin{array}{c}\text { dark yellowish } \\
\text { brown }\end{array}$ & Sand & - & - & $\mathrm{Y}$ & 1: Flake (secondary) Terminated at depth. \\
\hline \multirow{5}{*}{ 41LE348 } & \multirow{5}{*}{ XBAD02 } & 1 & $0-20$ & 10YR $4 / 4$ & $\begin{array}{l}\text { dark yellowish } \\
\text { brown }\end{array}$ & Sand & - & - & $\mathrm{Y}$ & 1: Flake (tertiary) \\
\hline & & 2 & $20-40$ & 10YR $4 / 4$ & $\begin{array}{l}\text { dark yellowish } \\
\text { brown }\end{array}$ & Sand & - & - & $\mathrm{N}$ & - \\
\hline & & 3 & $40-60$ & 10YR 5/4 & yellowish brown & Sand & - & - & $\mathrm{N}$ & 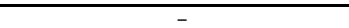 \\
\hline & & 4 & $60-80$ & 10YR 5/4 & yellowish brown & Sand & - & - & $\mathrm{Y}$ & 1: Flake (tertiary) \\
\hline & & 5 & $80-90$ & 5YR $5 / 4$ & reddish brown & Sandy Clay & - & - & $\mathrm{N}$ & Terminated at basal clay. \\
\hline \multirow{2}{*}{ 41LE348 } & \multirow{2}{*}{ XBAD03 } & 1 & $0-60$ & 10YR $4 / 4$ & $\begin{array}{c}\text { dark yellowish } \\
\text { brown }\end{array}$ & Sand & - & - & $\mathrm{N}$ & - \\
\hline & & 2 & $60-70$ & 10YR $4 / 4$ & $\begin{array}{l}\text { dark yellowish } \\
\text { brown }\end{array}$ & Sandy Clay & $10-20 \%$ & Mottles & $\mathrm{N}$ & Terminated at basal clay. \\
\hline \multirow[t]{2}{*}{ 41LE348 } & XBAD04 & 1 & $0-20$ & 10YR $4 / 4$ & $\begin{array}{l}\text { dark yellowish } \\
\text { brown }\end{array}$ & Sand & - & - & $\mathrm{N}$ & - \\
\hline & & 2 & $20-50$ & 10YR 5/6 & yellowish brown & Sand & $>20 \%$ & Mottles & $\mathrm{N}$ & Terminated at hydric soils. \\
\hline 41LE348 & XBAD05 & 1 & $0-40$ & 10YR $4 / 4$ & $\begin{array}{l}\text { dark yellowish } \\
\text { brown }\end{array}$ & Sandy Clay & $10-20 \%$ & Mottles & $\mathrm{N}$ & Terminated at basal clay. \\
\hline NA & XBAD06 & 1 & $0-100$ & 10YR $6 / 2$ & light brownish gray & Sand & - & - & $\mathrm{N}$ & Terminated at depth. \\
\hline $\mathrm{NA}$ & XBAD07 & 1 & $0-100$ & 10YR 5/8 & yellowish brown & Sand & 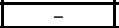 & 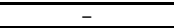 & $\mathrm{N}$ & Terminated at depth. \\
\hline 41LE349 & XBAD08 & 1 & $0-100$ & 10YR $4 / 4$ & $\begin{array}{l}\text { dark yellowish } \\
\text { brown }\end{array}$ & Sand & - & - & $\mathrm{N}$ & Terminated at depth. \\
\hline 41LE349 & XBAD09 & 1 & $0-100$ & 10YR $4 / 4$ & $\begin{array}{c}\text { dark yellowish } \\
\text { brown }\end{array}$ & Sand & - & - & $\mathrm{N}$ & Terminated at depth. \\
\hline 41LE349 & XBAD10 & 1 & $0-100$ & 10YR $4 / 4$ & $\begin{array}{c}\text { dark yellowish } \\
\text { brown }\end{array}$ & Sand & - & - & $\mathrm{N}$ & Terminated at depth. \\
\hline 41LE349 & XBAD11 & 1 & $0-100$ & 10YR 4/4 & $\begin{array}{l}\text { dark yellowish } \\
\text { brown }\end{array}$ & Sand & - & - & $\mathrm{N}$ & Terminated at depth. \\
\hline & & 1 & $0-20$ & 10YR $4 / 4$ & $\begin{array}{c}\text { dark yellowish } \\
\text { brown }\end{array}$ & Sand & $1-5 \%$ & Pebbles & $\mathrm{N}$ & - \\
\hline & & 2 & $20-40$ & 10YR $4 / 4$ & $\begin{array}{l}\text { dark yellowish } \\
\text { brown }\end{array}$ & Sand & $1-5 \%$ & Pebbles & $\mathrm{Y}$ & 2: Flake (primary) \\
\hline 41LE349 & XBAD12 & 3 & $40-60$ & 10YR $4 / 4$ & $\begin{array}{l}\text { dark yellowish } \\
\text { brown }\end{array}$ & Sand & $1-5 \%$ & Pebbles & $\mathrm{N}$ & - \\
\hline & & 4 & $60-80$ & 10YR 4/4 & $\begin{array}{l}\text { dark yellowish } \\
\text { brown }\end{array}$ & Sand & $1-5 \%$ & Pebbles & $\mathrm{Y}$ & 2: Flake (tertiary) \\
\hline & & 5 & $80-100$ & 10YR $4 / 4$ & $\begin{array}{l}\text { dark yellowish } \\
\text { brown }\end{array}$ & Sand & $1-5 \%$ & Pebbles & $\mathrm{N}$ & Terminated at depth. \\
\hline & & 1 & $0-20$ & 10YR $4 / 4$ & $\begin{array}{l}\text { dark yellowish } \\
\text { brown }\end{array}$ & Sand & - & - & $\mathrm{N}$ & - \\
\hline & & 2 & $20-40$ & 10YR $4 / 4$ & $\begin{array}{l}\text { dark yellowish } \\
\text { brown }\end{array}$ & Sand & - & - & Y & 1: Flake (secondary), Flake (tertiary) \\
\hline 41LE349 & XBAD13 & 3 & $40-60$ & $10 Y R 4 / 4$ & $\begin{array}{l}\text { dark yellowish } \\
\text { brown }\end{array}$ & Sand & - & - & $\mathrm{N}$ & - \\
\hline & & 4 & $60-80$ & 10YR $4 / 4$ & $\begin{array}{l}\text { dark yellowish } \\
\text { brown }\end{array}$ & Sand & - & - & $\mathrm{Y}$ & 1: Flake (tertiary) \\
\hline & & 5 & $80-100$ & 10YR $4 / 4$ & $\begin{array}{l}\text { dark yellowish } \\
\text { brown }\end{array}$ & Sand & - & - & $\mathrm{N}$ & Terminated at depth. \\
\hline 41LE349 & XBAD14 & 1 & $0-90$ & 10YR $3 / 6$ & $\begin{array}{c}\text { dark yellowish } \\
\text { brown }\end{array}$ & Sand & - & - & $\mathrm{N}$ & - \\
\hline 41LE349 & XBAD14 & 2 & $90-100$ & 10YR $3 / 6$ & $\begin{array}{l}\text { dark yellowish } \\
\text { brown }\end{array}$ & Sand & $5-10 \%$ & Pebbles & $\mathrm{N}$ & Terminated at depth. \\
\hline $\mathrm{NA}$ & XBAD15 & 1 & $0-40$ & 10YR 5/3 & brown & Sandy Clay & $>20 \%$ & Mottles & $\mathrm{N}$ & Terminated at hydric soils. \\
\hline $\mathrm{NA}$ & XBAD16 & 1 & $0-40$ & 10 YR $5 / 3$ & brown & Sandy Clay & $>20 \%$ & Mottles & $\mathrm{N}$ & Terminated at hydric soils. \\
\hline NA & XRAD17 & 1 & $0-30$ & 10YR 3/1 & very dark gray & Silty Clay & $5-10 \%$ & Mottles & $\mathrm{N}$ & 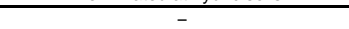 \\
\hline NA & XBAD17 & 2 & $30-65$ & $7.5 Y R 4 / 4$ & brown & Sandy Clay & $1-5 \%$ & Mottles & $\mathrm{N}$ & Terminated at compact soil. \\
\hline NA & XBAD18 & 1 & $0-30$ & 10YR 5/3 & brown & Sandy Clay Loam & - & - & $\mathrm{N}$ & - \\
\hline & & 2 & $30-50$ & $5 Y R \quad 4 / 4$ & reddish brown & Sandy Clay & - & - & $\mathrm{N}$ & Terminated at basal clay. \\
\hline & & 1 & $0-30$ & 10YR $4 / 2$ & dark grayish brown & Sandy Loam & $1-5 \%$ & Sandstone pebbles & $\mathrm{N}$ & - \\
\hline NA & XBAD19 & 2 & $30-40$ & 10YR 5/4 & yellowish brown & Sandy Loam & $1-5 \%$ & Pebbles & $\mathrm{N}$ & - \\
\hline & & 3 & $40+$ & $5 Y R 4 / 4$ & reddish brown & Clay & - & - & $\mathrm{N}$ & Terminated at basal clay. \\
\hline & & 1 & $0-30$ & 10YR $4 / 2$ & dark grayish brown & Sandy Loam & $1-5 \%$ & Sandstone pebbles & $\mathrm{N}$ & - \\
\hline NA & XBAD20 & 2 & $30-40$ & $10 Y R 5 / 4$ & yellowish brown & Sandy Loam & $1-5 \%$ & Pebbles & $\mathrm{N}$ & - \\
\hline & & 3 & $40+$ & $5 Y R \quad 4 / 4$ & reddish brown & Clay & - & - & $\mathrm{N}$ & Terminated at basal clay. \\
\hline & & 1 & $0-30$ & 10YR $4 / 2$ & dark grayish brown & Sandy Loam & $1-5 \%$ & Sandstone pebbles & $\mathrm{N}$ & - \\
\hline NA & XBAD21 & 2 & $30-80$ & 10YR 5/4 & yellowish brown & Sandy Loam & $1-5 \%$ & Pebbles & $\mathrm{N}$ & - \\
\hline & & 3 & $80+$ & $5 Y R 4 / 4$ & reddish brown & Clay & - & - & $\mathrm{N}$ & Terminated at basal clay. \\
\hline
\end{tabular}




\begin{tabular}{|c|c|c|c|c|c|c|c|c|c|c|}
\hline Site No. & $\begin{array}{c}\text { Shovel Test } \\
\text { No. }\end{array}$ & Level & $\begin{array}{l}\text { Depth } \\
\text { (cmbs) }\end{array}$ & $\begin{array}{l}\text { Munsell Soil } \\
\text { value }\end{array}$ & $\begin{array}{l}\text { Munsell Soil } \\
\text { Color }\end{array}$ & Soil Texture & \begin{tabular}{|c|} 
Inclusion \\
Percentage
\end{tabular} & Inclusion Type & $\begin{array}{c}\text { Positive }(\mathrm{P}) \\
\text { or Negative } \\
(\mathrm{N})\end{array}$ & Comments/ Reason for Termination \\
\hline \multirow{2}{*}{ NA } & \multirow{2}{*}{ XBAD22 } & 1 & $0-20$ & 10YR $4 / 2$ & dark grayish brown & Sandy Loam & - & - & $\mathrm{N}$ & - \\
\hline & & 2 & $20+$ & 5 YR $5 / 2$ & reddish gray & Clay & - & - & $\mathrm{N}$ & Terminated at basal clay. \\
\hline \multirow[t]{2}{*}{ NA } & \multirow[t]{2}{*}{ XBAD23 } & 1 & $0-65$ & 10YR $4 / 4$ & $\begin{array}{l}\text { dark yellowish } \\
\text { brown }\end{array}$ & Sandy Clay & $1-5 \%$ & Pebbles & $\mathrm{N}$ & - \\
\hline & & 2 & $65-80$ & 5YR $4 / 4$ & reddish brown & Sandy Clay & - & - & $\mathrm{N}$ & Terminated at basal clay. \\
\hline \multirow{2}{*}{ NA } & \multirow{2}{*}{ XBAD24 } & 1 & $0-20$ & 10YR 5/4 & yellowish brown & Silty Clay & $1-5 \%$ & Rootlets & $\mathrm{N}$ & - \\
\hline & & 2 & $20-60$ & 10YR 5/4 & yellowish brown & Sandy Clay & $10-20 \%$ & Mottles & $\mathrm{N}$ & Terminated at basal clay. \\
\hline $\mathrm{NA}$ & XBAD25 & 1 & $0-50$ & $10 R 5 / 3$ & weak red & Sandy Clay & - & - & $\mathrm{N}$ & Terminated at basal clay. \\
\hline NA & XDR01 & 1 & $0-50$ & 10YR 5/4 & yellowish brown & Silt Loam & - & - & $\mathrm{N}$ & Terminated at compact soil. \\
\hline \multirow[b]{2}{*}{ NA } & & 1 & $0-50$ & 10YR $6 / 6$ & brownish yellow & Sandy Loam & $1-5 \%$ & Pebbles & $\mathrm{N}$ & $\begin{array}{ll}- & \\
\end{array}$ \\
\hline & XDR01 & 2 & $50-100$ & 10YR $7 / 1$ & light gray & Sandy Loam & $1-5 \%$ & $\begin{array}{l}\text { Pebbles, Manganese } \\
\text { mottles }\end{array}$ & $\mathrm{N}$ & Terminated at depth. \\
\hline NA & XDR02 & 1 & $0-30$ & 10YR 5/4 & yellowish brown & Sandy Loam & - & - & $\mathrm{N}$ & - \\
\hline INA & XURUZ & 2 & $30-40$ & 5YR $5 / 8$ & yellowish red & Clay Loam & - & - & $\mathrm{N}$ & Terminated at basal clay. \\
\hline NA & XDR02 & 1 & $0-10$ & 7.5YR $5 / 4$ & brown & Sandy Clay Loam & - & - & $\mathrm{N}$ & - \\
\hline & & 2 & $10-30$ & $2.5 \mathrm{YR} 6 / 8$ & light red & Clay & - & - & $\mathrm{N}$ & Terminated at basal clay. \\
\hline NA & XDR03 & 1 & $0-50$ & 10YR $5 / 4$ & yellowish brown & Sandy Loam & - & 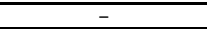 & $\mathrm{N}$ & $\begin{array}{lll}- & & \\
\end{array}$ \\
\hline NA & XURU3 & 2 & $50-60$ & 5YR 5/8 & yellowish red & Clay Loam & - & - & $\mathrm{N}$ & Terminated at basal clay. \\
\hline NA & XDR03 & 1 & $0-40$ & 7.5YR $5 / 4$ & brown & Sandy Clay Loam & - & - & $\mathrm{N}$ & - \\
\hline & & 2 & $40-50$ & $2.5 \mathrm{YR} 6 / 8$ & light red & Clay & 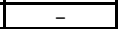 & 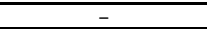 & $\mathrm{N}$ & Terminated at basal clay. \\
\hline $\mathrm{NA}$ & XDR04 & 1 & $0-65$ & 10YR 5/4 & yellowish brown & Silt Loam & - & - & $\mathrm{N}$ & Terminated at compact soil. \\
\hline NA & XDR04 & 1 & $0-40$ & 7.5YR $5 / 4$ & brown & Sandy Clay Loam & - & - & $\mathrm{N}$ & - \\
\hline & & 2 & $40-50$ & 2.5 YR $6 / 8$ & light red & Clay & - & - & $\mathrm{N}$ & Terminated at basal clay. \\
\hline & & 1 & $0-25$ & $10 Y R 6 / 3$ & pale brown & Sandy Loam & $>20 \%$ & Clay subsoil nodules & $\mathrm{N}$ & - \\
\hline 41LE348 & XMC01 & 2 & $25-30$ & 5 YR $5 / 3$ & reddish brown & Sandy Clay & - & 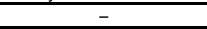 & $\mathrm{N}$ & Terminated at basal clay. \\
\hline & & 1 & $0-20$ & 10YR $5 / 3$ & brown & Sand & $1-5 \%$ & Gravels & $\mathrm{Y}$ & 2: Flake (tertiary) \\
\hline & & 2 & $20-40$ & 10YR $5 / 3$ & brown & Sand & $1-5 \%$ & Gravels & $\mathrm{Y}$ & 2: Flake (secondary), Flake (tertiary) \\
\hline 41LE348 & XMC02 & 3 & $40-60$ & 10YR $5 / 3$ & brown & Sand & $1-5 \%$ & Gravels & $\mathrm{N}$ & - \\
\hline & & 4 & $60+$ & $5 Y R 4 / 2$ & dark reddish gray & Sandy Clay & - & - & $\mathrm{N}$ & Terminated at basal clay. \\
\hline 41LE348 & $\mathrm{XMC03}$ & 1 & $0-30$ & 10YR 4/1 & dark gray & Sand & $5-10 \%$ & Redox staining & $\mathrm{N}$ & Terminated at water table. \\
\hline & & 1 & $0-20$ & 10YR $5 / 4$ & yellowish brown & Sand & $>20 \%$ & Pebbles & $\mathrm{Y}$ & $\begin{array}{l}\text { 6: Flake (tertiary) [Likely disturbed by existing } \\
\text { water line] }\end{array}$ \\
\hline 41LE348 & $\mathrm{XMC04}$ & 2 & $20-40$ & 10YR 5/4 & yellowish brown & Sand & $>20 \%$ & Pebbles & Y & $\begin{array}{c}\text { 4: Flake (secondary), Flake (tertiary) [Likely } \\
\text { disturbed by existing water line] }\end{array}$ \\
\hline & & 3 & $40-60$ & 10YR $5 / 4$ & yellowish brown & Sand & $5-10 \%$ & Pebbles & Y & $\begin{array}{l}\text { 2: Flake (tertiary) [Likely disturbed by existing } \\
\text { water line] }\end{array}$ \\
\hline & & 4 & $60-100$ & 10YR 5/4 & yellowish brown & Sand & $5-10 \%$ & Pebbles & $\mathrm{N}$ & Terminated at depth. \\
\hline & & 1 & $0-20$ & $7.5 Y R 5 / 4$ & brown & Sand & $1-5 \%$ & Pebbles & $\mathrm{N}$ & - \\
\hline 41LE348 & XMC05 & 2 & $20-40$ & 7.5 YR $5 / 4$ & brown & Sand & $1-5 \%$ & Pebbles & $\mathrm{Y}$ & 1: Flake (tertiary) \\
\hline & & 3 & $40-80$ & 10YR $5 / 2$ & grayish brown & Sand & $1-5 \%$ & Organics (decayed root) & N & Terminated at water table. \\
\hline $\mathrm{NA}$ & XMC06 & 1 & $0-60$ & $7.5 Y R 5 / 4$ & brown & Sand & $10-20 \%$ & Clay subsoil nodules & $\mathrm{N}$ & Terminated at basal clay. \\
\hline NA & $\mathrm{XMC07}$ & 1 & $0-100$ & $7.5 \mathrm{YR} 6 / 6$ & reddish yellow & Sand & $10-20 \%$ & Recent organics & $\mathrm{N}$ & Terminated at depth. \\
\hline & & 1 & $0-40$ & $7.5 Y R 5 / 6$ & strong brown & Sand & - & - & $\mathrm{N}$ & - \\
\hline NA & XMC08 & 2 & $40-60$ & $7.5 \mathrm{YR} 5 / 6$ & strong brown & Sand & - & - & $\overline{\mathrm{Y}}$ & 1: Flake (tertiary) \\
\hline NA & XMC08 & 3 & $60-80$ & $7.5 Y R 5 / 6$ & strong brown & Sand & - & - & $\mathrm{Y}$ & 1: Flake (tertiary) \\
\hline & & 4 & $80-100$ & 7.5 YR $5 / 6$ & strong brown & Sand & - & - & $\mathrm{N}$ & Terminated at depth. \\
\hline & & 1 & $0-40$ & $7.5 Y R 5 / 6$ & strong brown & Sand & - & - & $\mathrm{N}$ & - \\
\hline 41LE349 & XMC09 & 2 & $40-60$ & 7.5 YR $5 / 6$ & strong brown & Sand & - & - & $\mathrm{Y}$ & 2: Flake (tertiary) \\
\hline & & 3 & $60-100$ & $7.5 Y R 5 / 6$ & strong brown & Sand & - & - & $\mathrm{N}$ & Terminated at depth. \\
\hline 41LE349 & $\mathrm{XMC10}$ & 1 & $0-100$ & 7.5 YR $5 / 6$ & strong brown & Sand & $5-10 \%$ & Pebbles & $\mathrm{N}$ & Terminated at depth. \\
\hline & & 1 & $0-40$ & $7.5 Y R 5 / 6$ & strong brown & Sand & - & - & $\mathrm{N}$ & - \\
\hline 41LE349 & $\mathrm{XMC11}$ & 2 & $40-60$ & 7.5 YR $5 / 6$ & strong brown & Sand & - & - & $\mathrm{Y}$ & 1: Flake (tertiary) \\
\hline & & 3 & $60-80$ & $7.5 Y R 5 / 6$ & strong brown & Sand & - & - & $\mathrm{Y}$ & 1: Other Prehistoric Terminated at depth. \\
\hline $411=349$ & $\mathrm{XMC12}$ & 1 & $0-90$ & 7.5 YR $5 / 6$ & strong brown & Sand & - & - & $\mathrm{N}$ & - \\
\hline 41LE349 & XMC12 & 2 & $90-100$ & 7.5 YR $5 / 6$ & strong brown & Sand & - & - & $\mathrm{Y}$ & 1: Flake (primary) Terminated at depth. \\
\hline 41LE349 & $\mathrm{XMC13}$ & 1 & $0-20$ & $5 Y$ YR $4 / 4$ & reddish brown & Sandy Clay & - & - & $\mathrm{N}$ & Terminated at basal clay. \\
\hline NA & $\mathrm{XMC14}$ & 1 & $0-30$ & 10YR $4 / 2$ & dark grayish brown & Clay & $10-20 \%$ & Redox staining & $\mathrm{N}$ & Terminated at hydric clay. \\
\hline NA & $\mathrm{XMC15}$ & 1 & $0-30$ & 10YR $4 / 2$ & dark grayish brown & Clay & $10-20 \%$ & Redox staining & N & Terminated at hydric clay. \\
\hline NA & $\mathrm{XMC16}$ & 1 & $0-30$ & 10YR $4 / 2$ & dark grayish brown & Clay & $10-20 \%$ & Redox staining & N & Terminated at hydric clay. \\
\hline NA & $\mathrm{XMC17}$ & 1 & $0-30$ & 10YR $4 / 2$ & dark grayish brown & Clay & $10-20 \%$ & Redox staining & $\mathrm{N}$ & Terminated at hydric clay. \\
\hline NA & XMC18 & 1 & $0-50$ & 10YR 7/3 & very pale brown & Sandy Loam & $10-20 \%$ & Clay subsoil & $\mathrm{N}$ & - \\
\hline NA & XIMC18 & 2 & $50+$ & $7.5 Y R 6 / 4$ & light brown & Sandy Clay & 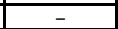 & 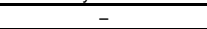 & $\mathrm{N}$ & Terminated at basal clay. \\
\hline $\mathrm{NA}$ & XMC19 & 1 & $0-50$ & 10YR $7 / 3$ & very pale brown & Sandy Loam & $10-20 \%$ & Clay subsoil & $\mathrm{N}$ & - \\
\hline NA & XMC19 & 2 & $50+$ & $7.5 Y R 6 / 4$ & light brown & Sandy Clay & - & - & $\mathrm{N}$ & Terminated at basal clay. \\
\hline $\mathrm{NA}$ & XMC20 & 1 & $0-50$ & $10 Y R 7 / 3$ & very pale brown & Sandy Loam & $10-20 \%$ & Clay subsoil & $\mathrm{N}$ & - \\
\hline NA & XMC20 & 2 & $50+$ & $7.5 Y R 6 / 4$ & light brown & Sandy Clay & $\begin{array}{ll}- \\
-\end{array}$ & 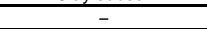 & $\mathrm{N}$ & Terminated at basal clay. \\
\hline $\mathrm{NA}$ & XMC21 & 1 & $0-40$ & $7.5 Y R 4 / 3$ & brown & Clay Loam & $>20 \%$ & Mottles & $\mathrm{N}$ & Terminated at basal clay. \\
\hline NA & XMC22 & 1 & $0-40$ & $7.5 Y R 4 / 3$ & brown & Clay Loam & $>20 \%$ & Mottles & $\mathrm{N}$ & Terminated at basal clay. \\
\hline $\mathrm{NA}$ & XTN01 & 1 & $0-15$ & 5 YYR $4 / 6$ & yellowish red & Clay Loam & $5-10 \%$ & Mottles & $\mathrm{N}$ & Terminated at basal clay. \\
\hline & & 1 & $0-50$ & $7.5 Y R 4 / 4$ & brown & Sandy Loam & $5-10 \%$ & Mottles & $\mathrm{N}$ & - \\
\hline NA & XTN02 & 2 & $50-60$ & $7.5 Y R 4 / 6$ & strong brown & Sandy Clay Loam & $>20 \%$ & Gravels, Mottles & $\mathrm{N}$ & Terminated at basal clay. \\
\hline NA & XTN03 & 1 & $0-10$ & 10YR $4 / 4$ & $\begin{array}{l}\text { dark yellowish } \\
\text { brown }\end{array}$ & Sandy Loam & - & - & N & - \\
\hline & & 2 & $10-35$ & $7.5 Y R 4 / 4$ & brown & Sandy Loam & $>20 \%$ & Cobbles, Mottles & N & Terminated at large sandstone cobbles at base. \\
\hline 41BP920 & YBAD01 & 1 & $0-30$ & 10YR 5/6 & yellowish brown & Sandy Clay Loam & - & - & Y & 1: Core, Flake (secondary), Flake (tertiary) \\
\hline & & 2 & $30-35$ & 10YR 5/8 & yellowish brown & Clay Loam & - & - & $\mathrm{N}$ & Terminated at basal clay. \\
\hline 41BP920 & YBAD02 & 1 & $0-30$ & 10YR 5/6 & yellowish brown & Sandy Clay Loam & - & - & Y & 3: Flake (tertiary), Other Prehistoric \\
\hline & & 2 & $30-40$ & 10YR $6 / 8$ & brownish yellow & Clay Loam & - & - & $\mathrm{N}$ & Terminated at basal clay. \\
\hline
\end{tabular}


Appendix B. Shovel Test Data

\begin{tabular}{|c|c|c|c|c|c|c|c|c|c|c|}
\hline Site No. & $\begin{array}{l}\text { Shovel Test } \\
\text { No. }\end{array}$ & Level & $\begin{array}{l}\text { Depth } \\
\text { (cmbs) }\end{array}$ & $\begin{array}{c}\text { Munsell Soil } \\
\text { value }\end{array} \mid$ & $\begin{array}{l}\text { Munsell Soil } \\
\text { Color }\end{array}$ & Soil Texture & \begin{tabular}{|c|} 
Inclusion \\
Percentage
\end{tabular} & Inclusion Type & $\begin{array}{c}\text { Positive (P) } \\
\text { or Negative } \\
(\mathrm{N})\end{array}$ & Comments/ Reason for Termination \\
\hline \multirow[t]{2}{*}{ 41BP920 } & \multirow[t]{2}{*}{ YBAD03 } & 1 & $0-30$ & 10YR 5/6 & yellowish brown & Clay Loam & - & - & $\mathrm{Y}$ & $\begin{array}{c}\text { 6: Biface, Flake (secondary), Flake (tertiary), } \\
\text { Other Prehistoric }\end{array}$ \\
\hline & & 2 & $30-40$ & 10YR $6 / 8$ & brownish yellow & Clay Loam & - & - & $\mathrm{N}$ & Terminated at basal clay. \\
\hline
\end{tabular}


Appendix C. Auger Probe, Backhoe Trench, and Column SAMPle Data 
This page intentionally left blank. 


\begin{tabular}{|c|c|c|c|c|c|c|c|c|c|c|}
\hline Site No. & $\begin{array}{l}\text { Auger Probe } \\
\text { Number }\end{array}$ & Level & Depth & Munsell Value & Munsell Description & Soil Texture & |nclusion (\%)| & Inclusion Type & $\begin{array}{c}\text { Cultural } \\
\text { Material } \\
\text { (P/N) }\end{array}$ & Comments \\
\hline NA & ATJFA01 & 1 & $0-200$ & 7.5 YR $6 / 4$ & light brown & Sandy Clay Loam & $1-5 \%$ & Pebbles & $\mathrm{N}$ & Terminated at depth. \\
\hline \multirow{3}{*}{ NA } & \multirow{3}{*}{ ATJFA02 } & 1 & $0-110$ & 10YR 3/2 & very dark grayish brown & Silty Clay Loam & $1-5 \%$ & Snail Shell & N & - \\
\hline & & 2 & $110-150$ & 10YR 4/2 & dark grayish brown & Silty Clay Loam & $1-5 \%$ & Snail Shell & $\mathrm{N}$ & - \\
\hline & & 3 & $150-200$ & 10YR 6/4 & light yellowish brown & Sandy Clay Loam & $1-5 \%$ & Snail Shell & $\mathrm{N}$ & Terminated at depth. \\
\hline \multirow{3}{*}{ NA } & \multirow{3}{*}{ ATJFA03 } & 1 & $0-110$ & 10YR 3/2 & very dark grayish brown & Silty Clay Loam & $1-5 \%$ & Snail Shell & N & - \\
\hline & & 2 & $110-150$ & 10YR 4/2 & dark grayish brown & Silty Clay Loam & $1-5 \%$ & Snail Shell & $\mathrm{N}$ & - \\
\hline & & 3 & $150-200$ & 10YR 6/4 & light yellowish brown & Sandy Clay Loam & $1-5 \%$ & Snail Shell & $\mathrm{N}$ & Terminated at depth. \\
\hline \multirow{3}{*}{ NA } & \multirow{3}{*}{ ATJFA04 } & 1 & $0-110$ & 10YR 3/2 & very dark grayish brown & Silty Clay Loam & $1-5 \%$ & Snail Shell & N & - \\
\hline & & 2 & $110-150$ & 10YR 4/2 & dark grayish brown & Silty Clay Loam & $1-5 \%$ & Snail Shell & $\mathrm{N}$ & - \\
\hline & & 3 & $150-200$ & $10 Y R 6 / 4$ & light yellowish brown & Sandy Clay Loam & $1-5 \%$ & Snail Shell & $\mathrm{N}$ & Terminated at depth. \\
\hline \multirow{3}{*}{ NA } & \multirow{3}{*}{ ATJFA05 } & 1 & $0-110$ & 10YR 3/2 & very dark grayish brown & Silty Clay Loam & $1-5 \%$ & Snail Shell & N & - \\
\hline & & 2 & $110-150$ & 10YR 4/2 & dark grayish brown & Silty Clay Loam & $1-5 \%$ & Snail Shell & $\mathrm{N}$ & - \\
\hline & & 3 & $150-200$ & $10 Y R 6 / 4$ & light yellowish brown & Sandy Clay Loam & $1-5 \%$ & Snail Shell & $\mathrm{N}$ & Terminated at depth. \\
\hline $\mathrm{NA}$ & ATJIS01 & 1 & $0-200$ & 10YR $7 / 4$ & very pale brown & Sand & $1-5 \%$ & Snail Shell & $\mathrm{N}$ & Terminated at depth. \\
\hline \multirow{4}{*}{ NA } & \multirow{4}{*}{ ATJIS02 } & 1 & $0-5$ & 10YR 4/3 & brown & Sandy Loam & $1-5 \%$ & Snail Shell & $\mathrm{N}$ & - \\
\hline & & 2 & $5-50$ & 10YR 3/2 & very dark grayish brown & Sandy Clay Loam & - & - & N & - \\
\hline & & 3 & $50-110$ & 10YR 4/3 & brown & Sandy Loam & - & - & $\mathrm{N}$ & - \\
\hline & & 4 & $110-210$ & $10 Y R$ 6/4 & light yellowish brown & Sand & $1-5 \%$ & Gravels & $\mathrm{N}$ & Terminated at depth. \\
\hline \multirow{3}{*}{$41 \mathrm{GU} 200$} & \multirow{3}{*}{ ATJIS03 } & 1 & $0-55$ & 10YR $2 / 2$ & very dark brown & Silt Loam & - & - & $\mathrm{N}$ & - \\
\hline & & 2 & $55-110$ & 10YR 5/3 & brown & Sandy Loam & - & - & $\mathrm{N}$ & - \\
\hline & & 3 & $110-210$ & $10 R 7 / 4$ & pale red & Sand & $1-5 \%$ & $\begin{array}{c}\begin{array}{c}\text { Pebbles, Snail } \\
\text { Shell }\end{array} \\
\end{array}$ & Y & $\begin{array}{l}\text { 1: Flake (tertiary) [One tertiary flake approximately 180- } \\
190 \mathrm{cmbs} \text { ] Terminated at depth. }\end{array}$ \\
\hline & & 1 & $0-45$ & 10YR 4/2 & dark grayish brown & Silt Loam & - & - & $\mathrm{N}$ & - \\
\hline NA & ATJIS04 & 2 & $45-210$ & 10YR 6/4 & light yellowish brown & Loamy Sand & $1-5 \%$ & \begin{tabular}{|c|}
$\begin{array}{c}\text { Pebbles, Snail } \\
\text { Shell }\end{array}$ \\
\end{tabular} & N & Terminated at depth. \\
\hline NA & ATJIS05 & 1 & $0-90$ & 10YR 4/2 & dark grayish brown & Clay Loam & $1-5 \%$ & Snail Shell & $\mathrm{N}$ & Terminated at impenetrable river cobbles. \\
\hline & & 1 & $0-30$ & 10YR 4/3 & brown & Silt Loam & - & - & $\mathrm{N}$ & - \\
\hline 41GU200 & ATJIS06 & 2 & $30-50$ & 10YR 5/3 & brown & Sandy Loam & - & - & $\mathrm{N}$ & - \\
\hline 年 & & 3 & $50-210$ & 10YR 6/4 & light yellowish brown & Sand & $1-5 \%$ & Pebbles & Y & $\begin{array}{l}\text { 1: Flake (tertiary) [One tertiary flake observed } \\
\text { approximately } 60 \mathrm{cmbs} \text { ] Terminated at depth. }\end{array}$ \\
\hline & & 1 & $0-70$ & 10YR 4/3 & brown & Sandy Loam & $1-5 \%$ & Snail Shell & $\mathrm{N}$ & - \\
\hline NA & ATMCC01 & 2 & $70-180$ & 10YR 6/4 & light yellowish brown & Sandy Clay Loam & $5-10 \%$ & Snail Shell & $\mathrm{N}$ & - \\
\hline & & 3 & $180-200$ & 10YR 6/4 & light yellowish brown & Sandy Clay & $5-10 \%$ & Snail Shell & $\mathrm{N}$ & Terminated at depth. \\
\hline 41GU200 & ATMCCO2 & 1 & $0-80$ & 10YR 4/2 & dark grayish brown & Silt Loam & $1-5 \%$ & Snail Shell & $\mathrm{N}$ & - \\
\hline 4100200 & ATIVUCOL & 2 & $80-200$ & 10YR 6/4 & light yellowish brown & Sandy Clay Loam & $1-5 \%$ & Snail Shell & $\mathrm{N}$ & Terminated at depth. \\
\hline & & 1 & $0-70$ & 10YR 4/3 & brown & Sandy Loam & $1-5 \%$ & Snail Shell & $\mathrm{N}$ & - \\
\hline NA & ATMCC03 & 2 & $70-180$ & 10YR 6/4 & light yellowish brown & Sandy Clay Loam & $5-10 \%$ & Snail Shell & $\mathrm{N}$ & - \\
\hline & & 3 & $180-200$ & 10YR 6/4 & light yellowish brown & Sandy Clay & $5-10 \%$ & Snail Shell & $\mathrm{N}$ & Terminated at depth. \\
\hline NA & ATMFV01 & 1 & $0-60$ & 10YR 4/3 & brown & Sandy Loam & $1-5 \%$ & Snail Shell & $\mathrm{N}$ & - \\
\hline n & 1 & 2 & $60-205$ & 10YR 6/4 & light yellowish brown & Sandy Loam & $1-5 \%$ & Snail Shell & $\mathrm{N}$ & Terminated at depth. \\
\hline NA & ATMFV02 & 1 & $0-100$ & 10YR 4/2 & dark grayish brown & Silt Loam & $1-5 \%$ & $\begin{array}{c}\text { Calcium } \\
\text { Carbonate, } \\
\text { Snail Shell } \\
\end{array}$ & N & - \\
\hline & & 2 & $100-200$ & 10YR 6/4 & light yellowish brown & Silt Loam & $1-5 \%$ & $\begin{array}{c}\text { Calcium } \\
\text { Carbonate }\end{array}$ & N & Terminated at depth. \\
\hline & & 1 & $0-80$ & 10YR 2/2 & very dark brown & Silt Loam & $1-5 \%$ & $\begin{array}{c}\text { Snail Shell, } \\
\text { Common roots } \\
\text { and rootlets }\end{array}$ & N & - \\
\hline $41 \mathrm{GU} 200$ & ATMFV03 & 2 & $80-100$ & 10YR 3/3 & dark brown & Silt Loam & $1-5 \%$ & \begin{tabular}{|c|} 
Snail Shell, \\
Common roots \\
and rootlets
\end{tabular} & N & - \\
\hline & & 3 & $100-200$ & 10YR 6/6 & brownish yellow & Silt Loam & $1-5 \%$ & $\begin{array}{c}\text { Snail Shell, } \\
\text { Common roots } \\
\text { and rootlets } \\
\end{array}$ & N & Terminated at depth. \\
\hline $41 \mathrm{GU} 200$ & ATMFV04 & 1 & $0-60$ & $2.5 \mathrm{YR} 4 / 3$ & reddish brown & Silt Loam & $5-10 \%$ & $\begin{array}{c}\text { Snail Shell, } \\
\text { Common roots } \\
\text { and worms }\end{array}$ & Y & 1: Flake (tertiary) [Flake at $30 \mathrm{cmbs}$ ] \\
\hline & & 2 & $60-200$ & $2.5 Y R 7 / 6$ & light red & Silt Loam & $1-5 \%$ & $\begin{array}{l}\text { Snail Shell, } \\
\text { Roots }\end{array}$ & N & Terminated at depth. \\
\hline NA & ATMFV05 & 1 & $0-80$ & $2.5 \mathrm{YR} 4 / 3$ & reddish brown & Silt Loam & $1-5 \%$ & Rootlets & $\mathrm{N}$ & - \\
\hline TNA & माivin vo & 2 & $80-200$ & $2.5 Y R 7 / 6$ & light red & Silt Loam & $1-5 \%$ & Rootlets & $\mathrm{N}$ & Terminated at depth. \\
\hline & & 1 & $0-60$ & $10 Y R 4 / 3$ & brown & Sandy Loam & $1-5 \%$ & Snail Shell & $\mathrm{N}$ & $\begin{array}{l}- \\
\end{array}$ \\
\hline NA & ATVM01 & 2 & $60-180$ & 10YR 6/4 & light yellowish brown & Silt & $1-5 \%$ & Snail Shell & $\mathrm{N}$ & - \\
\hline & & 3 & $180-210$ & $10 Y R 6 / 4$ & light yellowish brown & Silty Clay Loam & $1-5 \%$ & Snail Shell & $\mathrm{N}$ & Terminated at depth. \\
\hline $41 \mathrm{GU} 200$ & ATVM02 & 1 & $0-60$ & 10YR $4 / 3$ & brown & Silty Clay Loam & $1-5 \%$ & Snail Shell & Y & $\begin{array}{l}\text { 2: Flake (tertiary) [2 tertiary flakes documented between } \\
\qquad 30-40 \mathrm{cmbs} \text { (see photos)] } \\
\end{array}$ \\
\hline & & 2 & $60-210$ & $10 Y R 7 / 4$ & very pale brown & Sandy Clay Loam & $1-5 \%$ & Snail Shell & $\mathrm{N}$ & Terminated at depth. \\
\hline & & 1 & $0-60$ & 10YR 4/3 & brown & Sandy Loam & $1-5 \%$ & Snail Shell & $\mathrm{N}$ & - \\
\hline NA & ATVM03 & 2 & $60-180$ & $10 Y R$ 6/4 & light yellowish brown & Silt & $1-5 \%$ & Snail Shell & $\mathrm{N}$ & - \\
\hline & & 3 & $180-210$ & 10YR 6/4 & light yellowish brown & Silty Clay Loam & $1-5 \%$ & Snail Shell & $\mathrm{N}$ & Terminated at depth. \\
\hline NA & ATVMO4 & 1 & $0-80$ & $10 Y R 4 / 3$ & brown & Silty Clay Loam & $1-5 \%$ & Snail Shell & $\mathrm{N}$ & - \\
\hline $\mathrm{TNA}$ & Alv VIVIU 4 & 2 & $80-200$ & 10YR $7 / 4$ & very pale brown & Silty Clay Loam & $1-5 \%$ & Snail Shell & $\mathrm{N}$ & Terminated at depth. \\
\hline & & 1 & $0-20$ & 10YR 4/4 & dark yellowish brown & Loam & - & - & N & - \\
\hline & & 2 & $20-55$ & 10YR 6/4 & light yellowish brown & Sandy Clay Loam & - & - & $\mathrm{N}$ & - \\
\hline NA & AU01 & 3 & $55-80$ & 10YR 4/3 & brown & Silt Loam & - & - & $\mathrm{N}$ & - \\
\hline & & 4 & $80-120$ & 10YR 5/4 & yellowish brown & Silty Clay Loam & - & - & $\mathrm{N}$ & - \\
\hline & & 5 & $120-170$ & 10YR 5/6 & yellowish brown & Silty Clay Loam & - & - & $\mathrm{N}$ & - \\
\hline & & 6 & $170-200$ & 10YR $5 / 2$ & grayish brown & Clay Loam & - & - & $\mathrm{N}$ & Terminated at depth. \\
\hline
\end{tabular}


Appendix C

\begin{tabular}{|c|c|c|c|c|c|c|c|c|c|c|}
\hline Site No. & $\begin{array}{c}\text { Auger Probe } \\
\text { Number }\end{array}$ & Level & Depth & Munsell Value & Munsell Description & Soil Texture & |nclusion (\%)| & Inclusion Type & $\begin{array}{l}\text { Cultural } \\
\text { Material } \\
\text { (P/N) }\end{array}$ & Comments \\
\hline \multirow{6}{*}{ NA } & \multirow{6}{*}{ AU02 } & 1 & $0-20$ & 10YR 4/4 & dark yellowish brown & Loam & - & - & $\mathrm{N}$ & - \\
\hline & & 2 & $20-65$ & 10YR 6/4 & light yellowish brown & Sandy Clay Loam & - & - & $\mathrm{N}$ & - \\
\hline & & 3 & $65-85$ & 10YR 4/3 & brown & Silt Loam & - & - & $\mathrm{N}$ & - \\
\hline & & 4 & $85-100$ & 10 YR 5/4 & yellowish brown & Silty Clay Loam & 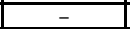 & - & $\mathrm{N}$ & 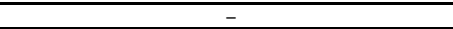 \\
\hline & & 5 & $100-140$ & 10YR 5/6 & yellowish brown & Silty Clay Loam & - & - & $\mathrm{N}$ & - \\
\hline & & 6 & $140-200$ & 10YR 5/2 & grayish brown & Clay Loam & - & - & $\mathrm{N}$ & Terminated at depth. \\
\hline \multirow[t]{2}{*}{ NA } & \multirow[t]{2}{*}{ AU03 } & 1 & $0-120$ & 10YR 5/4 & yellowish brown & Silty Clay & $1-5 \%$ & $\begin{array}{c}\text { Manganese } \\
\text { mottles }\end{array}$ & $\mathrm{N}$ & - \\
\hline & & 2 & $120-200$ & 10YR 3/4 & dark yellowish brown & Silty Clay & - & - & $\mathrm{N}$ & Terminated at depth. \\
\hline \multirow{2}{*}{ NA } & \multirow{2}{*}{ AU04 } & 1 & $0-130$ & 10YR 5/4 & yellowish brown & Silty Clay Loam & - & - & $\mathrm{N}$ & - \\
\hline & & 2 & $130-200$ & 10YR 4/4 & dark yellowish brown & Clay Loam & - & - & $\mathrm{N}$ & Terminated at depth. \\
\hline \multirow[b]{2}{*}{ 41BP961 } & \multirow[b]{2}{*}{ AU05 } & 1 & $0-140$ & 10YR 5/2 & grayish brown & Clay Loam & - & - & $\mathrm{N}$ & - \\
\hline & & 2 & $140-170$ & 10YR 5/6 & yellowish brown & Clay Loam & $10-20 \%$ & $\begin{array}{c}\text { Calcium } \\
\text { Carbonate, } \\
\text { Gravels, } \\
\text { Pebbles, Iron } \\
\text { concretions }\end{array}$ & $\mathrm{N}$ & Terminated at depth. \\
\hline \multirow[b]{2}{*}{ 41BP961 } & \multirow[b]{2}{*}{ AU06 } & 1 & $0-40$ & 10YR 5/2 & grayish brown & Clay Loam & - & - & $\mathrm{N}$ & - \\
\hline & & 2 & $40-110$ & 10YR 5/6 & yellowish brown & Clay Loam & $10-20 \%$ & $\begin{array}{c}\text { Calcium } \\
\text { Carbonate, } \\
\text { Gravels, } \\
\text { Pebbles, Iron } \\
\text { concretions }\end{array}$ & $\mathrm{N}$ & Terminated at depth. \\
\hline \multirow[b]{2}{*}{ 41BP961 } & \multirow[b]{2}{*}{ AU07 } & 1 & $0-140$ & 10YR 5/2 & grayish brown & Clay Loam & - & - & $\mathrm{N}$ & - \\
\hline & & 2 & $140-160$ & 10YR 5/6 & yellowish brown & Clay Loam & $10-20 \%$ & \begin{tabular}{c|} 
Calcium \\
Carbonate, \\
Gravels, \\
Pebbles, Iron \\
concretions \\
\end{tabular} & $\mathrm{N}$ & Terminated at depth. \\
\hline \multirow{4}{*}{ 41BP961 } & \multirow{4}{*}{ AU08 } & 1 & $0-40$ & 10YR 4/4 & dark yellowish brown & Silt Loam & - & - & $\mathrm{N}$ & - \\
\hline & & 2 & $40-120$ & $10 Y R 5 / 6$ & yellowish brown & Silt Loam & - & - & $\mathrm{N}$ & - \\
\hline & & 3 & $120-170$ & 10YR 6/4 & light yellowish brown & Sandy Loam & $1-5 \%$ & $\begin{array}{c}\text { Calcium } \\
\text { Carbonate, } \\
\text { White fungus } \\
\text { or calcium }\end{array}$ & $\mathrm{N}$ & - \\
\hline & & 4 & $170-200$ & 10YR 6/3 & pale brown & Silty Clay Loam & $1-5 \%$ & $\begin{array}{c}\text { Calcium } \\
\text { Carbonate }\end{array}$ & $\mathrm{N}$ & Terminated at depth. \\
\hline \multirow{4}{*}{ 41BP960 } & \multirow{4}{*}{ AU09 } & 1 & $0-30$ & 10YR 4/4 & dark yellowish brown & Silt Loam & - & - & $\mathrm{N}$ & - \\
\hline & & 2 & $30-160$ & 10YR 5/6 & yellowish brown & Silt Loam & - & - & $\mathrm{N}$ & - \\
\hline & & 3 & $160-170$ & 10YR 6/4 & light yellowish brown & Sandy Loam & $1-5 \%$ & $\begin{array}{c}\text { Calcium } \\
\text { Carbonate, } \\
\text { White fungus } \\
\text { or calcium } \\
\end{array}$ & $\mathrm{N}$ & - \\
\hline & & 4 & $170-200$ & 10YR 6/3 & pale brown & Silty Clay Loam & $1-5 \%$ & $\begin{array}{c}\text { Calcium } \\
\text { Carbonate }\end{array}$ & $\mathrm{N}$ & Terminated at depth. \\
\hline \multirow{3}{*}{ 41BP960 } & \multirow{3}{*}{ AU10 } & 1 & $0-65$ & 10YR $4 / 4$ & dark yellowish brown & Silt Loam & - & - & $\mathrm{N}$ & - \\
\hline & & 2 & $65-150$ & 10YR 6/4 & light yellowish brown & Silt Loam & - & - & $\mathrm{N}$ & - \\
\hline & & 3 & $165-200$ & 10YR 3/4 & dark yellowish brown & Silty Clay & - & - & $\mathrm{N}$ & Terminated at depth. \\
\hline & & 1 & $0-40$ & 10YR 4/4 & dark yellowish brown & Silt Loam & - & - & $\mathrm{N}$ & - \\
\hline 41BP960 & AU11 & 2 & $40-180$ & 10YR $6 / 4$ & light yellowish brown & Silt Loam & - & - & $\mathrm{N}$ & - \\
\hline & & 3 & $180-200$ & 10YR 3/4 & dark yellowish brown & Silty Clay & - & - & $\mathrm{N}$ & Terminated at depth. \\
\hline & & 1 & $0-40$ & $10 Y R$ 4/4 & dark yellowish brown & Silt Loam & - & - & $\mathrm{N}$ & - \\
\hline & & 2 & $40-150$ & 10YR 5/6 & yellowish brown & Silt Loam & - & - & $\mathrm{N}$ & - \\
\hline 41BP960 & AU12 & 3 & $150-200$ & 10YR 6/4 & light yellowish brown & Sandy Loam & $1-5 \%$ & $\begin{array}{c}\text { Calcium } \\
\text { Carbonate, } \\
\text { White fungus } \\
\text { or calcium }\end{array}$ & $\mathrm{N}$ & Terminated at depth. \\
\hline & & 1 & $0-40$ & 10YR $4 / 4$ & dark yellowish brown & Loam & - & - & $N$ & - \\
\hline 41BP960 & $\mathrm{AU} 13$ & 2 & $0-150$ & 10YR 5/4 & yellowish brown & Silty Clay Loam & - & - & $\mathrm{N}$ & - \\
\hline & & 3 & $150-200$ & 10YR 6/4 & light yellowish brown & Silty Clay Loam & $1-5 \%$ & $\begin{array}{c}\text { Calcium } \\
\text { Carbonate }\end{array}$ & $N$ & Terminated at depth. \\
\hline & & 1 & $0-80$ & 10YR 4/2 & dark grayish brown & Clay Loam & - & - & $\mathrm{N}$ & - \\
\hline 41BP960 & AU14 & 2 & $80-120$ & 10YR 4/1 & dark gray & Clay Loam & $1-5 \%$ & Snail Shell & $P$ & $\begin{array}{l}\text { 1: Ceramic (prehistoric) [Positive for shell tempered } \\
\text { pottery where, burnished on outside at } 90-100 \mathrm{cmbs} \text { ] }\end{array}$ \\
\hline & & 3 & $120-180$ & 10YR 5/2 & grayish brown & Silt Loam & $1-5 \%$ & $\begin{array}{c}\text { Calcium } \\
\text { Carbonate }\end{array}$ & $\mathrm{N}$ & Terminated at depth. \\
\hline & & 1 & $0-30$ & 10YR 4/3 & brown & Clay Loam & - & - & $\mathrm{N}$ & - \\
\hline & & 2 & $30-80$ & 10YR 5/2 & grayish brown & Clay Loam & - & - & $\mathrm{N}$ & - \\
\hline 41BP960 & AU15 & 3 & $80-120$ & 10YR 4/2 & dark grayish brown & Clay Loam & $1-5 \%$ & Snail Shell & $\mathrm{P}$ & 1: Ceramic (prehistoric) \\
\hline & & 4 & $120-180$ & 10YR 5/4 & yellowish brown & Silt Loam & $1-5 \%$ & $\begin{array}{c}\text { Calcium } \\
\text { Carbonate } \\
\end{array}$ & $\mathrm{N}$ & Terminated at depth. \\
\hline & & 1 & 30 & 10YR 4/1 & dark gray & Clay Loam & $1-5 \%$ & Roots & $\mathrm{N}$ & - \\
\hline & & 2 & $30-80$ & 10YR 5/2 & grayish brown & Clay Loam & $1-5 \%$ & None & $\mathrm{N}$ & - \\
\hline 41BP960 & AU16 & 3 & $80-120$ & 10YR 4/1 & dark gray & Clay Loam & $1-5 \%$ & None & $\mathrm{N}$ & - \\
\hline & & 4 & $120-165$ & 10YR $5 / 3$ & brown & Silty Clay Loam & $1-5 \%$ & $\begin{array}{c}\text { Calcium } \\
\text { Carbonate }\end{array}$ & $\mathrm{N}$ & Terminated at depth. \\
\hline & & 1 & $0-30$ & 10YR 4/2 & dark grayish brown & Clay Loam & - & - & $\mathrm{N}$ & - \\
\hline 41BP960 & AU17 & 2 & $30-120$ & 10YR 5/2 & grayish brown & Clay Loam & - & - & $\mathrm{N}$ & - \\
\hline & & 3 & $120-150$ & 10YR $5 / 3$ & brown & Silty Clay Loam & $1-5 \%$ & $\begin{array}{c}\text { Calcium } \\
\text { Carbonate }\end{array}$ & $N$ & Terminated at depth. \\
\hline
\end{tabular}


Appendix C

\begin{tabular}{|c|c|c|c|c|c|c|c|c|c|c|}
\hline Site No. & $\begin{array}{l}\text { Auger Probe } \\
\text { Number }\end{array}$ & Level & Depth & Munsell Value & Munsell Description & Soil Texture & |nclusion (\%)| & Inclusion Type & $\begin{array}{c}\text { Cultural } \\
\text { Material } \\
\text { (P/N) }\end{array}$ & Comments \\
\hline \multirow{4}{*}{ NA } & \multirow{4}{*}{ AU18 } & 1 & $0-30$ & 10YR 4/2 & dark grayish brown & Clay Loam & - & - & $\mathrm{N}$ & - \\
\hline & & 2 & $30-100$ & 10YR 5/2 & grayish brown & Clay Loam & 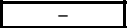 & $\begin{array}{ll}- \\
\end{array}$ & $\mathrm{N}$ & 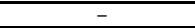 \\
\hline & & 3 & $100-140$ & 10YR 4/1 & dark gray & Clay Loam & - & - & $\mathrm{N}$ & - \\
\hline & & 4 & $140-160$ & 10YR 5/3 & brown & Silty Clay Loam & $1-5 \%$ & $\begin{array}{c}\text { Calcium } \\
\text { Carbonate }\end{array}$ & $\mathrm{N}$ & Terminated at depth. \\
\hline \multirow{4}{*}{ NA } & \multirow{4}{*}{ AU19 } & 1 & $0-30$ & 10YR 4/2 & dark grayish brown & Clay Loam & - & - & $\mathrm{N}$ & - \\
\hline & & 2 & $30-160$ & 10YR 5/2 & grayish brown & Clay Loam & - & - & $\mathrm{N}$ & - \\
\hline & & 3 & $160-190$ & 10YR 4/1 & dark gray & Clay Loam & - & - & $\mathrm{N}$ & - \\
\hline & & 4 & $190-200$ & 10YR 5/3 & brown & Silty Clay Loam & $1-5 \%$ & $\begin{array}{c}\text { Calcium } \\
\text { Carbonate }\end{array}$ & $\mathrm{N}$ & Terminated at depth. \\
\hline \multirow{3}{*}{ NA } & \multirow{3}{*}{$\mathrm{AU} 20$} & 1 & $0-50$ & 10YR 4/2 & dark grayish brown & Clay Loam & - & - & $\mathrm{N}$ & - \\
\hline & & 2 & $50-110$ & 10YR 5/3 & brown & Clay & $1-5 \%$ & $\begin{array}{c}\text { Calcium } \\
\text { Carbonate, } \\
\text { Mottles }\end{array}$ & $\mathrm{N}$ & - \\
\hline & & 3 & $110-120$ & 10YR 5/3 & brown & Clay & $1-5 \%$ & $\begin{array}{c}\text { Calcium } \\
\text { Carbonate }\end{array}$ & $\mathrm{N}$ & Terminated at depth. \\
\hline \multirow{4}{*}{ NA } & \multirow{4}{*}{ AU21 } & 1 & $0-40$ & 10YR 4/2 & dark grayish brown & Clay Loam & - & - & $\mathrm{N}$ & - \\
\hline & & 2 & $40-70$ & 10YR 5/2 & grayish brown & Clay Loam & - & - & $\mathrm{N}$ & - \\
\hline & & 3 & $70-100$ & 10YR 4/1 & dark gray & Clay Loam & - & - & $\mathrm{N}$ & - \\
\hline & & 4 & $100-150$ & 10YR 5/3 & brown & Silty Clay Loam & $1-5 \%$ & $\begin{array}{c}\text { Calcium } \\
\text { Carbonate }\end{array}$ & $\mathrm{N}$ & Terminated at depth. \\
\hline \multirow{2}{*}{ NA } & \multirow{2}{*}{ AU22 } & 1 & $0-150$ & 10YR 4/1 & dark gray & Clay & $1-5 \%$ & $\begin{array}{c}\text { Calcium } \\
\text { Carbonate }\end{array}$ & $\mathrm{N}$ & - \\
\hline & & 2 & $150-170$ & 10YR 4/2 & dark grayish brown & Clay & $1-5 \%$ & $\begin{array}{c}\text { Calcium } \\
\text { Carbonate }\end{array}$ & $\mathrm{N}$ & Terminated at depth. \\
\hline \multirow{4}{*}{ NA } & \multirow{4}{*}{$\mathrm{AU} 23$} & 1 & $0-40$ & 10YR $4 / 2$ & dark grayish brown & Clay Loam & - & - & $\mathrm{N}$ & - \\
\hline & & 2 & $40-100$ & 10YR 5/2 & grayish brown & Clay Loam & - & - & $\mathrm{N}$ & - \\
\hline & & 3 & $100-140$ & 10YR 4/1 & dark gray & Clay Loam & - & - & $\mathrm{N}$ & - \\
\hline & & 4 & $140-180$ & 10YR 5/3 & brown & Silty Clay Loam & $1-5 \%$ & $\begin{array}{c}\text { Calcium } \\
\text { Carbonate }\end{array}$ & $\mathrm{N}$ & Terminated at depth. \\
\hline \multirow{4}{*}{ NA } & \multirow{4}{*}{ AU24 } & 1 & $0-60$ & 10YR 4/2 & dark grayish brown & Clay Loam & - & - & $\mathrm{N}$ & - \\
\hline & & 2 & $60-120$ & 10YR 5/2 & grayish brown & Clay Loam & - & - & $\mathrm{N}$ & - \\
\hline & & 3 & $120-150$ & 10YR 4/1 & dark gray & Clay Loam & - & - & $\mathrm{N}$ & - \\
\hline & & 4 & $150-170$ & 10YR 5/3 & brown & Silty Clay Loam & $1-5 \%$ & $\begin{array}{c}\text { Calcium } \\
\text { Carbonate }\end{array}$ & N & Terminated at depth. \\
\hline & & 1 & $0-85$ & 10YR 4/2 & dark grayish brown & Clay Loam & - & - & $\mathrm{N}$ & - \\
\hline & & 2 & $85-140$ & 10YR 5/2 & grayish brown & Clay Loam & 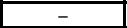 & 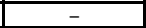 & $\mathrm{N}$ & $\begin{array}{c}- \\
\end{array}$ \\
\hline NA & $\mathrm{AU} 25$ & 3 & $140-170$ & 10YR 4/1 & dark gray & Clay Loam & - & - & $\mathrm{N}$ & - \\
\hline & & 4 & $170-180$ & 10YR $5 / 3$ & brown & Silty Clay Loam & $1-5 \%$ & $\begin{array}{c}\text { Calcium } \\
\text { Carbonate }\end{array}$ & $\mathrm{N}$ & Terminated at depth. \\
\hline & & 1 & $0-60$ & 10YR 4/2 & dark grayish brown & Clay Loam & - & - & $\mathrm{N}$ & - \\
\hline & & 2 & $60-100$ & 10YR 5/2 & grayish brown & Clay Loam & - & - & $\mathrm{N}$ & - \\
\hline NA & AU26 & 3 & $100-110$ & 10YR 4/1 & dark gray & Clay Loam & - & - & $\mathrm{N}$ & - \\
\hline & & 4 & $110-140$ & 10YR 5/3 & brown & Silty Clay Loam & $1-5 \%$ & $\begin{array}{c}\text { Calcium } \\
\text { Carbonate }\end{array}$ & $\mathrm{N}$ & Terminated at depth. \\
\hline & & 1 & $0-40$ & 10YR 4/2 & dark grayish brown & Silty Clay & - & - & $\mathrm{N}$ & - \\
\hline NA & AU27 & 2 & $40-90$ & 10YR 5/2 & grayish brown & Silty Clay Loam & - & - & $\mathrm{N}$ & - \\
\hline & & 3 & $90-120$ & 10YR 5/3 & brown & Silt Loam & $1-5 \%$ & $\begin{array}{c}\text { Calcium } \\
\text { Carbonate }\end{array}$ & $\mathrm{N}$ & Terminated at depth. \\
\hline & & 1 & $0-50$ & 10YR 4/2 & dark grayish brown & Silty Clay & - & - & $\mathrm{N}$ & - \\
\hline & & 2 & $50-90$ & 10YR 5/2 & grayish brown & Silty Clay Loam & - & - & $\mathrm{N}$ & - \\
\hline NA & AU28 & 3 & $90-110$ & 10YR 5/3 & brown & Silt Loam & - & - & $\mathrm{N}$ & - \\
\hline & & 4 & $110-140$ & 10YR 6/3 & pale brown & Silt Loam & $1-5 \%$ & $\begin{array}{c}\text { Calcium } \\
\text { Carbonate }\end{array}$ & $\mathrm{N}$ & Terminated at depth. \\
\hline & & 1 & $0-40$ & 10YR 4/2 & dark grayish brown & Silty Clay & - & - & $\mathrm{N}$ & - \\
\hline & & 2 & $40-90$ & 10YR 5/2 & grayish brown & Silty Clay Loam & - & - & $\mathrm{N}$ & - \\
\hline NA & AU29 & 3 & $90-120$ & $10 \mathrm{YR} 5 / 3$ & brown & Silt Loam & - & - & $\mathrm{N}$ & - \\
\hline & & 4 & $120-140$ & 10YR 6/3 & pale brown & Silt Loam & $1-5 \%$ & $\begin{array}{c}\text { Calcium } \\
\text { Carbonate }\end{array}$ & $\mathrm{N}$ & Terminated at depth. \\
\hline & & 1 & $0-40$ & 10YR 4/2 & dark grayish brown & Silty Clay & - & - & $\mathrm{N}$ & - \\
\hline & & 2 & $40-100$ & 10YR 5/2 & grayish brown & Silty Clay Loam & - & - & $\mathrm{N}$ & - \\
\hline NA & AU30 & 2 & $100-120$ & 10YR 5/2 & grayish brown & Silty Clay Loam & - & 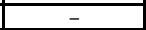 & $\mathrm{N}$ & 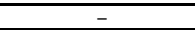 \\
\hline & & 4 & $120-140$ & 10YR 6/3 & pale brown & Silt Loam & $1-5 \%$ & $\begin{array}{c}\text { Calcium } \\
\text { Carbonate }\end{array}$ & $\mathrm{N}$ & Terminated at depth. \\
\hline & & 1 & $0-50$ & 10YR 4/2 & dark grayish brown & Silty Clay & - & - & $\mathrm{N}$ & - \\
\hline & & 2 & $50-90$ & 10YR 5/2 & grayish brown & Silty Clay Loam & - & 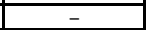 & $\mathrm{N}$ & 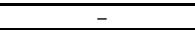 \\
\hline NA & AU31 & 3 & $90-110$ & $10 Y R 5 / 3$ & brown & Silt Loam & - & - & $\mathrm{N}$ & - \\
\hline & & 4 & $110-140$ & 10YR $6 / 3$ & pale brown & Silt Loam & $1-5 \%$ & $\begin{array}{c}\text { Calcium } \\
\text { Carbonate }\end{array}$ & $\mathrm{N}$ & Terminated at depth. \\
\hline & & 1 & $0-40$ & 10YR 4/2 & dark grayish brown & Silty Clay & - & - & $\mathrm{N}$ & - \\
\hline NA & AU32 & 2 & $40-110$ & 10YR 5/2 & grayish brown & Silty Clay Loam & - & - & $\mathrm{N}$ & - \\
\hline & & 3 & $110-160$ & 10YR 5/2 & grayish brown & Silty Clay Loam & $1-5 \%$ & $\begin{array}{c}\text { Calcium } \\
\text { Carbonate }\end{array}$ & $\mathrm{N}$ & Terminated at depth. \\
\hline & & 1 & $0-35$ & 10YR 4/2 & dark grayish brown & Silty Clay & - & - & $\mathrm{N}$ & - \\
\hline 41BP960 & AU33 & 2 & $35-110$ & 10YR 5/2 & grayish brown & Silty Clay Loam & - & - & $\mathrm{N}$ & - \\
\hline 4TBP960 & AU33 & 3 & $110-200$ & 10YR 5/3 & brown & Silt Loam & $1-5 \%$ & $\begin{array}{c}\text { Calcium } \\
\text { Carbonate }\end{array}$ & $\mathrm{N}$ & Terminated at depth. \\
\hline
\end{tabular}




\begin{tabular}{|c|c|c|c|c|c|c|c|c|c|c|}
\hline Site No. & $\begin{array}{l}\text { Auger Probe } \\
\text { Number }\end{array}$ & Level & Depth & Munsell Value & Munsell Description & Soil Texture & |nclusion (\%)| & Inclusion Type & $\begin{array}{c}\text { Cultural } \\
\text { Material } \\
\text { (P/N) }\end{array}$ & Comments \\
\hline \multirow{4}{*}{ 41BP960 } & \multirow{4}{*}{ AU34 } & 1 & $0-35$ & 10YR 4/2 & dark grayish brown & Silty Clay & - & - & $\mathrm{N}$ & - \\
\hline & & 2 & $35-120$ & 10YR 5/2 & grayish brown & Silty Clay Loam & - & - & $\mathrm{N}$ & - \\
\hline & & 3 & $120-150$ & 10YR $5 / 3$ & brown & Silt Loam & $1-5 \%$ & $\begin{array}{c}\text { Calcium } \\
\text { Carbonate }\end{array}$ & $\mathrm{N}$ & - \\
\hline & & 4 & $150-200$ & 10YR 4/1 & dark gray & Silty Clay Loam & $5-10 \%$ & $\begin{array}{c}\text { Calcium } \\
\text { Carbonate } \\
\end{array}$ & $\mathrm{N}$ & Terminated at depth. \\
\hline \multirow{4}{*}{ 41BP961 } & \multirow{4}{*}{ AU35 } & 1 & $0-40$ & 10YR 4/2 & dark grayish brown & Silty Clay & - & - & $\mathrm{N}$ & - \\
\hline & & 2 & $40-90$ & $10 Y R 5 / 2$ & grayish brown & Silty Clay Loam & - & - & $\mathrm{N}$ & - \\
\hline & & 3 & $90-120$ & 10YR 4/1 & dark gray & Silty Clay Loam & - & - & $\mathrm{P}$ & 1: Other Prehistoric [FCC found at $110 \mathrm{cmbs}]$ \\
\hline & & 4 & $120-160$ & 10YR 5/3 & brown & Silt Loam & $1-5 \%$ & $\begin{array}{c}\text { Calcium } \\
\text { Carbonate }\end{array}$ & $\mathrm{N}$ & Terminated at depth. \\
\hline \multirow{3}{*}{ 41BP961 } & \multirow{3}{*}{ AU36 } & 1 & $0-40$ & 10YR 4/2 & dark grayish brown & Silty Clay & - & - & $\mathrm{N}$ & - \\
\hline & & 2 & $40-90$ & 10YR 5/2 & grayish brown & Silty Clay Loam & - & - & $\mathrm{N}$ & - \\
\hline & & 3 & $90-165$ & 10YR 5/3 & brown & Silty Clay Loam & $1-5 \%$ & $\begin{array}{c}\text { Calcium } \\
\text { Carbonate }\end{array}$ & $\mathrm{N}$ & Terminated at depth. \\
\hline \multirow{5}{*}{ 41BP961 } & \multirow{5}{*}{ AU37 } & 1 & $0-60$ & 10YR 4/1 & dark gray & Silty Clay & - & - & $\mathrm{N}$ & - \\
\hline & & 2 & $40-90$ & $10 Y R 5 / 2$ & grayish brown & Silty Clay Loam & - & - & $\mathrm{N}$ & - \\
\hline & & 3 & $90-140$ & 10YR 4/1 & dark gray & Silty Clay & - & - & $\mathrm{N}$ & - \\
\hline & & 4 & $140-180$ & 10YR 4/1 & dark gray & Silty Clay & $1-5 \%$ & $\begin{array}{c}\text { Calcium } \\
\text { Carbonate }\end{array}$ & $\mathrm{P}$ & 1: Flake (tertiary) at $160-170 \mathrm{cmbs}$ \\
\hline & & 5 & $180-200$ & 10YR $5 / 3$ & brown & Silty Clay Loam & $5-10 \%$ & $\begin{array}{c}\text { Calcium } \\
\text { Carbonate } \\
\end{array}$ & $\mathrm{N}$ & Terminated at depth. \\
\hline \multirow{3}{*}{ 41BP961 } & \multirow{3}{*}{$\mathrm{AU} 38$} & 1 & $0-50$ & 10YR $4 / 2$ & dark grayish brown & Silty Clay & - & - & $\mathrm{P}$ & 1: Flake (secondary) \\
\hline & & 2 & $50-100$ & 10YR 5/2 & grayish brown & Silty Clay Loam & - & - & $\mathrm{N}$ & - \\
\hline & & 3 & 100-150 & 10YR $5 / 3$ & brown & Silty Clay Loam & $5-10 \%$ & $\begin{array}{c}\text { Calcium } \\
\text { Carbonate }\end{array}$ & $\mathrm{N}$ & Terminated at depth. \\
\hline \multirow{4}{*}{ 41BP961 } & \multirow{4}{*}{ AU39 } & 1 & $0-40$ & 10YR 4/1 & dark gray & Silty Clay & - & - & $\mathrm{N}$ & - \\
\hline & & 2 & $40-100$ & $10 Y R 5 / 2$ & grayish brown & Silty Clay Loam & - & - & $\mathrm{N}$ & - \\
\hline & & 3 & $100-140$ & 10YR 4/1 & dark gray & Loam & - & - & $\mathrm{N}$ & - \\
\hline & & 4 & $140-200$ & 10YR 5/3 & brown & Silt Loam & - & - & $\mathrm{N}$ & Terminated at depth. \\
\hline \multirow{4}{*}{ NA } & \multirow{4}{*}{$\mathrm{AU} 40$} & 1 & $0-50$ & 10YR 4/2 & dark grayish brown & Silty Clay & - & - & $\mathrm{N}$ & - \\
\hline & & 2 & $50-100$ & 10YR 5/2 & grayish brown & Silty Clay Loam & - & - & $\mathrm{N}$ & - \\
\hline & & 3 & $100-160$ & 10YR 4/1 & dark gray & Silty Clay & - & - & $\mathrm{N}$ & - \\
\hline & & 4 & $160-200$ & 10YR 5/2 & grayish brown & Silty Clay Loam & $1-5 \%$ & $\begin{array}{c}\text { Calcium } \\
\text { Carbonate }\end{array}$ & $\mathrm{N}$ & Terminated at depth. \\
\hline \multirow{4}{*}{ NA } & & 1 & $0-15$ & 10YR 4/2 & dark grayish brown & Silty Clay Loam & - & - & $\mathrm{N}$ & - \\
\hline & AU41 & 2 & $15-100$ & 10YR 6/3 & pale brown & Sandy Loam & - & - & $\mathrm{N}$ & - \\
\hline & $\mathrm{AUT}_{1}$ & 3 & $100-150$ & 10YR 4/1 & dark gray & Sandy Clay Loam & - & - & $\mathrm{N}$ & - \\
\hline & & 4 & $140-200$ & $10 Y R 5 / 3$ & brown & Sandy Clay Loam & - & - & $\mathrm{N}$ & Terminated at depth. \\
\hline & & 1 & $0-15$ & 10YR 4/1 & dark gray & Silty Clay Loam & - & - & $\mathrm{N}$ & - \\
\hline NA & AU42 & 2 & $15-190$ & 10YR 6/4 & light yellowish brown & Sandy Clay Loam & - & - & $\mathrm{N}$ & - \\
\hline & & 3 & $190-200$ & 10YR 5/3 & strong brown & Sandy Clay & - & - & $\mathrm{N}$ & Terminated at depth. \\
\hline NA & AUG DR01 & 1 & $0-40$ & 10YR 4/4 & dark yellowish brown & Sandy Clay Loam & $5-10 \%$ & $\begin{array}{l}\text { Gravels, } \\
\text { Pebbles }\end{array}$ & $\mathrm{N}$ & Terminated at bedrock. \\
\hline & & 1 & $0-30$ & $10 Y R 3 / 4$ & dark yellowish brown & Silty Clay Loam & $1-5 \%$ & Pebbles & $\mathrm{N}$ & $\begin{array}{c}- \\
\end{array}$ \\
\hline NA & AUG DR02 & 2 & $30-110$ & 10YR $2 / 2$ & very dark brown & Clay Loam & $1-5 \%$ & $\begin{array}{l}\text { Gravels, } \\
\text { Pebbles } \\
\end{array}$ & $\mathrm{N}$ & Terminated at bedrock or compact gravels. \\
\hline & & 1 & $0-50$ & 10YR $3 / 2$ & very dark grayish brown & Silty Clay Loam & $1-5 \%$ & Pebbles & $\mathrm{N}$ & - \\
\hline NA & AUG DR03 & 2 & $50-90$ & 10YR 4/1 & dark gray & Silty Clay & $1-5 \%$ & $\begin{array}{l}\text { Gravels, } \\
\text { Pebbles } \\
\end{array}$ & $\mathrm{N}$ & - \\
\hline & & 3 & $90-110$ & 10YR 5/2 & grayish brown & Sandy Clay Loam & $5-10 \%$ & $\begin{array}{c}\text { Calcium } \\
\text { Carbonate, } \\
\text { Gravels }\end{array}$ & $\mathrm{N}$ & Terminated at bedrock or dense gravels. \\
\hline NA & AUG DR04 & 1 & $0-60$ & 10YR 4/4 & dark yellowish brown & Sandy Clay Loam & $5-10 \%$ & $\begin{array}{l}\text { Gravels, } \\
\text { Pebbles } \\
\end{array}$ & $\mathrm{N}$ & - \\
\hline NA & AUG DRU4 & 2 & $60-70$ & 10YR 2/2 & very dark brown & Clay Loam & $1-5 \%$ & $\begin{array}{l}\text { Gravels, } \\
\text { Pebbles } \\
\end{array}$ & $\mathrm{N}$ & Terminated at bedrock or dense cobbles. \\
\hline NA & AUG DR05 & 1 & $0-67$ & 10YR 5/1 & gray & Silty Clay Loam & $1-5 \%$ & $\begin{array}{l}\text { Gravels, } \\
\text { Pebbles } \\
\end{array}$ & N & Terminated at bedrock or dense cobbles. \\
\hline$N A$ & AHCROR & 1 & $0-50$ & 10YR 5/2 & grayish brown & Sandy Loam & $10-20 \%$ & $\begin{array}{c}\text { Snail Shell, } \\
\text { Decaying wood }\end{array}$ & $\mathrm{N}$ & - \\
\hline 保 & 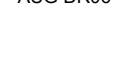 & 2 & $50-80$ & 10YR 4/2 & dark grayish brown & Sandy Clay Loam & $1-5 \%$ & $\begin{array}{c}\text { Mottles, } \\
\text { Decaying wood }\end{array}$ & $\mathrm{N}$ & Terminated at compact soil. \\
\hline & & 1 & $0-90$ & 10YR 5/1 & gray & Silty Clay & $1-5 \%$ & $\begin{array}{l}\text { Cobbles, } \\
\text { Pebbles } \\
\end{array}$ & $\mathrm{N}$ & - \\
\hline NA & AUG DR07a & 2 & $90-110$ & 10YR 5/1 & gray & Clay & $1-5 \%$ & $\begin{array}{c}\text { Calcium } \\
\text { Carbonate, } \\
\text { Gravels, } \\
\text { Pebbles } \\
\end{array}$ & $\mathrm{N}$ & Terminated at compact soil. \\
\hline & & 1 & $0-75$ & 10YR 5/2 & grayish brown & Silty Clay Loam & $1-5 \%$ & Pebbles & $\mathrm{N}$ & - \\
\hline NA & AUG DR07b & 2 & $75-90$ & 10YR $5 / 3$ & brown & Silty Clay & $1-5 \%$ & Pebbles & $\mathrm{N}$ & - \\
\hline TA & AUG DRUTD & 3 & $90-115$ & 10YR $7 / 3$ & very pale brown & Silty Clay & $1-5 \%$ & Pebbles & $\mathrm{N}$ & - \\
\hline & & 4 & $115-150$ & 10YR 6/1 & gray & Silt & $\begin{array}{lll}- & & \\
\end{array}$ & 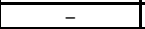 & $\mathrm{N}$ & Terminated at depth. \\
\hline & & 1 & $0-80$ & 10YR 4/4 & dark yellowish brown & Silty Clay Loam & - & - & $\mathrm{N}$ & - \\
\hline & & 2 & $80-110$ & $10 Y R 5 / 3$ & brown & Silty Clay Loam & $1-5 \%$ & Pebbles & $\mathrm{N}$ & - \\
\hline NA & AUG DR08 & 3 & $110-230$ & 10YR $7 / 3$ & very pale brown & Silt Loam & $1-5 \%$ & $\begin{array}{c}\text { Calcium } \\
\text { Carbonate, } \\
\text { Pebbles } \\
\end{array}$ & $\mathrm{N}$ & - \\
\hline & & 4 & $230-240$ & 10YR 5/1 & gray & Silty Clay Loam & - & - & $\mathrm{N}$ & Terminated at depth. \\
\hline $\mathrm{NA}$ & AUG DR09 & 1 & $0-150$ & 10YR 5/2 & grayish brown & Silty Clay & $1-5 \%$ & Pebbles & $\mathrm{N}$ & Terminated at depth. \\
\hline NA & AUG DR10 & 1 & $50-115$ & 10YR 3/2 & very dark grayish brown & Silty Clay Loam & $>20 \%$ & $\begin{array}{c}\text { Calcium } \\
\text { Carbonate, } \\
\text { Gravels, } \\
\text { Pebbles }\end{array}$ & $\mathrm{N}$ & Terminated at compact soil. \\
\hline
\end{tabular}


Appendix C

\begin{tabular}{|c|c|c|c|c|c|c|c|c|c|c|}
\hline Site No. & $\begin{array}{c}\text { Auger Probe } \\
\text { Number }\end{array}$ & Level & Depth & Munsell Value & Munsell Description & Soil Texture & |nclusion (\%) & Inclusion Type & $\begin{array}{c}\text { Cultural } \\
\text { Material } \\
\text { (P/N) }\end{array}$ & Comments \\
\hline \multirow{3}{*}{ NA } & \multirow{3}{*}{ CSMC01 } & 1 & $0-81$ & 10YR 3/1 & very dark gray & Clay & $1-5 \%$ & Snail Shell & $\mathrm{N}$ & 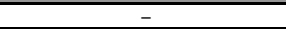 \\
\hline & & 2 & $81-180$ & 10YR 5/4 & yellowish brown & Clay Loam & $10-20 \%$ & $\begin{array}{c}\text { Calcium } \\
\text { Carbonate, } \\
\text { Snail Shell }\end{array}$ & $\mathrm{N}$ & - \\
\hline & & 3 & $180-200$ & 7.5YR 4/6 & strong brown & Clay Loam & $10-20 \%$ & $\begin{array}{c}\text { Calcium } \\
\text { Carbonate, } \\
\text { Snail Shell }\end{array}$ & N & Terminated at depth. \\
\hline \multirow{3}{*}{ NA } & \multirow{3}{*}{ CSMC02 } & 1 & $0-110$ & 10YR 3/1 & very dark gray & Clay & $1-5 \%$ & Snail Shell & $\mathrm{N}$ & - \\
\hline & & 2 & $110-160$ & 10YR 5/4 & yellowish brown & Clay Loam & $10-20 \%$ & $\begin{array}{c}\text { Calcium } \\
\text { Carbonate, } \\
\text { Snail Shell } \\
\end{array}$ & N & - \\
\hline & & 3 & $160-200$ & $7.5 Y R 4 / 6$ & strong brown & Clay Loam & $10-20 \%$ & $\begin{array}{c}\text { Calcium } \\
\text { Carbonate, } \\
\text { Snail Shell }\end{array}$ & N & Terminated at depth. \\
\hline \multirow{3}{*}{ NA } & \multirow{3}{*}{ CSMC03 } & 1 & $0-51$ & 10YR 3/1 & very dark gray & Clay & $1-5 \%$ & Snail Shell & $\mathrm{N}$ & - \\
\hline & & 2 & $51-110$ & 10YR 5/4 & yellowish brown & Clay Loam & $10-20 \%$ & $\begin{array}{c}\text { Calcium } \\
\text { Carbonate, } \\
\text { Snail Shell }\end{array}$ & N & - \\
\hline & & 3 & $110-200$ & 7.5YR 4/6 & strong brown & Clay Loam & $10-20 \%$ & $\begin{array}{c}\text { Calcium } \\
\text { Carbonate, } \\
\text { Snail Shell }\end{array}$ & N & Terminated at depth. \\
\hline \multirow[t]{2}{*}{ NA } & \multirow[t]{2}{*}{ CSMC04 } & 1 & $0-95$ & 10YR 3/1 & very dark gray & Clay & $1-5 \%$ & $\begin{array}{c}\text { Calcium } \\
\text { Carbonate }\end{array}$ & $\mathrm{N}$ & - \\
\hline & & 2 & $95-110$ & 10YR 5/4 & yellowish brown & Clay Loam & $>20 \%$ & Gravels & $\mathrm{N}$ & Terminated at bedrock. \\
\hline \multirow{3}{*}{ NA } & \multirow{3}{*}{ CSMC05 } & 1 & $0-53$ & 10YR 3/2 & very dark grayish brown & Clay Loam & $1-5 \%$ & Snail Shell & N & - \\
\hline & & 2 & $53-133$ & 7.5YR 4/6 & strong brown & Clay Loam & $10-20 \%$ & $\begin{array}{c}\text { Calcium } \\
\text { Carbonate, } \\
\text { Snail Shell } \\
\end{array}$ & N & - \\
\hline & & 3 & $133-200$ & 7.5YR 6/6 & reddish yellow & Clay Loam & $10-20 \%$ & \begin{tabular}{|c|} 
Calcium \\
Carbonate, \\
Gravels, Snail \\
Shell \\
\end{tabular} & N & Terminated at depth. \\
\hline \multirow{3}{*}{ NA } & \multirow{3}{*}{ CSMC06 } & 1 & $0-53$ & 10YR 3/2 & very dark grayish brown & Clay Loam & $1-5 \%$ & Snail Shell & N & - \\
\hline & & 2 & $53-167$ & 7.5YR 4/6 & strong brown & Clay Loam & $10-20 \%$ & $\begin{array}{c}\text { Calcium } \\
\text { Carbonate, } \\
\text { Snail Shell }\end{array}$ & N & - \\
\hline & & 3 & $167-179$ & 7.5 YR 5/6 & strong brown & Clay Loam & $10-20 \%$ & $\begin{array}{c}\text { Calcium } \\
\text { Carbonate, } \\
\text { Snail Shell } \\
\end{array}$ & N & Terminated at bedrock. \\
\hline \multirow{3}{*}{ NA } & \multirow{3}{*}{$\mathrm{CSMC07}$} & 1 & $0-100$ & 10YR $3 / 2$ & very dark grayish brown & Clay & $5-10 \%$ & Snail Shell & N & - \\
\hline & & 2 & $100-155$ & 10YR 4/2 & dark grayish brown & Clay Loam & $10-20 \%$ & $\begin{array}{c}\text { Calcium } \\
\text { Carbonate }\end{array}$ & N & - \\
\hline & & 3 & $155-200$ & 7.5YR 4/4 & brown & Clay & $10-20 \%$ & $\begin{array}{c}\text { Calcium } \\
\text { Carbonate }\end{array}$ & $\mathrm{N}$ & Terminated at depth. \\
\hline \multirow{3}{*}{ NA } & \multirow{3}{*}{ CSMC08 } & 1 & $0-77$ & 10YR $3 / 2$ & very dark grayish brown & Clay & $5-10 \%$ & Snail Shell & N & - \\
\hline & & 2 & $77-155$ & 10YR 4/2 & dark grayish brown & Clay Loam & $10-20 \%$ & $\begin{array}{c}\text { Calcium } \\
\text { Carbonate }\end{array}$ & N & - \\
\hline & & 3 & $155-200$ & 10YR 3/2 & very dark grayish brown & Clay & $5-10 \%$ & Snail Shell & N & Terminated at depth. \\
\hline \multirow{3}{*}{ NA } & \multirow{3}{*}{ CSMC09 } & 1 & $0-140$ & 10YR 3/2 & very dark grayish brown & Loam & $5-10 \%$ & Snail Shell & $\mathrm{N}$ & - \\
\hline & & 2 & $140-175$ & 10YR 4/2 & dark grayish brown & Clay Loam & $5-10 \%$ & Snail Shell & $\mathrm{N}$ & - \\
\hline & & 3 & $175-200$ & 7.5YR 4/4 & brown & Clay & - & - & $\mathrm{N}$ & Terminated at depth. \\
\hline \multirow[b]{2}{*}{ NA } & \multirow[b]{2}{*}{ CSMC10 } & 1 & $0-140$ & $2.5 Y 3 / 2$ & very dark grayish brown & Clay & $5-10 \%$ & $\begin{array}{c}\text { Calcium } \\
\text { Carbonate }\end{array}$ & N & - \\
\hline & & 2 & $140-200$ & 10YR 5/4 & yellowish brown & Clay Loam & $10-20 \%$ & $\begin{array}{c}\text { Calcium } \\
\text { Carbonate, } \\
\text { Snail Shell }\end{array}$ & N & Terminated at depth. \\
\hline NA & CSMC11 & 1 & $0-20$ & $2.5 Y 3 / 2$ & very dark grayish brown & Clay Loam & $>20 \%$ & Roots & N & Terminated at impassable roots. \\
\hline \multirow{2}{*}{ NA } & \multirow{2}{*}{ CSMR01 } & 1 & $0-61$ & 10YR 6/2 & light brownish gray & Clay Loam & - & - & $\mathrm{N}$ & - \\
\hline & & 2 & $61-98$ & $10 Y R$ 6/2 & light brownish gray & Silty Clay Loam & - & - & $\mathrm{N}$ & Terminated at root. \\
\hline \multirow{2}{*}{ NA } & CSMR02 & 1 & $0-64$ & 10YR 4/2 & dark grayish brown & Clay Loam & - & - & $\mathrm{N}$ & - \\
\hline & & 2 & $64-200$ & $10 Y R 6 / 2$ & light brownish gray & Silty Clay Loam & - & - & $\mathrm{N}$ & Terminated at depth. \\
\hline NA & CSMR03 & 1 & $0-64$ & 10YR 4/2 & dark grayish brown & Clay Loam & - & - & $\mathrm{N}$ & - \\
\hline $\mathrm{NA}$ & CSMIR03 & 2 & $64-200$ & 10YR 6/2 & light brownish gray & Silty Clay Loam & - & - & $\mathrm{N}$ & Terminated at depth. \\
\hline NA & CSMR04 & 1 & $0-61$ & 10YR 6/2 & light brownish gray & Clay Loam & 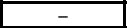 & 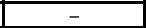 & $\mathrm{N}$ & $\begin{array}{llll}- & & & \end{array}$ \\
\hline & & 2 & $61-98$ & 10YR 6/2 & light brownish gray & Silty Clay Loam & 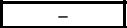 & 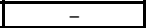 & $\mathrm{N}$ & Terminated at root. \\
\hline NA & CSMR05 & 1 & $0-200$ & 10YR 4/6 & dark yellowish brown & Clay Loam & - & - & $\mathrm{N}$ & Terminated at depth. \\
\hline NA & CSMR06 & 1 & $0-200$ & 10YR 4/6 & dark yellowish brown & Clay Loam & $\begin{array}{ll}- \\
\end{array}$ & $\begin{array}{ll}- \\
\end{array}$ & $\mathrm{N}$ & Terminated at depth. \\
\hline NA & CSMR07 & 1 & $0-200$ & 10YR 4/6 & dark yellowish brown & Clay Loam & - & - & $\mathrm{N}$ & Terminated at depth. \\
\hline NA & CSMR08 & 1 & $0-200$ & 10YR 4/6 & dark yellowish brown & Clay Loam & $\begin{array}{ll}- \\
\end{array}$ & 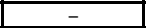 & $\mathrm{N}$ & Terminated at depth. \\
\hline
\end{tabular}




\begin{tabular}{|c|c|c|c|c|c|c|c|c|c|c|c|c|}
\hline BHT & County & Parcel & Depth (cmbs) & Munsell* & Soil Color* & Soil Texture & \begin{tabular}{|l|} 
Consistency \\
\end{tabular} & Structure Type & Grade & Inclusions & $\begin{array}{c}\text { Lower } \\
\text { Boundary } \\
\end{array}$ & Comment \\
\hline \multirow{4}{*}{$\begin{array}{l}\text { GU01- } \\
\text { Guadalupe } \\
\text { River }\end{array}$} & \multirow{4}{*}{ Guadalupe } & \multirow{4}{*}{50341} & $0-58$ & 10YR3/2 & $\begin{array}{c}\begin{array}{c}\text { very dark grayish } \\
\text { brown }\end{array} \\
\text { bro }\end{array}$ & silt loam & Friable & \begin{tabular}{|c|} 
Subangular \\
Blocky to \\
Angular Blocky
\end{tabular} & $\begin{array}{l}\text { Weak to } \\
\text { moderate }\end{array}$ & $\begin{array}{c}\text { roots-rootlets } 15-20 \% \text {, few snail shell (Heliodiscus) } \\
30 \% \text { pin holes, } 5 \% \text { worm burrows, } 5 \% \text { snail } \\
\text { fragments }\end{array}$ & $\begin{array}{l}\text { Gradual and } \\
\text { Smooth }\end{array}$ & Root zone $0-9 \mathrm{cmbs}$ \\
\hline & & & $58-99$ & 10YR $4 / 3$ & brown & Loam & Friable & $\begin{array}{c}\text { Subangular } \\
\text { Blocky }\end{array}$ & $\begin{array}{c}\text { Weak to } \\
\text { moderate }\end{array}$ & \begin{tabular}{|c|}
$5-10 \%$ rootlets, $30 \%$ pin holes, $5 \%$ worm burrows, \\
$1 \%$ snail fragments
\end{tabular} & $\begin{array}{c}\text { Gradual and } \\
\text { Smooth }\end{array}$ & Transitional \\
\hline & & & 99-183 & 10YR5/4 & yellowish brown & Silt Loam & Friable & $\begin{array}{l}\text { Subangular } \\
\text { Blocky }\end{array}$ & Moderate & $\begin{array}{c}3-5 \% \text { rootlets, } 30 \% \text { pin holes, } 5 \% \text { worm burrows, } \\
10 \% \text { snail - Rabdotus, } 1 \% \text { snail fragments }\end{array}$ & $\begin{array}{l}\text { Clear and } \\
\text { smooth }\end{array}$ & \\
\hline & & & $183-326$ & $\begin{array}{c}\text { 10YR5/6 to } \\
10 \mathrm{YR} 6 / 6\end{array}$ & $\begin{array}{c}\text { yellowish brown } \\
\text { to brownish } \\
\text { yellow }\end{array}$ & Clay loam & Friable & Angular Blocky & Moderate & $\begin{array}{c}1 \% \text { rootlets, } 5-10 \% \text { pin holes, } 1 \% \text { white filament } \\
(1 \mathrm{~mm}), 20-30 \% \text { snail - heliodiscus and rabdotus, } \\
10 \% \text { snail fragments }\end{array}$ & Unobserved & $\begin{array}{c}\text { CaCo3 filaments increase with } \\
\text { depth } 3-4 \mathrm{~mm}(5 \%) \sim 280 \mathrm{cmbs} \text {, } \\
\text { clay content increases with } \\
\text { depth } \\
\end{array}$ \\
\hline \multirow{4}{*}{$\begin{array}{l}\text { GU02- } \\
\text { Guadalupe } \\
\text { River }\end{array}$} & \multirow{4}{*}{ Guadalupe } & \multirow{4}{*}{50341} & $0-41$ & 10YR3/2 & $\begin{array}{c}\text { very dark grayish } \\
\text { brown }\end{array}$ & silt loam & Friable & \begin{tabular}{|c|} 
Subangular \\
Blocky to \\
Angular Blocky
\end{tabular} & $\begin{array}{l}\text { Weak to } \\
\text { moderate }\end{array}$ & $\begin{array}{c}\text { roots-rootlets } 15-20 \% \text {, few snail shell (Heliodiscus), } \\
30 \% \text { pin holes, } 5 \% \text { worm burrows, } 5 \% \text { snail } \\
\text { fragments }\end{array}$ & $\begin{array}{l}\text { Gradual and } \\
\text { Smooth }\end{array}$ & Root zone $0-9 \mathrm{cmbs}$ \\
\hline & & & 41-93 & 10YR $4 / 3$ & brown & Loam & Friable & $\begin{array}{l}\text { Subangular } \\
\text { Blocky }\end{array}$ & $\begin{array}{l}\text { Weak to } \\
\text { moderate }\end{array}$ & $\begin{array}{c}5-10 \% \text { rootlets, } 30 \% \text { pin holes, } 5 \% \text { worm burrows, } \\
1 \% \text { snail fragments }\end{array}$ & $\begin{array}{c}\text { Gradual to } \\
\text { clear and } \\
\text { slightly wavy }\end{array}$ & Transitional \\
\hline & & & 93-196 & 10YR5/4 & yellowish brown & Silt Loam & Friable & $\begin{array}{l}\text { Subangular } \\
\text { Blocky }\end{array}$ & Moderate & \begin{tabular}{|c|}
$3-5 \%$ rootlets, $30 \%$ pin holes, $5 \%$ worm burrows, \\
$10 \%$ snail - Rabdotus, $1 \%$ snail fragments, pockets \\
of snail - rabdotus, indeterminate burrow - $6 \mathrm{~mm}$ - \\
$1 \%$
\end{tabular} & $\begin{array}{l}\text { Clear and } \\
\text { smooth }\end{array}$ & \\
\hline & & & $196-306$ & $\begin{array}{l}10 \text { YR5/6 to } \\
10 Y R 6 / 6\end{array}$ & \begin{tabular}{|c|}
$\begin{array}{c}\text { yellowish brown } \\
\text { to brownish } \\
\text { yellow }\end{array}$ \\
\end{tabular} & Clay loam & Friable & Angular Blocky & Moderate & $\begin{array}{l}1 \% \text { rootlets, } 3 \% \text { pin holes, } 1 \% \text { white filament } \\
(1 \mathrm{~cm}), 20-30 \% \text { snail - heliodiscus and rabdotus, } \\
10 \% \text { snail fragments, large insect burrows }\end{array}$ & Unobserved & $\begin{array}{c}\text { CaCo3 filaments increase with } \\
\text { depth } 3-4 \mathrm{~mm}(5 \%) \sim 280 \mathrm{cmbs} \text {, } \\
\text { clay content increases with } \\
\text { depth }\end{array}$ \\
\hline \multirow{4}{*}{$\begin{array}{l}\text { GU03- } \\
\text { Guadalupe } \\
\text { River }\end{array}$} & \multirow{4}{*}{ Guadalupe } & \multirow{4}{*}{50341} & $0-34$ & 10YR3/2 & $\begin{array}{c}\text { very dark grayish } \\
\text { brown }\end{array}$ & silt loam & Friable & \begin{tabular}{|c|} 
Subangular \\
Blocky to \\
Angular Blocky
\end{tabular} & $\begin{array}{l}\text { Weak to } \\
\text { moderate }\end{array}$ & $\begin{array}{c}\text { roots-rootlets } 15-20 \% \text {, few snail shell (Heliodiscus), } \\
30 \% \text { pin holes, } 5 \% \text { worm burrows, } 5 \% \text { snail } \\
\text { fragments, couple of rare subangular gravels in } \\
\text { root zone }\end{array}$ & $\begin{array}{l}\text { Gradual and } \\
\text { Smooth }\end{array}$ & Root zone $0-8 \mathrm{cmbs}$ \\
\hline & & & $34-74$ & 10YR $4 / 3$ & brown & Loam & Friable & $\begin{array}{l}\text { Subangular } \\
\text { Blocky }\end{array}$ & $\begin{array}{l}\text { Weak to } \\
\text { moderate }\end{array}$ & $\begin{array}{c}5-10 \% \text { rootlets, } 30 \% \text { pin holes, } 5 \% \text { worm burrows, } \\
1 \% \text { snail fragments }\end{array}$ & $\begin{array}{c}\text { Gradual to } \\
\text { clear and } \\
\text { slightly wavy } \\
\end{array}$ & Transitional \\
\hline & & & $74-133$ & 10YR5/4 & yellowish brown & Silt Loam & Friable & $\begin{array}{l}\text { Subangular } \\
\text { Blocky }\end{array}$ & Moderate & \begin{tabular}{|c|}
$\begin{array}{c}3-5 \% \text { rootlets, } 30 \% \text { pin holes, } 2-3 \% \text { worm burrows, } \\
10 \% \text { snail - Rabdotus, } 1 \% \text { snail fragments, pockets } \\
\text { of snail - rabdotus, indeterminate burrow - } 6 \mathrm{~mm}- \\
1 \% \text {, white filament - } 1 \mathrm{~mm}-15 \%\end{array}$ \\
\end{tabular} & $\begin{array}{l}\text { Clear and } \\
\text { smooth }\end{array}$ & Subrounded gravel - $80-90 \mathrm{cmbs}$ \\
\hline & & & 133-311 & $\begin{array}{c}10 \mathrm{YR} 5 / 6 \text { to } \\
10 \mathrm{YRR} / 6\end{array}$ & $\begin{array}{c}\text { yellowish brown } \\
\text { to brownish } \\
\text { yellow }\end{array}$ & Clay loam & Friable & Angular Blocky & Moderate & $\begin{array}{l}1 \% \text { rootlets, } 3 \% \text { pin holes, } 1 \% \text { white filament } \\
\text { (1cm), } 20-30 \% \text { snail - heliodiscus and rabdotus, } \\
10 \% \text { snail fragments, large insect burrows }\end{array}$ & Unobserved & $\begin{array}{c}\text { CaCo3 filaments increase with } \\
\text { depth } 3-4 \mathrm{~mm}(5 \%) \sim 280 \mathrm{cmbs}, \\
\text { clay content increases with } \\
\text { depth, subrounded gravel at } 170 \\
\text { cmbs }\end{array}$ \\
\hline \multirow{4}{*}{$\begin{array}{l}\text { GU04- } \\
\text { Guadalupe } \\
\text { River }\end{array}$} & \multirow{4}{*}{ Guadalupe } & \multirow{4}{*}{50335} & $0-63$ & 10YR3/2 & $\begin{array}{c}\text { very dark grayish } \\
\text { brown }\end{array}$ & silty clay loam & Firm & \begin{tabular}{|c|} 
Subangular \\
Blocky to \\
Angular Blocky
\end{tabular} & $\begin{array}{l}\text { Weak to } \\
\text { moderate }\end{array}$ & $\begin{array}{l}\text { roots-rootlets } 30 \% \text {, few snail shell (Heliodiscus), } \\
30 \% \text { pin holes, } 5 \% \text { worm burrows, } 3-5 \% \text { snail } \\
\text { fragments, couple of rare subangular gravels in } \\
\text { root zone }\end{array}$ & $\begin{array}{c}\text { Gradual and } \\
\text { Smooth }\end{array}$ & Root zone $0-13 \mathrm{cmbs}$ \\
\hline & & & 63-164 & 10YR $4 / 3$ & brown & silty clay loam & Firm & $\begin{array}{l}\text { Subangular } \\
\text { Blocky }\end{array}$ & $\begin{array}{l}\text { Weak to } \\
\text { moderate }\end{array}$ & $\begin{array}{l}10 \% \text { rootlets, } 20 \% \text { pin holes, } 3 \% \text { worm burrows, } \\
\text { snail - small rabdotus } 1 \%, 30 \% \text { snail fragments }\end{array}$ & $\begin{array}{c}\text { Gradual to } \\
\text { clear and } \\
\text { sliahtly wave }\end{array}$ & Transitional \\
\hline & & & 164-197 & 10YR5/4 & yellowish brown & Silt Loam & Firm & $\begin{array}{l}\text { Subangular } \\
\text { Blocky }\end{array}$ & Moderate & $\begin{array}{c}3-5 \% \text { rootlets, } 30 \% \text { pin holes, } 2-3 \% \text { worm burrows, } \\
10 \% \text { snail - Rabdotus, } 1 \% \text { snail fragments, pockets } \\
\text { of snail - rabdotus, indeterminate burrow - } 6 \mathrm{~mm} \text { - } \\
1 \% \text {, white filament }-2 \mathrm{~mm}-5 \%\end{array}$ & $\begin{array}{l}\text { Clear and } \\
\text { smooth }\end{array}$ & Subrounded gravel - $80-90 \mathrm{cmbs}$ \\
\hline & & & $197-253$ & 10YR6/6 & brownish yellow & Clay loam & Firm to Friable & Angular Blocky & Moderate & $\begin{array}{c}1 \% \text { rootlets, } 3 \% \text { pin holes, } 1 \% \text { white filament } \\
(1 \mathrm{~cm}), 20-30 \% \text { snail - heliodiscus and rabdotus, } \\
10 \% \text { snail fragments, large insect burrows }\end{array}$ & Unobserved & $\begin{array}{c}\text { CaCo3 filaments increase with } \\
\text { depth } 3-4 \mathrm{~mm}(5 \%) \sim 280 \mathrm{cmbs} \text {, } \\
\text { clay content increases with } \\
\text { depth, more clay content than } \\
\text { previous trenches }\end{array}$ \\
\hline \multirow{4}{*}{$\begin{array}{l}\text { GU05- } \\
\text { Guadalupe } \\
\text { River }\end{array}$} & \multirow{4}{*}{ Guadalupe } & \multirow{4}{*}{50335} & $0-51$ & 10YR3/2 & $\begin{array}{c}\text { very dark grayish } \\
\text { brown }\end{array}$ & silty clay loam & Firm & \begin{tabular}{|c|} 
Subangular \\
Blocky to \\
Angular Blocky
\end{tabular} & $\begin{array}{l}\text { Weak to } \\
\text { moderate }\end{array}$ & $\begin{array}{c}\text { roots-rootlets } 30 \% \text {, few snail shell (Heliodiscus), } \\
40 \% \text { pin holes, } 5 \% \text { worm burrows, } 3-5 \% \text { snail } \\
\text { fragments, couple of rare subangular gravels in } \\
\text { root zone, insect burrows } 10 \% \text {, contains strat II } \\
\text { matrix } \\
\end{array}$ & $\begin{array}{l}\text { Gradual and } \\
\text { Smooth }\end{array}$ & Root zone $0-13 \mathrm{cmbs}$ \\
\hline & & & $51-83$ & $10 \mathrm{YR} 4 / 3$ & brown & silty clay loam & Firm & $\begin{array}{l}\text { Subangular } \\
\text { Blocky }\end{array}$ & $\begin{array}{l}\text { Weak to } \\
\text { moderate }\end{array}$ & $\begin{array}{c}10 \% \text { rootlets, } 20-30 \% \text { pin holes, } 10-15 \% \text { worm } \\
\text { burrows, snail - small rabdotus } 1 \%, 30 \% \text { snail } \\
\text { fragments, insect burrows } 10 \% \text {, contains strat III } \\
\text { matrix }\end{array}$ & $\begin{array}{l}\text { Gradual to } \\
\text { clear and } \\
\text { slightly wavy }\end{array}$ & Transitional \\
\hline & & & 83-212 & 10YR5/4 & yellowish brown & Silt Loam & Firm & $\begin{array}{l}\text { Subangular } \\
\text { Blocky }\end{array}$ & Moderate & \begin{tabular}{|c|}
$3-5 \%$ rootlets, $30 \%$ pin holes, $2-3 \%$ worm burrows, \\
$10 \%$ snail - Rabdotus, $1 \%$ snail fragments, pockets \\
of snail - rabdotus, indeterminate burrow - $6 \mathrm{~mm}$ - \\
$1 \%$, white filament $-2 \mathrm{~mm}-5 \%$
\end{tabular} & $\begin{array}{l}\text { Clear and } \\
\text { smooth }\end{array}$ & Subrounded gravel $-80-90 \mathrm{cmbs}$ \\
\hline & & & $212-306$ & 10YR6/6 & brownish yellow & Clay loam & Firm to Friable & Angular Blocky & Moderate & $\begin{array}{l}1 \% \text { rootlets, } 3 \% \text { pin holes, } 1 \% \text { white filament } \\
\text { (1cm), } 20-30 \% \text { snail - heliodiscus and rabdotus, } \\
10 \% \text { snail fragments, large insect burrows }\end{array}$ & Unobserved & $\begin{array}{c}\text { CaCo3 filaments increase with } \\
\text { depth } 3-4 \mathrm{~mm}(5 \%) \sim 280 \mathrm{cmbs} \text {, } \\
\text { clay content increases with } \\
\text { depth, more clay content than } \\
\text { previous trenches }\end{array}$ \\
\hline \multirow{4}{*}{$\begin{array}{l}\text { GU06- } \\
\text { Guadalupe } \\
\text { River }\end{array}$} & \multirow{4}{*}{ Guadalupe } & \multirow{4}{*}{50335} & $0-66$ & $10 \mathrm{YR} 4 / 3$ & brown & silt loam & Friable & \begin{tabular}{|c|} 
Subangular \\
Blocky to \\
Angular Blocky
\end{tabular} & $\begin{array}{l}\text { Weak to } \\
\text { moderate }\end{array}$ & $\begin{array}{c}\text { roots-rootlets } 20 \% \text {, few snail shell (rabdotus) } 15 \%, \\
20 \% \text { pin holes, } 5 \% \text { worm burrows, } 15 \% \text { snail } \\
\text { fragments, couple of rare subangular gravels in } \\
\text { root zone, insect burrows } 10 \%, \text { contains strat II } \\
\text { matrix }\end{array}$ & $\begin{array}{l}\text { Gradual and } \\
\text { Smooth }\end{array}$ & $\begin{array}{l}\text { Root zone } 0-14 \mathrm{cmbs} \text {, soil matrix } \\
\text { is vertically laminated }\end{array}$ \\
\hline & & & $66-162$ & 10YR5/6 & yellowish brown & silt loam & Friable & $\begin{array}{l}\text { Subangular } \\
\text { Blocky }\end{array}$ & $\begin{array}{l}\text { weak to } \\
\text { moderate }\end{array}$ & $\begin{array}{c}20 \% \text { rootlets, } 20 \% \text { pin holes, } 10-15 \% \text { worm } \\
\text { burrows, snail - rabdotus } 5-10 \%, 15 \% \text { snail } \\
\text { fragments, insect burrows } 10 \% \text {, contains strat III } \\
\text { matrix, white filaments } 1 \mathrm{~mm} 1 \% \\
\end{array}$ & $\begin{array}{l}\text { Gradual and } \\
\text { smooth }\end{array}$ & \\
\hline & & & $162-181$ & $\begin{array}{l}10 \mathrm{YR} 5 / 5 \text { to } \\
10 \mathrm{YR} 5 / 8\end{array}$ & yellowish brown & Silt Loam & Friable & $\begin{array}{l}\text { Subangular } \\
\text { Blocky }\end{array}$ & Weak & $\begin{array}{c}5-10 \% \text { rootlets, } 15 \% \text { pin holes, } 2-3 \% \text { worm } \\
\text { burrows, } 15 \% \text { small snail - Rabdotus, } 5 \% \text { snail } \\
\text { fragments, pockets of snail - rabdotus, } \\
\text { indeterminate burrow - } 6 \mathrm{~mm}-1 \% \text {, white filament - } \\
1 \mathrm{~mm}-1 \%\end{array}$ & $\begin{array}{l}\text { Gradual and } \\
\text { Smooth }\end{array}$ & $\begin{array}{l}\text { may have some heliodiscus } \\
\text { snail (couldn't verify) }\end{array}$ \\
\hline & & & $181-305$ & 10YR6/6 & brownish yellow & Clay loam & Friable & $\begin{array}{l}\text { Subangular } \\
\text { Blocky }\end{array}$ & Moderate & $\begin{array}{c}1 \% \text { rootlets, } 3 \% \text { pin holes, } 2-3 \% \text { white filament }(3- \\
5 \mathrm{~mm}), 20-30 \% \text { snail - heliodiscus and rabdotus, } \\
10 \% \text { snail fragments, large insect burrows }\end{array}$ & Unobserved & $\begin{array}{l}\text { Very similar to above but more } \\
\text { clay content and more white } \\
\text { filament }\end{array}$ \\
\hline
\end{tabular}




\begin{tabular}{|c|c|c|c|c|c|c|c|c|c|c|c|c|}
\hline BHT & County & Parcel & Depth (cmbs) & Munsell* & Soil Color* & Soil Texture & Consistency & Structure Type & Grade & Inclusions & $\begin{array}{l}\text { Lower } \\
\text { Boundary }\end{array}$ & Comment \\
\hline \multirow{7}{*}{$\begin{array}{l}\text { BHT01 } \\
\text { (Colorado) }\end{array}$} & \multirow{7}{*}{ Bastrop } & \multirow{7}{*}{30345} & $0-76$ & 10YR 4/3 & brown & Sandy clay loam & Loose & $\begin{array}{l}\text { Subangular } \\
\text { Blocky }\end{array}$ & Moderate & $\begin{array}{l}\text { rootlets }(20 \%) \text { at } 0-8 \mathrm{cmbs} \text { and }(2 \%) \text { at } 8-76 \mathrm{cmbs} \text {, } \\
\text { pinhole burrows }(1 \%) \text {, snail }(1 \% \text { heliodiscus), roots } \\
(1 \%) \text {, mussel shell }(1 \%)\end{array}$ & $\begin{array}{l}\begin{array}{l}\text { Abrupt and } \\
\text { wavy }\end{array} \\
\end{array}$ & Root zone $0-8 \mathrm{cmbs}$ \\
\hline & & & $76-83$ & 10YR 4/6 & $\begin{array}{c}\text { dark yellowish } \\
\text { brown }\end{array}$ & Sand & Loose & Granular & Weak & rootlets $(1 \%)$, pebbles $(2 \%<1 \mathrm{~cm})$ & $\begin{array}{l}\text { Abrupt and } \\
\text { broken }\end{array}$ & $\begin{array}{l}\text { Flood deposit, coarse grained } \\
\text { sand, does not continue across } \\
\text { the profile. }\end{array}$ \\
\hline & & & 83-92 & 10YR 4/3 & brown & Sandy clay & $\begin{array}{c}\text { Loose to } \\
\text { Friable }\end{array}$ & $\begin{array}{c}\text { Subangular } \\
\text { Blocky }\end{array}$ & Moderate & rootlets $(1 \%)$ & $\begin{array}{l}\begin{array}{l}\text { Clear and } \\
\text { smooth }\end{array} \\
\end{array}$ & Couplet with strat IV \\
\hline & & & $92-111$ & $7.5 Y R 4 / 4$ & brown & Sandy loam & Loose & \begin{tabular}{|c|}
$\begin{array}{c}\text { Structureless to } \\
\text { Subangular } \\
\text { Blocky }\end{array}$ \\
\end{tabular} & Weak & - & $\begin{array}{l}\text { Clear and } \\
\text { smooth }\end{array}$ & - \\
\hline & & & $111-200$ & 10YR 6/4 & $\begin{array}{c}\text { light yellowish } \\
\text { brown }\end{array}$ & Sand & Loose & Structureless & $\mathrm{N} / \mathrm{A}$ & rootlets (1\%), Large insect burrows (1cm). & Unobserved & $\begin{array}{l}\text { Observed only from above after } \\
134 \text { cmbs. }\end{array}$ \\
\hline & & & $200-260$ & 10YR 6/6 & brownish yellow & Sand & Loose & Granular & Weak & rootlets present & Unobserved & $\begin{array}{l}\text { Large river cobbles and pebbles. } \\
\text { Sand is coarse-grained. Cobbles } \\
\text { are subrounded to subangular } \\
\text { and reach sizes over } 10 \mathrm{~cm} \text {. }\end{array}$ \\
\hline & & & $260-290+$ & $7.5 Y R 5 / 6$ & strong brown & Sand & Loose & Granular & Weak & rootlets present & Unobserved & Slight clay content \\
\hline \multirow{7}{*}{$\begin{array}{l}\text { BHT02 } \\
\text { (Colorado) }\end{array}$} & \multirow{7}{*}{ Bastrop } & \multirow{7}{*}{30345} & $0-9$ & $\begin{array}{c}10 Y R 3 / 3 \text { to } \\
10 Y R 3 / 4\end{array}$ & $\begin{array}{c}\text { dark brown to } \\
\text { dark yellowish } \\
\text { brown } \\
\end{array}$ & Silt loam & Friable & $\begin{array}{c}\text { Subangular } \\
\text { Blocky }\end{array}$ & Weak & $\begin{array}{l}\text { roots and rootlets }(20 \%) \text {, insect burrows }(3 \%) \text {, and } \\
\text { snail fragments }(<1 \%)\end{array}$ & $\begin{array}{l}\text { Clear and } \\
\text { smooth }\end{array}$ & Root zone and plow zone \\
\hline & & & $9-69$ & $\begin{array}{l}10 Y R 3 / 3 \text { to } \\
10 Y R 3 / 4\end{array}$ & \begin{tabular}{|c|} 
dark brown to \\
dark yellowish \\
brown
\end{tabular} & Silt loam & Friable & $\begin{array}{c}\text { Subangular } \\
\text { Blocky }\end{array}$ & Weak & $\begin{array}{l}\text { roots and rootlets }(5-10 \%) \text {, snail fragments }(<1 \%), \\
\text { pinhole insect burrows }(3 \%)\end{array}$ & $\begin{array}{l}\text { Gradual and } \\
\text { smooth }\end{array}$ & $\begin{array}{l}\text { Apparent tree trunk cast } \sim 40 \mathrm{~cm} \\
\text { diameter ; slight clay content }\end{array}$ \\
\hline & & & 69-94 & 10YR 4/3 & brown & $\begin{array}{l}\text { Sandy loam (fine- } \\
\text { grained sand) }\end{array}$ & Friable & $\begin{array}{l}\text { Subangular } \\
\text { Blocky }\end{array}$ & Weak & rootlets $(4 \%)$, pinhole insect burrows $(10 \%)$ & $\begin{array}{l}\text { Clear and } \\
\text { irregular }\end{array}$ & $\begin{array}{l}\text { Very similar to strat II. Tree cast } \\
\text { with decomposing veg at } 86-96 \\
\text { cmbs. }\end{array}$ \\
\hline & & & $94-126$ & 7.5YR 6/4 & light brown & Sand (fine) & Loose & Granular & Weak & $\begin{array}{l}\text { rootlets ( } 4 \%) \text {, insect burrows ( } 4 \%) \text { and root burrows } \\
\text { present }\end{array}$ & $\begin{array}{l}\text { Clear to diffuse } \\
\text { and irregular }\end{array}$ & Tree cast present. \\
\hline & & & $126-148$ & $7.5 Y R 4 / 3$ & brown & Sandy loam & Friable & $\begin{array}{l}\text { Subangular } \\
\text { Blocky }\end{array}$ & Weak & rootlets $(1 \%)$, snail shell fragments $(1 \%)$ & Unobserved & \\
\hline & & & $148-230$ & 7.5YR 5/4 & brown & Sand (fine) & Loose & Structureless & $\mathrm{N} / \mathrm{A}$ & - & & $\begin{array}{l}\text { Observed only from above after } \\
148 \mathrm{cmbs} \text {. }\end{array}$ \\
\hline & & & $230-278+$ & 7.5YR 6/4 & light brown & Sand (medium) & - & - & - & - & & Rare, subangular pebbles \\
\hline \multirow{6}{*}{$\begin{array}{l}\text { BHT03 } \\
\text { (Colorado) }\end{array}$} & \multirow{6}{*}{ Bastrop } & \multirow{6}{*}{30345} & $0-11$ & 10YR 3/3 & dark brown & Silty loam & Friable & $\begin{array}{l}\text { Subangular } \\
\text { Blocky }\end{array}$ & Weak & rootlets $(20 \%)$, roots $(2 \%)$, worm burrows $(3 \%)$ & $\begin{array}{l}\text { Clear and } \\
\text { smooth }\end{array}$ & Root zone \\
\hline & & & $11-86$ & $\begin{array}{l}\text { 10YR } 5 / 4 \text { to } \\
\text { 10YR } 5 / 6\end{array}$ & yellowish brown & Silty clay loam & Friable & $\begin{array}{l}\text { Subangular } \\
\text { Blocky }\end{array}$ & Weak & $\begin{array}{l}\text { rootlets }(5 \%) \text {, worm burrows }(10 \%) \text {, insect burrows } \\
(5 \%)\end{array}$ & \begin{tabular}{|l} 
Abrupt and \\
wavy to \\
irregular
\end{tabular} & $\begin{array}{l}\text { Scapula \#1 at } 42 \text { to } 46 \mathrm{cmbs} \\
\text { (collected), scapula \#2 at } 38 \text { to } \\
42 \text { cmbs (collected); roots seem }\end{array}$ \\
\hline & & & 86-127 & 10YR 5/4 & yellowish brown & Sand (fine) & $\begin{array}{l}\text { Loose to } \\
\text { Friable }\end{array}$ & Granular & Weak & $\begin{array}{l}\text { rootlets }(1 \%) \text {, insect burrows filled with matrix from } \\
\text { strat II }(5 \%)\end{array}$ & $\begin{array}{l}\text { Abrupt and } \\
\text { sloping }\end{array}$ & $\begin{array}{l}\text { Microbands throughout 1-2 mm- } \\
\text { discontinuous. }\end{array}$ \\
\hline & & & $127-134$ & 10YR 6/4 & $\begin{array}{c}\text { light yellowish } \\
\text { brown }\end{array}$ & clay & Friable & $\begin{array}{l}\text { Subangular } \\
\text { Blocky }\end{array}$ & Weak & rootlets ( $1 \%)$, & $\begin{array}{l}\text { Abrupt and } \\
\text { sloping }\end{array}$ & $\begin{array}{l}\text { Clay band, fine matrix, top of } \\
\text { couplet. Thicker at the lowest } \\
\text { and thins as layer rises. Channel }\end{array}$ \\
\hline & & & $134-210$ & $\begin{array}{l}\text { 10YR } 6 / 4 \text { to } \\
10 Y R 7 / 4\end{array}$ & \begin{tabular}{|c|} 
light yellowish \\
brown to very \\
pale brown \\
\end{tabular} & Sand (medium) & Loose & Granular & Weak & $\begin{array}{l}\text { micro bands } 2-4 \mathrm{~mm} \text {, sloping, } 10 \mathrm{YR} 5 / 8(8 \text { to } 20 \mathrm{~cm} \\
\text { in section). Similar to strat IV above. }\end{array}$ & Unobserved & $\begin{array}{l}\text { Bottom of couplet. Observed } \\
\text { from above after } 158 \mathrm{cmbs} \text {. }\end{array}$ \\
\hline & & & $210-250+$ & 7.5YR 5/4 & brown & Sand & Loose & Structureless & - & - & Unobserved & - \\
\hline \multirow{5}{*}{$\begin{array}{l}\text { BHT04 } \\
\text { (Colorado) }\end{array}$} & \multirow{5}{*}{ Bastrop } & \multirow{5}{*}{30345} & $0-13$ & $\begin{array}{l}\text { 10YR } 4 / 2 \text { to } \\
10 Y R 3 / 2\end{array}$ & $\begin{array}{c}\text { dark grayish } \\
\text { brown to brown }\end{array}$ & Silty clay loam & Friable & $\begin{array}{l}\text { Subangular } \\
\text { Blocky }\end{array}$ & Weak & $\begin{array}{l}\text { roots and rootlets }(20 \%), \text { insect and worm burrows } \\
(10 \%)\end{array}$ & $\begin{array}{l}\text { Clear and } \\
\text { smooth }\end{array}$ & Root zone \\
\hline & & & 13-29 & $\begin{array}{l}\text { 10YR } 4 / 2 \text { to } \\
\text { 10YR } 4 / 3\end{array}$ & $\begin{array}{c}\text { dark grayish } \\
\text { brown to brown }\end{array}$ & $\begin{array}{l}\text { Clay loam (high } \\
\text { clay content) }\end{array}$ & Friable & $\begin{array}{l}\text { Subangular } \\
\text { Blocky }\end{array}$ & Weak & rootlets $(5 \%)$, insect and worm burrows $(15 \%)$ & $\begin{array}{l}\text { Clear and } \\
\text { smooth }\end{array}$ & Similar to strat I \\
\hline & & & $29-146$ & 10YR 4/3 & brown & Silty clay loam & Friable & $\begin{array}{l}\text { Subangular } \\
\text { Blocky }\end{array}$ & Moderate & \begin{tabular}{|l} 
slickensides (subtle, $5 \%, 1-2 \mathrm{~cm})$, rootlets $(2 \%)$ \\
insect and worm burrows $(10 \%)$
\end{tabular} & $\begin{array}{l}\text { Clear and } \\
\text { smooth }\end{array}$ & - \\
\hline & & & $146-230$ & $7.5 Y R$ 5/4 & brown & Silty clay loam & Friable & $\begin{array}{l}\text { Subangular } \\
\text { Blocky }\end{array}$ & Weak & rootlets $(10 \%)$, pinhole insect burrows $(10 \%)$ & Unobserved & $\begin{array}{l}\text { Observed from above after } 154 \\
\text { cmbs }\end{array}$ \\
\hline & & & $230-297+$ & 10YR 6/4 & yellowish brown & Sand (powder) & Loose & Granular & Weak & - & Unobserved & - \\
\hline \multirow{5}{*}{$\begin{array}{l}\text { BHT05 } \\
\text { (Colorado) }\end{array}$} & \multirow{5}{*}{ Bastrop } & \multirow{5}{*}{30345} & $0-9$ & 10YR 3/3 & dark brown & Silty clay loam & Loose & $\begin{array}{l}\text { Subangular } \\
\text { Blocky }\end{array}$ & Moderate & $\begin{array}{l}\text { rootlets }(20 \%) \text {, worm burrows }(2 \%) \text {, snail frags }(1 \% \\
\text { heliodiscus) }\end{array}$ & $\begin{array}{l}\text { Clear and } \\
\text { smooth }\end{array}$ & Root layer \\
\hline & & & $9-36$ & 10YR $3 / 3$ & dark brown & Silty clay loam & Loose & $\begin{array}{l}\text { Subangular } \\
\text { Blocky }\end{array}$ & Weak & $\begin{array}{l}\text { rootlets }(1 \%) \text {, worm burrows }(2 \%) \text {, pinhole insect } \\
\text { burrows }(1 \%)\end{array}$ & $\begin{array}{l}\text { Clear and } \\
\text { smooth }\end{array}$ & $\begin{array}{l}\text { Higher clay content than horizon } \\
\text { above }\end{array}$ \\
\hline & & & $36-72$ & 10YR $4 / 3$ & brown & Silt loam & Loose & $\begin{array}{l}\text { Subangular } \\
\text { Blocky }\end{array}$ & Weak & $\begin{array}{l}\text { pinhole insect burrows }(1 \%) \text {, snail fragments } \\
(<1 \%) \text {, mussel fragments }(<1 \%)\end{array}$ & $\begin{array}{l}\text { Clear and } \\
\text { smooth }\end{array}$ & Slight clay content \\
\hline & & & $72-225$ & 10YR $5 / 4$ & yellowish brown & Silt loam & Loose & $\begin{array}{l}\text { Subangular } \\
\text { Blocky }\end{array}$ & Weak & pinhole insect burrows $(<1 \%)$ & Unobserved & $\begin{array}{l}\text { Similar to strat IV in BHT 4; } \\
\text { slight clay content }\end{array}$ \\
\hline & & & $225-273+$ & 10YR $6 / 4$ & $\begin{array}{l}\text { light yellowish } \\
\text { brown }\end{array}$ & Sand (fine) & Loose & Granular & Weak & - & Unobserved & Same as strat $V$ in BHT 4. \\
\hline \multirow{5}{*}{$\begin{array}{l}\text { BHT06 } \\
\text { (Colorado) }\end{array}$} & \multirow{5}{*}{ Bastrop } & \multirow{5}{*}{30345} & $0-9$ & 10YR $3 / 3$ & dark brown & Silty clay loam & Loose & $\begin{array}{l}\text { Subangular } \\
\text { Blocky }\end{array}$ & Moderate & $\begin{array}{l}\text { rootlets }(20 \%) \text {, worm burrows }(2 \%) \text {, snail frags ( } 1 \% \\
\text { heliodiscus) }\end{array}$ & $\begin{array}{l}\text { Clear and } \\
\text { smooth }\end{array}$ & $\begin{array}{l}\text { Root layer. Same as BHT } 05 \\
\text { level I }\end{array}$ \\
\hline & & & $9-29$ & 10YR $3 / 3$ & dark brown & Silty clay loam & Loose & $\begin{array}{l}\text { Subangular } \\
\text { Blocky }\end{array}$ & Weak & $\begin{array}{l}\text { rootlets ( } 1 \%) \text {, worm burrows }(2 \%) \text {, pinhole insect } \\
\text { burrows }(1 \%)\end{array}$ & $\begin{array}{l}\text { Clear and } \\
\text { smooth }\end{array}$ & $\begin{array}{l}\text { Same as BHT } 05 \text { level II; higher } \\
\text { clay content than above }\end{array}$ \\
\hline & & & $29-71$ & 10YR 4/3 & brown & Silt loam & Loose & $\begin{array}{l}\text { Subangular } \\
\text { Blocky }\end{array}$ & Weak & $\begin{array}{l}\text { pinhole insect burrows }(1 \%) \text {, snail fragments } \\
(<1 \%), \text { mussel fragments }(<1 \%) \text { Heliodiscus and } \\
\text { Rabdotus. Cervid remains. }\end{array}$ & $\begin{array}{l}\begin{array}{l}\text { Clear and } \\
\text { smooth }\end{array} \\
\text { smots }\end{array}$ & $\begin{array}{l}\text { Same as BHT } 05 \text { level III; slight } \\
\text { clay content }\end{array}$ \\
\hline & & & 71-94 & 10YR 5/4 & yellowish brown & Silt loam & Loose & $\begin{array}{l}\text { Subangular } \\
\text { Blocky }\end{array}$ & Weak & pinhole insect burrows (<1\%) & Clear & $\begin{array}{l}\text { Same as BHT } 05 \text { level IV; slight } \\
\text { clay content }\end{array}$ \\
\hline & & & $94-150+$ & $\underset{6 / 4}{10 Y R 5 / 4 \text { to }}$ & $\begin{array}{l}\text { yellowish brown } \\
\text { to light yellowish } \\
\text { brown }\end{array}$ & Silty clay loam & Friable & $\begin{array}{l}\text { Subangular } \\
\text { Blocky }\end{array}$ & Weak & - & Unobserved & \\
\hline
\end{tabular}




\begin{tabular}{|c|c|c|c|c|c|c|c|c|c|c|c|c|}
\hline BHT & County & Parcel & $\mid$ Depth (cmbs) & Munsell* & Soil Color* & Soil Texture & Consistency & Structure Type & Grade & Inclusions & $\begin{array}{l}\text { Lower } \\
\text { Boundary }\end{array}$ & Comment \\
\hline \multirow{4}{*}{$\begin{array}{l}\text { BHT07 } \\
\text { (Colorado) }\end{array}$} & \multirow{4}{*}{ Bastrop } & \multirow{4}{*}{30345} & $0-13$ & 10YR $3 / 3$ & dark brown & Silty clay loam & Friable & \begin{tabular}{|c|} 
Subangular \\
Blocky to Platy
\end{tabular} & Weak & roots and rootlets $(10 \%)$, worm burrows $(10 \%)$ & $\begin{array}{l}\text { Abrupt and } \\
\text { smooth }\end{array}$ & $\begin{array}{l}\begin{array}{l}\text { North section compressed } \\
\text { looking }\end{array} \\
\end{array}$ \\
\hline & & & 13-36 & 10YR 4/3 & brown & Clay loam & Friable & $\begin{array}{l}\text { Subangular } \\
\text { Blocky }\end{array}$ & Weak & $\begin{array}{l}\text { rootlets }(5 \%) \text {, worm burrows }(20 \%) \text {, very subtle } \\
\text { slickensides }(5 \%, 1 \mathrm{~mm}) \text {, insect galleries common }\end{array}$ & $\begin{array}{l}\text { Gradual and } \\
\text { smooth }\end{array}$ & \\
\hline & & & $36-96$ & $\begin{array}{l}10 Y R 4 / 3 \text { to } \\
10 Y R 4 / 4\end{array}$ & $\begin{array}{c}\text { brown to dark } \\
\text { yellowish brown }\end{array}$ & Clay loam & Friable & $\begin{array}{l}\text { Subangular } \\
\text { Blocky }\end{array}$ & Moderate & $\begin{array}{l}\text { insect burrows }(2 \%) \text {, worm burrows }(5 \%) \text {, rootlets } \\
(5 \%) \text {, subtle slickensides }(5 \%, 2-4 \mathrm{~mm})\end{array}$ & \begin{tabular}{|l}
$\begin{array}{l}\text { Clear and } \\
\text { sloping } \\
\text { (southward) }\end{array}$ \\
\end{tabular} & $\begin{array}{l}\text { One whiteware sherd at } 82 \\
\text { cmbs (collected). Becomes } \\
\text { more clayey with depth. }\end{array}$ \\
\hline & & & $96-121+$ & 10YR 5/4 & yellowish brown & Silt loam & Friable & Angular Blocky & $\begin{array}{l}\text { Weak to } \\
\text { moderate }\end{array}$ & rootlets $(2 \%)$, rabdotus $(3 \%)$, snail fragments $(5 \%)$ & Unobserved & $\begin{array}{lll} \\
\end{array}$ \\
\hline \multirow{6}{*}{$\begin{array}{c}\text { BHT08 } \\
\text { (Colorado) }\end{array}$} & \multirow{6}{*}{ Bastrop } & \multirow{6}{*}{30345} & $0-19$ & $7.5 Y R 3 / 2$ & dark brown & Clay loam & Friable & $\begin{array}{c}\text { Subangular } \\
\text { Blocky }\end{array}$ & Moderate & $\begin{array}{l}\text { roots and rootlets }(20 \%) \text {, insect and worm burrows } \\
(5 \%)\end{array}$ & $\begin{array}{l}\text { Gradual and } \\
\text { wavy }\end{array}$ & Root layer \\
\hline & & & $19-65$ & 10YR 3/2 & $\begin{array}{c}\text { very dark grayish } \\
\text { brown }\end{array}$ & Clay loam & Firm & $\begin{array}{l}\text { Subangular } \\
\text { Blocky }\end{array}$ & Strong & $\begin{array}{l}\text { roots and rootlets }(5 \%) \text {, insect and worm burrows } \\
(2 \%) \text {, snail fragments }(1 \%)\end{array}$ & $\begin{array}{l}\text { Gradual and } \\
\text { smooth }\end{array}$ & - \\
\hline & & & $65-88$ & $7.5 Y R 4 / 2$ & brown & Clay loam & Firm & \begin{tabular}{|c|}
$\begin{array}{c}\text { Angular Blocky } \\
\text { to Subangular } \\
\text { Blocky }\end{array}$ \\
\end{tabular} & Moderate & $\begin{array}{l}\text { roots and rootlets }(2 \%) \text {, calcium carbonate } \\
\text { filaments }(10 \%)\end{array}$ & $\begin{array}{l}\text { Clear and } \\
\text { wavy }\end{array}$ & - \\
\hline & & & $88-116$ & $7.5 Y R 4 / 3$ & brown & Silty clay loam & Friable to Firm & $\begin{array}{l}\text { Subangular } \\
\text { Blocky }\end{array}$ & $\begin{array}{c}\text { Moderate to } \\
\text { Strong }\end{array}$ & $\begin{array}{l}\text { roots and rootlets (5\%), and calcium carbonate } \\
\text { filaments }(10 \%)\end{array}$ & $\begin{array}{l}\text { Gradual and } \\
\text { smooth }\end{array}$ & - \\
\hline & & & $116-237$ & $5 Y R 4 / 4$ & reddish brown & Clay loam & Friable to Firm & $\begin{array}{l}\text { Granular to } \\
\text { Subangular } \\
\text { Blocky }\end{array}$ & Moderate & $\begin{array}{l}\text { calcium carbonate filaments }(12 \%) \text {, rootlets }(5 \%) \text {, } \\
\text { insect and worm burrows }(1 \%)\end{array}$ & Unobserved & $\begin{array}{l}\text { Observed from above after } 162 \\
\text { cmbs }\end{array}$ \\
\hline & & & $237-280+$ & $7.5 Y R 4 / 6$ & strong brown & Silty clay loam & Friable & $\begin{array}{c}\text { Subangular } \\
\text { Blocky }\end{array}$ & Moderate & $\begin{array}{l}\text { calcium carbonate filaments }(30 \%) \text {, rootlets }(2 \%), \\
\text { pinhole insect burrows }(15 \%) \text {, Heliodiscus snail (1- } \\
2 \%)\end{array}$ & Unobserved & ]$^{-}$ \\
\hline \multirow{5}{*}{$\begin{array}{c}\text { BHT09 } \\
\text { (Colorado) }\end{array}$} & \multirow{5}{*}{ Bastrop } & \multirow{5}{*}{30345} & $0-22$ & 10YR $3 / 3$ & dark brown & $\begin{array}{l}\text { Sandy clay loam } \\
\text { (fine) }\end{array}$ & Friable & $\begin{array}{l}\text { Subangular } \\
\text { Blocky }\end{array}$ & Moderate & $\begin{array}{l}\text { Friable, subangular blocky, medium size and } \\
\text { moderate grade; rootlets }(20 \%) \text {, worm burrows } \\
(10 \%) \text {, snail fragments }(2 \%)\end{array}$ & $\begin{array}{l}\begin{array}{l}\text { Clear and } \\
\text { smooth }\end{array} \\
\text { smots }\end{array}$ & - \\
\hline & & & $22-63$ & 10YR 3/2 & $\begin{array}{l}\text { very dark gray } \\
\text { brown }\end{array}$ & $\begin{array}{l}\text { Sandy clay loam } \\
\text { (fine) }\end{array}$ & Friable to Firm & $\begin{array}{l}\text { Subangular } \\
\text { Blocky }\end{array}$ & Moderate & $\begin{array}{l}\text { rootlets }(1 \%) \text {, worm and insect burrows }(1 \%) \text {, snail } \\
\text { fragments }(1 \%)\end{array}$ & $\begin{array}{l}\text { Gradual and } \\
\text { slightly wavy to } \\
\text { smooth }\end{array}$ & - \\
\hline & & & 63-108 & $\begin{array}{l}7.5 Y R 4 / 3 \text { to } \\
7.5 Y R \text { R } 4 / 4\end{array}$ & brown & Silty clay loam & Friable & $\begin{array}{l}\text { Subangular } \\
\text { Blocky }\end{array}$ & Moderate & $\begin{array}{l}\text { worm and insect burrows (1-5\%), snail shell }(1 \% \\
\text { rabdotus and heliodiscus), calcium carbonate } \\
\text { filaments }(2-4 \%)\end{array}$ & $\begin{array}{l}\text { Gradual to } \\
\text { diffuse and } \\
\text { smooth }\end{array}$ & - \\
\hline & & & $108-230$ & $5 Y R 4 / 4$ & reddish brown & Silty clay loam & Friable & $\begin{array}{l}\text { Subangular } \\
\text { Blocky }\end{array}$ & Moderate & $\begin{array}{l}\text { insect and worm burrows }(1 \%) \text {, rootlets }(1 \%), \\
\text { calcium carbonate filaments }(2-4 \% \text { slightly smaller } \\
\text { than level above). }\end{array}$ & Unobserved & $\begin{array}{l}\text { Observed from above after } 140 \\
\text { cmbs }\end{array}$ \\
\hline & & & 230-304+ & $5 Y R 4 / 4$ & reddish brown & Clay loam & Firm & Angular Blocky & Moderate & $\begin{array}{l}\text { insect and worm burrows }(2 \%) \text {, calcium carbonate } \\
\text { filaments }(15-20 \%) \text {. }\end{array}$ & Unobserved & - \\
\hline \multirow{4}{*}{$\begin{array}{l}\text { BHT10 } \\
\text { (Colorado) }\end{array}$} & \multirow{4}{*}{ Bastrop } & \multirow{4}{*}{30345} & $0-14$ & $\begin{array}{l}10 Y R 3 / 2 \text { to } \\
10 Y R 3 / 3\end{array}$ & $\begin{array}{c}\text { very dark grayish } \\
\text { brown to dark } \\
\text { brown }\end{array}$ & $\begin{array}{l}\text { Sandy clay loam } \\
\text { (fine) }\end{array}$ & Friable & $\begin{array}{l}\text { Subangular } \\
\text { Blocky }\end{array}$ & $\begin{array}{l}\text { Weak to } \\
\text { Moderate }\end{array}$ & $\begin{array}{l}\text { roots and rootlets }(15-20 \%), \text { insect and worm } \\
\text { burrows }(20 \%) \text {, snail fragments }(3 \%)\end{array}$ & $\begin{array}{l}\begin{array}{l}\text { Clear and } \\
\text { smooth }\end{array} \\
\end{array}$ & $\begin{array}{l}\text { Trench is very similar to BHT } 9 . \\
\text { Root layer }\end{array}$ \\
\hline & & & $14-64$ & 10YR $3 / 2$ & $\begin{array}{c}\text { very dark grayish } \\
\text { brown }\end{array}$ & $\begin{array}{l}\text { Sandy clay loam } \\
\text { (fine) }\end{array}$ & Friable & \begin{tabular}{|c|} 
Subangular \\
Blocky to \\
Angular Blocky
\end{tabular} & Moderate & $\begin{array}{l}\text { rootlets ( } 10 \%) \text {, pinhole insect burrows }(10 \%) \text {, snail } \\
\text { fragments ( } 1 \% \text { heliodiscus), calcium carbonate } \\
(5 \%)\end{array}$ & $\begin{array}{l}\text { Gradual and } \\
\text { smooth }\end{array}$ & - \\
\hline & & & $64-102$ & $\begin{array}{l}7.5 \mathrm{YR} 3 / 3 \text { to } \\
7.5 \mathrm{YR} 4 / 3\end{array}$ & $\begin{array}{l}\text { dark brown to } \\
\text { brown }\end{array}$ & Silty clay loam & Friable & Angular Blocky & Moderate & $\begin{array}{l}\text { pinhole insect burrows }(15 \%) \text {, snail shell }(1 \% \\
\text { rabdotus), calcium carbonate filaments }(20 \%)\end{array}$ & $\begin{array}{l}\begin{array}{l}\text { Clear and } \\
\text { smooth }\end{array} \\
\text { smots }\end{array}$ & - \\
\hline & & & $102-140+$ & $\begin{array}{l}7.5 Y R 4 / 4 \text { to } \\
7.5 Y R \text { Y } 5 / 4\end{array}$ & brown & Silty clay loam & Friable & $\begin{array}{c}\text { Angular Blocky } \\
\text { to Subangular } \\
\text { Blocky }\end{array}$ & Moderate & $\begin{array}{l}\text { pinhole insect burrows }(5-10 \%) \text {, and calcium } \\
\text { carbonate filaments }(20 \%)\end{array}$ & Unobserved & - \\
\hline \multirow{4}{*}{$\begin{array}{c}\text { BHT11 } \\
\text { (Colorado) }\end{array}$} & \multirow{4}{*}{ Bastrop } & \multirow{4}{*}{30345} & $0-17$ & $\begin{array}{l}10 Y R 4 / 2 \text { to } \\
10 Y R 4 / 3\end{array}$ & $\begin{array}{c}\text { dark grayish } \\
\text { brown to brown }\end{array}$ & Loam & $\begin{array}{l}\text { Loose to } \\
\text { Friable }\end{array}$ & $\begin{array}{l}\text { Crumb to } \\
\text { Subangular } \\
\text { Blocky }\end{array}$ & Weak & $\begin{array}{l}\begin{array}{l}\text { roots and rootlets }(20 \%) \text {, worm burrows }(15 \%), \\
\text { snail fragments }(5 \%)\end{array} \\
\text { (5) }\end{array}$ & $\begin{array}{l}\begin{array}{l}\text { Clear and } \\
\text { smooth }\end{array} \\
\end{array}$ & $\begin{array}{l}\text { Root zone (not quite plow zone, } \\
\text { but disturbed layer). slight clay } \\
\text { content }\end{array}$ \\
\hline & & & $17-123$ & 10YR 4/3 & brown & Clay loam & Friable & Angular Blocky & Moderate & $\begin{array}{l}\begin{array}{l}\text { roots and rootlets (10\%), snail fragments (3-5\%, } \\
\text { rabdotus), insect burrows }(3 \%) \text {,white filaments } \\
(3 \%) \text {. }\end{array} \\
\end{array}$ & $\begin{array}{l}\begin{array}{l}\text { Clear and } \\
\text { smooth }\end{array} \\
\end{array}$ & - \\
\hline & & & $123-200$ & $\begin{array}{l}\text { 10YR } 4 / 3 \text { to } \\
10 Y R 5 / 3\end{array}$ & brown & Clay loam & Friable & Angular Blocky & $\begin{array}{l}\text { Weak to } \\
\text { Moderate }\end{array}$ & $\begin{array}{l}\text { pinhole insect burrows (5\%), snail shell (5-10\%, } \\
\text { rabdotus and heliodiscus), snail fragments (10\%), } \\
\text { rare white filaments (1\%) }\end{array}$ & Unobserved & $\begin{array}{l}\text { Observed from above after } 160 \\
\text { cmbs }\end{array}$ \\
\hline & & & $200-280+$ & $\begin{array}{l}\text { 10YR } 5 / 4 \text { to } \\
\text { 10YR } 5 / 6\end{array}$ & yellowish brown & Clay loam & Friable & $\begin{array}{l}\text { Subangular } \\
\text { Blocky }\end{array}$ & Moderate & $\begin{array}{l}\text { calcium carbonate ( } 3 \%) \text {, snail }(1 \% \text {, rabdotus), } \\
\text { pinhole insect burrows }(20 \%)\end{array}$ & Unobserved & - \\
\hline \multirow{3}{*}{$\begin{array}{c}\text { BHT12 } \\
\text { (Colorado) }\end{array}$} & \multirow{3}{*}{ Bastrop } & \multirow{3}{*}{30345} & $0-51$ & 10YR 4/3 & brown & Clay loam & Friable & $\begin{array}{c}\text { Angular Blocky } \\
\text { to Subangular } \\
\text { Blocky }\end{array}$ & Moderate & \begin{tabular}{|l} 
roots and rootlets $(10 \%)$, pinhole insect burrows \\
$(1 \%)$, snail shell $(1 \%$, rabdotus), snail fragments \\
$(3 \%)$
\end{tabular} & $\begin{array}{l}\begin{array}{l}\text { Clear and } \\
\text { smooth }\end{array} \\
\text { smots }\end{array}$ & Root layer from 0 to $9 \mathrm{cmbs}$ \\
\hline & & & $51-84$ & 10YR 3/2 & $\begin{array}{c}\text { very dark grayish } \\
\text { brown }\end{array}$ & Clay loam & Friable to Firm & $\begin{array}{l}\text { Subangular } \\
\text { Blocky }\end{array}$ & Moderate & $\begin{array}{l}\text { rootlets }(1 \%) \text {, fine white filaments }(5 \%) \text {, pinhole } \\
\text { insect burrows }(1 \%) \text {, snail fragments }(1 \%) \text {. }\end{array}$ & $\begin{array}{l}\begin{array}{l}\text { Clear and } \\
\text { smooth }\end{array} \\
\end{array}$ & Higher clay content than level I. \\
\hline & & & $84-140+$ & 10YR $3 / 3$ & dark brown & Clay loam & Firm & $\begin{array}{l}\text { Subangular } \\
\text { Blocky }\end{array}$ & $\begin{array}{c}\text { Moderate to } \\
\text { Strong }\end{array}$ & fine white filaments $(2 \%)$, snail shell ( $1 \%$, rabdotus) & Unobserved & - \\
\hline \multirow{4}{*}{$\begin{array}{l}\text { BHT13 } \\
\text { (Colorado) }\end{array}$} & \multirow{4}{*}{ Bastrop } & \multirow{4}{*}{30345} & $0-26$ & 10YR 2/2 & Very dark brown & Clay loam & Friable to Firm & $\begin{array}{l}\text { Crumb to } \\
\text { Subangular } \\
\text { Blocky }\end{array}$ & Weak & $\begin{array}{l}\text { roots and rootlets }(20 \%) \text {, worm burrows }(3 \%) \text {, snail } \\
\text { fragments }(5 \%) \text {, pinhole insect burrow }(5 \%) \text {, } \\
\text { slickensides }(4 \%, 2-4 \mathrm{~mm} \text { subtle). }\end{array}$ & $\begin{array}{l}\begin{array}{l}\text { Clear and } \\
\text { smooth }\end{array} \\
\end{array}$ & $\begin{array}{l}\text { Plow zone (disturbed) with } \\
\text { localized platy zones. }\end{array}$ \\
\hline & & & $26-56$ & $\begin{array}{l}10 Y R 3 / 3 \text { to } \\
10 Y R 3 / 4\end{array}$ & $\begin{array}{c}\text { dark brown to } \\
\text { dark yellowish } \\
\text { brown }\end{array}$ & Clay loam & Friable to Firm & Angular Blocky & Moderate & $\begin{array}{l}\text { rootlets }(3 \%) \text {, worm burrows }(3 \%) \text {, snail fragments } \\
(3 \% \text {, heliodiscus). }\end{array}$ & $\begin{array}{l}\begin{array}{l}\text { Clear and } \\
\text { smooth }\end{array} \\
\text { smo }\end{array}$ & \\
\hline & & & $56-119$ & $\begin{array}{l}7.5 Y R 4 / 4 \text { to } \\
7.5 Y R 4 / 6\end{array}$ & $\begin{array}{c}\begin{array}{c}\text { brown to strong } \\
\text { brown }\end{array} \\
\end{array}$ & Clay loam & Firm & Angular Blocky & Moderate & $\begin{array}{l}\text { rootlets ( } 1 \%) \text {, snail fragments }(3-4 \%) \text {, snail }(1 \% \text {, } \\
\text { heliodiscus), vertical cracks }(2 \%, 22 \mathrm{~cm}), \\
\text { slickensides }(5 \%, 05 \text {, to } 1 \mathrm{~cm} \text { subtle). }\end{array}$ & $\begin{array}{l}\begin{array}{l}\text { Clear and } \\
\text { smooth }\end{array} \\
\end{array}$ & - \\
\hline & & & 119-144+ & $7.5 Y R$ 5/3 & brown & Clay & Extremely Firm & Massive & N/A & $\begin{array}{l}\text { snail fragments }(<1 \%) \text {, pinhole insect burrows } \\
(<1 \%) \text {, rootlets }(<1 \%) \text {. }\end{array}$ & Unobserved & \\
\hline
\end{tabular}




\begin{tabular}{|c|c|c|c|c|c|c|c|c|c|c|c|c|}
\hline BHT & County & Parcel & Depth (cmbs) & Munsell|* & Soil Color & Soil Texture & Consistency & Structure Type & Grade & Inclusions & $\begin{array}{l}\text { Lower } \\
\text { Boundary }\end{array}$ & Comment \\
\hline \multirow{5}{*}{$\begin{array}{l}\text { BHT14 } \\
\text { (Colorado) }\end{array}$} & \multirow{5}{*}{ Bastrop } & \multirow{5}{*}{30345} & $0-24$ & $5 Y R 4 / 6$ & yellowish red & Sandy clay loam & Loose & Granular & Weak & $\begin{array}{l}\text { roots and rootlets }(5 \%) \text {, cobbles }(10 \%) \text {, gravels } \\
(30 \%) \text {, pebbles }(40 \%) .\end{array}$ & \begin{tabular}{|l} 
Abrupt and \\
irregular to \\
wavy
\end{tabular} & $\begin{array}{l}\text { Fill layer (matrix supported) with } \\
\text { sub-rounded gravels, pebbles, } \\
\text { and cobbles. }\end{array}$ \\
\hline & & & $24-44$ & $\begin{array}{l}5 \mathrm{YR} 4 / 2 \text { to } \\
5 \mathrm{YR} 4 / 3\end{array}$ & $\begin{array}{l}\text { dark reddish } \\
\text { gray to reddish } \\
\text { brown }\end{array}$ & Clay loam & Firm & \begin{tabular}{|c|} 
Subangular \\
Blocky to \\
Angular Blocky
\end{tabular} & $\begin{array}{l}\text { Weak to } \\
\text { Moderate }\end{array}$ & $\begin{array}{l}\text { rootlets }(5 \%) \text {, snail fragments }(3 \%) \text {, pinhole insect } \\
\text { burrows }(10 \%) \text {, fine pebbles }(5 \% \text {, in small pockets). }\end{array}$ & $\begin{array}{l}\text { Clear and } \\
\text { smooth }\end{array}$ & $\begin{array}{l}\text { South end of the profile is } \\
\text { thicker than the north end with } \\
\text { variable thickness in between. } \\
\text { Possibly truncated. }\end{array}$ \\
\hline & & & $44-76$ & $7.5 Y R 4 / 3$ & brown & Clay loam & Friable & $\begin{array}{l}\text { Subangular } \\
\text { Blocky }\end{array}$ & Weak & $\begin{array}{l}\text { rootlets (1\%), snail fragments (1-2\%), slickensides } \\
(10 \%,<1 \mathrm{~mm} \text { and subtle). }\end{array}$ & \begin{tabular}{|l|} 
Gradual and \\
smooth
\end{tabular} & \\
\hline & & & $76-111$ & $\begin{array}{l}\text { 7.5YR } 4 / 4 \text { to } \\
7.5 Y R 4 / 6\end{array}$ & $\begin{array}{c}\text { brown to strong } \\
\text { brown }\end{array}$ & Sandy clay loam & Friable to Firm & Angular Blocky & Moderate & $\begin{array}{l}\text { rootlets }(1 \%) \text {, insect burrows }(3 \%) \text {, snail fragments } \\
(1-2 \%) \text {, slickensides }(10 \%, 1-2 \mathrm{~mm} \text { and subtle). }\end{array}$ & $\begin{array}{l}\begin{array}{l}\text { Gradual and } \\
\text { smooth }\end{array} \\
\end{array}$ & $\begin{array}{l}\text { Increasing clay content with } \\
\text { depth }\end{array}$ \\
\hline & & & $111-135+$ & 7.5YR 5/6 & strong brown & $\begin{array}{l}\text { Clay loam (high } \\
\text { clay content) }\end{array}$ & Firm & Angular Blocky & Moderate & $\begin{array}{l}\text { rootlets }(1 \%) \text {, white filaments }(5 \%) \text {, small nodules } \\
\text { (10\% } 8 \mathrm{~mm} \text { possibly calcium carbonate). }\end{array}$ & Unobserved & $\begin{array}{l}\text { Nodules are similar to an } \\
\text { irregular shaped pebble. }\end{array}$ \\
\hline \multirow{5}{*}{$\begin{array}{l}\text { BHT15 } \\
\text { (Colorado) }\end{array}$} & \multirow{5}{*}{ Bastrop } & \multirow{5}{*}{30345} & $0-22$ & $5 Y R 4 / 6$ & yellowish red & Sandy clay loam & Loose & Granular & Weak & $\begin{array}{l}\text { roots and rootlets }(5 \%) \text {, cobbles }(10 \%) \text {, gravels } \\
(30 \%) \text {, pebbles }(40 \%) .\end{array}$ & \begin{tabular}{|l} 
Abrupt and \\
irregular to \\
wavy
\end{tabular} & \begin{tabular}{|l|} 
Trench is similar to BHT 14. Fill \\
layer (matrix supported) with sub \\
rounded gravels, pebbles, and
\end{tabular} \\
\hline & & & $22-29$ & $\begin{array}{l}5 Y R 4 / 2 \text { to } \\
5 Y R 4 / 3\end{array}$ & $\begin{array}{l}\text { dark reddish } \\
\text { gray to reddish } \\
\text { brown }\end{array}$ & Clay loam & Firm & \begin{tabular}{|c|} 
Subangular \\
Blocky to \\
Angular Blocky
\end{tabular} & $\begin{array}{l}\text { Weak to } \\
\text { Moderate }\end{array}$ & $\begin{array}{l}\text { rootlets }(5 \%) \text {, snail fragments }(3 \%) \text {, pinhole insect } \\
\text { burrows }(10 \%) \text {, fine pebbles }(5 \% \text {, in small pockets). }\end{array}$ & $\begin{array}{l}\text { Clear and } \\
\text { smooth }\end{array}$ & $\begin{array}{l}\text { South end of the profile is } \\
\text { thicker than the north end with } \\
\text { variable thickness in between. } \\
\text { Possibly truncated. }\end{array}$ \\
\hline & & & $29-66$ & $7.5 Y R$ 4/3 & brown & Clay loam & Friable & $\begin{array}{l}\text { Subangular } \\
\text { Blocky }\end{array}$ & Weak & $\begin{array}{l}\text { rootlets }(5 \%) \text {, snail shell (<1\%, Rabdotus), } \\
\text { slickensides ( } 10 \%, 2-3 \mathrm{~mm} \text { and subtle), worm } \\
\text { burrows }(3 \%) \text {. }\end{array}$ & $\begin{array}{l}\begin{array}{l}\text { Gradual and } \\
\text { smooth }\end{array} \\
\end{array}$ & - \\
\hline & & & $66-127$ & $\begin{array}{l}7.5 \mathrm{YR} 4 / 4 \text { to } \\
7.5 \mathrm{YR} 4 / 6\end{array}$ & $\begin{array}{c}\text { brown to strong } \\
\text { brown }\end{array}$ & Sandy clay loam & Friable to Firm & Angular Blocky & Moderate & $\begin{array}{l}\text { rootlets }(1 \%) \text {, insect burrows }(3 \%) \text {, snail fragments } \\
(1-2 \%) \text {, slickensides }(10 \%, 1-2 \mathrm{~mm} \text { and subtle). }\end{array}$ & $\begin{array}{l}\text { Gradual and } \\
\text { smooth }\end{array}$ & $\begin{array}{l}\text { Increasing clay content with } \\
\text { depth }\end{array}$ \\
\hline & & & 127-158+ & 7.5YR 5/6 & strong brown & $\begin{array}{l}\text { Clay loam (high } \\
\text { clay content) }\end{array}$ & Firm & Angular Blocky & Moderate & $\begin{array}{l}\text { rootlets }(1 \%) \text {, white filaments }(5 \%) \text {, small nodules } \\
\text { ( } 1 \% 2 \mathrm{~mm} \text { possibly calcium carbonate). }\end{array}$ & Unobserved & $\begin{array}{l}\text { Nodules are similar to an } \\
\text { irregular shaped pebble. }\end{array}$ \\
\hline \multirow{5}{*}{$\begin{array}{l}\text { BHT16 } \\
\text { (Colorado) }\end{array}$} & \multirow{5}{*}{ Bastrop } & \multirow{5}{*}{30345} & $0-33$ & $5 Y R \quad 4 / 6$ & yellowish red & Sandy clay loam & Loose & Granular & Weak & $\begin{array}{l}\text { roots and rootlets }(5 \%) \text {, cobbles }(10 \%) \text {, gravels } \\
(30 \%) \text {, pebbles }(40 \%) .\end{array}$ & $\begin{array}{l}\text { Abrupt and } \\
\text { sloping to the } \\
\text { east }\end{array}$ & $\begin{array}{l}\text { Trench is similar to BHT 14. Fill } \\
\text { layer (matrix supported) with sub } \\
\text { rounded gravels, pebbles, and }\end{array}$ \\
\hline & & & $33-44$ & $\begin{array}{l}5 Y R 4 / 2 \text { to } \\
5 Y R 4 / 3\end{array}$ & $\begin{array}{l}\text { dark reddish } \\
\text { gray to reddish } \\
\text { brown }\end{array}$ & Clay loam & Firm & \begin{tabular}{|c|} 
Subangular \\
Blocky to \\
Angular Blocky
\end{tabular} & $\begin{array}{l}\text { Weak to } \\
\text { Moderate }\end{array}$ & $\begin{array}{l}\text { rootlets }(5 \%) \text {, snail fragments }(3 \%) \text {, pinhole insect } \\
\text { burrows }(10 \%) \text {, fine pebbles }(5 \% \text {, in small pockets). }\end{array}$ & $\begin{array}{l}\text { Clear and } \\
\text { smooth }\end{array}$ & Truncated \\
\hline & & & $44-74$ & $7.5 Y R$ 4/3 & brown & Clay loam & Friable & $\begin{array}{l}\text { Subangular } \\
\text { Blocky }\end{array}$ & Weak & $\begin{array}{l}\text { rootlets }(1 \%) \text {, snail fragments }(1-2 \%) \text {, slickensides } \\
(10 \%,<1 \mathrm{~mm} \text { and subtle), Mottles similar to level I } \\
(3 \%) \text {, vertical cracks }(1 \%, \sim 15 \mathrm{~cm}) .\end{array}$ & $\begin{array}{l}\text { Gradual and } \\
\text { smooth }\end{array}$ & $\mid-$ \\
\hline & & & $74-139+$ & $\begin{array}{l}7.5 \mathrm{YR} 4 / 4 \text { to } \\
7.5 \mathrm{YR} 4 / 6\end{array}$ & $\begin{array}{c}\text { brown to strong } \\
\text { brown }\end{array}$ & Sandy clay loam & Friable to Firm & Angular Blocky & Moderate & $\begin{array}{l}\text { rootlets }(1 \%) \text {, insect burrows }(3 \%) \text {, snail fragments } \\
(3 \%) \text {, slickensides ( }(10 \%, 1-2 \mathrm{~mm} \text { and subtle), } \\
\text { mottles same as level } \mathrm{V}(20 \%) \text {. }\end{array}$ & $\begin{array}{l}\text { Gradual and } \\
\text { smooth }\end{array}$ & $\begin{array}{l}\text { Increasing clay content with } \\
\text { depth. Mottles are possibly } \\
\text { caused by insect burrows. }\end{array}$ \\
\hline & & & 139-181+ & 7.5YR 5/6 & strong brown & $\begin{array}{l}\text { Clay loam (high } \\
\text { clay content) }\end{array}$ & Firm & Angular Blocky & Moderate & $\begin{array}{l}\text { rootlets }(1 \%) \text {, white filaments }(5 \%) \text {, small nodules } \\
(5 \%, 0.5-1 \mathrm{~cm} \text {, possibly calcium carbonate). }\end{array}$ & Unobserved & $\begin{array}{l}\text { Nodules are similar to an } \\
\text { irregular shaped pebble. Sample } \\
\text { od nodules was collected. }\end{array}$ \\
\hline \multirow{4}{*}{$\begin{array}{l}\text { BHT17 } \\
\text { (Colorado) }\end{array}$} & \multirow{4}{*}{ Bastrop } & \multirow{4}{*}{30345} & $0-22$ & $5 Y R 4 / 6$ & yellowish red & Sandy clay loam & Loose & Granular & Weak & $\begin{array}{l}\text { roots and rootlets }(5 \%) \text {, cobbles }(10 \%) \text {, gravels } \\
(30 \%) \text {, pebbles }(40 \%) .\end{array}$ & \begin{tabular}{|l} 
Abrupt and \\
irregular to \\
wavy
\end{tabular} & $\begin{array}{l}\text { Trench is similar to BHT } 14 . \\
\text { However, BHT 14, level II is not } \\
\text { present. Fill layer (matrix } \\
\text { supported) with sub-rounded } \\
\text { gravels, pebbles, and cobbles. }\end{array}$ \\
\hline & & & $22-45$ & 7.5YR 4/3 & brown & Clay loam & Friable & $\begin{array}{l}\text { Subangular } \\
\text { Blocky }\end{array}$ & Weak & $\begin{array}{l}\text { rootlets }(1 \%) \text {, snail fragments }(1-2 \%) \text {, slickensides } \\
(10 \%,<1 \mathrm{~mm} \text { and subtle). }\end{array}$ & $\begin{array}{l}\text { Gradual and } \\
\text { smooth }\end{array}$ & - \\
\hline & & & $45-104$ & $\begin{array}{l}7.5 \mathrm{YR} 4 / 4 \text { to } \\
7.5 \mathrm{YR} 4 / 6\end{array}$ & $\begin{array}{c}\text { brown to strong } \\
\text { brown }\end{array}$ & Sandy clay loam & Friable to Firm & Angular Blocky & Moderate & $\begin{array}{l}\text { rootlets }(1 \%) \text {, insect burrows ( } 3 \%) \text {, snail fragments } \\
(1-2 \%) \text {, slickensides }(10 \%, 1-2 \mathrm{~mm} \text { and subtle). }\end{array}$ & $\begin{array}{l}\text { Gradual and } \\
\text { smooth }\end{array}$ & $\begin{array}{l}\text { Increasing clay content with } \\
\text { depth }\end{array}$ \\
\hline & & & $104-113+$ & $7.5 Y R$ 5/6 & strong brown & $\begin{array}{l}\text { Clay loam (high } \\
\text { clay content) }\end{array}$ & Firm & Angular Blocky & Moderate & $\begin{array}{l}\text { snail fragments (<1\%), rootlets }(1 \%) \text {, white } \\
\text { filaments }(5 \%) \text {, pebbles }(1 \% \text {, subangular, up to } \\
1 \mathrm{~cm}) \text {. }\end{array}$ & Unobserved & - \\
\hline \multirow{3}{*}{$\begin{array}{l}\text { BHT18 } \\
\text { (Colorado) }\end{array}$} & \multirow{3}{*}{ Bastrop } & \multirow{3}{*}{30345} & $0-34$ & $5 Y R \quad 4 / 6$ & yellowish red & Sandy clay loam & Loose & Granular & Weak & $\begin{array}{l}\text { roots and rootlets }(5 \%) \text {, cobbles }(10 \%) \text {, gravels } \\
(30 \%) \text {, pebbles }(40 \%) .\end{array}$ & $\begin{array}{l}\text { Abrupt and } \\
\text { irregular to } \\
\text { wavy }\end{array}$ & $\begin{array}{l}\text { Fill layer (matrix supported) with } \\
\text { sub-rounded gravels, pebbles, } \\
\text { and cobbles. }\end{array}$ \\
\hline & & & $34-128$ & 10YR 3/1 & very dark gray & $\begin{array}{l}\text { Clay loam (high } \\
\text { clay content) }\end{array}$ & Firm & $\begin{array}{c}\text { Angular Blocky } \\
\text { to Massive }\end{array}$ & Moderate & $\begin{array}{l}\text { small sand grains }(1 \%) \text {, subtle slickensides (15- } \\
20 \%, 1-3 \mathrm{~cm}) \text {, subrounded pebbles }(1 \%) \text {, snail } \\
\text { fragments }(5 \%) \text {, vertical cracks }(3 \%, 15-20 \mathrm{~cm}) \text {, } \\
\text { pinhole insect burrows }(3 \%) \text {, rootlets }(1 \%) \text {. }\end{array}$ & $\begin{array}{l}\begin{array}{l}\text { Clear and } \\
\text { smooth }\end{array} \\
\end{array}$ & \\
\hline & & & $128-151+$ & $\begin{array}{l}\text { 10YR } 3 / 1 \text { to } \\
\text { 10YR } 2 / 1\end{array}$ & $\begin{array}{c}\text { very dark gray to } \\
\text { black }\end{array}$ & Clay & Extremely Firm & Massive & $\mathrm{N} / \mathrm{A}$ & $\begin{array}{l}\text { calcium carbonate nodules }(5 \%, 3-5 \mathrm{~mm}), \\
\text { prominent slickensides }(20 \%) \text {, large sand grains } \\
(5 \%) \text {. }\end{array}$ & Unobserved & $\begin{array}{l}\text { No observed vertical cracks, } \\
\text { though their presence should be } \\
\text { expected. }\end{array}$ \\
\hline \multirow{3}{*}{$\begin{array}{l}\text { BHT19 } \\
\text { (Colorado) }\end{array}$} & \multirow{3}{*}{ Bastrop } & \multirow{3}{*}{30345} & $0-22$ & $7.5 Y R$ 4/3 & brown & Sandy loam & Friable & $\begin{array}{l}\text { Crumb to } \\
\text { Subangular } \\
\text { Blocky }\end{array}$ & Weak & $\begin{array}{l}\text { roots and rootlets }(20 \%) \text {, pinhole insect burrows } \\
(5 \%) \text {, rodent burrows }(5 \%) \text {, subrounded gravel } \\
(1 \%) \text {. }\end{array}$ & $\begin{array}{l}\begin{array}{l}\text { Clear and } \\
\text { smooth }\end{array} \\
\end{array}$ & $\begin{array}{l}\text { Root zone between } 0 \text { and } 6 \\
\text { cmbs }\end{array}$ \\
\hline & & & $22-113$ & $\begin{array}{l}5 \text { YR } 5 / 4 \text { to } \\
5 \text { YR } 5 / 6\end{array}$ & $\begin{array}{c}\text { brown to strong } \\
\text { brown }\end{array}$ & Sandy clay loam & Firm & Angular Blocky & Moderate & $\begin{array}{l}\text { distinct mottling (40-50\%, } 7.54 / 3) \text {, rootlets }(1-3 \%) \text {, } \\
\text { iron oxide streaks and nodules }(2 \%, 1-2 \mathrm{~mm}) \text {. }\end{array}$ & $\begin{array}{l}\text { Gradual and } \\
\text { smooth }\end{array}$ & $\begin{array}{l}\begin{array}{l}\text { Heavy mottled with sediment } \\
\text { from level above. Iron oxide } \\
\text { streaks and nodules increase } \\
\text { with depth }\end{array}\end{array}$ \\
\hline & & & $113-142+$ & 5YR 5/8 & strong brown & Sandy clay loam & Firm & Angular Blocky & Moderate & $\begin{array}{l}\text { distinct mottling }(4-5 \%, 7.54 / 3) \text {, rootlets }(1-3 \%) \text {, } \\
\text { iron oxide streaks and nodules }(2 \%, 1-2 \mathrm{~mm}) \text {. }\end{array}$ & Unobserved & $\begin{array}{l}\text { Very similar to level II. Mottling } \\
\text { is less distinct than above. }\end{array}$ \\
\hline \multirow{3}{*}{$\begin{array}{l}\text { BHT20 } \\
\text { (Colorado) }\end{array}$} & \multirow{3}{*}{ Bastrop } & \multirow{3}{*}{30345} & $0-7$ & $7.5 Y R$ 4/3 & brown & Sandy loam & Friable & $\begin{array}{l}\text { Crumb to } \\
\text { Subangular } \\
\text { Blocky }\end{array}$ & Weak & $\begin{array}{l}\text { roots and rootlets }(20 \%) \text {, pinhole insect burrows } \\
(5 \%) \text {, rodent burrows }(5 \%) \text {, subrounded gravel } \\
(1 \%) \text {. }\end{array}$ & $\begin{array}{l}\begin{array}{l}\text { Clear and } \\
\text { smooth }\end{array} \\
\end{array}$ & $\begin{array}{l}\text { Trench is similar to BHT } 19 . \\
\text { Level I is disturbed fill layer }\end{array}$ \\
\hline & & & $7-50$ & $\begin{array}{l}5 \text { YR } 5 / 4 \text { to } \\
5 Y R 5 / 6\end{array}$ & $\begin{array}{c}\text { brown to strong } \\
\text { brown }\end{array}$ & Sandy clay loam & Firm & Angular Blocky & Moderate & $\begin{array}{l}\text { distinct mottling }(40-50 \%, 7.54 / 3) \text {, rootlets }(1-3 \%) \text {, } \\
\text { iron oxide streaks and nodules }(2 \%, 1-2 \mathrm{~mm}), \\
\text { subrounded pebbles }(10 \%) .\end{array}$ & $\begin{array}{l}\text { Gradual and } \\
\text { smooth }\end{array}$ & $\begin{array}{l}\begin{array}{l}\text { Heavy mottled with sediment } \\
\text { from level above. Iron oxide } \\
\text { streaks and nodules increase } \\
\text { with depth }\end{array} \\
\end{array}$ \\
\hline & & & $50-119+$ & $5 Y R 5 / 8$ & strong brown & Sandy clay loam & Firm & Angular Blocky & Moderate & $\begin{array}{l}\text { distinct mottling ( }(4-5 \%, 7.54 / 3) \text {, rootlets }(1-3 \%) \text {, } \\
\text { iron oxide streaks and nodules }(2 \%, 1-2 \mathrm{~mm}) \text {. }\end{array}$ & Unobserved & $\begin{array}{l}\text { Very similar to level II. Mottling } \\
\text { is less distinct than above. }\end{array}$ \\
\hline
\end{tabular}




\begin{tabular}{|c|c|c|c|c|c|c|c|c|c|c|c|c|}
\hline BHT & County & Parcel & Depth (cmbs) & Munsell* & Soil Color* & Soil Texture & Consistency & Structure Type & Grade & Inclusions & $\begin{array}{l}\text { Lower } \\
\text { Boundary }\end{array}$ & Comment \\
\hline \multirow{7}{*}{$\begin{array}{l}\text { BHT21 } \\
\text { (Colorado) }\end{array}$} & \multirow{7}{*}{ Bastrop } & \multirow{7}{*}{30345} & $0-17$ & 7.5YR 3/2 & dark brown & Clay loam & Friable & $\begin{array}{c}\text { Subangular } \\
\text { Blocky }\end{array}$ & Moderate & $\begin{array}{l}\text { roots and rootlets }(20 \%), \text { insect and worm burrows } \\
(5 \%)\end{array}$ & $\begin{array}{l}\begin{array}{l}\text { Clear and } \\
\text { smooth }\end{array} \\
\end{array}$ & Trench is very similar to BHT 8 . \\
\hline & & & $17-61$ & 10YR 3/2 & $\begin{array}{c}\text { very dark grayish } \\
\text { brown }\end{array}$ & Clay loam & Friable & $\begin{array}{l}\text { Subangular } \\
\text { Blocky }\end{array}$ & Strong & $\begin{array}{l}\text { roots and rootlets }(5 \%) \text {, pinhole insect burrows } \\
(15 \%) \text {, worm burrows }(5 \%) \text {, snail sells (1\%, } \\
\text { heliodiscus) }\end{array}$ & $\begin{array}{l}\text { Gradual and } \\
\text { smooth }\end{array}$ & - \\
\hline & & & $61-84$ & $\begin{array}{l}7.5 \mathrm{YR} 4 / 2 \text { to } \\
7.5 \mathrm{YR} 4 / 3\end{array}$ & $\begin{array}{c}\text { dark grayish } \\
\text { brown to brown }\end{array}$ & Clay loam & Firm & $\begin{array}{c}\text { Angular Blocky } \\
\text { to Subangular } \\
\text { Blocky }\end{array}$ & Moderate & $\begin{array}{l}\text { roots and rootlets }(2 \%) \text {, calcium carbonate } \\
\text { filaments }(10 \%)\end{array}$ & $\begin{array}{l}\begin{array}{l}\text { Clear and } \\
\text { smooth }\end{array} \\
\text { smo }\end{array}$ & - \\
\hline & & & $84-170$ & $7.5 Y R 4 / 3$ & brown & Silty clay loam & Friable to Firm & $\begin{array}{l}\text { Subangular } \\
\text { Blocky }\end{array}$ & $\begin{array}{c}\text { Moderate to } \\
\text { Strong }\end{array}$ & $\begin{array}{l}\text { roots and rootlets (5\%), and calcium carbonate } \\
\text { filaments }(5 \%) \text {, snail fragments }(1-2 \%) \text {. }\end{array}$ & $\begin{array}{l}\begin{array}{l}\text { Gradual and } \\
\text { smooth }\end{array} \\
\end{array}$ & $\begin{array}{l}\text { Observed from above after } 136 \\
\text { cmbs }\end{array}$ \\
\hline & & & $170-240$ & $\begin{array}{l}7.5 \mathrm{YR} 5 / 4 \text { to } \\
7.5 \mathrm{YR} 5 / 6\end{array}$ & yellowish brown & Clay loam & Friable to Firm & $\begin{array}{c}\text { Angular Blocky } \\
\text { to Subangular } \\
\text { Blocky }\end{array}$ & Moderate & $\begin{array}{l}\text { calcium carbonate filaments (12\%), rootlets }(5 \%) \text {, } \\
\text { insect and worm burrows }(1 \%)\end{array}$ & Unobserved & - \\
\hline & & & $240-310$ & 7.5YR 5/6 & yellowish brown & Clay loam & Friable & $\begin{array}{c}\text { Angular Blocky } \\
\text { to Subangular } \\
\text { Blocky }\end{array}$ & Moderate & $\begin{array}{l}\text { calcium carbonate filaments }(7-10 \%) \text {, rootlets }(2 \%), \\
\text { pinhole insect burrows }(15 \%) \text {, Heliodiscus snail }(1- \\
2 \%)\end{array}$ & Unobserved & $\begin{array}{l}\text { Higher clay content than level } \\
\text { vil. }\end{array}$ \\
\hline & & & $310-430$ & 7.5YR 5/8 & yellowish brown & Clay loam & Friable & $\begin{array}{c}\text { Subangular } \\
\text { Blocky }\end{array}$ & Moderate & rootlets $(1 \%)$ and sand grains $(1 \%)$. & Unobserved & $\begin{array}{l}\text { Clay content increases with } \\
\text { depth. }\end{array}$ \\
\hline \multirow{6}{*}{ BHT01 } & \multirow{6}{*}{ Bastrop } & \multirow{6}{*}{30345} & $0-20$ & 10YR $4 / 2$ & $\begin{array}{l}\text { Dark Grayish } \\
\text { Brown }\end{array}$ & Clay Loam & Firm & $\begin{array}{c}\text { Subangular } \\
\text { Blocky }\end{array}$ & Moderate & $\begin{array}{l}\text { roots } 2-5 \% \text {, rootlets } 15 \% \text {, snail shell } 1 \% \text {, worm } \\
\text { casts } 2 \%\end{array}$ & $\begin{array}{l}\text { Gradual, } \\
\text { horizontal }\end{array}$ & \\
\hline & & & $20-70$ & 10YR $5 / 2$ & Grayish Brown & Sandy Clay Loam & Firm & $\begin{array}{l}\text { Subangular } \\
\text { Blocky }\end{array}$ & Strong & $\begin{array}{l}\begin{array}{l}\text { rootlets } 10 \% \text {, pin holes } 1-2 \% \text {, worm casts } 2 \% \text {, snail } \\
\text { shells } 1 \%\end{array}\end{array}$ & \begin{tabular}{|l|} 
Clear, \\
horizontal
\end{tabular} & \\
\hline & & & 70-101 & 10YR $4 / 2$ & $\begin{array}{l}\text { Dark Grayish } \\
\text { Brown }\end{array}$ & Clay Loam & Firm & $\begin{array}{l}\text { Crumb to } \\
\text { Subangular } \\
\text { Blocky }\end{array}$ & Moderate & rootlets $7 \%$, pinhole $5 \%$, snail shell $1-2 \%$ & Clear, smooth & \\
\hline & & & $101-142$ & 10YR 5/3 & Brown & Sandy Clay Loam & Firm & \begin{tabular}{|c|} 
Subangular \\
Blocky to Platy
\end{tabular} & $\begin{array}{c}\text { Moderate to } \\
\text { Strong }\end{array}$ & rootlets $1-2 \%$, pinholes $5 \%$, worm casts $1 \%$ & $\begin{array}{l}\text { Gradual, } \\
\text { smooth }\end{array}$ & \\
\hline & & & $142-195$ & 10YR $6 / 4$ & \begin{tabular}{|c|}
$\begin{array}{c}\text { Light Yellowish } \\
\text { Brown }\end{array}$ \\
\end{tabular} & Sandy Clay Loam & $\begin{array}{l}\text { Loose to } \\
\text { Friable }\end{array}$ & $\begin{array}{l}\text { Crumb to } \\
\text { Subangular } \\
\text { Blocky }\end{array}$ & Weak & $\begin{array}{l}\text { multiple lamina of sand and calcium carbonate } \\
(2 \mathrm{~cm} \text { long } 5 \%\end{array}$ & Clear, smooth & \\
\hline & & & $195-300$ & 10YR 2/2 & Very Dark Brown & Clay Loam & Extremely Firm & $\begin{array}{l}\text { Blocky to } \\
\text { Massive }\end{array}$ & Strong & $\begin{array}{l}\text { calcium carbonate } 1-5 \mathrm{~mm}(1-5 \%) \text {, some iron and } \\
\text { manganese mottles } 5 \%\end{array}$ & Unobserved & \\
\hline \multirow{6}{*}{ BHT02 } & \multirow{6}{*}{ Bastrop } & \multirow{6}{*}{30345} & $0-30$ & 10YR $4 / 2$ & $\begin{array}{l}\text { Dark Grayish } \\
\text { Brown }\end{array}$ & Clay Loam & Firm & $\begin{array}{l}\text { Subangular } \\
\text { Blocky }\end{array}$ & Moderate & $\begin{array}{l}\text { roots } 2-5 \% \text {, rootlets } 15 \% \text {, snail shell } 1 \% \text {, worm } \\
\text { casts } 2 \%\end{array}$ & $\begin{array}{l}\text { Gradual, } \\
\text { horizontal }\end{array}$ & \\
\hline & & & $30-81$ & 10YR 5/2 & Grayish Brown & Sandy Clay Loam & Firm & $\begin{array}{c}\text { Subangular } \\
\text { Blocky }\end{array}$ & Strong & $\begin{array}{l}10 \% \text {, pin holes } 1-2 \% \text {, worm casts } 2 \% \text {, snail shells } \\
1 \%\end{array}$ & \begin{tabular}{|l|} 
Clear, \\
horizontal
\end{tabular} & $\begin{array}{l}\text { Between } 52-65 \mathrm{cmbs} \text { there are } \\
\text { numerous sand lenses }\end{array}$ \\
\hline & & & $81-99$ & 10YR $4 / 2$ & $\begin{array}{l}\text { Dark Grayish } \\
\text { Brown }\end{array}$ & Clay Loam & Firm & $\begin{array}{l}\text { Crumb to } \\
\text { Subangular } \\
\text { Blocky }\end{array}$ & Moderate & rootlets $7 \%$, pinhole $5 \%$, snail shell $1-2 \%$ & $\begin{array}{l}\text { Slightly sloping } \\
\text { down to NE }\end{array}$ & \\
\hline & & & $99-147$ & 10YR $5 / 3$ & Brown & Sandy Clay Loam & Firm & \begin{tabular}{|c|} 
Subangular \\
Blocky to Platy
\end{tabular} & $\begin{array}{c}\text { Moderate to } \\
\text { Strong }\end{array}$ & rootlets $1-2 \%$, pinholes $5 \%$, worm casts $1 \%$ & $\begin{array}{l}\text { Gradual, } \\
\text { smooth }\end{array}$ & \\
\hline & & & $147-205$ & 10YR $6 / 4$ & $\begin{array}{c}\text { Light Yellowish } \\
\text { Brown }\end{array}$ & Sandy Clay Loam & $\begin{array}{l}\text { Loose to } \\
\text { Friable }\end{array}$ & $\begin{array}{l}\text { Crumb to } \\
\text { Subangular } \\
\text { Blocky }\end{array}$ & Weak & $\begin{array}{l}\text { multiple lamina of sand and calcium carbonate } \\
(2 \mathrm{~cm} \text { long } 5 \%\end{array}$ & Clear, smooth & \\
\hline & & & $205-290$ & 10YR 4/1 & Dark Gray & Clay Loam & Extremely Firm & $\begin{array}{l}\text { Blocky to } \\
\text { Massive }\end{array}$ & Strong & $\begin{array}{l}\text { calcium carbonate } 1-5 \mathrm{~mm}(5-10 \%) \text {, some iron and } \\
\text { manganese mottles } 5 \%\end{array}$ & Unobserved & \\
\hline \multirow{6}{*}{ BHT03 } & \multirow{6}{*}{ Bastrop } & \multirow{6}{*}{30345} & $0-27$ & 10YR $4 / 2$ & $\begin{array}{l}\text { Dark Grayish } \\
\text { Brown }\end{array}$ & Clay Loam & Firm & $\begin{array}{c}\text { Subangular } \\
\text { Blocky }\end{array}$ & Moderate & $\begin{array}{l}\text { roots } 2-5 \% \text {, rootlets } 15 \% \text {, snail shell } 1 \% \text {, worm } \\
\text { casts } 2 \%\end{array}$ & $\begin{array}{l}\begin{array}{l}\text { Gradual, } \\
\text { horizontal }\end{array} \\
\end{array}$ & \\
\hline & & & $27-116$ & 10YR 5/2 & Grayish Brown & Sandy Clay Loam & Firm & $\begin{array}{l}\text { Subangular } \\
\text { Blocky }\end{array}$ & Strong & $\begin{array}{l}\text { roots } 10 \% \text {, rootlets } 10 \% \text {, pin holes } 1-2 \% \text {, worm } \\
\text { casts } 2 \% \text {, snail shells } 1 \%\end{array}$ & $\begin{array}{l}\text { Clear, } \\
\text { horizontal }\end{array}$ & $\begin{array}{l}\text { Between } 48-64 \text { and } 81-116 \\
\text { cmbs there are numerous sand } \\
\text { lenses, which are more } \\
\text { numerous toward the bottom of } \\
\text { the layer }\end{array}$ \\
\hline & & & $116-137$ & 10YR $4 / 2$ & $\begin{array}{l}\text { Dark Grayish } \\
\text { Brown }\end{array}$ & Clay Loam & Firm & $\begin{array}{c}\text { Crumb to } \\
\text { Subangular } \\
\text { Blocky }\end{array}$ & Moderate & rootlets $7 \%$, pinhole $5 \%$, snail shell $1-2 \%$ & $\begin{array}{l}\text { Slightly sloping } \\
\text { down to NE }\end{array}$ & \\
\hline & & & $137-170$ & 10YR $5 / 3$ & Brown & Sandy Clay Loam & Firm & \begin{tabular}{|c|} 
Subangular \\
Blocky to Platy \\
\end{tabular} & \begin{tabular}{|c|} 
Moderate to \\
Strong \\
\end{tabular} & rootlets $1-2 \%$, pinholes $5 \%$, worm casts $1 \%$ & \begin{tabular}{|l|}
$\begin{array}{l}\text { Gradual, } \\
\text { smooth }\end{array}$ \\
\end{tabular} & \\
\hline & & & $170-230$ & 10YR $6 / 4$ & $\begin{array}{c}\text { Light Yellowish } \\
\text { Brown }\end{array}$ & Sandy Clay Loam & $\begin{array}{l}\text { Loose to } \\
\text { Friable }\end{array}$ & $\begin{array}{l}\text { Crumb to } \\
\text { Subangular } \\
\text { Blocky }\end{array}$ & Weak & $\begin{array}{l}\text { multiple lamina of sand and calcium carbonate } \\
(2 \mathrm{~cm} \text { long) } 5 \%\end{array}$ & Clear, smooth & \\
\hline & & & $230-300$ & 10YR 4/1 & Dark Gray & Clay Loam & Extremely Firm & $\begin{array}{l}\text { Blocky to } \\
\text { Massive }\end{array}$ & Strong & $\begin{array}{l}\text { calcium carbonate } 1-5 \mathrm{~mm}(5-10 \%) \text {, some iron and } \\
\text { manganese mottles } 5 \%\end{array}$ & Unobserved & \\
\hline \multirow{5}{*}{ ВНT04 } & \multirow{5}{*}{ Bastrop } & \multirow{5}{*}{30345} & $0-45$ & 10YR 4/2 & $\begin{array}{l}\text { Dark Grayish } \\
\text { Brown }\end{array}$ & Clay Loam & Firm & $\begin{array}{c}\text { Subangular } \\
\text { Blocky }\end{array}$ & Moderate & $\begin{array}{l}\text { roots } 2-5 \% \text {, rootlets } 15 \% \text {, snail shell } 1 \% \text {, worm } \\
\text { casts } 2 \%\end{array}$ & $\begin{array}{l}\text { Gradual, } \\
\text { horizontal }\end{array}$ & \\
\hline & & & $45-77$ & 10YR 5/2 & Grayish Brown & Sandy Clay Loam & Firm & $\begin{array}{c}\text { Subangular } \\
\text { Blocky }\end{array}$ & Strong & $\begin{array}{l}\begin{array}{l}\text { rootlets } 10 \% \text {, pin holes } 1-2 \% \text {, worm casts } 2 \% \text {, snail } \\
\text { shells } 1 \%\end{array} \\
\end{array}$ & \begin{tabular}{|l|}
$\begin{array}{l}\text { Clear, } \\
\text { horizontal }\end{array}$ \\
\end{tabular} & \\
\hline & & & $77-132$ & 10YR $4 / 2$ & $\begin{array}{l}\text { Dark Grayish } \\
\text { Brown }\end{array}$ & Clay Loam & Firm & $\begin{array}{l}\text { Crumb to } \\
\text { Subangular } \\
\text { Blocky }\end{array}$ & Moderate & rootlets $7 \%$, pinhole $5 \%$, snail shell $1-2 \%$ & Clear, smooth & $\begin{array}{l}\text { Tertiary flake at } 83 \mathrm{cmbs} \text {, fire- } \\
\text { cracked chert at } 79 \text { and } 85 \\
\text { cmbs. Column sample located } \\
\text { tertiary flake at } 80-90 \text { and } 90- \\
100 \text { cmbs. Backhoe scoops } \\
\text { were positive for tertiary flakes } \\
\text { from approximately } 140-150 \\
\text { cmbs. }\end{array}$ \\
\hline & & & $132-193$ & 10YR $4 / 2$ & $\begin{array}{c}\text { Dark Grayish } \\
\text { Brown }\end{array}$ & Clay Loam & Firm & Angular Blocky & Moderate & $\begin{array}{l}\text { prominent slickensides, calcium carbonate (2- } \\
5 \mathrm{~mm}) 3-5 \%\end{array}$ & \begin{tabular}{|l|}
$\begin{array}{l}\text { Clear, } \\
\text { horizontal }\end{array}$ \\
\end{tabular} & \\
\hline & & & $193-300$ & 10YR $6 / 4$ & $\begin{array}{c}\text { Light Yellowish } \\
\text { Brown }\end{array}$ & Sandy Clay Loam & Firm & $\begin{array}{c}\text { Subangular } \\
\text { Blocky }\end{array}$ & Strong & $\begin{array}{l}\text { Calcium carbonate } 1 \mathrm{~cm}(2 \%) \text {, prominent } \\
\text { slickensides }\end{array}$ & Unobserved & \\
\hline \multirow{7}{*}{ BHT05 } & \multirow{7}{*}{ Bastrop } & \multirow{7}{*}{30345} & $0-21$ & 10YR $4 / 2$ & $\begin{array}{l}\text { Dark Grayish } \\
\text { Brown }\end{array}$ & Loamy Clay Loam & Friable & $\begin{array}{c}\text { Subangular } \\
\text { Blocky }\end{array}$ & Moderate & $\begin{array}{l}\text { roots } 10 \% \text {, rootlets } 25 \% \text {, pin holes } 10 \% \text {, worm } \\
\text { casts } 5-10 \% \text {, snail fragments }(3 \%) \text {, decomposing } \\
\text { organics }(1 \%)\end{array}$ & $\begin{array}{l}\text { Clear, Slightly } \\
\text { Wavy }\end{array}$ & \\
\hline & & & $21-42$ & 10YR $4 / 3$ & Brown & $\begin{array}{l}\text { Loam to Clay } \\
\text { Loam }\end{array}$ & Friable & $\begin{array}{c}\text { Crumb to } \\
\text { Subangular } \\
\text { Blocky }\end{array}$ & Weak & $\begin{array}{l}\text { roots } 5 \% \text {, rootlets } 15 \% \text {, pin holes } 15 \% \text {, worm casts } \\
5 \% \text {, snail fragments } 5 \% \text {, whole snail, } 1 \% \\
\text { (Heliodiscus) }\end{array}$ & $\begin{array}{l}\text { Gradual, } \\
\text { smooth }\end{array}$ & \\
\hline & & & $42-81$ & 10YR $5 / 3$ & Brown & Sandy Clay Loam & Friable & Angular Blocky & Moderate & \begin{tabular}{|l|} 
roots $1-3 \%$, rootlets $1-5 \%$, pin holes $5-10 \%$, worm \\
casts $1 \%$, snail fragments $5 \%$, whole snail $1 \%$ \\
(Heliodiscus)
\end{tabular} & Abrupt, smooth & \\
\hline & & & 81-109 & 10YR 4/1-4/2 & $\begin{array}{l}\text { Dark Gray to } \\
\text { Dark Grayish } \\
\text { Brown } \\
\end{array}$ & Clay Loam & Friable to Firm & Angular Blocky & \begin{tabular}{|c|} 
Moderate to \\
Strong
\end{tabular} & $\begin{array}{l}\begin{array}{l}\text { rootlets } 5-10 \% \text {, pin holes } 5 \% \text {, worm casts } 1 \% \text {, } \\
\text { slickensides } 1-3 \mathrm{~mm}(5 \%) \text {, shrink-swell, snail } \\
\text { fragments } 1 \% \text {, whole snail } 1 \% \text { (liptooth) }\end{array} \\
\end{array}$ & Clear, smooth & $\begin{array}{l}\text { Matrix from insect burrows (5\%) } \\
\text { bring down strat III, possible } \\
\text { buried soil }\end{array}$ \\
\hline & & & $109-141$ & 10YR 5/3-6/3 & $\begin{array}{l}\text { Brown to Pale } \\
\text { Brown }\end{array}$ & Silty Clay Loam & Friable & Angular Blocky & Moderate & $\begin{array}{l}\text { rootlets } 3 \% \text {, pin holes } 5 \% \text {, worm casts } 1 \% \text {, insect } \\
\text { burrows with strat IV matrix } 3 \% \text {, white filaments ( } \\
1 \mathrm{~mm} / 3-5 \% \text { ) and increasing with depth }\end{array}$ & $\begin{array}{l}\text { Gradual, } \\
\text { smooth }\end{array}$ & \\
\hline & & & $141-253$ & 10YR 6/3-6/4 & \begin{tabular}{|c|}
$\begin{array}{c}\text { Pale Brown to } \\
\text { Light Yellowish } \\
\text { Brown }\end{array}$ \\
\end{tabular} & Silty Clay Loam & Friable & Angular Blocky & Moderate & $\begin{array}{l}\text { rootlets } 3 \% \text {, pinholes } 5 \% \text {, worm casts } 2 \% \text {, white } \\
\text { filaments }(2-3 \mathrm{~mm}) \text {, no snail shell }\end{array}$ & Abrupt, smooth & beds of fine sand \\
\hline & & & $253-290+$ & 10YR $3 / 1$ & Very Dark Gray & Loamy Clay & Firm & $\begin{array}{c}\text { Angular Blocky } \\
\text { to Massive }\end{array}$ & Moderate & $\begin{array}{l}\text { rootlets } 2 \% \text {, pin holes } 1 \% \text {, worm casts } 2 \% \text {, white } \\
\text { nodules }(5-10 \mathrm{~mm}) 10 \%\end{array}$ & Unobserved & Possible buried soil \\
\hline
\end{tabular}




\begin{tabular}{|c|c|c|c|c|c|c|c|c|c|c|c|c|}
\hline ВHт & County & Parcel & Depth (cmbs) & MunselI* & Soil Color* & Soil Texture & Consistency & Structure Type & Grade & Inclusions & $\begin{array}{c}\text { Lower } \\
\text { Boundary }\end{array}$ & Comment \\
\hline \multirow{6}{*}{ BHT06 } & \multirow{6}{*}{ Bastrop } & \multirow{6}{*}{30345} & $0-15$ & 10YR $4 / 2$ & $\begin{array}{l}\text { Dark Grayish } \\
\text { Brown }\end{array}$ & Loamy Clay Loam & Friable & $\begin{array}{l}\text { Subangular } \\
\text { Blocky }\end{array}$ & Moderate & $\begin{array}{l}\text { roots } 10 \% \text {, rootlets } 25 \% \text {, pin holes } 10 \% \text {, worm } \\
\text { casts } 5-10 \% \text {, snail fragments }(3 \%) \text {, decomposing } \\
\text { organics }(1 \%)\end{array}$ & $\begin{array}{l}\text { Clear, Slightly } \\
\text { Wavy }\end{array}$ & \\
\hline & & & $15-43$ & 10YR $5 / 3$ & Brown & Sandy Clay Loam & Friable & Angular Blocky & Moderate & $\begin{array}{l}\text { roots } 1-3 \% \text {, rootlets } 1-5 \% \text {, pin holes } 5-10 \% \text {, worm } \\
\text { casts } 1 \% \text {, nnail fragments } 5 \% \text {, whole snail } 1 \% \\
\text { (Heliodiscus) }\end{array}$ & Abrupt, smooth & \\
\hline & & & $43-62$ & 10YR $4 / 1-4 / 2$ & $\begin{array}{c}\text { Dark Gray to } \\
\text { Dark Grayish } \\
\text { Brown } \\
\end{array}$ & Clay Loam & Friable to Firm & Angular Blocky & $\begin{array}{l}\text { Moderate to } \\
\text { Strong }\end{array}$ & $\begin{array}{l}\text { rootlets } 5-10 \% \text {, pin holes } 5 \% \text {, worm casts } 1 \% \text {, } \\
\text { slickensides } 1-3 \mathrm{~mm}(5 \%) \text {, shrink-swell, snail } \\
\text { fragments } 1 \% \text {, whole snail } 1 \% \text { (liptooth) }\end{array}$ & Clear, smooth & $\begin{array}{l}\text { Slightly higher clay content than } \\
\text { BHT05 }\end{array}$ \\
\hline & & & $62-89$ & 10YR 5/3-6/3 & $\begin{array}{l}\text { Brown to Pale } \\
\text { Brown }\end{array}$ & Silty Clay Loam & Friable & Angular Blocky & Moderate & $\begin{array}{l}\text { rootlets } 3 \% \text {, pin holes } 5 \% \text {, worm casts } 1 \% \text {, insect } \\
\text { burrows with strat IV matrix } 3 \% \text {, white filaments ( } \\
1 \mathrm{~mm} / 3-5 \% \text { ) and increasing with depth }\end{array}$ & $\begin{array}{l}\text { Gradual, } \\
\text { smooth }\end{array}$ & $\begin{array}{l}\text { Slightly higher clay content than } \\
\text { BHT05 }\end{array}$ \\
\hline & & & $89-254$ & 10YR $6 / 3-6 / 4$ & $\begin{array}{c}\begin{array}{c}\text { Pale Brown to } \\
\text { Light Yellowish } \\
\text { Brown }\end{array} \\
\end{array}$ & Silty Clay Loam & Friable & Angular Blocky & Moderate & $\begin{array}{l}\text { rootlets } 3 \% \text {, pinholes } 5 \% \text {, worm casts } 2 \% \text {, white } \\
\text { filaments }(2-3 \mathrm{~mm}) \text {, no snail shell }\end{array}$ & Abrupt, smooth & \\
\hline & & & $254-290$ & 10YR 3/1 & Very Dark Gray & Loamy Clay & Firm & Angular Blocky & Moderate & $\begin{array}{l}\text { rootlets } 2 \% \text {, pin holes } 1 \% \text {, worm casts } 2 \% \text {, white } \\
\text { nodules }(5-10 \mathrm{~mm}) 10 \%\end{array}$ & Unobserved & Possible buried soil \\
\hline \multirow{5}{*}{ BHT07 } & \multirow{5}{*}{ Bastrop } & \multirow{5}{*}{30345} & $0-19$ & 10YR $4 / 2$ & $\begin{array}{l}\text { Dark Grayish } \\
\text { Brown }\end{array}$ & Loamy Clay Loam & Friable & $\begin{array}{l}\text { Subangular } \\
\text { Blocky }\end{array}$ & Moderate & $\begin{array}{l}\text { roots } 15 \% \text {, rootlets } 25 \% \text {, pin holes } 10 \% \text {, worm } \\
\text { casts } 5-10 \% \text {, snail fragments }(3 \%) \text {, decomposing } \\
\text { organics }(5 \%)\end{array}$ & $\begin{array}{l}\text { Clear, Slightly } \\
\text { Wavy }\end{array}$ & \\
\hline & & & $19-44$ & 10YR $5 / 3$ & Brown & Sandy Clay Loam & Friable & Angular Blocky & Moderate & $\begin{array}{l}\text { roots } 5-10 \% \text {, rootlets } 20 \% \text {, pin holes } 5-10 \% \text {, worm } \\
\text { casts } 1 \% \text {, snail fragments } 5 \% \text {, whole snail } 1 \% \\
\text { (Heliodiscus) }\end{array}$ & Abrupt, smooth & \\
\hline & & & $44-84$ & 10YR $4 / 1-4 / 2$ & $\begin{array}{l}\text { Dark Gray to } \\
\text { Dark Grayish } \\
\text { Brown }\end{array}$ & Clay Loam & Firm & Angular Blocky & $\begin{array}{l}\text { Moderate to } \\
\text { Strong }\end{array}$ & $\begin{array}{l}\text { rootlets } 5-10 \% \text {, roots } 5-10 \% \text {, pin holes } 5 \% \text {, worm } \\
\text { casts } 1 \% \text {, slickensides } 1-3 \mathrm{~mm}(5 \%) \text {, shrink-swell, } \\
\text { snail fragments } 1 \% \text {, whole snail } 1 \% \text { (liptooth) }\end{array}$ & Clear, smooth & \\
\hline & & & $84-119$ & 10YR $5 / 3-6 / 3$ & $\begin{array}{l}\text { Brown to Pale } \\
\text { Brown }\end{array}$ & Silty Clay Loam & Friable & Angular Blocky & Moderate & $\begin{array}{l}\text { rootlets } 3 \% \text {, pin holes } 5 \% \text {, worm casts } 1 \% \text {, insect } \\
\text { burrows with strat IV matrix } 3 \% \text {, white filaments ( } \\
1 \mathrm{~mm} / 3-5 \% \text { ) and increasing with depth }\end{array}$ & $\begin{array}{l}\text { Gradual, } \\
\text { smooth }\end{array}$ & $\begin{array}{l}\text { In sidewall: tertiary flake at } 93 \\
\text { cmbs, possible fired quartzite at } \\
105 \text { cmbs, tertiary flakes at } 92, \\
83,91, \text { and } 90 \text { cmbs. } \\
\end{array}$ \\
\hline & & & $119-137$ & 10YR $3 / 1$ & Very Dark Gray & Loamy Clay & Firm & $\begin{array}{c}\text { Angular Blocky } \\
\text { to Massive }\end{array}$ & Moderate & $\begin{array}{l}\text { rootlets } 2 \% \text {, pin holes } 1 \% \text {, worm casts } 2 \% \text {, white } \\
\text { filaments }(2-3 \mathrm{~mm}) 5 \%\end{array}$ & Unobserved & \\
\hline \multirow{9}{*}{ BHT08 } & \multirow{9}{*}{ Bastrop } & \multirow{9}{*}{30345} & $0-16$ & 10YR $4 / 2$ & $\begin{array}{l}\text { Dark Grayish } \\
\text { Brown }\end{array}$ & Loamy Clay Loam & Friable & $\begin{array}{l}\text { Subangular } \\
\text { Blocky }\end{array}$ & Moderate & $\begin{array}{l}\text { roots } 10 \% \text {, rootlets } 25 \% \text {, pin holes } 10 \% \text {, worm } \\
\text { casts } 5-10 \% \text {, snail fragments }(3 \%) \text {, decomposing } \\
\text { organics }(1 \%)\end{array}$ & $\begin{array}{l}\text { Clear, Slightly } \\
\text { Wavy }\end{array}$ & \\
\hline & & & $16-31$ & 10YR $4 / 3$ & Brown & $\begin{array}{l}\text { Loam to Clay } \\
\text { Loam }\end{array}$ & Friable & $\begin{array}{l}\text { Crumb to } \\
\text { Subangular } \\
\text { Blocky }\end{array}$ & Weak & $\begin{array}{l}\text { roots } 5 \% \text {, rootlets } 15 \% \text {, pin holes } 15 \% \text {, worm casts } \\
5 \% \text {, snail fragments } 5 \% \text {, whole snail, } 1 \% \\
\text { (rabdotus) }\end{array}$ & $\begin{array}{l}\text { Gradual, } \\
\text { smooth }\end{array}$ & \\
\hline & & & $31-52$ & 10YR $5 / 3$ & Brown & Sandy Clay Loam & Friable & Angular Blocky & Moderate & $\begin{array}{l}\text { roots } 1-3 \% \text {, rootlets } 1-5 \% \text {, pin holes } 5-10 \% \text {, worm } \\
\text { casts } 1 \% \text {, snail fragments } 5 \% \text {, whole snail } 1 \% \\
\text { (Heliodiscus) }\end{array}$ & Abrupt, smooth & \\
\hline & & & $52-72$ & 10YR $4 / 1-4 / 2$ & $\begin{array}{c}\text { Dark Gray to } \\
\text { Dark Grayish } \\
\text { Brown } \\
\end{array}$ & Clay Loam & Friable to Firm & Angular Blocky & $\begin{array}{l}\text { Moderate to } \\
\text { Strong }\end{array}$ & $\begin{array}{l}\text { rootlets } 5-10 \%, \text { pin holes } 5 \% \text {, worm casts } 1 \% \text {, } \\
\text { slickensides } 1-3 \mathrm{~mm}(5 \%) \text {, shrink-swell, snail } \\
\text { fragments } 1 \% \text {, whole snail } 1 \% \text { (liptooth) }\end{array}$ & Clear, smooth & Possible buried soil \\
\hline & & & $72-116$ & 10YR 5/3-6/3 & $\begin{array}{l}\text { Brown to Pale } \\
\text { Brown }\end{array}$ & Silty Clay Loam & Friable & Angular Blocky & Moderate & $\begin{array}{l}\text { Friable, angular, medium to coarse size, moderate } \\
\text { grade, rootlets } 3 \% \text {, pin holes } 5 \% \text {, worm casts } 1 \% \text {, } \\
\text { insect burrows with strat IV matrix } 3 \% \text {, white } \\
\text { filaments ( } 1 \mathrm{~mm} / 3-5 \% \text { ) and increasing with depth }\end{array}$ & $\begin{array}{l}\text { Gradual, } \\
\text { smooth }\end{array}$ & $\begin{array}{l}\text { Tan pockets of 10YR 7/3-7/4 silt } \\
(6-10 \mathrm{~mm} \text { thick) } 89-90 \text { and } 104- \\
105 \mathrm{cmbs} \text {, discontinuous, } \\
\text { possibly flood drape }\end{array}$ \\
\hline & & & $116-178$ & 10YR $6 / 3-6 / 4$ & \begin{tabular}{|c|}
$\begin{array}{c}\text { Pale Brown to } \\
\text { Light Yellowish } \\
\text { Brown }\end{array}$ \\
\end{tabular} & Silty Clay Loam & Friable & Angular Blocky & Moderate & $\begin{array}{l}\text { rootlets } 3 \% \text {, pinholes } 5 \% \text {, worm casts } 2 \% \text {, white } \\
\text { filaments }(2-3 \mathrm{~mm}) \text {, no snail shell }\end{array}$ & Abrupt, smooth & \\
\hline & & & $178-247$ & 10YR 3/1 & Very Dark Gray & Loamy Clay & Firm & $\begin{array}{c}\text { Angular Blocky } \\
\text { to Massive }\end{array}$ & Moderate & $\begin{array}{l}\text { rootlets } 2 \% \text {, pin holes } 1 \% \text {, worm casts } 2 \% \text {, white } \\
\text { nodules }(5-10 \mathrm{~mm}) 10 \%\end{array}$ & $\begin{array}{l}\text { Gradual, } \\
\text { smooth }\end{array}$ & $\begin{array}{l}\text { Mussel shell at } 186 \mathrm{cmbs} \text {, } \\
\text { possibly a buried soil }\end{array}$ \\
\hline & & & $247-305$ & 10YR $4 / 2-4 / 3$ & $\begin{array}{c}\text { Dark Grayish } \\
\text { Brown to Brown }\end{array}$ & Loamy Clay & Firm & $\begin{array}{c}\text { Angular Blocky } \\
\text { to Prismatic }\end{array}$ & $\begin{array}{l}\text { Moderate to } \\
\text { Strong }\end{array}$ & $\begin{array}{l}\text { white nodules }(5-8 \mathrm{~mm} / 15 \%) \text {, iron staining ( } 1-2 \\
\mathrm{~mm} / 1 \% \text { ), iron nodules, snail fragments } 1 \% \text {, insect } \\
\text { burrows } 2-3 \%\end{array}$ & $\begin{array}{l}\text { Gradual, } \\
\text { smooth }\end{array}$ & \\
\hline & & & $305-336$ & 10YR $5 / 3$ & Brown & Silty Clay Loam & Friable & Prismatic & Moderate & $\begin{array}{l}\text { rootlets } 1 \% \text {, slickensides } 2-3 \mathrm{~cm}(2 \%) \text {, white } \\
\text { nodules }(5-15 \mathrm{~mm} / 10-15 \%) \text {, snail fragments } 1 \% \text {, } \\
\text { iron pebbles }(2-4 \mathrm{~mm})<1 \%\end{array}$ & Unobserved & Shrink swell \\
\hline \multirow{6}{*}{ BHT09 } & \multirow{6}{*}{ Bastrop } & \multirow{6}{*}{30345} & $0-16$ & 10YR $4 / 2$ & $\begin{array}{l}\text { Dark Grayish } \\
\text { Brown }\end{array}$ & Loamy Clay Loam & Friable & $\begin{array}{l}\text { Subangular } \\
\text { Blocky }\end{array}$ & Moderate & $\begin{array}{l}\text { roots } 10 \% \text {, rootlets } 25 \% \text {, pin holes } 10 \% \text {, worm } \\
\text { casts } 5-10 \% \text {, snail fragments }(3 \%) \text {, decomposing } \\
\text { organics }(1 \%)\end{array}$ & $\begin{array}{l}\text { Clear, Slightly } \\
\text { Wavy }\end{array}$ & \\
\hline & & & $16-37$ & 10YR $5 / 3$ & Brown & Sandy Clay Loam & Friable & Angular Blocky & Moderate & $\begin{array}{l}\text { roots } 1-3 \% \text {, rootlets } 1-5 \% \text {, pin holes } 5-10 \% \text {, worm } \\
\text { casts } 1 \% \text {, nail fragments } 5 \% \text {, whole snail } 1 \% \\
\text { (Heliodiscus) }\end{array}$ & Abrupt, smooth & \\
\hline & & & $37-84$ & 10YR 4/1-4/2 & $\begin{array}{c}\text { Dark Gray to } \\
\text { Dark Grayish } \\
\text { Brown } \\
\end{array}$ & Clay Loam & Friable to Firm & Angular Blocky & $\begin{array}{l}\text { Moderate to } \\
\text { Strong }\end{array}$ & $\begin{array}{l}\text { rootlets } 5-10 \% \text {, pin holes } 5 \% \text {, worm casts } 1 \% \text {, } \\
\text { slickensides } 1-3 \mathrm{~mm}(5 \%) \text {, shrink-swell, snail } \\
\text { fragments } 1 \% \text {, whole snail } 1 \% \text { (liptooth) }\end{array}$ & Clear, smooth & \begin{tabular}{|l|} 
Tan lenses (discontinuities__ \\
10YR $7 / 4$, silt loam $(65-66,72-$ \\
$73,61-62$ cmbs)
\end{tabular} \\
\hline & & & $84-114$ & 10YR $5 / 3-6 / 3$ & $\begin{array}{l}\text { Brown to Pale } \\
\text { Brown }\end{array}$ & Silty Clay Loam & Friable & Angular Blocky & Moderate & $\begin{array}{l}\text { rootlets } 3 \% \text {, pin holes } 5 \% \text {, worm casts } 1 \% \text {, insect } \\
\text { burrows with strat IV matrix } 3 \% \text {, white filaments ( } \\
1 \mathrm{~mm} / 3-5 \% \text { ) and increasing with depth }\end{array}$ & $\begin{array}{l}\text { Gradual, } \\
\text { smooth }\end{array}$ & $\begin{array}{l}\text { Possible buried soil, bone } \\
\text { fragments at } 101 \text { and } 92 \mathrm{cmbs}, \\
\text { primary flake at } 97 \mathrm{cmbs}, \\
\text { secondary flakes at } 91 \text { and } 98 \\
\text { cmbs, ceramic sherd at } 97 \\
\text { cmbs, tertiary flakes at } 89-103 \\
(\mathrm{n}=17), \text { burned shatter at } 89 \\
\text { cmbs, burned chert at } 88 \mathrm{cmbs}\end{array}$ \\
\hline & & & $114-139$ & 10YR $6 / 3-6 / 4$ & $\begin{array}{c}\begin{array}{c}\text { Pale Brown to } \\
\text { Light Yellowish } \\
\text { Brown }\end{array} \\
\end{array}$ & Silty Clay Loam & Friable & Angular Blocky & Moderate & $\begin{array}{l}\text { rootlets } 3 \% \text {, pinholes } 5 \% \text {, worm casts } 2 \% \text {, white } \\
\text { filaments }(2-3 \mathrm{~mm}) \text {, no snail shell }\end{array}$ & Abrupt, smooth & \\
\hline & & & $139-165$ & 10YR 3/1 & Very Dark Gray & Loamy Clay & Firm & $\begin{array}{c}\text { Angular Blocky } \\
\text { to Massive }\end{array}$ & Moderate & $\begin{array}{l}\text { rootlets } 2 \% \text {, pin holes } 1 \% \text {, worm casts } 2 \% \text {, white } \\
\text { nodules }(5-10 \mathrm{~mm}) 10 \%\end{array}$ & Unobserved & \\
\hline
\end{tabular}




\begin{tabular}{|c|c|c|c|c|c|c|c|c|c|c|c|c|}
\hline BHT & County & Parcel & Depth (cmbs) & Munsell* & Soil Color* & Soil Texture & Consistency & Structure Type & Grade & Inclusions & $\begin{array}{c}\text { Lower } \\
\text { Boundary }\end{array}$ & Comment \\
\hline \multirow{7}{*}{ BHT10 } & \multirow{7}{*}{ Bastrop } & \multirow{7}{*}{30345} & $0-16$ & 10YR $4 / 2$ & $\begin{array}{l}\text { Dark Grayish } \\
\text { Brown }\end{array}$ & Loamy Clay Loam & Friable & $\begin{array}{l}\text { Subangular } \\
\text { Blocky }\end{array}$ & Moderate & $\begin{array}{l}\text { roots } 10 \% \text {, rootlets } 25 \% \text {, pin holes } 10 \% \text {, worm } \\
\text { casts } 5-10 \% \text {, snail fragments }(3 \%) \text {, decomposing } \\
\text { organics }(1 \%)\end{array}$ & $\begin{array}{l}\text { Clear, Slightly } \\
\text { Wavy }\end{array}$ & \\
\hline & & & $16-44$ & 10YR $4 / 3$ & Brown & $\begin{array}{l}\text { Loam to Clay } \\
\text { Loam }\end{array}$ & Friable & $\begin{array}{l}\text { Crumb to } \\
\text { Subangular } \\
\text { Blocky }\end{array}$ & Weak & $\begin{array}{l}\text { roots } 5 \% \text {, rootlets } 15 \% \text {, pin holes } 15 \% \text {, worm casts } \\
5 \% \text {, snail fragments } 2 \% \text {, whole snail, } 1 \% \\
\text { (Heliodiscus) }\end{array}$ & $\begin{array}{l}\text { Gradual, } \\
\text { smooth }\end{array}$ & Some charcoal and burned clay \\
\hline & & & $44-74$ & 10YR $5 / 3$ & Brown & Sandy Clay Loam & Friable & Angular Blocky & Moderate & $\begin{array}{l}\text { roots 3\%, rootlets } 1-5 \% \text {, pin holes } 5-10 \% \text {, worm } \\
\text { casts 2\%, snail fragments 2\%, whole snail } 1 \% \\
\text { (Heliodiscus) }\end{array}$ & Abrupt, smooth & \\
\hline & & & $74-101$ & 10YR 4/1-4/2 & $\begin{array}{l}\text { Dark Gray to } \\
\text { Dark Grayish } \\
\text { Brown }\end{array}$ & Clay Loam & Friable to Firm & Angular Blocky & $\begin{array}{l}\text { Moderate to } \\
\text { Strong }\end{array}$ & $\begin{array}{l}\text { rootlets } 5-10 \% \text {, pin holes } 5 \% \text {, worm casts } 1 \% \text {, } \\
\text { slickensides } 1-3 \mathrm{~mm}(5 \%) \text {, shrink-swell, snail } \\
\text { fragments } 1 \% \text {, whole snail } 1 \% \text { (liptooth) }\end{array}$ & Clear, smooth & $\begin{array}{l}\text { Burned rock fragment at } 90 \\
\text { cmbs }\end{array}$ \\
\hline & & & $101-151$ & 10YR 5/3-6/3 & $\begin{array}{l}\text { Brown to Pale } \\
\text { Brown }\end{array}$ & Silty Clay Loam & Friable & Angular Blocky & Moderate & $\begin{array}{l}\text { rootlets } 3 \% \text {, pin holes } 5 \% \text {, worm casts } 1 \% \text {, insect } \\
\text { burrows with strat IV matrix } 3 \% \text {, white filaments ( } \\
1 \mathrm{~mm} / 3-5 \% \text { ) and increasing with depth }\end{array}$ & $\begin{array}{l}\text { Gradual, } \\
\text { smooth }\end{array}$ & \\
\hline & & & $151-205$ & 10YR 6/3-6/4 & $\begin{array}{c}\begin{array}{c}\text { Pale Brown to } \\
\text { Light Yellowish } \\
\text { Brown }\end{array} \\
\end{array}$ & Silty Clay Loam & Friable & Angular Blocky & Moderate & $\begin{array}{l}\text { rootlets } 3 \% \text {, pinholes } 5 \% \text {, worm casts } 2 \% \text {, white } \\
\text { filaments }(2-3 \mathrm{~mm}) \text {, no snail shell }\end{array}$ & Abrupt, smooth & \\
\hline & & & 205-305 & 10YR 3/1 & Very Dark Gray & Loamy Clay & Firm & $\begin{array}{c}\text { Angular Blocky } \\
\text { to Massive }\end{array}$ & Moderate & $\begin{array}{l}\text { rootlets } 2 \% \text {, pin holes } 1 \% \text {, worm casts } 2 \% \text {, white } \\
\text { nodules }(5-10 \mathrm{~mm}) 10 \%\end{array}$ & Unobserved & \\
\hline \multirow{5}{*}{ BHT11 } & \multirow{5}{*}{ Bastrop } & \multirow{5}{*}{30345} & $0-10$ & 10YR $4 / 2$ & $\begin{array}{l}\text { Dark Grayish } \\
\text { Brown }\end{array}$ & Loamy Clay Loam & Friable & $\begin{array}{l}\text { Subangular } \\
\text { Blocky }\end{array}$ & Moderate & $\begin{array}{l}\text { roots } 15 \% \text {, rootlets } 25 \% \text {, pin holes } 10 \% \text {, worm } \\
\text { casts } 5-10 \% \text {, snail fragments }(3 \%) \text {, decomposing } \\
\text { organics }(5 \%)\end{array}$ & \begin{tabular}{|l|} 
Clear, Slightly \\
Wavy
\end{tabular} & $\begin{array}{l}\text { Ground surface slightly sloping } \\
\text { toward the west }\end{array}$ \\
\hline & & & $10-23$ & 10YR $5 / 3$ & Brown & Sandy Clay Loam & Friable & Angular Blocky & Moderate & $\begin{array}{l}\text { roots } 5-10 \%, \text { rootlets } 20 \% \text {, pin holes } 5-10 \% \text {, worm } \\
\text { casts } 1 \% \text {, snail fragments } 5 \% \text {, whole snail } 1 \% \\
\text { (Heliodiscus) }\end{array}$ & Irregular, wavy & \\
\hline & & & $23-41$ & 10YR 4/1-4/2 & $\begin{array}{l}\text { Dark Gray to } \\
\text { Dark Grayish } \\
\text { Brown }\end{array}$ & Clay Loam & Firm & Angular Blocky & $\begin{array}{l}\text { Moderate to } \\
\text { Strong }\end{array}$ & $\begin{array}{l}\text { rootlets } 5-10 \% \text {, roots } 5-10 \% \text {, pin holes } 5 \% \text {, worm } \\
\text { casts } 1 \% \text {, slickensides } 1-3 \mathrm{~mm} \text { (5\%), shrink-swell, } \\
\text { snail fragments } 1 \% \text {, whole snail } 1 \% \text { (liptooth) }\end{array}$ & Abrupt, wavy & \\
\hline & & & $41-82$ & 10YR $5 / 3-6 / 3$ & $\begin{array}{c}\text { Brown to Pale } \\
\text { Brown }\end{array}$ & Silty Clay Loam & Friable & Angular Blocky & Moderate & $\begin{array}{l}\text { rootlets } 3 \% \text {, pin holes } 5 \% \text {, worm casts } 1 \% \text {, insect } \\
\text { burrows with strat IV matrix } 3 \% \text {, white filaments ( } \\
1 \mathrm{~mm} / 3-5 \% \text { ) and increasing with depth }\end{array}$ & Clear, wavy & \begin{tabular}{|l|} 
Possible graver at $63 \mathrm{cmbs}$, \\
primary flake at $82 \mathrm{cmbs}$, two \\
tertiary flakes at 78 and $79 \mathrm{cmbs}$ \\
respectively
\end{tabular} \\
\hline & & & $82-146$ & 10YR $3 / 1$ & Very Dark Gray & Loamy Clay & Firm & $\begin{array}{c}\text { Angular Blocky } \\
\text { to Massive }\end{array}$ & Moderate & $\begin{array}{l}\text { rootlets } 2 \% \text {, pin holes } 1 \% \text {, worm casts } 2 \% \text {, white } \\
\text { filaments }(10-30 \mathrm{~mm}) 3-5 \%\end{array}$ & Unobserved & \\
\hline \multirow{4}{*}{ BHT12 } & \multirow{4}{*}{ Bastrop } & \multirow{4}{*}{30345} & $0-20$ & 10YR $4 / 2$ & $\begin{array}{c}\text { Dark Grayish } \\
\text { Brown }\end{array}$ & Loamy Clay Loam & Friable & $\begin{array}{l}\text { Subangular } \\
\text { Blocky }\end{array}$ & Moderate & $\begin{array}{l}\text { roots } 15 \% \text {, rootlets } 25 \% \text {, pin holes } 10 \% \text {, worm } \\
\text { casts } 5-10 \% \text {, snail fragments }(3 \%) \text {, decomposing } \\
\text { organics }(5 \%)\end{array}$ & $\begin{array}{l}\text { Clear, Slightly } \\
\text { sloping west }\end{array}$ & \\
\hline & & & $20-42$ & 10YR $5 / 3$ & Brown & Sandy Clay Loam & Friable & Angular Blocky & Moderate & $\begin{array}{l}\begin{array}{l}\text { roots } 5-10 \% \text {, rootlets } 20 \% \text {, pin holes } 5-10 \% \text {, worm } \\
\text { casts } 1 \% \text {, snail fragments } 5 \% \text {, whole snail } 1 \% \\
\text { (Heliodiscus) }\end{array} \\
\end{array}$ & Gradual, wavy & \\
\hline & & & $42-101$ & 10YR 4/1-4/2 & $\begin{array}{c}\text { Dark Gray to } \\
\text { Dark Grayish } \\
\text { Brown } \\
\end{array}$ & Loamy Clay & Firm & $\begin{array}{l}\text { Subangular } \\
\text { Blocky }\end{array}$ & Moderate & $\begin{array}{l}\text { less than } 1 \% \text { snail shell, roots } 5 \% \text {, rootlets } 5 \% \text {, pin } \\
\text { holes } 5 \% \text {, worm casts } 1 \%\end{array}$ & $\begin{array}{l}\text { Clear, } \\
\text { horizontal }\end{array}$ & $\begin{array}{l}\text { Tertiary flakes at } 62 \text { and } 74 \\
\text { cmbs, fire-cracked chert at } 62 \\
\text { and } 83 \text { cmbs. }\end{array}$ \\
\hline & & & $101-154$ & 10YR 3/1 & Very Dark Gray & Loamy Clay & Firm & $\begin{array}{c}\text { Angular Blocky } \\
\text { to Massive }\end{array}$ & Moderate & $\begin{array}{l}\text { rootlets } 2 \% \text {, pin holes } 1 \% \text {, worm casts } 2 \% \text {, white } \\
\text { filaments }(10-30 \mathrm{~mm}) 3-5 \%\end{array}$ & Unobserved & \\
\hline \multirow{5}{*}{ BHT13 } & \multirow{5}{*}{ Bastrop } & \multirow{5}{*}{30345} & $0-18$ & 10YR $4 / 2$ & $\begin{array}{l}\text { Dark Grayish } \\
\text { Brown }\end{array}$ & Loamy Clay Loam & Friable & $\begin{array}{l}\text { Subangular } \\
\text { Blocky }\end{array}$ & Moderate & $\begin{array}{l}\text { roots } 10 \% \text {, rootlets } 25 \% \text {, pin holes } 10 \% \text {, worm } \\
\text { casts } 5-10 \% \text {, snail fragments }(3 \%) \text {, decomposing } \\
\text { organics }(1 \%)\end{array}$ & $\begin{array}{l}\text { Clear, Slightly } \\
\text { Wavy }\end{array}$ & \\
\hline & & & $18-37$ & 10YR $4 / 3$ & Brown & $\begin{array}{l}\text { Loam to Clay } \\
\text { Loam }\end{array}$ & Friable & $\begin{array}{l}\text { Crumb to } \\
\text { Subangular } \\
\text { Blocky }\end{array}$ & Weak & $\begin{array}{l}\text { roots } 5 \% \text {, rootlets } 15 \% \text {, pin holes } 15 \% \text {, worm casts } \\
5 \% \text {, snail fragments } 5 \% \text {, whole snail, } 1 \% \\
\text { (Heliodiscus) }\end{array}$ & $\begin{array}{l}\text { Gradual, } \\
\text { smooth }\end{array}$ & \\
\hline & & & $37-51$ & 10YR $5 / 3$ & Brown & Sandy Clay Loam & Friable & Angular Blocky & Moderate & $\begin{array}{l}\text { roots } 1-3 \%, \text { rootlets } 1-5 \% \text {, pin holes } 5-10 \% \text {, worm } \\
\text { casts } 1 \% \text {, snail fragments } 5 \% \text {, whole snail } 1 \% \\
\text { (Heliodiscus) }\end{array}$ & $\begin{array}{l}\text { Gradual, } \\
\text { smooth }\end{array}$ & $\begin{array}{l}\text { Lower boundaries are very } \\
\text { gradual }\end{array}$ \\
\hline & & & $51-74$ & 10YR $4 / 1-4 / 2$ & $\begin{array}{c}\text { Dark Gray to } \\
\text { Dark Grayish } \\
\text { Brown } \\
\end{array}$ & Clay Loam & Friable to Firm & Angular Blocky & $\begin{array}{l}\text { Moderate to } \\
\text { Strong }\end{array}$ & $\begin{array}{l}\text { rootlets } 5-10 \% \text {, pin holes } 5 \% \text {, worm casts } 1 \% \text {, } \\
\text { slickensides } 1-3 \mathrm{~mm}(5 \%) \text {, shrink-swell, snail } \\
\text { fragments } 1 \% \text {, whole snail } 1 \% \text { (liptooth) }\end{array}$ & $\begin{array}{l}\text { Gradual, } \\
\text { smooth }\end{array}$ & $\begin{array}{l}\text { Tertiary flakes at } 63,69 \text {, and } 50 \\
\text { cmbs, lower boundaries are very } \\
\text { gradual }\end{array}$ \\
\hline & & & $74-147$ & 10YR 5/3-6/3 & $\begin{array}{l}\text { Brown to Pale } \\
\text { Brown }\end{array}$ & Silty Clay Loam & Friable & Angular Blocky & Moderate & $\begin{array}{l}\text { rootlets } 3 \% \text {, pin holes } 5 \% \text {, worm casts } 1 \% \text {, insect } \\
\text { burrows with strat IV matrix } 3 \% \text {, white filaments ( } \\
1 \mathrm{~mm} / 3-5 \% \text { ) and increasing with depth }\end{array}$ & Unobserved & \\
\hline \multirow{5}{*}{ BHT14 } & \multirow{5}{*}{ Bastrop } & \multirow{5}{*}{30345} & $0-15$ & 10YR $4 / 2$ & $\begin{array}{l}\text { Dark Grayish } \\
\text { Brown }\end{array}$ & Loamy Clay Loam & Friable & $\begin{array}{l}\text { Subangular } \\
\text { Blocky }\end{array}$ & Moderate & $\begin{array}{l}\text { roots } 10 \% \text {, rootlets } 25 \% \text {, pin holes } 10 \% \text {, worm } \\
\text { casts } 5-10 \% \text {, snail fragments }(3 \%) \text {, decomposing } \\
\text { organics }(1 \%)\end{array}$ & $\begin{array}{l}\text { Clear, Slightly } \\
\text { Wavy }\end{array}$ & \\
\hline & & & $15-38$ & 10YR $4 / 3$ & Brown & $\begin{array}{l}\text { Loam to Clay } \\
\text { Loam }\end{array}$ & Friable & $\begin{array}{l}\text { Crumb to } \\
\text { Subangular } \\
\text { Blocky }\end{array}$ & Weak & $\begin{array}{l}\text { roots } 5 \% \text {, rootlets } 15 \% \text {, pin holes } 15 \% \text {, worm casts } \\
5 \% \text {, snail fragments } 5 \% \text {, whole snail, } 1 \% \\
\text { (Heliodiscus) }\end{array}$ & $\begin{array}{l}\text { Gradual, } \\
\text { smooth }\end{array}$ & \\
\hline & & & $38-50$ & 10YR $5 / 3$ & Brown & Sandy Clay Loam & Friable & Angular Blocky & Moderate & $\begin{array}{l}\begin{array}{l}\text { roots } 1-3 \% \text {, rootlets } 1-5 \% \text {, pin holes } 5-10 \% \text {, worm } \\
\text { casts } 1 \% \text {, snail fragments } 5 \% \text {, whole snail } 1 \% \\
\text { (Heliodiscus) }\end{array} \\
\end{array}$ & $\begin{array}{l}\text { Gradual, } \\
\text { smooth }\end{array}$ & \\
\hline & & & $50-93$ & 10YR 4/1-4/2 & $\begin{array}{c}\text { Dark Gray to } \\
\text { Dark Grayish } \\
\text { Brown } \\
\end{array}$ & Clay Loam & Friable to Firm & Angular Blocky & $\begin{array}{l}\text { Moderate to } \\
\text { Strong }\end{array}$ & $\begin{array}{l}\text { rootlets } 5-10 \% \text {, pin holes } 5 \% \text {, worm casts } 1 \% \text {, } \\
\text { slickensides } 1-3 \mathrm{~mm}(5 \%) \text {, shrink-swell, snail } \\
\text { fragments } 1 \% \text {, whole snail } 1 \% \text { (liptooth) }\end{array}$ & $\begin{array}{l}\text { Gradual, } \\
\text { smooth }\end{array}$ & \\
\hline & & & $93-140$ & 10YR $5 / 3-6 / 3$ & $\begin{array}{l}\text { Brown to Pale } \\
\text { Brown }\end{array}$ & Silty Clay Loam & Friable & Angular Blocky & Moderate & $\begin{array}{l}\text { rootlets } 3 \% \text {, pin holes } 5 \% \text {, worm casts } 1 \% \text {, insect } \\
\text { burrows with strat IV matrix } 3 \% \text {, white filaments ( } \\
1 \mathrm{~mm} / 3-5 \% \text { ) and increasing with depth }\end{array}$ & Unobserved & $\begin{array}{l}\text { Tertiary flakes at } 90 \text { and } 95 \\
\text { cmbs, secondary flake at } 97 \\
\text { cmbs, fire-cracked chert at } 96 \\
\text { and } 98 \text { cmbs }\end{array}$ \\
\hline \multirow{7}{*}{ BHT15 } & \multirow{7}{*}{ Bastrop } & \multirow{7}{*}{30345} & $0-15$ & 10YR $4 / 2$ & $\begin{array}{l}\text { Dark Grayish } \\
\text { Brown }\end{array}$ & Loamy Clay Loam & Friable & $\begin{array}{l}\text { Subangular } \\
\text { Blocky }\end{array}$ & Moderate & $\begin{array}{l}\text { roots } 10 \% \text {, rootlets } 25 \% \text {, pin holes } 10 \% \text {, worm } \\
\text { casts } 5-10 \% \text {, snail fragments }(3 \%) \text {, decomposing } \\
\text { organics }(1 \%)\end{array}$ & $\begin{array}{l}\text { Clear, Slightly } \\
\text { Wavy }\end{array}$ & \\
\hline & & & $15-28$ & 10YR $4 / 3$ & Brown & $\begin{array}{l}\text { Loam to Clay } \\
\text { Loam }\end{array}$ & Friable & $\begin{array}{l}\text { Crumb to } \\
\text { Subangular } \\
\text { Blocky }\end{array}$ & Weak & \begin{tabular}{|l|} 
roots $5 \%$, rootlets $15 \%$, pin holes $15 \%$, worm casts \\
$5 \%$, snail fragments $5 \%$, whole snail, $1 \%$ \\
(Heliodiscus)
\end{tabular} & $\begin{array}{l}\text { Gradual, } \\
\text { smooth }\end{array}$ & \\
\hline & & & $28-55$ & 10YR $5 / 3$ & Brown & Sandy Clay Loam & Friable & Angular Blocky & Moderate & $\begin{array}{l}\text { Friable, angular, medium to coarse size, moderate } \\
\text { grade, roots } 1-3 \% \text {, rootlets } 1-5 \% \text {, pin holes } 5-10 \% \text {, } \\
\text { worm casts } 1 \% \text {, snail fragments } 5 \% \text {, whole snail } \\
1 \% \text { (Heliodiscus) }\end{array}$ & Abrupt, smooth & \\
\hline & & & $55-79$ & 10YR 4/1-4/2 & $\begin{array}{c}\text { Dark Gray to } \\
\text { Dark Grayish } \\
\text { Brown } \\
\end{array}$ & Clay Loam & Friable to Firm & Angular Blocky & $\begin{array}{l}\text { Moderate to } \\
\text { Strong }\end{array}$ & $\begin{array}{l}\text { rootlets } 5-10 \% \text {, pin holes } 5 \% \text {, worm casts } 1 \% \text {, } \\
\text { slickensides } 1-3 \mathrm{~mm}(5 \%) \text {, shrink-swell, snail } \\
\text { fragments } 1 \% \text {, whole snail } 1 \% \text { (liptooth) }\end{array}$ & Clear, smooth & \\
\hline & & & $79-121$ & 10YR 5/3-6/3 & $\begin{array}{l}\text { Brown to Pale } \\
\text { Brown }\end{array}$ & Silty Clay Loam & Friable & Angular Blocky & Moderate & $\begin{array}{l}\text { rootlets } 3 \% \text {, pin holes } 5 \% \text {, worm casts } 1 \% \text {, insect } \\
\text { burrows with strat IV matrix } 3 \% \text {, white filaments ( } \\
1 \mathrm{~mm} / 3-5 \% \text { ) and increasing with depth }\end{array}$ & Clear, smooth & \\
\hline & & & $121-210$ & 10YR $3 / 1$ & Very Dark Gray & Loamy Clay & Firm & $\begin{array}{c}\text { Angular Blocky } \\
\text { to Massive }\end{array}$ & Moderate & $\begin{array}{l}\text { rootlets } 2 \% \text {, pin holes } 1 \% \text {, worm casts } 2 \% \text {, white } \\
\text { nodules }(5-10 \mathrm{~mm}) 10 \%\end{array}$ & Abrupt, smooth & \\
\hline & & & $210-330$ & 10YR $5 / 3$ & Brown & Silty Clay Loam & Friable & Prismatic & Moderate & \begin{tabular}{|l} 
rootlets $1 \%$, slickensides $2-3 \mathrm{~cm}(2 \%)$, white \\
nodules $(5-15 \mathrm{~mm} / 10-15 \%)$, snail fragments $1 \%$, \\
iron pebbles $(2-4 \mathrm{~mm})<1 \%$
\end{tabular} & Unobserved & \\
\hline
\end{tabular}




\begin{tabular}{|c|c|c|c|c|c|c|c|c|c|c|c|c|}
\hline BHT & County & Parcel & Depth (cmbs) & Munsell* & Soil Color* & Soil Texture & Consistency & Structure Type & Grade & Inclusions & $\begin{array}{c}\text { Lower } \\
\text { Boundary } \\
\end{array}$ & Comment \\
\hline \multirow{7}{*}{ A } & \multirow{7}{*}{ Bastrop } & \multirow{7}{*}{30365} & $0-17$ & 10YR5/3 & Brown & Sandy Loam & $\begin{array}{l}\text { Loose to } \\
\text { Friable }\end{array}$ & $\begin{array}{l}\text { Crumbly to } \\
\text { Subangular } \\
\text { Blocky }\end{array}$ & Weak & $\begin{array}{c}\text { roots and rootlets } 30 \% \text {, pin hole burrows } 15-20 \%, \\
\text { worms } 10 \%\end{array}$ & \begin{tabular}{|c|} 
Clear and \\
Slightly Wavy \\
\end{tabular} & No cultural material \\
\hline & & & $17-49$ & 10YR4/2 & $\begin{array}{l}\text { Dark Grayish } \\
\text { Brown }\end{array}$ & $\begin{array}{l}\text { Sandy Loam to } \\
\text { Clay Loam }\end{array}$ & Friable & $\begin{array}{c}\text { Subangular } \\
\text { Blocky }\end{array}$ & Weak & \begin{tabular}{|c|} 
roots $3-5 \%$, rootlets $20 \%$, snail fragments $5 \%$, pin \\
hole burrows $15 \%$, worms $5 \%$
\end{tabular} & $\begin{array}{c}\text { Gradual and } \\
\text { Smooth }\end{array}$ & $\begin{array}{l}\text { Slight mottling with Strat I } \\
\text { matrix, no cultural material }\end{array}$ \\
\hline & & & $49-113$ & $\begin{array}{l}10 \mathrm{YR} 4 / 2 \text { to } \\
10 \mathrm{YR} 3 / 2\end{array}$ & \begin{tabular}{|c|} 
Dark Grayish \\
Brown to Brown
\end{tabular} & $\begin{array}{l}\text { Sandy Loam to } \\
\text { Clay Loam }\end{array}$ & Friable & $\begin{array}{l}\text { Subangular } \\
\text { Blocky }\end{array}$ & $\begin{array}{l}\text { Weak to } \\
\text { Moderate }\end{array}$ & \begin{tabular}{|c|}
$\begin{array}{c}\text { rootlets } 10 \%, \text { pin hole burrows } 10 \% \text {, worms } 3-5 \%, \\
\text { subtle slickensides } 10 \%(1-2 \mathrm{~mm}) \text {, snail fragments } \\
2-5 \%\end{array}$ \\
\end{tabular} & $\begin{array}{l}\text { Gradual and } \\
\text { Smooth }\end{array}$ & No cultural material \\
\hline & & & $133-229$ & $\begin{array}{l}10 Y R 3 / 2 \text { to } \\
10 Y R 3 / 3\end{array}$ & \begin{tabular}{|c|} 
Brown to Dark \\
Brown
\end{tabular} & Clay Loam to Clay & Friable to Firm & \begin{tabular}{|c|} 
Subangular \\
Blocky to \\
Angular Blocky
\end{tabular} & Moderate & $\begin{array}{c}\text { rootlets } 5 \% \text {, pin hole burrows } 2-5 \% \text {, white nodules } \\
\text { of possible } \mathrm{CaC} 033 \%(5-15 \mathrm{~mm}) \text { and increasing } \\
\text { with depth }\end{array}$ & $\begin{array}{l}\text { Clear and } \\
\text { Smooth }\end{array}$ & $\begin{array}{l}\text { Observed from surface below } \\
153 \mathrm{cmbs} \text {, no cultural material }\end{array}$ \\
\hline & & & $229-271$ & $\begin{array}{l}\text { 10YR5/6 to } \\
\text { 10YR6/6 }\end{array}$ & $\begin{array}{c}\text { Yellowish Brown } \\
\text { to Brownish } \\
\text { Yellow }\end{array}$ & Clay Loam to Clay & Firm & Angular Blocky & Moderate & $\begin{array}{l}\text { white nodules } 15 \%(5-20 \mathrm{~mm}) \text {, manganese } 2 \% \\
\qquad(1 \mathrm{~mm})\end{array}$ & $\begin{array}{l}\text { Gradual to } \\
\text { Diffuse and } \\
\text { Smooth }\end{array}$ & No cultural material \\
\hline & & & $271-300$ & 10YR5/8 & Yellowish Brown & Clay Loam & Firm & Angular Blocky & Moderate & $\begin{array}{l}\text { white nodules } 15 \% \text { (5-20mm), manganese } 2 \% \\
\qquad(1 \mathrm{~mm})\end{array}$ & Unobserved & $\begin{array}{c}\begin{array}{c}\text { Increased sand and moisture, } \\
\text { water seeping from wall, no } \\
\text { cultural material }\end{array} \\
\end{array}$ \\
\hline & & & 300-334 & $\begin{array}{c}7.5 Y R 5 / 6 \text { to } \\
7.5 Y R 5 / 8\end{array}$ & Strong Brown & Clay Loam & Firm & Angular Blocky & Moderate & $\begin{array}{c}\text { white nodules } 3-5 \%(20-30 \mathrm{~mm}) \text {, snail fragments } \\
3 \%\end{array}$ & Unobserved & No cultural material \\
\hline \multirow{7}{*}{ B } & \multirow{7}{*}{ Bastrop } & \multirow{7}{*}{30365} & $0-17$ & 10YR5/3 & Brown & Sandy Loam & $\begin{array}{l}\text { Loose to } \\
\text { Friable }\end{array}$ & $\begin{array}{c}\text { Crumbly to } \\
\text { Subangular } \\
\text { Blocky }\end{array}$ & Weak & \begin{tabular}{|c|} 
rootlets $25-30 \%$, roots $10 \%$, pin hole burrows $10 \%$, \\
worm casts $5-6 \%$
\end{tabular} & $\begin{array}{c}\text { Clear and } \\
\text { Slightly Wavy }\end{array}$ & No cultural material \\
\hline & & & $17-49$ & 10YR4/2 & $\begin{array}{l}\text { Dark Grayish } \\
\text { Brown }\end{array}$ & $\begin{array}{l}\text { Sandy Loam to } \\
\text { Clay Loam }\end{array}$ & Friable & $\begin{array}{c}\text { Subangular } \\
\text { Blocky }\end{array}$ & Weak & $\begin{array}{c}\text { rootlets } 30 \% \text {, pin hole burrows } 15-20 \% \text {, worm casts } \\
5-10 \% \text {, snail shell fragments }<1 \%\end{array}$ & $\begin{array}{c}\text { Gradual and } \\
\text { Smooth }\end{array}$ & $\begin{array}{l}\text { Slight mottling with Strat I } \\
\text { matrix, no cultural material }\end{array}$ \\
\hline & & & $49-96$ & $\begin{array}{c}10 Y R 4 / 2 \text { to } \\
10 Y R 3 / 2\end{array}$ & \begin{tabular}{|c|} 
Dark Grayish \\
Brown to Brown
\end{tabular} & $\begin{array}{l}\text { Sandy Loam to } \\
\text { Clay Loam }\end{array}$ & Friable & $\begin{array}{l}\text { Subangular } \\
\text { Blocky }\end{array}$ & $\begin{array}{l}\text { Weak to } \\
\text { Moderate }\end{array}$ & \begin{tabular}{|c|}
$\begin{array}{c}\text { rootlets } 15 \% \text {, pin hole burrows } 10-15 \% \text {, worm casts } \\
5 \% \text {, subtle slickensides } 10 \%(5-15 \mathrm{~mm}) \text {, snail shell } \\
\text { fragments } 1 \%\end{array}$ \\
\end{tabular} & $\begin{array}{l}\text { Gradual and } \\
\text { Smooth }\end{array}$ & No cultural material \\
\hline & & & $96-214$ & $\begin{array}{l}10 \mathrm{YR} 3 / 2 \text { to } \\
10 \mathrm{YR} 3 / 3\end{array}$ & $\begin{array}{l}\text { Brown to Dark } \\
\text { Brown }\end{array}$ & Clay Loam to Clay & Friable to Firm & \begin{tabular}{|c|} 
Subangular \\
Blocky to \\
Angular Blocky
\end{tabular} & Moderate & $\begin{array}{l}\text { white nodules } 5-10 \%(10-15 \mathrm{~mm}) \text { and increasing } \\
\text { with depth, rootlets } 3 \% \text {, pin hole burrows } 5 \% \text {, } \\
\text { slickensides } 15 \%(20-30 \mathrm{~mm})\end{array}$ & $\begin{array}{l}\text { Clear and } \\
\text { Smooth }\end{array}$ & $\begin{array}{l}\text { Observed from surface below } \\
141 \mathrm{cmbs} \text {, no cultural material }\end{array}$ \\
\hline & & & $214-273$ & $\begin{array}{l}\text { 10YR5/6 to } \\
\text { 10YR6/6 }\end{array}$ & $\begin{array}{c}\text { Yellowish Brown } \\
\text { to Brownish } \\
\text { Yellow }\end{array}$ & Clay Loam to Clay & Firm & Angular Blocky & Moderate & $\begin{array}{l}\text { white nodules } 15 \%(5-20 \mathrm{~mm}) \text {, manganese } 2 \% \\
\qquad(1 \mathrm{~mm})\end{array}$ & $\begin{array}{l}\text { Gradual to } \\
\text { Diffuse and } \\
\text { Smooth }\end{array}$ & No cultural material \\
\hline & & & $273-321$ & 10YR5/8 & Yellowish Brown & Clay Loam & Firm & Angular Blocky & Moderate & $\begin{array}{c}\text { white nodules } 10-20 \%(30-40 \mathrm{~mm}) \text {, manganese } 2 \% \\
(1 \mathrm{~mm})\end{array}$ & Unobserved & $\begin{array}{c}\begin{array}{c}\text { Increased sand and moisture, } \\
\text { water seeping from wall, no } \\
\text { cultural material }\end{array} \\
\end{array}$ \\
\hline & & & $321-332$ & $\begin{array}{c}7.5 Y R 5 / 6 \text { to } \\
7.5 Y R 5 / 8 \\
\end{array}$ & Strong Brown & Clay Loam & Firm & Angular Blocky & Moderate & $\begin{array}{c}\text { white nodules } 3-5 \%(20-30 \mathrm{~mm}) \text {, snail fragments } \\
3 \%\end{array}$ & Unobserved & No cultural material \\
\hline \multirow{5}{*}{ c } & \multirow{5}{*}{ Bastrop } & \multirow{5}{*}{30365} & 0-19 & $\begin{array}{c}10 Y R 4 / 2 \\
\text { to10YR4/3 }\end{array}$ & $\begin{array}{c}\text { Dark Grayish } \\
\text { Brown to Brown }\end{array}$ & Sandy Loam & Friable & $\begin{array}{c}\text { Crumbly to } \\
\text { Subangular } \\
\text { Blocky }\end{array}$ & Weak & \begin{tabular}{|c|} 
roots $5 \%$, rootlets $30 \%$, pin hole burrows $10-15 \%$, \\
worms $5 \%$
\end{tabular} & $\begin{array}{c}\text { Clear and } \\
\text { Slightly Wavy }\end{array}$ & No cultural material \\
\hline & & & $19-96$ & $\begin{array}{c}\text { 10YR3/2 to } \\
\text { 10YR2/2 }\end{array}$ & $\begin{array}{c}\text { Brown to Very } \\
\text { Dark Brown }\end{array}$ & Sandy Loam & Friable & $\begin{array}{c}\text { Subangular } \\
\text { Blocky }\end{array}$ & Moderate & $\begin{array}{c}\text { rootlets } 20 \% \text {, pin hole burrows } 20 \% \text {, worms } 5 \% \text {, } \\
\text { mottling due to insect burrows } 3 \%\end{array}$ & $\begin{array}{c}\text { Gradual and } \\
\text { Smooth }\end{array}$ & $\begin{array}{l}\text { Slight mottling with Strat I } \\
\text { matrix, no cultural material }\end{array}$ \\
\hline & & & $96-226$ & $\begin{array}{l}\text { 10YR } 4 / 3 \text { to } \\
10 Y R 4 / 4\end{array}$ & \begin{tabular}{|c|} 
Brown to Dark \\
Yellowish Brown
\end{tabular} & Clay Loam to Clay & Firm & Angular Blocky & Moderate & $\begin{array}{l}\text { rootlets } 3-5 \% \text {, white filaments and small nodules } \\
\qquad 1 \%(1 \mathrm{~mm})\end{array}$ & $\begin{array}{l}\text { Clear and } \\
\text { Smooth }\end{array}$ & $\begin{array}{l}\text { Observed from surface below } \\
148 \mathrm{cmbs} \text {, no cultural material }\end{array}$ \\
\hline & & & $226-300$ & $\begin{array}{l}10 \mathrm{YR} 3 / 2 \text { to } \\
10 \mathrm{YR} 3 / 3\end{array}$ & $\begin{array}{l}\text { Brown to Dark } \\
\text { Brown }\end{array}$ & Clay Loam to Clay & Friable to Firm & \begin{tabular}{|c|} 
Subangular \\
Blocky to \\
Angular Blocky
\end{tabular} & Moderate & $\begin{array}{l}\text { white nodules } 5-10 \%(10-15 \mathrm{~mm}) \text { and increasing } \\
\text { with depth, rootlets } 3 \% \text {, pin hole burrows } 5 \% \text {, } \\
\text { slickensides } 15 \%(20-30 \mathrm{~mm})\end{array}$ & $\begin{array}{l}\text { Clear and } \\
\text { Smooth }\end{array}$ & No cultural material \\
\hline & & & $300-326$ & $\begin{array}{l}10 Y R 5 / 6 \text { to } \\
10 Y R 6 / 6\end{array}$ & $\begin{array}{c}\text { Yellowish Brown } \\
\text { to Brownish } \\
\text { Yellow }\end{array}$ & Clay Loam to Clay & Firm & Angular Blocky & Moderate & $\begin{array}{l}\text { white nodules } 15 \%(5-20 \mathrm{~mm}) \text {, manganese } 2 \% \\
\qquad(1 \mathrm{~mm})\end{array}$ & $\begin{array}{l}\text { Gradual to } \\
\text { Diffuse and } \\
\text { Smooth }\end{array}$ & No cultural material \\
\hline \multirow{5}{*}{ D } & \multirow{5}{*}{ Bastrop } & \multirow{5}{*}{30365} & $0-23$ & $\begin{array}{c}10 Y R 4 / 2 \\
\text { to10YR } 4 / 3\end{array}$ & $\begin{array}{c}\text { Dark Grayish } \\
\text { Brown to Brown } \\
\end{array}$ & Sandy Loam & $\begin{array}{l}\text { Loose to } \\
\text { Friable }\end{array}$ & $\begin{array}{c}\text { Crumbly to } \\
\text { Subangular } \\
\text { Blocky }\end{array}$ & Weak & $\begin{array}{c}\text { roots } 5 \% \text {, rootlets } 30 \% \text {, pin hole burrows } 10-15 \%, \\
\text { worms } 5 \%\end{array}$ & $\begin{array}{c}\text { Clear and } \\
\text { Slightly Wavy }\end{array}$ & No cultural material \\
\hline & & & $23-61$ & $\begin{array}{c}10 Y R 3 / 2 \text { to } \\
10 Y R 2 / 2 \\
\end{array}$ & $\begin{array}{c}\text { Brown to Very } \\
\text { Dark Brown }\end{array}$ & Sandy Loam & Friable & $\begin{array}{c}\begin{array}{c}\text { Subangular } \\
\text { Blocky }\end{array} \\
\end{array}$ & Moderate & $\begin{array}{c}\text { rootlets } 20 \% \text {, pin hole burrows } 20 \% \text {, worms } 5 \% \text {, } \\
\text { mottling due to insect burrows } 3 \%\end{array}$ & $\begin{array}{c}\begin{array}{c}\text { Gradual and } \\
\text { Smooth }\end{array} \\
\end{array}$ & $\begin{array}{l}\text { Slight mottling with Strat I } \\
\text { matrix, no cultural material }\end{array}$ \\
\hline & & & $61-218$ & $\begin{array}{l}10 Y R 4 / 3 \text { to } \\
10 Y R 4 / 4\end{array}$ & \begin{tabular}{|c|} 
Brown to Dark \\
Yellowish Brown
\end{tabular} & $\begin{array}{l}\text { Sandy Loam to } \\
\text { Clay Loam }\end{array}$ & Friable & \begin{tabular}{|c|} 
Subangular \\
Blocky to \\
Angular Blocky
\end{tabular} & Moderate & $\begin{array}{c}\text { two subrounded gravel (one located at top of level } \\
\text { and one in the middle) }\end{array}$ & $\begin{array}{l}\text { Clear and } \\
\text { Smooth }\end{array}$ & $\begin{array}{l}\text { Horizon is less dense than } \\
\text { previously, observed from } \\
\text { surface from } 148 \mathrm{cmbs}\end{array}$ \\
\hline & & & 218-294 & $\begin{array}{l}10 Y R 4 / 3 \text { to } \\
10 Y R 3 / 3\end{array}$ & \begin{tabular}{|c|} 
Brown to Dark \\
Brown
\end{tabular} & Clay Loam & Firm & Angular Blocky & Moderate & $\begin{array}{c}\text { rootlets } 3 \% \text {, prominent slickensides }(10 \mathrm{~cm}), \mathrm{CaCO} \\
\text { filaments } 10 \% \text { and nodules } 5 \%(.5-1 \mathrm{~mm})\end{array}$ & $\begin{array}{l}\text { Clear and } \\
\text { Smooth }\end{array}$ & No cultural material \\
\hline & & & $294-304$ & $\begin{array}{l}7.5 Y R 5 / 4 \text { to } \\
7.5 Y R 5 / 6\end{array}$ & \begin{tabular}{|c|} 
Brown to Strong \\
Brown
\end{tabular} & Clay Loam & Firm & Angular Blocky & Moderate & white nodules $5 \%(20-30 \mathrm{~mm})$ & $\begin{array}{l}\text { Gradual to } \\
\text { Diffuse and } \\
\text { Smooth }\end{array}$ & No cultural material \\
\hline \multirow{5}{*}{$\mathrm{E}$} & \multirow{5}{*}{ Bastrop } & \multirow{5}{*}{30365} & $0-18$ & $\begin{array}{c}10 Y R 4 / 2 \\
\text { to } 10 Y R 4 / 3\end{array}$ & \begin{tabular}{|c|} 
Dark Grayish \\
Brown to Brown
\end{tabular} & Sandy Loam & $\begin{array}{l}\text { Loose to } \\
\text { Friable }\end{array}$ & $\begin{array}{c}\text { Crumbly to } \\
\text { Subangular } \\
\text { Blocky }\end{array}$ & Weak & $\begin{array}{c}\text { roots } 10 \% \text {, rootlets } 15-20 \% \text {, pin hole burrows } 10 \%, \\
\text { worm casts } 5 \%\end{array}$ & $\begin{array}{c}\text { Clear and } \\
\text { Slightly Wavy }\end{array}$ & No cultural material \\
\hline & & & $18-98$ & $\begin{array}{l}10 Y R 3 / 2 \text { to } \\
10 Y R 2 / 2\end{array}$ & $\begin{array}{l}\text { Brown to Very } \\
\text { Dark Brown }\end{array}$ & Sandy Loam & Friable & $\begin{array}{l}\text { Subangular } \\
\text { Blocky }\end{array}$ & Moderate & $\begin{array}{l}\text { rootlets } 15-20 \% \text {, pin hole burrows } 15 \% \text {, worm } 5 \text { - } \\
10 \% \text {, mottling due to insect burrows with strat I } \\
\text { matrix } 3-4 \%\end{array}$ & $\begin{array}{c}\text { Gradual and } \\
\text { Smooth }\end{array}$ & $\begin{array}{l}\text { Slight mottling with Strat I } \\
\text { matrix, no cultural material, } \\
\text { transitional horizon at } 73 \mathrm{cmbs}\end{array}$ \\
\hline & & & 98-263 & $\begin{array}{l}10 Y R 4 / 3 \text { to } \\
10 Y R 4 / 4\end{array}$ & \begin{tabular}{|c|} 
Brown to Dark \\
Yellowish Brown
\end{tabular} & $\begin{array}{l}\text { Sandy Loam to } \\
\text { Clay Loam }\end{array}$ & Friable & \begin{tabular}{|c|} 
Subangular \\
Blocky to \\
Angular Blocky
\end{tabular} & Moderate & $\begin{array}{l}\text { rootlets } 2 \% \text {, pin hole burrows }<1 \% \text {, subrounded } \\
\text { gravel }<1 \% \text { at top of horizon, no white filaments }\end{array}$ & $\begin{array}{c}\text { Gradual and } \\
\text { Smooth }\end{array}$ & $\begin{array}{l}\text { Horizon is less dense than } \\
\text { previously, observed from } \\
\text { surface from } 144 \mathrm{cmbs}\end{array}$ \\
\hline & & & 263-294 & $\begin{array}{l}10 \mathrm{YR} 6 / 4 \text { to } \\
10 \mathrm{YR} 6 / 6\end{array}$ & $\begin{array}{l}\text { Light Yellowish } \\
\text { Brown and } \\
\text { Brownish Yellow }\end{array}$ & Clay Loam to Clay & Friable to Firm & Angular Blocky & $\begin{array}{l}\text { Moderate to } \\
\text { Prismatic }\end{array}$ & Prominent slickensides $(10 \mathrm{~cm})$ & $\begin{array}{l}\text { Gradual and } \\
\text { Smooth }\end{array}$ & No cultural material \\
\hline & & & $294-301$ & $\begin{array}{l}\text { 10YR6/4 to } \\
\text { 10YR6/6 }\end{array}$ & \begin{tabular}{|} 
Light Yellowish \\
Brown and \\
Brownish Yellow
\end{tabular} & Clay Loam to Clay & Firm & Angular Blocky & Moderate & $\begin{array}{c}\text { Prominent slickensides }(10 \mathrm{~cm}), \text { CaC03 } 10 \%(1 \mathrm{~cm}) \\
\text { and } 5 \%(2-3 \mathrm{~cm})\end{array}$ & Unobserved & No cultural material \\
\hline
\end{tabular}




\begin{tabular}{|c|c|c|c|c|c|c|c|c|c|c|c|c|}
\hline BHT & County & Parcel & $\mid$ Depth (cmbs) $\mid$ & Munsell* & Soil Color* & Soil Texture & Consistency & Structure Type & Grade & Inclusions & $\begin{array}{c}\text { Lower } \\
\text { Boundary }\end{array}$ & Comment \\
\hline \multirow{5}{*}{$\mathrm{F}$} & \multirow{5}{*}{ Bastrop } & \multirow{5}{*}{30365} & $0-11$ & $\begin{array}{c}10 Y R 4 / 2 \\
\text { to } 10 Y R 4 / 3\end{array}$ & $\begin{array}{c}\text { Dark Grayish } \\
\text { Brown to Brown }\end{array}$ & Sandy Loam & Friable & $\begin{array}{c}\text { Crumbly to } \\
\text { Subangular } \\
\text { Blocky }\end{array}$ & Weak & $\begin{array}{c}\text { rootlets } 25 \% \text {, roots } 5-10 \% \text {, pin hole burrows } 5-10 \% \\
\text { worm casts } 5 \%\end{array}$ & \begin{tabular}{|c|} 
Clear and \\
Slightly Wavy
\end{tabular} & No cultural material \\
\hline & & & $11-48$ & $\begin{array}{l}10 \mathrm{YR} 3 / 2 \text { to } \\
10 \mathrm{YR} 2 / 2\end{array}$ & $\begin{array}{l}\text { Brown to Very } \\
\text { Dark Brown }\end{array}$ & Sandy Loam & Friable & $\begin{array}{l}\text { Subangular } \\
\text { Blocky }\end{array}$ & Moderate & $\begin{array}{l}\text { rootlets } 10 \% \text {, pin hole burrows } 15 \% \text {, worm casts } \\
\qquad 10 \%\end{array}$ & $\begin{array}{c}\text { Gradual and } \\
\text { Smooth }\end{array}$ & $\begin{array}{l}\text { Slight mottling with Strat I } \\
\text { matrix, no cultural material, } \\
\text { transitional horizon at } 73 \mathrm{cmbs}\end{array}$ \\
\hline & & & 48-134 & $\begin{array}{l}\text { 10YR6/4 to } \\
\text { 10YR6/6 }\end{array}$ & $\begin{array}{l}\text { Light Yellowish } \\
\text { Brown and } \\
\text { Brownish Yellow }\end{array}$ & Clay Loam to Clay & Firm & \begin{tabular}{|c|} 
Subangular \\
Blocky to \\
Angular Blocky
\end{tabular} & Moderate & cracks infilled with strat II $2-5 \%$, rootlets $5 \%$ & $\begin{array}{l}\text { Gradual and } \\
\text { Smooth }\end{array}$ & $\begin{array}{l}\text { Horizon is less dense than } \\
\text { previously, no cultural material }\end{array}$ \\
\hline & & & $134-205$ & $\begin{array}{l}\text { 10YR6/4 to } \\
\text { 10YR6/6 }\end{array}$ & $\begin{array}{l}\text { Light Yellowish } \\
\text { Brown and } \\
\text { Brownish Yellow }\end{array}$ & Clay Loam to Clay & Friable to Firm & Angular Blocky & $\begin{array}{l}\text { Moderate to } \\
\text { Prismatic }\end{array}$ & Prominent slickensides $(10 \mathrm{~cm})$ & $\begin{array}{l}\text { Gradual and } \\
\text { Smooth }\end{array}$ & $\begin{array}{c}\text { More friable than strat III due to } \\
\text { moisture, observed from surface } \\
\text { from } 145 \mathrm{cmbs} \text {, no cultural } \\
\text { material }\end{array}$ \\
\hline & & & 205-301 & $\begin{array}{l}\text { 10YR6/4 to } \\
\text { 10YR6/6 }\end{array}$ & $\begin{array}{l}\text { Light Yellowish } \\
\text { Brown and } \\
\text { Brownish Yellow }\end{array}$ & Clay Loam to Clay & Firm & Angular Blocky & Moderate & CaC03 nodules $5-10 \%(2-3 \mathrm{~cm})$ & Unobserved & No cultural material \\
\hline \multirow{3}{*}{ G } & \multirow{3}{*}{ Bastrop } & \multirow{3}{*}{30365} & $0-12$ & $\begin{array}{c}10 Y R 4 / 2 \\
\text { to10YR3/2 }\end{array}$ & $\begin{array}{c}\text { Dark Grayish } \\
\text { Brown to Brown }\end{array}$ & Sandy Loam & $\begin{array}{l}\text { Loose to } \\
\text { Friable }\end{array}$ & $\begin{array}{c}\text { Crumbly to } \\
\text { Subangular } \\
\text { Blocky }\end{array}$ & Weak & $\begin{array}{l}\text { roots } 5 \% \text {, rootlets } 20 \% \text {, pin hole burrows } 5 \% \text {, worm } \\
\text { casts } 5 \%\end{array}$ & $\begin{array}{c}\text { Clear and } \\
\text { Slightly Wavy }\end{array}$ & No cultural material \\
\hline & & & $12-66$ & 10YR $4 / 2$ & $\begin{array}{l}\text { Dark Grayish } \\
\text { Brown }\end{array}$ & Sandy Loam & Friable & $\begin{array}{l}\text { Subangular } \\
\text { Blocky }\end{array}$ & Moderate & $\begin{array}{l}\text { rootlets } 10 \% \text {, pin hole burrows } 15-20 \% \text {, worm casts } \\
5-10 \%\end{array}$ & $\begin{array}{l}\text { Gradual to } \\
\text { Diffuse and } \\
\text { Smooth }\end{array}$ & $\begin{array}{c}\text { No cultural material, transitional } \\
\text { horizon at } 44 \mathrm{cmbs}\end{array}$ \\
\hline & & & $66-124$ & $\begin{array}{c}10 \mathrm{YR} 6 / 3 \text { to } \\
10 \mathrm{YR} 6 / 4\end{array}$ & $\begin{array}{c}\text { Pale Brown to } \\
\text { Light Yellowish } \\
\text { Brown }\end{array}$ & Sandy Clay Loam & Extra Firm & Angular Blocky & Moderate & $\begin{array}{c}\text { rootlets } 3-5 \% \text {, white nodules } 20 \%(.5-15 \mathrm{~mm}) \text { and } \\
\text { increasing with depth }\end{array}$ & Unobserved & $\begin{array}{l}\text { Horizon is less dense than } \\
\text { previously, no cultural material }\end{array}$ \\
\hline \multirow{3}{*}{$\mathrm{H}$} & \multirow{3}{*}{ Bastrop } & \multirow{3}{*}{30365} & $0-13$ & $\begin{array}{c}10 Y R 4 / 2 \\
\text { to10YR3/2 }\end{array}$ & $\begin{array}{c}\text { Dark Grayish } \\
\text { Brown to Brown }\end{array}$ & Sandy Loam & $\begin{array}{l}\text { Loose to } \\
\text { Friable }\end{array}$ & $\begin{array}{c}\text { Crumbly to } \\
\text { Subangular } \\
\text { Blocky }\end{array}$ & Weak & $\begin{array}{c}\text { roots } 5 \% \text {, rootlets } 25 \% \text {, pin hole burrow } 10 \% \text {, worm } \\
\text { casts } 10 \%\end{array}$ & $\begin{array}{c}\text { Clear and } \\
\text { Slightly Wavy }\end{array}$ & No cultural material \\
\hline & & & $13-85$ & 10YR $4 / 2$ & $\begin{array}{l}\text { Dark Grayish } \\
\text { Brown }\end{array}$ & Sandy Loam & Friable & $\begin{array}{l}\text { Subangular } \\
\text { Blocky }\end{array}$ & Moderate & $\begin{array}{c}\text { rootlets } 10 \% \text {, pin hole burrows } 15-20 \% \text {, worm casts } \\
5-10 \%\end{array}$ & $\begin{array}{l}\text { Gradual and } \\
\text { Smooth }\end{array}$ & $\begin{array}{l}\text { No cultural material, transitional } \\
\text { horizon at } 55 \mathrm{cmbs}\end{array}$ \\
\hline & & & $85-146$ & $\begin{array}{c}\text { 10YR6/3 to } \\
\text { 10YR6/4 }\end{array}$ & $\begin{array}{c}\text { Pale Brown to } \\
\text { Light Yellowish } \\
\text { Brown }\end{array}$ & Sandy Clay Loam & Very Dense & Angular Blocky & Moderate & White nodules $10-15 \%(10-30 \mathrm{~cm})$ and increasing & Unobserved & $\begin{array}{l}\text { Almost massive, no cultural } \\
\text { material }\end{array}$ \\
\hline \multirow{4}{*}{1} & \multirow{4}{*}{ Bastrop } & \multirow{4}{*}{30365} & $0-13$ & $\begin{array}{l}\text { 10YR2/1 to } \\
\text { 10YR2/2 }\end{array}$ & $\begin{array}{l}\text { Black to Very } \\
\text { Dark Brown }\end{array}$ & Clay Loam & Friable & $\begin{array}{c}\text { Subangular } \\
\text { Block }\end{array}$ & Weak & $\begin{array}{c}\text { roots } 5 \% \text {, rootlets } 35 \% \text {, pin hole burrows } 15 \% \text {, } \\
\text { worm cases } 5 \% \text {, no slickensides }\end{array}$ & $\begin{array}{c}\begin{array}{c}\text { Gradual and } \\
\text { Smooth }\end{array} \\
\end{array}$ & No cultural material \\
\hline & & & $13-69$ & 10YR2/2 & Very Dark Brown & Clay Loam to Clay & $\begin{array}{l}\text { Firm to Extra } \\
\text { Firm }\end{array}$ & Angular Blocky & Moderate & $\begin{array}{l}\text { rootlets } 15 \% \text {, pin hole burrows } 5 \% \text {, worm casts } \\
<5 \%\end{array}$ & $\begin{array}{l}\text { Gradual and } \\
\text { Smooth }\end{array}$ & $\begin{array}{c}\text { Approaching massive with } \\
\text { vertical cracking, no cultural } \\
\text { material }\end{array}$ \\
\hline & & & 69-211 & 10YR2/2 & Very Dark Brown & Clay Loam to Clay & Extra Firm & Angular Blocky & Moderate & $\begin{array}{c}\text { pin hole burrows } 5 \% \text {, no worms, white nodules } 10 \% \\
(.5-3 \mathrm{~mm}) \text { increasing with depth }\end{array}$ & $\begin{array}{l}\text { Gradual and } \\
\text { Smooth }\end{array}$ & $\begin{array}{c}\text { Approaching massive with } \\
\text { vertical cracking, no cultural } \\
\text { material }\end{array}$ \\
\hline & & & $211-293$ & $\begin{array}{c}\text { 10YR5/4 to } \\
\text { 10YR5/6 }\end{array}$ & Yellowish Brown & Clay Loam to Clay & Extra Firm & Angular Blocky & Moderate & $\begin{array}{l}\text { white nodules } 20-25 \%(1-3 \mathrm{~cm}) \text { increasing with } \\
\text { depth, structure approaching massive }\end{array}$ & Unobserved & No cultural material \\
\hline \multirow{4}{*}{ J } & \multirow{4}{*}{ Bastrop } & \multirow{4}{*}{30365} & $0-13$ & $\begin{array}{l}\text { 10YR2/1 to } \\
10 Y R 2 / 2\end{array}$ & $\begin{array}{l}\text { Black to Very } \\
\text { Dark Brown }\end{array}$ & Clay Loam & Friable & $\begin{array}{l}\text { Subangular } \\
\text { Block }\end{array}$ & Weak & roots $20 \%$, rootlets $20 \%$ & $\begin{array}{c}\text { Gradual and } \\
\text { Smooth }\end{array}$ & No cultural material \\
\hline & & & $13-87$ & 10YR2/2 & Very Dark Brown & Clay Loam to Clay & $\begin{array}{c}\text { Firm to Extra } \\
\text { Firm }\end{array}$ & Angular Blocky & Moderate & roots $10 \%$, rootlets $15 \%$, prominent slickensides & $\begin{array}{l}\text { Gradual and } \\
\text { Smooth }\end{array}$ & $\begin{array}{l}\text { Approaching massive with } \\
\text { vertical cracking, no cultural } \\
\text { material }\end{array}$ \\
\hline & & & 87-170 & 10YR $2 / 2$ & Very Dark Brown & Clay Loam to Clay & Extra Firm & Angular Blocky & Moderate & rootlets $5 \%$, white nodules $5-10 \%(1-10 \mathrm{~mm})$ & $\begin{array}{l}\text { Gradual and } \\
\text { Smooth }\end{array}$ & $\begin{array}{c}\text { Approaching massive with } \\
\text { vertical cracking, observed } \\
\text { visually from } 122 \mathrm{cmbs}, \text { no } \\
\text { cultural material } \\
\end{array}$ \\
\hline & & & $170-231$ & $\begin{array}{l}\text { 10YR5/4 to } \\
\text { 10YR5/6 }\end{array}$ & Yellowish Brown & Clay Loam to Clay & Extra Firm & Angular Blocky & Moderate & infilled cracks with strat III matrix & Unobserved & No cultural material \\
\hline \multirow{5}{*}{ A } & \multirow{5}{*}{ Guadalupe } & \multirow{5}{*}{50330} & $0-25$ & 10YR $4 / 2$ & $\begin{array}{l}\text { Dark Grayish } \\
\text { Brown }\end{array}$ & Loam & $\begin{array}{l}\text { Loose to } \\
\text { Friable }\end{array}$ & $\begin{array}{l}\text { Crumbly to } \\
\text { Subangular } \\
\text { Blocky }\end{array}$ & Weak & $\begin{array}{l}\text { roots } 10 \% \text {, rootlets } 15-20 \% \text {, snail fragments } 5- \\
10 \% \text {, pin hole burrows } 10 \% \text {, worm casts } 3-5 \%\end{array}$ & $\begin{array}{l}\text { Gradual and } \\
\text { Smooth }\end{array}$ & $\begin{array}{c}\text { Root zone } 7 \mathrm{~cm} \text { thick, no cultural } \\
\text { material }\end{array}$ \\
\hline & & & $25-55$ & $\begin{array}{l}\text { 10YR } 4 / 2 \text { to } \\
10 Y R 4 / 4\end{array}$ & $\begin{array}{c}\text { Dark Grayish } \\
\text { Brown to Dark } \\
\text { Yellowish Brown }\end{array}$ & Sandy Loam & Friable & $\begin{array}{l}\text { Crumbly to } \\
\text { Subangular } \\
\text { Blocky }\end{array}$ & Weak & \begin{tabular}{|c|}
$\begin{array}{c}\text { rootlets } 10-15 \%, \text { rabdotus snail shell } 3-5 \% \text {, other } \\
\text { snail shell } 15-20 \%, \text { pin hole burrows } 10 \% \text {, worm } \\
\text { casts 5\%, mottling due to insect burrows with strat } \\
\text { III } 5 \%\end{array}$ \\
\end{tabular} & $\begin{array}{l}\text { Gradual and } \\
\text { Smooth }\end{array}$ & $\begin{array}{l}\text { Lens of snail cluster at } 45 \mathrm{cmbs} \text {, } \\
\text { no cultural material }\end{array}$ \\
\hline & & & $55-145$ & 10YR5/4 & Yellowish Brown & Sandy Loam & Friable & $\begin{array}{l}\text { Subangular } \\
\text { Blocky }\end{array}$ & Weak & $\begin{array}{c}\text { rootlets } 5-10 \% \text {, pin hole burrows } 10 \% \text {, krotovina } \\
\text { with strat II matrix } 2 \%(10 \mathrm{~cm}) \text {, rabdotus } 3 \% \text {, other } \\
\text { snail fragments } 5 \%\end{array}$ & $\begin{array}{l}\text { Clear and } \\
\text { Smooth }\end{array}$ & $\begin{array}{l}\text { Linear horizon of krotovina at } \\
70 \mathrm{cmbs} \text {, increase in more } \\
\text { complete snail fragments } \\
\text { compared to above strat, lens of } \\
\text { snail fragments at } 114 \mathrm{~cm}\end{array}$ \\
\hline & & & $145-212$ & 10YR $7 / 4$ & Very Pale Brown & Sandy Loam & Friable & $\begin{array}{l}\text { Subangular } \\
\text { Blocky }\end{array}$ & $\begin{array}{l}\text { Weak to } \\
\text { Moderate }\end{array}$ & $\begin{array}{c}\text { rabdotus } 5-10 \% \text {, pin hole burrows } 10-15 \% \text {, rootlets } \\
1-2 \% \text {, white flecking } 1 \%(.5 \mathrm{~mm})\end{array}$ & $\begin{array}{l}\text { Gradual and } \\
\text { Smooth }\end{array}$ & $\begin{array}{l}\text { Observed from surface below } \\
156 \mathrm{cmbs} \text {, no cultural material }\end{array}$ \\
\hline & & & 212-301 & 10YR5/6 & Yellowish Brown & Sandy Loam & Friable & $\begin{array}{l}\text { Subangular } \\
\text { Blocky }\end{array}$ & Moderate & \begin{tabular}{|c|} 
rabdotus $20 \%$, other snail fragments $10-15 \%$, worm \\
casts $5 \%$, pin hole burrow $5 \%$, rootlets $1-2 \%$, white \\
filaments $1-3 \%(1 \mathrm{~mm})$
\end{tabular} & Unobserved & No cultural material \\
\hline \multirow{5}{*}{ B } & \multirow{5}{*}{ Guadalupe } & \multirow{5}{*}{50330} & $0-32$ & 10YR4/2 & $\begin{array}{l}\text { Dark Grayish } \\
\text { Brown }\end{array}$ & Loam & $\begin{array}{l}\text { Loose to } \\
\text { Friable }\end{array}$ & $\begin{array}{c}\text { Crumbly to } \\
\text { Subangular } \\
\text { Blocky }\end{array}$ & Weak & $\begin{array}{c}\text { roots } 10 \% \text {, rootlets } 20 \% \text {, pin hole burrow } 5 \% \text {, worm } \\
\text { casts } 5 \% \text {, sail fragments } 5 \%\end{array}$ & $\begin{array}{c}\text { Gradual and } \\
\text { Smooth }\end{array}$ & $\begin{array}{c}\text { Root zone } 5 \mathrm{~cm} \text { thick, no cultural } \\
\text { material }\end{array}$ \\
\hline & & & $32-62$ & $\begin{array}{l}\text { 10YR } 4 / 2 \text { to } \\
10 Y R 4 / 4\end{array}$ & $\begin{array}{c}\text { Dark Grayish } \\
\text { Brown to Dark } \\
\text { Yellowish Brown }\end{array}$ & Sandy Loam & Friable & $\begin{array}{l}\text { Crumbly to } \\
\text { Subangular } \\
\text { Blocky }\end{array}$ & Weak & $\begin{array}{l}\text { rabdotus } 3-5 \% \text {, snail fragments } 10 \% \text {, pin hole } \\
\text { burrows } 5-10 \% \text {, worm casts } 5 \% \text {, rootlets } 10 \%\end{array}$ & $\begin{array}{l}\text { Gradual and } \\
\text { Smooth }\end{array}$ & No cultural material \\
\hline & & & 62-167 & 10YR5/4 & Yellowish Brown & Sandy Loam & Friable & $\begin{array}{l}\text { Subangular } \\
\text { Blocky }\end{array}$ & Weak & $\begin{array}{l}\text { rootlets } 5-10 \% \text {, snail fragments } 10 \% \text {, rabdotus } 3 \text { - } \\
5 \% \text {, pin hole burrows } 5 \% \text {, worm casts }<1 \%\end{array}$ & $\begin{array}{l}\text { Clear and } \\
\text { Smooth }\end{array}$ & $\begin{array}{c}\text { Increase in more complete snail } \\
\text { fragments compared to above } \\
\text { strat, observed from surface } \\
\text { below } 141 \mathrm{cmbs} \text {, no cultural } \\
\text { material }\end{array}$ \\
\hline & & & $167-220$ & 10YR7/4 & Very Pale Brown & Sandy Loam & Friable & $\begin{array}{l}\text { Subangular } \\
\text { Blocky }\end{array}$ & $\begin{array}{l}\text { Weak to } \\
\text { Moderate }\end{array}$ & \begin{tabular}{|c|} 
rabdotus $5-10 \%$, pin hole burrows $10-15 \%$, rootlets \\
$1-2 \%$, white flecking $1 \%(.5 \mathrm{~mm})$
\end{tabular} & $\begin{array}{c}\text { Gradual and } \\
\text { Smooth }\end{array}$ & $\begin{array}{c}\text { Mottled with strat III matrix } \\
\text { possibly from bioturbation } 10 \%, \\
\text { no cultural material }\end{array}$ \\
\hline & & & 220-307 & 10YR5/6 & Yellowish Brown & Sandy Loam & Friable & $\begin{array}{l}\text { Subangular } \\
\text { Blocky }\end{array}$ & Moderate & $\begin{array}{l}\text { rabdotus } 20 \% \text {, other snail fragments } 10-15 \% \text {, worm } \\
\text { casts } 5 \% \text {, pin hole burrow } 5 \% \text {, rootlets } 1-2 \% \text {, white } \\
\text { filaments } 1-3 \%(1 \mathrm{~mm})\end{array}$ & Unobserved & No cultural material \\
\hline
\end{tabular}




\begin{tabular}{|c|c|c|c|c|c|c|c|c|c|c|c|c|}
\hline BHT & County & Parcel & Depth (cmbs) & Munsel|* & Soil Color* & Soil Texture & Consistency & Structure Type & Grade & Inclusions & $\begin{array}{c}\text { Lower } \\
\text { Boundary }\end{array}$ & Comment \\
\hline \multirow{4}{*}{ c } & \multirow{4}{*}{ Guadalupe } & \multirow{4}{*}{50330} & $0-23$ & 10YR $4 / 2$ & $\begin{array}{l}\text { Dark Grayish } \\
\text { Brown }\end{array}$ & Loam & $\begin{array}{l}\text { Loose to } \\
\text { Friable }\end{array}$ & $\begin{array}{l}\text { Crumbly to } \\
\text { Subangular } \\
\text { Blocky }\end{array}$ & Weak & subangular pebbles $1 \%$ & $\begin{array}{l}\text { Gradual and } \\
\text { Smooth }\end{array}$ & $\begin{array}{c}\text { Root zone } 5 \mathrm{~cm} \text { thick, no cultural } \\
\text { material }\end{array}$ \\
\hline & & & 23-92 & $\begin{array}{l}10 Y R 4 / 2 \text { to } \\
10 Y R 4 / 4\end{array}$ & \begin{tabular}{|} 
Dark Grayish \\
Brown to Dark \\
Yellowish Brown
\end{tabular} & Sandy Loam & Friable & $\begin{array}{l}\text { Crumbly to } \\
\text { Subangular } \\
\text { Blocky }\end{array}$ & Weak & snail fragments $15 \%$, worm casts $5 \%$ & $\begin{array}{c}\text { Gradual and } \\
\text { Smooth }\end{array}$ & No cultural material \\
\hline & & & $92-224$ & 10YR5/4 & Yellowish Brown & Sandy Loam & Friable & $\begin{array}{l}\text { Subangular } \\
\text { Blocky }\end{array}$ & Weak & $\begin{array}{l}\text { pinholes } 20 \% \text {, rabdotus } 10 \% \text {, white filaments } 5 \text { - } \\
10 \%(.5 \mathrm{~mm}) \text {, snail fragments } 15-20 \%\end{array}$ & $\begin{array}{l}\text { Clear and } \\
\text { Smooth }\end{array}$ & \begin{tabular}{|c} 
Increase in more complete snail \\
fragments compared to above \\
strat, observed from surface \\
below $156 \mathrm{cmbs}$, no cultural \\
material
\end{tabular} \\
\hline & & & $224-312$ & 10YR5/6 & Yellowish Brown & Sandy Loam & Friable & $\begin{array}{l}\text { Subangular } \\
\text { Blocky }\end{array}$ & Moderate & \begin{tabular}{|c|} 
rabdotus $20 \%$, other snail fragments $10-15 \%$, worm \\
casts $5 \%$, pin hole burrow $5 \%$, rootlets $1-2 \%$, white \\
filaments $1-3 \%(1 \mathrm{~mm})$
\end{tabular} & Unobserved & No cultural material \\
\hline \multirow{5}{*}{ D } & \multirow{5}{*}{ Guadalupe } & \multirow{5}{*}{50330} & $0-15$ & 10YR4/2 & $\begin{array}{l}\text { Dark Grayish } \\
\text { Brown }\end{array}$ & Loam & $\begin{array}{l}\text { Loose to } \\
\text { Friable }\end{array}$ & $\begin{array}{l}\text { Crumbly to } \\
\text { Subangular } \\
\text { Blocky }\end{array}$ & Weak & roots $5 \%$, snail fragments $10-15 \%$ & $\begin{array}{l}\text { Gradual and } \\
\text { Smooth }\end{array}$ & $\begin{array}{c}\text { Root zone } 8 \mathrm{~cm} \text { thick, no cultural } \\
\text { material }\end{array}$ \\
\hline & & & $15-69$ & $\begin{array}{l}\text { 10YR } 4 / 2 \text { to } \\
10 Y R 4 / 4\end{array}$ & \begin{tabular}{|c|} 
Dark Grayish \\
Brown to Dark \\
Yellowish Brown
\end{tabular} & Sandy Loam & Friable & $\begin{array}{l}\text { Crumbly to } \\
\text { Subangular } \\
\text { Blocky }\end{array}$ & Weak & $\begin{array}{l}\text { rabdotus } 5 \% \text {, other snail fragments } 15 \% \text {, worm } \\
\text { casts } 5-7 \%\end{array}$ & $\begin{array}{l}\text { Gradual and } \\
\text { Smooth }\end{array}$ & No cultural material \\
\hline & & & $69-121$ & 10YR5/4 & Yellowish Brown & Sandy Loam & Friable & $\begin{array}{l}\text { Subangular } \\
\text { Blocky }\end{array}$ & Weak & $\begin{array}{l}\text { rootlets } 10 \% \text {, krotovina }<1 \% \text { and } 10 \mathrm{~cm} \text { thick, } \\
\text { rabdotus } 5 \% \text {, snail fragments } 5-10 \%\end{array}$ & $\begin{array}{l}\text { Clear and } \\
\text { Smooth }\end{array}$ & $\begin{array}{c}\text { Increase in more complete snail } \\
\text { fragments compared to above } \\
\text { strat, observed from surface } \\
\text { below } 141 \mathrm{cmbs} \text {, no cultural } \\
\text { material }\end{array}$ \\
\hline & & & $121-172$ & 10YR7/4 & Very Pale Brown & Sandy Loam & Friable & $\begin{array}{l}\text { Subangular } \\
\text { Blocky }\end{array}$ & $\begin{array}{l}\text { Weak to } \\
\text { Moderate }\end{array}$ & rabdotus $5-10 \%$, pin hole burrows $15-20 \%$ & $\begin{array}{l}\text { Gradual and } \\
\text { Smooth }\end{array}$ & $\begin{array}{c}\text { Mottled with strat III matrix } \\
\text { possibly from bioturbation } 10 \% \text {, } \\
\text { no cultural material }\end{array}$ \\
\hline & & & $172-316$ & 10YR5/6 & Yellowish Brown & Sandy Loam & Friable & $\begin{array}{l}\text { Subangular } \\
\text { Blocky }\end{array}$ & Moderate & white filaments $15-20 \%(1-3 \mathrm{~mm})$ & Unobserved & $\begin{array}{l}\text { Subrounded gravels begin at } \\
275 \mathrm{cmbs} 3-5 \% \text {, no cultural } \\
\text { material }\end{array}$ \\
\hline \multirow{5}{*}{ E } & \multirow{5}{*}{ Guadalupe } & \multirow{5}{*}{50330} & $0-19$ & 10YR $4 / 2$ & $\begin{array}{l}\text { Dark Grayish } \\
\text { Brown }\end{array}$ & Loam & $\begin{array}{l}\text { Loose to } \\
\text { Friable }\end{array}$ & $\begin{array}{c}\text { Crumbly to } \\
\text { Subangular } \\
\text { Blocky }\end{array}$ & Weak & worm casts $5-10 \%$ & $\begin{array}{l}\text { Gradual and } \\
\text { Smooth }\end{array}$ & $\begin{array}{c}\text { Root zone } 8 \mathrm{~cm} \text { thick, no cultural } \\
\text { material }\end{array}$ \\
\hline & & & $19-84$ & $\begin{array}{l}10 Y R 4 / 2 \text { to } \\
10 Y R 4 / 4\end{array}$ & $\begin{array}{c}\text { Dark Grayish } \\
\text { Brown to Dark } \\
\text { Yellowish Brown }\end{array}$ & Sandy Loam & Friable & $\begin{array}{l}\text { Crumbly to } \\
\text { Subangular } \\
\text { Blocky }\end{array}$ & Weak & $\begin{array}{l}\text { rootlets } 15 \% \text {, snail shell fragments } 10-15 \% \text {, } \\
\text { rabdotus } 5 \% \text {, pin hole burrows } 20 \% \text {, mottling due } \\
\text { to insect burrows from strat III matrix } 15-20 \%\end{array}$ & $\begin{array}{l}\text { Gradual and } \\
\text { Smooth }\end{array}$ & No cultural material \\
\hline & & & 84-193 & 10YR5/4 & Yellowish Brown & Sandy Loam & Friable & $\begin{array}{l}\text { Subangular } \\
\text { Blocky }\end{array}$ & Weak & $\begin{array}{c}\text { rootlets } 3-5 \% \text {, snail fragments } 10 \% \text {, rabdotus } 5 \% \text {, } \\
\text { krotovina } 3 \% \text { and } 10-25 \mathrm{~cm} \text { in diameter with matrix } \\
\text { from strat II }\end{array}$ & $\begin{array}{l}\text { Clear and } \\
\text { Smooth }\end{array}$ & $\begin{array}{c}\text { Increase in more complete snail } \\
\text { fragments compared to above } \\
\text { strat, observed from surface } \\
\text { below } 148 \mathrm{cmbs} \text {, no cultural } \\
\text { material }\end{array}$ \\
\hline & & & 193-204 & $10 Y R 7 / 4$ & Very Pale Brown & Sandy Loam & Friable & $\begin{array}{l}\text { Subangular } \\
\text { Blocky }\end{array}$ & $\begin{array}{l}\text { Weak to } \\
\text { Moderate }\end{array}$ & rabdotus $5-10 \%$, pin hole burrows $15-20 \%$ & $\begin{array}{c}\text { Gradual and } \\
\text { Smooth }\end{array}$ & $\begin{array}{c}\text { Mottled with strat III matrix } \\
\text { possibly from bioturbation } 10 \%, \\
\text { no cultural material }\end{array}$ \\
\hline & & & 204-311 & 10YR5/6 & Yellowish Brown & Sandy Loam & Friable & $\begin{array}{l}\text { Subangular } \\
\text { Blocky }\end{array}$ & Moderate & white filaments $15-20 \%(1-3 \mathrm{~mm})$ & Unobserved & No cultural material \\
\hline \multirow{6}{*}{ BHT01 } & \multirow{6}{*}{ Bastrop } & \multirow{6}{*}{30310} & $0-20$ & 10YR $4 / 2$ & $\begin{array}{l}\text { Dark grayish } \\
\text { brown }\end{array}$ & Clay Loam & Firm & $\begin{array}{l}\text { Subangular } \\
\text { Blocky }\end{array}$ & Moderate & $\begin{array}{l}\text { roots } 2-5 \% \text {, rootlets } 15 \% \text {, snail shell } 1 \% \text {, worm } \\
\text { casts } 2 \% \text {, }\end{array}$ & $\begin{array}{l}\text { Gradual, } \\
\text { horizontal }\end{array}$ & \\
\hline & & & $20-70$ & 10YR 5/2 & Grayish brown & Sandy Clay Loam & Firm & $\begin{array}{l}\text { Subangular } \\
\text { Blocky }\end{array}$ & Strong & $\begin{array}{l}\begin{array}{l}\text { rootlets } 10 \% \text {, pin holes } 1-2 \% \text {, worm casts } 2 \% \text {, snail } \\
\text { shells } 1 \%\end{array} \\
\end{array}$ & $\begin{array}{l}\text { Clear, } \\
\text { horizontal }\end{array}$ & \\
\hline & & & $70-101$ & 10YR 4/2 & $\begin{array}{l}\text { Dark grayish } \\
\text { brown }\end{array}$ & Clay Loam & Firm & $\begin{array}{l}\text { Crumbly to } \\
\text { Subangular } \\
\text { Blocky }\end{array}$ & Moderate & rootlets $7 \%$, pinhole $5 \%$, snail shell $1-2 \%$ & Clear, smooth & \\
\hline & & & $101-142$ & 10YR $5 / 3$ & Brown & Sandy Clay Loam & Firm & \begin{tabular}{|c|} 
Subangular to \\
Platy
\end{tabular} & $\begin{array}{c}\text { Moderate to } \\
\text { Strong }\end{array}$ & rootlets $1-2 \%$, pinholes $5 \%$, worm casts $1 \%$ & $\begin{array}{l}\text { Gradual, } \\
\text { smooth }\end{array}$ & \\
\hline & & & $142-195$ & 10YR 6/4 & $\begin{array}{c}\text { Light Yellowish } \\
\text { Brown }\end{array}$ & Sandy Clay Loam & $\begin{array}{l}\text { Loose to } \\
\text { Friable }\end{array}$ & $\begin{array}{l}\text { Crumb to } \\
\text { Subangular } \\
\text { Blocky }\end{array}$ & Weak & $\begin{array}{l}\text { multiple lamina of sand and calcium carbonate } \\
(2 \mathrm{~cm} \text { long) } 5 \%\end{array}$ & Clear, smooth & \\
\hline & & & $195-300$ & 10YR 2/2 & Very dark brown & Clay Loam & Extremely Firm & $\begin{array}{l}\text { Blocky to } \\
\text { Massive }\end{array}$ & Strong & $\begin{array}{l}\text { Extremely firm, blocky almost massive, coarse } \\
\text { size, strong grade, calcium carbonate } 1-5 \mathrm{~mm} \text { (1- } \\
5 \% \text { ), some iron and manganese mottles } 5 \%\end{array}$ & Unobserved & \\
\hline \multirow{6}{*}{ ВНT02 } & \multirow{6}{*}{ Bastrop } & \multirow{6}{*}{30310} & $0-30$ & 10YR 4/2 & $\begin{array}{l}\text { Dark grayish } \\
\text { brown }\end{array}$ & Clay Loam & Firm & $\begin{array}{l}\text { Subangular } \\
\text { Blocky }\end{array}$ & Moderate & $\begin{array}{l}\text { roots } 2-5 \% \text {, rootlets } 15 \% \text {, snail shell } 1 \% \text {, worm } \\
\text { casts } 2 \% \text {. }\end{array}$ & $\begin{array}{l}\text { Gradual, } \\
\text { horizontal }\end{array}$ & \\
\hline & & & $30-81$ & 10YR $5 / 2$ & Grayish brown & Sandy Clay Loam & Firm & $\begin{array}{c}\text { Subangular } \\
\text { Blocky }\end{array}$ & Strong & $\begin{array}{l}\text { rootlets } 10 \% \text {, pin holes } 1-2 \% \text {, worm casts } 2 \% \text {, snail } \\
\text { shells } 1 \%\end{array}$ & $\begin{array}{l}\text { Clear, } \\
\text { horizontal }\end{array}$ & $\begin{array}{l}\text { Between } 52-65 \mathrm{cmbs} \text { there are } \\
\text { numerous sand lenses }\end{array}$ \\
\hline & & & $81-99$ & 10YR 4/2 & $\begin{array}{l}\text { Dark grayish } \\
\text { brown }\end{array}$ & Clay Loam & Firm & $\begin{array}{l}\text { Crumb to } \\
\text { Subangular } \\
\text { Blocky }\end{array}$ & Moderate & rootlets $7 \%$, pinhole $5 \%$, snail shell $1-2 \%$ & $\begin{array}{l}\text { Slightly sloping } \\
\text { down to NE }\end{array}$ & \\
\hline & & & $99-147$ & 10YR $5 / 3$ & Brown & Sandy Clay Loam & Firm & \begin{tabular}{|c|} 
Subangular \\
Blocky to Platy
\end{tabular} & Strong & rootlets $1-2 \%$, pinholes $5 \%$, worm casts $1 \%$ & $\begin{array}{l}\text { Gradual, } \\
\text { smooth }\end{array}$ & \\
\hline & & & $147-205$ & 10YR $6 / 4$ & $\begin{array}{c}\text { Light Yellowish } \\
\text { Brown }\end{array}$ & Sandy Clay Loam & $\begin{array}{l}\text { Loose to } \\
\text { Friable }\end{array}$ & $\begin{array}{l}\text { Crumb to } \\
\text { Subangular } \\
\text { Blocky }\end{array}$ & Weak & $\begin{array}{l}\text { multiple lamina of sand and calcium carbonate } \\
(2 \mathrm{~cm} \text { long } 5 \%\end{array}$ & Clear, smooth & \\
\hline & & & $205-290$ & 10YR 4/1 & $\begin{array}{l}\text { Dark grayish } \\
\text { brown }\end{array}$ & Clay Loam & Extremely Firm & $\begin{array}{l}\text { Blocky to } \\
\text { Massive }\end{array}$ & Strong & $\begin{array}{l}\text { calcium carbonate } 1-5 \mathrm{~mm}(5-10 \%) \text {, some iron and } \\
\text { manganese mottles } 5 \%\end{array}$ & Unobserved & \\
\hline \multirow{6}{*}{ Внт03 } & \multirow{6}{*}{ Bastrop } & \multirow{6}{*}{30310} & $0-27$ & 10YR 4/2 & $\begin{array}{c}\text { Dark grayish } \\
\text { brown }\end{array}$ & Clay Loam & Firm & $\begin{array}{c}\text { Subangular } \\
\text { Blocky }\end{array}$ & Moderate & $\begin{array}{l}\text { roots } 2-5 \% \text {, rootlets } 15 \% \text {, snail shell } 1 \% \text {, worm } \\
\text { casts } 2 \%\end{array}$ & $\begin{array}{l}\text { Gradual, } \\
\text { horizontal }\end{array}$ & \\
\hline & & & $27-116$ & 10YR 5/2 & Grayish brown & Sandy Clay Loam & Firm & $\begin{array}{l}\text { Subangular } \\
\text { Blocky }\end{array}$ & Strong & $\begin{array}{l}\text { roots } 10 \% \text {, rootlets } 10 \% \text {, pin holes } 1-2 \% \text {, worm } \\
\text { casts } 2 \% \text {, snail shells } 1 \%\end{array}$ & $\begin{array}{l}\text { Clear, } \\
\text { horizontal }\end{array}$ & $\begin{array}{l}\text { Between } 48-64 \text { and } 81-116 \\
\text { cmbs there are numerous sand } \\
\text { lenses, which are more } \\
\text { numerous toward the bottom of } \\
\text { the layer }\end{array}$ \\
\hline & & & $116-137$ & 10YR 4/2 & $\begin{array}{l}\text { Dark grayish } \\
\text { brown }\end{array}$ & Clay Loam & Firm & $\begin{array}{l}\text { Crumb to } \\
\text { Subangular } \\
\text { Blocky }\end{array}$ & Moderate & rootlets $7 \%$, pinhole $5 \%$, snail shell $1-2 \%$ & $\begin{array}{l}\text { Slightly sloping } \\
\text { down to } \mathrm{NE}\end{array}$ & \\
\hline & & & $137-170$ & 10YR 5/3 & Brown & Sandy Clay Loam & Firm & \begin{tabular}{|c|} 
Subangular \\
Blocky to Platy
\end{tabular} & Strong & rootlets $1-2 \%$, pinholes $5 \%$, worm casts $1 \%$ & $\begin{array}{l}\text { Gradual, } \\
\text { smooth }\end{array}$ & \\
\hline & & & $170-230$ & 10YR 6/4 & $\begin{array}{c}\text { Light Yellowish } \\
\text { Brown }\end{array}$ & Sandy Clay Loam & $\begin{array}{l}\text { Loose to } \\
\text { Friable }\end{array}$ & $\begin{array}{l}\text { Crumb to } \\
\text { Subangular } \\
\text { Blocky }\end{array}$ & Weak & $\begin{array}{l}\text { multiple lamina of sand and calcium carbonate } \\
(2 \mathrm{~cm} \text { long } 5 \%\end{array}$ & Clear, smooth & \\
\hline & & & $230-300$ & 10YR 4/1 & Dark gray & Clay Loam & Extremely Firm & $\begin{array}{l}\text { Blocky to } \\
\text { Massive }\end{array}$ & Strong & $\begin{array}{l}\text { calcium carbonate } 1-5 \mathrm{~mm}(5-10 \%) \text {, some iron and } \\
\text { manganese mottles } 5 \%\end{array}$ & Unobserved & \\
\hline
\end{tabular}




\begin{tabular}{|c|c|c|c|c|c|c|c|c|c|c|c|c|}
\hline BHT & County & Parcel & Depth (cmbs) & Munsell* & Soil Color* & Soil Texture & Consistency & Structure Type & Grade & Inclusions & $\begin{array}{l}\text { Lower } \\
\text { Boundary }\end{array}$ & Comment \\
\hline \multirow{5}{*}{ BHT04 } & \multirow{5}{*}{ Bastrop } & \multirow{5}{*}{30305} & $0-45$ & 10YR $4 / 2$ & $\begin{array}{l}\text { Dark grayish } \\
\text { brown }\end{array}$ & Clay Loam & Firm & $\begin{array}{c}\text { Subangular } \\
\text { Blocky }\end{array}$ & Moderate & $\begin{array}{l}\text { roots } 2-5 \% \text {, rootlets } 15 \% \text {, snail shell } 1 \% \text {, worm } \\
\text { casts } 2 \%\end{array}$ & $\begin{array}{l}\text { Gradual, } \\
\text { horizontal }\end{array}$ & \\
\hline & & & $45-77$ & 10YR $5 / 2$ & Grayish brown & Sandy Clay Loam & Firm & $\begin{array}{c}\text { Subangular } \\
\text { Blocky }\end{array}$ & Strong & $\begin{array}{l}\text { rootlets } 10 \% \text {, pin holes } 1-2 \% \text {, worm casts } 2 \% \text {, snail } \\
\text { shells } 1 \%\end{array}$ & \begin{tabular}{|l|}
$\begin{array}{l}\text { Clear, } \\
\text { horizontal }\end{array}$ \\
\end{tabular} & \\
\hline & & & $77-132$ & 10YR $4 / 2$ & $\begin{array}{l}\text { Dark grayish } \\
\text { brown }\end{array}$ & Clay Loam & Firm & $\begin{array}{l}\text { Crumb to } \\
\text { Subangular } \\
\text { Blocky }\end{array}$ & Moderate & rootlets $7 \%$, pinhole $5 \%$, snail shell $1-2 \%$ & Clear, smooth & $\begin{array}{l}9 \text { tertiary flakes were identified in } \\
\text { the backhoe spoil pile during } \\
\text { excavation and came from a } \\
\text { depth of between } 140 \text { to } 150 \\
\text { cmbs. Additionally: } 1 \text { secondary } \\
\text { flake and } 7 \text { pieces of thermal } \\
\text { shatter were collected from an } \\
\text { unknown depth. }\end{array}$ \\
\hline & & & $132-193$ & 10YR $4 / 2$ & $\begin{array}{l}\text { Dark grayish } \\
\text { brown }\end{array}$ & Clay Loam & Firm & Angular Blocky & Moderate & $\begin{array}{l}\text { prominent slickensides, calcium carbonate (2- } \\
5 \mathrm{~mm}) 3-5 \%\end{array}$ & \begin{tabular}{|l|} 
Clear, \\
horizontal
\end{tabular} & \\
\hline & & & $193-300$ & 10YR $6 / 4$ & \begin{tabular}{|c|} 
Light Yellowish \\
Brown
\end{tabular} & Sandy Clay Loam & Firm & $\begin{array}{c}\text { Subangular } \\
\text { Blocky }\end{array}$ & Strong & $\begin{array}{l}\text { calcium carbonate } 1 \mathrm{~cm}(2 \%) \text {, prominent } \\
\text { slickensides }\end{array}$ & Unobserved & \\
\hline \multirow{7}{*}{ BHT05 } & \multirow{7}{*}{ Bastrop } & \multirow{7}{*}{30310} & $0-21$ & 10YR $4 / 2$ & $\begin{array}{l}\text { Dark grayish } \\
\text { brown }\end{array}$ & Loamy Clay Loam & Friable & $\begin{array}{c}\text { Subangular } \\
\text { Blocky }\end{array}$ & Moderate & $\begin{array}{l}\text { roots } 10 \% \text {, rootlets } 25 \% \text {, pin holes } 10 \% \text {, worm } \\
\text { casts } 5-10 \% \text {, snail fragments }(3 \%) \text {, decomposing } \\
\text { organics }(1 \%)\end{array}$ & \begin{tabular}{|l|}
$\begin{array}{l}\text { Clear, Slightly } \\
\text { Wavy }\end{array}$ \\
\end{tabular} & \\
\hline & & & $21-42$ & 10YR $4 / 3$ & Brown & $\begin{array}{l}\text { Loam to Clay } \\
\text { Loam }\end{array}$ & Friable & $\begin{array}{l}\text { Crumb to } \\
\text { Subangular } \\
\text { Blocky }\end{array}$ & Weak & $\begin{array}{l}\text { roots } 5 \% \text {, rootlets } 15 \% \text {, pin holes } 15 \% \text {, worm casts } \\
5 \% \text {, snail fragments } 5 \% \text {, whole snail, } 1 \% \\
\text { (Heliodiscus) }\end{array}$ & $\begin{array}{l}\text { Gradual, } \\
\text { smooth }\end{array}$ & \\
\hline & & & $42-81$ & 10YR $5 / 3$ & Brown & Sandy Clay Loam & Friable & Angular Blocky & Moderate & $\begin{array}{l}\text { roots } 1-3 \% \text {, rootlets } 1-5 \% \text {, pin holes } 5-10 \% \text {, worm } \\
\text { casts } 1 \% \text {, snail fragments } 5 \% \text {, whole snail } 1 \% \\
\text { (Heliodiscus) }\end{array}$ & Abrupt, smooth & \\
\hline & & & 81-109 & 10YR 4/1-4/2 & $\begin{array}{l}\text { Dark gray to } \\
\text { dark grayish } \\
\text { brown }\end{array}$ & Clay Loam & Friable to Firm & Angular Blocky & $\begin{array}{c}\text { Moderate to } \\
\text { Strong }\end{array}$ & \begin{tabular}{|l|} 
Friable to slightly firm, angular, medium to coarse \\
size, moderate to strong grade, rootlets $5-10 \%$, pin \\
holes $5 \%$, worm casts $1 \%$, slickensides $1-3 \mathrm{~mm}$ \\
$(5 \%)$, shrink-swell, snail fragments $1 \%$, whole snail \\
$1 \%$ (liptooth) \\
\end{tabular} & Clear, smooth & $\begin{array}{l}\text { Matrix from insect burrows }(5 \%) \\
\text { bring down strat III, possible } \\
\text { buried soil }\end{array}$ \\
\hline & & & $109-141$ & 10YR 5/3-6/3 & $\begin{array}{l}\text { Brown to pale } \\
\text { brown }\end{array}$ & Silty Clay Loam & Friable & Angular Blocky & Moderate & $\begin{array}{l}\text { rootlets } 3 \% \text {, pin holes } 5 \% \text {, worm casts } 1 \% \text {, insect } \\
\text { burrows with strat IV matrix } 3 \% \text {, white filaments ( } \\
1 \mathrm{~mm} / 3-5 \% \text { ) and increasing with depth }\end{array}$ & $\begin{array}{l}\text { Gradual, } \\
\text { smooth }\end{array}$ & \\
\hline & & & $141-253$ & 10YR 6/3-6/4 & $\begin{array}{c}\begin{array}{c}\text { Pale brown to } \\
\text { light yellowish } \\
\text { brown }\end{array} \\
\end{array}$ & Silty Clay Loam & Friable & Angular Blocky & Moderate & $\begin{array}{l}\text { rootlets } 3 \% \text {, pinholes } 5 \% \text {, worm casts } 2 \% \text {, white } \\
\text { filaments }(2-3 \mathrm{~mm}) \text {, no snail shell }\end{array}$ & Abrupt, smooth & beds of fine sand \\
\hline & & & 253-290+ & 10YR 3/1 & Very dark gray & Loamy Clay & Firm & $\begin{array}{c}\text { Angular Blocky } \\
\text { to Massive }\end{array}$ & Moderate & $\begin{array}{l}\text { rootlets } 2 \% \text {, pin holes } 1 \% \text {, worm casts } 2 \% \text {, white } \\
\text { nodules }(5-10 \mathrm{~mm}) 10 \%\end{array}$ & Unobserved & Possible buried soil \\
\hline \multirow{6}{*}{ BHT06 } & \multirow{6}{*}{ Bastrop } & \multirow{6}{*}{30310} & $0-15$ & 10YR $4 / 2$ & $\begin{array}{l}\text { Dark grayish } \\
\text { brown }\end{array}$ & Loamy Clay Loam & Friable & $\begin{array}{l}\text { Subangular } \\
\text { Blocky }\end{array}$ & Moderate & $\begin{array}{l}\text { roots } 10 \% \text {, rootlets } 25 \% \text {, pin holes } 10 \% \text {, worm } \\
\text { casts } 5-10 \% \text {, snail fragments }(3 \%) \text {, decomposing } \\
\text { organics }(1 \%)\end{array}$ & $\begin{array}{l}\text { Clear, Slightly } \\
\text { Wavy }\end{array}$ & \\
\hline & & & $15-43$ & 10YR $5 / 3$ & Brown & Sandy Clay Loam & Friable & Angular Blocky & Moderate & $\begin{array}{l}\text { roots } 1-3 \% \text {, rootlets } 1-5 \% \text {, pin holes } 5-10 \%, \text { worm } \\
\text { casts } 1 \% \text {, snail fragments } 5 \% \text {, whole snail } 1 \% \\
\text { (Heliodiscus) }\end{array}$ & Abrupt, smooth & \\
\hline & & & $43-62$ & 10YR 4/1-4/2 & $\begin{array}{l}\text { Dark gray to } \\
\text { dark grayish } \\
\text { brown }\end{array}$ & Clay Loam & Friable to Firm & Angular Blocky & $\begin{array}{c}\text { Moderate to } \\
\text { Strong }\end{array}$ & \begin{tabular}{|l|} 
Friable to slightly firm, angular, medium to coarse \\
size, moderate to strong grade, rootlets $5-10 \%$, pin \\
holes $5 \%$, worm casts $1 \%$, slickensides $1-3 \mathrm{~mm}$ \\
$(5 \%)$, shrink-swell, snail fragments $1 \%$, whole snail \\
$1 \%$ (liptooth)
\end{tabular} & Clear, smooth & $\begin{array}{l}\text { Slightly higher clay content than } \\
\text { BHT05 }\end{array}$ \\
\hline & & & $62-89$ & 10YR 5/3-6/3 & $\begin{array}{c}\text { Brown to pale } \\
\text { brown }\end{array}$ & Silty Clay Loam & Friable & Angular Blocky & Moderate & $\begin{array}{l}\text { rootlets } 3 \% \text {, pin holes } 5 \% \text {, worm casts } 1 \% \text {, insect } \\
\text { burrows with strat IV matrix } 3 \% \text {, white filaments ( } \\
1 \mathrm{~mm} / 3-5 \% \text { ) and increasing with depth }\end{array}$ & $\begin{array}{l}\text { Gradual, } \\
\text { smooth }\end{array}$ & $\begin{array}{l}\text { Slightly higher clay content than } \\
\text { BHT05 }\end{array}$ \\
\hline & & & $89-254$ & 10YR 6/3-6/4 & $\begin{array}{c}\text { Pale brown to } \\
\text { light yellowish } \\
\text { brown }\end{array}$ & Silty Clay Loam & Friable & Angular Blocky & Moderate & $\begin{array}{l}\text { rootlets } 3 \% \text {, pinholes } 5 \% \text {, worm casts } 2 \% \text {, white } \\
\text { filaments }(2-3 \mathrm{~mm}) \text {, no snail shell }\end{array}$ & Abrupt, smooth & \\
\hline & & & $254-290$ & 10YR 3/1 & Very dark gray & Loamy Clay & Firm & $\begin{array}{c}\text { Angular Blocky } \\
\text { to Massive }\end{array}$ & Moderate & $\begin{array}{l}\text { rootlets } 2 \% \text {, pin holes } 1 \% \text {, worm casts } 2 \% \text {, white } \\
\text { nodules }(5-10 \mathrm{~mm}) 10 \%\end{array}$ & Unobserved & Possible buried soil \\
\hline \multirow{5}{*}{ BHT07 } & \multirow{5}{*}{ Bastrop } & \multirow{5}{*}{30310} & $0-19$ & 10YR $4 / 2$ & $\begin{array}{l}\text { Dark grayish } \\
\text { brown }\end{array}$ & Loamy Clay Loam & Friable & $\begin{array}{l}\text { Subangular } \\
\text { Blocky }\end{array}$ & Moderate & $\begin{array}{l}\text { roots } 15 \% \text {, rootlets } 25 \% \text {, pin holes } 10 \% \text {, worm } \\
\text { casts } 5-10 \% \text {, snail fragments }(3 \%) \text {, decomposing } \\
\text { organics }(5 \%)\end{array}$ & \begin{tabular}{|l|}
$\begin{array}{l}\text { Clear, Slightly } \\
\text { Wavy }\end{array}$ \\
\end{tabular} & \\
\hline & & & $19-44$ & 10YR $5 / 3$ & Brown & Sandy Clay Loam & Friable & Angular Blocky & Moderate & \begin{tabular}{|l|}
$\begin{array}{l}\text { roots } 5-10 \%, \text { rootlets } 20 \% \text {, pin holes } 5-10 \%, \text { worm } \\
\text { casts } 1 \% \text {, snail fragments } 5 \% \text {, whole snail } 1 \% \\
\text { (Heliodiscus) }\end{array}$ \\
\end{tabular} & Abrupt, smooth & \\
\hline & & & $44-84$ & 10YR 4/1-4/2 & $\begin{array}{l}\text { Dark gray to } \\
\text { dark grayish } \\
\text { brown }\end{array}$ & Clay Loam & Firm & Angular Blocky & $\begin{array}{c}\text { Moderate to } \\
\text { Strong }\end{array}$ & $\begin{array}{l}\text { rootlets } 5-10 \% \text {, roots } 5-10 \% \text {, pin holes } 5 \% \text {, worm } \\
\text { casts } 1 \% \text {, slickensides } 1-3 \mathrm{~mm}(5 \%) \text {, shrink-swell, } \\
\text { snail fragments } 1 \% \text {, whole snail } 1 \% \text { (liptooth) }\end{array}$ & Clear, smooth & \\
\hline & & & $84-119$ & 10YR 5/3-6/3 & $\begin{array}{c}\text { Brown to pale } \\
\text { brown }\end{array}$ & Silty Clay Loam & Friable & Angular Blocky & Moderate & $\begin{array}{l}\text { rootlets } 3 \% \text {, pin holes } 5 \% \text {, worm casts } 1 \% \text {, insect } \\
\text { burrows with strat IV matrix } 3 \% \text {, white filaments ( } \\
1 \mathrm{~mm} / 3-5 \% \text { ) and increasing with depth }\end{array}$ & $\begin{array}{l}\text { Gradual, } \\
\text { smooth }\end{array}$ & $\begin{array}{l}\text { Between } 83 \text { to } 105 \text { cmbs: } 1 \\
\text { projectile point distal tip, } 2 \\
\text { modified flakes, } 2 \text { scrapers, } 1 \\
\text { biface, } 2 \text { primary flakes, } 9 \\
\text { secondary flakes, } 9 \text { tertiary } \\
\text { flakes, and nine unidentified } \\
\text { bones. }\end{array}$ \\
\hline & & & $119-137$ & 10YR 3/1 & Very dark gray & Loamy Clay & Firm & $\begin{array}{c}\text { Angular Blocky } \\
\text { to Massive }\end{array}$ & Moderate & $\begin{array}{l}\text { rootlets } 2 \% \text {, pin holes } 1 \% \text {, worm casts } 2 \% \text {, white } \\
\text { filaments }(2-3 \mathrm{~mm}) 5 \%\end{array}$ & Unobserved & \\
\hline
\end{tabular}




\begin{tabular}{|c|c|c|c|c|c|c|c|c|c|c|c|c|}
\hline BHT & County & Parcel & Depth (cmbs) & Munsell* & Soil Color* & Soil Texture & Consistency & Structure Type & Grade & Inclusions & $\begin{array}{l}\text { Lower } \\
\text { Boundary }\end{array}$ & Comment \\
\hline \multirow{9}{*}{ ВНT08 } & \multirow{9}{*}{ Bastrop } & \multirow{9}{*}{30310} & $0-16$ & 10YR $4 / 2$ & $\begin{array}{l}\text { Dark grayish } \\
\text { brown }\end{array}$ & Loamy Clay Loam & Friable & $\begin{array}{l}\text { Subangular } \\
\text { Blocky }\end{array}$ & Moderate & $\begin{array}{l}\text { roots } 10 \% \text {, rootlets } 25 \% \text {, pin holes } 10 \% \text {, worm } \\
\text { casts } 5-10 \% \text {, snail fragments }(3 \%) \text {, decomposing } \\
\text { organics ( } 1 \%)\end{array}$ & $\begin{array}{l}\text { Clear, Slightly } \\
\text { Wavy }\end{array}$ & \\
\hline & & & $16-31$ & 10YR $4 / 3$ & Brown & $\begin{array}{l}\text { Loam to Clay } \\
\text { Loam }\end{array}$ & Friable & $\begin{array}{l}\text { Crumb to } \\
\text { Subangular } \\
\text { Blocky }\end{array}$ & Weak & $\begin{array}{l}\text { roots } 5 \% \text {, rootlets } 15 \% \text {, pin holes } 15 \% \text {, worm casts } \\
5 \% \text {, snail fragments } 5 \% \text {, whole snail, } 1 \% \\
\text { (rabdotus) }\end{array}$ & $\begin{array}{l}\text { Gradual, } \\
\text { smooth }\end{array}$ & \\
\hline & & & $31-52$ & 10YR $5 / 3$ & Brown & Sandy Clay Loam & Friable & Angular Blocky & Moderate & $\begin{array}{l}\text { roots } 1-3 \% \text {, rootlets } 1-5 \% \text {, pin holes } 5-10 \% \text {, worm } \\
\text { casts } 1 \% \text {, snail fragments } 5 \% \text {, whole snail } 1 \% \\
\text { (Heliodiscus) }\end{array}$ & Abrupt, smooth & \\
\hline & & & $52-72$ & 10YR 4/1-4/2 & $\begin{array}{l}\text { Dark gray to } \\
\text { dark grayish } \\
\text { brown } \\
\end{array}$ & Clay Loam & Friable to Firm & Angular Blocky & \begin{tabular}{|c|} 
Moderate to \\
Strong
\end{tabular} & $\begin{array}{l}\text { rootlets } 5-10 \% \text {, pin holes } 5 \% \text {, worm casts } 1 \% \text {, } \\
\text { slickensides } 1-3 \mathrm{~mm}(5 \%) \text {, shrink-swell, snail } \\
\text { fragments } 1 \% \text {, whole snail } 1 \% \text { (liptooth) }\end{array}$ & Clear, smooth & Possible buried soil \\
\hline & & & $72-116$ & 10YR 5/3-6/3 & $\begin{array}{l}\text { Brown to pale } \\
\text { brown }\end{array}$ & Silty Clay Loam & Friable & Angular Blocky & Moderate & $\begin{array}{l}\text { rootlets } 3 \% \text {, pin holes } 5 \% \text {, worm casts } 1 \% \text {, insect } \\
\text { burrows with strat IV matrix } 3 \% \text {, white filaments ( } \\
1 \mathrm{~mm} / 3-5 \% \text { ) and increasing with depth }\end{array}$ & $\begin{array}{l}\text { Gradual, } \\
\text { smooth }\end{array}$ & $\begin{array}{l}\text { Tan pockets of } 10 Y R \text { 7/3-7/4 silt } \\
\text { (6-10 mm thick) } 89-90 \text { and } 104- \\
105 \mathrm{cmbs} \text {, discontinuous, } \\
\text { possibly flood drape }\end{array}$ \\
\hline & & & $116-178$ & 10YR 6/3-6/4 & $\begin{array}{c}\text { Pale brown to } \\
\text { light yellowish } \\
\text { brown }\end{array}$ & Silty Clay Loam & Friable & Angular Blocky & Moderate & $\begin{array}{l}\text { rootlets } 3 \% \text {, pinholes } 5 \% \text {, worm casts } 2 \% \text {, white } \\
\text { filaments }(2-3 \mathrm{~mm}) \text {, no snail shell }\end{array}$ & Abrupt, smooth & \\
\hline & & & $178-247$ & 10YR 3/1 & Very dark gray & Loamy Clay & Firm & $\begin{array}{c}\text { Angular Blocky } \\
\text { to Massive }\end{array}$ & Moderate & $\begin{array}{l}\text { rootlets } 2 \% \text {, pin holes } 1 \% \text {, worm casts } 2 \% \text {, white } \\
\text { nodules }(5-10 \mathrm{~mm}) 10 \%\end{array}$ & $\begin{array}{l}\text { Gradual, } \\
\text { smooth }\end{array}$ & $\begin{array}{l}\text { Mussel shell at } 186 \mathrm{cmbs} \text {, } \\
\text { possibly a buried soil }\end{array}$ \\
\hline & & & $247-305$ & 10YR $4 / 2-4 / 3$ & $\begin{array}{l}\text { Dark gray to } \\
\text { dark grayish } \\
\text { brown }\end{array}$ & Loamy Clay & Firm & $\begin{array}{c}\text { Angular Blocky } \\
\text { to Prismatic }\end{array}$ & $\begin{array}{l}\text { Moderate to } \\
\text { Strong }\end{array}$ & $\begin{array}{l}\text { white nodules }(5-8 \mathrm{~mm} / 15 \%) \text {, iron staining }(1-2 \\
\mathrm{mm} / 1 \%) \text {, iron nodules, snail fragments } 1 \% \text {, insect } \\
\text { burrows } 2-3 \%\end{array}$ & $\begin{array}{l}\text { Gradual, } \\
\text { smooth }\end{array}$ & \\
\hline & & & $305-336$ & 10YR $5 / 3$ & Brown & Silty Clay Loam & Friable & Prismatic & Moderate & $\begin{array}{l}\text { rootlets } 1 \% \text {, slickensides } 2-3 \mathrm{~cm}(2 \%) \text {, white } \\
\text { nodules }(5-15 \mathrm{~mm} / 10-15 \%) \text {, snail fragments } 1 \% \text {, } \\
\text { iron pebbles }(2-4 \mathrm{~mm})<1 \%\end{array}$ & Unobserved & Shrink swell \\
\hline \multirow{6}{*}{ ВНT09 } & \multirow{6}{*}{ Bastrop } & \multirow{6}{*}{30310} & $0-16$ & 10YR $4 / 2$ & $\begin{array}{l}\text { Dark grayish } \\
\text { brown }\end{array}$ & Loamy Clay Loam & Friable & $\begin{array}{l}\text { Subangular } \\
\text { Blocky }\end{array}$ & Moderate & \begin{tabular}{|l|} 
roots $10 \%$, rootlets $25 \%$, pin holes $10 \%$, worm \\
casts $5-10 \%$, snail fragments $(3 \%)$, decomposing \\
organics $(1 \%)$
\end{tabular} & \begin{tabular}{|l|} 
Clear, Slightly \\
Wavy
\end{tabular} & \\
\hline & & & $16-37$ & 10YR $5 / 3$ & Brown & Sandy Clay Loam & Friable & Angular Blocky & Moderate & $\begin{array}{l}\text { roots } 1-3 \% \text {, rootlets } 1-5 \% \text {, pin holes } 5-10 \% \text {, worm } \\
\text { casts } 1 \% \text {, snail fragments } 5 \% \text {, whole snail } 1 \% \\
\text { (Heliodiscus) }\end{array}$ & Abrupt, smooth & \\
\hline & & & $37-84$ & 10YR 4/1-4/2 & $\begin{array}{l}\text { Dark gray to } \\
\text { dark grayish } \\
\text { brown } \\
\end{array}$ & Clay Loam & Friable to Firm & Angular Blocky & $\begin{array}{l}\text { Moderate to } \\
\text { Strong }\end{array}$ & $\begin{array}{l}\begin{array}{l}\text { rootlets } 5-10 \% \text {, pin holes } 5 \% \text {, worm casts } 1 \% \text {, } \\
\text { slickensides } 1-3 \mathrm{~mm}(5 \%) \text {, shrink-swell, snail } \\
\text { fragments } 1 \% \text {, whole snail } 1 \% \text { (liptooth) }\end{array} \\
\end{array}$ & Clear, smooth & \begin{tabular}{|l|} 
Tan lenses (discontinuities_- \\
10YR 7/4, silt loam $(65-66,72-$ \\
$73,61-62 \mathrm{cmbs})$ \\
\end{tabular} \\
\hline & & & $84-114$ & 10YR 5/3-6/3 & $\begin{array}{l}\text { Brown to pale } \\
\text { brown }\end{array}$ & Silty Clay Loam & Friable & Angular Blocky & Moderate & $\begin{array}{l}\text { rootlets } 3 \% \text {, pin holes } 5 \% \text {, worm casts } 1 \% \text {, insect } \\
\text { burrows with strat IV matrix } 3 \% \text {, white filaments ( } \\
1 \mathrm{~mm} / 3-5 \% \text { ) and increasing with depth }\end{array}$ & $\begin{array}{l}\text { Gradual, } \\
\text { smooth }\end{array}$ & $\begin{array}{l}\text { Possible buried soil with: } 2 \\
\text { unidentified bone fragments, } 1 \\
\text { modified flake, } 3 \text { primary flakes, } \\
16 \text { secondary flakes, } 17 \text { tertiary } \\
\text { flakes, and } 1 \text { scraper from } 100 \\
\text { to } 110 \text { cmbs. Additionally: } 7 \\
\text { ceramic sherds, } 3 \text { primary } \\
\text { flakes, } 7 \text { secondary flakes, and } \\
14 \text { tertiary flakes were } \\
\text { encountered in the trench with } \\
\text { no depth recorded. }\end{array}$ \\
\hline & & & $114-139$ & 10YR 6/3-6/4 & $\begin{array}{c}\text { Pale brown to } \\
\text { light yellowish } \\
\text { brown }\end{array}$ & Silty Clay Loam & Friable & Angular Blocky & Moderate & $\begin{array}{l}\text { rootlets } 3 \% \text {, pinholes } 5 \% \text {, worm casts } 2 \% \text {, white } \\
\text { filaments }(2-3 \mathrm{~mm}) \text {, no snail shell }\end{array}$ & Abrupt, smooth & \\
\hline & & & $139-165$ & 10YR 3/1 & Very dark gray & Loamy Clay & Firm & $\begin{array}{c}\text { Angular Blocky } \\
\text { to Massive }\end{array}$ & Moderate & $\begin{array}{l}\text { rootlets } 2 \% \text {, pin holes } 1 \% \text {, worm casts } 2 \% \text {, white } \\
\text { nodules }(5-10 \mathrm{~mm}) 10 \%\end{array}$ & Unobserved & \\
\hline \multirow{7}{*}{ BHT10 } & \multirow{7}{*}{ Bastrop } & \multirow{7}{*}{30305} & $0-16$ & 10YR $4 / 2$ & $\begin{array}{l}\text { Dark grayish } \\
\text { brown }\end{array}$ & Loamy Clay Loam & Friable & $\begin{array}{l}\text { Subangular } \\
\text { Blocky }\end{array}$ & Moderate & $\begin{array}{l}\text { roots } 10 \% \text {, rootlets } 25 \% \text {, pin holes } 10 \% \text {, worm } \\
\text { casts } 5-10 \% \text {, snail fragments }(3 \%) \text {, decomposing } \\
\text { organics }(1 \%)\end{array}$ & $\begin{array}{l}\text { Clear, Slightly } \\
\text { Wavy }\end{array}$ & \\
\hline & & & $16-44$ & 10YR $4 / 3$ & Brown & $\begin{array}{l}\text { Loam to Clay } \\
\text { Loam }\end{array}$ & Friable & $\begin{array}{l}\text { Crumb to } \\
\text { Subangular } \\
\text { Blocky }\end{array}$ & Weak & $\begin{array}{l}\text { roots } 5 \% \text {, rootlets } 15 \% \text {, pin holes } 15 \% \text {, worm casts } \\
5 \% \text {, snail fragments } 2 \% \text {, whole snail, } 1 \% \\
\text { (Heliodiscus) }\end{array}$ & $\begin{array}{l}\text { Gradual, } \\
\text { smooth }\end{array}$ & $\begin{array}{l}\text { Some charcoal and burned clay } \\
\text { material was not collected and } \\
\text { exact quantity is not known. }\end{array}$ \\
\hline & & & $44-74$ & 10YR $5 / 3$ & Brown & Sandy Clay Loam & Friable & Angular Blocky & Moderate & $\begin{array}{l}\text { roots } 3 \% \text {, rootlets } 1-5 \% \text {, pin holes } 5-10 \% \text {, worm } \\
\text { casts 2\%, snail fragments } 2 \% \text {, whole snail } 1 \% \\
\text { (Heliodiscus) }\end{array}$ & Abrupt, smooth & \\
\hline & & & $74-101$ & 10YR 4/1-4/2 & $\begin{array}{l}\text { Dark gray to } \\
\text { dark grayish } \\
\text { brown } \\
\end{array}$ & Clay Loam & Friable to Firm & Angular Blocky & $\begin{array}{l}\text { Moderate to } \\
\text { Strong }\end{array}$ & $\begin{array}{l}\begin{array}{l}\text { rootlets } 5-10 \% \text {, pin holes } 5 \% \text {, worm casts } 1 \% \text {, } \\
\text { slickensides } 1-3 \mathrm{~mm}(5 \%) \text {, shrink-swell, snail } \\
\text { fragments } 1 \% \text {, whole snail } 1 \% \text { (liptooth) }\end{array} \\
\end{array}$ & Clear, smooth & $\begin{array}{l}\text { Burned rock fragment at } 90 \\
\text { cmbs - material was not } \\
\text { collected. }\end{array}$ \\
\hline & & & 101-151 & 10YR 5/3-6/3 & $\begin{array}{l}\text { Brown to pale } \\
\text { brown }\end{array}$ & Silty Clay Loam & Friable & Angular Blocky & Moderate & $\begin{array}{l}\text { rootlets } 3 \% \text {, pin holes } 5 \% \text {, worm casts } 1 \% \text {, insect } \\
\text { burrows with strat IV matrix } 3 \% \text {, white filaments ( } \\
1 \mathrm{~mm} / 3-5 \% \text { ) and increasing with depth }\end{array}$ & $\begin{array}{l}\text { Gradual, } \\
\text { smooth }\end{array}$ & \\
\hline & & & $151-205$ & 10YR 6/3-6/4 & $\begin{array}{c}\text { Pale brown to } \\
\text { light yellowish } \\
\text { brown }\end{array}$ & Silty Clay Loam & Friable & Angular Blocky & Moderate & $\begin{array}{l}\text { rootlets } 3 \% \text {, pinholes } 5 \% \text {, worm casts } 2 \% \text {, white } \\
\text { filaments }(2-3 \mathrm{~mm}) \text {, no snail shell }\end{array}$ & Abrupt, smooth & \\
\hline & & & 205-305 & 10YR $3 / 1$ & Very dark gray & Loamy Clay & Firm & $\begin{array}{c}\text { Angular Blocky } \\
\text { to Massive }\end{array}$ & Moderate & $\begin{array}{l}\text { rootlets } 2 \% \text {, pin holes } 1 \% \text {, worm casts } 2 \% \text {, white } \\
\text { nodules }(5-10 \mathrm{~mm}) 10 \%\end{array}$ & Unobserved & \\
\hline \multirow{5}{*}{ BHT11 } & \multirow{5}{*}{ Bastrop } & \multirow{5}{*}{30305} & $0-10$ & 10YR $4 / 2$ & $\begin{array}{l}\text { Dark grayish } \\
\text { brown }\end{array}$ & Loamy Clay Loam & Friable & $\begin{array}{l}\text { Subangular } \\
\text { Blocky }\end{array}$ & Moderate & $\begin{array}{l}\text { roots } 15 \% \text {, rootlets } 25 \% \text {, pin holes } 10 \% \text {, worm } \\
\text { casts } 5-10 \% \text {, snail fragments }(3 \%) \text {, decomposing } \\
\text { organics }(5 \%)\end{array}$ & $\begin{array}{l}\text { Clear, Slightly } \\
\text { Wavy }\end{array}$ & $\begin{array}{l}\text { Ground surface slightly sloping } \\
\text { toward the west }\end{array}$ \\
\hline & & & $10-23$ & 10YR $5 / 3$ & Brown & Sandy Clay Loam & Friable & Angular Blocky & Moderate & $\begin{array}{l}\text { roots } 5-10 \% \text {, rootlets } 20 \% \text {, pin holes } 5-10 \% \text {, worm } \\
\text { casts } 1 \% \text {, snail fragments } 5 \% \text {, whole snail } 1 \% \\
\text { (Heliodiscus) }\end{array}$ & Irregular, wavy & \\
\hline & & & $23-41$ & 10YR 4/1-4/2 & $\begin{array}{l}\text { Dark gray to } \\
\text { dark grayish } \\
\text { brown }\end{array}$ & Clay Loam & Firm & Angular Blocky & $\begin{array}{l}\text { Moderate to } \\
\text { Strong }\end{array}$ & $\begin{array}{l}\text { rootlets } 5-10 \% \text {, roots } 5-10 \% \text {, pin holes } 5 \% \text {, worm } \\
\text { casts } 1 \% \text {, slickensides } 1-3 \mathrm{~mm}(5 \%) \text {, shrink-swell, } \\
\text { snail fragments } 1 \% \text {, whole snail } 1 \% \text { (liptooth) }\end{array}$ & Abrupt, wavy & \\
\hline & & & $41-82$ & 10YR 5/3-6/3 & $\begin{array}{l}\text { Brown to pale } \\
\text { brown }\end{array}$ & Silty Clay Loam & Friable & Angular Blocky & Moderate & $\begin{array}{l}\text { rootlets } 3 \% \text {, pin holes } 5 \% \text {, worm casts } 1 \% \text {, insect } \\
\text { burrows with strat IV matrix } 3 \% \text {, white filaments ( } \\
1 \mathrm{~mm} / 3-5 \% \text { ) and increasing with depth }\end{array}$ & Clear, wavy & $\begin{array}{l}\text { Possible graver at } 63 \mathrm{cmbs} \text {, two } \\
\text { tertiary flakes at } 78 \text { and } 79 \\
\text { cmbs, and a primary flake at } 82 \\
\text { cmbs. }\end{array}$ \\
\hline & & & $82-146$ & 10YR $3 / 1$ & Very dark gray & Loamy Clay & Firm & $\begin{array}{c}\text { Angular Blocky } \\
\text { to Massive }\end{array}$ & Moderate & $\begin{array}{l}\text { rootlets } 2 \% \text {, pin holes } 1 \% \text {, worm casts } 2 \% \text {, white } \\
\text { filaments }(10-30 \mathrm{~mm}) 3-5 \%\end{array}$ & Unobserved & \\
\hline \multirow{4}{*}{$\mathrm{BHT} 12$} & \multirow{4}{*}{ Bastrop } & \multirow{4}{*}{30305} & $0-20$ & 10YR $4 / 2$ & $\begin{array}{l}\text { Dark grayish } \\
\text { brown }\end{array}$ & Loamy Clay Loam & Friable & $\begin{array}{l}\text { Subangular } \\
\text { Blocky }\end{array}$ & Moderate & $\begin{array}{l}\text { roots } 15 \% \text {, rootlets } 25 \% \text {, pin holes } 10 \% \text {, worm } \\
\text { casts } 5-10 \% \text {, snail fragments ( } 3 \%) \text {, decomposing } \\
\text { organics (5\%) }\end{array}$ & $\begin{array}{l}\text { Clear, Slightly } \\
\text { sloping west }\end{array}$ & \\
\hline & & & $20-42$ & 10YR $5 / 3$ & Brown & Sandy Clay Loam & Friable & Angular Blocky & Moderate & $\begin{array}{l}\begin{array}{l}\text { roots } 5-10 \% \text {, rootlets } 20 \% \text {, pin holes } 5-10 \% \text {, worm } \\
\text { casts } 1 \% \text {, snail fragments } 5 \% \text {, whole snail } 1 \% \\
\text { (Heliodiscus) }\end{array} \\
\end{array}$ & Gradual, wavy & \\
\hline & & & $42-101$ & 10YR 4/1-4/2 & $\begin{array}{l}\text { Dark gray to } \\
\text { dark grayish } \\
\text { brown }\end{array}$ & Loamy Clay & Firm & $\begin{array}{l}\text { Subangular } \\
\text { Blocky }\end{array}$ & Moderate & $\begin{array}{l}\text { less than } 1 \% \text { snail shell, roots } 5 \% \text {, rootlets } 5 \% \text {, pin } \\
\text { holes } 5 \% \text {, worm casts } 1 \%\end{array}$ & $\begin{array}{l}\text { Clear, } \\
\text { horizontal }\end{array}$ & $\begin{array}{l}\text { A secondary flake and piece of } \\
\text { thermal shatter at } 62 \mathrm{cmbd} \text {, a } \\
\text { tertiary flake at } 74 \mathrm{cmbs} \text {, and a } \\
\text { piece of thermal shatter at } 83 \\
\text { cmbs. }\end{array}$ \\
\hline & & & $101-154$ & 10YR 3/1 & Very dark gray & Loamy Clay & Firm & $\begin{array}{c}\text { Angular Blocky } \\
\text { to Massive }\end{array}$ & Moderate & $\begin{array}{l}\text { rootlets } 2 \% \text {, pin holes } 1 \%, \text { worm casts } 2 \% \text {, white } \\
\text { filaments }(10-30 \mathrm{~mm}) 3-5 \%\end{array}$ & Unobserved & \\
\hline
\end{tabular}




\begin{tabular}{|c|c|c|c|c|c|c|c|c|c|c|c|c|}
\hline BHT & County & Parcel & Depth (cmbs) & Munsell* & Soil Color* & Soil Texture & Consistency & Structure Type & Grade & Inclusions & $\begin{array}{c}\text { Lower } \\
\text { Boundary } \\
\end{array}$ & Comment \\
\hline \multirow{5}{*}{ BHT13 } & \multirow{5}{*}{ Bastrop } & \multirow{5}{*}{30305} & $0-18$ & 10YR $4 / 2$ & $\begin{array}{l}\text { Dark grayish } \\
\text { brown }\end{array}$ & Loamy Clay Loam & Friable & $\begin{array}{l}\text { Subangular } \\
\text { Blocky }\end{array}$ & Moderate & $\begin{array}{l}\text { roots } 10 \% \text {, rootlets } 25 \% \text {, pin holes } 10 \% \text {, worm } \\
\text { casts } 5-10 \% \text {, snail fragments }(3 \%) \text {, decomposing } \\
\text { organics ( } 1 \% \text { ) }\end{array}$ & \begin{tabular}{|l|}
$\begin{array}{l}\text { Clear, Slightly } \\
\text { Wavy }\end{array}$ \\
\end{tabular} & \\
\hline & & & $18-37$ & 10YR $4 / 3$ & Brown & $\begin{array}{l}\text { Loam to Clay } \\
\text { Loam }\end{array}$ & Friable & $\begin{array}{l}\text { Crumb to } \\
\text { Subangular } \\
\text { Blocky }\end{array}$ & Weak & $\begin{array}{l}\text { roots } 5 \% \text {, rootlets } 15 \% \text {, pin holes } 15 \% \text {, worm casts } \\
5 \% \text {, snail fragments } 5 \% \text {, whole snail, } 1 \% \\
\text { (Heliodiscus) }\end{array}$ & $\begin{array}{l}\text { Gradual, } \\
\text { smooth }\end{array}$ & \\
\hline & & & $37-51$ & 10YR $5 / 3$ & Brown & Sandy Clay Loam & Friable & Angular Blocky & Moderate & $\begin{array}{l}\text { roots } 1-3 \% \text {, rootlets } 1-5 \% \text {, pin holes } 5-10 \% \text {, worm } \\
\text { casts } 1 \% \text {, snail fragments } 5 \% \text {, whole snail } 1 \% \\
\text { (Heliodiscus) }\end{array}$ & $\begin{array}{l}\text { Gradual, } \\
\text { smooth }\end{array}$ & $\begin{array}{l}\text { Lower boundaries are very } \\
\text { gradual }\end{array}$ \\
\hline & & & $51-74$ & 10YR $4 / 1-4 / 2$ & $\begin{array}{l}\text { Dark gray to } \\
\text { dark grayish } \\
\text { brown }\end{array}$ & Clay Loam & $\begin{array}{l}\text { Friable to } \\
\text { Slightly Firm }\end{array}$ & Angular Blocky & $\begin{array}{c}\text { Moderate to } \\
\text { Strong }\end{array}$ & $\begin{array}{l}\text { rootlets } 5-10 \% \text {, pin holes } 5 \% \text {, worm casts } 1 \% \text {, } \\
\text { slickensides } 1-3 \mathrm{~mm}(5 \%) \text {, shrink-swell, snail } \\
\text { fragments } 1 \% \text {, whole snail } 1 \% \text { (liptooth) }\end{array}$ & $\begin{array}{l}\text { Gradual, } \\
\text { smooth }\end{array}$ & $\begin{array}{l}\text { A single tertiary flake at } 50,63 \text {, } \\
\text { and } 69 \mathrm{cmbs} \text {. Additionally, a } \\
\text { secondary flake and five tertiary } \\
\text { flakes were identified in the } \\
\text { backhoe spoil pile with no known } \\
\text { depths of origin. Lower } \\
\text { boundaries are very gradual }\end{array}$ \\
\hline & & & $74-147$ & 10YR 5/3-6/3 & $\begin{array}{l}\text { Brown to pale } \\
\text { brown }\end{array}$ & Silty Clay Loam & Friable & Angular Blocky & Moderate & $\begin{array}{l}\text { rootlets } 3 \% \text {, pin holes } 5 \% \text {, worm casts } 1 \% \text {, insect } \\
\text { burrows with strat IV matrix } 3 \% \text {, white filaments ( } \\
1 \mathrm{~mm} / 3-5 \% \text { ) and increasing with depth }\end{array}$ & Unobserved & \\
\hline \multirow{5}{*}{ BHT14 } & \multirow{5}{*}{ Bastrop } & \multirow{5}{*}{30305} & $0-15$ & 10YR $4 / 2$ & $\begin{array}{c}\text { Dark grayish } \\
\text { brown }\end{array}$ & Loamy Clay Loam & Friable & $\begin{array}{c}\text { Subangular } \\
\text { Blocky }\end{array}$ & Moderate & $\begin{array}{l}\text { roots } 10 \% \text {, rootlets } 25 \% \text {, pin holes } 10 \% \text {, worm } \\
\text { casts } 5-10 \% \text {, snail fragments }(3 \%) \text {, decomposing } \\
\text { organics }(1 \%)\end{array}$ & \begin{tabular}{|l|}
$\begin{array}{l}\text { Clear, Slightly } \\
\text { Wavy }\end{array}$ \\
\end{tabular} & \\
\hline & & & $15-38$ & 10YR $4 / 3$ & Brown & $\begin{array}{l}\text { Loam to Clay } \\
\text { Loam }\end{array}$ & Friable & $\begin{array}{l}\text { Crumb to } \\
\text { Subangular } \\
\text { Blocky }\end{array}$ & Weak & $\begin{array}{l}\text { roots } 5 \% \text {, rootlets } 15 \% \text {, pin holes } 15 \% \text {, worm casts } \\
5 \% \text {, snail fragments } 5 \% \text {, whole snail, } 1 \% \\
\text { (Heliodiscus) }\end{array}$ & \begin{tabular}{|l} 
Gradual, \\
smooth
\end{tabular} & \\
\hline & & & $38-50$ & 10YR $5 / 3$ & Brown & Sandy Clay Loam & Friable & Angular Blocky & Moderate & $\begin{array}{l}\text { roots } 1-3 \% \text {, rootlets } 1-5 \% \text {, pin holes } 5-10 \% \text {, worm } \\
\text { casts } 1 \% \text {, snail fragments } 5 \% \text {, whole snail } 1 \% \\
\text { (Heliodiscus) }\end{array}$ & \begin{tabular}{|l} 
Gradual, \\
smooth
\end{tabular} & \\
\hline & & & $50-93$ & 10YR $4 / 1-4 / 2$ & $\begin{array}{l}\text { Dark gray to } \\
\text { dark grayish } \\
\text { brown } \\
\end{array}$ & Clay Loam & $\begin{array}{l}\text { Friable to } \\
\text { Slightly Firm }\end{array}$ & Angular Blocky & $\begin{array}{c}\text { Moderate to } \\
\text { Strong }\end{array}$ & \begin{tabular}{|l|}
$\begin{array}{l}\text { rootlets } 5-10 \% \text {, pin holes } 5 \% \text {, worm casts } 1 \% \text {, } \\
\text { slickensides } 1-3 \mathrm{~mm}(5 \%) \text {, shrink-swell, snail } \\
\text { fragments } 1 \% \text {, whole snail } 1 \% \text { (liptooth) }\end{array}$ \\
\end{tabular} & $\begin{array}{l}\text { Gradual, } \\
\text { smooth }\end{array}$ & Single tertiary flake at $90 \mathrm{cmbs}$. \\
\hline & & & $93-140$ & 10YR 5/3-6/3 & $\begin{array}{l}\text { Brown to pale } \\
\text { brown }\end{array}$ & Silty Clay Loam & Friable & Angular Blocky & Moderate & $\begin{array}{l}\text { rootlets } 3 \% \text {, pin holes } 5 \% \text {, worm casts } 1 \% \text {, insect } \\
\text { burrows with strat IV matrix } 3 \% \text {, white filaments ( } \\
1 \mathrm{~mm} / 3-5 \% \text { ) and increasing with depth }\end{array}$ & Unobserved & $\begin{array}{l}\text { Single tertiary flake at } 95 \mathrm{cmbs} \text {, } \\
\text { one piece of thermal shatter at } \\
96 \mathrm{cmbs} \text {, and one piece of } \\
\text { thermal shatter at } 98 \mathrm{cmbs} \text {. } \\
\text { Within the backhoe spoil pile } \\
\text { one tertiary flake and one piece } \\
\text { of FCR was collected. } \\
\text { Additionally, two tertiary flakes } \\
\text { were collected from an unkonwn } \\
\text { depth. }\end{array}$ \\
\hline \multirow{7}{*}{ BHT15 } & \multirow{7}{*}{ Bastrop } & \multirow{7}{*}{30305} & $0-15$ & 10YR $4 / 2$ & $\begin{array}{l}\text { Dark grayish } \\
\text { brown }\end{array}$ & Loamy Clay Loam & Friable & $\begin{array}{l}\text { Subangular } \\
\text { Blocky }\end{array}$ & Moderate & $\begin{array}{l}\text { roots } 10 \% \text {, rootlets } 25 \% \text {, pin holes } 10 \% \text {, worm } \\
\text { casts } 5-10 \% \text {, snail fragments }(3 \%) \text {, decomposing } \\
\text { organics }(1 \%)\end{array}$ & \begin{tabular}{|l|} 
Clear, Slightly \\
Wavy
\end{tabular} & \\
\hline & & & $15-28$ & 10YR $4 / 3$ & Brown & $\begin{array}{l}\text { Loam to Clay } \\
\text { Loam }\end{array}$ & Friable & $\begin{array}{l}\text { Crumb to } \\
\text { Subangular } \\
\text { Blocky }\end{array}$ & Weak & $\begin{array}{l}\text { roots } 5 \% \text {, rootlets } 15 \% \text {, pin holes } 15 \% \text {, worm casts } \\
5 \% \text {, snail fragments } 5 \% \text {, whole snail, } 1 \% \\
\text { (Heliodiscus) }\end{array}$ & $\begin{array}{l}\text { Gradual, } \\
\text { smooth }\end{array}$ & \\
\hline & & & $28-55$ & 10YR $5 / 3$ & Brown & Sandy Clay Loam & Friable & Angular Blocky & Moderate & $\begin{array}{l}\text { roots } 1-3 \% \text {, rootlets } 1-5 \% \text {, pin holes } 5-10 \% \text {, worm } \\
\text { casts } 1 \% \text {, snail fragments } 5 \% \text {, whole snail } 1 \% \\
\text { (Heliodiscus) }\end{array}$ & Abrupt, smooth & \\
\hline & & & $55-79$ & 10YR 4/1-4/2 & $\begin{array}{l}\text { Dark gray to } \\
\text { dark grayish } \\
\text { brown } \\
\end{array}$ & Clay Loam & $\begin{array}{l}\text { Friable to } \\
\text { Slightly Firm }\end{array}$ & Angular Blocky & $\begin{array}{c}\text { Moderate to } \\
\text { Strong }\end{array}$ & $\begin{array}{l}\begin{array}{l}\text { rootlets } 5-10 \% \text {, pin holes } 5 \% \text {, worm casts } 1 \% \text {, } \\
\text { slickensides } 1-3 \mathrm{~mm}(5 \%) \text {, shrink-swell, snail } \\
\text { fragments } 1 \% \text {, whole snail } 1 \% \text { (liptooth) }\end{array} \\
\end{array}$ & Clear, smooth & \\
\hline & & & $79-121$ & 10YR 5/3-6/3 & $\begin{array}{l}\text { Brown to pale } \\
\text { brown }\end{array}$ & Silty Clay Loam & Friable & Angular Blocky & Moderate & $\begin{array}{l}\text { rootlets } 3 \% \text {, pin holes } 5 \% \text {, worm casts } 1 \% \text {, insect } \\
\text { burrows with strat IV matrix } 3 \% \text {, white filaments ( } \\
1 \mathrm{~mm} / 3-5 \% \text { ) and increasing with depth }\end{array}$ & Clear, smooth & \\
\hline & & & $121-210$ & 10YR 3/1 & Very dark gray & Loamy Clay & Firm & \begin{tabular}{|c|}
$\begin{array}{c}\text { Subangular to } \\
\text { Massive }\end{array}$ \\
\end{tabular} & Moderate & $\begin{array}{l}\text { rootlets } 2 \% \text {, pin holes } 1 \% \text {, worm casts } 2 \% \text {, white } \\
\text { nodules }(5-10 \mathrm{~mm}) 10 \%\end{array}$ & Abrupt, smooth & \\
\hline & & & $210-330$ & 10YR $5 / 3$ & Brown & Silty Clay Loam & Friable & Prismatic & Moderate & $\begin{array}{l}\text { rootlets } 1 \% \text {, slickensides } 2-3 \mathrm{~cm}(2 \%) \text {, white } \\
\text { nodules }(5-15 \mathrm{~mm} / 10-15 \%) \text {, snail fragments } 1 \% \text {, } \\
\text { iron pebbles }(2-4 \mathrm{~mm})<1 \%\end{array}$ & Unobserved & \\
\hline \multirow{6}{*}{ BHT16 } & \multirow{6}{*}{ Bastrop } & \multirow{6}{*}{30305} & $0-17$ & 10YR $5 / 4$ & Yellowish Brown & Sandy Loam & Friable & $\begin{array}{l}\text { Subangular } \\
\text { Blocky }\end{array}$ & Moderate & $\begin{array}{l}\text { roots } 5 \% \text {, rootlets } 5 \% \text {, pinholes } 5 \% \text {, worm casts } \\
3 \% \text {, insect burrows } 3 \% \text {, mottles }(7.5 Y R 4 / 6) 10 \%\end{array}$ & Clear, smooth & \\
\hline & & & $17-53$ & 10YR $4 / 4$ & \begin{tabular}{|c|} 
Dark Yellowish \\
Brown \\
\end{tabular} & Sandy Loam & Friable & $\begin{array}{c}\text { Subangular } \\
\text { Blocky }\end{array}$ & Weak & $\begin{array}{l}\text { roots } 2 \% \text {, rootlets } 10 \% \text {, pinholes } 10 \% \text {, worm casts } \\
1 \%\end{array}$ & \begin{tabular}{|l|}
$\begin{array}{l}\text { Abrupt, Slightly } \\
\text { Wavy }\end{array}$ \\
\end{tabular} & Mottled clay pocket 10YR 4/2 \\
\hline & & & $53-73$ & 10YR $3 / 2$ & \begin{tabular}{|c|} 
Very Dark \\
Grayish Brown \\
\end{tabular} & Clay Loam & Friable & Angular Blocky & Moderate & $\begin{array}{l}\text { roots } 1 \% \text {, rootlets } 3 \% \text {, pinholes } 5 \% \text {, insect burrows } \\
1 \%\end{array}$ & Clear, smooth & $\begin{array}{l}\text { sandy loam pockets from } \\
\text { previous strat }\end{array}$ \\
\hline & & & 73-89 & 10YR $4 / 4$ & \begin{tabular}{|c|}
$\begin{array}{c}\text { Dark Yellowish } \\
\text { Brown }\end{array}$ \\
\end{tabular} & Sandy Clay Loam & Friable & $\begin{array}{c}\begin{array}{c}\text { Subangular } \\
\text { Blocky }\end{array} \\
\end{array}$ & $\begin{array}{l}\text { Weak to } \\
\text { Moderate }\end{array}$ & roots $<1 \%$, rootlets $<1 \%$, pinholes $3 \%$ & Clear, smooth & \\
\hline & & & $89-183$ & 10YR $3 / 3$ & Dark Brown & Sandy Clay Loam & Friable to Firm & Angular Blocky & Moderate & roots $<1 \%$, rootlets $<1 \%$, pinholes $2 \%$ & Unobserved & Pockets of previous strat \\
\hline & & & $183+$ & 10YR $4 / 2$ & $\begin{array}{c}\text { Dark Grayish } \\
\text { Brown }\end{array}$ & - & - & - & - & Mottles (7.5YR 5/8) 40\% & Unobserved & \\
\hline \multirow{6}{*}{ BHT17 } & \multirow{6}{*}{ Bastrop } & \multirow{6}{*}{30305} & $0-24$ & 10YR $5 / 4$ & Yellowish Brown & Sandy Clay Loam & Friable to Firm & $\begin{array}{l}\text { Subangular } \\
\text { Blocky }\end{array}$ & Strong & $\begin{array}{l}\text { roots } 2 \% \text {, rootlets } 5 \% \text {, pinholes } 5 \% \text {, worm casts } \\
3 \% \text {, insect burrows } 3 \% \text {, mottles }(7.5 Y R \text { Y } 4 / 6) 5 \%\end{array}$ & Clear, smooth & \\
\hline & & & $24-49$ & 10YR $4 / 4$ & \begin{tabular}{|c|} 
Dark Yellowish \\
Brown
\end{tabular} & Sandy Clay Loam & Friable to Firm & $\begin{array}{c}\text { Subangular } \\
\text { Blocky }\end{array}$ & Weak & $\begin{array}{l}\text { roots }<1 \% \text {, rootlets } 2 \% \text {, pinholes } 10 \% \text {, worm casts } \\
1 \%\end{array}$ & Abrupt, smooth & \\
\hline & & & $49-66$ & 10YR $3 / 2$ & \begin{tabular}{|c|} 
Very Dark \\
Grayish Brown \\
\end{tabular} & Clay Loam & Firm & Angular Blocky & Weak & roots $1 \%$, rootlets $3 \%$, pinholes $5 \%$ & Clear, smooth & $\begin{array}{l}\text { sandy loam pockets from } \\
\text { previous strat }\end{array}$ \\
\hline & & & 66-102 & 10YR $4 / 4$ & \begin{tabular}{|c|} 
Dark Yellowish \\
Brown
\end{tabular} & Clay & Firm & $\begin{array}{c}\text { Subangular } \\
\text { Blocky }\end{array}$ & $\begin{array}{l}\text { Weak to } \\
\text { Moderate }\end{array}$ & rootlets $<1 \%$, pinholes $<1 \%$ & Clear, smooth & \\
\hline & & & $102-240$ & 10YR 2/1 & Black & Clay & Friable to Firm & Angular Blocky & \begin{tabular}{|c|}
$\begin{array}{c}\text { Moderate to } \\
\text { Strong }\end{array}$ \\
\end{tabular} & $\begin{array}{l}\text { rootlets }<1 \% \text {, pinholes }<1 \% \text {, white filaments }(1-2 \\
\text { mm } 1 \%\end{array}$ & Unobserved & Pockets of 10 YR 5/6 sandy loam \\
\hline & & & $240+$ & 10YR $4 / 2$ & $\begin{array}{c}\text { Dark Grayish } \\
\text { Brown }\end{array}$ & - & - & - & - & Mottles (7.5YR 5/8) $30 \%$ & Unobserved & \\
\hline \multirow{4}{*}{ BHT18 } & \multirow{4}{*}{ Bastrop } & \multirow{4}{*}{30305} & $0-31$ & 10YR $3 / 2$ & \begin{tabular}{|c|} 
Very Dark \\
Grayish Brown \\
\end{tabular} & Clay to Clay Loam & Firm & Angular Blocky & Weak & $\begin{array}{l}\text { roots } 5 \% \text {, rootlets } 15 \% \text {, worm casts } 3 \% \text {, insect } \\
\text { burrows } 3 \% \text {, pinholes } 5-8 \%\end{array}$ & Clear, Smooth & West wall $40 \times 30 \mathrm{~cm}$ ant gallery \\
\hline & & & $31-54$ & 10YR $3 / 3$ & Dark Brown & Clay Loam & Friable to Firm & $\begin{array}{l}\text { Subangular } \\
\text { Blocky }\end{array}$ & $\begin{array}{l}\text { Weak to } \\
\text { Moderate }\end{array}$ & $\begin{array}{l}\text { roots }<1 \% \text {, rootlets } 5 \% \text {, pinholes } 5 \% \text {, worm casts } \\
1 \% \text {, insect burrows } 1 \% \text {, mottles (10YR } 4 / 4 \text { ) } 10 \%\end{array}$ & $\begin{array}{l}\text { Gradual, } \\
\text { smooth }\end{array}$ & \\
\hline & & & $54-102$ & 10YR $3 / 3$ & Dark Brown & Clay to Clay Loam & $\begin{array}{c}\text { Firm to } \\
\text { Extremely Firm }\end{array}$ & $\begin{array}{l}\text { Subangular } \\
\text { Blocky }\end{array}$ & Weak & rootlets $<1 \%$, pinholes $5 \%$, insect burrows $<1 \%$ & $\begin{array}{l}\text { Abrupt, } \\
\text { Smooth }\end{array}$ & \\
\hline & & & $102-143$ & 10YR $4 / 3$ & Brown & Clay & Firm & Massive & N/A & $\begin{array}{l}\text { rootlets }<1 \% \text {, pinholes } 1 \% \text {, calcium carbonate } \\
\text { nodules }(2-3 \mathrm{~mm}) 10-15 \%\end{array}$ & Unobserved & \\
\hline
\end{tabular}




\begin{tabular}{|c|c|c|c|c|c|c|c|c|c|c|c|c|}
\hline BHT & County & Parcel & Depth (cmbs) & Munsell* & Soil Color* & Soil Texture & Consistency & \begin{tabular}{|l|l|} 
Structure Type \\
\end{tabular} & Grade & Inclusions & $\begin{array}{c}\text { Lower } \\
\text { Boundary } \\
\end{array}$ & Comment \\
\hline \multirow{5}{*}{ BHT19 } & \multirow{5}{*}{ Bastrop } & \multirow{5}{*}{30305} & $0-36$ & 10YR 2/2 & Very Dark Brown & Clay to Clay Loam & Friable to Firm & $\begin{array}{l}\text { Subangular } \\
\text { Blocky }\end{array}$ & Weak & $\begin{array}{l}\text { roots } 3 \% \text {, rootlets } 15 \% \text {, pinholes } 5 \% \text {, insect } \\
\text { burrows } 2 \% \text {, vertical cracking }\end{array}$ & $\begin{array}{l}\text { Gradual, } \\
\text { Smooth }\end{array}$ & $\begin{array}{l}\text { Column sample excavated on } \\
\text { west wall across from profile, } \\
\text { NCM, excavated to } 130 \mathrm{cmbs}\end{array}$ \\
\hline & & & $36-75$ & 10YR $4 / 2$ & $\begin{array}{l}\text { Dark Grayish } \\
\text { Brown }\end{array}$ & Clay & Firm & $\begin{array}{l}\text { Subangular } \\
\text { Blocky }\end{array}$ & Weak & $\begin{array}{l}\text { rootlets } 5 \% \text {, pinholes } 2 \% \text {, mottles (10YR } 5 / 4) 5 \% \text {, } \\
\text { white nodules }(2-4 \mathrm{~mm}) 3 \%\end{array}$ & $\begin{array}{l}\text { Gradual, } \\
\text { Smooth }\end{array}$ & \\
\hline & & & $75-116$ & 10YR 4/3 & Brown & Clay & Firm & $\begin{array}{l}\text { Subangular } \\
\text { Blocky }\end{array}$ & Weak & $\begin{array}{l}\text { rootlets }<1 \% \text {, pebbles }(1-3 \mathrm{~mm}) 1 \% \text {, mottles (10YR } \\
5 / 4) 15 \% \text {, white nodules }(2-4 \mathrm{~mm}) 1 \%\end{array}$ & Clear, Smooth & \\
\hline & & & $116-240$ & 10YR 4/4 & \begin{tabular}{|c|} 
Dark Yellowish \\
Brown
\end{tabular} & Clay & Firm & $\begin{array}{c}\text { Subangular } \\
\text { Blocky }\end{array}$ & Weak & $\begin{array}{l}\begin{array}{l}\text { rootlets }<1 \% \text {, pebbles }(1-7 \mathrm{~mm}) 1 \% \text {, pinholes }<1 \%, \\
\text { white nodules }(3-7 \mathrm{~mm})<1 \%\end{array}\end{array}$ & Unobserved & \\
\hline & & & $240+$ & 10YR $4 / 2$ & $\begin{array}{l}\text { Dark Grayish } \\
\text { Brown }\end{array}$ & - & - & - & - & Mottles (7.5YR 5/8) 30\% & Unobserved & \\
\hline \multirow{4}{*}{ BHT20 } & \multirow{4}{*}{ Bastrop } & \multirow{4}{*}{30310} & $0-37$ & 10YR 3/2 & $\begin{array}{c}\text { Very Dark } \\
\text { Grayish Brown }\end{array}$ & Clay Loam & $\begin{array}{c}\text { Firm to } \\
\text { Extremely Firm }\end{array}$ & $\begin{array}{l}\text { Subangular } \\
\text { Blocky }\end{array}$ & $\begin{array}{l}\text { Weak to } \\
\text { Moderate }\end{array}$ & $\begin{array}{l}\text { roots } 5 \% \text {, rootlets } 20 \% \text {, insect burrows } 5 \% \text {, worm } \\
\text { casts } 3 \% \text {, pinholes } 5 \% \text {, vertical cracking } 5 \%\end{array}$ & $\begin{array}{l}\text { Clear, Slightly } \\
\text { Wavy }\end{array}$ & \\
\hline & & & $37-114$ & 10YR 3/1 & Dark Gray & Clay to Clay Loam & Extremely Firm & $\begin{array}{l}\text { Subangular } \\
\text { Blocky }\end{array}$ & Strong & $\begin{array}{l}\text { rootlets } 2 \% \text {, insect burrows } 1 \% \text {, snail shell } \\
\text { fragments }<1 \% \text {, pinholes } 2 \% \text {, white nodules }(1-3 \\
\text { mm) } 1 \% \text {, subrounded pebbles }(1-3 \mathrm{~mm})<1 \%\end{array}$ & $\begin{array}{l}\text { Gradual to } \\
\text { Diffuse, } \\
\text { Smooth }\end{array}$ & $\begin{array}{l}\text { White nodules are more } \\
\text { prominent } 70-114 \mathrm{cmbs}\end{array}$ \\
\hline & & & $114-200$ & 10YR $4 / 3$ & Brown & Clay & Extremely Firm & Massive & $\mathrm{N} / \mathrm{A}$ & $\begin{array}{l}\text { mottles (10YR 6/8) 5-10\%, white nodules_1-3 mm) } \\
5 \% \text {, pebbles }(1-3 \mathrm{~mm}) 5 \%\end{array}$ & Unobserved & \\
\hline & & & $200+$ & $2.5 Y 5 / 3$ & $\begin{array}{l}\text { Light Olive } \\
\text { Brown } \\
\end{array}$ & - & - & - & - & - & Unobserved & \\
\hline \multirow{4}{*}{ BHT21 } & \multirow{4}{*}{ Bastrop } & \multirow{4}{*}{30310} & $0-37$ & 10YR 3/2 & $\begin{array}{c}\text { Very Dark } \\
\text { Grayish Brown }\end{array}$ & Clay Loam & $\begin{array}{c}\text { Firm to } \\
\text { Extremely Firm }\end{array}$ & $\begin{array}{l}\text { Subangular } \\
\text { Blocky }\end{array}$ & Weak & $\begin{array}{l}\text { roots } 10 \% \text {, rootlets } 15 \% \text {, snail shell fragments } 2 \% \text {, } \\
\text { pinholes } 5 \% \text {, insect burrows } 5 \%\end{array}$ & $\begin{array}{l}\text { Clear, Slightly } \\
\text { Wavy }\end{array}$ & $\begin{array}{l}\text { Column sample excavated on } \\
\text { west wall down to } 70 \mathrm{cmbs}\end{array}$ \\
\hline & & & $37-71$ & 10YR 3/2 & $\begin{array}{c}\text { Very Dark } \\
\text { Grayish Brown }\end{array}$ & Clay to Clay Loam & $\begin{array}{c}\text { Firm to } \\
\text { Extremely Firm }\end{array}$ & $\begin{array}{l}\text { Subangular } \\
\text { Blocky }\end{array}$ & Moderate & $\begin{array}{l}\text { roots } 3 \% \text {, rootlets } 1 \% \text {, mottles (10YR } 5 / 2 \text { ) } 20 \% \text {, } \\
\text { snail shell fragments } 2 \% \text {, insect burrows } 1 \% \text {, } \\
\text { pinholes } 5 \%\end{array}$ & Clear, Smooth & $\begin{array}{l}\text { Charcoal lens } 54-63 \mathrm{cmbs} \text {, } \\
\text { possible root burns; } \\
\text { decomposing organics }\end{array}$ \\
\hline & & & $71-128$ & 10YR $3 / 2$ & \begin{tabular}{c|} 
Very Dark \\
Grayish Brown \\
\end{tabular} & Clay & Extremely Firm & Massive & $\mathrm{N} / \mathrm{A}$ & $\begin{array}{l}\text { rootlets }<1 \% \text {, snail shell fragments }<1 \% \text {, pinholes } \\
2 \% \text {, white nodules }(1-3 \mathrm{~mm}) 5 \%\end{array}$ & $\begin{array}{l}\text { Gradual, } \\
\text { Smooth }\end{array}$ & \\
\hline & & & $128-148$ & $2.5 Y 4 / 3$ & Olive Brown & Clay & Extremely Firm & Massive & N/A & $\begin{array}{l}\text { rootlets < } 1 \% \text {, pinholes } 1 \% \text {, white nodules }(5-10 \\
\text { mm) } 10 \%\end{array}$ & Unobserved & \\
\hline \multirow{3}{*}{ BHT22 } & \multirow{3}{*}{ Bastrop } & \multirow{3}{*}{30310} & $0-21$ & 10YR 3/2 & $\begin{array}{l}\text { Very Dark } \\
\text { Grayish Brown }\end{array}$ & Clay Loam & $\begin{array}{c}\text { Firm to } \\
\text { Extremely Firm }\end{array}$ & $\begin{array}{l}\text { Subangular } \\
\text { Blocky }\end{array}$ & Weak & $\begin{array}{l}\text { roots } 10 \% \text {, rootlets } 15 \% \text {, snail shell fragments } 2 \% \text {, } \\
\text { pinholes } 5 \% \text {, insect burrows } 5 \%\end{array}$ & $\begin{array}{l}\text { Clear, Slightly } \\
\text { Wavy }\end{array}$ & \\
\hline & & & $21-111$ & 10YR 3/2 & \begin{tabular}{c|} 
Very Dark \\
Grayish Brown \\
\end{tabular} & Clay & Extremely Firm & Massive & $\mathrm{N} / \mathrm{A}$ & $\begin{array}{l}\text { rootlets }<1 \% \text {, snail shell fragments }<1 \% \text {, pinholes } \\
2 \% \text {, white nodules }(1-3 \mathrm{~mm}) 5 \%\end{array}$ & $\begin{array}{l}\text { Gradual, } \\
\text { Smooth }\end{array}$ & \\
\hline & & & $111-140$ & $2.5 Y 4 / 3$ & Olive Brown & Clay & Extremely Firm & Massive & $\mathrm{N} / \mathrm{A}$ & $\begin{array}{l}\text { rootlets }<1 \% \text {, pinholes } 1 \% \text {, white nodules }(5-10 \\
\mathrm{mm}) 10 \% \text {, worm casts }<1 \%\end{array}$ & Unobserved & \\
\hline \multirow{3}{*}{ BHT23 } & \multirow{3}{*}{ Bastrop } & \multirow{3}{*}{30310} & $0-50$ & 10YR 3/2 & $\begin{array}{l}\text { Very Dark } \\
\text { Grayish Brown }\end{array}$ & Clay Loam & $\begin{array}{c}\text { Firm to } \\
\text { Extremely Firm }\end{array}$ & $\begin{array}{l}\text { Subangular } \\
\text { Blocky }\end{array}$ & Weak & $\begin{array}{l}\text { roots } 10 \% \text {, rootlets } 15 \% \text {, snail shell fragments } 2 \% \text {, } \\
\text { pinholes } 5 \% \text {, insect burrows } 5 \%\end{array}$ & $\begin{array}{l}\text { Clear, Slightly } \\
\text { Wavy }\end{array}$ & \\
\hline & & & $50-89$ & $2.5 Y 4 / 3$ & Olive Brown & Clay & Extremely Firm & Massive & $\mathrm{N} / \mathrm{A}$ & $\begin{array}{l}\text { rootlets }<1 \% \text {, pinholes } 1 \% \text {, white nodules }(1-3 \mathrm{~mm}) \\
2 \%\end{array}$ & $\begin{array}{l}\text { Gradual, } \\
\text { Smooth }\end{array}$ & \\
\hline & & & $89-155$ & 10YR 3/1 & Very Dark Gray & Clay & Extremely Firm & Massive & $\mathrm{N} / \mathrm{A}$ & $\begin{array}{l}\text { rootlets }<1 \% \text {, snail shell fragments }<1 \% \text {, pinholes } \\
2 \% \text {, white nodules }(1-3 \mathrm{~mm}) 5 \%\end{array}$ & Unobserved & \\
\hline \multirow{3}{*}{ BHT24 } & \multirow{3}{*}{ Bastrop } & \multirow{3}{*}{30310} & $0-38$ & 10YR 3/2 & $\begin{array}{c}\text { Very Dark } \\
\text { Grayish Brown }\end{array}$ & Clay Loam & $\begin{array}{c}\text { Firm to } \\
\text { Extremely Firm }\end{array}$ & $\begin{array}{l}\text { Subangular } \\
\text { Blocky }\end{array}$ & Weak & $\begin{array}{l}\text { roots } 10 \% \text {, rootlets } 15 \% \text {, snail shell fragments } 2 \% \text {, } \\
\text { pinholes } 5 \% \text {, insect burrows } 5 \%\end{array}$ & $\begin{array}{l}\text { Clear, Slightly } \\
\text { Wavy }\end{array}$ & \\
\hline & & & $38-84$ & 10YR 3/2 & \begin{tabular}{c|} 
Very Dark \\
Grayish Brown \\
\end{tabular} & Clay & Extremely Firm & Massive & $\mathrm{N} / \mathrm{A}$ & $\begin{array}{l}\text { rootlets }<1 \% \text {, snail shell fragments }<1 \% \text {, pinholes } \\
2 \% \text {, white nodules }(1-3 \mathrm{~mm}) 5 \%\end{array}$ & $\begin{array}{l}\text { Diffuse, } \\
\text { Smooth }\end{array}$ & \\
\hline & & & $84-146$ & $2.5 Y 4 / 2$ & $\begin{array}{l}\text { Dark Grayish } \\
\text { Brown }\end{array}$ & Clay & Extremely Firm & Massive & $\mathrm{N} / \mathrm{A}$ & $\begin{array}{l}\text { rootlets }<1 \% \text {, pinholes } 1 \% \text {, white nodules }(5-10 \\
\text { mm) } 10 \% \text {, worm casts }<1 \%\end{array}$ & Unobserved & \\
\hline \multirow{4}{*}{ BHT25 } & \multirow{4}{*}{ Bastrop } & \multirow{4}{*}{30310} & $0-35$ & 10YR 3/2 & $\begin{array}{l}\text { Very Dark } \\
\text { Grayish Brown }\end{array}$ & Clay Loam & $\begin{array}{c}\text { Firm to } \\
\text { Extremely Firm }\end{array}$ & $\begin{array}{l}\text { Subangular } \\
\text { Blocky }\end{array}$ & Weak & $\begin{array}{l}\text { roots } 10 \% \text {, rootlets } 15 \% \text {, snail shell fragments } 2 \% \text {, } \\
\text { pinholes } 5 \% \text {, insect burrows } 5 \%\end{array}$ & $\begin{array}{l}\text { Clear, Slightly } \\
\text { Wavy }\end{array}$ & \\
\hline & & & $35-98$ & 10YR $3 / 2$ & \begin{tabular}{c|} 
Very Dark \\
Grayish Brown \\
\end{tabular} & Clay & Extremely Firm & Massive & $\mathrm{N} / \mathrm{A}$ & $\begin{array}{l}\text { rootlets }<1 \% \text {, snail shell fragments }<1 \% \text {, pinholes } \\
2 \% \text {, white nodules }(1-3 \mathrm{~mm}) 5 \%\end{array}$ & $\begin{array}{l}\text { Diffuse, } \\
\text { Smooth }\end{array}$ & \\
\hline & & & $98-150$ & $2.5 Y 4 / 2$ & $\begin{array}{l}\text { Dark Grayish } \\
\text { Brown }\end{array}$ & Clay & Extremely Firm & Massive & $\mathrm{N} / \mathrm{A}$ & $\begin{array}{l}\text { rootlets }<1 \% \text {, pinholes } 1 \% \text {, white nodules }(5-10 \\
\text { mm) } 10 \% \text {, worm casts }<1 \%\end{array}$ & Clear, Smooth & \\
\hline & & & $150-161$ & 10YR $4 / 4$ & $\begin{array}{c}\text { Dark Yellowish } \\
\text { Brown }\end{array}$ & Clay & Extremely Firm & Massive & $\mathrm{N} / \mathrm{A}$ & $\begin{array}{l}\text { iron redox } 20 \% \text {, mottles (10YR } 7 / 2) 5 \% \text {, mottles } \\
\text { (10YR } 4 / 1) 3 \% \text {, white nodules }(1-3 \mathrm{~mm}) 3 \%\end{array}$ & Unobserved & \\
\hline \multirow[t]{2}{*}{ BHT26 } & \multirow[t]{2}{*}{ Bastrop } & \multirow[t]{2}{*}{30310} & $0-60$ & 10YR $3 / 2$ & $\begin{array}{c}\text { Very Dark } \\
\text { Grayish Brown }\end{array}$ & Clay Loam & $\begin{array}{c}\text { Firm to } \\
\text { Extremely Firm }\end{array}$ & $\begin{array}{l}\text { Subangular } \\
\text { Blocky }\end{array}$ & Weak & $\begin{array}{l}\text { roots } 10 \% \text {, rootlets } 15 \% \text {, snail shell fragments } 2 \% \text {, } \\
\text { pinholes } 5 \% \text {, insect burrows } 5 \%\end{array}$ & $\begin{array}{l}\text { Clear, Slightly } \\
\text { Wavy }\end{array}$ & \\
\hline & & & $60-146$ & 10YR 3/2 & \begin{tabular}{c|} 
Very Dark \\
Grayish Brown
\end{tabular} & Clay & Extremely Firm & Massive & $\mathrm{N} / \mathrm{A}$ & $\begin{array}{l}\text { rootlets }<1 \% \text {, snail shell fragments }<1 \% \text {, pinholes } \\
2 \% \text {, white nodules }(1-3 \mathrm{~mm}) 5 \%\end{array}$ & Unobserved & \\
\hline \multirow{3}{*}{ BHT01 } & & & $0-56$ & $7.5 Y R 4 / 2$ & Brown & Sandy Clay Loam & Friable & $\begin{array}{l}\text { Subangular } \\
\text { Blocky }\end{array}$ & Moderate & $\begin{array}{l}\text { rootlets } 5-20 \% \text {, iron oxide }(>.5 \mathrm{~cm}) 2 \% \text {, insect } \\
\text { burrows } 1 \% \text {, pinholes } 5 \%\end{array}$ & \begin{tabular}{|l|} 
Clear - \\
Gradual, \\
Smooth - \\
Wavy
\end{tabular} & $\begin{array}{l}\text { Rootzone } 0-10 \mathrm{~cm} \text {, sand } \\
\text { pockets }(1-4 \mathrm{~cm}) 1 \% 10 \mathrm{YR} 5 / 4\end{array}$ \\
\hline & Lee & 20265 & $56-88$ & 10YR $4 / 3$ & Brown & Clay Loam & Firm & Angular Blocky & \begin{tabular}{|c|}
$\begin{array}{c}\text { Moderate to } \\
\text { Strong }\end{array}$ \\
\end{tabular} & rootlets $2 \%$, pinholes $2 \%$ & Diffuse, Wavy & \\
\hline & & & $88-156$ & 10YR $5 / 4$ & Yellowish Brown & Sandy Clay & Loose & Granular & Unobserved & Mottles (10YR $5 / 1 ; 1-5 \mathrm{~cm}$ ) $15-20 \%$, rootlets $5 \%$ & Unobserved & $\begin{array}{l}\text { Saturated, water seeping in from } \\
\text { walls at top of level, standing } \\
\text { water at bottom of trench }\end{array}$ \\
\hline & & & $0-41$ & 7.5YR $2.5 / 2$ & Very Dark Brown & Sandy Clay Loam & Friable & $\begin{array}{l}\text { Subangular } \\
\text { Blocky }\end{array}$ & Moderate & $\begin{array}{l}\text { rounded pebbles }(<2 \% \text { limestone) } 5 \% \text {, cobbles } \\
<1 \% \text {, roots } 15 \% \text {, rootlets } 20 \% \text {, sand pockets } \\
(7.5 \text { YR } 5 / 4)>5 \% \text {, pebbles } 5 \% \text {, insect burrows } 5 \%\end{array}$ & Clear, Wavy & Root zone $0-5 \mathrm{~cm}$ \\
\hline BHT02 & Lee & 20265 & $41-89$ & $7.5 Y R$ 4/3 & Brown & Sandy Clay Loam & Friable & $\begin{array}{l}\text { Subangular } \\
\text { Blocky }\end{array}$ & Moderate & $\begin{array}{l}\text { rounded to subrounded gravels }<5 \% \text {, rootlets } 5 \% \text {, } \\
\text { insect burrows }<5 \% \text {, pinholes }<5 \% \text {, iron oxide }(1-2 \\
\mathrm{mm}) 10 \%\end{array}$ & $\begin{array}{l}\text { Gradual, } \\
\text { smooth }\end{array}$ & $\begin{array}{l}\text { granular sand, sand lenses after } \\
70 \mathrm{~cm}\end{array}$ \\
\hline & & & 89-104 & 7.5YR 4/4 & Brown & Sandy Loam & Friable & Granular & Unobserved & $\begin{array}{l}\text { iron oxide }(2-5 \mathrm{~cm}) 15-20 \% \text {, gray mottles (10YR } \\
5 / 2-5 / 1) 30-40 \%\end{array}$ & Clear, smooth & Saturated \\
\hline & & & $104-126$ & $2.5 Y R 4 / 8$ & Red & Sandy Clay & Friable & Angular Blocky & Moderate & gray mottle (10YR 5/2-5/1) 20-30\% & Unobserved & \\
\hline
\end{tabular}




\begin{tabular}{|c|c|c|c|c|c|c|c|c|c|}
\hline Site No. & $\begin{array}{l}\text { Temp Site } \\
\text { No. }\end{array}$ & $\begin{array}{l}\text { Backhoe } \\
\text { Trench } \\
\text { No. }\end{array}$ & Level & Depth (cmbs) & $\begin{array}{l}\text { Munsell Soil } \\
\text { Value }\end{array}$ & Munsell Soil Color & Soil Texture & $\begin{array}{l}\text { Positive (P) } \\
\text { or } \\
\text { Negative (N) }\end{array}$ & $\begin{array}{l}\text { Comments/ } \\
\text { Cultural Materials }\end{array}$ \\
\hline \multirow{13}{*}{ 41BP960 } & \multirow{13}{*}{ FS63 } & \multirow{13}{*}{ ВНT07 } & 1 & $0-10$ & 10YR 4/2 & Dark grayish brown & Loamy Clay Loam & $\mathrm{N}$ & - \\
\hline & & & 2 & $10-20$ & 10YR 4/2 & Dark grayish brown & Loamy Clay Loam & $\mathrm{N}$ & - \\
\hline & & & 3 & $20-30$ & 10YR 5/3 & Brown & Sandy Clay Loam & $\mathrm{N}$ & - \\
\hline & & & 4 & $30-40$ & 10YR 5/3 & Brown & Sandy Clay Loam & $\mathrm{N}$ & - \\
\hline & & & 5 & $40-50$ & 10YR 4/1-4/2 & $\begin{array}{c}\text { Dark gray to } \\
\text { dark grayish brown }\end{array}$ & Clay Loam & $\mathrm{N}$ & - \\
\hline & & & 6 & $50-60$ & 10YR 4/1-4/2 & $\begin{array}{c}\text { Dark gray to } \\
\text { dark grayish brown }\end{array}$ & Clay Loam & $\mathrm{N}$ & - \\
\hline & & & 7 & $60-70$ & 10YR 4/1-4/2 & $\begin{array}{c}\text { Dark gray to } \\
\text { dark grayish brown }\end{array}$ & Clay Loam & $\mathrm{N}$ & - \\
\hline & & & 8 & $70-80$ & 10YR 4/1-4/2 & $\begin{array}{c}\text { Dark gray to } \\
\text { dark grayish brown }\end{array}$ & Clay Loam & $\mathrm{N}$ & - \\
\hline & & & 9 & $80-90$ & 10YR 5/3-6/3 & Brown to pale brown & Silty Clay Loam & $\mathrm{P}$ & 1 tertiary flake at $83 \mathrm{cmbs}$. \\
\hline & & & 10 & $90-100$ & 10YR 5/3-6/3 & Brown to pale brown & Silty Clay Loam & $\mathrm{P}$ & 4 tertiary flakes at $90,91,92$, and $93 \mathrm{cmbs}$. \\
\hline & & & 11 & $100-110$ & 10YR 5/3-6/3 & Brown to pale brown & Silty Clay Loam & $\mathrm{P}$ & Possible fired quartzite at $105 \mathrm{cmbs}$. \\
\hline & & & 12 & $110-120$ & 10YR 5/3-6/3 & Brown to pale brown & Silty Clay Loam & $\mathrm{N}$ & \\
\hline & & & 13 & $120-130$ & 10YR 3/1 & Very dark gray & Loamy Clay & $\mathrm{N}$ & - \\
\hline \multirow{13}{*}{ 41BP960 } & \multirow{13}{*}{ FS63 } & \multirow{13}{*}{ ВНT09 } & 1 & $0-10$ & 10YR 4/2 & Dark grayish brown & Loamy Clay Loam & $\mathrm{N}$ & - \\
\hline & & & 2 & $10-20$ & 10YR 4/2 & Dark grayish brown & Loamy Clay Loam & $\mathrm{N}$ & - \\
\hline & & & 3 & $20-30$ & 10YR 5/3 & Brown & Sandy Clay Loam & $\mathrm{N}$ & - \\
\hline & & & 4 & $30-40$ & 10YR 5/3 & Brown & Sandy Clay Loam & $\mathrm{N}$ & - \\
\hline & & & 5 & $40-50$ & 10YR 4/1-4/2 & $\begin{array}{c}\text { Dark gray to } \\
\text { dark grayish brown }\end{array}$ & Clay Loam & $\mathrm{N}$ & - \\
\hline & & & 6 & $50-60$ & 10YR 4/1-4/2 & $\begin{array}{c}\text { Dark gray to } \\
\text { dark grayish brown }\end{array}$ & Clay Loam & $\mathrm{N}$ & - \\
\hline & & & 7 & $60-70$ & 10YR 4/1-4/2 & $\begin{array}{c}\text { Dark gray to } \\
\text { dark grayish brown }\end{array}$ & Clay Loam & $\mathrm{N}$ & - \\
\hline & & & 8 & $70-80$ & 10YR 4/1-4/2 & $\begin{array}{c}\text { Dark gray to } \\
\text { dark grayish brown }\end{array}$ & Clay Loam & $\mathrm{N}$ & - \\
\hline & & & 9 & $80-90$ & 10YR 5/3-6/3 & $\begin{array}{c}\text { Brown to } \\
\text { pale brown }\end{array}$ & Silty Clay Loam & $\mathrm{P}$ & 17 tertiary flakes from 89 to $103 \mathrm{cmbs}$. \\
\hline & & & 10 & $90-100$ & 10YR 5/3-6/3 & $\begin{array}{l}\text { Brown to } \\
\text { pale brown }\end{array}$ & Silty Clay Loam & $\mathrm{P}$ & $\begin{array}{l}1 \text { secondary flake at } 91 \mathrm{cmbs}, 1 \text { unidentified bone at } \\
92 \mathrm{cmbs}, 1 \text { ceramic sherd and } 1 \text { primary flake at } 97 \\
\mathrm{cmbs} \text {, and } 1 \text { secondary flake at } 98 \mathrm{cmbs} \text {. }\end{array}$ \\
\hline & & & 11 & $100-110$ & 10YR 5/3-6/3 & $\begin{array}{l}\text { Brown to } \\
\text { pale brown }\end{array}$ & Silty Clay Loam & $\mathrm{P}$ & 1 unidentified bone at $101 \mathrm{cmbs}$. \\
\hline & & & 12 & $110-120$ & 10YR 6/3-6/4 & $\begin{array}{c}\text { Pale brown to } \\
\text { light yellowish brown }\end{array}$ & Silty Clay Loam & $\mathrm{N}$ & - \\
\hline & & & 13 & $120-130$ & 10YR 6/3-6/4 & $\begin{array}{c}\text { Pale brown to } \\
\text { light yellowish brown }\end{array}$ & Silty Clay Loam & $\mathrm{N}$ & - \\
\hline \multirow{30}{*}{ 41BP961 } & \multirow{30}{*}{ FS64 } & \multirow{30}{*}{ BHT04 } & 1 & $0-10$ & 10YR 4/2 & Dark grayish brown & Clay Loam & $\mathrm{N}$ & - \\
\hline & & & 2 & $10-20$ & 10YR 4/2 & Dark grayish brown & Clay Loam & $\mathrm{N}$ & - \\
\hline & & & 3 & $20-30$ & 10YR 4/2 & Dark grayish brown & Clay Loam & $\mathrm{N}$ & - \\
\hline & & & 4 & $30-40$ & 10YR 4/2 & Dark grayish brown & Clay Loam & $\mathrm{N}$ & - \\
\hline & & & 5 & $40-50$ & 10YR 5/2 & Grayish brown & Sandy Clay Loam & $\mathrm{N}$ & - \\
\hline & & & 6 & $50-60$ & 10YR 5/2 & Grayish brown & Sandy Clay Loam & $\mathrm{N}$ & - \\
\hline & & & 7 & $60-70$ & 10YR 5/2 & Grayish brown & Sandy Clay Loam & $\mathrm{N}$ & - \\
\hline & & & 8 & $70-80$ & 10YR 5/2 & Grayish brown & Sandy Clay Loam & $\mathrm{P}$ & 1 piece of thermal shatter at $79 \mathrm{cmbs}$. \\
\hline & & & 9 & $80-90$ & 10YR 4/2 & Dark grayish brown & Clay Loam & $\mathrm{P}$ & $\begin{array}{l}1 \text { tertiary flake at } 83 \mathrm{cmbs}, 1 \text { piece of thermal shatter } \\
\text { at } 85 \mathrm{cmbs} \text {, and } 1 \text { tertiary flake from } 80 \text { to } 90 \mathrm{cmbs} \text {. }\end{array}$ \\
\hline & & & 10 & $90-100$ & 10YR 4/2 & Dark grayish brown & Clay Loam & $\mathrm{P}$ & 1 tertiary flake from 90 to $100 \mathrm{cmbs}$. \\
\hline & & & 11 & $100-110$ & 10YR 4/2 & Dark grayish brown & Clay Loam & $\mathrm{N}$ & - \\
\hline & & & 12 & $110-120$ & 10YR 4/2 & Dark grayish brown & Clay Loam & $\mathrm{N}$ & - \\
\hline & & & 13 & $120-130$ & 10YR 4/2 & Dark grayish brown & Clay Loam & $\mathrm{N}$ & - \\
\hline & & & 14 & $130-140$ & $10 \mathrm{YR} 4 / 2$ & Dark grayish brown & Clay Loam & $\mathrm{N}$ & - \\
\hline & & & 15 & $140-150$ & $10 \mathrm{YR} 4 / 2$ & Dark grayish brown & Clay Loam & $\mathrm{N}$ & - \\
\hline & & & 16 & $150-160$ & 10YR 4/2 & Dark grayish brown & Clay Loam & $\mathrm{N}$ & - \\
\hline & & & 17 & $160-170$ & 10YR 4/2 & Dark grayish brown & Clay Loam & $\mathrm{N}$ & - \\
\hline & & & 18 & $170-180$ & 10YR 4/2 & Dark grayish brown & Clay Loam & $\mathrm{N}$ & - \\
\hline & & & 19 & $180-190$ & 10YR 4/2 & Dark grayish brown & Clay Loam & $\mathrm{N}$ & - \\
\hline & & & 20 & $190-200$ & 10YR 6/4 & Light Yellowish Brown & Sandy Clay Loam & $\mathrm{N}$ & - \\
\hline & & & 21 & $200-210$ & 10YR 6/4 & Light Yellowish Brown & Sandy Clay Loam & $\mathrm{N}$ & - \\
\hline & & & 22 & $210-220$ & 10YR 6/4 & Light Yellowish Brown & Sandy Clay Loam & $\mathrm{N}$ & - \\
\hline & & & 23 & $220-230$ & 10YR 6/4 & Light Yellowish Brown & Sandy Clay Loam & $\mathrm{N}$ & - \\
\hline & & & 24 & $230-240$ & 10YR 6/4 & Light Yellowish Brown & Sandy Clay Loam & $\mathrm{N}$ & - \\
\hline & & & 25 & $240-250$ & 10YR 6/4 & Light Yellowish Brown & Sandy Clay Loam & $\mathrm{N}$ & - \\
\hline & & & 26 & $250-260$ & 10YR 6/4 & Light Yellowish Brown & Sandy Clay Loam & $\mathrm{N}$ & - \\
\hline & & & 27 & $260-270$ & 10YR 6/4 & Light Yellowish Brown & Sandy Clay Loam & $\mathrm{N}$ & - \\
\hline & & & 28 & $270-280$ & 10YR 6/4 & Light Yellowish Brown & Sandy Clay Loam & $\mathrm{N}$ & - \\
\hline & & & 29 & $280-290$ & 10YR 6/4 & Light Yellowish Brown & Sandy Clay Loam & $\mathrm{N}$ & - \\
\hline & & & 30 & $290-300$ & 10YR 6/4 & Light Yellowish Brown & Sandy Clay Loam & $\mathrm{N}$ & - \\
\hline
\end{tabular}




\begin{tabular}{|c|c|c|c|c|c|c|c|c|c|}
\hline Site No. & \begin{tabular}{|c|} 
Temp Site \\
No.
\end{tabular} & $\begin{array}{c}\text { Backhoe } \\
\text { Trench } \\
\text { No. }\end{array}$ & Level & Depth (cmbs) & $\begin{array}{c}\text { Munsell Soil } \\
\text { Value }\end{array}$ & Munsell Soil Color & Soil Texture & $\begin{array}{c}\text { Positive (P) } \\
\text { or } \\
\text { Negative (N) }\end{array}$ & $\begin{array}{c}\text { Comments/ } \\
\text { Cultural Materials }\end{array}$ \\
\hline \multirow{30}{*}{ 41BP961 } & \multirow{30}{*}{ FS64 } & \multirow{30}{*}{ BHT10 } & 1 & $0-10$ & 10YR 4/2 & Dark grayish brown & Loamy Clay Loam & $\mathrm{N}$ & - \\
\hline & & & 2 & $10-20$ & 10YR 4/2 & Dark grayish brown & Loamy Clay Loam & $\mathrm{N}$ & - \\
\hline & & & 3 & $20-30$ & 10YR 4/3 & Brown & Loam to Clay Loam & $\mathrm{N}$ & - \\
\hline & & & 4 & $30-40$ & 10YR 4/3 & Brown & Loam to Clay Loam & $\mathrm{N}$ & - \\
\hline & & & 5 & $40-50$ & 10YR 5/3 & Brown & Sandy Clay Loam & $\mathrm{N}$ & - \\
\hline & & & 6 & $50-60$ & 10YR 5/3 & Brown & Sandy Clay Loam & $\mathrm{N}$ & - \\
\hline & & & 7 & $60-70$ & 10YR 5/3 & Brown & Sandy Clay Loam & $\mathrm{N}$ & - \\
\hline & & & 8 & $70-80$ & 10YR 4/1-4/2 & $\begin{array}{c}\text { Dark gray to } \\
\text { dark grayish brown }\end{array}$ & Clay Loam & $\mathrm{N}$ & - \\
\hline & & & 9 & $80-90$ & 10YR 4/1-4/2 & $\begin{array}{c}\text { Dark gray to } \\
\text { dark grayish brown }\end{array}$ & Clay Loam & $\mathrm{N}$ & - \\
\hline & & & 10 & $90-100$ & 10YR 4/1-4/2 & $\begin{array}{c}\text { Dark gray to } \\
\text { dark grayish brown }\end{array}$ & Clay Loam & $\mathrm{N}$ & - \\
\hline & & & 11 & $100-110$ & 10YR 5/3-6/3 & $\begin{array}{c}\text { Brown to } \\
\text { pale brown }\end{array}$ & Silty Clay Loam & $\mathrm{N}$ & - \\
\hline & & & 12 & $110-120$ & 10YR 5/3-6/3 & $\begin{array}{l}\text { Brown to } \\
\text { pale brown }\end{array}$ & Silty Clay Loam & $\mathrm{N}$ & - \\
\hline & & & 13 & $120-130$ & 10YR 5/3-6/3 & $\begin{array}{l}\text { Brown to } \\
\text { pale brown }\end{array}$ & Silty Clay Loam & $\mathrm{N}$ & - \\
\hline & & & 14 & $130-140$ & 10YR 5/3-6/3 & $\begin{array}{l}\text { Brown to } \\
\text { pale brown }\end{array}$ & Silty Clay Loam & $\mathrm{N}$ & - \\
\hline & & & 15 & $140-150$ & 10YR 5/3-6/3 & $\begin{array}{l}\text { Brown to } \\
\text { pale brown }\end{array}$ & Silty Clay Loam & $\mathrm{N}$ & - \\
\hline & & & 16 & $150-160$ & 10YR 6/3-6/4 & $\begin{array}{c}\text { Pale brown to } \\
\text { light yellowish brown }\end{array}$ & Silty Clay Loam & $\mathrm{N}$ & - \\
\hline & & & 17 & $160-170$ & 10YR 6/3-6/4 & $\begin{array}{c}\text { Pale brown to } \\
\text { light yellowish brown }\end{array}$ & Silty Clay Loam & $\mathrm{N}$ & - \\
\hline & & & 18 & $170-180$ & 10YR 6/3-6/4 & $\begin{array}{c}\text { Pale brown to } \\
\text { light yellowish brown }\end{array}$ & Silty Clay Loam & $\mathrm{N}$ & - \\
\hline & & & 19 & $180-190$ & 10YR 6/3-6/4 & $\begin{array}{c}\text { Pale brown to } \\
\text { light yellowish brown }\end{array}$ & Silty Clay Loam & $\mathrm{N}$ & - \\
\hline & & & 20 & $190-200$ & 10YR 6/3-6/4 & $\begin{array}{c}\text { Pale brown to } \\
\text { light yellowish brown }\end{array}$ & Silty Clay Loam & $\mathrm{N}$ & - \\
\hline & & & 21 & $200-210$ & 10YR 3/1 & Very dark gray & Loamy Clay & $\mathrm{N}$ & - \\
\hline & & & 22 & $210-220$ & 10YR 3/1 & Very dark gray & Loamy Clay & $\mathrm{N}$ & - \\
\hline & & & 23 & $220-230$ & 10YR 3/1 & Very dark gray & Loamy Clay & $\mathrm{N}$ & - \\
\hline & & & 24 & $230-240$ & 10YR 3/1 & Very dark gray & Loamy Clay & $\mathrm{N}$ & - \\
\hline & & & 25 & $240-250$ & 10YR 3/1 & Very dark gray & Loamy Clay & $\mathrm{N}$ & - \\
\hline & & & 26 & $250-260$ & 10YR 3/1 & Very dark gray & Loamy Clay & $\mathrm{N}$ & - \\
\hline & & & 27 & $260-270$ & 10YR 3/1 & Very dark gray & Loamy Clay & $\mathrm{N}$ & - \\
\hline & & & 28 & $270-280$ & 10YR 3/1 & Very dark gray & Loamy Clay & $\mathrm{N}$ & - \\
\hline & & & 29 & $280-290$ & 10YR 3/1 & Very dark gray & Loamy Clay & $\mathrm{N}$ & - \\
\hline & & & 30 & $290-305$ & 10YR 3/1 & Very dark gray & Loamy Clay & $\mathrm{N}$ & - \\
\hline \multirow{14}{*}{ 41BP961 } & \multirow{14}{*}{ FS64 } & \multirow{14}{*}{ BHT11 } & 1 & $0-10$ & 10YR 4/2 & Dark grayish brown & Loamy Clay Loam & $\mathrm{N}$ & - \\
\hline & & & 2 & $10-20$ & 10YR 5/3 & Brown & Sandy Clay Loam & $\mathrm{N}$ & - \\
\hline & & & 3 & $20-30$ & 10YR 4/1-4/2 & $\begin{array}{c}\text { Dark gray to } \\
\text { dark grayish brown }\end{array}$ & Clay Loam & $\mathrm{N}$ & - \\
\hline & & & 4 & $30-40$ & 10YR 4/1-4/2 & $\begin{array}{c}\text { Dark gray to } \\
\text { dark grayish brown }\end{array}$ & Clay Loam & $\mathrm{N}$ & - \\
\hline & & & 5 & $40-50$ & 10YR 5/3-6/3 & $\begin{array}{c}\text { Brown to } \\
\text { pale brown }\end{array}$ & Silty Clay Loam & $\mathrm{N}$ & - \\
\hline & & & 6 & $50-60$ & 10YR 5/3-6/3 & $\begin{array}{l}\text { Brown to } \\
\text { pale brown }\end{array}$ & Silty Clay Loam & $\mathrm{N}$ & - \\
\hline & & & 7 & $60-70$ & 10YR 5/3-6/3 & $\begin{array}{c}\text { Brown to } \\
\text { pale brown }\end{array}$ & Silty Clay Loam & $\mathrm{N}$ & - \\
\hline & & & 8 & $70-80$ & 10YR 5/3-6/3 & $\begin{array}{l}\text { Brown to } \\
\text { pale brown }\end{array}$ & Silty Clay Loam & $\mathrm{N}$ & - \\
\hline & & & 9 & $80-90$ & 10YR 3/1 & Very dark gray & Loamy Clay & $\mathrm{N}$ & - \\
\hline & & & 10 & $90-100$ & 10YR 3/1 & Very dark gray & Loamy Clay & $\mathrm{N}$ & - \\
\hline & & & 11 & $100-110$ & 10YR 3/1 & Very dark gray & Loamy Clay & $\mathrm{N}$ & - \\
\hline & & & 12 & $110-120$ & 10YR 3/1 & Very dark gray & Loamy Clay & $\mathrm{N}$ & - \\
\hline & & & 13 & $120-130$ & 10YR 3/1 & Very dark gray & Loamy Clay & $\mathrm{N}$ & - \\
\hline & & & 14 & $130-140$ & 10YR 3/1 & Very dark gray & Loamy Clay & $\mathrm{N}$ & - \\
\hline
\end{tabular}




\begin{tabular}{|c|c|c|c|c|c|c|c|c|c|}
\hline Site No. & $\begin{array}{c}\text { Temp Site } \\
\text { No. }\end{array}$ & $\begin{array}{c}\text { Backhoe } \\
\text { Trench } \\
\text { No. }\end{array}$ & Level & Depth (cmbs) & $\begin{array}{l}\text { Munsell Soil } \\
\text { Value }\end{array}$ & Munsell Soil Color & Soil Texture & $\begin{array}{c}\text { Positive (P) } \\
\text { or } \\
\text { Negative (N) }\end{array}$ & $\begin{array}{c}\text { Comments/ } \\
\text { Cultural Materials }\end{array}$ \\
\hline \multirow{15}{*}{ 41BP961 } & \multirow{15}{*}{ FS64 } & \multirow{15}{*}{ BHT12 } & 1 & $0-10$ & 10YR $4 / 2$ & Dark grayish brown & Loamy Clay Loam & $\mathrm{N}$ & - \\
\hline & & & 2 & $10-20$ & 10YR 4/2 & Dark grayish brown & Loamy Clay Loam & $\mathrm{N}$ & - \\
\hline & & & 3 & $20-30$ & 10YR $5 / 3$ & Brown & Sandy Clay Loam & $\mathrm{N}$ & - \\
\hline & & & 4 & $30-40$ & 10YR $5 / 3$ & Brown & Sandy Clay Loam & $\mathrm{N}$ & - \\
\hline & & & 5 & $40-50$ & 10YR $4 / 1-4 / 2$ & $\begin{array}{c}\text { Dark gray to } \\
\text { dark grayish brown }\end{array}$ & Loamy Clay & $\mathrm{N}$ & - \\
\hline & & & 6 & $50-60$ & 10YR 4/1-4/2 & $\begin{array}{c}\text { Dark gray to } \\
\text { dark grayish brown }\end{array}$ & Loamy Clay & $\mathrm{N}$ & - \\
\hline & & & 7 & $60-70$ & 10YR 4/1-4/2 & $\begin{array}{c}\text { Dark gray to } \\
\text { dark grayish brown }\end{array}$ & Loamy Clay & $\mathrm{N}$ & - \\
\hline & & & 8 & $70-80$ & 10YR 4/1-4/2 & $\begin{array}{c}\text { Dark gray to } \\
\text { dark grayish brown }\end{array}$ & Loamy Clay & $\mathrm{N}$ & - \\
\hline & & & 9 & $80-90$ & 10YR 4/1-4/2 & $\begin{array}{c}\text { Dark gray to } \\
\text { dark grayish brown }\end{array}$ & Loamy Clay & $\mathrm{N}$ & - \\
\hline & & & 10 & $90-100$ & 10YR 4/1-4/2 & $\begin{array}{c}\text { Dark gray to } \\
\text { dark grayish brown }\end{array}$ & Loamy Clay & $\mathrm{N}$ & - \\
\hline & & & 11 & $100-110$ & 10YR 3/1 & Very dark gray & Loamy Clay & $\mathrm{N}$ & - \\
\hline & & & 12 & $110-120$ & 10YR 3/1 & Very dark gray & Loamy Clay & $\mathrm{N}$ & - \\
\hline & & & 13 & $120-130$ & 10YR 3/1 & Very dark gray & Loamy Clay & $\mathrm{N}$ & - \\
\hline & & & 14 & $130-140$ & 10YR 3/1 & Very dark gray & Loamy Clay & $\mathrm{N}$ & - \\
\hline & & & 15 & $140-150$ & 10YR 3/1 & Very dark gray & Loamy Clay & $\mathrm{N}$ & - \\
\hline \multirow{15}{*}{ 41BP961 } & \multirow{15}{*}{ FS64 } & \multirow{15}{*}{ BHT13 } & 1 & $0-10$ & 10YR 4/2 & Dark grayish brown & Loamy Clay Loam & $\mathrm{N}$ & - \\
\hline & & & 2 & $10-20$ & 10YR 4/2 & Dark grayish brown & Loamy Clay Loam & $\mathrm{N}$ & - \\
\hline & & & 3 & $20-30$ & 10YR 4/3 & Brown & Loam to Clay Loam & $\mathrm{N}$ & - \\
\hline & & & 4 & $30-40$ & 10YR 4/3 & Brown & Loam to Clay Loam & $\mathrm{N}$ & - \\
\hline & & & 5 & $40-50$ & 10YR $5 / 3$ & Brown & Sandy Clay Loam & $\mathrm{N}$ & - \\
\hline & & & 6 & $50-60$ & 10YR $4 / 1-4 / 2$ & $\begin{array}{c}\text { Dark gray to } \\
\text { dark grayish brown }\end{array}$ & Clay Loam & $\mathrm{N}$ & - \\
\hline & & & 7 & $60-70$ & 10YR 4/1-4/2 & $\begin{array}{c}\text { Dark gray to } \\
\text { dark grayish brown }\end{array}$ & Clay Loam & $\mathrm{N}$ & - \\
\hline & & & 8 & $70-80$ & 10YR 5/3-6/3 & $\begin{array}{c}\text { Brown to } \\
\text { pale brown }\end{array}$ & Silty Clay Loam & $\mathrm{N}$ & - \\
\hline & & & 9 & $80-90$ & 10YR 5/3-6/3 & $\begin{array}{c}\text { Brown to } \\
\text { pale brown }\end{array}$ & Silty Clay Loam & $\mathrm{N}$ & - \\
\hline & & & 10 & $90-100$ & 10YR 5/3-6/3 & $\begin{array}{c}\text { Brown to } \\
\text { pale brown }\end{array}$ & Silty Clay Loam & $\mathrm{N}$ & - \\
\hline & & & 11 & $100-110$ & 10YR 5/3-6/3 & $\begin{array}{c}\text { Brown to } \\
\text { pale brown }\end{array}$ & Silty Clay Loam & $\mathrm{N}$ & - \\
\hline & & & 12 & $110-120$ & 10YR 5/3-6/3 & $\begin{array}{c}\text { Brown to } \\
\text { pale brown }\end{array}$ & Silty Clay Loam & $\mathrm{N}$ & - \\
\hline & & & 13 & $120-130$ & 10YR 5/3-6/3 & $\begin{array}{c}\text { Brown to } \\
\text { pale brown }\end{array}$ & Silty Clay Loam & $\mathrm{N}$ & - \\
\hline & & & 14 & $130-140$ & 10YR 5/3-6/3 & $\begin{array}{c}\text { Brown to } \\
\text { pale brown }\end{array}$ & Silty Clay Loam & $\mathrm{N}$ & - \\
\hline & & & 15 & $140-150$ & 10YR 5/3-6/3 & $\begin{array}{c}\text { Brown to } \\
\text { pale brown }\end{array}$ & Silty Clay Loam & $\mathrm{N}$ & - \\
\hline \multirow{14}{*}{ 41BP961 } & \multirow{14}{*}{ FS64 } & \multirow{14}{*}{ BHT14 } & 1 & $0-10$ & 10YR 4/2 & Dark grayish brown & Loamy Clay Loam & $\mathrm{N}$ & - \\
\hline & & & 2 & $10-20$ & 10YR $4 / 2$ & Dark grayish brown & Loamy Clay Loam & $\mathrm{N}$ & - \\
\hline & & & 3 & $20-30$ & 10YR $4 / 3$ & Brown & Loam to Clay Loam & $\mathrm{N}$ & - \\
\hline & & & 4 & $30-40$ & 10YR $4 / 3$ & Brown & Loam to Clay Loam & $\mathrm{N}$ & - \\
\hline & & & 5 & $40-50$ & 10YR 5/3 & Brown & Sandy Clay Loam & $\mathrm{N}$ & - \\
\hline & & & 6 & $50-60$ & 10YR $4 / 1-4 / 2$ & $\begin{array}{c}\text { Dark gray to } \\
\text { dark grayish brown }\end{array}$ & Clay Loam & $\mathrm{N}$ & - \\
\hline & & & 7 & $60-70$ & 10YR $4 / 1-4 / 2$ & $\begin{array}{c}\text { Dark gray to } \\
\text { dark grayish brown }\end{array}$ & Clay Loam & $\mathrm{N}$ & - \\
\hline & & & 8 & $70-80$ & 10YR $4 / 1-4 / 2$ & $\begin{array}{c}\text { Dark gray to } \\
\text { dark grayish brown }\end{array}$ & Clay Loam & $\mathrm{N}$ & - \\
\hline & & & 9 & $80-90$ & 10YR $4 / 1-4 / 2$ & $\begin{array}{c}\text { Dark gray to } \\
\text { dark grayish brown }\end{array}$ & Clay Loam & $\mathrm{N}$ & - \\
\hline & & & 10 & $90-100$ & 10YR 5/3-6/3 & $\begin{array}{l}\text { Brown to } \\
\text { pale brown }\end{array}$ & Silty Clay Loam & $\mathrm{P}$ & A single secondary flake at $97 \mathrm{cmbs}$. \\
\hline & & & 11 & $100-110$ & 10YR $5 / 3-6 / 3$ & $\begin{array}{c}\text { Brown to } \\
\text { pale brown }\end{array}$ & Silty Clay Loam & $\mathrm{N}$ & - \\
\hline & & & 12 & $110-120$ & 10YR 5/3-6/3 & $\begin{array}{c}\text { Brown to } \\
\text { pale brown }\end{array}$ & Silty Clay Loam & $\mathrm{N}$ & - \\
\hline & & & 13 & $120-130$ & 10YR 5/3-6/3 & $\begin{array}{c}\text { Brown to } \\
\text { pale brown }\end{array}$ & Silty Clay Loam & $\mathrm{N}$ & - \\
\hline & & & 14 & $130-140$ & 10YR 5/3-6/3 & $\begin{array}{c}\text { Brown to } \\
\text { pale brown }\end{array}$ & Silty Clay Loam & $\mathrm{N}$ & - \\
\hline
\end{tabular}




\section{APPENDix D. 41GU177 InTERIM TeSTING REPORT AND RESEARCH DESIGN}


This page intentionally left blank. 


\section{Interim Report: Archaeological Investigations at 41GU177 on the Guadalupe River, Guadalupe County, Texas}

Texas Antiquities Permit No. 7295

November 2017

SUBMITTED TO:

VRRSP Consultants, LLC.

SUBMITTED BY:

SWCA Environmental Consultants 4407 Monterey Oaks Boulevard

Building 1, Suite 110

Austin, Texas 78749 



\title{
INTERIM REPORT: ARCHAEOLOGICAL INVESTIGATIONS AT 41GU177 ON THE GUADALUPE RIVER, GUADALUPE COUNTY, TEXAS
}

\author{
Prepared for \\ VRRSP CONSULTANTS, LLC. \\ 2000 NW Loop 410 \\ San Antonio, Texas 78213 \\ Prepared by \\ Daniel Rodriguez, Ken Lawrence, and Brandon S. Young \\ Principal Investigator \\ Brandon Young, M.A., RPA \\ SWCA ENVIRONMENTAL CONSULTANTS \\ 4407 Monterey Oaks Boulevard \\ Building 1, Suite 110 \\ Austin, Texas 78749 \\ www.swca.com
}

Texas Antiquities Permit No. 7295

SWCA Project No. 31410

November 2, 2017 
This page intentionally left blank. 


\section{TABLE OF CONTENTS}

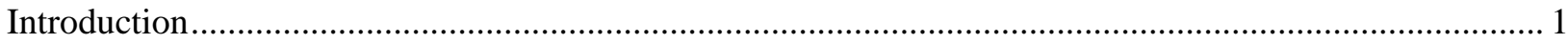

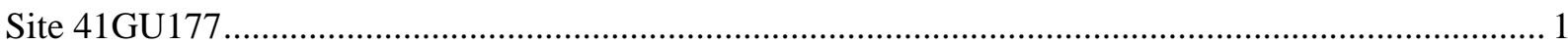

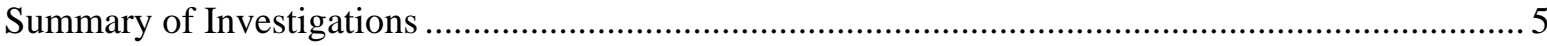

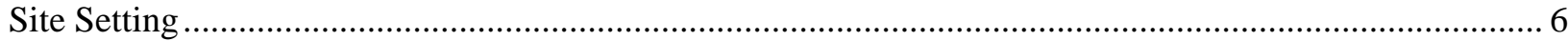

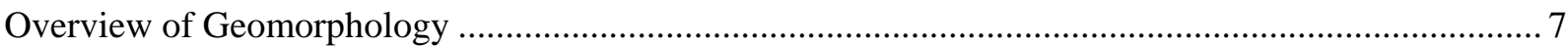

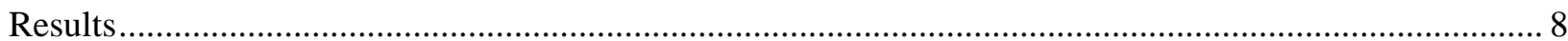

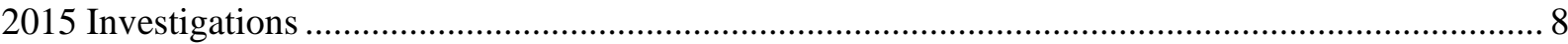

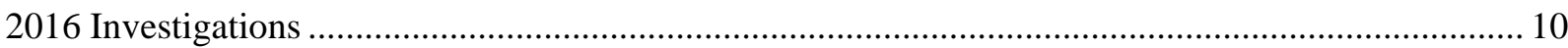

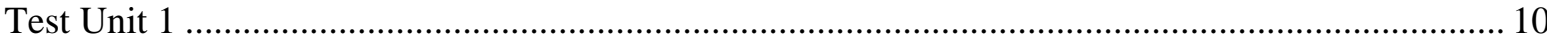

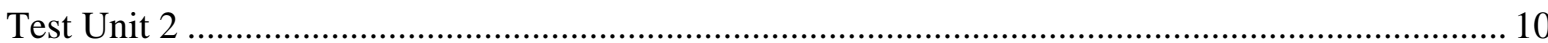

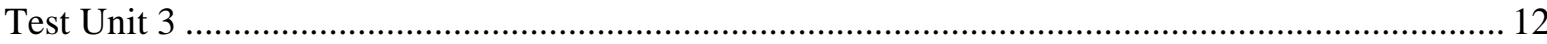

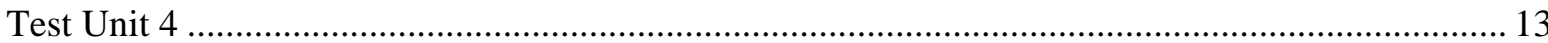

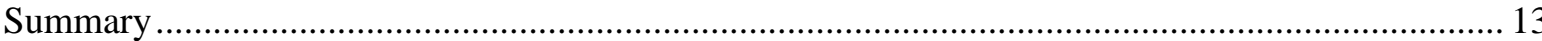

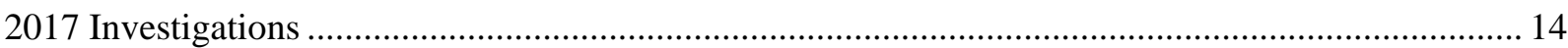

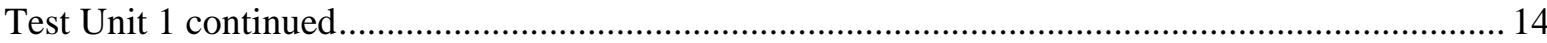

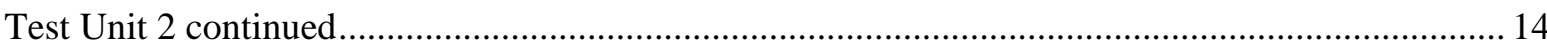

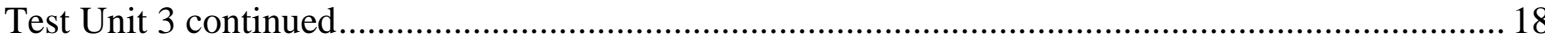

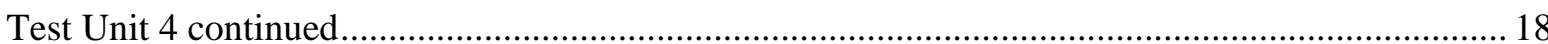

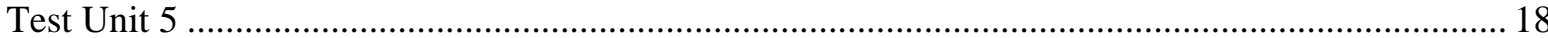

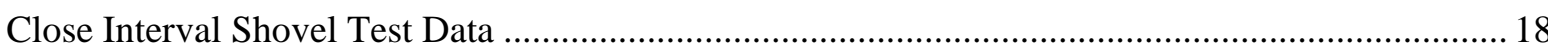

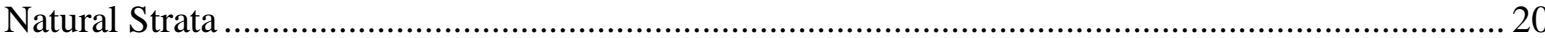

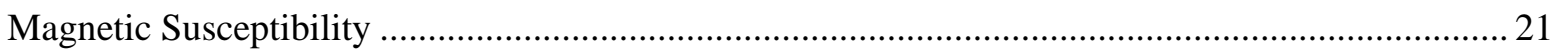

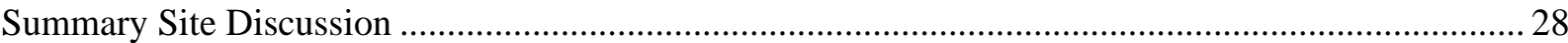

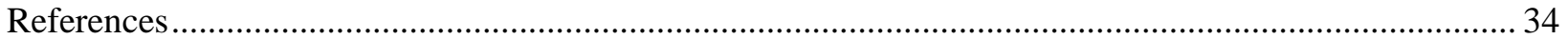




\section{LIST OF FIGURES}

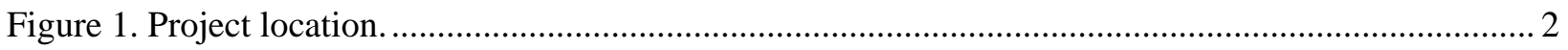

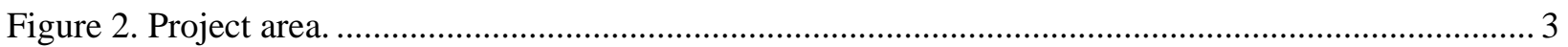

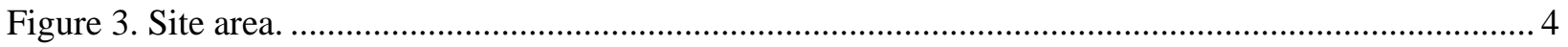

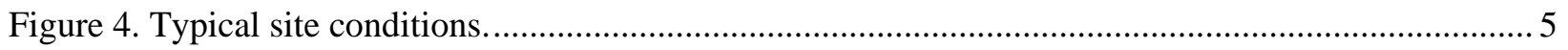

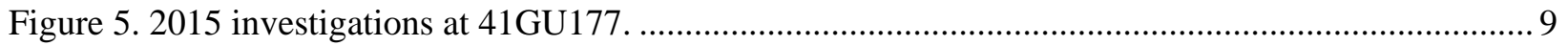

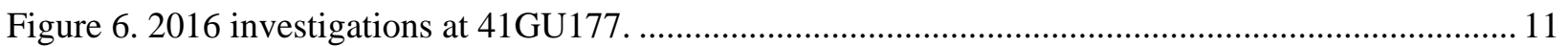

Figure 7. Arrow points and arrow point fragments recovered from 41GU177: a-c. cornernotched, broad stem variant Scallorn arrow points; d. Scallorn preform; e. untyped arrow point fragment; f. untyped arrow point fragment; g. untyped arrow point (possible Sabinal specimen); h. Untyped arrow point preform; i-j. distal tips of an untyped arrow points; k. untyped arrow point fragment; and l. untyped arrow point

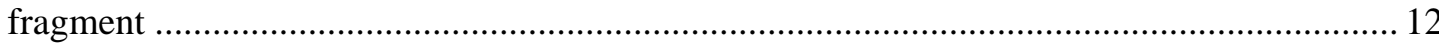

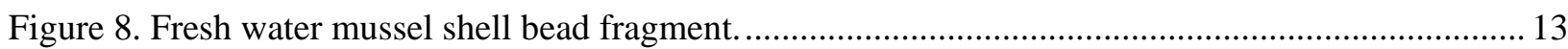

Figure 9. 2017 additional excavations in the proposed bore pit and adjacent work area......................... 15

Figure 10. 2017 close interval shovel test and additional backhoe trench plots. ......................................... 16

Figure 11. Artifact density plot generated from close interval shovel testing data, backhoe trench

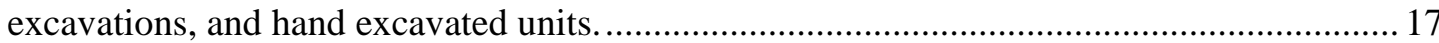

Figure 12. Dart point fragments recovered from 41GU177: a. Montell dart point base; b. Possible Frio or Ensor dart point fragment; and c. untyped dart point distal tip................................... 19

Figure 13. Unifacial axe recovered from TU05 excavations ................................................................. 19

Figure 14. Magnetic susceptibility results from BHT04.................................................................... 23

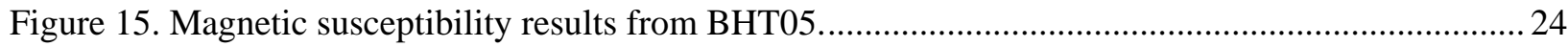

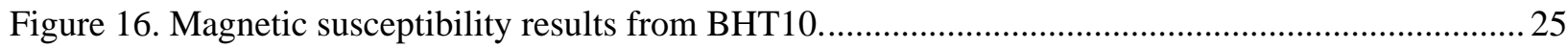

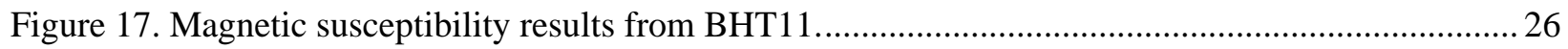

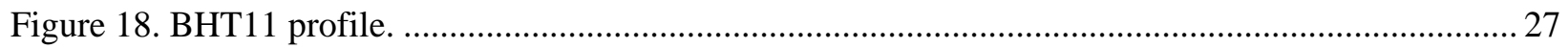

Figure 19. BHT11 overview. The zip-ties in the trench walls are marking artifacts. ...............................2

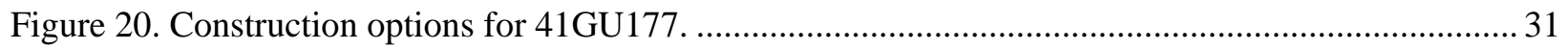

\section{LIST OF APPENDICES}

APPENDIX A Shovel Test Results

APPENDIX B Backhoe Trench Results

APPENDIX C Test Unit Specimen Inventory 


\section{INTRODUCTION}

On behalf of VRRSP Consultants, LLC and the Central Texas Regional Water Supply Corporation (CTRWSC), SWCA Environmental Consultants (SWCA) has prepared this interim report to present the findings of SWCA's ongoing investigations at prehistoric site $41 \mathrm{GU} 177$ on project parcel 50360 (Guadalupe County) and the implications of these investigations regarding potential site preservation and/or data recovery excavations at the site. It is the professional opinion of SWCA that the site warrants State Antiquities Landmark (SAL) designation, based on the density and quality of data recovered from the site to date, as well as the overall integrity of the site's natural and cultural stratigraphy. These investigations are one component of the larger overarching cultural resources investigations for the proposed Vista Ridge Regional Water Supply (Vista Ridge) Project. The project will involve installation of a 140-mile-long, 60inch-diameter water pipeline from north-central San Antonio, Bexar County to Deanville, Burleson County, Texas (Figure 1). The project will also include three pump station locations in Guadalupe, Bastrop, and Burleson Counties. Most of the alignment will follow existing utilities and traverse undeveloped, agricultural parcels in rural settings. The area of potential effects (APE) will consist of the proposed centerline alignment and a 100-foot corridor (50 feet on either side of centerline) for temporary and permanent construction easements. Between June 2015 and the present, the cultural resources inventory has identified 69 cultural resources, including 61 archaeological sites and eight isolated finds. All investigations described in this interim report were conducted under Texas Antiquities Permit No. 7295 issued to Principal Investigator Brandon S. Young. All work has been and will continue to be conducted in accordance with the Antiquities Code of Texas (ACT).

\section{SITE 41GU177}

This report presents the results of a series of investigations at prehistoric site 41GU177 in Guadalupe County (Figure 2). Site 41GU177 is a prehistoric campsite on forested rangeland in northwestern Guadalupe County (Figure 3). The site is on the western high bank of the Guadalupe River with a 30- to 40-foot vertical drop to the river bottom to the east and gently sloping (2-5 percent slope) terrain to the west. Vegetation consists of mixed hardwood trees, large live oak trees, and moderately dense shrub undergrowth (Figure 4). Ground surface visibility ranges from 0 to 20 percent with limestone gravels and cobbles at ground surface. The Guadalupe River is the nearest natural water source, forming the eastern boundary of the site. Soils of the site consist of very dark grayish brown to brown silt loams with 1 to 5 percent inclusions. Inclusions vary with depth, but include limestone cobbles, gravels, Rabdotus snail shell, a variety of other snail shell, and calcium carbonates. Previous impacts to the site area include natural erosion, vegetation clearing, grading, fence lines, and residential house and drive construction.

Certain potential adverse impacts have been proposed (i.e., an approximately $300 \times 8 \times 10$-foot construction trench, a $65 \times 200$-foot temporary workspace, a 20- to 25 -foot-wide haul road for construction activities, vegetation/tree clearing, and a horizontal directional drill [HDD] bore pit) to those portions of the site within the 85-foot-wide pipeline easement (see Figure 3). These impacts will result from work areas needed to tunnel the pipeline beneath the adjacent Guadalupe River and install the 60-inch diameter pipeline. Preliminary survey-level investigations indicated potential for intact, subsurface cultural components. As described in this interim report, SWCA conducted a series of phased survey investigations to fully assess the significance and potential eligibility of site $41 \mathrm{GU} 177$ for listing as a SAL. 


\section{Restricted Information}

\section{Not for Public Disclosure}

Figure 1. Project location. 


\title{
Restricted Information
}

\author{
Not for Public Disclosure
}

Figure 2. Project area. 


\title{
Restricted Information
}

\author{
Not for Public Disclosure
}

Figure 3. Site area. 


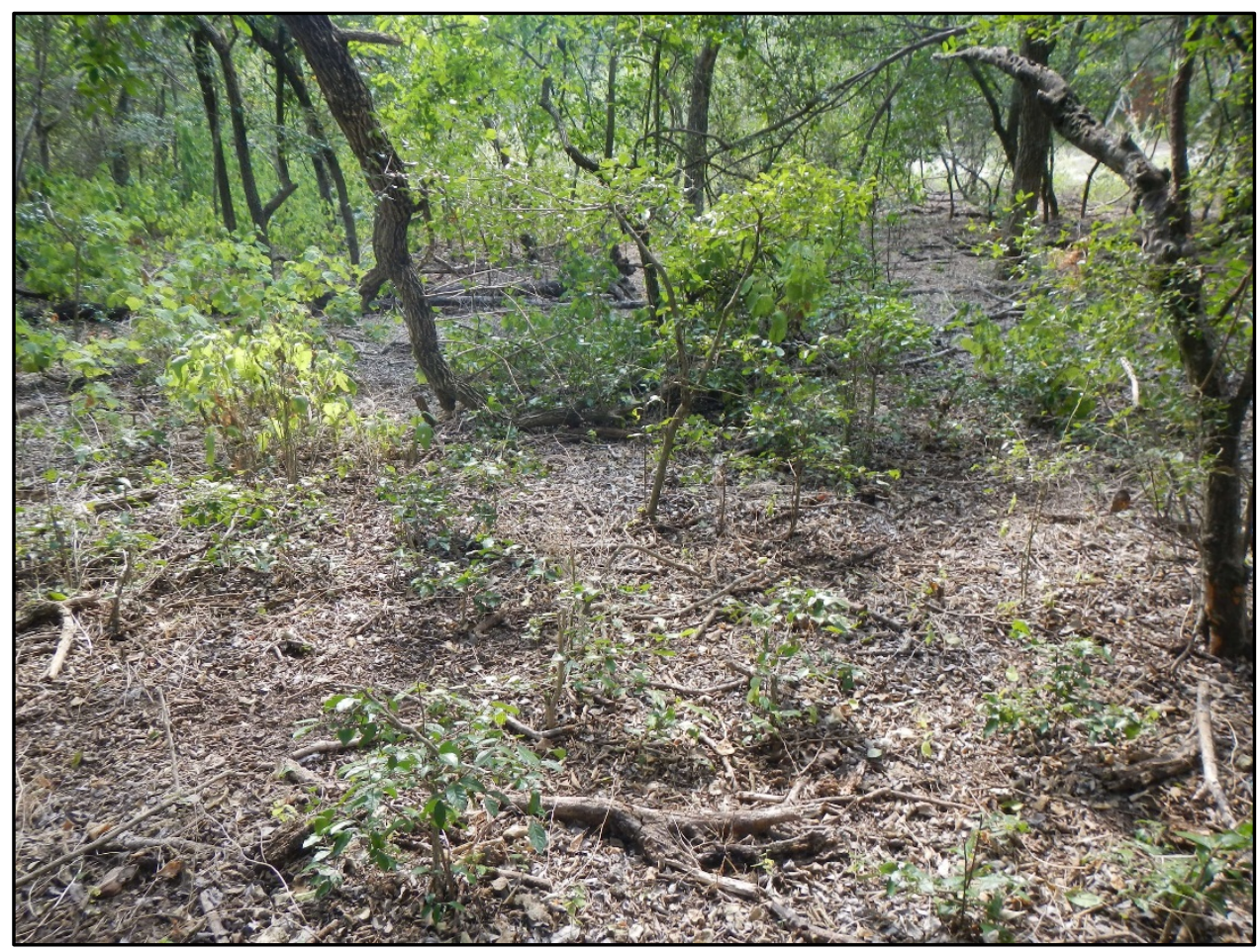

Figure 4. Typical site conditions.

\section{SUMMARY OF INVESTIGATIONS}

Site 41GU177 measures 137 meters (m) northeast/southwest by 30 m northwest/southeast; however, the site likely extends to the northwest and southeast beyond the project boundaries (see Figure 3 ). The site was originally discovered on August 31, 2015, during SWCA's initial Phase I pedestrian survey of the proposed water pipeline alignment. Site boundaries were determined by shovel testing for subsurface cultural deposits within project area boundaries during survey efforts. SWCA initially excavated five shovel tests across the site; however, based upon the nature and depth of the soils identified at the site and the assemblage of artifacts noted during shovel testing, a second phase of survey-level investigations consisting of systematic backhoe trenching occurred at the site on October 16, 2015. Those initial backhoe excavations were limited due to landowner access and clearing restrictions (i.e., no trees could be removed or damaged); as such, the excavation of three backhoe trenches (BHT01-BHT03) occurred only where access was practical. BHT01 and BHT03 contained no cultural materials; however, BHT02, near the northeastern end of the site, contained a partially intact burned rock feature and a moderate density of chipped-stone debitage and faunal remains. Ultimately, the 2015 investigations revealed intact prehistoric subsurface cultural materials and a buried cultural feature in the northeastern/eastern portion of the site.

Given the apparent integrity of the cultural deposit and the depth of observed artifacts, SWCA recommended that a phase additional work was warranted to better explore the cultural deposits through hand excavations and to determine if the cultural deposits retained sufficient integrity to warrant SAL designation. This phase occurred on October 12-14, 2016, until work was halted at the request of the landowner. Investigations involved reopening BHT02 (and extending it for several meters), the excavation of BHT04 that intersected at a right angle with BHT02, and the hand excavation of four, $1 \times 1-\mathrm{m}$ units (Test Units [TUs] 1-4) off BHT02 and BHT04. Due to the recovery of a possible human bone from TU03 on October 13, excavations were halted to contact the Guadalupe County Sheriff's office. Ultimately, the bone was determined to be not human; however, the landowner halted all activity on the site. 
Following negotiations with the landowner, the proposed easement on parcel 50360 was purchased for the project and access was again made available to the site beginning in June 2017. SWCA returned to site 41GU177 on June 28, 2017, to complete the excavation units originally established in 2016, as well as excavate two additional backhoe trenches (BHT05 and BHT06) at the location of a proposed bore pit for a planned HDD that could impact parts of the site. During the excavation of BHT05 and BHT06, in situ cultural materials (including a very large chipped-stone axe and burned rock) were observed in the trench profiles and SWCA excavated a fifth hand excavation unit (TU05) at the intersection of BHT05 and BHT06 to explore the artifact and burned rock feature. Following completion of the limited excavations on July 6, 2017, there was sufficient evidence to recommend that portions of the site warranted SAL designation and potentially a phase of data recovery excavations. However, due to the previous landowner access restrictions, the remaining portions of the site still needed systematic examination to determine the integrity and potential significance of those areas. To accomplish this, in August 2017, SWCA proposed a program of close interval shovel testing and additional backhoe trenching across the remaining site area.

In September and October 2017, SWCA conducted a program of close interval shovel testing followed by additional backhoe trenching at the site to better determine the nature, depth, and extent of its cultural deposits (i.e., was there more than one temporal component represented) and to ultimately refine the proposed data recovery areas. SWCA performed the close interval shovel testing to determine the presence/absence and depth of cultural materials in parts of the site that were not previously subject to intensive examination. SWCA initiated the close interval shovel testing the week of September 10, 2017, and that was completed the following week. The hand excavations involved 53 shovel tests on an approximate $10 \times 10 \mathrm{~m}$ grid. One of the primary goals of the shovel testing was to excavate all shovel tests to a depth of at least 100 centimeters $(\mathrm{cm})$ below ground surface $(\mathrm{cmbs})$, based on the known depth of artifacts determined from previous work on the site. As artifacts were also discovered to extend to depths of $160 \mathrm{cmbs}$ during the previous investigations, every fifth shovel test was extended to a depth of $200 \mathrm{cmbs}$ via a hand auger, to test for more deeply buried cultural materials. The results of the close interval shovel testing and augering indicate that artifacts extend from ground surface to a maximum depth of $140 \mathrm{cmbs}$. All artifacts from the shovel tests were collected and have been processed, washed and analyzed; these artifacts will be curated with the artifacts recovered from the prior investigations, as well as the artifacts that may be collected during any potential future data recovery excavations.

Following completion of the close interval shovel testing, SWCA was scheduled to complete additional mechanical trenching on the site the week of September 24, 2017; due to heavy rains and thunderstorms, those investigations were rescheduled and completed on October 4-5, 2017. The locations of the backhoe trenches were determined by the results of the close interval shovel testing (i.e., areas where shovel testing revealed potentially deeply buried artifacts and possible cultural features). Seven additional trenches (i.e., BHT07- BHT13) were excavated across the site. These deeper excavations revealed similar stratigraphy and artifact densities to those observed during the close interval shovel testing; however, several artifacts were noted at significantly deeper depths (i.e., close to $200 \mathrm{cmbs}$ ) than those in the shovel tests.

Based on the results of the phased investigations at the site, SWCA has refined the location and extent of any proposed data recovery effort, focusing efforts on the more significant and intact parts of the site that may be impacted by construction-related activities. The primary objective for the proposed undertaking is to collect data that complements and expands on what is already known about the site from SWCA's prior investigations between 2015 and 2017. Following is a detailed synopsis of SWCA's phased investigations on 41GU177 between August 2015 and October 2017.

\section{SITE SETTING}

The site is located approximately 4.7 kilometers $(\mathrm{km})$ (2.9 miles) north of McQueeney in Guadalupe Counties, Texas. Site 41GU177 is on the western high bank of the Guadalupe River, with a 30- to 40-foot 
vertical drop to the river bottom to the east and gently sloping (2-5 percent slope) terrain to the west. SWCA's investigations were confined to the portion of the site within the project area; however, SWCA suspects the site continues beyond the limits of the project area to the east and west.

Site 41GU177 is located within forested rangeland with mixed hardwood trees, large live oak trees, and moderately dense shrub undergrowth. Ground surface visibility ranges from 0 to 20 percent, with limestone gravels and cobbles exposed on the ground surface. Vegetation clearing and grading, fence line construction, and natural erosion have impacted site integrity to varying degrees. One property fence and private cemetery borders the northwestern site boundary, and natural erosion from the high bank of the Guadalupe River has impacted the northeastern site boundary.

\section{OVERVIEW OF GEOMORPHOLOGY}

SWCA reviewed the local geology and soils as mapped by the Bureau of Economic Geology and the U.S. Department of Agriculture's Soil Conservation Service, as well as local U.S. Geological Survey (USGS) topographic maps, aerial photographs, and excavation and site profiles, which provided the basis for the general geomorphology of site 41GU177. The site is located on the right bank (west side) of the Guadalupe River, situated roughly 30 to 35 feet above the river.

The surface geology for this area indicates that the project alignment crosses Pleistocene-age terrace deposits (Barnes 1983). These deposits are characterized as gravel, sand, silt, and clay largely derived from the Edwards Plateau situated a few miles upstream (Barnes 1983). These deposits in local areas have calcium carbonate-cemented quartz sand, silt, clay, and gravel intermixed and interbedded in terraces along streams. Low terraces of major rivers are capped by 2 to $4 \mathrm{~m}$ of clayey sand and silt. Sandy gravel on higher terraces varies somewhat in composition from river to river.

The soils at 41GU177 are mapped as Sunev loam (1 to 5 percent slopes) (Natural Resources Conservation Service 2017; Ramsey and Bade 1977). Briefly, the Sunev loams are occasionally identified as Venus loams (Sunev spelled backward) in older soil surveys (Ramsey and Bade 1977; Taylor et al. 1991). These are characterized as occurring on terraces or alluvial fans of rivers and large streams and composed of calcareous brown-dark brown loams and clay loams (Ramsey and Bade 1977; Taylor et al. 1991).

At 41GU177, the Guadalupe River is a competent drainage with an approximately 43-m-wide (142-foot) base and a slow southeast flowing channel. The Guadalupe River, as it winds past the site, has a high sinuosity ratio of 1.4 indicating that it is a sinuous waterway, which is apparent from the New Braunfels East and McQueeney 7.5-minute USGS topographic quadrangle maps (Charlton 2008:138-139). This sinuosity suggests a partially dynamic depositional history where the channel has moved laterally. In this type of setting, the lateral movement can significantly erode the deposits of outside meander bends and, in contrast, deposit significant amounts of sediment upon interior meanders (Charlton 2008). Site 41GU177 is situated on an exterior bend of a meander. Not surprisingly, the right bank of the river, below 41GU177, does not contain broad alluvial landforms.

At this location, the Guadalupe River valley is an unpaired, stair-stepped terrace system consisting of a series of alluvial terraces that bracket the drainage created by various episodes of overbank deposition (Waters 1992:149-151). The left bank (east side) of the Guadalupe River exhibits three terrace landforms that from youngest (closest to the channel) to oldest consist of the $T_{0}, T_{1}$, and $T_{2}$ terraces. In contrast, the right bank, containing 41GU177, has one apparent alluvial terrace landform $\left(\mathrm{T}_{2}\right)$.

On the right bank, the $\mathrm{T}_{2}$ landform abruptly rises about 9.5 to $11 \mathrm{~m}$ (31 to 36 feet) above the Guadalupe River. The $\mathrm{T}_{2}$ landform on both banks is broad (roughly $1 \mathrm{~km}$ ) and gradually grades into the valley margins aligning the drainage valley. Another landform occurs upon the $T_{2}$ terrace near site 41GU177, which could 
be part of the $T_{2}$ landform or remnants of an older alluvial landform (i.e., $T_{3}$ ). This landform parallels the Guadalupe River and is situated at roughly 580 to 585 feet above mean sea level (amsl) and about $1.5 \mathrm{~m}$ (5 feet) above the $T_{2}$ terrace that surrounds it. Site $41 \mathrm{GU} 177$ is primarily situated on the $T_{2}$ terrace between 575 to 580 feet amsl.

\section{RESULTS}

\section{INVESTIGATIONS}

SWCA discovered 41GU177 on August 31, 2015, as part of the intensive pedestrian survey of the Vista Ridge project area. The site was initially identified by a scatter of surface artifacts (Figure 5). SWCA excavated five shovel tests (KS139-KS141 and RW342-RW343), with three (KS139 and RW342-RW343) being positive for cultural materials (Appendix A). Subsurface materials ranged from the ground surface to beyond $80 \mathrm{cmbs}$ and consisted primarily of tertiary flakes with a few secondary flakes and cultural shatter also observed. Materials observed during the ground surface inspection consisted of: two fragmented untyped projectile points (not collected), five to 10 scrapers, two to four choppers, 50 to 80 primary flakes, 100 to 200 secondary flakes, and 100 to 200 pieces of lithic shatter. All lithic materials observed were composed of chert raw material types. SWCA also observed fragments of iridescent water mussel shells during shovel testing. No diagnostic materials or cultural features were observed during these initial shovel test excavations.

Due to the potential for deeply buried cultural deposits, backhoe trench investigations were then conducted at the site on October 16, 2015. A total of three backhoe trenches (BHT01- BHT03) were excavated; BHT01 and BHT02 were excavated within the site boundary and BHT03 was excavated approximately $40 \mathrm{~m}$ southwest of the site (see Figure 5). Due to landowner restrictions (i.e., no damage to oak trees) and the forested terrain, the placement of backhoe trenches was constrained. BHT01 and BHT03 encountered friable brown (10YR 5/3) silt loam overlying light yellowish brown (10YR 6/4) to very pale brown (10YR 7/4) silt loam with increasing gravel and pebble inclusions (Appendix B). In contrast, BHT02 encountered friable very dark grayish brown (10YR 3/2) to brown (10YR 4/3) silt loam horizons containing cultural materials separated by a sterile loose brown (10YR 4/3) silt loam horizon (see Appendix B). Artifacts in BHT02, including numerous lithic flakes and three burned rocks, which were initially observed in the trench wall profile between 0 and 60 cmbs. A second cultural horizon, containing lithic flakes and a blade, was observed from 90 to 120 cmbs.

To investigate the nature of the burned rock and determine if a cultural feature was present, a column sample was excavated off the north wall of BHT02. A total of 10 flakes, two animal bone fragments, one small piece of charcoal, and two burned rocks were recovered from the column sample between 0 and $55 \mathrm{cmbs}$ (Appendix A). In addition, SWCA encountered four small- to medium-sized burned rocks (one 0-5 cm diameter and three 5-10 cm diameter) in a cluster at the base of the column sample. The feature was truncated on the south side by the backhoe; however, a large burned rock appears to continue into the column sample wall, suggesting portions of the feature may remain intact. After documentation was complete, the feature and associated artifacts were covered with soil and the trench was backfilled. 


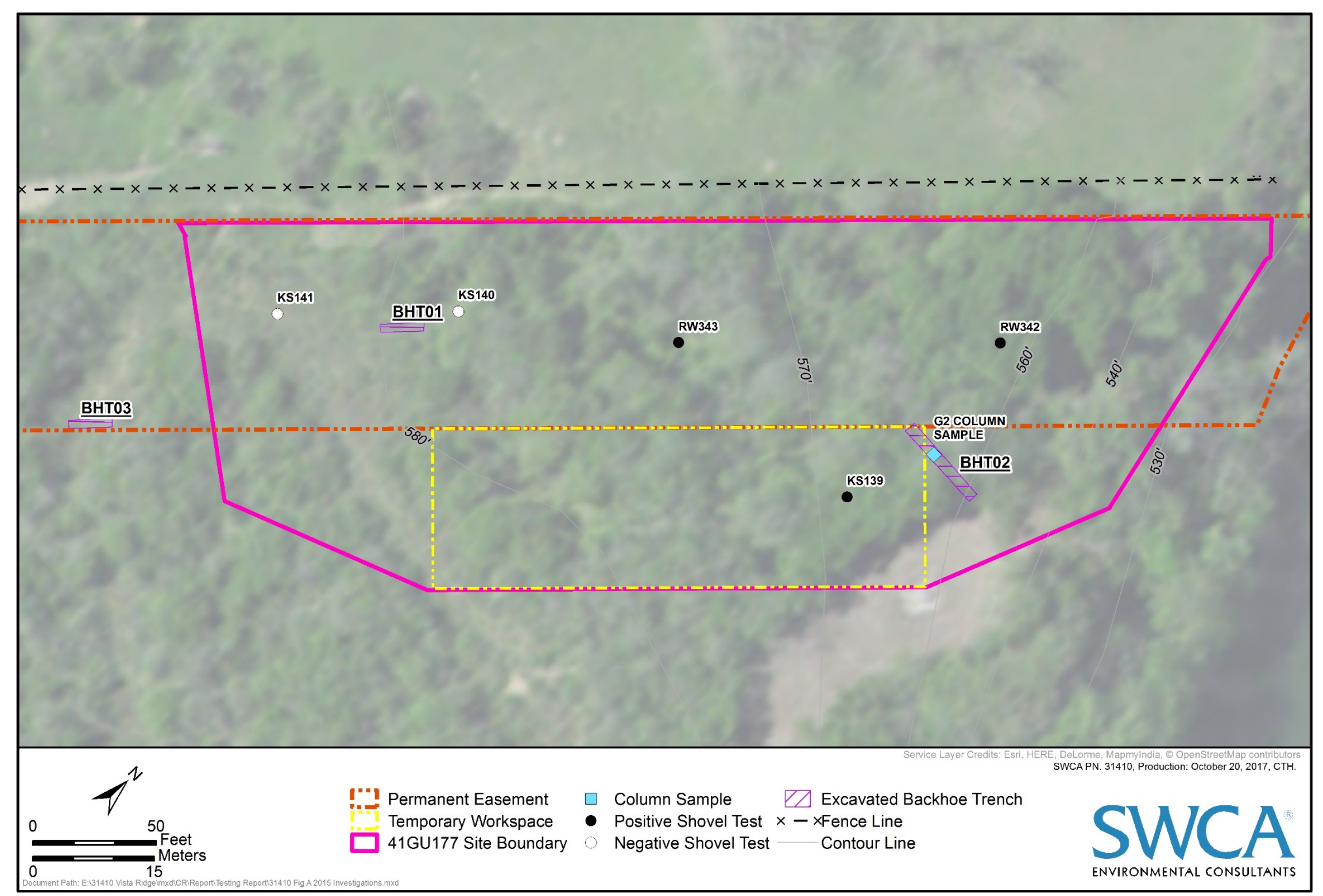

Figure 5. 2015 investigations at 41GU177. 


\section{INVESTIGATIONS}

SWCA revisited site 41GU177 between October 12-14, 2016, to further evaluate the site's significance and potential for deeply buried deposits through further mechanical trenching and hand excavations. SWCA reopened one of the original survey trenches (BHT02) from 2015 and excavated BHT04, which intersected BHT02 (Figure 6). These two trenches bisect each other in a cruciform formation in the eastern-most portion of the site, surrounded by the positive shovel tests and the densest amount of cultural materials observed. The trenches revealed moderately dense cultural materials and one cultural burned rock feature.

BHT02 was originally roughly $5 \mathrm{~m}$ long and excavated to a depth of approximately $180 \mathrm{cmbs}$ during survey investigations (Appendix B). The trench was reopened and extended to the east to a total length of roughly $9 \mathrm{~m}$ long and approximately $122 \mathrm{cmbs}$. Most of the cultural materials were identified along the north wall profile in two cultural zones identified from 0 to $60 \mathrm{cmbs}$ and 90 to $120 \mathrm{cmbs}$ during survey efforts; SWCA observed a similar range and density of artifacts during the subsequent reopening of BHT02. One of the goals of reopening the trench was to locate the previously excavated column sample and truncated partial feature from previous survey investigations and to then establish a $1 \times 1-\mathrm{m}$ excavation unit over it, which was accomplished. BHT04, placed in the southwestern portion of the designated test area, was $8 \mathrm{~m}$ long and excavated to a depth of approximately $120 \mathrm{cmbs}$ (see Figure 6). BHT04 served as an expansion of the trenching area, which allowed for the placement of test units off the east wall. Investigations in October 2016 involved the excavation of four hand excavated $1 \times 1-\mathrm{m}$ test units (i.e., TU01-TU04); SWCA excavated TU01 and TU02 along the north wall of BHT02, and excavated TU03 and TU04 along the east wall of BHT04 (see Figure 6). SWCA excavated the test units to varying depths before the landowner revoked land access on October 14, 2016.

\section{TEST UNIT 1}

TU01 was hand excavated to a depth of $150 \mathrm{cmbs}$ ( $98.5 \mathrm{~cm}$ below datum [cmbd]). TU01 was located on the north wall of BHT02, west of TU02 (see Figure 6). Lithic artifacts include 80 primary lithic flakes, 128 secondary flakes, 574 tertiary flakes, a mano (ground stone artifact) fragment, two utilized flakes, an earlystage biface, a lithic core, a tested cobble, and three projectile points, as well as 75 faunal bones. The projectile points and point fragments consist of two untyped arrow point fragments (Figure 7, Specimens e and k) and one corner-notched, broad stem Scallorn arrow point variant (see Figure 7, Specimen a) (Appendix C). Other artifacts include burned rock between 20 and $90 \mathrm{cmbs}$, a burned nut shell at 70 to 80 cmbs, two fragments of burned seed at 140 to $150 \mathrm{cmbs}$, and freshwater mussel shell throughout.

\section{TEST UNIT 2}

TU02 was hand excavated to a depth of $140 \mathrm{cmbs}$ (98.6 cmbd). TU02 was also located on the north wall of BHT02, east of TU01 (see Figure 6). Lithic artifacts include 129 primary lithic flakes, 217 secondary flakes, 873 tertiary flakes, two blades, one core, two utilized flakes, one hammerstone, one bifacial distal tip, and two projectile points. The projectile points and point fragments include one corner-notched, broad stem Scallorn arrow point variant (see Figure 7, Specimen b), an untyped arrow point preform that may be a Scallorn preform (see Figure 7, Specimen d), and the distal tip of an untyped arrow point (see Figure 7, Specimen i). Other artifacts include 10 animal bone fragments, a probable shell bead fragment (Figure 8), and burned rock at approximately 60 to $70 \mathrm{cmbs}$ (Appendix C) 


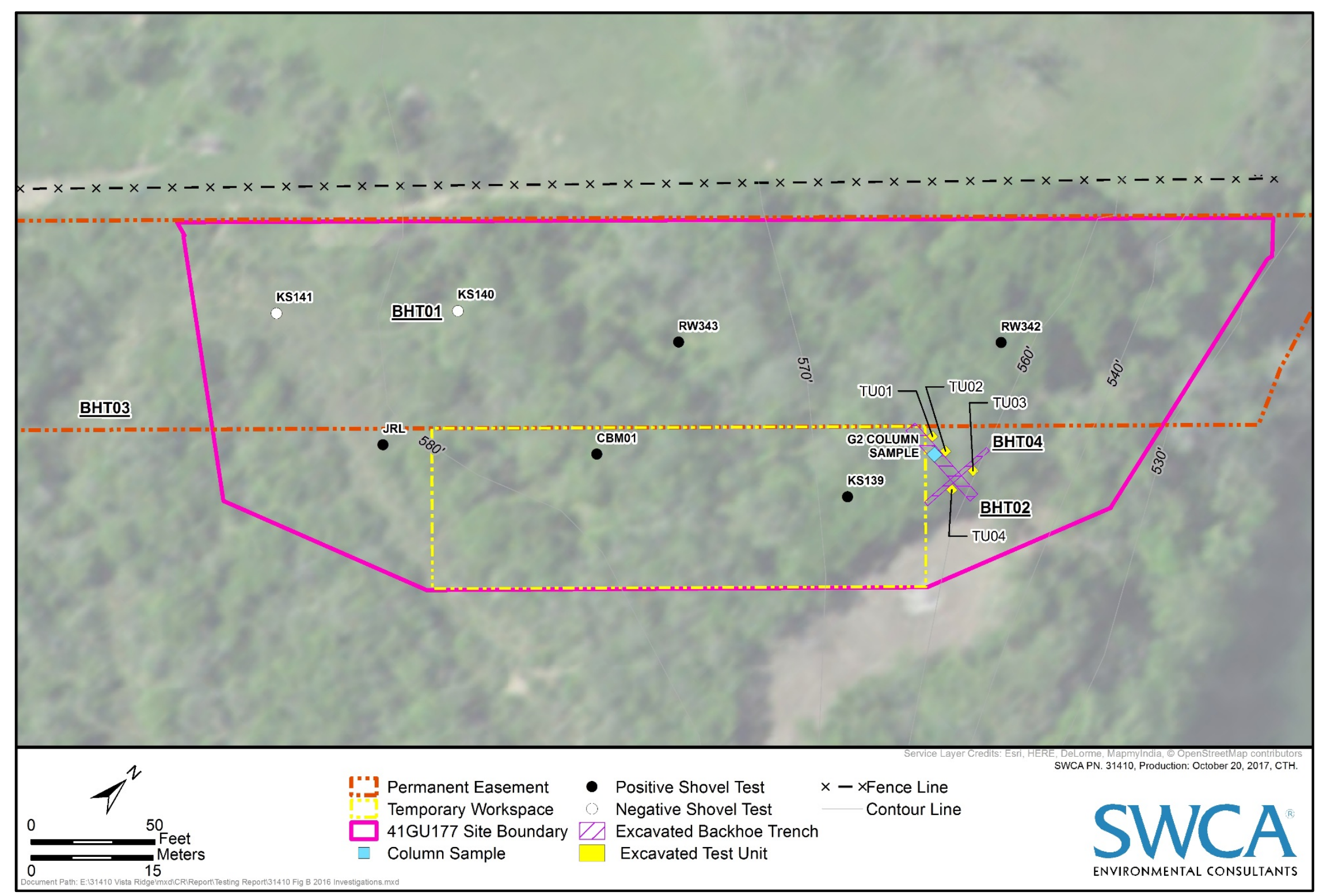

Figure 6. 2016 investigations at 41GU177. 


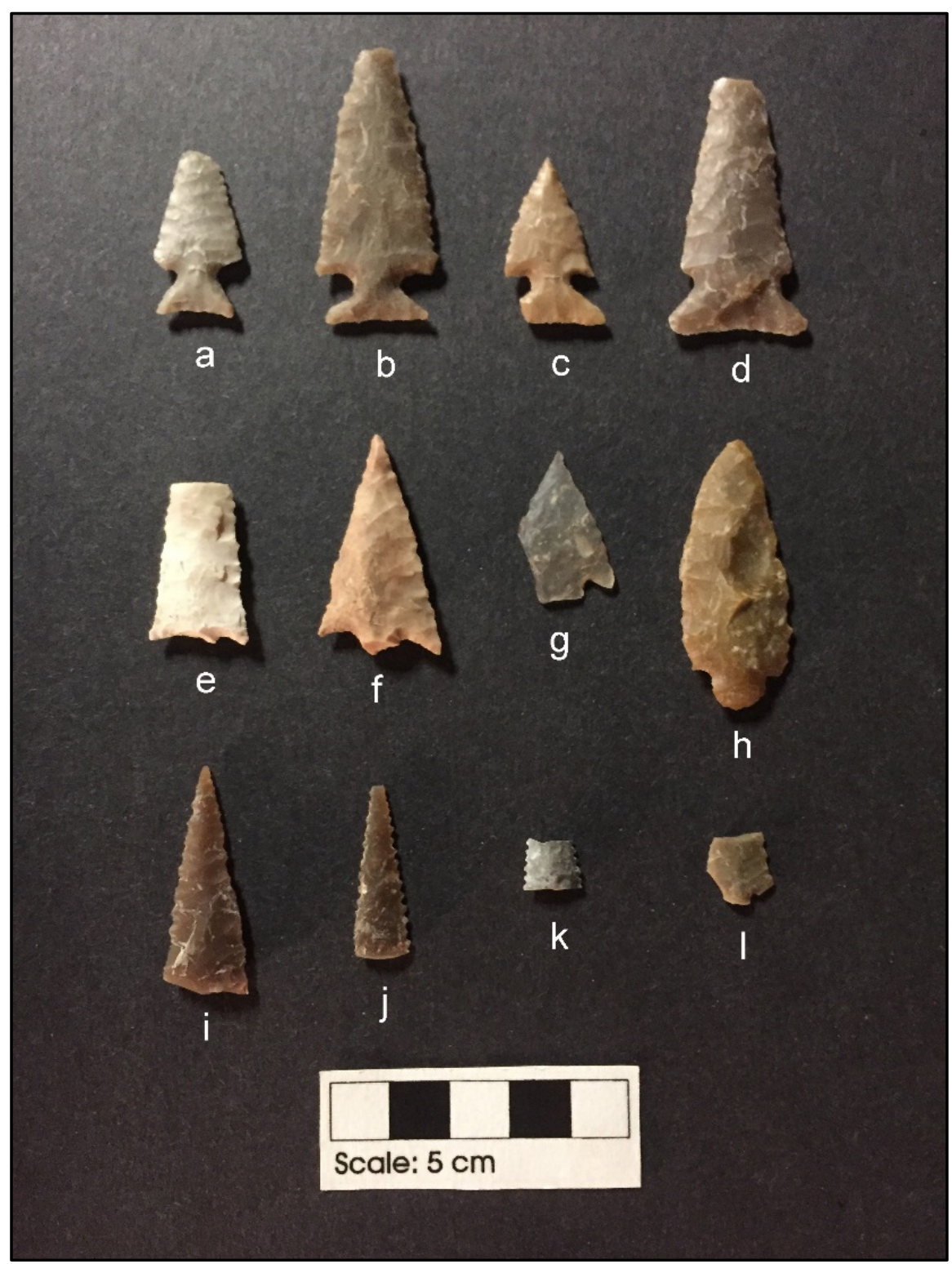

Figure 7. Arrow points and arrow point fragments recovered from 41GU177: a-c. corner-notched, broad stem variant Scallorn arrow points; d. Scallorn preform; e. untyped arrow point fragment; f. untyped arrow point fragment; g. untyped arrow point (possible Sabinal specimen); h. Untyped arrow point preform; i-j. distal tips of an untyped arrow points; k. untyped arrow point fragment; and I. untyped arrow point fragment

\section{TEST UNIT 3}

TU03 was excavated to a depth of $40 \mathrm{cmbs}(99.6 \mathrm{cmbd})$. The unit was located on the east wall of BHT04, just north of the intersection of BHT02 and BHT04 (see Figure 6). Lithic artifacts include nine primary flakes, 21 secondary flakes, 84 tertiary flakes, a utilized flake, several burned rocks, and one large bone initially thought to have the potential to be human (Appendix C). 


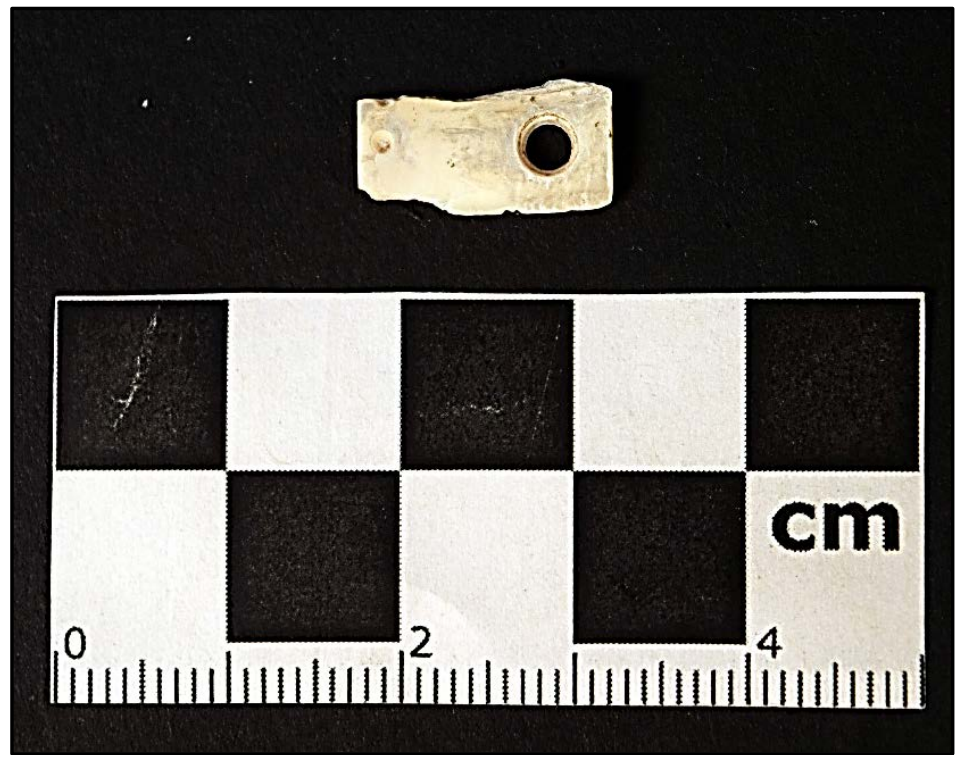

Figure 8. Fresh water mussel shell bead fragment.

Following recovery of the large bone on October 13, 2017, SWCA contacted the Guadalupe County Sheriff's Office and the landowner to inform them of the bone. The Guadalupe County Sheriff's Office assumed custody of the bone to determine if it was human and if the excavation area represented a crime scene. At this point, the landowner revoked access to the site and a 6-week process to definitively identify the bone as human or non-human began. As such, TU03 was only minimally investigated before access to the site was revoked. SWCA's osteologist initially identified the bone as potentially human based on examination of photographs; however, once the Guadalupe County Sheriff's department assumed custody of the bone, they sent photographs to an osteologist at Texas State University, who indicated the bone was not human and probably belonged to a deer. Given that there were two conflicting opinions as to whether the bone was human or not, a third opinion was solicited from osteologist Dr. Michelle D. Hamilton of Texas State University. Following her examination of the bone, Dr. Hamilton indicated that the specimen was non-human and is likely from a bovid/ungulate (i.e., cow, bison, etc.). Given that two of the three osteologists agreed that the specimen was non-human, the bone is not considered a human remain.

\section{TEST UNIT 4}

TU04 was excavated to a depth of $30 \mathrm{cmbs}(99.7 \mathrm{cmbd})$. The unit was located on the east wall of BHT04, just south of the intersection of BHT02 and BHT04 (see Figure 6). Lithic artifacts include 27 primary flakes, 15 secondary flakes, 171 tertiary flakes, and one unifacial scraper (Appendix C). The majority of tertiary flakes came from Level 3, 20 to 30 cmbs, with a total of 145 tertiary flakes recovered. As with TU03, this unit was minimally excavated before access to the site was revoked.

\section{SUMMARY}

The phase of site assessment occurred on October 12-14, 2016, until work was halted at the request of the landowner. Due to the recovery of a possible human bone from TU03 on October 13, excavations were stopped to contact the Guadalupe County Sheriff's office. Ultimately, the bone was determined not to be human; however, the landowner had additional concerns and would not allow any further investigations. 


\section{INVESTIGATIONS}

SWCA returned to site 41GU177 from June 28-July 6, 2017 (following VRRSP's purchase of the easement from the private landowner), to complete the hand excavation units started in 2016 and continue to assess the site and its potential for deeply buried deposits. SWCA cleaned the four excavation units that had been left open from the prior year and continued the excavations to a maximum depth of $180 \mathrm{cmbs}$. In addition to completing the open units, investigators excavated two more trenches (BHT05 and BHT06) in a cruciform pattern to the northwest of the open excavation area, in and adjacent to the proposed bore pit for the HDD. This phase of investigations also excavated a fifth test unit (TU05) based on those results (Figure 9). After hand excavations were complete, SWCAs geoarchaeologist, Ken Lawrence (MA), conducted geoarchaeological analyses of the soil consisting of soil and stratigraphic documentation and magnetic susceptibility testing.

Following completion of hand excavations on July 6, 2017, SWCA determined that additional data from across the site was warranted to further test the site and narrow down the potential data recovery areas. SWCA returned to the site in late September and from October 4-5, 2017, to conduct systematic close interval shovel testing on a $10 \times 10$-m grid across the site to further test the depth, nature, and extent of the cultural deposits (Figure 10). During the late September 2017 mobilization, 53 shovel tests were systematically excavated across the site and, based on the results, SWCA created an artifact density plot map to illustrate where artifacts were recovered (Figure 11; Appendix A). Based on that data, additional backhoe trenches (BHT07-BHT13) were then excavated on October 4-5, 2017, to explore the site further (see Figure 10; Appendix B). SWCA also conducted additional magnetic susceptibility testing during this later phase.

As Figure 11 illustrates, there is an area of high to moderate artifact density in the north-central part of the site. The portion of the site within the high and moderate density areas appears to contain intact archaeological deposits that could be impacted during construction-related activities associated with rightof-way clearing, bore hole excavation, haul road construction and use, and machinery and equipment laydown. Based on the density of cultural materials recovered, and the degree of preservation observed in the high and moderate density areas, it is SWCA's professional opinion that the parts of 41GU177 within those areas may warrant designation as a SAL. The following provides a summary of the completed test unit excavations and additional backhoe trenching results from the 2017 investigations.

\section{TEST UNIT 1 CONTINUED}

TU01 was extended from a depth of $150 \mathrm{cmbs}$ to a maximum depth of $170 \mathrm{cmbs}$ (98.3 cmbd). These lower levels contained one secondary lithic flake, six tertiary lithic flakes, and five bone fragments (Appendix C). Due to the sparse number of artifacts within the lower levels, it was determined that the unit was below any occupation level and those artifacts within were likely from a secondary context, possibly due to artifact migration and/or bioturbation.

\section{TEST UNIT 2 CONTINUED}

TU02 was extended from a depth of $140 \mathrm{cmbs}$ to a maximum depth of $160 \mathrm{cmbs}$ ( $98.4 \mathrm{cmbd})$. These lower levels contained four secondary lithic flakes and three tertiary lithic flakes (see Appendix C). Like TU01, the lower excavation levels were determined to be below any occupation level, due to the paucity of artifacts, and the unit was terminated. 


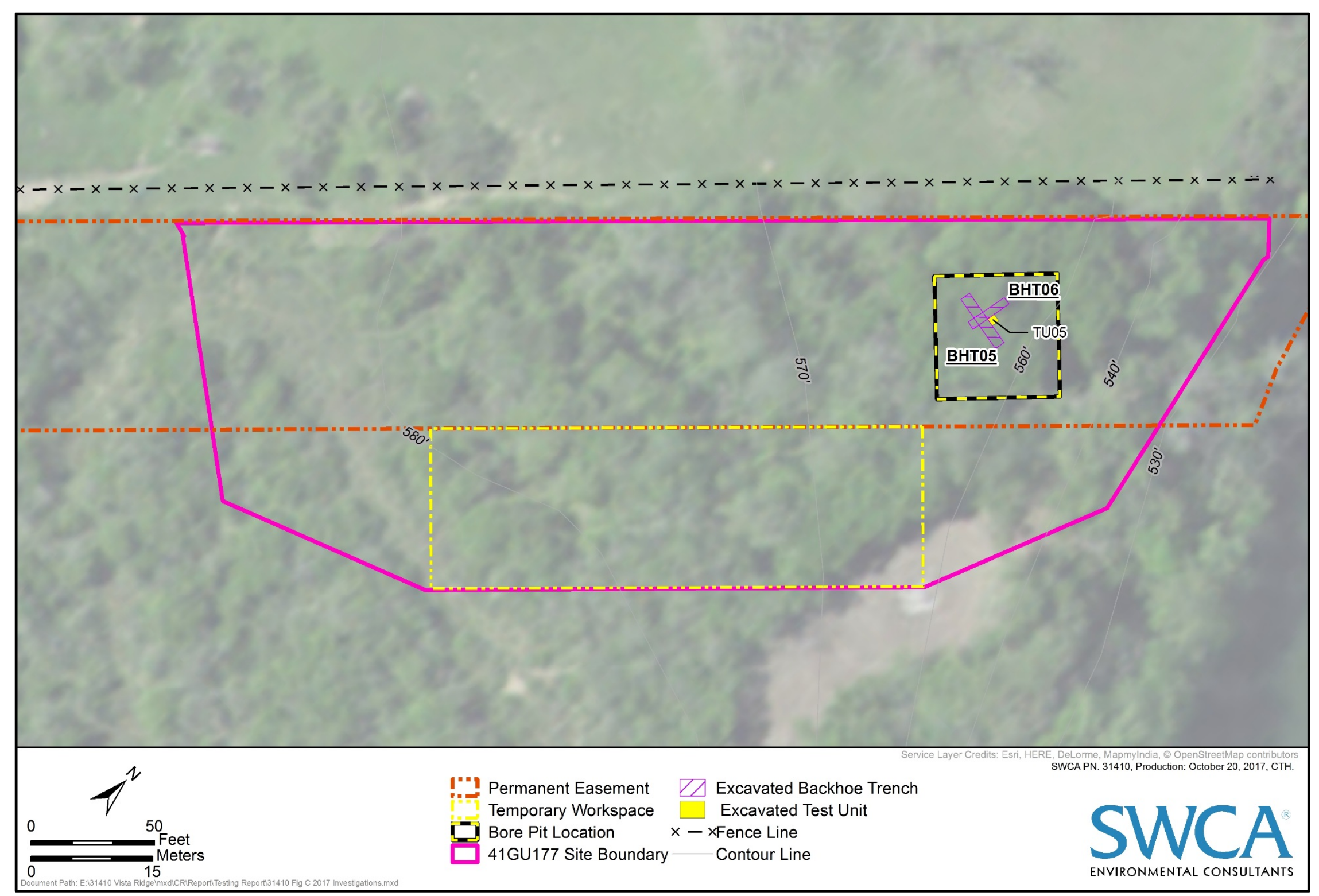

Figure 9. 2017 additional excavations in the proposed bore pit and adjacent work area. 


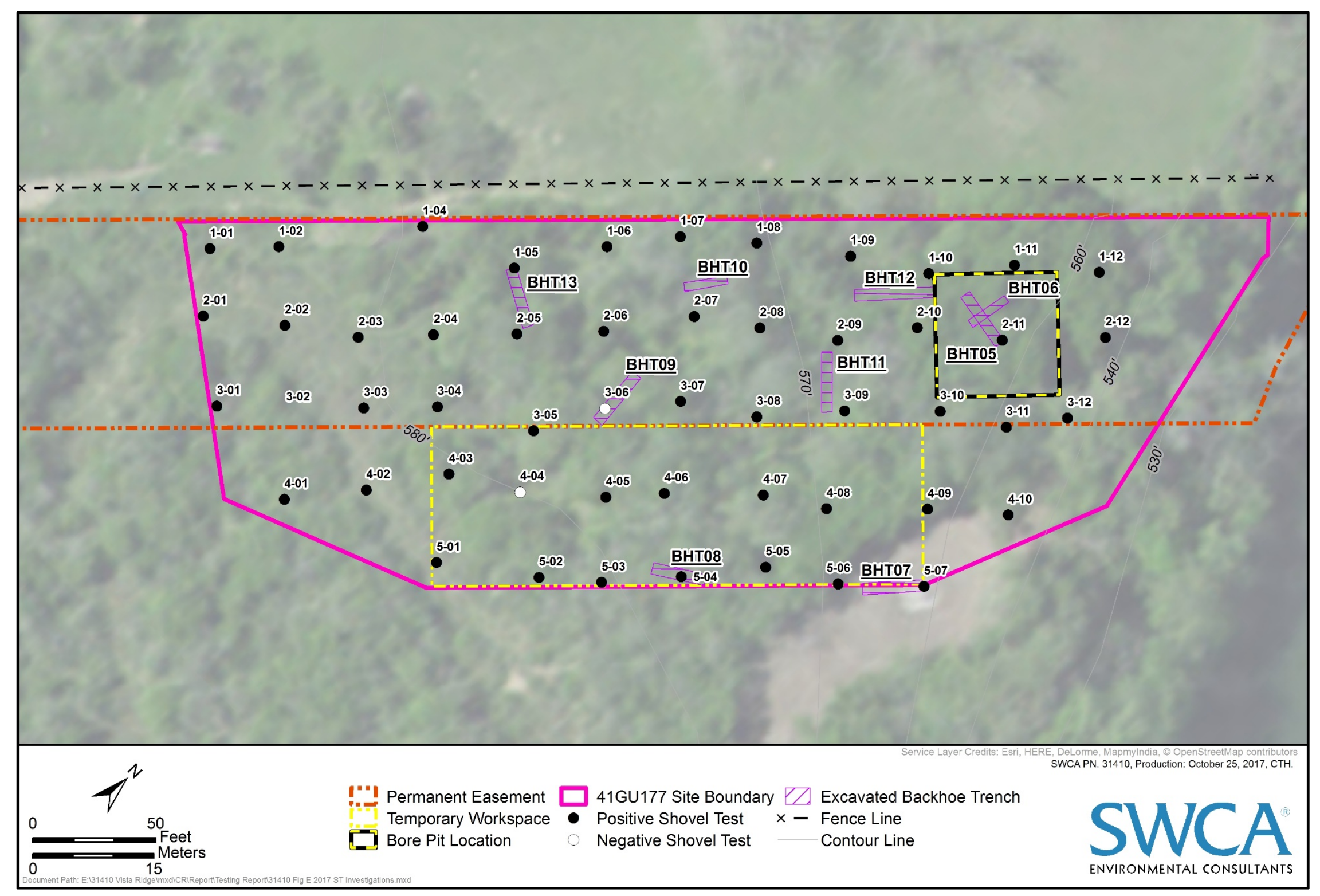

Figure 10. 2017 close interval shovel test and additional backhoe trench plots. 


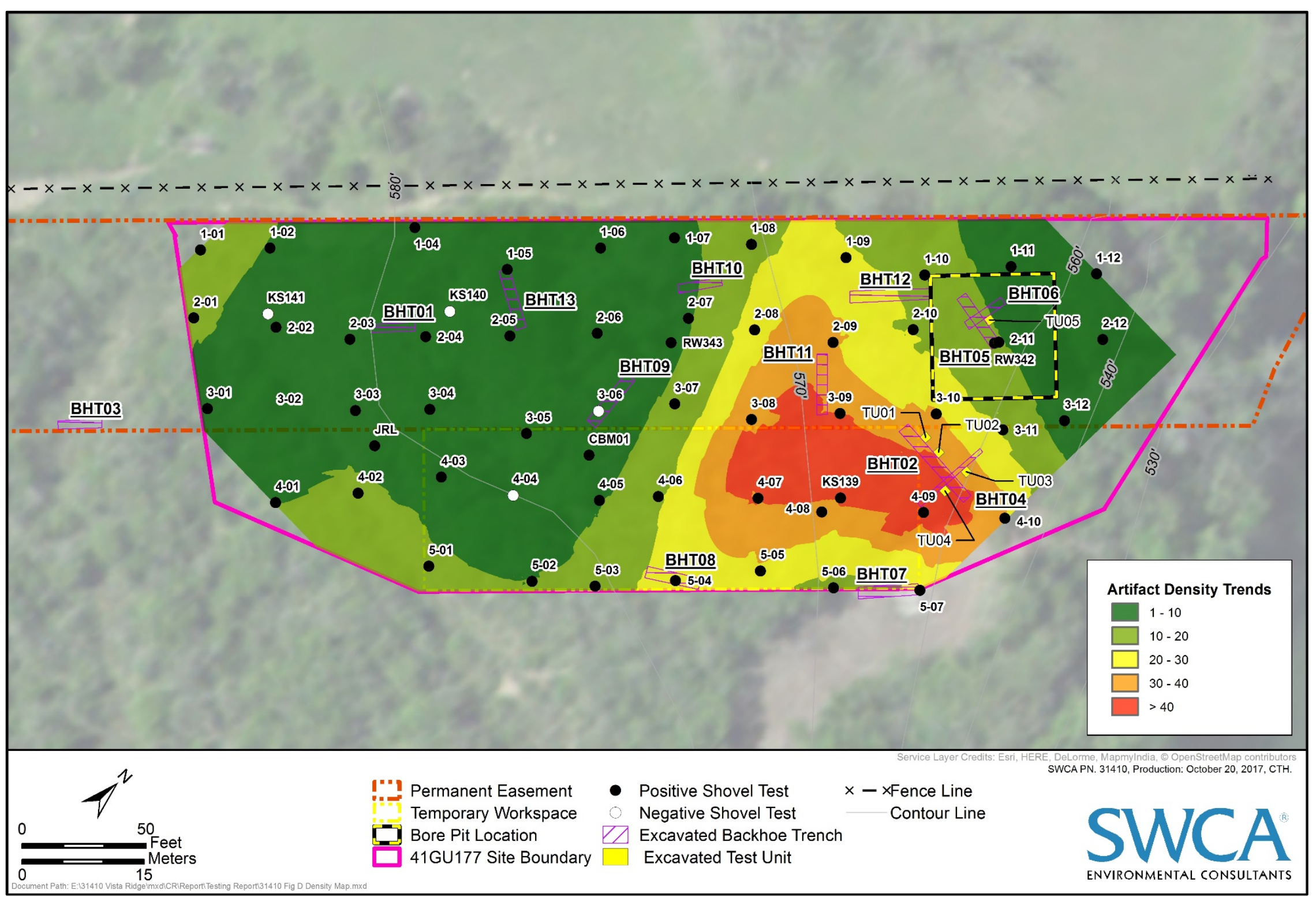

Figure 11. Artifact density plot generated from close interval shovel testing data, backhoe trench excavations, and hand excavated units. 


\section{TEST UNIT 3 CONTINUED}

TU03 was continued from a depth of $40 \mathrm{cmbs}$ to a maximum depth of $180 \mathrm{cmbs}(98.2 \mathrm{cmbd})$. The prehistoric artifact assemblage of the continued levels includes 37 primary lithic flakes, 134 secondary flakes, 553 tertiary flakes, two ground stone fragments, one bifacial tool fragment, two modified flakes, one core, and three projectile points; two untyped arrow point fragments (see Figure 7, Specimens $\mathrm{f}$ and $\mathrm{j}$ ) and an untyped dart point that is possibly a Frio or Ensor specimen (see Figure 12, Specimen b). Additional artifacts include 34 bone fragments and two fresh water mussel shell (Appendix C). The mussel shell was observed between 40 to $50 \mathrm{cmbs}$ and 60 to $70 \mathrm{cmbs}$, while faunal bone fragments were collected throughout the levels. Like TU01 and TU02, the lower excavation levels were determined to be below any occupation level, due to the paucity of recovered artifacts and the unit was terminated.

\section{TEST UNIT 4 CONTINUED}

TU04 was continued from a depth of $30 \mathrm{cmbs}$ to a maximum depth of $160 \mathrm{cmbs}$ (98.4 cmbd). The prehistoric artifact assemblage of the continued levels includes 51 primary lithic flakes, 148 secondary flakes, 466 tertiary flakes, five bifacial fragments, one bifacial blank, six ground stone fragments, one utilized flake, two lithic choppers, and one untyped arrow point preform (see Figure 7, Specimen h and Appendix C). Additional artifacts include 114 bone fragments, 11 freshwater mussel shell fragments, and eight pieces of burned clay (Appendix C). The mussel shell fragments and burned clay were observed above $90 \mathrm{cmbs}$, whereas bone fragments were observed throughout the unit. Most of the unit below $50 \mathrm{cmbs}$ has been heavily bioturbated by rodent burrowing activities. Excavations encountered a hollow rodent den between 50 and $60 \mathrm{cmbs}$, with numerous infilled tunnels above and below the den. Due to the heavy bioturbation and paucity of cultural material in the lower levels, excavations in TU04 was terminated.

\section{TEST UNIT 5}

TU05 was excavated at the northeastern corner of the intersection of BHT05 and BHT06. The unit was placed to investigate a small cluster of burned rocks exposed in the corner of the trenches. TU05 was excavated from surface to a depth of $110 \mathrm{cmbs}(98.9 \mathrm{cmbd})$. The prehistoric artifact assemblage includes 15 primary lithic flakes, 29 secondary flakes, 122 tertiary flakes, one lithic core, four bone fragments, and one fresh water mussel shell fragment (Appendix C). Additionally, during excavation of BHT06, a lithic unifacial axe was uncovered on the E wall near the intersection of BHT05 and BHT06 at a depth of 65 to $70 \mathrm{cmbs}$ (Figure 13). Prehistoric artifacts within the unit become sparse below $70 \mathrm{cmbs}$, and the unit was terminated at the depth of BHT05 (i.e., $150 \mathrm{cmbs}$ ).

\section{Close INTERVAL SHOVEL TEST DATA}

During the close interval shovel testing program conducted on September 15 and 20-22, 2017, SWCA excavated a total of 53 additional shovel tests on a $10 \times 10-\mathrm{m}$ grid to further refine the subsurface data and provide a guide for the backhoe trenching that followed on October 4-5, 2017. Due to variations in the underlying eroded limestone bedrock, the 53 shovel tests ranged in depth from surficial bedrock to as deep as $250 \mathrm{cmbs}$ with the aid of a hand auger. Archaeologists observed cultural material within the shovel tests on surface to a depth of $200 \mathrm{cmbs}$, with most of material located between 20 and $100 \mathrm{cmbs}$. Stratigraphy observed during the shovel testing generally correlated with the strata recorded during the previous phases of investigations (see Natural Strata discussion, below). 


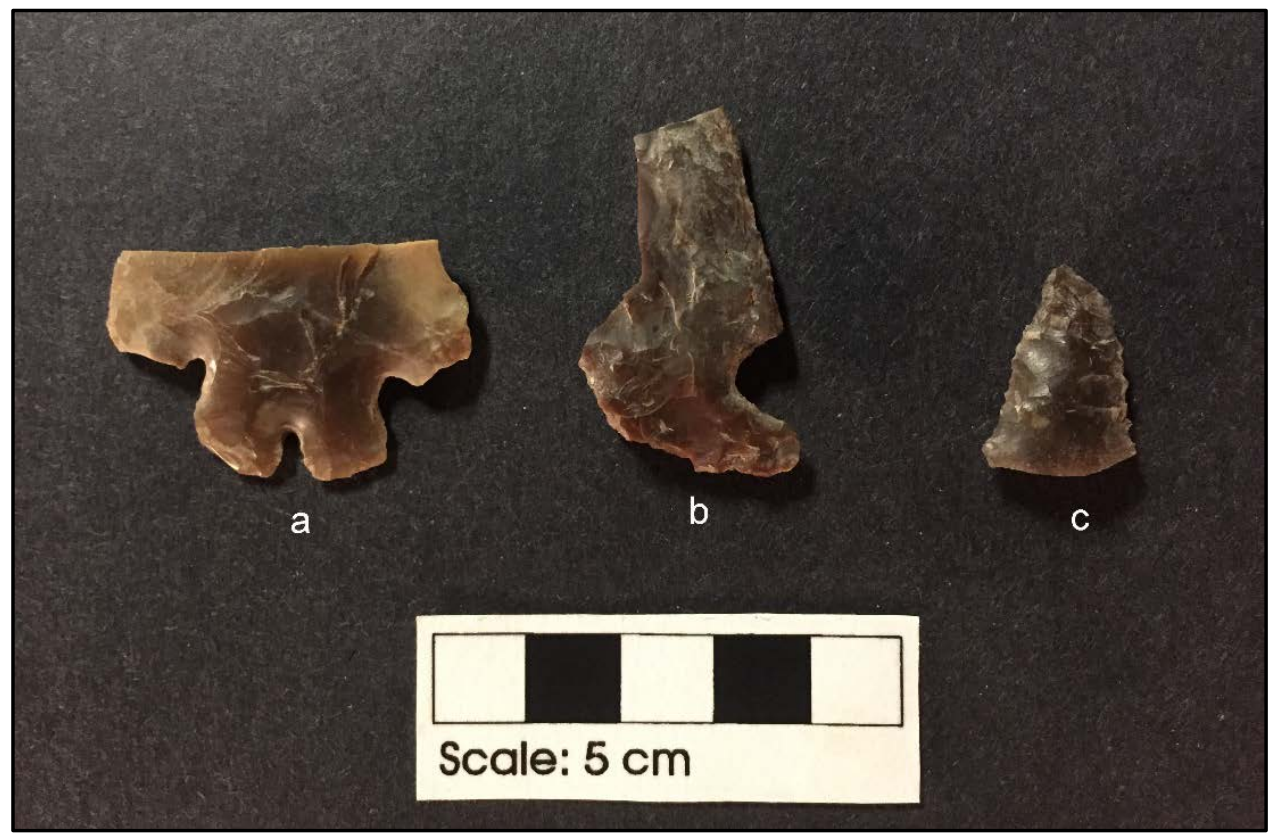

Figure 12. Dart point fragments recovered from 41GU177: a. Montell dart point base; b. Possible Frio or Ensor dart point fragment; and c. untyped dart point distal tip.

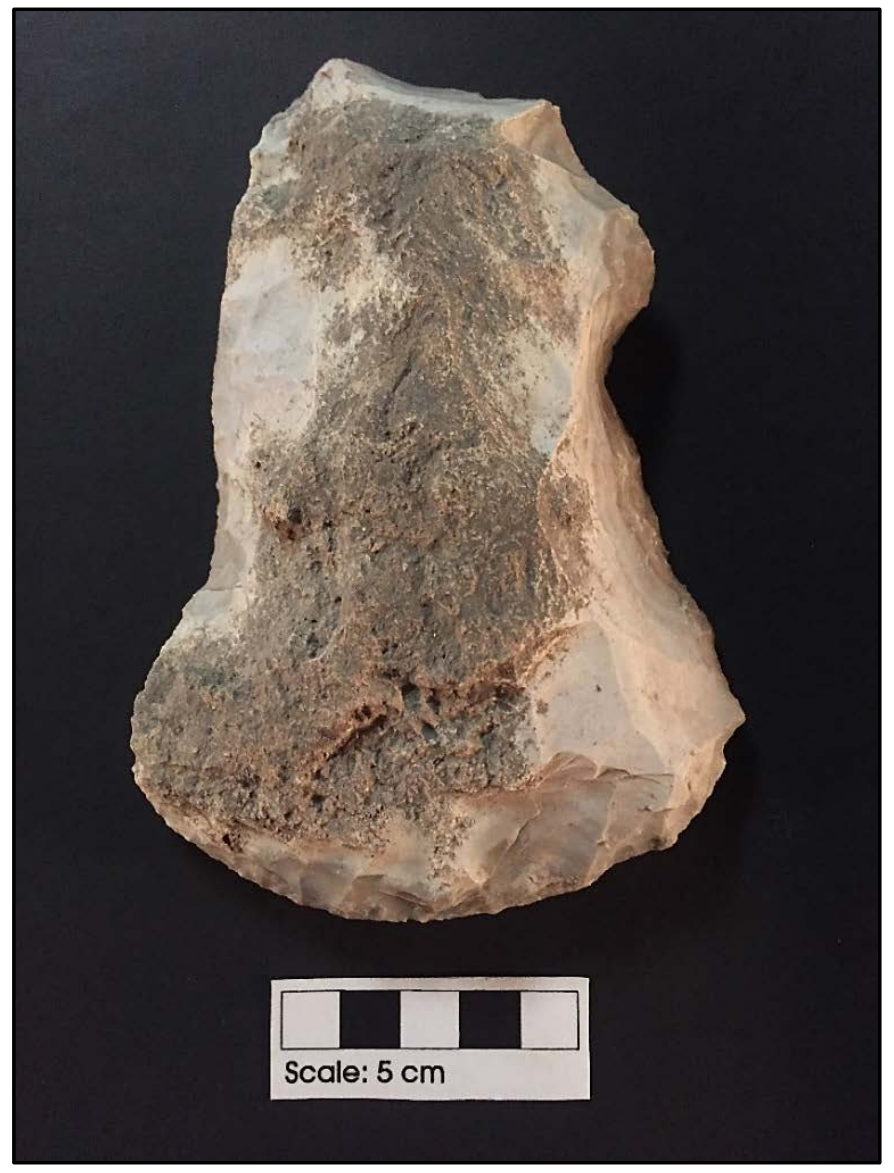

Figure 13. Unifacial axe recovered from TU05 excavations 
Artifactual recovery from the 53 additional shovel tests consist of a total 1,027 pieces of lithic debitage, which included 47 primary flakes, 162 secondary flakes, 758 tertiary flakes, and 60 pieces of lithic shatter. Within the shovel tests of $41 \mathrm{GU} 177$, SWCA also recovered five projectile point fragments, one lithic core, one modified flake, two ground stone fragments, seven pieces of faunal remains, and 108 pieces of burned rock. The projectile points recovered from these shovel tests include the base of a Montell dart point (see Figure 12, Specimen a); the distal tip of a dart point (see Figure 12, Specimen c); one corner-notched, broad stem Scallorn arrow point variant (see Figure 7, Specimen c); one translucent untyped arrow point that may be a Sabinal specimen (see Figure 7, Specimen g); and one medial section of an untyped arrow point (see Figure 7, Specimen k).

\section{NATURAL STRATA}

As previously indicated, 58 shovel tests, 13 backhoe trenches (BHT01-BHT13) and five test units (TU01TU05) have been excavated at $41 \mathrm{GU} 177$ (see Figure 10). The stratigraphy is distinctly different across the site depending on topography and proximity to the Guadalupe River. Specifically, the backhoe trenches on the western end of the site (BHTs 1, 3, 9, and 13) suggest an older deposition than those trenches on the eastern portions of the site (BHTs $2,4,5-8,10-12$ ). The western trenches are situated on a landform roughly 580 to 585 feet amsl and about $1.5 \mathrm{~m}$ ( 5 feet) above the eastern trenches. These trenches contain relatively shallow $\mathrm{CaCO}_{3}$ filaments and nodules beginning around 30 to $40 \mathrm{cmbs}$, which appear to be Pleistocene terrace deposits. The eastern trenches coincide with the $T_{2}$ terrace landform at 575 to 580 feet amsl (discussed above), whereas the western trenches are situated on the adjacent landform that could be part of the $\mathrm{T}_{2}$ landform or remnants of an older alluvial landform (i.e., $\mathrm{T}_{3}$ ). The stratigraphy in the eastern trenches have deep alluvial deposits that appear younger in age (Holocene) than the western trenches on the adjacent landform. The discussion below summarizes the western and eastern trenches on the two landforms.

\section{EASTERN TRENCHES (T, TERRACE)}

Overall, SWCA observed six strata in the excavations on the $\mathrm{T}_{2}$ terrace (BHTs 2, 4, 5-8, 10-12) (see Figure 10) at $41 \mathrm{GU} 177$ extending to $330 \mathrm{cmbs}$. Below the $6-\mathrm{cm}$-thick root zone, the upper two horizons (Strata I and II) extending to roughly $52 \mathrm{cmbs}$ are dark gray brown to brown (10YR 4/2-4/3) fine silt loam with a subangular blocky structure, friable consistency, common roots-rootlets (20-30 percent), and Heliodiscus singleyanus snail shell (10 percent). The second horizon (Stratum II) contains some white filaments that are interpreted to be michoryzal fungi (1 percent) and Heliodiscus singleyanus and Rabdotus mooreanus snail shell (10 percent). The lower boundary of Stratum I was clear and slightly wavy, while Stratum II was clear and smooth. Notably, the lower boundary in BHT04 was abrupt and smooth, reflecting the disturbances in the area (e.g., vegetation clearing and earth movement) that likely truncated a portion of Stratum III.

The roughly 35- to 50-cm-thick third horizon (Stratum III) begins at roughly 50 to $75 \mathrm{cmbs}$ and exhibits grayish brown (10YR 5/2) silt loam with a subangular blocky structure, friable consistency; with common roots-rootlets (15 to 20 percent), common insect and worm burrows (10 to 15 percent), and white filaments that are interpreted to be michoryzal fungi $(<1$ percent), and Heliodiscus singleyanus ( 1 to 5 percent) and Rabdotus mooreanus (1 to 3 percent) snail shell. SWCA observed rare ( $<1$ percent) subrounded cobbles at the top and bottom of this horizon. The lower boundary of Stratum III was gradual and smooth.

The roughly 50- to 70 -cm thick Stratum IV begins at 75 to $85 \mathrm{cmbs}$ and is brown to pale brown (10YR 5/3$6 / 3$ ) silt loam with a friable consistency, a subangular blocky structure; with roots-rootlets (5 to 15 percent), insect and worm burrows ( 5 to 10 percent), and white filaments that are interpreted to be michoryzal fungi $(<1$ percent), and Heliodiscus singleyanus (10 percent) and Rabdotus mooreanus (2 percent) snail shell. The lower boundary of Stratum IV was gradual and smooth. 
Stratum V generally begins at $151 \mathrm{cmbs}$ and is a light yellowish brown (10YR 6/4) silt loam with a friableloose consistency and a subangular blocky structure parting to crumb structure; with rootlets (15 percent), insect and worm burrows (5 percent), and Heliodiscus singleyanus (3 percent). This horizon was observed to extend to roughly $230 \mathrm{cmbs}$ and had a gradual and smooth lower boundary.

The last observed stratum (VI) was observed only in BHT06 and BHT07. This horizon typically begins at roughly $230 \mathrm{cmbs}$ and is a light yellowish brown to very pale brown (10YR 6/4-7/4) fine to very fine silt loam. This horizon has a friable consistency, a crumb parting to subangular blocky structure, insect burrows (10 percent), Heliodiscus singleyanus ( $<2$ percent) and Rabdotus mooreanus ( $<5$ percent) snail shell, and calcium carbonate $\left(\mathrm{CaCO}_{3}\right)$ filaments (3-5 percent). The lower boundary of this horizon was unobserved.

\section{WESTERN TRENCHES (T 3 TERRACE?)}

In general, SWCA observed five strata in the western excavations (BHTs 1, 3, 9, and 13) (see Figure 10) at 41GU177 extending to $253 \mathrm{cmbs}$. Notably, the upper three horizons are similar to that observed in the eastern trenches (BHTs 2, 4, 5-8, 10-12), but are thinner and shallower that the stratigraphy observed down slope.

The fourth horizon (Stratum IV) typically begins at roughly 40 to $50 \mathrm{cmbs}$ and exhibits brown to light yellowish brown (10YR 5/4-6/4) silt loam with a crumb to subangular blocky structure, friable consistency; with roots-rootlets (3 to 10 percent), common (5 percent) infilled burrows containing Strat II matrix, small (3 to 4 millimeters) diameter $\mathrm{CaCO}_{3}$ nodules (2 percent), and a gradual and smooth lower boundary.

The fifth horizon (Stratum V) begins around $80 \mathrm{cmbs}$ and contains a light yellowish brown to very pale brown (10YR 6/4-7/6) silt loam with a subangular blocky structure, friable to firm consistency, rootlets (5 percent), $\mathrm{CaCO}_{3}$ nodules ( 2 to $3 \mathrm{~cm}$ ) diameter (3 to 5 percent) that increase in size and prevalence with depth. The lower boundary of this stratum was unobserved, extending to at least $253 \mathrm{cmbs}$. Notably, the horizon appeared to lighten in color toward a very pale brown to yellow (10YR 8/4-8/6) beginning around 140 cmbs.

\section{SUMMARY OF NATURAL STRATA}

In summary, the natural strata (I-VI) observed at 41GU177 suggests some disturbances localized at or near the ground surface. The disturbances are primarily associated with extensive tree root growth, possible earth movement, and erosion. The vertical extent of evident disturbance across the site varied. The excavation areas amongst extensive trees (i.e., BHT05 and BHT06) had moderate, localized disturbance to approximately $75 \mathrm{cmbs}$. In contrast, the excavation areas in proximity to existing roads and previously cleared areas (i.e., BHT02 and BHT04) displayed evidence related to vegetation clearing and earth movement. These disturbances, suggested by the abrupt lower boundary of Stratum II, were shallower (32 cmbs), but more extensive, and may have truncated the upper horizon of Stratum III. The underlying strata (Strata III-VI) across 41GU177 appears generally intact with some disturbance from tree roots and small burrows.

\section{MAGNETIC SUSCEPTIBILITY}

Magnetic susceptibility (MS) analyses of soils have been utilized in archaeological investigations for several decades, and have largely been directed toward surveys (e.g., Crowther and Barker 1995; Dalan 1996, 2008; Rosendahl et al. 2014; Van Leusen et al. 2014; Wiewel and Kvamme 2014). More recently, these investigations have focused on archaeological site formation and associated depositional processes (Dalan 2006, 2008). These analyses have assisted in identifying buried or thermally altered soils associated with cultural activities, as well as identifying the horizontal extent of cultural features (e.g., Dalan and 
Banerjee 1998; Dalan and Bevan 2002; Ellwood et al. 1995; Frederick 2010; Jones and Leffler 2003; Nickels 2010; Peters and Thompson 1999; Mauldin and Figueroa 2006; Rivers et al. 2004).

Extensive reviews of the processes of environmental magnetism and particularly the application of MS have been produced (e.g., Dearing 1999a, 1999b; Gale and Hoare 1991:201-229; Maher et al. 1999; Thompson and Oldfield 1986; Verosub and Roberts 1995). Briefly, magnetic minerals are prevalent in the natural environment and are sensitive to environmental changes (Gale and Hoare 1991:202). The measurement of MS $\chi$ (Chi) is a quantification of the 'magnetisability' of the material (Dalan 2008; Dalan and Banerjee 1998; Dearing 1999b:5; Gale and Hoare 1991:202-204). The mineralogy, the size and shape of the grains, internal stress, and other factors can initially influence the susceptibility value (Dearing 1999a, 1999b; Gale and Hoare 1991:204). However, of relevance to this discussion, factors including organic content, pedogenesis, thermal alteration, and cultural activities (e.g., ash-charcoal and refuse) can subsequently alter (usually increase) the susceptibility values. The implications of using MS for archaeological research is that when examining either vertical or horizontal areas, the susceptibility values can assist in identifying cultural activities areas that may otherwise be blurred at a macro level. Horizontally, the application of MS analysis has been used to define the limits of cultural features and living spaces in excavation blocks (e.g., Mauldin and Figueroa 2006; Wiewel and Kvamme 2014). Vertically, the MS results have been applied to recognizing and delineating cultural horizons (e.g., Frederick 2010, 2012; Lawrence et al. 2013).

Notably, this form of in situ analysis of MS is unable to differentiate between low ( $\chi \mathrm{lf})$ and high ( $\chi$ hf) frequency (470 to $4700 \mathrm{~Hz}$, respectively) and does not examine mass-specific susceptibility. Rather, the in situ analysis examines the volume susceptibility of a specific radius around the probe. Although not as accurate, these analyses are beneficial in that the data can be quickly collected and analyzed in real-time. Although the data derived with this type of analysis (in situ MS) within this setting may not provide definitive identification of cultural versus natural influences, the analysis can be informative regarding integrity of the deposits and the presence of high or low MS values. Specifically, elevated values of MS can suggest an influence by factors including organic content, pedogenesis, thermal alteration, and cultural activities (e.g., ash-charcoal and refuse). Typically, the upper horizons closer to the ground surface will have higher values of MS from the presence of organic matter. Conversely, a stable, intact profile typically has steadily decreasing MS values. Further, "wiggles" are expected in these analyses, but dramatic, sustained changes (increase or decrease) in values may suggest cultural activities or disturbance. This is particularly applicable at recognized horizon boundaries.

MS analysis of four vertical columns were conducted at 41GU177 using either in situ analysis or matrix analysis in the lab. The in situ MS analyses were conducted using a Bartington MS2F probe that collected two readings of data in 2- to 5-cm intervals down profile for each backhoe trench. Briefly, the MS2F probe is $1.5 \mathrm{~cm}$ in diameter and is inserted $2 \mathrm{~cm}$ deep into an exposed profile to collect MS readings. The MS analyses were collected down profile (ground surface to base of exposed profile) at the high sensitivity (0.1) setting at three locations (BHT4 in TU03, BHT5 near TU05, and in BHT10). Due to Occupational Safety and Health Administration (OSHA) safety requirements, these recordings were only able to examine the in situ profile down to a maximum depth of $180 \mathrm{cmbs}$ (6 feet). In contrast, the MS analyses in the fourth column consisted of collecting matrix in 4 to $5 \mathrm{~cm}$ in the western profile of BHT11 ( $\mathrm{n}=33)$.

\section{MS RESULTS}

\section{BHT04 (TU03)}

Regarding the vertical MS results in BHT4/TU03 area, the in situ MS values had several apparent spikes and trends (Figure 14). Examining the MS data down profile, Strata I and II exhibit dynamic fluctuations supporting the interpretation that it is disturbed from recent landform modification. The underlying 
Stratum III exhibits values ranging from 30 to 40 throughout the horizon. The Stratum III results do exhibit two prominent spikes between 70 and $83 \mathrm{cmbs}$ that may coincide with cultural activities. At the transition of Strata III/IV, there is a dramatic drop in values until roughly $103 \mathrm{cmbs}$. At this depth, the values spike until $130 \mathrm{cmbs}$ where the values gradually decrease and transition into Stratum V. The Stratum IV elevated values between 103 and 130 cmbs is likely attributed to cultural activities. Within the underlying Stratum $\mathrm{V}$, a very subtle increase in values occurs around 155 to $170 \mathrm{cmbs}$. Although intriguing, this increase in MS value is inconclusive as to whether this could be attributed to cultural activity or something else with the present data.

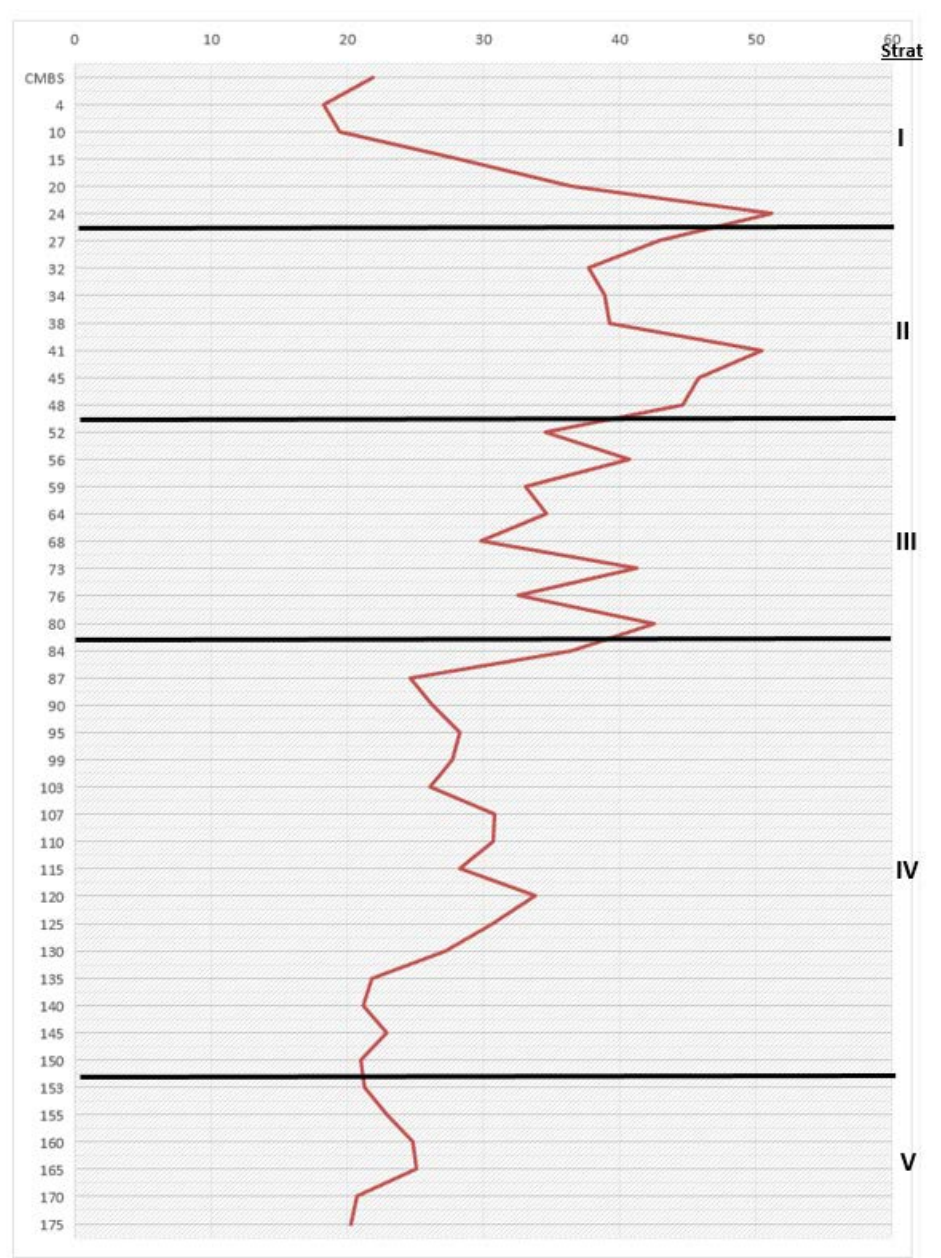

Figure 14. Magnetic susceptibility results from BHT04.

\section{BHT05}

Regarding the vertical MS results in the BHT05 area, the in situ MS values are similar to that exhibited in BHT04 (Figure 15). Interestingly, in Strata I and II (where tree roots and bioturbation were the most extensive) the values are high, but do not have dramatic fluctuations that may indicate a highly organic and homogenous mix. The underlying Stratum III exhibits two prominent spikes. One spike is between 27 and $46 \mathrm{cmbs}$, while the second spike is between 59 and $74 \mathrm{cmbs}$. Since these two "plateaus" are derived from several contiguous readings and separated by consistent decreases, one or both plateaus may indicate distinct cultural zones. Similar to the trends observed in BHT4, the transition between Strata III/IV exhibits a drop-in value from above 48 to below 30 and gradually decreases in values with depth. The underlying Stratum IV does have an increase in values between 81 and $92 \mathrm{cmbs}$. This plateau is like that observed in 
Stratum IV of BHT04 (between 103 and $130 \mathrm{cmbs}$ ), as it has several contiguous readings of higher values and could suggest the presence of cultural activities. Below this slight increase and continuing into Stratum $\mathrm{V}$, no evident values are present to suggest extensive cultural activities in this area. However, the beginnings of an increase in values is evident in Stratum V between 132 and 136 cmbs. This increase in MS value is inconclusive as to whether this could be attributed to cultural activity or something else with the present data.

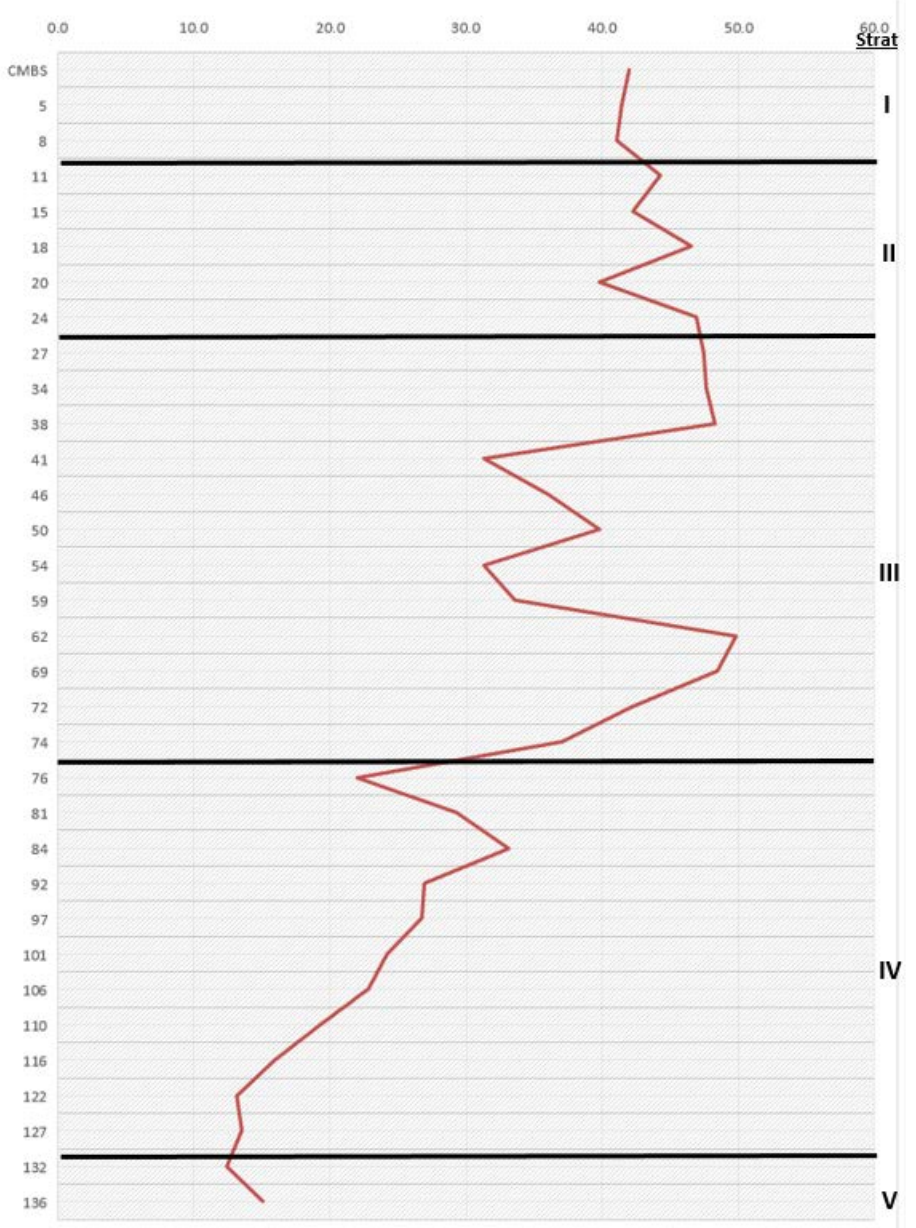

Figure 15. Magnetic susceptibility results from BHT05.

\section{BHT10}

Regarding the vertical MS results in the BHT10 area, the in situ MS values are similar to that exhibited in BHT04 and BHT05 (Figure 16). The upper Strata I and II (where tree roots and bioturbation were again the most extensive) have MS values exhibiting dramatic fluctuations. This likely indicates a highly organic and disturbed mix with cultural activities present. Specifically, a fragment of fire-cracked rock was observed in Stratum II at 39 to $42 \mathrm{cmbs}$ that seems to coincide with the prominent spike in MS values in the horizon (see Figure 16). The underlying Stratum III contains several prominent spikes. One spike is between 65 and $80 \mathrm{cmbs}$, while the second spike is between 95 and 115 cmbs. SWCA observed individual fragments of fire-cracked rock in Stratum III at $76 \mathrm{cmbs}$ and at $103 \mathrm{cmbs}$, respectively, which coincides with these two spikes in MS value. Interestingly, there is a gradual decrease in values between Stratum III and Stratum IV, but then the MS values increase. Stratum IV has one very prominent spike in value between 135 and 145 cmbs (see Figure 16). Not surprisingly, a fragment of fire-cracked rock was observed at 139 cmbs that 
coincides with the prominent spike in MS values for the horizon. Below the spike, the values steadily decrease and transition into Stratum V. This base horizon, Stratum V, contains a very subtle increase in values around 160 to $170 \mathrm{cmbs}$. Although intriguing, this increase in MS value is inconclusive as to whether this could be attributed to cultural activity or something else with the present data.

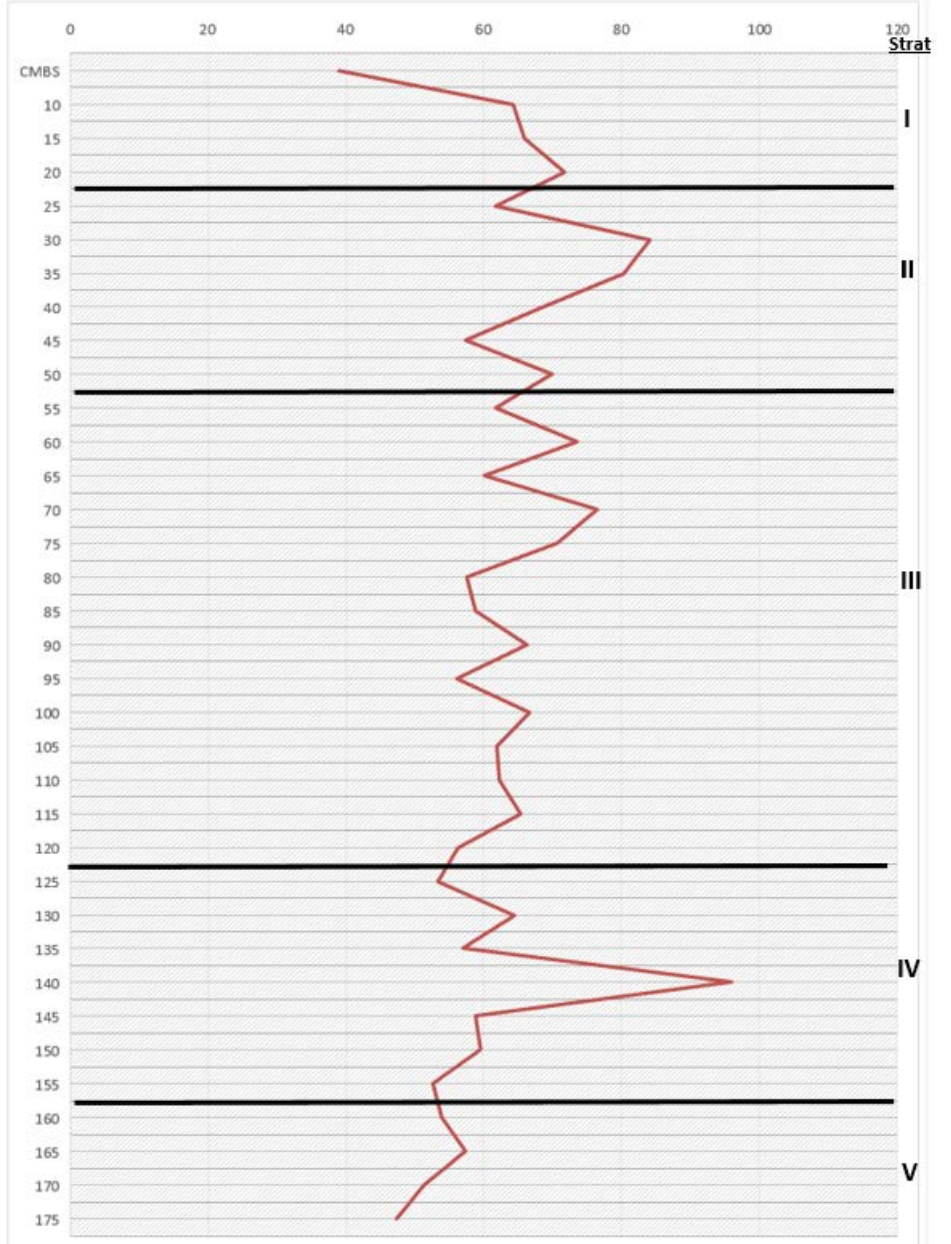

Figure 16. Magnetic susceptibility results from BHT10.

\section{BHT11}

As mentioned above, the MS analysis in BHT11 was conducted differently from the other vertical column analyses that used in situ analysis. The MS analysis in BHT11 utilized collected matrix from the profile that were subsequently examined in the lab. The results of the MS analysis exhibited several notable items (Figure 17). The upper Strata I and II (where tree roots and bioturbation were the most extensive) have MS values that were relatively stable with no dramatic fluctuations. These data suggest a relatively homogenous matrix. The underlying Stratum III exhibited a gradual decrease in values until 45 to $50 \mathrm{cmbs}$, where a slight increase is present. Below that, the gradual decrease in MS values continues into Stratum IV to roughly 55 to $70 \mathrm{cmbs}$, where another spike in value occurs. Below that spike in Stratum IV, the MS values steadily decrease until 120 to 125 cmbs, where a prominent spike in value occurs. At this depth in BHT11, SWCA observed a discontinuous and sloping lens of dark matrix (Figure 18). The lens (also observed in BHT12) is interpreted to be a thin cultural zone, a thin buried soil, or both. Because the lens contained at least one fragment of fire-cracked rock, it is more likely interpreted as a cultural horizon. Below the lens, the MS values decrease until 135 to 160 cmbs, where another prominent spike in MS values is evident. 
Most notable about these MS value spikes is that SWCA observed scattered fragments of fire-cracked rock throughout the trench that coincided with most of these spikes. The one exception is the prominent MS value spike in Stratum V at 135 to $160 \mathrm{cmbs}$ (Figure 19), where no fire-cracked rock fragments were observed in BHT11 at this depth.

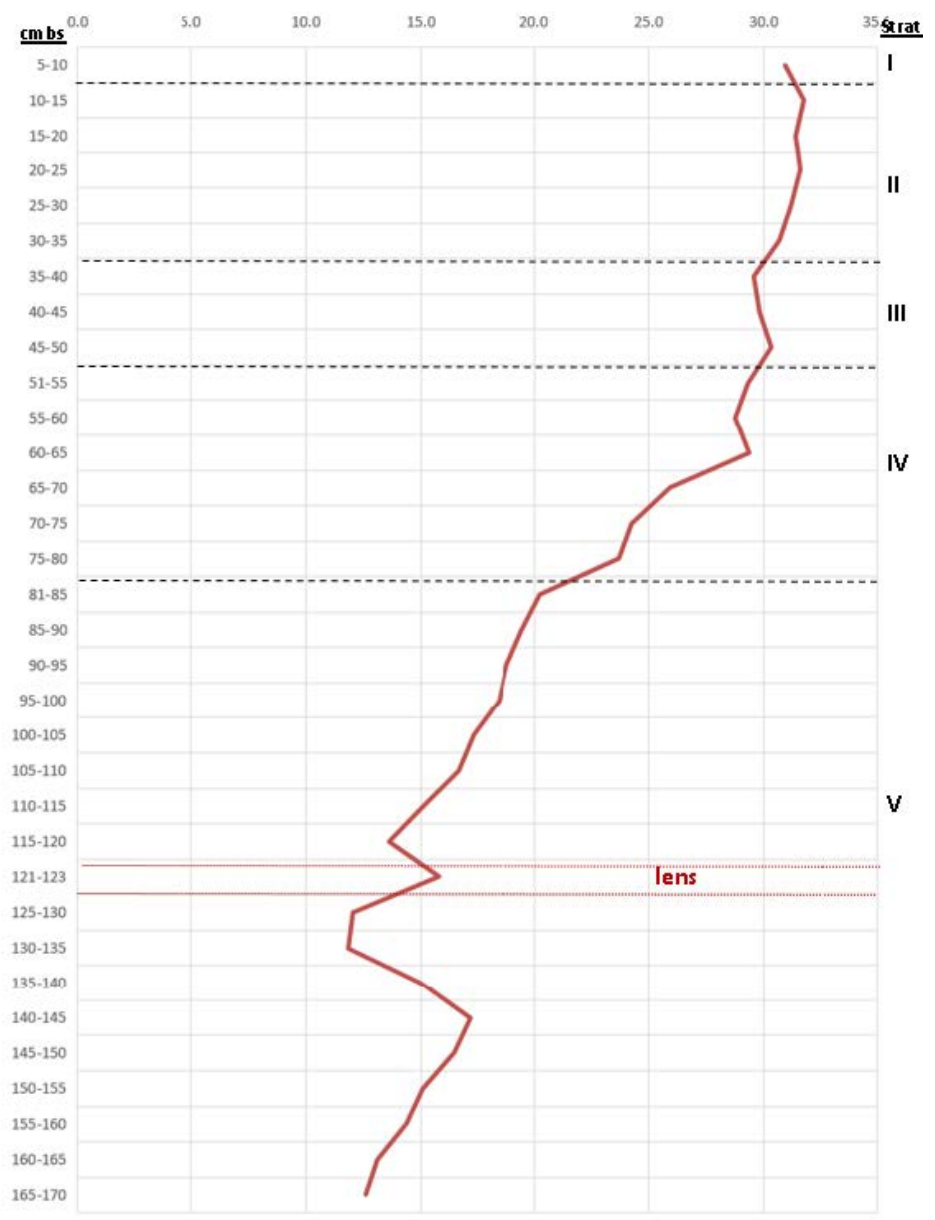

Figure 17. Magnetic susceptibility results from BHT11.

\section{SUMMARY MS RESULTS}

The results of the MS analyses at four different locations across the site provide some interesting data. When the strata and MS results of each vertical column are compared against each other, the data suggests similar factors affecting all the deposits. Specifically, in Stratum II there is an increase in MS values exhibited in BHT04, BHT10, and possibly BHT05 (see Figures 14-16). In Stratum III across all four vertical columns there is at least one plateau exhibited around 70 to $80 \mathrm{cmbs}$; conversely, this occurs at 45 to $50 \mathrm{cmbs}$ in BHT11. Similarly, in Stratum IV, a consistent increase in values is exhibited at roughly 100 to 130 in BHT04, BHT05, and BHT10, while a similar spike is represented from 55 to $70 \mathrm{cmbs}$ in BHT11 (see Figures 14-17). Finally, in Stratum V, an increase in MS is evident in BHT04, BHT10, and BHT11 at roughly 130 to $160 \mathrm{cmbs}$ (see Figures 14-17). Although BHT05 did not extend this deep, there is the beginnings of an increase in MS values between 132 and $136 \mathrm{cmbs}$. Of note, the increase in Stratum V MS values across all trenches was not directly associated with cultural materials. This increase in MS value in Stratum V is inconclusive as to whether this could be attributed to cultural activity or something else with the present data. 


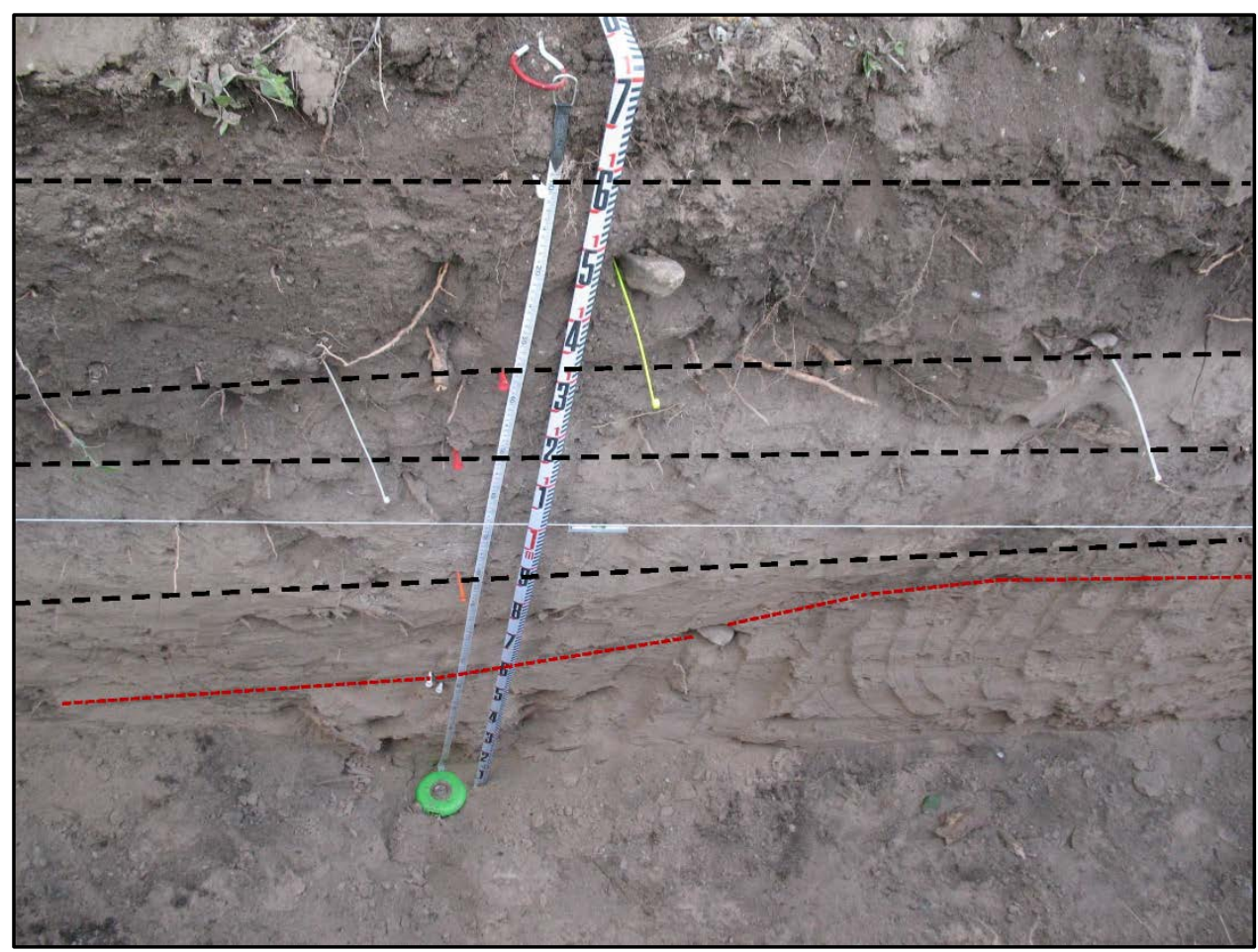

Figure 18. BHT11 profile.

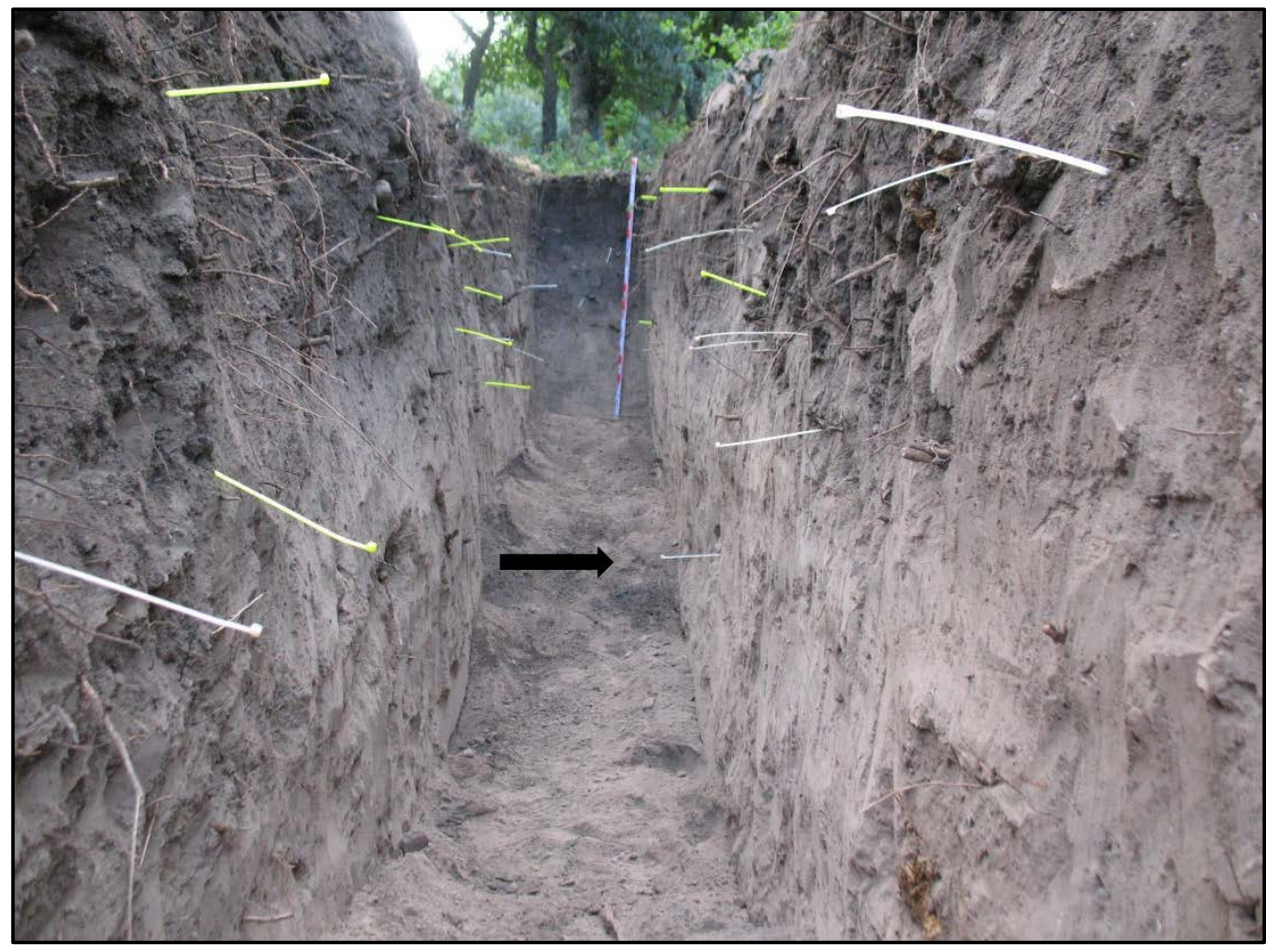

Figure 19. BHT11 overview. The zip-ties in the trench walls are marking artifacts. 
Overall, the data from the MS analyses suggests that although some disturbances from bioturbation and landform modification have disturbed portions of 41GU177, there does appear to be several well-defined, stratified cultural zones present.

\section{SUMMARY SITE DISCUSSION}

From the data collected to date, several data realms have been preliminarily addressed, which in turn have implications for more detailed research questions and concerns. The phased investigations have allowed preliminary determinations of the general integrity of the cultural deposits, site chronology, and potential data yield.

Based on the site's natural stratigraphy and tentatively identified cultural zones, the cultural deposits at 41GU177 are relatively intact, with some disturbances from tree roots and krotovina observed. The natural stratigraphy (Strata I-VI) observed at 41GU177 suggests some localized disturbances at or near the ground surface from previous vegetation clearing, extensive tree root growth, possible earth movement, and erosion. The vertical extent of evident disturbance across the site varies. The excavation areas amongst extensive trees (i.e., BHT05 and BHT06) exhibited moderate, localized disturbance to approximately 75 cmbs. In contrast, the excavation areas in proximity to existing roads and previously cleared areas (i.e., BHT02 and BHT04) had evidence that may be related to vegetation clearing and earth movement. These disturbances, suggested by the abrupt lower boundary of Strata II, were shallower (32 cmbs), but more extensive and may have truncated the upper horizon of Strat III. The underlying strata (III-VI) across 41GU177 appear generally intact, with some minor disturbance from tree roots and small burrows.

Investigations to date have yielded a relatively dense assemblage of cultural materials, given that only approximately 7.8 cubic meters have been hand excavated from $1 \times 1$-m test units and 3.9 cubic meters from the close interval shovel testing (for a total of 11.7 cubic meters). The total assemblage encompasses 5,406 artifacts and floral/faunal specimens, including abundant chipped-stone debitage, formal and informal chipped-stone tools (i.e., projectile points, one chipped-stone axe, utilized flakes, bifaces, etc.), ground stone specimens (i.e., mano fragments), and the well-preserved faunal and floral specimens mentioned below (Appendix C). The artifact assemblage is predominately (91 percent) debitage, with a total of 3,897 debitage specimens recovered to date from TU01-TU05 and 1,043 from the shovel testing.

As Appendix C indicates, the majority ( $n=4,469$ [83 percent]) of the debitage assemblage reflects middle to late reduction activities, with secondary and tertiary flakes, and decorticate chips and chunks representing the bulk of the specimens. This suggests that much of the initial reduction of lithic raw materials was occurring off site at raw material source locations, which appear, based on cortex analysis, to include both fluvial gravels (i.e., corticate specimens exhibit smooth water-worn cortex) and in situ outcrops (i.e., corticate specimens exhibiting coarse and/or weathered cortex). Incomplete and complete bifaces (other than projectile points) are poorly represented in the assemblage. Given the preponderance of later-stage reduction debitage (particularly tertiary specimens that represent 67 percent of the debitage assemblage) and the general lack of complete and incomplete bifaces (except occasional broken preforms and the finished and broken projectile points), biface and projectile point manufacturing was a common activity on site, with the completed bifaces (complete projectile points, preforms, and Stage IV bifaces) leaving the site.

In terms of site chronology, temporally diagnostic artifacts recovered from the site to date indicate a general Late Prehistoric use of the site, including a probable Austin Phase (ca. A.D. 600-1200) occupation and hints of an earlier Transitional Archaic (ca. 200 BC to AD 600) occupation. A total of 15 projectile points or point fragments were recovered during the phased investigations. The majority $(n=10)$ are identified as untyped arrow point fragments, whereas three specimens are typed as corner-notched, broad stemmed Scallorn arrow point variants associated with Austin phase occupations. Additional recovered arrow points, 
due to missing bases or reworked bases and stems, are untyped but indicate general Late Prehistoric (ca. A.D. 600-1700) occupations. Traces of earlier site use is potentially evident in the recovery of a dart point fragment identified as belonging to the Montell type that dates to the Late Archaic (ca. 800-400 B.C.), as well as an untyped dart point fragment that may represent a Frio or Ensor type projectile point (Transitional Archaic, ca. 200 B.C. - A.D. 600).

The temporally diagnostic data, when considered in conjunction with the stratigraphic analyses and MS data, suggests site 41GU177 contains evidence for at least two stratified cultural zones with hints of possibly two additional, deeper stratified cultural zones. In the upper reaches of the deposits from roughly 45 to 80 cmbs there are several Scallorn arrow points, suggesting a probable Austin phase occupation that contains some stratigraphic disturbances as previously described. Additionally, a possible trace of an underlying Transitional Archaic occupation is marked by the presence of a possible Frio or Ensor dart point fragment, burned rock, and a spike in the MS data at a depth of approximately 60 to $80 \mathrm{cmbs}$. At this juncture, given the variable depth and thickness of the site stratigraphy and cultural zones due to undulations, data recovery would clarify the actual number of stratified cultural zones, as there is also some evidence of two possible deeper occupations, based on the presence of burned rock and spikes and dips in the MS data from roughly 120 to 150 cmbs.

Within the strata, floral and faunal preservation is good, with a total of 274 recovered faunal remains (262 bones and bone fragments, and 12 mussel shells and shell fragments) recovered from approximately 11.7 cubic meters of hand excavated sediments. TU01 yielded a burned nut shell from 70 to $80 \mathrm{cmbs}$ in the upper possible Austin phase occupation, as well as two burned seed fragments from a depth of 140 to $150 \mathrm{cmbs}$ in the deeper, suggest a possible Transitional Archaic occupation. The recovery of those wellpreserved faunal and floral specimens suggests that additional charred macrobotanical remains are present on site that can be recovered and analyzed to help build a picture of site use and foraging strategies.

A total of 574 burned rock fragments, weighing approximately 27.1 kilograms, were recovered within the five excavation units. All the test units show a rise in burned rock count and weight at approximately 60 cmbs. In addition, TU01 and TU04 display an increase in burned rock counts and weights at approximately 90 to $100 \mathrm{cmbs}$, with TU01 and TU02 indicating a third spike in burned rock weights at 120 to $140 \mathrm{cmbs}$. Although the charred floral remains and the scattered burned rocks and burned rock fragments recovered during excavations suggest that burned rock features (i.e., hearths) were utilized on site, the densities of burned and fire-cracked rock from various excavation contexts has thus far been relatively low and specimens were typically not clustered. This may suggest some degree of disturbance, but the presence of several clustered burned rocks in BHT02 and TU01 also shows that some feature integrity remains and that additional features and/or feature remnants are anticipated. Investigations to date have not identified any evidence for large thermal features, such as a burned rock midden or slab-lined hearths, not uncommon in similar Late Archaic to Transitional Archaic and Late Prehistoric period camp sites.

Following completion of the hand excavations and additional trenching, SWCA proposes that, horizontally, the core of the site/densest cultural materials are concentrated in the area around BHT11, and extending to the east-southeast to BHT02 (TU01 and TU02) and BHT04 (TU03), with TU04 containing compromised data from extensive bioturbation stemming from rodent activities (see Figure 11). The TU05 area exhibits a significantly lower artifact density than the BHT02, BHT04, and TU01-TU03 areas; however, excavations there were halted at $110 \mathrm{cmbs}$, due to time constraints. Similarly, the excavation of closeinterval shovel tests and BHT07-BHT10 to the south and west of BHT11 did not identify a high density of cultural materials. Vertically, cultural materials in the upper 50 to $75 \mathrm{~cm}$ (0 to $75 \mathrm{cmbs}$ ) exhibit some disturbance from tree roots, rodents, and, in some areas, mechanical impacts from prior vegetation clearing. Below $75 \mathrm{cmbs}$, the natural stratigraphy and cultural materials appear relatively intact and have a potential to contain significant intact cultural deposits when considered in conjunction with the stratigraphic, 
artifactual, and MS data collected from the site to date. Based on these data, it is the opinion of SWCA that the site warrants listing as a SAL.

To reiterate, construction impacts to $41 \mathrm{GU} 177$ would include the excavation and use of the $50 \times 50$ - $\mathrm{ft}$ bore pit area for tunneling the adjacent Guadalupe River, open cut trenching, a $65 \times 200-\mathrm{ft}$ temporary work space, and a temporary haul road for construction activities. Based on the recovered data, the north-central portions of the site, in SWCA's opinion, represent the core of the potentially significant cultural deposits. In contrast, the parts of the site west-southwest of STs 1-08, 2-08, 3-07, and 4-06 are low artifact density areas with poor preservation and few cultural materials that, in the opinion of SWCA, do not contribute to the site's overall potential SAL eligibility; as a result, SWCA recommends no further investigations are warranted for the southern two-thirds of the site.

Understanding the sensitive nature of the cultural deposits at 41GU177, VRRSP have developed two construction options to minimize construction impacts to the core of the site considered potentially significant by SWCA; Figure 20 was prepared by VRRSP to illustrate those options. As Figure 20 displays, VRRSP has arbitrarily labeled the moderate to high density artifact concentration areas within the existing easement and proposed temporary workspace as Area A. In addition, Area B on the figure denotes portions of the planned construction centerline and associated impact area, while Area $\mathrm{C}$ represents a small area that VRRSP proposes does not need additional work as it would be outside of any surface (i.e., haul road) and subsurface construction impacts, and has been previously investigated. The two construction options (1 and 2) and their respective steps are presented below:

\section{Option 1-Open Cut Trenching Through the Site}

1. Vegetation would be mechanically cleared in Areas A and B using a rubber-tired grinder (fellerbuncher) to not disturb the ground surface and subsurface.

2. Area A would be covered with geotechnical fabric to establish a boundary between the existing ground surface and a 1-foot-thick cap of fill would be placed over the geotechnical fabric to avoid subsurface impacts. An archaeological monitor would be present; the contractor would be responsible for ensuring there would be no impacts to the ground surface and subsurface.

3. Bore pit excavation would proceed, as well as installation of pipe via the open trench in Area B; all areas would then be backfilled upon completion.

4. The protective cap of fill and geotechnical fabric would be carefully removed from Area A with an archaeological monitor present; the contractor would be responsible for ensuring there would be no impacts to the ground surface and subsurface.

\section{Option 2-Tunneling and Limited Open Cut Trenching:}

1. Vegetation would be mechanically cleared in Areas A and B using a rubber-tired grinder (fellerbuncher) to not disturb the ground surface and subsurface.

2. Areas A and B would be covered with geotechnical fabric to establish a boundary between the existing ground surface and a 1-foot-thick cap of fill to be placed over the geotechnical fabric to avoid subsurface impacts.

3. Contractor excavates bore pit, installs tunnel, installs pipe via open trench to the southwest of the delineated sensitive site area, and backfills all areas. The top of the tunnel casing pipe will be at least 6.5 feet below the existing ground surface to avoid disruption to the lower cultural deposits. Potentially significant cultural deposits along the centerline within Area B are therefore avoided.

4. The protective cap of fill and geotechnical fabric would be carefully removed from Area A with an archaeological monitor present; the contractor would be responsible for ensuring there would be no impacts to the ground surface and subsurface. 


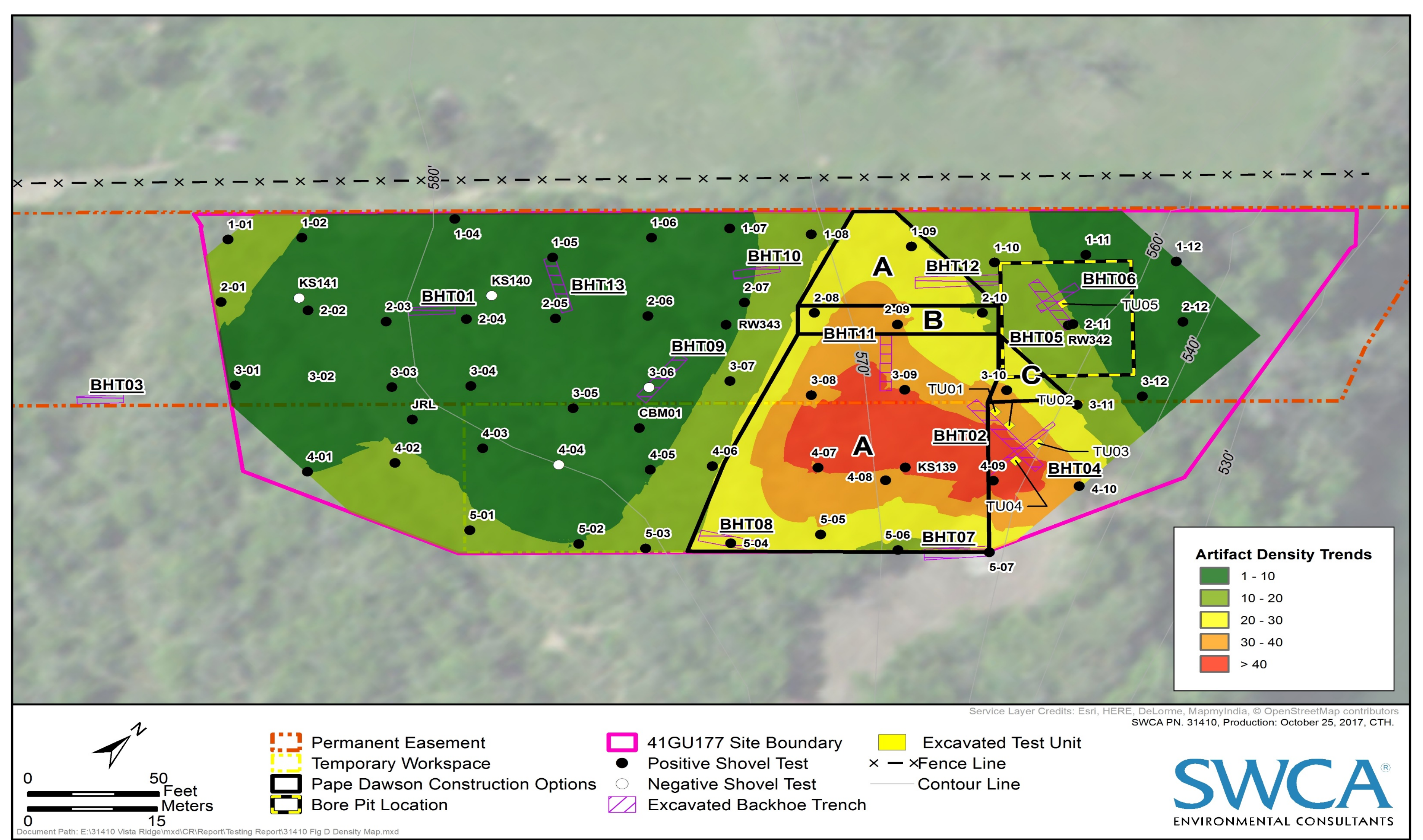

Figure 20. Construction options for 41GU177. 
Given the silty soils on the site, the option to cap the site with fill must consider the potential effects of soil compaction on those cultural materials buried close to the surface. Site capping or burial involves carefully covering an archaeological site with fill to allow project construction or other activities to proceed unimpeded over the site. However, site capping is only an appropriate mitigative measure when it can be demonstrated that important site data will not be lost through soil compaction, accelerated decomposition, horizontal displacement of cultural materials, or changes in soil chemistry. Investigations to date on 41GU177 suggest that approximately the upper 75 centimeters of the site have experienced some localized impacts from bioturbation (i.e., tree roots and burrowing animals) and mechanical impacts during vegetation clearing; however, the extent of the impacts appear moderate and there remain partially intact cultural deposits that should be protected, if the site is capped with fill.

\section{RECOMMENDATIONS}

Given the chronological data currently available from the site, the relative degree of intactness of the natural stratigraphy and cultural deposits, good macrobotanical preservation, and the types and densities of cultural materials recovered during the phased investigations, site 41GU177 appears to have the potential to yield new or important data regarding the Late Prehistoric period from the eastern margins of the Balcones Escarpment. Additionally, the deeper cultural occupation(s) may represent a Transitional Archaic use of the site and may provide valuable information concerning the shift from the Transitional Archaic to the Late Prehistoric period. Based on these data, it is the opinion of SWCA that the site is eligible for listing as a SAL and therefore warrants data recovery in the areas described above, if construction impacts cannot be avoided.

Complete avoidance of the site is currently not possible. The parts of the site west-southwest of STs 1-08, 2-08, 3-07, and 4-06 are low artifact density areas with poor preservation and few cultural materials that, in SWCA's opinion, do not contribute to the site's overall potential SAL eligibility; as a result, no further investigations are recommended for this area. In contrast, the north-central portions of site 41GU177 exhibit a much higher density of cultural materials and good stratigraphic integrity and faunal and floral preservation; this area is associated with tunneling of the Guadalupe River (adjacent to the site) and, in SWCA's opinion, additional investigations are warranted in the bore pit, associated temporary work space, and a proposed haul road.

Although the bore pit area exhibits a relatively lower artifact density, only one controlled hand unit was excavated to a depth of $110 \mathrm{cmbs}$ within the bore pit area; BHTs 5 and 6 were excavated for exploratory purposes. The presence of the unusual unifacial, large chipped-stone axe and potentially associated burned and fire-cracked rocks from TU05 suggests an entirely different activity from the other site activity areas (i.e., tool manufacture and possible mussel shell work areas) may have occurred in the bore pit area. Data recovery here would provide a sample from outside the presumed concentrated core of the site (where multiple living surfaces may be compressed), providing access to potentially more discrete activities and isolable components. Initial MS data collected from BHT 5 also suggests that there is a potential for deeper cultural deposits in this area. As there was a time limitation influencing the work in the bore pit area, we do not feel it has been adequately sampled, considering the potential for the complete destruction of this $50 \times 50$-foot area due to the bore excavation. Including portions of this area for data recovery would allow a further sample of the location; if initial data recovery excavations there determined the location to not be as productive, or the activity areas poorly defined, investigations would then be halted for lack of data.

Based on all the available data collected to date, it is the opinion of SWCA that the cultural deposits at 41GU177 within the identified high and moderate density area in the north-central part of the site (including the bore pit area) is eligible for SAL designation and warrants some level of data recovery investigations and/or measures to minimize site impacts prior to the potential construction impacts. Successful solutions for the treatment of $41 \mathrm{GU} 177$ will require discussions amongst VRRSP, SWCA, and THC to ensure a 
balance between construction needs and schedule, and regulatory compliance. For both construction options, technical discussions will be necessary with THC to address the proposed temporary capping of the site with fill to ensure an appropriate process and suitable materials are used to preserve portions of the site in place, should that be determined a feasible option. 


\section{REFERENCES}

Ashman, M. R. and G. Puri

2002 Essential Soil Science: A Clear and Concise Introduction to Soil Science. Blackwell Publishing, Malden, MA.

Barnes, V. E.

1983 Geologic Atlas of Texas: San Antonio Sheet. Robert Hamilton Cuyler Memorial Edition, Bureau of Economic Geology, University of Texas, Austin.

Charlton, R.

2008 Fundamentals of Fluvial Geomorphology. Routledge, London and New York.

Crowther, J., and P. Barker

1995 Magnetic Susceptibility: Distinguishing Anthropogenic Effects from the Natural. Archaeological Prospection 2:207-215.

Dalan, R. A.

1996 Soil Magnetism, An Approach for Examining Archaeological Landscapes. Geophysical Research Letters 23(2): 185-188.

2006 Magnetic Susceptibility. In Remote Sensing in Archaeology: An Explicitly North American Perspective. J. Johnson, M. Giardano, and K. Kvamme (editors), pp. 161-203. University of Alabama Press, Tuscaloosa, Alabama.

2008 A Review of the Role of Magnetic Susceptibility in Archaeologeophysical Studies in the USA: Recent Developments and Prospects. Archaeological Prospection 15: 1-31.

Dalan, Rinita A. and Subir K. Banerjee

1998 Solving Archaeological Problems Using Techniques of Soil Magnetism. Geoarchaeology: An International Journal 13: 3-36.

Dalan, R. A. and B. W. Bevan

2002 Geophysical Indicators of Culturally Embraced Soils and Sediments. Geoarchaeology: An International Journal 17 (8): 779-810.

Dearing, J.

1999a Magnetic Susceptibility. In Environmental Magnetism: A Practical Guide. J. Walden, F. Oldfield, and J. Smith (editors), pp. 35-62. Technical Guide No. 6. Quaternary Research Association, London.

1999b Environmental Magnetic Susceptibility Using the Bartington MS2 System. Available at: http://www.gmw.com/magnetic_properties/MS2_support.html. Accessed 10/20/17.

Ellwood, B. B., D. E. Peter, W. Balsam, and J. Schieber.

1995 Magnetic and Geochemical Variations as Indicators of Palaeoclimate and Archaeological Site Evolution: Examples from 41TR68, Fort Worth, Texas. Journal of Archaeological Science 22: 409-415.

Frederick, Charles D

2010 Geoarchaeological Investigations. In Archaeological Data Recovery on Three Sites Along the San Antonio River, Bexar County, Texas, by Antonio E. Padilla and David L. Nickels, pp. 449-462. Ecological Communications, Corporation, Austin, Texas. 
2012 Site Formation Processes and Implications for Archeology in the South Fork of the San Gabriel. In The Siren Site (41WM1126) and the Long Transition from Archaic to Late Prehistoric Lifeways on the Eastern Edwards Plateau, Williamson County, Texas, by Steve Carpenter, Kevin A. Miller, Brett Houk, Mary Jo Galindo, Charles Frederick, John Lowe, Ken Lawrence, Kevin Hanselka, and Abby Peyton, pp. 8-1-8-24. SWCA Environmental Consultants, Austin, Texas.

Gale, S. J. and P. G. Hoare

1991 Quaternary Sediments: Petrographic Methods for the Study of Unlithified Rocks. Bellhaven Press and Halsted, Press, New York and Toronto.

Jones, R. S., and J. J. Leffler

2003 Phase I and II Archaeological Investigations on Camp Mabry, Travis County, Texas, Archaeological Studies Report No. 2. Center for Archaeological Studies, Texas State University-San Marcos, Texas.

Lawrence, Ken, J. Kevin Hanselka, John D. Lowe, Christina Nielsen, and Kevin A. Miller

2013 Results of Archaeological Significance Testing at the Turkey Terrace Site (41FR70), Frio County, Texas. SWCA Environmental Consultants, Archaeological Report 12-518 Austin, Texas.

Maher, Barbara A., Roy Thompson, and Mark W. Hounslow

1999 Introduction. In Quaternary Climates, Environments, and Magnetism. B.A. Maher and R. Thompson (editors), pp. 1-48. Cambridge University Press. Cambridge.

Mauldin, R. P., and A. L. Figueroa

2006 Data Recovery Excavations at 41PR44, Fort Wolters, Parker County, Texas, Archaeological Report, No. 369, Center for Archaeological Research, University of Texas at San Antonio, San Antonio, Texas.

Natural Resources Conservation Service (NRCS)

2017 Web Soil Survey 2.1. National Cooperative Soil Survey. Available at: http://websoilsurvey.nrcs.usda.gov/app/WebSoilSurvey.aspx, Accessed July 2017.

Nickels, D. L.

2010 Stratigraphy, Chronology, and Site Formation Processes. In Archaeological Testing at the San Marcos Springs (41HY160) for the Texas River Center, Hays County, Texas, by David L. Nickels and C. Britt Bousman, pp. 61-82. Archaeological Studies Report No. 13. Center for Archaeological Studies, Texas State University-San Marcos, Texas.

Peters, Clare, and Roy Thompson

1999 Supermagnetic Enhancement, Superparamagnetism, and Archaeological Soils. Geoarchaeology: An International Journal 14 (5): 401-413.

Ramsey, R.N. and N. P. Bade

1977 Soil Survey of Guadalupe County, Texas. United States Department of Agriculture, Washington, D.C.

Rivers, J.M., J.E. Nyquist, Y. Roh, D.O. Terry Jr., and W.E. Doll

2004 Investigation into the Origin of Magnetic Soils on the Oak Ridge Reservation, Tennessee. Soil Science of America Journal 68(5): 1772-1779.

Rosendahl, Daniel, Kelsey M. Lowe, Lynley A. Wallis, and Sean Ulm

2014 Integrating Geoarchaeology and Magnetic Susceptibility at Three Shell Mounds: A Pilot Study from Mornington Island, Gulf of Carpentaria, Australia. Journal of Archaeological Science 49:21-32. 
Taylor, F. B., R. B. Hailey, and D. L. Richmond

1991 Soil Survey of Bexar County, Texas. United States Department of Agriculture, Washington, D.C.

Thompson, R. and F. Oldfield

1986 Environmental Magnetism. Allen \& Unwin Press. London, Boston, and Sydney.

Van Leusen, P. M., A. Kattenberg, and K. Armstrong

2014 Magnetic Susceptibility Detection of Small Protohistoric Sites in the Raganello Basin, Calabria (Italy). Archaeological Prospection (in press).

Verosub, K. L. and A. P. Roberts

1995 Environmental Magnetism: Past, Present, and Future. Journal of Geophysical Research 100(B2): 2175-2192.

Waters, Michael R.

1992 Principles of Geoarchaeology: A North American Perspective. University of Arizona Press, Tucson.

Wiewel, Adam S., and Kenneth L. Kvamme

2014 Magnetic Investigations of Nomadic Group Encampments at Fort Clark State Historic Site, North Dakota. Plains Anthropologist 59(231):261-278. 


\section{APPENDIX A}





\begin{tabular}{|c|c|c|c|c|c|c|c|c|c|c|}
\hline ST & Level & $\begin{array}{l}\text { Depth } \\
\text { (cmbs) }\end{array}$ & $\begin{array}{c}\text { Artifact } \\
\text { Type }\end{array}$ & $\begin{array}{c}\text { Artifact } \\
\text { Description }\end{array}$ & Material & $\begin{array}{c}\text { Artifact } \\
\text { No. }\end{array}$ & $\begin{array}{l}\text { Weight } \\
\text { (g) }\end{array}$ & Recorders & Date & Comments \\
\hline $1-1$ & 1 & $0-10$ & Debitage & Tertiary & Lithic & 1 & 1.94 & JU & $9 / 18 / 2017$ & \\
\hline $1-1$ & 3 & $20-30$ & Debitage & Primary & Lithic & 2 & 3.03 & JU & $9 / 18 / 2017$ & \\
\hline $1-1$ & 3 & $20-30$ & Debitage & Secondary & Lithic & 1 & 3.37 & $\mathrm{JU}$ & 9/18/2017 & \\
\hline $1-1$ & 3 & $20-30$ & Debitage & Tertiary & Lithic & 3 & 1.52 & JU & $9 / 18 / 2017$ & 3 bifacial thinning flakes \\
\hline $1-1$ & 4 & $30-40$ & Debitage & Secondary & Lithic & 1 & 0.37 & $\mathrm{JU}$ & $9 / 18 / 2017$ & 1 bifacial thinning flake \\
\hline $1-1$ & 4 & $30-40$ & Debitage & Tertiary & Lithic & 5 & 1.38 & JU & $9 / 18 / 2017$ & 4 bifacial thinning flakes \\
\hline $1-1$ & 5 & $40-50$ & Debitage & Secondary & Lithic & 1 & 0.77 & $\mathrm{JU}$ & 9/18/2017 & \\
\hline $1-1$ & 5 & $40-50$ & Debitage & Tertiary & Lithic & 5 & 1.71 & $\mathrm{JU}$ & 9/18/2017 & 4 bifacial thinning flakes \\
\hline $1-1$ & 6 & $50-60$ & Debitage & Tertiary & Lithic & 4 & 0.94 & JU & $9 / 18 / 2017$ & 4 bifacial thinning flakes \\
\hline $1-2$ & 2 & $10-20$ & Debitage & Secondary & Lithic & 1 & 5.16 & $\mathrm{JU}$ & $9 / 18 / 2017$ & 1 bifacial thinning flake \\
\hline $1-2$ & 2 & $10-20$ & Debitage & Tertiary & Lithic & 1 & 0.17 & $\mathrm{JU}$ & 9/18/2017 & 1 bifacial thinning flake \\
\hline $1-2$ & 5 & $40-50$ & Debitage & Tertiary & Lithic & 2 & 0.91 & $\mathrm{JU}$ & 9/18/2017 & 1 bifacial thinning flake \\
\hline $1-2$ & 6 & $50-60$ & Debitage & Secondary & Lithic & 1 & 0.24 & JU & $9 / 18 / 2017$ & 1 bifacial thinning flake \\
\hline $1-2$ & 6 & $50-60$ & Debitage & Tertiary & Lithic & 1 & 1.78 & JU & $9 / 18 / 2017$ & 1 bifacial thinning flake \\
\hline $1-4$ & 1 & $0-10$ & Glass & Colorless & Glass & 1 & 2.61 & $\mathrm{JU}$ & 9/18/2017 & \\
\hline $1-4$ & 1 & $0-10$ & Glass & Milk & Glass & 3 & 4.55 & JU & $9 / 18 / 2017$ & \\
\hline $1-4$ & 2 & $10-20$ & Glass & Colorless & Glass & 2 & 1.25 & JU & $9 / 18 / 2017$ & \\
\hline $1-4$ & 2 & $10-20$ & Glass & Milk & Glass & 1 & 1.47 & $\mathrm{JU}$ & 9/18/2017 & \\
\hline $1-4$ & 3 & $20-30$ & Glass & Colorless & Glass & 2 & 3.84 & JU & $9 / 18 / 2017$ & \\
\hline $1-4$ & 3 & $20-30$ & Glass & Milk & Glass & 1 & 0.48 & JU & 9/18/2017 & \\
\hline $1-4$ & 3 & $20-30$ & Debitage & Tertiary & Lithic & 1 & 1.76 & JU & $9 / 18 / 2017$ & 1 bifacial thinning flake \\
\hline $1-4$ & 4 & $30-40$ & Glass & Colorless & Glass & 1 & 0.9 & $\mathrm{JU}$ & 9/18/2017 & \\
\hline $1-5$ & 1 & $0-10$ & Debitage & Tertiary & Lithic & 2 & 0.49 & $\mathrm{JU}$ & $9 / 18 / 2017$ & 1 bifacial thinning flake \\
\hline $1-5$ & 2 & $10-20$ & Debitage & Tertiary & Lithic & 1 & 0.29 & $\mathrm{JU}$ & 9/18/2017 & \\
\hline $1-6$ & 7 & $60-70$ & Debitage & Secondary & Lithic & 1 & 8.32 & $\mathrm{JU}$ & 9/18/2017 & 1 bifacial thinning flake \\
\hline $1-6$ & 8 & $70-80$ & Debitage & Secondary & Lithic & 1 & 1.07 & $\mathrm{JU}$ & 9/18/2017 & \\
\hline $1-6$ & 9 & $80-90$ & $\begin{array}{l}\text { Burned } \\
\text { Rock }\end{array}$ & Burned Rock & Lithic & 2 & 4.33 & JU & 9/18/2017 & \\
\hline $1-7$ & 3 & $20-30$ & Debitage & Tertiary & Lithic & 2 & 0.33 & JU & 9/18/2017 & \\
\hline $1-8$ & 2 & $10-20$ & Debitage & Tertiary & Lithic & 1 & 0.95 & $\mathrm{JU}$ & 9/18/2017 & 1 bifacial thinning flake \\
\hline $1-8$ & 3 & $20-30$ & Debitage & Tertiary & Lithic & 1 & 0.46 & $\mathrm{JU}$ & 9/18/2017 & 1 bifacial thinning flake \\
\hline $1-8$ & 4 & $30-40$ & Debitage & Secondary & Lithic & 1 & 0.86 & $\mathrm{JU}$ & 9/18/2017 & \\
\hline $1-8$ & 4 & $30-40$ & Debitage & Tertiary & Lithic & 2 & 0.57 & $\mathrm{JU}$ & 9/18/2017 & 2 bifacial thinning flakes \\
\hline $1-9$ & 1 & $0-10$ & Debitage & Tertiary & Lithic & 1 & 2.34 & $\mathrm{JU}$ & 9/18/2017 & 1 bifacial thinning flake \\
\hline $1-9$ & 5 & $40-50$ & $\begin{array}{l}\text { Faunal } \\
\text { Remains }\end{array}$ & Bone & & 3 & 2.25 & JU & 9/18/2017 & \\
\hline $1-9$ & 6 & $50-60$ & Debitage & Secondary & Lithic & 1 & 22.86 & JU & $9 / 18 / 2017$ & \\
\hline $1-9$ & 6 & $50-60$ & Debitage & Tertiary & Lithic & 1 & 0.91 & JU & $9 / 18 / 2017$ & 1 bifacial thinning flake \\
\hline $1-9$ & 7 & $60-70$ & Debitage & Primary & Lithic & 1 & 0.23 & $\mathrm{JU}$ & 9/18/2017 & \\
\hline $1-9$ & 7 & $60-70$ & Debitage & Tertiary & Lithic & 1 & 0.24 & $\mathrm{JU}$ & 9/18/2017 & 1 bifacial thinning flake \\
\hline $1-9$ & 8 & $70-80$ & Debitage & Tertiary & Lithic & 1 & 0.47 & JU & 9/18/2017 & \\
\hline $1-9$ & 9 & $80-90$ & Debitage & Tertiary & Lithic & 1 & 0.47 & $\mathrm{JU}$ & 9/18/2017 & 1 bifacial thinning flake \\
\hline $1-10$ & 1 & $0-10$ & Debitage & Tertiary & Lithic & 1 & 0.19 & $\mathrm{JU}$ & 9/27/2017 & \\
\hline $1-10$ & 2 & $10-20$ & Debitage & Primary & Lithic & 1 & 15.98 & $\mathrm{JU}$ & 9/27/2017 & \\
\hline $1-10$ & 4 & $40-50$ & $\begin{array}{l}\text { Faunal } \\
\text { Remains }\end{array}$ & Mussel Shell & Shell & 1 & 7.27 & JU & 9/27/2017 & Complete \\
\hline $1-10$ & 4 & $40-50$ & Debitage & Secondary & Lithic & 1 & 11.03 & $\mathrm{JU}$ & 9/27/2017 & 1 bifacial thinning flake \\
\hline $1-10$ & 4 & $40-50$ & Debitage & Tertiary & Lithic & 1 & 0.07 & $\mathrm{JU}$ & 9/27/2017 & \\
\hline $1-10$ & 8 & $70-80$ & Debitage & Secondary & Lithic & 1 & 2.15 & $\mathrm{JU}$ & 9/27/2017 & \\
\hline $1-11$ & 6 & $50-60$ & $\begin{array}{l}\text { Faunal } \\
\text { Remains }\end{array}$ & Mussel Shell & Shell & 2 & 1.29 & JU & 9/27/2017 & 1 umbo \\
\hline $1-12$ & 1 & $0-10$ & Glass & Colorless & Glass & 1 & 1.08 & $\mathrm{JU}$ & 9/27/2017 & \\
\hline $2-1$ & 1 & $0-10$ & Metal & Staple & Metal & 1 & 1 & $\mathrm{JU}$ & 9/18/2017 & Fence Staple \\
\hline $2-1$ & 1 & $0-10$ & Debitage & Tertiary & Lithic & 3 & 0.58 & $\mathrm{JU}$ & 9/18/2017 & 3 bifacial thinning flakes \\
\hline $2-1$ & 2 & $10-20$ & Debitage & Secondary & Lithic & 1 & 2.8 & $\mathrm{JU}$ & 9/18/2017 & 1 bifacial thinning flake \\
\hline $2-1$ & 2 & $10-20$ & Debitage & Tertiary & Lithic & 2 & 1.27 & $\mathrm{JU}$ & 9/18/2017 & 1 bifacial thinning flake \\
\hline $2-1$ & 3 & $20-30$ & Debitage & Secondary & Lithic & 4 & 4.38 & $\mathrm{JU}$ & 9/18/2017 & \\
\hline $2-1$ & 3 & $20-30$ & Debitage & Tertiary & Lithic & 3 & 1.11 & $\mathrm{JU}$ & 9/18/2017 & 3 bifacial thinning flakes \\
\hline $2-1$ & 5 & 46 & $\begin{array}{l}\text { Projectile } \\
\text { Point }\end{array}$ & Montell Point & Lithic & 1 & 4.93 & JU & 9/18/2017 & Proximal point base \\
\hline
\end{tabular}




\begin{tabular}{|c|c|c|c|c|c|c|c|c|c|c|}
\hline ST & Level & $\begin{array}{c}\text { Depth } \\
\text { (cmbs) }\end{array}$ & $\begin{array}{c}\text { Artifact } \\
\text { Type }\end{array}$ & $\begin{array}{c}\text { Artifact } \\
\text { Description }\end{array}$ & Material & $\begin{array}{c}\text { Artifact } \\
\text { No. }\end{array}$ & $\begin{array}{l}\text { Weight } \\
\text { (g) }\end{array}$ & Recorders & Date & Comments \\
\hline $2-1$ & 5 & $40-50$ & Debitage & Tertiary & Lithic & 2 & 0.54 & JU & $9 / 18 / 2017$ & \\
\hline $2-1$ & 6 & $50-60$ & Debitage & Secondary & Lithic & 1 & 0.23 & JU & $9 / 18 / 2017$ & 1 bifacial thinning flake \\
\hline $2-2$ & 1 & $0-10$ & Debitage & Secondary & Lithic & 1 & 0.48 & $\mathrm{JU}$ & 9/18/2017 & 1 bifacial thinning flake \\
\hline $2-2$ & 1 & $0-10$ & Debitage & Tertiary & Lithic & 4 & 3.23 & JU & $9 / 18 / 2017$ & 3 bifacial thinning flakes \\
\hline $2-2$ & 2 & $10-20$ & Debitage & Tertiary & Lithic & 1 & 1.12 & $\mathrm{JU}$ & $9 / 18 / 2017$ & \\
\hline $2-3$ & 1 & $0-10$ & Debitage & Secondary & Lithic & 2 & 0.9 & JU & $9 / 18 / 2017$ & \\
\hline $2-3$ & 1 & $0-10$ & Debitage & Tertiary & Lithic & 2 & 0.23 & $\mathrm{JU}$ & 9/18/2017 & 2 bifacial thinning flakes \\
\hline $2-3$ & 3 & $20-30$ & Debitage & Tertiary & Lithic & 2 & 1.54 & $\mathrm{JU}$ & 9/18/2017 & 2 bifacial thinning flakes \\
\hline $2-4$ & 2 & $10-20$ & Debitage & Tertiary & Lithic & 1 & 0.79 & JU & $9 / 18 / 2017$ & \\
\hline $2-4$ & 3 & $20-30$ & Debitage & Secondary & Lithic & 1 & 0.96 & $\mathrm{JU}$ & $9 / 18 / 2017$ & 1 bifacial thinning flake \\
\hline $2-4$ & 3 & $20-30$ & Debitage & Tertiary & Lithic & 1 & 0.29 & JU & $9 / 18 / 2017$ & 1 bifacial thinning flake \\
\hline $2-5$ & 3 & $20-30$ & Debitage & Secondary & Lithic & 1 & 0.75 & $\mathrm{JU}$ & 9/19/2017 & \\
\hline $2-5$ & 3 & $20-30$ & Debitage & Tertiary & Lithic & 1 & 0.18 & JU & 9/19/2017 & 1 bifacial thinning flake \\
\hline $2-5$ & 4 & $30-40$ & Debitage & Primary & Lithic & 1 & 0.75 & JU & 9/19/2017 & \\
\hline $2-5$ & 4 & $30-40$ & Debitage & Tertiary & Lithic & 1 & 0.85 & $\mathrm{JU}$ & 9/19/2017 & \\
\hline $2-6$ & 1 & $0-10$ & $\begin{array}{l}\text { Historic } \\
\text { Ceramic }\end{array}$ & Stoneware & Ceramic & 1 & 3.87 & JU & 9/18/2017 & Light blue slip \\
\hline $2-6$ & 1 & $0-10$ & Debitage & Secondary & Lithic & 1 & 5.98 & JU & $9 / 18 / 2017$ & 1 bifacial thinning flake \\
\hline $2-6$ & 1 & $0-10$ & Debitage & Tertiary & Lithic & 3 & 1.69 & JU & 9/18/2017 & 3 bifacial thinning flakes \\
\hline $2-6$ & 2 & $10-20$ & Debitage & Primary & Lithic & 2 & 22.62 & JU & $9 / 18 / 2017$ & \\
\hline $2-6$ & 2 & $10-20$ & Debitage & Secondary & Lithic & 1 & 0.69 & JU & $9 / 18 / 2017$ & \\
\hline $2-6$ & 2 & $10-20$ & Debitage & Tertiary & Lithic & 7 & 3.2 & $\mathrm{JU}$ & 9/18/2017 & 5 bifacial thinning flakes \\
\hline $2-6$ & 3 & $20-30$ & $\begin{array}{l}\text { Faunal } \\
\text { Remains }\end{array}$ & Bone & & 2 & $<.01$ & JU & 9/18/2017 & 2 burned \\
\hline $2-6$ & 3 & $20-30$ & Debitage & Primary & Lithic & 1 & 0.19 & $\mathrm{JU}$ & $9 / 18 / 2017$ & \\
\hline $2-6$ & 3 & $20-30$ & Debitage & Secondary & Lithic & 1 & 0.14 & $\mathrm{JU}$ & 9/18/2017 & \\
\hline $2-6$ & 4 & $30-40$ & $\begin{array}{l}\text { Faunal } \\
\text { Remains }\end{array}$ & Bone & & 1 & 0.03 & JU & 9/18/2017 & 1 burned \\
\hline $2-6$ & 4 & $30-40$ & Debitage & Secondary & Lithic & 2 & 13.63 & $\mathrm{JU}$ & 9/18/2017 & \\
\hline $2-6$ & 5 & $40-50$ & Debitage & Tertiary & Lithic & 1 & 0.2 & $\mathrm{JU}$ & 9/18/2017 & 1 bifacial thinning flake \\
\hline $2-6$ & 6 & $50-60$ & $\begin{array}{l}\text { Burned } \\
\text { Rock }\end{array}$ & Burned Rock & Lithic & 1 & 12.98 & JU & 9/18/2017 & \\
\hline $2-6$ & 6 & $50-60$ & Debitage & Secondary & Lithic & 1 & 0.74 & $\mathrm{JU}$ & 9/18/2017 & \\
\hline $2-6$ & 6 & $50-60$ & Debitage & Tertiary & Lithic & 3 & 2.79 & $\mathrm{JU}$ & 9/18/2017 & 3 bifacial thinning flakes \\
\hline $2-7$ & 1 & $0-10$ & Debitage & Tertiary & Lithic & 2 & 1.22 & $\mathrm{JU}$ & 9/18/2017 & 1 bifacial thinning flake \\
\hline $2-7$ & 4 & $30-40$ & Debitage & Secondary & Lithic & 1 & 1.11 & JU & $9 / 18 / 2017$ & \\
\hline $2-7$ & 4 & $30-40$ & Debitage & Tertiary & Lithic & 2 & 0.23 & JU & $9 / 18 / 2017$ & 2 bifacial thinning flakes \\
\hline $2-7$ & 5 & $40-50$ & Debitage & Tertiary & Lithic & 2 & 0.53 & $\mathrm{JU}$ & 9/18/2017 & 2 bifacial thinning flakes \\
\hline $2-7$ & 6 & $50-60$ & Debitage & Tertiary & Lithic & 1 & 0.11 & JU & $9 / 18 / 2017$ & 1 bifacial thinning flake \\
\hline $2-7$ & 8 & $70-80$ & Debitage & Secondary & Lithic & 1 & 2.09 & JU & $9 / 18 / 2017$ & \\
\hline $2-8$ & 1 & $0-10$ & Debitage & Tertiary & Lithic & 3 & 1.12 & $\mathrm{JU}$ & $9 / 19 / 2017$ & 1 bifacial thinning flake \\
\hline $2-8$ & 2 & $10-20$ & Debitage & Tertiary & Lithic & 1 & 0.66 & $\mathrm{JU}$ & 9/19/2017 & 1 bifacial thinning flake \\
\hline $2-8$ & 3 & $20-30$ & Debitage & Tertiary & Lithic & 5 & 4.2 & JU & 9/19/2017 & \\
\hline $2-8$ & 4 & $30-40$ & Debitage & Primary & Lithic & 1 & 0.54 & JU & $9 / 19 / 2017$ & \\
\hline $2-8$ & 4 & $30-40$ & Debitage & Tertiary & Lithic & 2 & 2.55 & JU & 9/19/2017 & 2 bifacial thinning flakes \\
\hline $2-8$ & 5 & $40-50$ & Debitage & Primary & Lithic & 1 & 0.43 & $\mathrm{JU}$ & 9/19/2017 & \\
\hline $2-8$ & 5 & $40-50$ & Debitage & Tertiary & Lithic & 3 & 1.86 & $\mathrm{JU}$ & 9/19/2017 & 3 bifacial thinning flakes \\
\hline $2-8$ & 6 & $50-60$ & Debitage & Primary & Lithic & 1 & 0.24 & $\mathrm{JU}$ & 9/19/2017 & \\
\hline $2-8$ & 6 & $50-60$ & Debitage & Tertiary & Lithic & 2 & 2.88 & $\mathrm{JU}$ & 9/19/2017 & 2 bifacial thinning flakes \\
\hline $2-8$ & 7 & $60-70$ & Debitage & Tertiary & Lithic & 1 & 0.37 & $\mathrm{JU}$ & 9/19/2017 & Burned \\
\hline $2-8$ & 8 & $70-80$ & Debitage & Tertiary & Lithic & 1 & 0.27 & $\mathrm{JU}$ & 9/19/2017 & 1 bifacial thinning flake \\
\hline $2-8$ & 9 & $80-90$ & Debitage & Tertiary & Lithic & 3 & 0.86 & $\mathrm{JU}$ & 9/19/2017 & 3 bifacial thinning flakes \\
\hline $2-8$ & 10 & $90-100$ & Debitage & Tertiary & Lithic & 5 & 6.45 & $\mathrm{JU}$ & 9/19/2017 & 3 bifacial thinning flakes \\
\hline $2-8$ & 12 & $110-120$ & Debitage & Tertiary & Lithic & 1 & 0.23 & $\mathrm{JU}$ & 9/19/2017 & 1 bifacial thinning flake \\
\hline $2-8$ & 14 & $130-140$ & Debitage & Secondary & Lithic & 1 & 4.28 & $\mathrm{JU}$ & 9/19/2017 & \\
\hline $2-8$ & 14 & $130-140$ & Debitage & Tertiary & Lithic & 1 & 0.25 & $\mathrm{JU}$ & 9/19/2017 & 1 bifacial thinning flake \\
\hline $2-9$ & 3 & $20-30$ & Debitage & Secondary & Lithic & 1 & 0.44 & $\mathrm{JU}$ & 9/19/2017 & \\
\hline $2-9$ & 3 & $20-30$ & Debitage & Tertiary & Lithic & 4 & 0.99 & $\mathrm{JU}$ & 9/19/2017 & 3 bifacial thinning flakes \\
\hline $2-9$ & 4 & $30-40$ & $\begin{array}{l}\text { Faunal } \\
\text { Remains }\end{array}$ & Mussel Shell & Shell & 1 & 1.48 & $\mathrm{JU}$ & $9 / 19 / 2017$ & \\
\hline
\end{tabular}




\begin{tabular}{|c|c|c|c|c|c|c|c|c|c|c|}
\hline ST & Level & $\begin{array}{l}\text { Depth } \\
\text { (cmbs) }\end{array}$ & $\begin{array}{l}\text { Artifact } \\
\text { Type }\end{array}$ & $\begin{array}{c}\text { Artifact } \\
\text { Description }\end{array}$ & Material & $\begin{array}{l}\text { Artifact } \\
\text { No. }\end{array}$ & $\begin{array}{l}\text { Weight } \\
\text { (g) }\end{array}$ & Recorders & Date & Comments \\
\hline $2-9$ & 4 & $30-40$ & Debitage & Tertiary & Lithic & 4 & 2.31 & $\mathrm{JU}$ & 9/19/2017 & 3 bifacial thinning flakes \\
\hline $2-9$ & 5 & $40-50$ & Debitage & Secondary & Lithic & 1 & 5.71 & $\mathrm{JU}$ & 9/19/2017 & 1 bifacial thinning flake \\
\hline $2-9$ & 6 & $50-60$ & Debitage & Secondary & Lithic & 1 & 2.06 & $\mathrm{JU}$ & 9/19/2017 & \\
\hline $2-9$ & 6 & $50-60$ & Debitage & Tertiary & Lithic & 6 & 4.2 & JU & $9 / 19 / 2017$ & 3 bifacial thinning flakes \\
\hline $2-9$ & 7 & $60-70$ & Debitage & Tertiary & Lithic & 3 & 3.54 & JU & 9/19/2017 & 2 bifacial thinning flakes \\
\hline $2-9$ & 8 & $70-80$ & Debitage & Secondary & Lithic & 1 & 4.41 & JU & 9/19/2017 & \\
\hline $2-9$ & 8 & $70-80$ & Debitage & Tertiary & Lithic & 2 & 1.66 & $\mathrm{JU}$ & 9/19/2017 & 2 bifacial thinning flakes \\
\hline $2-10$ & 1 & $0-10$ & Debitage & Secondary & Lithic & 1 & 1.1 & $\mathrm{JU}$ & $9 / 27 / 2017$ & \\
\hline $2-10$ & 2 & $10-20$ & $\begin{array}{l}\text { Ground } \\
\text { Stone }\end{array}$ & Ground Stone & Lithic & 1 & 35.06 & JU & 9/27/2017 & \\
\hline $2-10$ & 3 & $20-30$ & $\begin{array}{l}\text { Burned } \\
\text { Rock }\end{array}$ & Burned Rock & Lithic & 1 & 42.57 & JU & 9/27/2017 & \\
\hline $2-10$ & 3 & $20-30$ & Debitage & Tertiary & Lithic & 2 & 2.55 & $\mathrm{JU}$ & 9/27/2017 & 1 bifacial thinning flake \\
\hline $2-10$ & 4 & $30-40$ & Debitage & Tertiary & Lithic & 5 & 2.53 & JU & $9 / 27 / 2017$ & 3 bifacial thinning flakes \\
\hline $2-10$ & 5 & $40-50$ & Debitage & Secondary & Lithic & 1 & 50.5 & $\mathrm{JU}$ & 9/27/2017 & \\
\hline $2-10$ & 5 & $40-50$ & Debitage & Tertiary & Lithic & 8 & 3.39 & JU & $9 / 27 / 2017$ & 5 bifacial thinning flakes \\
\hline $2-10$ & 7 & $60-70$ & Debitage & Tertiary & Lithic & 7 & 11.85 & $\mathrm{JU}$ & 9/27/2017 & 6 bifacial thinning flakes \\
\hline $2-10$ & 7 & $60-70$ & Debitage & Shatter & Lithic & 1 & 1.21 & $\mathrm{JU}$ & $9 / 27 / 2017$ & \\
\hline $2-10$ & 8 & $70-80$ & Debitage & Secondary & Lithic & 1 & 1.22 & JU & $9 / 27 / 2017$ & 1 bifacial thinning flake \\
\hline $2-10$ & 8 & $70-80$ & Debitage & Tertiary & Lithic & 3 & 3.06 & JU & $9 / 27 / 2017$ & $\begin{array}{l}1 \text { burned, } 2 \text { bifacial thinning } \\
\text { flakes }\end{array}$ \\
\hline $2-10$ & 9 & $80-90$ & Debitage & Tertiary & Lithic & 1 & 2.36 & JU & $9 / 27 / 2017$ & \\
\hline $2-10$ & 10 & $90-100$ & Debitage & Secondary & Lithic & 1 & 1.32 & JU & $9 / 27 / 2017$ & \\
\hline $2-10$ & 10 & $90-100$ & Debitage & Shatter & Lithic & 1 & 0.08 & JU & $9 / 27 / 2017$ & \\
\hline $2-11$ & 5 & $40-50$ & Debitage & Tertiary & Lithic & 2 & 1.61 & JU & $9 / 27 / 2017$ & 2 bifacial thinning flakes \\
\hline $2-11$ & 6 & $50-60$ & Debitage & Primary & Lithic & 1 & 11.82 & JU & 9/27/2017 & \\
\hline $2-11$ & 6 & $50-60$ & Debitage & Secondary & Lithic & 1 & 1.42 & $\mathrm{JU}$ & 9/27/2017 & 1 bifacial thinning flake \\
\hline $2-11$ & 6 & $50-60$ & Debitage & Tertiary & Lithic & 1 & 0.14 & JU & $9 / 27 / 2017$ & 1 bifacial thinning flake \\
\hline $2-11$ & 8 & $70-80$ & Debitage & Secondary & Lithic & 1 & 0.29 & $\mathrm{JU}$ & 9/27/2017 & 1 bifacial thinning flake \\
\hline $2-11$ & 8 & $70-80$ & Debitage & Tertiary & Lithic & 2 & 0.52 & JU & $9 / 27 / 2017$ & 2 bifacial thinning flakes \\
\hline $2-12$ & 6 & $50-60$ & Debitage & Secondary & Lithic & 1 & 0.9 & JU & 9/27/2017 & \\
\hline $3-1$ & 3 & $20-30$ & Debitage & Tertiary & Lithic & 2 & 0.28 & $\mathrm{JU}$ & 9/19/2017 & 1 bifacial thinning flake \\
\hline $3-1$ & 5 & $40-50$ & Debitage & Tertiary & Lithic & 2 & 0.32 & $\mathrm{JU}$ & 9/19/2017 & \\
\hline $3-1$ & 6 & $50-60$ & Debitage & Tertiary & Lithic & 1 & 0.08 & $\mathrm{JU}$ & 9/19/2017 & \\
\hline $3-2$ & 1 & $0-10$ & Debitage & Tertiary & Lithic & 1 & 2.48 & $\mathrm{JU}$ & 9/19/2017 & 1 bifacial thinning flake \\
\hline $3-2$ & 2 & $10-20$ & Debitage & Tertiary & Lithic & 1 & 5.81 & JU & $9 / 19 / 2017$ & \\
\hline $3-3$ & 1 & $0-10$ & Debitage & Primary & Lithic & 1 & 0.98 & $\mathrm{JU}$ & 9/19/2017 & \\
\hline $3-3$ & 1 & $0-10$ & Debitage & Tertiary & Lithic & 1 & 0.36 & JU & $9 / 19 / 2017$ & 1 bifacial thinning flake \\
\hline $3-3$ & 2 & $10-20$ & Debitage & Tertiary & Lithic & 3 & 0.73 & JU & $9 / 19 / 2017$ & 2 bifacial thinning flakes \\
\hline $3-3$ & 3 & $20-30$ & Debitage & Secondary & Lithic & 2 & 3.05 & JU & 9/19/2017 & \\
\hline $3-3$ & 3 & $20-30$ & Debitage & Tertiary & Lithic & 3 & 0.74 & JU & $9 / 19 / 2017$ & 3 bifacial thinning flakes \\
\hline $3-3$ & 4 & $30-40$ & Debitage & Primary & Lithic & 1 & 4.31 & $\mathrm{JU}$ & 9/19/2017 & \\
\hline $3-3$ & 4 & $30-40$ & Debitage & Tertiary & Lithic & 1 & 0.43 & JU & 9/19/2017 & \\
\hline $3-4$ & 2 & $10-20$ & Debitage & Secondary & Lithic & 1 & 0.09 & JU & 9/19/2017 & \\
\hline $3-4$ & 3 & $20-30$ & Debitage & Tertiary & Lithic & 1 & 1.81 & JU & 9/19/2017 & 1 bifacial thinning flake \\
\hline $3-5$ & 3 & $20-30$ & Debitage & Tertiary & Lithic & 1 & 0.37 & $\mathrm{JU}$ & 9/19/2017 & 1 bifacial thinning flake \\
\hline $3-5$ & 4 & $30-40$ & Debitage & Tertiary & Lithic & 2 & 0.46 & $\mathrm{JU}$ & 9/19/2017 & 1 bifacial thinning flake \\
\hline $3-5$ & 5 & $40-50$ & Debitage & Tertiary & Lithic & 1 & 0.17 & $\mathrm{JU}$ & 9/19/2017 & \\
\hline $3-5$ & 6 & $50-60$ & Debitage & Tertiary & Lithic & 1 & 0.39 & $\mathrm{JU}$ & 9/19/2017 & \\
\hline $3-7$ & 3 & $20-30$ & Debitage & Secondary & Lithic & 1 & 0.63 & $\mathrm{JU}$ & 9/19/2017 & \\
\hline $3-7$ & 4 & $30-40$ & Core & Core & Lithic & 1 & 52.67 & $\mathrm{JU}$ & 9/19/2017 & Exhausted \\
\hline $3-7$ & 5 & $40-50$ & Debitage & Tertiary & Lithic & 1 & 3.96 & JU & 9/19/2017 & 1 bifacial thinning flake \\
\hline $3-7$ & 8 & $70-80$ & Debitage & Secondary & Lithic & 1 & 6.46 & $\mathrm{JU}$ & 9/19/2017 & \\
\hline $3-8$ & 2 & $10-20$ & Debitage & Secondary & Lithic & 1 & 0.23 & JU & $9 / 19 / 2017$ & \\
\hline $3-8$ & 2 & $10-20$ & Debitage & Tertiary & Lithic & 4 & 3.7 & $\mathrm{JU}$ & 9/19/2017 & 2 bifacial thinning flakes \\
\hline $3-8$ & 3 & $20-30$ & Debitage & Tertiary & Lithic & 4 & 6.47 & $\mathrm{JU}$ & 9/19/2017 & 1 bifacial thinning flake \\
\hline $3-8$ & 4 & $30-40$ & Debitage & Primary & Lithic & 1 & 0.5 & $\mathrm{JU}$ & 9/19/2017 & \\
\hline $3-8$ & 4 & $30-40$ & Debitage & Tertiary & Lithic & 3 & 9.38 & JU & 9/19/2017 & 2 bifacial thinning flakes \\
\hline $3-8$ & 5 & $40-50$ & Debitage & Secondary & Lithic & 7 & 20.21 & $\mathrm{JU}$ & 9/19/2017 & 2 bifacial thinning flakes \\
\hline $3-8$ & 5 & $40-50$ & Debitage & Tertiary & Lithic & 11 & 7.2 & $\mathrm{JU}$ & 9/19/2017 & 8 bifacial thinning flakes \\
\hline
\end{tabular}




\begin{tabular}{|c|c|c|c|c|c|c|c|c|c|c|}
\hline ST & Level & $\begin{array}{l}\text { Depth } \\
\text { (cmbs) }\end{array}$ & $\begin{array}{c}\text { Artifact } \\
\text { Type }\end{array}$ & $\begin{array}{c}\text { Artifact } \\
\text { Description }\end{array}$ & Material & $\begin{array}{c}\text { Artifact } \\
\text { No. }\end{array}$ & $\begin{array}{l}\text { Weight } \\
\text { (g) }\end{array}$ & Recorders & Date & Comments \\
\hline $3-8$ & 6 & $50-60$ & Debitage & Secondary & Lithic & 2 & 2.29 & $\mathrm{JU}$ & $9 / 19 / 2017$ & 1 bifacial thinning flake \\
\hline $3-8$ & 6 & $50-60$ & Debitage & Tertiary & Lithic & 9 & 2.71 & $\mathrm{JU}$ & $9 / 19 / 2017$ & 5 bifacial thinning flakes \\
\hline $3-8$ & 7 & $60-70$ & Debitage & Secondary & Lithic & 1 & 1.27 & $\mathrm{JU}$ & 9/19/2017 & \\
\hline $3-8$ & 7 & $60-70$ & Debitage & Tertiary & Lithic & 5 & 4.49 & $\mathrm{JU}$ & 9/19/2017 & 3 bifacial thinning flakes \\
\hline $3-8$ & 8 & $70-80$ & Debitage & Primary & Lithic & 2 & 1.36 & JU & 9/19/2017 & \\
\hline $3-8$ & 8 & $70-80$ & Debitage & Secondary & Lithic & 4 & 8.61 & $\mathrm{JU}$ & $9 / 19 / 2017$ & 1 bifacial thinning flake \\
\hline $3-8$ & 8 & $70-80$ & Debitage & Tertiary & Lithic & 11 & 3.48 & $\mathrm{JU}$ & 9/19/2017 & 7 bifacial thinning flakes \\
\hline $3-8$ & 9 & $80-90$ & Debitage & Primary & Lithic & 1 & 0.85 & $\mathrm{JU}$ & 9/19/2017 & \\
\hline $3-8$ & 9 & $80-90$ & Debitage & Tertiary & Lithic & 12 & 14.98 & JU & $9 / 19 / 2017$ & 8 bifacial thinning flakes \\
\hline $3-9$ & 2 & $10-20$ & Debitage & Secondary & Lithic & 3 & 9.23 & JU & $9 / 19 / 2017$ & 1 bifacial thinning flake \\
\hline $3-9$ & 2 & $10-20$ & Debitage & Tertiary & Lithic & 1 & 0.29 & $\mathrm{JU}$ & $9 / 19 / 2017$ & 1 bifacial thinning flake \\
\hline $3-9$ & 3 & $20-30$ & Debitage & Primary & Lithic & 1 & 0.62 & $\mathrm{JU}$ & 9/19/2017 & \\
\hline $3-9$ & 3 & $20-30$ & Debitage & Tertiary & Lithic & 1 & 0.6 & JU & $9 / 19 / 2017$ & \\
\hline $3-9$ & 4 & $30-40$ & Debitage & Secondary & Lithic & 2 & 40.47 & JU & $9 / 19 / 2017$ & 1 bifacial thinning flake \\
\hline $3-9$ & 4 & $30-40$ & Debitage & Tertiary & Lithic & 7 & 13.24 & JU & $9 / 19 / 2017$ & 3 bifacial thinning flakes \\
\hline $3-9$ & 5 & $40-50$ & Core & Core & Lithic & 1 & 331.27 & JU & $9 / 19 / 2017$ & \\
\hline $3-9$ & 5 & $40-50$ & Debitage & Tertiary & Lithic & 10 & 7 & JU & 9/19/2017 & 9 bifacial thinning flakes \\
\hline $3-9$ & 6 & $50-60$ & Debitage & Primary & Lithic & 1 & 0.25 & JU & $9 / 19 / 2017$ & \\
\hline $3-9$ & 6 & $50-60$ & Debitage & Secondary & Lithic & 1 & 3.36 & JU & 9/19/2017 & \\
\hline $3-9$ & 6 & $50-60$ & Debitage & Tertiary & Lithic & 11 & 2.55 & JU & $9 / 19 / 2017$ & 7 bifacial thinning flakes \\
\hline $3-9$ & 7 & $60-70$ & Debitage & Secondary & Lithic & 1 & 41.72 & JU & 9/19/2017 & \\
\hline $3-9$ & 7 & $60-70$ & Debitage & Tertiary & Lithic & 6 & 2.05 & $\mathrm{JU}$ & 9/19/2017 & 6 bifacial thinning flakes \\
\hline $3-9$ & 8 & $70-80$ & Debitage & Secondary & Lithic & 2 & 3.29 & JU & $9 / 19 / 2017$ & 1 bifacial thinning flake \\
\hline $3-9$ & 8 & $70-80$ & Debitage & Tertiary & Lithic & 4 & 4.98 & $\mathrm{JU}$ & $9 / 19 / 2017$ & 3 bifacial thinning flakes \\
\hline $3-9$ & 9 & $80-90$ & Debitage & Primary & Lithic & 1 & 0.38 & JU & $9 / 19 / 2017$ & \\
\hline $3-9$ & 9 & $80-90$ & Debitage & Secondary & Lithic & 1 & 18.71 & $\mathrm{JU}$ & 9/19/2017 & 1 bifacial thinning flake \\
\hline $3-9$ & 9 & $80-90$ & Debitage & Tertiary & Lithic & 5 & 7.25 & $\mathrm{JU}$ & 9/19/2017 & 3 bifacial thinning flakes \\
\hline $3-9$ & 10 & $90-100$ & Debitage & Tertiary & Lithic & 2 & 0.84 & $\mathrm{JU}$ & $9 / 19 / 2017$ & 2 bifacial thinning flakes \\
\hline $3-10$ & 5 & $40-50$ & Debitage & Tertiary & Lithic & 2 & 7.96 & $\mathrm{JU}$ & 9/27/2017 & 1 bifacial thinning flake \\
\hline $3-10$ & 7 & $60-70$ & Debitage & Tertiary & Lithic & 5 & 43.88 & $\mathrm{JU}$ & 9/27/2017 & 3 bifacial thinning flakes \\
\hline $3-10$ & 8 & $70-80$ & Debitage & Tertiary & Lithic & 8 & 3.76 & $\mathrm{JU}$ & 9/27/2017 & 6 bifacial thinning flakes \\
\hline $3-10$ & 9 & $80-90$ & Debitage & Tertiary & Lithic & 4 & 4.93 & $\mathrm{JU}$ & $9 / 27 / 2017$ & 3 bifacial thinning flakes \\
\hline $3-10$ & 9 & $80-90$ & Debitage & Shatter & Lithic & 1 & 0.4 & $\mathrm{JU}$ & 9/27/2017 & \\
\hline $3-10$ & 9 & $80-90$ & $\begin{array}{l}\text { Faunal } \\
\text { Remains }\end{array}$ & Mussel Shell & Shell & 1 & 0.44 & JU & 9/27/2017 & No umbo \\
\hline $3-10$ & 10 & $90-100$ & Debitage & Tertiary & Lithic & 1 & 0.87 & $\mathrm{JU}$ & 9/27/2017 & 1 bifacial thinning flake \\
\hline $3-11$ & 4 & $30-40$ & Debitage & Secondary & Lithic & 2 & 1.41 & JU & $9 / 27 / 2017$ & \\
\hline $3-11$ & 4 & $30-40$ & Debitage & Tertiary & Lithic & 1 & 0.47 & $\mathrm{JU}$ & $9 / 27 / 2017$ & 1 bifacial thinning flake \\
\hline $3-11$ & 5 & $40-50$ & Debitage & Secondary & Lithic & 2 & 4.09 & $\mathrm{JU}$ & 9/27/2017 & 1 bifacial thinning flake \\
\hline $3-11$ & 5 & $40-50$ & Debitage & Tertiary & Lithic & 2 & 4.95 & JU & 9/27/2017 & 2 bifacial thinning flakes \\
\hline $3-11$ & 6 & $50-60$ & Debitage & Tertiary & Lithic & 2 & 0.83 & $\mathrm{JU}$ & 9/27/2017 & 1 bifacial thinning flake \\
\hline $3-11$ & 8 & $70-80$ & Debitage & Secondary & Lithic & 3 & 5.24 & JU & $9 / 27 / 2017$ & 1 bifacial thinning flake \\
\hline $3-11$ & 8 & $70-80$ & Debitage & Tertiary & Lithic & 15 & 12.38 & $\mathrm{JU}$ & 9/27/2017 & 10 bifacial thinning flakes \\
\hline $3-11$ & 8 & $70-80$ & Debitage & Shatter & Lithic & 2 & 3.71 & $\mathrm{JU}$ & $9 / 27 / 2017$ & \\
\hline $3-11$ & 9 & $80-90$ & Debitage & Tertiary & Lithic & 4 & 2.32 & $\mathrm{JU}$ & 9/27/2017 & 4 bifacial thinning flakes \\
\hline $3-11$ & 10 & $90-100$ & Debitage & Secondary & Lithic & 1 & 0.53 & JU & $9 / 27 / 2017$ & 1 bifacial thinning flake \\
\hline $3-12$ & 8 & $70-80$ & Debitage & Tertiary & Lithic & 3 & 2.11 & $\mathrm{JU}$ & $9 / 27 / 2017$ & 1 bifacial thinning flake \\
\hline $3-12$ & 9 & $80-90$ & Debitage & Tertiary & Lithic & 3 & 2.04 & JU & 9/27/2017 & 2 bifacial thinning flakes \\
\hline $3-12$ & 10 & $90-100$ & Debitage & Tertiary & Lithic & 1 & 2.72 & $\mathrm{JU}$ & 9/27/2017 & 1 bifacial thinning flake \\
\hline $3-12$ & 16 & $150-160$ & Debitage & Tertiary & Lithic & 3 & 6.2 & $\mathrm{JU}$ & $9 / 27 / 2017$ & 1 bifacial thinning flake \\
\hline $4-1$ & 2 & $10-20$ & Debitage & Tertiary & Lithic & 3 & 2.35 & $\mathrm{JU}$ & 9/27/2017 & 3 bifacial thinning flakes \\
\hline $4-1$ & 2 & $10-20$ & Debitage & Shatter & Lithic & 1 & 0.5 & $\mathrm{JU}$ & 9/27/2017 & \\
\hline $4-2$ & 1 & $0-10$ & Debitage & Tertiary & Lithic & 1 & 2.07 & JU & 9/27/2017 & 1 bifacial thinning flake \\
\hline $4-2$ & 2 & $10-20$ & Debitage & Secondary & Lithic & 1 & 0.56 & $\mathrm{JU}$ & $9 / 27 / 2017$ & \\
\hline $4-2$ & 2 & $10-20$ & Debitage & Tertiary & Lithic & 8 & 3.86 & $\mathrm{JU}$ & 9/27/2017 & 5 bifacial thinning flakes \\
\hline $4-2$ & 2 & $10-20$ & Debitage & Shatter & Lithic & 1 & 0.29 & $\mathrm{JU}$ & 9/27/2017 & \\
\hline $4-2$ & 3 & $20-30$ & Debitage & Secondary & Lithic & 1 & 0.74 & $\mathrm{JU}$ & 9/27/2017 & \\
\hline $4-2$ & 3 & $20-30$ & Debitage & Tertiary & Lithic & 1 & 0.13 & $\mathrm{JU}$ & 9/27/2017 & \\
\hline $4-2$ & 5 & $40-50$ & Debitage & Secondary & Lithic & 1 & 0.83 & $\mathrm{JU}$ & 9/27/2017 & \\
\hline
\end{tabular}




\begin{tabular}{|c|c|c|c|c|c|c|c|c|c|c|}
\hline ST & Level & $\begin{array}{l}\text { Depth } \\
\text { (cmbs) }\end{array}$ & $\begin{array}{l}\text { Artifact } \\
\text { Type }\end{array}$ & $\begin{array}{c}\text { Artifact } \\
\text { Description }\end{array}$ & Material & $\begin{array}{l}\text { Artifact } \\
\text { No. }\end{array}$ & $\begin{array}{l}\text { Weight } \\
\text { (g) }\end{array}$ & Recorders & Date & Comments \\
\hline $4-2$ & 5 & $40-50$ & Debitage & Tertiary & Lithic & 4 & 1.96 & JU & $9 / 27 / 2017$ & 2 bifacial thinning flakes \\
\hline $4-2$ & 6 & $50-60$ & Debitage & Secondary & Lithic & 2 & 1.4 & $\mathrm{JU}$ & $9 / 27 / 2017$ & 1 bifacial thinning flake \\
\hline $4-2$ & 6 & $50-60$ & Debitage & Tertiary & Lithic & 3 & 1.04 & JU & $9 / 27 / 2017$ & 2 bifacial thinning flakes \\
\hline $4-2$ & 9 & $80-90$ & Debitage & Secondary & Lithic & 1 & 1.09 & JU & $9 / 27 / 2017$ & 1 bifacial thinning flake \\
\hline $4-3$ & 1 & $0-10$ & Debitage & Tertiary & Lithic & 2 & 0.27 & JU & $9 / 27 / 2017$ & 1 bifacial thinning flake \\
\hline $4-3$ & 3 & $20-30$ & Debitage & Tertiary & Lithic & 3 & 2.64 & JU & 9/27/2017 & 3 bifacial thinning flakes \\
\hline $4-5$ & 3 & $20-30$ & Debitage & Tertiary & Lithic & 2 & 0.86 & $\mathrm{JU}$ & 9/27/2017 & 1 bifacial thinning flake \\
\hline $4-6$ & 2 & $10-20$ & Debitage & Tertiary & Lithic & 1 & 15.67 & $\mathrm{JU}$ & $9 / 27 / 2017$ & 1 bifacial thinning flake \\
\hline $4-6$ & 3 & $20-30$ & Debitage & Secondary & Lithic & 1 & 30.7 & $\mathrm{JU}$ & $9 / 27 / 2017$ & \\
\hline $4-6$ & 5 & $40-50$ & Debitage & Tertiary & Lithic & 1 & 0.35 & JU & 9/27/2017 & 1 bifacial thinning flake \\
\hline $4-6$ & 5 & $40-50$ & Debitage & Shatter & Lithic & 2 & 1.92 & $\mathrm{JU}$ & 9/27/2017 & \\
\hline $4-6$ & 6 & $50-60$ & Debitage & Tertiary & Lithic & 2 & 2.25 & JU & $9 / 27 / 2017$ & 2 bifacial thinning flakes \\
\hline $4-7$ & 1 & $0-10$ & Debitage & Primary & Lithic & 1 & 1.15 & $\mathrm{JU}$ & 9/27/2017 & \\
\hline $4-7$ & 1 & $0-10$ & Debitage & Secondary & Lithic & 2 & 1.83 & $\mathrm{JU}$ & $9 / 27 / 2017$ & \\
\hline $4-7$ & 1 & $0-10$ & Debitage & Tertiary & Lithic & 14 & 23.12 & $\mathrm{JU}$ & $9 / 27 / 2017$ & 9 bifacial thinning flakes \\
\hline $4-7$ & 2 & $10-20$ & $\begin{array}{l}\text { Projectile } \\
\text { Point }\end{array}$ & Scallorn Point & Lithic & 1 & 1.55 & JU & 9/27/2017 & $\begin{array}{l}\text { Corner-notched broad stemmed } \\
\text { variant }\end{array}$ \\
\hline $4-7$ & 2 & $10-20$ & Debitage & Secondary & Lithic & 4 & 5.64 & JU & $9 / 27 / 2017$ & 2 bifacial thinning flakes \\
\hline $4-7$ & 2 & $10-20$ & Debitage & Tertiary & Lithic & 5 & 2.58 & $\mathrm{JU}$ & $9 / 27 / 2017$ & 3 bifacial thinning flakes \\
\hline $4-7$ & 4 & $30-40$ & Debitage & Secondary & Lithic & 4 & 2.41 & JU & $9 / 27 / 2017$ & 1 bifacial thinning flake \\
\hline $4-7$ & 4 & $30-40$ & Debitage & Tertiary & Lithic & 9 & 4.71 & JU & $9 / 27 / 2017$ & 6 bifacial thinning flakes \\
\hline $4-7$ & 4 & $30-40$ & Debitage & Shatter & Lithic & 2 & 1.73 & JU & $9 / 27 / 2017$ & \\
\hline $4-7$ & 5 & $40-50$ & Debitage & Secondary & Lithic & 1 & 5.07 & JU & $9 / 27 / 2017$ & \\
\hline $4-7$ & 5 & $40-50$ & Debitage & Tertiary & Lithic & 3 & 3.45 & JU & $9 / 27 / 2017$ & 2 bifacial thinning flakes \\
\hline $4-7$ & 6 & $50-60$ & Debitage & Tertiary & Lithic & 11 & 17.96 & $\mathrm{JU}$ & 9/27/2017 & 7 bifacial thinning flakes \\
\hline $4-7$ & 6 & $50-60$ & Debitage & Shatter & Lithic & 2 & 1.29 & JU & $9 / 27 / 2017$ & \\
\hline $4-7$ & 7 & $60-70$ & Debitage & Tertiary & Lithic & 2 & 0.68 & JU & 9/27/2017 & 2 bifacial thinning flakes \\
\hline $4-7$ & 8 & $70-80$ & Debitage & Primary & Lithic & 1 & 2.32 & JU & $9 / 27 / 2017$ & \\
\hline $4-7$ & 8 & $70-80$ & Debitage & Secondary & Lithic & 2 & 2.93 & JU & 9/27/2017 & 1 bifacial thinning flake \\
\hline $4-7$ & 8 & $70-80$ & Debitage & Tertiary & Lithic & 4 & 9.66 & JU & 9/27/2017 & 2 bifacial thinning flakes \\
\hline $4-7$ & 9 & $80-90$ & Debitage & Tertiary & Lithic & 4 & 6.13 & $\mathrm{JU}$ & 9/27/2017 & 2 bifacial thinning flakes \\
\hline $4-7$ & 10 & $90-100$ & Debitage & Secondary & Lithic & 2 & 21.51 & $\mathrm{JU}$ & 9/27/2017 & \\
\hline $4-7$ & 10 & $90-100$ & Debitage & Tertiary & Lithic & 3 & 0.59 & $\mathrm{JU}$ & $9 / 27 / 2017$ & 4 bifacial thinning flakes \\
\hline $4-8$ & 1 & $0-10$ & Debitage & Secondary & Lithic & 2 & 2.74 & JU & $9 / 27 / 2017$ & \\
\hline $4-8$ & 1 & $0-10$ & Debitage & Tertiary & Lithic & 18 & 23.21 & $\mathrm{JU}$ & 9/27/2017 & 10 bifacial thinning flakes \\
\hline $4-8$ & 1 & $0-10$ & Debitage & Shatter & Lithic & 2 & 2.42 & $\mathrm{JU}$ & 9/27/2017 & \\
\hline $4-8$ & 1 & $0-10$ & $\begin{array}{l}\text { Burned } \\
\text { Rock }\end{array}$ & Burned Rock & Lithic & 2 & 8 & JU & 9/27/2017 & \\
\hline $4-8$ & 2 & $10-20$ & $\begin{array}{l}\text { Faunal } \\
\text { Remains }\end{array}$ & Bone & & 1 & 0.39 & JU & 9/27/2017 & \\
\hline $4-8$ & 2 & $10-20$ & Debitage & Secondary & Lithic & 1 & 2.82 & JU & $9 / 27 / 2017$ & \\
\hline $4-8$ & 2 & $10-20$ & Debitage & Tertiary & Lithic & 9 & 13.88 & JU & $9 / 27 / 2017$ & 4 bifacial thinning flakes \\
\hline $4-8$ & 3 & $20-30$ & Debitage & Primary & Lithic & 1 & 0.74 & JU & $9 / 28 / 2017$ & \\
\hline $4-8$ & 3 & $20-30$ & Debitage & Secondary & Lithic & 4 & 10.01 & JU & $9 / 28 / 2017$ & 2 bifacial thinning flakes \\
\hline $4-8$ & 3 & $20-30$ & Debitage & Tertiary & Lithic & 8 & 13.15 & JU & $9 / 28 / 2017$ & 5 bifacial thinning flakes \\
\hline $4-8$ & 3 & $20-30$ & Debitage & Shatter & Lithic & 5 & 5.06 & JU & $9 / 28 / 2017$ & \\
\hline $4-8$ & 4 & $30-40$ & Debitage & Primary & Lithic & 1 & 1.39 & JU & $9 / 28 / 2017$ & \\
\hline $4-8$ & 4 & $30-40$ & Debitage & Tertiary & Lithic & 10 & 6.47 & JU & $9 / 28 / 2017$ & 7 bifacial thinning flakes \\
\hline $4-8$ & 4 & $30-40$ & Debitage & Shatter & Lithic & 5 & 3.62 & JU & $9 / 28 / 2017$ & \\
\hline $4-8$ & 5 & $40-50$ & Debitage & Secondary & Lithic & 1 & 0.54 & JU & $9 / 28 / 2017$ & \\
\hline $4-8$ & 5 & $40-50$ & Debitage & Tertiary & Lithic & 6 & 2.39 & $\mathrm{JU}$ & 9/28/2017 & 3 bifacial thinning flakes \\
\hline $4-8$ & 6 & $50-60$ & Debitage & Primary & Lithic & 2 & 37.56 & JU & 9/28/2017 & \\
\hline $4-8$ & 6 & $50-60$ & Debitage & Tertiary & Lithic & 1 & 2.3 & $\mathrm{JU}$ & $9 / 28 / 2017$ & \\
\hline $4-8$ & 7 & $60-70$ & Debitage & Tertiary & Lithic & 4 & 3.05 & JU & $9 / 28 / 2017$ & 3 bifacial thinning flakes \\
\hline $4-8$ & 8 & $70-80$ & Debitage & Primary & Lithic & 1 & 0.53 & JU & $9 / 28 / 2017$ & \\
\hline $4-8$ & 8 & $70-80$ & Debitage & Secondary & Lithic & 1 & 0.13 & $\mathrm{JU}$ & 9/28/2017 & \\
\hline $4-8$ & 8 & $70-80$ & Debitage & Tertiary & Lithic & 8 & 3.57 & $\mathrm{JU}$ & $9 / 28 / 2017$ & 5 bifacial thinning flakes \\
\hline $4-8$ & 8 & $70-80$ & Debitage & Shatter & Lithic & 3 & 6.33 & JU & $9 / 28 / 2017$ & \\
\hline $4-8$ & 9 & $80-90$ & Debitage & Secondary & Lithic & 1 & 0.19 & $\mathrm{JU}$ & 9/28/2017 & \\
\hline $4-8$ & 9 & $80-90$ & Debitage & Tertiary & Lithic & 7 & 4.14 & $\mathrm{JU}$ & $9 / 28 / 2017$ & 3 bifacial thinning flakes \\
\hline
\end{tabular}




\begin{tabular}{|c|c|c|c|c|c|c|c|c|c|c|}
\hline ST & Level & $\begin{array}{l}\text { Depth } \\
\text { (cmbs) }\end{array}$ & $\begin{array}{l}\text { Artifact } \\
\text { Type }\end{array}$ & $\begin{array}{c}\text { Artifact } \\
\text { Description }\end{array}$ & Material & $\begin{array}{l}\text { Artifact } \\
\text { No. }\end{array}$ & $\begin{array}{l}\text { Weight } \\
\text { (g) }\end{array}$ & Recorders & Date & Comments \\
\hline $4-8$ & 10 & $90-100$ & Debitage & Primary & Lithic & 1 & 1.88 & JU & $9 / 28 / 2017$ & \\
\hline $4-8$ & 10 & $90-100$ & Debitage & Secondary & Lithic & 4 & 5.76 & JU & $9 / 28 / 2017$ & 2 bifacial thinning flakes \\
\hline $4-8$ & 10 & $90-100$ & Debitage & Tertiary & Lithic & 2 & 1.95 & $\mathrm{JU}$ & 9/28/2017 & 1 bifacial thinning flake \\
\hline $4-9$ & 1 & $0-10$ & Debitage & Secondary & Lithic & 1 & 0.46 & JU & $9 / 28 / 2017$ & \\
\hline $4-9$ & 1 & $0-10$ & Debitage & Tertiary & Lithic & 3 & 4.56 & $\mathrm{JU}$ & $9 / 28 / 2017$ & 1 bifacial thinning flake \\
\hline $4-9$ & 2 & $10-20$ & Debitage & Tertiary & Lithic & 2 & 0.75 & $\mathrm{JU}$ & $9 / 28 / 2017$ & 2 bifacial thinning flakes \\
\hline $4-9$ & 3 & $20-30$ & Debitage & Tertiary & Lithic & 4 & 1.48 & $\mathrm{JU}$ & 9/28/2017 & 3 bifacial thinning flakes \\
\hline $4-9$ & 4 & $30-40$ & Debitage & Secondary & Lithic & 2 & 1.42 & JU & $9 / 28 / 2017$ & 1 bifacial thinning flake \\
\hline $4-9$ & 4 & $30-40$ & Debitage & Tertiary & Lithic & 3 & 0.63 & JU & $9 / 28 / 2017$ & 2 bifacial thinning flakes \\
\hline $4-9$ & 5 & $40-50$ & Debitage & Secondary & Lithic & 1 & 8.29 & $\mathrm{JU}$ & 9/28/2017 & 1 bifacial thinning flake \\
\hline $4-9$ & 5 & $40-50$ & Debitage & Tertiary & Lithic & 5 & 2.76 & $\mathrm{JU}$ & 9/28/2017 & 3 bifacial thinning flakes \\
\hline $4-9$ & 6 & $50-60$ & Debitage & Secondary & Lithic & 1 & 12.19 & JU & $9 / 28 / 2017$ & 1 bifacial thinning flake \\
\hline $4-9$ & 6 & $50-60$ & Debitage & Tertiary & Lithic & 5 & 2.95 & JU & $9 / 28 / 2017$ & 4 bifacial thinning flakes \\
\hline $4-9$ & 8 & $70-80$ & Debitage & Primary & Lithic & 2 & 4.55 & JU & $9 / 28 / 2017$ & \\
\hline $4-9$ & 8 & $70-80$ & Debitage & Tertiary & Lithic & 4 & 3.11 & JU & $9 / 28 / 2017$ & 3 bifacial thinning flakes \\
\hline $4-9$ & 8 & $70-80$ & Debitage & Shatter & Lithic & 1 & 0.46 & JU & $9 / 28 / 2017$ & \\
\hline $4-9$ & 10 & $90-100$ & Debitage & Primary & Lithic & 1 & 1.56 & $\mathrm{JU}$ & 9/28/2017 & \\
\hline $4-9$ & 10 & $90-100$ & Debitage & Secondary & Lithic & 1 & 0.27 & $\mathrm{JU}$ & 9/28/2017 & 1 bifacial thinning flake \\
\hline $4-9$ & 10 & $90-100$ & Debitage & Tertiary & Lithic & 1 & 0.13 & $\mathrm{JU}$ & 9/28/2017 & \\
\hline $4-10$ & 6 & $50-60$ & $\begin{array}{l}\text { Projectile } \\
\text { Point }\end{array}$ & $\begin{array}{l}\text { Untyped Arrow } \\
\text { Point }\end{array}$ & Lithic & 1 & 1 & JU & 9/28/2017 & $\begin{array}{l}\text { Missing proximal end of base; } \\
\text { translucent; probable Sabinal }\end{array}$ \\
\hline $4-10$ & 6 & $50-60$ & Debitage & Primary & Lithic & 1 & 22.75 & $\mathrm{JU}$ & 9/28/2017 & \\
\hline $4-10$ & 6 & $50-60$ & Debitage & Secondary & Lithic & 1 & 0.43 & $\mathrm{JU}$ & 9/28/2017 & \\
\hline $4-10$ & 6 & $50-60$ & Debitage & Tertiary & Lithic & 2 & 0.18 & JU & 9/28/2017 & 1 bifacial thinning flake \\
\hline $4-10$ & 7 & $60-70$ & Debitage & Secondary & Lithic & 1 & 17.54 & $\mathrm{JU}$ & 9/28/2017 & \\
\hline $4-10$ & 8 & $70-80$ & Debitage & Tertiary & Lithic & 2 & 0.88 & JU & $9 / 28 / 2017$ & 2 bifacial thinning flakes \\
\hline $4-10$ & 9 & $80-90$ & Debitage & Secondary & Lithic & 1 & 0.71 & $\mathrm{JU}$ & 9/28/2017 & \\
\hline $4-10$ & 10 & $90-100$ & Debitage & Shatter & Lithic & 1 & 0.09 & $\mathrm{JU}$ & 9/28/2017 & \\
\hline $5-1$ & 1 & $0-10$ & Debitage & Primary & Lithic & 1 & 3.68 & JU & $9 / 28 / 2017$ & \\
\hline $5-1$ & 1 & $0-10$ & Debitage & Tertiary & Lithic & 1 & 0.39 & JU & $9 / 28 / 2017$ & \\
\hline $5-1$ & 2 & $10-20$ & Debitage & Tertiary & Lithic & 1 & 0.62 & JU & 9/28/2017 & 1 bifacial thinning flake \\
\hline $5-1$ & 3 & $20-30$ & Debitage & Secondary & Lithic & 1 & 10.3 & $\mathrm{JU}$ & 9/28/2017 & \\
\hline $5-1$ & 3 & $20-30$ & Debitage & Tertiary & Lithic & 2 & 3.38 & $\mathrm{JU}$ & 9/28/2017 & 1 bifacial thinning flake \\
\hline $5-1$ & 4 & $30-40$ & Debitage & Tertiary & Lithic & 3 & 2.16 & JU & 9/28/2017 & 3 bifacial thinning flakes \\
\hline $5-1$ & 5 & $40-50$ & Debitage & Secondary & Lithic & 1 & 1.04 & $\mathrm{JU}$ & 9/28/2017 & \\
\hline $5-1$ & 5 & $40-50$ & Debitage & Tertiary & Lithic & 2 & 1.62 & $\mathrm{JU}$ & 9/28/2017 & 1 bifacial thinning flake \\
\hline $5-2$ & 2 & $10-20$ & Debitage & Tertiary & Lithic & 2 & 0.69 & $\mathrm{JU}$ & 9/28/2017 & 2 bifacial thinning flakes \\
\hline $5-2$ & 2 & $10-20$ & Debitage & Shatter & Lithic & 1 & 0.86 & $\mathrm{JU}$ & 9/28/2017 & \\
\hline $5-2$ & 3 & $20-30$ & Debitage & Shatter & Lithic & 2 & 0.88 & $\mathrm{JU}$ & 9/28/2017 & \\
\hline $5-2$ & 4 & $30-40$ & Debitage & Tertiary & Lithic & 2 & 2.28 & $\mathrm{JU}$ & 9/28/2017 & 2 bifacial thinning flakes \\
\hline $5-2$ & 5 & $40-50$ & Debitage & Secondary & Lithic & 1 & 2 & $\mathrm{JU}$ & $9 / 28 / 2017$ & \\
\hline $5-3$ & 1 & $0-10$ & Debitage & Secondary & Lithic & 2 & 1.4 & JU & $9 / 28 / 2017$ & \\
\hline $5-3$ & 1 & $0-10$ & Debitage & Tertiary & Lithic & 14 & 5.68 & $\mathrm{JU}$ & 9/28/2017 & 11 bifacial thinning flakes \\
\hline $5-3$ & 1 & $0-10$ & Debitage & Shatter & Lithic & 2 & 0.67 & $\mathrm{JU}$ & 9/28/2017 & \\
\hline $5-3$ & 2 & $10-20$ & $\begin{array}{l}\text { Projectile } \\
\text { Point }\end{array}$ & $\begin{array}{l}\text { Untyped Arrow } \\
\text { Point }\end{array}$ & Lithic & 1 & 0.3 & JU & $9 / 28 / 2017$ & Medial section \\
\hline $5-3$ & 2 & $10-20$ & Debitage & Secondary & Lithic & 1 & 2.62 & JU & $9 / 28 / 2017$ & 1 bifacial thinning flake \\
\hline $5-3$ & 2 & $10-20$ & Debitage & Tertiary & Lithic & 12 & 20.39 & $\mathrm{JU}$ & 9/28/2017 & 5 bifacial thinning flakes \\
\hline $5-3$ & 2 & $10-20$ & Debitage & Shatter & Lithic & 2 & 0.72 & $\mathrm{JU}$ & 9/28/2017 & \\
\hline $5-3$ & 4 & $30-40$ & Debitage & Secondary & Lithic & 2 & 6.81 & $\mathrm{JU}$ & 9/28/2017 & \\
\hline $5-3$ & 4 & $30-40$ & Debitage & Tertiary & Lithic & 2 & 1.21 & $\mathrm{JU}$ & 9/28/2017 & 2 bifacial thinning flakes \\
\hline $5-3$ & 6 & $50-60$ & Debitage & Secondary & Lithic & 1 & 0.76 & $\mathrm{JU}$ & 9/28/2017 & \\
\hline $5-3$ & 6 & $50-60$ & Debitage & Tertiary & Lithic & 2 & 2.75 & $\mathrm{JU}$ & 9/28/2017 & 2 bifacial thinning flakes \\
\hline $5-3$ & 7 & $60-70$ & Debitage & Tertiary & Lithic & 2 & 1.17 & $\mathrm{JU}$ & 9/28/2017 & 2 bifacial thinning flakes \\
\hline $5-4$ & 1 & $0-10$ & Debitage & Secondary & Lithic & 4 & 2.23 & $\mathrm{JU}$ & 9/28/2017 & 1 bifacial thinning flake \\
\hline $5-4$ & 1 & $0-10$ & Debitage & Tertiary & Lithic & 15 & 11.7 & $\mathrm{JU}$ & 9/28/2017 & 10 bifacial thinning flakes \\
\hline $5-4$ & 1 & $0-10$ & Debitage & Shatter & Lithic & 4 & 9.92 & JU & 9/28/2017 & \\
\hline $5-4$ & 2 & $10-20$ & Debitage & Primary & Lithic & 1 & 4.97 & $\mathrm{JU}$ & 9/28/2017 & \\
\hline $5-4$ & 2 & $10-20$ & Debitage & Secondary & Lithic & 5 & 11.48 & JU & $9 / 28 / 2017$ & \\
\hline
\end{tabular}




\begin{tabular}{|c|c|c|c|c|c|c|c|c|c|c|}
\hline ST & Level & $\begin{array}{l}\text { Depth } \\
\text { (cmbs) }\end{array}$ & $\begin{array}{l}\text { Artifact } \\
\text { Type }\end{array}$ & $\begin{array}{c}\text { Artifact } \\
\text { Description }\end{array}$ & Material & $\begin{array}{l}\text { Artifact } \\
\text { No. }\end{array}$ & $\begin{array}{l}\text { Weight } \\
\text { (g) }\end{array}$ & Recorders & Date & Comments \\
\hline $5-4$ & 2 & $10-20$ & Debitage & Tertiary & Lithic & 13 & 14.74 & JU & $9 / 28 / 2017$ & 8 bifacial thinning flakes \\
\hline $5-4$ & 2 & $10-20$ & Debitage & Shatter & Lithic & 4 & 1.64 & JU & $9 / 28 / 2017$ & \\
\hline $5-4$ & 3 & $20-30$ & Debitage & Primary & Lithic & 2 & 1.03 & $\mathrm{JU}$ & 9/28/2017 & \\
\hline $5-4$ & 3 & $20-30$ & Debitage & Secondary & Lithic & 3 & 5.18 & JU & $9 / 28 / 2017$ & \\
\hline $5-4$ & 3 & $20-30$ & Debitage & Tertiary & Lithic & 6 & 12.22 & $\mathrm{JU}$ & $9 / 28 / 2017$ & 5 bifacial thinning flakes \\
\hline $5-4$ & 3 & $20-30$ & Debitage & Shatter & Lithic & 2 & 3.34 & $\mathrm{JU}$ & $9 / 28 / 2017$ & \\
\hline $5-4$ & 4 & $30-40$ & Debitage & Tertiary & Lithic & 1 & 0.24 & $\mathrm{JU}$ & 9/28/2017 & 1 bifacial thinning flake \\
\hline $5-4$ & 8 & $70-80$ & Debitage & Tertiary & Lithic & 3 & 8.26 & JU & $9 / 28 / 2017$ & 2 bifacial thinning flakes \\
\hline $5-4$ & 9 & $80-90$ & Debitage & Tertiary & Lithic & 4 & 0.62 & JU & $9 / 28 / 2017$ & 2 bifacial thinning flakes \\
\hline $5-4$ & 10 & $90-100$ & Debitage & Primary & Lithic & 1 & 4.52 & $\mathrm{JU}$ & 9/28/2017 & \\
\hline $5-4$ & 10 & $90-100$ & Debitage & Tertiary & Lithic & 1 & 1.79 & $\mathrm{JU}$ & $9 / 28 / 2017$ & 1 bifacial thinning flake \\
\hline $5-5$ & 1 & $0-10$ & Debitage & Secondary & Lithic & 1 & 5.25 & JU & $9 / 28 / 2017$ & \\
\hline $5-5$ & 1 & $0-10$ & Debitage & Tertiary & Lithic & 10 & 14.78 & JU & $9 / 28 / 2017$ & 7 bifacial thinning flakes \\
\hline $5-5$ & 2 & $10-20$ & Debitage & Primary & Lithic & 1 & 1.86 & JU & $9 / 28 / 2017$ & \\
\hline $5-5$ & 2 & $10-20$ & Debitage & Secondary & Lithic & 1 & 1.36 & JU & $9 / 28 / 2017$ & \\
\hline $5-5$ & 2 & $10-20$ & Debitage & Tertiary & Lithic & 3 & 1.78 & JU & $9 / 28 / 2017$ & 2 bifacial thinning flakes \\
\hline $5-5$ & 4 & $30-40$ & Debitage & Primary & Lithic & 1 & 4.41 & $\mathrm{JU}$ & 9/28/2017 & \\
\hline $5-5$ & 4 & $30-40$ & Debitage & Tertiary & Lithic & 10 & 22.1 & JU & $9 / 28 / 2017$ & 7 bifacial thinning flakes \\
\hline $5-5$ & 7 & $60-70$ & Debitage & Primary & Lithic & 1 & 6.27 & $\mathrm{JU}$ & 9/28/2017 & \\
\hline $5-5$ & 7 & $60-70$ & Debitage & Secondary & Lithic & 3 & 10.9 & $\mathrm{JU}$ & 9/28/2017 & 1 bifacial thinning flake \\
\hline $5-5$ & 7 & $60-70$ & Debitage & Tertiary & Lithic & 9 & 4.12 & $\mathrm{JU}$ & 9/28/2017 & 8 bifacial thinning flakes \\
\hline $5-5$ & 8 & $70-80$ & Debitage & Secondary & Lithic & 1 & 0.36 & $\mathrm{JU}$ & 9/28/2017 & \\
\hline $5-5$ & 9 & $80-90$ & Debitage & Secondary & Lithic & 1 & 1.67 & JU & 9/28/2017 & \\
\hline $5-5$ & 9 & $80-90$ & Debitage & Tertiary & Lithic & 1 & 0.43 & $\mathrm{JU}$ & 9/28/2017 & 1 bifacial thinning flake \\
\hline $5-6$ & 1 & $0-10$ & Debitage & Secondary & Lithic & 1 & 45.91 & JU & $9 / 28 / 2017$ & \\
\hline $5-6$ & 2 & $10-20$ & Debitage & Tertiary & Lithic & 4 & 3.27 & $\mathrm{JU}$ & $9 / 28 / 2017$ & 4 bifacial thinning flakes \\
\hline $5-6$ & 2 & $10-20$ & Debitage & Shatter & Lithic & 1 & 0.93 & JU & $9 / 28 / 2017$ & \\
\hline $5-6$ & 3 & $20-30$ & $\begin{array}{l}\text { Modified } \\
\text { Flake }\end{array}$ & Modified Flake & Lithic & 1 & 11.91 & JU & 9/28/2017 & \\
\hline $5-6$ & 4 & $30-40$ & Debitage & Tertiary & Lithic & 7 & 2.76 & JU & $9 / 28 / 2017$ & 5 bifacial thinning flakes \\
\hline $5-6$ & 4 & $30-40$ & Debitage & Shatter & Lithic & 2 & 0.98 & JU & $9 / 28 / 2017$ & \\
\hline $5-6$ & 4 & $30-40$ & $\begin{array}{l}\text { Burned } \\
\text { Rock }\end{array}$ & Burned Rock & Lithic & 1 & 5.13 & JU & 9/28/2017 & \\
\hline $5-6$ & 5 & $40-50$ & Debitage & Tertiary & Lithic & 4 & 5.64 & $\mathrm{JU}$ & $9 / 28 / 2017$ & 2 bifacial thinning flakes \\
\hline $5-6$ & 6 & $50-60$ & Debitage & Secondary & Lithic & 1 & 16.99 & $\mathrm{JU}$ & $9 / 28 / 2017$ & 1 bifacial thinning flake \\
\hline $5-6$ & 6 & $50-60$ & Debitage & Tertiary & Lithic & 15 & 19.16 & $\mathrm{JU}$ & 9/28/2017 & 12 bifacial thinning flakes \\
\hline $5-6$ & 6 & $50-60$ & $\begin{array}{l}\text { Ground } \\
\text { Stone }\end{array}$ & Ground Stone & Lithic & 1 & 285.57 & JU & $9 / 28 / 2017$ & \\
\hline $5-6$ & 7 & $60-70$ & $\begin{array}{l}\text { Projectile } \\
\text { Point }\end{array}$ & $\begin{array}{l}\text { Untyped Point } \\
\text { Tip }\end{array}$ & Lithic & 1 & 1.66 & JU & 9/28/2017 & Distal end \\
\hline $5-6$ & 7 & $60-70$ & Debitage & Tertiary & Lithic & 6 & 2.97 & $\mathrm{JU}$ & 9/28/2017 & 4 bifacial thinning flakes \\
\hline $5-6$ & 7 & $60-70$ & Debitage & Shatter & Lithic & 1 & 0.63 & $\mathrm{JU}$ & 9/28/2017 & \\
\hline $5-6$ & 8 & $70-80$ & Debitage & Tertiary & Lithic & 4 & 1.49 & $\mathrm{JU}$ & $9 / 28 / 2017$ & 3 bifacial thinning flakes \\
\hline $5-6$ & 9 & $80-90$ & Debitage & Secondary & Lithic & 1 & 5.94 & $\mathrm{JU}$ & 9/28/2017 & \\
\hline $5-6$ & 9 & $80-90$ & Debitage & Tertiary & Lithic & 10 & 15.02 & JU & 9/28/2017 & 7 bifacial thinning flakes \\
\hline $5-6$ & 9 & $80-90$ & $\begin{array}{l}\text { Burned } \\
\text { Rock }\end{array}$ & Burned Rock & Lithic & 1 & 3.33 & JU & 9/28/2017 & \\
\hline $5-6$ & 10 & $90-100$ & Debitage & Tertiary & Lithic & 3 & 0.69 & JU & $9 / 28 / 2017$ & 2 bifacial thinning flakes \\
\hline $5-7$ & 1 & $0-10$ & Debitage & Tertiary & Lithic & 3 & 3.54 & JU & 9/29/2017 & 3 bifacial thinning flakes \\
\hline $5-7$ & 2 & $10-20$ & Debitage & Tertiary & Lithic & 2 & 11.14 & $\mathrm{JU}$ & 9/29/2017 & 2 bifacial thinning flakes \\
\hline $5-7$ & 5 & $40-50$ & Debitage & Tertiary & Lithic & 3 & 1.8 & $\mathrm{JU}$ & 9/29/2017 & 2 bifacial thinning flakes \\
\hline $5-7$ & 5 & $40-50$ & Debitage & Shatter & Lithic & 1 & 0.23 & JU & 9/29/2017 & \\
\hline $5-7$ & 8 & $70-80$ & Debitage & Tertiary & Lithic & 3 & 1.18 & $\mathrm{JU}$ & 9/29/2017 & 2 bifacial thinning flakes \\
\hline $5-7$ & 14 & $130-140$ & Debitage & Tertiary & Lithic & 1 & 0.13 & JU & 9/29/2017 & \\
\hline KS139 & 1 & $0-10$ & Debitage & Tertiary & Lithic & 13 & - & DR & $10 / 19 / 2017$ & Not collected \\
\hline KS139 & 2 & $10-20$ & Debitage & Primary & Lithic & 6 & - & DR & $10 / 19 / 2017$ & Not collected \\
\hline KS139 & 3 & $20-30$ & Debitage & Tertiary & Lithic & 9 & - & $\mathrm{DR}$ & $10 / 19 / 2017$ & Not collected \\
\hline KS139 & 4 & $30-40$ & Debitage & Tertiary & Lithic & 15 & - & $\mathrm{DR}$ & $10 / 19 / 2017$ & Not collected \\
\hline KS139 & 5 & $40-50$ & Debitage & Tertiary & Lithic & 10 & - & DR & $10 / 19 / 2017$ & Not collected \\
\hline KS139 & 6 & $50-60$ & Debitage & Tertiary & Lithic & 6 & - & DR & $10 / 19 / 2017$ & Not collected \\
\hline
\end{tabular}




\begin{tabular}{|c|c|c|c|l|c|c|c|c|c|c|}
\hline ST & Level & $\begin{array}{c}\text { Depth } \\
\text { (cmbs) }\end{array}$ & $\begin{array}{c}\text { Artifact } \\
\text { Type }\end{array}$ & $\begin{array}{c}\text { Artifact } \\
\text { Description }\end{array}$ & Material & $\begin{array}{c}\text { Artifact } \\
\text { No. }\end{array}$ & $\begin{array}{c}\text { Weight } \\
\text { (g) }\end{array}$ & Recorders & Date & Comments \\
\hline KS139 & 7 & $70-80$ & Debitage & Tertiary & Lithic & 5 & - & DR & $10 / 19 / 2017$ & Not collected \\
\hline RW342 & $4-8$ & $30-80$ & Debitage & Tertiary & Lithic & 6 & - & DR & $10 / 19 / 2017$ & Not collected \\
\hline RW342 & $4-8$ & $30-80$ & Debitage & Shatter & Lithic & 4 & - & DR & $10 / 19 / 2017$ & Not collected \\
\hline RW343 & $3-4$ & $20-40$ & Debitage & Tertiary & Lithic & 1 & - & DR & $10 / 19 / 2017$ & Not collected \\
\hline
\end{tabular}




\section{APPENDIX B}

\section{BACKHOE TRENCH RESULTS}





\begin{tabular}{|c|c|c|c|c|c|c|c|c|c|c|}
\hline BHT & $\begin{array}{c}\text { Depth } \\
\text { (cmbs) }\end{array}$ & Munsell* & Soil Color* & $\begin{array}{l}\text { Soil } \\
\text { Texture }\end{array}$ & Consistency & $\begin{array}{l}\text { Structure } \\
\text { Type }\end{array}$ & Grade & Inclusions & $\begin{array}{l}\text { Lower } \\
\text { Boundary }\end{array}$ & Comments \\
\hline \multirow{4}{*}{ ВНT01 } & $0-58$ & 10YR3/2 & $\begin{array}{l}\text { very dark } \\
\text { grayish } \\
\text { brown }\end{array}$ & silt loam & Friable & $\begin{array}{l}\text { Subangular } \\
\text { Blocky to } \\
\text { Angular Blocky }\end{array}$ & $\begin{array}{l}\text { Weak to } \\
\text { moderate }\end{array}$ & $\begin{array}{l}\text { roots-rootlets } 15-20 \% \text {, few snail shell } \\
\text { (Helio), 30\% pin holes, } 5 \% \text { worm } \\
\text { burrows, } 5 \% \text { snail fragments }\end{array}$ & $\begin{array}{l}\text { Gradual and } \\
\text { Smooth }\end{array}$ & Root zone $0-9 \mathrm{cmbs}$ \\
\hline & $58-99$ & 10YR4/3 & brown & Loam & Friable & $\begin{array}{l}\text { Subangular } \\
\text { Blocky }\end{array}$ & $\begin{array}{l}\text { Weak to } \\
\text { moderate }\end{array}$ & $\begin{array}{l}5-10 \% \text { rootlets, } 30 \% \text { pin holes, } 5 \% \\
\text { worm burrows, } 1 \% \text { snail fragments }\end{array}$ & $\begin{array}{l}\text { Gradual and } \\
\text { Smooth }\end{array}$ & Transitional \\
\hline & $99-183$ & 10YR5/4 & $\begin{array}{l}\text { yellowish } \\
\text { brown }\end{array}$ & Silt Loam & Friable & $\begin{array}{l}\text { Subangular } \\
\text { Blocky }\end{array}$ & Moderate & $\begin{array}{c}\text { 3-5\% rootlets, } 30 \% \text { pin holes, } 5 \% \text { worm } \\
\text { burrows, } 10 \% \text { snail - Rabdotus, } 1 \% \\
\text { snail fragments }\end{array}$ & $\begin{array}{l}\text { Clear and } \\
\text { smooth }\end{array}$ & \\
\hline & $183-326$ & $\begin{array}{l}\text { 10YR5/6 to } \\
\text { 10YR6/6 }\end{array}$ & $\begin{array}{l}\text { yellowish } \\
\text { brown to } \\
\text { brownish } \\
\text { yellow }\end{array}$ & $\begin{array}{l}\text { Clay } \\
\text { loam }\end{array}$ & Friable & Angular Blocky & Moderate & $\begin{array}{l}1 \% \text { rootlets, } 5-10 \% \text { pin holes, } 1 \% \text { white } \\
\text { filament }(1 \mathrm{~mm}), 20-30 \% \text { snail - helio } \\
\text { and rabdotus, } 10 \% \text { snail fragments }\end{array}$ & Unobserved & $\begin{array}{l}\mathrm{CaCO}_{3} \text { filaments increase with depth } 3-4 \mathrm{~mm} \\
(5 \%) \sim 280 \mathrm{cmbs} \text {, clay content increases with } \\
\text { depth }\end{array}$ \\
\hline \multirow{4}{*}{ ВНT02 } & $0-41$ & 10YR3/2 & $\begin{array}{l}\text { very dark } \\
\text { grayish } \\
\text { brown }\end{array}$ & silt loam & Friable & $\begin{array}{l}\text { Subangular } \\
\text { Blocky to } \\
\text { Angular Blocky }\end{array}$ & $\begin{array}{l}\text { Weak to } \\
\text { moderate }\end{array}$ & $\begin{array}{l}\text { roots-rootlets } 15-20 \% \text {, few snail shell } \\
\text { (Helio), } 30 \% \text { pin holes, } 5 \% \text { worm } \\
\text { burrows, } 5 \% \text { snail fragments }\end{array}$ & $\begin{array}{l}\text { Gradual and } \\
\text { Smooth }\end{array}$ & Root zone $0-9 \mathrm{cmbs}$ \\
\hline & $41-93$ & 10YR4/3 & brown & Loam & Friable & $\begin{array}{l}\text { Subangular } \\
\text { Blocky }\end{array}$ & $\begin{array}{l}\text { Weak to } \\
\text { moderate }\end{array}$ & $\begin{array}{l}5-10 \% \text { rootlets, } 30 \% \text { pin holes, } 5 \% \\
\text { worm burrows, } 1 \% \text { snail fragments }\end{array}$ & $\begin{array}{l}\text { Gradual to } \\
\text { clear and } \\
\text { slightly wavy }\end{array}$ & Transitional \\
\hline & $93-196$ & 10YR5/4 & $\begin{array}{l}\text { yellowish } \\
\text { brown }\end{array}$ & Silt Loam & Friable & $\begin{array}{l}\text { Subangular } \\
\text { Blocky }\end{array}$ & Moderate & $\begin{array}{l}3-5 \% \text { rootlets, } 30 \% \text { pin holes, } 5 \% \text { worm } \\
\text { burrows, } 10 \% \text { snail - Rabdotus, } 1 \% \\
\text { snail fragments, pockets of snail - } \\
\text { rabdotus, Insect burrows - } 6 \mathrm{~mm} \mathrm{-1} \%\end{array}$ & $\begin{array}{l}\text { Clear and } \\
\text { smooth }\end{array}$ & \\
\hline & $196-306$ & $\begin{array}{l}\text { 10YR5/6 to } \\
\text { 10YR6/6 }\end{array}$ & $\begin{array}{l}\text { yellowish } \\
\text { brown to } \\
\text { brownish } \\
\text { yellow }\end{array}$ & $\begin{array}{l}\text { Clay } \\
\text { loam }\end{array}$ & Friable & Angular Blocky & Moderate & $\begin{array}{l}1 \% \text { rootlets, } 3 \% \text { pin holes, } 1 \% \text { white } \\
\text { filament }(1 \mathrm{~cm}), 20-30 \% \text { snail }- \text { helio and } \\
\text { rabdotus, } 10 \% \text { snail fragments, large } \\
\text { insect burrows }\end{array}$ & Unobserved & $\begin{array}{l}\mathrm{CaCO}_{3} \text { filaments increase with depth } 3-4 \mathrm{~mm} \\
(5 \%) \sim 280 \mathrm{cmbs} \text {, clay content increases with } \\
\text { depth }\end{array}$ \\
\hline \multirow{3}{*}{ ВНT03 } & $0-26$ & 10YR 5/3 & brown & $\begin{array}{l}\text { Silty clay } \\
\text { loam }\end{array}$ & $\begin{array}{l}\text { Friable to } \\
\text { Firm }\end{array}$ & $\begin{array}{l}\text { Subangular } \\
\text { Blocky }\end{array}$ & Moderate & $\begin{array}{l}5 \% \text { roots, } 5 \% \text { rootlets, rare gravels, rare } \\
\text { insect casts, } 10 \% \text { white filament }\end{array}$ & $\begin{array}{l}\text { Clear and } \\
\text { irregular }\end{array}$ & No snail shell observed \\
\hline & $26-149$ & 10YR 6/4 & $\begin{array}{l}\text { Light } \\
\text { yellowish } \\
\text { brown }\end{array}$ & Silt loam & Friable & $\begin{array}{l}\text { Subangular } \\
\text { Crumb }\end{array}$ & $\begin{array}{l}\text { Weak to } \\
\text { moderate }\end{array}$ & $\begin{array}{l}1 \% \text { roots, } 1 \% \text { rootlets, } 25 \% \text { limestone } \\
\text { gravels, rare insect casts }\end{array}$ & $\begin{array}{l}\text { Gradual and } \\
\text { smooth }\end{array}$ & $\begin{array}{l}5 \% \mathrm{CaCO}_{3} \text { filaments decrease with depth } \\
\text { starting at approximately } 70 \mathrm{cmbs}\end{array}$ \\
\hline & $149-170$ & 10YR 7/4 & $\begin{array}{l}\text { Very pale } \\
\text { brown }\end{array}$ & Silt loam & Friable & Platy & $\begin{array}{l}\text { Weak to } \\
\text { moderate }\end{array}$ & $\begin{array}{c}>1 \% \text { rootlets, } 20 \% \text { limestone gravels, } \\
1 \% \text { white filament }\end{array}$ & Unobserved & \\
\hline \multirow{5}{*}{ ВНT04 } & $0-11$ & 10YR3/2 & $\begin{array}{l}\text { very dark } \\
\text { grayish } \\
\text { brown }\end{array}$ & silt loam & Friable & $\begin{array}{l}\text { Subangular } \\
\text { Blocky to } \\
\text { Angular Blocky }\end{array}$ & $\begin{array}{l}\text { Weak to } \\
\text { moderate }\end{array}$ & $\begin{array}{l}\text { roots-rootlets } 15-20 \% \text {, few snail shell } \\
\text { (Helio), } 30 \% \text { pin holes, } 5 \% \text { worm } \\
\text { burrows, } 5 \% \text { snail fragments }\end{array}$ & $\begin{array}{l}\text { Gradual and } \\
\text { Smooth }\end{array}$ & Root zone $0-9 \mathrm{cmbs}$ \\
\hline & $11-35$ & 10YR4/3 & brown & Loam & Friable & $\begin{array}{l}\text { Subangular } \\
\text { Blocky }\end{array}$ & $\begin{array}{l}\text { Weak to } \\
\text { moderate }\end{array}$ & $\begin{array}{l}5-10 \% \text { rootlets, } 30 \% \text { pin holes, } 5 \% \\
\text { worm burrows, } 1 \% \text { snail fragments }\end{array}$ & $\begin{array}{l}\text { Gradual to } \\
\text { clear and } \\
\text { slightly wavy }\end{array}$ & Transitional \\
\hline & $35-83$ & 10YR5/4 & $\begin{array}{l}\text { yellowish } \\
\text { brown }\end{array}$ & Silt Loam & Friable & $\begin{array}{l}\text { Subangular } \\
\text { Blocky }\end{array}$ & Moderate & $\begin{array}{l}3-5 \% \text { rootlets, } 30 \% \text { pin holes, } 5 \% \text { worm } \\
\text { burrows, } 10 \% \text { snail - Rabdotus, } 1 \% \\
\text { snail fragments, pockets of snail - } \\
\text { rabdotus, Insect burrows - } 6 \mathrm{~mm} \mathrm{-1} \%\end{array}$ & $\begin{array}{l}\text { Clear and } \\
\text { smooth }\end{array}$ & \\
\hline & $83-130$ & $\begin{array}{l}10 Y R 5 / 6 \text { to } \\
10 Y R 6 / 6\end{array}$ & $\begin{array}{l}\text { yellowish } \\
\text { brown to } \\
\text { brownish } \\
\text { yellow }\end{array}$ & $\begin{array}{l}\text { Clay } \\
\text { loam }\end{array}$ & Friable & Angular Blocky & Moderate & $\begin{array}{l}1 \% \text { rootlets, } 3 \% \text { pin holes, } 1 \% \text { white } \\
\text { filament }(1 \mathrm{~cm}), 20-30 \% \text { snail }- \text { helio and } \\
\text { rabdotus, } 10 \% \text { snail fragments, large } \\
\text { insect burrows }\end{array}$ & Unobserved & $\begin{array}{l}\mathrm{CaCO}_{3} \text { filaments increase with depth } 3-4 \mathrm{~mm} \\
(5 \%) \sim 280 \mathrm{cmbs} \text {, clay content increases with } \\
\text { depth }\end{array}$ \\
\hline & $130-170$ & $\begin{array}{c}10 Y R 6 / 2- \\
6 / 3\end{array}$ & $\begin{array}{l}\text { Light } \\
\text { brownish } \\
\text { gray }\end{array}$ & Silt Loam & Friable & $\begin{array}{l}\text { Subangular, } \\
\text { medium }\end{array}$ & moderate & $\begin{array}{c}\text { rootlets } 5-10 \% \text {, rabdotus }<3 \% \text {, white } \\
\text { filaments } 10 \% \text { - dispersed, limestone } \\
\text { subangular fragments }<19 \%\end{array}$ & Unobserved & \\
\hline
\end{tabular}




\begin{tabular}{|c|c|c|c|c|c|c|c|c|c|c|}
\hline BHT & $\begin{array}{c}\text { Depth } \\
\text { (cmbs) }\end{array}$ & Munsel|* & Soil Color* & $\begin{array}{l}\text { Soil } \\
\text { Texture }\end{array}$ & Consistency & $\begin{array}{l}\text { Structure } \\
\text { Type }\end{array}$ & Grade & Inclusions & $\begin{array}{l}\text { Lower } \\
\text { Boundary }\end{array}$ & Comments \\
\hline \multirow{5}{*}{ ВHT05 } & $0-12$ & 10YR3/2 & $\begin{array}{l}\text { very dark } \\
\text { grayish } \\
\text { brown }\end{array}$ & silt loam & Friable & $\begin{array}{l}\text { Subangular } \\
\text { Blocky to } \\
\text { Angular Blocky }\end{array}$ & $\begin{array}{l}\text { Weak to } \\
\text { moderate }\end{array}$ & $\begin{array}{l}\text { roots-rootlets } 15-20 \% \text {, few snail shell } \\
\text { (Helio), } 30 \% \text { pin holes, } 5 \% \text { worm } \\
\text { burrows, } 5 \% \text { snail fragments }\end{array}$ & $\begin{array}{l}\text { Gradual and } \\
\text { Smooth }\end{array}$ & Root zone $0-9 \mathrm{cmbs}$ \\
\hline & $12-40$ & 10YR4/3 & brown & Loam & Friable & $\begin{array}{l}\text { Subangular } \\
\text { Blocky }\end{array}$ & $\begin{array}{l}\text { Weak to } \\
\text { moderate }\end{array}$ & $\begin{array}{l}5-10 \% \text { rootlets, } 30 \% \text { pin holes, } 5 \% \\
\text { worm burrows, } 1 \% \text { snail fragments }\end{array}$ & $\begin{array}{l}\text { Gradual to } \\
\text { clear and } \\
\text { slightly wavy }\end{array}$ & Transitional \\
\hline & $40-76$ & 10YR5/4 & $\begin{array}{l}\text { yellowish } \\
\text { brown }\end{array}$ & Silt Loam & Friable & $\begin{array}{l}\text { Subangular } \\
\text { Blocky }\end{array}$ & Moderate & $\begin{array}{l}\text { 3-5\% rootlets, } 30 \% \text { pin holes, } 5 \% \text { worm } \\
\text { burrows, } 10 \% \text { snail - Rabdotus, } 1 \% \\
\text { snail fragments, pockets of snail - } \\
\text { rabdotus, Insect burrows - } 6 \mathrm{~mm}-1 \%\end{array}$ & $\begin{array}{l}\text { Clear and } \\
\text { smooth }\end{array}$ & \\
\hline & $76-128$ & $\begin{array}{l}10 \mathrm{YR} 5 / 6 \text { to } \\
10 \mathrm{YR} 6 / 6\end{array}$ & $\begin{array}{l}\text { yellowish } \\
\text { brown to } \\
\text { brownish } \\
\text { yellow }\end{array}$ & $\begin{array}{l}\text { Clay } \\
\text { loam }\end{array}$ & Friable & Angular Blocky & Moderate & $\begin{array}{l}1 \% \text { rootlets, } 3 \% \text { pin holes, } 1 \% \text { white } \\
\text { filament }(1 \mathrm{~cm}), 20-30 \% \text { snail - helio and } \\
\text { rabdotus, } 10 \% \text { snail fragments, large } \\
\text { insect burrows }\end{array}$ & Unobserved & $\begin{array}{l}\mathrm{CaCO}_{3} \text { filaments increase with depth } 3-4 \mathrm{~mm} \\
(5 \%) \sim 280 \mathrm{cmbs} \text {, clay content increases with } \\
\text { depth }\end{array}$ \\
\hline & $128-138$ & $\begin{array}{c}10 Y R 6 / 2- \\
6 / 3\end{array}$ & $\begin{array}{l}\text { Light } \\
\text { brownish } \\
\text { gray }\end{array}$ & Silt Loam & Friable & $\begin{array}{l}\text { Subangular, } \\
\text { medium }\end{array}$ & moderate & $\begin{array}{c}\text { rootlets } 5-10 \% \text {, rabdotus }<3 \% \text {, white } \\
\text { filaments } 10 \% \text { - dispersed, limestone } \\
\text { subangular fragments }<19 \%\end{array}$ & Unobserved & \\
\hline \multirow{5}{*}{ BHT06 } & $0-10$ & 10YR3/2 & $\begin{array}{l}\text { very dark } \\
\text { grayish } \\
\text { brown }\end{array}$ & silt loam & Friable & $\begin{array}{l}\text { Subangular } \\
\text { Blocky to } \\
\text { Angular Blocky }\end{array}$ & $\begin{array}{l}\text { Weak to } \\
\text { moderate }\end{array}$ & $\begin{array}{l}\text { roots-rootlets } 15-20 \% \text {, few snail shell } \\
\text { (Helio), } 30 \% \text { pin holes, } 5 \% \text { worm } \\
\text { burrows, } 5 \% \text { snail fragments }\end{array}$ & $\begin{array}{l}\text { Gradual and } \\
\text { Smooth }\end{array}$ & Root zone $0-9 \mathrm{cmbs}$ \\
\hline & $10-38$ & 10YR4/3 & brown & Loam & Friable & $\begin{array}{l}\text { Subangular } \\
\text { Blocky }\end{array}$ & $\begin{array}{l}\text { Weak to } \\
\text { moderate }\end{array}$ & $\begin{array}{l}5-10 \% \text { rootlets, } 30 \% \text { pin holes, } 5 \% \\
\text { worm burrows, } 1 \% \text { snail fragments }\end{array}$ & $\begin{array}{l}\text { Gradual to } \\
\text { clear and } \\
\text { slightly wavy }\end{array}$ & Transitional \\
\hline & $38-80$ & 10YR5/4 & $\begin{array}{l}\text { yellowish } \\
\text { brown }\end{array}$ & Silt Loam & Friable & $\begin{array}{l}\text { Subangular } \\
\text { Blocky }\end{array}$ & Moderate & $\begin{array}{l}\text { 3-5\% rootlets, } 30 \% \text { pin holes, } 5 \% \text { worm } \\
\text { burrows, } 10 \% \text { snail - Rabdotus, } 1 \% \\
\text { snail fragments, pockets of snail - } \\
\text { rabdotus, Insect burrows- } 6 \mathrm{~mm}-1 \%\end{array}$ & $\begin{array}{l}\text { Clear and } \\
\text { smooth }\end{array}$ & \\
\hline & 08-132 & $\begin{array}{l}10 \mathrm{YR} 5 / 6 \text { to } \\
10 \mathrm{YR} 6 / 6\end{array}$ & $\begin{array}{l}\text { yellowish } \\
\text { brown to } \\
\text { brownish } \\
\text { yellow }\end{array}$ & $\begin{array}{l}\text { Clay } \\
\text { loam }\end{array}$ & Friable & Angular Blocky & Moderate & $\begin{array}{l}1 \% \text { rootlets, } 3 \% \text { pin holes, } 1 \% \text { white } \\
\text { filament }(1 \mathrm{~cm}), 20-30 \% \text { snail - helio and } \\
\text { rabdotus, } 10 \% \text { snail fragments, large } \\
\text { insect burrows }\end{array}$ & Unobserved & $\begin{array}{l}\mathrm{CaCO}_{3} \text { filaments increase with depth } 3-4 \mathrm{~mm} \\
(5 \%) \sim 280 \mathrm{cmbs} \text {, clay content increases with } \\
\text { depth }\end{array}$ \\
\hline & $132-140$ & $\begin{array}{c}10 Y R 6 / 2- \\
6 / 3\end{array}$ & $\begin{array}{l}\text { Light } \\
\text { brownish } \\
\text { gray }\end{array}$ & Silt Loam & Friable & $\begin{array}{l}\text { Subangular, } \\
\text { medium }\end{array}$ & moderate & $\begin{array}{l}\text { rootlets } 5-10 \% \text {, rabdotus }<3 \% \text {, white } \\
\text { filaments } 10 \% \text { - dispersed, limestone } \\
\text { subangular fragments }<19 \%\end{array}$ & Unobserved & \\
\hline
\end{tabular}




\begin{tabular}{|c|c|c|c|c|c|c|c|c|c|c|}
\hline BHT & $\begin{array}{l}\text { Depth } \\
\text { (cmbs) }\end{array}$ & MunselI* & Soil Color* & $\begin{array}{c}\text { Soil } \\
\text { Texture }\end{array}$ & Consistency & $\begin{array}{c}\text { Structure } \\
\text { Type }\end{array}$ & Grade & Inclusions & $\begin{array}{c}\text { Lower } \\
\text { Boundary }\end{array}$ & Comments \\
\hline \multirow{6}{*}{ ВHT07 } & $0-21$ & $\begin{array}{l}\text { 10YR3/2- } \\
2 / 3\end{array}$ & $\begin{array}{l}\text { Very dark } \\
\text { grayish } \\
\text { brown }\end{array}$ & Silt Loam & Friable & $\begin{array}{l}\text { crumb to } \\
\text { subangular, } \\
\text { fine }\end{array}$ & weak & $\begin{array}{c}\text { Roots } 3 \% \text {, rootlets } 2 \% \text {, worm burrows } \\
5 \% \text {, pin holes } 5-10 \% \text {, limestone pebbles } \\
3 \% \text { (subangular) }\end{array}$ & $\begin{array}{l}\text { clear, sloping } \\
\text { to east }\end{array}$ & $\begin{array}{l}\text { Mottled 10YR 5/3 (disturbed), secondary colors } \\
\text { as lenses } 20 \% \text {, cultural material: debitage, } \\
\text { some fire cracked rock (FCR), and burned chert }\end{array}$ \\
\hline & 21-39 & $\begin{array}{l}10 Y R 4 / 2- \\
5 / 2\end{array}$ & $\begin{array}{l}\text { Dark grayish } \\
\text { brown }\end{array}$ & Silt Loam & Friable to firm & $\begin{array}{l}\text { subangular to } \\
\text { angular, } \\
\text { medium }\end{array}$ & moderate & $\begin{array}{c}\text { Roots } 10 \% \text {, rootlets } 15-20 \% \text {, rabdotus } \\
3 \% \text {, snail fragments } 20 \% \text {, worm } 3-5 \% \text {, } \\
\text { pinhole } 5-10 \% \text {, limestone subangular } \\
\text { pebbles } 3 \%\end{array}$ & $\begin{array}{l}\text { clear, smooth } \\
\text { to slightly } \\
\text { sloping }\end{array}$ & $\begin{array}{l}\text { No secondary colors, possibly truncated from } \\
\text { above, Cultural material: debitage and } \\
\text { occasional FCR fragment }\end{array}$ \\
\hline & $39-71$ & 10YR 5/3 & Brown & Silt Loam & Friable & $\begin{array}{l}\text { Subangular to } \\
\text { angular, } \\
\text { medium }\end{array}$ & moderate & $\begin{array}{c}\text { Roots } 5-10 \% \text {, rootlets } 15 \% \text {, snail } \\
\text { fragments } 15 \% \text {, rabdotus } 3 \% \text {, pinholes } \\
5 \%\end{array}$ & $\begin{array}{l}\text { clear, smooth } \\
\text { to slightly } \\
\text { sloping }\end{array}$ & $\begin{array}{l}\text { Cultural material: scattered debitage, no } \\
\text { concentrations }\end{array}$ \\
\hline & $71-101$ & $\begin{array}{l}\text { 10YR } 5 / 3- \\
5 / 4\end{array}$ & Brown & Silt Loam & Friable & $\begin{array}{l}\text { Subangular, } \\
\text { fine to medium }\end{array}$ & moderate & $\begin{array}{l}\text { Rootlets } 15 \% \text {, pinholes } 5 \% \text {, white } \\
\text { filaments } 3-5 \% \text {, rabdotus } 3-5 \% \text {, } \\
\text { vertically arranged and clustered (root } \\
\text { activity), heliodiscus } 1 \% \text {, snail } \\
\text { fragments } 5 \%\end{array}$ & $\begin{array}{l}\text { Gradual, } \\
\text { smooth }\end{array}$ & $\begin{array}{l}\text { Cultural material: small scattered FCR, low } \\
\text { density debitage, }\end{array}$ \\
\hline & $101-139$ & $\begin{array}{c}10 Y R 6 / 2- \\
6 / 3\end{array}$ & $\begin{array}{l}\text { Light } \\
\text { brownish } \\
\text { gray }\end{array}$ & Silt Loam & Friable & $\begin{array}{c}\text { Subangular, } \\
\text { medium }\end{array}$ & moderate & $\begin{array}{c}\text { rootlets } 5-10 \% \text {, rabdotus }<3 \% \text {, white } \\
\text { filaments } 10 \% \text { - dispersed, limestone } \\
\text { subangular fragments }<19 \%\end{array}$ & $\begin{array}{l}\text { Gradual, } \\
\text { smooth }\end{array}$ & $\begin{array}{c}\text { Cultural material; FCR, larger debitage than } \\
\text { strats above, calcine coated artifacts, several } \\
\text { large FCR at } 131 \mathrm{cmbs}\end{array}$ \\
\hline & $139-183$ & 10YR7/3 & $\begin{array}{l}\text { Very pale } \\
\text { brown }\end{array}$ & $\begin{array}{l}\text { Fine Silt } \\
\text { Loam }\end{array}$ & $\begin{array}{l}\text { Loose to } \\
\text { Friable }\end{array}$ & $\begin{array}{l}\text { Crumb to } \\
\text { subangular, } \\
\text { fine }\end{array}$ & weak & root $<1 \%$, rootlets $<5 \%$, snail $<1 \%$ & $\begin{array}{l}\text { Gradual, } \\
\text { smooth }\end{array}$ & \\
\hline \multirow{4}{*}{ ВНT08 } & $0-17$ & $\begin{array}{c}\text { 10YR3/2- } \\
4 / 2\end{array}$ & $\begin{array}{l}\text { Very dark } \\
\text { grayish } \\
\text { brown }\end{array}$ & Silt Loam & $\begin{array}{l}\text { Loose to } \\
\text { Friable }\end{array}$ & $\begin{array}{l}\text { crumb to } \\
\text { subangular, } \\
\text { fine }\end{array}$ & weak & $\begin{array}{l}\text { Roots } 5 \% \text {, rootlets } 20 \% \text {, rabdotus } 10 \% \text {, } \\
\text { worm } 5 \% \text {, pinholes } 15-20 \% \text {, partially } \\
\text { decomposed vegetation in upper } 4 \mathrm{~cm}\end{array}$ & $\begin{array}{l}\text { Clear, slightly } \\
\text { wavy }\end{array}$ & \\
\hline & $17-42$ & $\begin{array}{c}10 Y R 5 / 2- \\
5 / 3\end{array}$ & Brown & Silt Loam & Friable & $\begin{array}{l}\text { Subangular, } \\
\text { fine to medium }\end{array}$ & weak & $\begin{array}{c}\text { Roots } 3 \% \text {, rootlets } 15 \% \text {, rabdotus } 10- \\
15 \% \text {, limestone gravels and cobbles } \\
3 \% \text {, pinholes } 10-15 \%\end{array}$ & $\begin{array}{l}\text { Clear, slightly } \\
\text { irregular }\end{array}$ & $\begin{array}{l}\text { Flake at } 28 \mathrm{cmbs} \text { (chert) early stage (secondary } \\
1 \text { or } 3 \text { ), one FCR at } 28-32 \mathrm{cmbs}\end{array}$ \\
\hline & $42-84$ & 10YR5/3 & Brown & Silt Loam & Friable & $\begin{array}{l}\text { Subangular, } \\
\text { medium }\end{array}$ & Weak & $\begin{array}{c}\text { Roots } 1 \% \text {, rootlets } 10 \% \text {, rabdotus } 3-5 \% \text {, } \\
\text { white filaments } 3 \% \text {, worm burrows 5-6 } \\
\text { cm diameter 3-5\% }\end{array}$ & Clear, irregular & $\begin{array}{l}\text { 10YR6/2 } 15 \% \text { mottles, Flake/debitage at } \\
62 \mathrm{cmbs} \text {, many roots/burrows }\end{array}$ \\
\hline & $\begin{array}{c}84- \\
302+\end{array}$ & $\begin{array}{c}\text { 10YR7/3- } \\
7 / 4\end{array}$ & $\begin{array}{l}\text { Very pale } \\
\text { brown }\end{array}$ & Silt Loam & Friable & $\begin{array}{l}\text { Subangular, } \\
\text { fine }\end{array}$ & Weak & $\begin{array}{c}\text { Rootlets } 15 \% \text {, subangular limestone } \\
\text { gravels and pebbles } 20-30 \% \text {, no large } \\
\text { cobbles of limestone, prominent } \\
\text { burrows with strat } 2 / 3 \text { matrix, large } \\
\text { chamber/den or burrow } 38 \times 44 \mathrm{~cm} \text { in } \\
\text { size, rabdotus } 10 \% \text {, rootlets in clustered } \\
\text { burrows } \\
\end{array}$ & Unobserved & \\
\hline
\end{tabular}




\begin{tabular}{|c|c|c|c|c|c|c|c|c|c|c|}
\hline BHT & $\begin{array}{l}\text { Depth } \\
\text { (cmbs) }\end{array}$ & Munsell* & Soil Color* & $\begin{array}{c}\text { Soil } \\
\text { Texture }\end{array}$ & Consistency & $\begin{array}{c}\text { Structure } \\
\text { Type }\end{array}$ & Grade & Inclusions & $\begin{array}{c}\text { Lower } \\
\text { Boundary }\end{array}$ & Comments \\
\hline \multirow{6}{*}{ ВНT09 } & $0-14$ & 10YR4/2 & $\begin{array}{l}\text { Dark grayish } \\
\text { brown }\end{array}$ & Silt Loam & $\begin{array}{l}\text { Loose to } \\
\text { Friable }\end{array}$ & Crumb, fine & Weak & $\begin{array}{l}\text { Roots } 5 \% \text {, rootlets } 20 \% \text {, rabdotus } 10 \% \text {, } \\
\text { worm burrows } 5 \% \text {, pinholes } 5-10 \%\end{array}$ & $\begin{array}{c}\text { Clear, slightly } \\
\text { wavy }\end{array}$ & $\begin{array}{c}\text { O horizon (decomposing vegetation), Base at } \\
\text { Strat } 1 \text { = Fist size FCR (limestone) }\end{array}$ \\
\hline & $14-37$ & 10YR4/3 & Brown & Silt Loam & Friable & $\begin{array}{c}\text { crumb to } \\
\text { subangular, } \\
\text { fine to medium }\end{array}$ & weak & $\begin{array}{c}\text { Roots } 5 \% \text {, rootlets } 20 \% \text {, rabdotus } 5 \% \text {, } \\
\text { subangular limestone pebbles } 5-10 \% \text {, } \\
\text { worm } 5 \% \text {, pinholes } 10 \%\end{array}$ & $\begin{array}{l}\text { Gradual - } \\
\text { slopes to N }\end{array}$ & Artifact \\
\hline & $37-56$ & $\begin{array}{c}\text { 10YR5/3- } \\
5 / 4\end{array}$ & Brown & Silt Loam & Friable & $\begin{array}{l}\text { Subangular, } \\
\text { fine to medium }\end{array}$ & $\begin{array}{l}\text { Weak to } \\
\text { moderate }\end{array}$ & $\begin{array}{c}\text { Roots } 5-10 \% \text {, rootlets } 15-10 \% \text {, rabdotus } \\
10 \% \text {, worms 3-5\%, pinholes 3-5\%, } \\
\text { subangular limestone pebbles (5-10\%) }\end{array}$ & $\begin{array}{l}\text { Gradual, } \\
\text { slightly wavy }\end{array}$ & \\
\hline & $56-78$ & 10YR6/3 & Pale brown & Silt Loam & $\begin{array}{l}\text { Loose to } \\
\text { Friable }\end{array}$ & $\begin{array}{l}\text { Crumb to } \\
\text { subangular, } \\
\text { fine }\end{array}$ & Weak & $\begin{array}{c}\text { Roots } 3 \% \text {, rootlets } 10-15 \% \text {, rabdotus } \\
5 \% \text {, heliodiscus } 1-2 \% \text {, pinholes } 5-10 \% \text {, } \\
\text { worm burrows }<3 \% \text {, white filaments } \\
<5 \%\end{array}$ & $\begin{array}{l}\text { Clear, slightly } \\
\text { irregular }\end{array}$ & $\begin{array}{l}\text { Bottom of Strat 4: } 1 \text { debitage specimen in situ } \\
\text { in west wall, this may be a transition strat }\end{array}$ \\
\hline & $78-141$ & $\begin{array}{l}\text { 10YR6/4- } \\
7 / 4\end{array}$ & $\begin{array}{l}\text { Light } \\
\text { yellowish } \\
\text { brown }\end{array}$ & Silt Loam & Friable & $\begin{array}{l}\text { Subangular, } \\
\text { fine to medium }\end{array}$ & $\begin{array}{l}\text { Weak to } \\
\text { moderate }\end{array}$ & $\begin{array}{c}\text { Rootlets } 10 \% \text {, pinholes } 5 \% \text {, roots }<1 \% \text {, } \\
\text { no earth worms, subangular limestone } \\
\text { pebbles ( } 10-15 \%) \text {, gravels } 5-10 \% \text {, snail } \\
\text { fragments } 5 \%\end{array}$ & $\begin{array}{l}\text { Gradual, } \\
\text { smooth }\end{array}$ & $\begin{array}{l}\text { No cultural material, small burrows } 2 \% \text { infilled } \\
\text { with strat } 3 \text { or } 4 \text { matrix }\end{array}$ \\
\hline & $\begin{array}{l}141- \\
176+\end{array}$ & 10YR8/4 & $\begin{array}{l}\text { Very pale } \\
\text { brown }\end{array}$ & Silt Loam & $\begin{array}{l}\text { Friable to } \\
\text { Slightly firm }\end{array}$ & $\begin{array}{l}\text { subangular to } \\
\text { angular, } \\
\text { medium }\end{array}$ & moderate & $\begin{array}{l}\text { Rootlets } 5 \% \text {, pinholes } 3 \% \text {, white } \\
\text { filaments } 5 \% \text {, worm burrows } 3 \% \text {, No } \\
\text { pebbles or rabdotus }\end{array}$ & Unobserved & No Cultural material \\
\hline \multirow{5}{*}{ BHT10 } & $0-22$ & 10YR3/2 & $\begin{array}{l}\text { Very dark } \\
\text { grayish } \\
\text { brown }\end{array}$ & Silt Loam & Loose & Crumb, fine & Weak & $\begin{array}{l}\text { Roots } 3 \% \text {, rootlets } 15-20 \% \text {, pinholes } \\
5 \% \text {, worm burrows } 5 \% \text {, rabdotus } 5-10 \%\end{array}$ & $\begin{array}{l}\text { Clear, slightly } \\
\text { wavy }\end{array}$ & Partially decomposed vegetation O horizon \\
\hline & $22-54$ & $\begin{array}{l}\text { 10YR } 4 / 2- \\
4 / 3\end{array}$ & $\begin{array}{l}\text { Dark grayish } \\
\text { brown }\end{array}$ & Silt Loam & $\begin{array}{l}\text { Loose to } \\
\text { Friable }\end{array}$ & $\begin{array}{l}\text { Crumb to } \\
\text { subangular, } \\
\text { fine }\end{array}$ & Weak & $\begin{array}{l}\text { Roots } 10 \% \text {, rootlets } 20 \% \text {, pinholes } 5- \\
10 \% \text {, worm burrows } 5 \% \text {, rabdotus } 3-5 \%\end{array}$ & $\begin{array}{l}\text { Gradual, } \\
\text { smooth }\end{array}$ & Cultural Material: 1 FCR $39-42$ \\
\hline & $54-122$ & $\begin{array}{c}\text { 10YR5/3- } \\
5 / 4\end{array}$ & Brown & Silt Loam & Friable & $\begin{array}{l}\text { Subangular, } \\
\text { fine to medium }\end{array}$ & Weak & $\begin{array}{l}\text { Root } 5 \% \text {, Rootlets } 20 \% \text {, worm burrows } \\
10 \% \text {, rabdotus } 5 \% \text {, pinholes } 20 \% \text {, white } \\
\text { filaments } 10-15 \%\end{array}$ & $\begin{array}{l}\text { Gradual, } \\
\text { smooth }\end{array}$ & FCR fragment $103 \mathrm{cmbs}$, one FCR $76 \mathrm{cmbs}$ \\
\hline & $122-159$ & $\begin{array}{l}\text { 10YR5/4- } \\
6 / 4\end{array}$ & $\begin{array}{l}\text { Yellowish } \\
\text { brown }\end{array}$ & Silt Loam & Friable & $\begin{array}{l}\text { subangular to } \\
\text { angular, } \\
\text { medium }\end{array}$ & moderate & $\begin{array}{c}\text { Root }<1 \% \text {, rootlets }<1 \%, \text { Rabdotus } 5 \% \text {, } \\
\text { pinhole }<1 \% \text {, worm burrows } 5 \% \text {, white } \\
\text { filaments }<10 \%\end{array}$ & Clear, smooth & One FCR at $139 \mathrm{cmbs}$ \\
\hline & $159-185$ & 10YR7/3 & $\begin{array}{l}\text { Very pale } \\
\text { brown }\end{array}$ & Silt Loam & $\begin{array}{l}\text { Loose to } \\
\text { Friable }\end{array}$ & $\begin{array}{l}\text { subangular to } \\
\text { angular, } \\
\text { medium }\end{array}$ & moderate & $\begin{array}{c}\text { Limestone pebble subangular }<2 \% \text {, } \\
\text { snail fragments } 5 \% \text {, filaments }<5 \% \text {, } \\
\text { heliodiscus }\end{array}$ & Unobserved & Single FCR at $179 \mathrm{cmbs}$ \\
\hline
\end{tabular}




\begin{tabular}{|c|c|c|c|c|c|c|c|c|c|c|}
\hline BHT & $\begin{array}{l}\text { Depth } \\
\text { (cmbs) }\end{array}$ & Munsell* & Soil Color* & $\begin{array}{c}\text { Soil } \\
\text { Texture }\end{array}$ & Consistency & $\begin{array}{l}\text { Structure } \\
\text { Type }\end{array}$ & Grade & Inclusions & $\begin{array}{l}\text { Lower } \\
\text { Boundary }\end{array}$ & Comments \\
\hline \multirow{6}{*}{ BHT11 } & $0-9$ & $10 Y 3 / 2$ & $\begin{array}{l}\text { Very dark } \\
\text { grayish } \\
\text { brown }\end{array}$ & Loam & Loose & Crumb, fine & Weak & snail rabdotus $5 \%$ & Gradual, wavy & Decomposing vegetation O horizon \\
\hline & 9-35 & $\begin{array}{l}\text { 10YR } 4 / 2- \\
4 / 3\end{array}$ & $\begin{array}{l}\text { Dark grayish } \\
\text { brown }\end{array}$ & Silt Loam & Friable & $\begin{array}{l}\text { Subangular, } \\
\text { fine }\end{array}$ & weak & $\begin{array}{c}\text { Root } 5 \% \text {, Rootlets } 20 \% \text {, rabdotus } 15 \% \text {, } \\
\text { heliodiscus } 3 \% \text {, pinholes } 15 \% \text {, worm } \\
\text { burrows } 5-10 \% \text {, roots are clustered at } \\
\text { base of strat } \\
\end{array}$ & $\begin{array}{l}\text { Clear, slightly } \\
\text { wavy }\end{array}$ & \\
\hline & $35-51$ & $\begin{array}{l}\text { 10YR } 4 / 2- \\
4 / 3\end{array}$ & $\begin{array}{l}\text { Dark grayish } \\
\text { brown }\end{array}$ & Silt Loam & Friable & $\begin{array}{l}\text { Subangular, } \\
\text { medium }\end{array}$ & $\begin{array}{l}\text { Weak to } \\
\text { moderate }\end{array}$ & $\begin{array}{c}\text { Roots 3-5\%, rootlets } 15 \% \text {, pinholes } \\
15 \% \text {, worm burrows } 5 \% \text {, white filaments } \\
5-10 \% \text { dendritic, rabdotus } 5 \% \text { fragments } \\
15-20 \% \text {, subangular pebbles }<1 \% \\
\text { transitional? }\end{array}$ & $\begin{array}{l}\text { Clear, slightly } \\
\text { wavy }\end{array}$ & \\
\hline & $51-81$ & 10YR5/3 & Brown & Silt Loam & Friable & $\begin{array}{l}\text { subangular to } \\
\text { angular, } \\
\text { medium }\end{array}$ & moderate & $\begin{array}{c}\text { Roots } 3 \% \text {, rootlets } 10 \% \text {, worm burrows } \\
3-5 \% \text {, pinholes } 10-15 \% \text {, white filaments } \\
5-10 \% \text { dendritic, rabdotus } 3-5 \% \text {, snail } \\
\text { fragments } 5 \% \text {, unidentified snail }<1 \% \\
\end{array}$ & $\begin{array}{l}\text { Gradual, } \\
\text { slightly wavy }\end{array}$ & \\
\hline & $81-243$ & 10YR $6 / 3$ & Pale brown & Silt Loam & Friable & $\begin{array}{l}\text { Subangular, } \\
\text { medium }\end{array}$ & moderate & $\begin{array}{l}\text { Roots } 2 \% \text {, rootlets } 5 \% \text {, pinholes } 5-10 \% \text {, } \\
\text { worm burrows }<3 \% \text {, white filaments } \\
<5 \% \text {, rabdotus } 3 \% \text {, snail fragments } 10 \%\end{array}$ & $\begin{array}{l}\text { Gradual, } \\
\text { smooth }\end{array}$ & $\begin{array}{c}\text { Lenses of } 10 Y R \text { R } 4 / 2 \text { - silt loam, friable, } \\
\text { subangular, fine, weak, rootlets } 3 \% \text {, abrupt } \\
\text { sloping eastward, variable thickness, averaging } \\
3 \mathrm{cmbs} \text {, one burned rock at } 121 \mathrm{cmbs} \text {, ranged } \\
\text { from } 89 \mathrm{cmbs} \text { at } \mathrm{W} \text { end to } 144 \text { on east end and } \\
\text { dives to floor stops } 1 / 3 \text { of way to east end of } \\
\text { trench }\end{array}$ \\
\hline & $\begin{array}{l}243- \\
244+\end{array}$ & $\begin{array}{c}\text { 10YR6/4- } \\
7 / 4\end{array}$ & $\begin{array}{l}\text { Light } \\
\text { yellowish } \\
\text { brown }\end{array}$ & Silt Loam & Firm & $\begin{array}{l}\text { Subangular, } \\
\text { coarse }\end{array}$ & moderate & $\begin{array}{c}\text { pinholes } 10 \% \text {, worm burrows }<3 \% \text {, } \\
\text { white filaments (CaCO3) } 5-10 \% \\
\text { increases (1-3mm), rabdotus 3-5\%, } \\
\text { snail fragments } 5 \%\end{array}$ & Unobserved & No cultural material, slightly inundated \\
\hline \multirow{6}{*}{ BHT12 } & $0-11$ & 10YRY3/2 & $\begin{array}{l}\text { Very dark } \\
\text { grayish } \\
\text { brown }\end{array}$ & Loam & Loose & Crumb, fine & Weak & snail rabdotus $5 \%$ & Gradual, wavy & Decomposing vegetation O horizon \\
\hline & $11-39$ & $\begin{array}{l}\text { 10YR } 4 / 2- \\
4 / 3\end{array}$ & $\begin{array}{l}\text { Dark grayish } \\
\text { brown }\end{array}$ & Silt Loam & Friable & $\begin{array}{l}\text { Subangular, } \\
\text { fine }\end{array}$ & weak & $\begin{array}{c}\text { Root } 5 \% \text {, Rootlets } 20 \% \text {, rabdotus } 15 \% \text {, } \\
\text { heliodiscus } 3 \% \text {, pinholes } 15 \% \text {, worm } \\
\text { burrows } 5-10 \% \text {, roots are clustered at } \\
\text { base of strat } \\
\end{array}$ & $\begin{array}{l}\text { Clear, slightly } \\
\text { wavy }\end{array}$ & \\
\hline & $39-54$ & $\begin{array}{l}\text { 10YR } 4 / 2- \\
4 / 3\end{array}$ & $\begin{array}{l}\text { Dark grayish } \\
\text { brown }\end{array}$ & Silt Loam & Friable & $\begin{array}{l}\text { Subangular, } \\
\text { medium }\end{array}$ & $\begin{array}{l}\text { Weak to } \\
\text { moderate }\end{array}$ & $\begin{array}{c}\text { Roots 3-5\%, rootlets } 15 \% \text {, pinholes } \\
15 \% \text {, worm burrows } 5 \% \text {, white filaments } \\
5-10 \% \text { dendritic, rabdotus } 5 \% \text { fragments } \\
15-20 \% \text {, subangular pebbles }<1 \% \\
\text { transitional? }\end{array}$ & $\begin{array}{l}\text { Clear, slightly } \\
\text { wavy }\end{array}$ & \\
\hline & $54-73$ & 10YR5/3 & Brown & Silt Loam & Friable & $\begin{array}{l}\text { subangular to } \\
\text { angular, } \\
\text { medium }\end{array}$ & moderate & $\begin{array}{c}\text { Roots } 3 \% \text {, rootlets } 10 \% \text {, worm burrows } \\
3-5 \% \text {, pinholes } 10-15 \% \text {, white filaments } \\
5-10 \% \text { dendritic, rabdotus } 3-5 \% \text {, snail } \\
\text { fragments } 5 \% \text {, unidentified snail }<1 \% \\
\end{array}$ & $\begin{array}{l}\text { Gradual, } \\
\text { slightly wavy }\end{array}$ & insect burrows infilled with strat 5 matrix \\
\hline & $73-126$ & 10YR5/3 & Brown & Silt Loam & Friable & $\begin{array}{l}\text { subangular to } \\
\text { angular, } \\
\text { medium }\end{array}$ & moderate & $\begin{array}{l}\text { pinholes } 3 \% \text {, worm burrows }<3 \% \text {, white } \\
\text { filaments }<3 \% \text {, snail fragments } 5 \%\end{array}$ & Clear, smooth & Lenses prominent \\
\hline & $126-156$ & $\begin{array}{c}\text { 10YR6/3- } \\
6 / 4\end{array}$ & Pale brown & Silt Loam & $\begin{array}{l}\text { Loose to } \\
\text { Friable }\end{array}$ & $\begin{array}{l}\text { crumb to } \\
\text { subangular, } \\
\text { fine to medium }\end{array}$ & Weak & $\begin{array}{c}\text { rootlets } 5 \% \text {, snail rabdotus } 3 \% \text {, root } \\
\text { burrows } 1 \% \text {, white filaments } 1 \% \text { (very } \\
\text { diffuse) }\end{array}$ & Unobserved & $\begin{array}{l}\text { Gritty matrix, became denser and none } \\
\text { compact around } 200 \mathrm{cmbs} \text { very similar to basal } \\
\text { strat BHT11, Lens } 10 Y R 4 / 2-5 / 2 \text { sloping to NE, } \\
\text { discontinuous horizon in all directions }\end{array}$ \\
\hline
\end{tabular}


Interim Report: Archaeological Investigations at 41GU177 on the Guadalupe River

\begin{tabular}{|c|c|c|c|c|c|c|c|c|c|c|}
\hline BHT & $\begin{array}{l}\text { Depth } \\
\text { (cmbs) }\end{array}$ & MunselI* & Soil Color* & $\begin{array}{c}\text { Soil } \\
\text { Texture }\end{array}$ & Consistency & $\begin{array}{l}\text { Structure } \\
\text { Type }\end{array}$ & Grade & Inclusions & $\begin{array}{c}\text { Lower } \\
\text { Boundary }\end{array}$ & Comments \\
\hline \multirow{4}{*}{ BHT13 } & $0-9$ & $\begin{array}{c}\text { 10YR 3/1- } \\
3 / 2\end{array}$ & $\begin{array}{l}\text { very dark } \\
\text { grayish } \\
\text { brown }\end{array}$ & Loam & Loose & Crumb, fine & Weak & snail rabdotus $5 \%$ & Gradual, wavy & Decomposing vegetation $\mathrm{O}$ horizon \\
\hline & $9-32$ & 10YR 4/3 & $\begin{array}{l}\text { dark grayish } \\
\text { brown }\end{array}$ & $\begin{array}{l}\text { Silty clay } \\
\text { loam }\end{array}$ & $\begin{array}{l}\text { Loose to } \\
\text { Friable }\end{array}$ & $\begin{array}{l}\text { Crumb to } \\
\text { Subangular }\end{array}$ & Weak & $\begin{array}{l}5 \% \text { Roots, } 20 \% \text { Rootlets, } 10 \% \text { Worm } \\
\text { casts, } 10 \% \text { pin holes, insect burrows, } \\
10 \% \text { limestone pebbles (subangular to } \\
\text { sub rounded) }\end{array}$ & $\begin{array}{l}\text { Clear, Slightly } \\
\text { wavy due to } \\
\text { bioturbation }\end{array}$ & Some Rabdotus (3-5\%) \\
\hline & $32-59$ & $\begin{array}{c}10 Y R \text { 6/4- } \\
6 / 6\end{array}$ & Pale brown & Silt loam & Friable & $\begin{array}{l}\text { Crumb to } \\
\text { Subangular }\end{array}$ & Weak & $\begin{array}{c}3 \% \text { roots, } 10 \% \text { rootlets, } 2 \% \text { small } \\
\text { nodules }(3-4 \mathrm{~mm}) \text { of } \mathrm{CaCO}_{3}, 5 \% \text { pin } \\
\text { holes, } 5 \% \text { worm casts, } 5 \% \text { krotovina } \\
\text { infilled with Strat II }\end{array}$ & $\begin{array}{l}\text { Gradual, } \\
\text { smooth }\end{array}$ & Transitional \\
\hline & $59-253$ & $\begin{array}{c}\text { 10YR } 7 / 4- \\
7 / 6\end{array}$ & $\begin{array}{l}\text { Very pale } \\
\text { brown to } \\
\text { yellow } \\
\text { brown }\end{array}$ & Silt loam & $\begin{array}{l}\text { Friable to } \\
\text { Firm }\end{array}$ & $\begin{array}{l}\text { Subangular to } \\
\text { angular }\end{array}$ & Moderate & $\begin{array}{c}5 \% \text { rootlets decreasing with depth, } 3-5 \% \\
\mathrm{CaCO}_{3} \text { nodules }(2-3 \mathrm{~mm}), 5 \% \text { pin holes, } \\
3 \% \text { worm burrows }\end{array}$ & Unobserved & Hue is lighter with depth \\
\hline
\end{tabular}




\section{APPENDIX C}

\section{TEST UNIT SPECIMEN INVENTORY}





\begin{tabular}{|c|c|c|c|c|c|c|c|c|c|c|}
\hline Unit & Level & \begin{tabular}{|l|} 
Depth \\
(cmbs)
\end{tabular} & Artifact Type & $\begin{array}{c}\text { Artifact } \\
\text { Description }\end{array}$ & Material & \begin{tabular}{|c|}
$\begin{array}{c}\text { Artifact } \\
\text { No. }\end{array}$ \\
\end{tabular} & $\begin{array}{c}\text { Weight } \\
\text { (g) }\end{array}$ & Recorders & Date & Comments \\
\hline 1 & 1 & $0-10$ & Debitage & Primary & Lithic & 2 & 7.28 & $\mathrm{JL}$ & $10 / 13 / 2016$ & Shatter \\
\hline 1 & 1 & $0-10$ & Debitage & Tertiary & Lithic & 14 & 14.4 & $\mathrm{JL}$ & $10 / 13 / 2016$ & Shatter \\
\hline 1 & 1 & $0-10$ & \begin{tabular}{|l} 
Faunal \\
Remains
\end{tabular} & Mussel Shell & Shell & 1 & 0.38 & $\mathrm{JL}$ & $10 / 12 / 2016$ & $\begin{array}{l}\text { Unmodified } \\
\text { fragment }\end{array}$ \\
\hline 1 & 1 & 3 & Groundstone & Mano & Lithic & 1 & 304.81 & $\mathrm{JL}$ & $10 / 12 / 2016$ & $\begin{array}{l}\text { Roughly half } \\
\text { complete }\end{array}$ \\
\hline 1 & 2 & $10-20$ & Biface & $\begin{array}{l}\text { Early-stage } \\
\text { biface }\end{array}$ & Lithic & 1 & 61.97 & $\mathrm{JL}$ & $10 / 13 / 2016$ & Thick and Crude \\
\hline 1 & 2 & $10-20$ & Debitage & Primary & Lithic & 7 & 8.19 & $\mathrm{JL}$ & 10/13/2016 & \\
\hline 1 & 2 & $10-20$ & Debitage & Secondary & Lithic & 15 & 35.9 & $\mathrm{JL}$ & $10 / 13 / 2016$ & $\begin{array}{l}4 \text { Bifacial thinning } \\
\text { flakes }\end{array}$ \\
\hline 1 & 2 & $10-20$ & Debitage & Tertiary & Lithic & 71 & 47.54 & $\mathrm{JL}$ & $10 / 13 / 2016$ & $\begin{array}{l}56 \text { Bifacial } \\
\text { thinning flakes }\end{array}$ \\
\hline 1 & 2 & $10-20$ & \begin{tabular}{|l} 
Faunal \\
Remains
\end{tabular} & Burned Bone & & 1 & 0.17 & $\mathrm{JL}$ & $10 / 13 / 2016$ & \\
\hline 1 & 3 & $20-30$ & Blade & Blade & & 1 & 9.08 & $\mathrm{JL}$ & $10 / 12 / 2016$ & \\
\hline 1 & 3 & $20-30$ & Burned Rock & Burned Rock & Lithic & 4 & 18.26 & $\mathrm{JL}$ & $10 / 12 / 2016$ & \\
\hline 1 & 3 & $20-30$ & Debitage & Primary & Lithic & 12 & 23.63 & $\mathrm{JL}$ & $10 / 12 / 2016$ & \\
\hline 1 & 3 & $20-30$ & Debitage & Secondary & Lithic & 10 & 14.05 & $\mathrm{JL}$ & $10 / 12 / 2016$ & $\begin{array}{l}7 \text { Bifacial thinning } \\
\text { flakes }\end{array}$ \\
\hline 1 & 3 & $20-30$ & Debitage & Tertiary & Lithic & 38 & 28.86 & $\mathrm{JL}$ & $10 / 12 / 2016$ & $\begin{array}{l}30 \text { Bifacial } \\
\text { thinning flakes }\end{array}$ \\
\hline 1 & 4 & $30-40$ & Debitage & Primary & Lithic & 6 & 62.4 & $\mathrm{JL}$ & $10 / 12 / 2016$ & \\
\hline 1 & 4 & $30-40$ & Debitage & Secondary & Lithic & 10 & 26.3 & $\mathrm{JL}$ & $10 / 12 / 2016$ & $\begin{array}{l}7 \text { Bifacial thinning } \\
\text { flakes }\end{array}$ \\
\hline 1 & 4 & $30-40$ & Debitage & Tertiary & Lithic & 53 & 54.92 & $\mathrm{JL}$ & $10 / 12 / 2016$ & $\begin{array}{l}48 \text { Bifacial } \\
\text { thinning flakes }\end{array}$ \\
\hline 1 & 4 & $30-40$ & \begin{tabular}{|l|} 
Burned Rock \\
\end{tabular} & Burned Rock & Lithic & 6 & 14.5 & $\mathrm{JL}$ & $10 / 12 / 2016$ & \\
\hline 1 & 4 & $30-40$ & \begin{tabular}{|l} 
Faunal \\
Remains
\end{tabular} & Mussel Shell & Shell & 2 & 0.69 & $\mathrm{JL}$ & $10 / 12 / 2016$ & Unmodified \\
\hline 1 & 4 & $30-40$ & \begin{tabular}{|l} 
Projectile \\
Point
\end{tabular} & $\begin{array}{l}\text { Untyped Arrow } \\
\text { Point }\end{array}$ & Lithic & 1 & 2.15 & $\mathrm{JL}$ & $10 / 12 / 2016$ & $\begin{array}{l}\text { Missing distal tip } \\
\text { and base }\end{array}$ \\
\hline 1 & 5 & 50 & Charcoal & Charcoal & & 4 & 0.15 & $\mathrm{JL}$ & $10 / 13 / 2016$ & \\
\hline 1 & 5 & $40-50$ & \begin{tabular}{|l} 
Faunal \\
Remains
\end{tabular} & Bone & & 3 & 4.63 & $\mathrm{JL}$ & $10 / 13 / 2016$ & 1 Burned fragment \\
\hline 1 & 5 & $40-50$ & Debitage & Primary & Lithic & 2 & 9.25 & $\mathrm{JL}$ & 10/13/2016 & Shatter \\
\hline 1 & 5 & $40-50$ & Debitage & Secondary & Lithic & 11 & 54.3 & $\mathrm{JL}$ & $10 / 13 / 2016$ & $\begin{array}{l}2 \text { Bifacial thinning } \\
\text { flakes }\end{array}$ \\
\hline 1 & 5 & $40-50$ & Debitage & Tertiary & Lithic & 37 & 37.57 & $\mathrm{JL}$ & $10 / 13 / 2016$ & $\begin{array}{l}23 \text { Bifacial } \\
\text { thinning flakes }\end{array}$ \\
\hline 1 & 5 & $40-50$ & Utilized Flake & Utilized Flake & Lithic & 1 & 1.15 & $\mathrm{JL}$ & $10 / 13 / 2016$ & \\
\hline 1 & 6 & $50-60$ & Biface & \begin{tabular}{|l|} 
Bifacial \\
Fragment \\
\end{tabular} & Lithic & 1 & 53.15 & $\mathrm{JL}$ & $10 / 13 / 2016$ & \\
\hline 1 & 6 & $50-60$ & Core & Core & Lithic & 1 & 133.85 & $\mathrm{JL}$ & $10 / 13 / 2016$ & \\
\hline 1 & 6 & $50-60$ & Debitage & Primary & Lithic & 18 & 29.95 & $\mathrm{JL}$ & 10/13/2016 & \\
\hline 1 & 6 & $50-60$ & Debitage & Secondary & Lithic & 24 & 113.78 & $\mathrm{JL}$ & $10 / 13 / 2016$ & $\begin{array}{l}8 \text { Bifacial thinning } \\
\text { flakes }\end{array}$ \\
\hline 1 & 6 & $50-60$ & Debitage & Tertiary & Lithic & 100 & 84.23 & $\mathrm{JL}$ & 10/13/2016 & $\begin{array}{l}76 \text { Bifacial } \\
\text { thinning flakes }\end{array}$ \\
\hline 1 & 6 & $50-60$ & \begin{tabular}{|l} 
Faunal \\
Remains
\end{tabular} & Bone & & 5 & 3.33 & $\mathrm{JL}$ & $10 / 13 / 2016$ & \\
\hline 1 & 6 & $50-60$ & $\begin{array}{l}\text { Tested } \\
\text { Cobble }\end{array}$ & Tested Cobble & Lithic & 1 & 163.13 & $\mathrm{JL}$ & $10 / 13 / 2016$ & \\
\hline 1 & 7 & $60-70$ & Burned Rock & Burned Rock & Lithic & 1 & 1.3 & $\mathrm{JL}$ & 10/12/2016 & \\
\hline 1 & 7 & $60-70$ & Debitage & Primary & Lithic & 1 & 0.67 & $\mathrm{JL}$ & $10 / 12 / 2016$ & \\
\hline 1 & 7 & $60-70$ & Debitage & Secondary & Lithic & 11 & 11.22 & $\mathrm{JL}$ & $10 / 12 / 2016$ & $\begin{array}{l}7 \text { Bifacial thinning } \\
\text { flakes }\end{array}$ \\
\hline 1 & 7 & $60-70$ & Debitage & Tertiary & Lithic & 60 & 64.2 & $\mathrm{JL}$ & $10 / 12 / 2016$ & $\begin{array}{l}48 \text { Bifacial } \\
\text { thinning flakes }\end{array}$ \\
\hline 1 & 7 & $60-70$ & \begin{tabular}{|l} 
Faunal \\
Remains
\end{tabular} & Bone & & 6 & 7.57 & $\mathrm{JL}$ & $10 / 12 / 2016$ & \\
\hline 1 & 7 & $60-70$ & $\begin{array}{l}\text { Projectile } \\
\text { Point }\end{array}$ & Scallorn Point & Lithic & 1 & 1.25 & $\mathrm{JL}$ & $10 / 12 / 2016$ & $\begin{array}{l}\text { Missing distal tip; } \\
\text { corner-notched } \\
\text { broad stemmed } \\
\text { variant }\end{array}$ \\
\hline
\end{tabular}




\begin{tabular}{|c|c|c|c|c|c|c|c|c|c|c|}
\hline Unit & Level & \begin{tabular}{|l|} 
Depth \\
(cmbs)
\end{tabular} & Artifact Type & $\begin{array}{c}\text { Artifact } \\
\text { Description }\end{array}$ & Material & $\begin{array}{c}\text { Artifact } \\
\text { No. }\end{array}$ & $\begin{array}{c}\text { Weight } \\
\text { (g) }\end{array}$ & Recorders & Date & Comments \\
\hline 1 & 8 & $70-80$ & Debitage & Primary & Lithic & 8 & 36.06 & $\mathrm{JL}$ & $10 / 14 / 2016$ & $\begin{array}{l}2 \text { Bifacial thinning } \\
\text { flakes }\end{array}$ \\
\hline 1 & 8 & $70-80$ & Debitage & Secondary & Lithic & 13 & 59.03 & $\mathrm{JL}$ & $10 / 14 / 2016$ & $\begin{array}{l}6 \text { Bifacial thinning } \\
\text { flakes }\end{array}$ \\
\hline 1 & 8 & $70-80$ & Debitage & Tertiary & Lithic & 64 & 96.89 & $\mathrm{JL}$ & $10 / 14 / 2016$ & $\begin{array}{l}49 \text { Bifacial } \\
\text { thinning flakes }\end{array}$ \\
\hline 1 & 8 & $70-80$ & \begin{tabular}{|l} 
Faunal \\
Remains \\
\end{tabular} & Bone & & 13 & 6.48 & $\mathrm{JL}$ & $10 / 14 / 2016$ & 1 Burned fragmen \\
\hline 1 & 8 & $70-80$ & \begin{tabular}{|l|} 
Faunal \\
Remains \\
\end{tabular} & Mussel Shell & Shell & 2 & 33.36 & $\mathrm{JL}$ & $10 / 14 / 2016$ & \begin{tabular}{|l|} 
Unmodified \\
fragments
\end{tabular} \\
\hline 1 & 8 & $70-80$ & $\begin{array}{l}\text { Organic } \\
\text { remains }\end{array}$ & $\begin{array}{l}\text { Burned Nut } \\
\text { Shell }\end{array}$ & & 2 & 0.27 & $\mathrm{JL}$ & $10 / 14 / 2016$ & \\
\hline 1 & 8 & $70-80$ & Utilized Flake & Utilized Flake & Lithic & 1 & 6.52 & $\mathrm{JL}$ & $10 / 14 / 2016$ & \\
\hline 1 & 9 & $80-90$ & Burned Rock & Burned Rock & Lithic & 3 & 28.34 & $\mathrm{JL}$ & $10 / 14 / 2016$ & \\
\hline 1 & 9 & $80-90$ & Core & Core & Lithic & 1 & 68.3 & $\mathrm{JL}$ & $10 / 14 / 2016$ & $\begin{array}{l}\text { Broken into } 3 \\
\text { pieces }\end{array}$ \\
\hline 1 & 9 & $80-90$ & Debitage & Primary & Lithic & 3 & 28.58 & $\mathrm{JL}$ & $10 / 14 / 2016$ & $\begin{array}{l}1 \text { Bifacial thinning } \\
\text { flake }\end{array}$ \\
\hline 1 & 9 & $80-90$ & Debitage & Secondary & Lithic & 4 & 30.54 & $\mathrm{JL}$ & $10 / 14 / 2016$ & $\begin{array}{l}1 \text { Bifacial thinning } \\
\text { flake }\end{array}$ \\
\hline 1 & 9 & $80-90$ & Debitage & Tertiary & Lithic & 24 & 47.94 & $\mathrm{JL}$ & $10 / 14 / 2016$ & $\begin{array}{l}20 \text { Bifacial } \\
\text { thinning flakes }\end{array}$ \\
\hline 1 & 9 & $80-90$ & \begin{tabular}{|l} 
Faunal \\
Remains
\end{tabular} & Bone & & 3 & 0.96 & $\mathrm{JL}$ & $10 / 14 / 2016$ & 1 Burned fragmen \\
\hline 1 & 9 & $80-90$ & \begin{tabular}{|l|} 
Faunal \\
Remains \\
\end{tabular} & Mussel Shell & Shell & 3 & 15.35 & $\mathrm{JL}$ & $10 / 14 / 2016$ & $\begin{array}{l}\text { Unmodified } \\
\text { fragments }\end{array}$ \\
\hline 1 & 10 & $90-100$ & Debitage & Primary & Lithic & 7 & 20.05 & $\mathrm{JL}$ & $10 / 12 / 2016$ & $\begin{array}{l}1 \text { Bifacial thinning } \\
\text { flake }\end{array}$ \\
\hline 1 & 10 & $90-100$ & Debitage & Secondary & Lithic & 10 & 36.96 & $\mathrm{JL}$ & $10 / 12 / 2016$ & $\begin{array}{l}7 \text { Bifacial thinning } \\
\text { flakes }\end{array}$ \\
\hline 1 & 10 & $90-100$ & Debitage & Tertiary & Lithic & 33 & 64 & $\mathrm{JL}$ & $10 / 12 / 2016$ & \begin{tabular}{|l|}
31 Bifacial \\
thinning flakes
\end{tabular} \\
\hline 1 & 10 & $90-100$ & \begin{tabular}{|l} 
Faunal \\
Remains \\
\end{tabular} & Bone & & 5 & 0.07 & $\mathrm{JL}$ & $10 / 12 / 2016$ & \\
\hline 1 & 11 & $\begin{array}{c}100- \\
110\end{array}$ & Debitage & Primary & Lithic & 1 & 0.91 & $\mathrm{JL}$ & $10 / 13 / 2016$ & \\
\hline 1 & 11 & $\begin{array}{c}100- \\
110 \\
\end{array}$ & Debitage & Secondary & Lithic & 7 & 20.15 & $\mathrm{JL}$ & $10 / 13 / 2016$ & $\begin{array}{l}3 \text { Bifacial thinning } \\
\text { flakes }\end{array}$ \\
\hline 1 & 11 & $\begin{array}{c}100- \\
110 \\
\end{array}$ & Debitage & Tertiary & Lithic & 33 & 35.1 & $\mathrm{JL}$ & $10 / 13 / 2016$ & $\begin{array}{l}25 \text { Bifacial } \\
\text { thinning flakes }\end{array}$ \\
\hline 1 & 11 & $\begin{array}{c}100- \\
110 \\
\end{array}$ & \begin{tabular}{|l} 
Faunal \\
Remains \\
\end{tabular} & Bone & & 8 & 1.57 & $\mathrm{JL}$ & $10 / 13 / 2016$ & \\
\hline 1 & 11 & $\begin{array}{c}100- \\
110\end{array}$ & \begin{tabular}{|l} 
Faunal \\
Remains
\end{tabular} & Mussel Shell & Shell & 3 & 6.32 & $\mathrm{JL}$ & $10 / 13 / 2016$ & $\begin{array}{l}\text { Unmodified } \\
\text { fragments }\end{array}$ \\
\hline 1 & 12 & $\begin{array}{c}110- \\
120\end{array}$ & Debitage & Primary & Lithic & 7 & 54.47 & $\mathrm{JL}$ & $10 / 14 / 2016$ & $\begin{array}{l}4 \text { Bifacial thinning } \\
\text { flakes }\end{array}$ \\
\hline 1 & 12 & $\begin{array}{c}110- \\
120 \\
\end{array}$ & Debitage & Secondary & Lithic & 6 & 39.54 & JL & $10 / 14 / 2016$ & $\begin{array}{l}4 \text { Bifacial thinning } \\
\text { flakes }\end{array}$ \\
\hline 1 & 12 & $\begin{array}{c}110- \\
120 \\
\end{array}$ & Debitage & Tertiary & Lithic & 15 & 8.52 & $\mathrm{JL}$ & $10 / 14 / 2016$ & \begin{tabular}{|l|l}
13 Bifacial \\
thinning flakes
\end{tabular} \\
\hline 1 & 12 & $\begin{array}{c}110- \\
120 \\
\end{array}$ & \begin{tabular}{|l} 
Faunal \\
Remains \\
\end{tabular} & Bone & & 12 & 8.31 & $\mathrm{JL}$ & $10 / 14 / 2016$ & \\
\hline 1 & 13 & $\begin{array}{c}120- \\
130 \\
\end{array}$ & Debitage & Primary & Lithic & 2 & 3.12 & $\mathrm{JL}$ & $10 / 13 / 2016$ & \\
\hline 1 & 13 & $\begin{array}{c}120- \\
130 \\
\end{array}$ & Debitage & Tertiary & Lithic & 6 & 5.9 & $\mathrm{JL}$ & $10 / 13 / 2016$ & $\begin{array}{l}5 \text { Bifacial thinning } \\
\text { flakes }\end{array}$ \\
\hline 1 & 13 & $\begin{array}{c}120- \\
130 \\
\end{array}$ & \begin{tabular}{|l} 
Faunal \\
Remains
\end{tabular} & Mussel Shell & Shell & 1 & 9.52 & $\mathrm{JL}$ & $10 / 13 / 2016$ & $\begin{array}{l}\text { Unmodified } \\
\text { fragments }\end{array}$ \\
\hline 1 & 14 & $\begin{array}{c}130- \\
140 \\
\end{array}$ & Debitage & Primary & Lithic & 4 & 82.57 & $\mathrm{JL}$ & $10 / 13 / 2016$ & \\
\hline 1 & 14 & $\begin{array}{c}130- \\
140\end{array}$ & Debitage & Secondary & Lithic & 5 & 110.35 & $\mathrm{JL}$ & $10 / 13 / 2016$ & $\begin{array}{l}2 \text { Bifacial thinning } \\
\text { flakes }\end{array}$ \\
\hline 1 & 14 & $\begin{array}{c}130- \\
140 \\
\end{array}$ & Debitage & Tertiary & Lithic & 17 & 19.68 & $\mathrm{JL}$ & $10 / 13 / 2016$ & $\begin{array}{l}16 \text { Bifacial } \\
\text { thinning flakes }\end{array}$ \\
\hline 1 & 14 & $\begin{array}{c}130- \\
140\end{array}$ & \begin{tabular}{|l} 
Faunal \\
Remains
\end{tabular} & Bone & & 14 & 5.83 & $\mathrm{JL}$ & $10 / 13 / 2016$ & \\
\hline
\end{tabular}




\begin{tabular}{|c|c|c|c|c|c|c|c|c|c|c|}
\hline Unit & Level & $\begin{array}{c}\text { Depth } \\
\text { (cmbs) }\end{array}$ & Artifact Type & $\begin{array}{c}\text { Artifact } \\
\text { Description }\end{array}$ & Material & \begin{tabular}{|c|}
$\begin{array}{c}\text { Artifact } \\
\text { No. }\end{array}$ \\
\end{tabular} & \begin{tabular}{|c|}
$\begin{array}{c}\text { Weight } \\
\text { (g) }\end{array}$ \\
\end{tabular} & Recorders & Date & Comments \\
\hline 1 & 15 & $\begin{array}{c}140- \\
150\end{array}$ & Debitage & Secondary & Lithic & 2 & 2.4 & $\mathrm{JL}$ & 10/13/2016 & \\
\hline 1 & 15 & $\begin{array}{c}140- \\
150\end{array}$ & Debitage & Tertiary & Lithic & 9 & 9.74 & $\mathrm{JL}$ & $10 / 13 / 2016$ & $\begin{array}{l}8 \text { Bifacial thinning } \\
\text { flakes }\end{array}$ \\
\hline 1 & 15 & $\begin{array}{c}140- \\
150 \\
\end{array}$ & \begin{tabular}{|l} 
Faunal \\
Remains \\
\end{tabular} & Bone & & 5 & 3.05 & $\mathrm{JL}$ & $10 / 13 / 2016$ & \\
\hline 1 & 15 & $\begin{array}{c}140- \\
150 \\
\end{array}$ & $\begin{array}{l}\text { Organic } \\
\text { remains }\end{array}$ & Burned Seed & & 2 & 0.04 & $\mathrm{JL}$ & $10 / 13 / 2016$ & \\
\hline 1 & 15 & $\begin{array}{c}140- \\
150\end{array}$ & $\begin{array}{l}\text { Projectile } \\
\text { Point }\end{array}$ & $\begin{array}{l}\text { Untyped Arrow } \\
\text { Point }\end{array}$ & Lithic & 1 & 0.25 & $\mathrm{JL}$ & $10 / 13 / 2016$ & $\begin{array}{l}\text { Serrated medial } \\
\text { arrow point } \\
\text { fragment }\end{array}$ \\
\hline 1 & 16 & $\begin{array}{l}150- \\
160\end{array}$ & $\begin{array}{l}\text { Faunal } \\
\text { Remains }\end{array}$ & Bone & & 5 & 15.75 & JU & 8/31/2017 & \\
\hline 1 & 16 & $\begin{array}{l}150- \\
160 \\
\end{array}$ & Debitage & Secondary & Lithic & 1 & 6.28 & JU & 8/31/2017 & $\begin{array}{l}1 \text { bifacial thinning } \\
\text { flake }\end{array}$ \\
\hline 1 & 16 & $\begin{array}{l}150- \\
160\end{array}$ & Debitage & Tertiary & Lithic & 2 & 2.75 & JU & $8 / 31 / 2017$ & $\begin{array}{l}1 \text { bifacial thinning } \\
\text { flake }\end{array}$ \\
\hline 1 & 17 & $\begin{array}{l}160- \\
170 \\
\end{array}$ & Debitage & Tertiary & Lithic & 4 & 5.98 & JU & 8/31/2017 & $\begin{array}{l}3 \text { bifacial thinning } \\
\text { flakes }\end{array}$ \\
\hline 1 & 6,7 & $56-70$ & Soil Sample & Matrix Sample & & & & & & 3 gal. bags \\
\hline 2 & 1 & $0-10$ & Debitage & Primary & Lithic & 1 & 10.76 & $\mathrm{JL}$ & $10 / 14 / 2016$ & \\
\hline 2 & 1 & $0-10$ & Debitage & Tertiary & Lithic & 16 & 11.48 & $\mathrm{JL}$ & $10 / 14 / 2016$ & \begin{tabular}{|l|}
14 Bifacial \\
thinning flakes
\end{tabular} \\
\hline 2 & 2 & $10-20$ & Debitage & Primary & Lithic & 1 & 89.07 & $\mathrm{JL}$ & 10/13/2016 & \\
\hline 2 & 2 & $10-20$ & Debitage & Secondary & Lithic & 6 & 34.9 & $\mathrm{JL}$ & $10 / 13 / 2016$ & $\begin{array}{l}4 \text { Bifacial thinning } \\
\text { flakes }\end{array}$ \\
\hline 2 & 2 & $10-20$ & Debitage & Tertiary & Lithic & 19 & 23.15 & $\mathrm{JL}$ & $10 / 13 / 2016$ & $\begin{array}{l}18 \text { Bifacial } \\
\text { thinning flakes }\end{array}$ \\
\hline 2 & 3 & $20-30$ & Debitage & Primary & Lithic & 2 & 19.64 & $\mathrm{JL}$ & $10 / 13 / 2016$ & \\
\hline 2 & 3 & $20-30$ & Debitage & Secondary & Lithic & 3 & 4.56 & $\mathrm{JL}$ & $10 / 13 / 2016$ & $\begin{array}{l}1 \text { Bifacial thinning } \\
\text { flake }\end{array}$ \\
\hline 2 & 3 & $20-30$ & Debitage & Tertiary & Lithic & 8 & 3.66 & $\mathrm{JL}$ & $10 / 13 / 2016$ & $\begin{array}{l}4 \text { Bifacial thinning } \\
\text { flakes }\end{array}$ \\
\hline 2 & 4 & $30-40$ & Debitage & Secondary & Lithic & 2 & 1.16 & $\mathrm{JL}$ & $10 / 14 / 2016$ & \\
\hline 2 & 4 & $30-40$ & Debitage & Tertiary & Lithic & 2 & 0.3 & $J \mathrm{~L}$ & $10 / 14 / 2016$ & $\begin{array}{l}2 \text { Bifacial thinning } \\
\text { flakes }\end{array}$ \\
\hline 2 & 5 & $40-50$ & Blade & Blade & & 1 & 22.17 & $\mathrm{JL}$ & 10/14/2016 & \\
\hline 2 & 5 & $40-50$ & Core & Core & Lithic & 1 & 44.26 & $\mathrm{JL}$ & \begin{tabular}{|l|}
$10 / 14 / 2016$ \\
\end{tabular} & \\
\hline 2 & 5 & $40-50$ & Debitage & Primary & Lithic & 21 & 154.45 & $\mathrm{JL}$ & $10 / 14 / 2016$ & $\begin{array}{l}1 \text { Bifacial thinning } \\
\text { flake }\end{array}$ \\
\hline 2 & 5 & $40-50$ & Debitage & Secondary & Lithic & 24 & 70.78 & $\mathrm{JL}$ & $10 / 14 / 2016$ & $\begin{array}{l}13 \text { Bifacial } \\
\text { thinning flakes }\end{array}$ \\
\hline 2 & 5 & $40-50$ & Debitage & Tertiary & Lithic & 88 & 76.77 & $\mathrm{JL}$ & $10 / 14 / 2016$ & $\begin{array}{l}70 \text { Bifacial } \\
\text { thinning flakes }\end{array}$ \\
\hline 2 & 6 & $50-60$ & Charcoal & Charcoal & & 4 & 0.27 & $\mathrm{JL}$ & $10 / 14 / 2016$ & \\
\hline 2 & 6 & $50-60$ & Debitage & Primary & Lithic & 23 & 115.08 & $\mathrm{JL}$ & $10 / 14 / 2016$ & $\begin{array}{l}5 \text { Bifacial thinning } \\
\text { flakes }\end{array}$ \\
\hline 2 & 6 & $50-60$ & Debitage & Secondary & Lithic & 28 & 211.09 & $\mathrm{JL}$ & $10 / 14 / 2016$ & \begin{tabular}{|l|}
14 Bifacial \\
thinning flakes
\end{tabular} \\
\hline 2 & 6 & $50-60$ & Debitage & Tertiary & Lithic & 149 & 119.02 & $\mathrm{JL}$ & $10 / 14 / 2016$ & $\begin{array}{l}126 \text { Bifacial } \\
\text { thinning flakes }\end{array}$ \\
\hline 2 & 6 & $50-60$ & $\begin{array}{l}\text { Projectile } \\
\text { Point }\end{array}$ & Scallorn Point & Lithic & 1 & 3.79 & JL & $10 / 14 / 2016$ & $\begin{array}{l}\text { Missing distal tip; } \\
\text { corner-notched } \\
\text { broad stemmed } \\
\text { variant; very large } \\
\text { for arrow point }\end{array}$ \\
\hline 2 & 7 & $60-70$ & Burned Rock & Burned Rock & Lithic & 21 & 270.5 & $\mathrm{JL}$ & 10/12/2016 & \\
\hline 2 & 7 & $60-70$ & Charcoal & Charcoal & & 6 & 0.71 & $\mathrm{JL}$ & 10/12/2016 & \\
\hline 2 & 7 & $60-70$ & Debitage & Primary & Lithic & 53 & 389.05 & $\mathrm{JL}$ & $10 / 12 / 2016$ & \begin{tabular}{|l|}
11 Bifacial \\
thinning flakes \\
\end{tabular} \\
\hline 2 & 7 & $60-70$ & Debitage & Secondary & Lithic & 86 & 418.54 & JL & $10 / 12 / 2016$ & $\begin{array}{l}46 \text { Bifacial } \\
\text { thinning flakes }\end{array}$ \\
\hline 2 & 7 & $60-70$ & Debitage & Tertiary & Lithic & 226 & 200.05 & $\mathrm{JL}$ & $10 / 12 / 2016$ & $\begin{array}{l}194 \text { Bifacial } \\
\text { thinning flakes }\end{array}$ \\
\hline 2 & 7 & $60-70$ & $\begin{array}{l}\text { Faunal } \\
\text { Remains }\end{array}$ & Burned Bone & & 8 & 6.93 & JL & $10 / 12 / 2016$ & $\begin{array}{l}1 \text { Calcified } \\
\text { fragment }\end{array}$ \\
\hline
\end{tabular}




\begin{tabular}{|c|c|c|c|c|c|c|c|c|c|c|}
\hline Unit & Level & $\begin{array}{l}\text { Depth } \\
\text { (cmbs) }\end{array}$ & Artifact Type & $\begin{array}{c}\text { Artifact } \\
\text { Description }\end{array}$ & Material & $\begin{array}{c}\text { Artifact } \\
\text { No. }\end{array}$ & $\begin{array}{c}\text { Weight } \\
\text { (g) }\end{array}$ & Recorders & Date & Comments \\
\hline 2 & 7 & $60-70$ & Shell Artifact & Shell Bead & Shell & 1 & 0.3 & $\mathrm{JL}$ & $10 / 12 / 2016$ & \begin{tabular}{|l} 
Modified shell \\
bead with beveled \\
drill hole and an \\
another decorative \\
incised drill mark
\end{tabular} \\
\hline 2 & 8 & $70-80$ & Debitage & Primary & Lithic & 10 & 20.9 & $\mathrm{JL}$ & $10 / 12 / 2016$ & $\begin{array}{l}4 \text { Bifacial thinning } \\
\text { flakes }\end{array}$ \\
\hline 2 & 8 & $70-80$ & Debitage & Secondary & Lithic & 19 & 41.23 & $\mathrm{JL}$ & $10 / 12 / 2016$ & $\begin{array}{l}8 \text { Bifacial thinning } \\
\text { flakes }\end{array}$ \\
\hline 2 & 8 & $70-80$ & Debitage & Tertiary & Lithic & 77 & 50.01 & $\mathrm{JL}$ & $10 / 12 / 2016$ & $\begin{array}{l}66 \text { Bifacial } \\
\text { thinning flakes }\end{array}$ \\
\hline 2 & 8 & $70-80$ & $\begin{array}{l}\text { Projectile } \\
\text { Point }\end{array}$ & $\begin{array}{l}\text { Untyped Arrow } \\
\text { Point Preform }\end{array}$ & Lithic & 1 & 5.4 & $\mathrm{JL}$ & $10 / 12 / 2016$ & \begin{tabular}{|l|} 
Missing distal tip; \\
incomplete \\
manufacturing \\
failure?; unifacially \\
trimmed; likely \\
Scallorn preform \\
\end{tabular} \\
\hline 2 & 8 & $70-80$ & \begin{tabular}{|l|} 
Projectile \\
Point
\end{tabular} & $\begin{array}{l}\text { Untyped Arrow } \\
\text { Point }\end{array}$ & Lithic & 1 & 1.41 & $\mathrm{JL}$ & 10/12/2016 & $\begin{array}{l}\text { Distal arrow point } \\
\text { frag missing base }\end{array}$ \\
\hline 2 & 8 & $70-80$ & Utilized Flake & Utilized Flake & Lithic & 1 & 4.96 & $\mathrm{JL}$ & 10/12/2016 & \\
\hline 2 & 9 & $80-90$ & Blade & Blade & & 1 & 5.29 & $\mathrm{JL}$ & 10/13/2016 & \\
\hline 2 & 9 & $80-90$ & Debitage & Primary & Lithic & 7 & 21.69 & $\mathrm{JL}$ & 10/13/2016 & \\
\hline 2 & 9 & $80-90$ & Debitage & Secondary & Lithic & 12 & 23.21 & $\mathrm{JL}$ & $10 / 13 / 2016$ & $\begin{array}{l}8 \text { Bifacial thinning } \\
\text { flakes }\end{array}$ \\
\hline 2 & 9 & $80-90$ & Debitage & Tertiary & Lithic & 63 & 49.64 & $\mathrm{JL}$ & $10 / 13 / 2016$ & $\begin{array}{l}60 \text { Bifacial } \\
\text { thinning flakes }\end{array}$ \\
\hline 2 & 9 & $80-90$ & Utilized Flake & Utilized Flake & Lithic & 1 & 11.6 & $\mathrm{JL}$ & 10/13/2016 & \\
\hline 2 & 10 & $90-100$ & Debitage & Primary & Lithic & 1 & 0.79 & $\mathrm{JL}$ & 10/12/2016 & \\
\hline 2 & 10 & $90-100$ & Debitage & Secondary & Lithic & 7 & 51.83 & $\mathrm{JL}$ & $10 / 12 / 2016$ & $\begin{array}{l}4 \text { Bifacial thinning } \\
\text { flakes }\end{array}$ \\
\hline 2 & 10 & $90-100$ & Debitage & Tertiary & Lithic & 52 & 73.71 & $\mathrm{JL}$ & $10 / 12 / 2016$ & $\begin{array}{l}38 \text { Bifacial } \\
\text { thinning flakes }\end{array}$ \\
\hline 2 & 11 & $\begin{array}{c}100- \\
110 \\
\end{array}$ & Charcoal & Charcoal & & 5 & 0.59 & $\mathrm{JL}$ & $10 / 13 / 2016$ & \\
\hline 2 & 11 & $\begin{array}{c}100- \\
110 \\
\end{array}$ & Debitage & Primary & Lithic & 4 & 49.89 & $\mathrm{JL}$ & $10 / 13 / 2016$ & \\
\hline 2 & 11 & $\begin{array}{c}100- \\
110 \\
\end{array}$ & Debitage & Secondary & Lithic & 8 & 100.74 & $\mathrm{JL}$ & $10 / 13 / 2016$ & $\begin{array}{l}\text { 3 Bifacial thinning } \\
\text { flakes }\end{array}$ \\
\hline 2 & 11 & $\begin{array}{c}100- \\
110 \\
\end{array}$ & Debitage & Tertiary & Lithic & 36 & 52.51 & $\mathrm{JL}$ & $10 / 13 / 2016$ & $\begin{array}{l}25 \text { Bifacial } \\
\text { thinning flakes }\end{array}$ \\
\hline 2 & 12 & $\begin{array}{c}110- \\
120 \\
\end{array}$ & Debitage & Primary & Lithic & 2 & 0.61 & $\mathrm{JL}$ & $10 / 14 / 2016$ & $\begin{array}{l}2 \text { Bifacial thinning } \\
\text { flakes }\end{array}$ \\
\hline 2 & 12 & $\begin{array}{c}110- \\
120 \\
\end{array}$ & Debitage & Secondary & Lithic & 18 & 23.2 & $\mathrm{JL}$ & $10 / 14 / 2016$ & $\begin{array}{l}6 \text { Bifacial thinning } \\
\text { flakes }\end{array}$ \\
\hline 2 & 12 & $\begin{array}{c}110- \\
120\end{array}$ & Debitage & Tertiary & Lithic & 64 & 37.15 & $\mathrm{JL}$ & $10 / 14 / 2016$ & $\begin{array}{l}40 \text { Bifacial } \\
\text { thinning flakes }\end{array}$ \\
\hline 2 & 12 & $\begin{array}{c}110- \\
120 \\
\end{array}$ & \begin{tabular}{|l|} 
Faunal \\
Remains
\end{tabular} & Bone & & 2 & 2.18 & $\mathrm{JL}$ & $10 / 14 / 2016$ & \\
\hline 2 & 12 & $\begin{array}{c}110- \\
120\end{array}$ & Hammerstone & Hammerstone & Lithic & 1 & 434.52 & $\mathrm{JL}$ & $10 / 14 / 2016$ & \\
\hline 2 & 13 & $\begin{array}{c}120- \\
130 \\
\end{array}$ & Charcoal & Charcoal & & 1 & 0.23 & $\mathrm{JL}$ & $10 / 14 / 2016$ & \\
\hline 2 & 13 & $\begin{array}{c}120- \\
130\end{array}$ & Debitage & Primary & Lithic & 2 & 4.35 & $\mathrm{JL}$ & $10 / 14 / 2016$ & \\
\hline 2 & 13 & $\begin{array}{c}120- \\
130\end{array}$ & Debitage & Secondary & Lithic & 3 & 13.48 & JL & $10 / 14 / 2016$ & \\
\hline 2 & 13 & $\begin{array}{c}120- \\
130\end{array}$ & Debitage & Tertiary & Lithic & 59 & 46.88 & $\mathrm{JL}$ & $10 / 14 / 2016$ & $\begin{array}{l}36 \text { Bifacial } \\
\text { thinning flakes }\end{array}$ \\
\hline 2 & 14 & $\begin{array}{c}130- \\
140 \\
\end{array}$ & Biface & \begin{tabular}{|l|} 
Bifacial \\
Fragment
\end{tabular} & Lithic & 1 & 56.08 & $\mathrm{JL}$ & $10 / 14 / 2016$ & \\
\hline 2 & 14 & $\begin{array}{c}130- \\
140\end{array}$ & Debitage & Primary & Lithic & 2 & 5.78 & $\mathrm{JL}$ & $10 / 14 / 2016$ & \\
\hline 2 & 14 & $\begin{array}{c}130- \\
140\end{array}$ & Debitage & Secondary & Lithic & 1 & 0.72 & JL & $10 / 14 / 2016$ & \\
\hline 2 & 14 & $\begin{array}{c}130- \\
140\end{array}$ & Debitage & Tertiary & Lithic & 14 & 12 & $\mathrm{JL}$ & $10 / 14 / 2016$ & $\begin{array}{l}10 \text { Bifacial } \\
\text { thinning flakes }\end{array}$ \\
\hline
\end{tabular}




\begin{tabular}{|c|c|c|c|c|c|c|c|c|c|c|}
\hline Unit & Level & $\begin{array}{c}\text { Depth } \\
\text { (cmbs) }\end{array}$ & Artifact Type & $\begin{array}{c}\text { Artifact } \\
\text { Description }\end{array}$ & Material & \begin{tabular}{|c|}
$\begin{array}{c}\text { Artifact } \\
\text { No. }\end{array}$ \\
\end{tabular} & $\begin{array}{c}\text { Weight } \\
\text { (g) }\end{array}$ & Recorders & Date & Comments \\
\hline 2 & 15 & $\begin{array}{l}140- \\
150 \\
\end{array}$ & \begin{tabular}{|l|} 
Faunal \\
Remains \\
\end{tabular} & Snail Shell & Shell & 1 & 3.21 & JU & $8 / 31 / 2017$ & $\begin{array}{l}\text { Unknown, } \\
\text { complete shell }\end{array}$ \\
\hline 2 & 15 & $\begin{array}{l}140- \\
150\end{array}$ & Debitage & Secondary & Lithic & 3 & 3.76 & JU & $8 / 31 / 2017$ & $\begin{array}{l}1 \text { bifacial thinning } \\
\text { flake }\end{array}$ \\
\hline 2 & 15 & $\begin{array}{l}140- \\
150 \\
\end{array}$ & Debitage & Tertiary & Lithic & 3 & 0.88 & JU & $8 / 31 / 2017$ & $\begin{array}{l}1 \text { bifacial thinning } \\
\text { flake }\end{array}$ \\
\hline 2 & 16 & $\begin{array}{l}150- \\
160 \\
\end{array}$ & Debitage & Secondary & Lithic & 1 & 2.94 & JU & $8 / 31 / 2017$ & \\
\hline 3 & 1 & $0-10$ & Debitage & Primary & Lithic & 1 & 50.16 & $\mathrm{JL}$ & 10/14/2016 & \\
\hline 3 & 1 & $0-10$ & Debitage & Secondary & Lithic & 1 & 0.35 & $\mathrm{JL}$ & 10/14/2016 & \\
\hline 3 & 1 & $0-10$ & Debitage & Tertiary & Lithic & 6 & 2.44 & $\mathrm{JL}$ & $10 / 14 / 2016$ & $\begin{array}{l}5 \text { Bifacial thinning } \\
\text { flakes }\end{array}$ \\
\hline 3 & 1 & $0-10$ & Utilized Flake & Utilized Flake & Lithic & 1 & 2.58 & $\mathrm{JL}$ & 10/14/2016 & \\
\hline 3 & 2 & $10-20$ & Debitage & Secondary & Lithic & 2 & 1.6 & $\mathrm{JL}$ & 10/14/2016 & \\
\hline 3 & 2 & $10-20$ & Debitage & Tertiary & Lithic & 6 & 0.98 & $\mathrm{JL}$ & $10 / 14 / 2016$ & $\begin{array}{l}6 \text { Bifacial thinning } \\
\text { flakes }\end{array}$ \\
\hline 3 & 3 & $20-30$ & Debitage & Primary & Lithic & 1 & 0.19 & $\mathrm{JL}$ & $10 / 14 / 2016$ & \\
\hline 3 & 3 & $20-30$ & Debitage & Tertiary & Lithic & 12 & 2.9 & $\mathrm{JL}$ & $10 / 14 / 2016$ & $\begin{array}{l}10 \text { Bifacial } \\
\text { thinning flakes }\end{array}$ \\
\hline 3 & 4 & $30-40$ & Burned Rock & Burned Rock & Lithic & 2 & 18.18 & $\mathrm{JL}$ & \begin{tabular}{|l|}
$10 / 14 / 2016$ \\
\end{tabular} & \\
\hline 3 & 4 & $30-40$ & Debitage & Primary & Lithic & 7 & 48.46 & $\mathrm{JL}$ & $10 / 14 / 2016$ & $\begin{array}{l}1 \text { Bifacial thinning } \\
\text { flake } \\
\end{array}$ \\
\hline 3 & 4 & $30-40$ & Debitage & Secondary & Lithic & 18 & 36.29 & $\mathrm{JL}$ & $10 / 14 / 2016$ & $\begin{array}{l}6 \text { Bifacial thinning } \\
\text { flakes }\end{array}$ \\
\hline 3 & 4 & $30-40$ & Debitage & Tertiary & Lithic & 60 & 31.1 & $\mathrm{JL}$ & $10 / 14 / 2016$ & $\begin{array}{l}54 \text { Bifacial } \\
\text { thinning flakes }\end{array}$ \\
\hline 3 & 5 & $40-50$ & \begin{tabular}{|l|} 
Faunal \\
Remains \\
\end{tabular} & Mussel Shell & Shell & 1 & 2.47 & $\mathrm{JU}$ & $8 / 31 / 2017$ & \\
\hline 3 & 5 & $40-50$ & Ground Stone & Ground Stone & & 1 & 85.14 & $\mathrm{JU}$ & $8 / 31 / 2017$ & \\
\hline 3 & 5 & $40-50$ & \begin{tabular}{|l|} 
Modified \\
Flake \\
\end{tabular} & Modified Flake & Lithic & 1 & 10.33 & JU & $8 / 31 / 2017$ & \\
\hline 3 & 5 & $40-50$ & Debitage & Primary & Lithic & 6 & 63.93 & $\mathrm{JU}$ & $8 / 31 / 2017$ & \\
\hline 3 & 5 & $40-50$ & Debitage & Secondary & Lithic & 21 & 238.78 & JU & 8/31/2017 & $\begin{array}{l}8 \text { bifacial thinning } \\
\text { flakes }\end{array}$ \\
\hline 3 & 5 & $40-50$ & Debitage & Tertiary & Lithic & 74 & 112.97 & JU & $8 / 31 / 2017$ & $\begin{array}{l}53 \text { bifacial thinning } \\
\text { flakes }\end{array}$ \\
\hline 3 & 6 & $50-60$ & \begin{tabular}{|l} 
Faunal \\
Remains
\end{tabular} & Bone & & 9 & 0.94 & JU & $8 / 31 / 2017$ & \\
\hline 3 & 6 & $50-60$ & Debitage & Primary & Lithic & 8 & 32.41 & $\mathrm{JU}$ & $8 / 31 / 2017$ & \\
\hline 3 & 6 & $50-60$ & Debitage & Secondary & Lithic & 43 & 122.26 & JU & $8 / 31 / 2017$ & $\begin{array}{l}15 \text { bifacial thinning } \\
\text { flakes }\end{array}$ \\
\hline 3 & 6 & $50-60$ & Debitage & Tertiary & Lithic & 128 & 119.41 & JU & $8 / 31 / 2017$ & $\begin{array}{l}85 \text { bifacial thinning } \\
\text { flakes }\end{array}$ \\
\hline 3 & 6 & $50-60$ & Tool & Biface & Lithic & 1 & 5.13 & $\mathrm{JU}$ & $8 / 31 / 2017$ & thin, proximal \\
\hline 3 & 6 & $50-60$ & \begin{tabular}{|l} 
Projectile \\
Point
\end{tabular} & \begin{tabular}{|l|} 
Untyped Arrow \\
Point Tip
\end{tabular} & Lithic & 1 & 0.63 & JU & $8 / 31 / 2017$ & $\begin{array}{l}\text { Distal tip; serrated } \\
\text { well-thinned }\end{array}$ \\
\hline 3 & 6 & $50-60$ & \begin{tabular}{|l|} 
Projectile \\
Point
\end{tabular} & $\begin{array}{l}\text { Untyped Arrow } \\
\text { Point }\end{array}$ & Lithic & 1 & 3.07 & JU & $8 / 31 / 2017$ & Nearly complete \\
\hline 3 & 7 & $60-70$ & $\begin{array}{l}\text { Projectile } \\
\text { Point }\end{array}$ & $\begin{array}{l}\text { Untyped Dart } \\
\text { Point }\end{array}$ & Lithic & 1 & 4.5 & JU & $8 / 31 / 2017$ & \begin{tabular}{|l|} 
Proximal half of \\
point; heavily \\
burned; probable \\
Frio or Ensor \\
\end{tabular} \\
\hline 3 & 7 & $60-70$ & \begin{tabular}{|l} 
Faunal \\
Remains \\
\end{tabular} & Mussel Shell & Shell & 1 & 0.21 & JU & $8 / 31 / 2017$ & \\
\hline 3 & 7 & $60-70$ & Debitage & Primary & Lithic & 3 & 55.44 & JU & $8 / 31 / 2017$ & $\begin{array}{l}1 \text { bifacial thinning } \\
\text { flake }\end{array}$ \\
\hline 3 & 7 & $60-70$ & Debitage & Secondary & Lithic & 7 & 21.6 & JU & $8 / 31 / 2017$ & $\begin{array}{l}2 \text { bifacial thinning } \\
\text { flakes }\end{array}$ \\
\hline 3 & 7 & $60-70$ & Debitage & Tertiary & Lithic & 18 & 22.47 & JU & $8 / 31 / 2017$ & $\begin{array}{l}13 \text { bifacial thinning } \\
\text { flakes }\end{array}$ \\
\hline 3 & 8 & $70-80$ & Debitage & Primary & Lithic & 3 & 51.34 & JU & $8 / 31 / 2017$ & \\
\hline 3 & 8 & $70-80$ & Debitage & Secondary & Lithic & 12 & 76.02 & JU & $8 / 31 / 2017$ & $\begin{array}{l}6 \text { bifacial thinning } \\
\text { flakes }\end{array}$ \\
\hline 3 & 8 & $70-80$ & Debitage & Tertiary & Lithic & 27 & 36.42 & JU & $8 / 31 / 2017$ & $\begin{array}{l}19 \text { bifacial thinning } \\
\text { flakes }\end{array}$ \\
\hline
\end{tabular}




\begin{tabular}{|c|c|c|c|c|c|c|c|c|c|c|}
\hline Unit & Level & $\begin{array}{l}\text { Depth } \\
\text { (cmbs) }\end{array}$ & Artifact Type & $\begin{array}{c}\text { Artifact } \\
\text { Description }\end{array}$ & Material & $\begin{array}{c}\text { Artifact } \\
\text { No. }\end{array}$ & $\begin{array}{c}\text { Weight } \\
\text { (g) }\end{array}$ & Recorders & Date & Comments \\
\hline 3 & 9 & $80-90$ & \begin{tabular}{|l} 
Faunal \\
Remains
\end{tabular} & Bone & & 2 & 0.12 & $\mathrm{JU}$ & 8/31/2017 & \\
\hline 3 & 9 & $80-90$ & Debitage & Secondary & Lithic & 4 & 45.03 & JU & 8/31/2017 & $\begin{array}{l}2 \text { bifacial thinning } \\
\text { flakes }\end{array}$ \\
\hline 3 & 9 & $80-90$ & Debitage & Tertiary & Lithic & 25 & 20.72 & JU & $8 / 31 / 2017$ & $\begin{array}{l}13 \text { bifacial thinning } \\
\text { flakes }\end{array}$ \\
\hline 3 & 10 & $90-100$ & \begin{tabular}{|l} 
Organic \\
Remains
\end{tabular} & Charcoal & & 1 & 0.71 & JU & 8/31/2017 & \\
\hline 3 & 10 & $90-100$ & Ground Stone & Ground Stone & & 3 & 62.89 & $\mathrm{JU}$ & $8 / 31 / 2017$ & \\
\hline 3 & 10 & $90-100$ & Debitage & Secondary & Lithic & 7 & 19.02 & JU & $8 / 31 / 2017$ & $\begin{array}{l}1 \text { bifacial thinning } \\
\text { flake }\end{array}$ \\
\hline 3 & 10 & $90-100$ & Debitage & Tertiary & Lithic & 25 & 17.51 & JU & $8 / 31 / 2017$ & $\begin{array}{l}17 \text { bifacial thinning } \\
\text { flakes }\end{array}$ \\
\hline 3 & 10 & $90-100$ & \begin{tabular}{|l|} 
Modified \\
Flake
\end{tabular} & Modified Flake & Lithic & 1 & 3.05 & JU & $8 / 31 / 2017$ & \\
\hline 3 & 11 & $\begin{array}{l}100- \\
110 \\
\end{array}$ & Debitage & Primary & Lithic & 3 & 111.05 & JU & $8 / 31 / 2017$ & \\
\hline 3 & 11 & $\begin{array}{l}100- \\
110 \\
\end{array}$ & Debitage & Secondary & Lithic & 10 & 31.49 & JU & $8 / 31 / 2017$ & $\begin{array}{l}3 \text { bifacial thinning } \\
\text { flakes }\end{array}$ \\
\hline 3 & 11 & $\begin{array}{l}100- \\
110 \\
\end{array}$ & Debitage & Tertiary & Lithic & 55 & 81.03 & JU & $8 / 31 / 2017$ & $\begin{array}{l}38 \text { bifacial thinning } \\
\text { flakes }\end{array}$ \\
\hline 3 & 12 & $\begin{array}{l}110- \\
120 \\
\end{array}$ & \begin{tabular}{|l} 
Faunal \\
Remains
\end{tabular} & Bone & & 5 & 1.04 & JU & $8 / 31 / 2017$ & 2 burned \\
\hline 3 & 12 & $\begin{array}{l}110- \\
120 \\
\end{array}$ & Debitage & Primary & Lithic & 5 & 107.78 & JU & 8/31/2017 & \\
\hline 3 & 12 & $\begin{array}{l}110- \\
120 \\
\end{array}$ & Debitage & Secondary & Lithic & 5 & 22.76 & JU & $8 / 31 / 2017$ & $\begin{array}{l}2 \text { bifacial thinning } \\
\text { flakes }\end{array}$ \\
\hline 3 & 12 & $\begin{array}{l}110- \\
120 \\
\end{array}$ & Debitage & Tertiary & Lithic & 62 & 41.93 & JU & 8/31/2017 & $\begin{array}{l}43 \text { bifacial thinning } \\
\text { flakes }\end{array}$ \\
\hline 3 & 12 & $\begin{array}{l}110- \\
120 \\
\end{array}$ & Core & Core & Lithic & 1 & 217.1 & JU & 8/31/2017 & \\
\hline 3 & 13 & $\begin{array}{l}120- \\
130 \\
\end{array}$ & Debitage & Primary & Lithic & 3 & 12.55 & JU & $8 / 31 / 2017$ & \\
\hline 3 & 13 & $\begin{array}{l}120- \\
130\end{array}$ & Debitage & Secondary & Lithic & 4 & 3.81 & JU & $8 / 31 / 2017$ & $\begin{array}{l}2 \text { bifacial thinning } \\
\text { flakes }\end{array}$ \\
\hline 3 & 13 & $\begin{array}{l}120- \\
130 \\
\end{array}$ & Debitage & Tertiary & Lithic & 25 & 22.88 & JU & $8 / 31 / 2017$ & $\begin{array}{l}17 \text { bifacial thinning } \\
\text { flakes }\end{array}$ \\
\hline 3 & 14 & $\begin{array}{l}130- \\
140 \\
\end{array}$ & \begin{tabular}{|l} 
Faunal \\
Remains
\end{tabular} & Bone & & 9 & 3.16 & JU & 8/31/2017 & \\
\hline 3 & 14 & $\begin{array}{l}130- \\
140\end{array}$ & \begin{tabular}{|l} 
Faunal \\
Remains
\end{tabular} & Bone & & 1 & 0.12 & JU & $8 / 31 / 2017$ & \\
\hline 3 & 14 & $\begin{array}{l}130- \\
140 \\
\end{array}$ & Debitage & Secondary & Lithic & 2 & 1.68 & JU & $8 / 31 / 2017$ & \\
\hline 3 & 14 & $\begin{array}{l}130- \\
140 \\
\end{array}$ & Debitage & Tertiary & Lithic & 23 & 18.76 & JU & $8 / 31 / 2017$ & $\begin{array}{l}17 \text { bifacial thinning } \\
\text { flakes }\end{array}$ \\
\hline 3 & 15 & $\begin{array}{l}140- \\
150 \\
\end{array}$ & \begin{tabular}{|l} 
Faunal \\
Remains \\
\end{tabular} & Bone & & 3 & 0.85 & JU & $8 / 31 / 2017$ & \\
\hline 3 & 15 & $\begin{array}{l}140- \\
150 \\
\end{array}$ & Debitage & Secondary & Lithic & 4 & 4.72 & JU & 8/31/2017 & $\begin{array}{l}1 \text { bifacial thinning } \\
\text { flake }\end{array}$ \\
\hline 3 & 15 & $\begin{array}{l}140- \\
150 \\
\end{array}$ & Debitage & Tertiary & Lithic & 19 & 17.18 & JU & $8 / 31 / 2017$ & $\begin{array}{l}11 \text { bifacial thinning } \\
\text { flakes }\end{array}$ \\
\hline 3 & 16 & $\begin{array}{l}150- \\
160 \\
\end{array}$ & Debitage & Primary & Lithic & 5 & 12.33 & JU & 8/31/2017 & \\
\hline 3 & 16 & $\begin{array}{l}150- \\
160\end{array}$ & Debitage & Secondary & Lithic & 10 & 30.48 & JU & $8 / 31 / 2017$ & $\begin{array}{l}4 \text { bifacial thinning } \\
\text { flakes }\end{array}$ \\
\hline 3 & 16 & $\begin{array}{l}150- \\
160 \\
\end{array}$ & Debitage & Tertiary & Lithic & 44 & 26.89 & JU & $8 / 31 / 2017$ & $\begin{array}{l}25 \text { bifacial thinning } \\
\text { flakes }\end{array}$ \\
\hline 3 & 17 & $\begin{array}{l}160- \\
170\end{array}$ & \begin{tabular}{|l|} 
Faunal \\
Remains \\
\end{tabular} & Bone & & 2 & 0.85 & JU & $8 / 31 / 2017$ & \\
\hline 3 & 17 & $\begin{array}{l}160- \\
170 \\
\end{array}$ & Debitage & Primary & Lithic & 1 & 3.42 & JU & $8 / 31 / 2017$ & \\
\hline 3 & 17 & $\begin{array}{l}160- \\
170\end{array}$ & Debitage & Secondary & Lithic & 3 & 3.26 & JU & $8 / 31 / 2017$ & $\begin{array}{l}1 \text { bifacial thinning } \\
\text { flake }\end{array}$ \\
\hline 3 & 17 & $\begin{array}{l}160- \\
170 \\
\end{array}$ & Debitage & Tertiary & Lithic & 15 & 15.66 & JU & $8 / 31 / 2017$ & $\begin{array}{l}8 \text { bifacial thinning } \\
\text { flakes }\end{array}$ \\
\hline 3 & 18 & $\begin{array}{l}170- \\
180 \\
\end{array}$ & \begin{tabular}{|l|} 
Faunal \\
Remains \\
\end{tabular} & Bone & & 3 & 2.88 & JU & $8 / 31 / 2017$ & \\
\hline
\end{tabular}




\begin{tabular}{|c|c|c|c|c|c|c|c|c|c|c|}
\hline Unit & Level & $\begin{array}{c}\text { Depth } \\
\text { (cmbs) }\end{array}$ & Artifact Type & $\begin{array}{c}\text { Artifact } \\
\text { Description }\end{array}$ & Material & \begin{tabular}{|c|}
$\begin{array}{c}\text { Artifact } \\
\text { No. }\end{array}$ \\
\end{tabular} & $\begin{array}{c}\text { Weight } \\
\text { (g) }\end{array}$ & Recorders & Date & Comments \\
\hline 3 & 18 & $\begin{array}{l}170- \\
180 \\
\end{array}$ & Debitage & Secondary & Lithic & 2 & 1.62 & JU & $8 / 31 / 2017$ & $\begin{array}{l}1 \text { bifacial thinning } \\
\text { flake }\end{array}$ \\
\hline 3 & 18 & $\begin{array}{l}170- \\
180\end{array}$ & Debitage & Tertiary & Lithic & 13 & 24.8 & JU & $8 / 31 / 2017$ & $\begin{array}{l}9 \text { bifacial thinning } \\
\text { flakes }\end{array}$ \\
\hline 4 & 1 & $0-10$ & Debitage & Primary & Lithic & 1 & 12.19 & $\mathrm{JL}$ & 10/14/2016 & \\
\hline 4 & 1 & $0-10$ & Debitage & Tertiary & Lithic & 14 & 7.15 & $\mathrm{JL}$ & $10 / 14 / 2016$ & $\begin{array}{l}12 \text { Bifacial } \\
\text { thinning flakes }\end{array}$ \\
\hline 4 & 2 & $10-20$ & Debitage & Primary & Lithic & 1 & 3.81 & $\mathrm{JL}$ & 10/13/2016 & \\
\hline 4 & 2 & $10-20$ & Debitage & Secondary & Lithic & 1 & 35.43 & $\mathrm{JL}$ & 10/13/2016 & \\
\hline 4 & 2 & $10-20$ & Debitage & Tertiary & Lithic & 12 & 10.11 & $\mathrm{JL}$ & $10 / 13 / 2016$ & \begin{tabular}{|l|l}
10 Bifacial \\
thinning flakes
\end{tabular} \\
\hline 4 & 3 & $20-30$ & Debitage & Primary & Lithic & 25 & 29.05 & $\mathrm{JL}$ & $10 / 12 / 2016$ & $\begin{array}{l}11 \text { Bifacial } \\
\text { thinning flakes }\end{array}$ \\
\hline 4 & 3 & $20-30$ & Debitage & Secondary & Lithic & 14 & 11.42 & $\mathrm{JL}$ & $10 / 12 / 2016$ & $\begin{array}{l}\text { 4 Bifacial thinning } \\
\text { flakes }\end{array}$ \\
\hline 4 & 3 & $20-30$ & Debitage & Tertiary & Lithic & 145 & 68.05 & $\mathrm{JL}$ & $10 / 12 / 2016$ & $\begin{array}{l}129 \text { Bifacial } \\
\text { thinning flakes }\end{array}$ \\
\hline 4 & 3 & $20-30$ & Scraper & \begin{tabular}{|l|} 
Unifacial \\
scraper
\end{tabular} & Lithic & 1 & 4.07 & $\mathrm{JL}$ & 10/13/2016 & Unifacially worked \\
\hline 4 & 4 & $30-40$ & Tool & Biface & Lithic & 1 & 3.74 & $\mathrm{JU}$ & $8 / 30 / 2017$ & thin, proximal \\
\hline 4 & 4 & $30-40$ & \begin{tabular}{|l} 
Faunal \\
Remains \\
\end{tabular} & Mussel Shell & Shell & 2 & 7.76 & JU & 8/30/2017 & Shell with hole \\
\hline 4 & 4 & $30-40$ & Ground Stone & Ground Stone & & 4 & 143.67 & $\mathrm{JU}$ & $8 / 30 / 2017$ & \\
\hline 4 & 4 & $30-40$ & \begin{tabular}{|l|} 
Organic \\
Remains
\end{tabular} & Charcoal & & 3 & 0.4 & JU & 8/30/2017 & From screen \\
\hline 4 & 4 & $30-40$ & \begin{tabular}{|l|} 
Special \\
Sample
\end{tabular} & DAUB & Clay & 5 & 6.45 & JU & $8 / 30 / 2017$ & \\
\hline 4 & 4 & $30-40$ & \begin{tabular}{|l} 
Faunal \\
Remains \\
\end{tabular} & Bone & & 7 & 4.96 & JU & $8 / 30 / 2017$ & 1 burned \\
\hline 4 & 4 & $30-40$ & Debitage & Primary & Lithic & 7 & 72.6 & JU & $8 / 30 / 2017$ & $\begin{array}{l}1 \text { bifacial thinning } \\
\text { flake }\end{array}$ \\
\hline 4 & 4 & $30-40$ & Debitage & Secondary & Lithic & 27 & 75.38 & JU & $8 / 30 / 2017$ & $\begin{array}{l}9 \text { bifacial thinning } \\
\text { flakes }\end{array}$ \\
\hline 4 & 4 & $30-40$ & Debitage & Tertiary & Lithic & 121 & 151.42 & JU & $8 / 30 / 2017$ & $\begin{array}{l}70 \text { bifacial thinning } \\
\text { flakes }\end{array}$ \\
\hline 4 & 5 & $40-50$ & Ground Stone & Ground Stone & & 1 & & $\mathrm{JU}$ & $8 / 30 / 2017$ & \\
\hline 4 & 5 & $40-50$ & \begin{tabular}{|l} 
Faunal \\
Remains \\
\end{tabular} & Bone & & 1 & 7.14 & JU & $8 / 30 / 2017$ & \\
\hline 4 & 5 & $40-50$ & Debitage & Primary & Lithic & 8 & 55.47 & JU & $8 / 30 / 2017$ & $\begin{array}{l}2 \text { bifacial thinning } \\
\text { flakes }\end{array}$ \\
\hline 4 & 5 & $40-50$ & Debitage & Secondary & Lithic & 17 & 33.69 & JU & $8 / 30 / 2017$ & $\begin{array}{l}9 \text { bifacial thinning } \\
\text { flakes }\end{array}$ \\
\hline 4 & 5 & $40-50$ & Debitage & Tertiary & Lithic & 69 & 56.92 & JU & $8 / 30 / 2017$ & $\begin{array}{l}39 \text { bifacial thinning } \\
\text { flakes }\end{array}$ \\
\hline 4 & 6 & $50-60$ & $\begin{array}{l}\text { Organic } \\
\text { Remains }\end{array}$ & Charcoal & & 3 & 0.37 & JU & 8/30/2017 & \\
\hline 4 & 6 & $50-60$ & Tool & Biface & Lithic & 1 & 6.36 & JU & $8 / 30 / 2017$ & thin, proximal \\
\hline 4 & 6 & $50-60$ & \begin{tabular}{|l|} 
Special \\
Sample
\end{tabular} & DAUB & Clay & 3 & 20.61 & JU & $8 / 30 / 2017$ & \\
\hline 4 & 6 & $50-60$ & \begin{tabular}{|l|} 
Faunal \\
Remains \\
\end{tabular} & Bone & & 12 & 13.34 & JU & $8 / 30 / 2017$ & 1 burned \\
\hline 4 & 6 & $50-60$ & Debitage & Primary & Lithic & 8 & 10.49 & JU & $8 / 30 / 2017$ & $\begin{array}{l}1 \text { bifacial thinning } \\
\text { flake }\end{array}$ \\
\hline 4 & 6 & $50-60$ & Debitage & Secondary & Lithic & 18 & 114.01 & JU & 8/30/2017 & $\begin{array}{l}5 \text { bifacial thinning } \\
\text { flakes }\end{array}$ \\
\hline 4 & 6 & $50-60$ & Debitage & Tertiary & Lithic & 49 & 44.32 & JU & 8/30/2017 & $\begin{array}{l}26 \text { bifacial thinning } \\
\text { flakes }\end{array}$ \\
\hline 4 & 7 & $60-70$ & \begin{tabular}{|l} 
Faunal \\
Remains
\end{tabular} & Mussel Shell & Shell & 1 & 2.57 & JU & 8/30/2017 & \\
\hline 4 & 7 & $60-70$ & $\begin{array}{l}\text { Organic } \\
\text { Remains }\end{array}$ & Charcoal & & 5 & 2.19 & JU & 8/30/2017 & \\
\hline 4 & 7 & $60-70$ & Ground Stone & Ground Stone & & 1 & 46.81 & JU & $8 / 30 / 2017$ & \\
\hline 4 & 7 & $60-70$ & Debitage & Primary & Lithic & 3 & 14.9 & $\mathrm{JU}$ & $8 / 30 / 2017$ & \\
\hline 4 & 7 & $60-70$ & Debitage & Secondary & Lithic & 11 & 59.73 & JU & $8 / 30 / 2017$ & $\begin{array}{l}2 \text { bifacial thinning } \\
\text { flakes }\end{array}$ \\
\hline
\end{tabular}




\begin{tabular}{|c|c|c|c|c|c|c|c|c|c|c|}
\hline Unit & Level & \begin{tabular}{|l|} 
Depth \\
(cmbs)
\end{tabular} & Artifact Type & $\begin{array}{c}\text { Artifact } \\
\text { Description }\end{array}$ & Material & $\begin{array}{c}\text { Artifact } \\
\text { No. }\end{array}$ & $\begin{array}{c}\text { Weight } \\
\text { (g) }\end{array}$ & Recorders & Date & Comments \\
\hline 4 & 7 & $60-70$ & Debitage & Tertiary & Lithic & 17 & 42.08 & JU & $8 / 30 / 207$ & $\begin{array}{l}12 \text { bifacial thinning } \\
\text { flakes }\end{array}$ \\
\hline 4 & 8 & $70-80$ & \begin{tabular}{|l} 
Faunal \\
Remains
\end{tabular} & Mussel Shell & Shell & 3 & 6.86 & JU & 8/30/2017 & \\
\hline 4 & 8 & $70-80$ & \begin{tabular}{|l} 
Faunal \\
Remains \\
\end{tabular} & Bone & & 3 & 5.3 & JU & 8/30/2017 & \\
\hline 4 & 8 & $70-80$ & Debitage & Primary & Lithic & 2 & 5.13 & JU & $8 / 30 / 2017$ & \\
\hline 4 & 8 & $70-80$ & Debitage & Secondary & Lithic & 10 & 60.67 & $\mathrm{JU}$ & 8/30/2017 & $\begin{array}{l}3 \text { bifacial thinning } \\
\text { flakes }\end{array}$ \\
\hline 4 & 8 & $70-80$ & Debitage & Tertiary & Lithic & 27 & 60.79 & JU & 8/30/2017 & $\begin{array}{l}15 \text { bifacial thinning } \\
\text { flakes }\end{array}$ \\
\hline 4 & 9 & $80-90$ & \begin{tabular}{|l} 
Faunal \\
Remains
\end{tabular} & Mussel Shell & Shell & 4 & 8.46 & JU & 8/30/2017 & \\
\hline 4 & 9 & $80-90$ & \begin{tabular}{|l} 
Faunal \\
Remains
\end{tabular} & Tooth & Bone & 1 & 2.52 & JU & 8/30/2017 & \\
\hline 4 & 9 & $80-90$ & \begin{tabular}{|l|} 
Faunal \\
Remains
\end{tabular} & Bone & & 18 & 36.17 & JU & 8/30/2017 & \\
\hline 4 & 9 & $80-90$ & Debitage & Primary & Lithic & 13 & 80.91 & JU & 8/30/2017 & $\begin{array}{l}1 \text { bifacial thinning } \\
\text { flake } \\
\end{array}$ \\
\hline 4 & 9 & $80-90$ & Debitage & Secondary & Lithic & 27 & 176.2 & JU & 8/30/2017 & $\begin{array}{l}7 \text { bifacial thinning } \\
\text { flakes }\end{array}$ \\
\hline 4 & 9 & $80-90$ & Debitage & Tertiary & Lithic & 61 & 110.78 & $\mathrm{JU}$ & 8/30/2017 & $\begin{array}{l}39 \text { bifacial thinning } \\
\text { flakes }\end{array}$ \\
\hline 4 & 10 & $90-100$ & Tool & Biface & Lithic & 1 & 0.51 & JU & $8 / 30 / 2017$ & Distal \\
\hline 4 & 10 & $90-100$ & \begin{tabular}{|l|} 
Faunal \\
Remains \\
\end{tabular} & Bone & & 10 & 17.02 & JU & $8 / 30 / 2017$ & \\
\hline 4 & 10 & $90-100$ & Debitage & Primary & Lithic & 6 & 36.61 & JU & 8/30/2017 & $\begin{array}{l}1 \text { bifacial thinning } \\
\text { flake }\end{array}$ \\
\hline 4 & 10 & $90-100$ & Debitage & Secondary & Lithic & 11 & 62.59 & JU & 8/30/2017 & $\begin{array}{l}4 \text { bifacial thinning } \\
\text { flakes }\end{array}$ \\
\hline 4 & 10 & $90-100$ & Debitage & Tertiary & Lithic & 33 & 62.77 & JU & $8 / 30 / 2017$ & $\begin{array}{l}25 \text { bifacial thinning } \\
\text { flakes }\end{array}$ \\
\hline 4 & 11 & $\begin{array}{l}100- \\
110 \\
\end{array}$ & \begin{tabular}{|l|} 
Faunal \\
Remains \\
\end{tabular} & Bone & & 3 & 2.85 & JU & 8/30/2017 & \\
\hline 4 & 11 & $\begin{array}{l}100- \\
110 \\
\end{array}$ & Tool & Biface & Lithic & 1 & 4.74 & JU & 8/30/2017 & thin, distal \\
\hline 4 & 11 & $\begin{array}{l}100- \\
110 \\
\end{array}$ & Debitage & Primary & Lithic & 3 & 6.97 & JU & 8/30/2017 & \\
\hline 4 & 11 & $\begin{array}{l}100- \\
110 \\
\end{array}$ & Debitage & Secondary & Lithic & 8 & 38.54 & JU & 8/30/2017 & $\begin{array}{l}3 \text { bifacial thinning } \\
\text { flakes }\end{array}$ \\
\hline 4 & 11 & $\begin{array}{l}100- \\
110 \\
\end{array}$ & Debitage & Tertiary & Lithic & 24 & 15.09 & JU & 8/30/2017 & $\begin{array}{l}17 \text { bifacial thinning } \\
\text { flakes }\end{array}$ \\
\hline 4 & 11 & $\begin{array}{l}100- \\
110 \\
\end{array}$ & Tool & Biface & Lithic & 1 & 116.2 & JU & 8/30/2017 & $\begin{array}{l}\text { Biface blank, } \\
\text { chunky }\end{array}$ \\
\hline 4 & 12 & $\begin{array}{l}110- \\
120 \\
\end{array}$ & Debitage & Secondary & Lithic & 7 & 31.4 & JU & 8/30/2017 & $\begin{array}{l}3 \text { bifacial thinning } \\
\text { flakes }\end{array}$ \\
\hline 4 & 12 & $\begin{array}{l}110- \\
120\end{array}$ & Debitage & Tertiary & Lithic & 18 & 20.9 & JU & 8/30/2017 & $\begin{array}{l}15 \text { bifacial thinning } \\
\text { flakes }\end{array}$ \\
\hline 4 & 13 & $\begin{array}{l}120- \\
130\end{array}$ & $\begin{array}{l}\text { Projectile } \\
\text { Point }\end{array}$ & $\begin{array}{l}\text { Untyped Arrow } \\
\text { Point Preform }\end{array}$ & Lithic & 1 & 4.45 & JU & $8 / 30 / 2017$ & \begin{tabular}{|l|} 
probable \\
unfinished \\
preform-failure to \\
thin; unifacial \\
\end{tabular} \\
\hline 4 & 13 & $\begin{array}{l}120- \\
130\end{array}$ & \begin{tabular}{|l} 
Faunal \\
Remains
\end{tabular} & Bone & & 1 & 0.47 & JU & 8/30/2017 & \\
\hline 4 & 13 & $\begin{array}{l}120- \\
130 \\
\end{array}$ & Debitage & Secondary & Lithic & 9 & 52.35 & JU & 8/30/2017 & $\begin{array}{l}2 \text { bifacial thinning } \\
\text { flakes }\end{array}$ \\
\hline 4 & 13 & $\begin{array}{l}120- \\
130 \\
\end{array}$ & Debitage & Tertiary & Lithic & 14 & 29.85 & JU & 8/30/2017 & $\begin{array}{l}12 \text { bifacial thinning } \\
\text { flakes }\end{array}$ \\
\hline 4 & 13 & $\begin{array}{l}120- \\
130 \\
\end{array}$ & Tool & Biface & Lithic & 1 & 35.09 & JU & 8/30/2017 & thin, proximal \\
\hline 4 & 13 & $\begin{array}{l}120- \\
130 \\
\end{array}$ & Tool & Utilized Flake & Lithic & 1 & 23.13 & JU & 8/30/2017 & \\
\hline 4 & 14 & $\begin{array}{l}130- \\
140 \\
\end{array}$ & Debitage & Tertiary & Lithic & 11 & 14.25 & $\mathrm{JU}$ & 8/30/2017 & $\begin{array}{l}8 \text { bifacial thinning } \\
\text { flakes }\end{array}$ \\
\hline 4 & 14 & $\begin{array}{l}130- \\
140\end{array}$ & \begin{tabular}{|l|} 
Faunal \\
Remains \\
\end{tabular} & Bone & & 6 & 1.53 & JU & 8/30/2017 & \\
\hline
\end{tabular}




\begin{tabular}{|c|c|c|c|c|c|c|c|c|c|c|}
\hline Unit & Level & $\begin{array}{c}\text { Depth } \\
\text { (cmbs) }\end{array}$ & Artifact Type & $\begin{array}{c}\text { Artifact } \\
\text { Description }\end{array}$ & Material & $\begin{array}{c}\text { Artifact } \\
\text { No. }\end{array}$ & $\begin{array}{l}\text { Weight } \\
\text { (g) }\end{array}$ & Recorders & Date & Comments \\
\hline 4 & 14 & $\begin{array}{l}130- \\
140\end{array}$ & \begin{tabular}{|l|} 
Organic \\
Remains
\end{tabular} & Charcoal & & 4 & 0.28 & JU & 8/30/2017 & \\
\hline 4 & 14 & $\begin{array}{l}130- \\
140 \\
\end{array}$ & Tool & Chopper & Lithic & 1 & 91.32 & JU & 8/30/2017 & \\
\hline 4 & 15 & $\begin{array}{l}140- \\
150\end{array}$ & \begin{tabular}{|l|} 
Faunal \\
Remains
\end{tabular} & Bone & & 9 & 3.64 & JU & 8/30/2017 & \\
\hline 4 & 15 & 140 & \begin{tabular}{|l|} 
Faunal \\
Remains \\
\end{tabular} & Bone & & 13 & 10.13 & JU & 8/30/2017 & \\
\hline 4 & 15 & 140 & Tool & Chopper & Lithic & 1 & 152.49 & $\mathrm{JU}$ & $8 / 30 / 2017$ & \\
\hline 4 & 15 & $\begin{array}{l}140- \\
150 \\
\end{array}$ & \begin{tabular}{|l|} 
Faunal \\
Remains \\
\end{tabular} & Tooth & Bone & 1 & 0.86 & JU & 8/30/2017 & \\
\hline 4 & 15 & $\begin{array}{l}140- \\
150 \\
\end{array}$ & \begin{tabular}{|l} 
Faunal \\
Remains
\end{tabular} & Bone & & 29 & 8.94 & JU & 8/30/2017 & \\
\hline 4 & 15 & $\begin{array}{l}140- \\
150 \\
\end{array}$ & Debitage & Primary & Lithic & 1 & 5.92 & JU & 8/30/2017 & \\
\hline 4 & 15 & $\begin{array}{l}140- \\
150\end{array}$ & Debitage & Secondary & Lithic & 2 & 18.65 & JU & 8/30/2017 & \\
\hline 4 & 15 & $\begin{array}{l}140- \\
150 \\
\end{array}$ & Debitage & Tertiary & Lithic & 13 & 12.45 & JU & 8/30/2017 & $\begin{array}{l}9 \text { bifacial thinning } \\
\text { flakes }\end{array}$ \\
\hline 4 & 16 & $\begin{array}{l}150- \\
160 \\
\end{array}$ & \begin{tabular}{|l|} 
Faunal \\
Remains \\
\end{tabular} & Bone & & 2 & 0.48 & JU & 8/31/2017 & \\
\hline 4 & 16 & $\begin{array}{l}150- \\
160 \\
\end{array}$ & Debitage & Secondary & Lithic & 1 & 75.89 & JU & 8/31/2017 & \\
\hline 4 & 16 & $\begin{array}{l}150- \\
160\end{array}$ & Debitage & Tertiary & Lithic & 9 & 12.33 & JU & 8/31/2017 & $\begin{array}{l}8 \text { bifacial thinning } \\
\text { flakes }\end{array}$ \\
\hline 4 & $5-6$ & - & $\begin{array}{l}\text { Faunal } \\
\text { Remains }\end{array}$ & Mussel Shell & Shell & 1 & 7.13 & JU & 8/30/2017 & $\begin{array}{l}\text { In rodent burrow } \\
\text { between levels } 5 \\
\text { and } 6\end{array}$ \\
\hline 5 & 1 & $0-10$ & Debitage & Secondary & Lithic & 1 & 18.24 & JU & 9/1/2017 & \\
\hline 5 & 2 & $10-20$ & Debitage & Tertiary & Lithic & 3 & 1.48 & JU & 9/1/2017 & $\begin{array}{l}1 \text { bifacial thinning } \\
\text { flake }\end{array}$ \\
\hline 5 & 2 & $10-20$ & Core & Core & Lithic & 1 & 150.39 & JU & 9/1/2017 & \\
\hline 5 & 3 & $20-30$ & \begin{tabular}{|l} 
Faunal \\
Remains
\end{tabular} & Bone & & 1 & 0.73 & JU & 9/1/2017 & \\
\hline 5 & 3 & $20-30$ & Debitage & Secondary & Lithic & 1 & 0.35 & JU & 9/1/2017 & \\
\hline 5 & 3 & $20-30$ & Debitage & Tertiary & Lithic & 3 & 6.1 & JU & 9/1/2017 & $\begin{array}{l}2 \text { bifacial thinning } \\
\text { flakes }\end{array}$ \\
\hline 5 & 4 & $30-40$ & \begin{tabular}{|l|} 
Faunal \\
Remains
\end{tabular} & Mussel Shell & Shell & 1 & 4.32 & JU & 9/1/2017 & \\
\hline 5 & 4 & $30-40$ & \begin{tabular}{|l|} 
Debitage \\
\end{tabular} & Primary & Lithic & 3 & 4.3 & $\mathrm{JU}$ & \begin{tabular}{|l|l|}
$9 / 1 / 2017$ \\
\end{tabular} & \\
\hline 5 & 4 & $30-40$ & Debitage & Secondary & Lithic & 5 & 36.14 & JU & 9/1/2017 & $\begin{array}{l}1 \text { bifacial thinning } \\
\text { flake }\end{array}$ \\
\hline 5 & 4 & $30-40$ & Debitage & Tertiary & Lithic & 18 & 33.86 & JU & 9/1/2017 & $\begin{array}{l}11 \text { bifacial thinning } \\
\text { flakes }\end{array}$ \\
\hline 5 & 5 & $40-50$ & Debitage & Primary & Lithic & 2 & 3.25 & JU & 9/1/2017 & $\begin{array}{l}1 \text { bifacial thinning } \\
\text { flake }\end{array}$ \\
\hline 5 & 5 & $40-50$ & Debitage & Secondary & Lithic & 7 & 13.98 & JU & 9/1/2017 & $\begin{array}{l}3 \text { bifacial thinning } \\
\text { flakes }\end{array}$ \\
\hline 5 & 5 & $40-50$ & Debitage & Tertiary & Lithic & 34 & 20.32 & JU & 9/1/2017 & $\begin{array}{l}21 \text { bifacial thinning } \\
\text { flakes }\end{array}$ \\
\hline 5 & 6 & $50-60$ & \begin{tabular}{|l|} 
Faunal \\
Remains
\end{tabular} & Bone & & 2 & 0.51 & JU & 9/1/2017 & 1 burned \\
\hline 5 & 6 & $50-60$ & Debitage & Primary & Lithic & 3 & 3.56 & $\mathrm{JU}$ & $9 / 1 / 2017$ & \\
\hline 5 & 6 & $50-60$ & Debitage & Secondary & Lithic & 4 & 1.35 & JU & 9/1/2017 & $\begin{array}{l}1 \text { bifacial thinning } \\
\text { flake }\end{array}$ \\
\hline 5 & 6 & $50-60$ & Debitage & Tertiary & Lithic & 28 & 29.77 & JU & 9/1/2017 & $\begin{array}{l}21 \text { bifacial thinning } \\
\text { flakes }\end{array}$ \\
\hline 5 & 7 & $60-70$ & \begin{tabular}{|l|} 
Faunal \\
Remains \\
\end{tabular} & Bone & & 1 & 0.26 & JU & 9/1/2017 & Burned \\
\hline 5 & 7 & $60-70$ & Debitage & Primary & Lithic & 5 & 34.48 & JU & 9/1/2017 & $\begin{array}{l}1 \text { bifacial thinning } \\
\text { flake }\end{array}$ \\
\hline 5 & 7 & $60-70$ & Debitage & Secondary & Lithic & 4 & 20.65 & JU & 9/1/2017 & $\begin{array}{l}2 \text { bifacial thinning } \\
\text { flakes }\end{array}$ \\
\hline 5 & 7 & $60-70$ & Debitage & Tertiary & Lithic & 19 & 22.87 & JU & 9/1/2017 & $\begin{array}{l}8 \text { bifacial thinning } \\
\text { flakes }\end{array}$ \\
\hline 5 & 8 & $70-80$ & Debitage & Secondary & Lithic & 1 & 1.74 & $\mathrm{JU}$ & 9/1/2017 & \\
\hline
\end{tabular}




\begin{tabular}{|c|c|c|c|c|c|c|c|c|c|c|}
\hline Unit & Level & $\begin{array}{l}\text { Depth } \\
\text { (cmbs) }\end{array}$ & Artifact Type & $\begin{array}{c}\text { Artifact } \\
\text { Description }\end{array}$ & Material & $\begin{array}{c}\text { Artifact } \\
\text { No. }\end{array}$ & $\begin{array}{c}\text { Weight } \\
\text { (g) }\end{array}$ & Recorders & Date & Comments \\
\hline 5 & 8 & $70-80$ & Debitage & Tertiary & Lithic & 5 & 2.59 & JU & 9/1/2017 & $\begin{array}{l}3 \text { bifacial thinning } \\
\text { flakes }\end{array}$ \\
\hline 5 & 9 & $80-90$ & Debitage & Primary & Lithic & 1 & 1.04 & $\mathrm{JU}$ & 9/1/2017 & \\
\hline 5 & 9 & $80-90$ & \begin{tabular}{|l|} 
Debitage \\
\end{tabular} & Secondary & Lithic & 2 & 4.8 & $\mathrm{JU}$ & 9/1/2017 & \\
\hline 5 & 9 & $80-90$ & Debitage & Tertiary & Lithic & 6 & 11.15 & $\mathrm{JU}$ & $9 / 1 / 2017$ & $\begin{array}{l}5 \text { bifacial thinning } \\
\text { flakes }\end{array}$ \\
\hline 5 & 10 & $90-100$ & Debitage & Primary & Lithic & 1 & 17.5 & $\mathrm{JU}$ & 9/1/2017 & \\
\hline 5 & 10 & $90-100$ & Debitage & Secondary & Lithic & 2 & 8.49 & JU & $9 / 1 / 2017$ & \\
\hline 5 & 10 & $90-100$ & Debitage & Tertiary & Lithic & 3 & 5.45 & $\mathrm{JU}$ & 9/1/2017 & $\begin{array}{l}1 \text { bifacial thinning } \\
\text { flake }\end{array}$ \\
\hline 5 & 11 & $\begin{array}{l}100- \\
110 \\
\end{array}$ & Debitage & Secondary & Lithic & 2 & 7.61 & JU & $9 / 1 / 2017$ & \\
\hline 5 & 11 & $\begin{array}{l}100- \\
110 \\
\end{array}$ & Debitage & Tertiary & Lithic & 3 & 8.4 & JU & 9/1/2017 & $\begin{array}{l}2 \text { bifacial thinning } \\
\text { flakes }\end{array}$ \\
\hline 1 & 2 & $10-20$ & Burned Rock & Burned Rock & Lithic & 7 & 500 & DR & 10/19/2017 & Not collected \\
\hline 1 & 3 & $20-30$ & Burned Rock & Burned Rock & Lithic & 1 & $<100$ & DR & 10/19/2017 & Not collected \\
\hline 1 & 4 & $30-40$ & Burned Rock & Burned Rock & Lithic & 4 & 200 & $\mathrm{DR}$ & 10/19/2017 & Not collected \\
\hline 1 & 5 & $40-50$ & \begin{tabular}{|l|} 
Burned Rock \\
\end{tabular} & Burned Rock & Lithic & 8 & 800 & DR & 10/19/2017 & Not collected \\
\hline 1 & 6 & $50-60$ & Burned Rock & Burned Rock & Lithic & 11 & 600 & DR & 10/19/2017 & Not collected \\
\hline 1 & 7 & $60-70$ & Burned Rock & Burned Rock & Lithic & 8 & 600 & DR & \begin{tabular}{|l|}
$10 / 19 / 2017$ \\
\end{tabular} & Not collected \\
\hline 1 & 8 & $70-80$ & Burned Rock & Burned Rock & Lithic & 13 & 600 & DR & 10/19/2017 & Not collected \\
\hline 1 & 9 & $80-90$ & \begin{tabular}{|l|} 
Burned Rock \\
\end{tabular} & Burned Rock & Lithic & 12 & 750 & DR & 10/19/2017 & Not collected \\
\hline 1 & 10 & $90-100$ & \begin{tabular}{|l|} 
Burned Rock \\
\end{tabular} & Burned Rock & Lithic & 17 & 1250 & DR & 10/19/2017 & Not collected \\
\hline 1 & 11 & $\begin{array}{c}100- \\
110 \\
\end{array}$ & Burned Rock & Burned Rock & Lithic & 8 & 600 & $\mathrm{DR}$ & 10/19/2017 & Not collected \\
\hline 1 & 13 & $\begin{array}{c}120- \\
130 \\
\end{array}$ & Burned Rock & Burned Rock & Lithic & 7 & 205 & DR & 10/19/2017 & Not collected \\
\hline 2 & 1 & $0-10$ & Burned Rock & Burned Rock & Lithic & 2 & 100 & DR & 10/19/2017 & Not collected \\
\hline 2 & 2 & $10-20$ & Burned Rock & Burned Rock & Lithic & 16 & 300 & DR & 10/19/2017 & Not collected \\
\hline 2 & 3 & $20-30$ & Burned Rock & Burned Rock & Lithic & 2 & 110 & DR & 10/19/2017 & Not collected \\
\hline 2 & 5 & $40-50$ & Burned Rock & Burned Rock & Lithic & 15 & 300 & $\mathrm{DR}$ & 10/19/2017 & Not collected \\
\hline 2 & 6 & $50-60$ & Burned Rock & Burned Rock & Lithic & 4 & 250 & $\mathrm{DR}$ & 10/19/2017 & Not collected \\
\hline 2 & 7 & $60-70$ & Burned Rock & Burned Rock & Lithic & 5 & $>600$ & $\mathrm{DR}$ & 10/19/2017 & Not collected \\
\hline 2 & 8 & $70-80$ & Burned Rock & Burned Rock & Lithic & 12 & 400 & DR & 10/19/2017 & Not collected \\
\hline 2 & 9 & $80-90$ & \begin{tabular}{|l|} 
Burned Rock \\
\end{tabular} & \begin{tabular}{|l|} 
Burned Rock \\
\end{tabular} & Lithic & 6 & 100 & $\mathrm{DR}$ & 10/19/2017 & Not collected \\
\hline 2 & 10 & $90-100$ & Burned Rock & Burned Rock & Lithic & 11 & 500 & DR & 10/19/2017 & Not collected \\
\hline 2 & 11 & $\begin{array}{c}100- \\
110 \\
\end{array}$ & Burned Rock & Burned Rock & Lithic & 5 & 400 & $\mathrm{DR}$ & $10 / 19 / 2017$ & Not collected \\
\hline 2 & 12 & $\begin{array}{c}110- \\
120 \\
\end{array}$ & Burned Rock & Burned Rock & Lithic & 7 & 2700 & DR & $10 / 19 / 2017$ & Not collected \\
\hline 2 & 13 & $\begin{array}{c}120- \\
130\end{array}$ & Burned Rock & Burned Rock & Lithic & 7 & 500 & $\mathrm{DR}$ & $10 / 19 / 2017$ & Not collected \\
\hline 3 & 1 & $0-10$ & Burned Rock & Burned Rock & Lithic & 2 & $<100$ & DR & 10/19/2017 & Not collected \\
\hline 3 & 5 & $40-50$ & Burned Rock & Burned Rock & Lithic & 5 & 150 & DR & 10/19/2017 & Not collected \\
\hline 3 & 6 & $50-60$ & Burned Rock & Burned Rock & Lithic & 32 & 200 & DR & 10/19/2017 & Not collected \\
\hline 3 & 9 & $80-90$ & Burned Rock & Burned Rock & Lithic & 5 & 100 & DR & 10/19/2017 & Not collected \\
\hline 3 & 11 & $\begin{array}{l}100- \\
110 \\
\end{array}$ & Burned Rock & Burned Rock & Lithic & 5 & 200 & $\mathrm{DR}$ & 10/19/2017 & Not collected \\
\hline 3 & 12 & $\begin{array}{l}110- \\
120 \\
\end{array}$ & Burned Rock & Burned Rock & Lithic & 13 & 600 & DR & 10/19/2017 & Not collected \\
\hline 3 & 13 & $\begin{array}{l}120- \\
130 \\
\end{array}$ & Burned Rock & Burned Rock & Lithic & 1 & 100 & $\mathrm{DR}$ & 10/19/2017 & Not collected \\
\hline 3 & 16 & $\begin{array}{l}150- \\
160 \\
\end{array}$ & Burned Rock & Burned Rock & Lithic & 2 & 200 & DR & 10/19/2017 & Not collected \\
\hline 4 & 3 & $20-30$ & Burned Rock & Burned Rock & Lithic & 4 & 100 & DR & 10/19/2017 & Not collected \\
\hline 4 & 4 & $30-40$ & Burned Rock & Burned Rock & Lithic & 16 & 600 & DR & 10/19/2017 & Not collected \\
\hline 4 & 5 & $40-50$ & Burned Rock & Burned Rock & Lithic & 21 & 1000 & DR & 10/19/2017 & Not collected \\
\hline 4 & 6 & $50-60$ & Burned Rock & Burned Rock & Lithic & 20 & 800 & DR & 10/19/2017 & Not collected \\
\hline 4 & 7 & $60-70$ & Burned Rock & Burned Rock & Lithic & 17 & 600 & DR & \begin{tabular}{|l|}
$10 / 19 / 2017$ \\
\end{tabular} & Not collected \\
\hline 4 & 8 & $70-80$ & Burned Rock & Burned Rock & Lithic & 21 & 400 & DR & 10/19/2017 & Not collected \\
\hline 4 & 9 & $80-90$ & \begin{tabular}{|l|} 
Burned Rock \\
\end{tabular} & Burned Rock & Lithic & 60 & 1100 & DR & 10/19/2017 & Not collected \\
\hline 4 & 10 & $90-100$ & Burned Rock & Burned Rock & Lithic & 20 & 1300 & $\mathrm{DR}$ & \begin{tabular}{|l|}
$10 / 19 / 2017$ \\
\end{tabular} & Not collected \\
\hline
\end{tabular}




\begin{tabular}{|c|c|c|c|c|c|c|c|c|c|c|}
\hline Unit & Level & $\begin{array}{l}\text { Depth } \\
\text { (cmbs) }\end{array}$ & Artifact Type & $\begin{array}{c}\text { Artifact } \\
\text { Description }\end{array}$ & Material & $\begin{array}{c}\text { Artifact } \\
\text { No. }\end{array}$ & $\begin{array}{l}\text { Weight } \\
\text { (g) }\end{array}$ & Recorders & Date & Comments \\
\hline 4 & 11 & $\begin{array}{l}100- \\
110 \\
\end{array}$ & Burned Rock & Burned Rock & Lithic & 14 & 600 & DR & $10 / 19 / 2017$ & Not collected \\
\hline 4 & 12 & $\begin{array}{l}110- \\
120 \\
\end{array}$ & Burned Rock & Burned Rock & Lithic & 9 & 200 & DR & $10 / 19 / 2017$ & Not collected \\
\hline 4 & 13 & $\begin{array}{c}120- \\
130\end{array}$ & Burned Rock & Burned Rock & Lithic & 14 & 400 & DR & $10 / 19 / 2017$ & Not collected \\
\hline 4 & 14 & $\begin{array}{l}130- \\
140\end{array}$ & Burned Rock & Burned Rock & Lithic & 6 & 100 & DR & $10 / 19 / 2017$ & Not collected \\
\hline 4 & 15 & $\begin{array}{l}140- \\
150\end{array}$ & Burned Rock & Burned Rock & Lithic & 8 & 100 & DR & $10 / 19 / 2017$ & Not collected \\
\hline 4 & 16 & $\begin{array}{l}150- \\
160\end{array}$ & Burned Rock & Burned Rock & Lithic & 3 & 200 & DR & $10 / 19 / 2017$ & Not collected \\
\hline 5 & 4 & $30-40$ & Burned Rock & Burned Rock & Lithic & 3 & 100 & $\mathrm{DR}$ & 10/19/2017 & Not collected \\
\hline 5 & 5 & $40-50$ & Burned Rock & Burned Rock & Lithic & 17 & 1000 & DR & $10 / 19 / 2017$ & Not collected \\
\hline 5 & 6 & $50-60$ & Burned Rock & Burned Rock & Lithic & 31 & 2200 & DR & 10/19/2017 & Not collected \\
\hline 5 & 7 & $60-70$ & Burned Rock & Burned Rock & Lithic & 17 & 1200 & DR & 10/19/2017 & Not collected \\
\hline 5 & 8 & $70-80$ & Burned Rock & Burned Rock & Lithic & 2 & 100 & DR & $10 / 19 / 2017$ & Not collected \\
\hline 5 & 9 & $80-90$ & Burned Rock & Burned Rock & Lithic & 13 & 100 & DR & $10 / 19 / 2017$ & Not collected \\
\hline 5 & 10 & $90-100$ & Burned Rock & Burned Rock & Lithic & 2 & 100 & DR & $10 / 19 / 2017$ & Not collected \\
\hline 5 & 11 & $\begin{array}{l}100- \\
110 \\
\end{array}$ & Burned Rock & Burned Rock & Lithic & 2 & 100 & DR & $10 / 19 / 2017$ & Not collected \\
\hline Surface & Surface & & Biface & $\begin{array}{l}\text { Late-stage, } \\
\text { thin biface }\end{array}$ & Lithic & 1 & 56.3 & $\mathrm{JL}$ & $10 / 14 / 2016$ & $\begin{array}{l}\text { Surface collection. } \\
\text { Thin biface. }\end{array}$ \\
\hline
\end{tabular}

